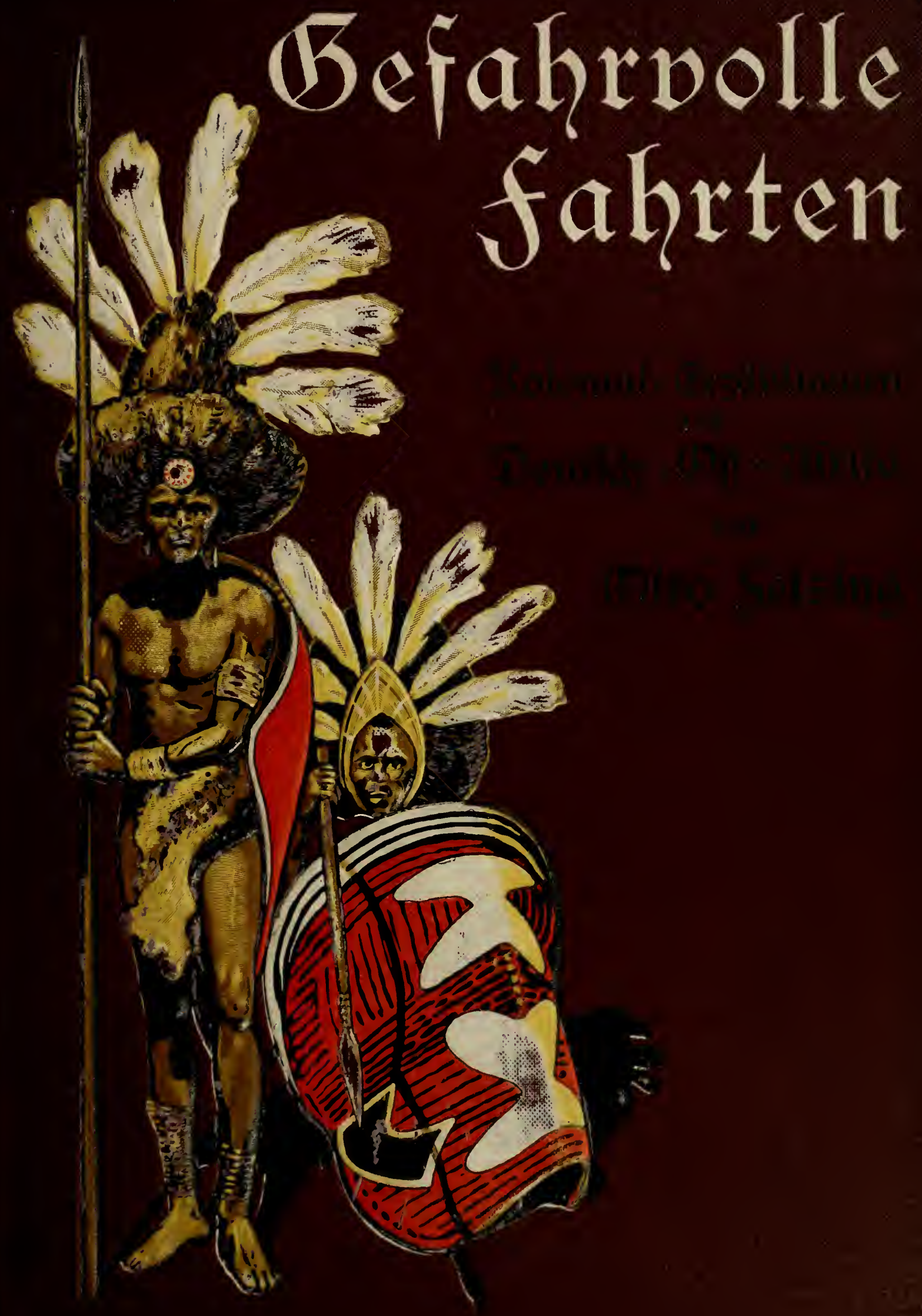



$120-120$

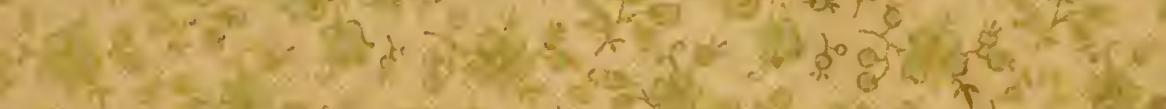

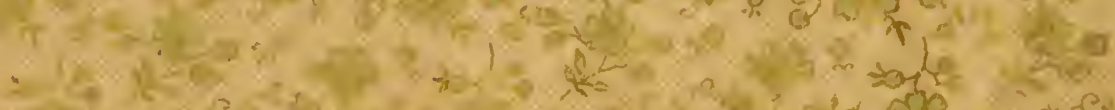

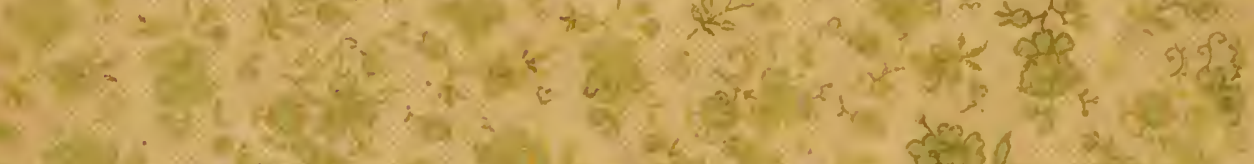

a

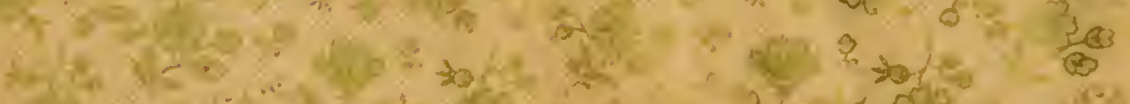

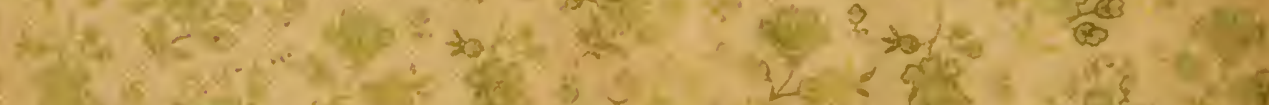

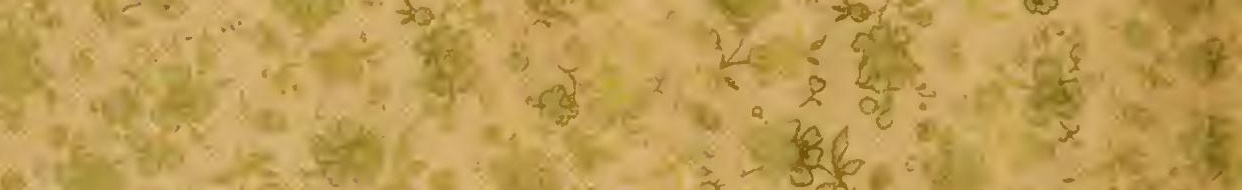

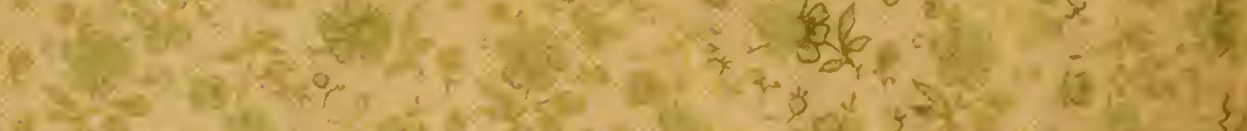

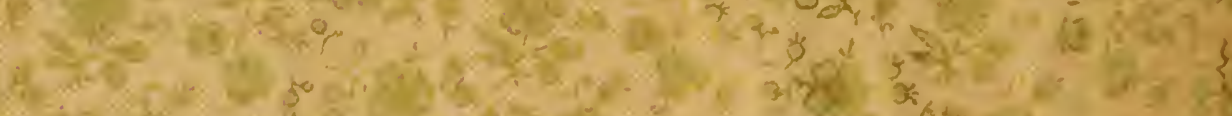

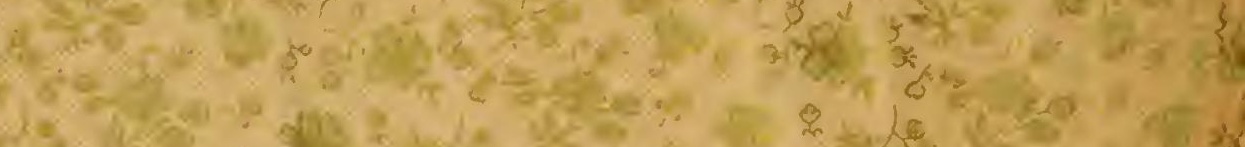

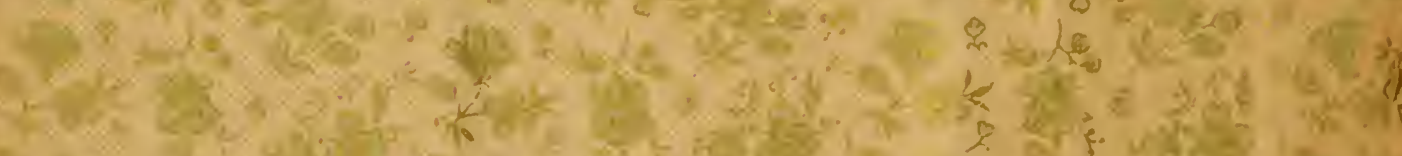

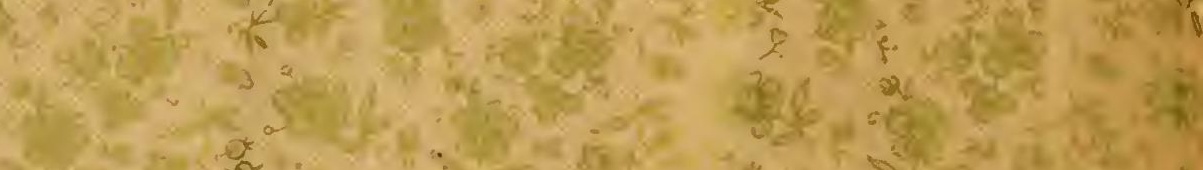

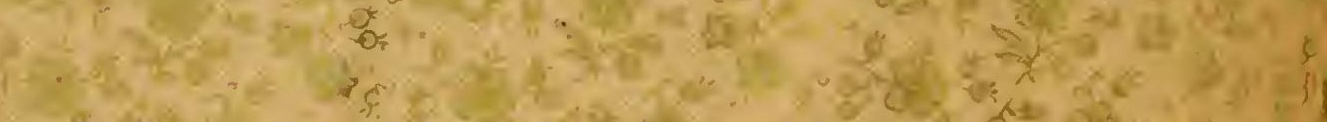

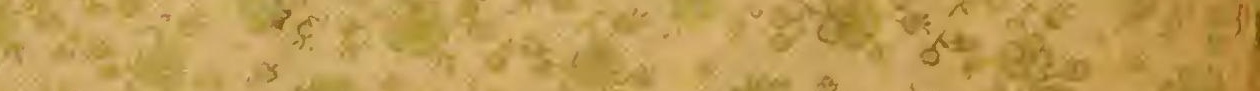
, a

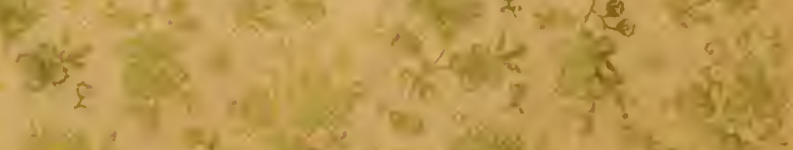




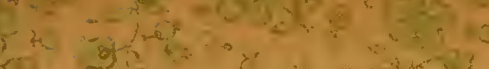

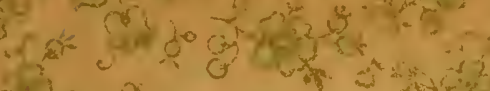

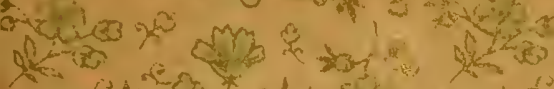

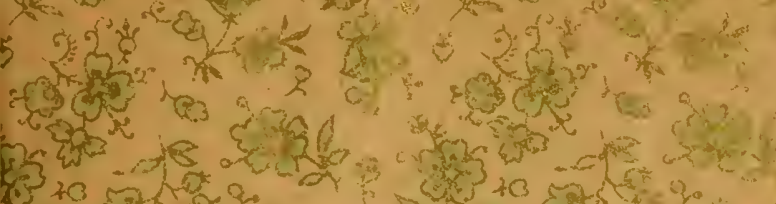

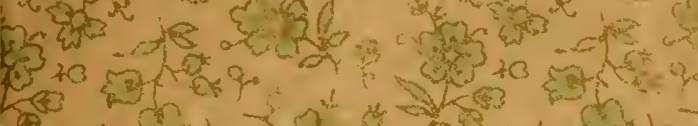

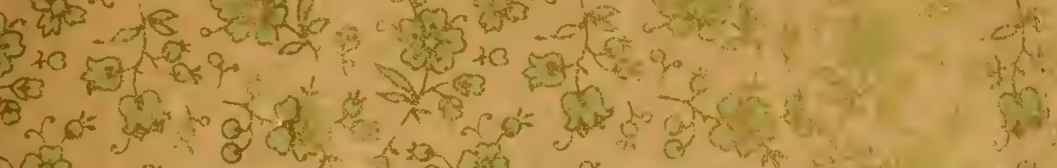

सe

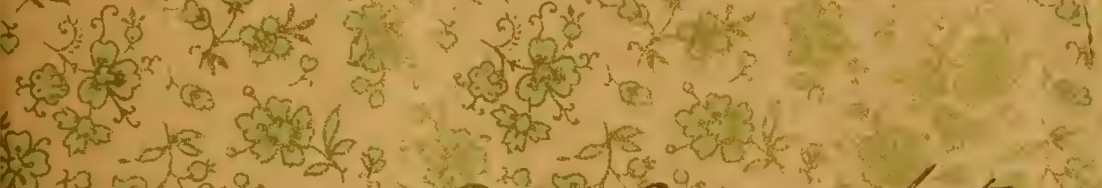

56 क

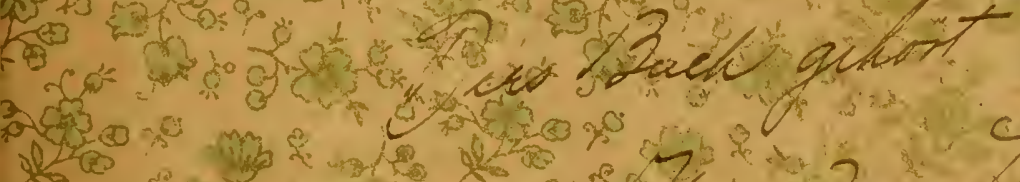

सQ

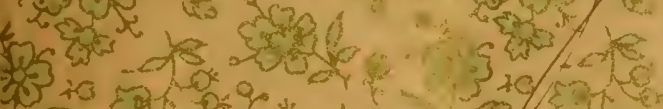

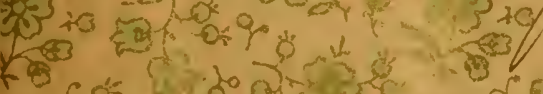

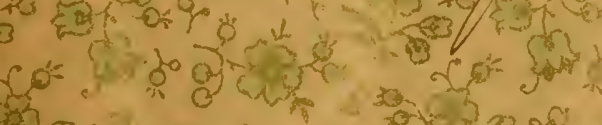

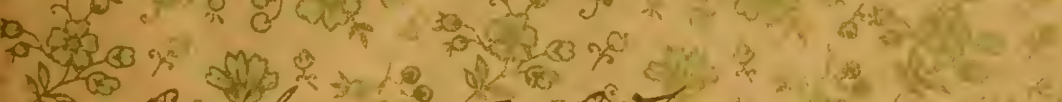

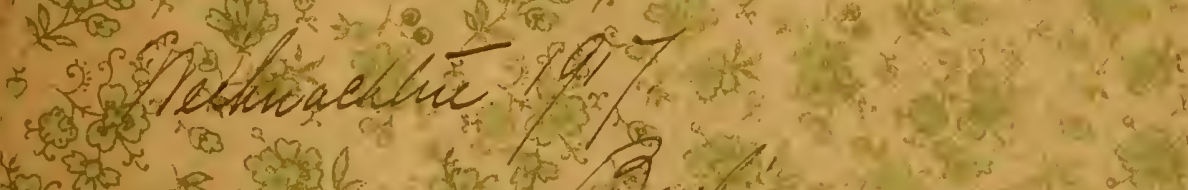

of

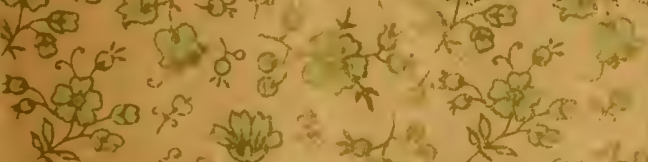

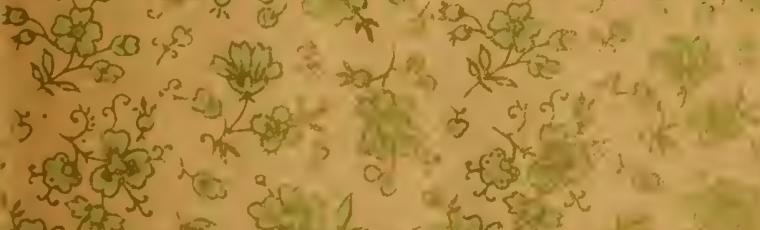

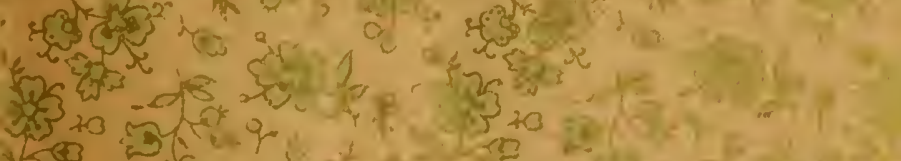
* $e^{\infty}$ is

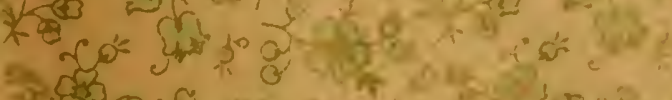
, सह

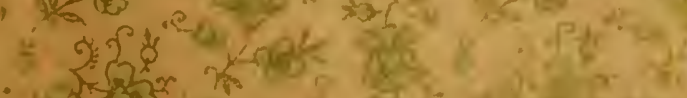
की 




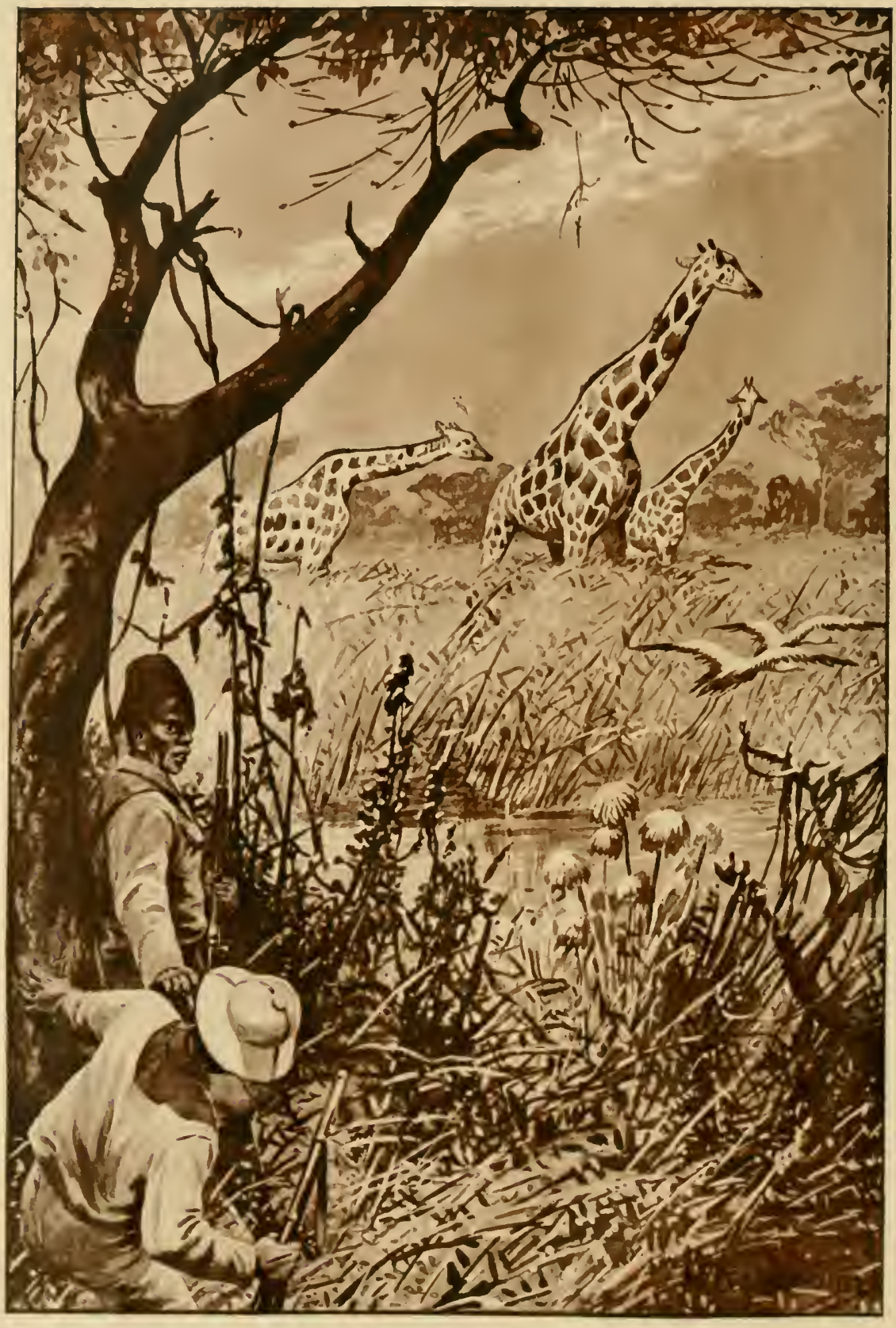

311 Esite 5839 


\section{Gefahrnolle Fahrten.}

\section{Kolonialerzählung aus Deutích-Oítafrika}

von

\section{Otto Felsing.}

\section{$\infty$}

Mit 11 Vollbildern und zahlreichen in den Text gedruckten lliustrationen von $\mathrm{H}$. Tiedemann.
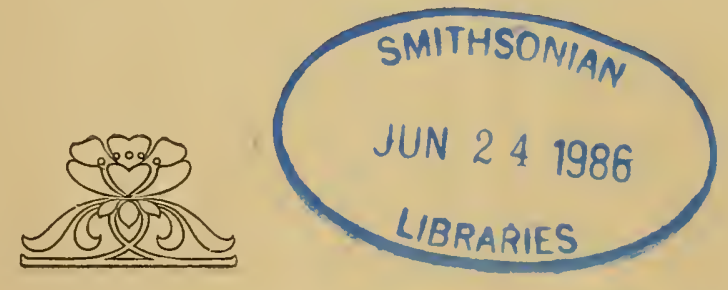

Elberfeld

Druik und Verlag von Sam. Lucas. 



\section{Vorwort.}

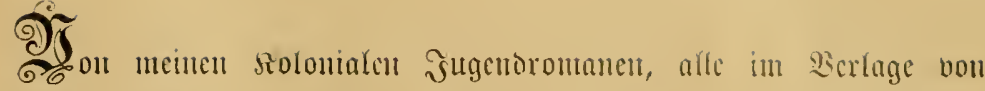

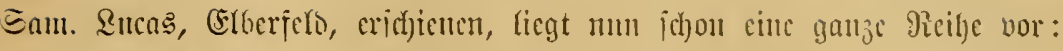
"Der blume Diamant", "Sturmogel", "Mote Wlämer in Ruanoa",

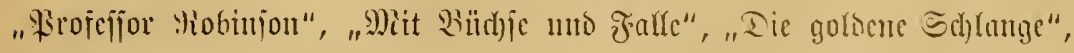

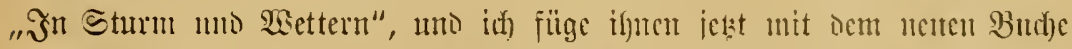

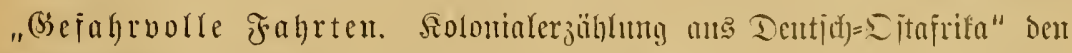

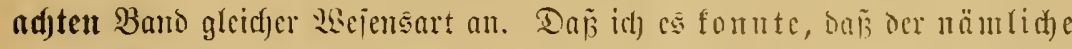

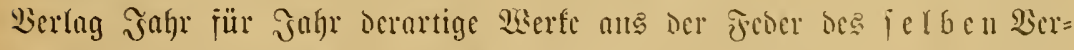

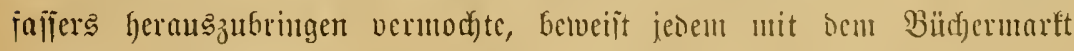

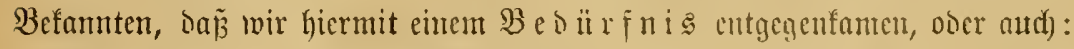

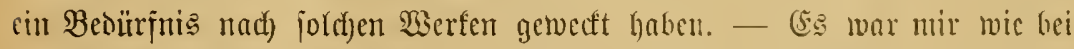

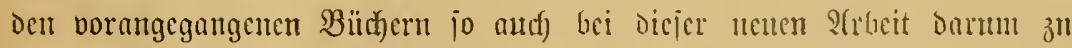

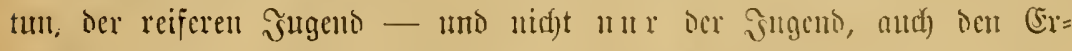
mad)jenten der dentichen Rejerivelt! - eine Solonialerä̈blung zu geben,

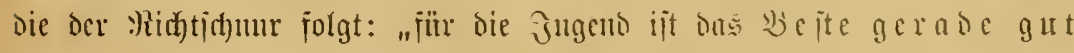
genug", uno juvar d a

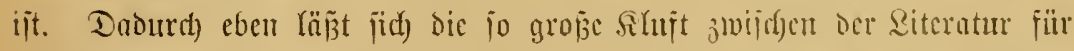

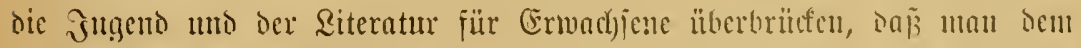

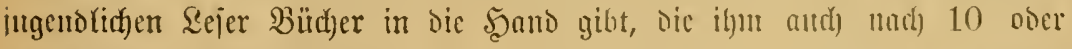

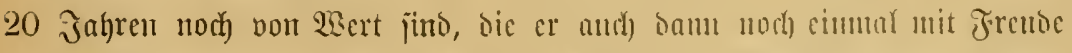

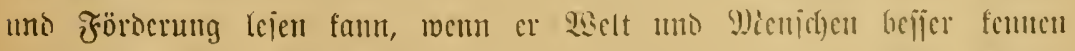

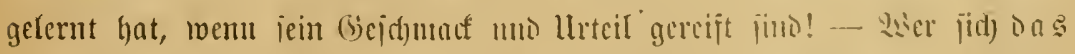
als Biel jetrt, hiljt mit saran, Der victbeffagten jogenumuten "3ngent= literatur" mit ifrer unfünitlerijd)en Tariteltmen, ilfren ïberbisten, dic

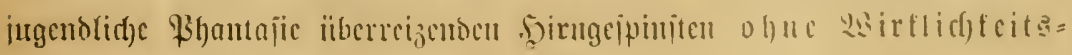
gruno cinen Danum entgegenzmerjen.

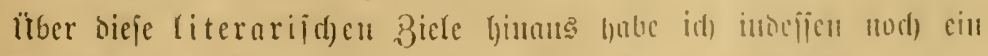

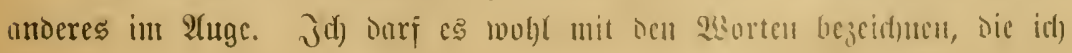


tercits แeinen früh)eren noloniaten Jugentromanen mit anj ben Siseg gab:

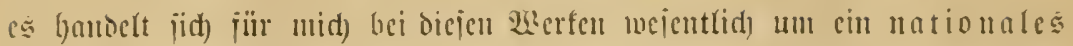

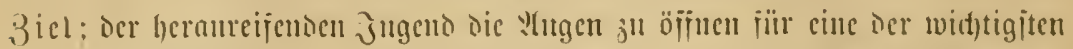

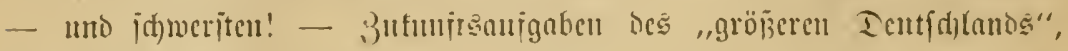

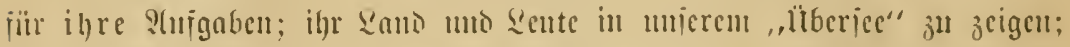

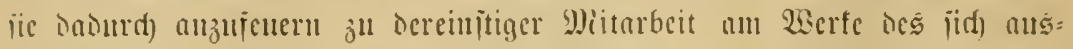
breitenden umo höber ridjtenten Baterlanocs - jei le hicr ani alter

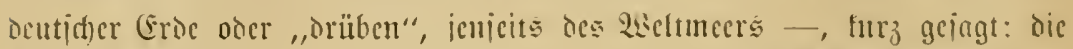

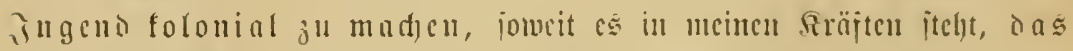

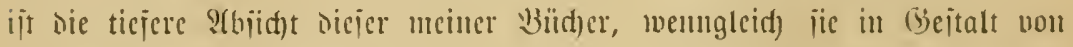

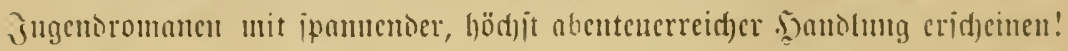

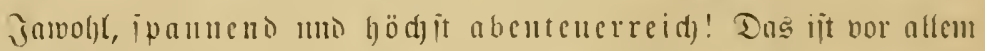

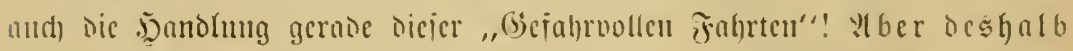
rod) nidht unwhrhajtig! Dem ielbit bas allermmabrideinlidjte

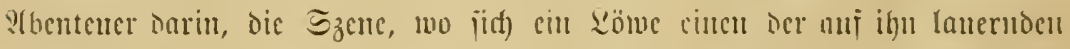

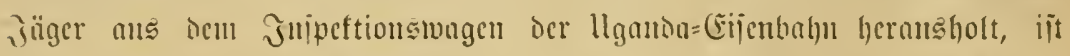

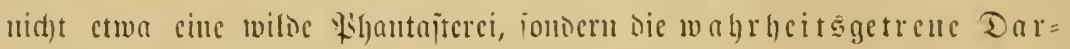

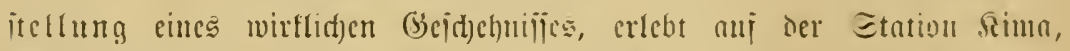

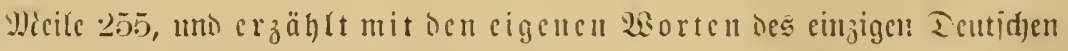

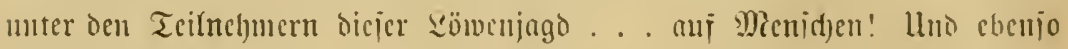
verbält co jid) mit all ben ïbrigen, io abcutenterlid)en, bunten, ojt jeltjan= unbegreifl(id)en unto iogar cimmal "untheinlid) geipenitigen“, aber jid) idsliejs.

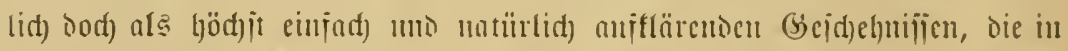

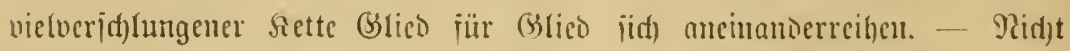

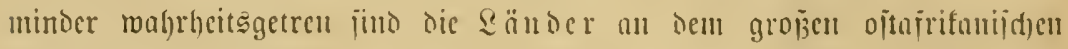

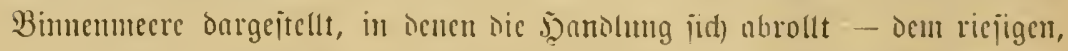

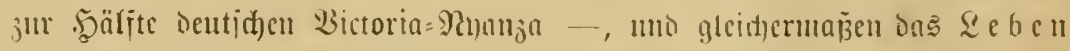

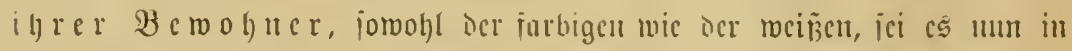
Dem aus der "Etntion" jur Etnot werientoll, won Den Eeedampjern Der

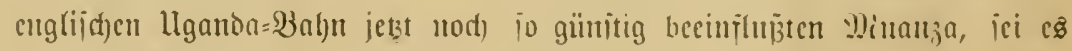
auj dem sriegsjuge gegen dic aus jinterhalten hervorbred)enden oder jich

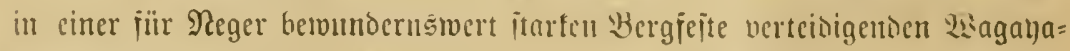

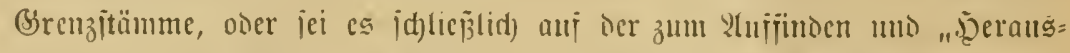

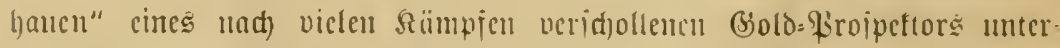

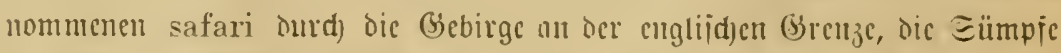

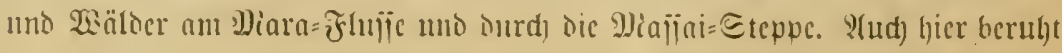




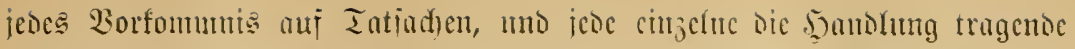

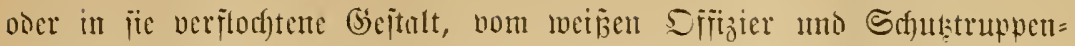

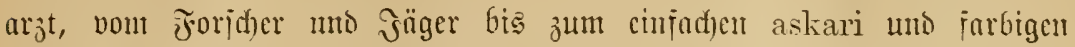

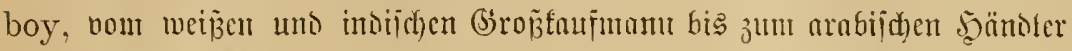

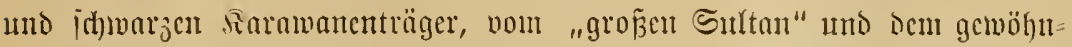

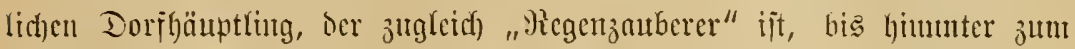

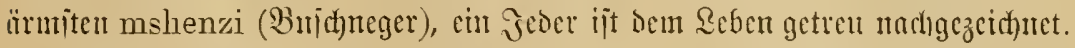

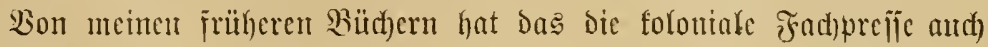

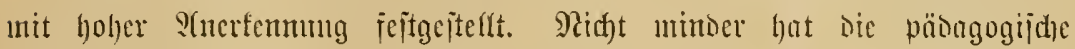

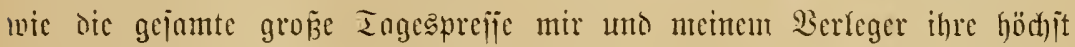

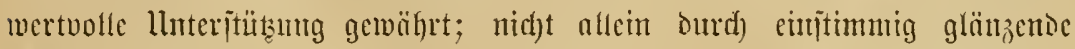

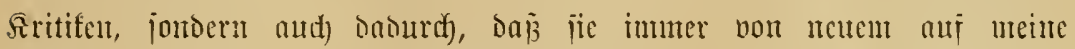

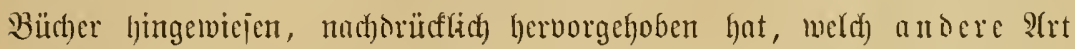
non jutgennliteratur hier vorliegt, uno jtets nabei betonte: "aud hier miro mationale :labeit gelcijtet, - negmt umb reit!"

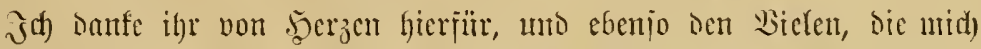

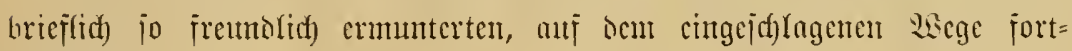
jufahren!

\section{Dr. Otto Felsing.}

Berrit, Sftober 1909. 



\section{Sprachliche und geichichtliche Vorbemerkungen.}

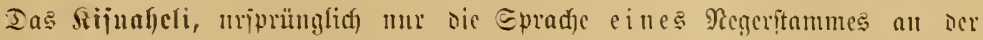

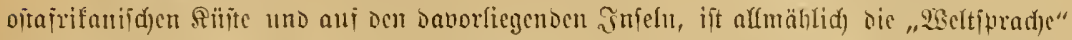

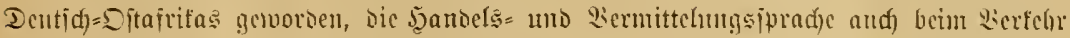
mit Farbigen aus Bimnentänmen. - Das in Sanje der 3eit mit Sehmmörtern

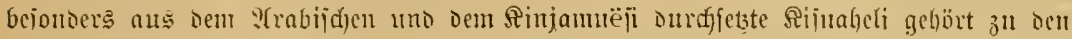
Bantu=Viegeriprad)en uno ijt cine Der agghtinterenocn ("nuflebenden") Eprad)en.

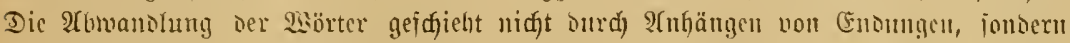

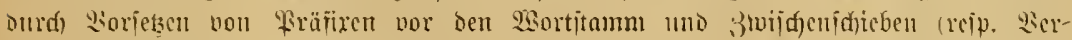

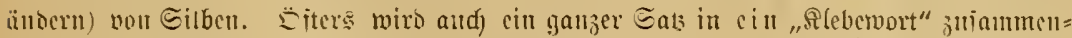

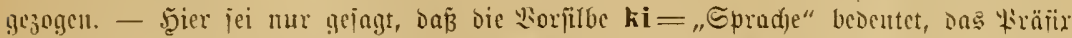

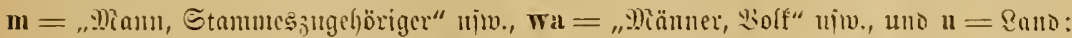

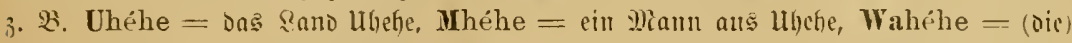

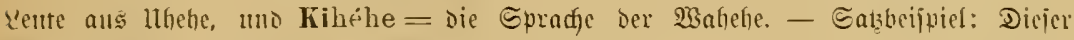

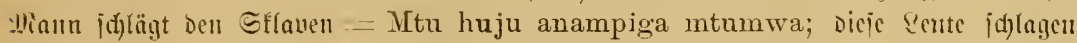
Dic Cflaber = watu hawa wanawapiga watumwa. - Piga ift io jiemlid) ons

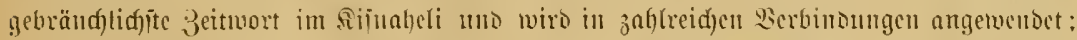
3. B. piga bunduki $=$ cine flinte nbjetcern, piga kengele $=$ flingeln, piga kelele $=$ lärmen, itreiten, piga darubini $=$ ourd)'s fermrohr iehen, nis. 3m.

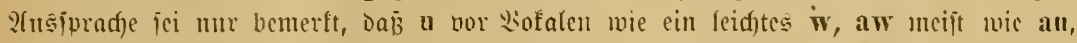

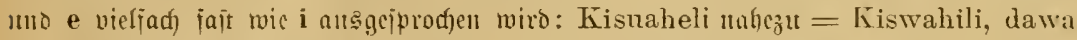

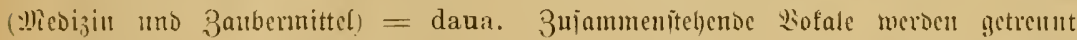

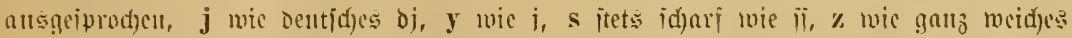

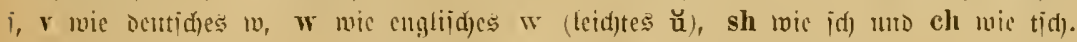
- Der sisorton liegt iu Rijuaheli, mit iefr menigen 2(ustahmen, auf ber nor:

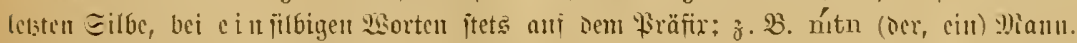

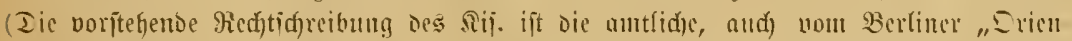

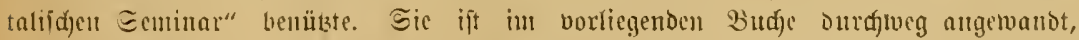

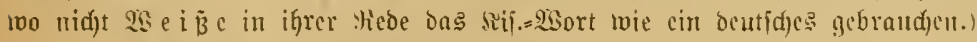

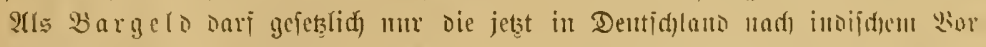

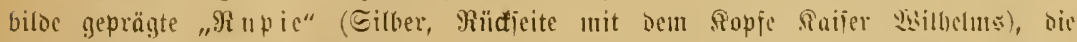

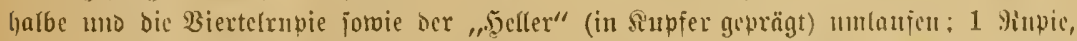

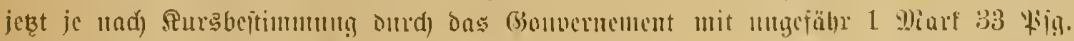

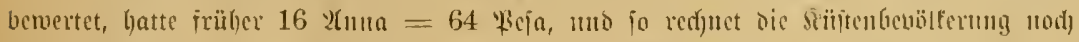
hente, obmoht antlid) nur bic Ieilung it "100 5̧eller" g̣ilt.

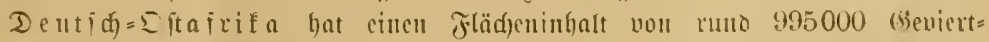
filometern, ijt aljo ungeiähr doppelt jo groß̉ mic das Deutide Reid). (F) hat etma

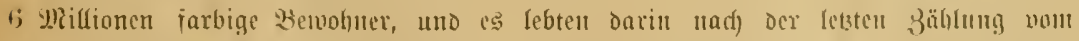

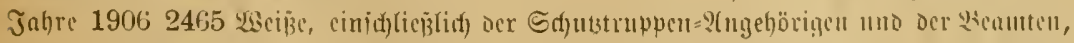

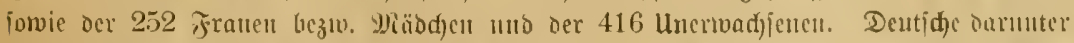

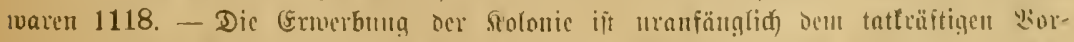

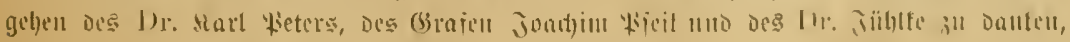




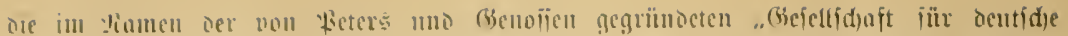

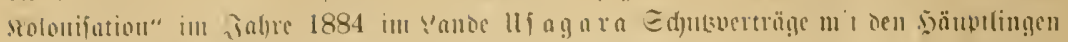

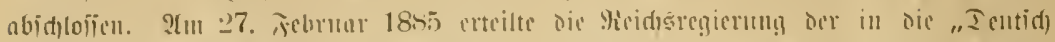

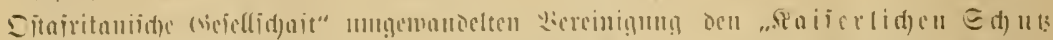

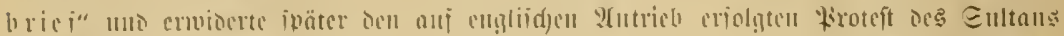

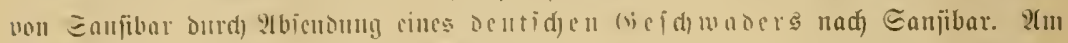

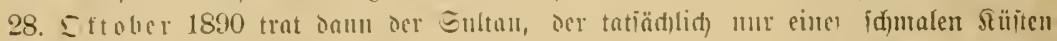

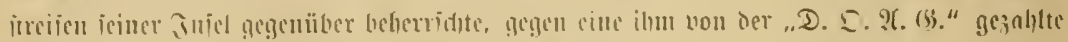

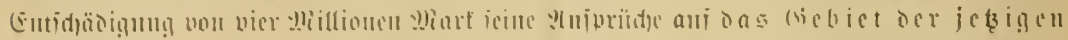

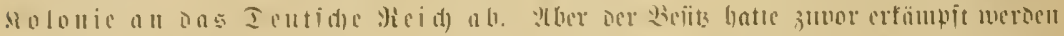

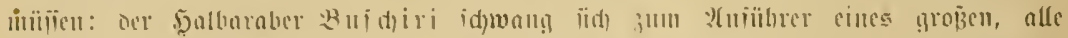

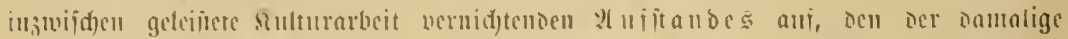

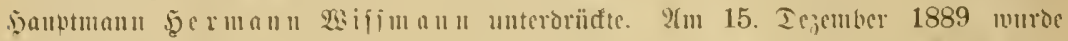

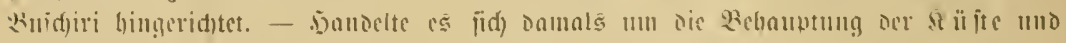

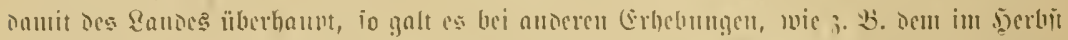

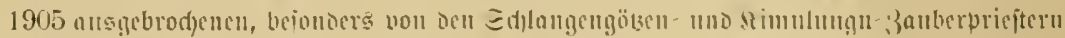

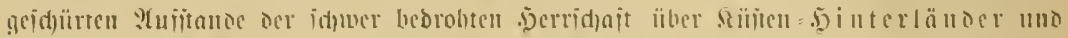

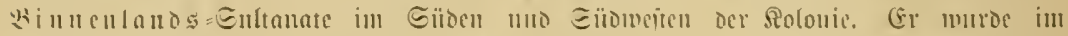

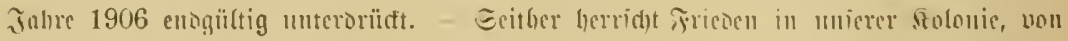

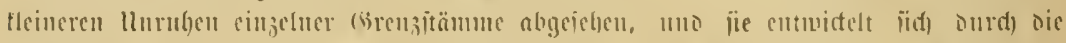

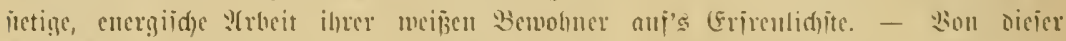

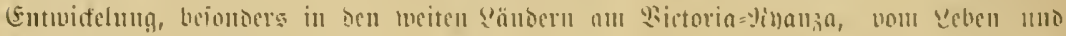

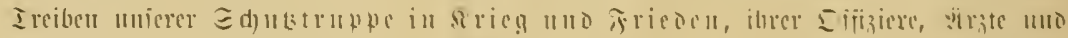

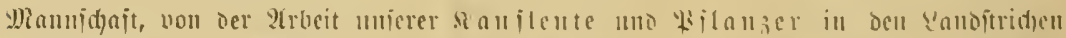

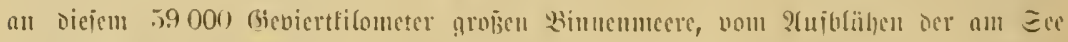
belegenen "Etant" "llinanza, wie nid)t minder vou Qeben mierer joridger, Jäg̣er

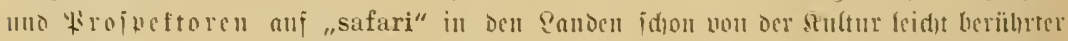

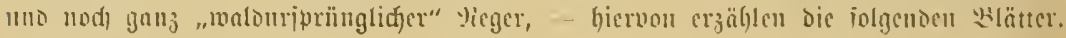




\section{Erites Kapitel.}

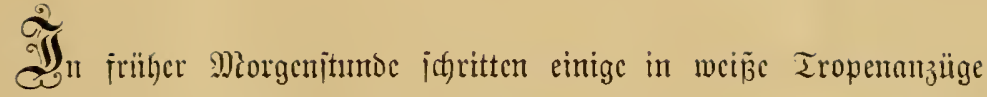

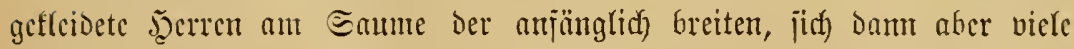
Mecilen weit johnal in's Samo hineinziehenton jmaragigrünen Budjt von

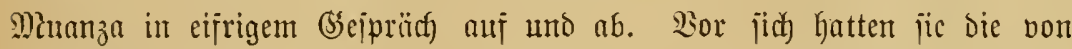
bcr höheriteigendon Eonne golbig überijtrahlte, jajt bemegungsloje Flädje

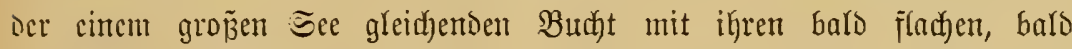
non Giranitjcljen umzogenen $\mathfrak{H}$ jern, hinter jid. mehrere bis zum Ctrande Gintablaufendc, in Blüte umb Frucht juglcich) itchende (Furopäergärtcn, die

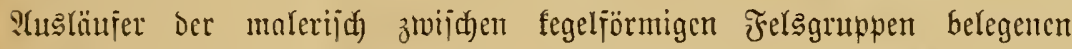

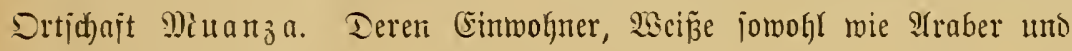
Jnocr, uno erjt redit dic Sifwarzen, nannten den Sort jreilid gern

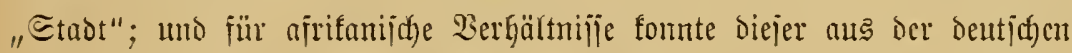

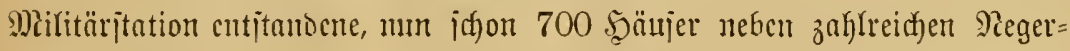

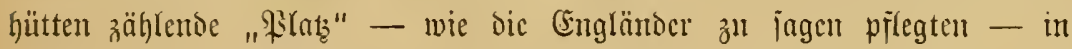
ber Iat als cinc Stnot gelten; als eine redyt amiegnlidue jogar.

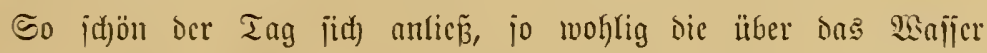

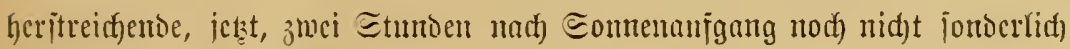

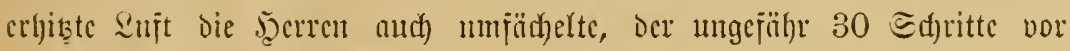

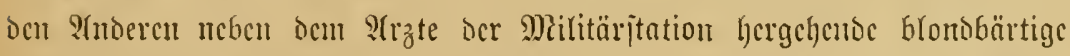

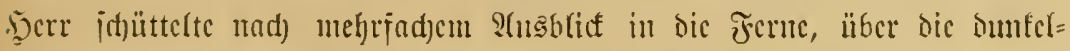
bewaldeten Berge uno den blizection Ea bin, Dodh jweifelno den Siopi tuno crflärte:

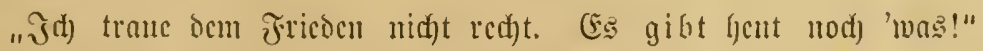

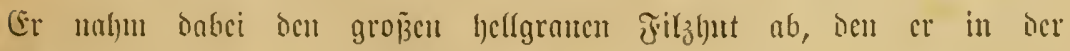

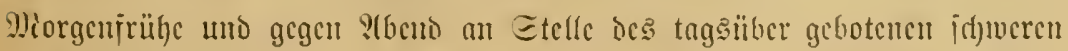




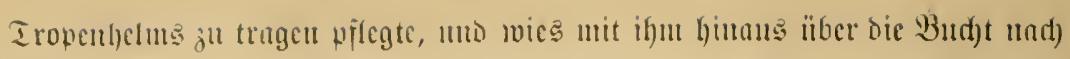

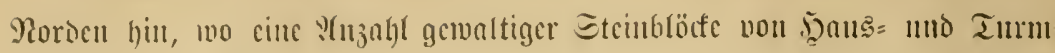

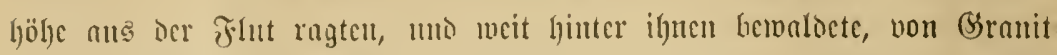

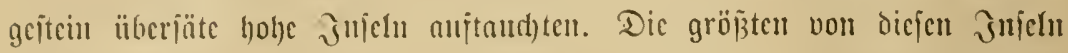
waren ier Butd) vorgelagert, id)lojien jie förmlid) ab, uno hinter ihuen erjit

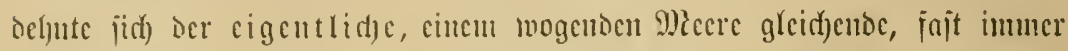

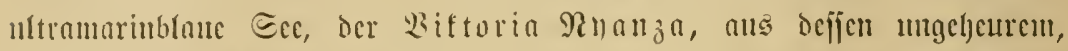

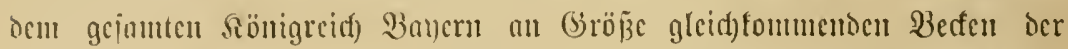

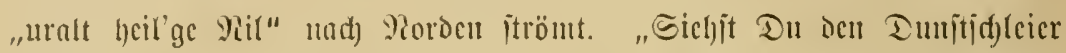
nid)t?" fragte Der Blonnbärtige, mo mics nod) cimmal weit hinnus nach

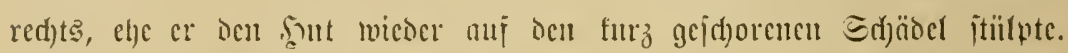

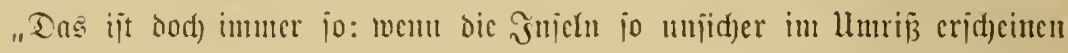
non diejen Flimuneroumit, Damu friegen bir allemal Regen."

Etabearzt Dr. Brumer, fein "Eectter in żweitem Brade", oder

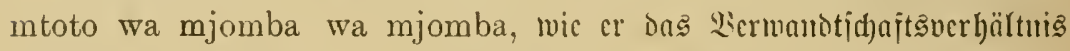
id)erzeno auj Rijunlyeli, Der Wierfefregiprache Ditajrifas, bezcid)uete, ,Der

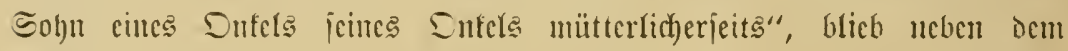

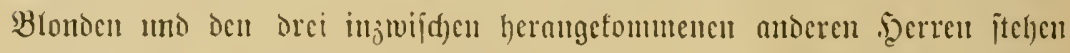

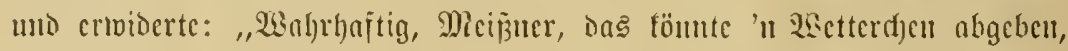

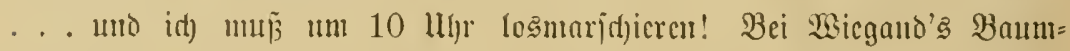
mollpîlanzern foll ja angeblid) dic Ed)laftranffeit cingejd)leppt worben

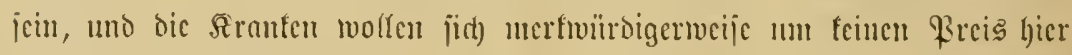
auf Der Station unterfuden lafien!"

„Na, Socr Etabsarzt, on warten Eic chen cinfad) mit ocm

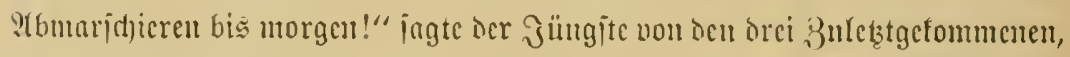

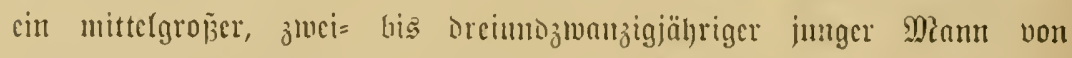

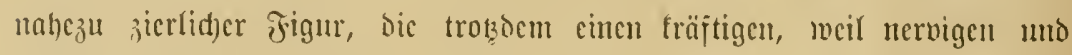

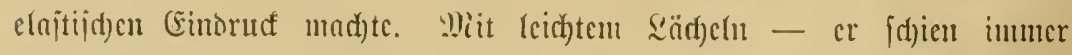

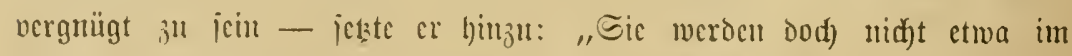
Tropenregen bic Dörfer abtlappern nad) Siranten?!"

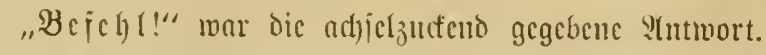

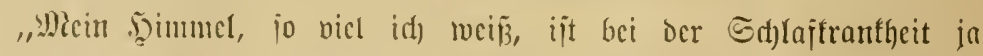

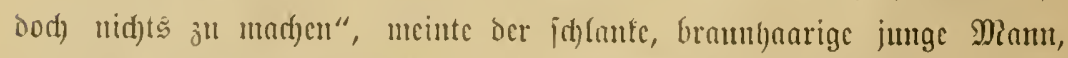

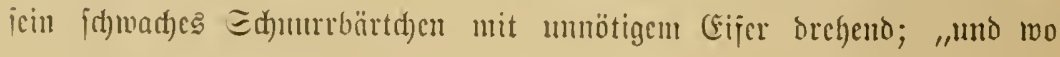


Dic Rranflyeit bod) nid)t non heut whi morgen jum Tooc führt, fondern

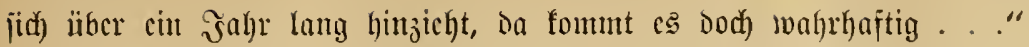

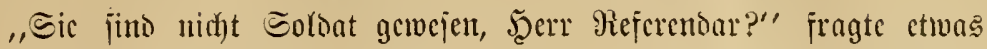
ironifich der Stabsarzt.

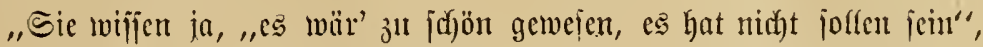

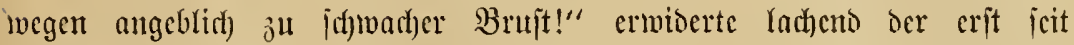

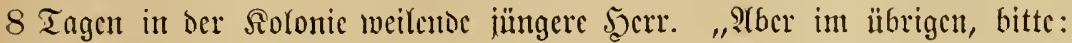

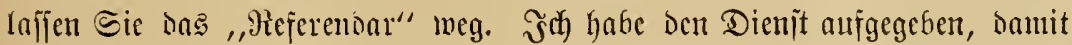

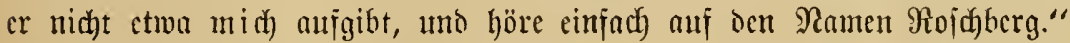

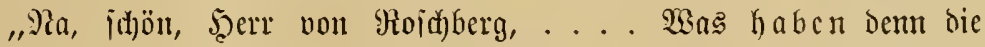
Nigger ba vorn eigentlid)?!" unterbrad) ber 9 (rat jith und Dentete alf eine Bruppe von Eingcborencn, dic bishcr ruhig ein halbce Dußzento von Ejeln uno cin paar Maultiere nuf einem bis zım See jidh hinjiehenoen,

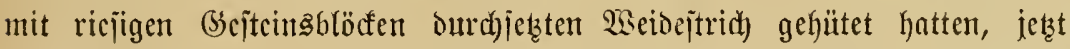
aber von ben will gewordenen Tieren üherrannt jein mušten, Denn einige der शieger flüd)teten, andere wurben von ben Ejeln gebiffen; idfricen ober

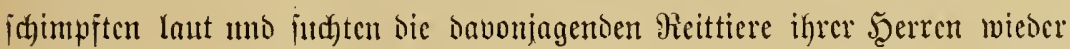
einzujaugen, währento ciner von ben Reuten chen von Dem itärfïten, fajt

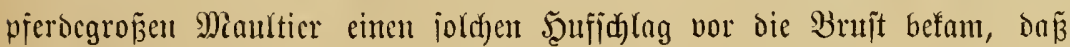
cr hintenübcr zu Boden fiel.

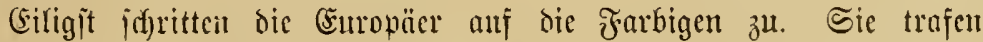

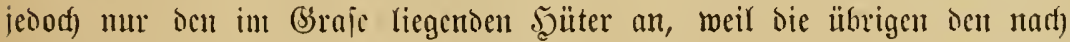
veridjiedenen Riddtungen bavongejtürmten Tieren nod) immer id)reiento nad)liejen uno jic erji mit jolfie einiger entgegengefonmenen $\Re$ cger aut

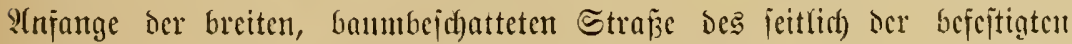

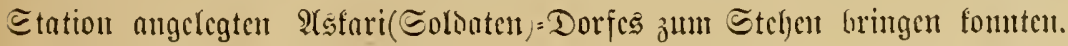

„Matürlich, utcin Witoro!" ricf ocr blonobärtige Wetter bes Stabs=

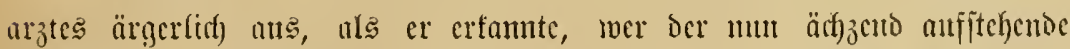

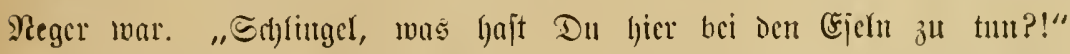

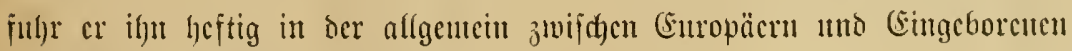

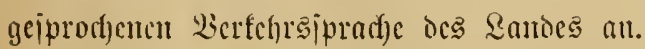

Der junge Jarbige, cin musfelitrannter Mianu aus oter his nahe

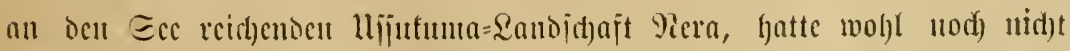

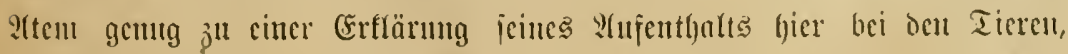




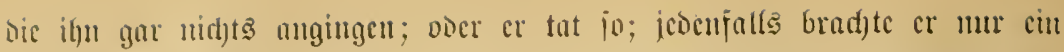
fendentes: „Bana, bana (h)err)!" hervor, tmo hiclt bauad) geourbig itill,

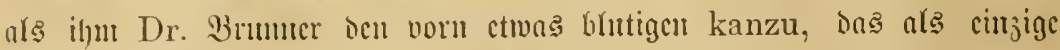

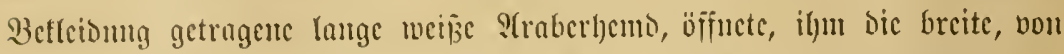

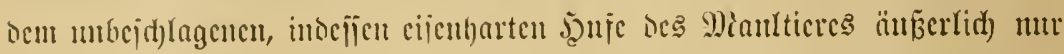

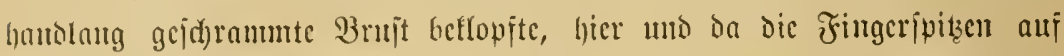

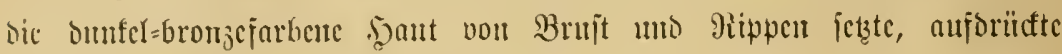
mo same "ticf CEnatmes!!" bcfahl.

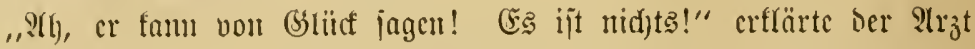
mad) Beendigumg Der furzen luterinduntug.

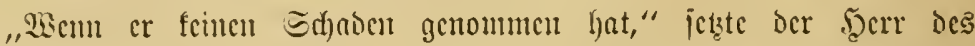

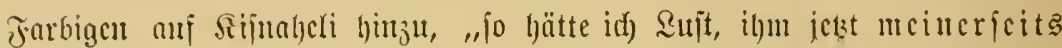
nod) ctwas ju verabjolgen, kofi nämlich (ciute Shrfeigc)", veriscutlichte

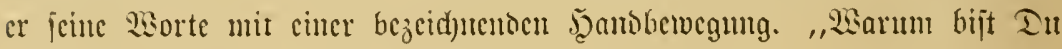
von Deiner 9 trbeit im Şauje fortgclaufcn, Mitoro?"

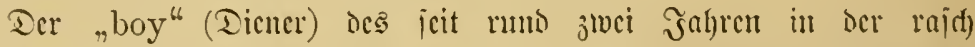

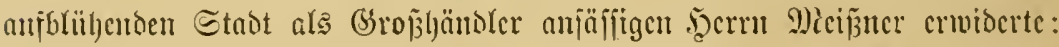

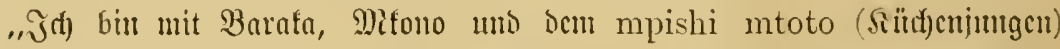
jum $\Xi_{e c}$ gegangen, um Deine fiteiber mo Deine Tild

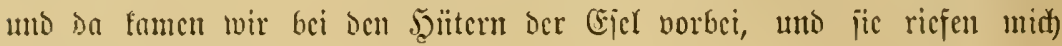
an, und Da jagten jic - - - ".

"ll no da blicb idf itehen, und ba idjmaz̧te idf lieber ale ju

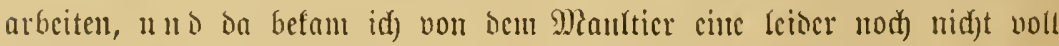

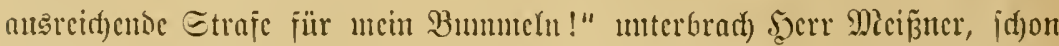

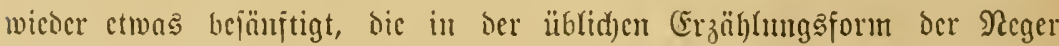

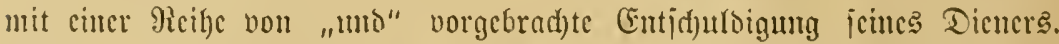

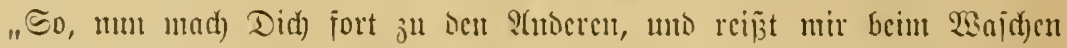

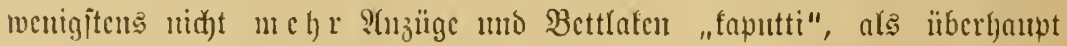

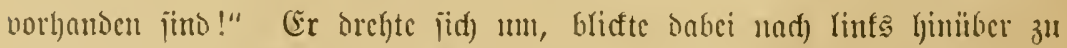

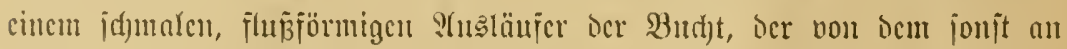

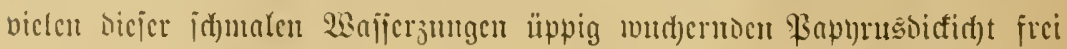
war unto cincu jejönch, cbenen Eantiptranto anfwies, umo jah bort banf

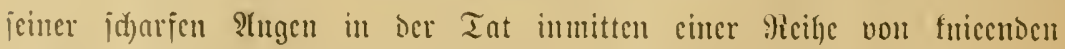

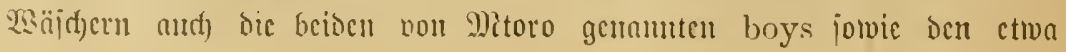




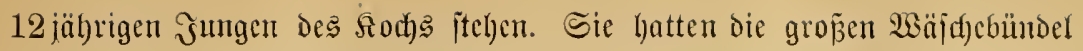

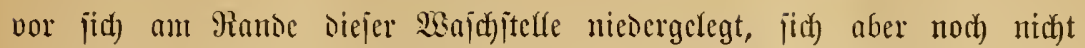

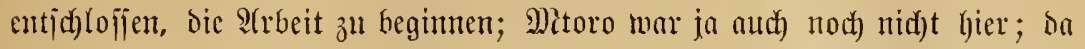
fonnte man bod) ganz gut noch warten! llno die oor ignen gefommenen

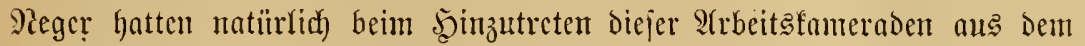

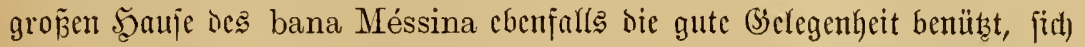
cin wenig auszunuhen, hatten jofon jeit gerauner Zcit aufgehört, bie najị,

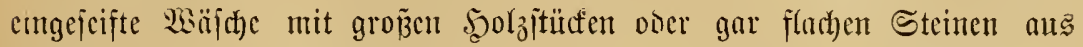

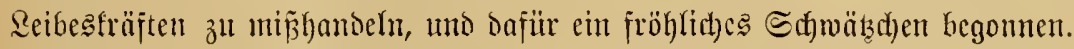

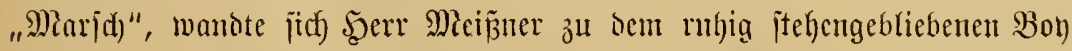
zurüđf, "und treibe, troł der eigenen Faulenzerei, bie Faulenzer bort gehörig an!" Er war im Begriff, Den mit Dr. Brumer wieder ungefebrten umo auf bie von hier aนร hinter jhattigen Bäumen halb verborgene Station juj Ejeljunge hes bicfen Şerrn" - „bana mnene" uno jajt niemals mit

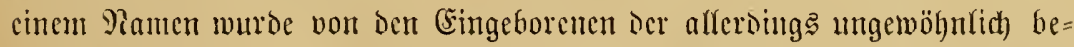

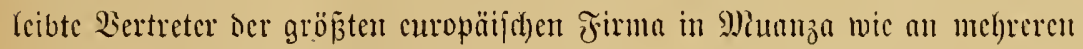
anoeren Drten Dentich= Ditafrifas genannt, ber Dortige Dberleiter Der

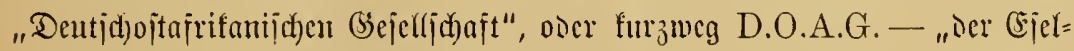

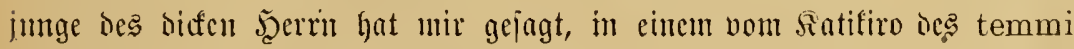

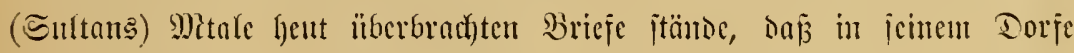

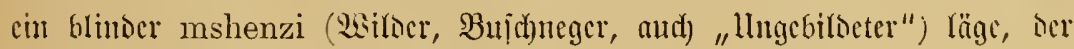
zu Dir wolle." .

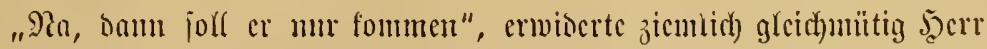

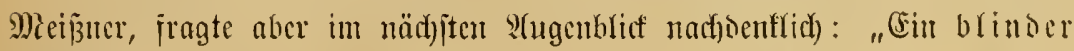
Micicneni ?"

"Ndivyo, bana; mshenzi kipofu kabisa (ja, jo ijt's, Scerr;

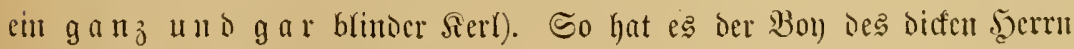
Dem (Eịelbou) des .jerm erzählt."

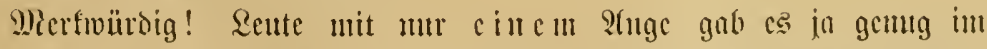

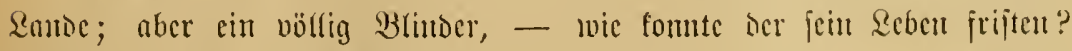

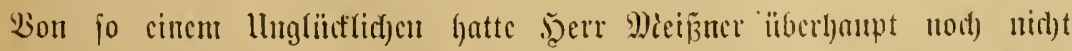

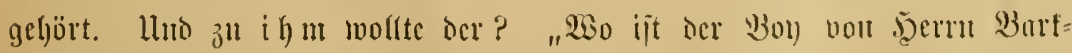
mant? Der jollte midh Dod wohl betad)ridytigen?" 


\section{$-6-$}

S(ber Mitoro hatte ies Boy jelber midyt geiehen. Bermutlid) hatte

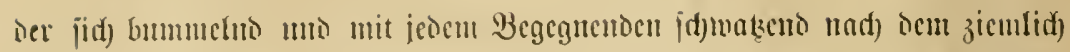

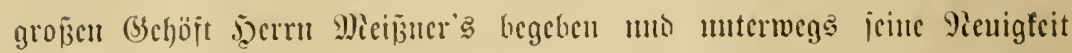

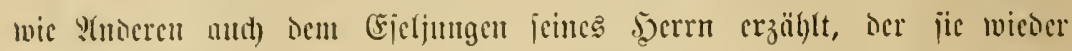

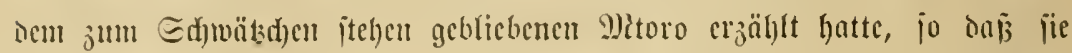

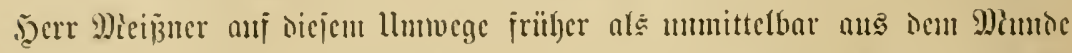

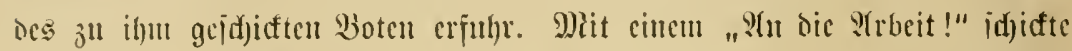

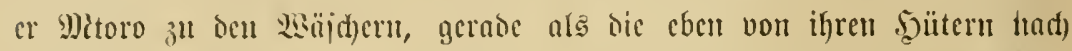

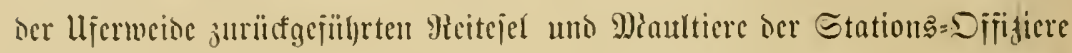

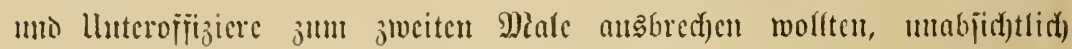

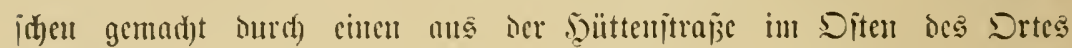

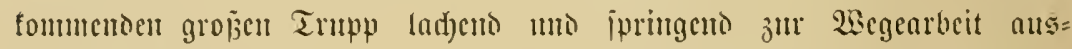

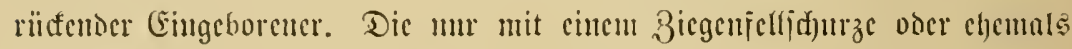

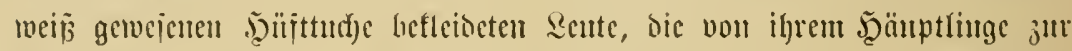
Station gejants waren, un hier anitatt der vor cincm Jahye erit ciuge=

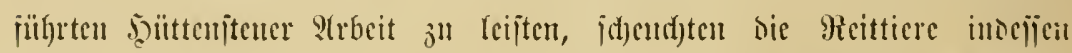
3uriư, ehe jic micocrum ourd) ihren wildon (jalopp

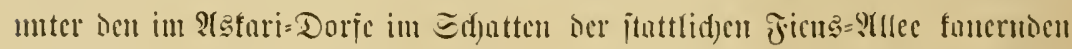
2scibern mo den hernmpictenton Rinoern ber ja meijt nerbeirateten Soldaten verbreiten fomten, unt danu zog Der Irupp Doppeft uerguïgt Davon,

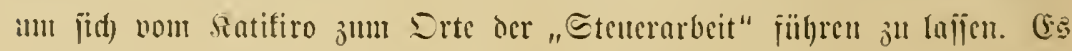
war bas ciner non Den (Fingeborenen, die jrïber mut gelegeutli d) aL

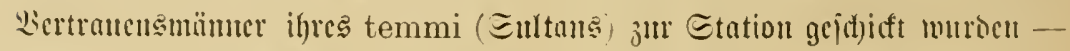
cigentlid) mar ber Satifiro Der Berater, "Mituifter" icuncs Eultuns -,

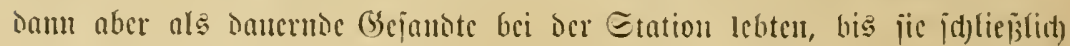

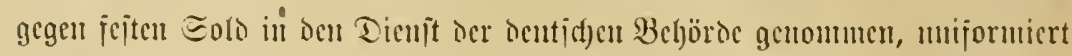

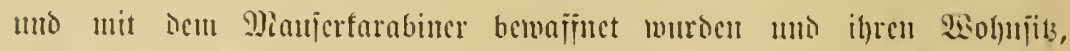

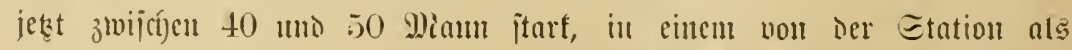

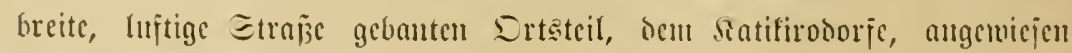

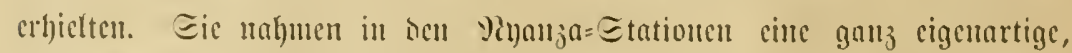
in ocr Srofonic jonjt nidgt vorfonmento Etclfung ein: jie, Die ganı militäriiit)

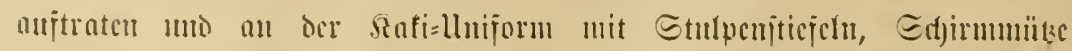
mit grojem 将ejïngabler jowie einer breiten roten હd)ärpe id)räg über bie Brujt jort temutlid) maren, batten sie Sujgabe, jid) über alle 
Sorgänge in ifhrem Sande unterridutet 3 h halten mo jie ocr Station mitzuteilen, aber aud bie Befeljle umb Befamutmadyungen oer Deutjichen

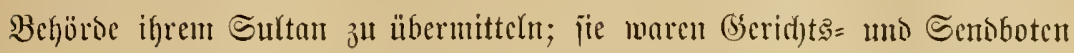
jomie Stcucrerbeber für igren Bezirf, jugleid) Dolmetid)er der Station,

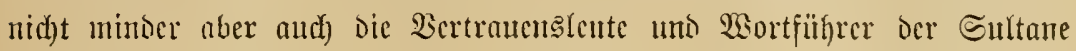

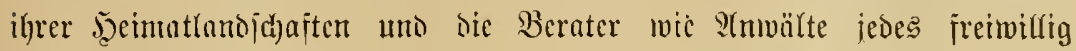
ober vorgeforbert nad) Mitanja foumenten Samißmames.

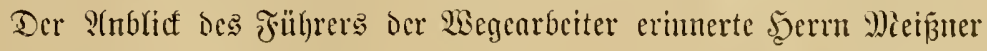

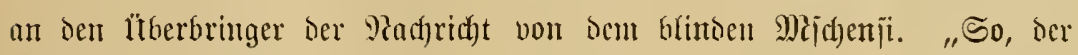

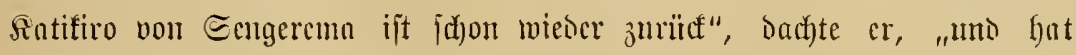

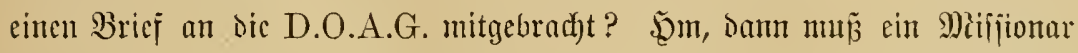
ober jonjt eill Suropäer in Mitale's (Dorfe) jein, Dem ier alte Sallaufopi

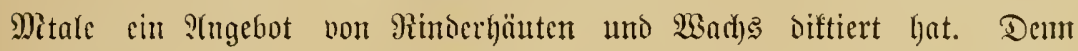

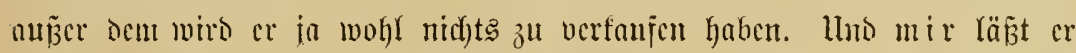

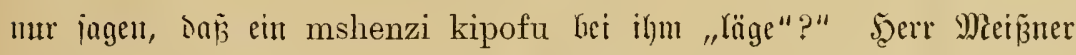

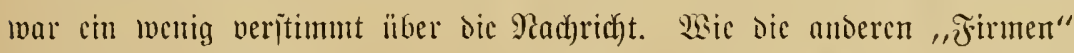

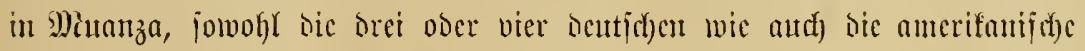

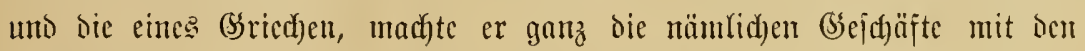
Eingeborenest wie bie alte, fapitalträftige "Becjelfichaft", wns jtanto baher,

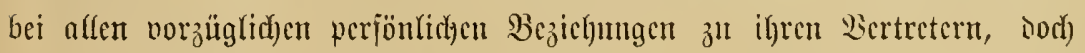

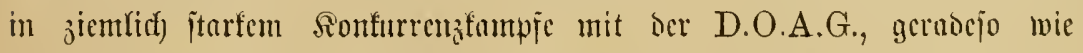

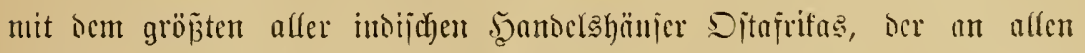

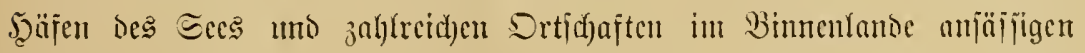

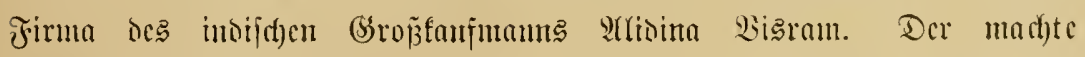

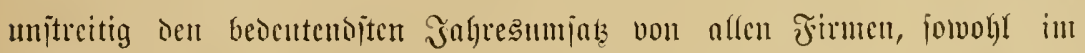

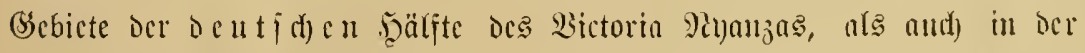

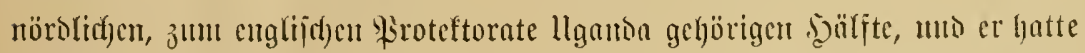
nicht nötig, feine $28 a r e n$ mit cimem ocr beisen englijafen Dampfer ïber ocn

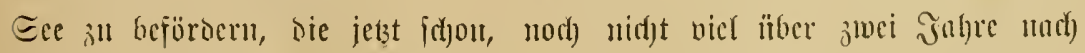

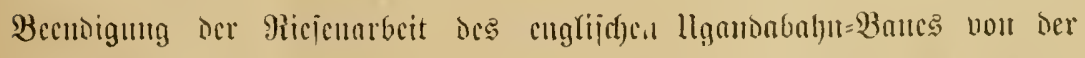

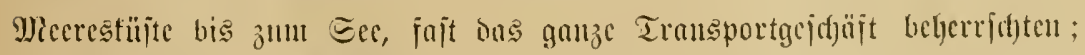

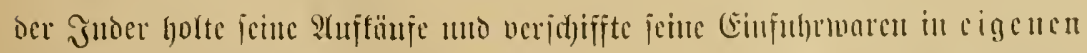

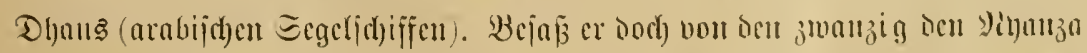

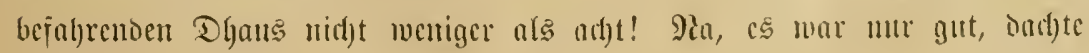




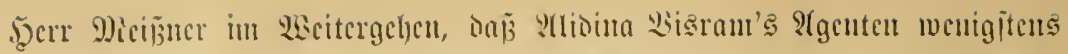

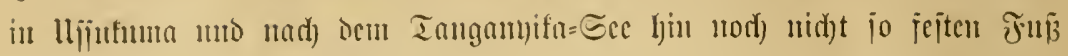

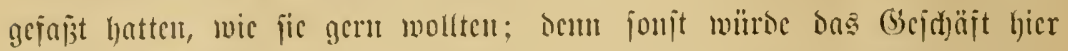

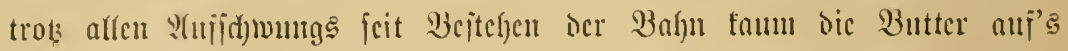
Brot cinbringen! - Das war ja mut recht arg ïbertrieben, trokzom

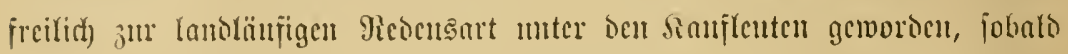

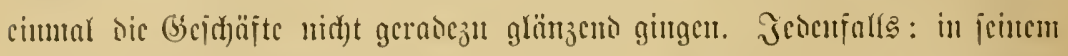

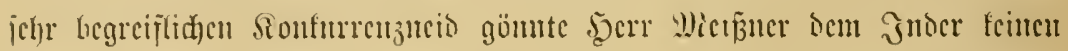

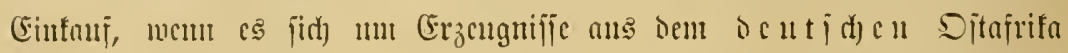

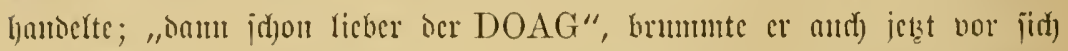

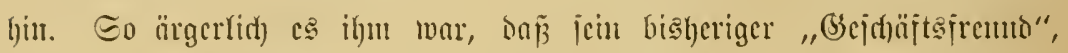

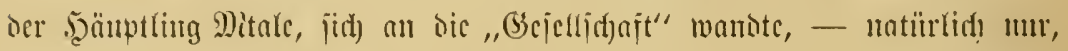

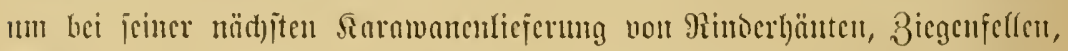

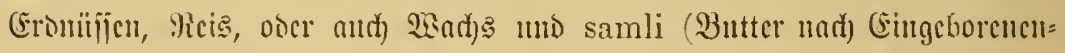

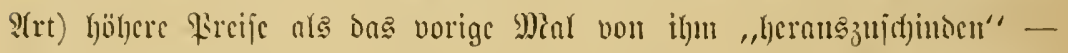

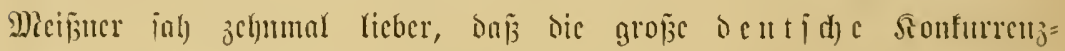

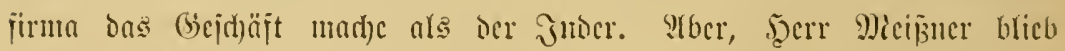

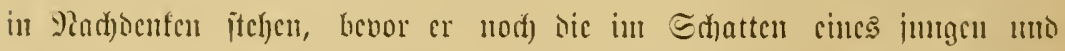

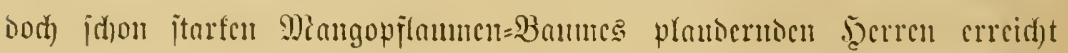
batte, aber was wat das mur mit ocm blinoen Mijd)enji, ocr mad)

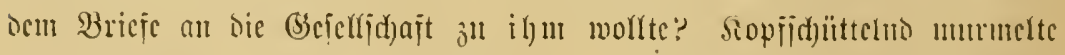

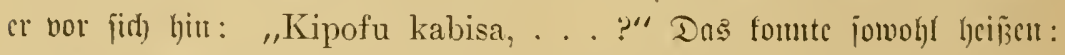

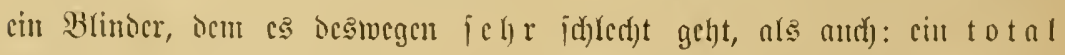

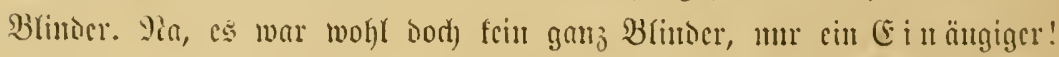
Demu cin völlig Błh

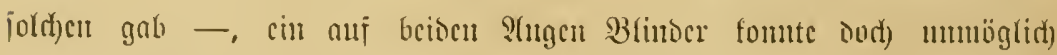
cinc Trïgerfarawane herambringen! Mitoro hatte geiagt: ocr Whimic "läge" bci Mitale's. Das hicís hod): er läge mit jeincr Siaramanc

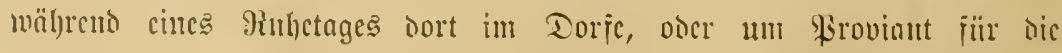

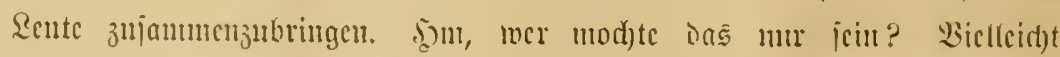
cin cinäingiger Jäger! I(ber dam bätte Barfmmun's Bol) tod) jidf)erlid)

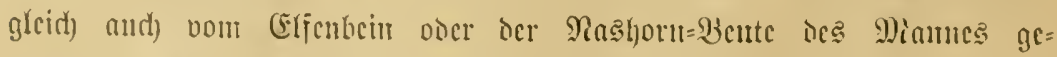

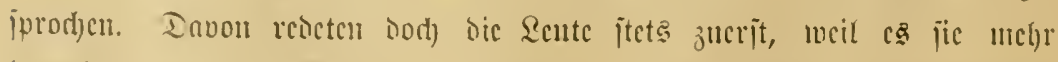
interejïicrte ale dic \$erjout tes Jügers. - Sun bejten, er ging jelber 


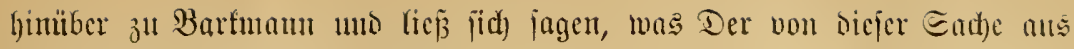
dom Sayreiben Mitale's mujpte!

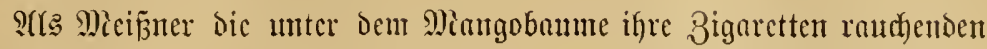
Şerren erreicht hatte, fam aus ocr wenige humbert Mieter entfernt Yicgenden iteinernen Bona, oer von crföhten Bajtionen fluntierten Unmualfung ocs

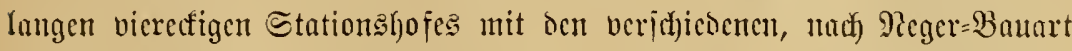

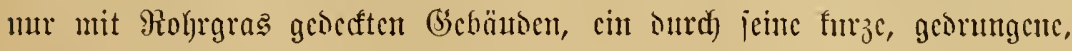

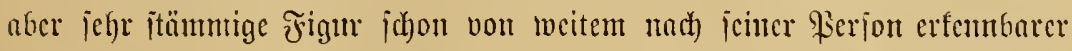

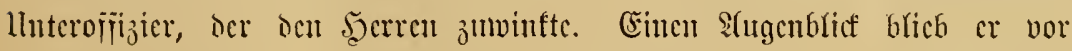

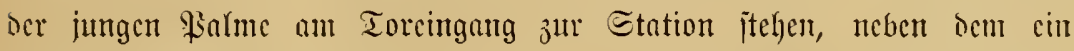

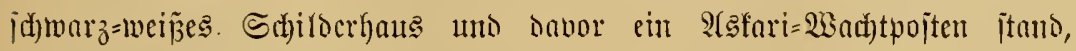

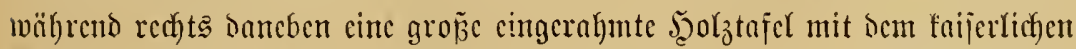

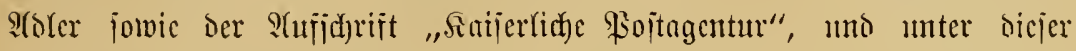

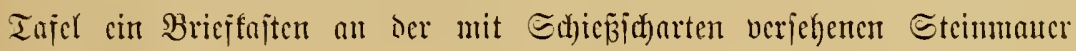

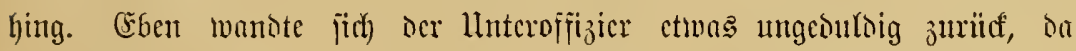
fau aher auth jofon ber bon ihm Erwartete aus bem Stationghoje, cin

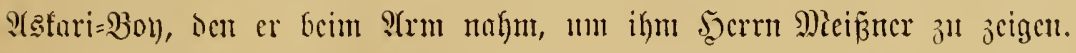
Der in einer abgelegten nod) leislich weijen Europäerjacfe mo cince

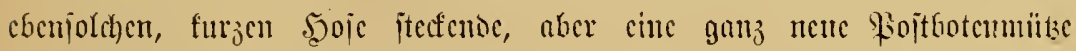

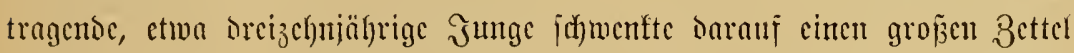

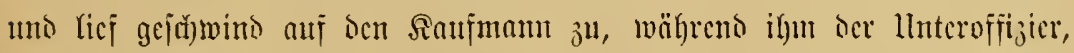

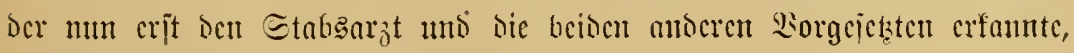
in itrammerer Daltung als bishcr jolgte.

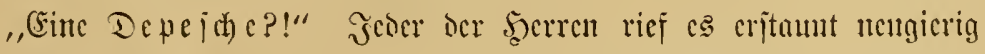

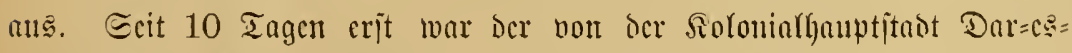

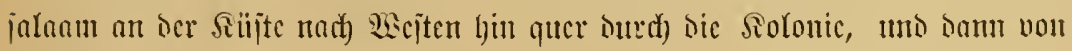
ocr Bimnen=(5rojitadt Tabora norbuärts jum Eec gejührte Telcgraphen=

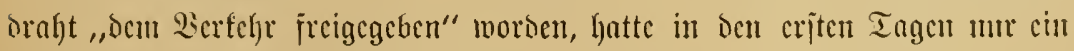

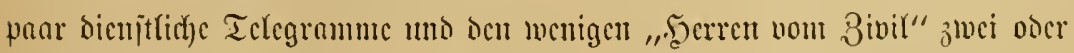

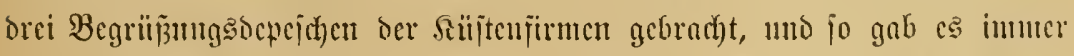

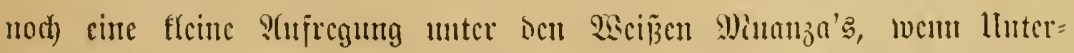

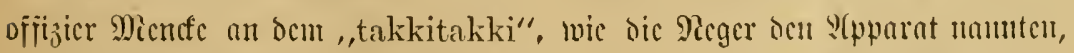
cin Telegramm. anjnalgn. Denn megen ser geringen Emropäcraghl ber

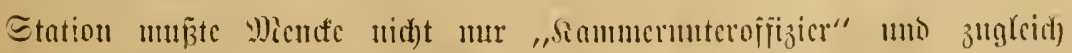




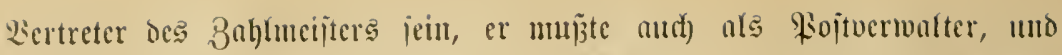
Danf cintes im Sorjafje mitgcmad)ten Surjus, ars Ielcgraphijt Sicmit

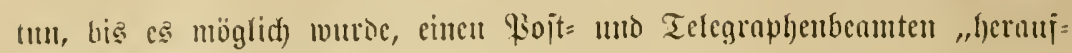
зuid)itfen" แn oen @ee.

M) iit gewid)tiger Mitene ıno ben Worten: "Unapata simu,

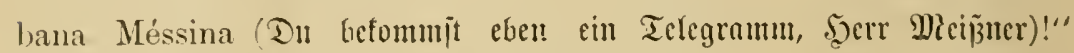

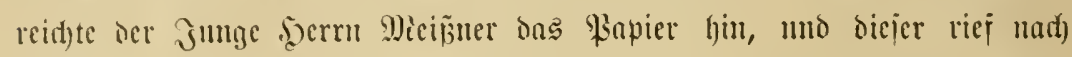

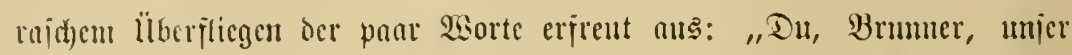

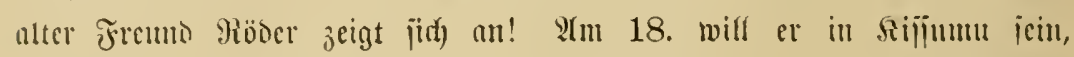
...er foum afio mit bem nädjiten Dampjer! Fauns! Famos!

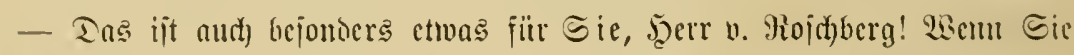

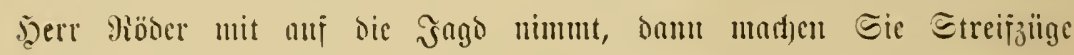

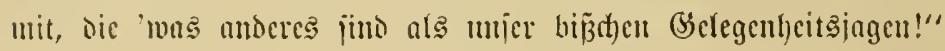

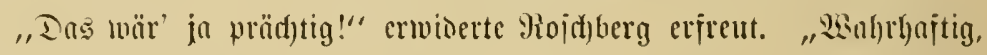
das wär' gunz ausgezcidfuct!" (Er war nur Ber Jago wegent nud) Oit= afrifa getommen uno batte geglaubt, and) in ber beutid)en fiolonic fämen

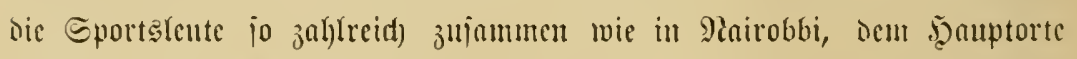

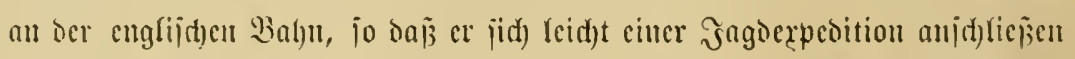

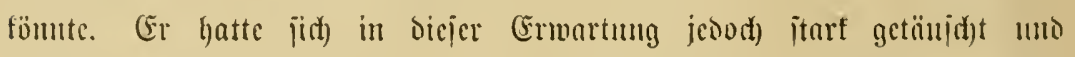

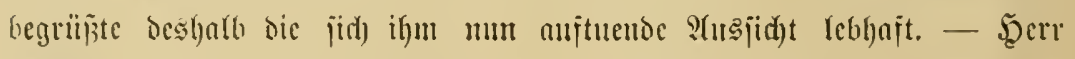

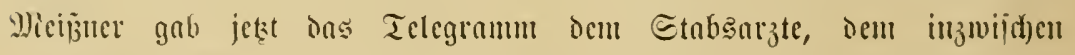

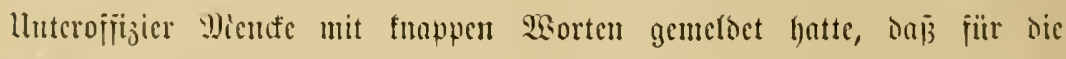
"Siruntenvijite in Den Dörfern" alfes bereit jei, uno Dr. Brummer riej

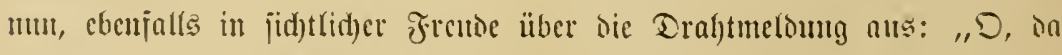

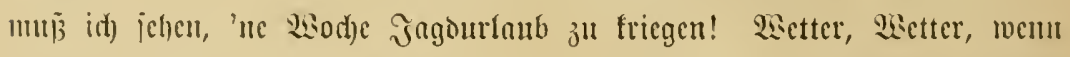

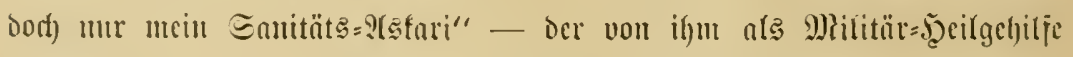

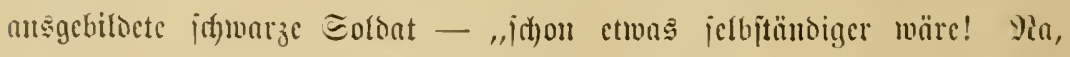

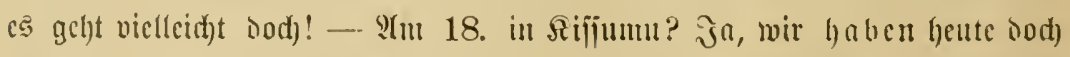

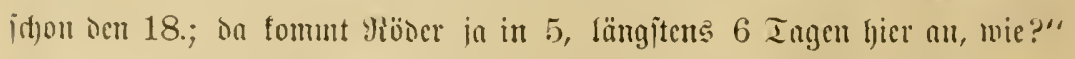

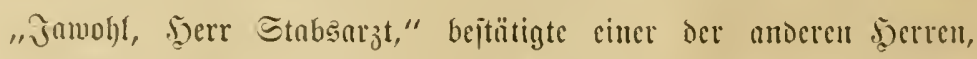

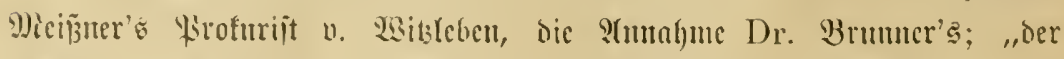

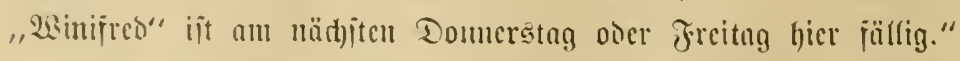

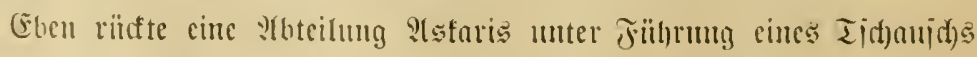

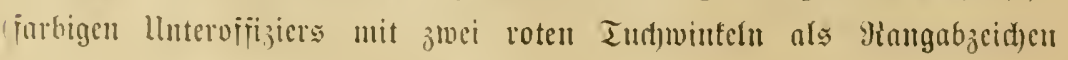




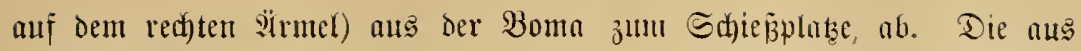

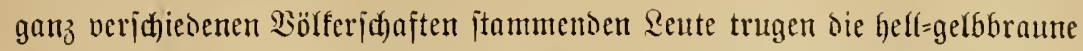

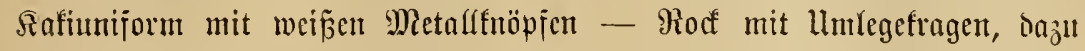

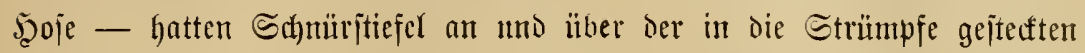

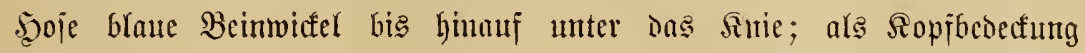
biente ein mit Safiōtofi überzogener, topiförmiger Strohhut ofne Srempe,

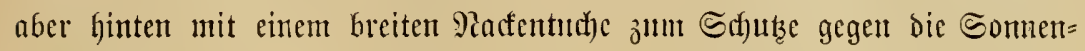
bejtrahlung; vorn an sem 5jut war sie aus Miejïng gejtante fompagnie=

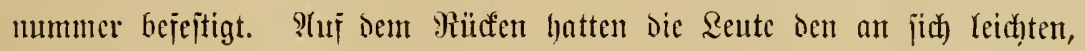

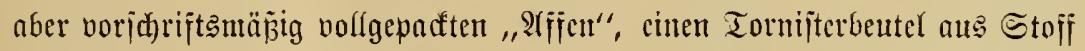

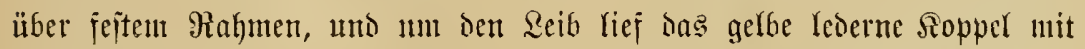

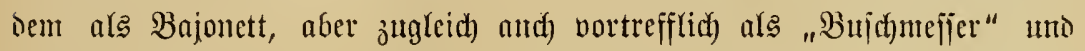
5)acfebeil dienenoen Seitengewehr jomie unit jwei gelben, vor dem Reibe

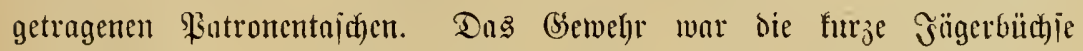

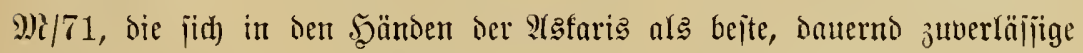

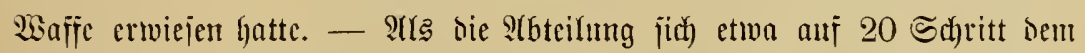
Miangobaume genähert hatte, in dejī Schatten die Entropäer itanten,

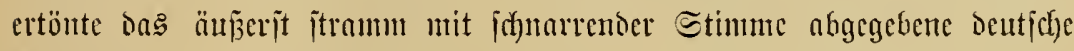

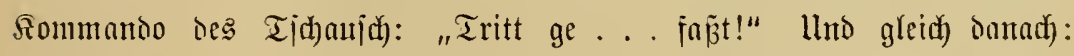

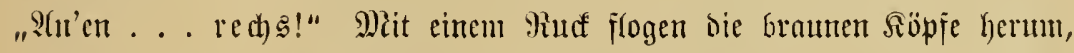

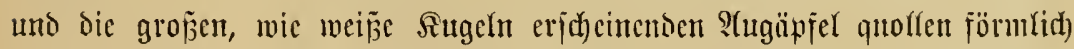

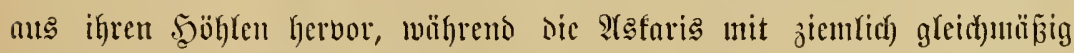
geidultertem (Setwehr an ihren etwas vor Den Drei anderen Ėmopäern itehenden Borgejezten vorübermarichierten.

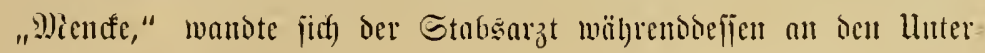

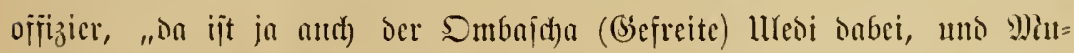
haumed Mitonde! Die beciden Rerle worlte idf) dodt) mit unter ber Bciecfungamanuichajt haben!"

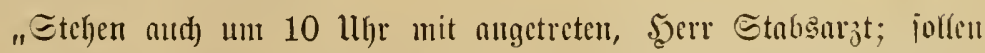

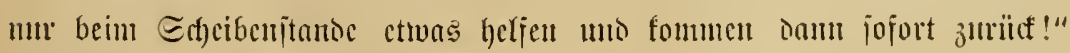

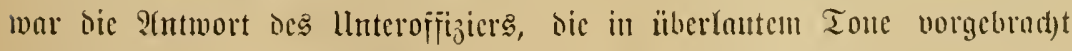

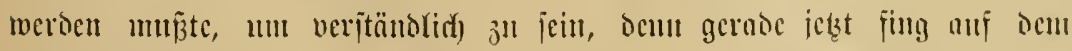

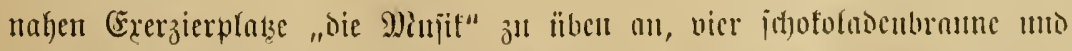

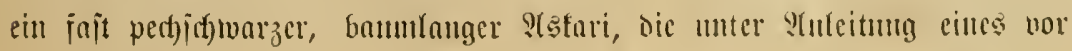




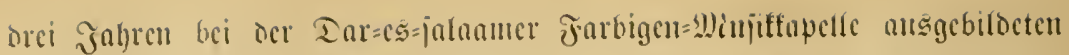
brumen Sorniften dic Cignule blajen uto piga ngoma ya Ulaya, dic Emopü̈r=₹rommel jid)lugen lernen jollten. Sic waren neben bem ricjigen

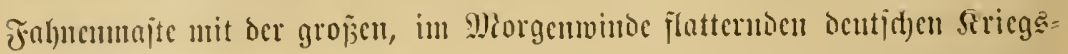

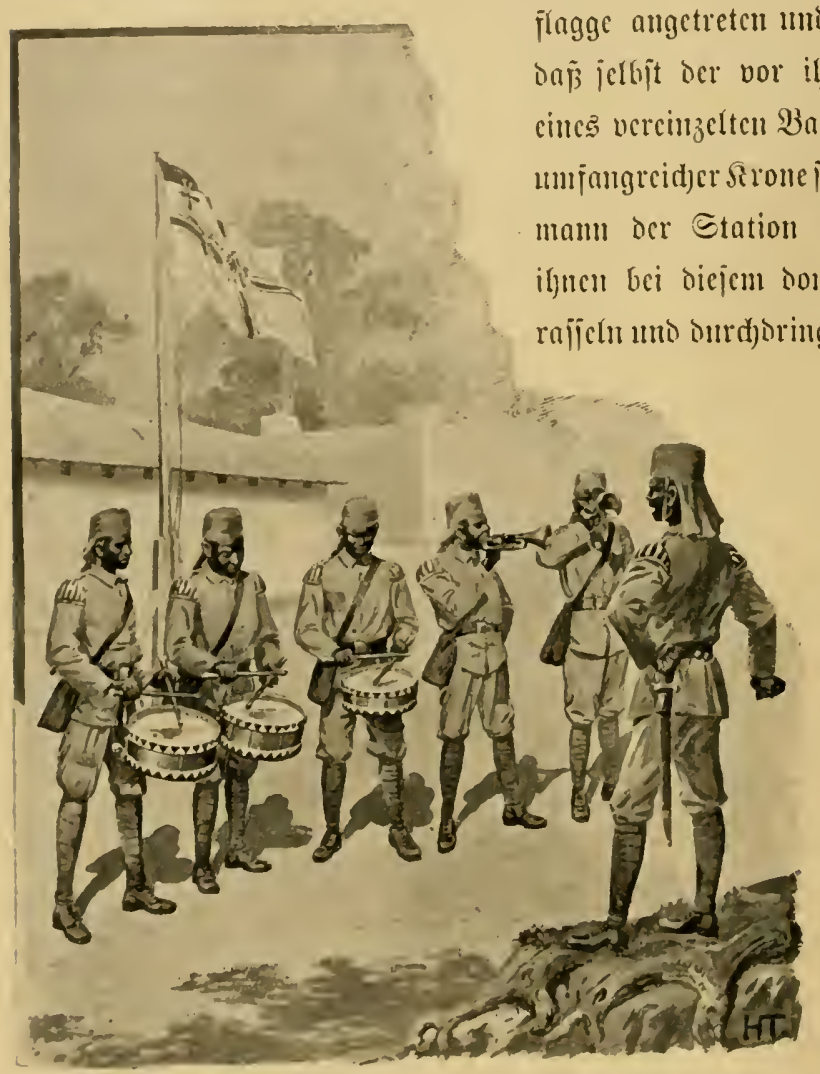

Fagge angetreten unt ïbten dermajecll,

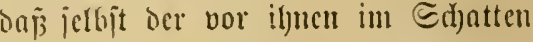
cinte ucrinzctch Daunes unit gewaltig ene itchentic erite Epicl=

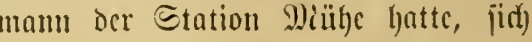

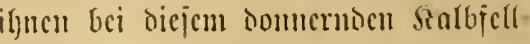
ajicls uno ourdjoringentom Trompeten verịtünolich) $3^{u}$ muct)en, jo lout or and) jeine ani Sijungcli gegebencll, aber von melyrjaticus, in Bor siiijtces= louptifant auj geidjumptent

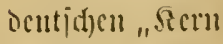
morten" unter: brod)cutell 2 ablor amuciijungen ba $=$ jwijid)en idfric.

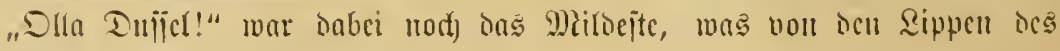
braumen "Sapellmeijters" fam.

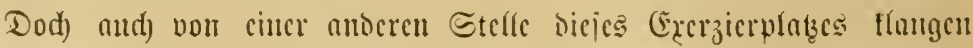

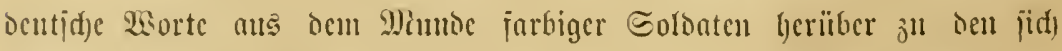
jekzt nor ber "Minjif" förmlid) flüd)tenocn, ucben ber Etationamancr jun

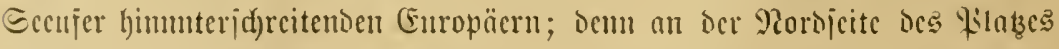

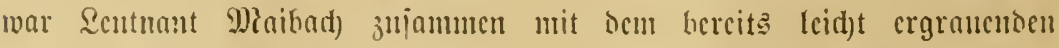
Enduncien=Tidbuid) S(li bin Eci, jomie ocm flemen, nber bejonders

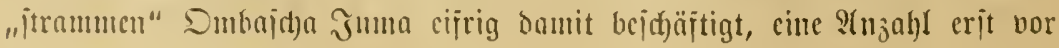




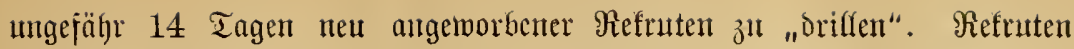
wurben eigentlidi) immer mur in Dar=e $=\{$ alaam eingejtellt; aber hier hatte

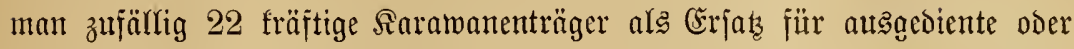
wegen Dienjtumfähigfeit nach) unto nach entlaffene Seutc anwerben fömen, uno hoffte, bie meiiten von ifnen nach der ̈̈blichen \$robezeit von drei Mionaten enogültig cinreifen zu föınen. Sic mušten freilich, ,idyarf 'rangenommen merden". Der inmer etwas hajtig, jidh vor Dienjteifer oft= mals fajt atemlos iprectuctide und dabei dod) ftets wohlüberlegt handelnde rotbacfige junge Reutnant - Den jich) Die Station aus Dem 18 Tagemäriche jüblicher gelegenten Tabora, "eigentfich mur ausgeliefen hatte", wie er zu jagen pflegte - swar eben dabei, bie in zwei Ssliedern angetretenen, ,Neuen" vor affem erjt im 2tusrichten ju üben, wobei er auf Rifuabeli: ,Nummer 14, Bautd 'rein!" - „15, 16, אopf hoch!" unt gleich danach wieder und wiederunt: "14, Bautch 'reint"“ hent jo häufig mie gejtern und all bie Tage vorker rufen muß̧te. Denn die Reute legten ihre Fehler in der

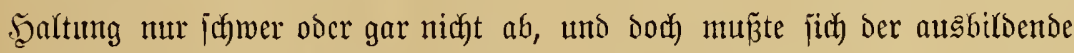

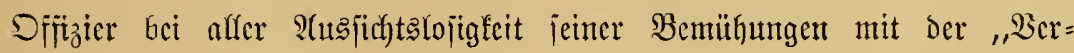
bejferung ber Şaltung" abplagen, weil Das eben eines Der Mittel war, Die jafwarzen Soldaten an Disziplin jut getwöhnen umb dadurch die Truppe jejt in die Şand des Führers zu bringen. Fs hatte bieje eifrige "Siorreftur" bei Dem ziemlich bicffäuchigen Kumi ńna ne (14) freiliç)

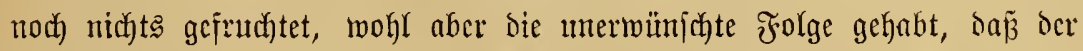
jo oit von Reutnant Maibach) Dem 2 (sfari zugerufene $\mathfrak{B}$ ejehl "tumbo dani!“

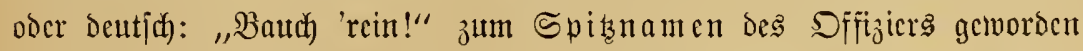
war, uno bie Benentung „bana tumbo dani" Gatte jid) um jo rajcher eingehïrgert, als Maibad) merfmïrdigermeije Den 2 (sfaris aud bcr

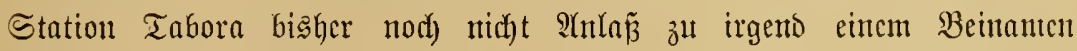
gegeben hatte. Seder andere Curopäer, Sffizier wie Sianfunann oder

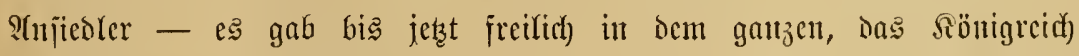

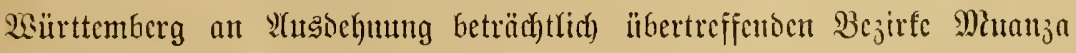

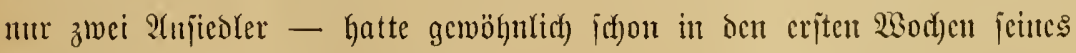

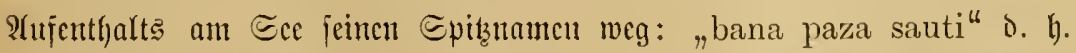

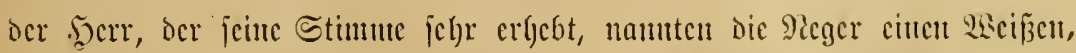

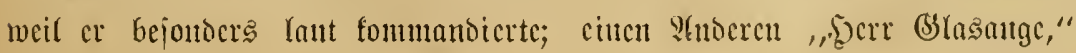




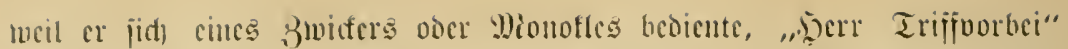

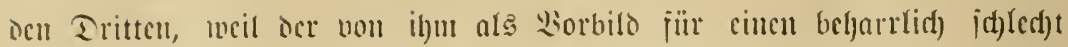

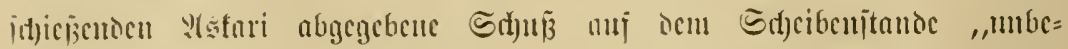
greiflidfermeije" bancben gegangen won, uno nod) cincu anderen Difizizicr

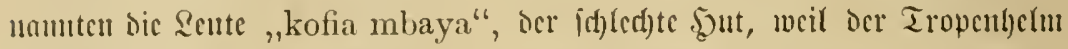

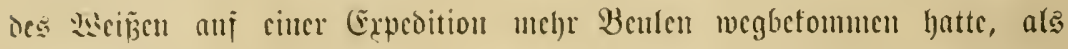
f́rincm Bej̈izer lieb wat. „Bana tumbo dani" foumte ïbrigens nod)

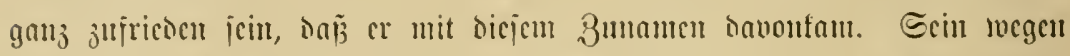

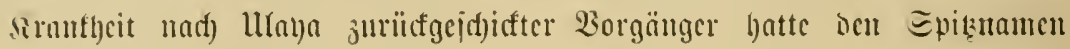

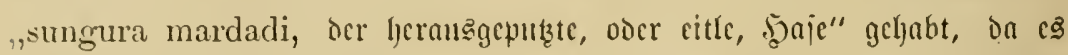

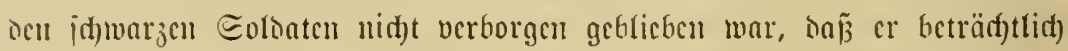
bicl mrhy alli das gutc Eizen jeince lluijorul gab, als man das int

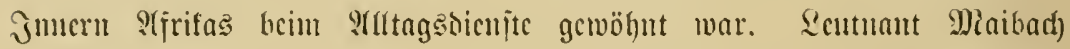

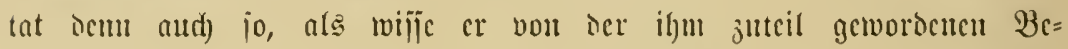
nemumg nid)te, mo ricj bem rmolcibigen "SEtari $14^{\prime \prime}$ - wic der

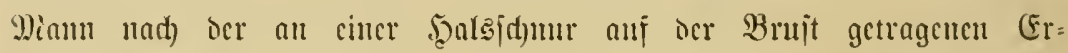
femungsmare vorlänp̈ig bis jur cnogültigen Einjtellung in dic Irupwe

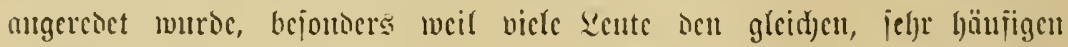

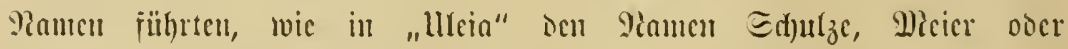

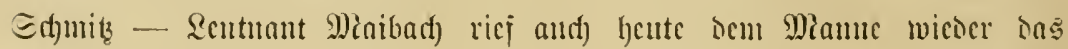

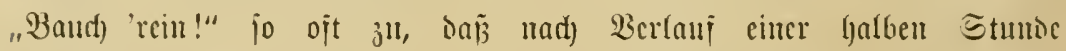

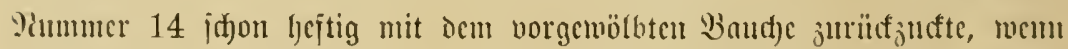

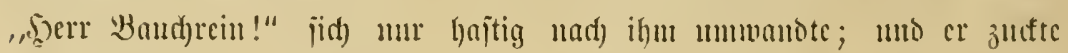
aud) nad)ber mit bem Scibe, ule dic ?(btcifung beim "Grifïc üben" war,

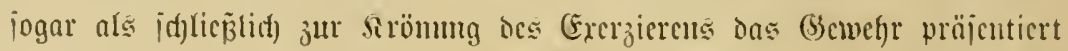

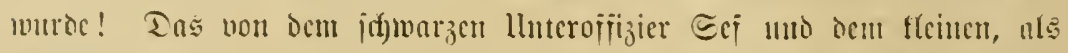
Y(bzeid)en mur ciucu roten Tud)mintel tragentocu Dubaja) Juma hicrbci abgegehenc Sommanto batte ïbrigens glcidjalls bic wirtung, dic Bant)-

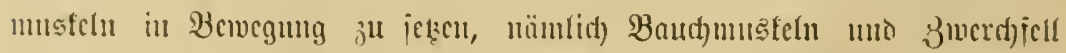

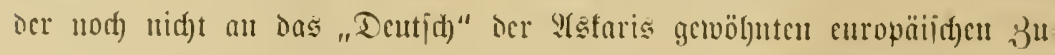

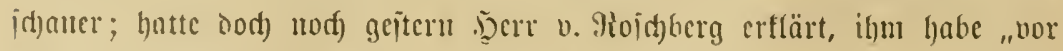

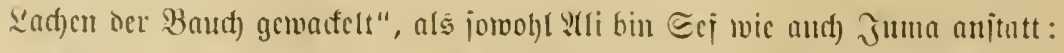

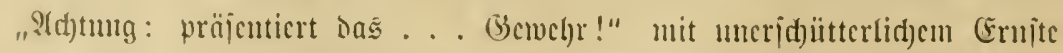
mebr gebrüllt als fommandicrt hatten: „9luton präicuticrt das (Scmebr!" 


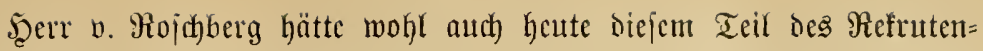
exerzierens gern mit zugejehen, ment ifhn nicht das Berlantgen, mchl

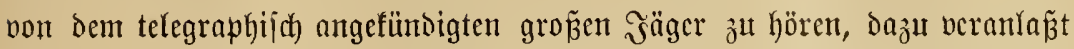
hätte, bei den fidy vor Der, "Majüt" in Sirherheit bringenden Şerren zu

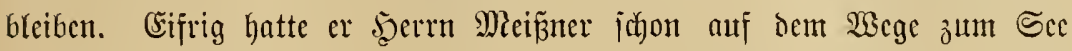
nach Şerrn Röser gefragt, gleid) nachocm jich Stabsarzt Brumer verab= idjiedet und in bas vort ifm bemohnte grasbedachte Şaus inncrharb ocr Station zur "Sprechjütunic für Farbigc" begeben hatte, nod) bevor bic beisen anocren Sffiziere jidh nach Beendigutg oes halbjtïndigen Spazier= gangs jum Dienjt in Das, ,Burcau Der Station" verfügten. Dort hatten

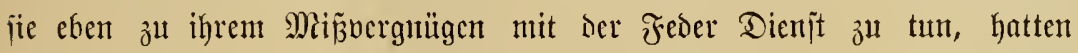

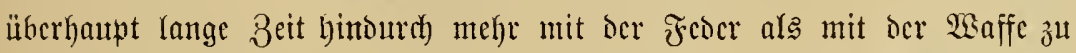
hantieren; denn dic vom fommando in Dar=cs=jałaam geforderte "amtliche

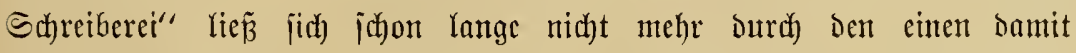
betrauten Unteroffizicr bewältigen; jie erforderte viełnehr, namentlich ba der neben jeinem jonjtigen Dienjte aud nod) ben des Rompagnie= Bureaut= farreibers verjekente Unterofifizicr jurzeit fieberfrant war, ocn ange=

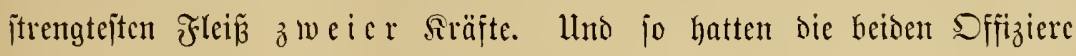

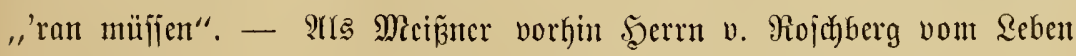

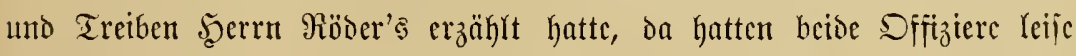
gejeufzt, uno gleich Danach hatte jeder noch einmal cinen Seufzer ausgejtozen, Reutnant v. Borbect einen iclbjtironijch fomijchen, Sberlcutnant Etrömer aber einen recht ernjt gemeinten; Denn jie berglidyen im Stillen ihr jeksiges

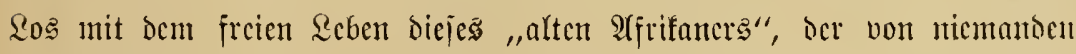

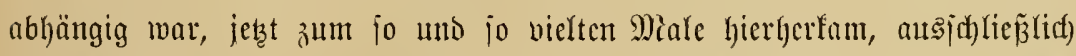

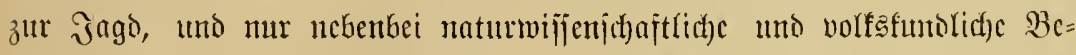

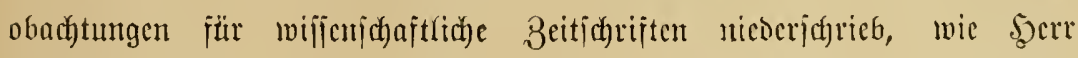

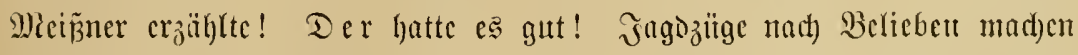

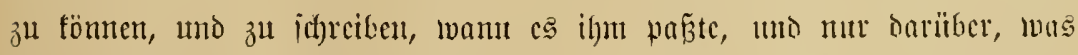
ibn interejîterte, währeno fie anß̧er ihrem jonjtigen Dienjte cine llumentge

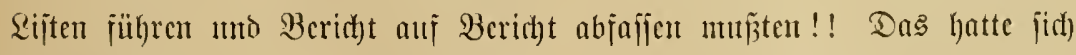

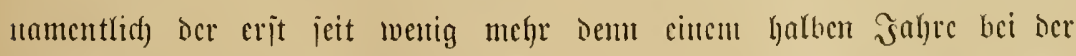

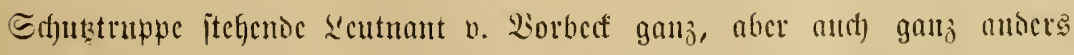

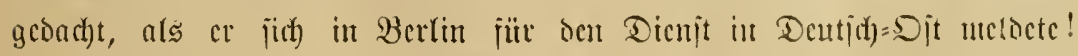


(Er hatte แriprïngfidf) Jurijt werben wollen, cin paar Semejter itudicrs,

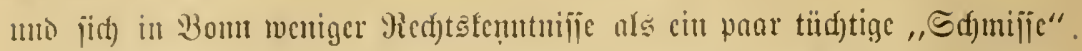

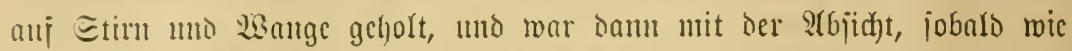
möglich) 3ur Edunk̨truppe ïberzutreten, Eoldat geworden, weil ihm ein

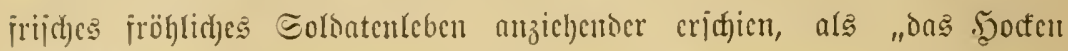

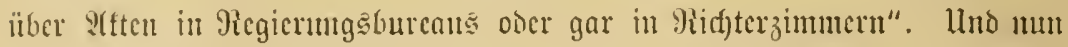
mar's jo gefoumen! Freilid) hatten ihn ja)on während Der Dienjtzeit Dahcim die (Erzählungen Der Sumeraden uno mand)e Weröffentfiçungen

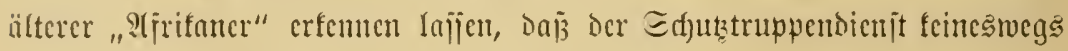
mur ans jortwährenden friegerijd)en Expeditionen gegen fampifujtige, bfut=

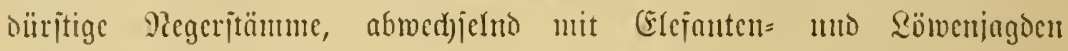

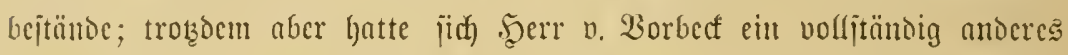

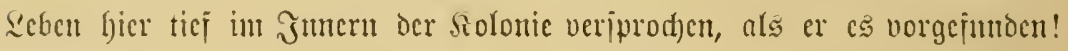

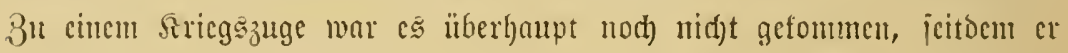

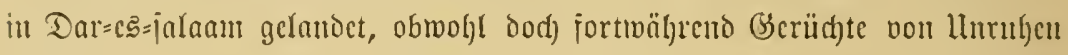

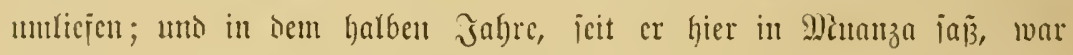
er fuum ants der Edjecibjtube und vom Exerzicrplatz oder Dem Edjeifen=

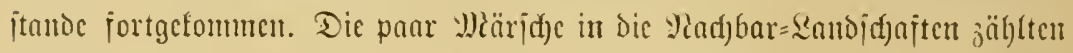

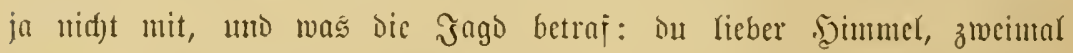
hatte cr, alles in allem, Jagdurlaub jür cin paar Tage fricgen Łömtnen,

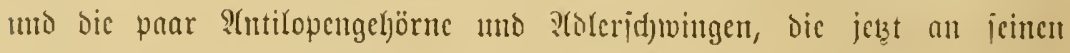

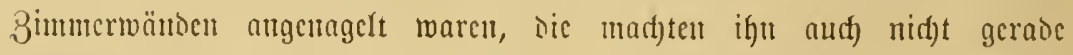

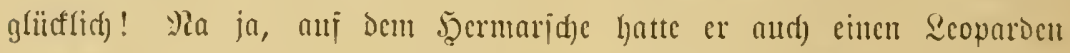

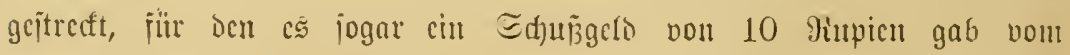
Şouvernement; ba cr aber das fell gerı behalten wollte, muñte cr cs jür

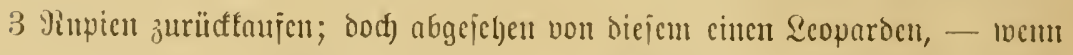
hicr nidft dic "efelfajten Bejticn", die Firotobile, io zab)(reid) in ocn

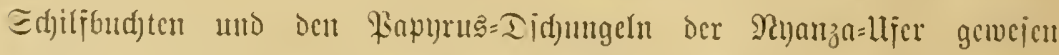

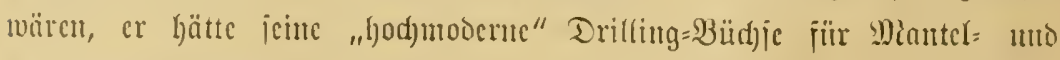

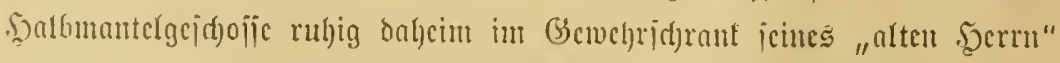

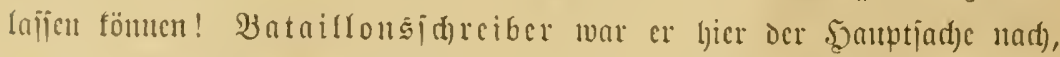

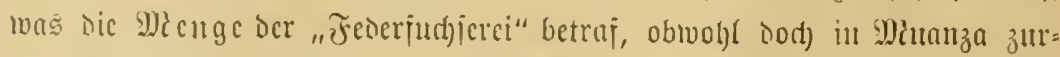

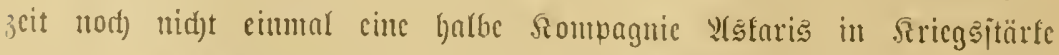

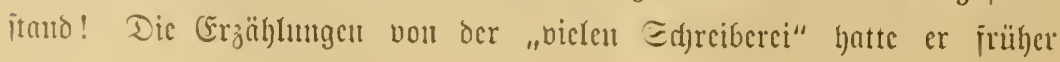




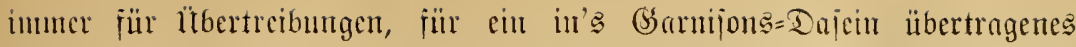

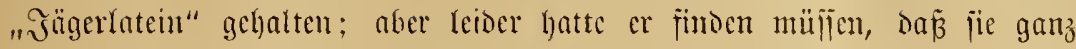

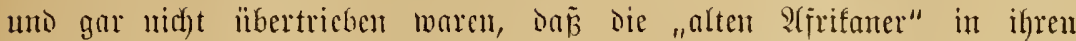
Broidfüren ober Zeitunggartifeh bie Sathe in (Segenteil nod) lange nidht

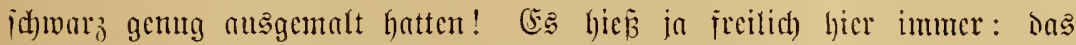

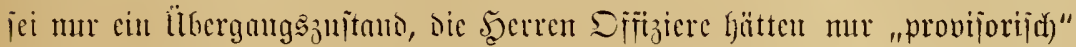

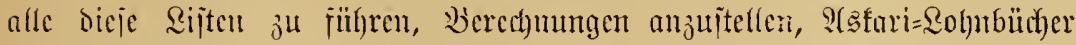
"auf Dem Raufenten zu halten", dic Protofolle bei Den shauris (Beridytaverbandlutgen) abłujajien, Darüfber und noch) "nad) oben" - an bas

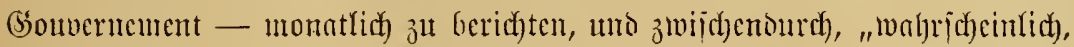

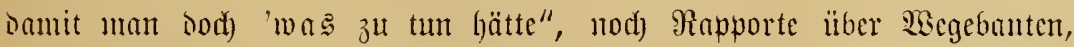

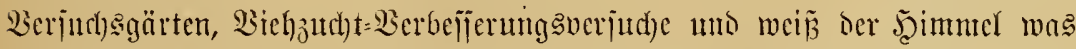
jonjt nod) jut eritatten; aber bas wäre eben afles nur cin "Brobijorium"; baro

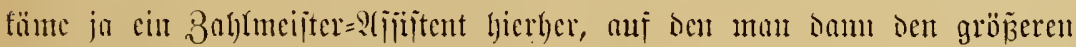

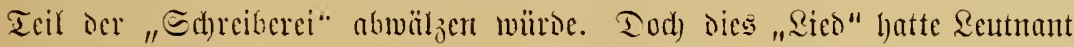
v. Worbect hier in Misanja mun idjon 5 Mionate lang jingen hören,

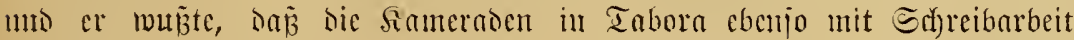

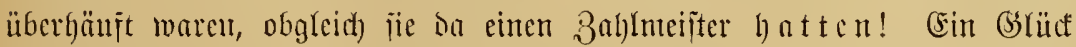

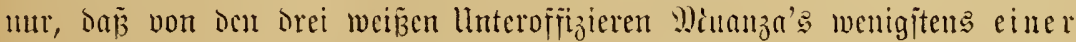
Dienjt;ähig mo anj Der Etation war - icr Sergeant war nad) Siljente

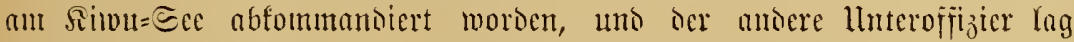

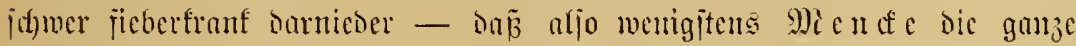

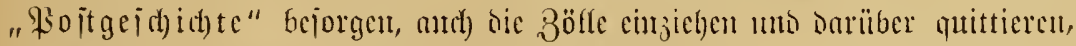

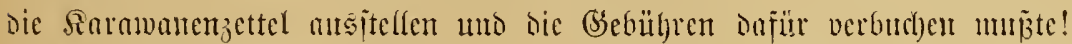

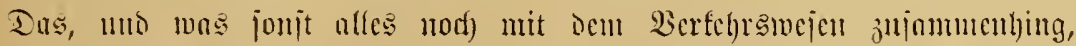

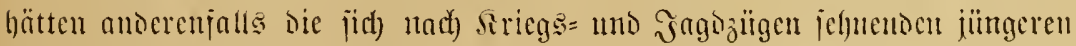

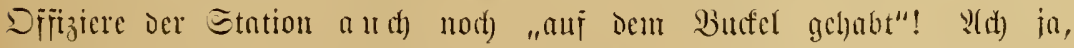

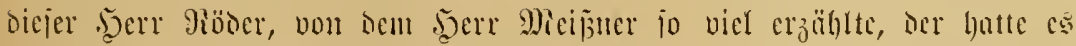
gut! 'lluo er mujite obencin "müchtiges Sd)mein hnben", meinte Borbed

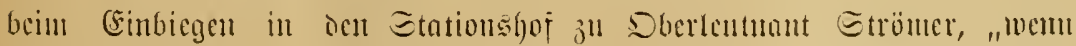

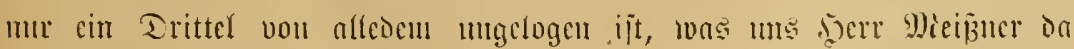

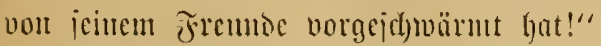

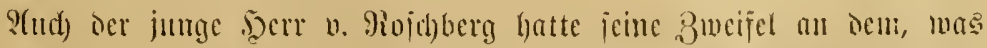

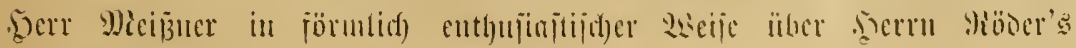




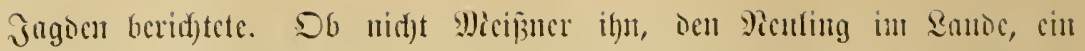

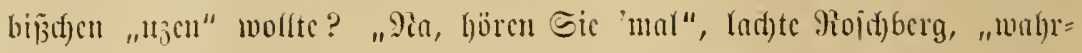

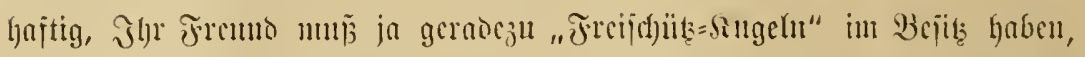

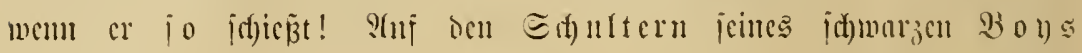

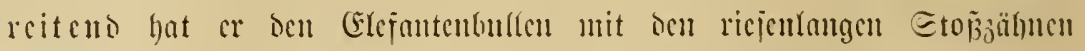

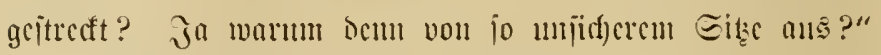

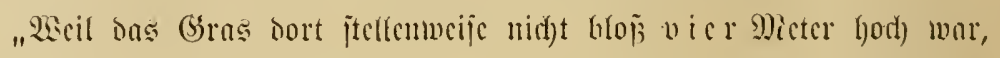

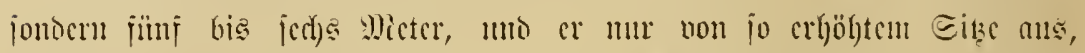

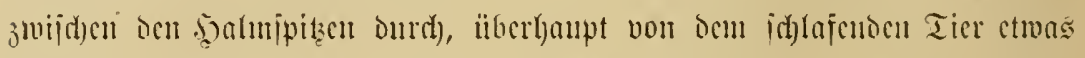

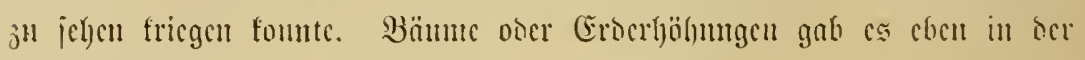
?ähe mid)t."

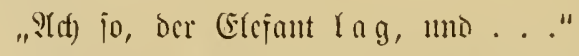

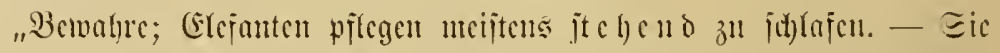

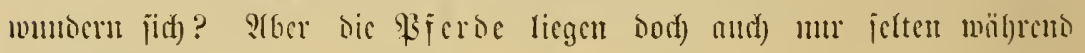

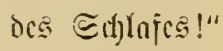

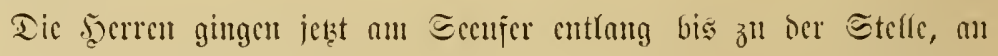

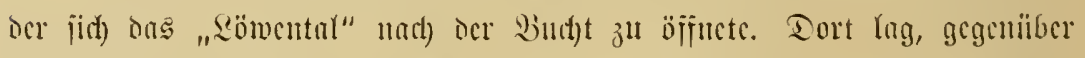

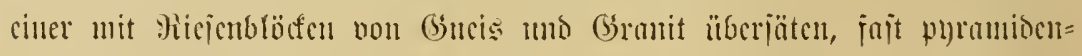

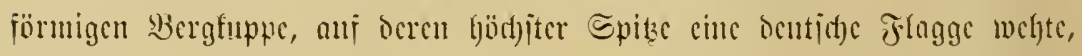

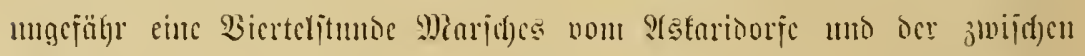

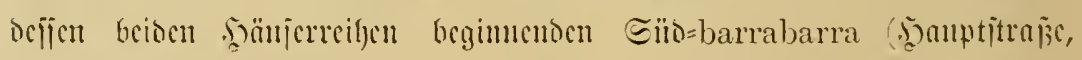

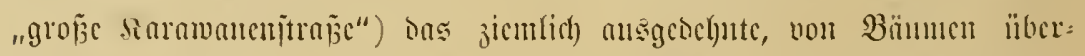

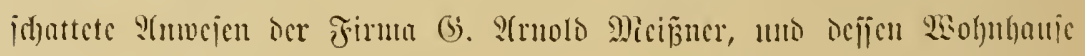

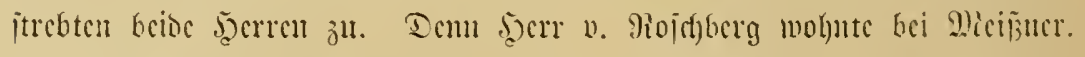

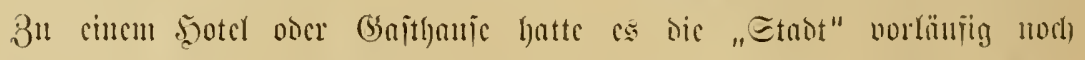

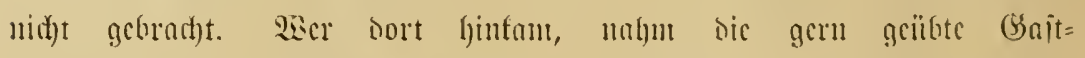

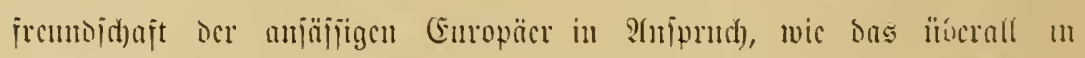

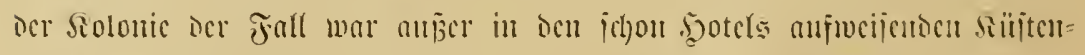

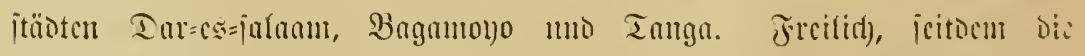

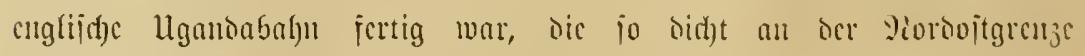

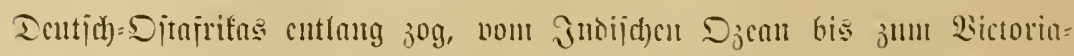

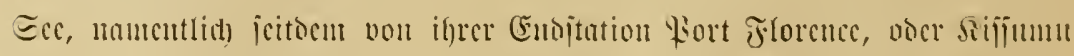

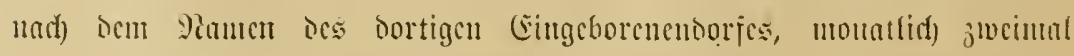

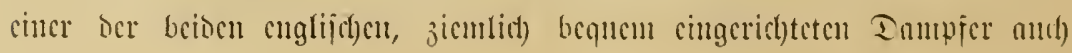


Sic Statiomen icr beutidgen Sechälfte anfici, feit ber Beit murbe

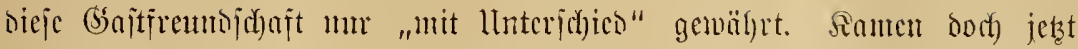
jait alle 14 Tage cimmal cin paat şarten in bie Solonic, "Slohetrotten", bic gar feinte Bejichuntgen jut irgent einten Menichen am See hatten,

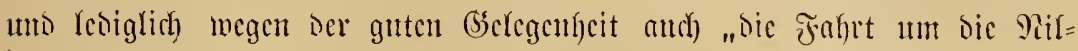
quelle mitnabmen". "2lilquelfe" namten ia Bicle ben Bictoria શinanja,

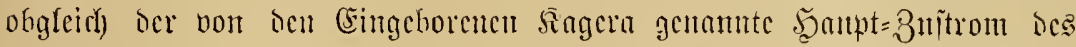

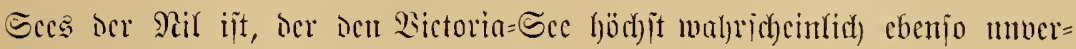

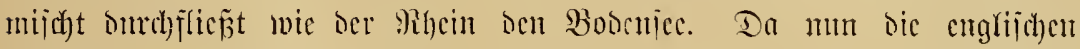

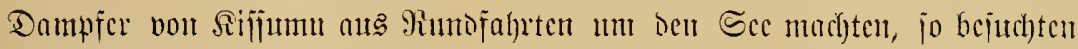

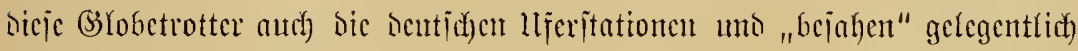

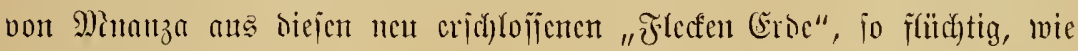

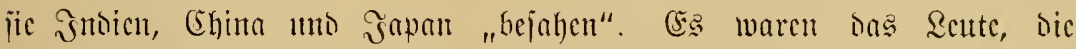

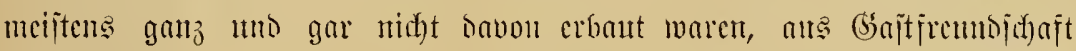

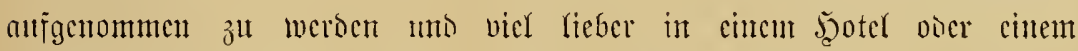

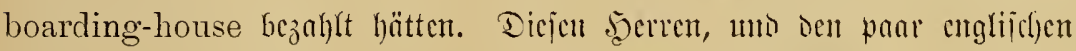
Danten, dic biş⿻上丨 dic fünt= Gis ject)entägige Dantpferfalyt non fiort

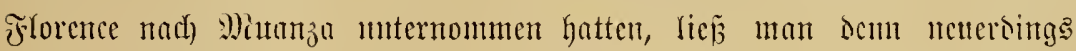

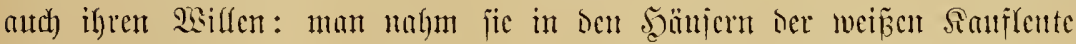

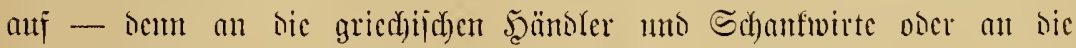

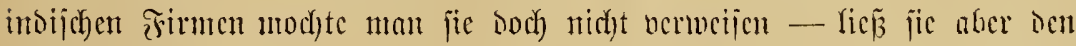

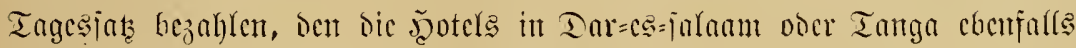

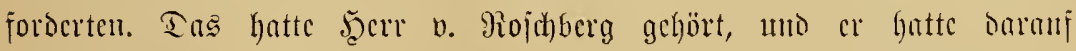

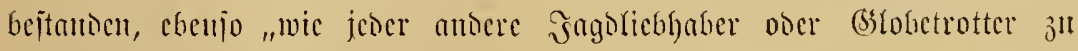
bezalylen". Er war jreifich mit einer warnten (Empfehlung an ben (E) fef

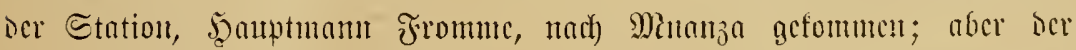

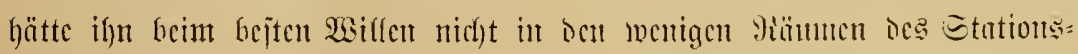

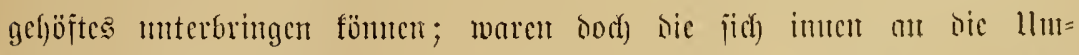

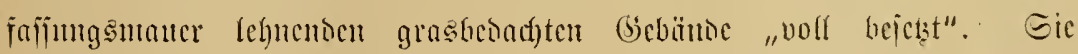

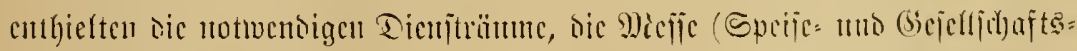

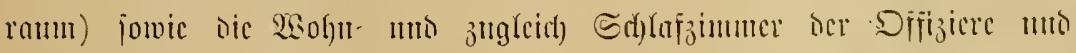

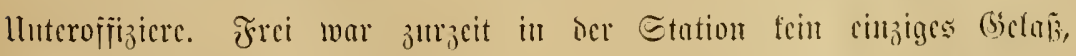

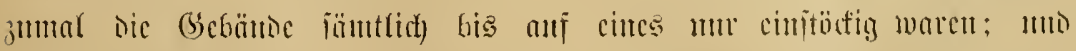

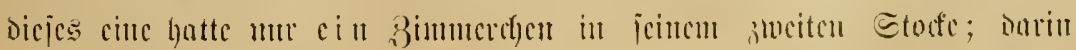




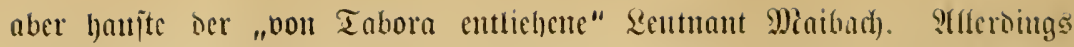

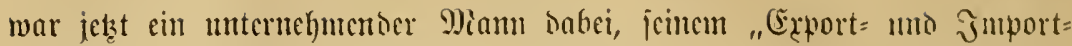

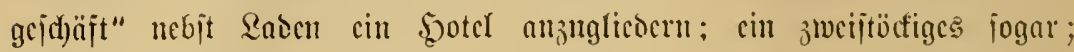

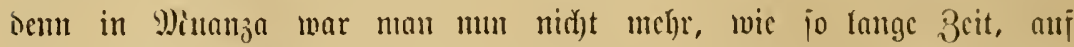

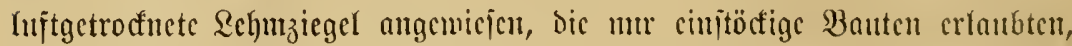
jontern brannte fid) gute Bacfefteine in cintem grofäen gingojen, hatte

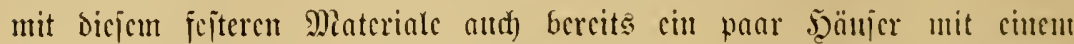

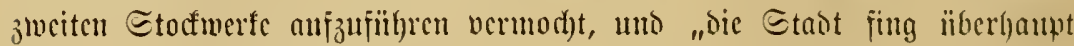
an, fid) herauszumaujern", wic Dr. Brumer jagte, ocr "auj jein

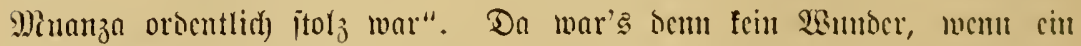

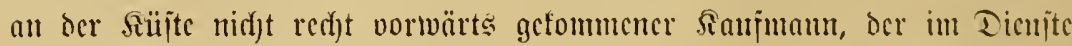

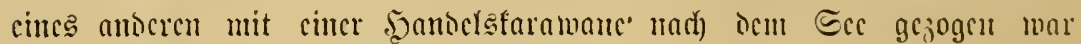

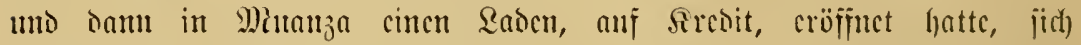

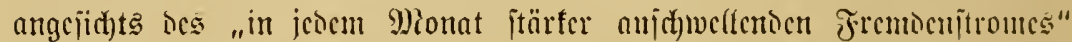
- wic Sberlentnant Etrömer gcipöttelt lyatte - jul icm frïhcr, ielbit

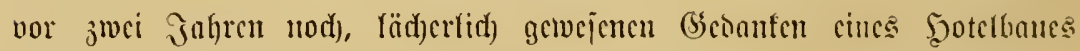

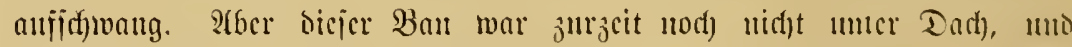

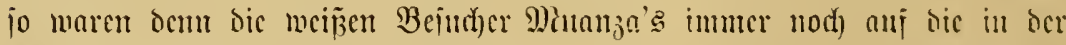

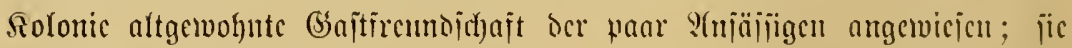

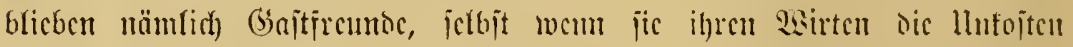

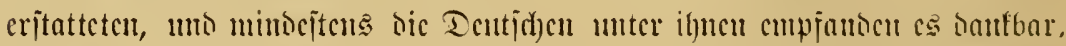

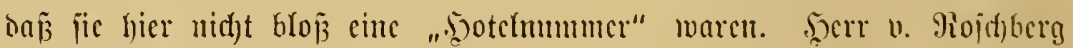
zumal pries in jeinen nad) ocr Scimat gejanten Bricjen jecuen "fremil=

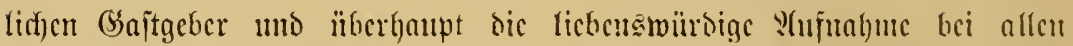

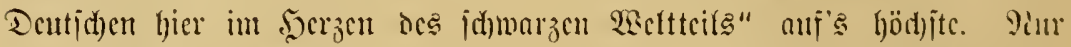

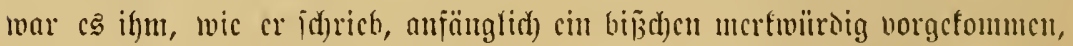

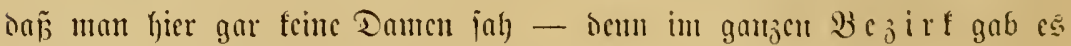

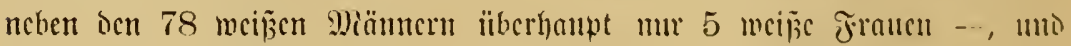

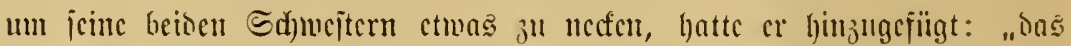
wäre ilym abcr mur in ben criten paar Tagen jo fonterbar vorgetomuten;

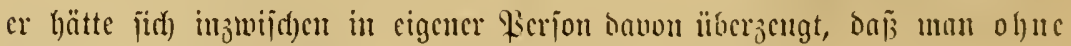
Damen c be nio glüuflid) uno behaglid) leben fömnc."

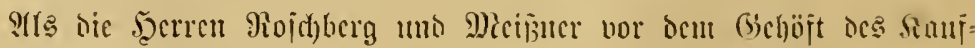

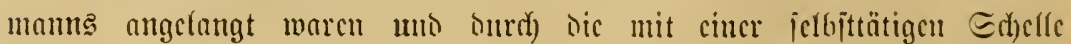


verichenc Bautür ithritten - Das Siehöft war von einer johultergohen

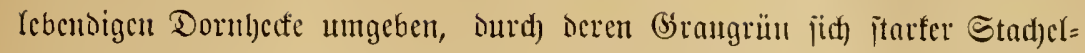
oraht jog, weil dic vielcu Bicgen Miuanza's jid jonjt wohl trots ber Dornen citten Bugung in ton bis nahe an bie Butht fiunntergehenten

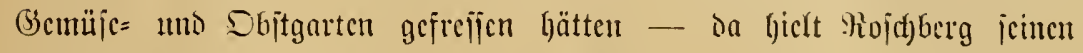

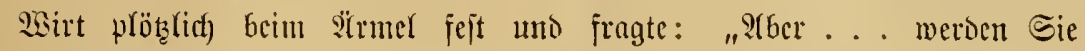

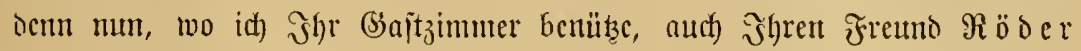

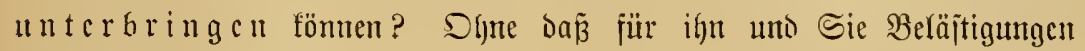
entîtchen? Sonit quartieren Sie mich ohuc llmitänoe aus; ich ...."

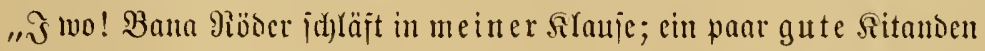
(Negerbettifeflen) find vorhanocn; wir werden ocu ßiotbart uno jeinc Begleitung

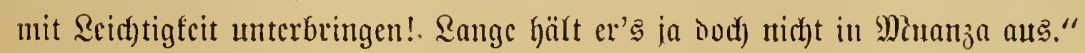
"Begleitung?"

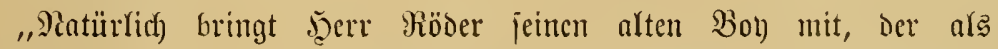

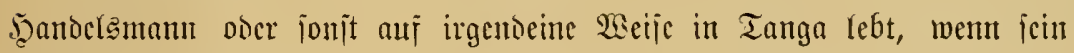

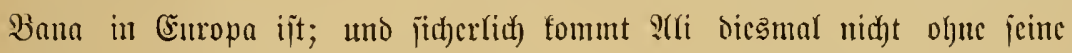

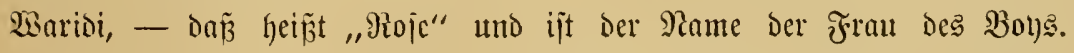

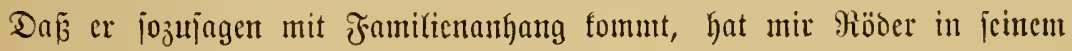

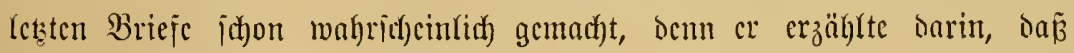
Waribi fomiidferweijc ciferjüd)tig auf Die Crrjolge ifres brannen Bratten bei Don jarbigcn Schönen jei, umo ein getwaltiges kelele (Sejd)rci,

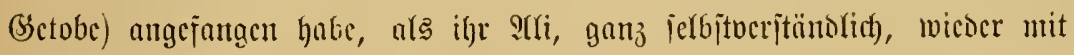
fincm alten bana ndevu nyekundu in's Jamere reijen ıolite."

"Bana . . . ?"

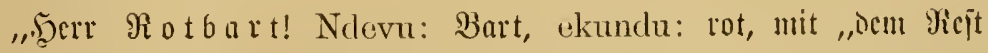

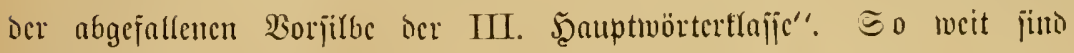

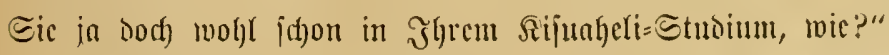

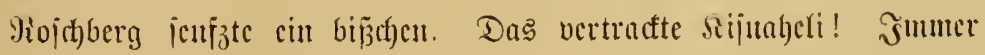

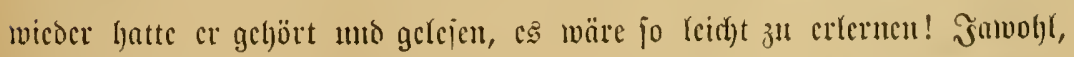

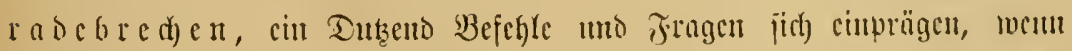

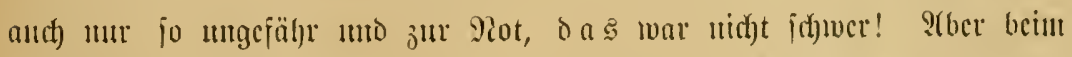

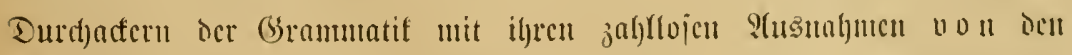

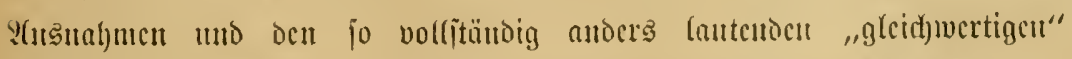

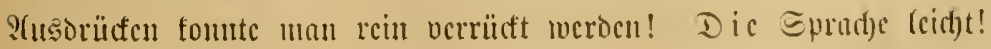




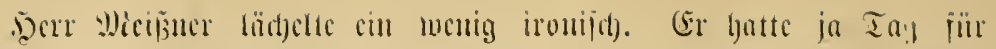

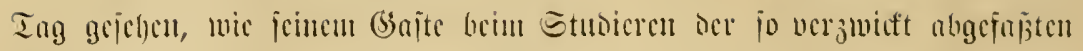

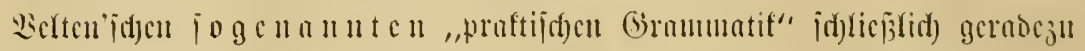

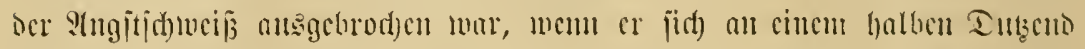
Etclleu jujanmenjudt)en mulite, wa er meder im Texte nod) ill ocu

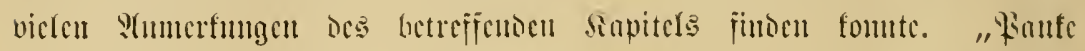

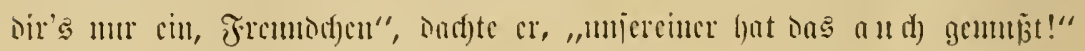
Rout nber jugte cr: .Bana nderu nyekundu, obcr ciufoct) ., Bana

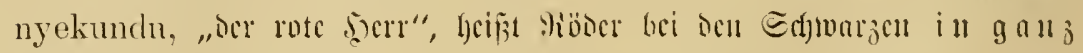

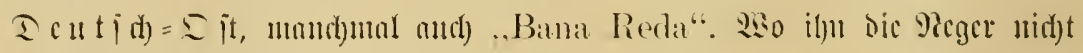

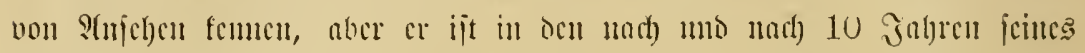

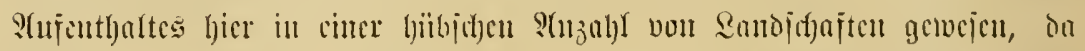

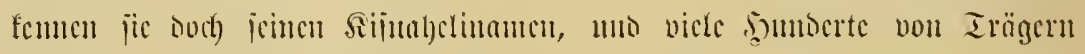

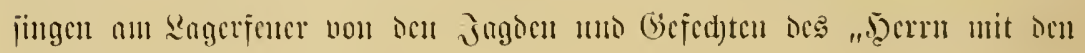
Fencrflamuten an (sijict)t ..."

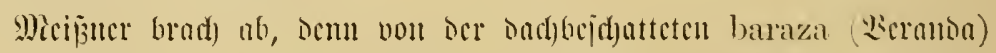

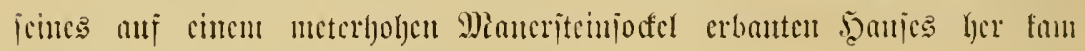

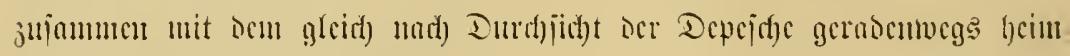
gegangencu je)

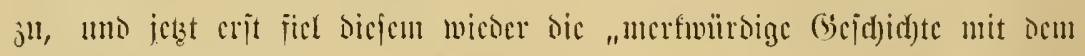

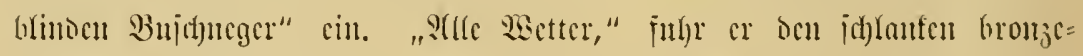

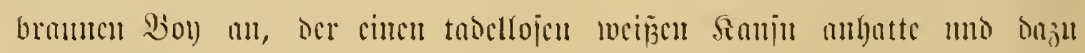

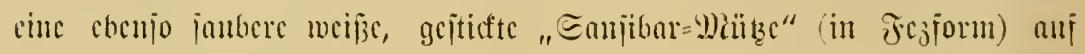

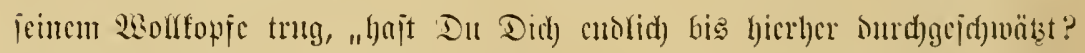

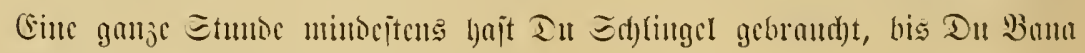

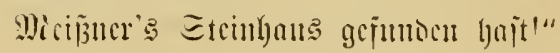

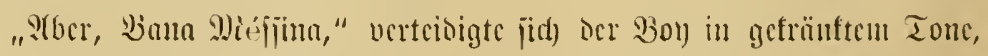

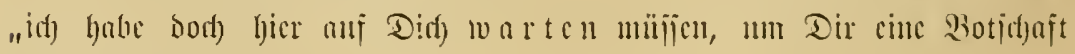
aแรวแนidatcu!"

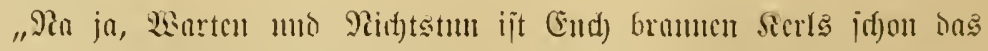

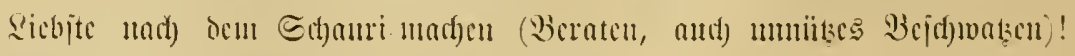
:(ljo: waz lonjt In mir щu ju bejtellen?"

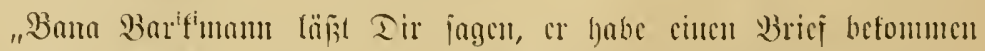

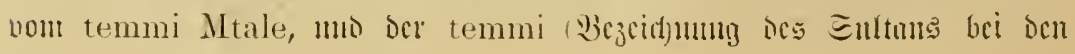




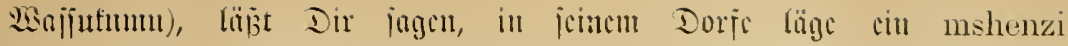

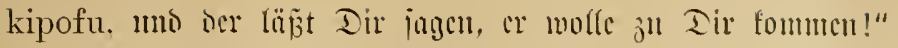

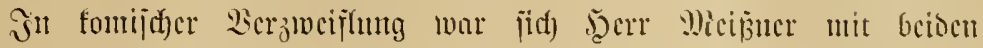

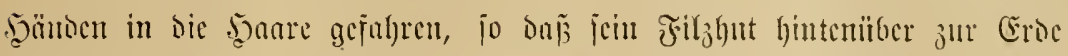

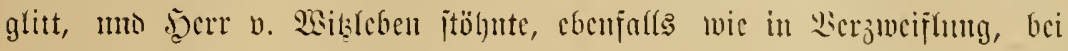

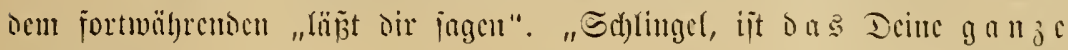
Botjd)ajt?"

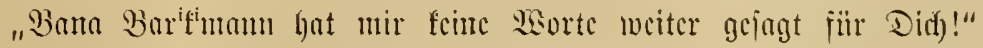

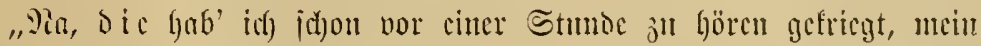

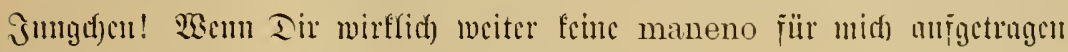
jïl, Dann madt' Didt) nur anj bic Strümpje!"

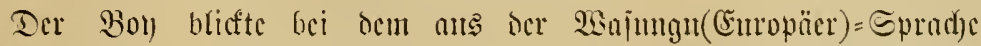

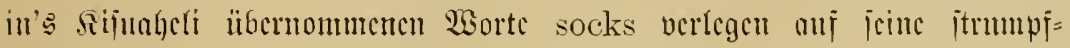

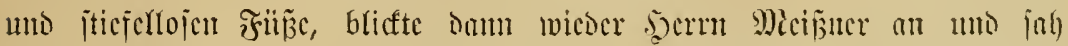

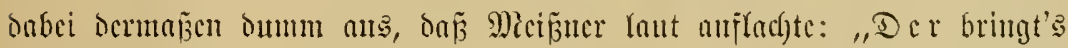

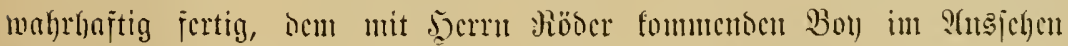

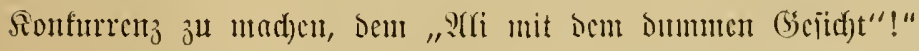

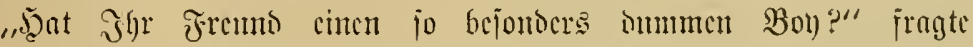

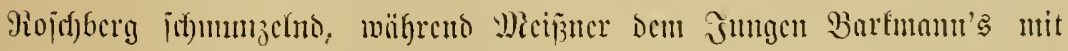
Der Şats Entloffung zumintte.

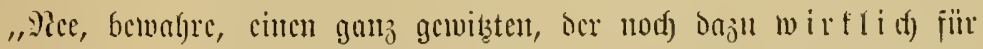

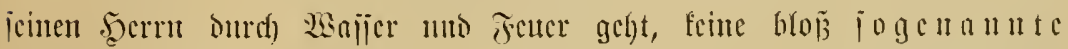

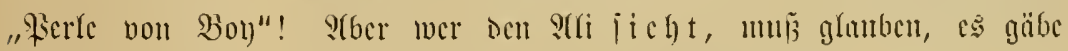

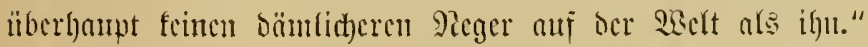

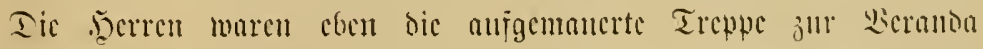
cmporgeitiegen, anj ber nicht dic jonjt jo oft vermendeten grof befoutenen

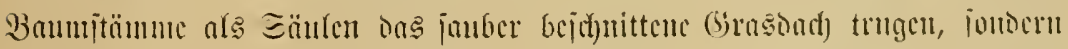

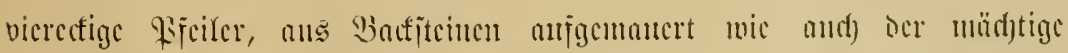

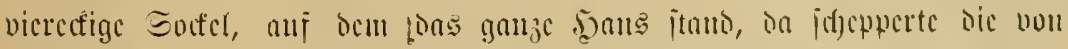

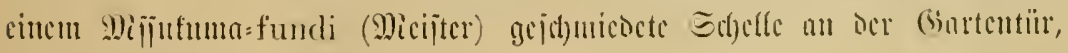
utit) cin Polizijt trat cin.

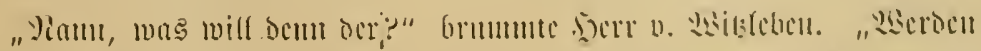

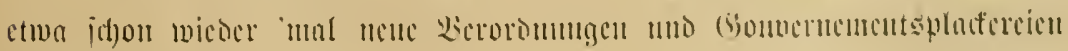
fumi geunad)t?" 


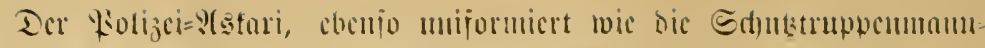

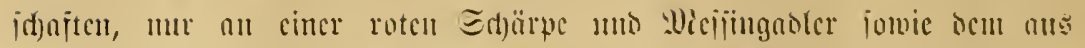

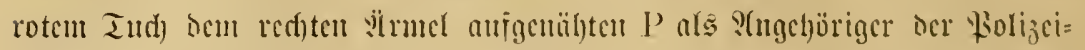

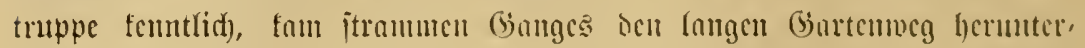

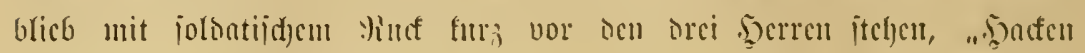

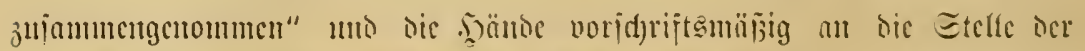

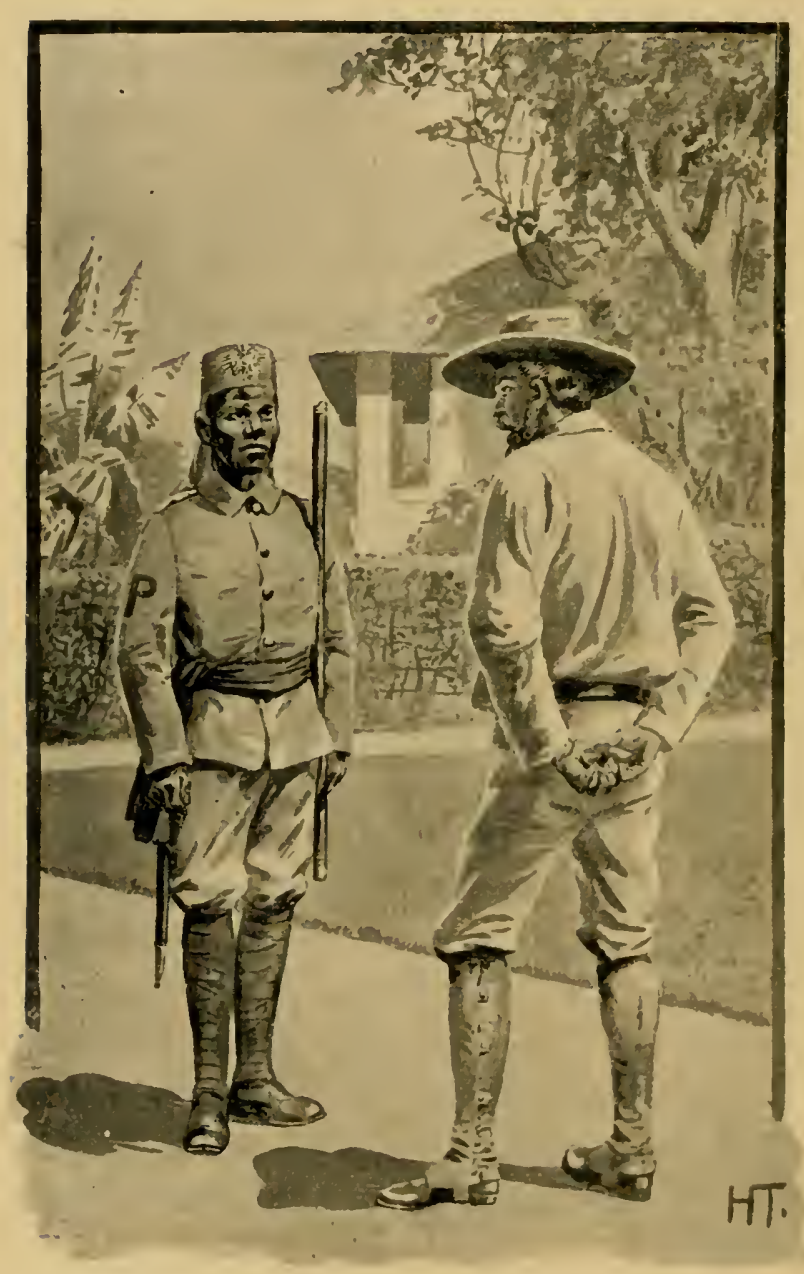

nidt) vorhandecuen "गुojenthicje" gelegt. Eciutell jtorfen, ats "Dromungswaffe" auser icm Ectten gemel)r getragencur kiboko (Etout ans Pilfiferibaut) biclt ocr Mianu sobei in ocr Vict)ten. entg an ?'rul IIIt) riörper

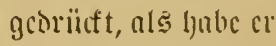
"(Bicuel)r anit" ge noumucu. „9)icloumg uom bana mkubwa

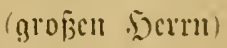
Donentutam! " jogtc

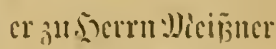
iil id)griftelligem siijulgcli, Deun $\mathrm{cr}$ itmunte non jenicits ice Inngannita= Eccs mus jekzt fougo HT. itantlid)en (sichict. moli boar, all ben

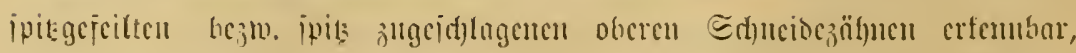

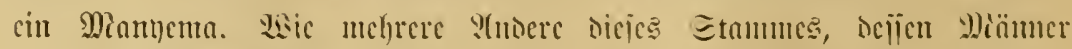

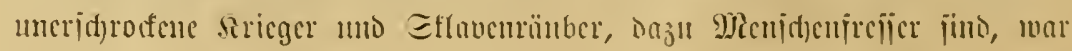




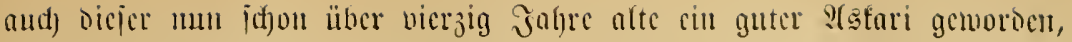

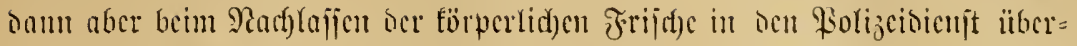

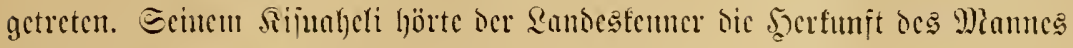
id)on bei ben unenigen Worten ber Mecloung an.

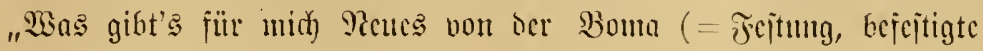
Station)?"

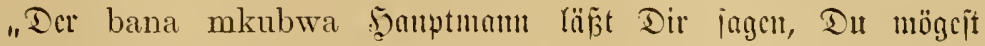

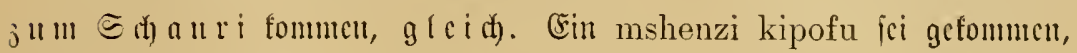

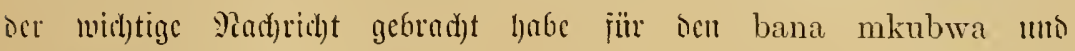
fiit Did)."

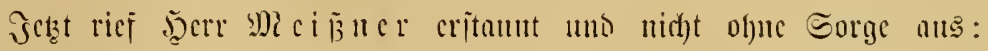

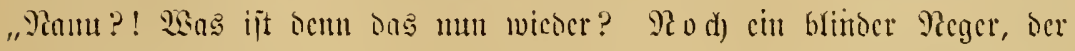

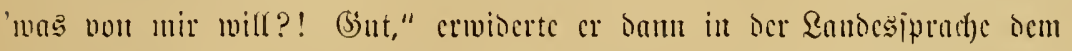

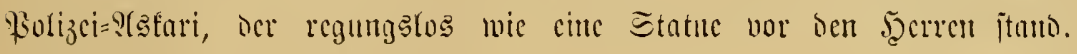
, Diclice, ich märc int Siommen!"

„Hewallah (arabija)c $\mathfrak{B}$ cjulyung, chua: $\mathfrak{i c h}$ s ıobl) bana; Du märejt im foumcu, inshallah (io (jott wifl)!." Damit mad)te ce fehtt

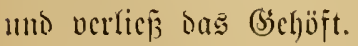

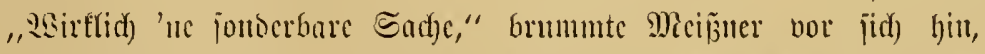

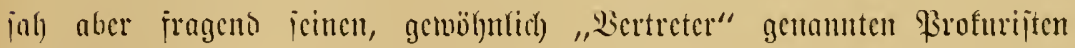

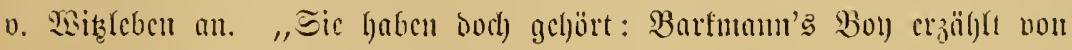

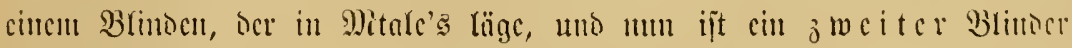
in oer Station, bic be i to e 'was mit uns ju tun haben joflen, oder wollen?!"

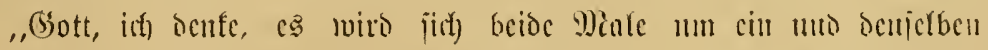

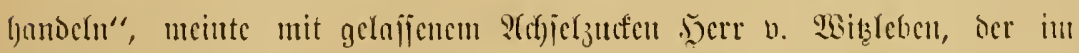

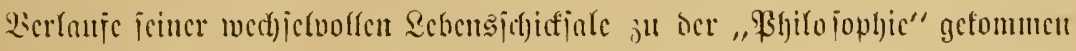

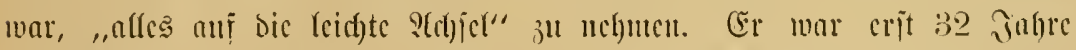

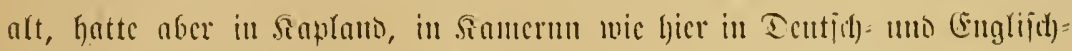

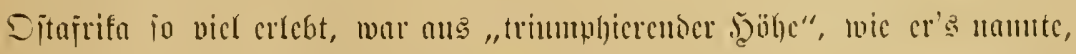

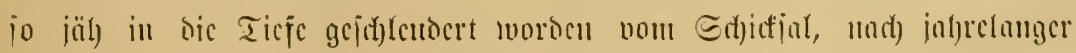

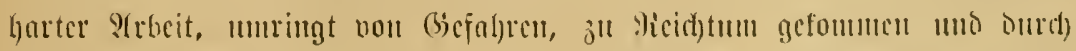

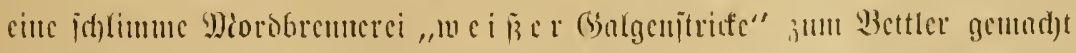

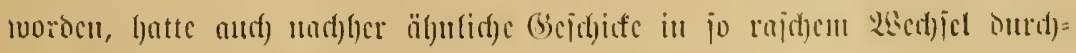

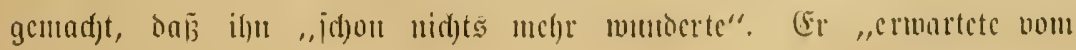




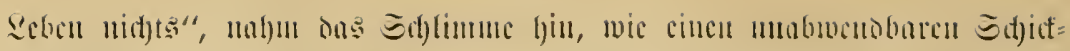

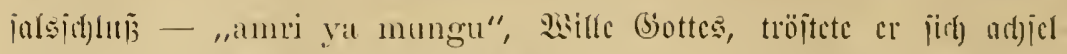

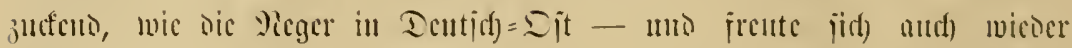

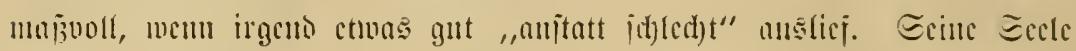

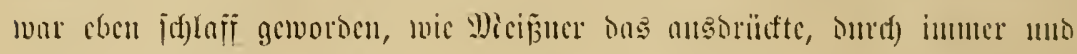

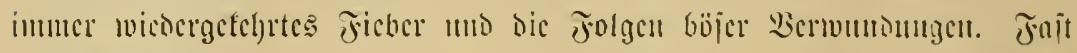

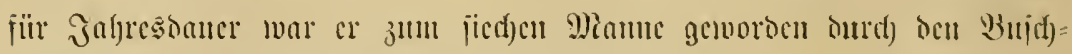

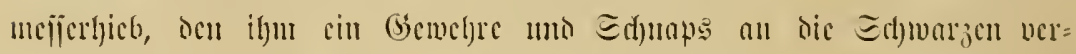

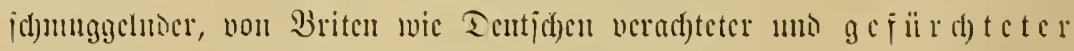

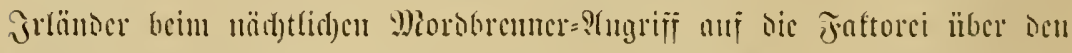

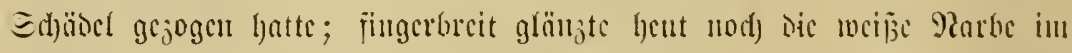

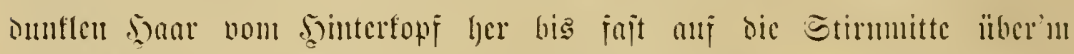

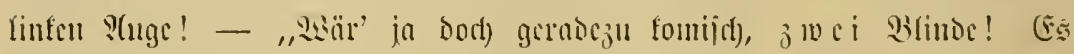

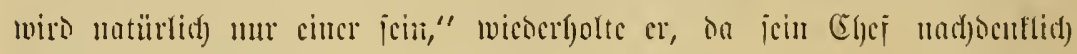
id)roicg.

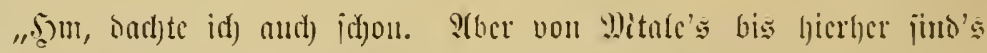

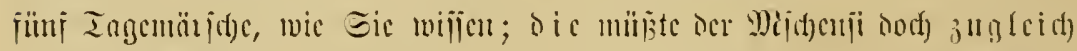

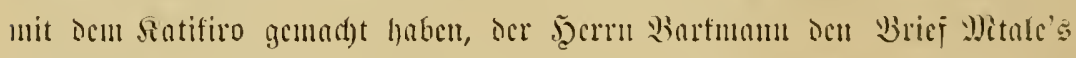

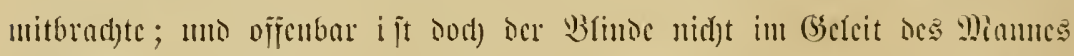

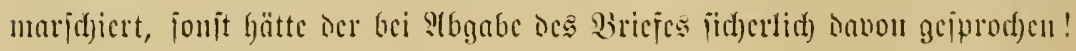
Ectrjam!"

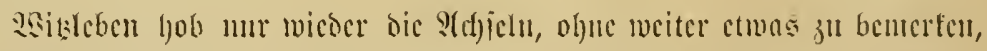

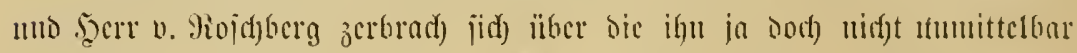

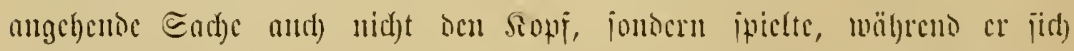

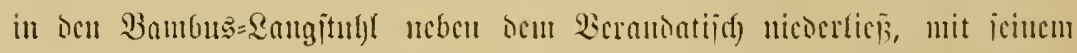

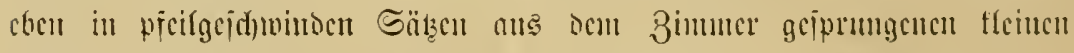

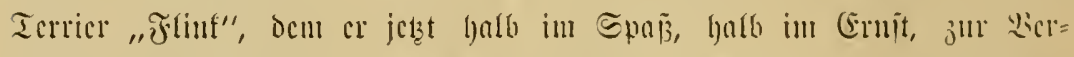

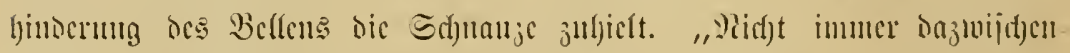

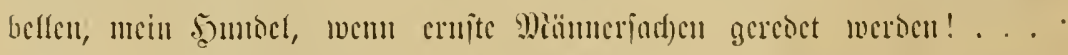

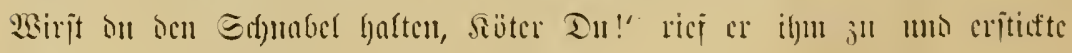

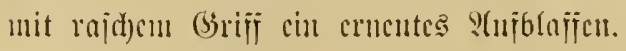

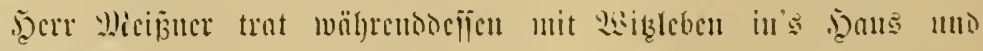

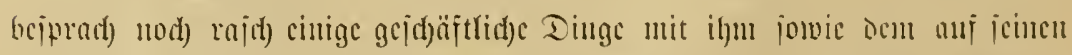

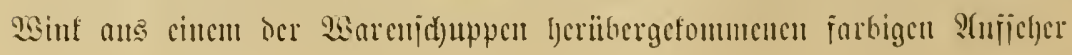




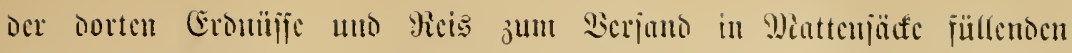

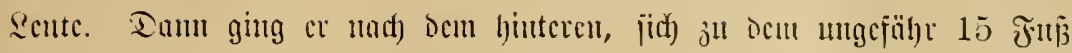

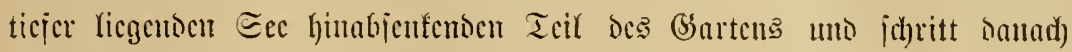

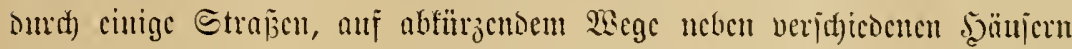
lint, raidh anf bic boma ju. Einc unbeitinnte Sorge fing an, in ibm

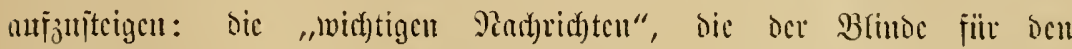
Stationslciter uno ihn jelber gebrad)t hatte, - es wïrocn jebr wah)r=

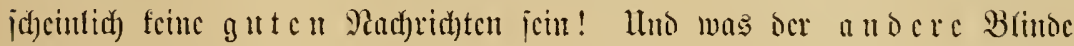

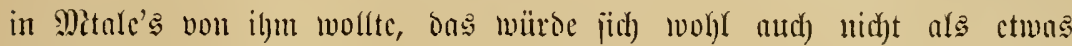

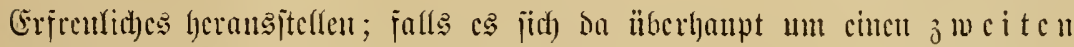

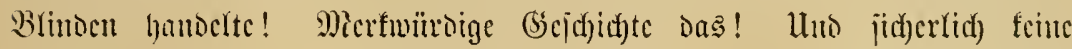
crquicflict)c!

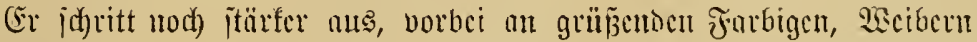

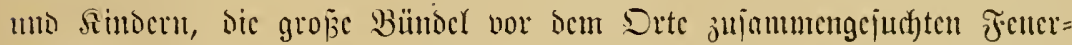
boljes nuf Den Siöpfen balancierten, und vorïber an cincr bic Strajze

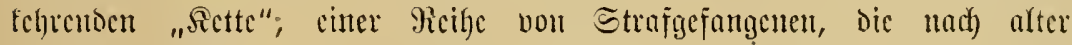
ajrifanijicher Sitte an cims Iange Eijentette gejd)lojicn waren umo jomit

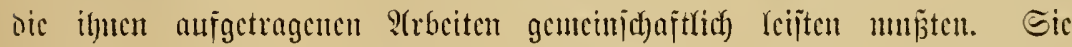

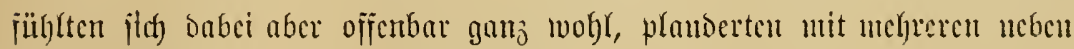

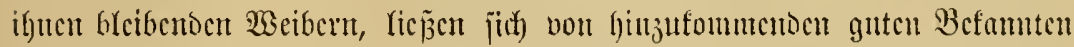

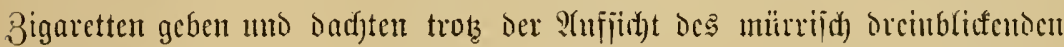

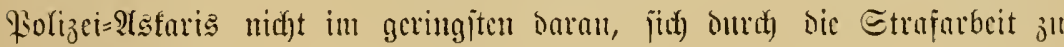
ïbcranjtrengen.

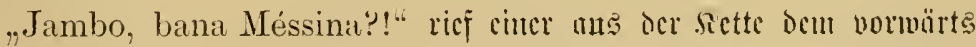

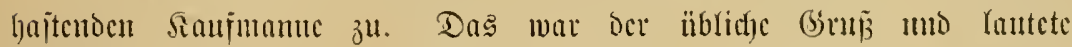

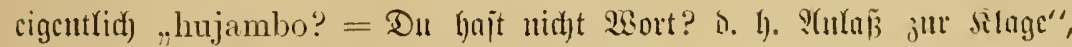
bcjagte aljo: "Bicht's Dir gutt?"

"Jambo (cigentlidt) sijambo, $=3$ h) habe tidft Wisort, i. h. cs

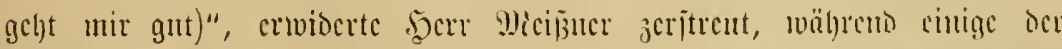

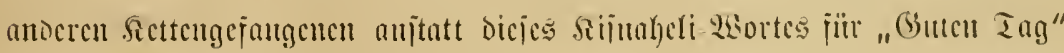

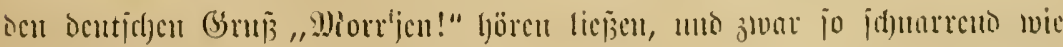

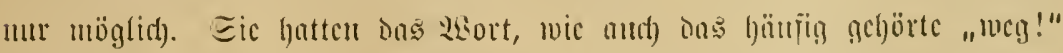

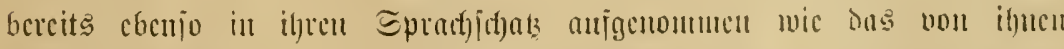

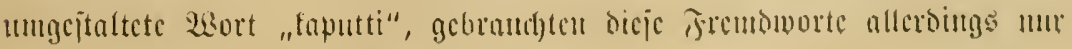




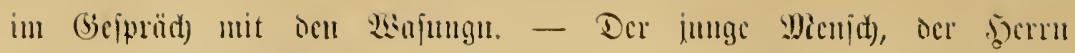

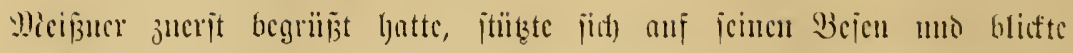

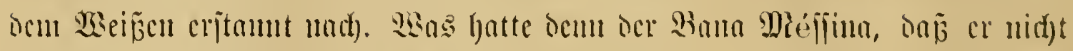

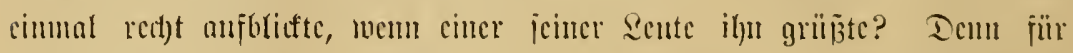

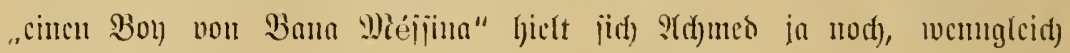

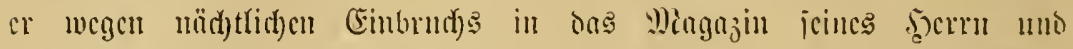

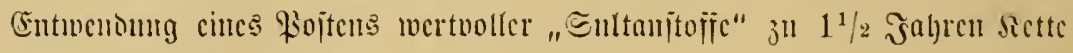
verntcilt bortien war!

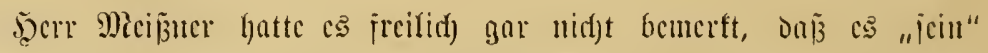

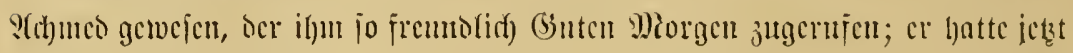

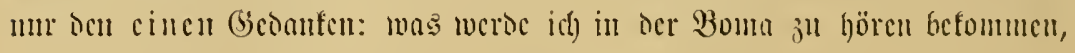

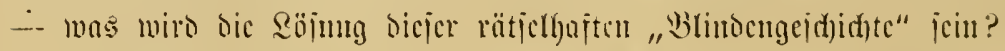

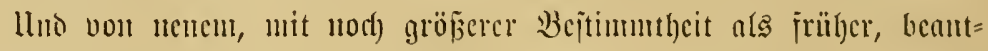

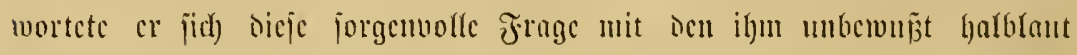

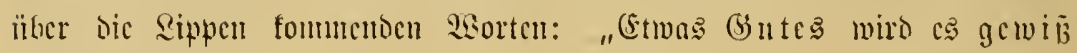
nicht jein!"

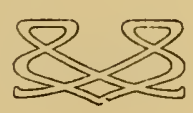




\section{Zweites Kapitel.}

G.

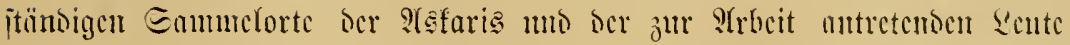

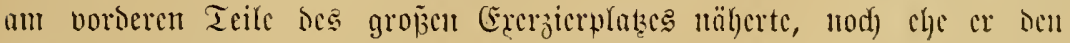
Wisc jum Etationgtor crreid)t hatte, jah Miciāncr, mic bie un bicje

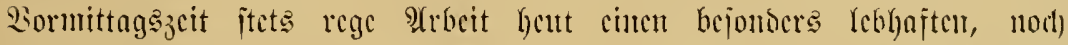

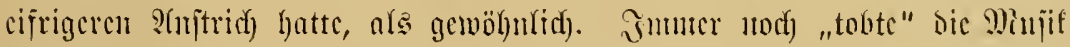

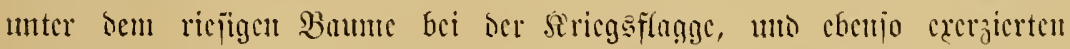

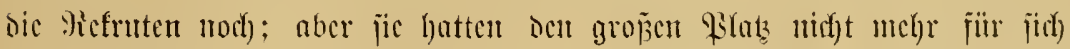

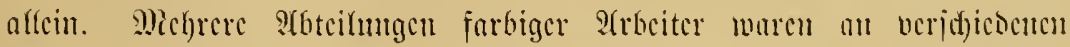

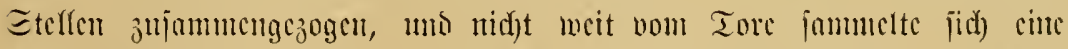

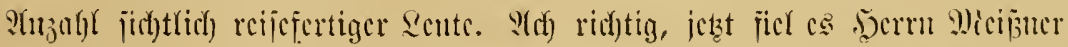

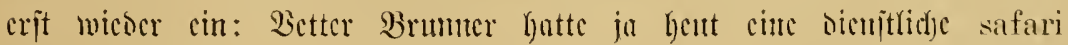

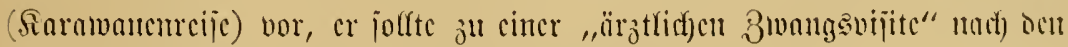

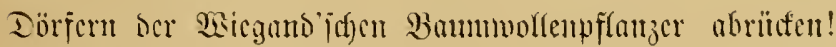

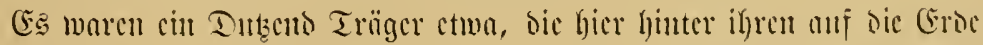

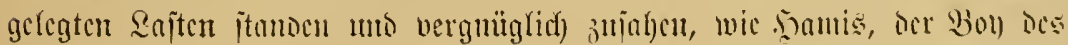

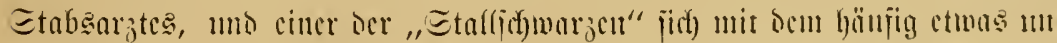

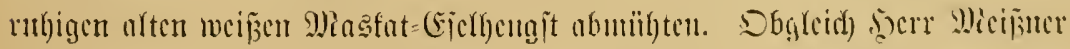

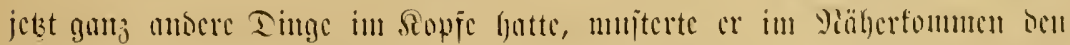

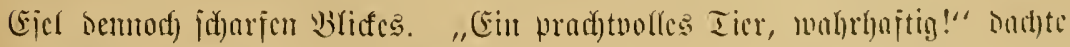

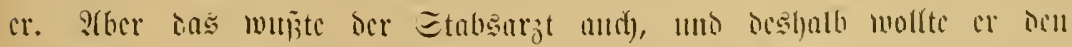

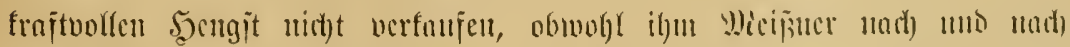

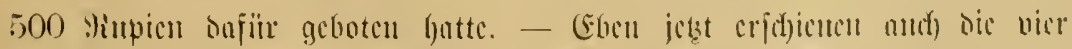

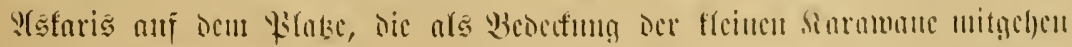

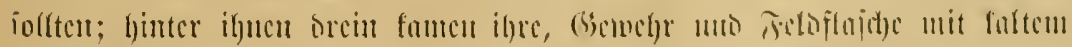




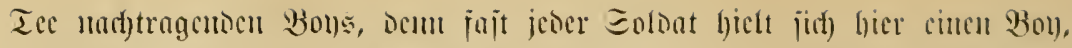

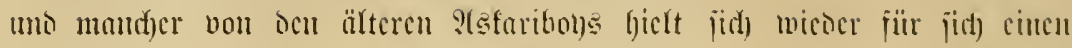

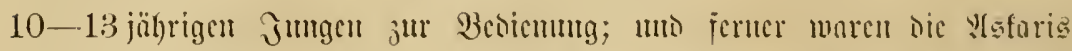

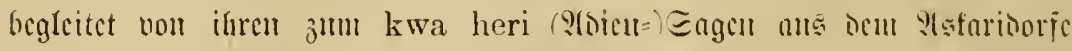

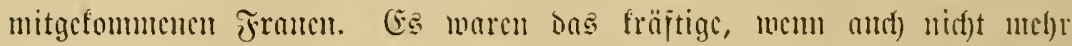

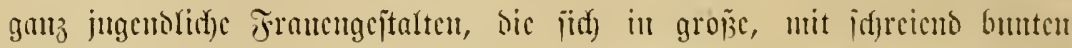

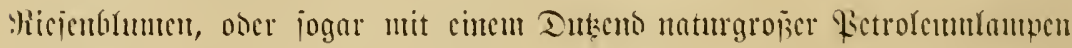

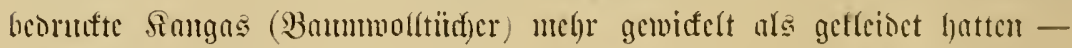

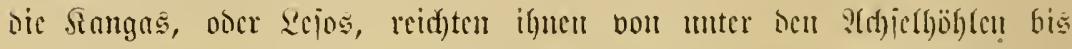

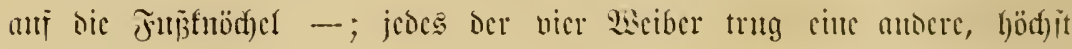

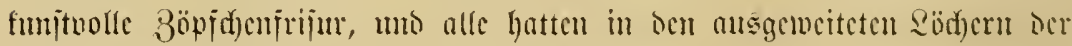

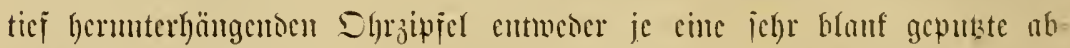

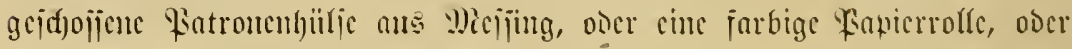

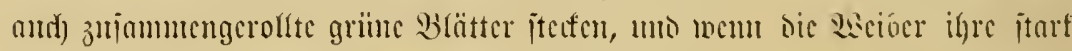

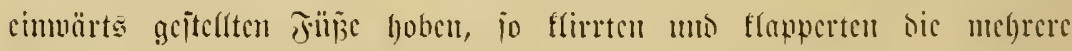

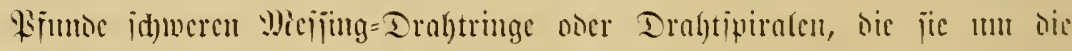

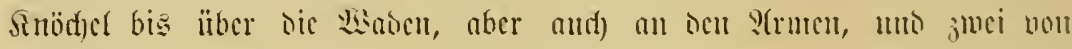

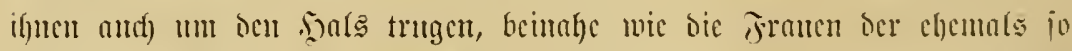

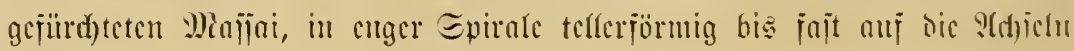
reidjents.

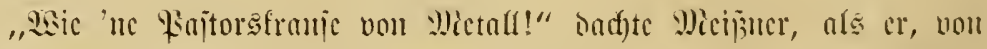

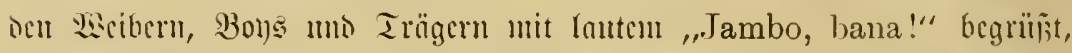

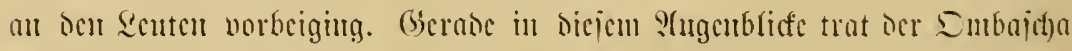

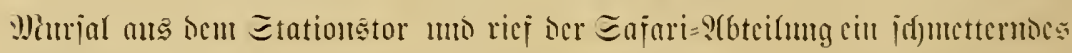

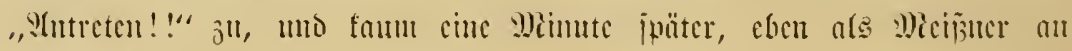

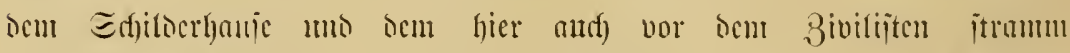

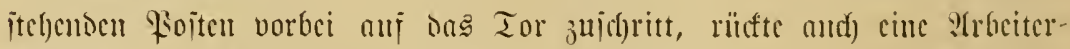

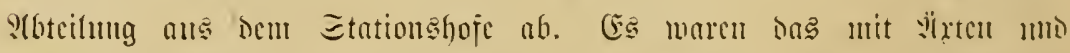

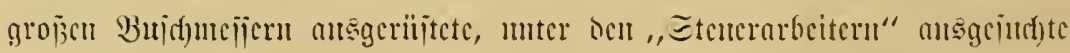

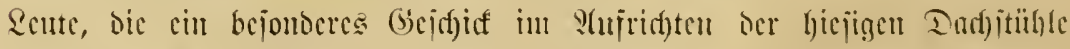
gezeigt lyatten, es bejīer als antere veritanoen, ats mittleren umo bïmuen,

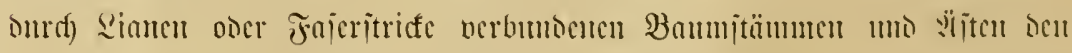

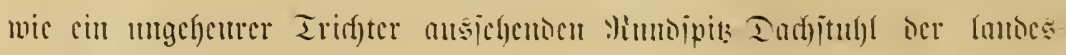

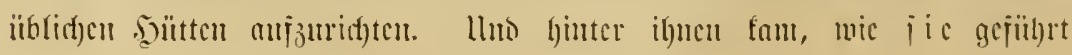




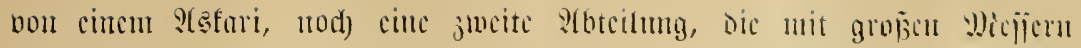

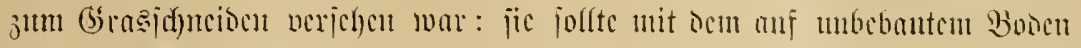

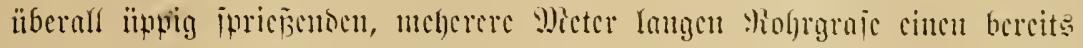

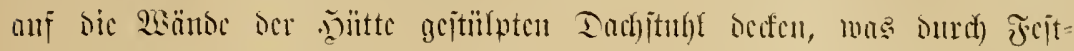

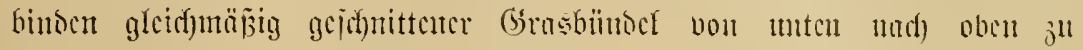

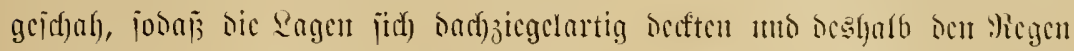

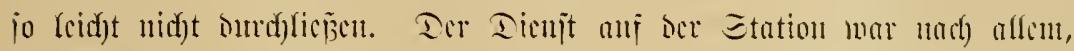

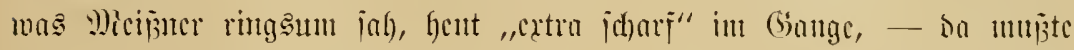

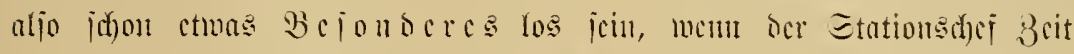

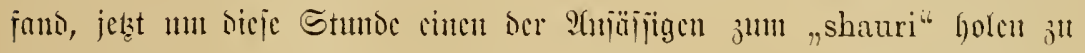

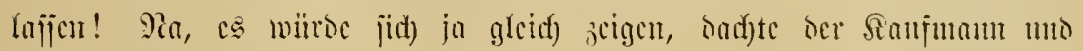
trat in ocu Etationghoj.

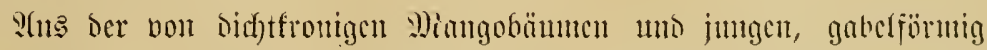

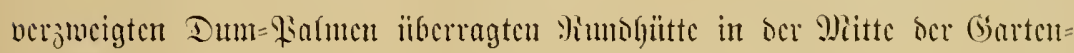

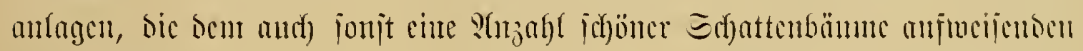

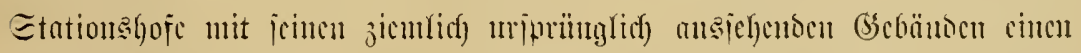

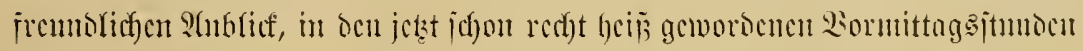

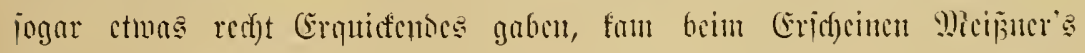

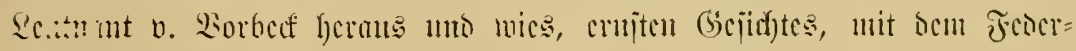

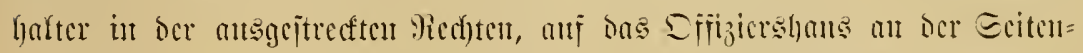

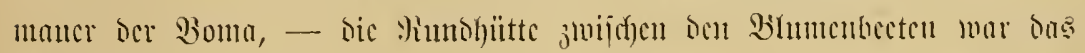
Siompagnicburcan, bas ocr fricg $=$ mo jagocifrige \&entunant in Etillen jo

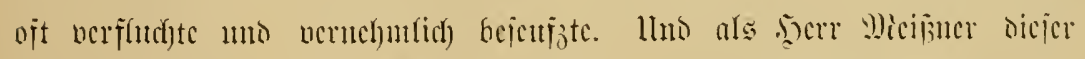

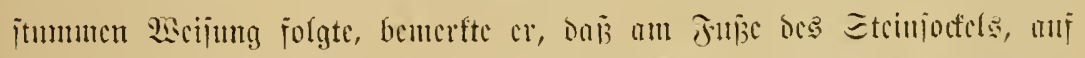

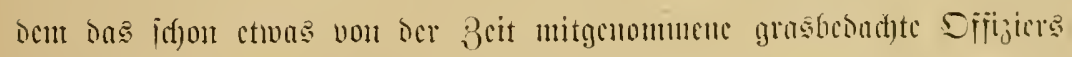

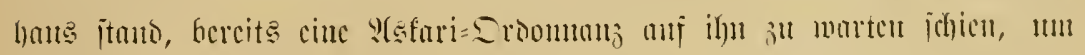

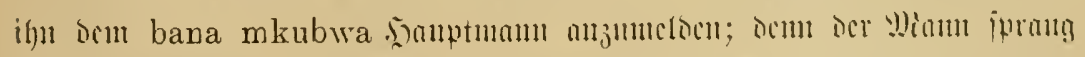

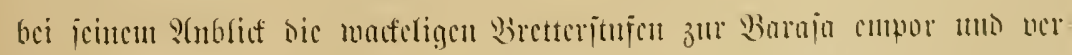

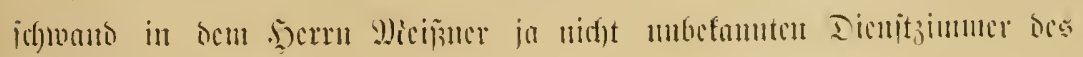
Etutionsct)cis.

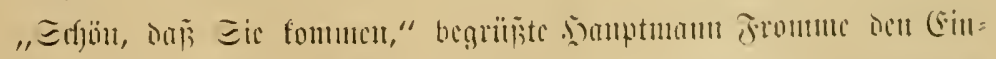

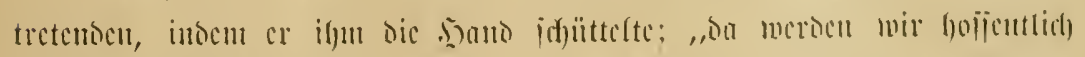

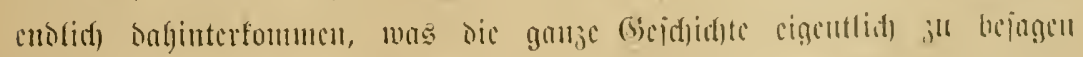

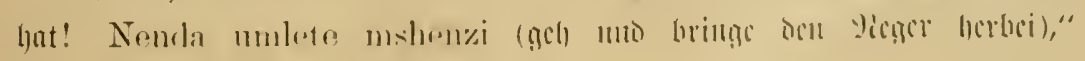


bejabl er ber jtramm cintu Echritt red)ts bon ocr Lïr itchen geblicbenen

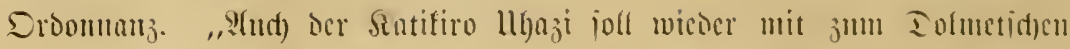
hereinfommen: — Ngóya halt)!" riej cr bem !nad) gurgeligem, „Ecrrr

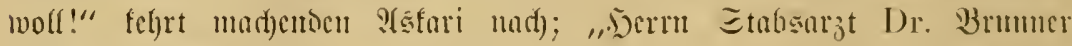
lajic id) cbenfalls nod) 'mal bitten', ..hakim bana dotta Brunner", wic cr es mit ocm fïr curopäije :

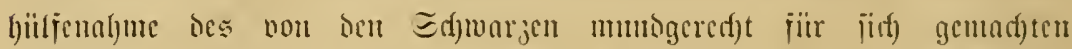

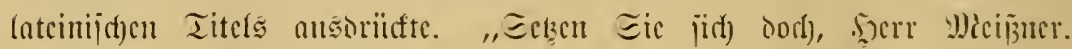

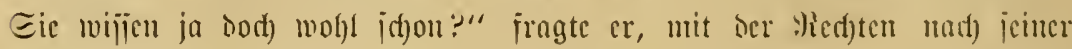

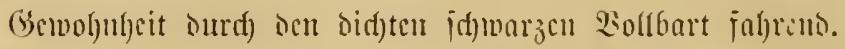

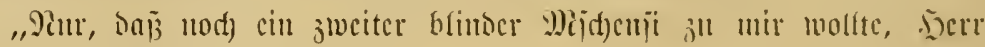
5)antmann, jonjt weiter nidxts."

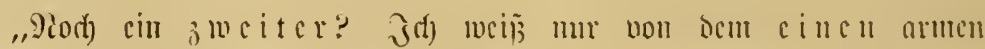

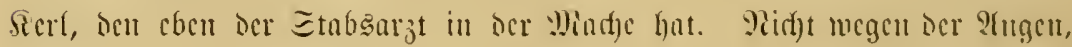

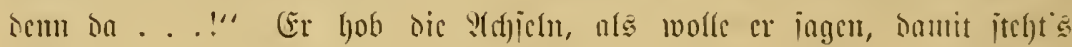

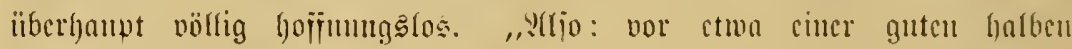

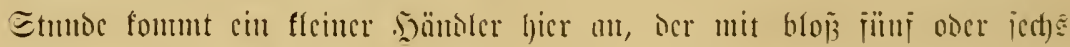

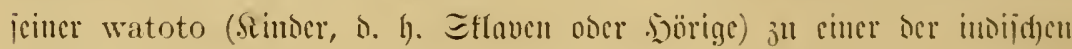

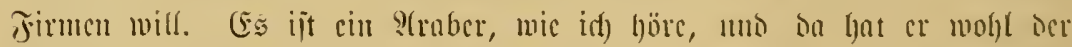

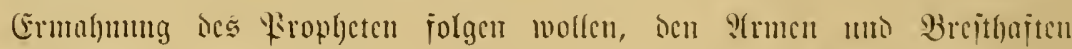

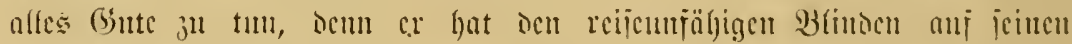

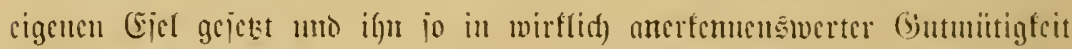

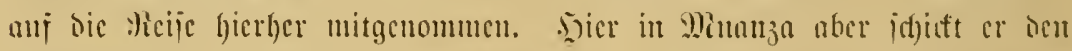

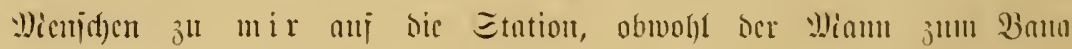

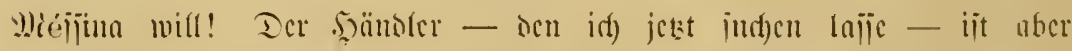

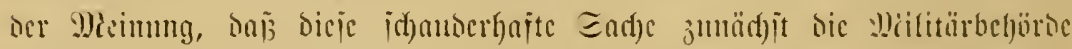

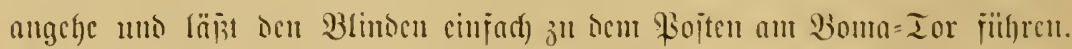

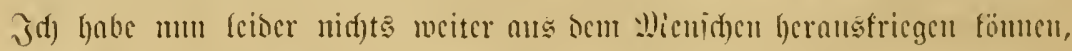

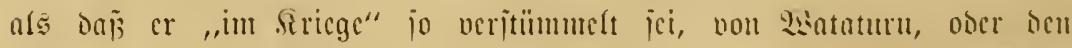

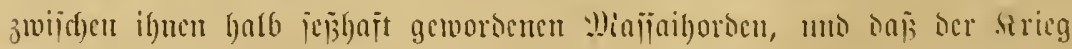

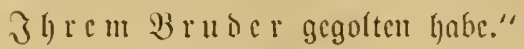

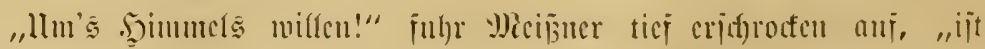

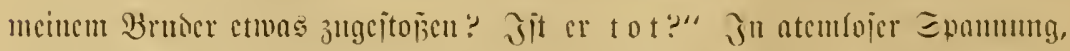

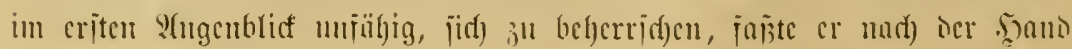




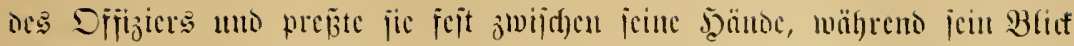

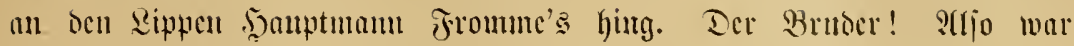

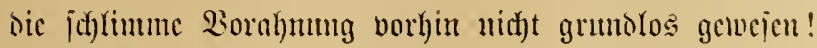

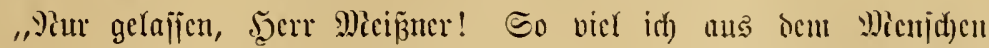

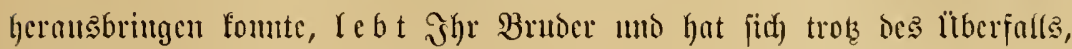
sor ifm fajt alfe jeisc Sente unt bic von ifm crrid)teten f̧itten fojtete,

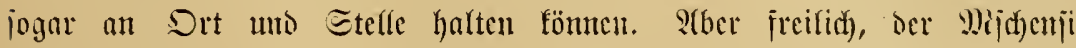

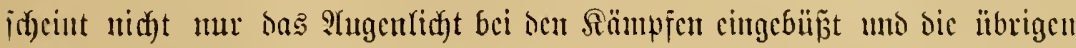

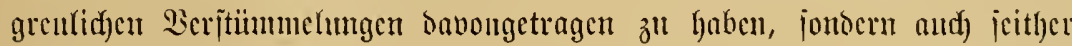
oen flaren Seritano nid)t mehr ganz beijammen ju haben; wenigitens zeit=

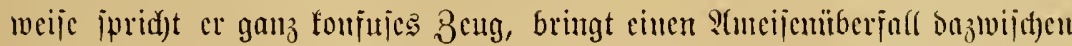

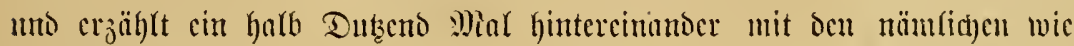
cingclernten 2 sorten, Daj $\mathfrak{\beta}$ er Den bana Méssina ndugúye mkubwa (Den älteren Brutor bes becru Meciñner) holen jolfe. - Son woher hatten Sic Dic Yekzte Pad)ridgt non Shrem Bruber? Ilno mam ?"

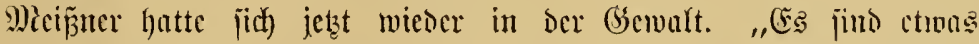

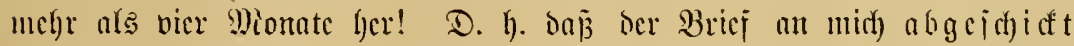

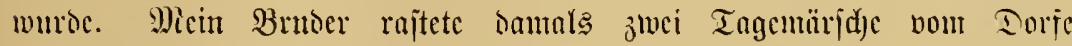
Girtumanu in Sramba uno gab dic Briefichaften cincm bortfiu ver=

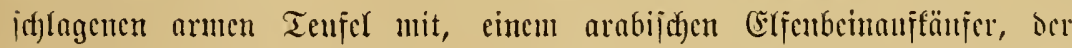
aber baun nad) ber $\Re$ ü j̈t jog. Son ba ans befam id) icu Briç. Dic

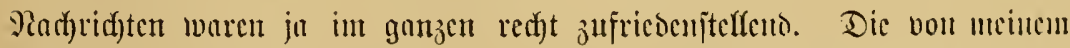

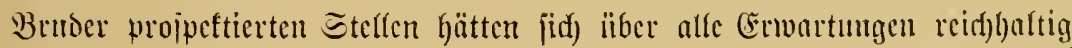

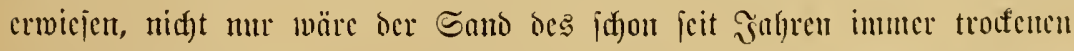

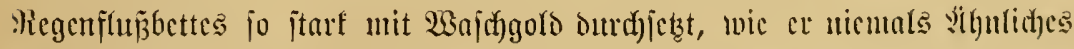

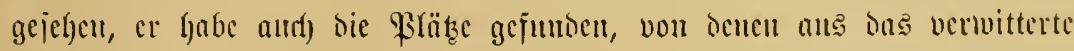

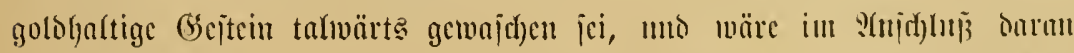

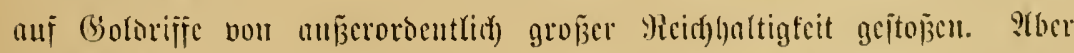

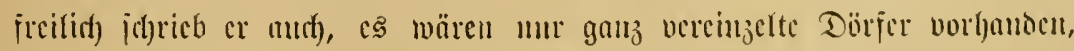

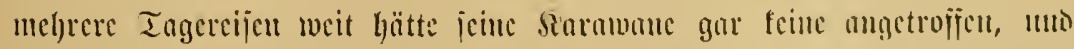
wo er unit ben Lenten 3ujumunengefoumen jei, bu bätten jic jist) nls idfulerig erwicjen."

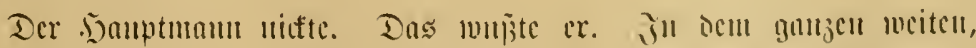

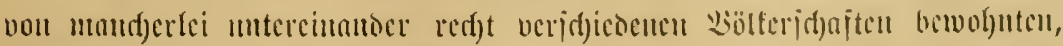




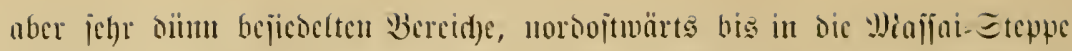

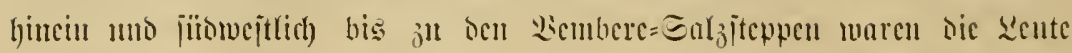

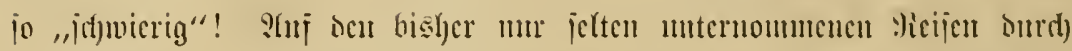
iene (begenocn hatte man in sen menigen Drtidjajten gewö̈lyulid) aud) für

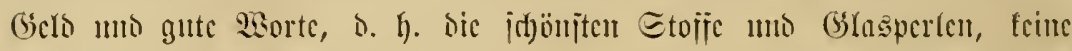

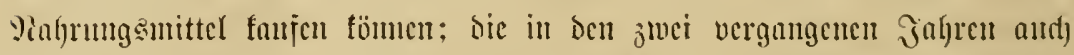

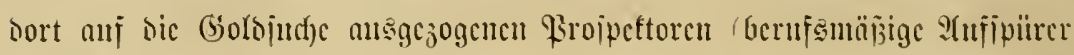

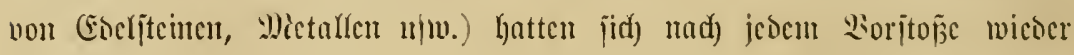

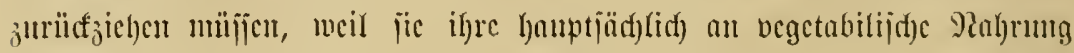

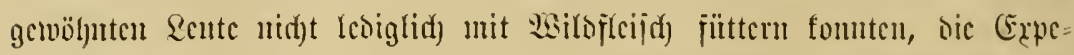

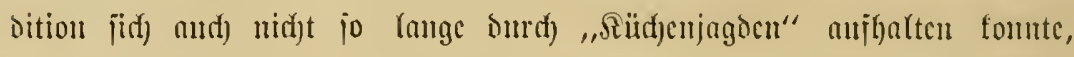

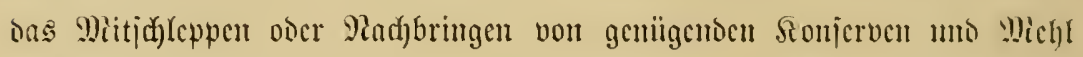

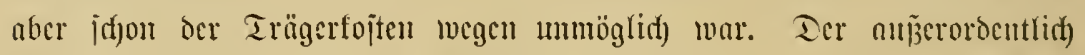

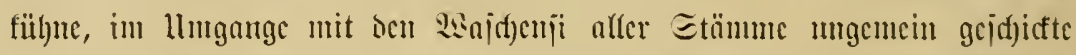
jïngere Wicijuter allein hatte $\mathfrak{c} s$ bislang vermod)t, fid) cinige Mionate

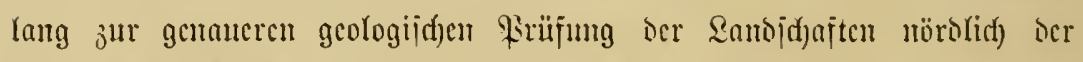

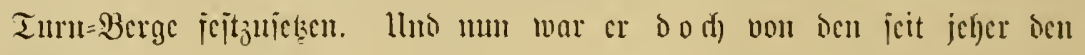

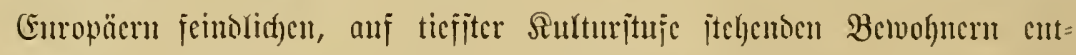
weice ber Feljengebirge oder ber Ealj̈teppen ïberjallen, waren jeine

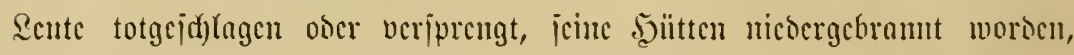

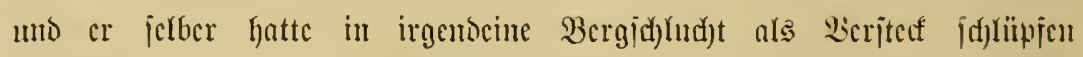

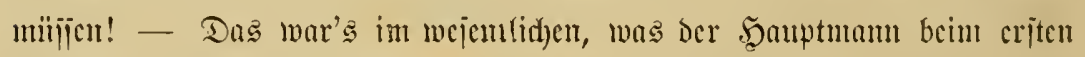
Serhör ocs B(inocn aus dem Mamte herauşabringen vermod)t hattc.

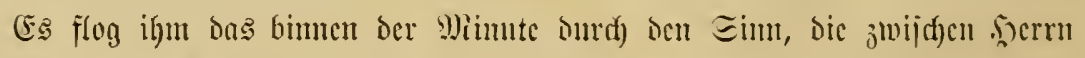

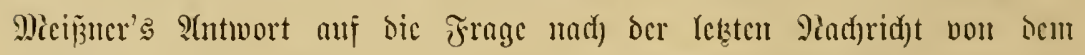

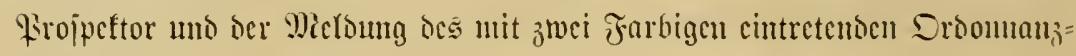
P(sfaris lag:

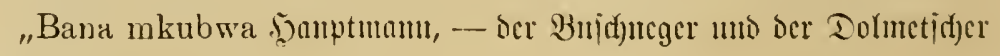 żll Etclle!"}

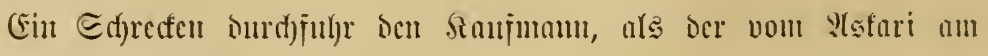
Dantogelenf gejajte umo mitten in bas Bimmer gefülyrte, nur mit cincul

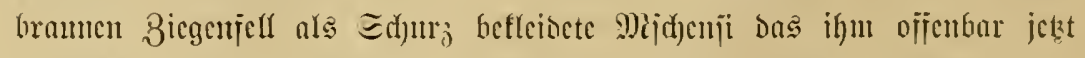

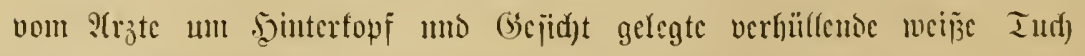

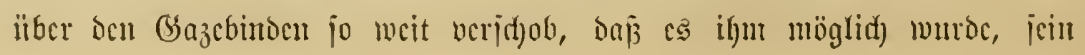




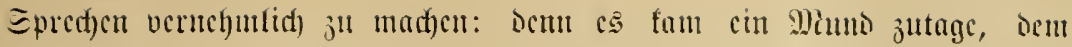

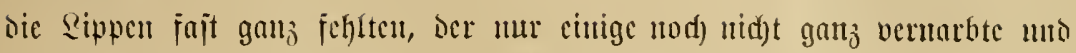

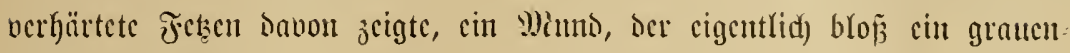

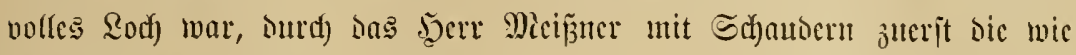

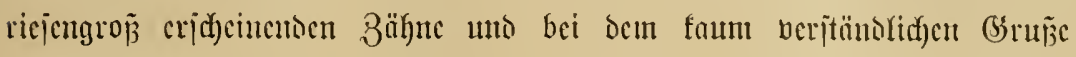

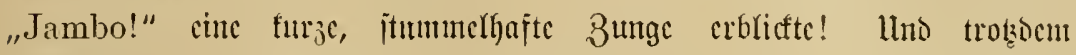

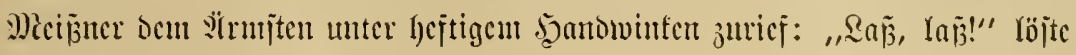

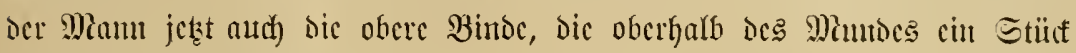

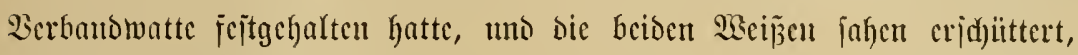

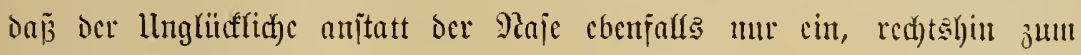
Ed)liz̧e meriendes, nod) nidyt völfig verfyciltes sod) im (bcjid)t hatte!

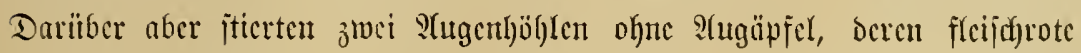

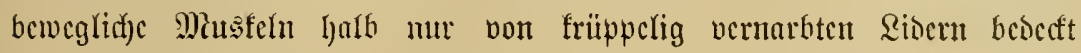

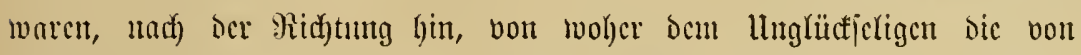

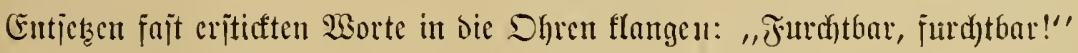

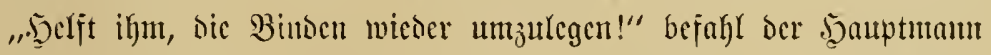

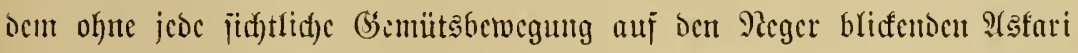
uns sem Satifiro. Dodf che es gejdechen tounte, hatte ber blinde unt

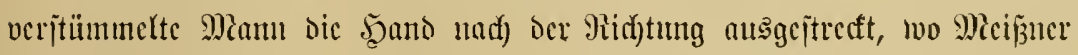
jtans, uno lalleno, taum verittändfich wegen ber vorn jum flumpen ver= unjtalteten 3unge uno ocr jum Epred)en faum nod) braudbbaren Rippen= ltberrejte, auf Sijuaheli gejragt:

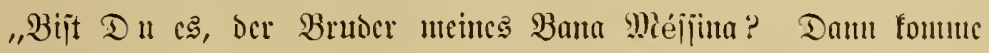
mit mir, ocr idf Didf füfyen weroc, utto rette Deinen $\mathcal{B}$ tutoce!"

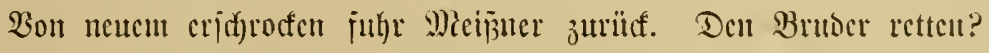

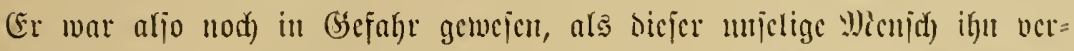

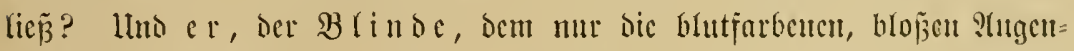

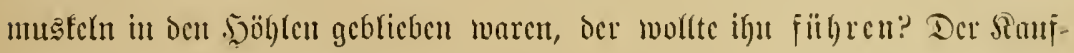

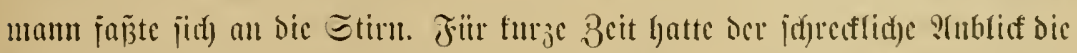

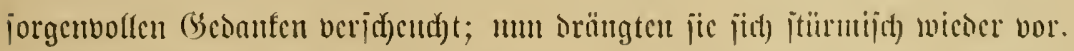

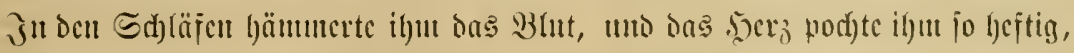

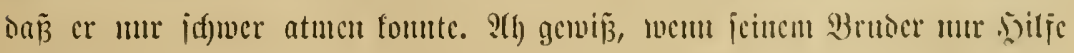

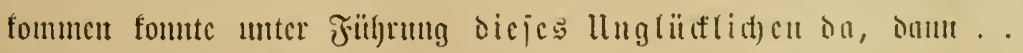

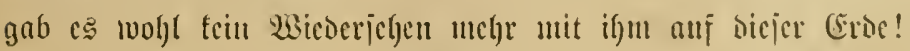




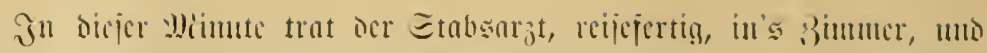

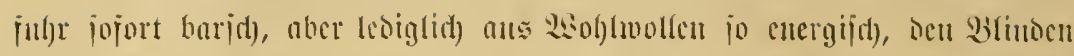

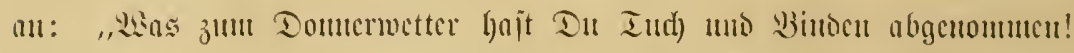

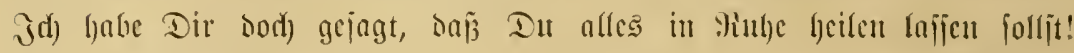

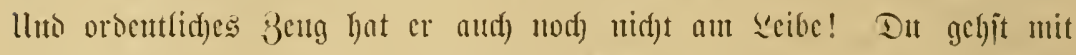
ihm nad)her gleid) 3n lluterofïjicr Whiente desmegen, S(stari!" bejahl

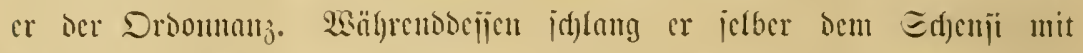

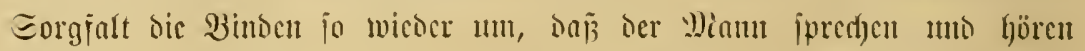

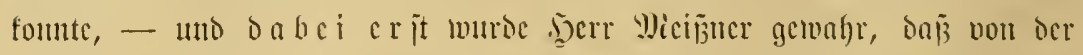

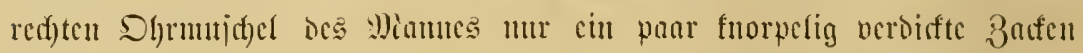

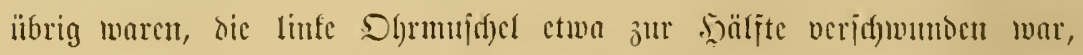

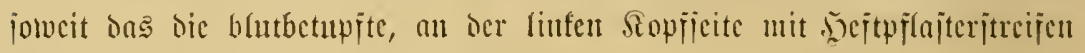
befejtigte Berbantomatte erfeumen ließj.

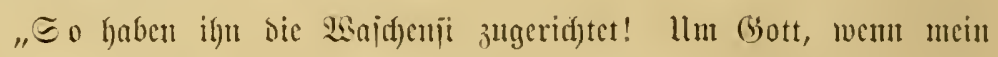

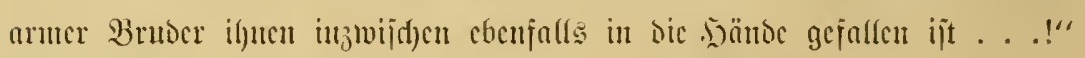

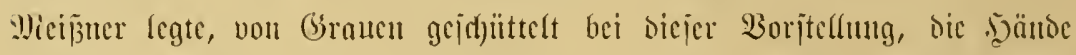

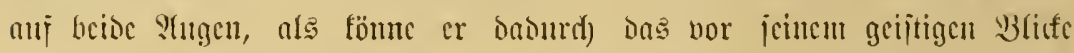

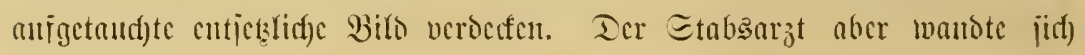
an ocn 5̧auptmaun:

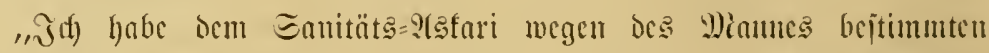
Wejebl gegeben. Jum Farbigen=

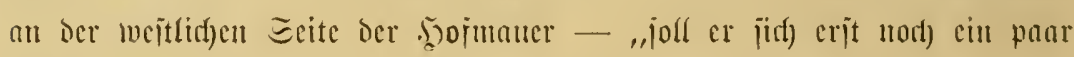

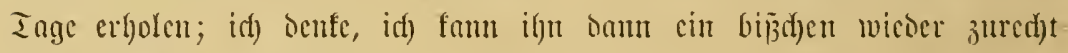
flicfen; Dic Plajengej(d)idf)te meinte idf)."

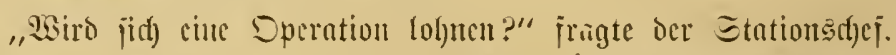

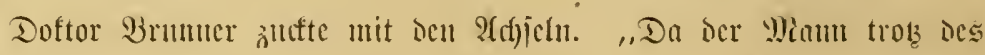
Soches über ocm Miunto uno ocr flumpig vernarbten Bumge Mabrung

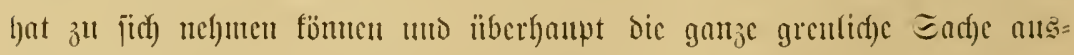

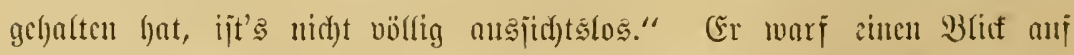

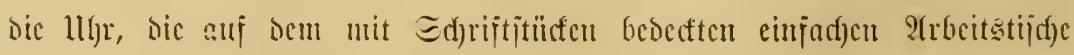

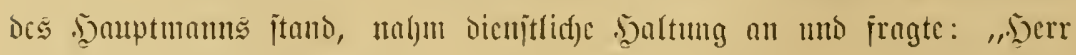

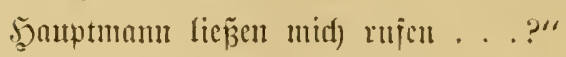

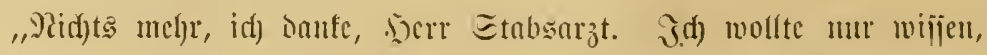

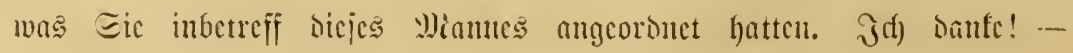




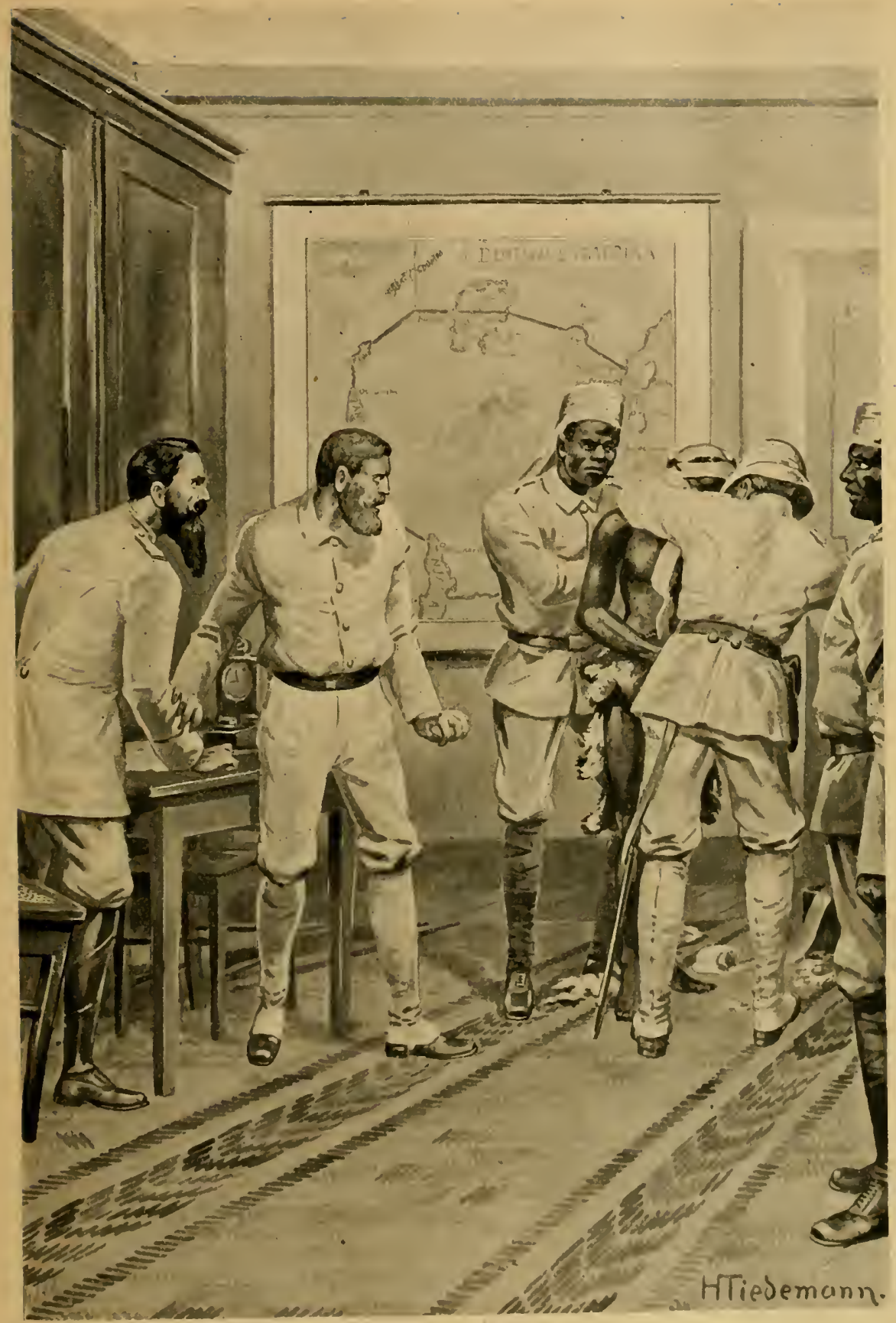

Währenddeflen fhlang er felber dem Schenfi mit Sorglalt die Binde fo wieder um, daj; der Manı (prechen und hören kounte. (Ecite 36 . 



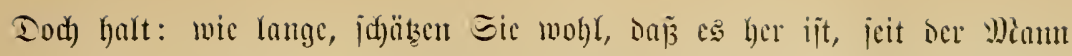

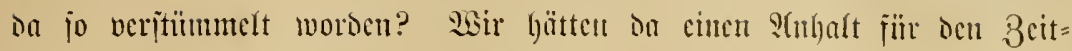

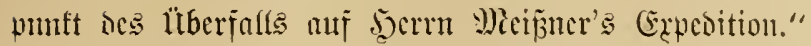

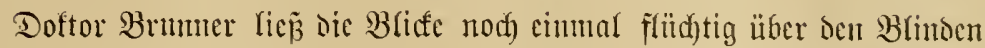

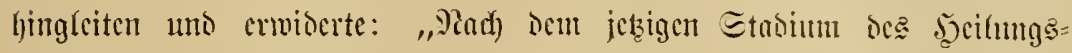

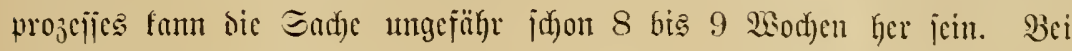

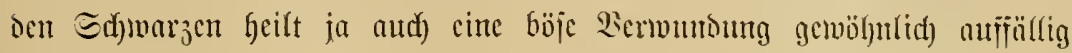
id)nell."

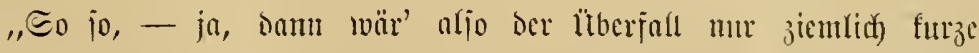
3eit nad) ber :(bjendung des Shuten jo veripätet jutgegangenen Briefes

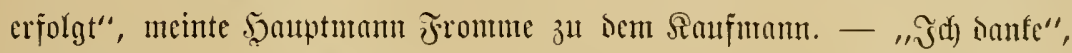
wicberffolte cr int Dienittoute nod) cinmal, 3ll Doftor Brunner gemanot,

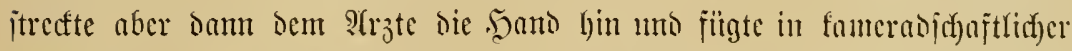

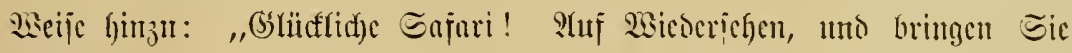

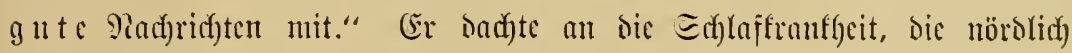

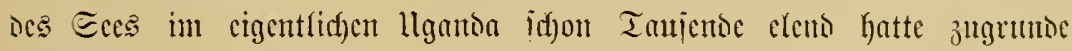

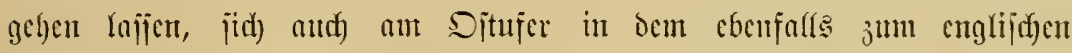
Proteftorat gehörigen Saviromo=?anoe in erid)rectemoer Ed)nelligfeit ans= gebreitet hatte und ourd zugemanterte Peger bereits anf cinjelne Drt=

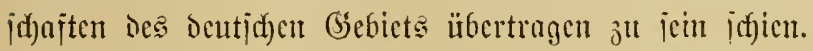

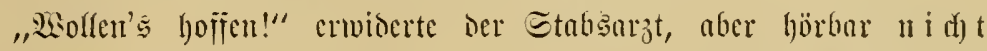

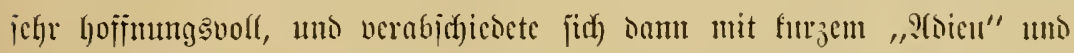

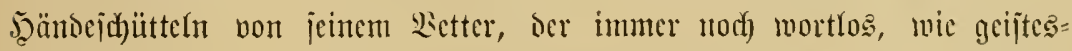

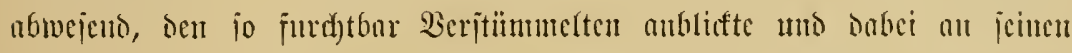

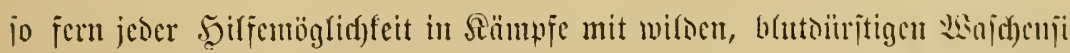

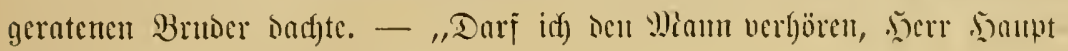
murn?" jragte er jekzt.

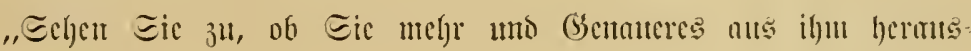
bringen als $i d$ !)!"

„Njóo (fomm, = hörce), jina lako nani, wéwe (Minut Deinc! welder, Dil)?"

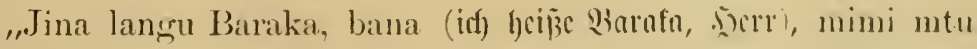

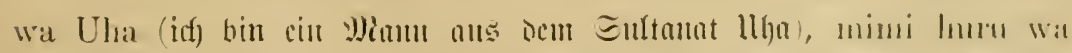

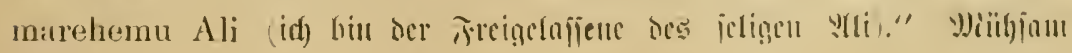




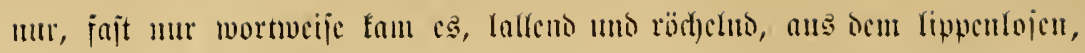

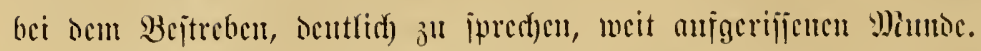

"(Sut, Barafin, wir wolten aber bören, was Du bou Deincut

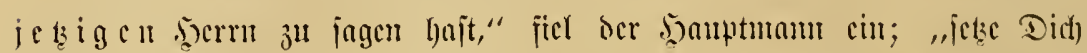

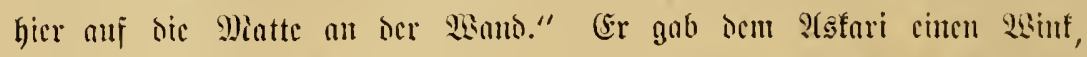

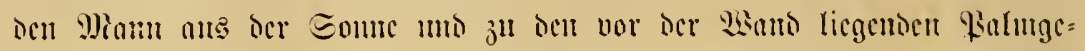

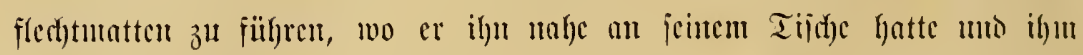
Dod) nitft gerabeaus in Das zmar surd) Doftor Brumer mit bem wein̈su

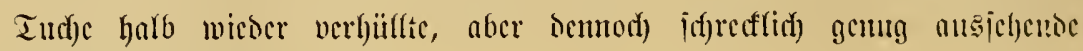

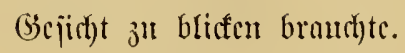

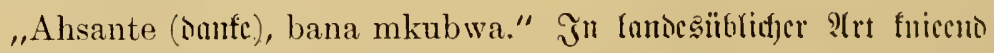

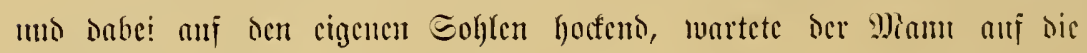
weitcren Fragen, ofme Erregung ju jeigen, obme merfen ju Yajjen, ob er

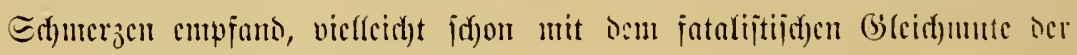
Neger ergeben in jein mu cimmal unabämberlid)es (bejuctef.

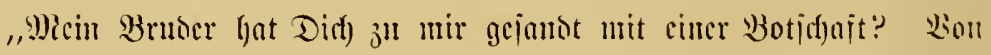
wo ?" iragte Micijner.

,Plein, J)err, mit Bricien!"

"llito wo it ind dicje Bricie?"

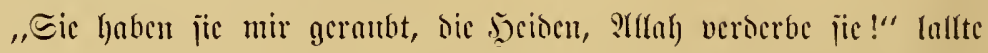
Barafa, megen hajtigeren Epredgens faum verïtündich. (Er war juncifel

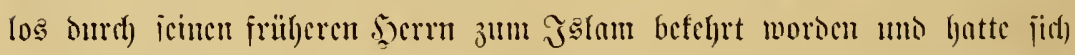

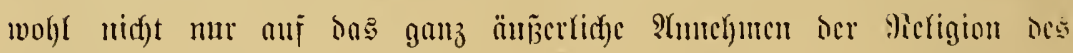

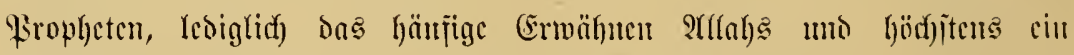

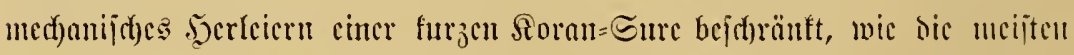

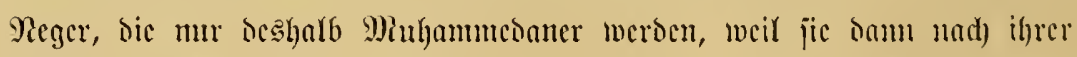

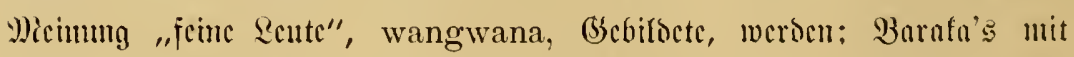

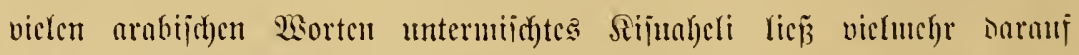

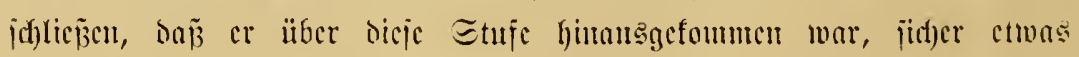

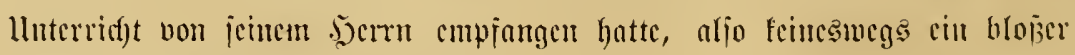
mshenzi, „Buid)meger", melgr war.

"Dic Bricic geraubt? . . . Kaser war çs, her bas tot?"

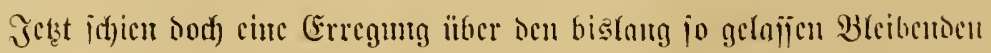

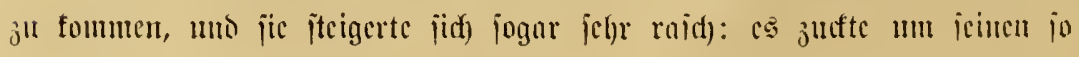




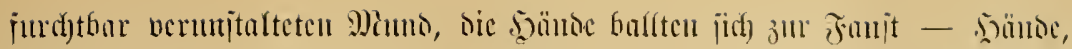
Dic an Rä̈fen wic ben Fingern

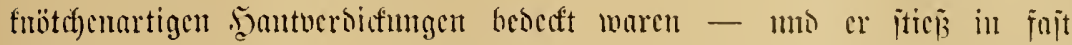
jijffentem Tone hervor: "Die siafu, dic siafu!!" Dobci muct)te il

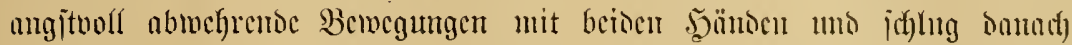

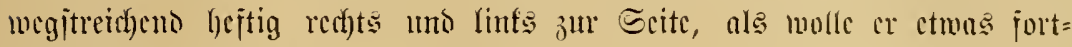

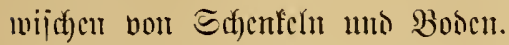

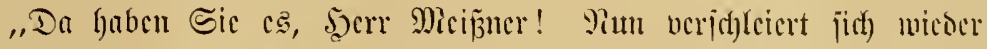

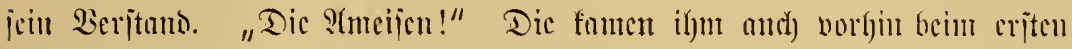

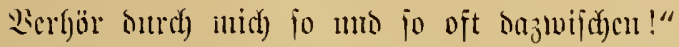

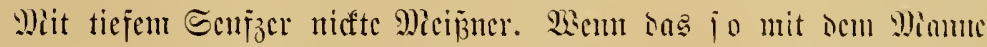
itnuts, Dam war wohl joberlid) cine brand)bare \$(t) Tenjel heratizutholen!

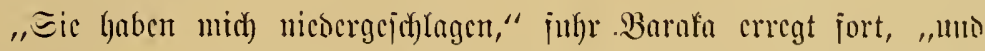

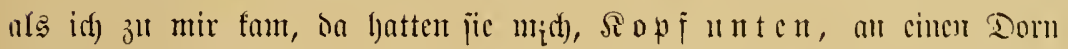
baum geffängt, an

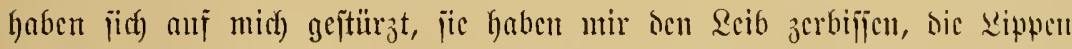

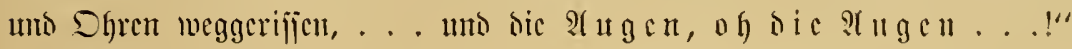

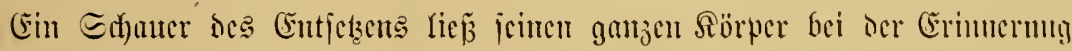

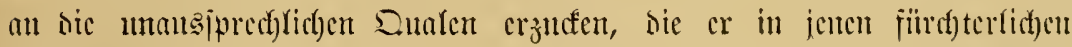

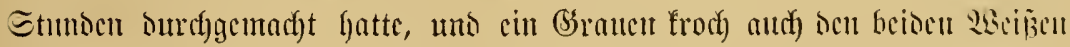

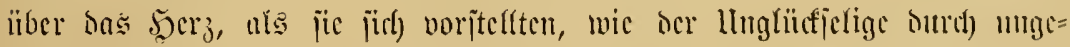

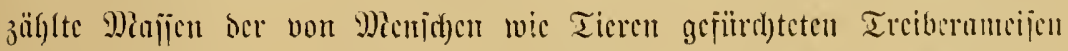

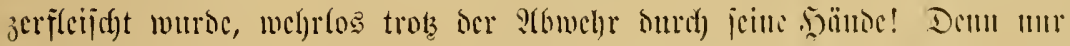

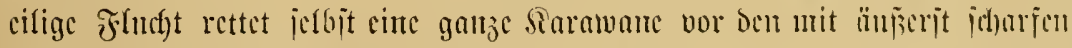

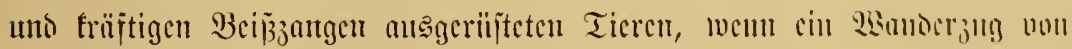

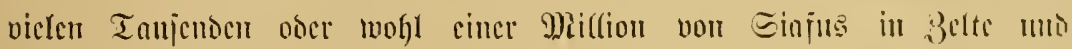

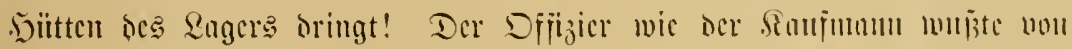

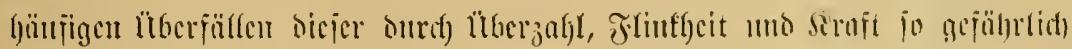

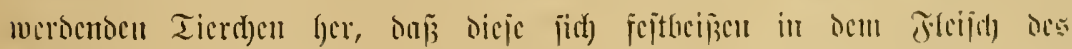

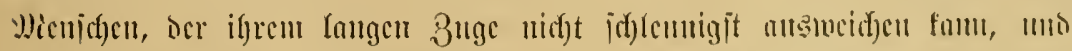

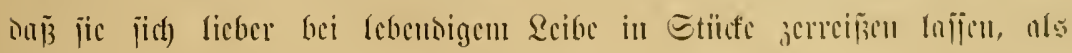

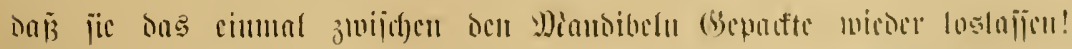

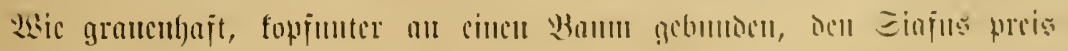


gegeben ju jein! Freilich, gauj alfein tounten bic Einju den Miann

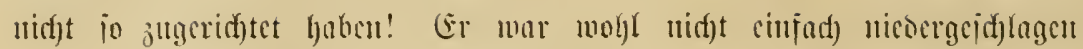

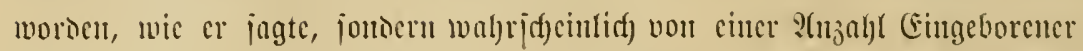

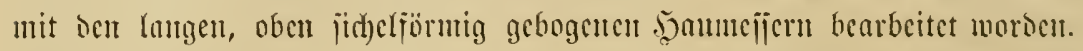

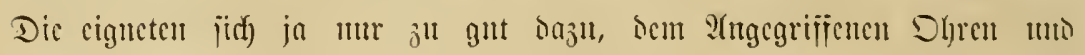

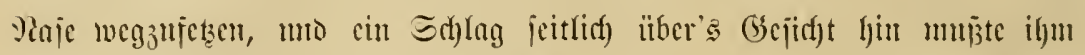

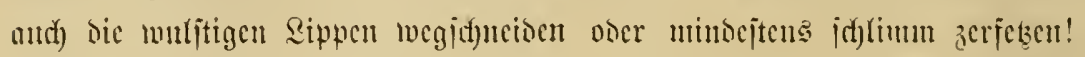

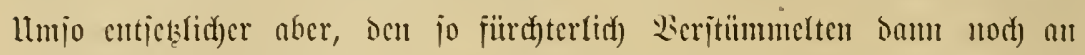

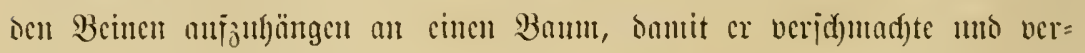

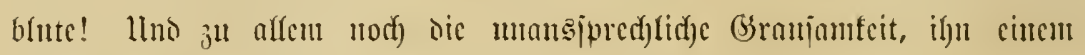

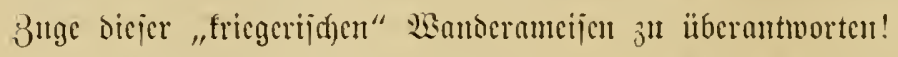

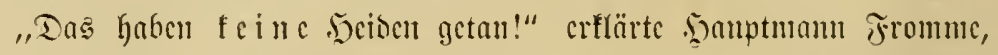

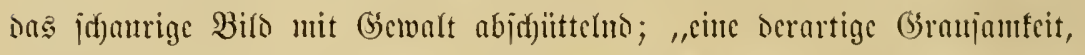

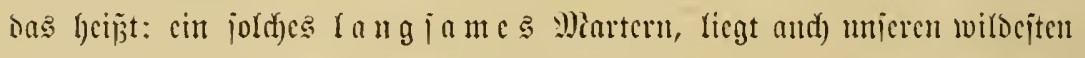

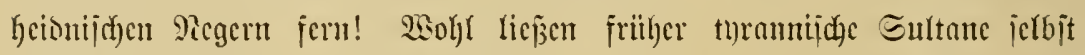

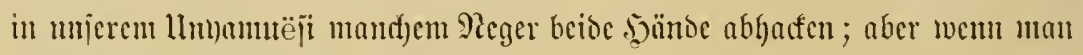
cinen $\Xi$ d)warjen fant, sem bie S(ugen anşgeitod)en waren, fo founte man

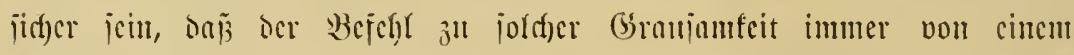
Nrabermijd linge ansgegangen war: Dicje Mitidglinge haben ju

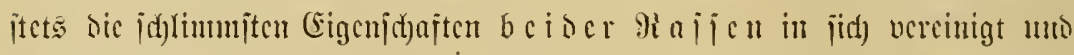

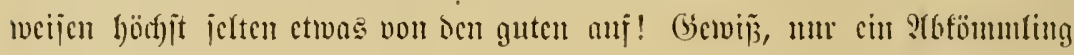

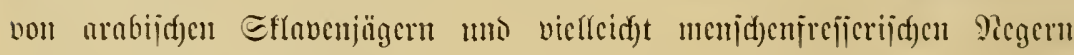

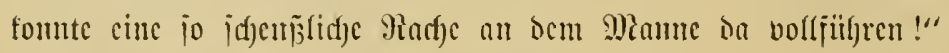

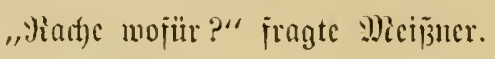

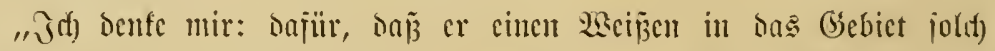

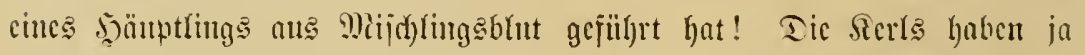

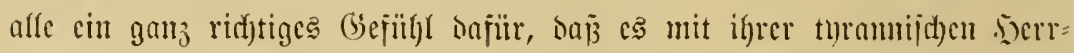

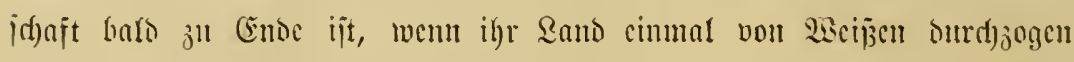

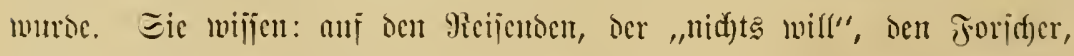

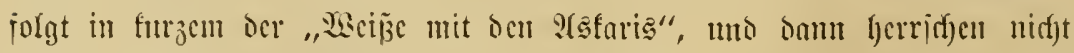

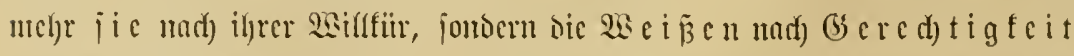

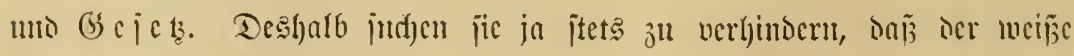

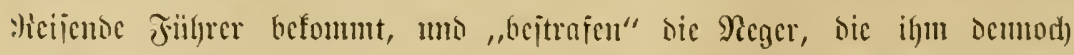
als Siarnvanenteiter gebient haben! (Es gibt nod) mel)e als cimen joldfer 


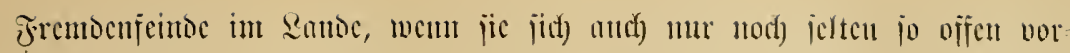

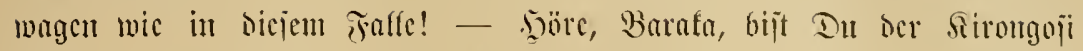

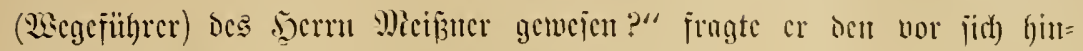

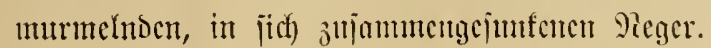

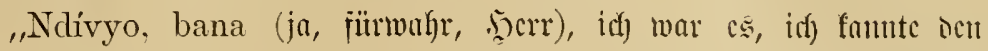

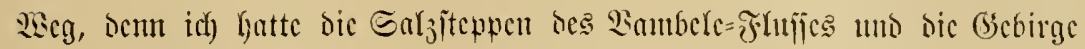

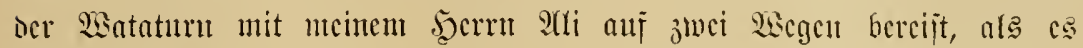

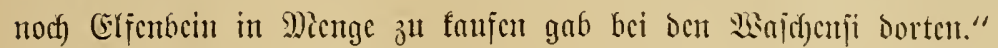

"Echen Eic woht? Eirrer der şäutptringe ba hat woht noch, mic

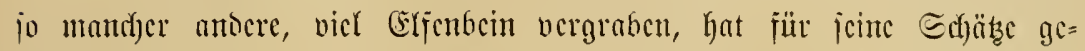

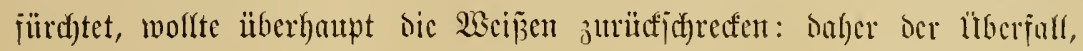
baber bieje unntenidglidide Rathe!"

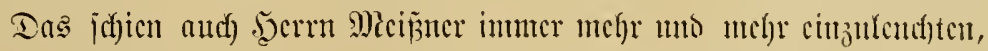

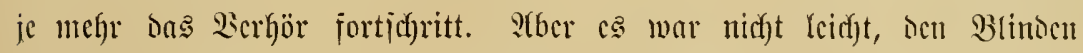

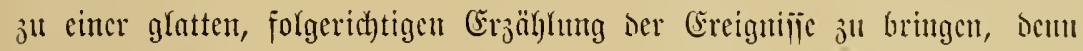

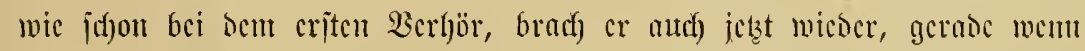

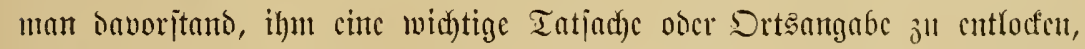
in jein cutictzes: "Dic Siaju! Tic Sinfu!!" aus, wefrte mit jitten=

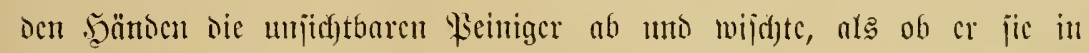

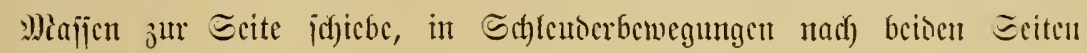
übcr bic Miatten hin. Bwar gab cr jwijchenturth cinc gantz verītündigc

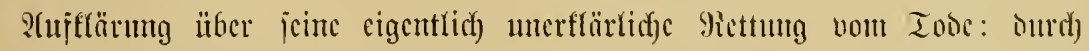

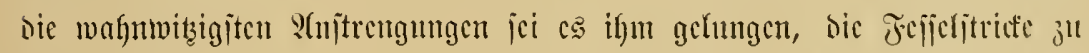

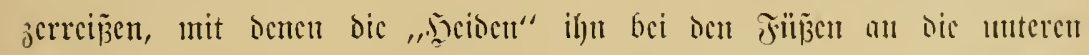

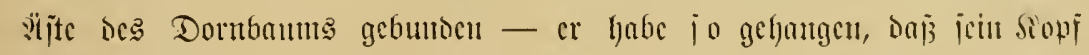

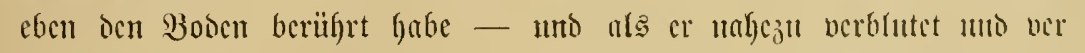

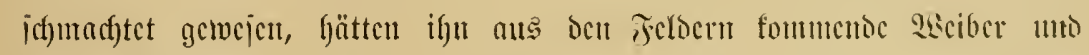

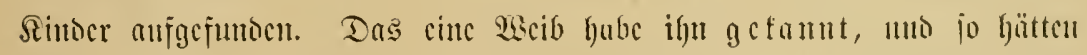

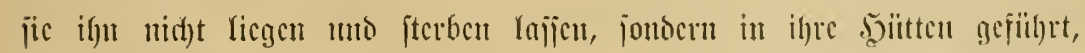
zuntal bic Siricger ja weiter gejogen jeien, un bus "Dorj" jeincs Diana

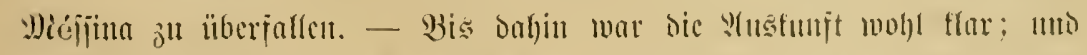

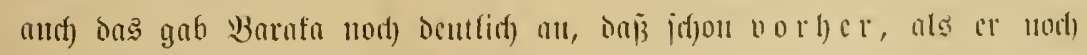

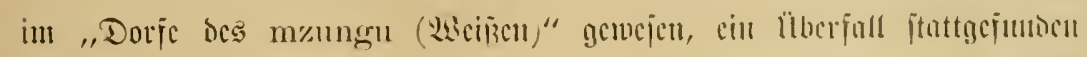

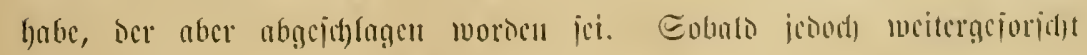




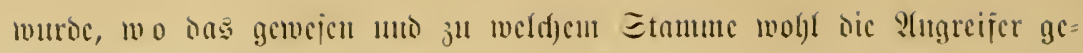
gel)ört hätten, veriagte das Gedödhtuis Barafa's, oder jein Weriotant un= wölfte jict) vollitünoig. Ahıj bic jrage: "Vilikwendaje (wic war ber s)ergang)?" mit ocr ganz bejtimuten ?(ngabe, wa a

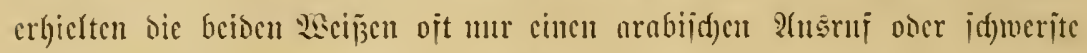

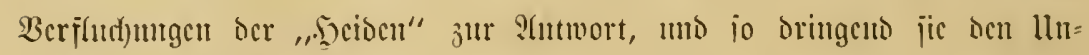

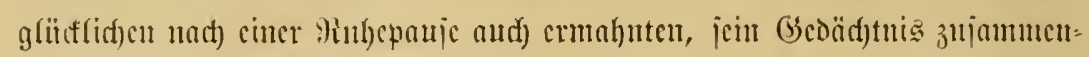

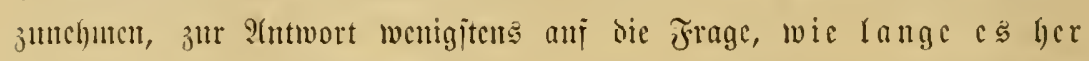

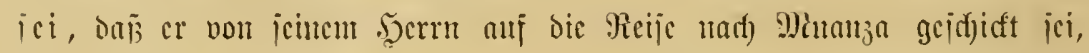

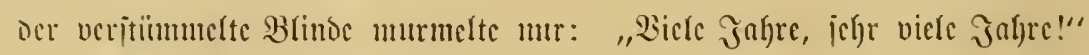

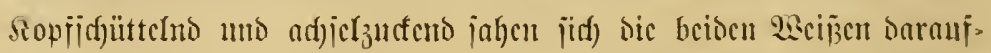
hiu an, unto "Yeye ana wazimu (cr, cr hat 2 crriidfthcit)!" raunten jid)

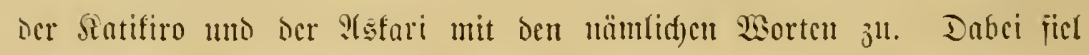

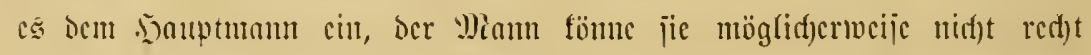
werïtchen; iprad) er bod) bas Sijutaheli nidyt bejier als jie jelber, cher

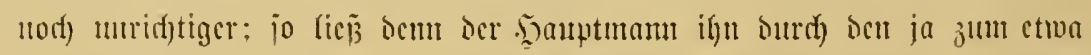
notwendig merdenden Dofuctịt)en herbejolfencu Sentifiro and nod) cimmal

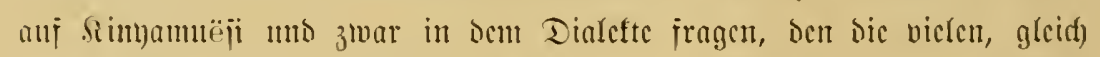

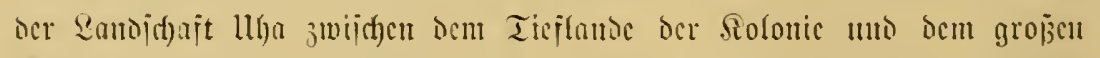

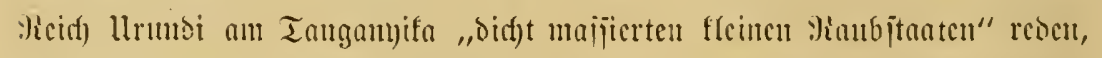

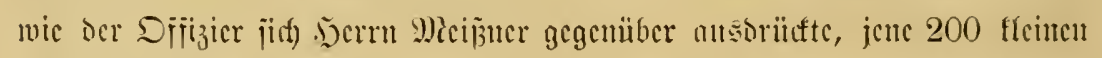

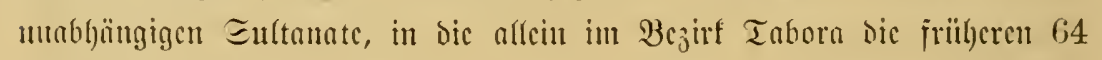

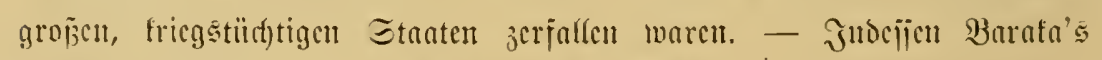

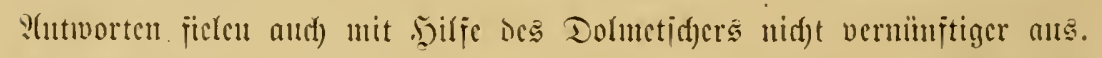

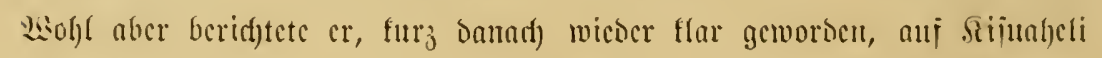

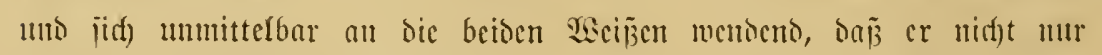

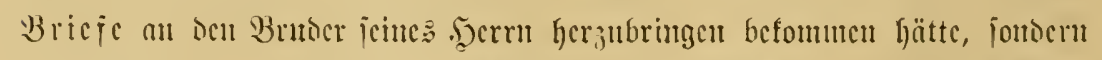
and) vicle vicle rahamani. Das war bas arabijd), ben meijten Viegern

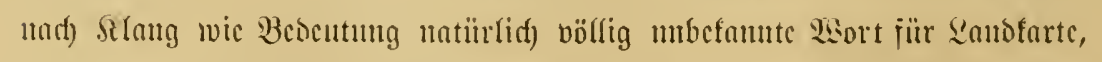

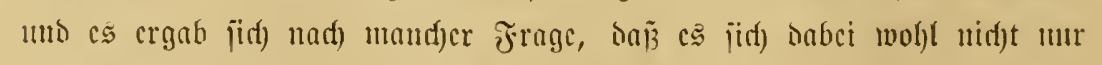

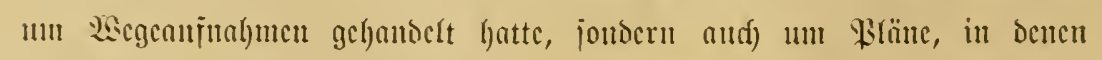
sic "Bolsoorfomunen" cingezcid)net waren; Dem Barafa, ocr muntorbarer=

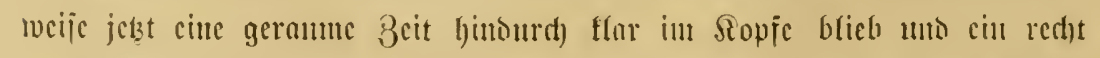

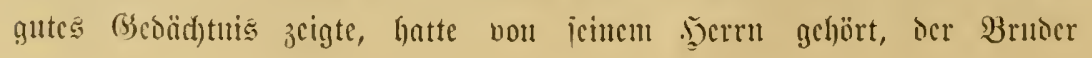


jolle Bricic unto rahamani uad) Dar=cs=julaam an ons serkali (oic Mic=

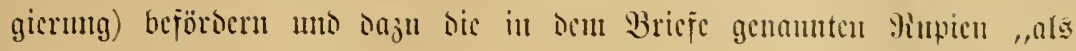

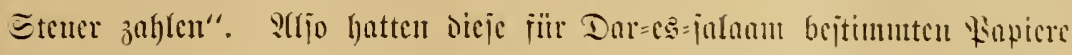

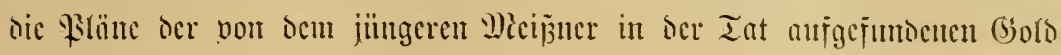
icloce euthalten, Der vom (Ślïa begïnjtigte \$roipettor hatte bereits mad)

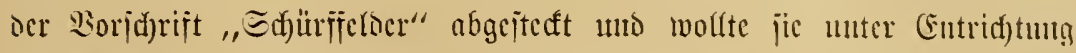

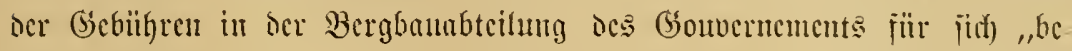
legen" lajfen! Socr er hatte gleid) cine Eiungabe jull (Erlangung ciner

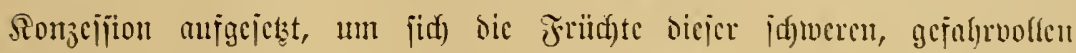

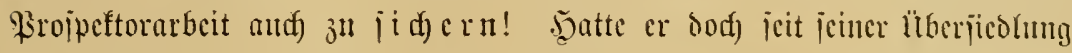

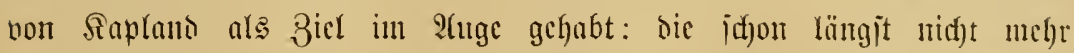
31weifelhajten Goldoortommen in Den Binnen= แmo Morobejirfen ier Siolonic nact) Rage uno llmiang möglid)jt genun jejtzujtelfen, un baun nad) (Evle=

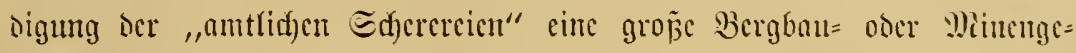

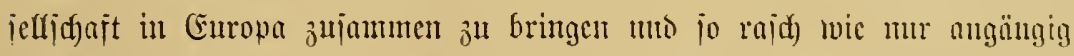

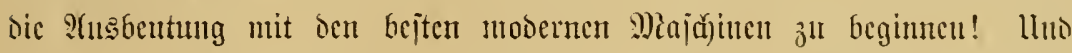
mun . . . S Saum hatte er bic erichnten (Entocefungen gemad)t, on mujiste cr auf Reben oder Tod mit ben bortigen Eingeborenen fümpjen, unjtatt,

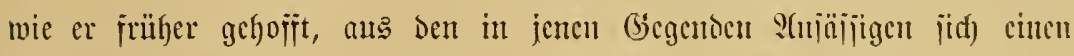

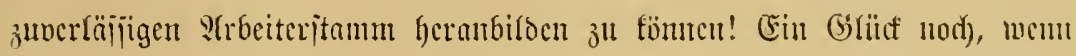

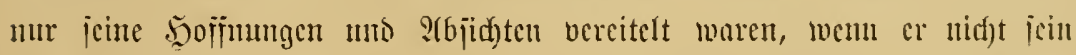

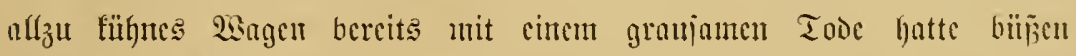

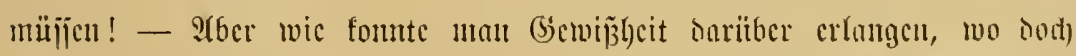
niemano aup̃er bicjem veritümmelten Blinden mit verjagenoen (sesüd)tnis:

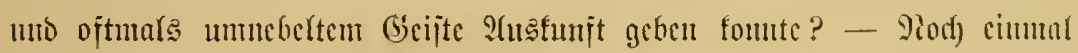

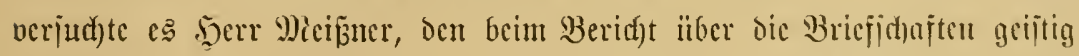
bod) gauz flur gewejenen Barafa auj bic $3 \mathrm{c}$ it des llberjalls mul nancut=

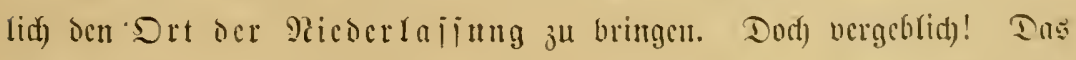

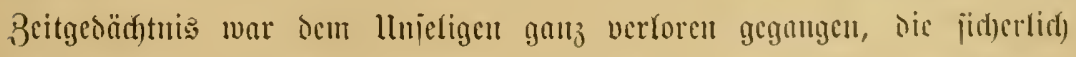

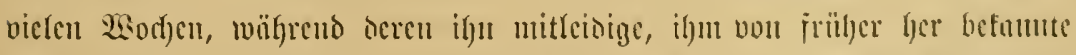

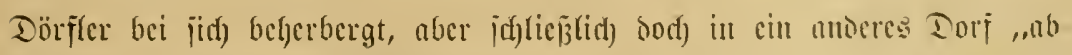

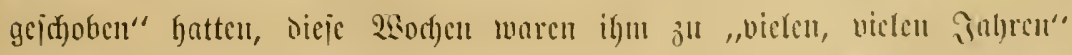

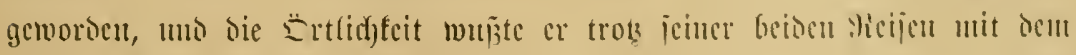

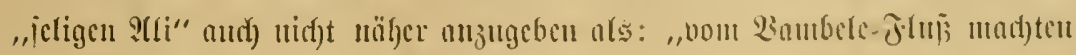


mix bic Eafnri immer or Eomm entgegen bis jenjeits ore Felsoürfer ocr sisntatmm".

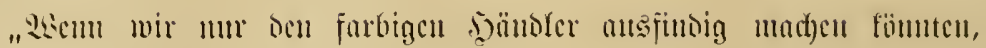

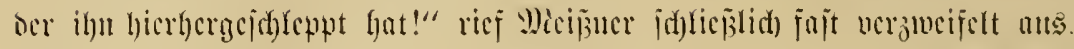

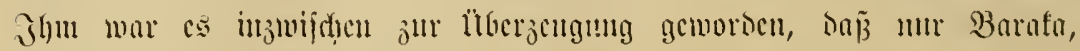

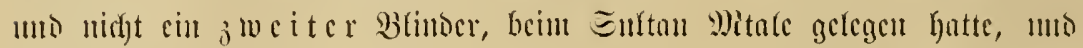

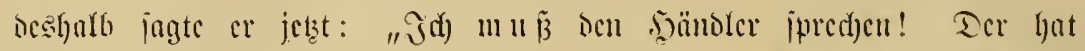
Barafa madf cincu an serrn Bartmum gefangten Bricje in Ecugerema

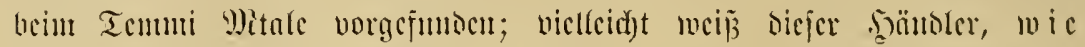

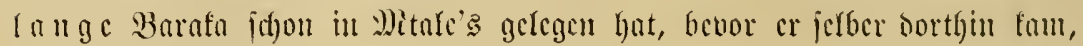

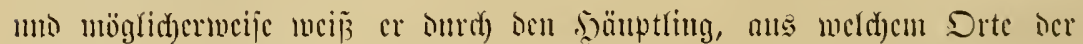

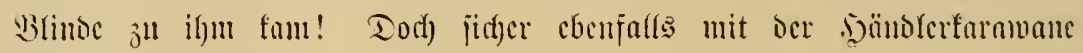
ciuc: Бd)warjen!"

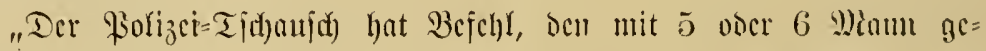

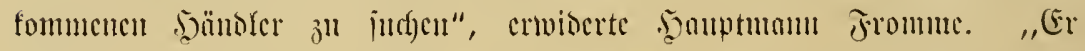

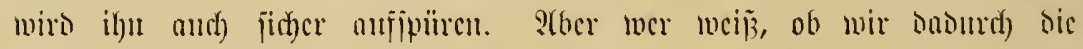

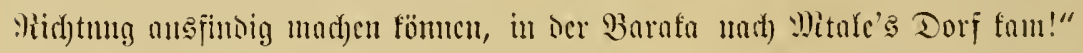

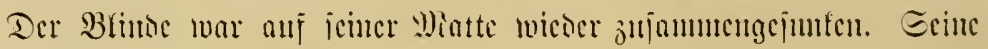

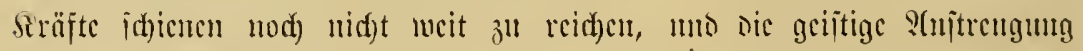

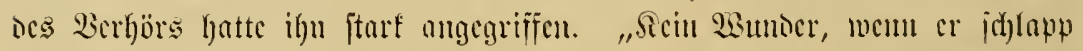

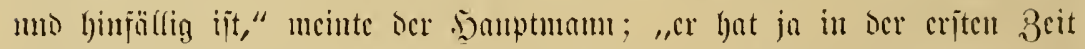

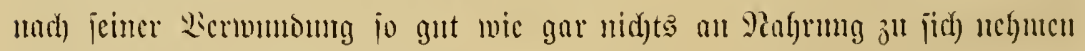

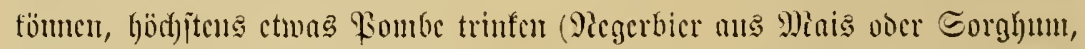

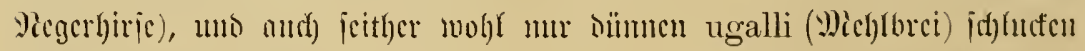
fönucu. Wéwe (Du)!" riç a seu mit vornïbergejunfenem Sopfe an

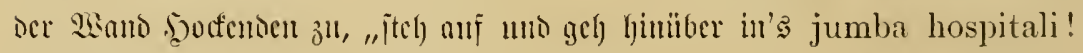

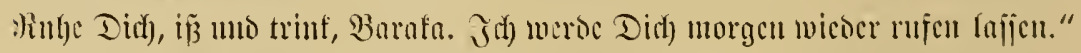

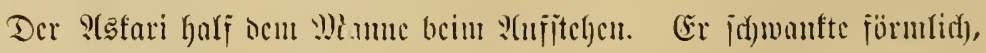
griißjte aber bod) nad) S(roberart, murmelte "Alisante, bana mkubwa,"

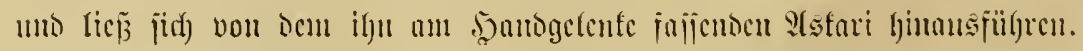

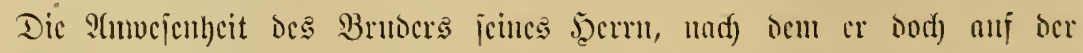

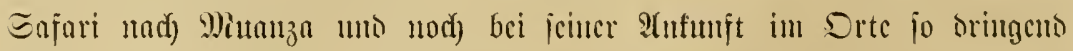

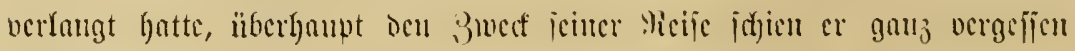
jul haben. 


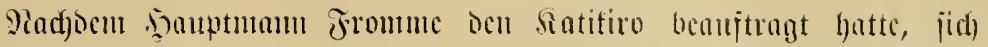

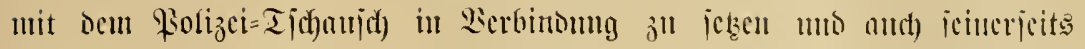

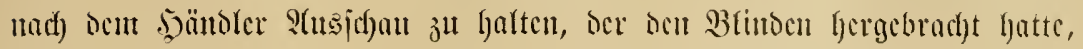

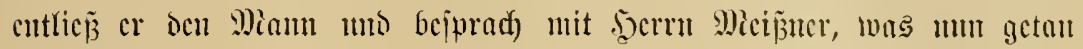

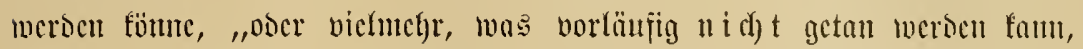

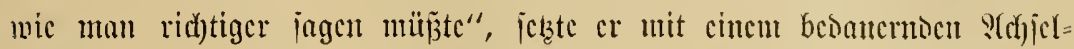

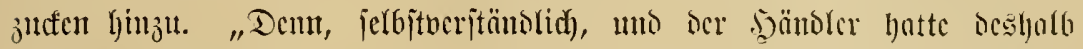

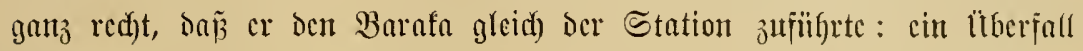

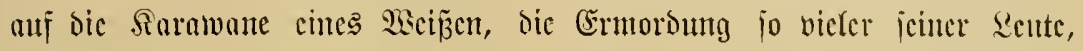
bic Berautumg uno graujante Marterung bes bon cincm Europäcr mit

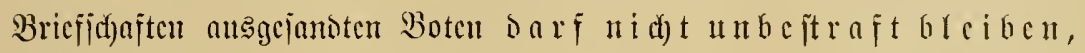

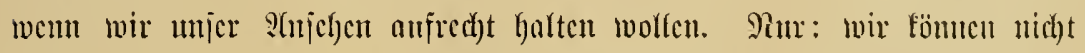
lesiglida nuf bic angaben cincs boch affe Bicrtelftumbe cimmal geiftig

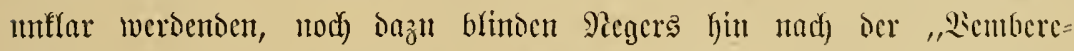
Steppe und immer der Some entgegen $i ̈ b e r$ bie Turt= Berge" marjejicten umb da in Dem ungefeucr ausgenefgnten (sebicte hermmjuchen nad) Den

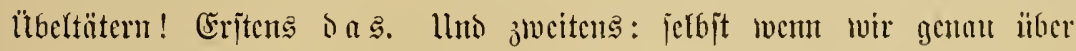
ben Sit ber Untaten unterridftet wären, - id bin gar nid)t in ser Sage,

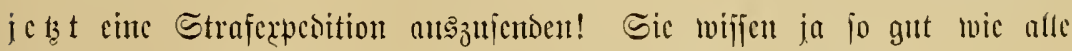

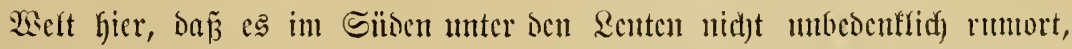

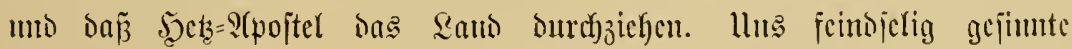

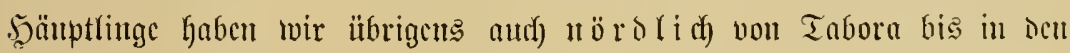
umunittelbaren Mindytbereich) unjerer Station. Sic büten jidh jum, Das

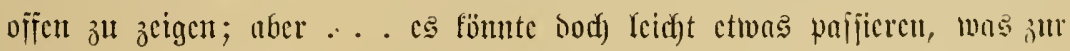
eiligen Berwendung aller Miamijafjaften fülf)rt!"

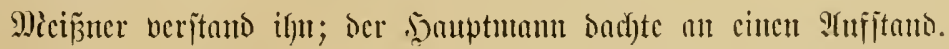

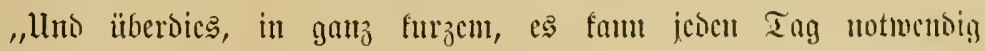

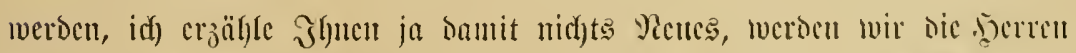

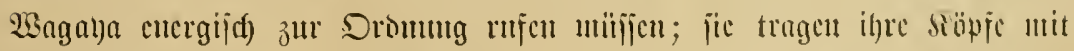

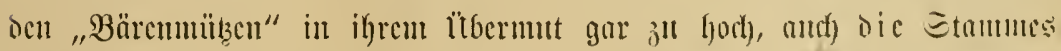

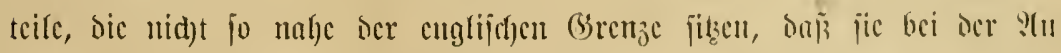

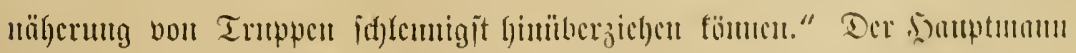

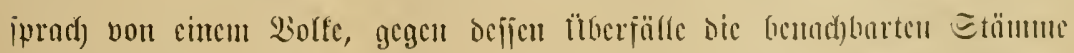

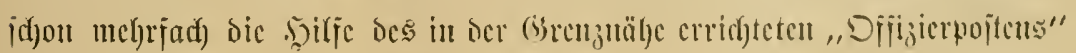




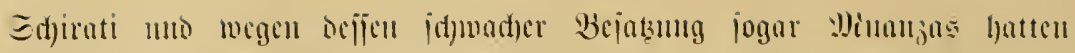

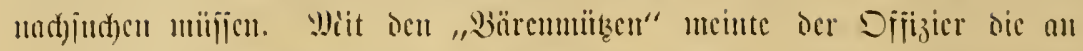

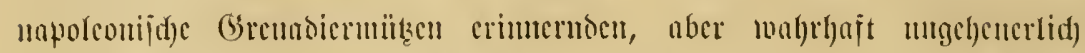

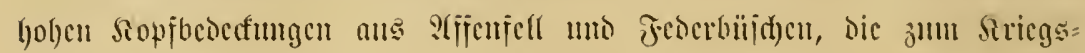

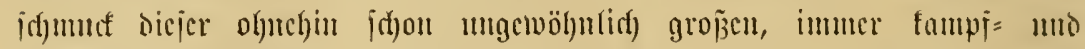

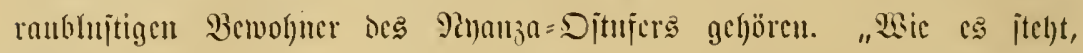

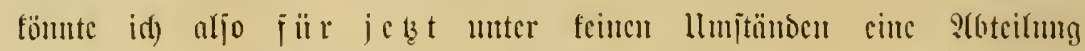

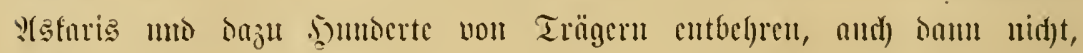

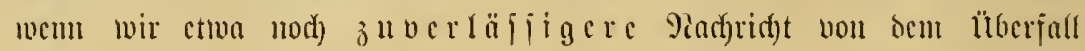

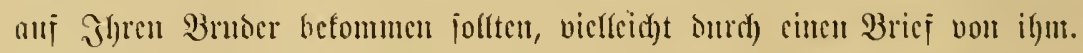

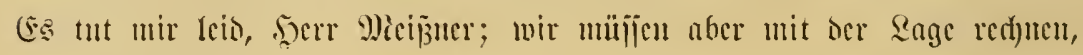
wic jie cimmal ijt."

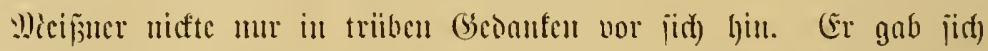

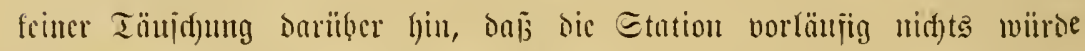

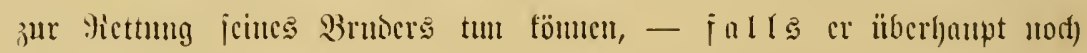

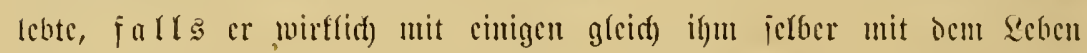

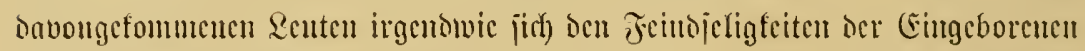

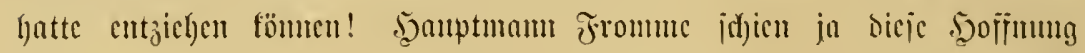

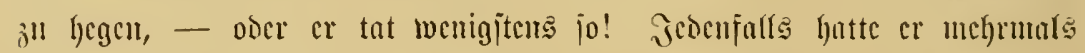

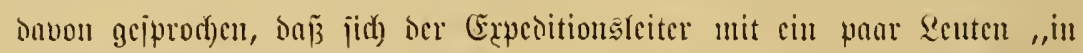

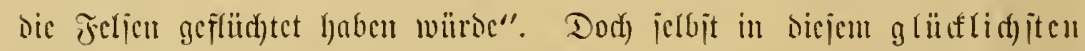
Falle war jein Bruber ganz auj jid) jetber angewiejen; bic Bebjöroc fomte

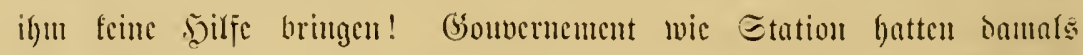

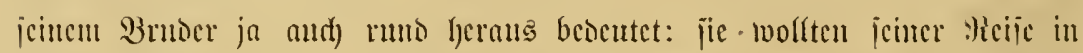

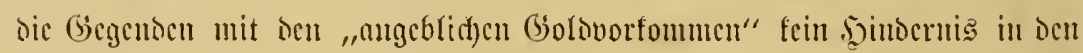

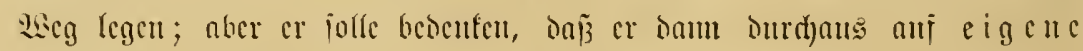

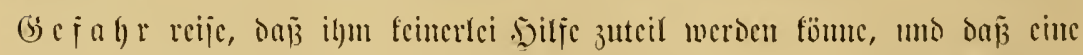

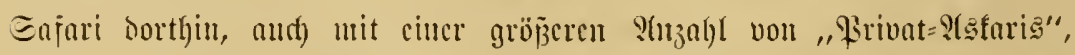

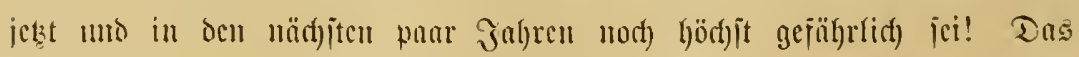

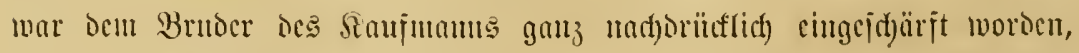

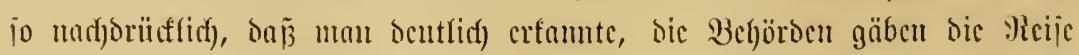

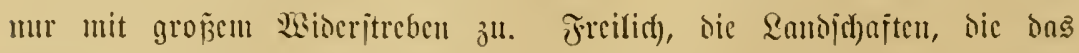

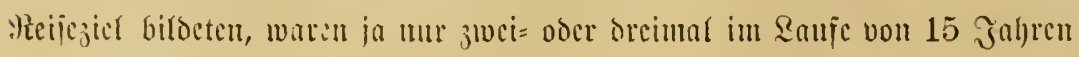

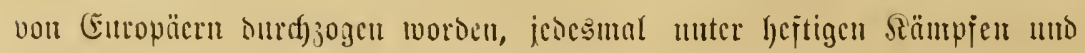




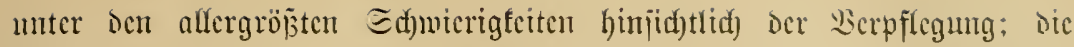
Eingeborenen waren nod) meit entFernt Davon, bic șerrichajt ber (Ẽuropäcr

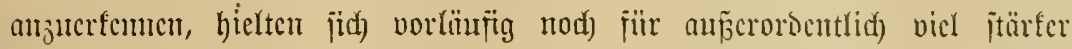

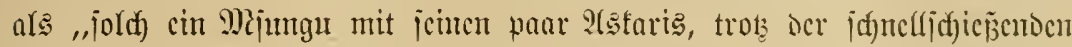

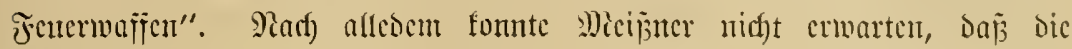

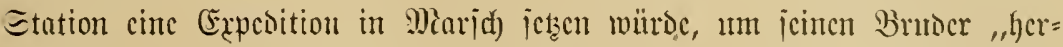

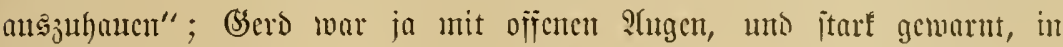

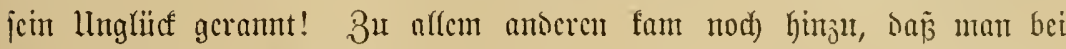

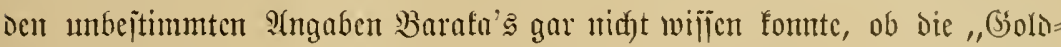

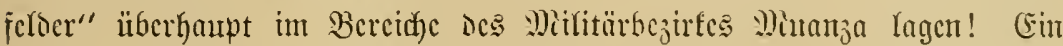
Icir Der Sembere=Steppe gefjörte j̈̈therfid) zum Bejirt von Tabora, Der ausgeochnter war afs bas halbe fiönigretd) Pren

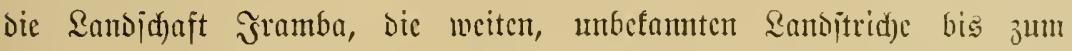

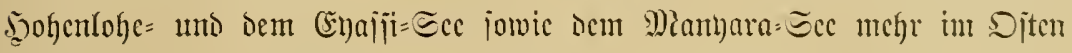
jtanoen unter ber Militäritation Silimatinoc, - ober viclmegr jie maren

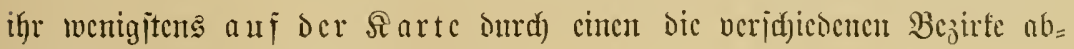
grenzenocn Stridy zugetcilt worden!

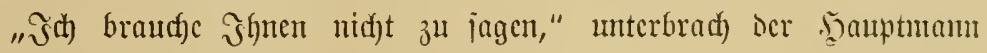

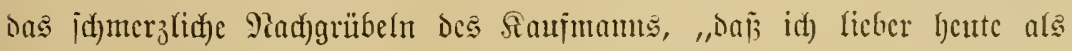

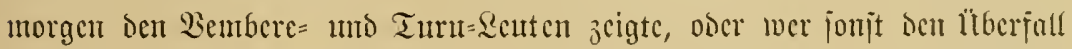

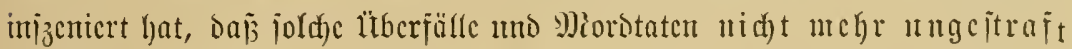

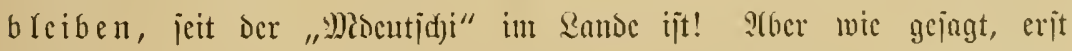

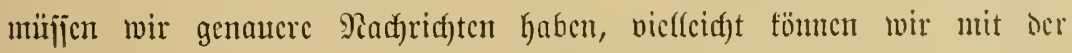

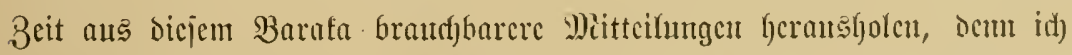

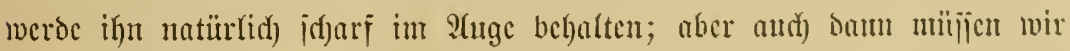

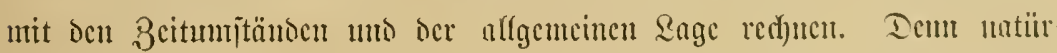

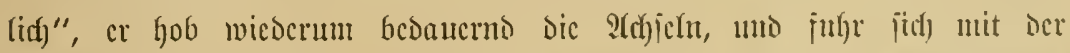

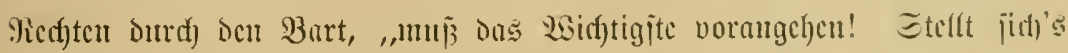

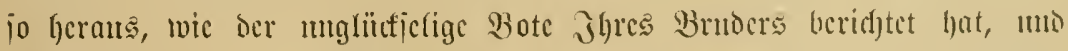

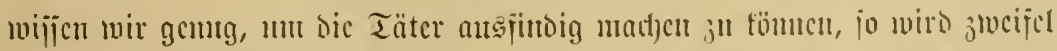

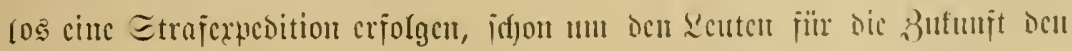

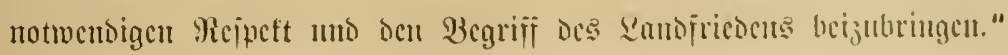

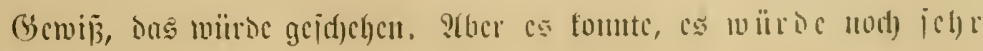
lange Dautern! 


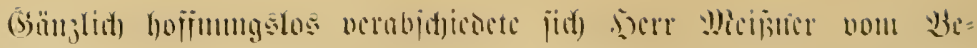

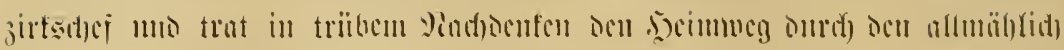

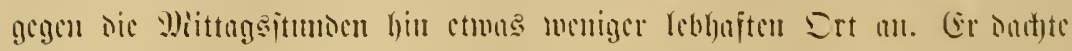

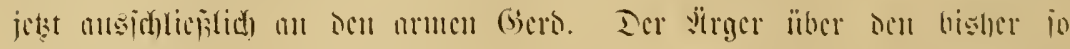

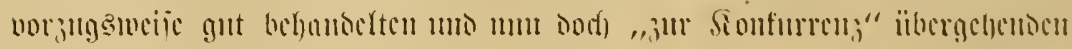

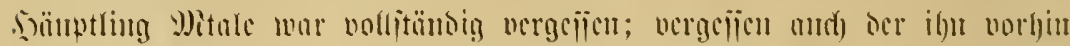

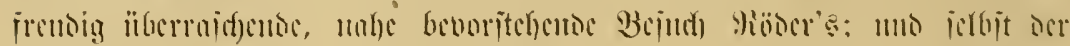

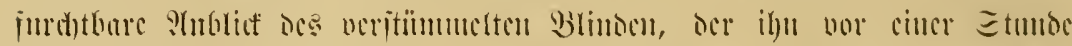

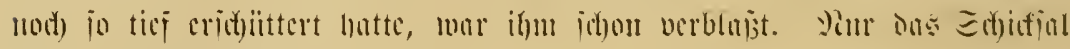

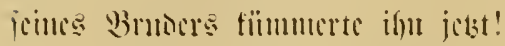

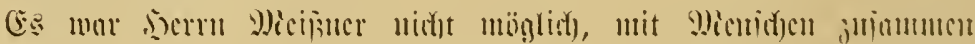

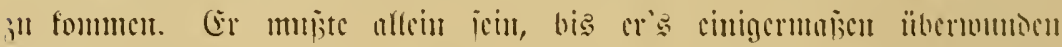

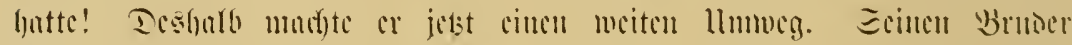

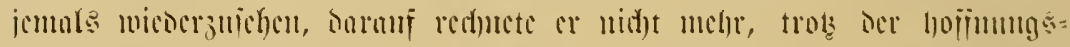

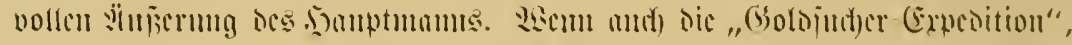

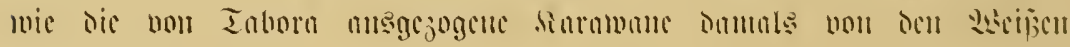

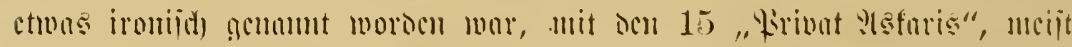

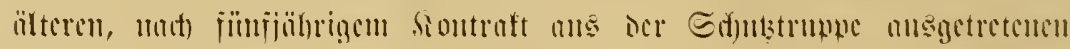

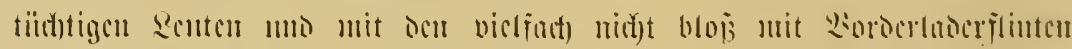

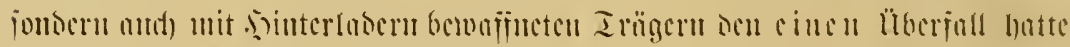

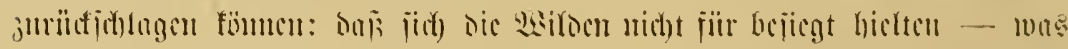

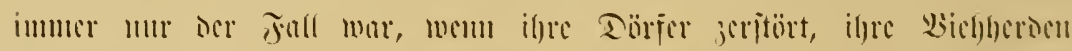

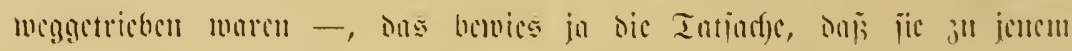

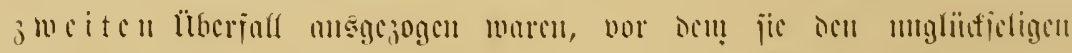

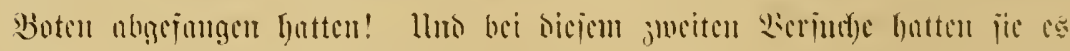

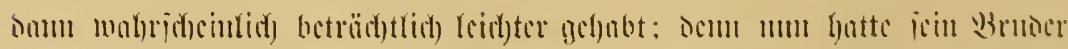

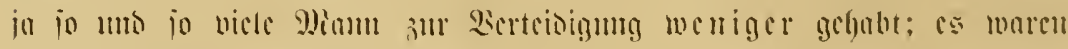

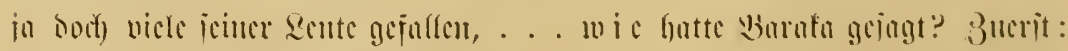

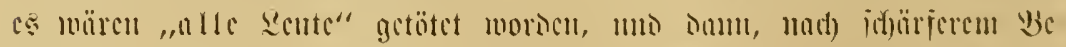

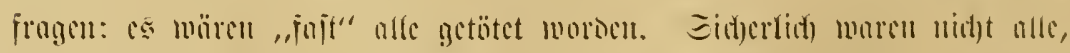

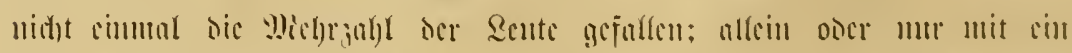

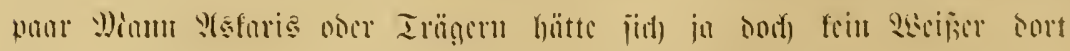

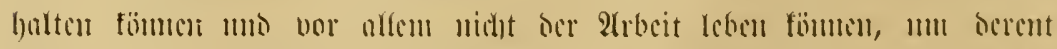

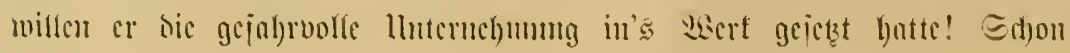




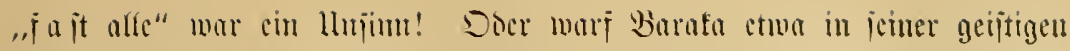

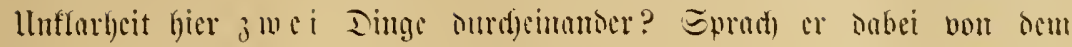

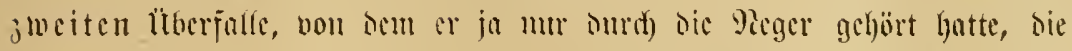

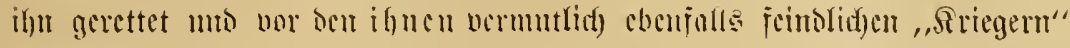

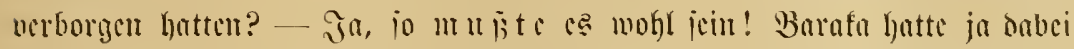

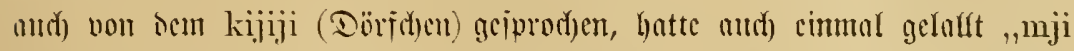

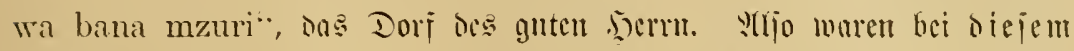

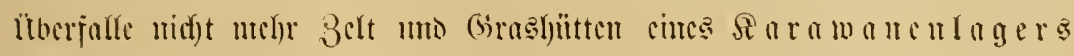

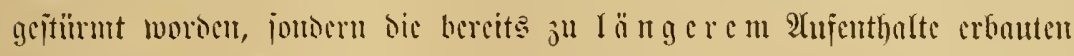

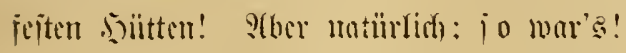

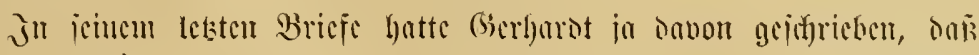

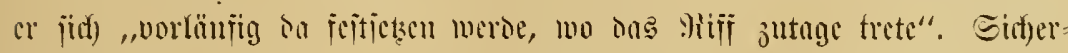

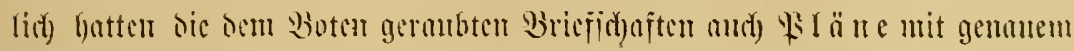
: Yujithlu;

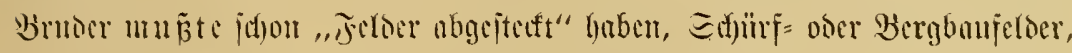

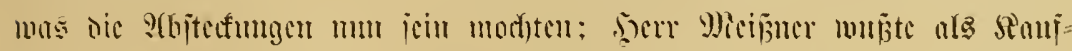

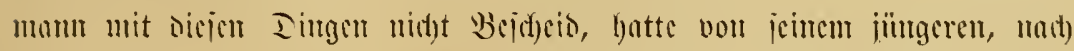

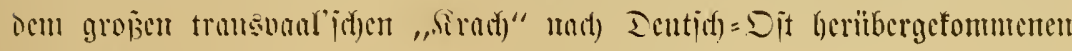

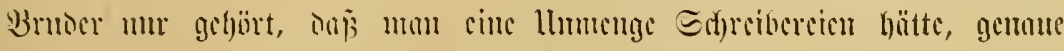

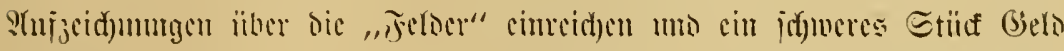

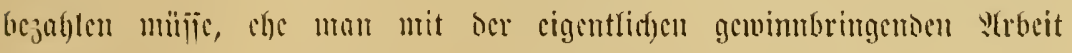

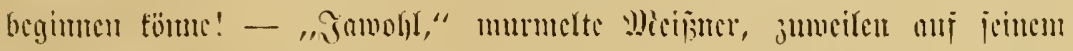

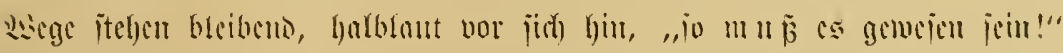

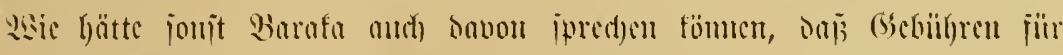

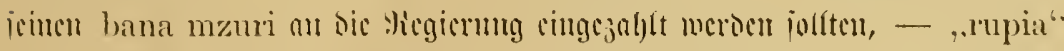

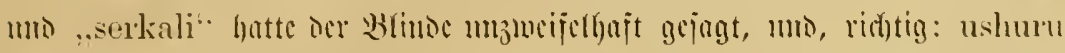

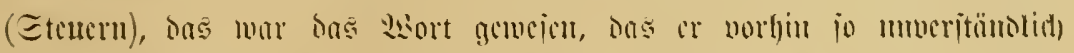

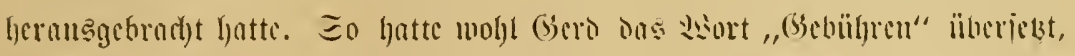

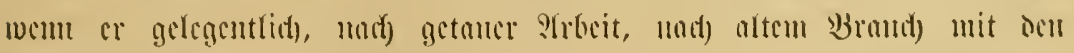

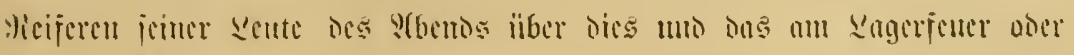
nuj Der Barain (meter Dem Liortach) Ber Eorfhitte Hanterte. - Der

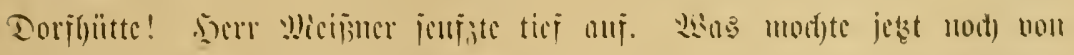

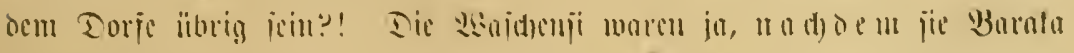

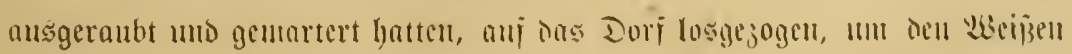




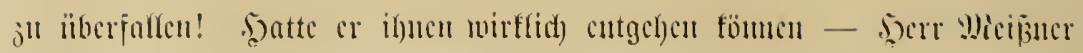

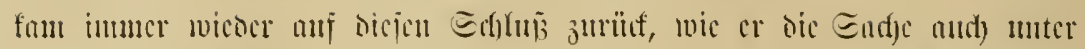

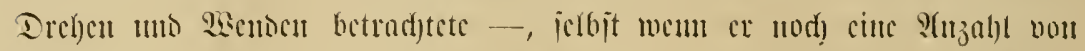

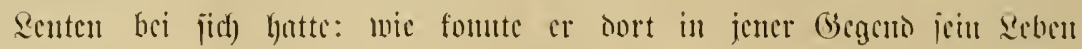

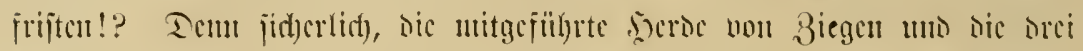

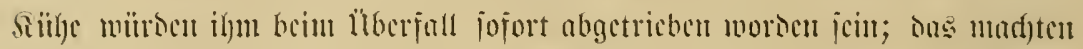

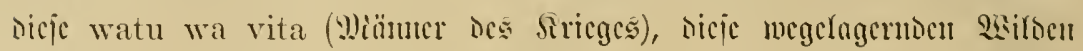

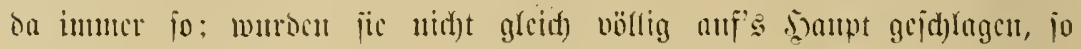

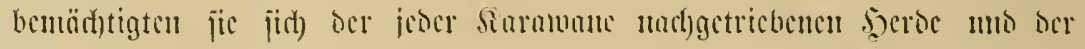

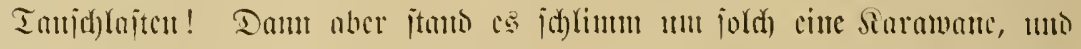

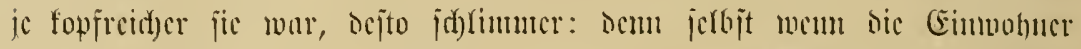

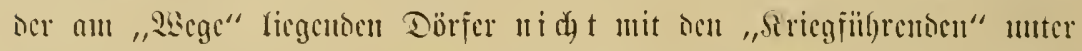

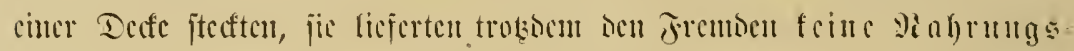

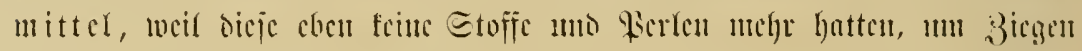

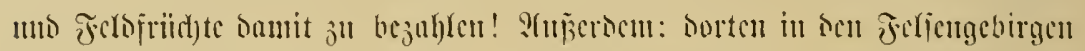

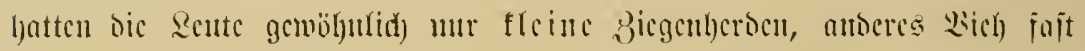

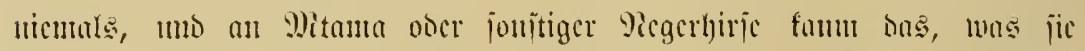

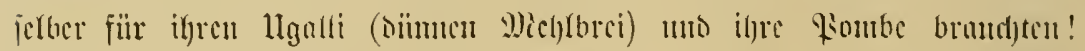

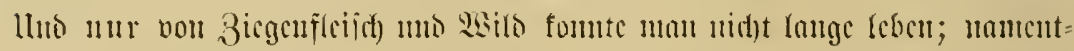

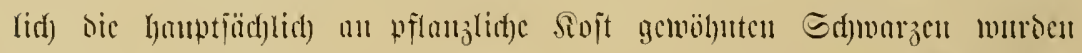

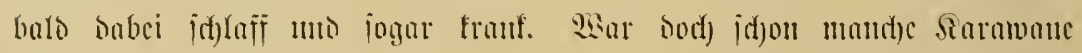

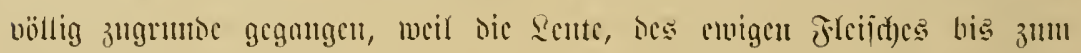
(Efel ïberorijijig, jid) Den Wingen mit gefod)ten Blättern und gebucften

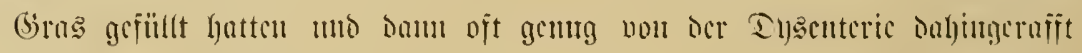

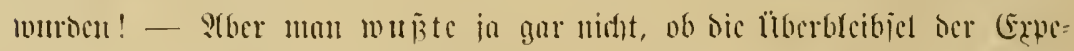

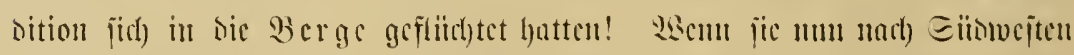

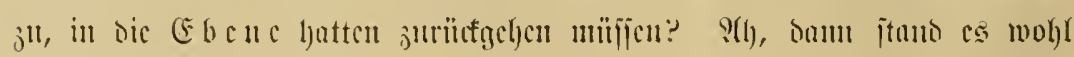

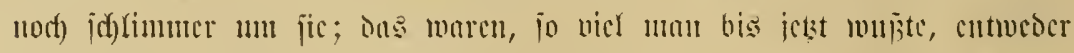

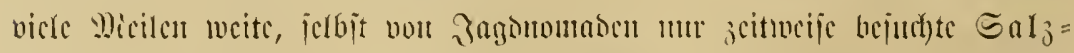

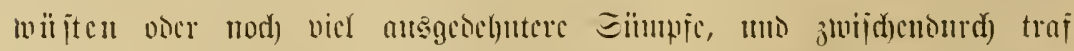

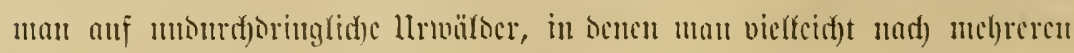

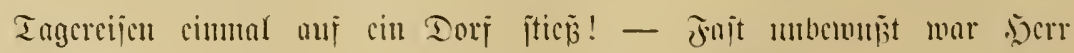

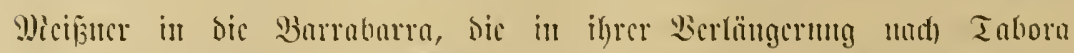

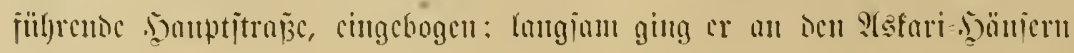




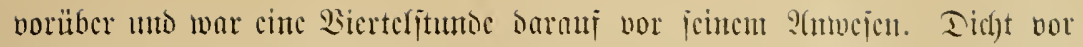

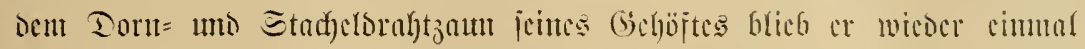

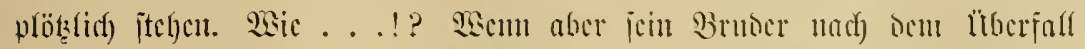

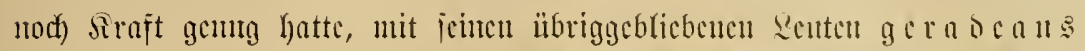

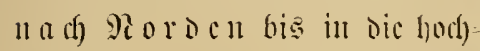
gelegencn, iwajjerreidjen umi jehr jumbtbaren Eamojojajten Jratu,

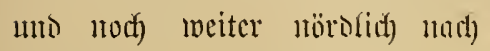
Wintucf, 3u marichicren?

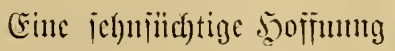

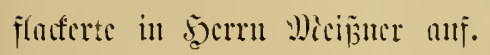
, s)errgott," ricf cr ats, ,menn Doch) bas wäre!" Jn jeinem ticjen P(ac)grübcln veripürte cr crĩt gar

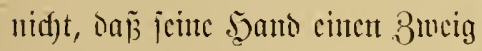
Des Dormjautc:s gepacft hattc. "Domm wäre cr gerettet!"

Freifid), bic siajucmï bort oben wel)rten ji(f) ie(br cucrgijd) gegeu jrentoc, bic in ifgr \&uto tamen. (Es mar jafou cimmal ber Eicruch gemadht woritu, Buren Dort allinjicdelli; aber das Gatte jait cincen siriegszug julr folge gelyabt, unto man hatte fidt) mit dem Bcjicicluntgaplanc anf bi: llugcbung ics 5 bis 6 Tage

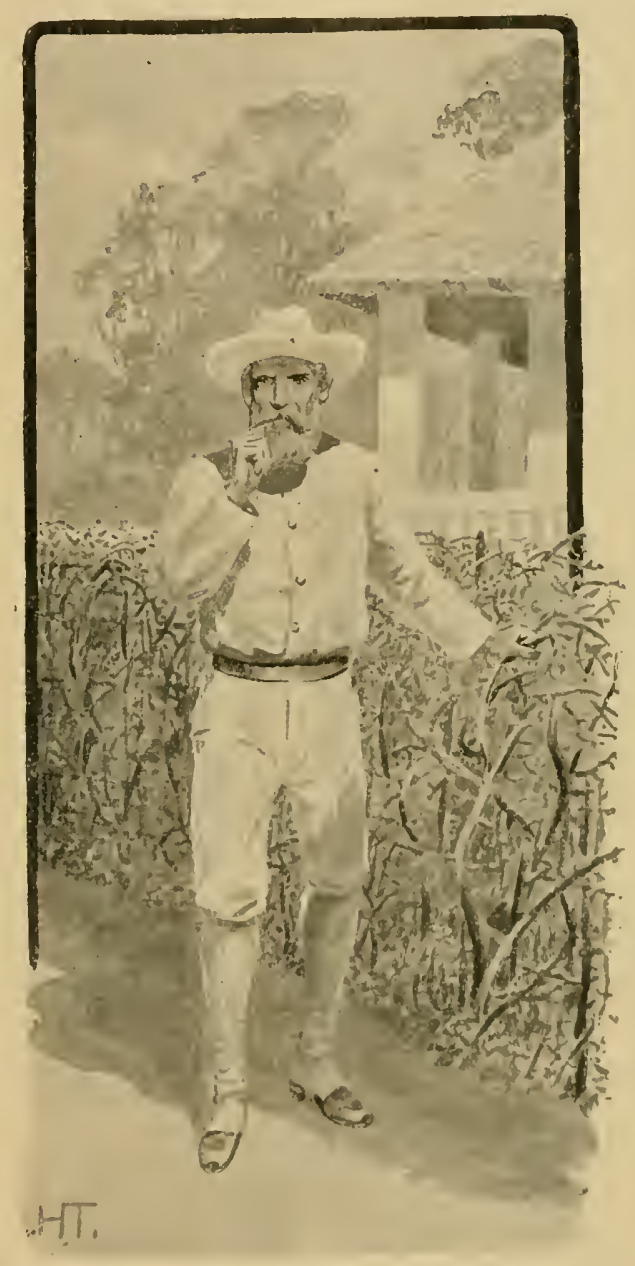
reijen weiter öjtlich nad) der Siliite HT. biu gefegentu Wieru Berges be

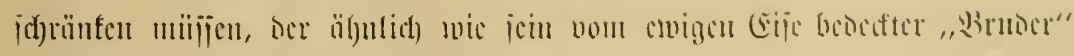

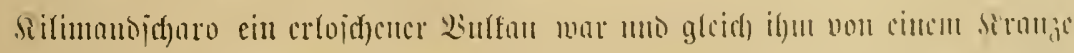

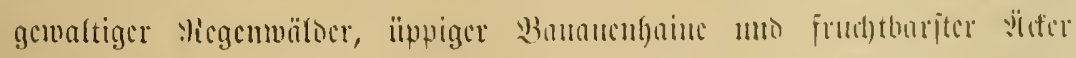

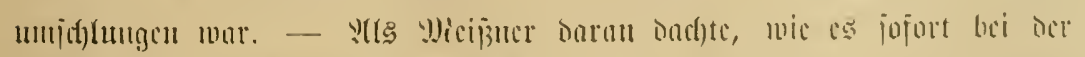

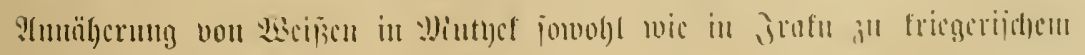




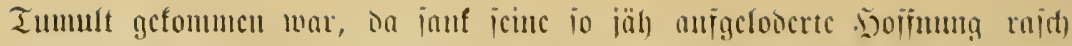

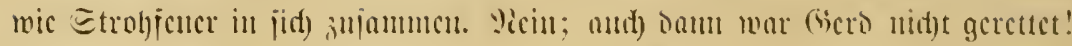

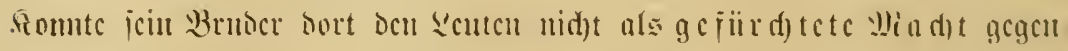

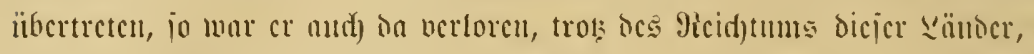

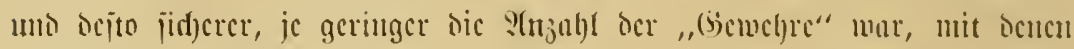

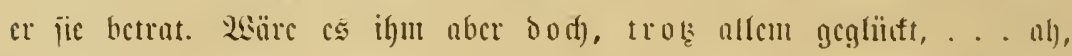

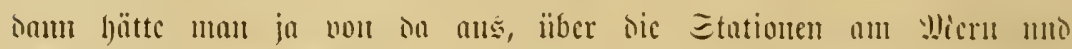

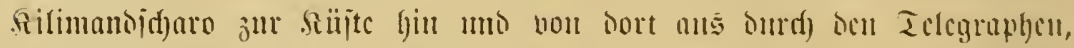
längit bic Vad)rid)t von (Gert: "Expedition vergeblicf), aber geretect!"

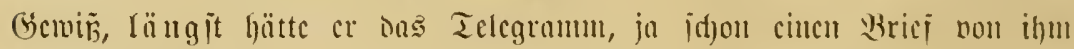

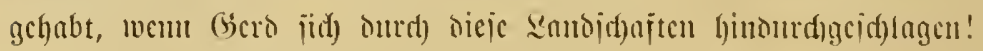

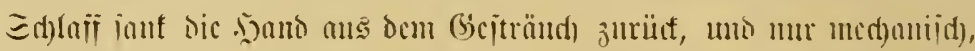

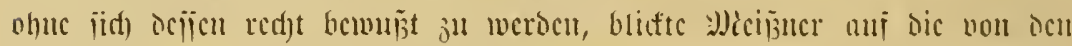

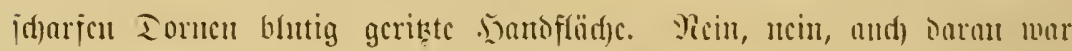
uid)t in icufen!

:llit cincu ucucu id)mereu Ecujace id)ritt or ocu : Zaum cutloug jur

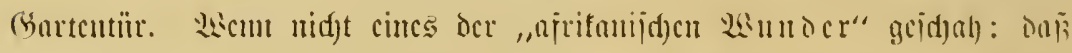

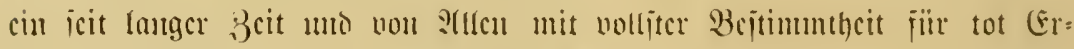

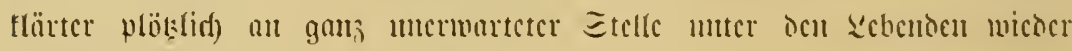

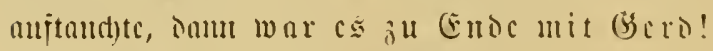

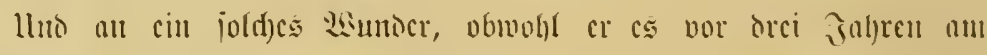

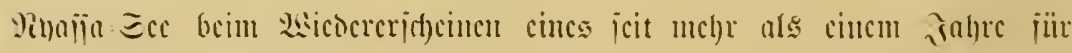

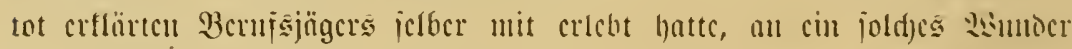
magte Wicijarer bei icincm Bruter nich)t ill glanben.

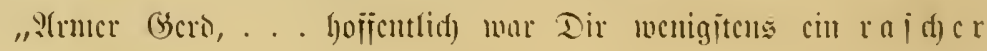
Tod heidjicoen!!"

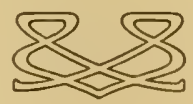




\section{Drittes Kapitel.}

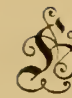

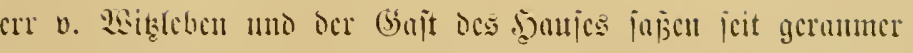

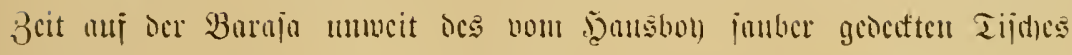

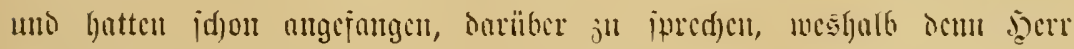

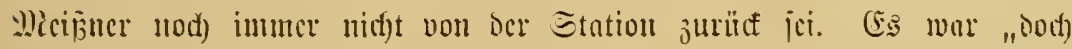

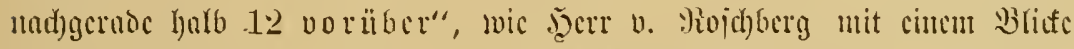

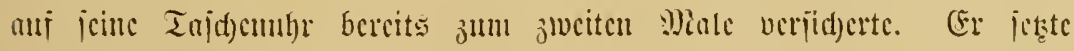

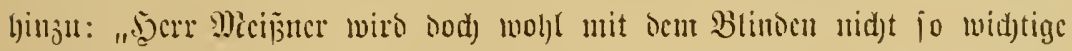

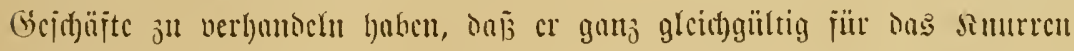

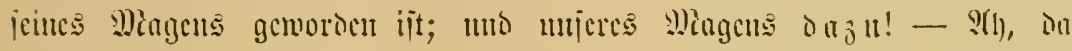

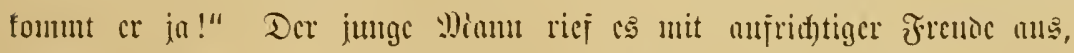

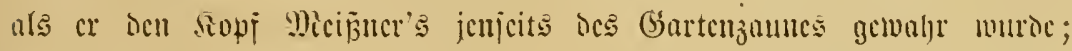

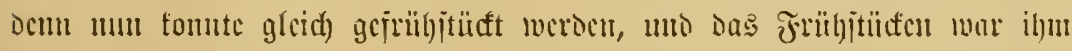

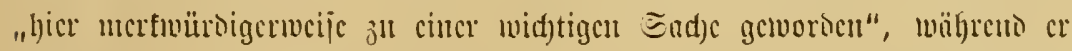

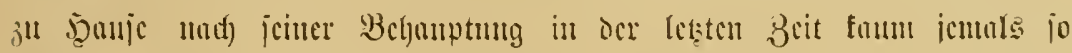

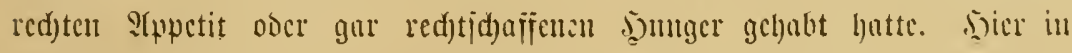

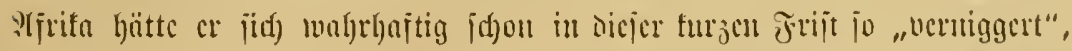

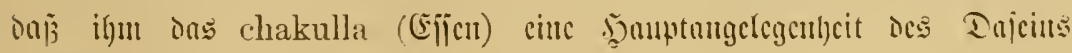
gemorden ici.

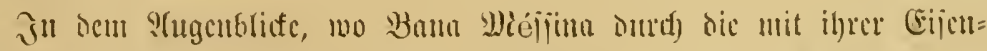

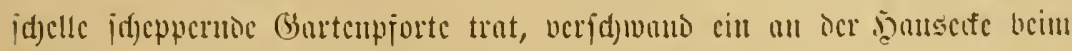

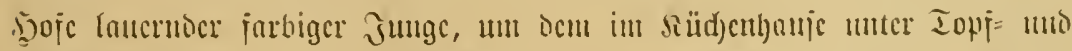

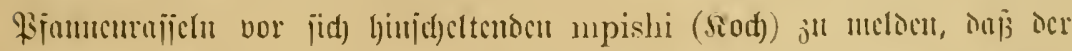
Banta "im Siomucu" jei, aljo Dic Écripcije gemat)t meroen tömt. Dabei

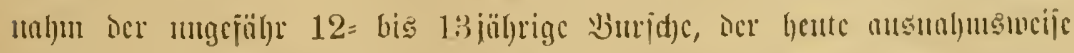

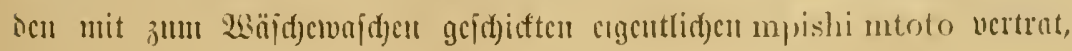




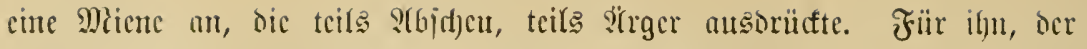

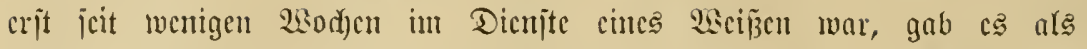

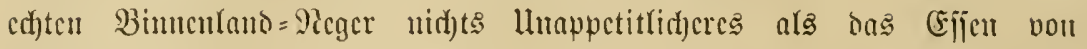

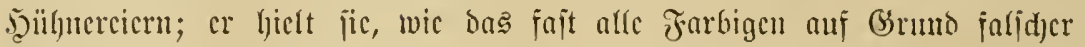

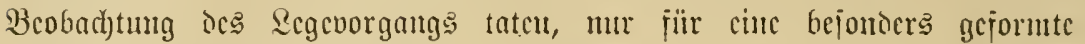

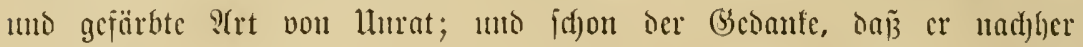
an Etclle Llyari's dic Tel(er mit don l̈berrejten vom Piüf)rei abwaichen

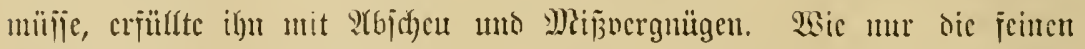

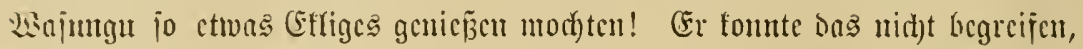

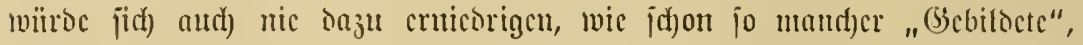

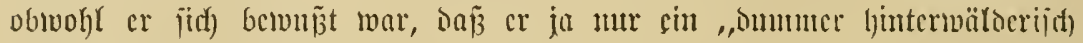

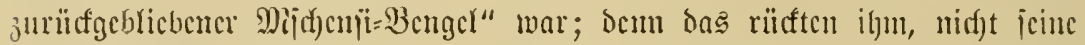

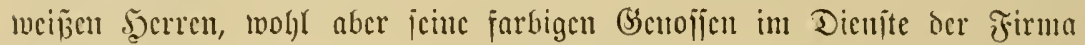

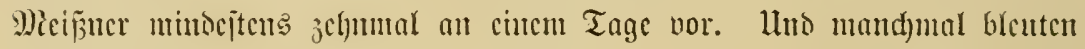

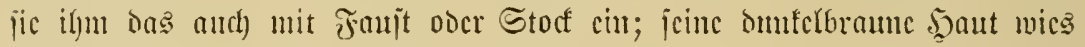

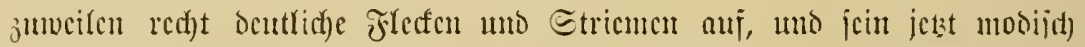

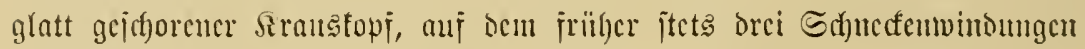

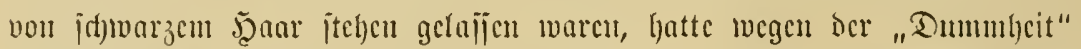

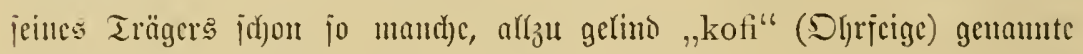

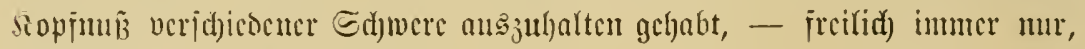
mem feincr ocr Sajmugu tabci war.

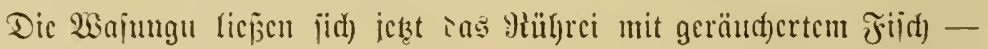

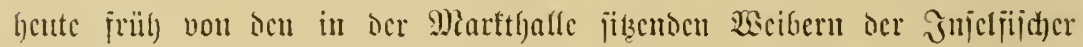

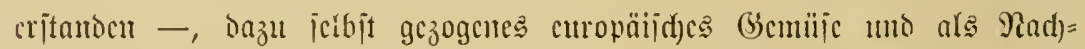

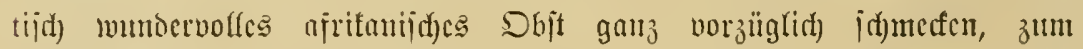

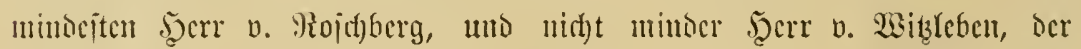

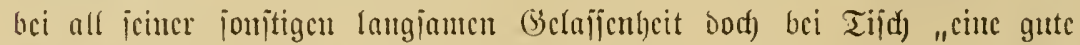

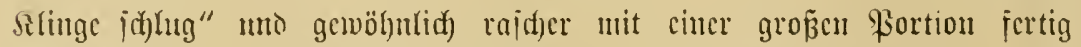

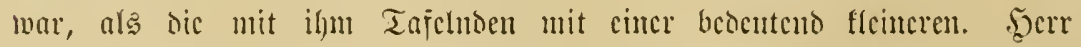

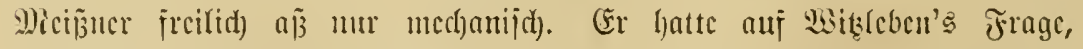

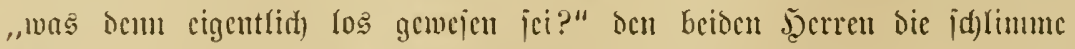

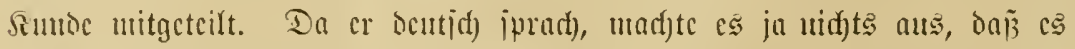

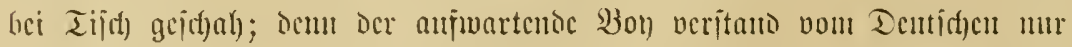

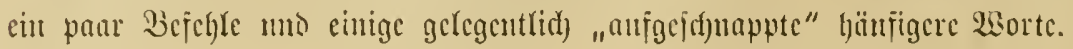




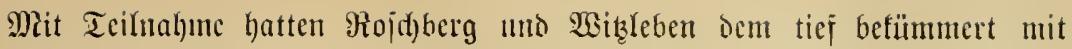

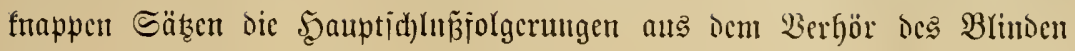

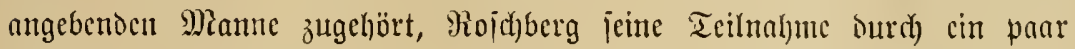
in herzlichem Tone geäuñerte Worte bezeugt, uno Wibleben Durd) Die

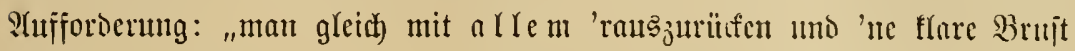

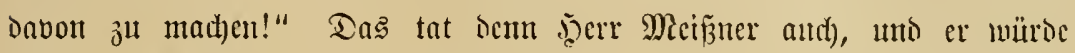

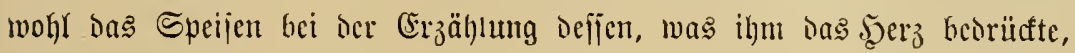

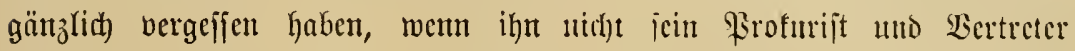
mehtfach gemahnt hätte: "Zugreifen, Şerr Mcip̈ner! Efïn uno Trinfen

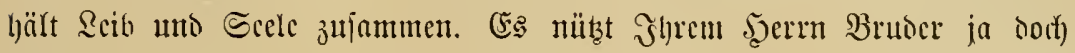

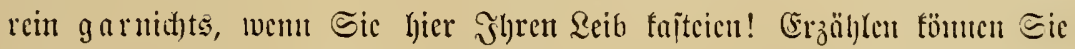

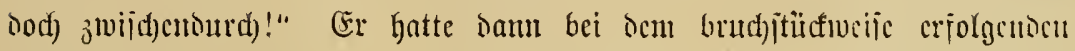

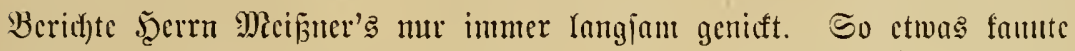

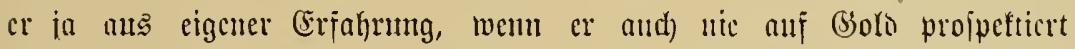

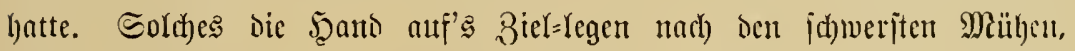

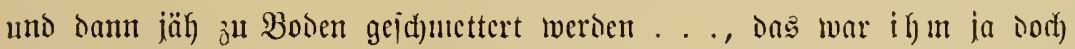
nidhts Reucs! Waar aud) mantd)en anderen Reuten fo gegantgen! (ver

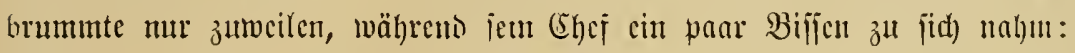

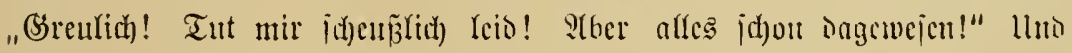

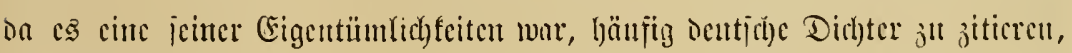

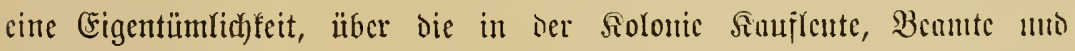

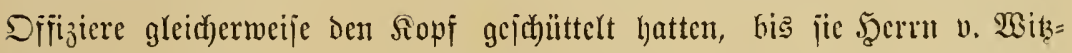

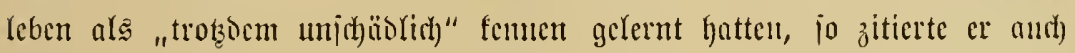

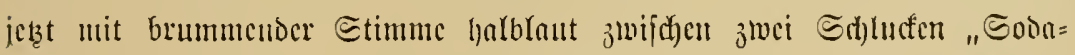

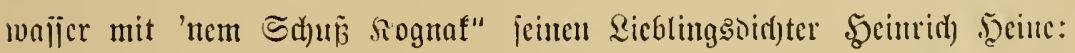

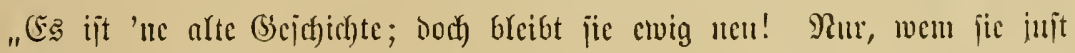

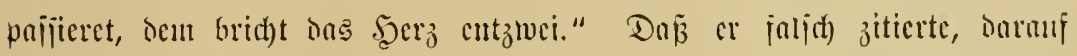

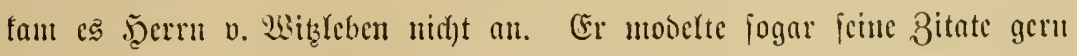

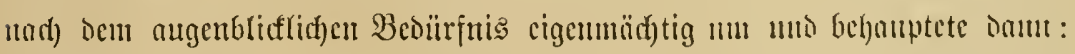

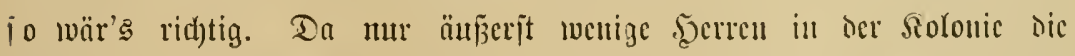

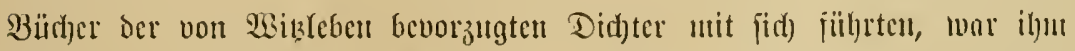

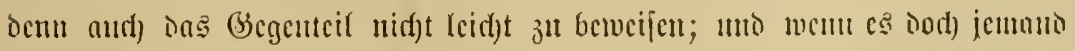

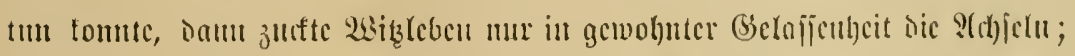

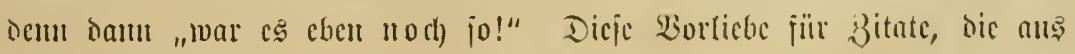




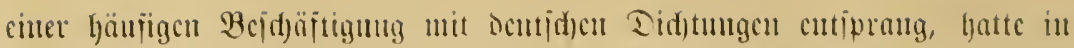

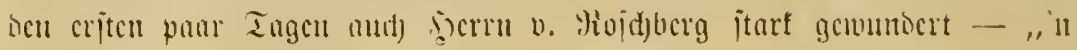
drolfiger bect)t!" hatte or mit cincu jeincr Ricbfing

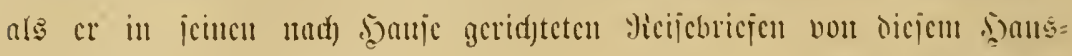

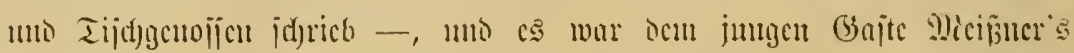

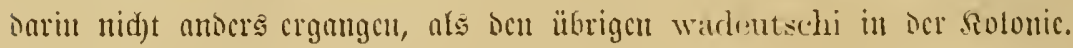

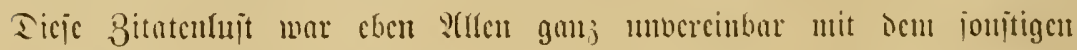

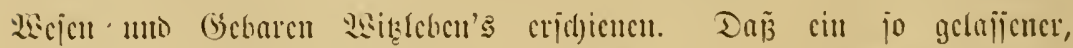

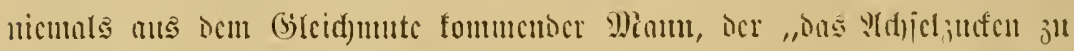

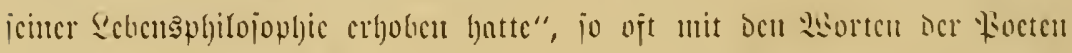

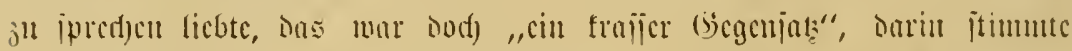

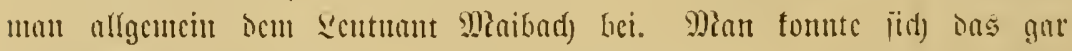

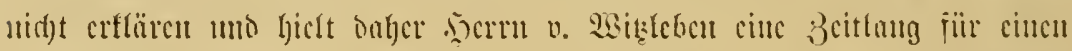

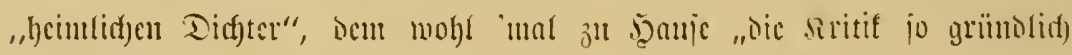

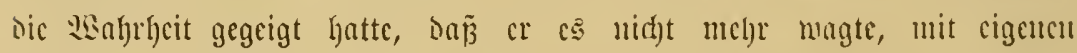

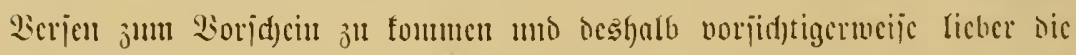

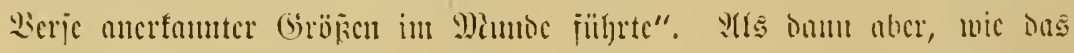

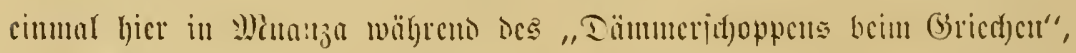

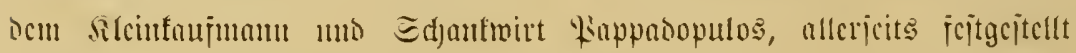

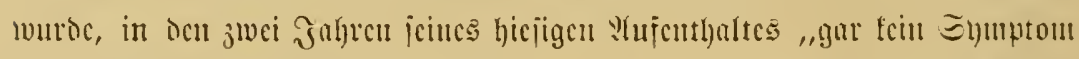
ocr bejürd)teten Pidfteritis" jutage getreten war, ba hiclt man berru

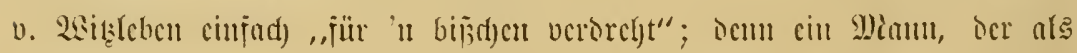

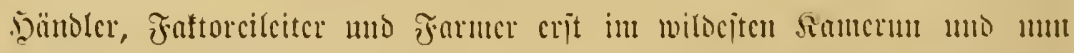

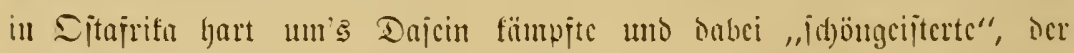

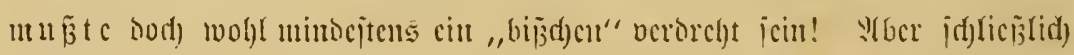

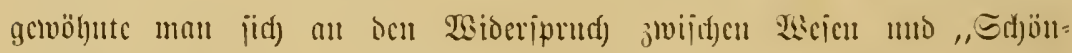

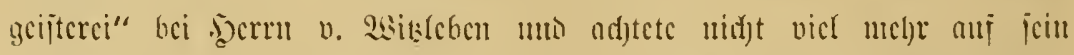

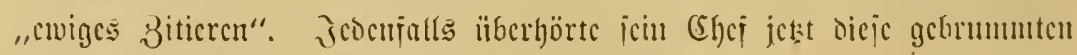

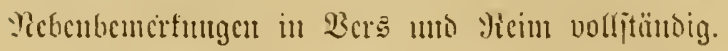

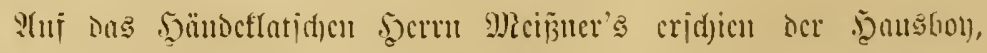

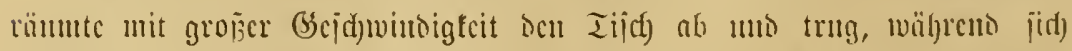

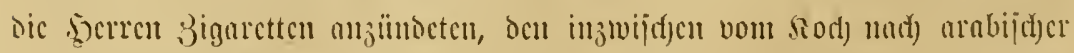

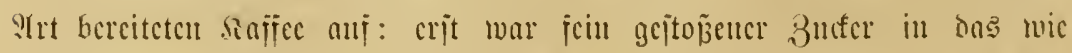

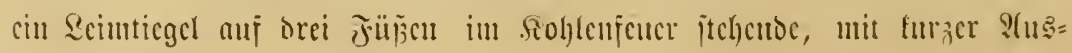




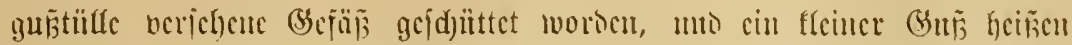

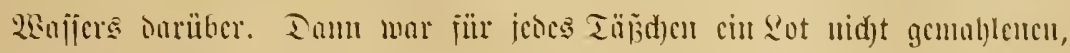

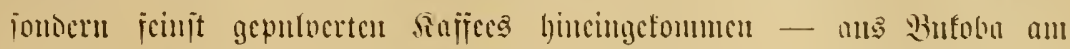
2.

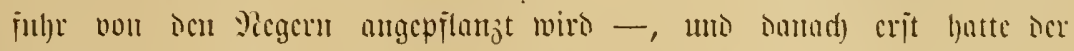

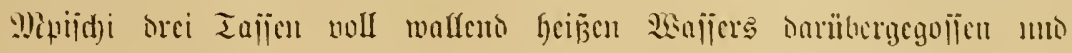

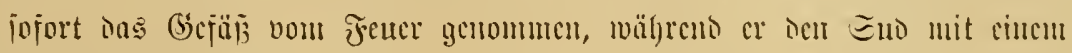

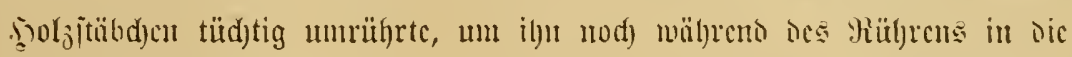

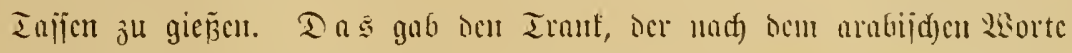

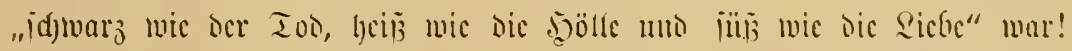

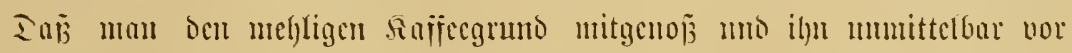

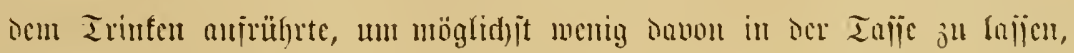

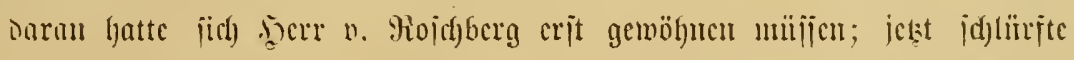
or aber Ben jogenumten Mioffa trok Der "Ditflidffett" Des Getrünts mit mahrem $\mathfrak{B}$ crgü̈gen cis.

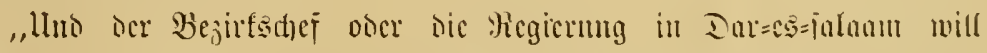

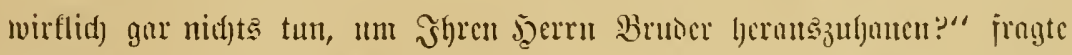

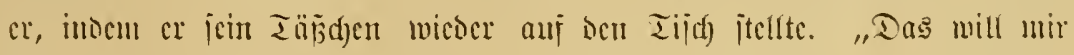

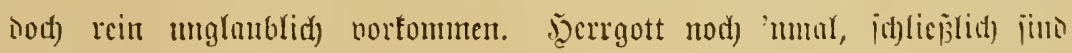

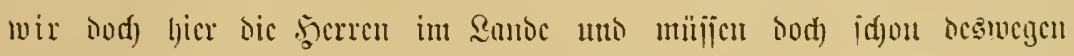

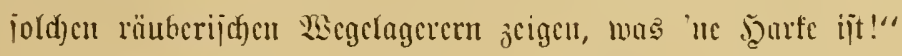

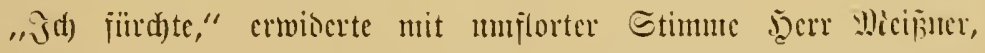

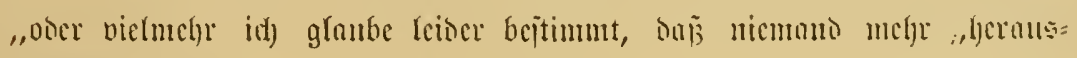
julljaıten" ijt."

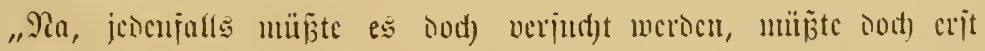

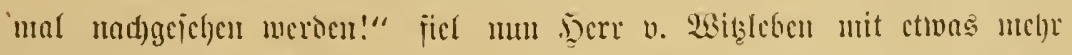

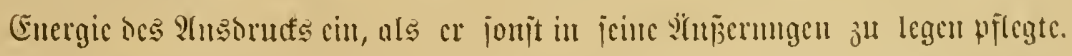

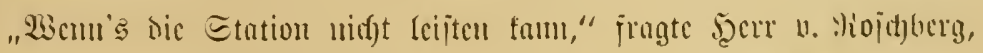

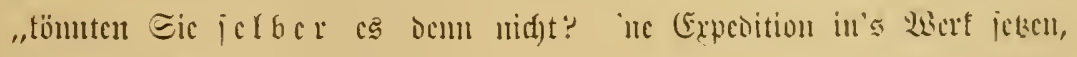

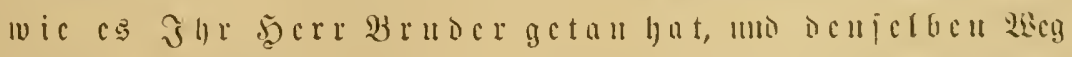

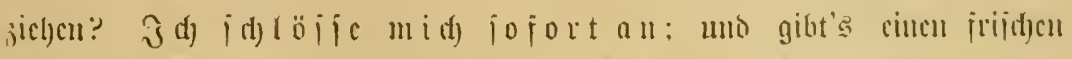

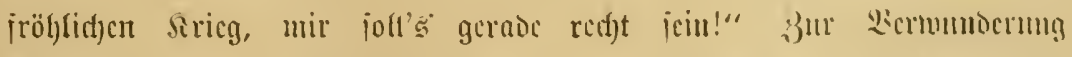

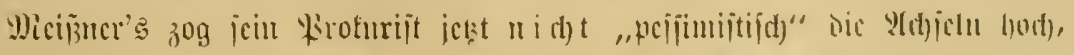

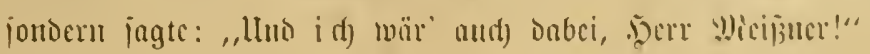




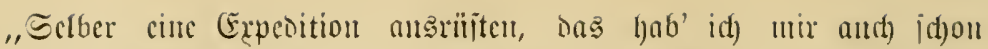

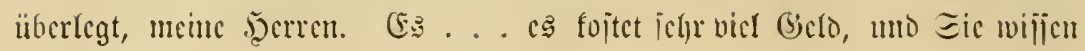

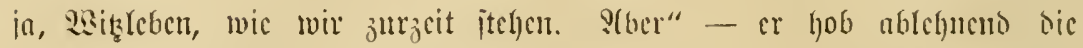

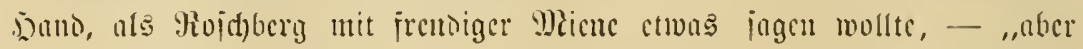

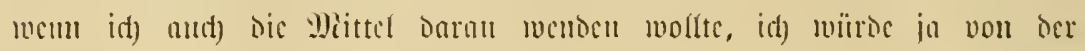
Station gat uid)

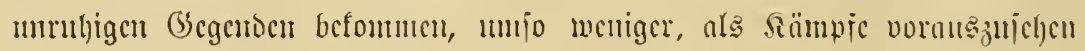

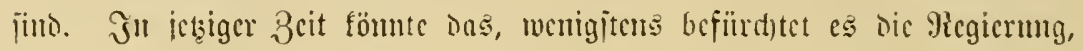

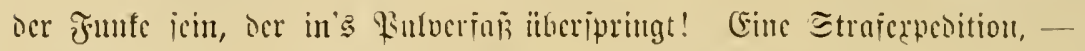
Die beljält jïl) Die Fegicruntg iclver vor. Begreijlidjerwerie."

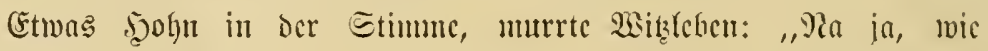

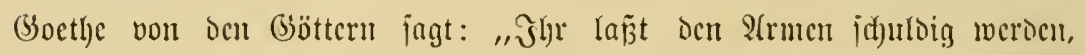

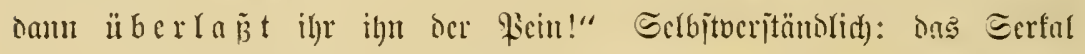
wirb die Strajedpcoition ansjül)ren; aber vermutlicf crit, wem $\mathfrak{g h r}$

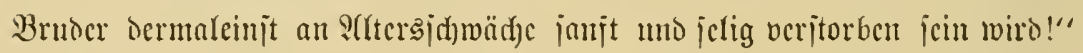

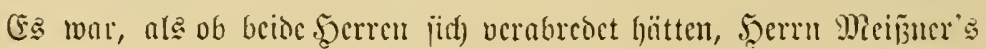

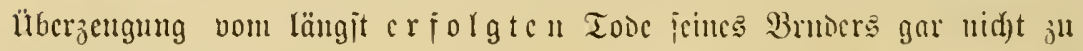
berüdfiedtigen. Sic ipradyen aud) meiterfin nur jo non ifym, als gelte

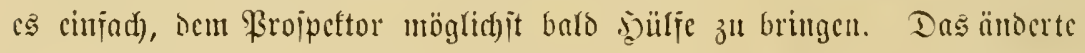

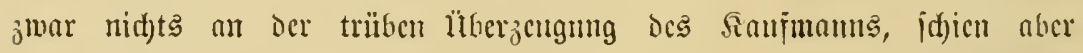

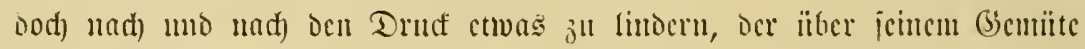

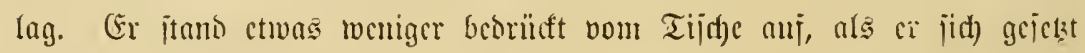

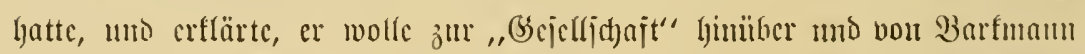
fören, ob Der Satifiro amjer ocm Bricje nitht nod) irgemo weld)e Witt=

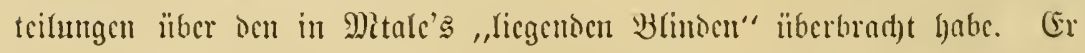

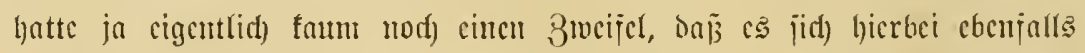
um Barafa handelte; inocs, wom aud), man fomte viefleidht, entweber

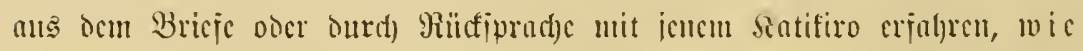

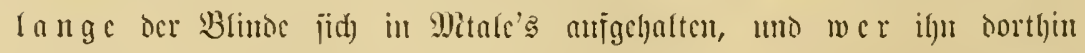
gelcitct hatte. 然uñte man ong, jo war's leid)ter, uon ocu verid)

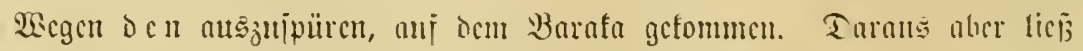

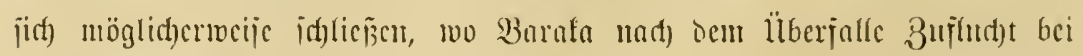
ocen ifm von frither her hefauten Est)marzen gejmiden hatte, aljo mo ungẹ̈̈hs der l̈therjall gejd)chen war. 


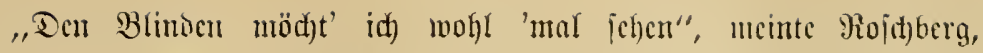

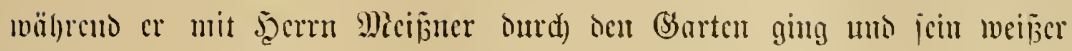
Terrier "S̛lint" mit wiloen Säzzen voramiprang. Der Ş)uno blicb dabei

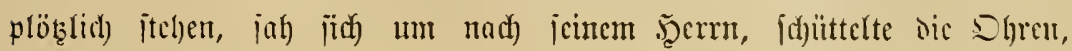

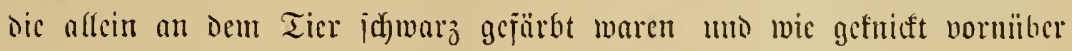

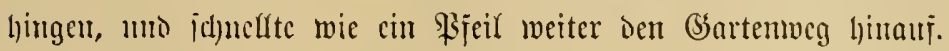

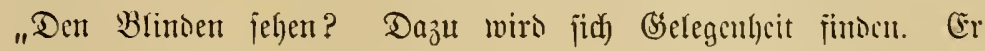
bleibt ja ill Farbigenlajarett, Doftor Brunner will joüter icine sumjt au tem armen Sierl verjucthen. Ïtbrigens, Sie fönnen ja mitgchen, wemn ith den Miam mieser anfiuche. Bernutlid) hat $\mathfrak{e r}$, menn er jidc) crit cill

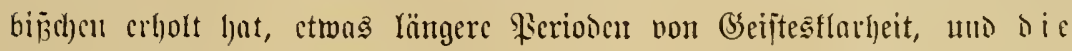

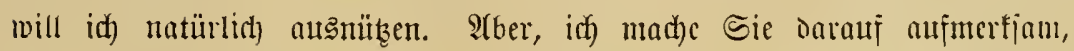

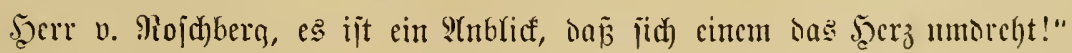

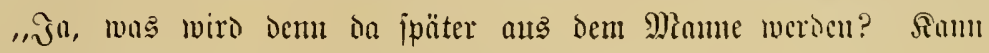
er Dem als Blinocr jeinen Rebensunterhalt verdicnen?"

„O, er würoc nidjt umftommen, jelbjt wenn er anj jid aflein angemiejen jein mürde. Wir haben ja in ganjen cine red)t gutmïtige Bevölfermy hicr an unjeren Schwarjen, unt es gibt nod) aus jrüherer

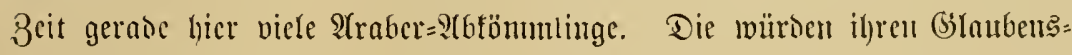

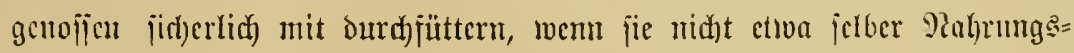

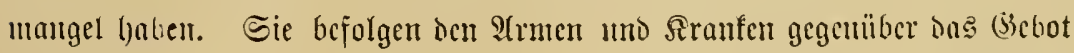

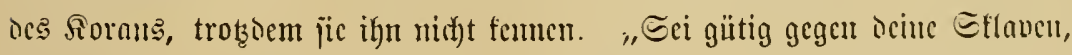

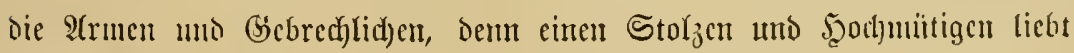

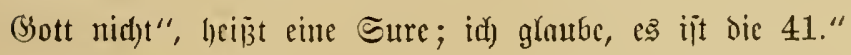

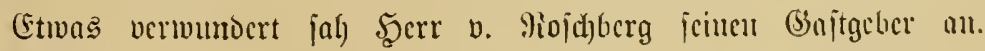

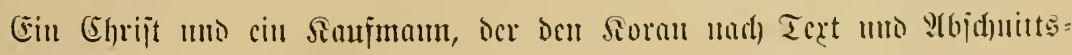

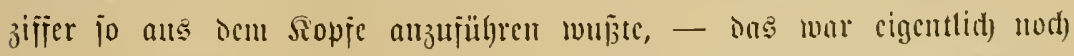

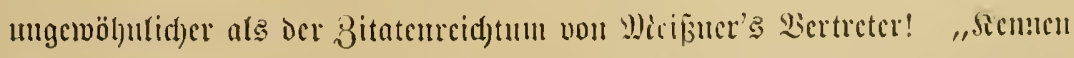

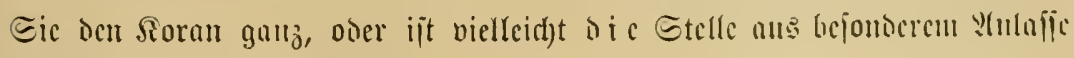
bei Эhuen haften geblicbeu?"

"(5) a 11 z feunen ihn wohl autd) nod) nitht cimunal sic arabij(t)en

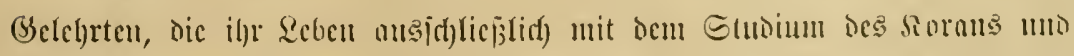
ser Erläuterungen jubringen, ier sunna, was jo vicl wic "Trabition" bedentet. Der Soran hat ju nid)t uveniger ats 114 Emen, mund)e Bnmou 


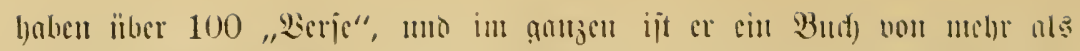

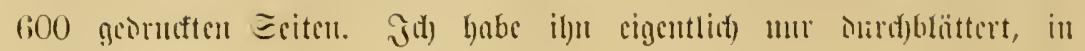

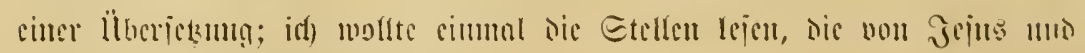

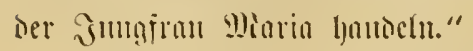

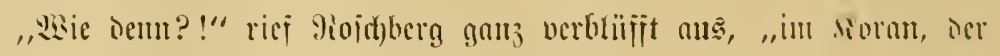

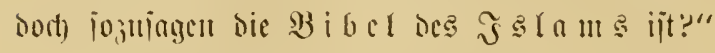

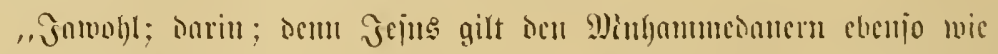

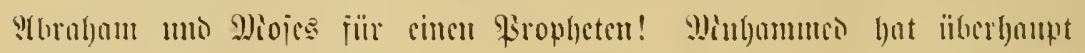

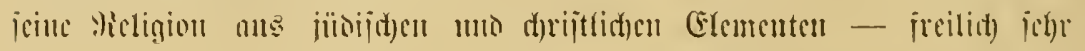

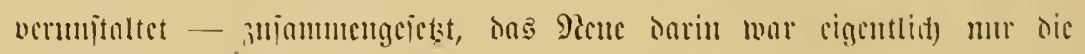

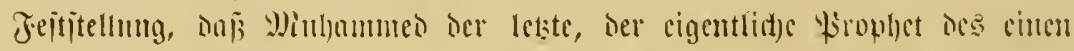

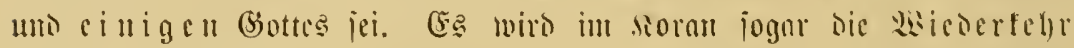

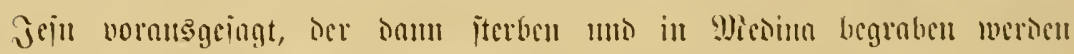

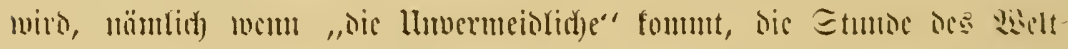

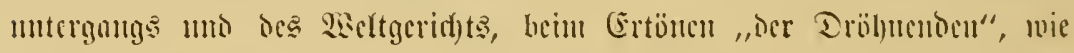

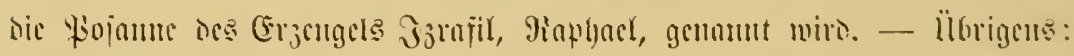

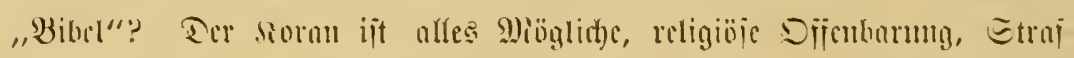

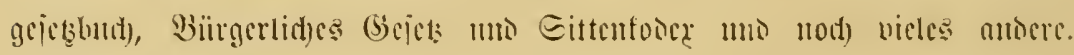

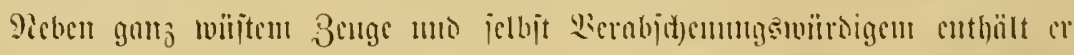

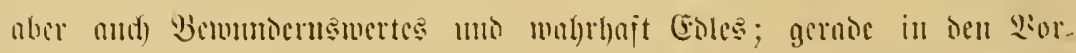

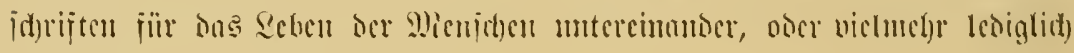

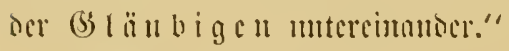

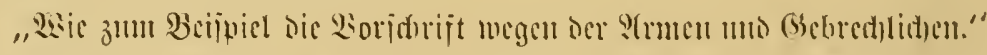

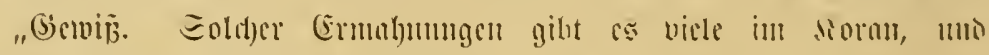

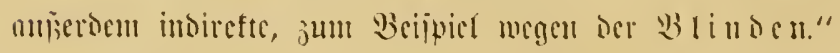

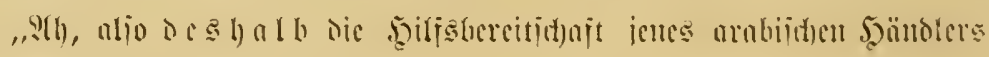
gegen Den Boten Jyres Bruders. . ."

,"

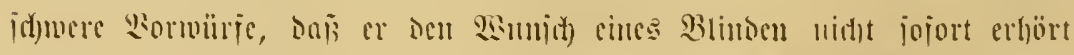

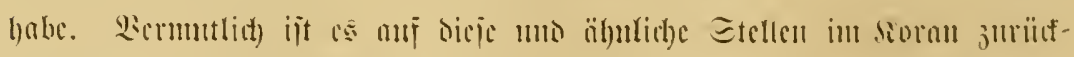

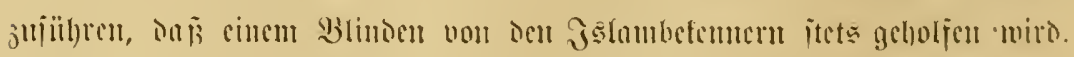
(Es ijt mir aber ansisertem nod), frïher, in :ïgupten, ganj io vorgetomuten,

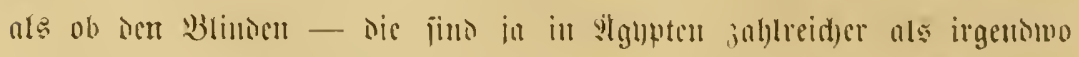

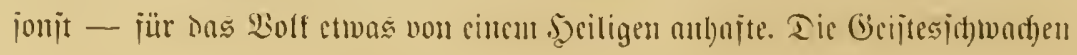




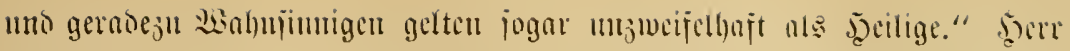

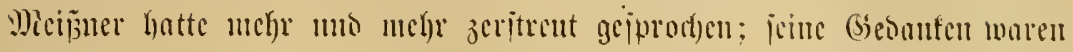

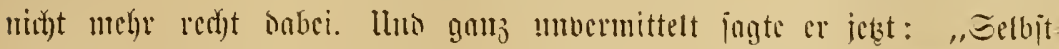

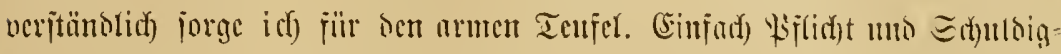

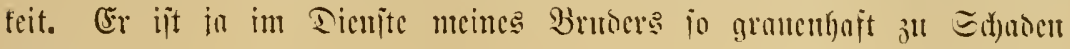
gcfommen."

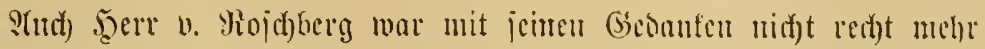

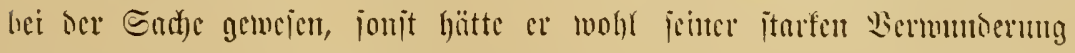

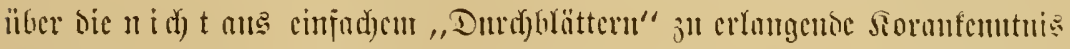

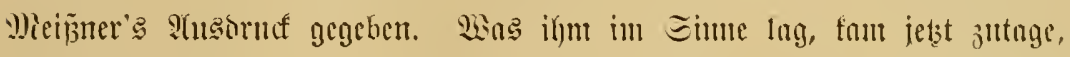

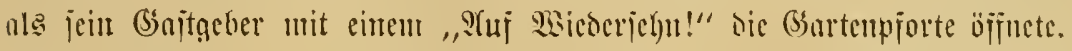

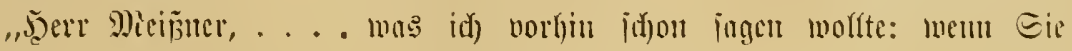

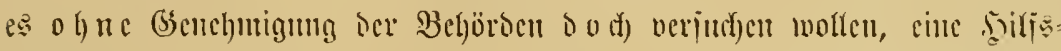

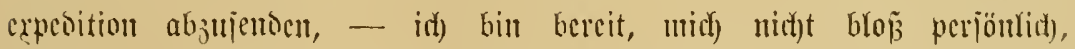

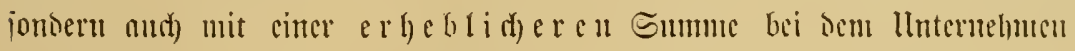

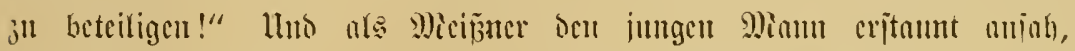

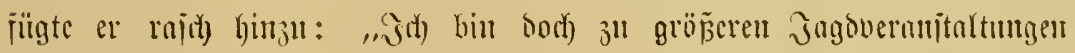

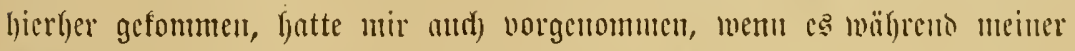

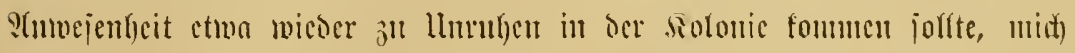

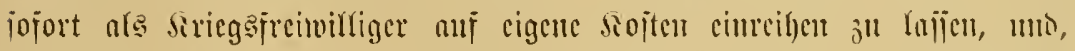

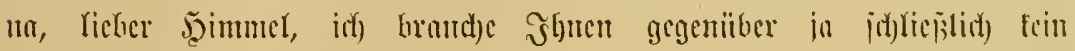

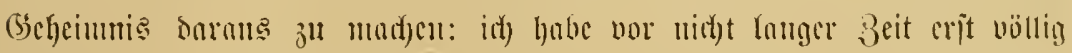

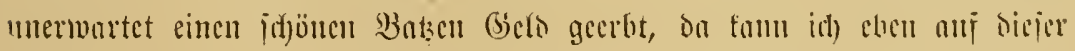

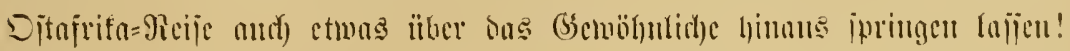

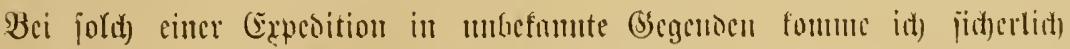

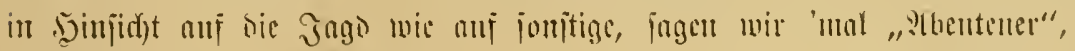
reict)(inf) nuf meine sojten!"

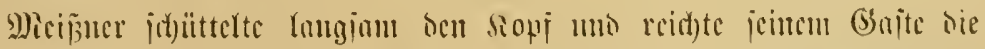

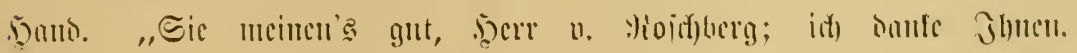

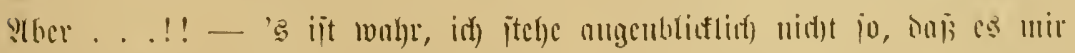

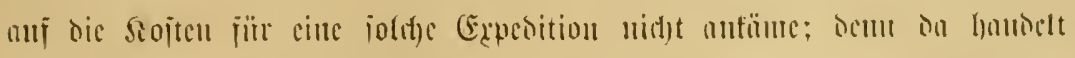

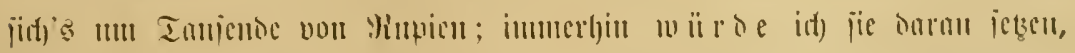

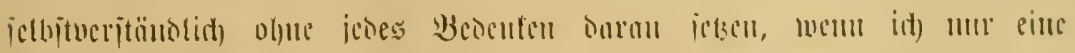

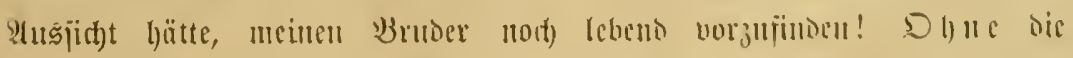




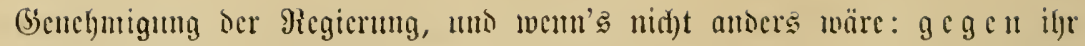

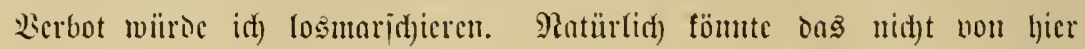

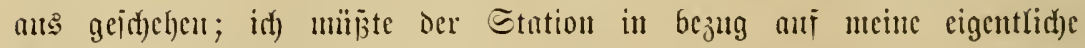

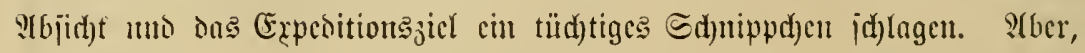

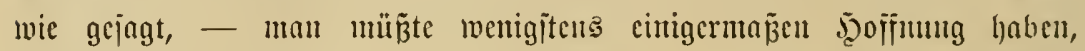

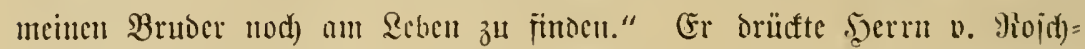

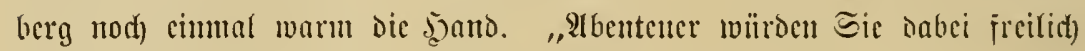
reidylid) erleben! sienn Jymen o a n a df) oer Giun iteht ...."

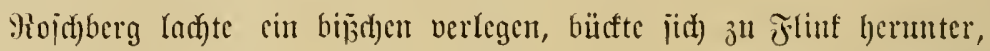

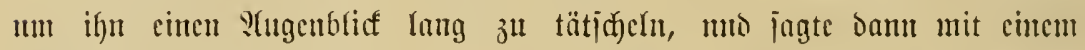

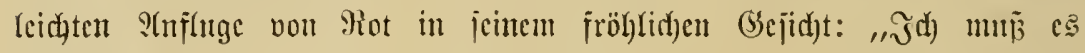

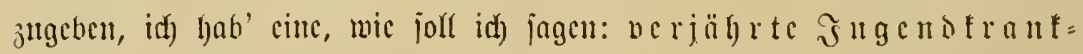
he it im 2 eibe, oder viclmelyr im Siopje, — bic Peigumg jull allerlei gejahr

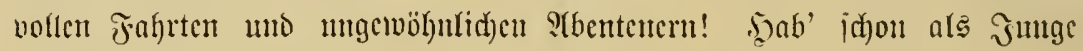

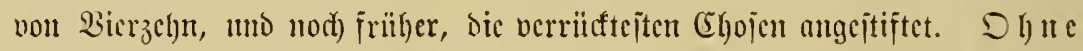

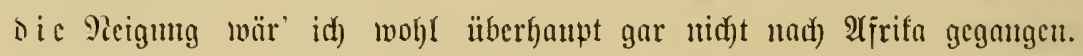

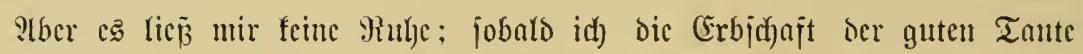

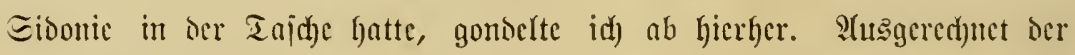

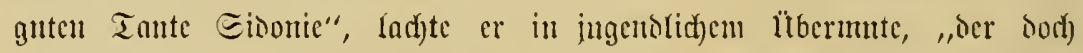
3eit ihres Sebens jede Extravaganj mo jeses :(benteuterlidye bas gröjte

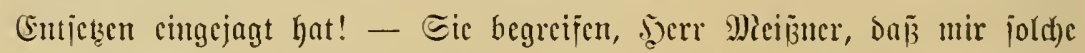

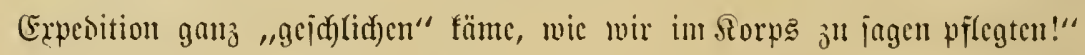

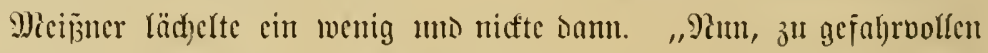

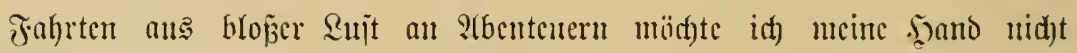
gerabe bieten: indes, Eic fömten aud) ofme Icilnahme an cincr Expedition

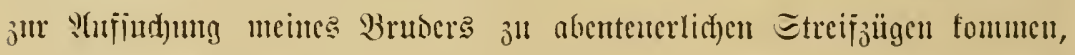

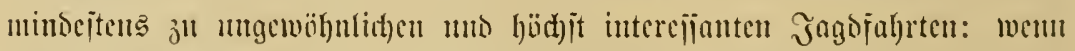

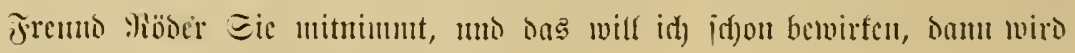
Эhre Eefuju(d)t j(f)on geitil(t w..."

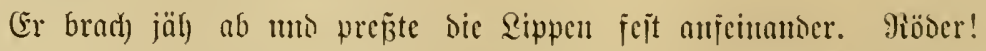

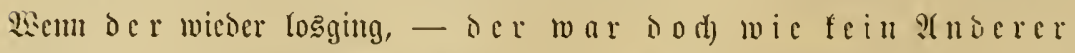
gecignet, mit jeiner Jugn = (xpecsition bic Enct)e nact) (serd ju verbinden!

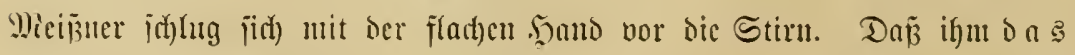
nod) nid)t eingejallen mar! "Jjerrgott," murmelte er jut Bermunderung 


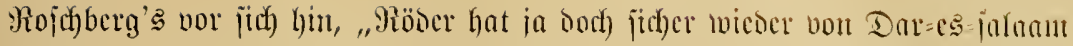

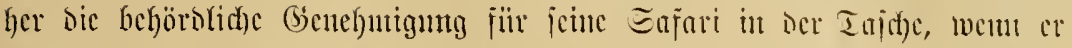

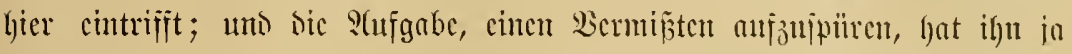

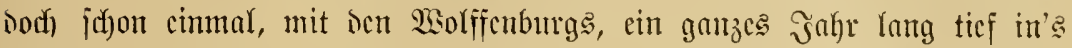

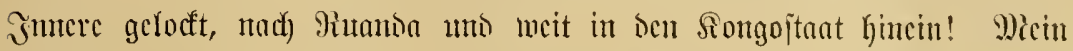
Gott, mein Giott," fait inbrünjtig flangen dic halblout ïfer sic jitternoen

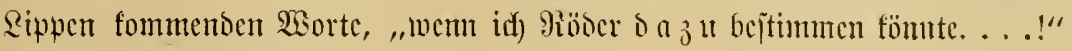

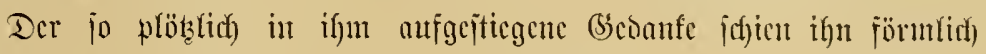

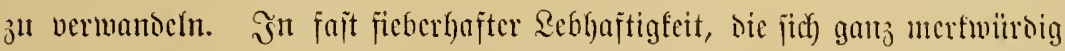
von jeiner jonjtigen überlegenoen Sprect)weije abgob, jez̧te or in unmill

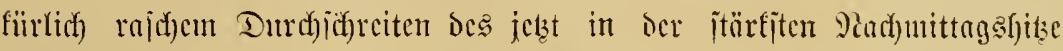

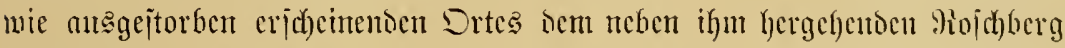

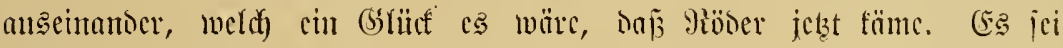

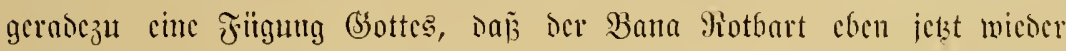

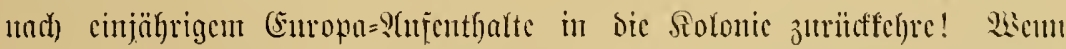

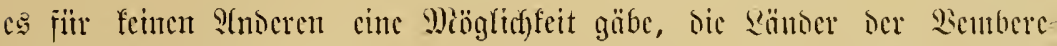

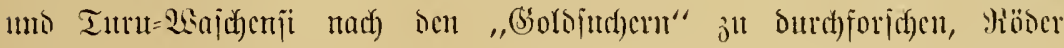

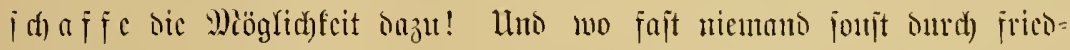
liche Echantri vormärtafomme, on gelinge cs ocm ndevu nyekundu, -

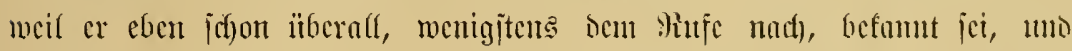

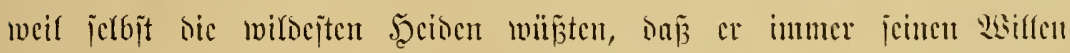

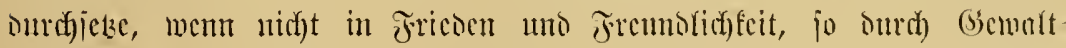

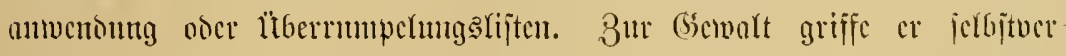

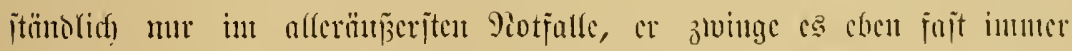

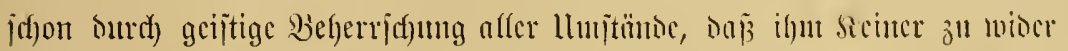

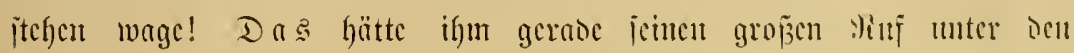

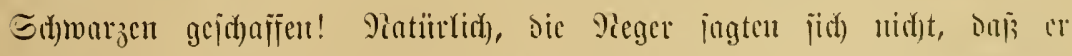

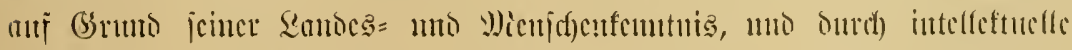

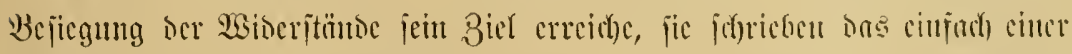

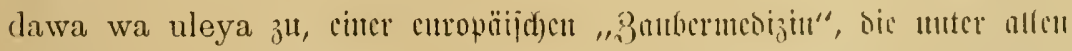

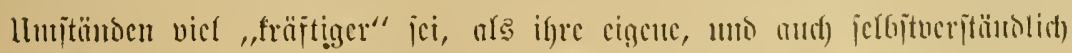

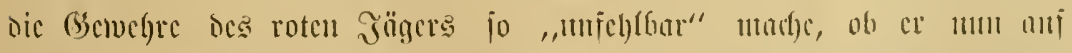

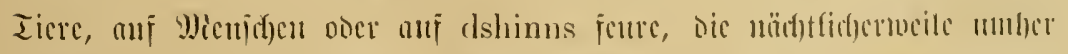

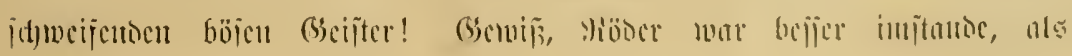




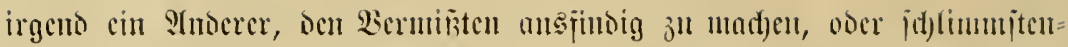

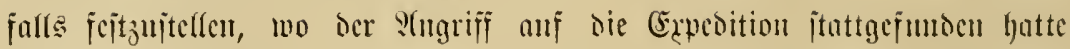

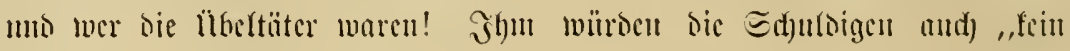
ฉ. fiir cin $n^{\prime \prime}$ normad)en tömten, iljm nicht, wic bas jonjt ja ojteres

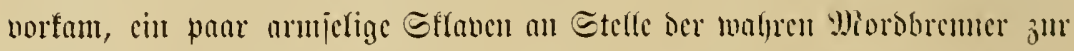

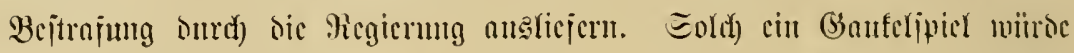

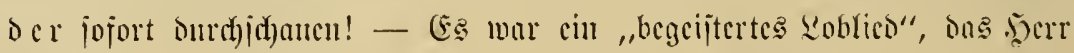

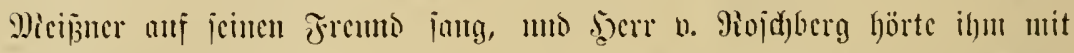

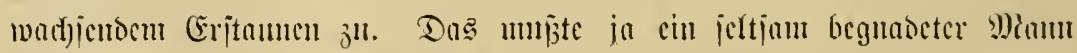

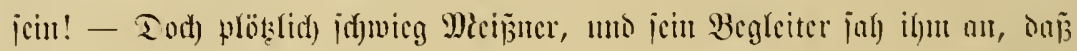

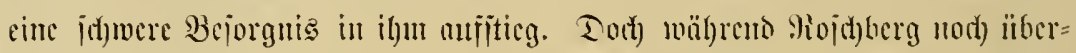

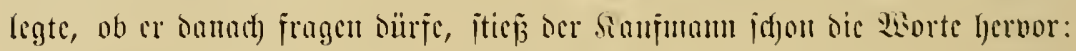

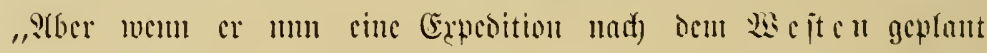

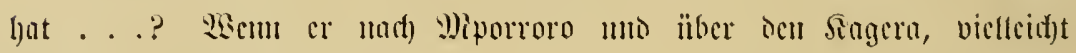

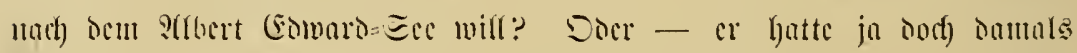

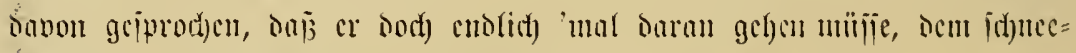

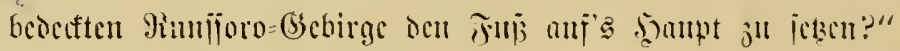

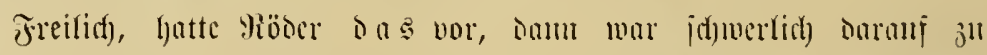

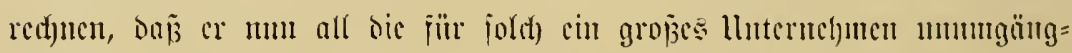

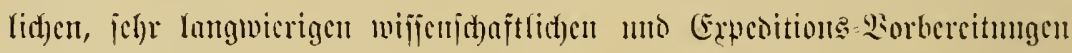

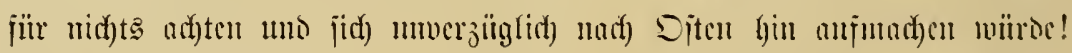

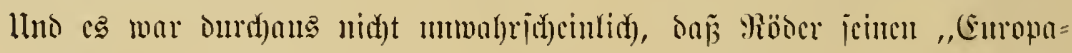

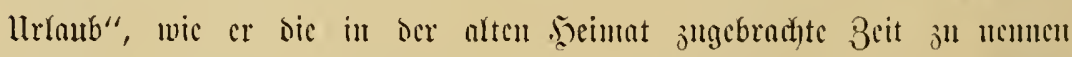

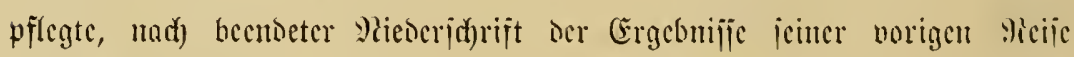

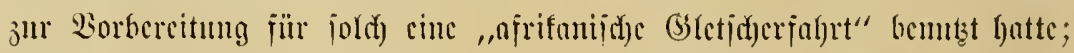

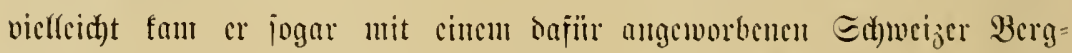

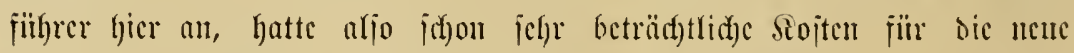

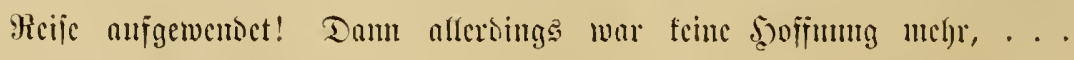

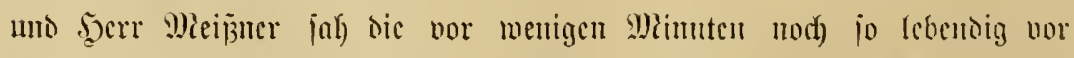

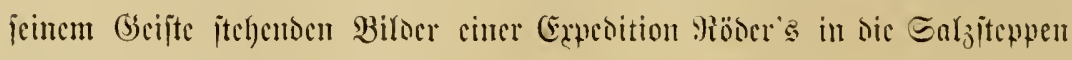

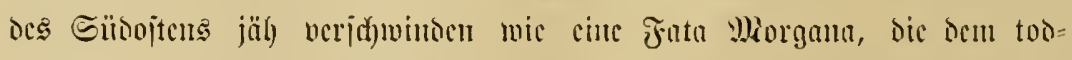

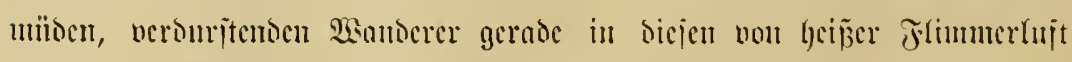

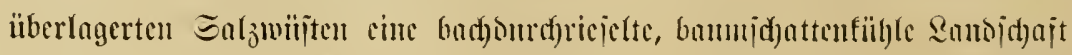

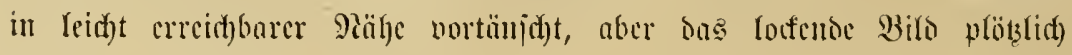




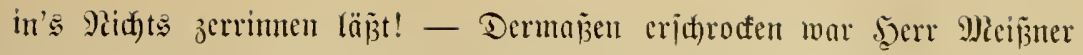
bei Der Crrinnerumg an bie von Röber tamals erwogenen, ,für ein nächites

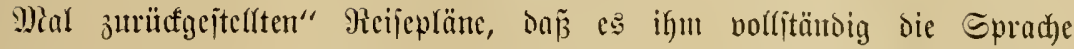
verjh)lug. So ungewohnt lebhaft er bordem gewejen, jeķt fielt er bie

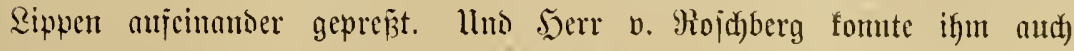
feinen tröjtlict)eren 3ujprud) geben als ben:

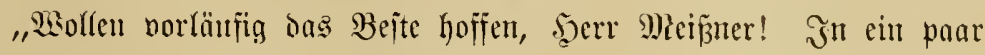
Tagen werden wit ja hören, of Jeer ?höder jo etwas borfat, und we $\mathrm{nn}$,

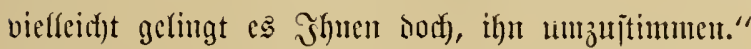

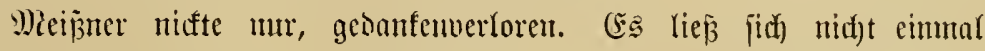
ertermen, ob er ïberhaupt gebört hatte, was jeir Gsajtireumo da an "Tröjtlid)em" gejagt hatte. Dod) jie waren mun bor dem :(mecjen der

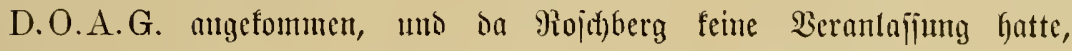

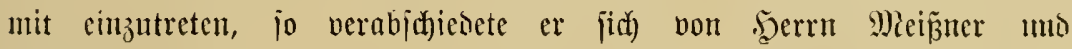
feyrte un.

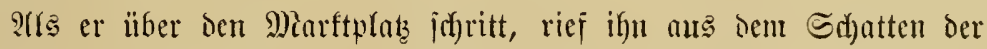
ansgedehnten uno hohen "alten" Maarfthalle, die freilich) mur cin riejiges

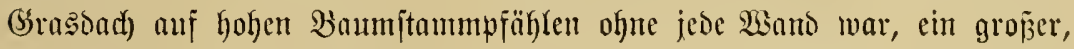

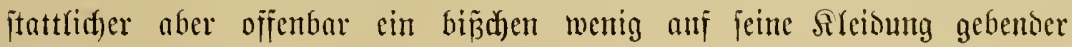
Europäer an. "toerr Riejerendar, 'n Miorgen! - Sic mollten ja 'mal mit Gintüber nad) Der Werft . . !" (5r fufr nad) furzem "(Grü̈ß Bott"

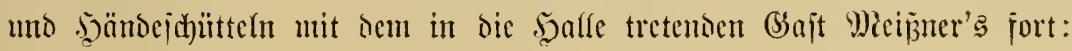

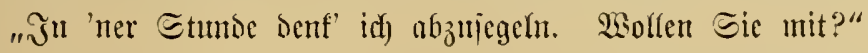

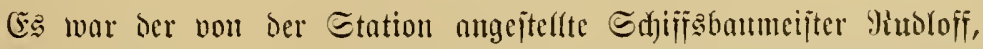

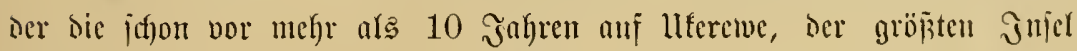

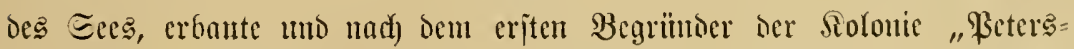

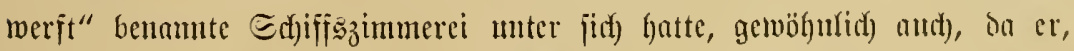

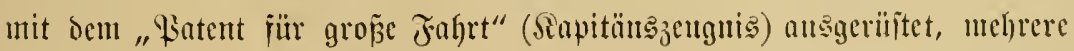
Jahre bie Dzeane als Etcuerman befahren hatte, das bou ihm erbante

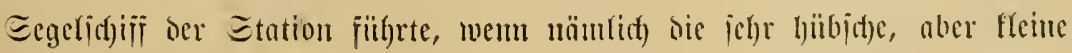

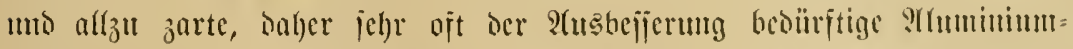

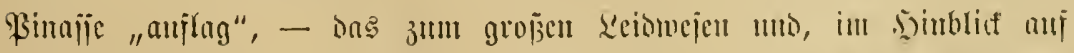

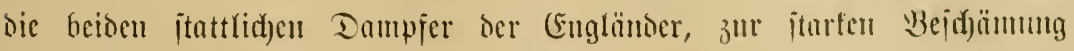
aller Dentiden einzige Dampiboot ber Solonie anj beut Sinanja. 


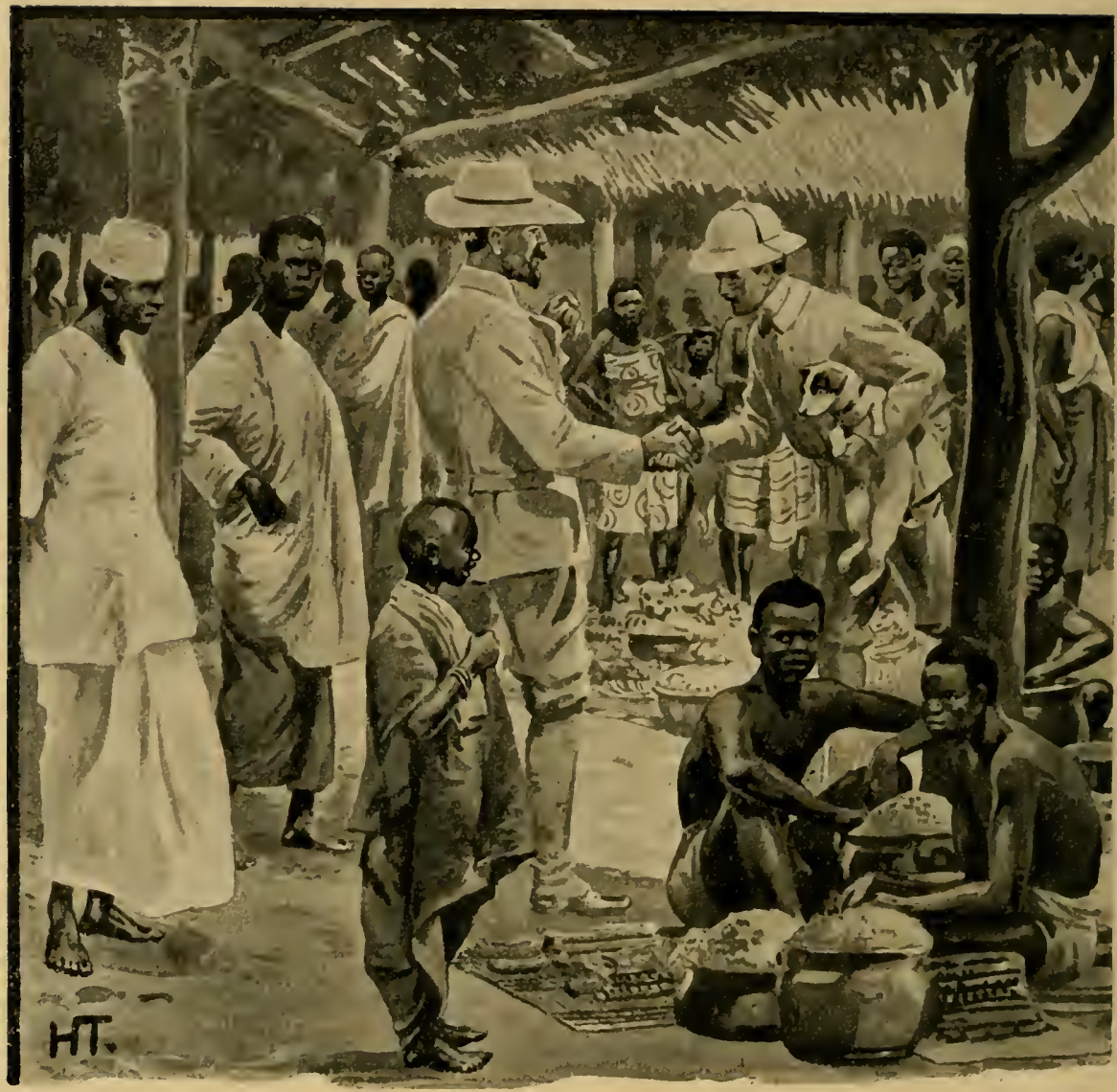

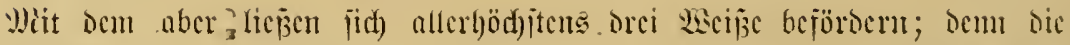

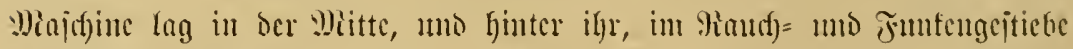

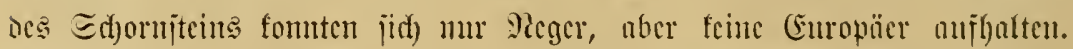

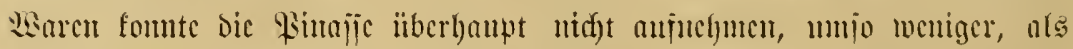

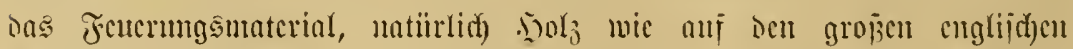

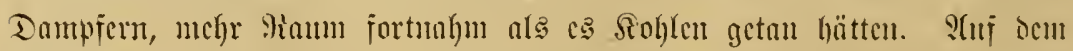

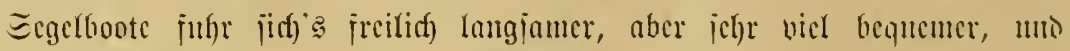

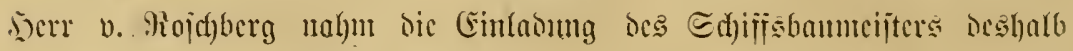

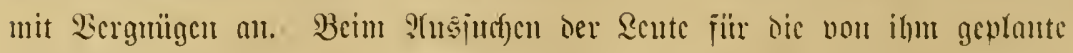

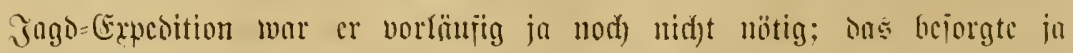

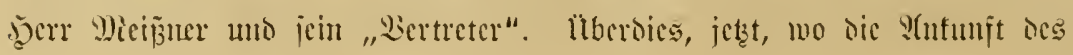




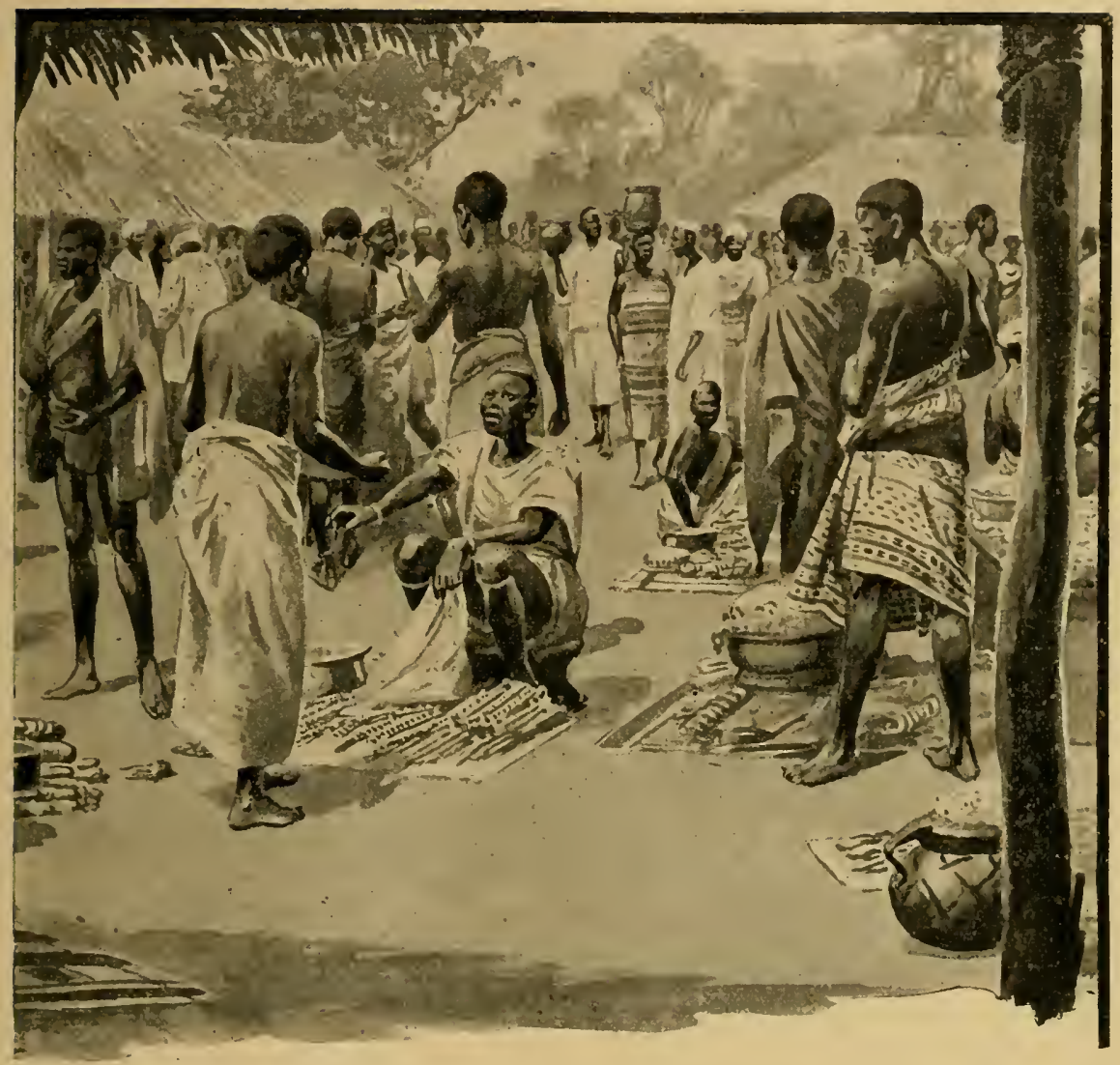

"roten Jägers" bevoritanto, mürde jidf) jia wohl die ganje Endje ctmas

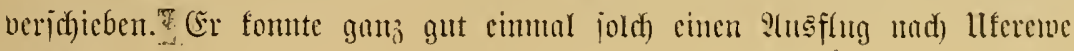
mactert.

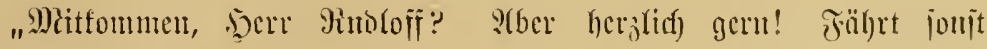
nock) jemanto mit ?"

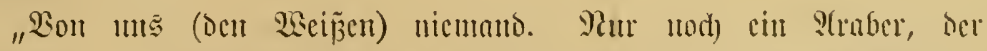

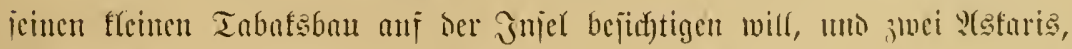

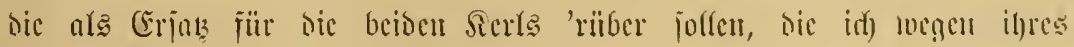
Ficbers "an's s'aznectt abgelicjert habe."

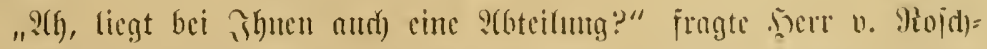

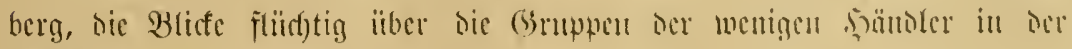
Wiarfthalle jajweifen Yajiento. 


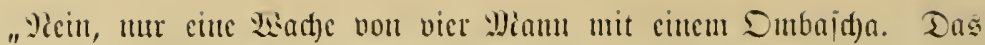
war lange Beit finturdf) überhaupt nidft nötig! S(ber natïrlid), Dic Maferewe jino nidgt durdfweg elyrliche Seute. Ein par Dörfer haben

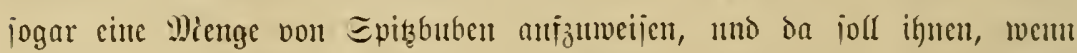

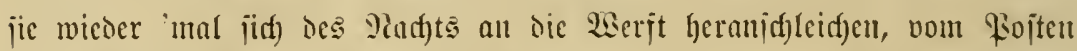

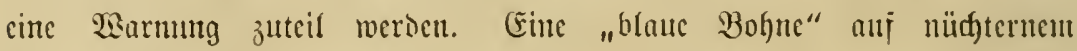

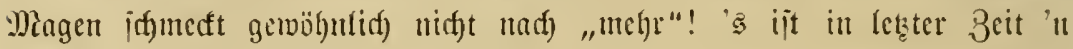
biß̄ंd)en gar zu ara gewejen mit ifnen!"

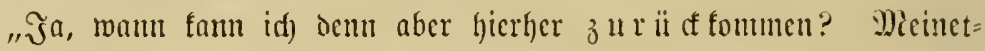
wegen allein werden Eie bod) mohl weber das Eegelidfiff nod) cine

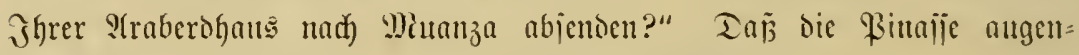

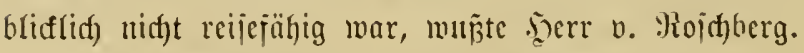

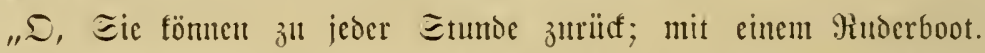

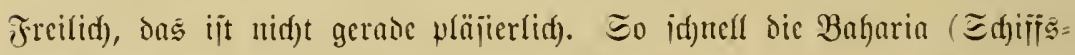
leute, Ruberer) jold) Boot aud) über's 2 sajier treiben, 7 bi 5 Stunden fönnt' es mohl datern; bei (Gegemvinto noch utehr."

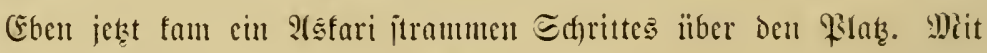

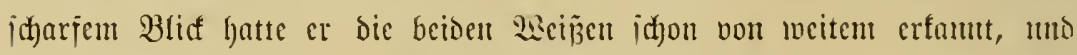

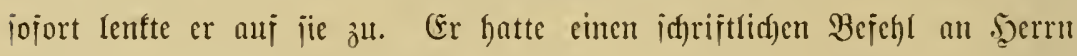

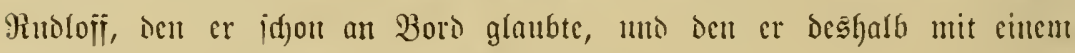
Boote auj der "Neumico" aujiutben wollte.

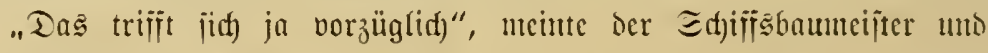

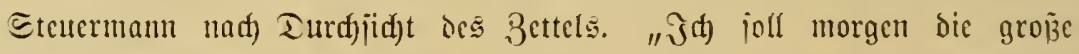
Dhan heridjiden - feine Ahnung: $\mathfrak{w} \mathfrak{a} \mathfrak{r} \mathfrak{m}$ ! - da tömuten Sie ja

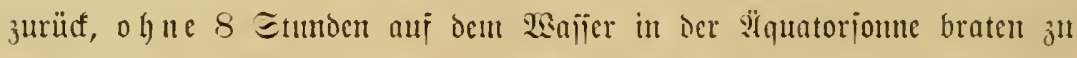
miijien. Sic hahen bam gerade 24 Etunton Anjenthalt auj llferewe, -

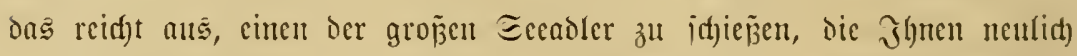

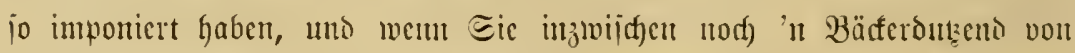

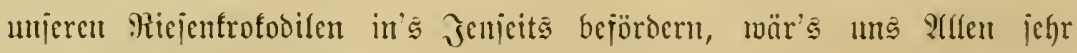

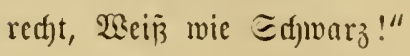

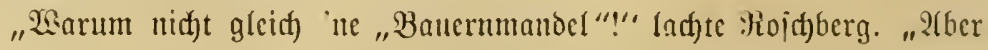

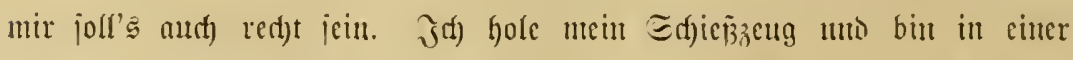
Etunde an Bord." (Er mollte jix nadf) Donile, hatte jid) iedoch) faum

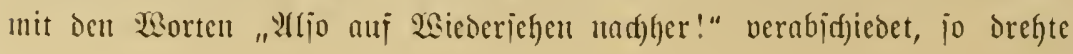




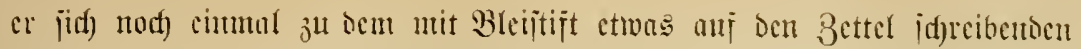

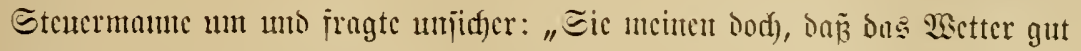

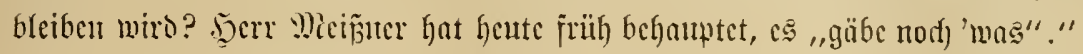

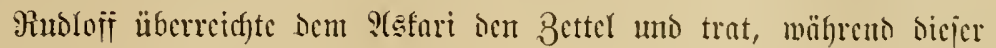

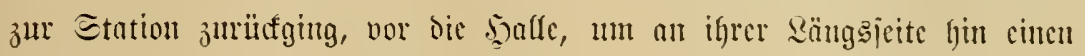
Blicf übcr das jum Teil umbuichte, jum Teil non gemaltigen (sincisblöcten

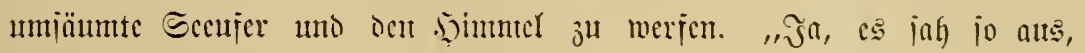

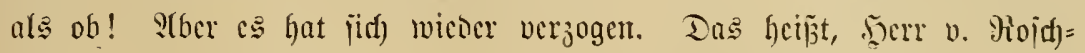

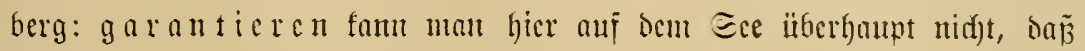

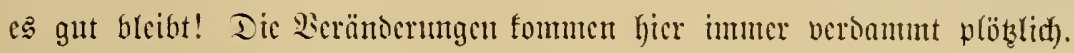
\$sen Sic Besenfen haben, - jureden will idh Jghen nidyt."

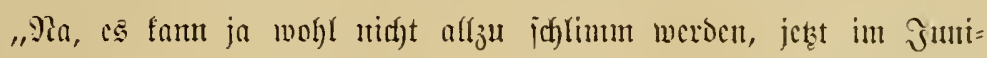

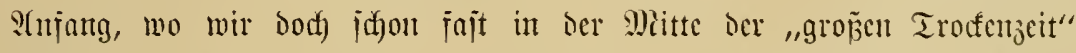

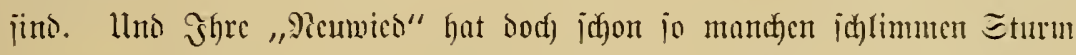
abgemettert, wie Eie nir ja jelber crjäglt haben! Sd) bin aljo in längitens cincr Stumbe an Bord!"

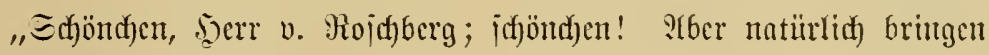
Sic audf Jyren Boy mit."

"Ulno meinen Domo bari id Dod) aud nutbringen?"

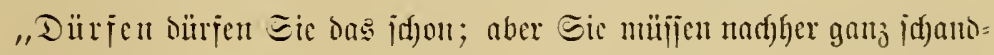

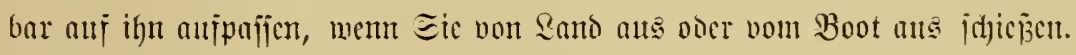

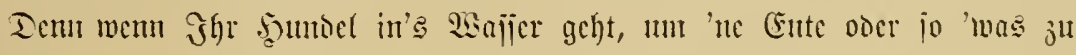

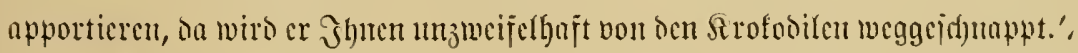
"Ente? Jd) hofie auj beijeres 2 sillit Jedenjalts mug' idf's. Micin Frlinf hat Ippell! - Kwa heri jo lantge!"

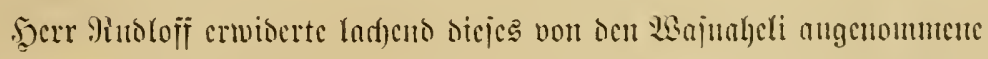

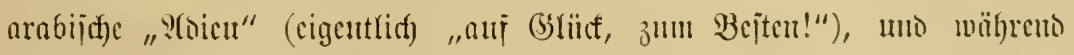

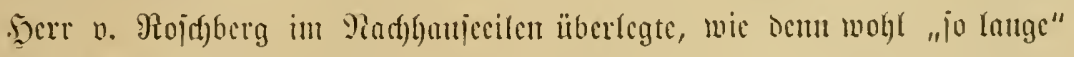

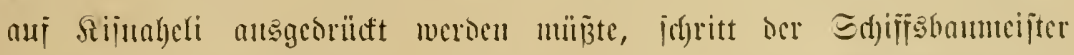

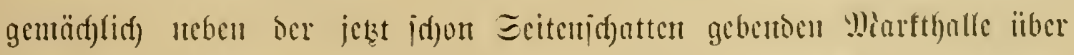

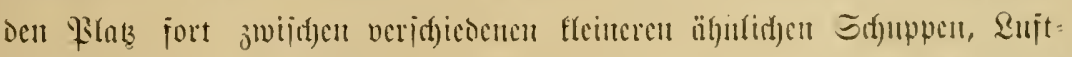

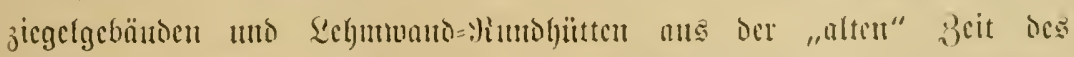

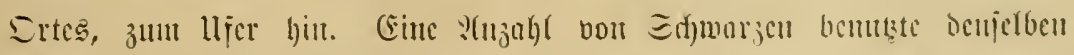

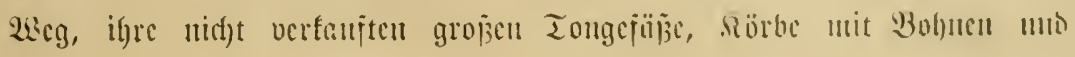




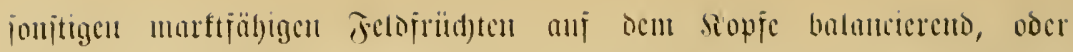

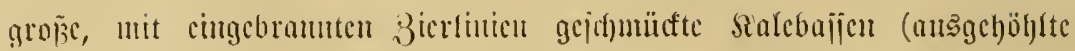

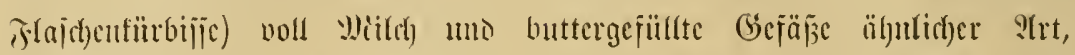

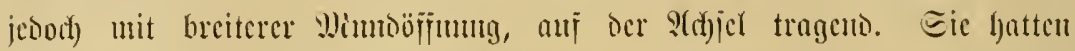

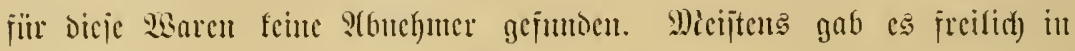

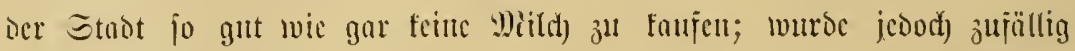

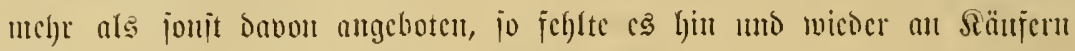

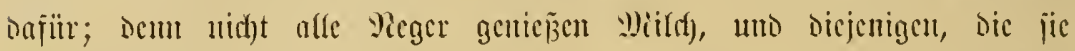

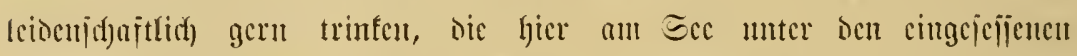

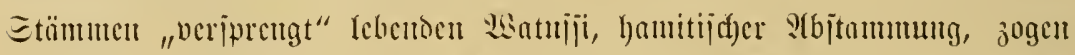

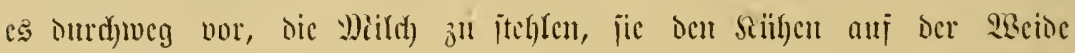

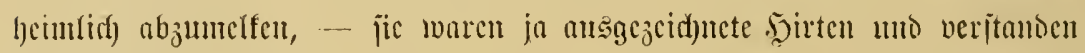

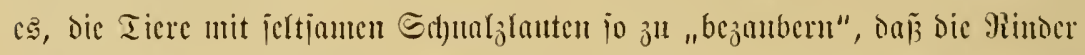

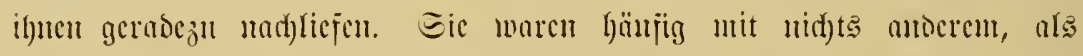

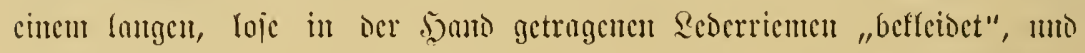

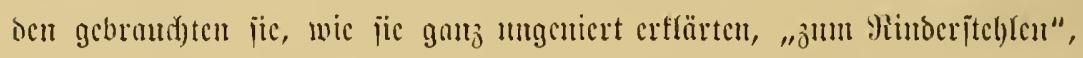

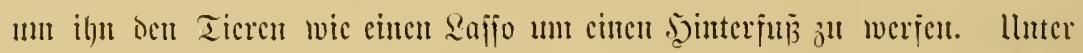

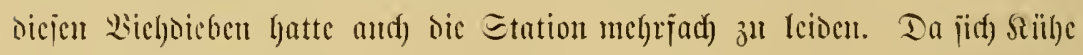

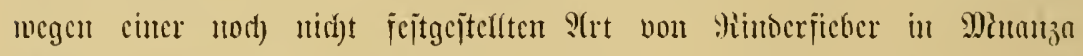

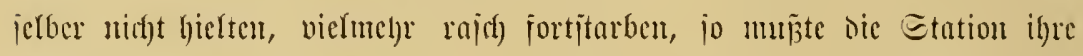

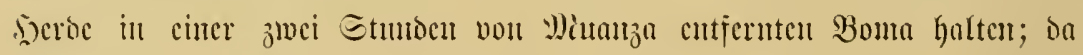

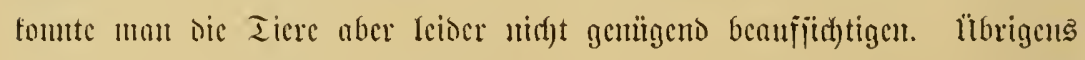

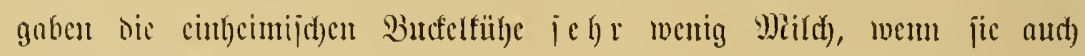
aujerorosutfict) jettreid) war, mu $1 / 2$ bis $3 / 4$ Siter am Tage, wic

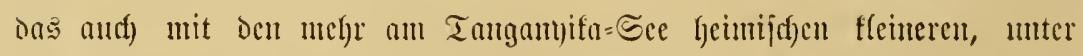

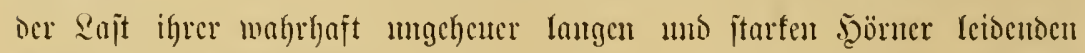

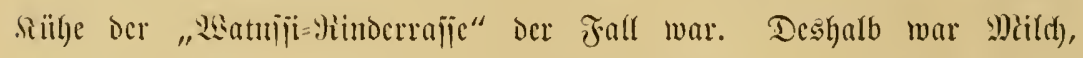
jrijche umo jautre, jowohl fïr die wentigen Europäer als and) für bic

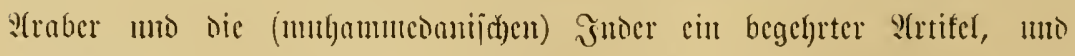

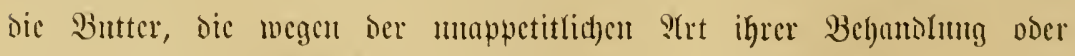

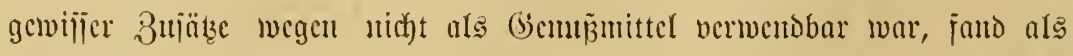

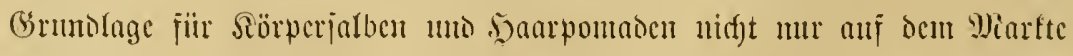

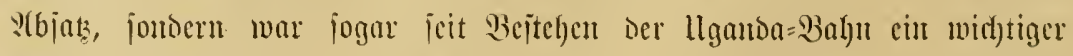

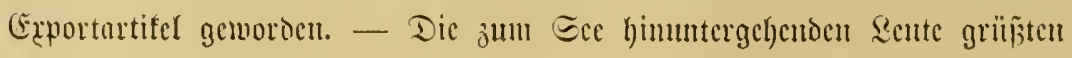




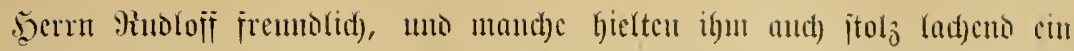

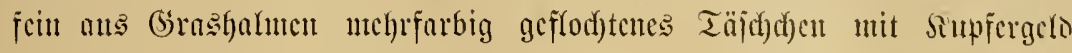

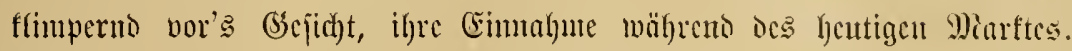

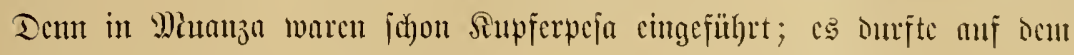

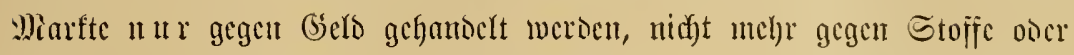

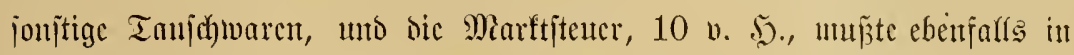
Supfergelo oder bei gelegentfichen hohen Beträgen in Silbermupien mo

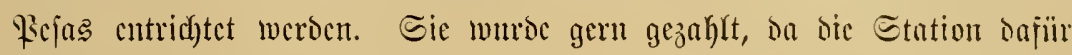

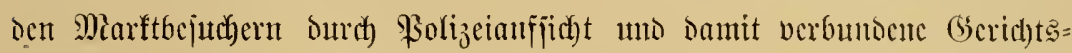
barfeit cine früfer nie gefunnte Sid)crbeit gegen gemaltjanc l̈bcrgrific

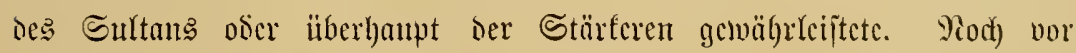

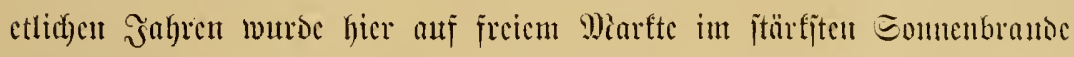

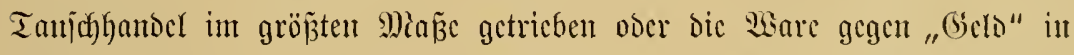

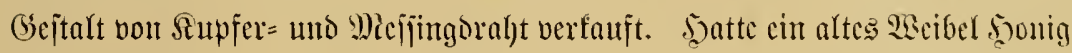

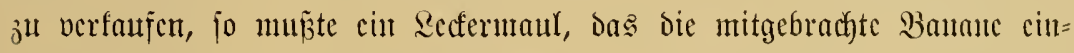

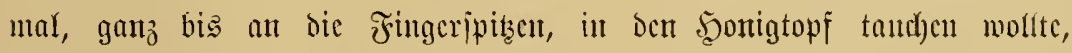
dajür. Wicjïngoraht "cinmul um Den Daumen herum" bezahlen. Bci

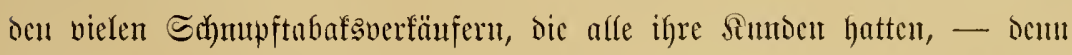

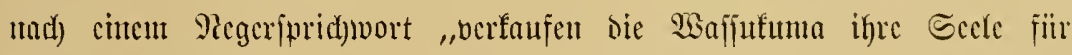
cinte Srije Sdymuftabaf" - fojtete cine Sirife des anj cintem Blattititct

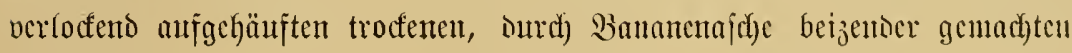

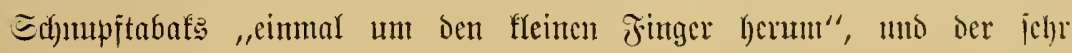

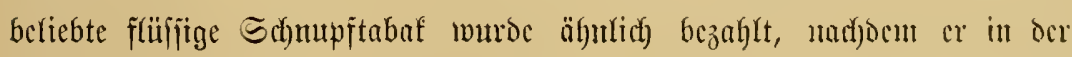

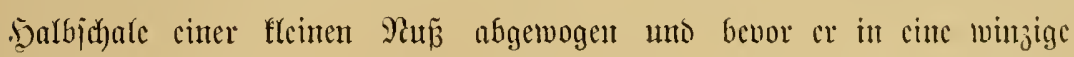

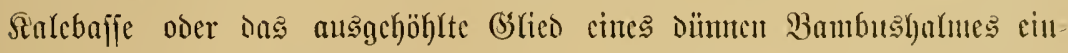
gefüllft war. Dicjes chakulla cha pua, Ejīen für dic Maje, fïlyrte

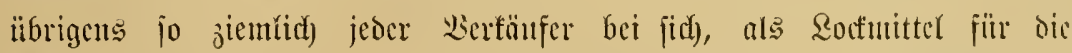

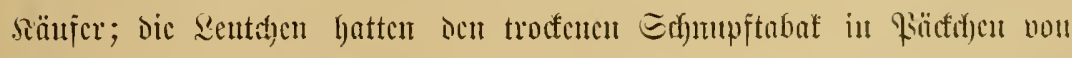
Bajt ober gelb getrocfucten itrohjgen Blättern, ocn fliiffigen in ciuter tleinen Sialebajic, an Bujen verwahrt, im Baujch des Simujts oder in ocu Fulten ihres litbermurfes ans weid) geffopfter unto rot gefürbter Jeigen

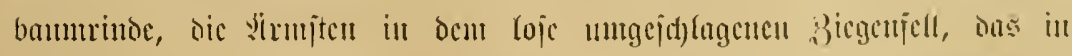

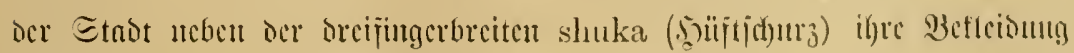

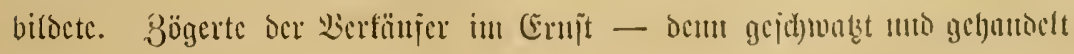




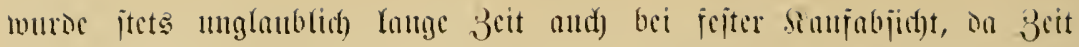

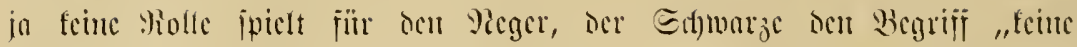

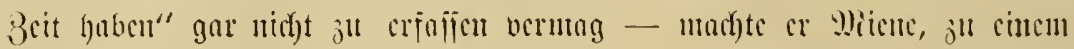

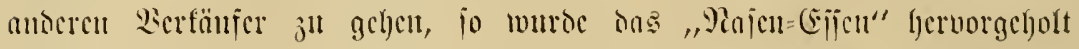

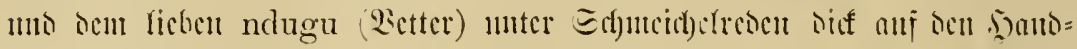

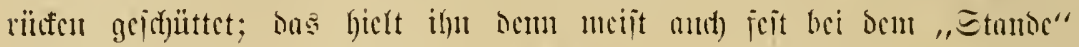

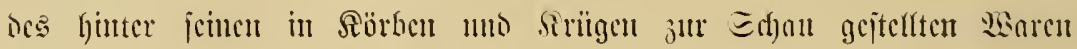

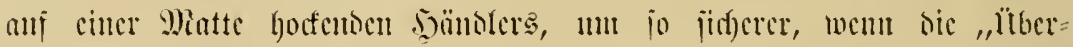

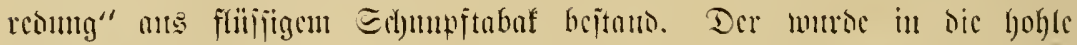

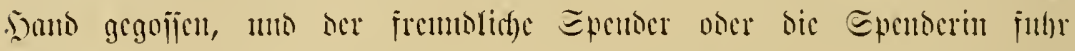

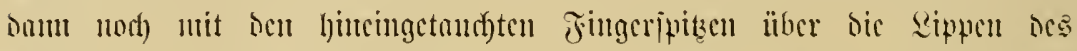

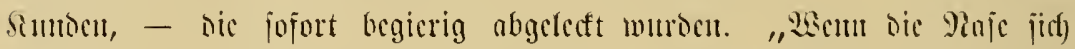

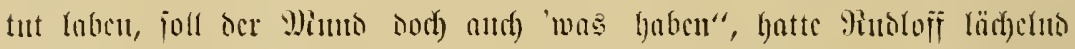

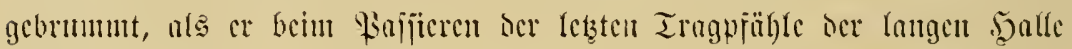

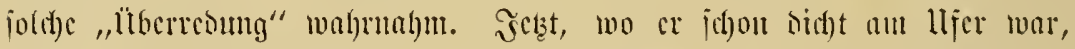

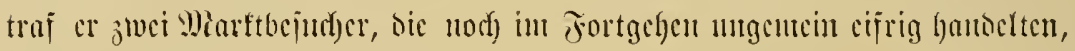

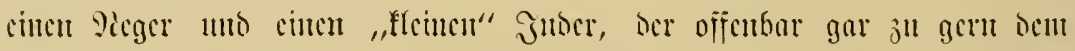

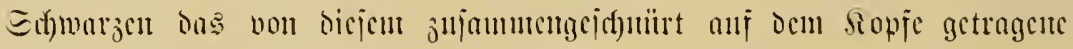

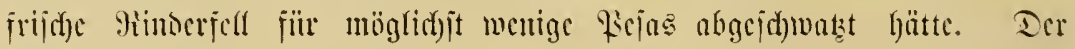

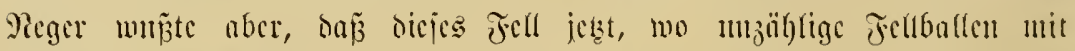

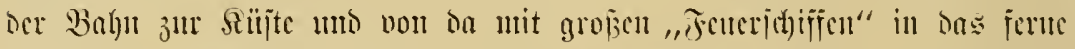
llfaba bejörbert muroch, fajt cbenjo mertwoll mar, wic bns Flcija thes

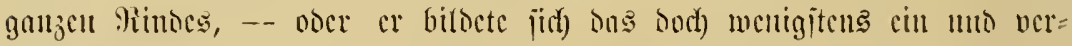

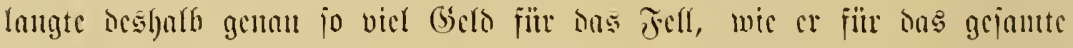
Fleijh) cingenoumenten hatte. Das Tier war hent friih nad ärytlidfer

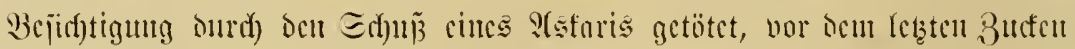

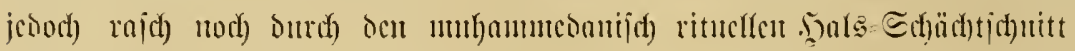
"abgejaugen" morton, weil ionjt feiner ber "gläıbigen" Peger Banon

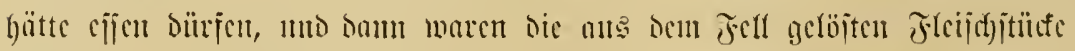

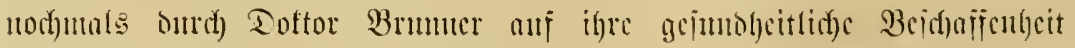

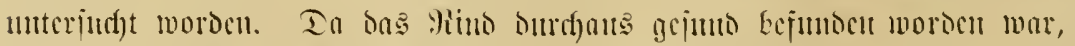

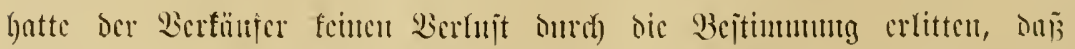

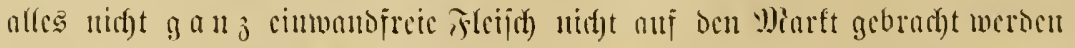

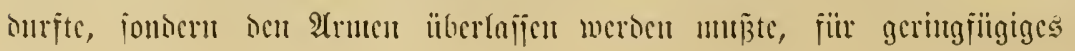




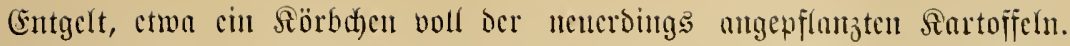

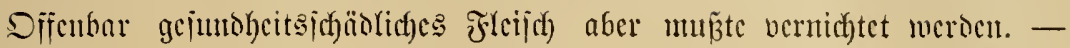

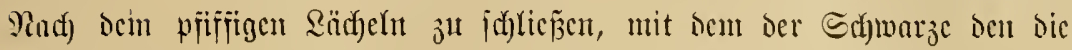

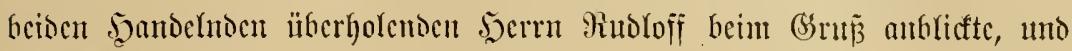

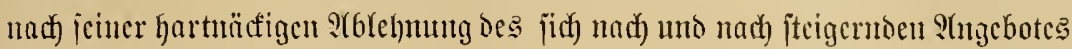

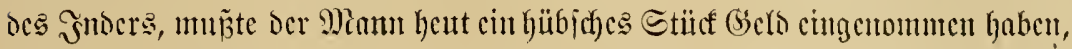

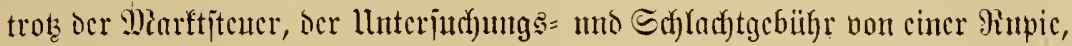
unto trobzocm Flcijd) itl Miuanza jeyr filfig war, - ungead)tet ber Tat=

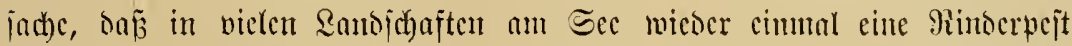

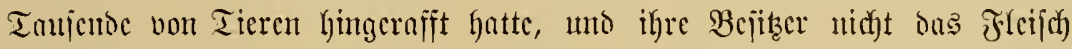
jontorn un bic Felfe verwerten founten, bic Felfe, bic vor ocr Bafnzcit wegen bes hohen Trägerlohntes jur Rüjte böllig wertlos gcwejen waren.

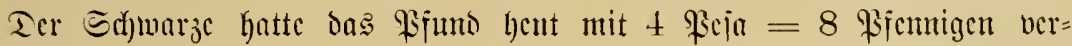
faujt, juglcich aher aud cin Icbenocs Sinlb für 3 Rupicn $=4$ Miarf

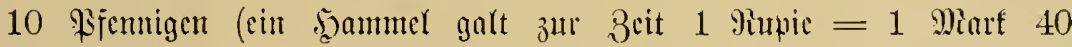
Pícunige, wie dic Stationstajic hout redbute, cill Schaflanm $1 / 2$ Miupie,

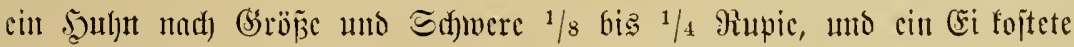

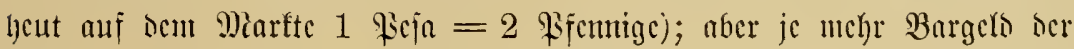

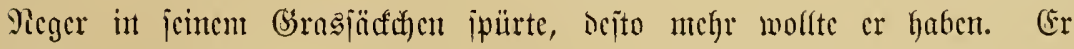

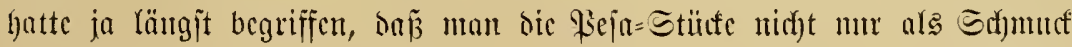

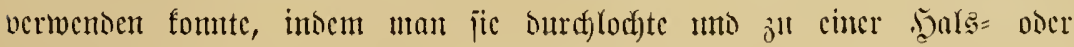
Scibfette aujreifte, oder jic, was früher nod) beliebter war, ju 50 bis 100) Stüuf cinzelnt in bie büjd)elig itchenton 5ूanre einfnotete. Er mujtc,

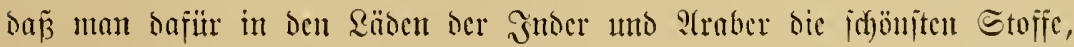

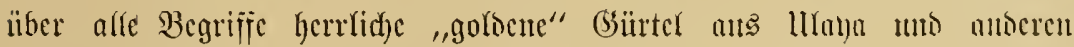

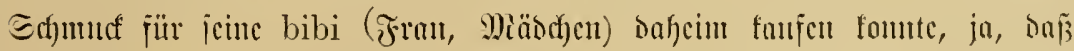

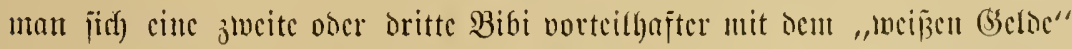

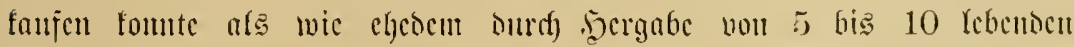

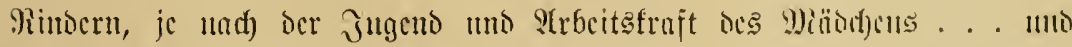

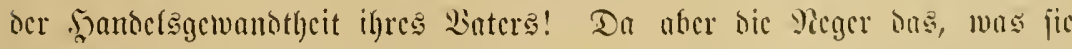

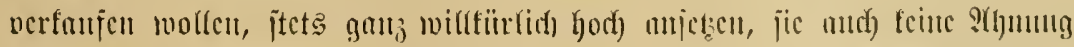

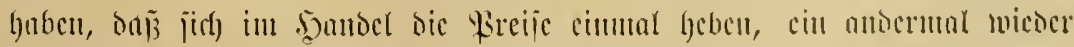

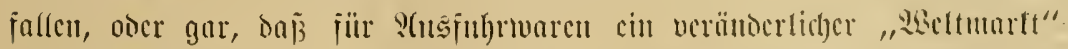

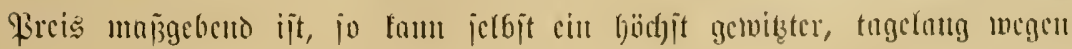




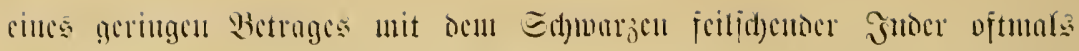

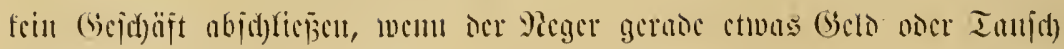

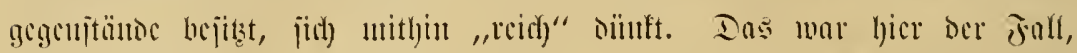

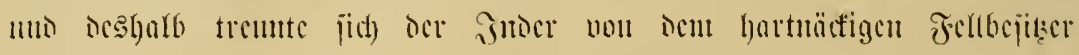

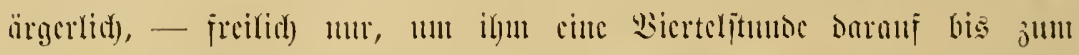

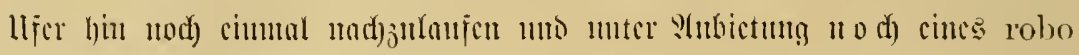

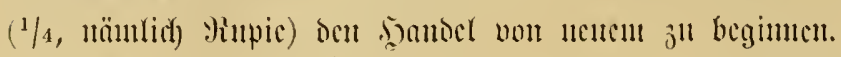

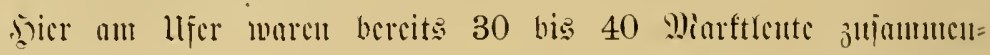

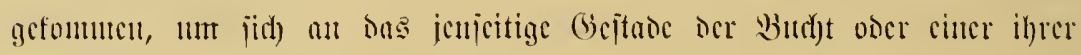

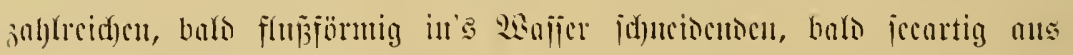

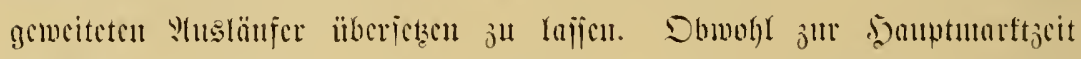

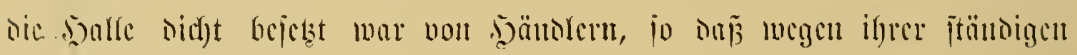

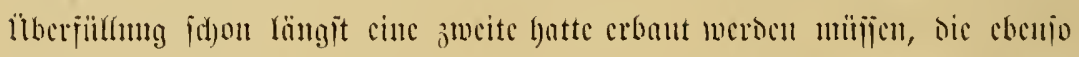
bejud)t war wic bie alte, hatten bod) sic aum jum Eec hermutergefoumutencu

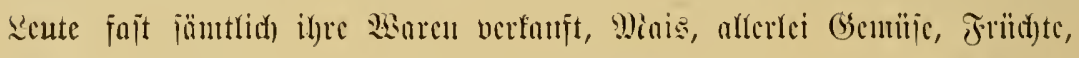

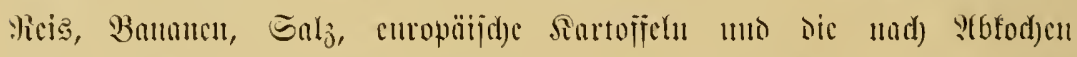

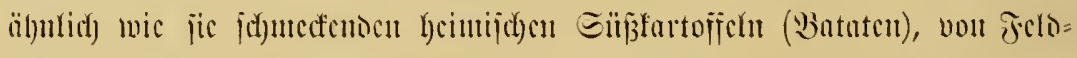

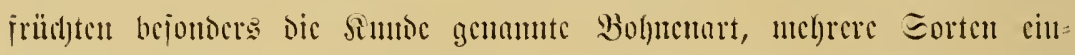

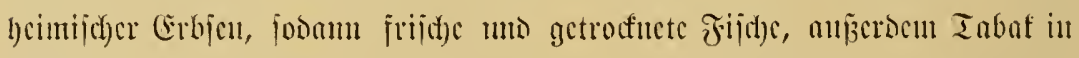

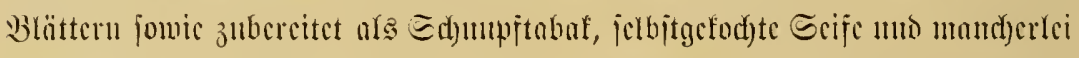

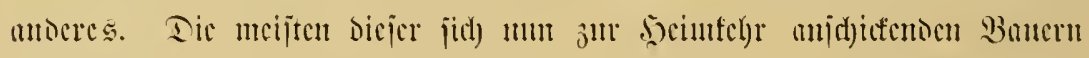

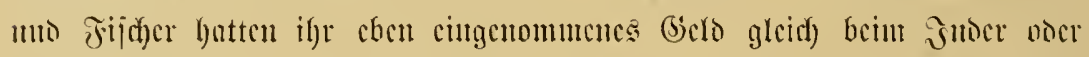

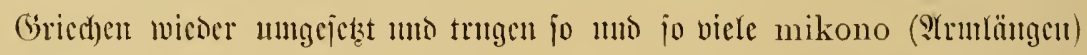

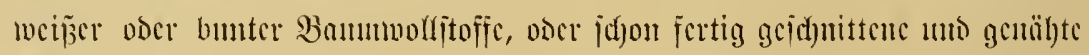

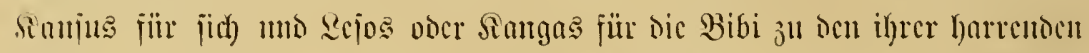

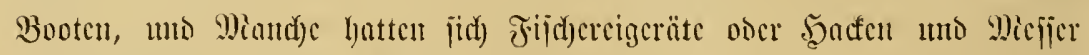

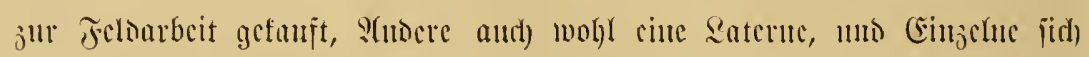

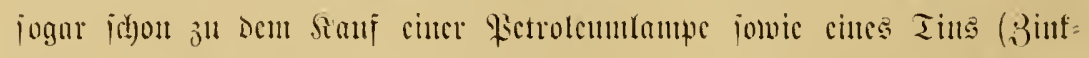

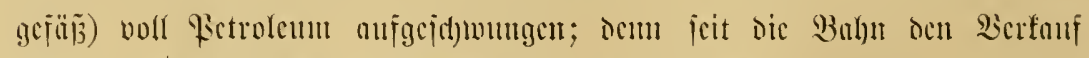

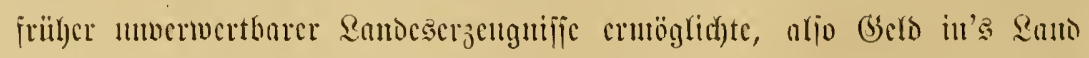

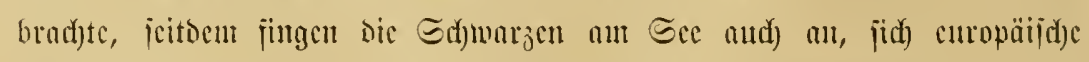

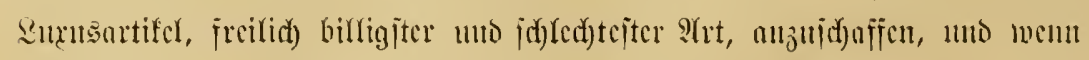
and bier, 6 Dunpfertnge jïblid) Der Enojtation Der llganonbalyn, bic

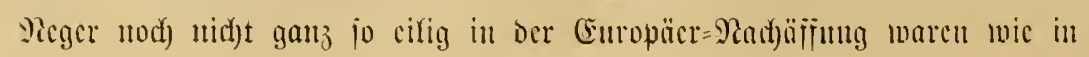




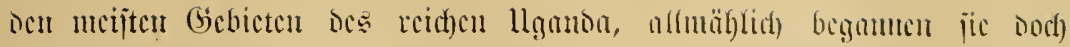

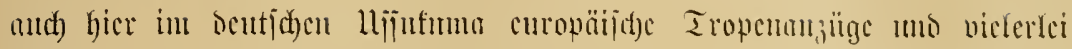

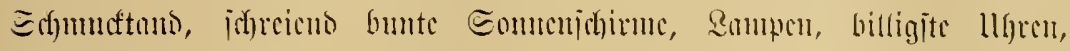

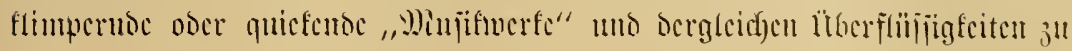

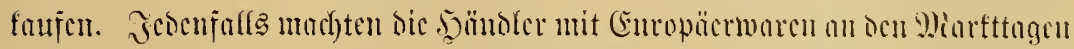

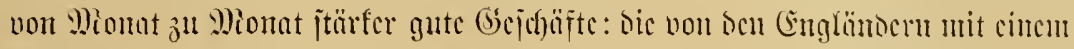

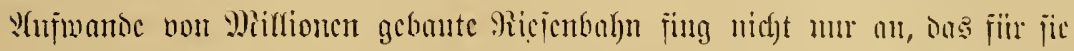

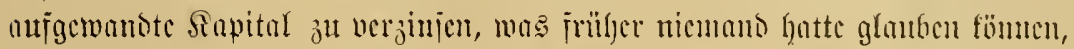

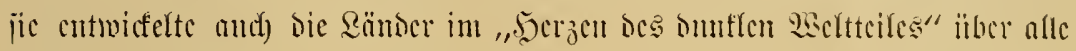

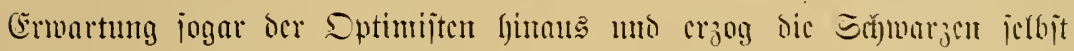

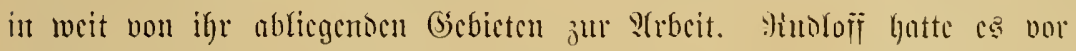

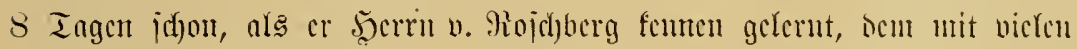
vorgefañ̈ten Micinnngen nach Sor Siofonic gcfommenen Piculing gcjugt:

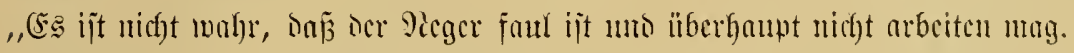

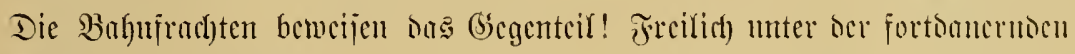

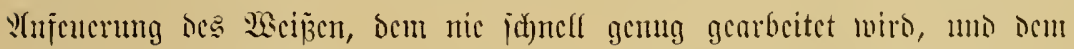

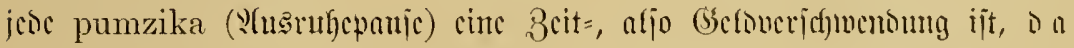

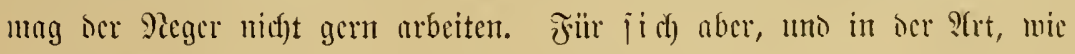

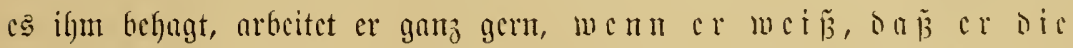

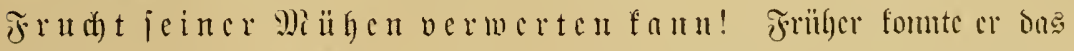

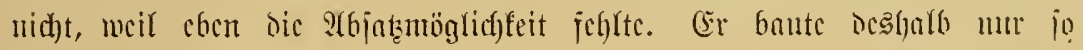

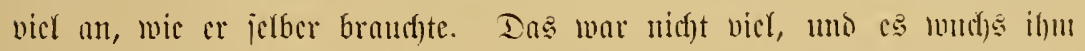

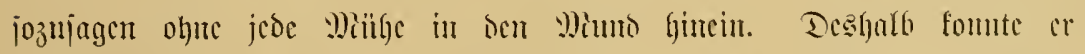

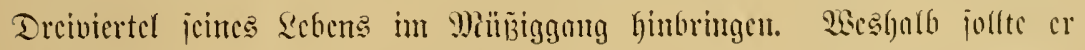

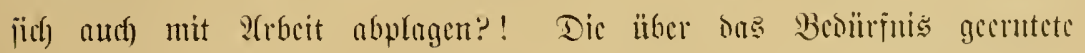

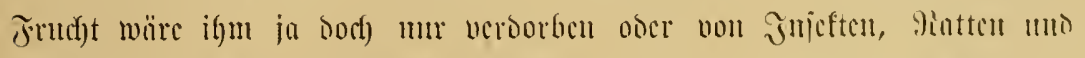

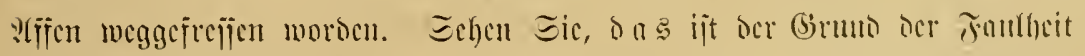

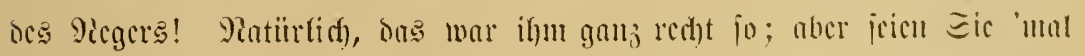

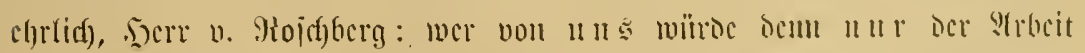

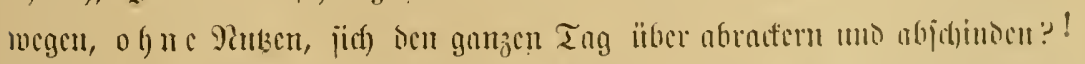

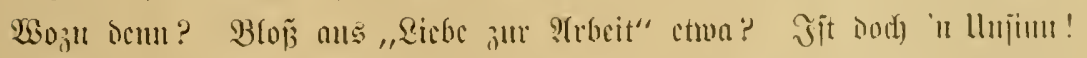

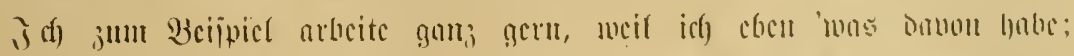

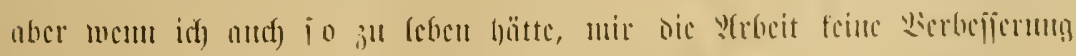

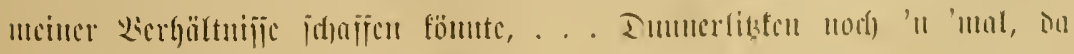




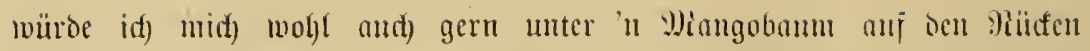

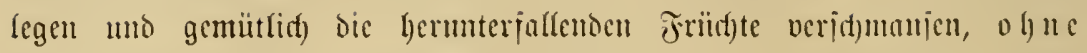

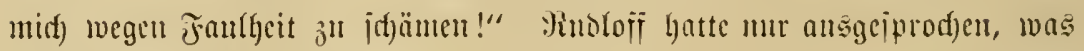

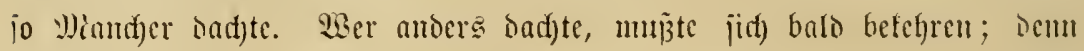

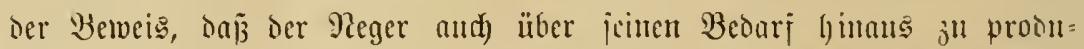
jieren gencigt ijt, lag ja mun jeit der Eimbirfung ber Bolnt flar auj ocr

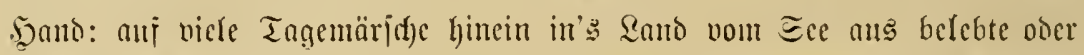

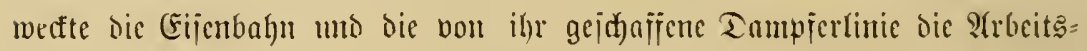
luit ber Eafwarzent. Das bewiejen in unwiderlegbaren 3 ahlen die 3 ölle, mit denen dic deutj(hen Behörocn die $\mathfrak{B a r c n}$ vor sem l̈bergange in's AnElant, jekzt aljo nuj bie englijd)en Dampier, belegten; benn die Boll= ciunalymen mudjen uon Monat ju Mionat in famm ie geabuter Etärfe an. (Fs wäre ja taujenomal bejier gewejen, Deutjd) (and bätte bie Baly gebaut uni quer ourd) die eigene Solonic getegt. Da bas aber jum

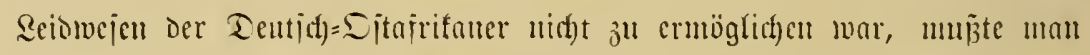

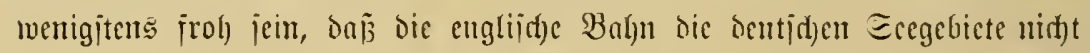
einjad) "ansjangte", wie man jelyr bejür(d)tet hatte, jontonn ocr folonic

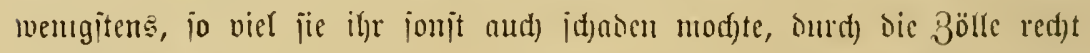
anjelynlid)e (Fimnahmen brad)te. "Fragen $\widetilde{S i c}$ 'mal auj ber Etation an,

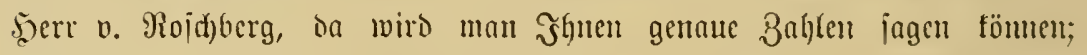

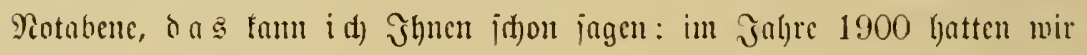
l)ier cint Bollimulyue von ganjen 120 Minpient, unb idfon im jueiten

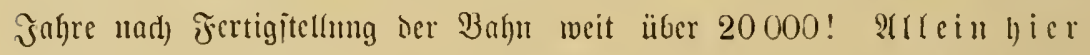
in Miuanza! llno an oer (Grenjitation Ecthirati find sic zölle in gleid)em

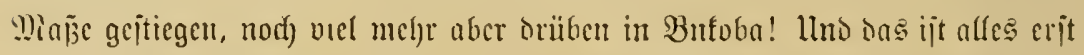

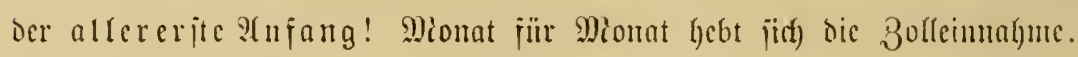

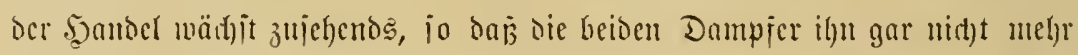

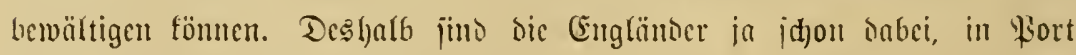

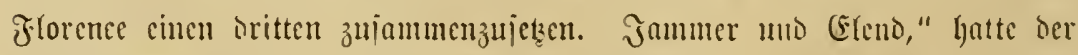

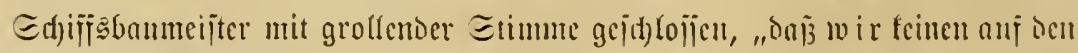

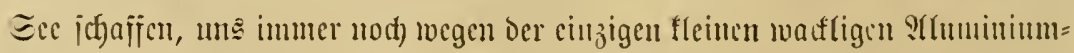

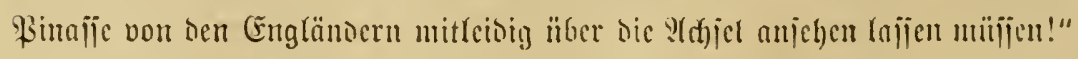

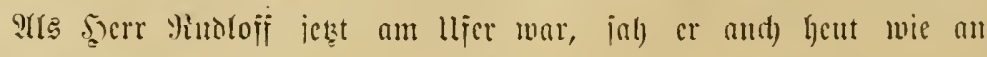
jesen Mharttage vicle Dnkente von Bivoten, die anj Etencrabjertigung 


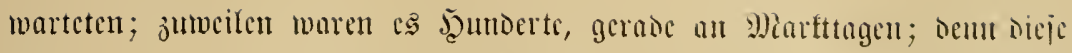

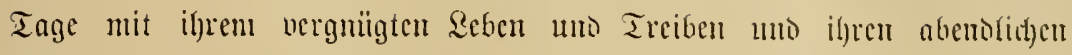

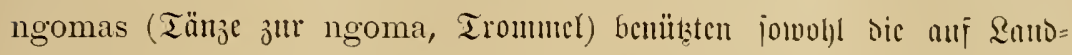

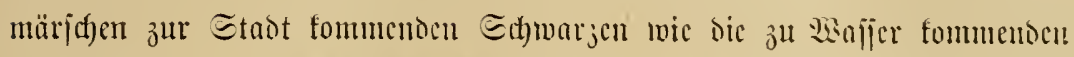
nut 2orliebe, un ifre $230 r e n$ herunzubringen. Sin Gegelboot batte feiner

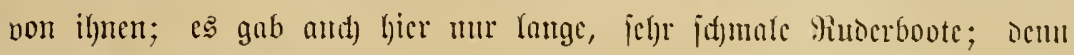

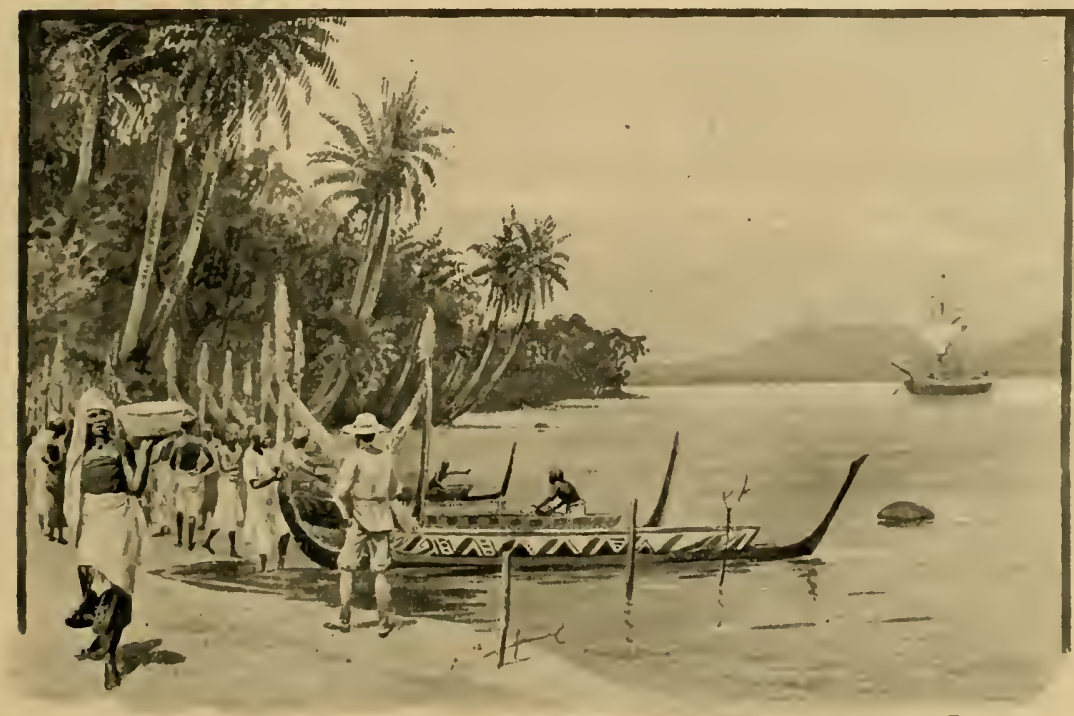

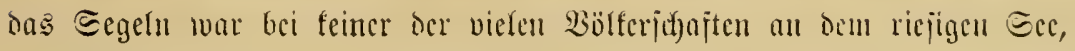

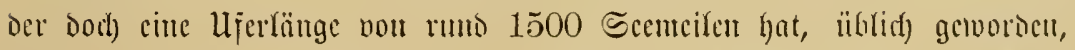

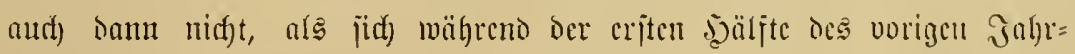
funtorts cine SHabl ber vou ber Diceresfiijte her bis ant sie Eecu vor=

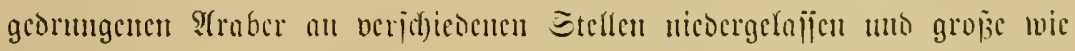

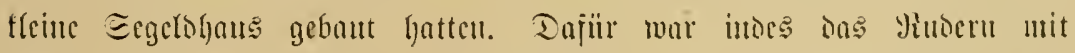

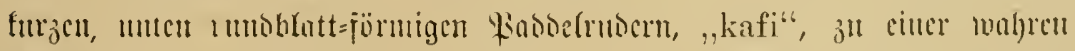
Semijt gemorben: Dic jür 6 bie 40 Ninterer cingerichteten jogen. Uganta=

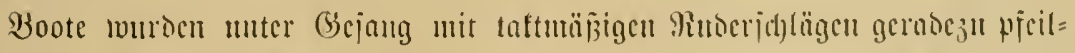

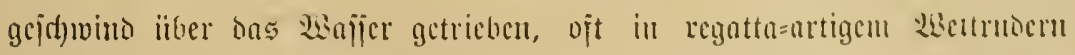

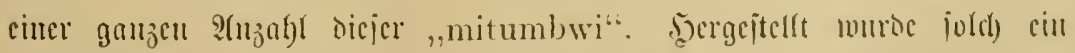

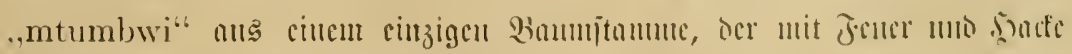

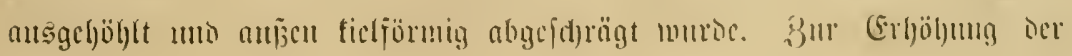


Boromänto bicjer niçrigen mo jüt)malen Boote, bic jelbjt hei ciner Ränge

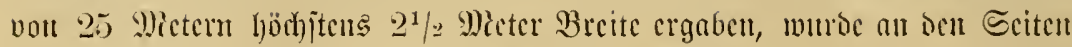

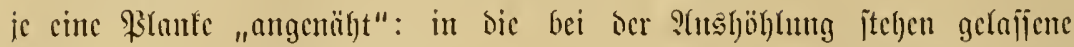
Bootsmantung murbe bidyt unter ifgrem oberen Rante cine gieihe vont

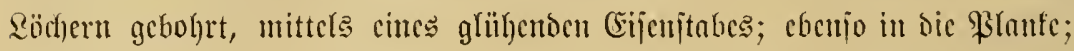
sicje wurbe auj ben Sians gejekt, mo bann verbanto man beises, inscm

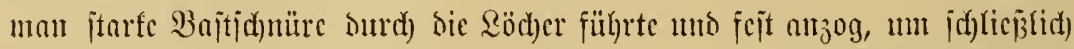
Dic \&öd)er mit B̧aumlyarz ju "fulfatcrn". Bug uno Stern uvaren bei

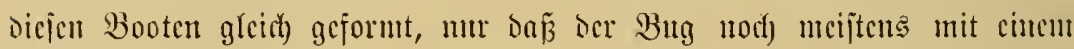
nom Sìiel ans weit vorïtehenden mo fajt redhtwinffig hod) cmporgehenoen

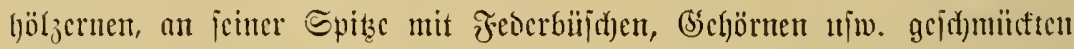

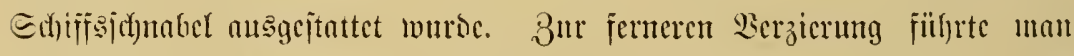

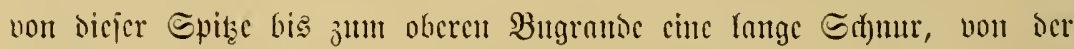

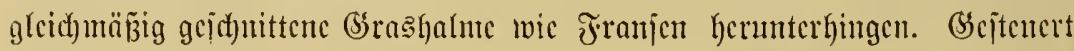

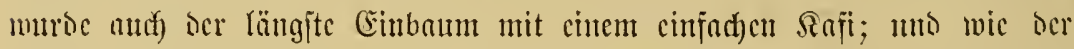
Eteucrer, jo wansten aud die Rutberer bas (Sejejd ber 8 ichridtung.

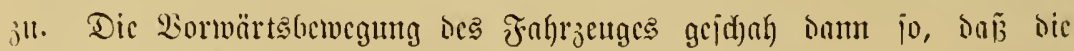

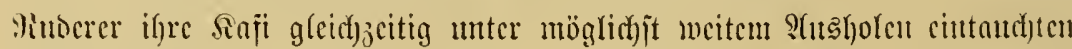

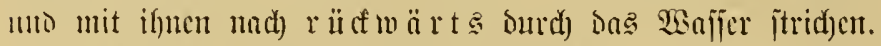

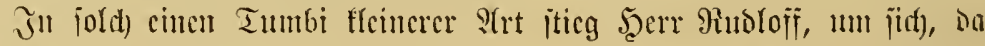
Dns nad)enartige Beiboot ber "פecumico" von ber ifm aufgetrugencu fallyt

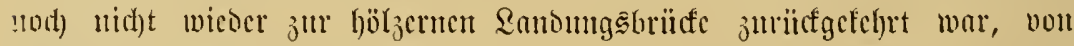

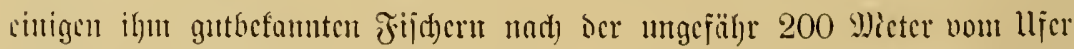

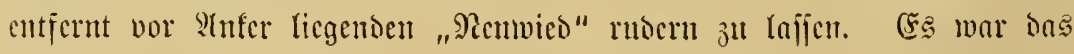
ıur cin fleines Fahrzeng, bas unter jwei Raajegeln uno cincun Rlüver

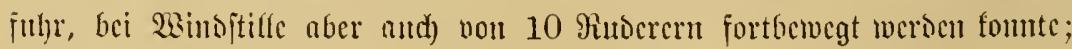

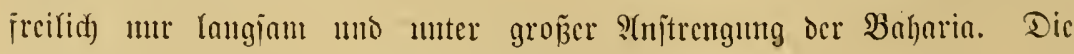
iiir bic Station non arabijacn Sdjifjezimmerern gebautc Dhan war

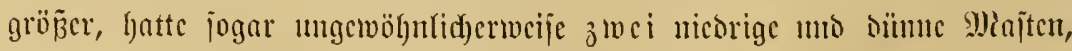

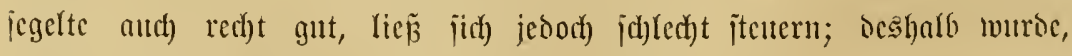

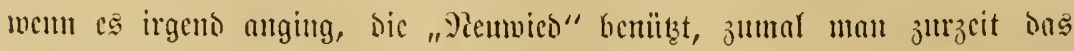
Fahrmafifer nod) lange nid)t ilberafl "jeitgelegt" batte; man batte bislang mur an Den midftigiten Eteffen Rotungen vornefjuen umo Eesjeidfen in

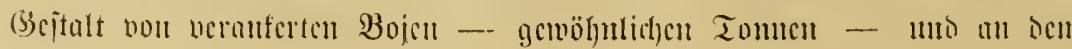




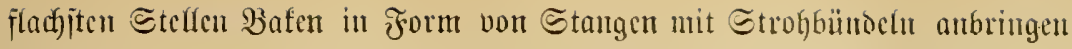
fönnen. Das Jalurwaffer war übrigens and) anf engliid)em (bscbicte nod)

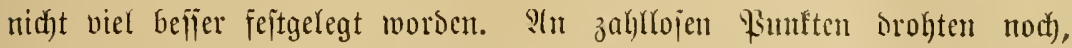

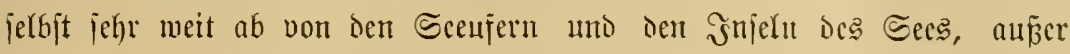

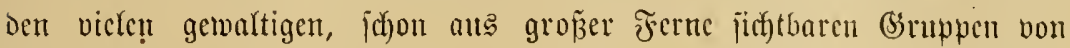
Steinblöten cinc Mienge fdjon bei geringem \$sellengange überipülter

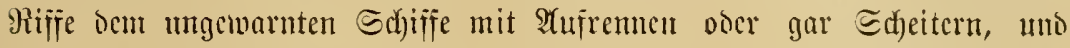
nod) viel mefor geidfah bas durdh bie viclen mur gelegentlid) erfaunten

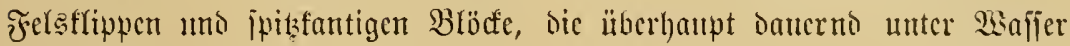
blieben; Darum magten benn aud) Die englifiden Daunpfer jo wenig wic

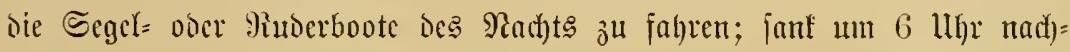
mittags dic Some uno trat bie hier in Der Pähe des ïlquators jahrein jahrans faum länger als einte Biertelftunde banembe Dämmerung ein,

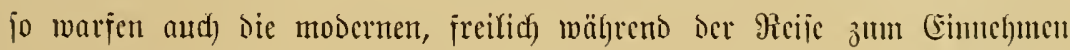
von Feucrung

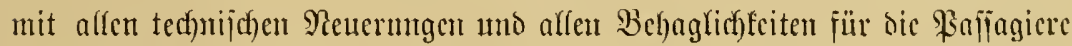
ausgejtatteten beioen Dampjer. SYnfer, un crft an anderen Miorgen un

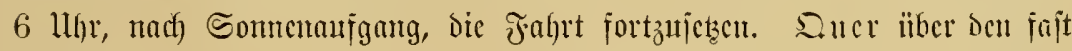
300 Silometer breiten Eec war ïberbaupt .nod) nic cin Memich gefahren,

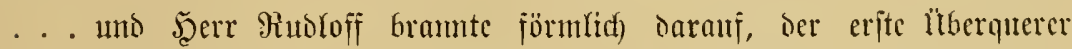

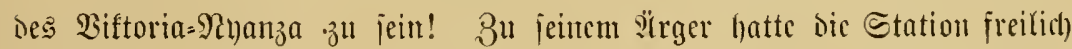

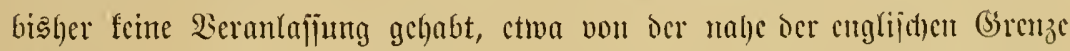

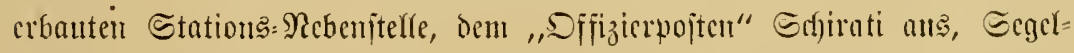

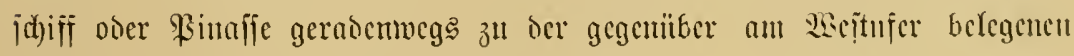
Etation Bufoba 3u ichicfen. Wiohl hatte die "Nembico" in $S=$ bis

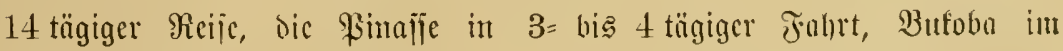

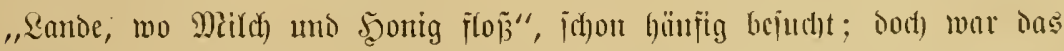

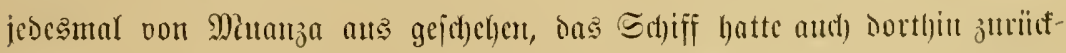

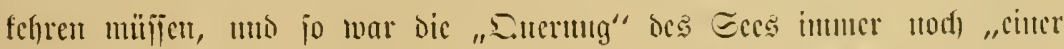

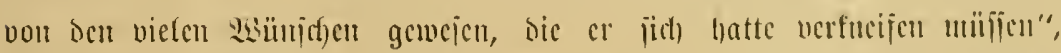

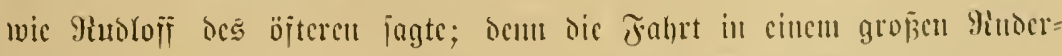

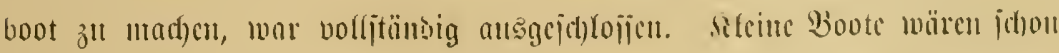

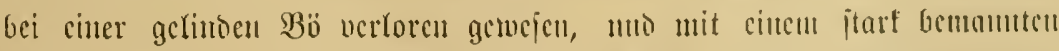

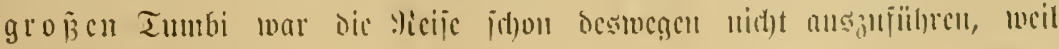




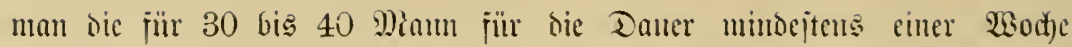

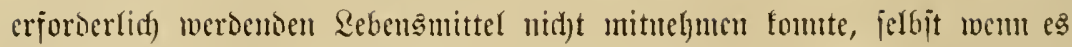

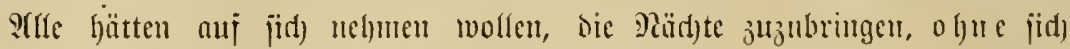

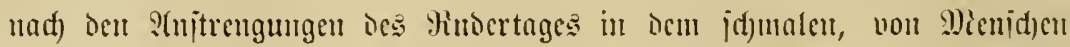

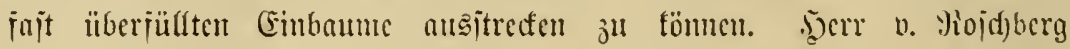

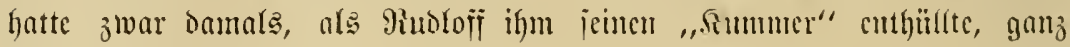
vermumbert gejagt:

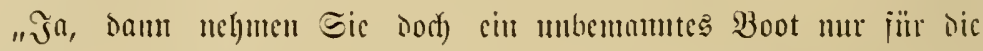

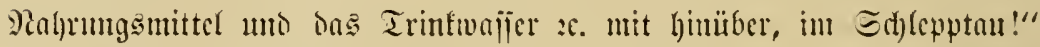

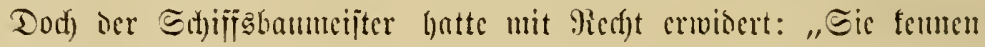
weier ben Plyanja, nod) Dic llgantaboote, verehrier jecr; jonjt wïrten

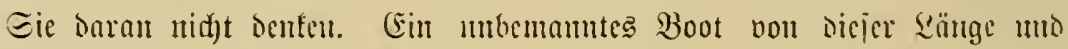

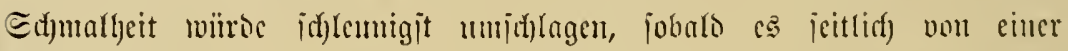

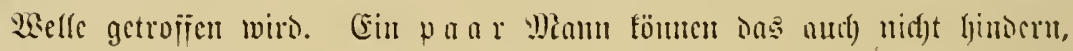
unto wiro das Boot ftärfer bemamut, na, Damu ichlt eben wieder ier

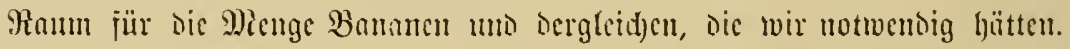

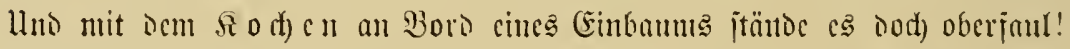

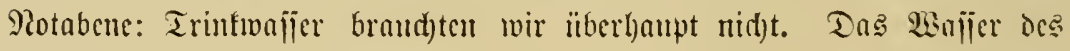

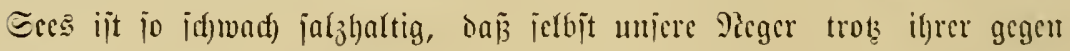

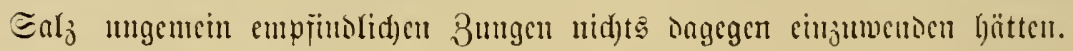

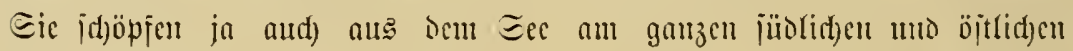

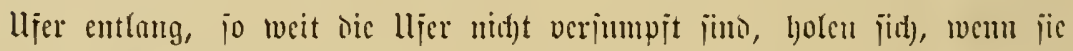

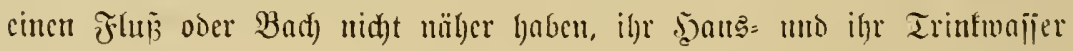
aus Dem Sec, obwohl cs, notabene, gewöhnlid) melyr als 20 (Śrad (Eeljim

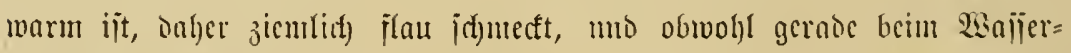
idjöpien bic Sirofosilbejtien ihre Epjer jull jaljen piflegen! Miotnbenc: in

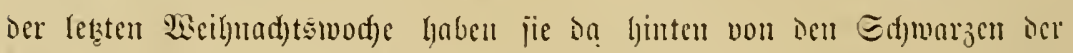

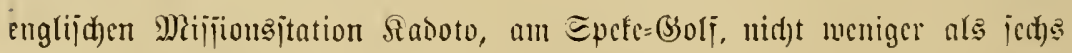
Sente beim Edjöpjen gepautt mo unter's 2:ajier gerijīen! Wotabene uid)t

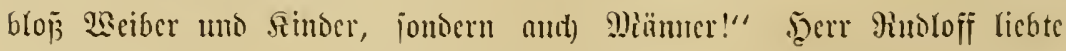

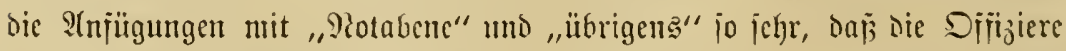
Der Station jeferzentermeije idfon ihre Bermumberming barüber ansge= iprod)en hatten, da jer jein "emiges Plotabene" nicht aud) zwijd)en jeine

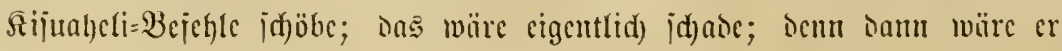




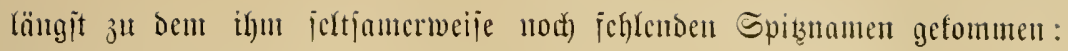
"Bana Notabcne."

Rurz nachoem Rubloff bas Segelboot bejticgen, bog um cinc ganz mit fnorrigen niedcren Bäumen แnto Bujđ)twerf bejtantene Felsgruppe, mchr lantocin an ber Butcht, bas nad) curopaiijacr S(rt gebnute Beciboot Der "Aieumied" und hiclt, von jull Babarias ocs Seglers auf kizungu (in ẹropäijd)er 23 cije) gerubert, auj

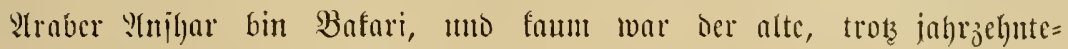

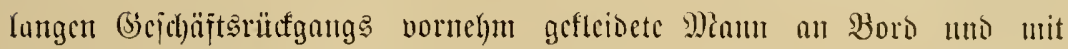
jeinen Berbeugungen uto "Snlanms" fertig, jo eridyien aud bereits, viel

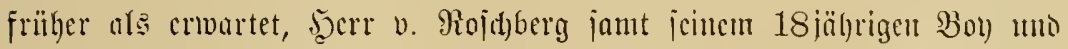

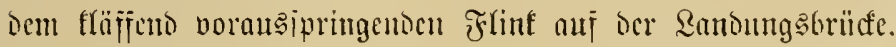

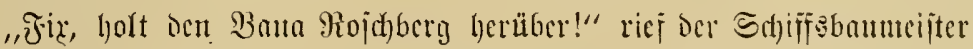

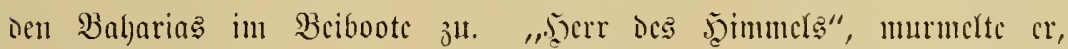

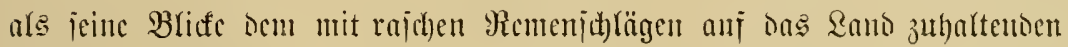

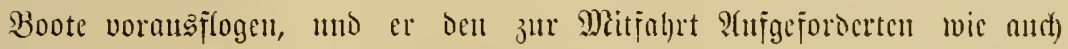

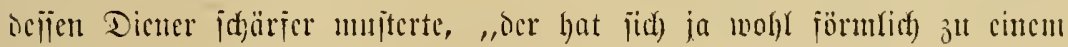

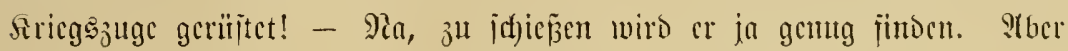

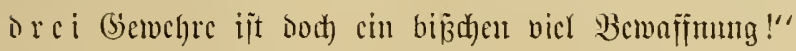

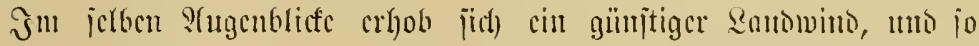

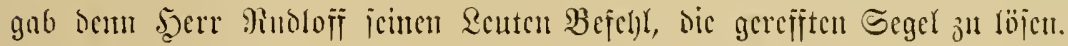

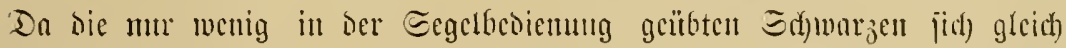

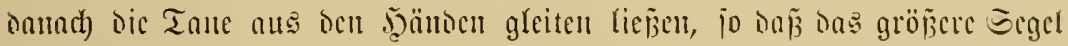

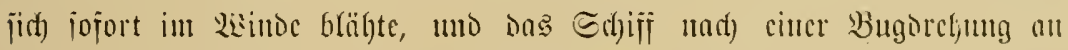

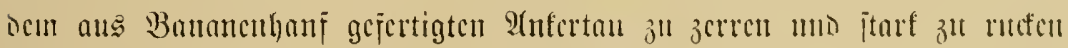

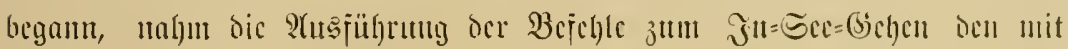

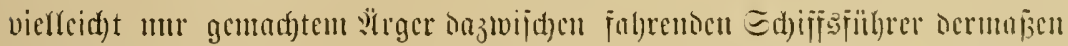

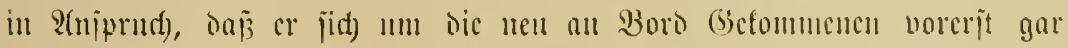

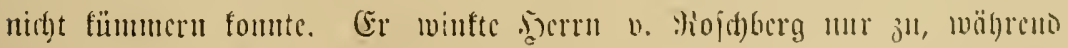

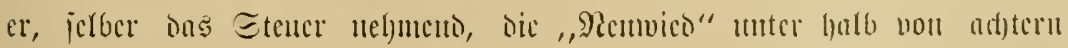

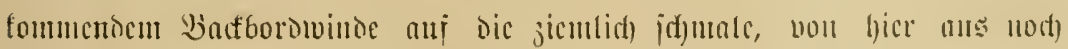

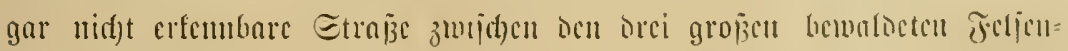

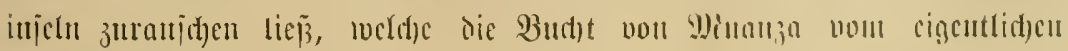
Ecc jotheinbar völlig abjatoijcu. 


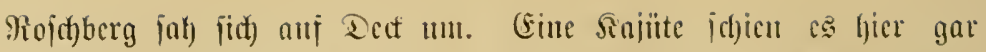

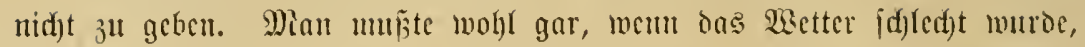

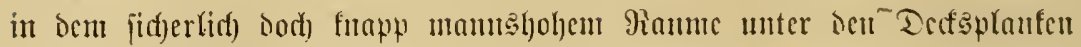

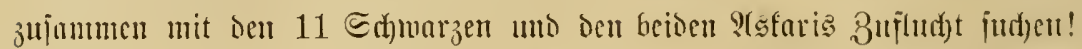

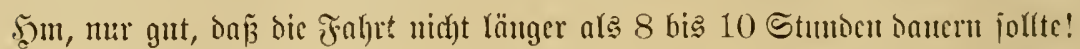

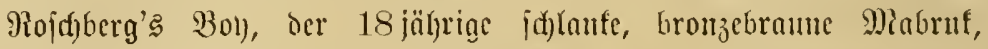

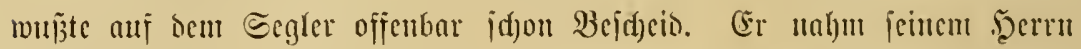

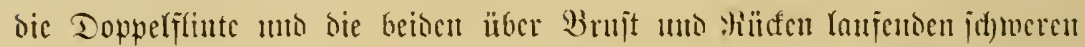
Fatronenbandeliere ab unt trug fie mit den non ifju gcichleppten beiden

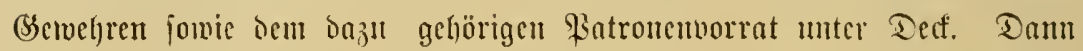

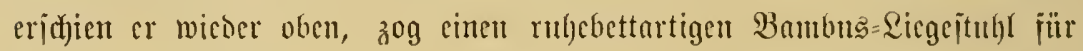

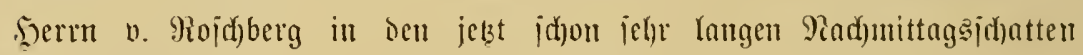

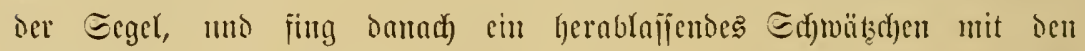
Baharias an. Err iwoltte ihnen zeigen, da er bod) ale mguana (īcin (bebirtoeter, eigentl. Frcier) hod) ïber bicjen

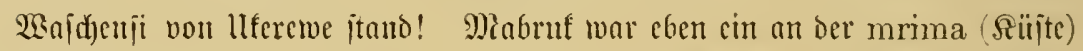

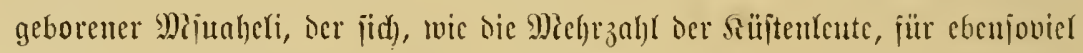
wie cin edfter Samjibarit hielt, aud) Sedem vorlog, er jei anf llıguja -ober Binjibari, ถ. h. Samibar - geboren. Sielleid)t hatte er bas

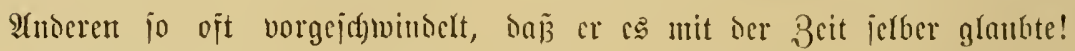

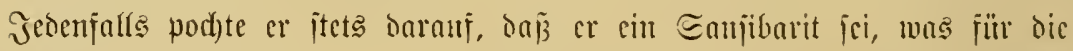
Pieger jo viel war, wie fïr die Frnnzojen ober jonjtige, alles Frunzöjiiche

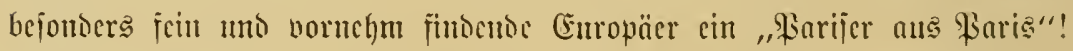

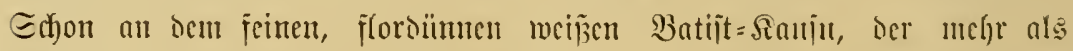

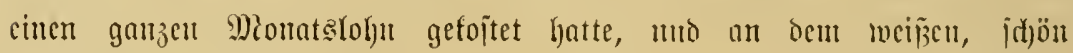

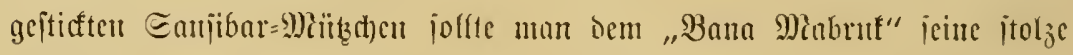

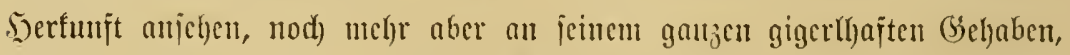

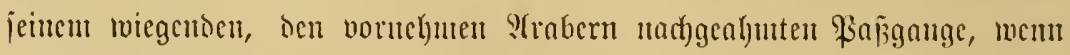

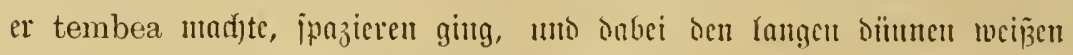

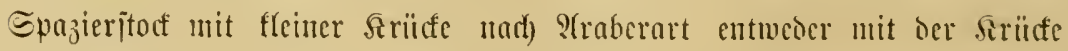

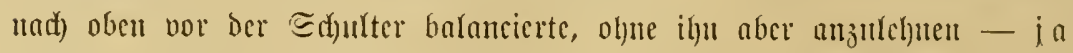

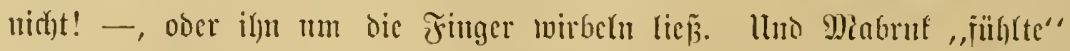

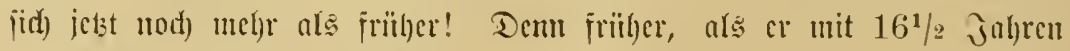

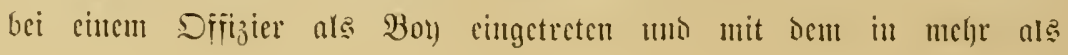




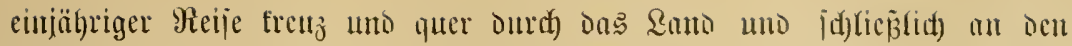
Ryanza gefommen war, da hattc er cimen bwana kali sana ( $j \mathfrak{c h r}$

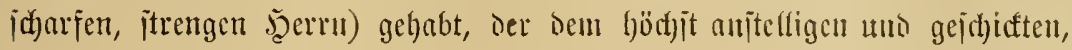
aber ebenjo veridgmiz̧ten umo gern berumfau Yenjenten Boy gebörig auj Den Dienjt und bie gern und) Dem (Eigentum Des J̧errn greifenden Finger

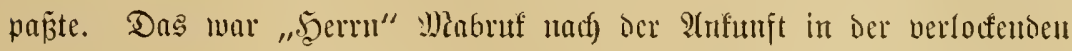
Stadt Tabora "untertrïglich" geworien, umo obwoht Der Dienjt bei gutem

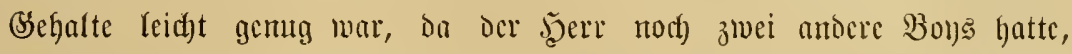

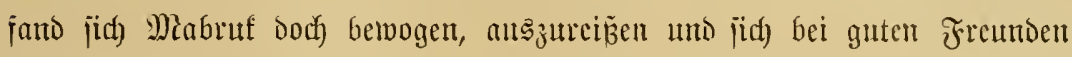

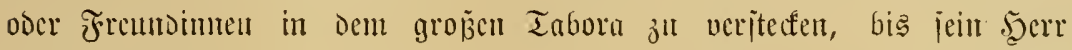

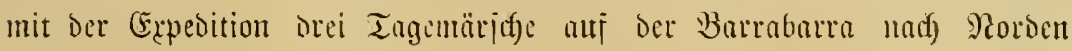

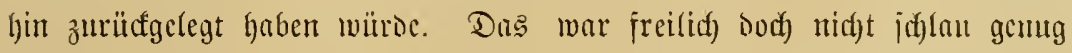

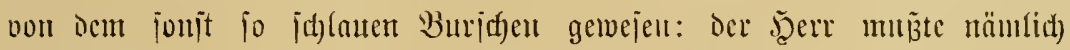

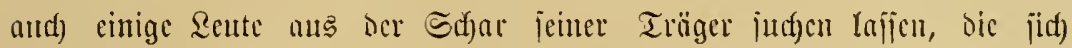

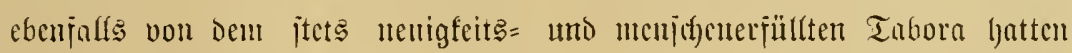
verlocfen lailen ju denfen: "haithuru, - mimi kimbia (was fanu da

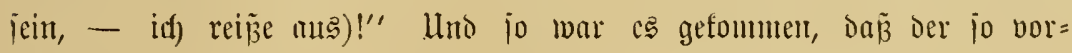

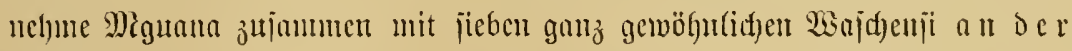
Sträfling Barrabarra unter Dem Spott Der Lorïber jiehenden nordwärts marjificren

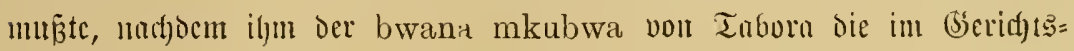

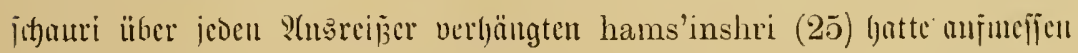

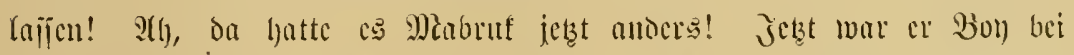

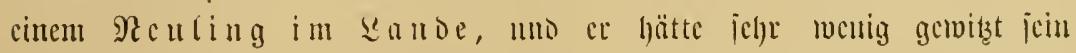

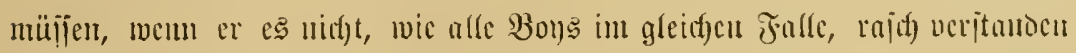

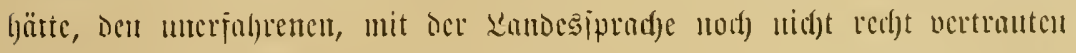

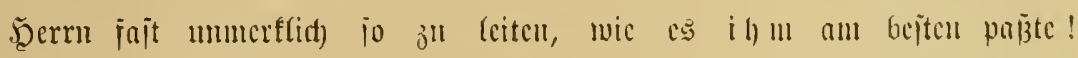

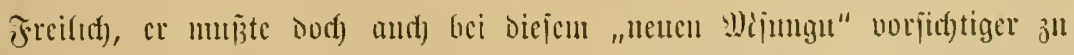

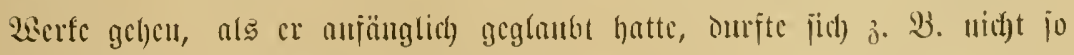

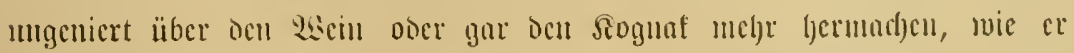
Das in Den crijten Ingen verjud)t hattc, wo bana Roshebegg es ilju

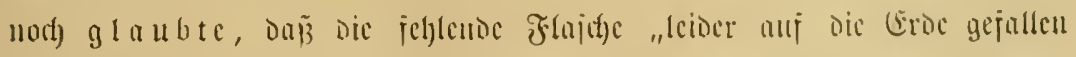

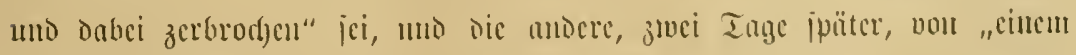

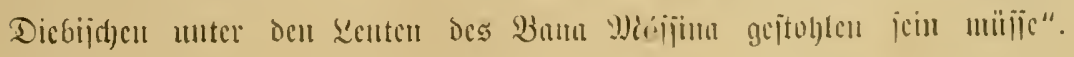


Bana Rojtherg mar beim Jeblen ter britten, erit bier in Miunja

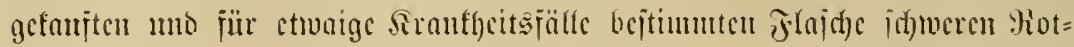

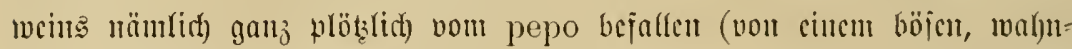

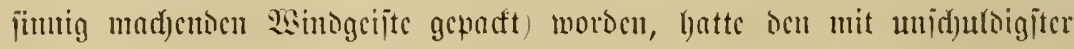

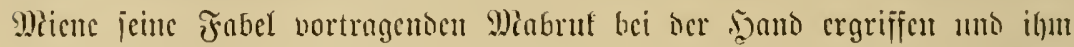

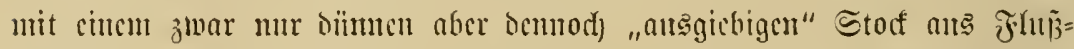

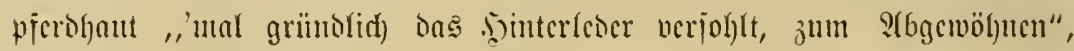

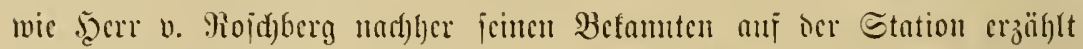

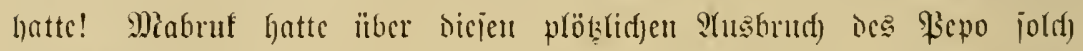

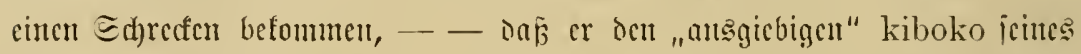

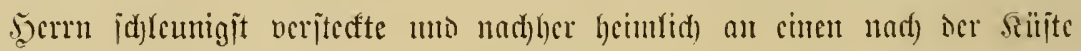

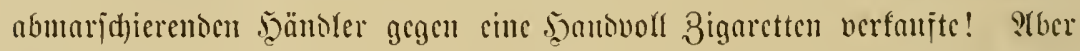

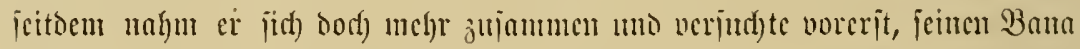

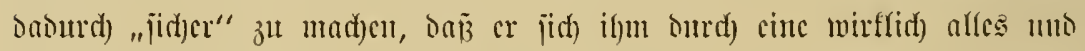

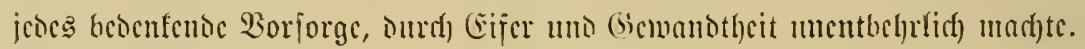

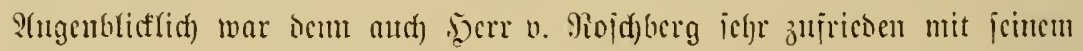

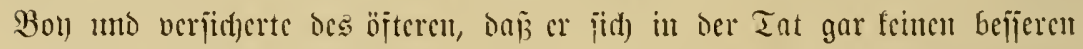

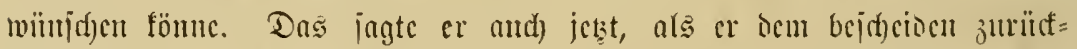

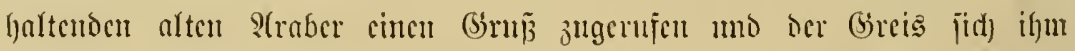

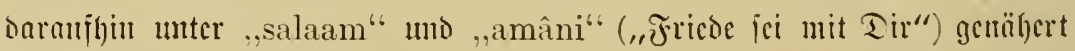
hatte. Nur ganz altmählid) war ber junge Sentjd)e mit S(mifar bin

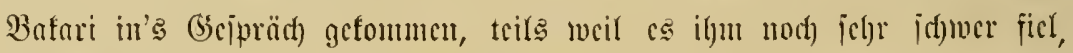

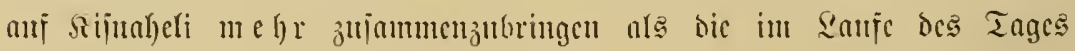

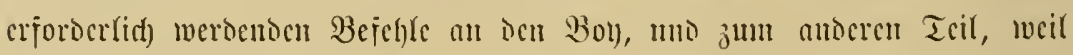

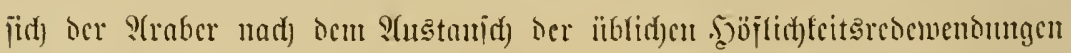

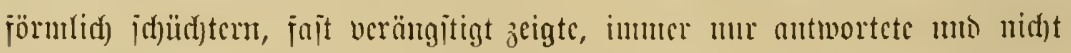

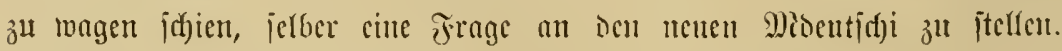

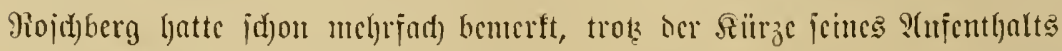
da

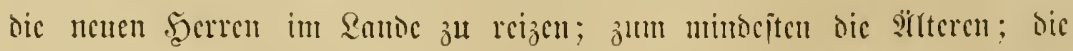
Süngeren traten alleroings viel jreicr auy, wenn jic aud itets jircumblict)=

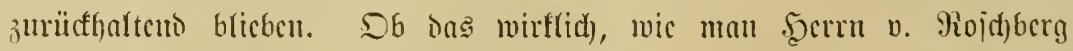

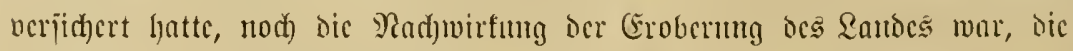
Peicherwerjung des von bem sealbaraber Bujdjiri angezettelten und von 


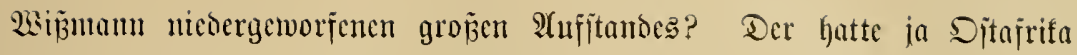

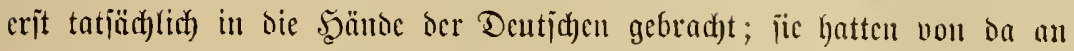

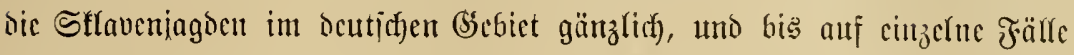
auth) den Durd)trangport Der jenjeits, im fiongogebiet, zujamutengcraubten

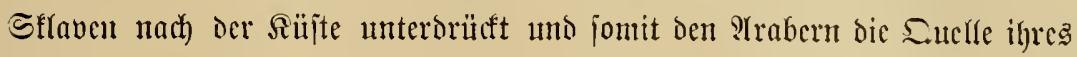

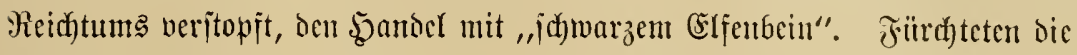

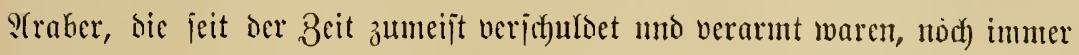

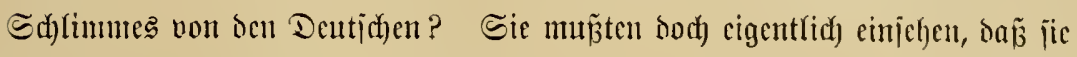

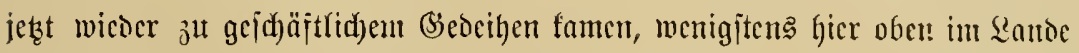

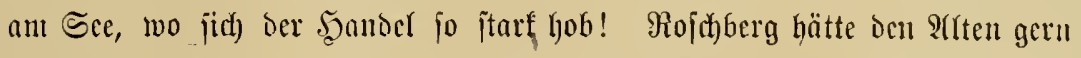

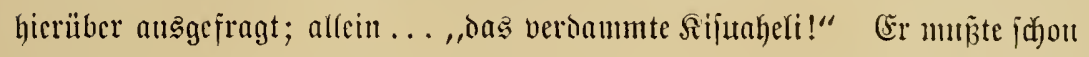

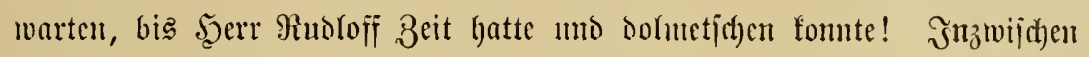

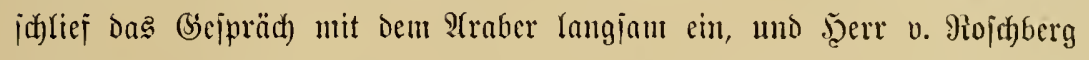
begnügte jid) bamit, oen auf einer feingeflorbtenen (Srasmatte fauternoen S(rten umauffärfig genauer ju mujtern. Wie alt mo(a)te cr wohl cigentlich jein? Man hätte ihn ebenjowohl für eimen fnappen Eedjziger wie an bic Ilthtzig

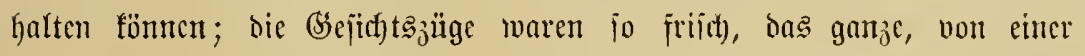

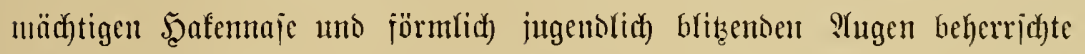

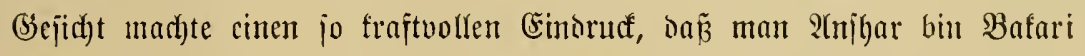

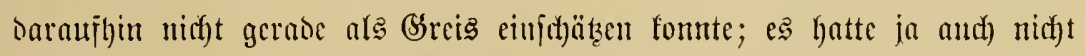

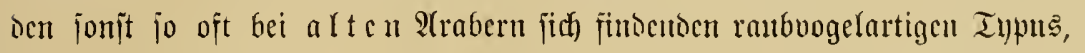

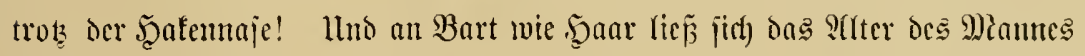

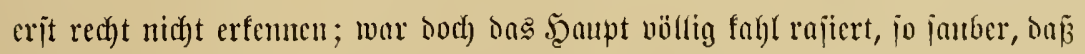

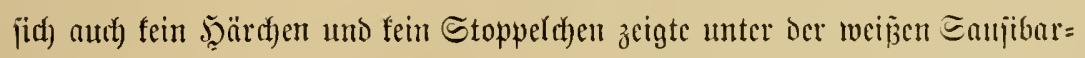

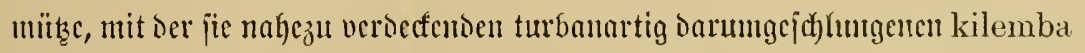

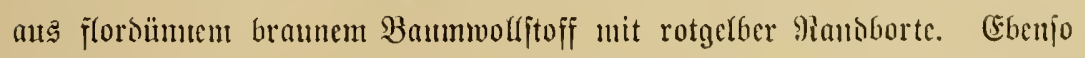
jorgïlttig war ber Schumurbart abrajiert; ber rvïrbevolle, breit auf bic Brujt faffenoc Bacfen= uno Simnbart aber war ganz offenbar rot gejürbt.

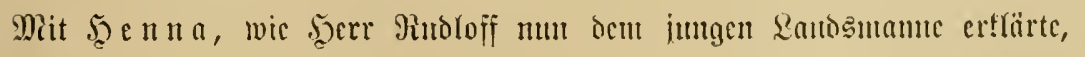
uno 3.war, แut bas

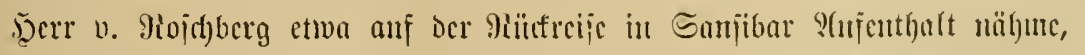

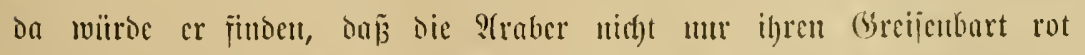

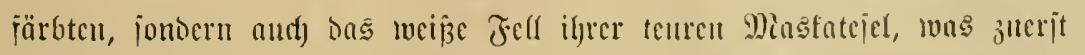

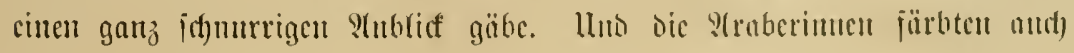




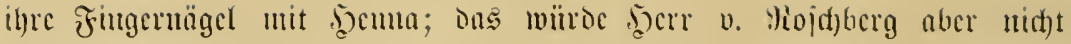
3n ichen friegen, on dic ?lrabcrimen, wentigitens in ocr Etadt, nic ans Dcm Şarem düriten.

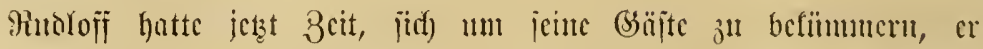

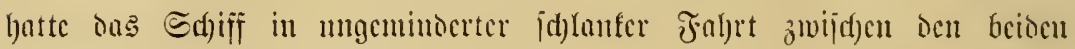

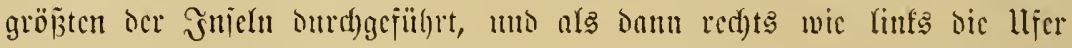

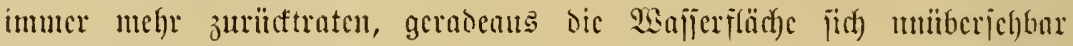

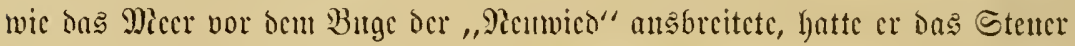

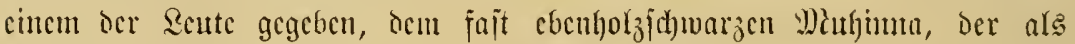

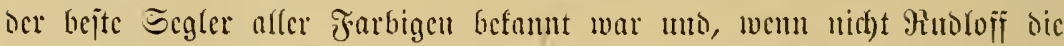
Fahrt jelfor mitmad)te, jowohl die Phan der Station wic aud dic

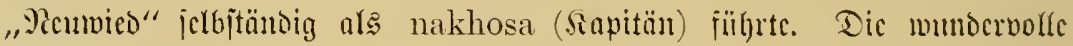
Sjeneric, bic jidf) vor bem jungen Dentid)en anjtat, ehe audf jeitlich bic

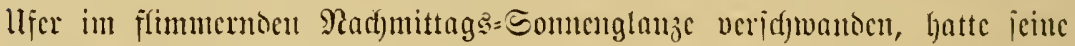
Bricfe balo von Dem langiam eime Bigarette nad) Der anderen Drehention

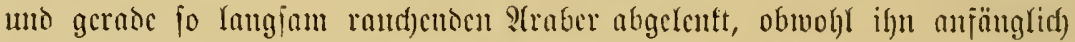

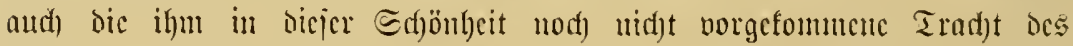

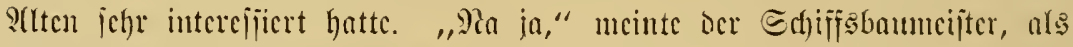
Bojdbery ibn gleid) nad) M(bgabe bes Stencrs über ben Mitpajijagier

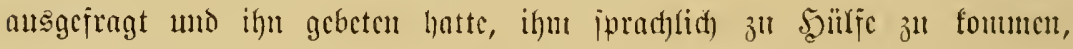

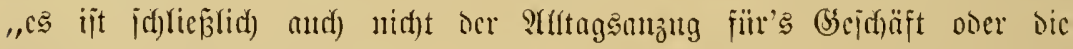

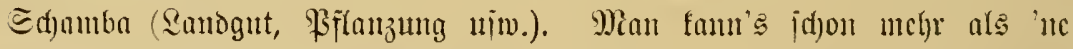

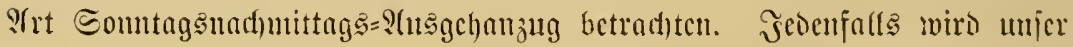

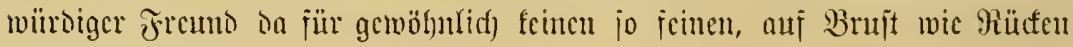

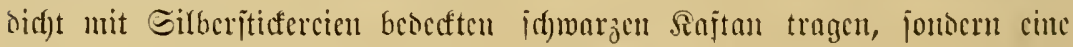

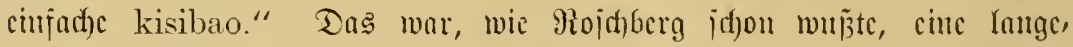

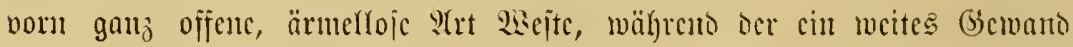

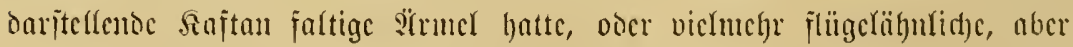

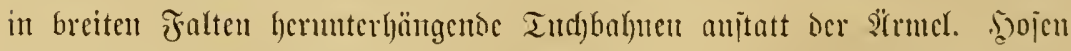

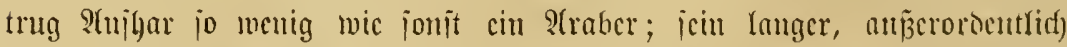

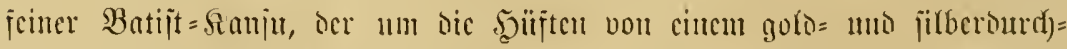
wirften Gürtcl icitgchalten wurbe, war mit émen Зipfel aujgerafift mo

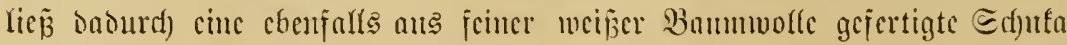

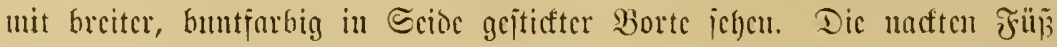




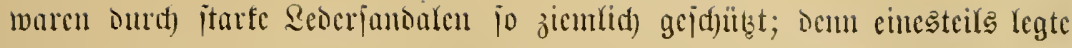

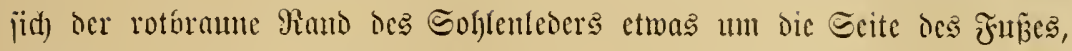

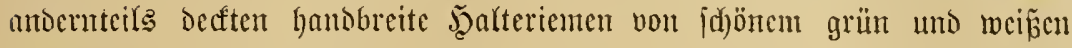

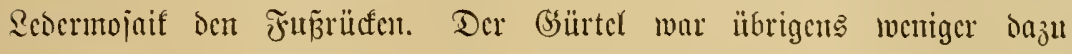

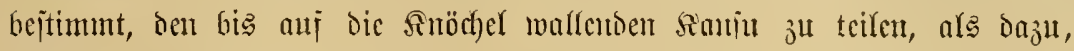

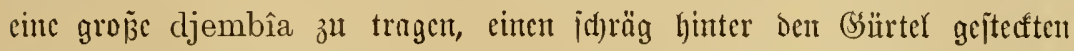

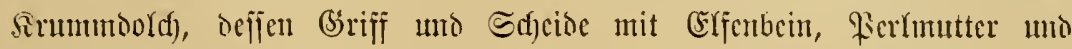

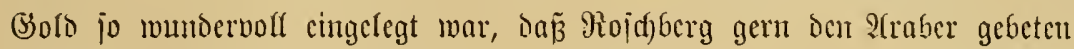

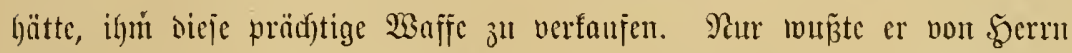

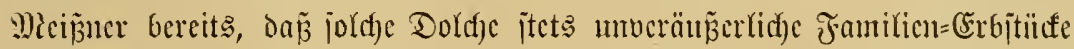
jint, uno cbenfo bie breiten geraben Sdjwerter ohne farariertange, ober

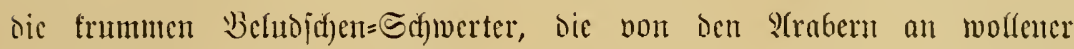

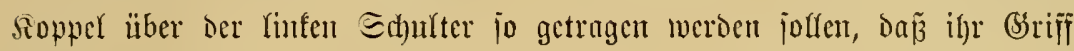

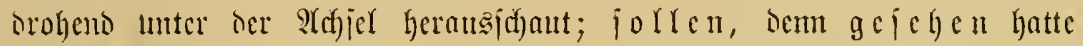

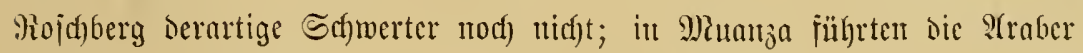

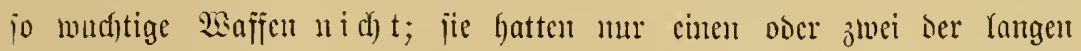

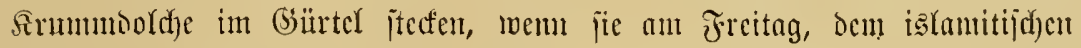

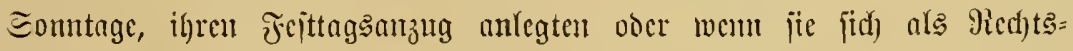

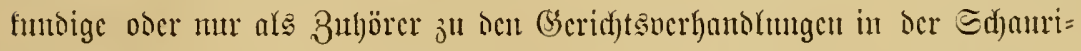

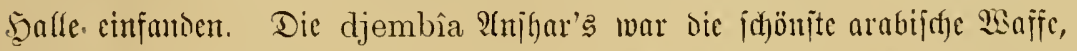

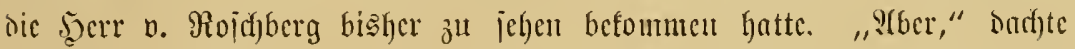

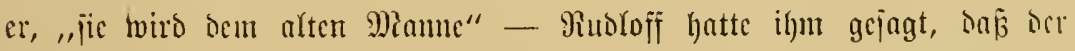

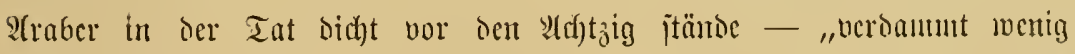

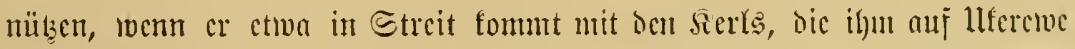

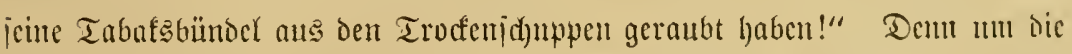

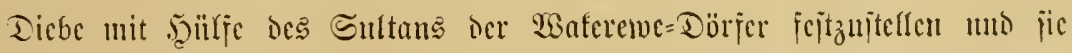
nor oen bana shauri nad) der Station zu bringen, futhr Stujbar bin

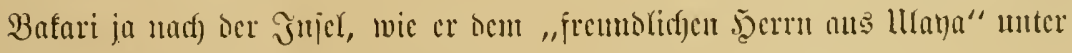

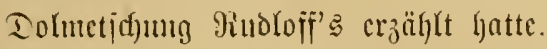

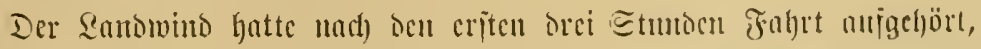

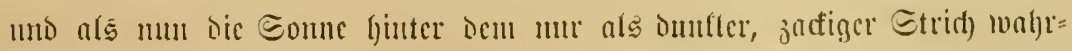

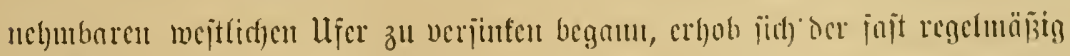

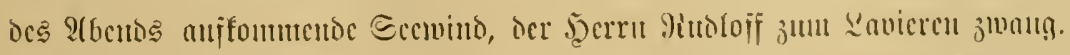

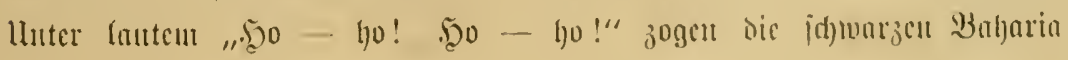




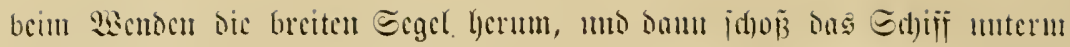

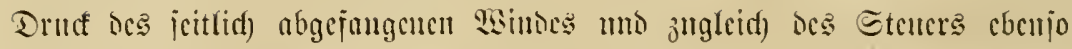

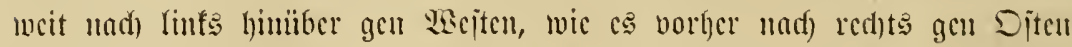
ju geflogen war, um uad) faum ciner Witertelitmbe vou ucueu nad) Diten jul wemtill.

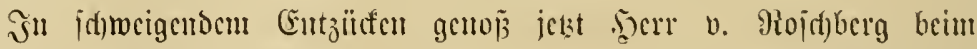

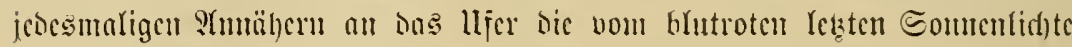
wic in Fencrsbrmijt getand)te Sjencric. Stellemucije traten Dic hicr im

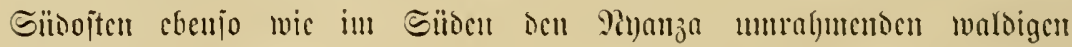

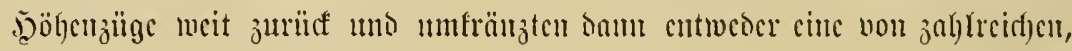

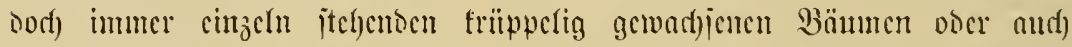

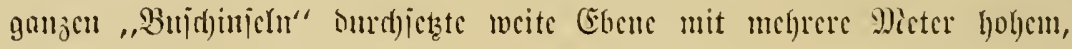

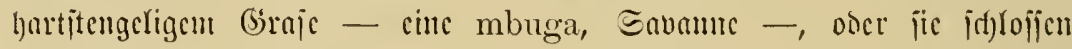

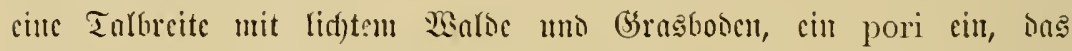

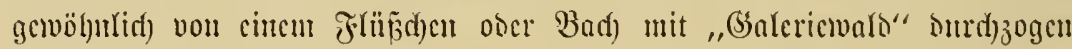

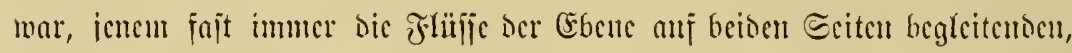

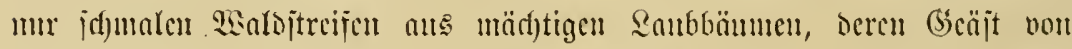

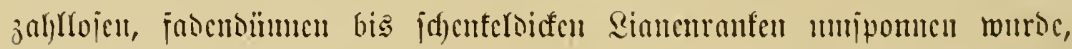

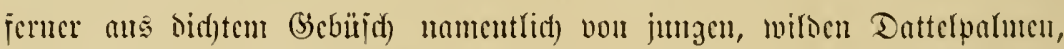

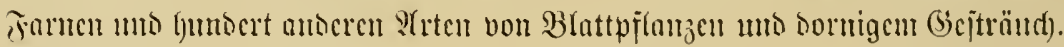

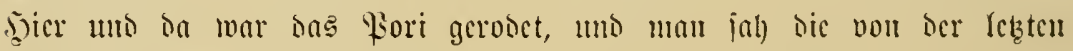
Somenglut beleud)teten Felser in oer Deähe fleiner Dörjer, beren ipitze

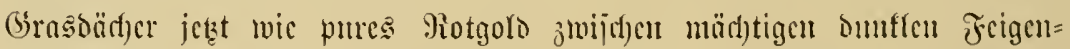

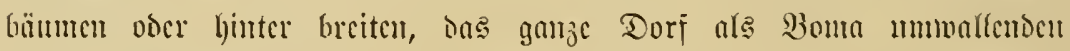

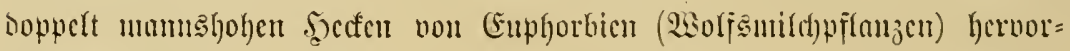

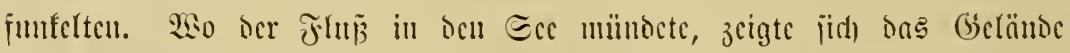

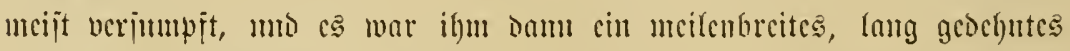

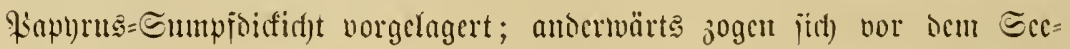

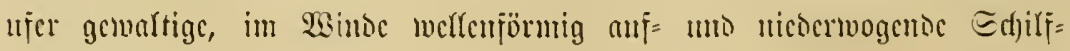

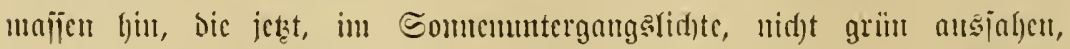

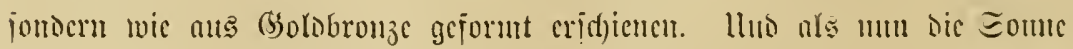

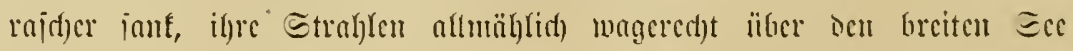

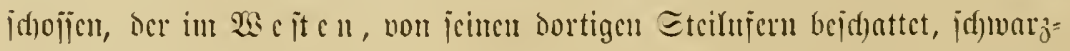

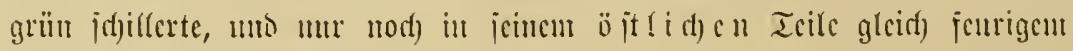


Bhut mogte, da prallte das rotblinfente sidft auj die glatten Exfyiljblätter

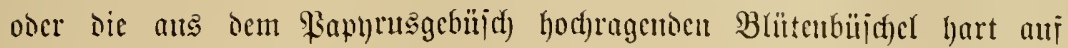

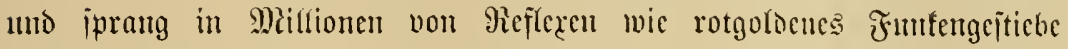

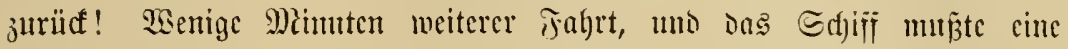
S(nzahl rotglühender, iteil aus ocn Fluten aufragenier idfunaler Ferlen umjahren, Dic wie ichlanfe Türme, wie ungcrüge Shelistcn unt jelbit mie

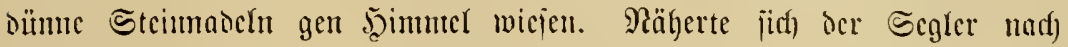

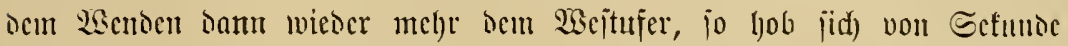

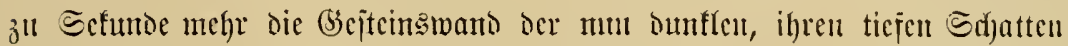

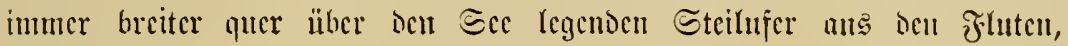

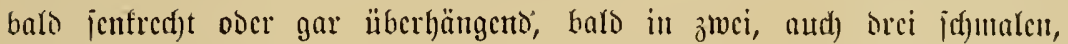

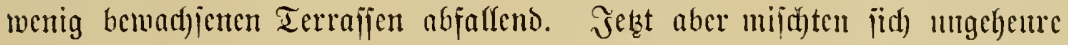
j(f)wejelge(be uno bald Dantad) jeltjant hellgrüne હtrablen it dos jeurige

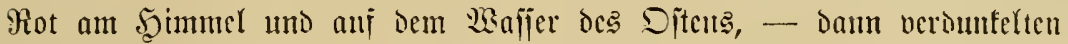

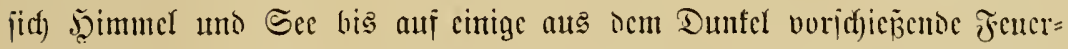

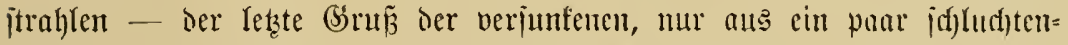

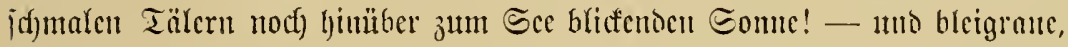
rajd) Dunfler unto Dunfler werbente Dämmerung hüllte bic chen nod) io

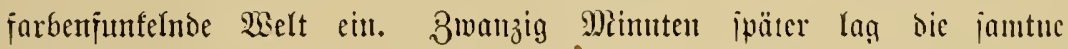

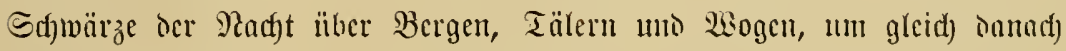

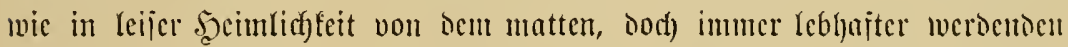

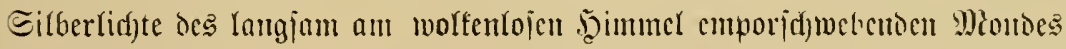

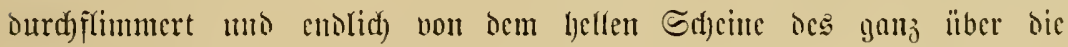

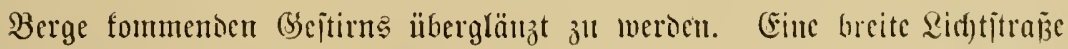
zog (iid) mun über oen leidgt nogenden See, uno wic cill Tranmbilo glitt in ifrem Sdjimmer das Segelidjiff jeinem Bicłe entgegen!

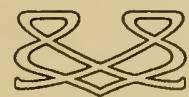




\section{Viertes Kapitel.}

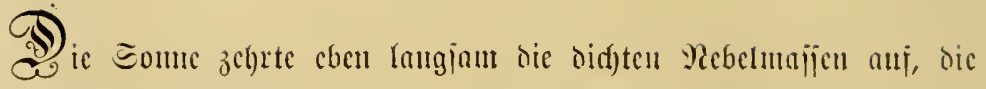

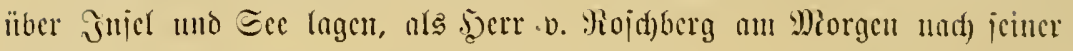

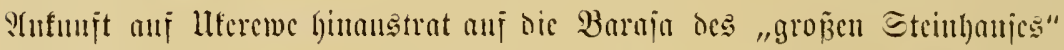

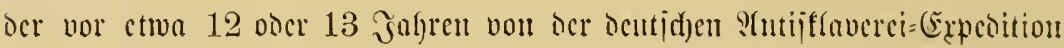

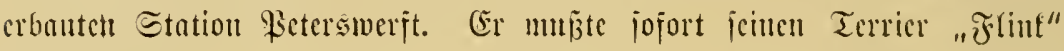

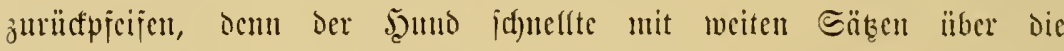
Berantotreppe in Den jogenamente "Barten" und untreijte belfend cin

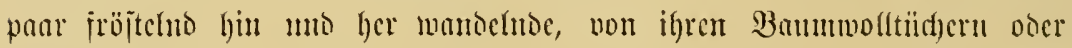

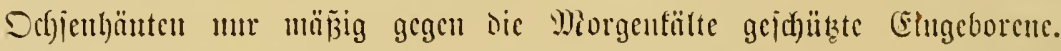

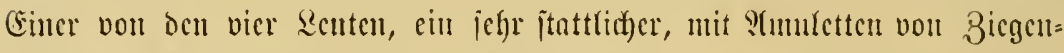

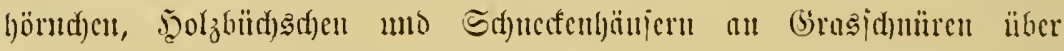
uno ïber befä̈rgter Manm von beinabe curopäijthen (Sejict)tรjü̈gen aber

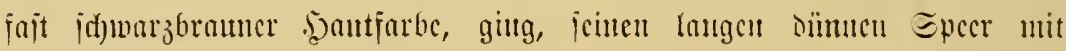

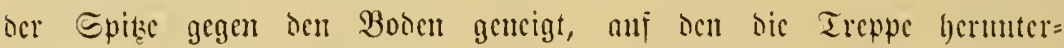

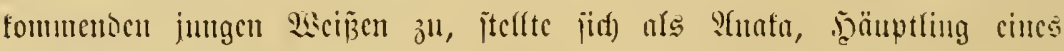

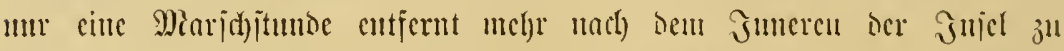

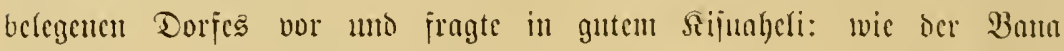
Viojd)chegg gejd)lafen babe?

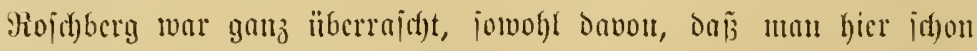

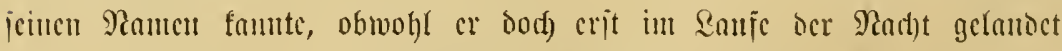

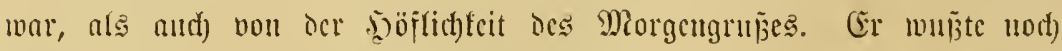

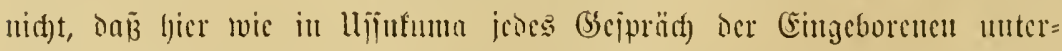

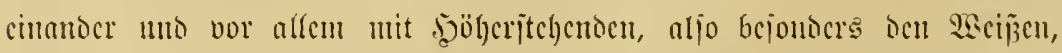

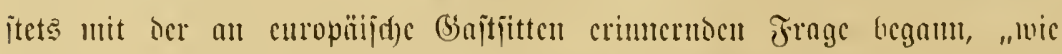

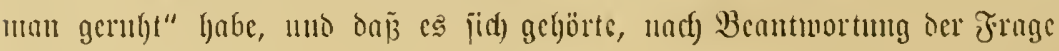




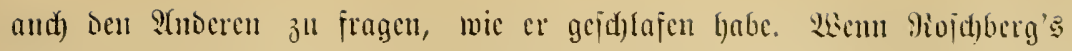
Spradyfenntuiffe id)on fo meit gereid)t hätten, mürde er haben jagen

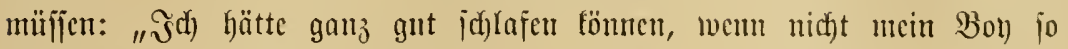

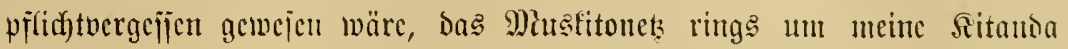

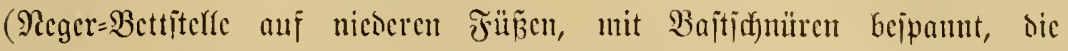

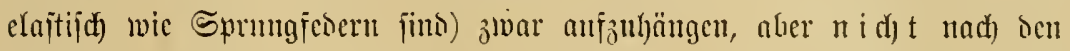

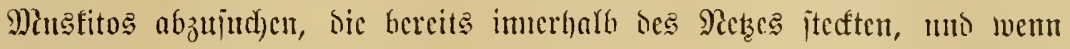

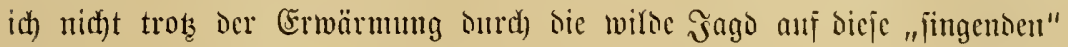

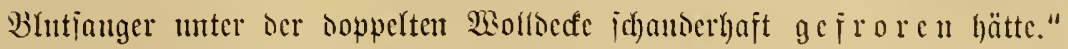

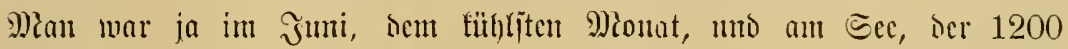
Meter ïber Micreshühe liegt, founte es gegen Morgen ganj bitterlid) falt merden. SHe Miangel an Epradjfertigfeit blieb indejfen toem jungen Miam nichts übrig, ale „Mbaya, mbaya sana“ zu jagen, ,ifhlecht, fehr

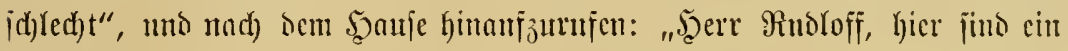
paar Sd)warze, die augenid)einlich zu $\mathfrak{\Im} \mathfrak{h} \mathfrak{n} \mathfrak{e}$ n woflen."

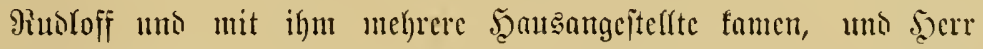

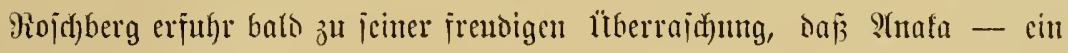

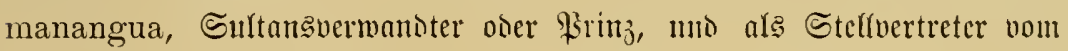
Temmi eingejetzter Dorffultan - mit ben ihn begleitenten wanyampara

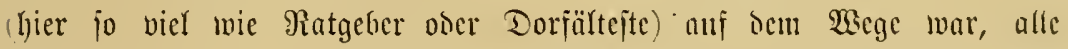

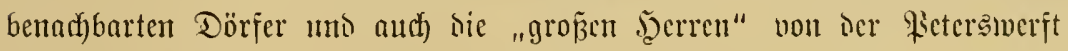

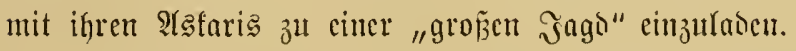

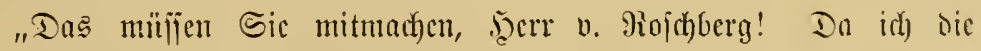
Than nad) Mitanza idjidfen muŕ, fömmen wir butrdy ciu paur Zcilcu

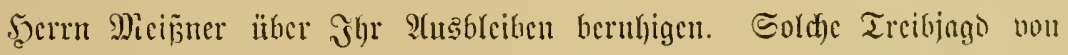

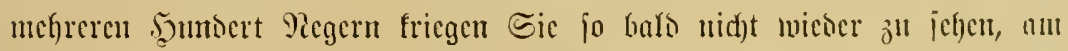
aflerwenigiten cine Treibjago im Hrwarse."

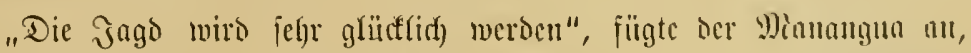

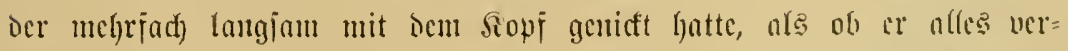

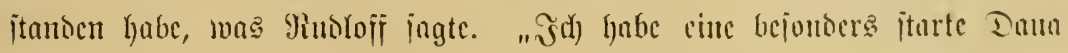

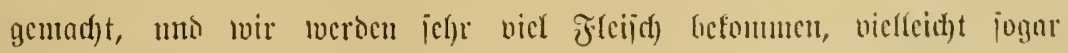

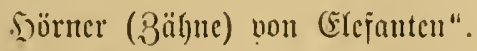

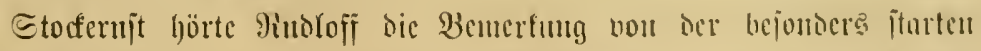

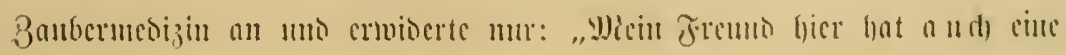




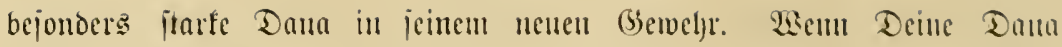
uns an bie (Elejanten bringt, daun bringen wir jie aud) jïd)er ju falle."

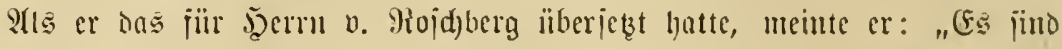

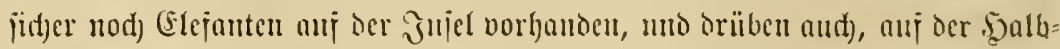

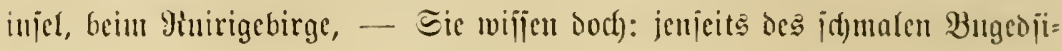

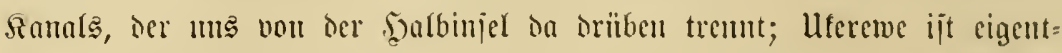

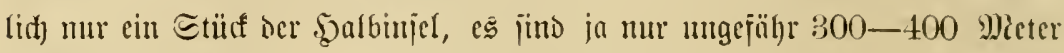

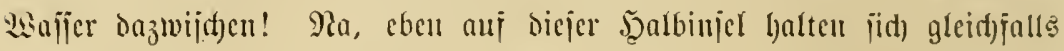
Exejanten auj, als Standmild. Stber bie hier anj ber Jnjiel jüt, bie

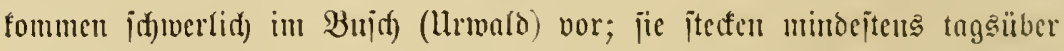

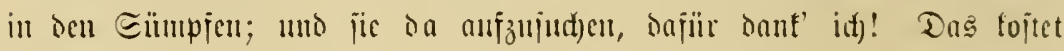
audf) fidferlidf) melgrere Tage 3cit."

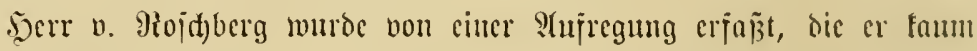

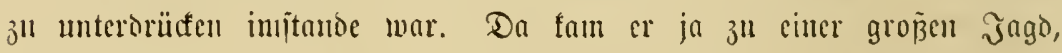

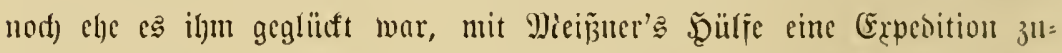

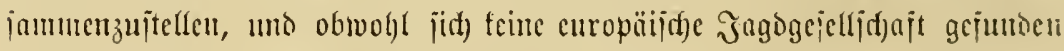

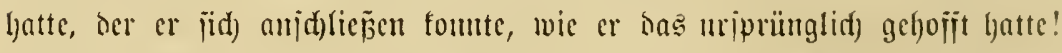

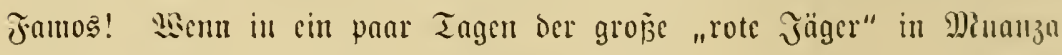

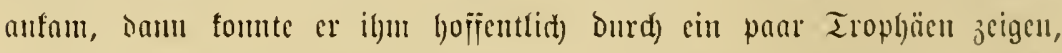

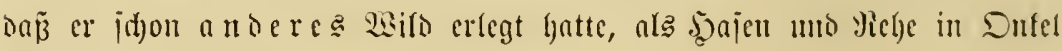

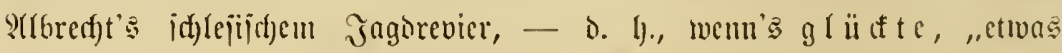
Drocntlid)es" ju jtrecten! Mit "uem 2(ntilopenget)örn ober jonjtigem

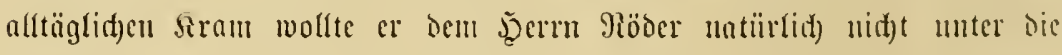

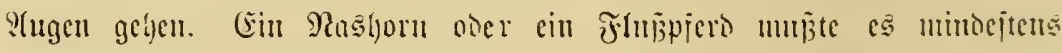
jein, wenu er beu Manue aud) unt cinigermajen iunoniercu wollte!

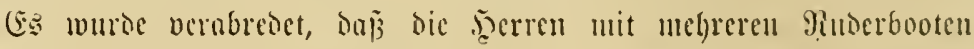

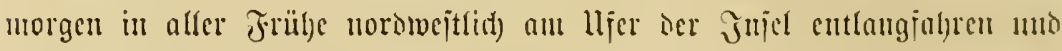

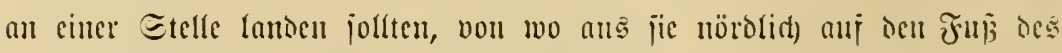

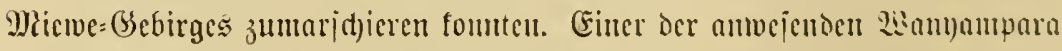
jollte jie an ber Raubungajtelle erwarten umo mit einigen Trögeru it dos Jagdgebiet geleiten.

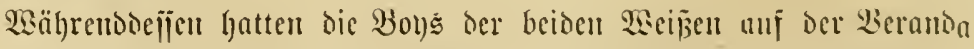

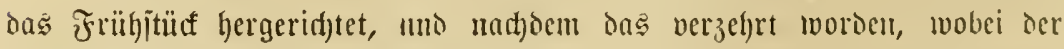
Dorfiultan uno ieine Begleiter mit cinem bei ibnen reihum gehentou 


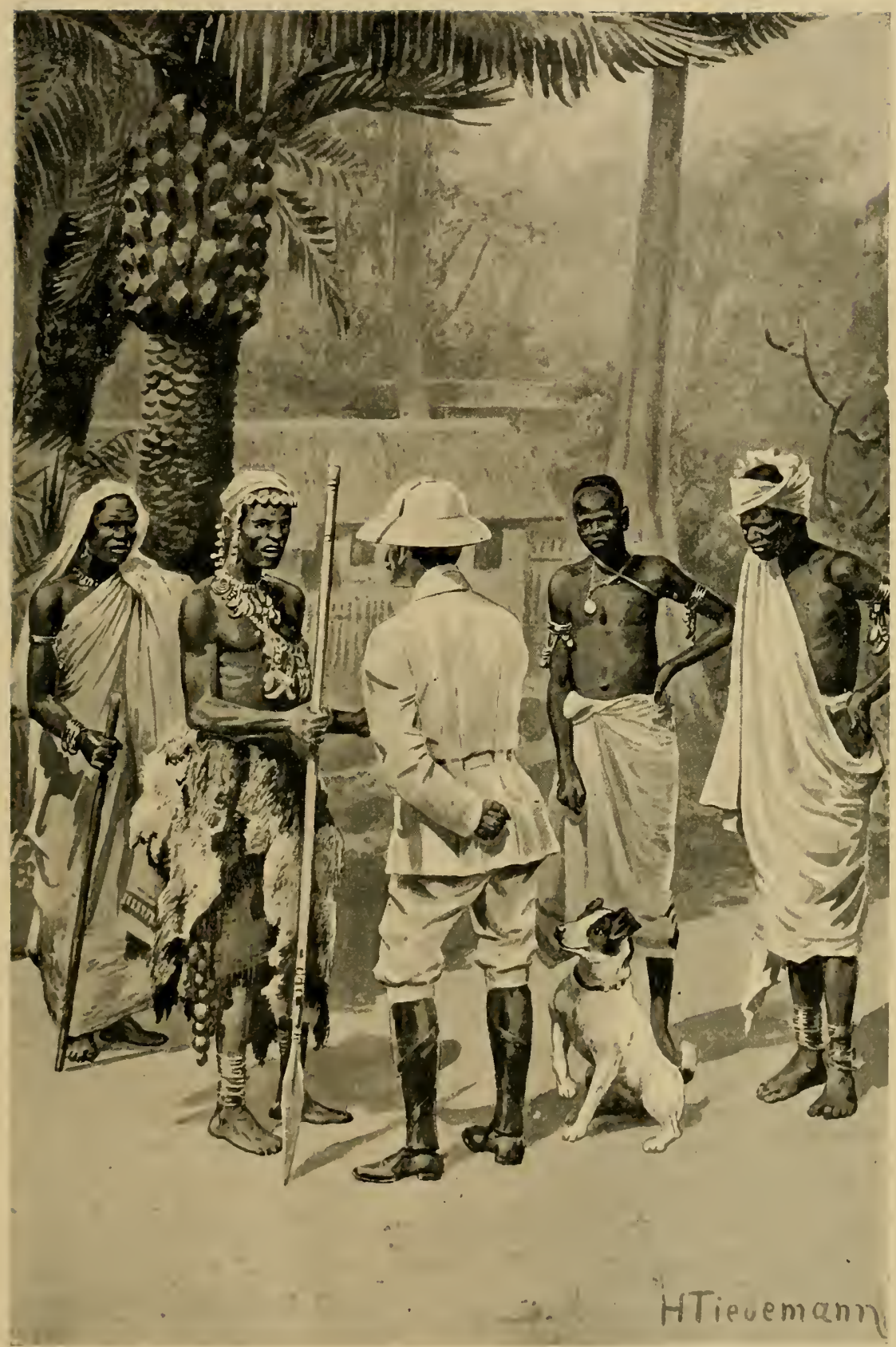

.... und fragte in gutem Kifuabeli: wie der Bana Rof(hebegy gefchlafen habe? (Ecite 92.) 



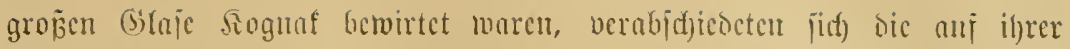

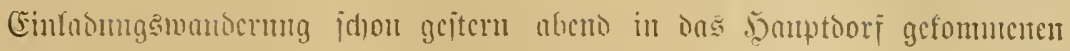

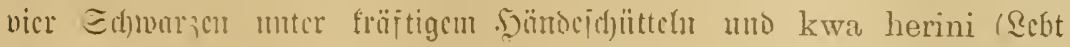

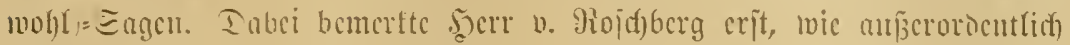

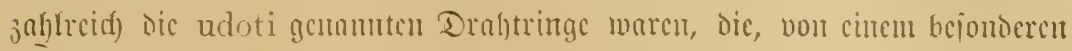

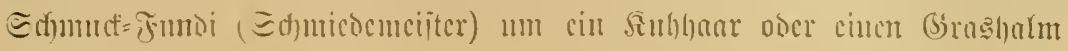

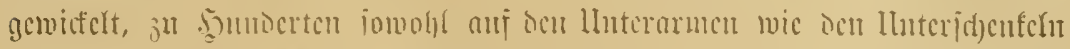

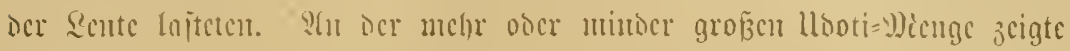
cben oce Defereme iemen :licid)tum, - jomeit ar nodi) nidjt vou Ental)cli=

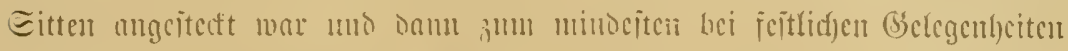

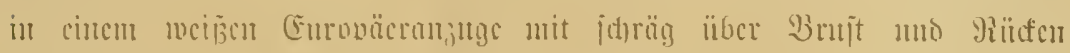

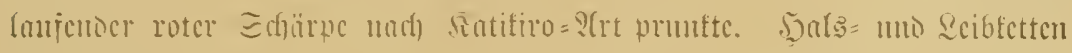

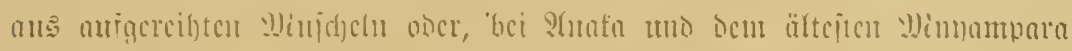

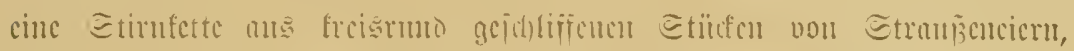

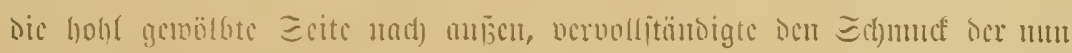

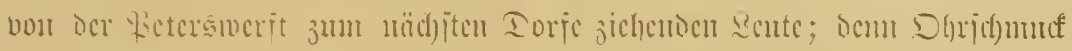

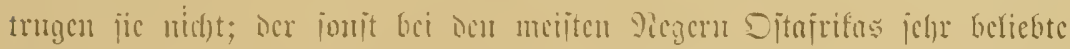

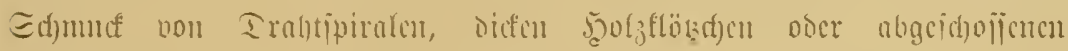

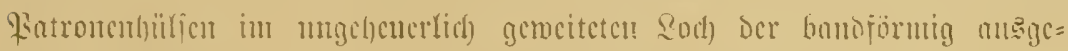

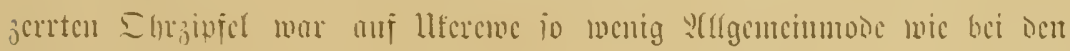
然nijutumn.

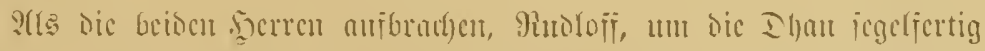
ju mad)en, unt gioj(f)berg, um jief) die Srtichajt uno inre llutgebung

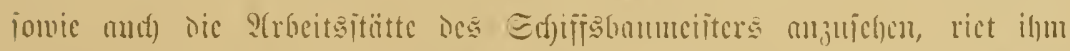

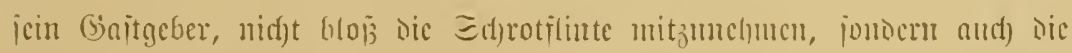

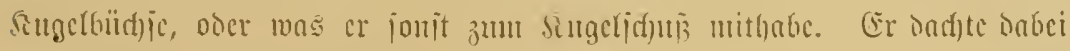

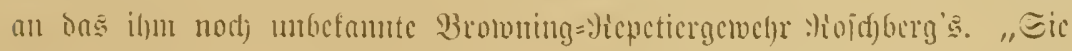

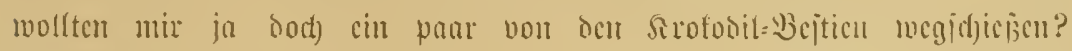
ঐa aljo!"

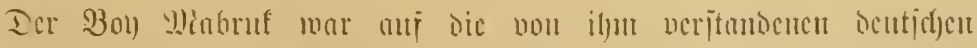

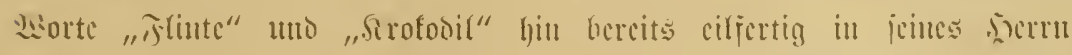

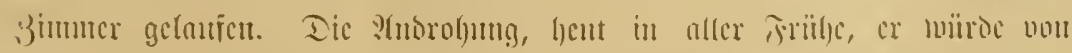

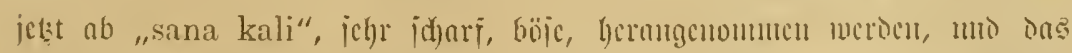

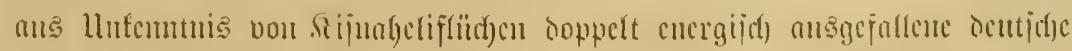




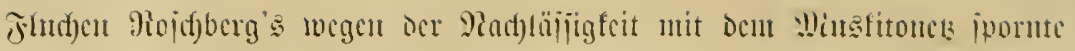

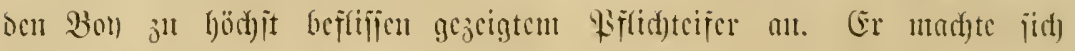

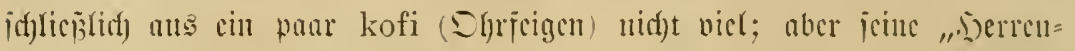

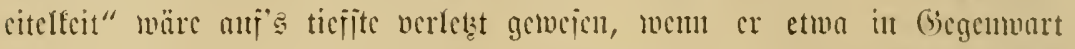
ocr wout ifm io verad)teten ïfrigen Edfwarjen, in jemen shtgen alles

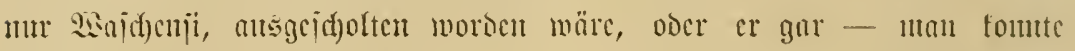

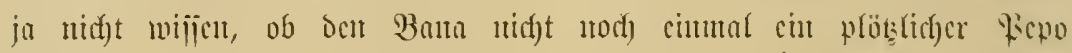

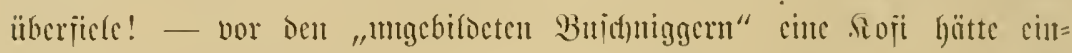

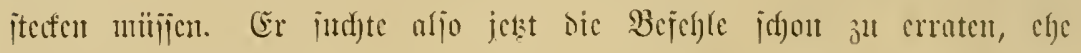
jic ertcilt wurben, mo fau ichr rajid mit ben drei Gemehren Bunta

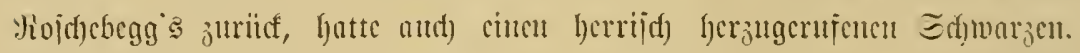

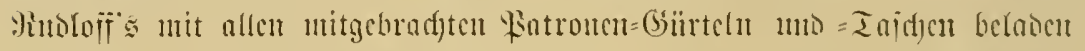

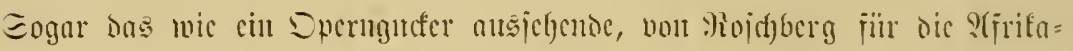

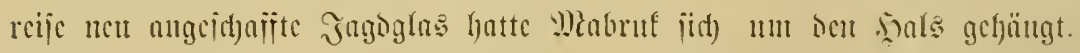

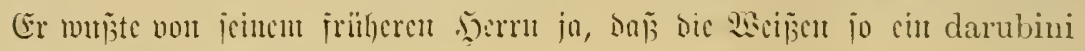
anj Der Jago gechrantdect.

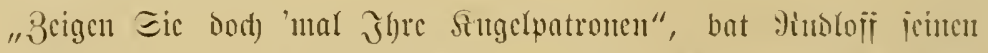

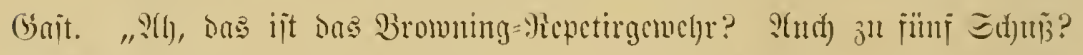

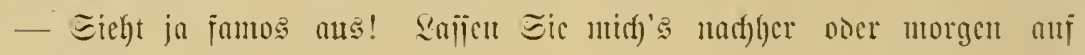

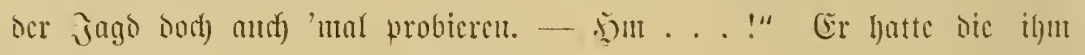

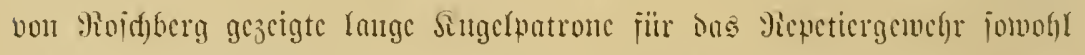

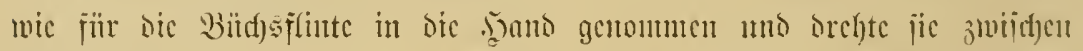

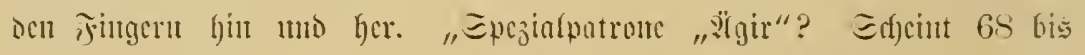

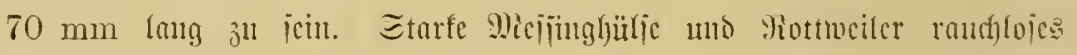

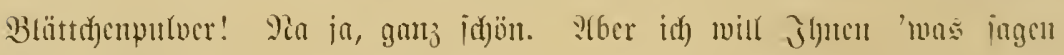

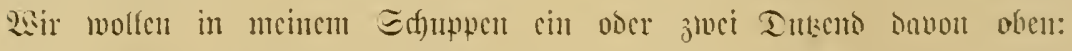

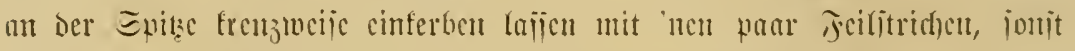

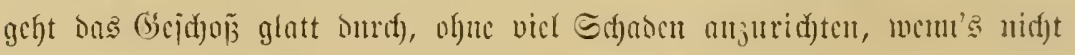

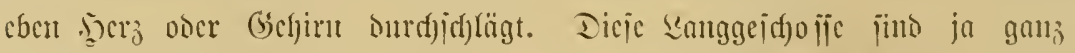

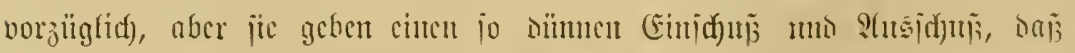

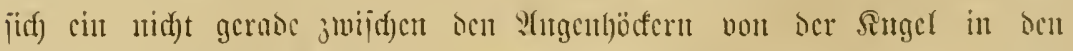

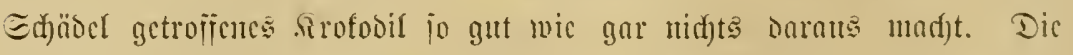

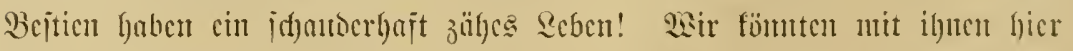

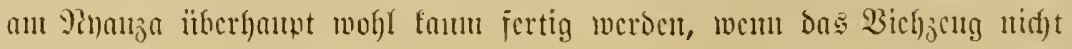




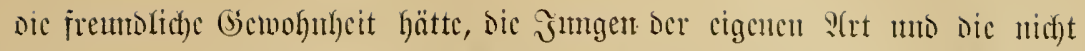

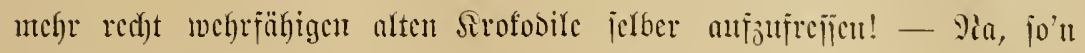

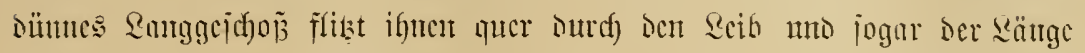

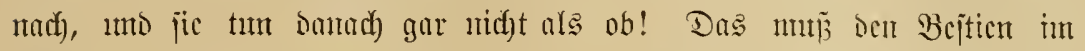

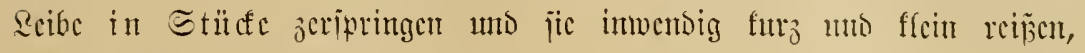
menu's fiecteu joll!"

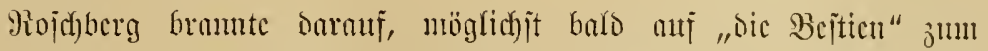

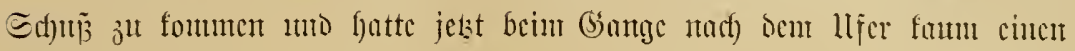

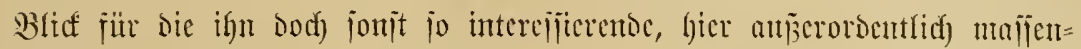

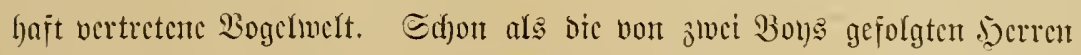

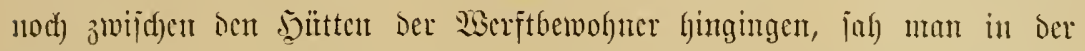

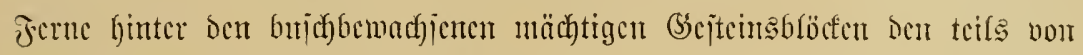

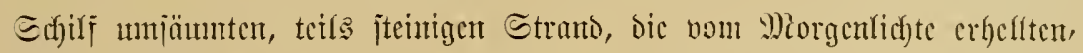

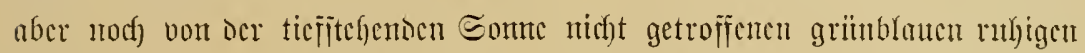

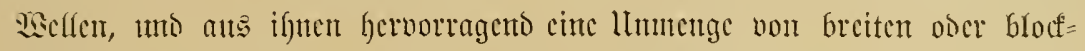

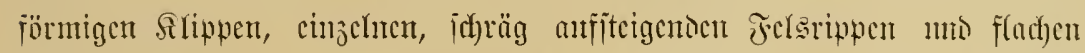

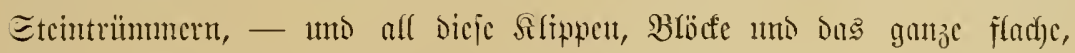

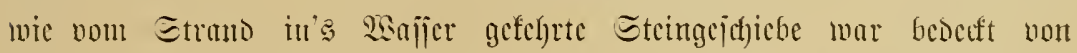

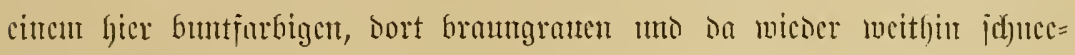

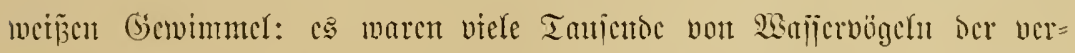

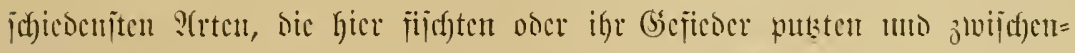

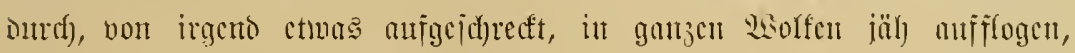

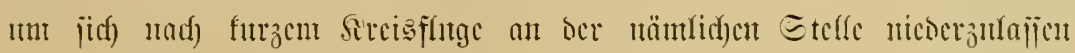

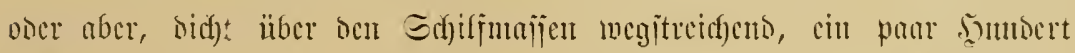

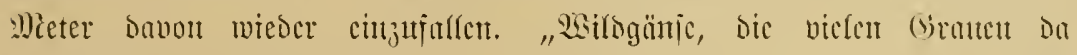

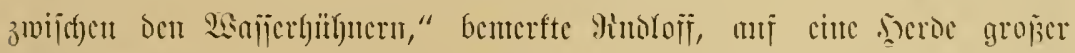

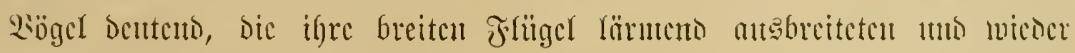

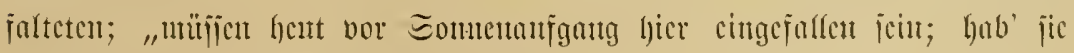
mut jeften un bicje Etumio hicr gejehen."

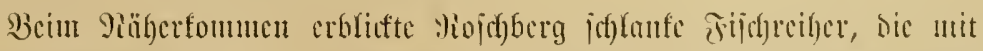

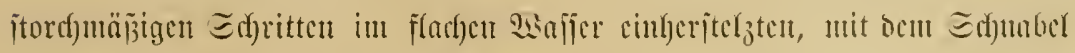

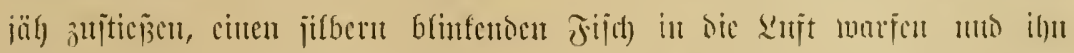

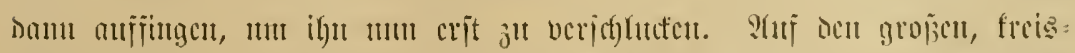

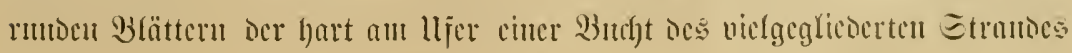




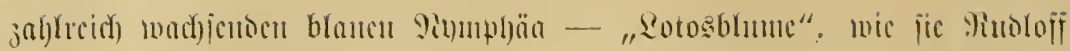

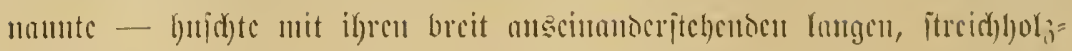

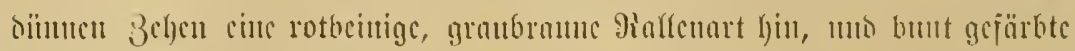

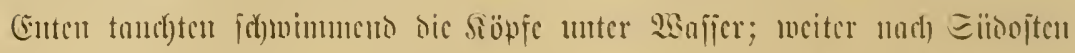

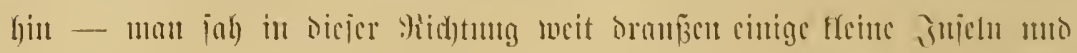

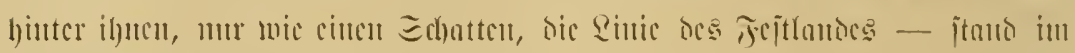

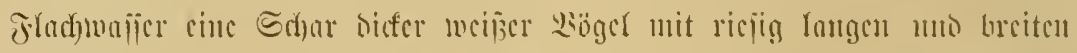

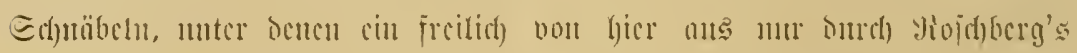

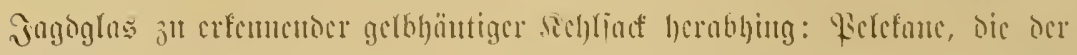

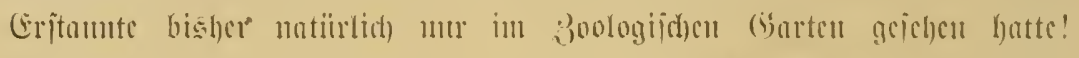

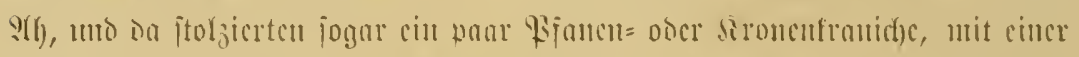

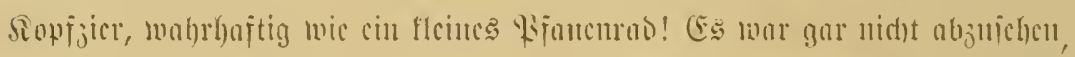

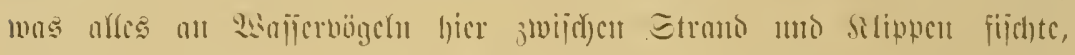

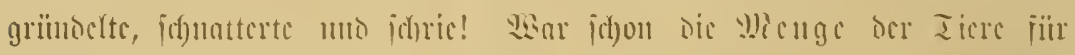

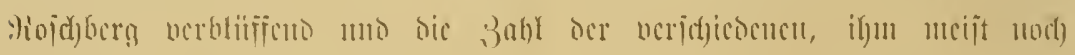

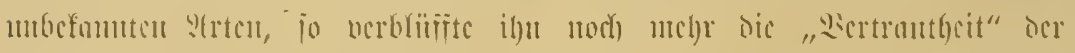

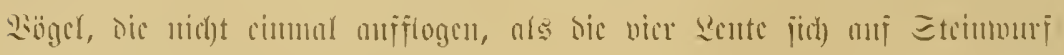
nä̉) dout Etrumbe genül)ort hatten.

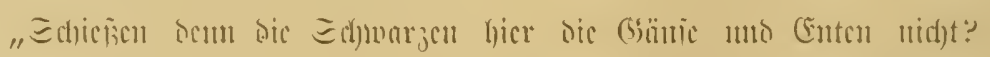

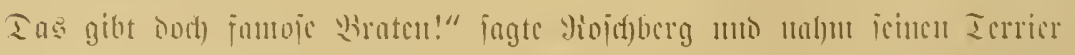

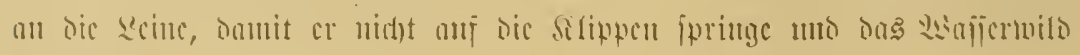
verif(t)cutic)c.

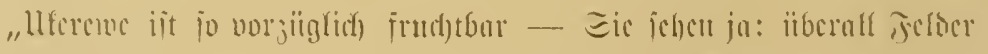

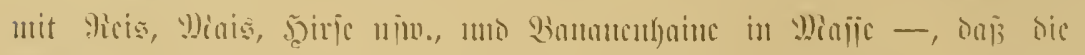

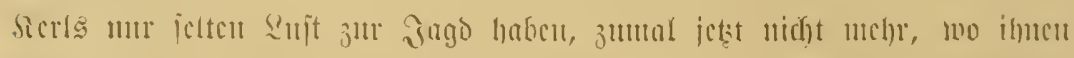

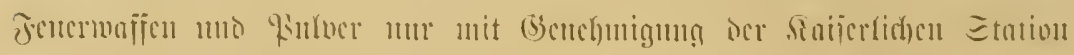

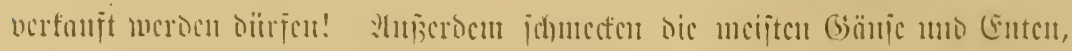

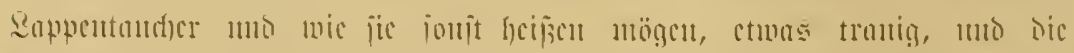

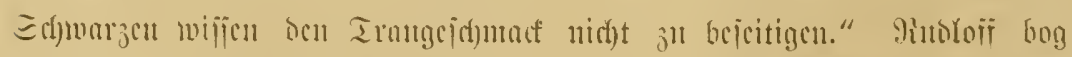

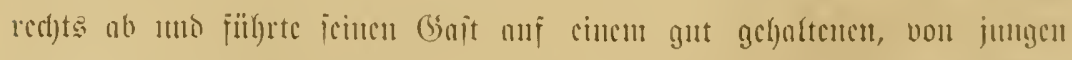

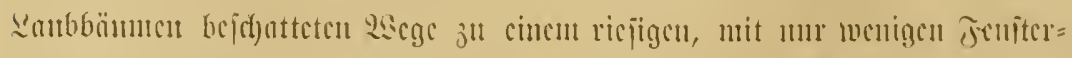

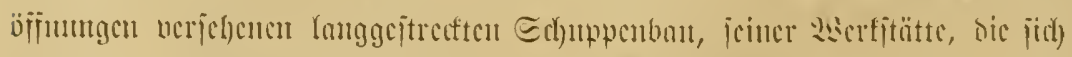

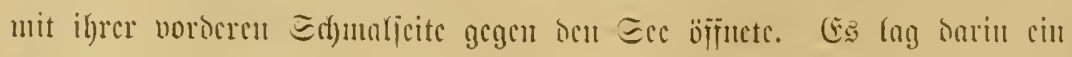

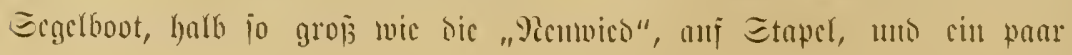




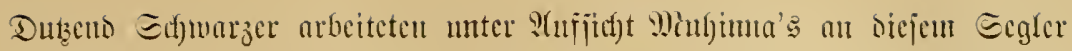

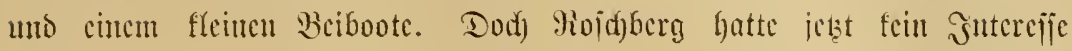

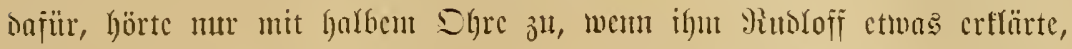

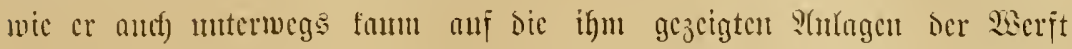

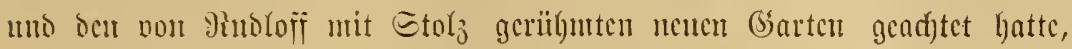

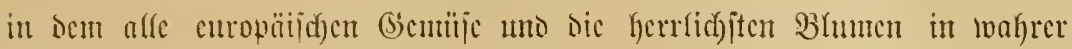

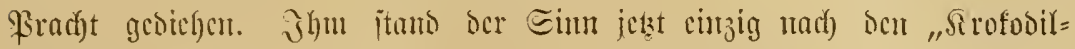

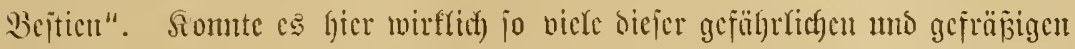

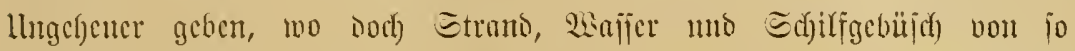

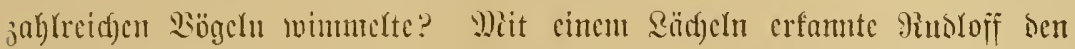

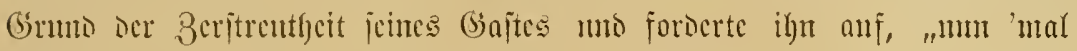

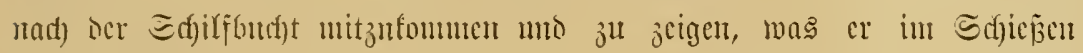
reijtcn fömul".

Pad) cincr funpen halfen Stmme itanden jie an einer Steffe des

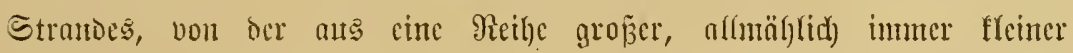

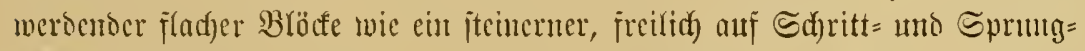

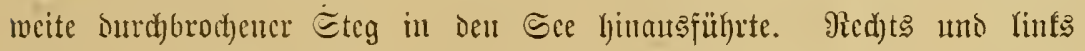

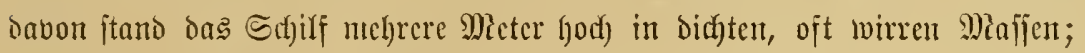

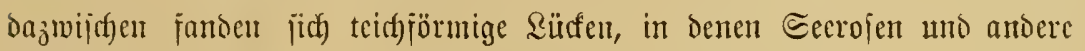

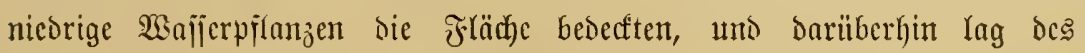

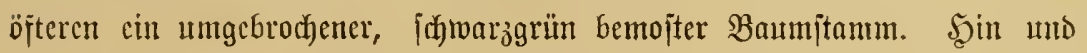

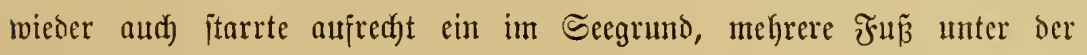

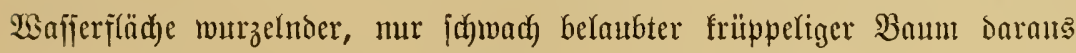

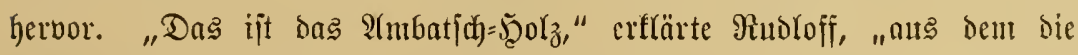
Wafereme ilgre jumalen, buntbemalten $\Xi$ dillo madjten. Notabene, wohl bos einzige ફolz hier, bas im Wajןer nidgt unterjinft; es ijt ebest nod) leidter als Sorf. Sie fömnten foldh einen Baumitanm mit ausgepitreftem S(rme wageredyt bor jich hingalten in bie \&uft!“

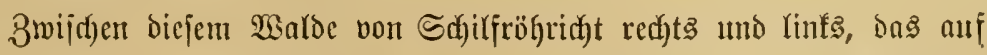
ganze Strecfen niebergebrod)en war, als hätten fidj) ivirflid) Eelefanten hier gejuhlt, fonnte man über bie Steinblöcfe fort wie durd) cine fdumale Sd)luth) auj den See hinansbliden; uno dort brauneen, gauz vorute, vor

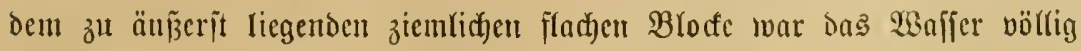

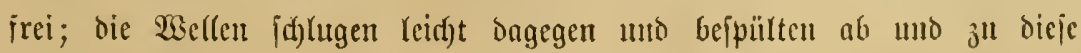




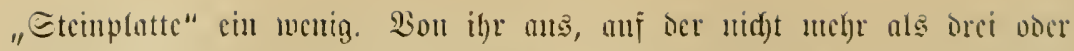
vice Ferjouten ohue gegenjeitige Becintrüd)tigung ïtchen fomuten, piflegten

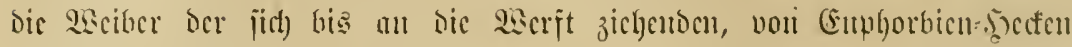

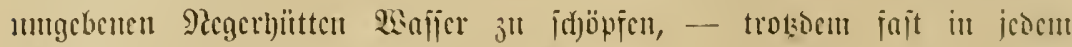

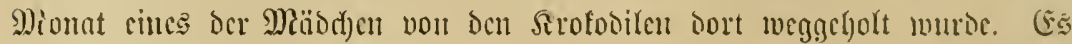

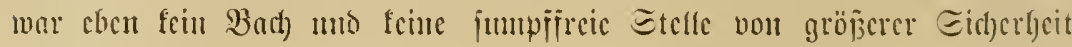
in ber Pä̈lyc.

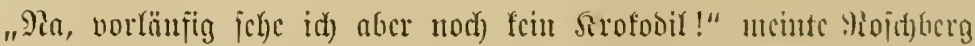

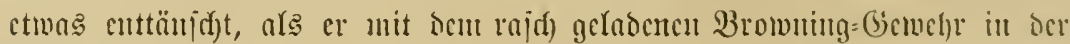

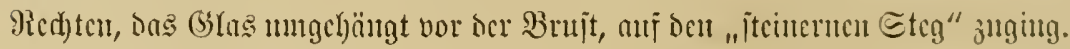

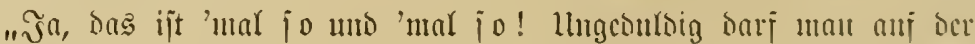

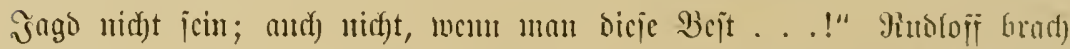

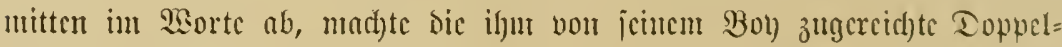

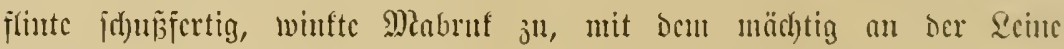

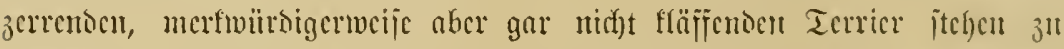

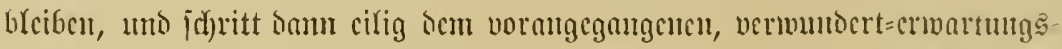

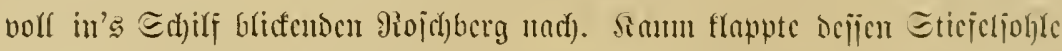
nuf ben nad) fleinem Eprunge errecid)tent britten Blocte, io gub's linfes

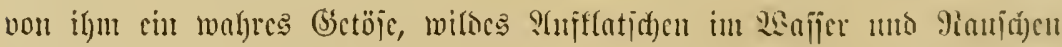

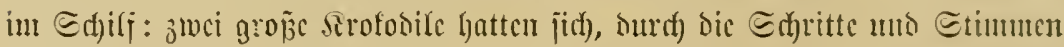

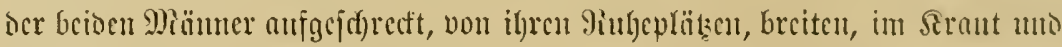

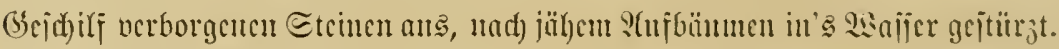

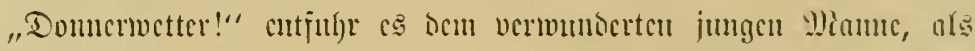

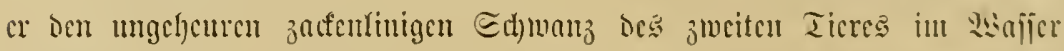

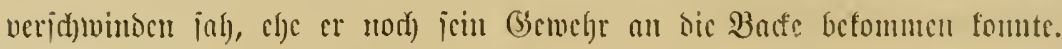

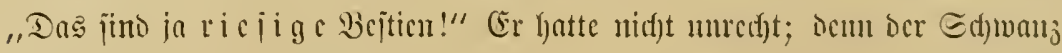
allein war offenbur länger als das gauze "gitejenftotobil", bus cr cumnal

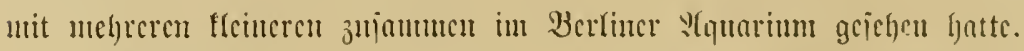

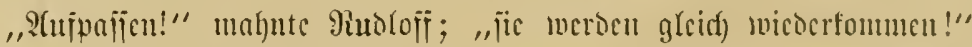

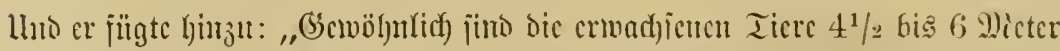

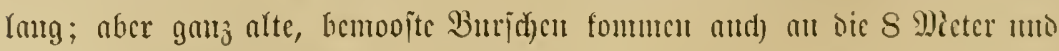
jerbjt beträd)tliç) Darïbcr!" Daun fing $\mathfrak{c r}$ ant, mit cinem fingetlangen

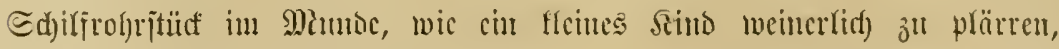

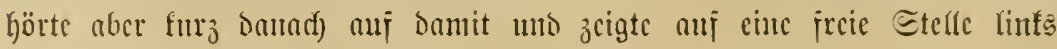




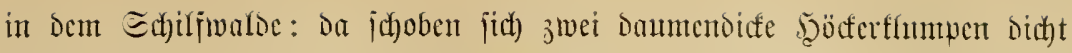
nefoucinantor aus som leije bewegten

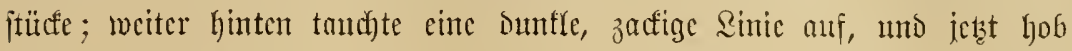

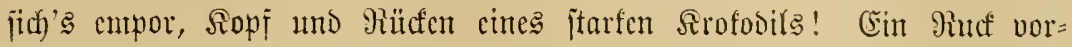

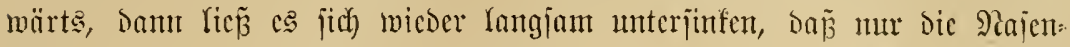

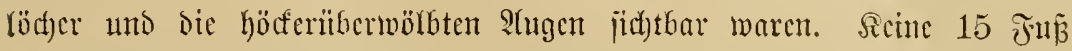
von bem "Trittiteine" entfernt blieb das Tier fo, fajt ganz bon 2 safier

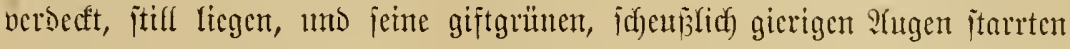

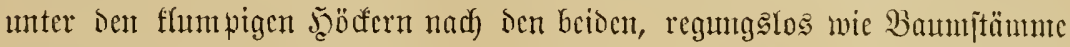
itchen bleibenden Mänmern. Stber ichon nad) cinter Nimute völfigiter

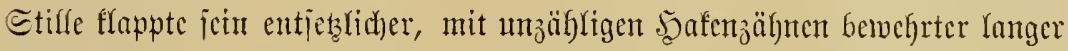

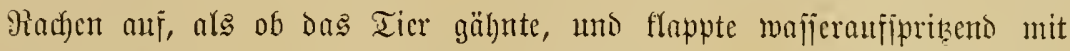
itarfem, ,frnact!" mieder zujammen, während der gezacfte \$anzerrü fen jich

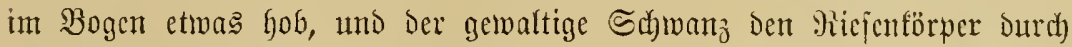
cinc leichte Bemegung einen Meter weiter vortrieb, fơhräg auf bic Etcine

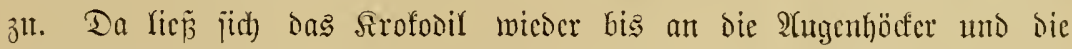

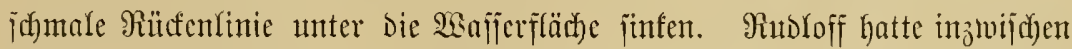

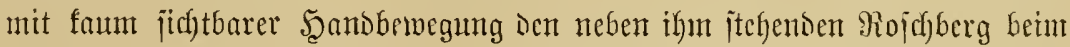

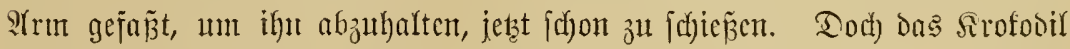

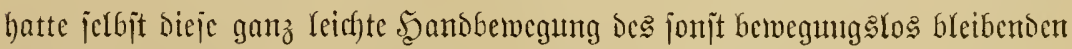

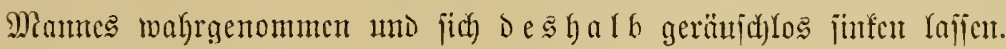

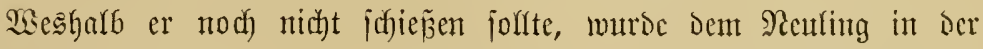
näbjiten Mimute ffar: von zmei Eeiten idfwammen Sirofobile beran, un

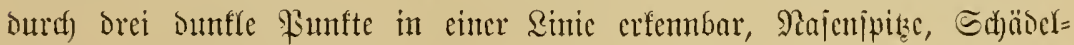

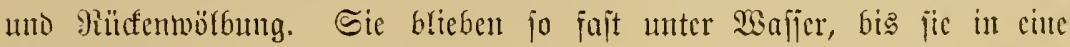

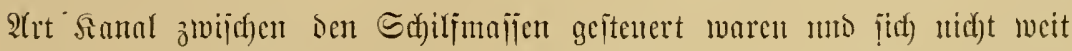
von ocm erijten firotodil in freicrem Wafjer ctroas höher heranshobcu.

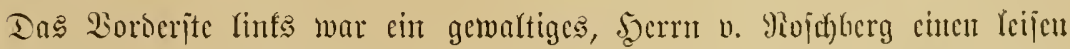

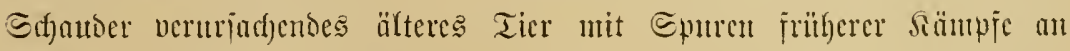

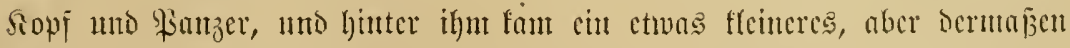

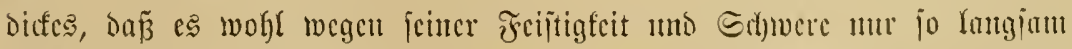

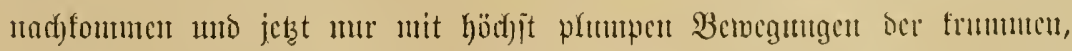

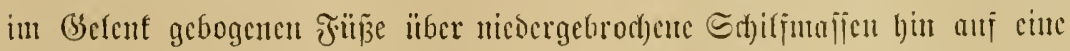

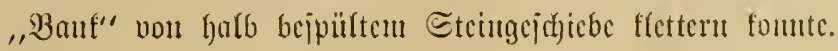




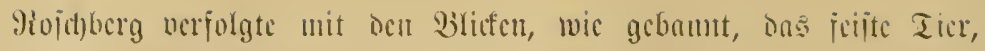

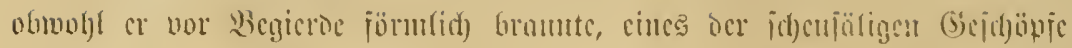

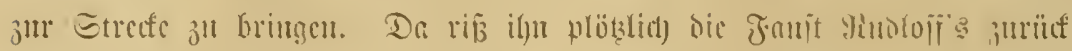

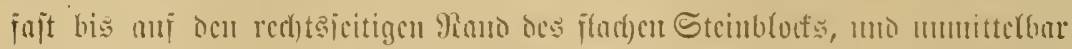

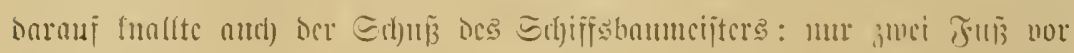

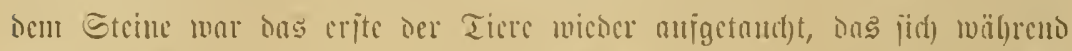

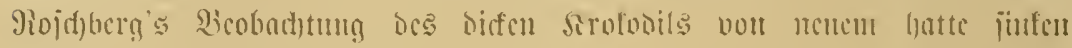

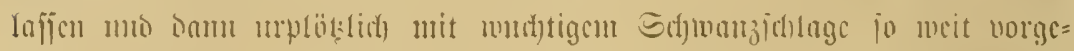

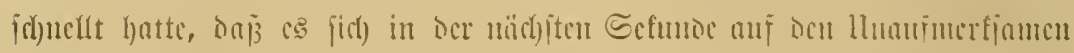

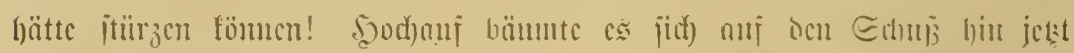

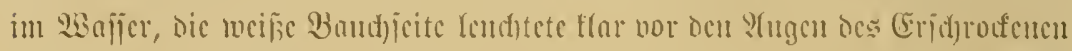

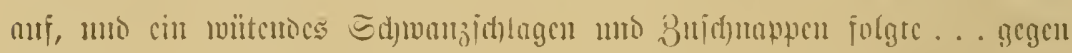

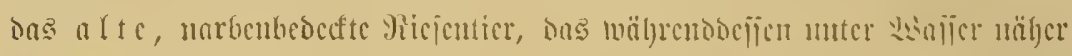

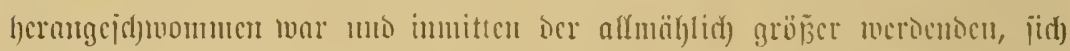

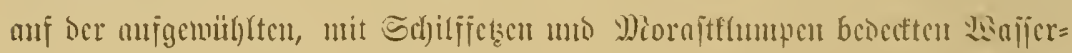

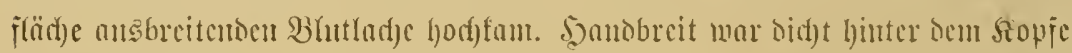

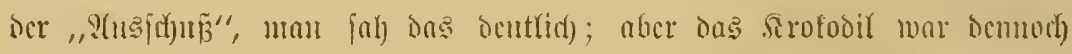

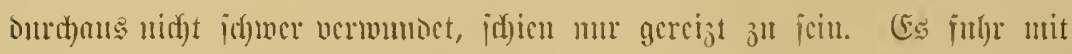

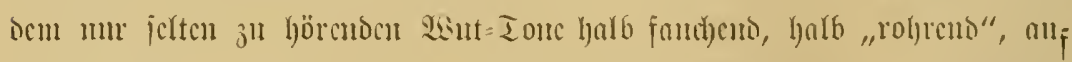

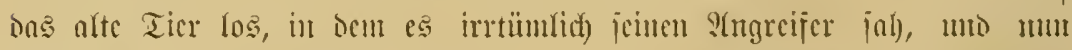

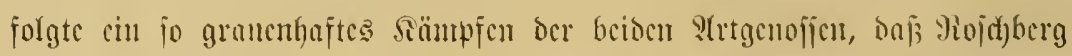

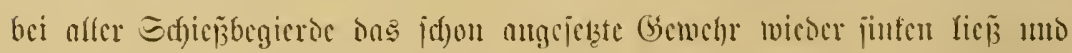

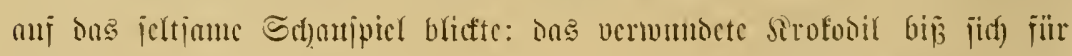

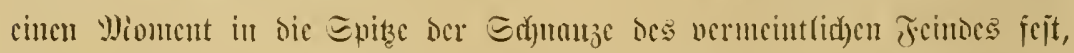

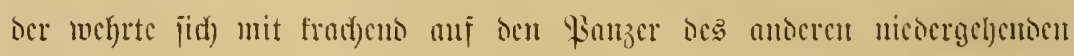

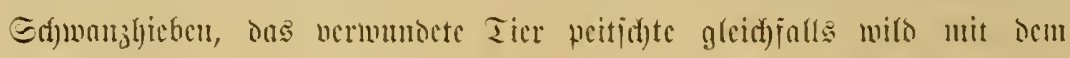

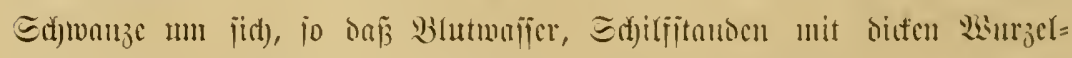

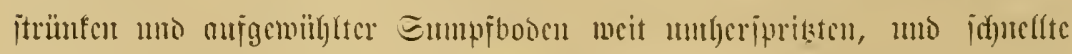

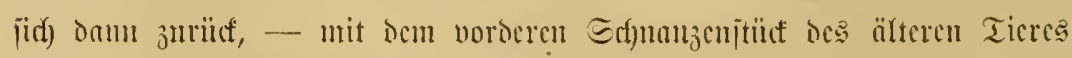

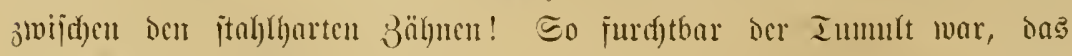

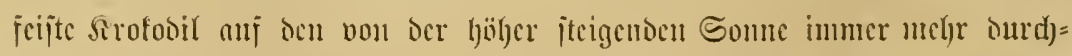

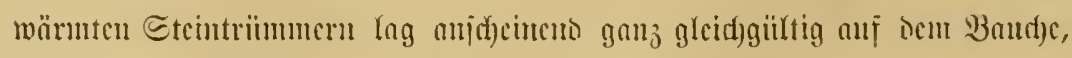

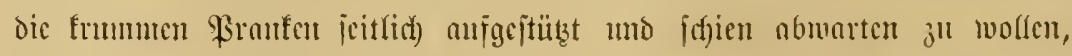

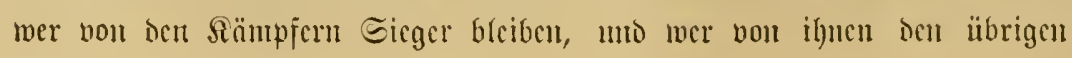




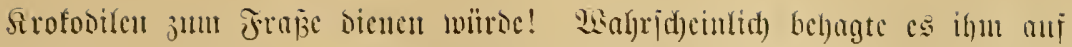

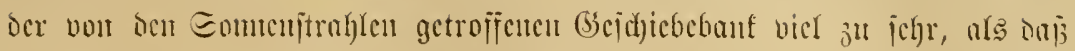
es teifurchmen modjte an ocm Simute. Dic anocren beisen aber bificu

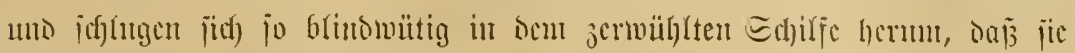

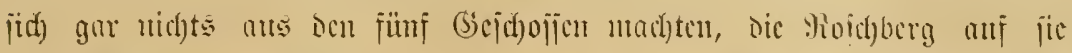

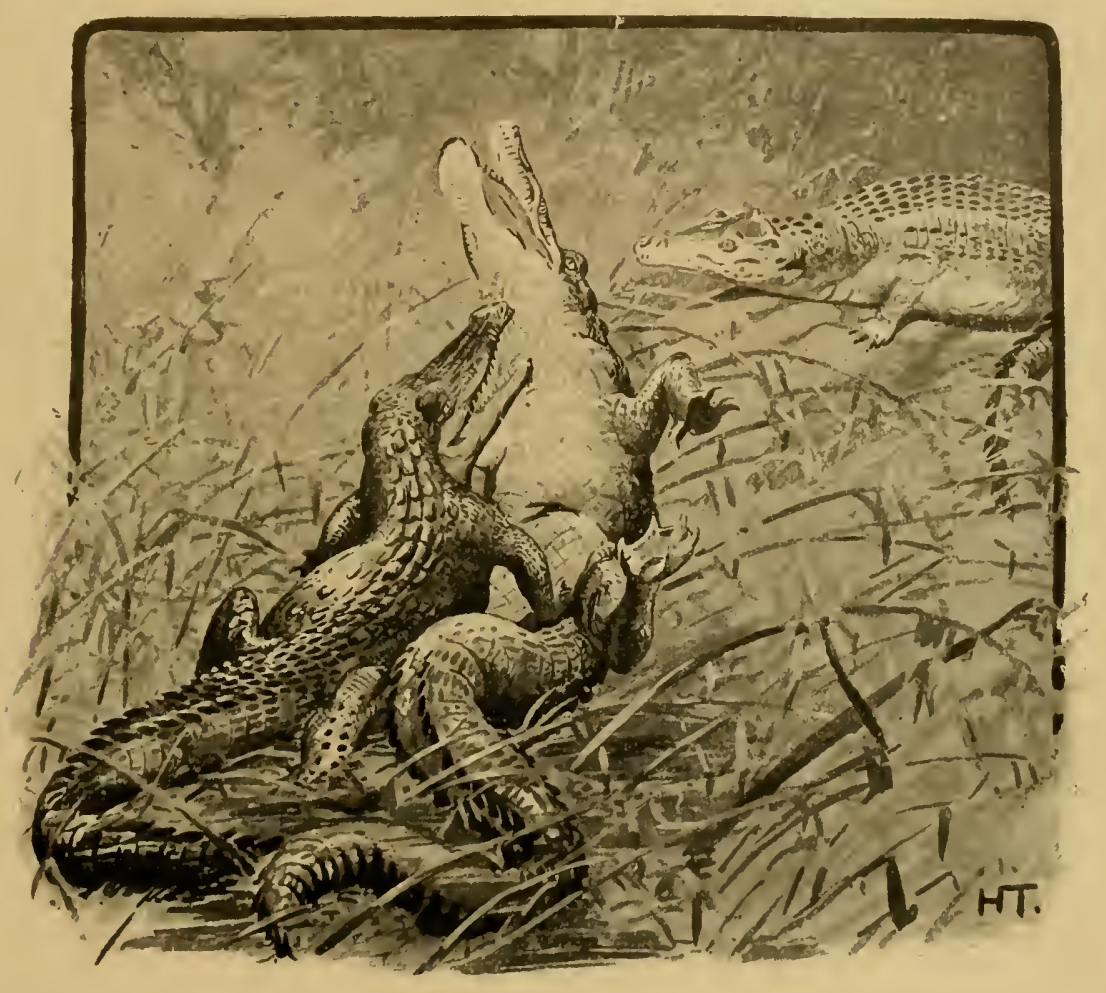

feucrte, nad)oem es ifm gelungen, Jొerr über jeine Errregung, bas Bittern

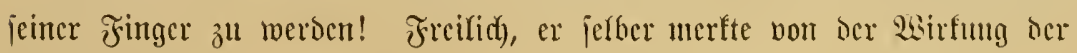
Ed)üfje auch nid(d)

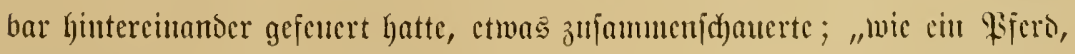

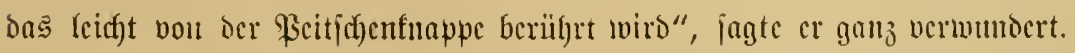
"Ja, wir haben aud) bergeffen, hic (bejdyoffe an ber Eptize cinju=

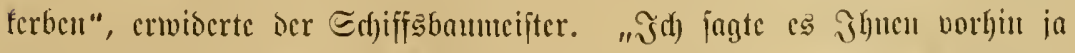

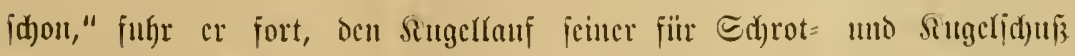

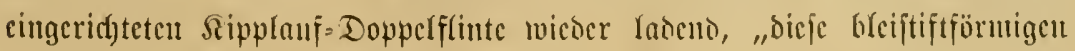




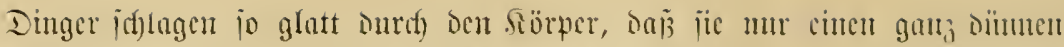
Edy) Ergane jerreipen. Llno baju madyen jie jo flesten (Fimidums, oft jogar

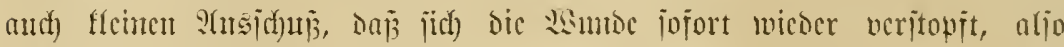
nd

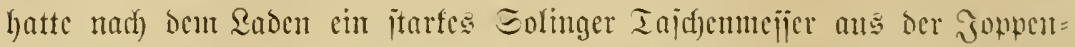

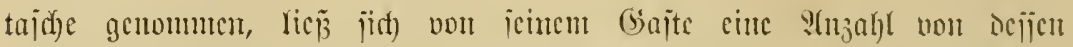

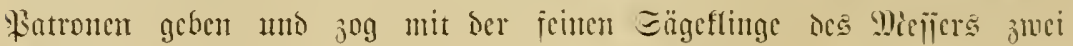

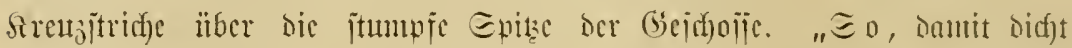

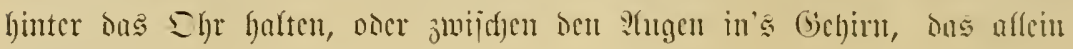
fam hclîfn!"

Ecin Giajt hatte men gelaben, während Mublofi ihm bic Fintrouten

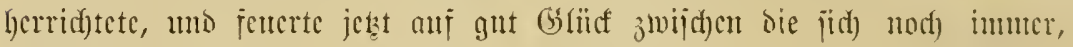

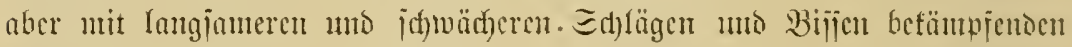

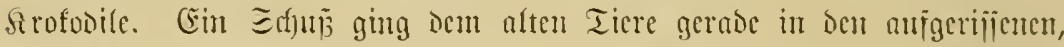

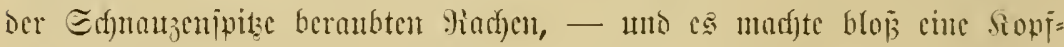

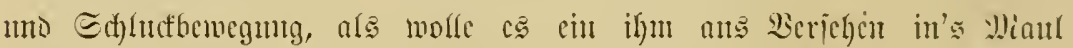

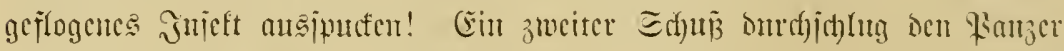

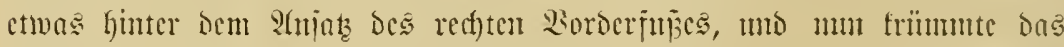

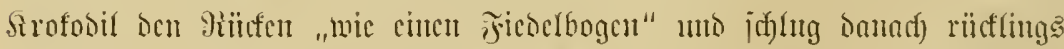
hintenüber in das focfanfflatid)ende s:afjer, wäfrend das antere Iicr,

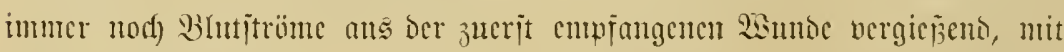

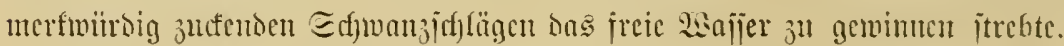

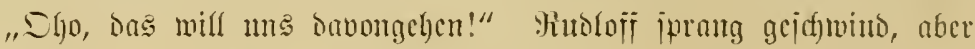

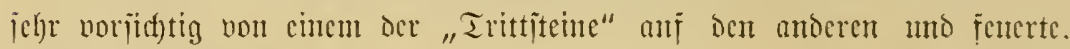

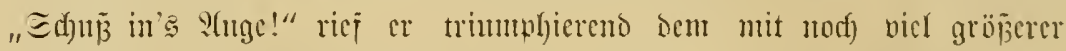
Worjicht bic brei Eprïnge non Etcin jul Etcin magentom Piojdfberg 3n.

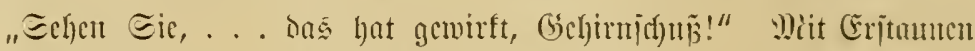

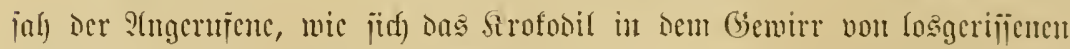

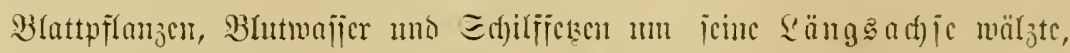

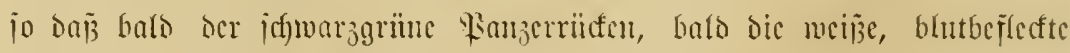

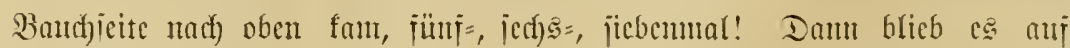

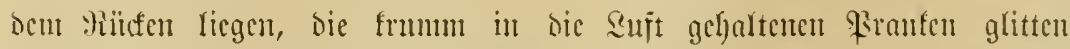

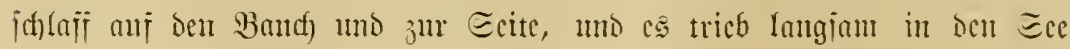




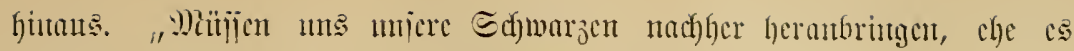
anfgeprejist miro", utcinte ber Edjiffębaumciiter.

"searum Demn?"

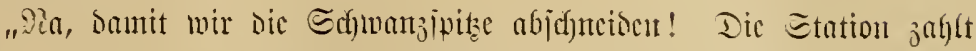

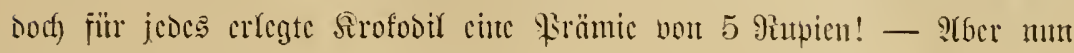

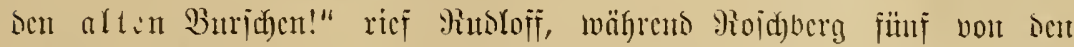

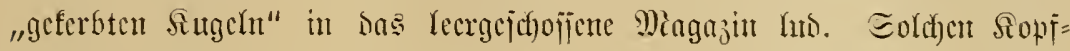
jufur mic Giutolofif molfte er jetżt bem alten Ticre "antragen", wic es itt

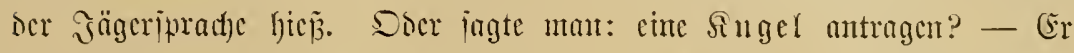

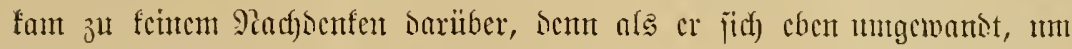

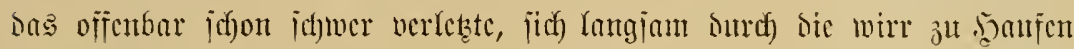
geidflagenen Ecfilfmaijen jableppente Tier "bon born ju fricgen", hörte

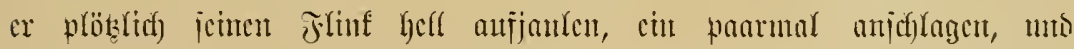

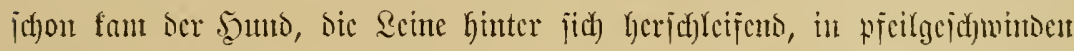
Eäßsen, hopp! hopp! hopp! über ton itciucrnett Steg herangerajt, jprung

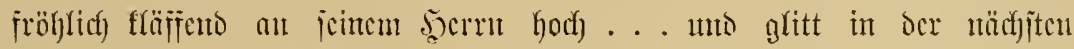

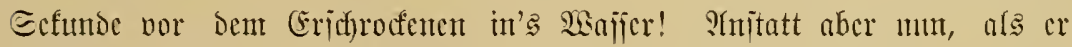

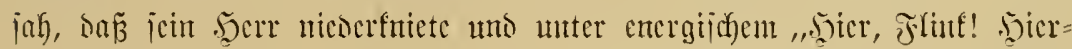

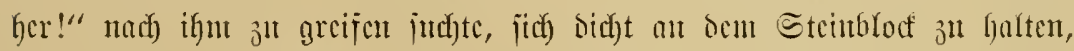

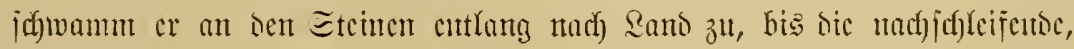

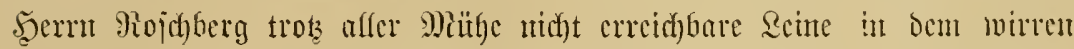

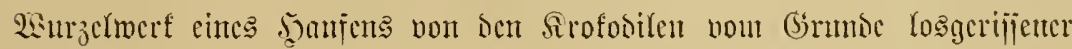

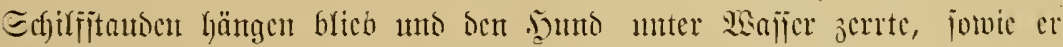

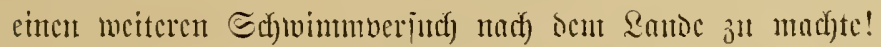

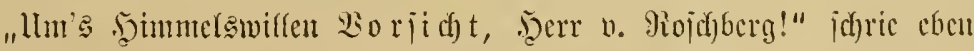

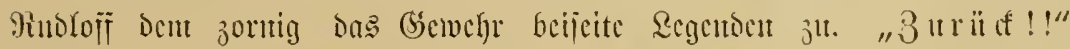

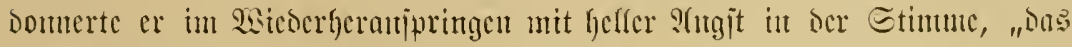

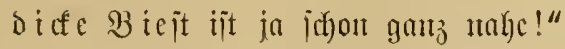

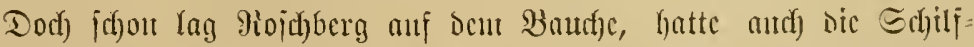

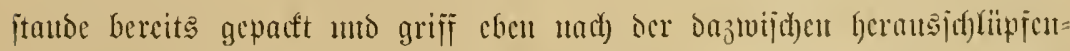

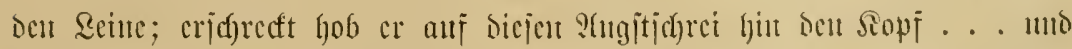

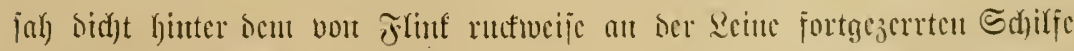

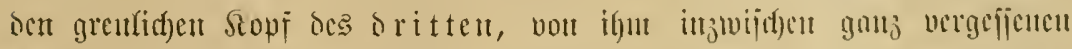

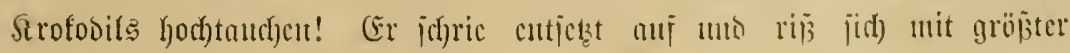




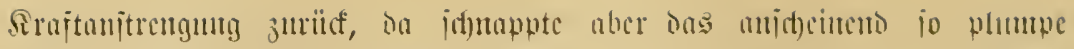

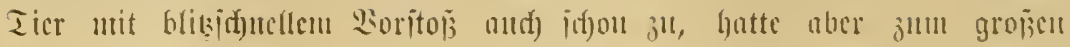

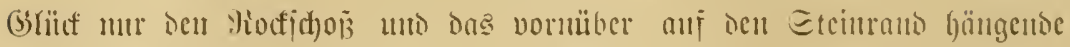

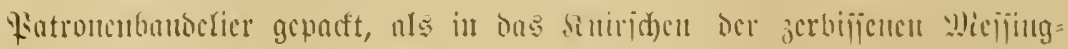

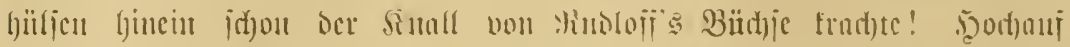

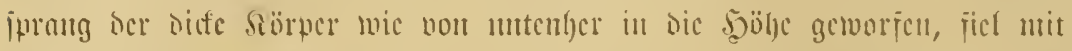

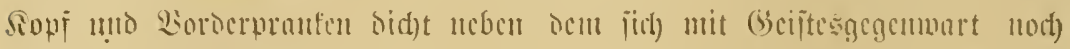

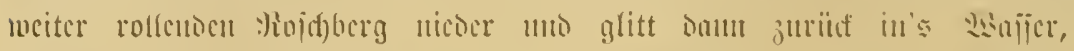

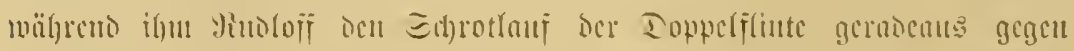

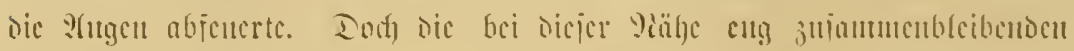

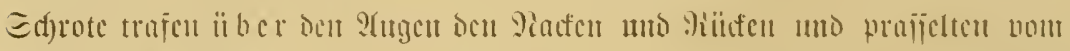

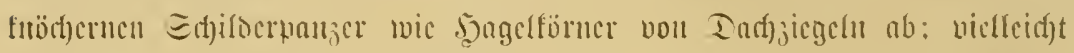

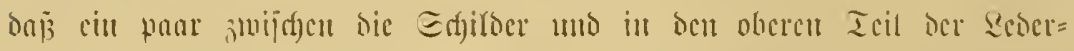

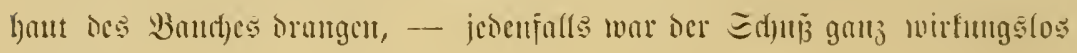
geblicbeut!

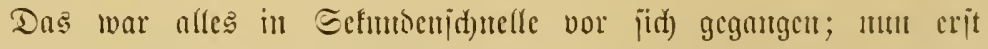

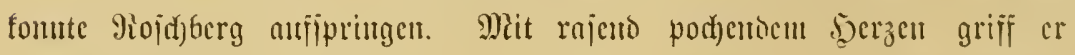
und) jeinem (Bjewelgr. Dod) er founte nidgt anlegen auf bas eben wieter

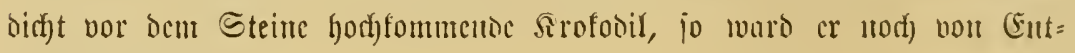
¡eţę) gej jülttelt!

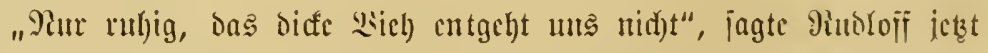

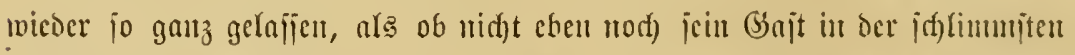
Qebensgejal)r gejd)webt, uno er jelber nid)t cinen gelfenten s(ugitidf)rei

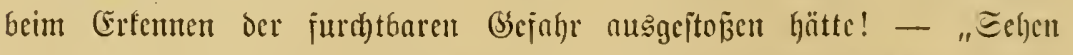

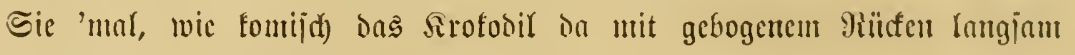

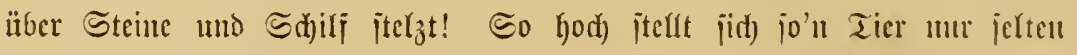

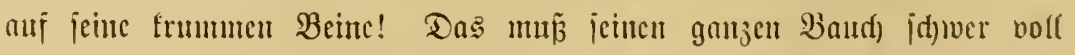

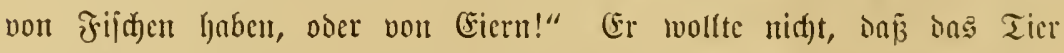

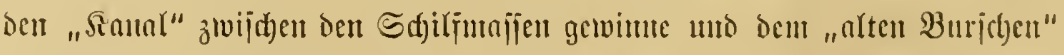
nad)folge, der jidf) injwijichen auf Nimmerwiedcrichen danongemnad)t hatte,

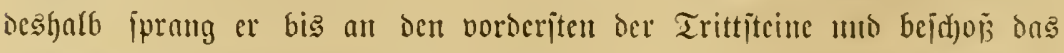

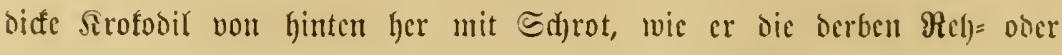

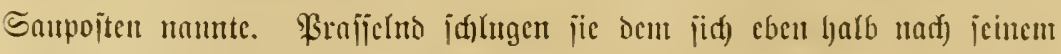

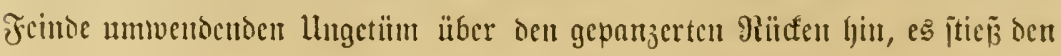




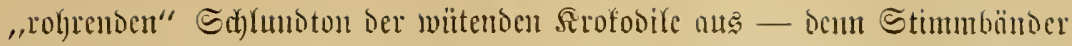

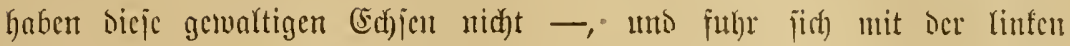

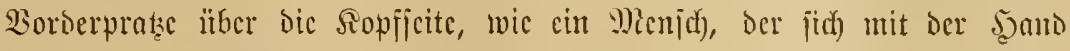

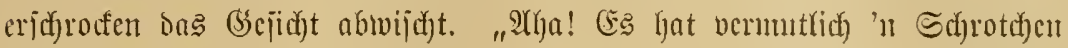

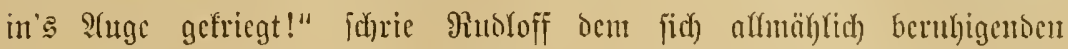
giojd)berg ju, ber brei Stcinc nülyer nach Santo jull jtant unto jul jeincr

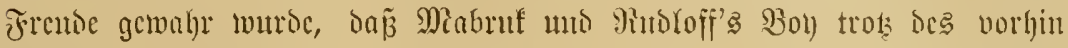
gegcbenct Berbotes anf Dent "Steg" gelaujen fanten, dic treibenton

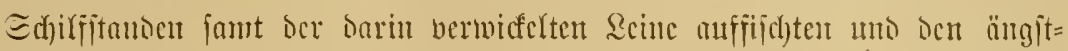

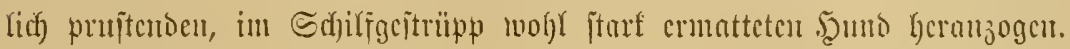

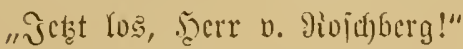

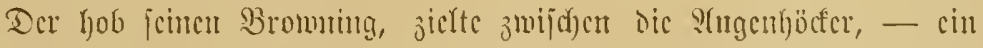

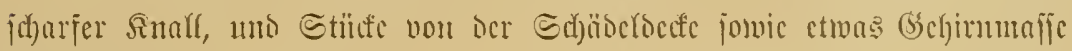

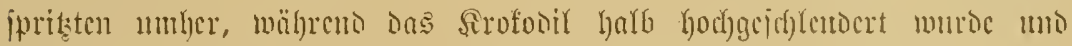

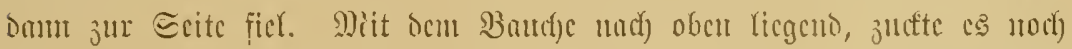

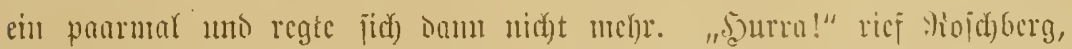

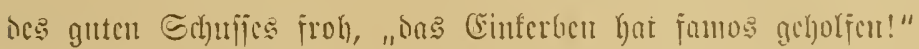

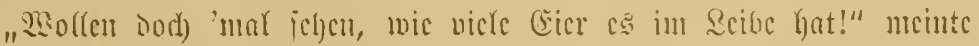

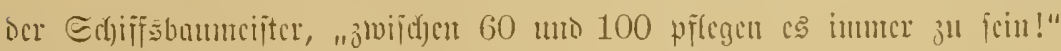

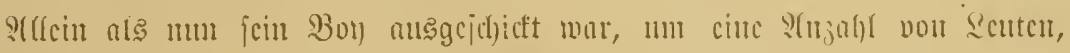

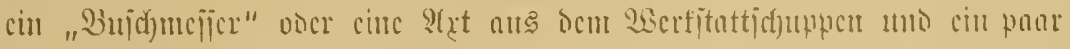

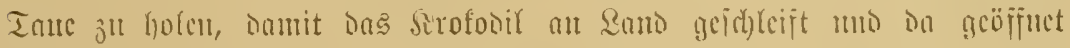

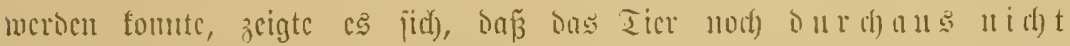

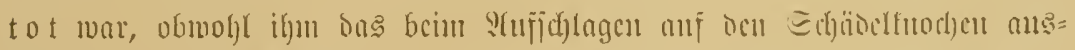

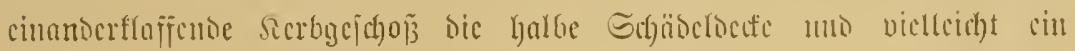

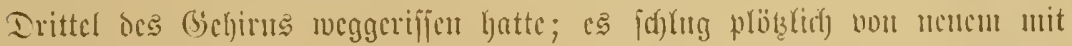

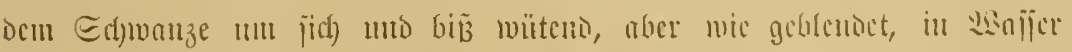

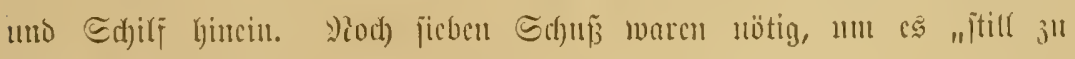

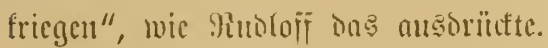

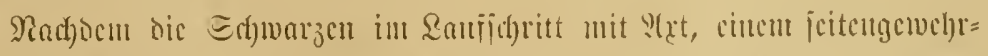

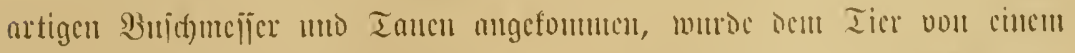

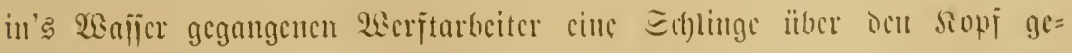

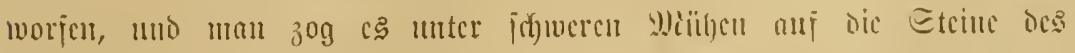

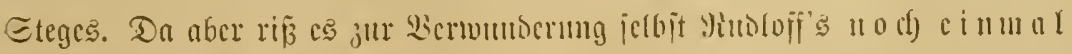




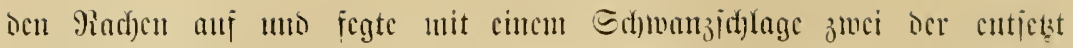

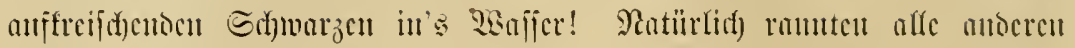

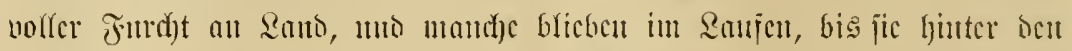

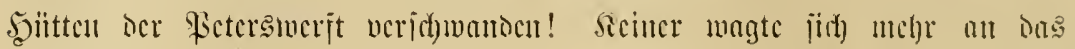

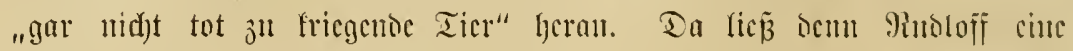

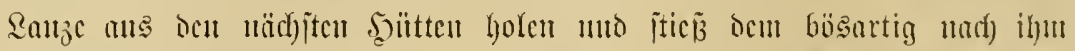

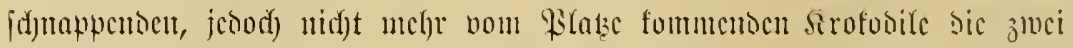

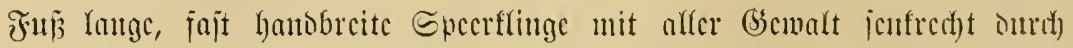

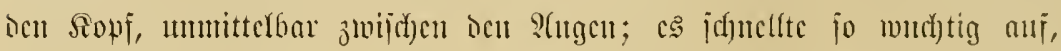

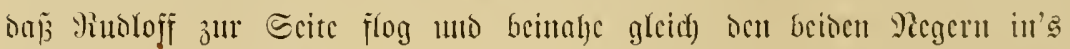

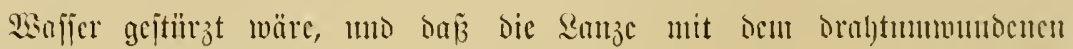

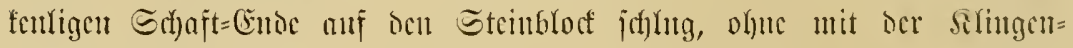

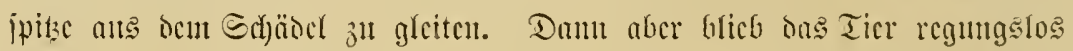

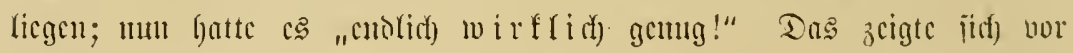
alfem toran, baj

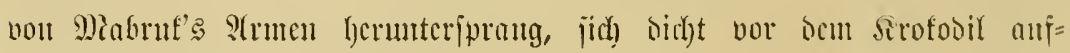

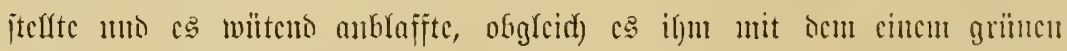

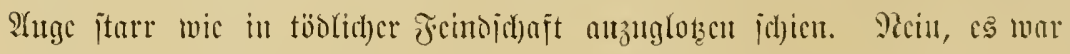

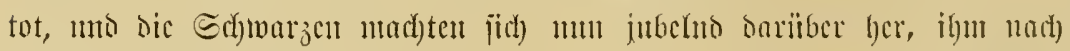

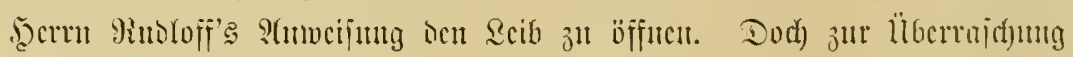

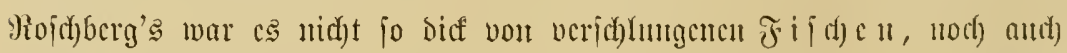

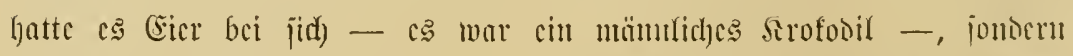

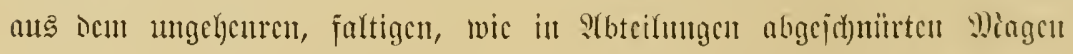

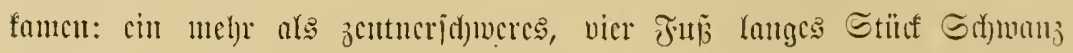

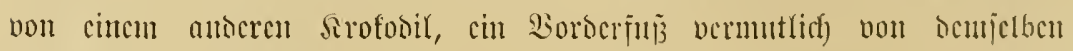

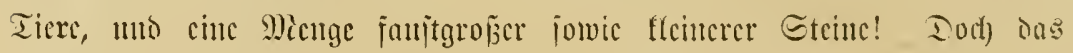

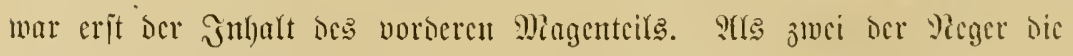

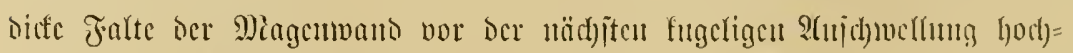

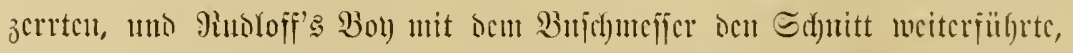

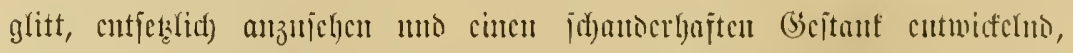
ocr halb von toen Magenjäftel verbante Doerförper cines

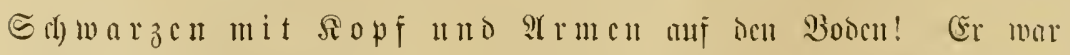

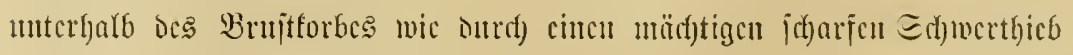

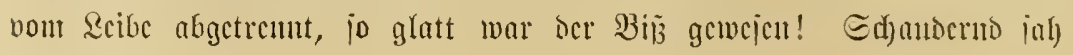




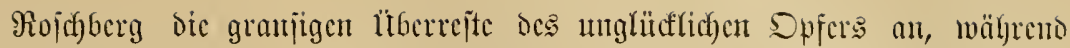

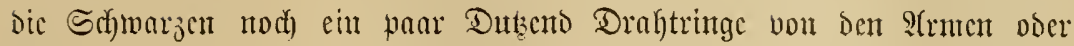

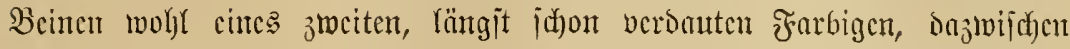
cine $\mathfrak{A}$ (nzahl Mejīing=llniformtnöpfe und noch eimmal cine Menge bon Stcinen auts Der leţ̧ten Magenfalte herborfgolten.

"Dic Ranaiffe lyat aljo audd) cinten Stationsangciteliten erwijdyt

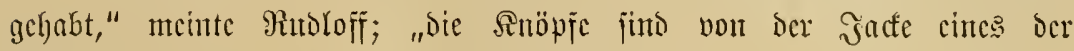

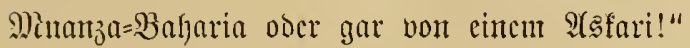

"Jan, wic fomte bas Tier dem aber hier bicjen halben Menjeden u $\|_{z} \mathrm{c} r$ it $\ddot{i}$ of $\mathrm{c} \mathfrak{L}$ t himunterbringen?" fragte, ganz benommen vor Braujen

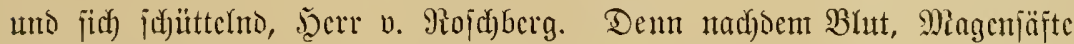

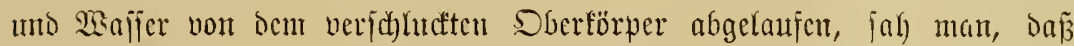

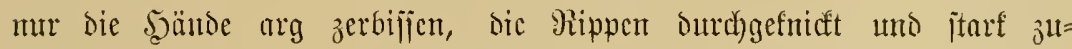

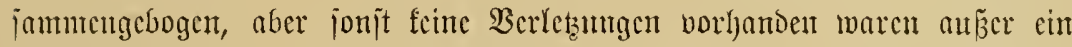

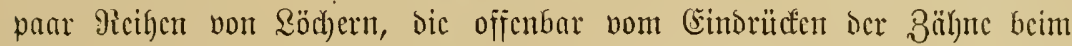
Şimutterwitrgen ocs Spfers berrifferten. "Das Sivofosil hat Doch gar feinen jo veiten Madhen! Waie ijt Das mur DenfGar?"

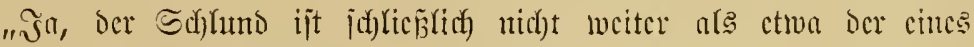

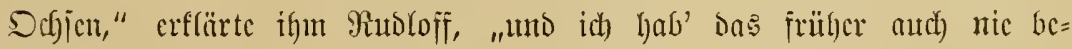
greipen fömnen. Da hat mir aber Stabsargt Dr. Şilibbranot 'mal

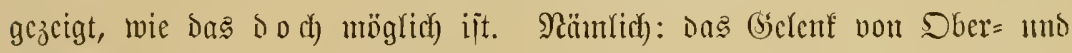
Unterfiefer bei ben firofobilen uno bei ben Schlangen ijt anocrs cinge=

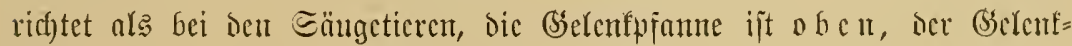

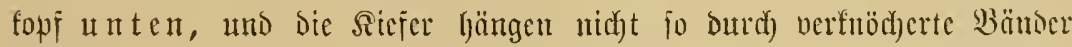

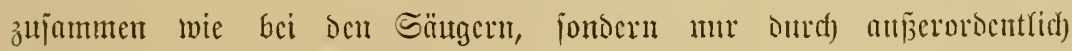

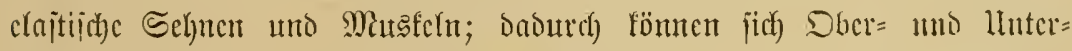

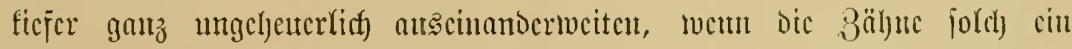

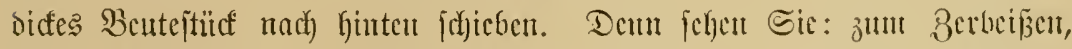

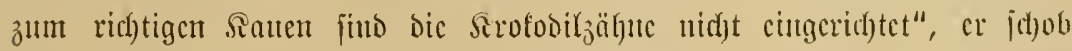

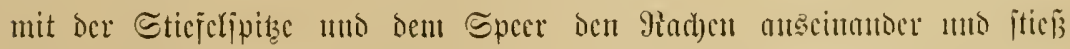

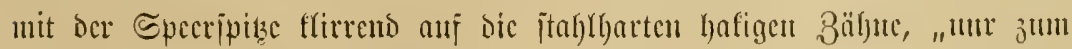

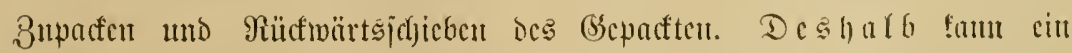

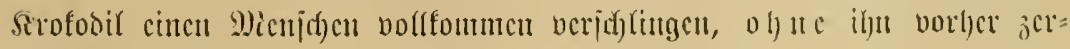
itïcteln zn miilijen!" 


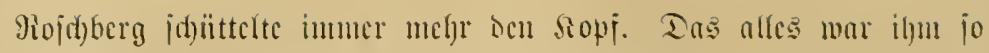

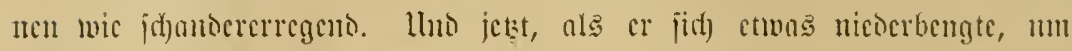

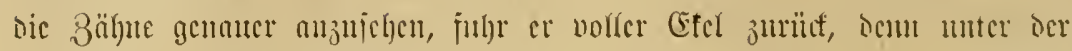

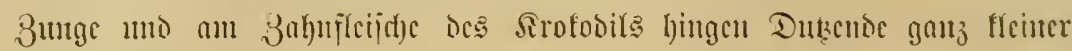
jd)warzer B̈lutegel!

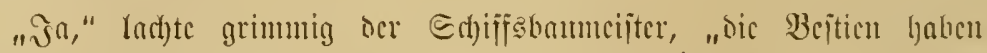

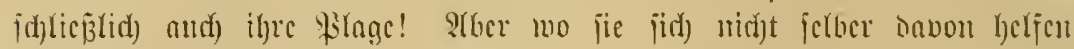

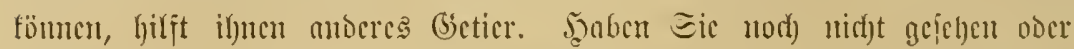

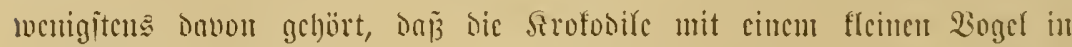

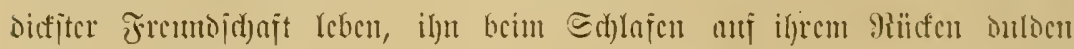

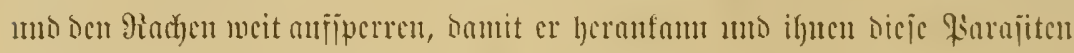

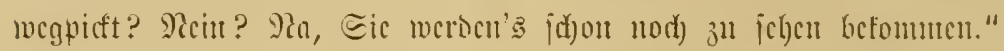

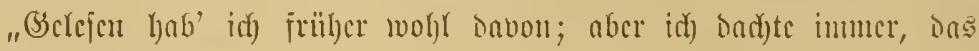

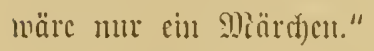

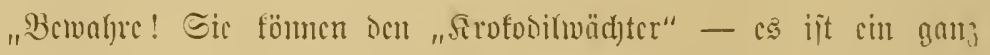

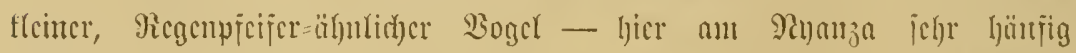

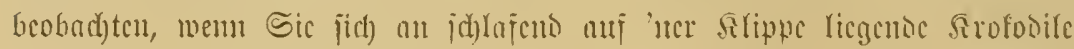
vorjichtig gemeg lgcroupirid)en."

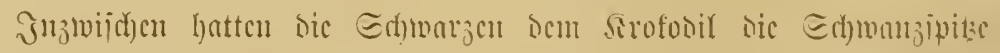

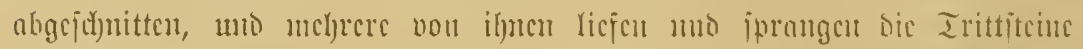

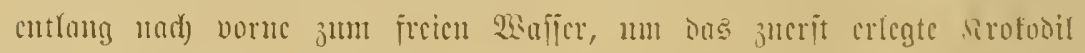

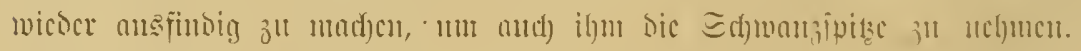

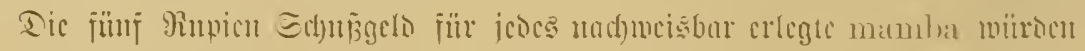

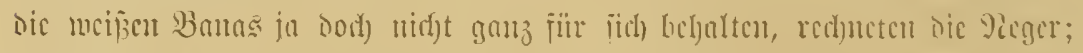

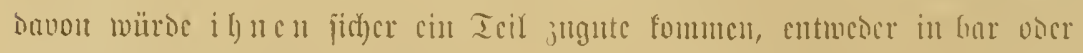
(oscichentiact)en, ofer in Fombe, mornuter lier anj llfereme mentiger cin

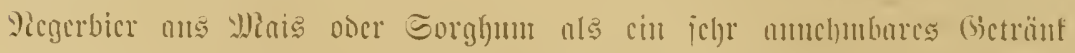

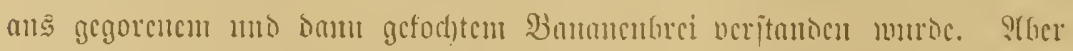

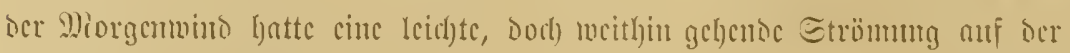

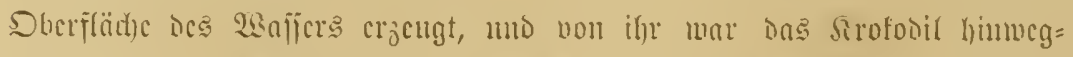

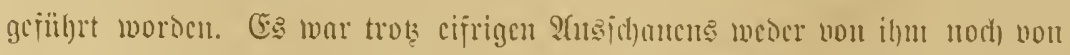

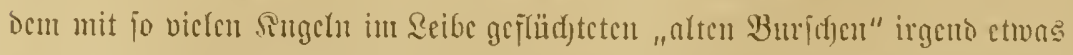

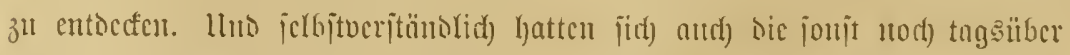

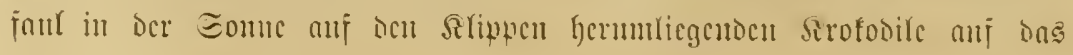




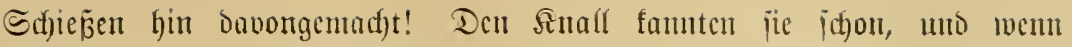

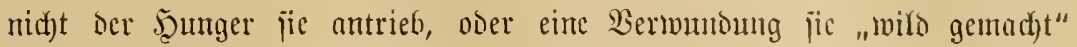

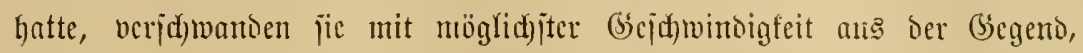

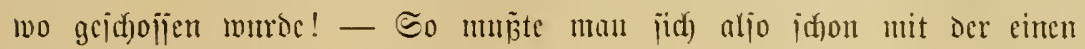

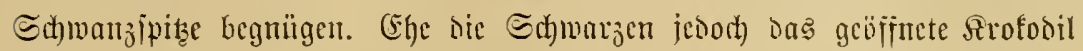
uno jeinen grumigen Mingeningalt an Etriffen vorn nad) icm "Stege"

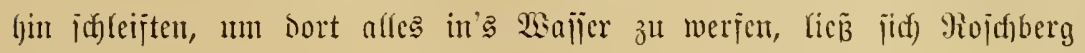
einige Der aนs bem Meagen genommencn Drabtringe uno Micipingfnöpfe

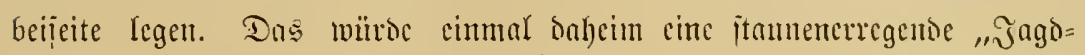
Trophäe" abgeben! (sonz betrofifen jahen iln aber bie gieger an, ale er

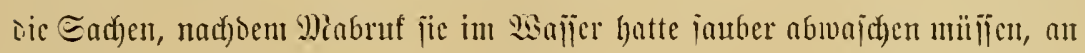

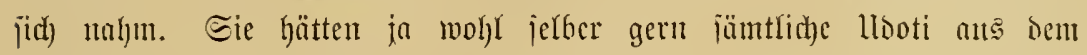

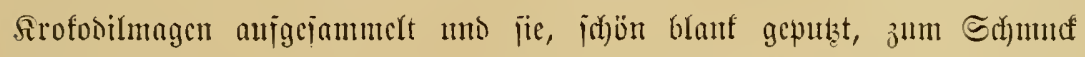
verwentet; aber... Dann wären jic, „jift)er über furz oser lang a nd d)

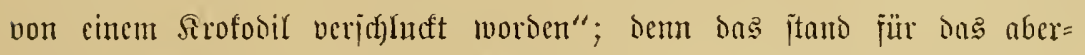

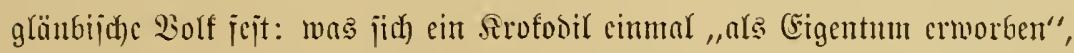

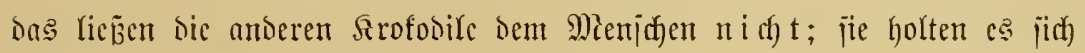
wicicr, mit Dem Mienjidy, ocr es trug!

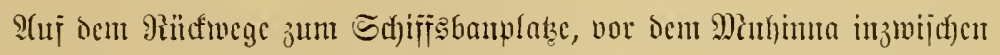

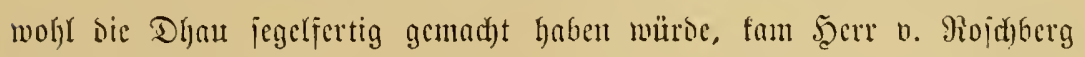

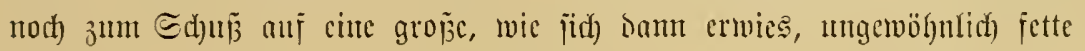

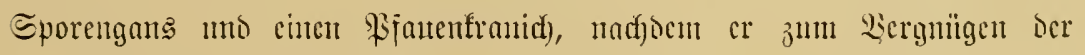

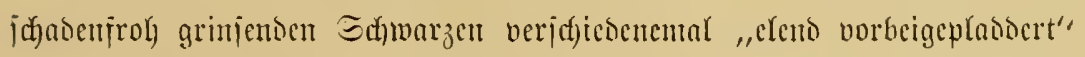

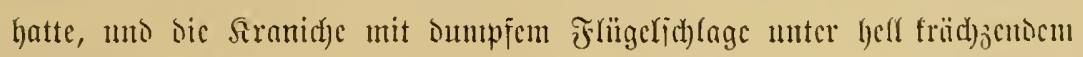
Sd)reffon "fio-rrann, fio-rman!" abgeitridfen marcu. Dic bront=

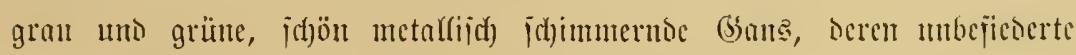

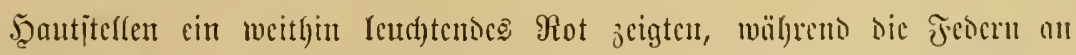

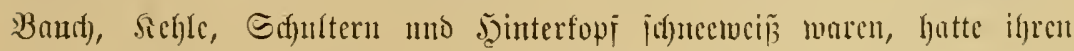
Pamen von cimem itarten Eporn aun Fltïgclbuge. Doch un bicjer Bejonder=

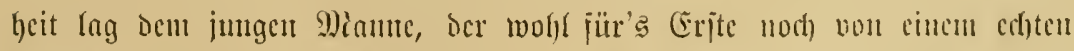

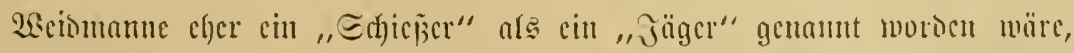

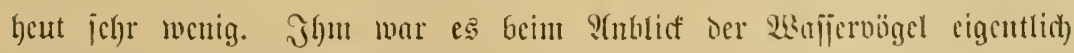

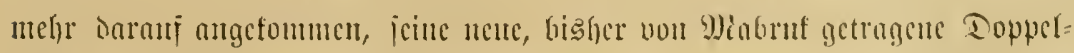

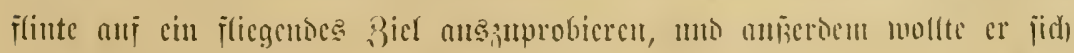




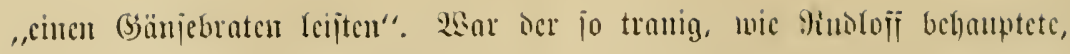

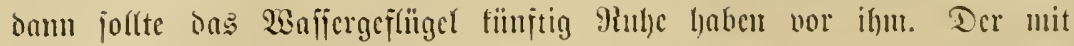

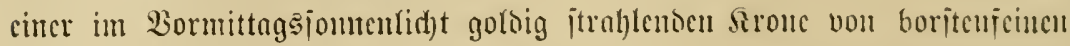

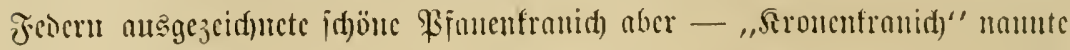

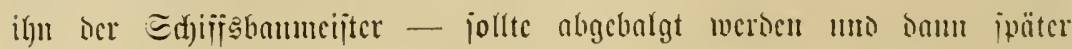

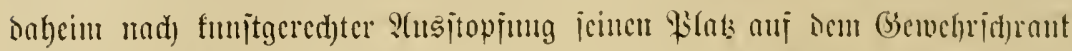

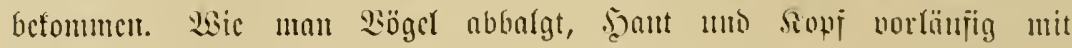

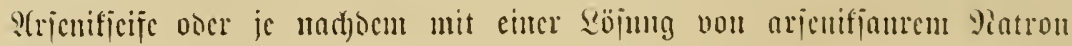

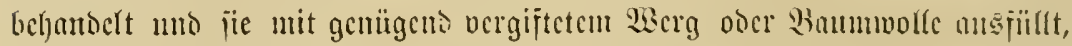

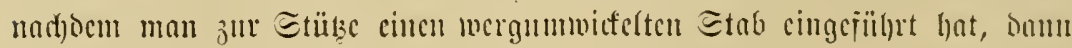

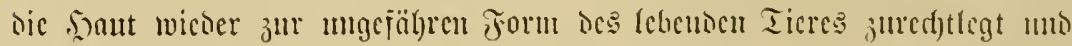

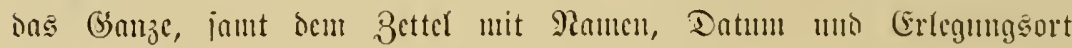

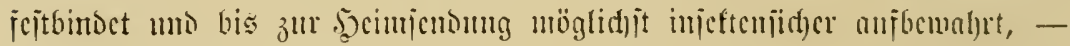

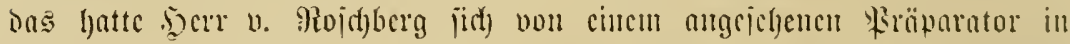

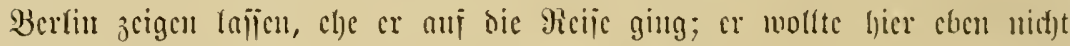

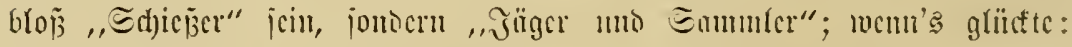

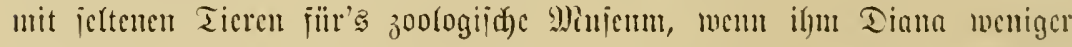

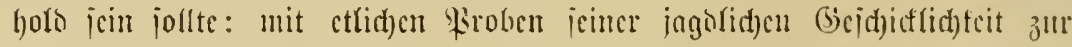

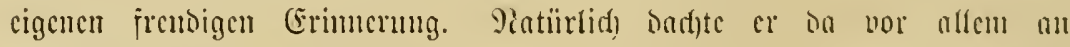

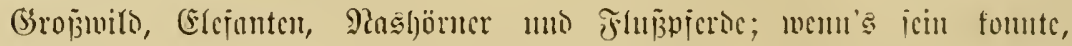
wollte er and) cinen ier gewaltigen Biiffer itretfen. Dod) Bas märe sum

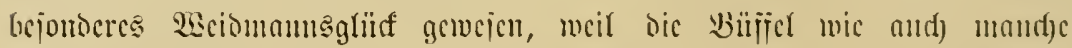

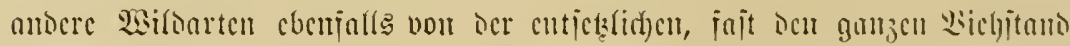

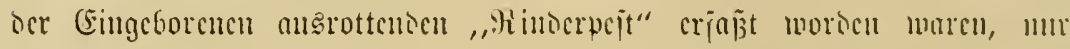

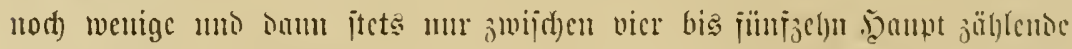

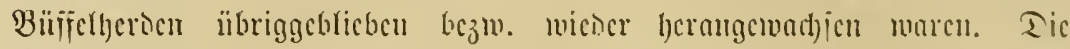

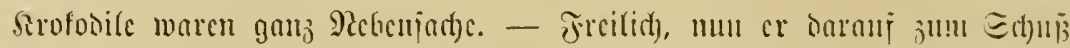

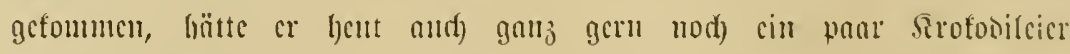

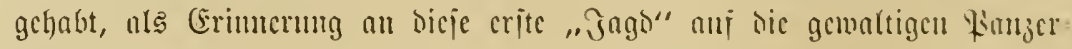
(ct)jert.

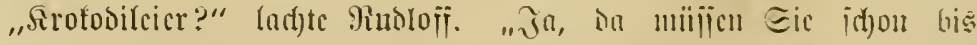

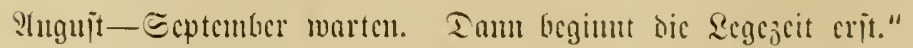

"ISther Eic jagten Dod) vorbin, bas diffe firofodil miije voll vou

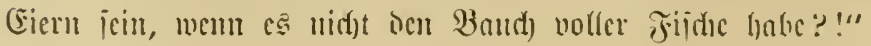




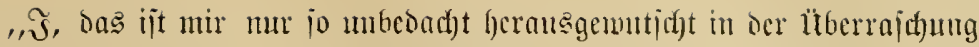
beim Senblict des jo plumpuolten Biefyes. Blciben Sie nod) die paar Mionate bis dabin in ier Siolonte, uno Sie werden frofodifeier genug ju ief)en, mo wenn Sic mollen, nuth) ju toitten friegen!"

"Siojten? Simn man bic berm cifjen?"

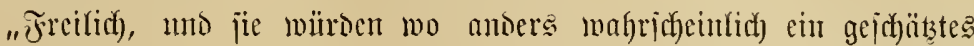

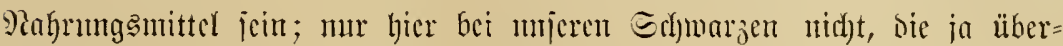

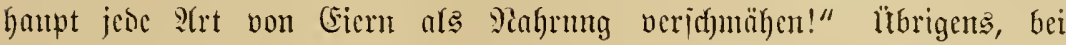

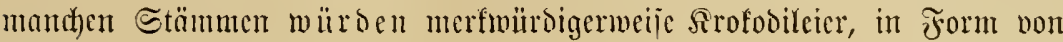

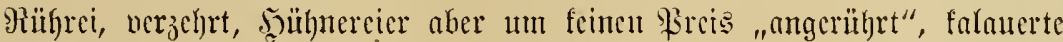

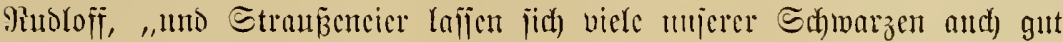

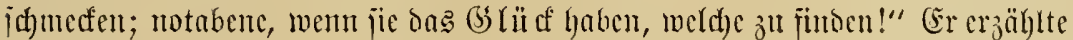

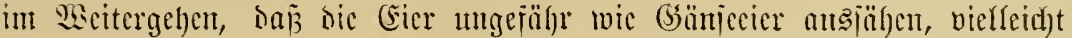

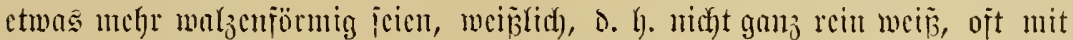

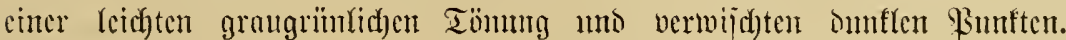

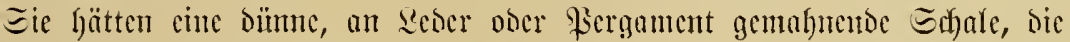

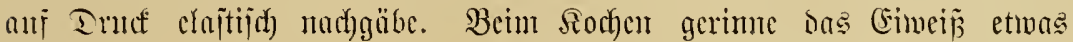

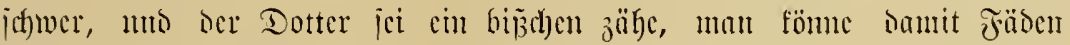

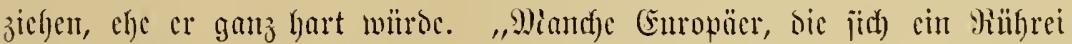

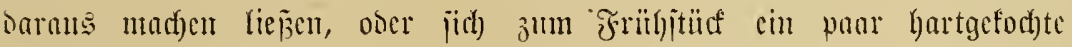
Sirofositeier bein Mipijdji bejteflten, haben hinterfyer erflärt, ons Sirofosilei

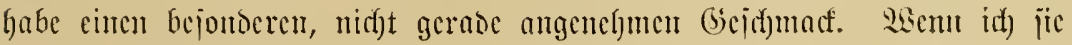

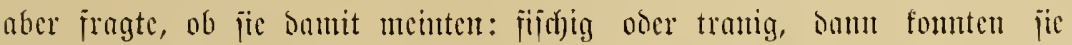

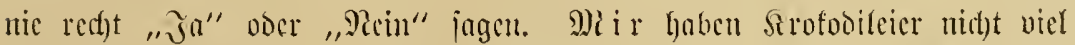

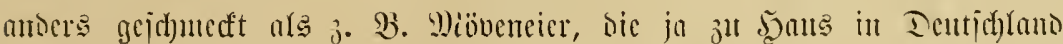

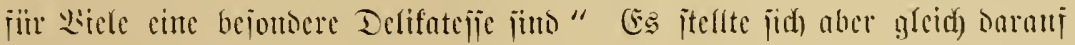

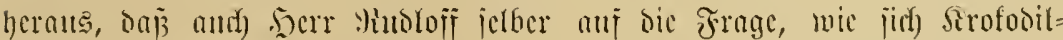

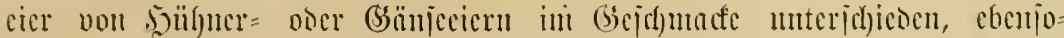
menig cine flare stutmort geben fonnte mie dic s)erren, ïber beren

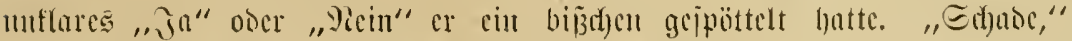

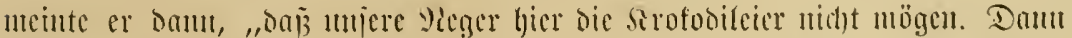

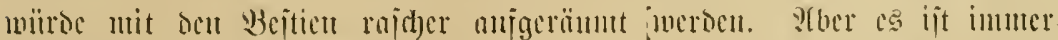

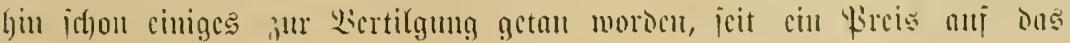

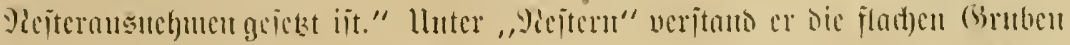




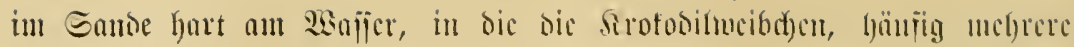

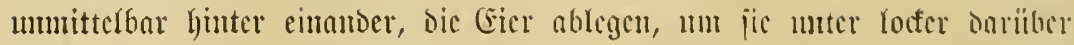

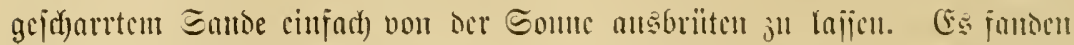

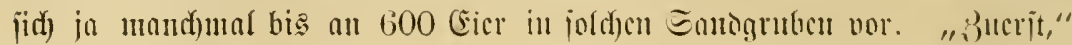

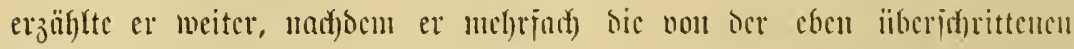

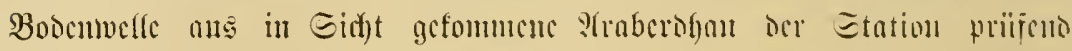

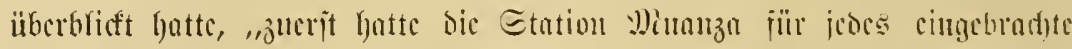

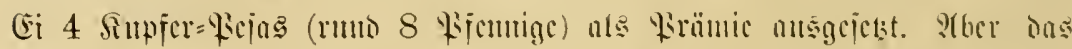

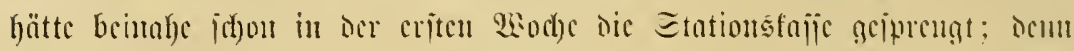

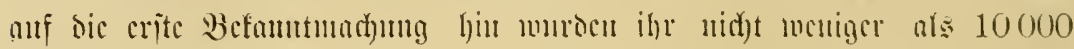

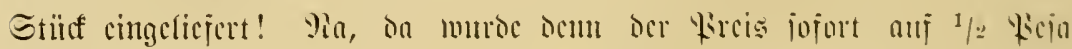

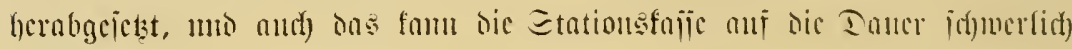
meshalten."

"Was miro bem mit ben (Ficm mun gemtad)t?"

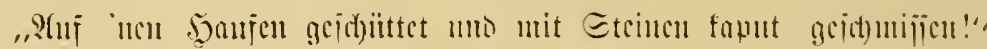

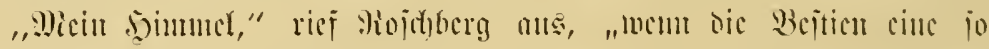

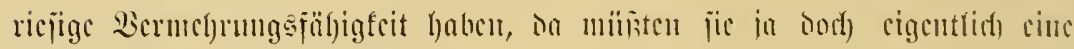
ungelyeucriche Santorlage icin!"

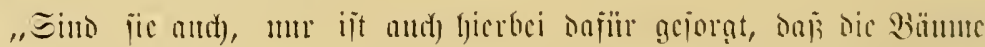

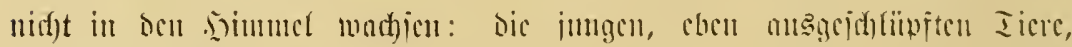

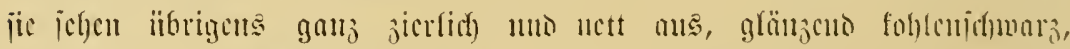

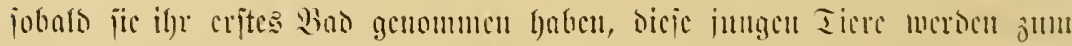

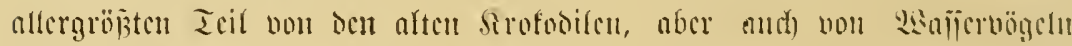

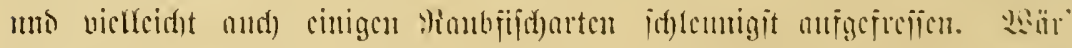

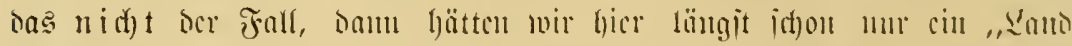

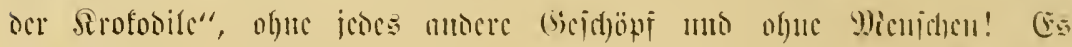

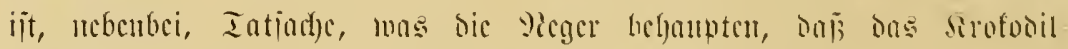

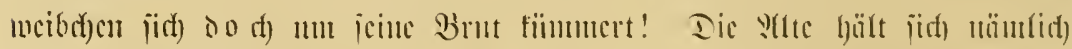

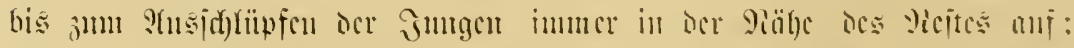

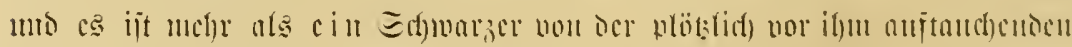

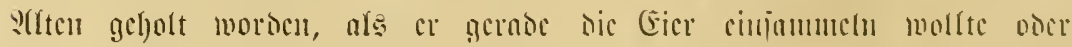

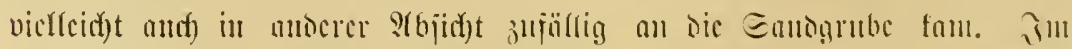

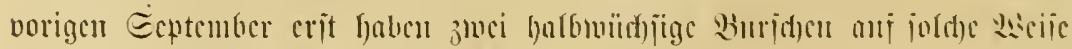

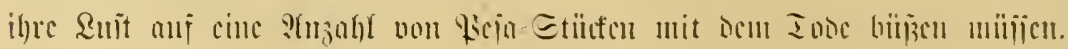




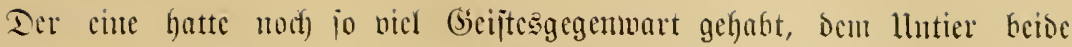

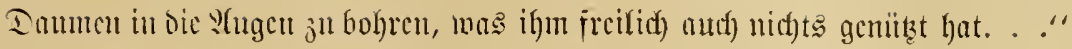

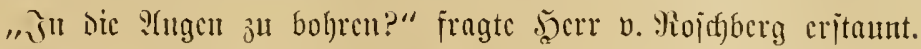

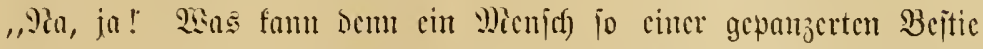

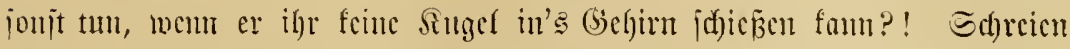

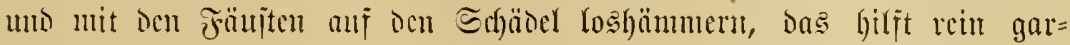

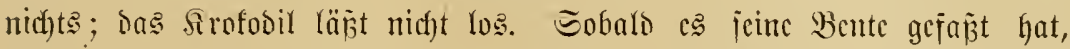

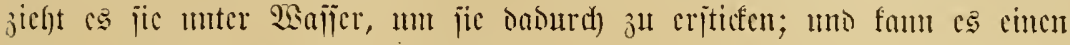

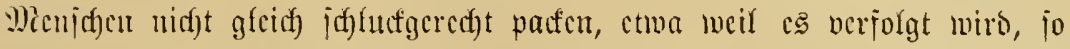

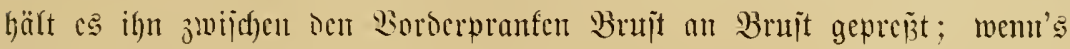
nid) antors geht, itumoculang; dic Picger behaupten jogar tagelang.

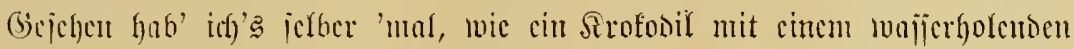

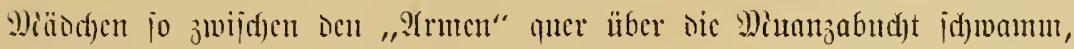

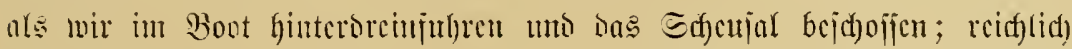

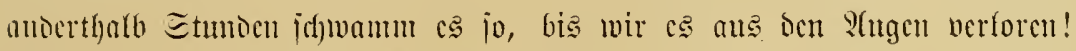

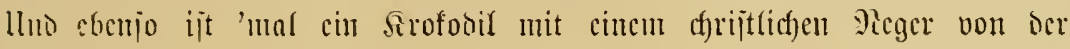
hicpigen Diijions = Etation bavongeid)mommen, - Sie wifien bod), von ben

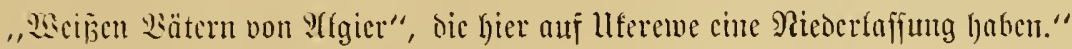
(Er riej ocn an Bord Der Dhan bejuäftigten Farbigen etwas anj Sijuabcli

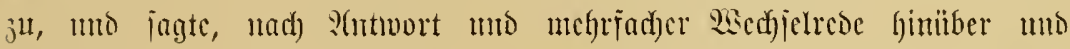

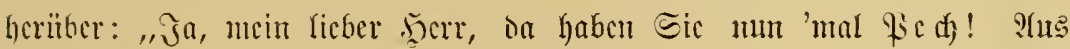
ocr Irribjago Der Dörfer wiro nidbts! Edhade, Sic fommen ba um cine wirf(ict) ganj intercijante Eadfe!"”

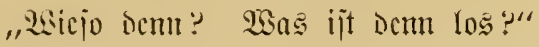

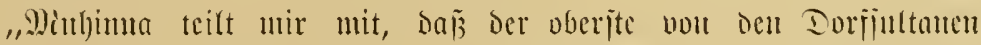
heute ganj jrïh totgcitocfen worden ijt. Der Wian, Der Dic Ireibjago anforanme bat mo nach) bicjiger Sitte allein Iciten Barr."

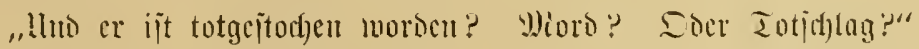

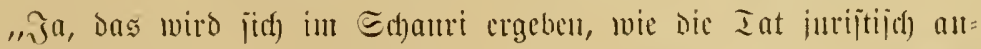

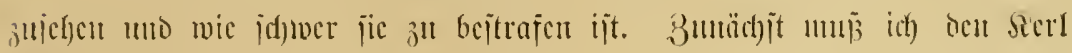
cintbringen."

,P(l), dor Täter ijt betamt? :"

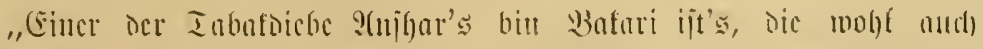

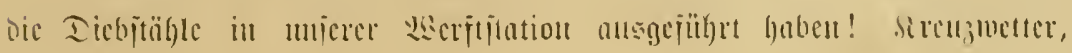




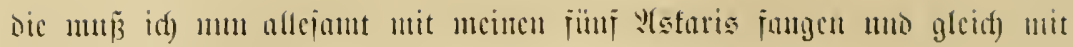

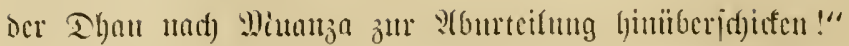

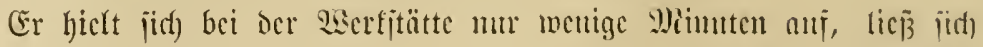
vou dem ifn ermertenten Smbaidna anj dem $19 \mathrm{sgc}$ anu bauje beridyten,

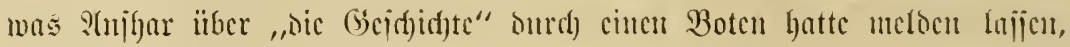

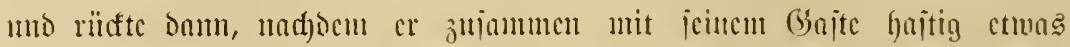

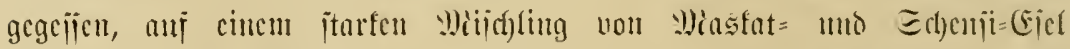

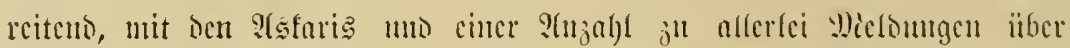

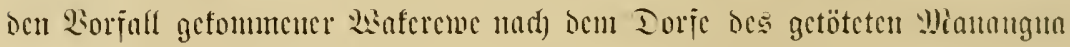

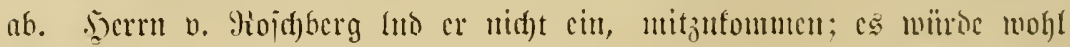

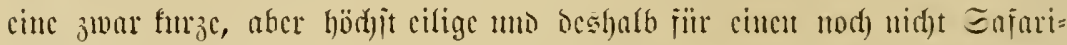

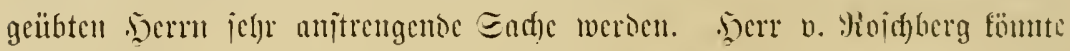

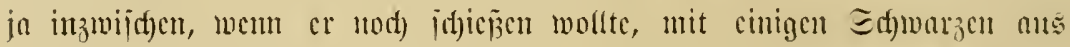

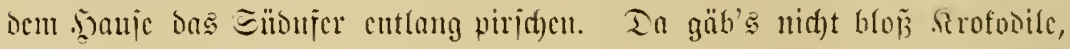

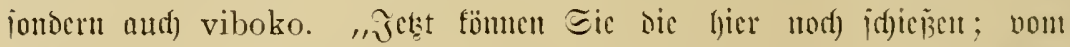

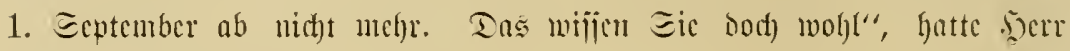

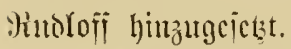

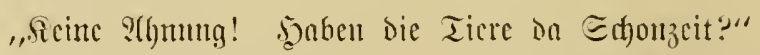

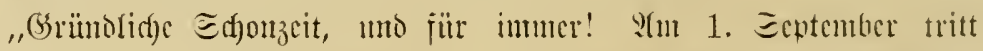

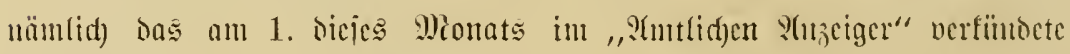

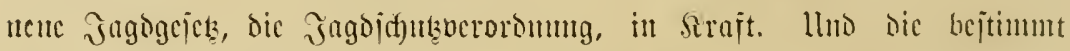

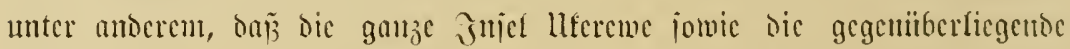

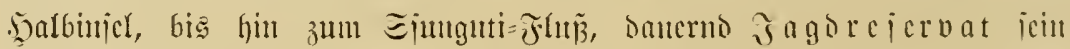

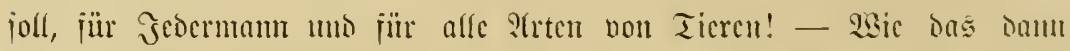

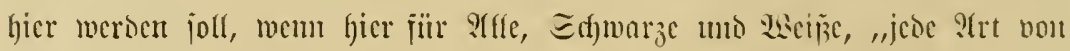
Jago" bei einer Etraje non 3000 :lumien verboten iit, bas mag oce

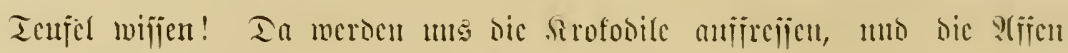
merden sic Feliber lecr frefien! ES famu nett meroen!"

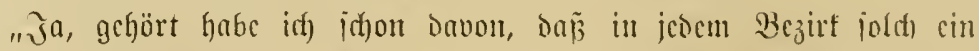

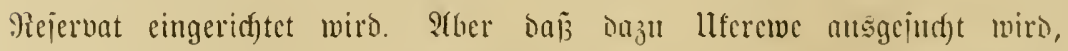

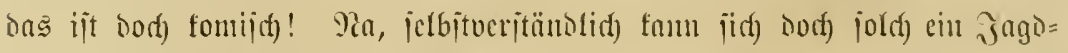
verbot nicht auj Raubticre critrecfen, uno ïberfount ïd) nidgt auj Sörjer

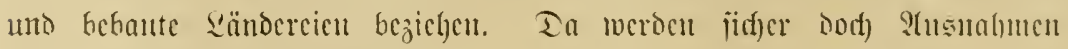
ieitgcictst werden miijīen!" 


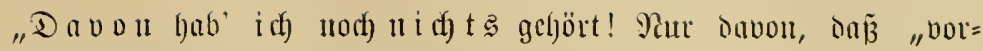

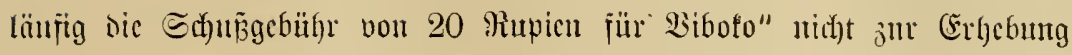

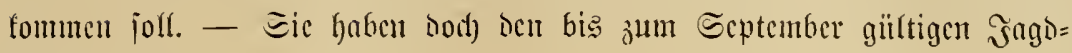
ic)cin gelöjt?"

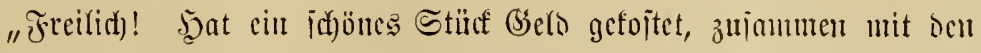

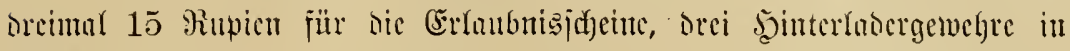

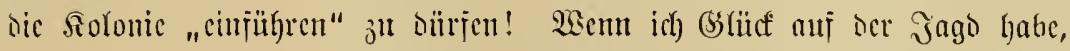
famn idh and wohl nodh cin paar Taujent Rupien Sahuzgelior bled)en vor הer .̧cintrife!"

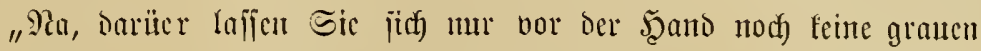

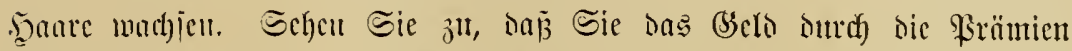

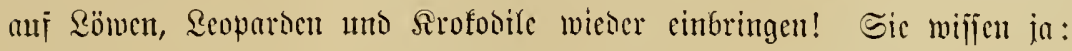

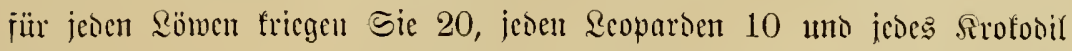

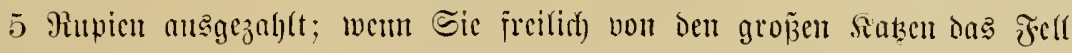

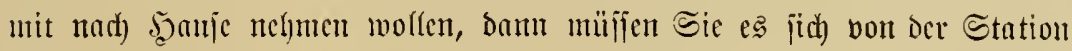

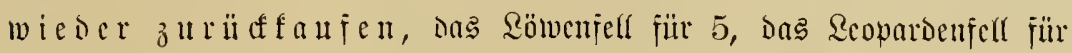

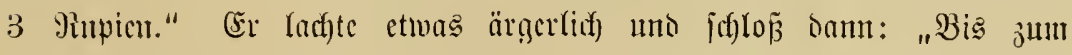
1. September ijt's aber noch weit lyin. Ziehen. Sie mur heut nadhmittag

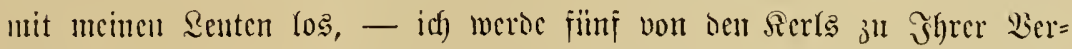
jïgıung lyalten - uno legen Sie cin paar $\mathfrak{B}$ ibofo auf dic Decfe. Llnicre

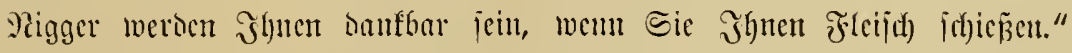

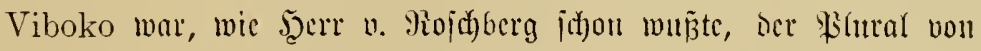

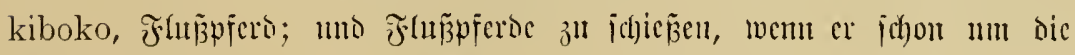
Neger= Treibjago fommen joffte, war ifm cine ichr vicl angenebuncre

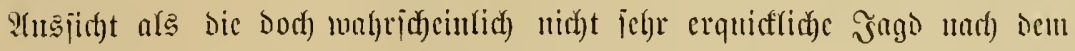

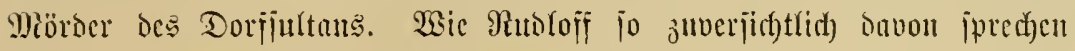

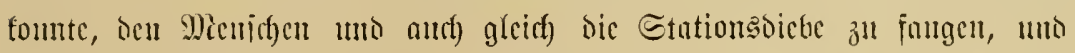

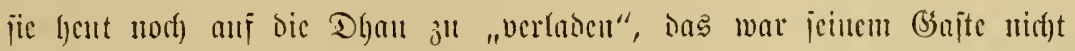

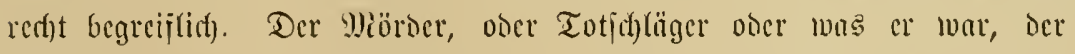

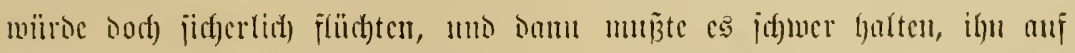
ber ungejüly 60) Sillometer langen, 15 bis 18 silometer breiten Sujer

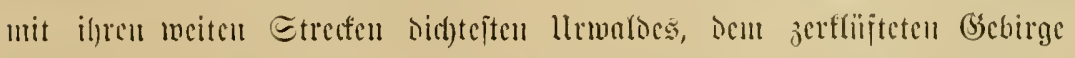

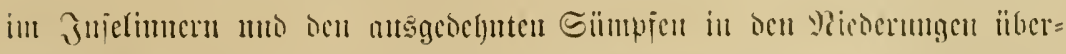

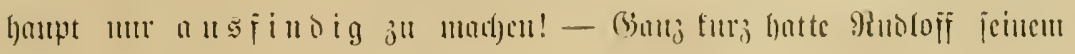




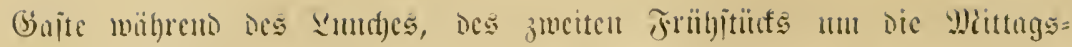

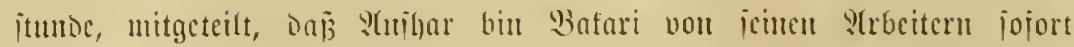

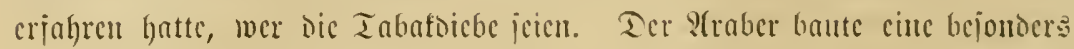

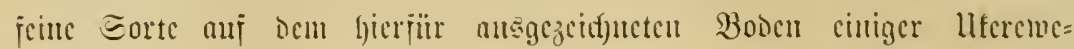

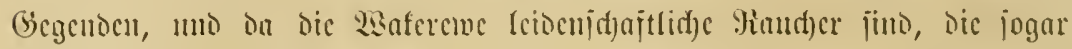
il)ren cben cingebradten Siriegsgcjangenen Tabaf unt cine Inugrolurige

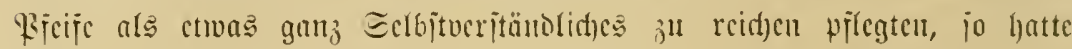

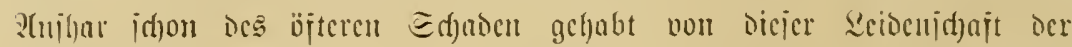

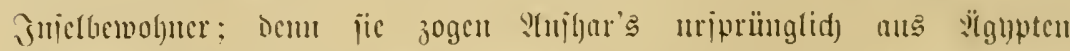

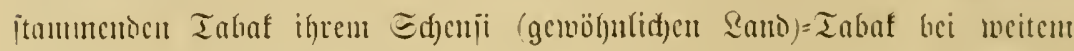

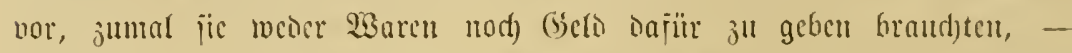

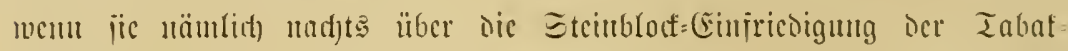

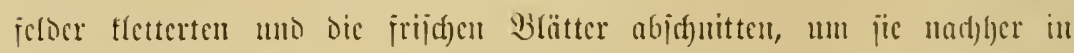

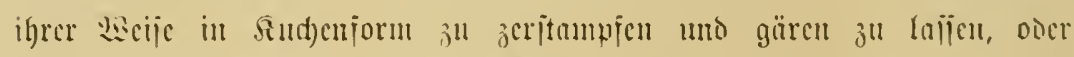
wenu ïe, jut Exiparming jold)er : Strbeit, fumz vor der ?(bholumg der von

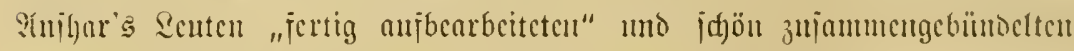

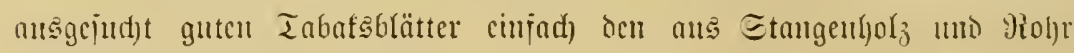

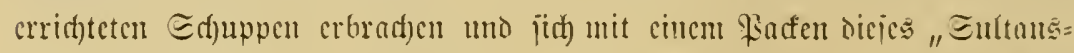

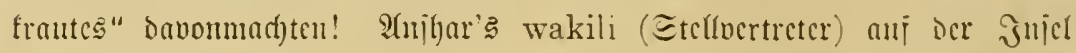

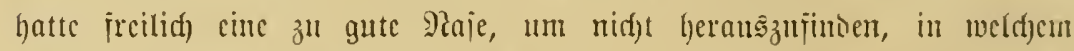

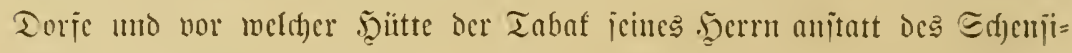

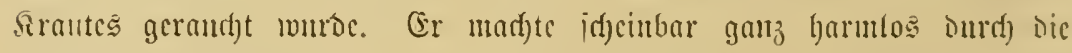
Nachbar= Drtid)ajten tembea (cinen Epajiergang), mil iteflte babci die

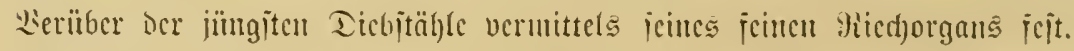

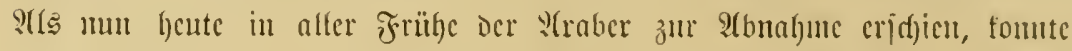

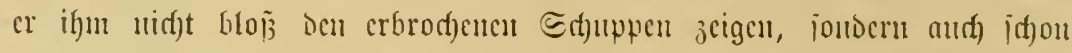

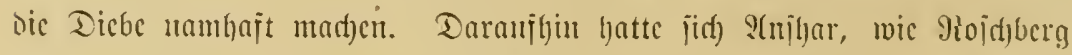

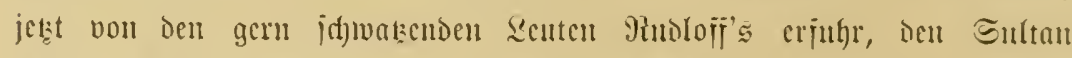
geholt. Stber als jie beide mit eitur ganjen Echar ifjrer Ecute die Dicbe

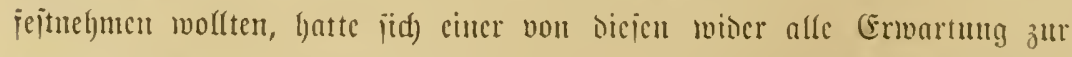

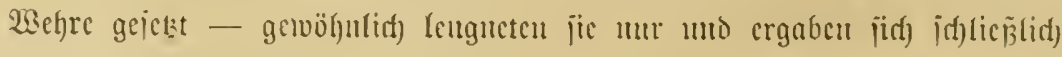

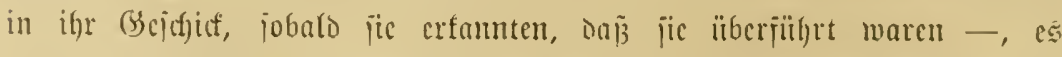

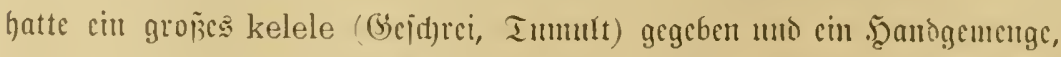
ber Micnid) war in jeine bütte gejloben, hatte in jeincr blinden 2 sut 


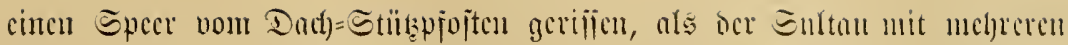

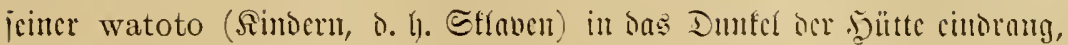

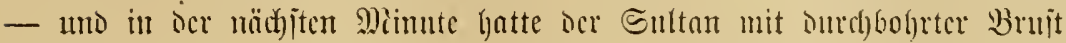

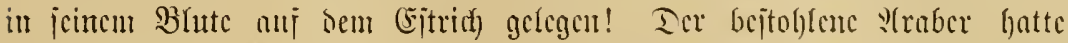

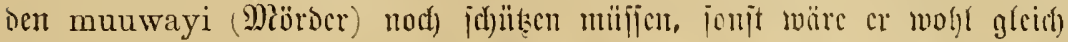
von iclt sistoto ics Sultans niescrgejtof̌en wortien; aber cr lyatte inas CEin= treten 9njigar's jür il)n rajd) beniïţt, mm jill cutfificlich, mo ljiclt jicf) mul ver= horgen, erjül)lten bic

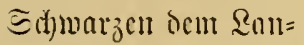
inçitremoch unter $\mathfrak{l e b}=$ hajten Bsçtifulationcn umo viclen 2 orten. llno cE war gut, baj jic Had) Micgerweije bci leblyafter Erzä̈h= lung sic $\bigodot_{j}$ cure förmu= (id) id)aupiclerij(d) barjtellten, jonjt Gätte গioid)berg iffen $B c=$ richt trotz der viclen

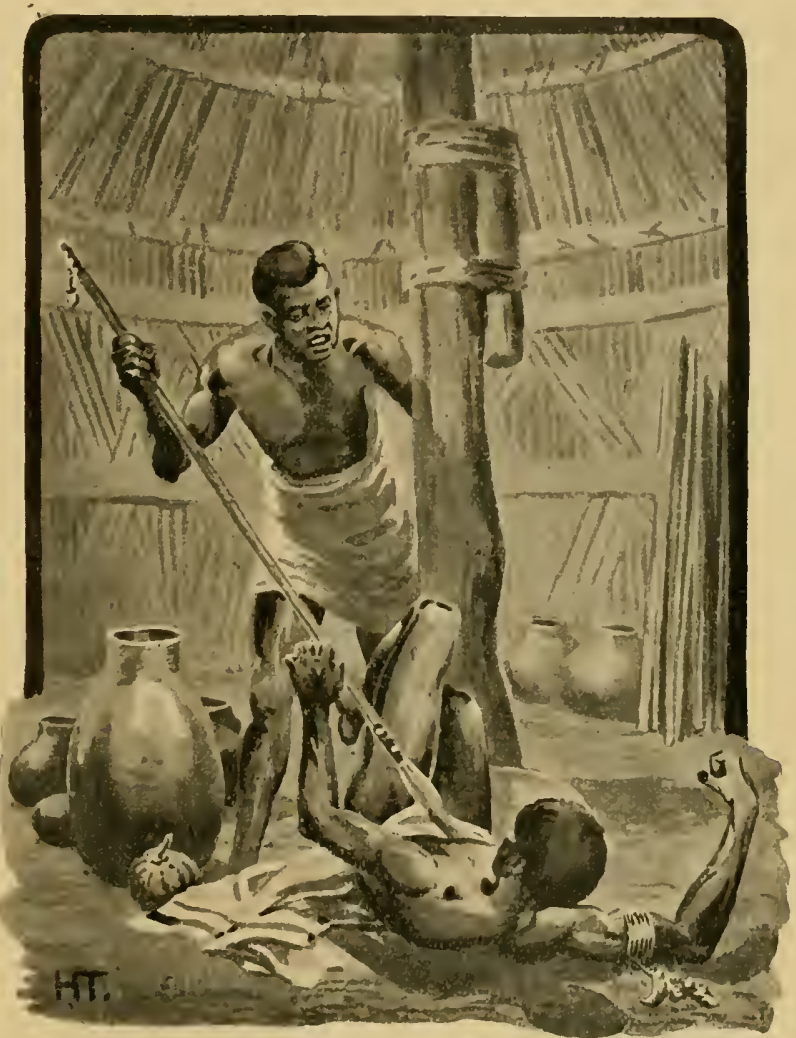
maneno bod Midft veritanden. (5s wurbe ilju immer flater: cr war jwat Gauptiäd)lich) żun Jagen in bic siolonie getounnen; aber menn $\mathrm{cr}$ jid) bic

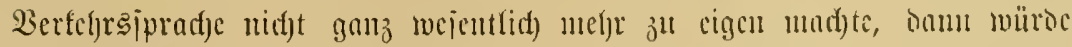

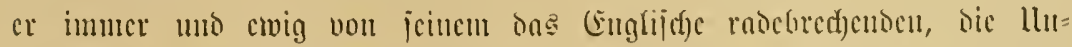

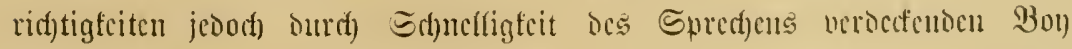
oder von antoren dofuctidyenten fierjoncu abhäugig bleiben; umb dic

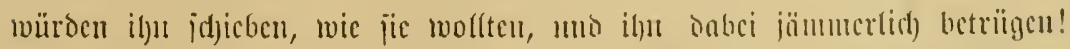

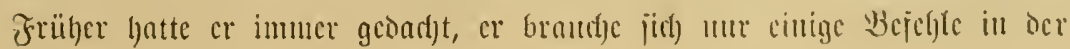




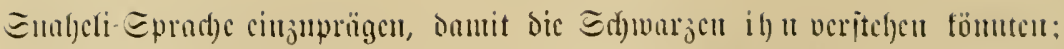

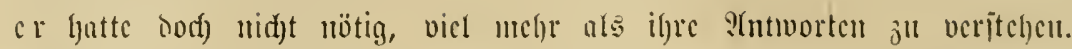

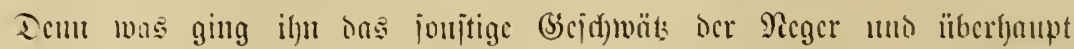

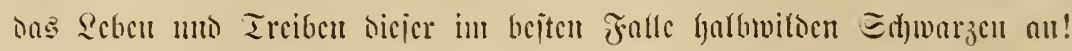

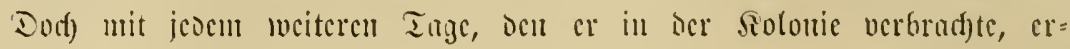

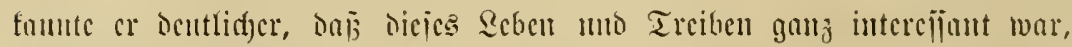

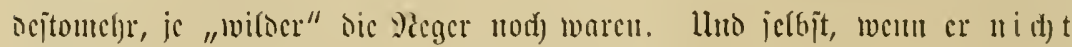

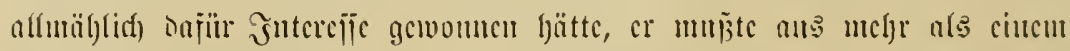

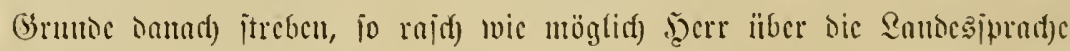

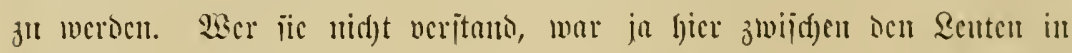

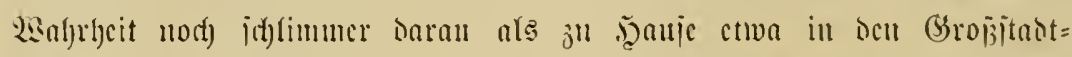

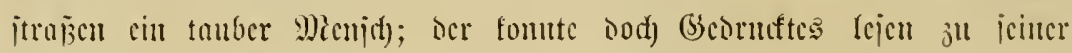

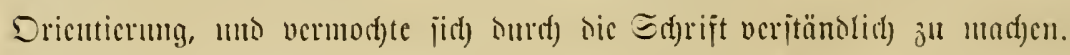

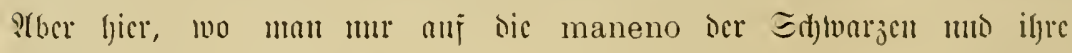
(Scitifulutionen angevicicu mar..... llno wic, ment er bic jago =

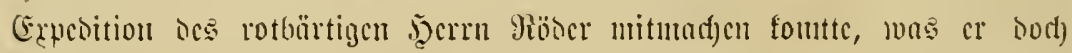

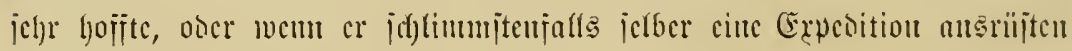

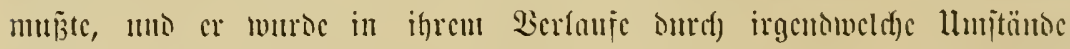

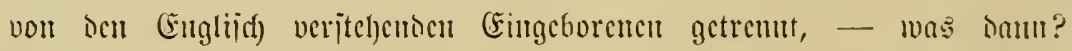

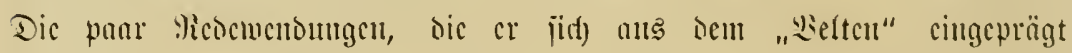

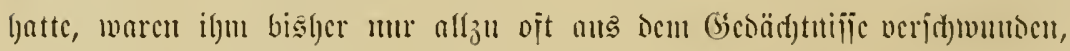

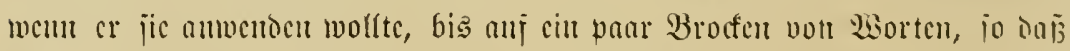

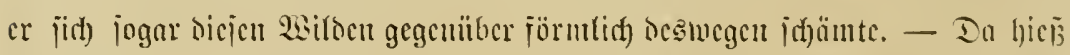

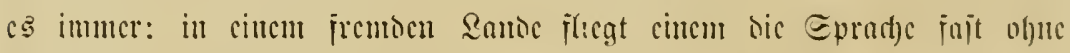

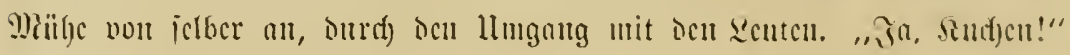

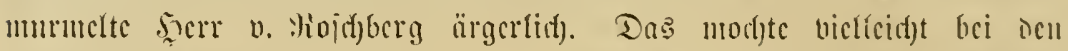

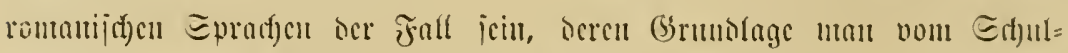

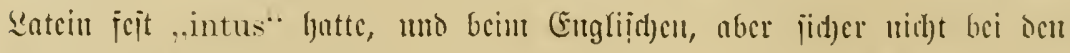

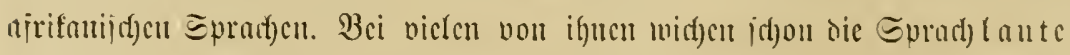

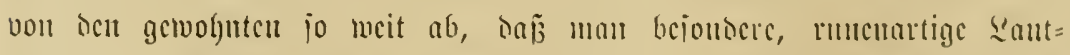

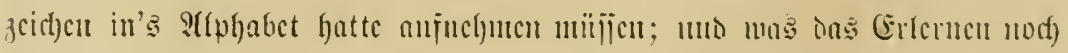

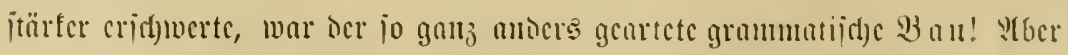

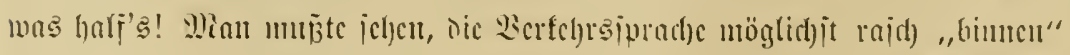

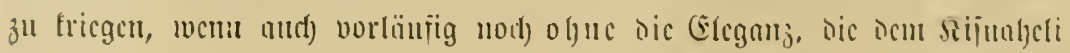




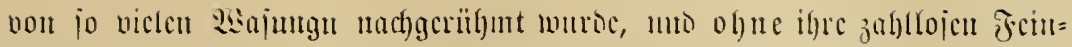

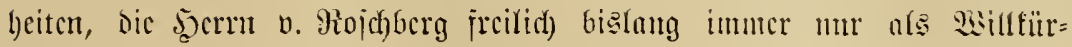

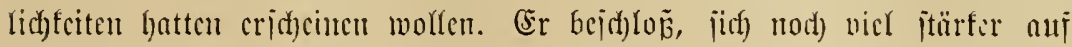

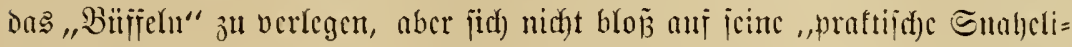

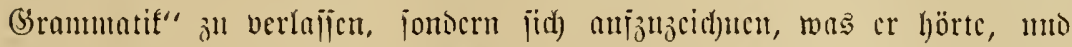

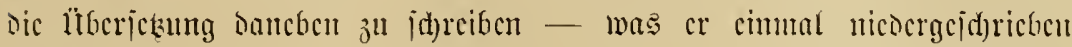

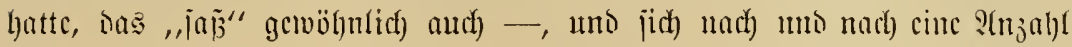

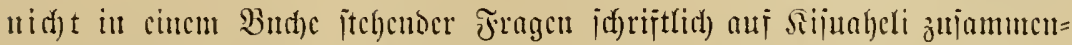

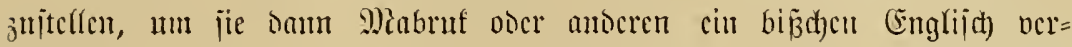
itchenton Farbigen zur Sorreftur borzulejen. So wäroc es wohl etwas

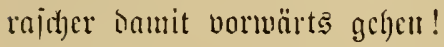

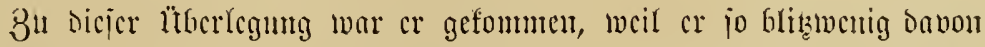

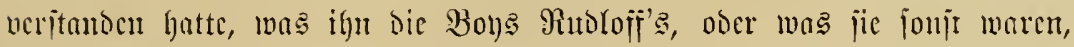
bei ber Erwähnung ics Eimfangens jencs muwwayi gejragt battert. Erit

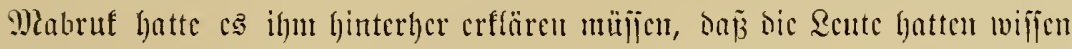

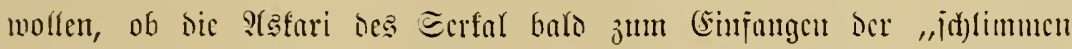

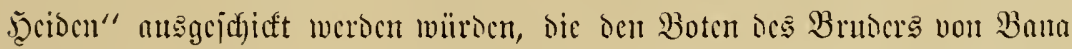

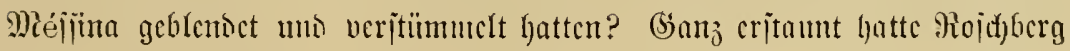

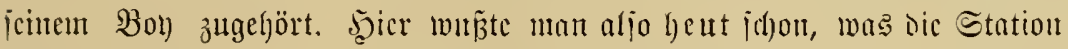

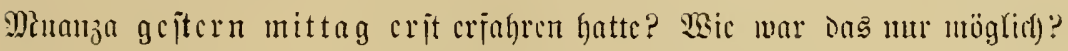

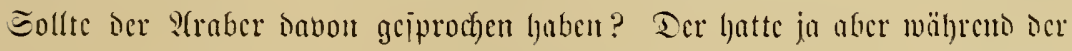

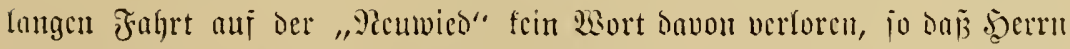

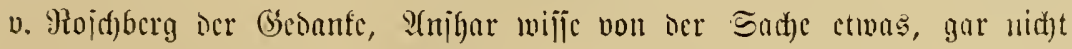

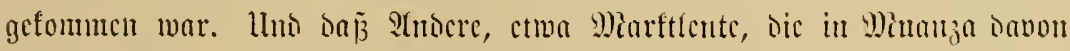

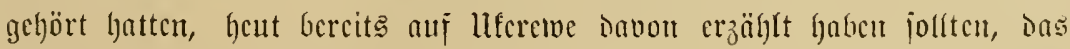
wotlte igm faum maghridgciufict) vorfonmen; or bätte cs

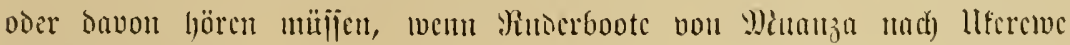
gcjał)ren mürcu!

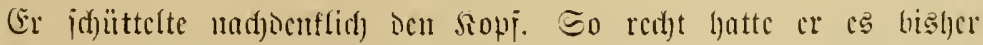

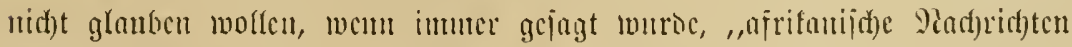

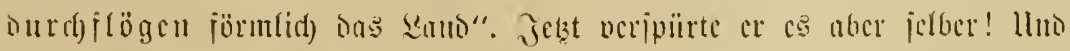

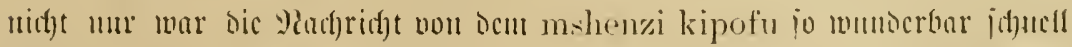

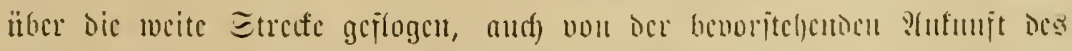

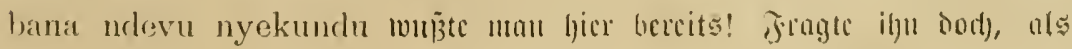




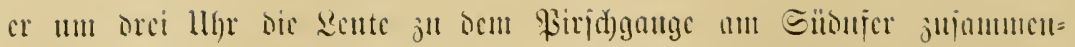

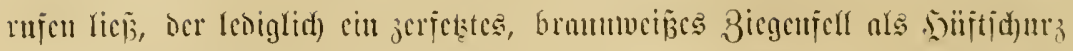

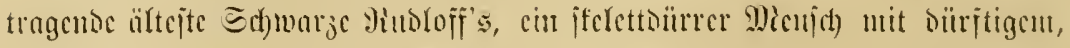

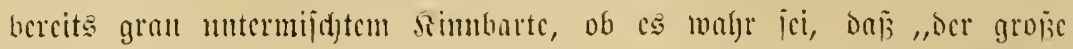

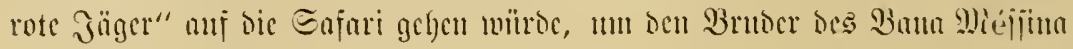

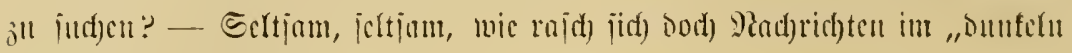
此eltcile" verbreiteten!

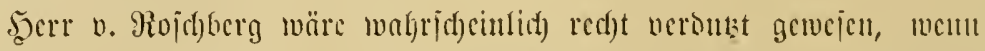

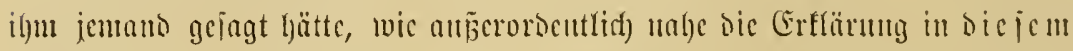

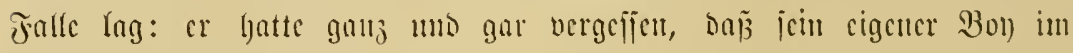

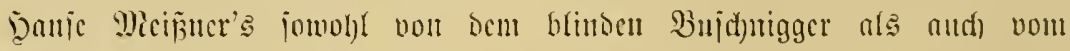

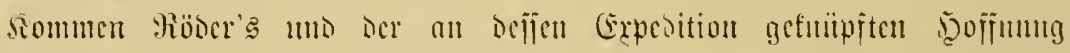

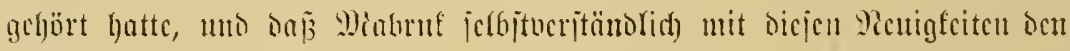

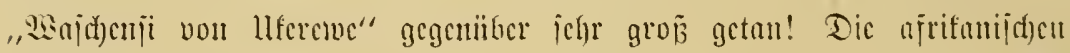

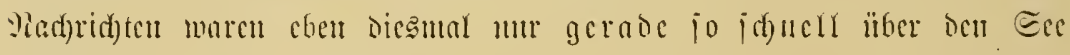

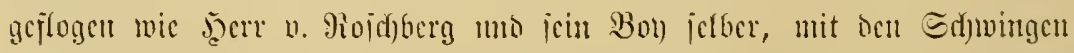

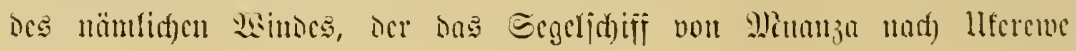
getrichen hatte!

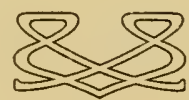




\section{Fünftes Kapitel.}

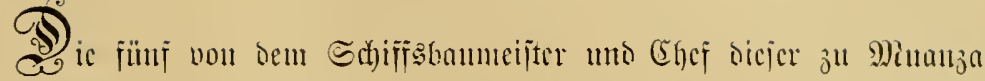

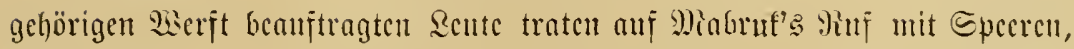

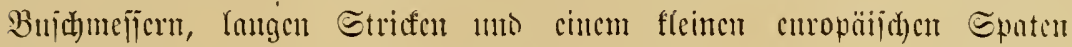

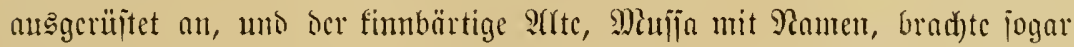

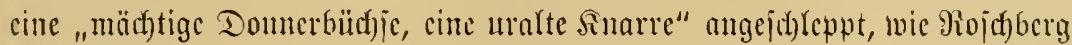

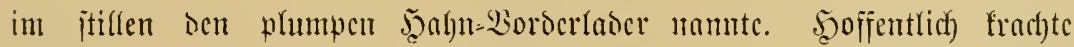

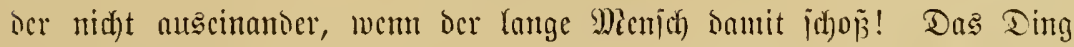

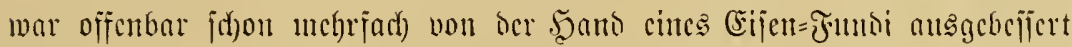

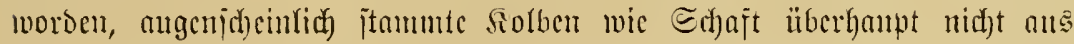

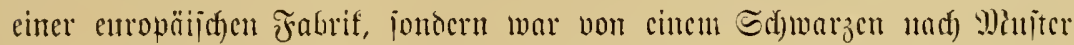

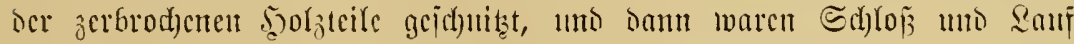

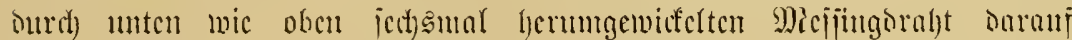

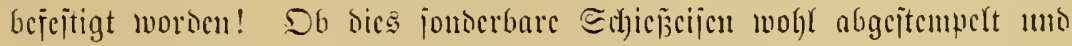

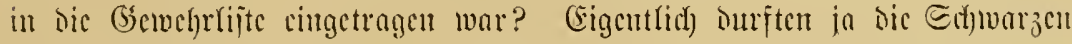

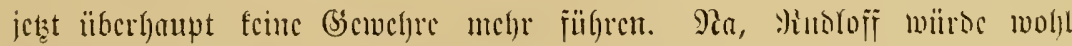

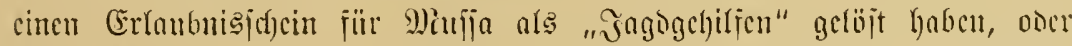

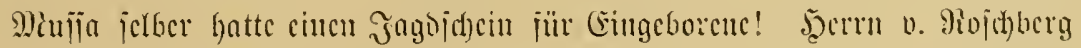

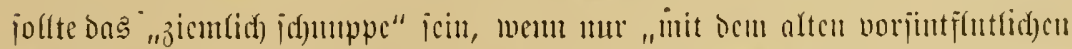

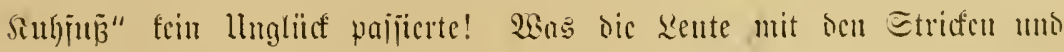

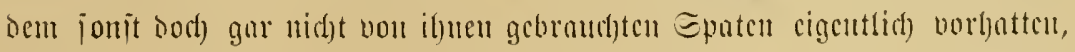

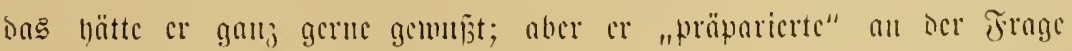

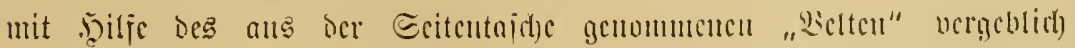

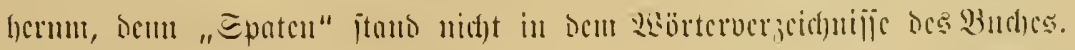
"Patürlid)," brmmute cr, "Dcmu do

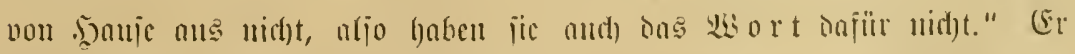

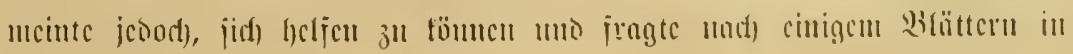




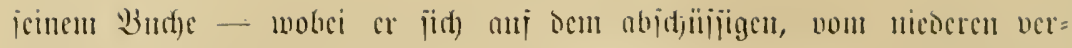

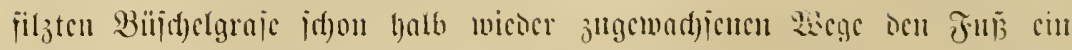

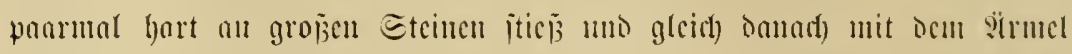

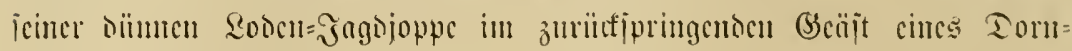

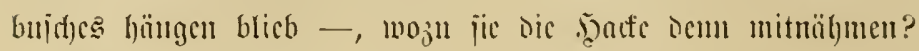

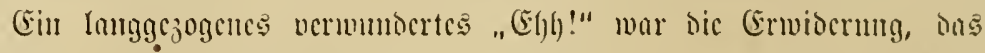

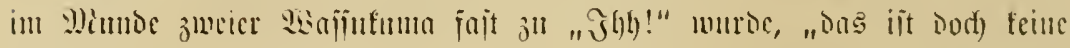

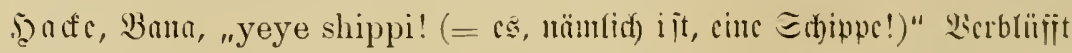

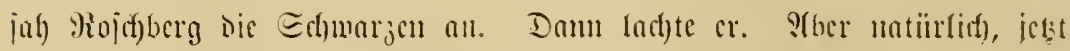

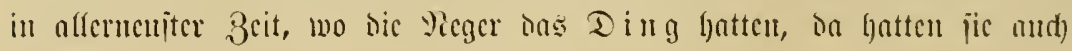

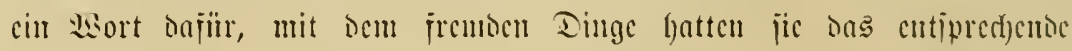

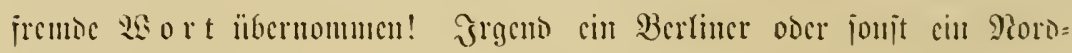

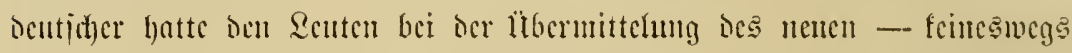

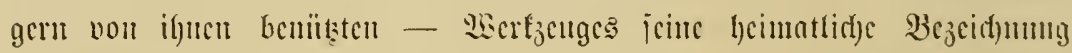

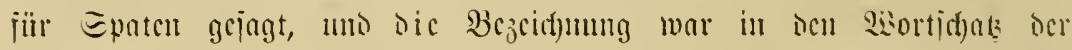

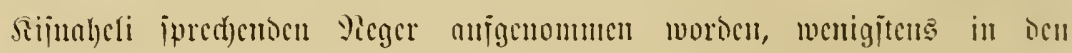

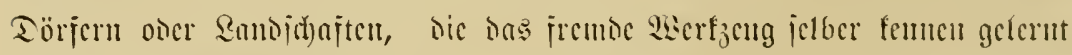

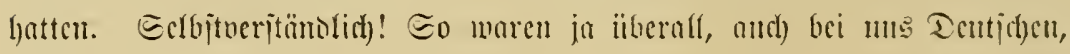

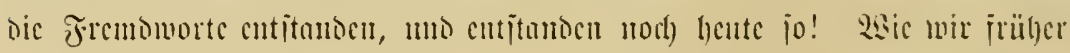
von ben dï̈mern mit ben Dingen bie 然orte porta mo currus befoumen

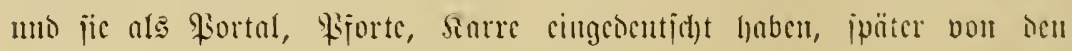
Fra jojen mit ocr Eadye bic Fremburte Soge mis Billett, von icu (E)

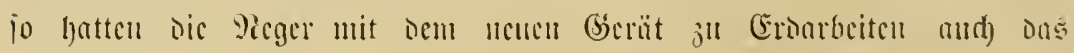

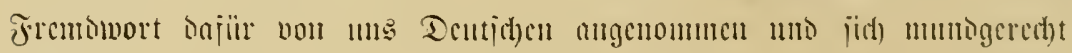

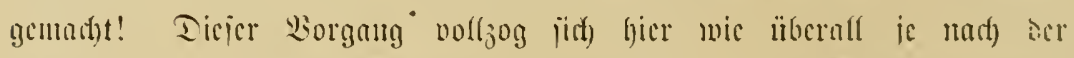

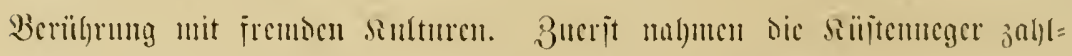

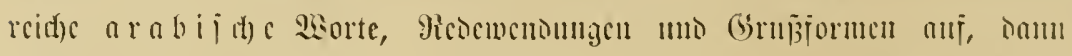

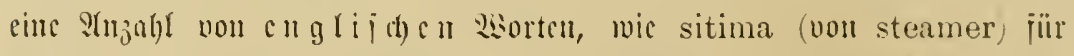

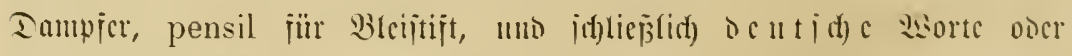

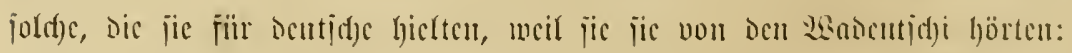
shippi, umorjen! weg! mo kaputti. Plumentlid) tons leste sisort mar

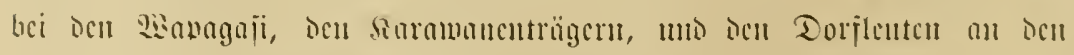

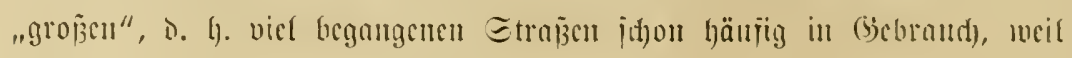




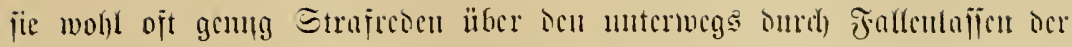
Traglajten faput gemachten Julgnlt ber Saijten umo Baffen gebört hatten!

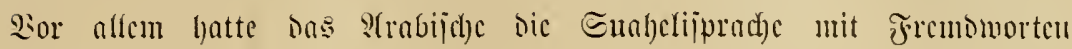

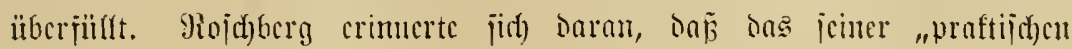

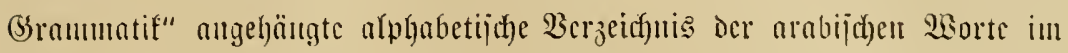

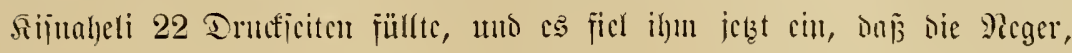

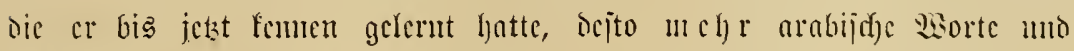

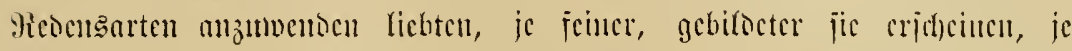

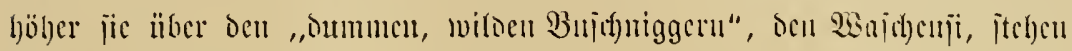

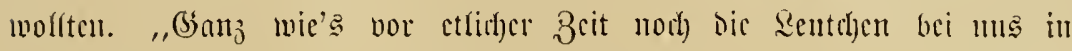

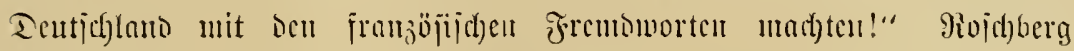

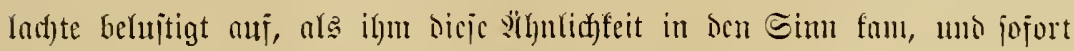

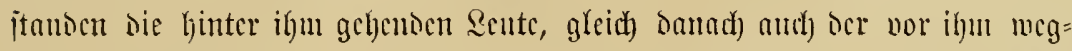

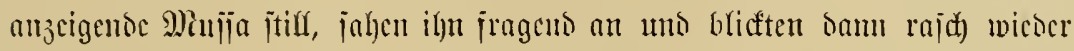

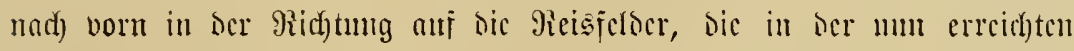

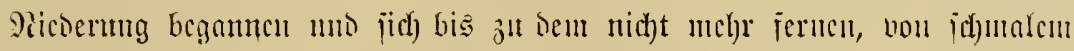

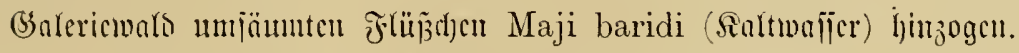

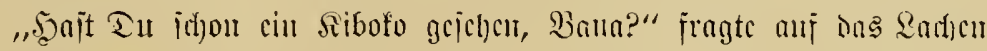

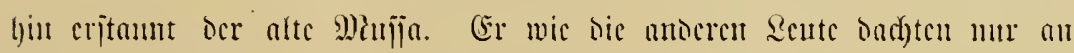

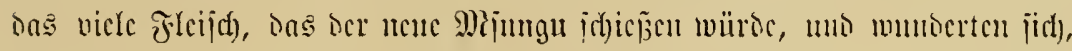

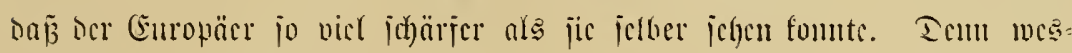

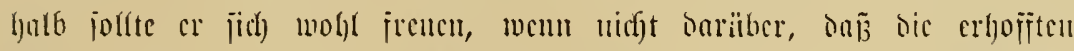

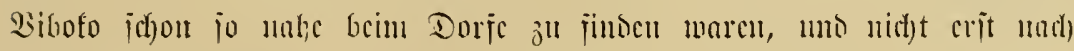

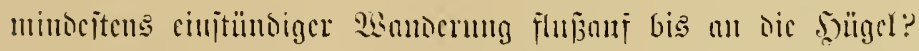

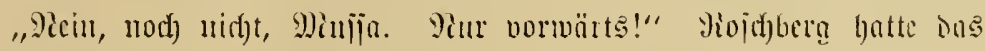
beutich) gejprochen, aher 9)

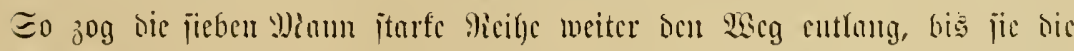

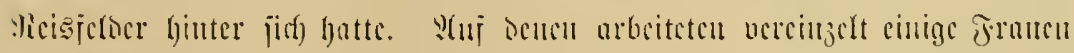

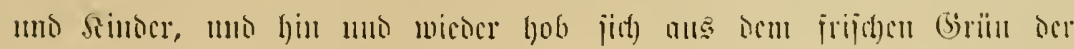

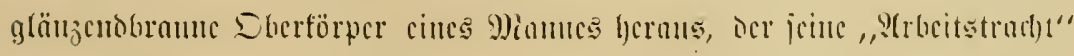

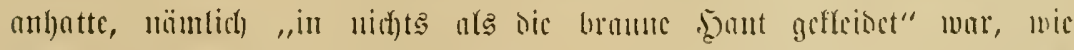

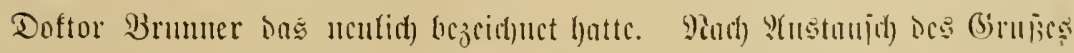

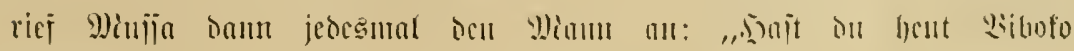
geiclycn!" 
„(E), vicle!" war regelmä̈rig Dic 9futmort.

"Sint jic noct) weit von fjicr?"

"Karibu, simbali (nabe, utid)t utelye weit)" gab ber erite, ber

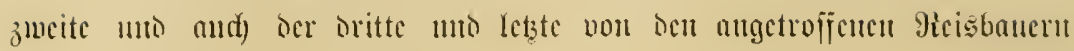

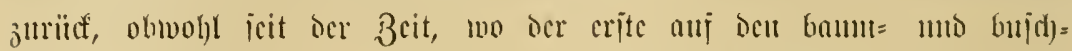

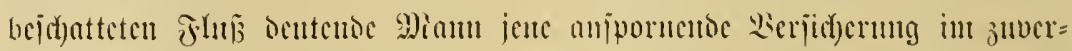

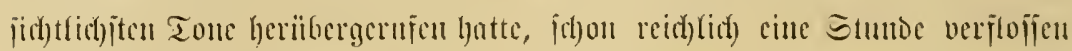

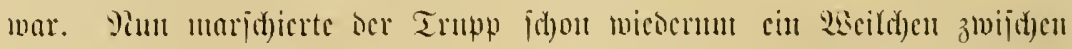

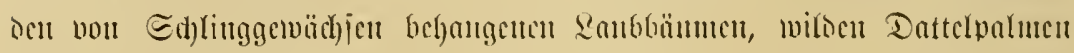

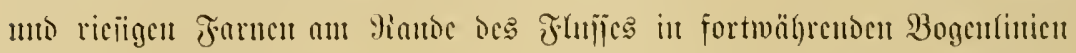

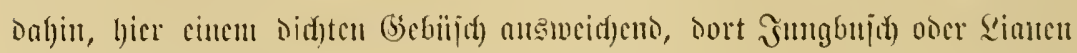

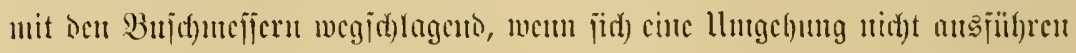

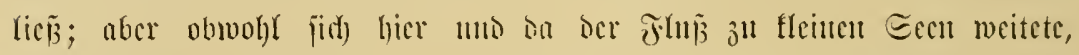

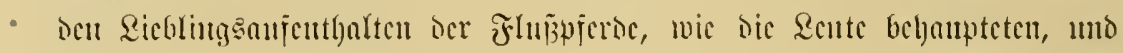

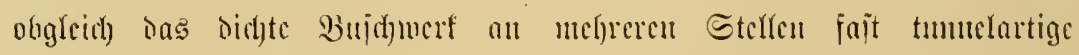

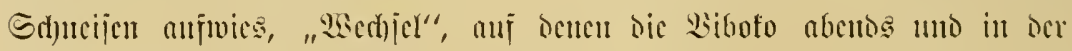

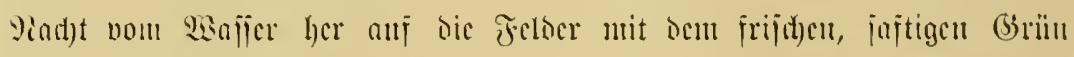

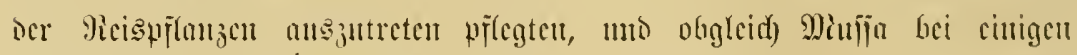

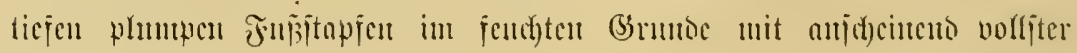

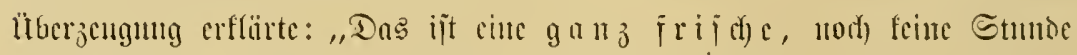

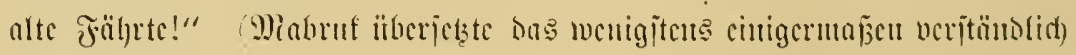

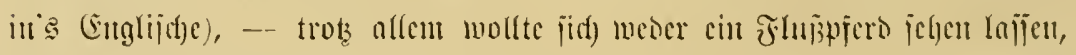
nod) börte Fojd)berg bei affer ?(nitrengung aud) nur in ber frerme das

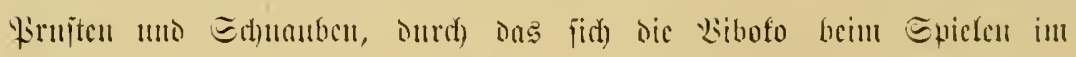

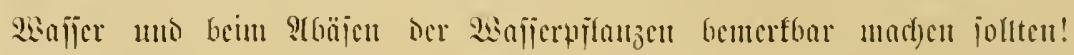

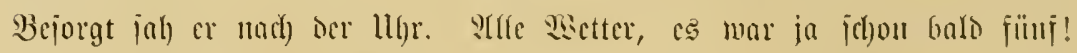

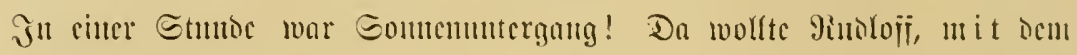

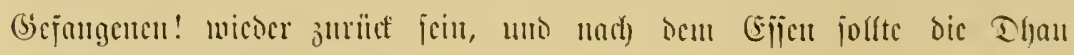

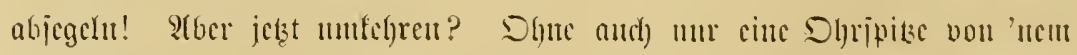

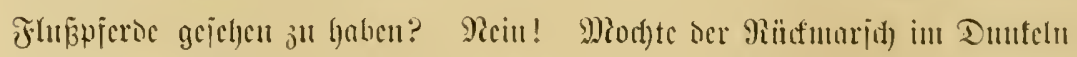

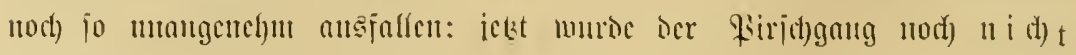

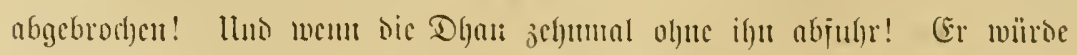

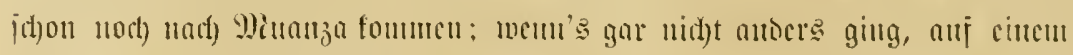

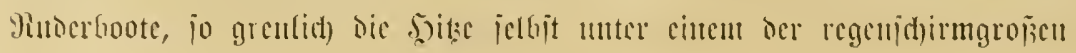


flacten Strohbüte jein mod)te, bie ar geftem ale Sad)uts gegen bie Eome

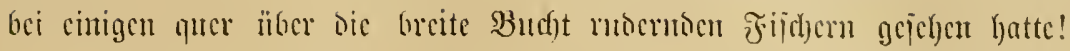

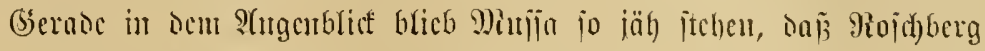

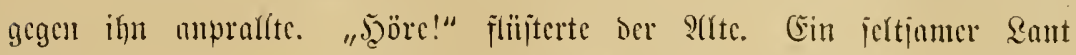

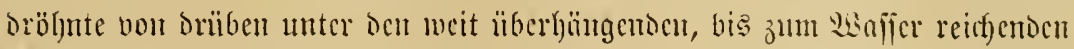

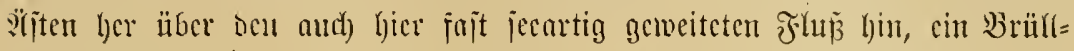

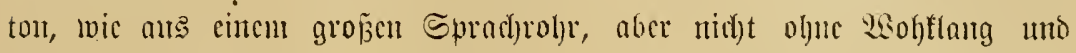

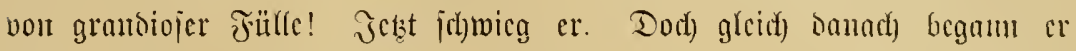
wieser, j(d)wolf mäat)tig an mit merflid)em Bifricren mo bradf) baum nnd)

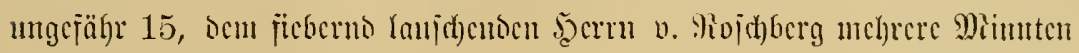

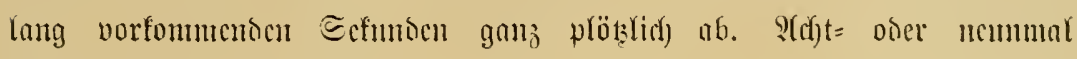
viescrlyoltc jïd) ons Brï̈lfen.

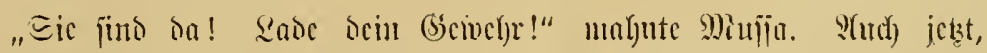
wic fajt bei jeser jeiner s̈ujerungen, dofmetjobte Miabrul, mo jugleid)

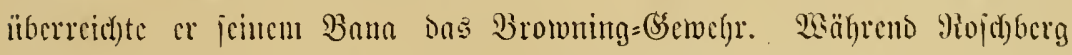

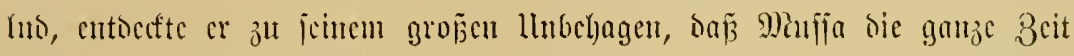

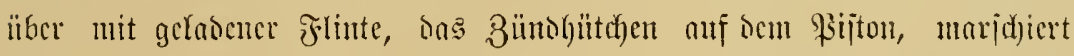

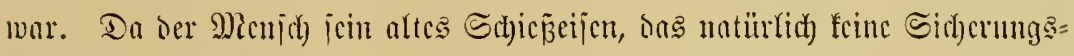

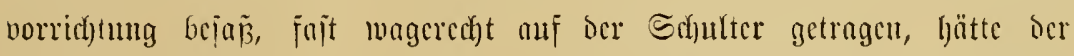

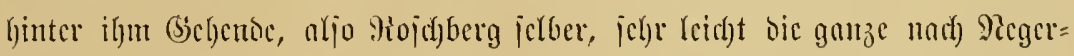

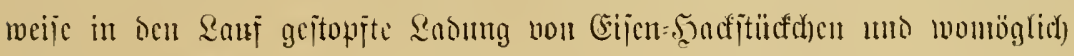
Steintacn in Sopj mo Burt fricgen fömen, jobars Minfia mu cimmal

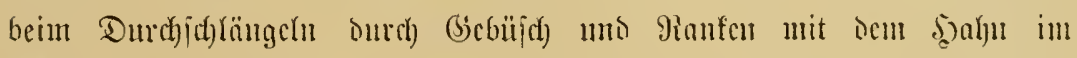

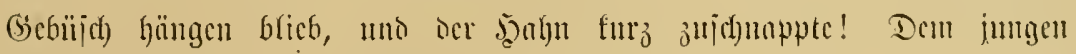

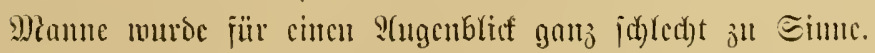

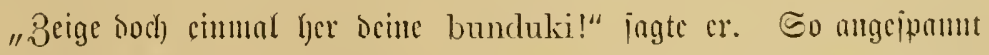

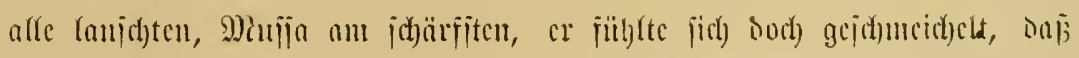

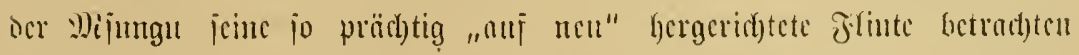

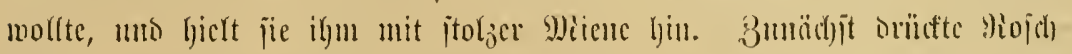

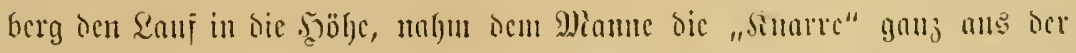

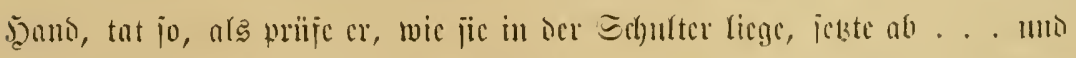

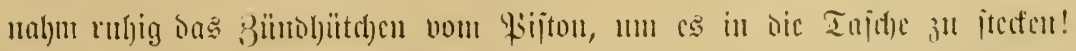

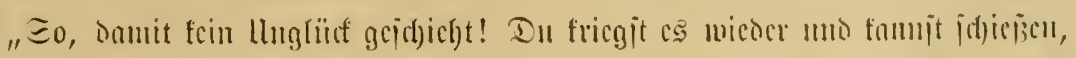

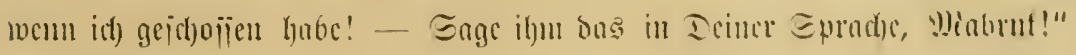




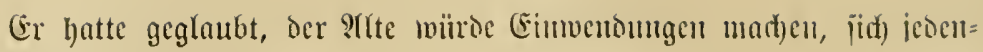

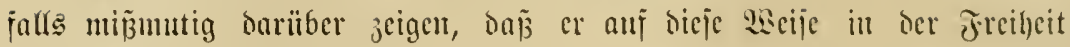

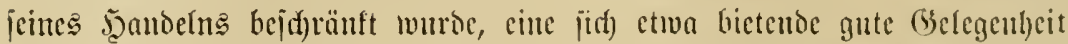

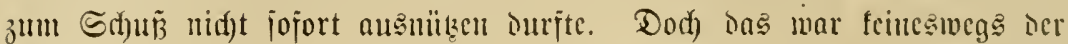

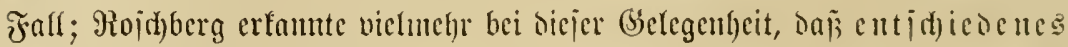

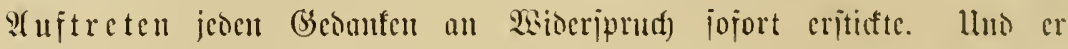

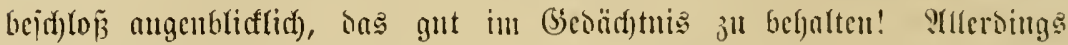

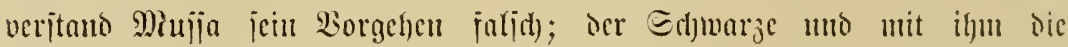

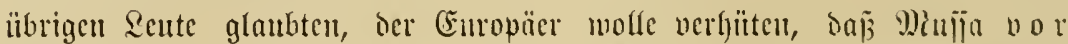

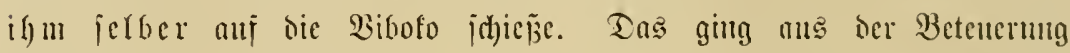

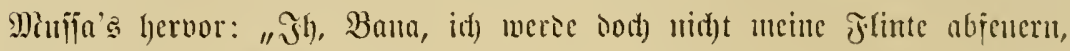
beodr Du cilt Rifofo geidfoifen hajt!"

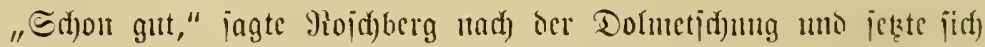

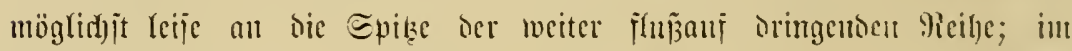
jitiffen aber bad)te er hei Mintija's "piga bunduki" (mörtlidf): Die Flinte

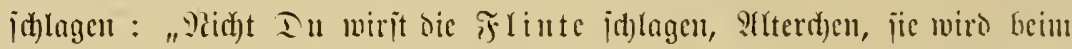

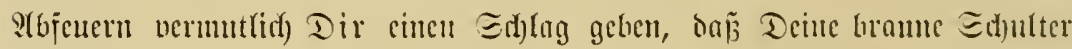

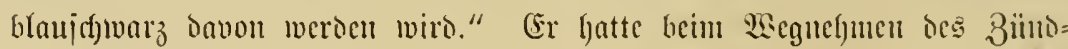

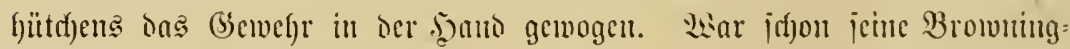

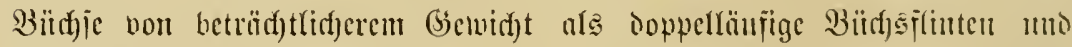

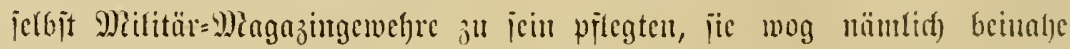
4 Silogramm, io fau ifju das (Bewehr Mijija's gar nod) jajt um bie

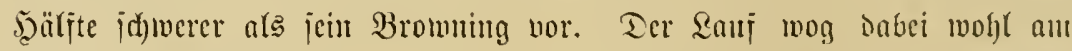
meif̈ter. Sonenjalle gut, ba $\tilde{\beta}$ er jo bicf war! Siojthberg hatte chen

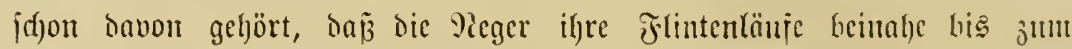

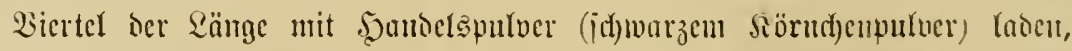

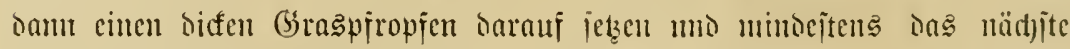

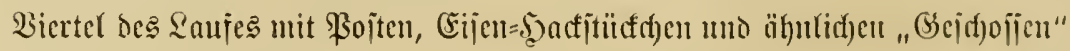

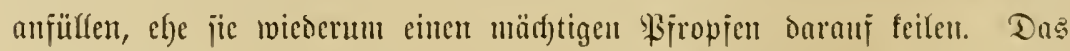
gab nid)t nur cin Donnernose Srad)en beim \$(bjencrn mo cinen ganz

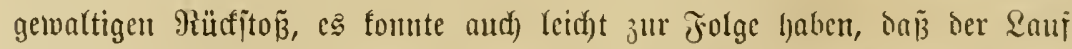

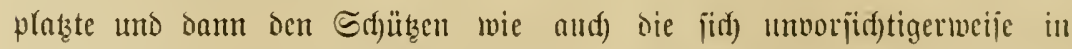

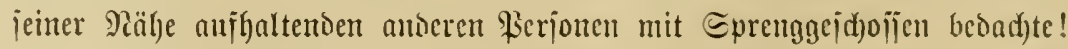

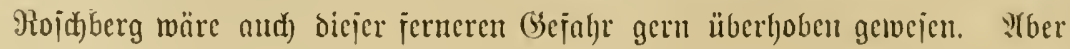




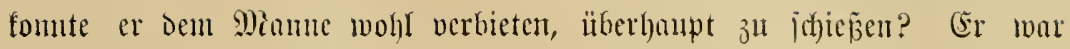
iid) nicht flar Durüber!

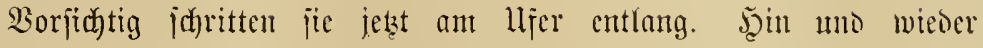

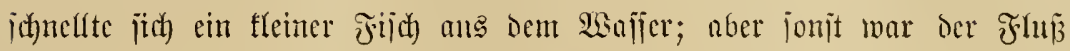

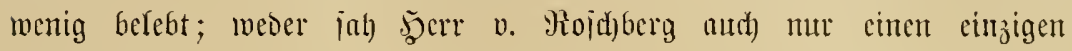

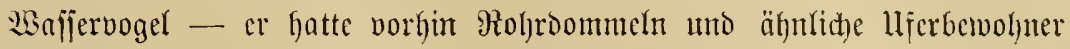
3u hören geglauht -, noch) entoecte er cin Sirofobil, trotzoem Miuja beim

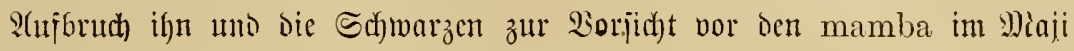

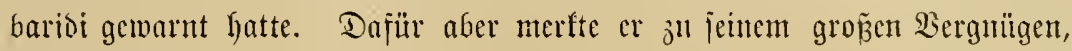

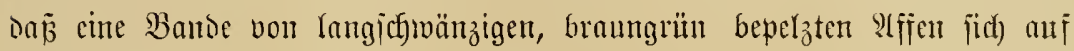

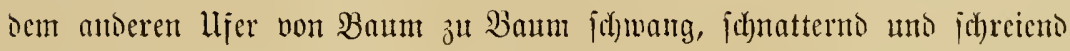

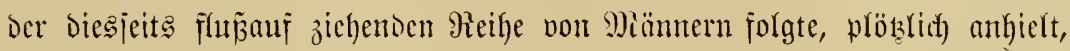
in itummer Peugier zwijhen don शijten herüberitarte unto sam wieder

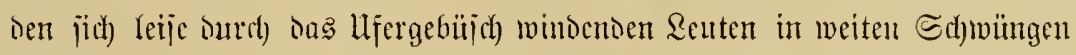

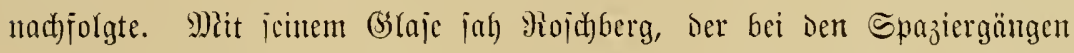

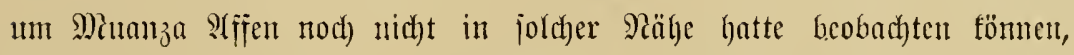

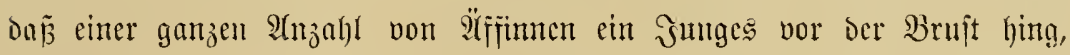

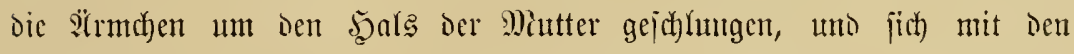

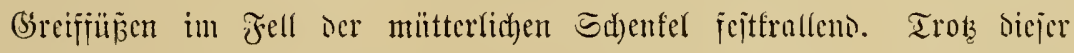

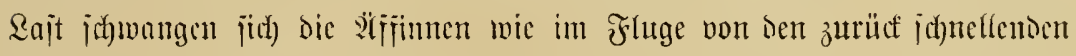

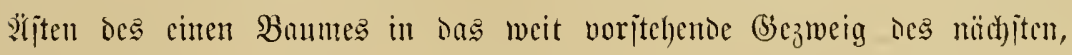
uno zmijhendurd fletterten mand)e Tiere mit malurbajt "affenartiger

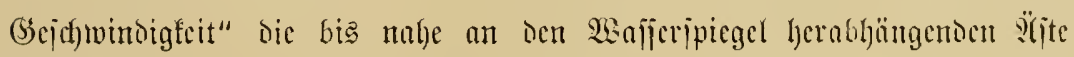
abmürts, um cineu Dicbsgriff in flcint jurzeit tcils mit EFicrn, tcils

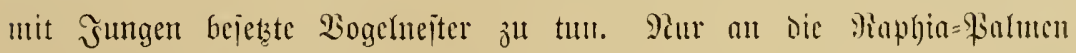

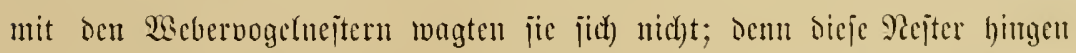

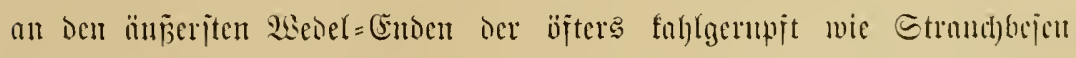

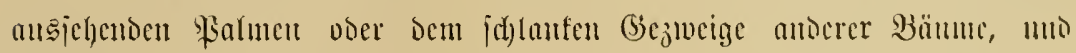

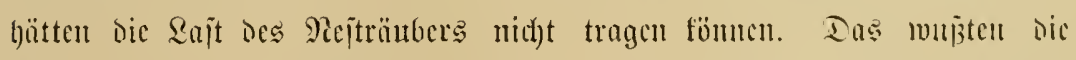

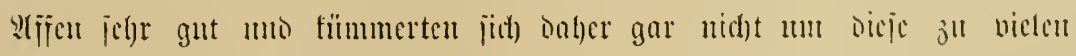

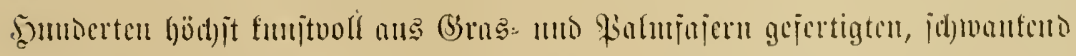

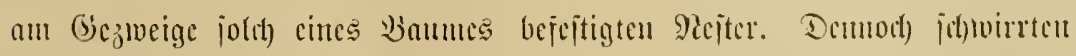

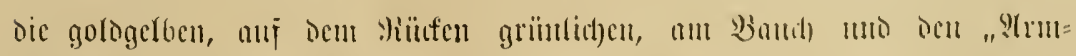

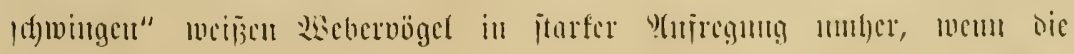




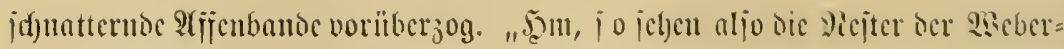

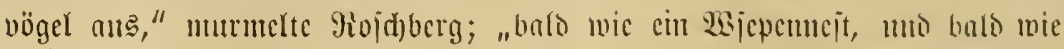
cin Ianger Strumpi, ober wie cin umngetchrt nujgchängter Micitcriticjel!"

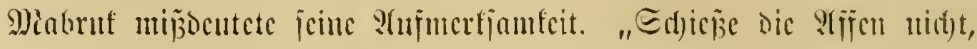

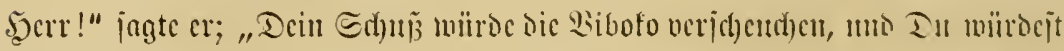

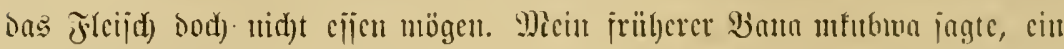

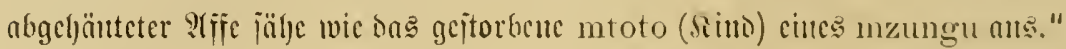

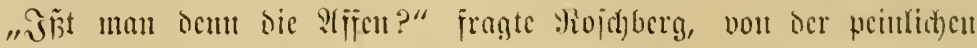

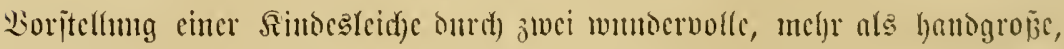

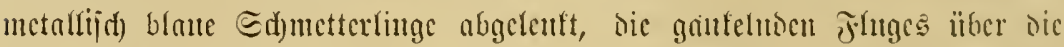

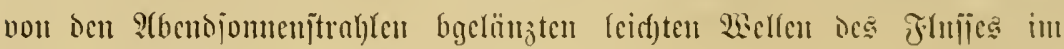
Siebcsipicl onginidguchten.

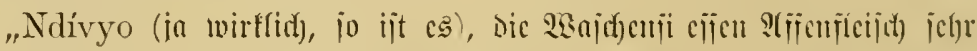

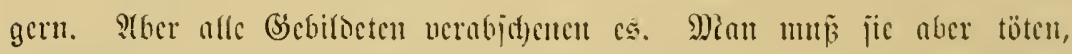

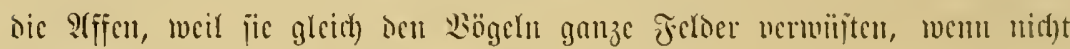
genïgens siandye dabei gebalten werben fum."

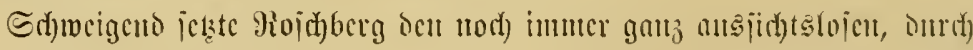

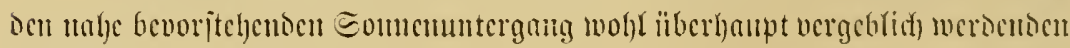

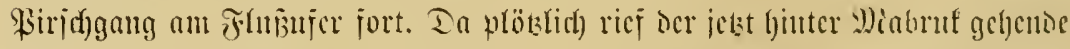

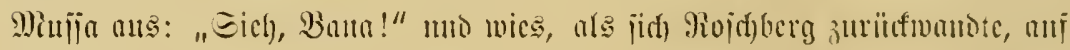

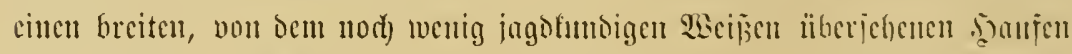

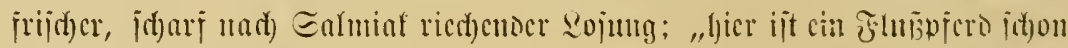

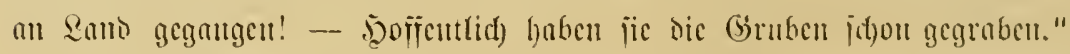

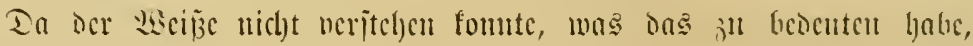

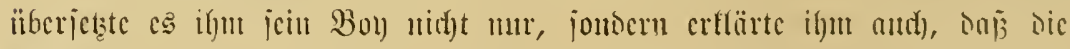

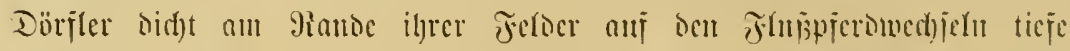

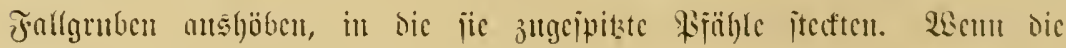

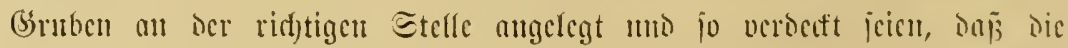

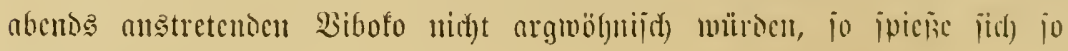

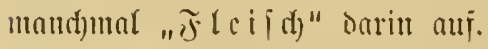

"Micinjt Du, Daj wir bem Tier Had)geben jollten?"

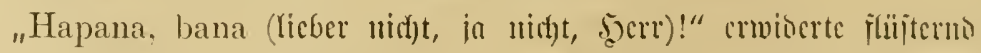

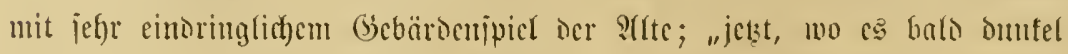

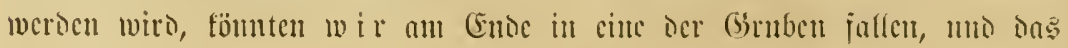




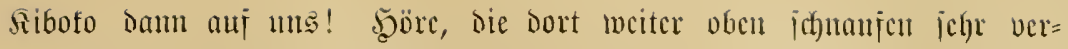
guüglid)! Ta werdocu wir's wohl Ycidyter haben!"

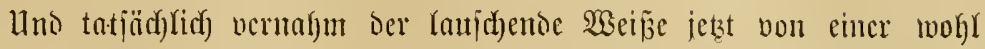

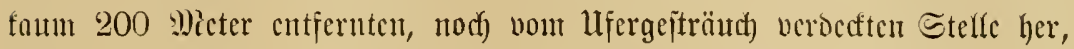

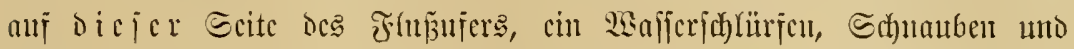

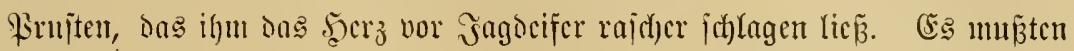

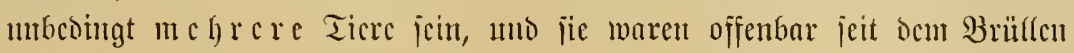

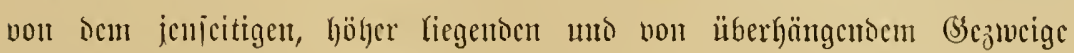

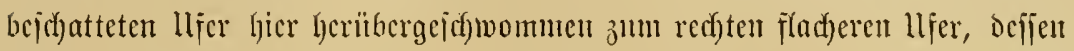

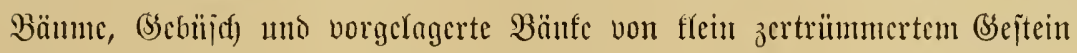
nod) rotgolocn von ber bercite jefre ticf jtehenden Some belcuchtet waren.

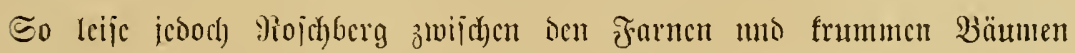

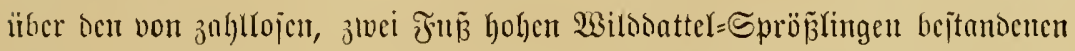

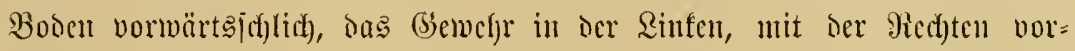

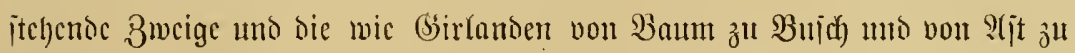

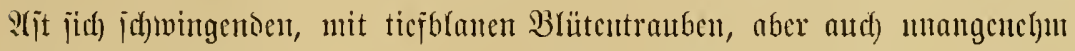

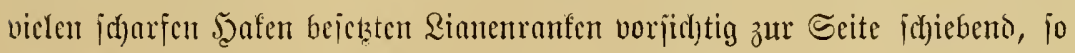

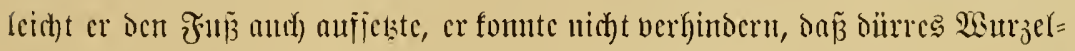
merf unter jeinem Tritt fnacte und das non den jungen Dattelpfläujlingen wie

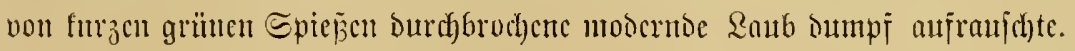

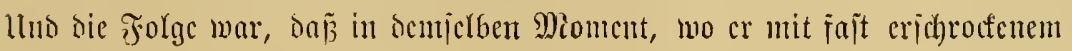
Etaunch jun crîtenmal in jeincu \&ebon onen ricjigen, fajt einen Wieter

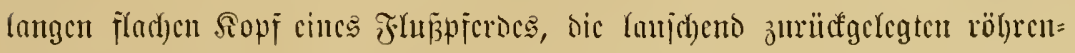

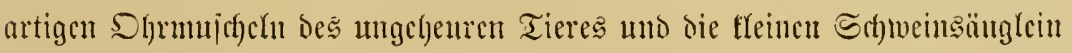

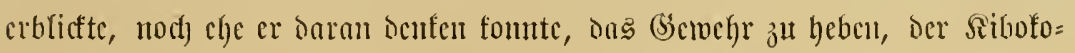

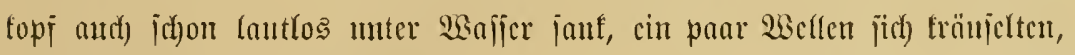
mo ber Epicgel ocs Fluffes dam jo glatt vor ocm ïtberrafaten balag,

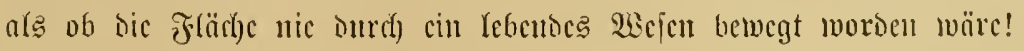

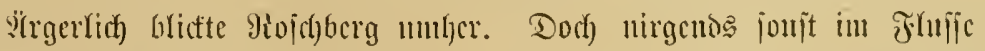

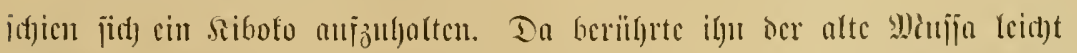

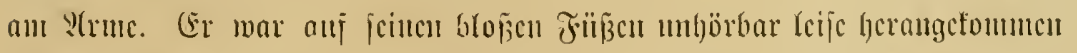
uno Deutete aujwärts. Tort lag cin mäd)tigcr, granflancr, fajt gunz vou ricichnocn

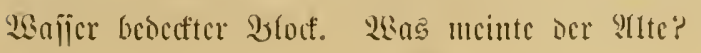




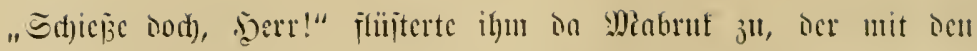

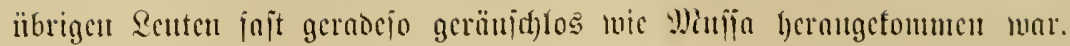

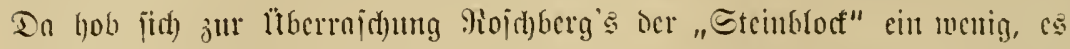
flajite cin ungel)eurer, rojajorbener, mit nuit)citeno regellos verteilteu

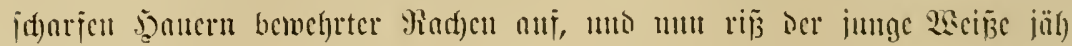
Den Brouming an bic Bacfe uno jeuterte, jajt olute nu's Biclen zu Deufen,

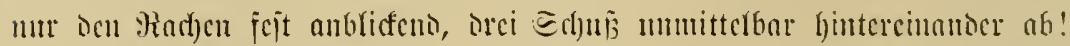

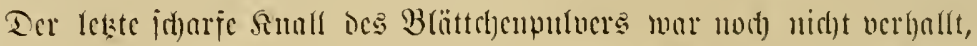

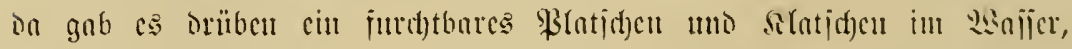

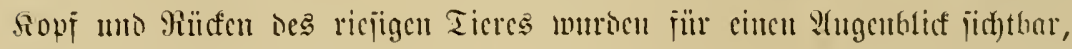

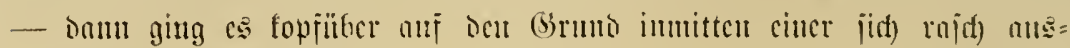
breitenden ungel)euren Bluttache!

"Es ijt tot," jagte Manjia Icije, mto Miabrut dolmetict)te; "cs mirt

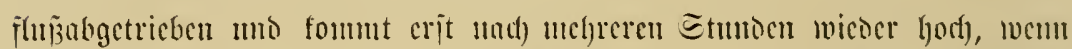

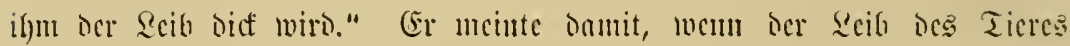

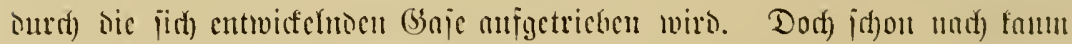

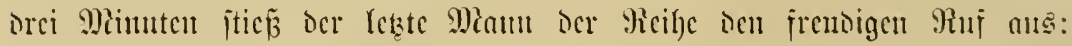

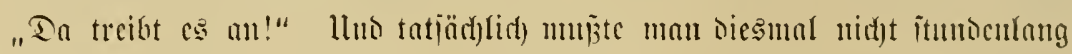

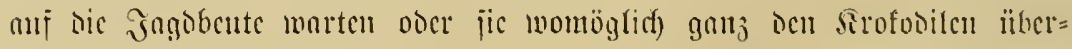

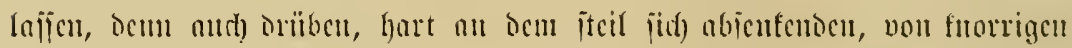

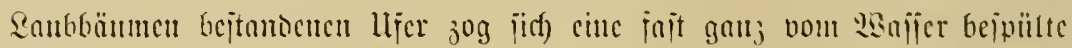

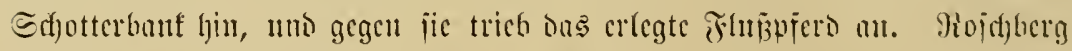

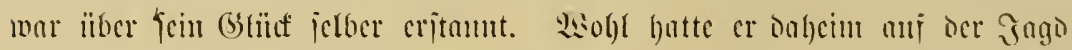

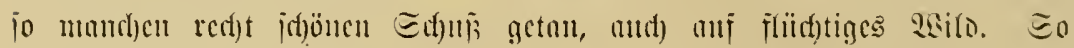

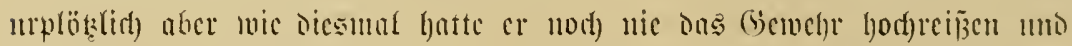

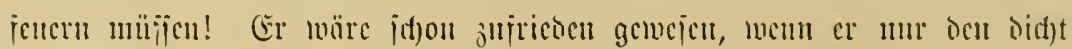

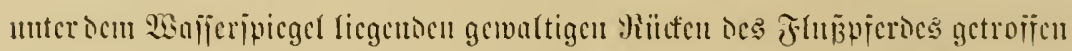

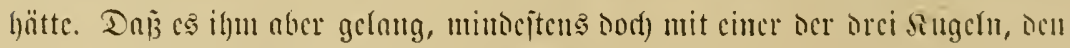

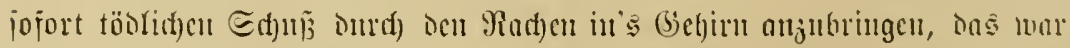

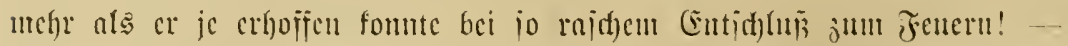

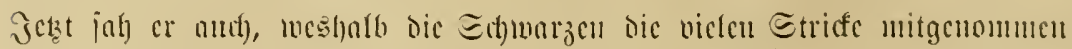

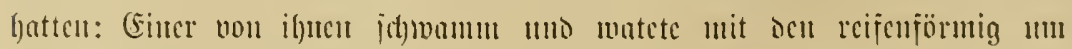

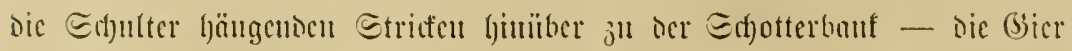

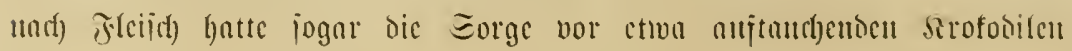


bejiegt -, befeittigte um die jüulenartigen 2orbcriürīe bes nod) immer

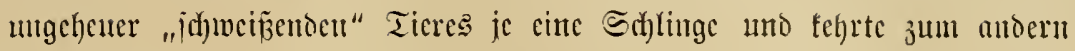

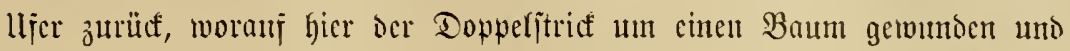

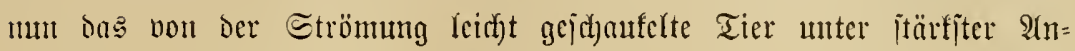

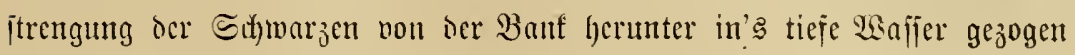
wurte. Sangjan tricb cs cill wenig ablwärts, uno ale dic Stricfe jich nun

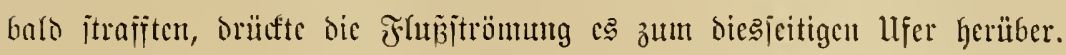

Dic Rcute hatten ifhn in ien näd)ĭten paar Minuten nod) ein paar

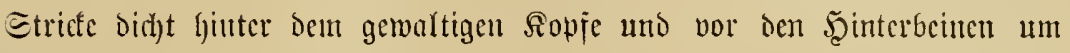

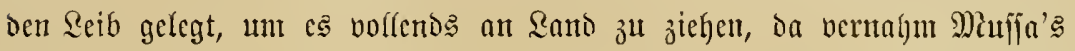

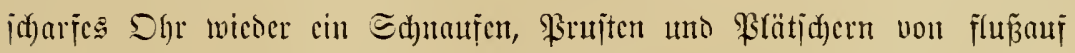

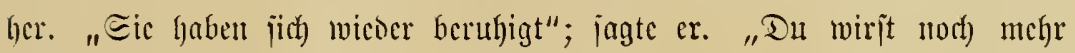
Ş́lïaf jïr Dein Sscmegr haben, Bana."

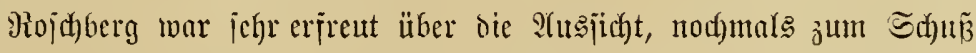
fommen ju fönmen. Das erjtemal war es ja im Grunte mur "Edymein"

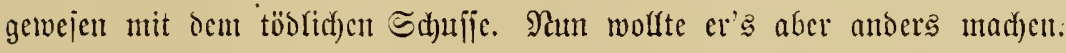

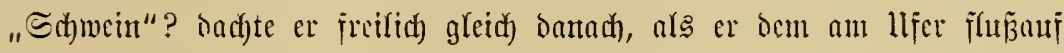

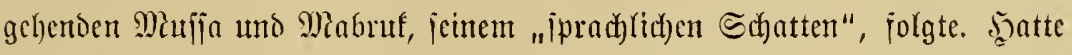
er's ocrn nidjt gemadyt, wie es ber alte Förjter Schwarze bei Onfel

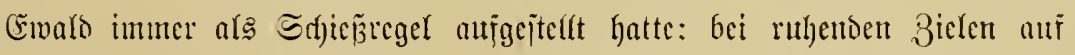

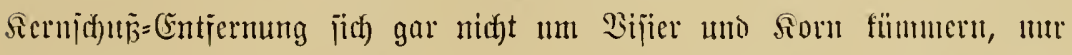

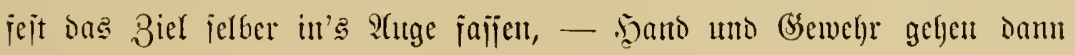

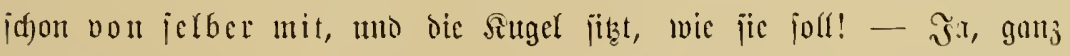

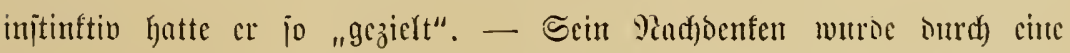

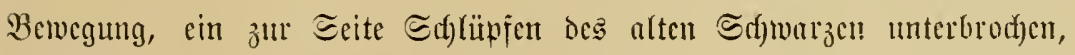

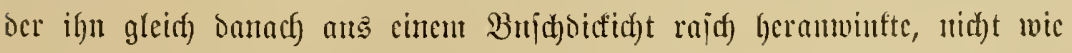
wir wit ocm 3eigcïnger, jonocrn nach Piegerweije, intom er ifm oic ganze

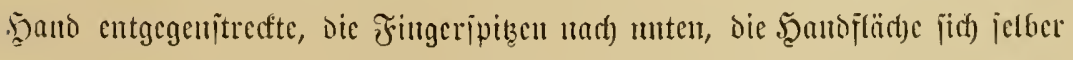

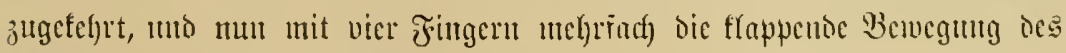

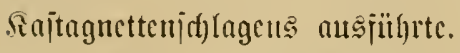

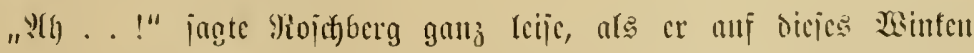

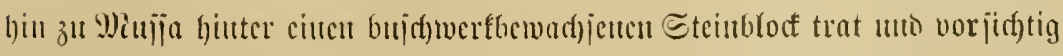

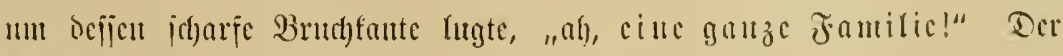

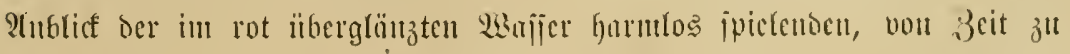


3eit ein par zarte sajjerpilanzen ausrupenten pier Tiere intereijiente ihn io, da

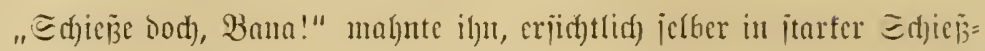

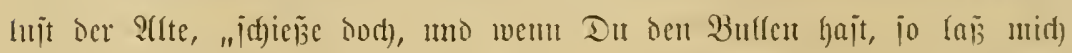

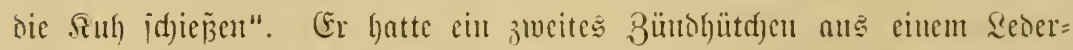

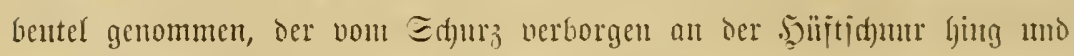
malyrid)einfid) autser cinigen Sutgeln nod) cin Söctd)en mit Rulver enthielt;

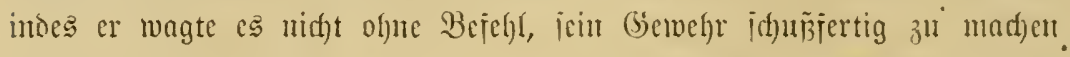

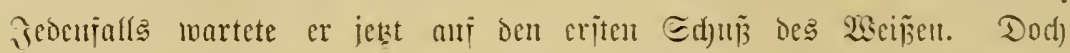

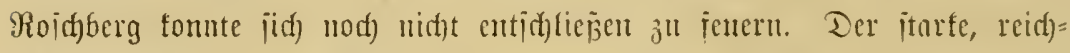

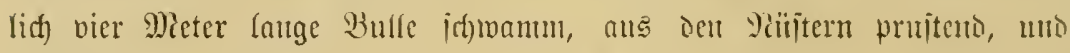

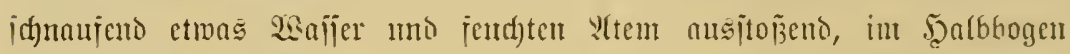
um die Ceinen herum, wie um jie beijammen jut haltert. Der müdtige, jtarf gemölbte, im siajier blanjichmarz idjimmerntoe Riüufen hob unto ientte

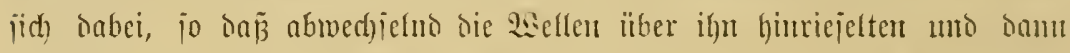

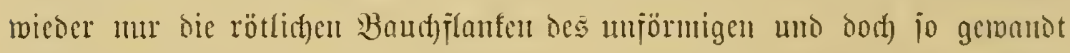

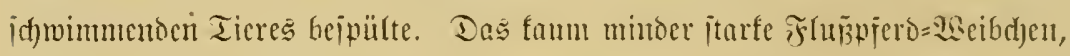

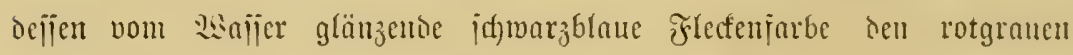

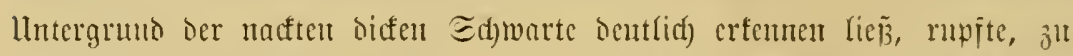

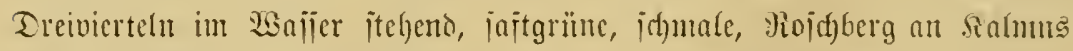
erimmentue $\mathfrak{B}$ lätter ab, blicfte dabei aber bie beiben jungen Iiere neben jid) in einer 然cije an, als mollte es ifnetr jagen: Selyt bod) her, jo ntilizt ihr's

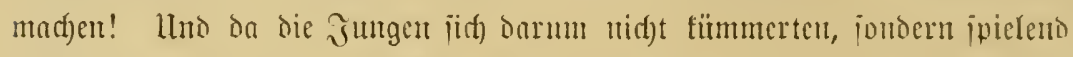

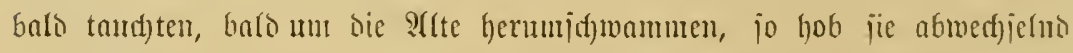

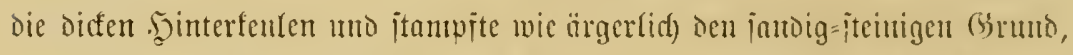

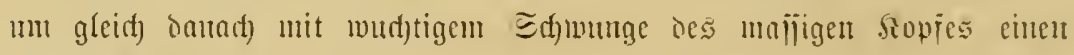

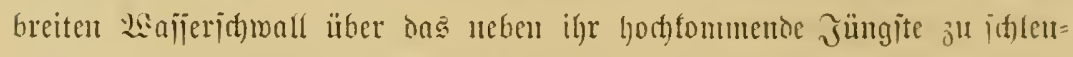

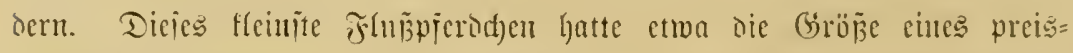

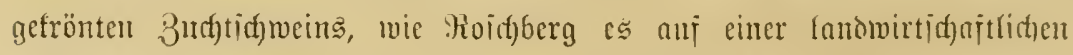

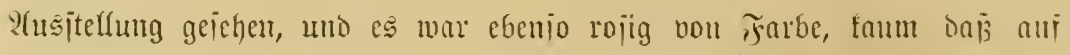

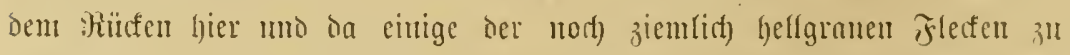
jehen maren, die mit der Beit jajt den gejanten Win̈ten bis himunter zum

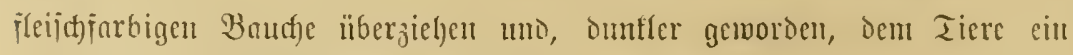
Glaugraues, nacftglänjentoes Stušjehen geben. Das antore Junge war 


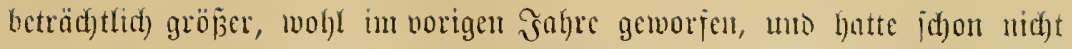

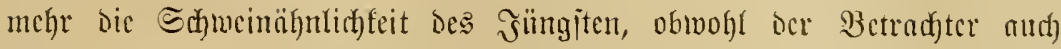

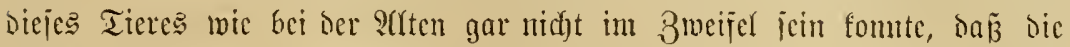

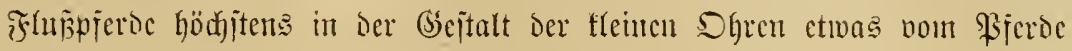
hahen, jonjt aber melyr Berwanotidaft mit oen Edyweinen nis mit irgento weldyen anoeren (sicjübijen aujmeijen.

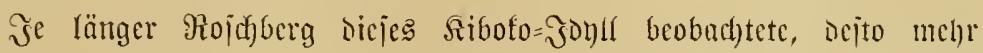

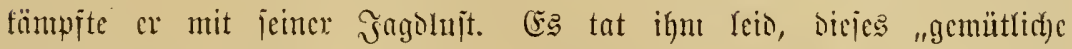
F̧amiliculehen" jeritören ju jollen! Stllerbings, bic Biboto waren arge Schamben=2ermüiter überall on, wo jie es bom fruz obcr Sec nicht all=

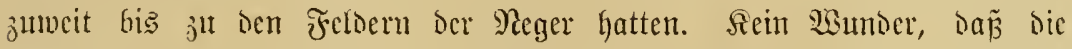
Scute ifnen mit Fallen; und wem jie Schupiwaffen hatten, auch mit

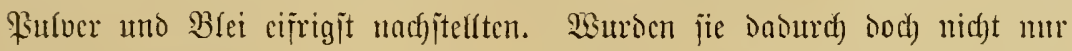
Dic jd)limmen Räuber und 3ertrampler ifrer viel 2 trbeit fojtenden Felder

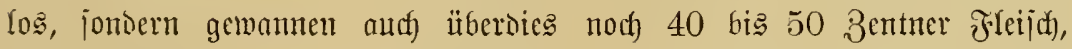

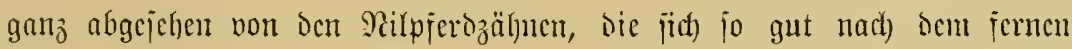

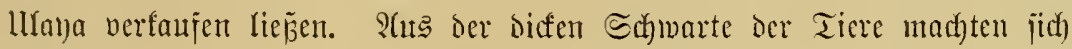
dic Peger meniger. Sie jelher hatten feine Berwentung dajür, unb jie

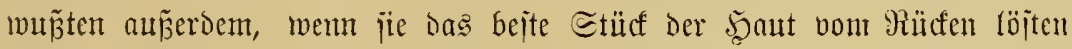

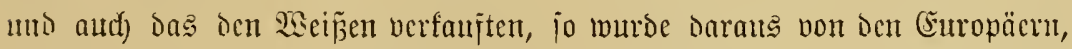
nad) Dem Borbirse tyrmuijher Sultune, Der furzweg "Sibofo" genamite Etoct ooer das jwiegeffodtente peitichenartige juitrument gentad)t, das,

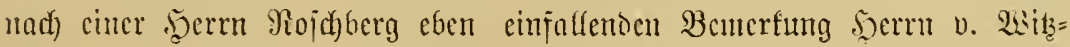

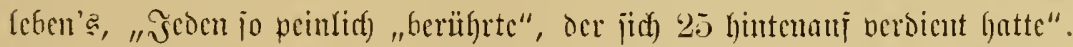

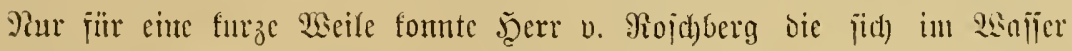
tuntmefnocn Tiere bevbachten. Dem eben fnacte cin bürrer slit unter

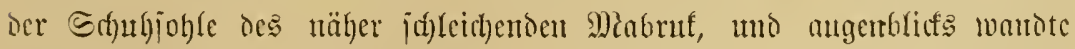

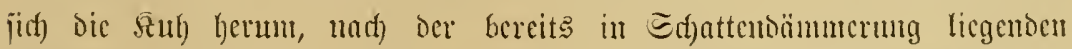

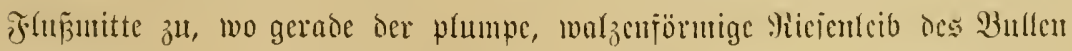

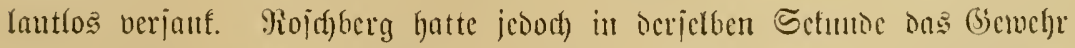

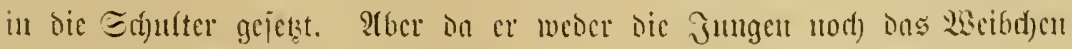

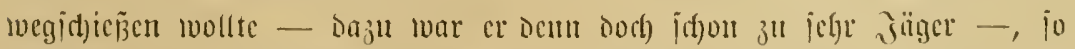

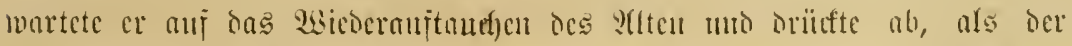

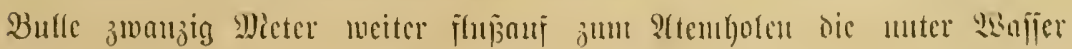




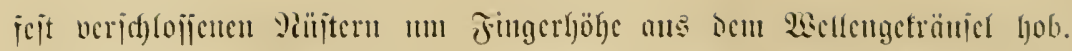

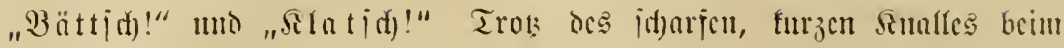

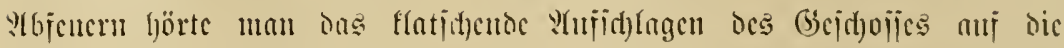

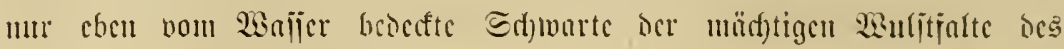

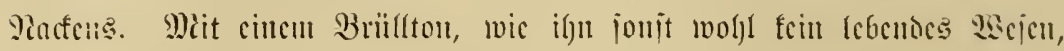

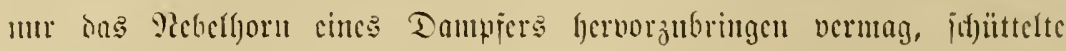

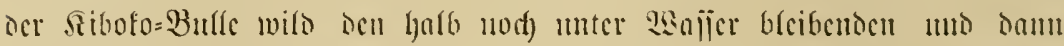

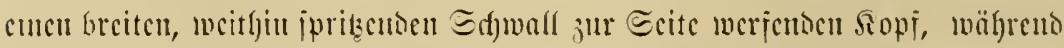

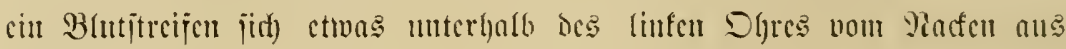

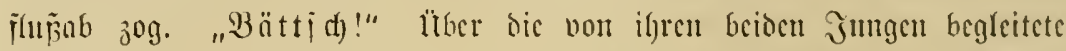

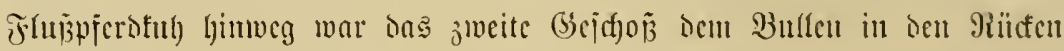

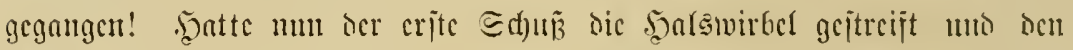

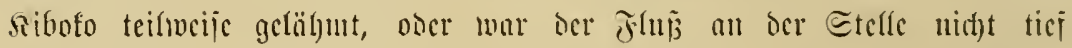

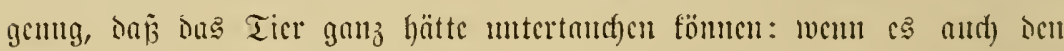

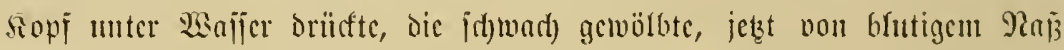

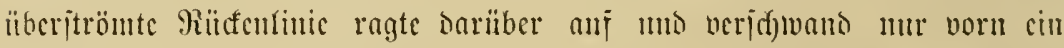

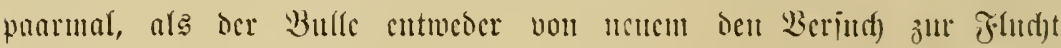

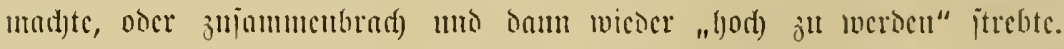

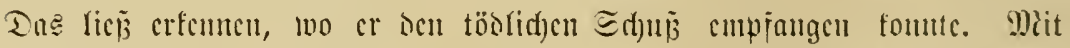

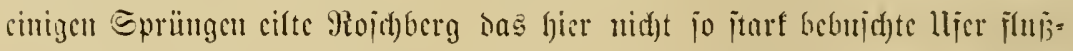

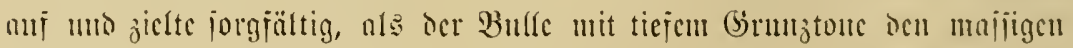

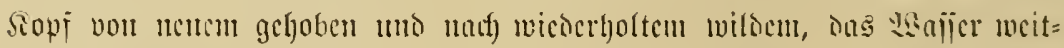

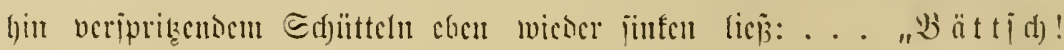

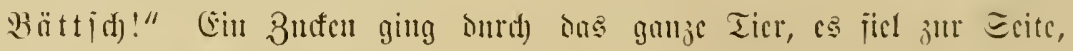

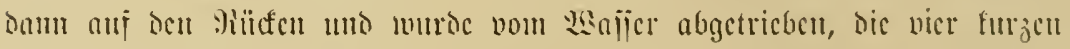

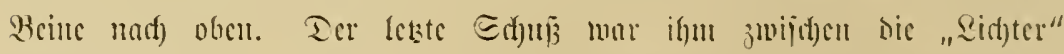

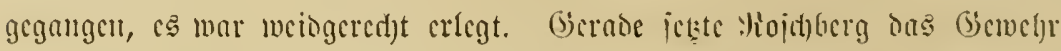

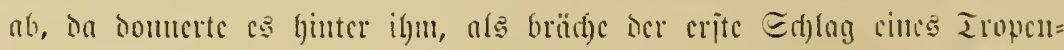

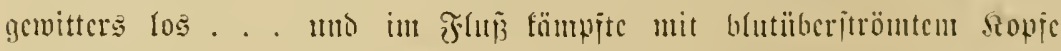

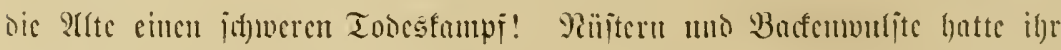

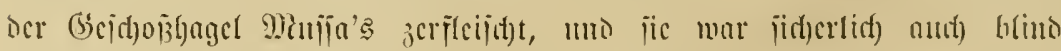

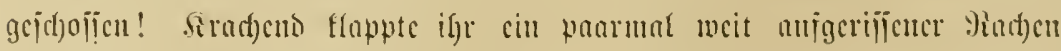

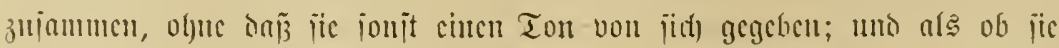

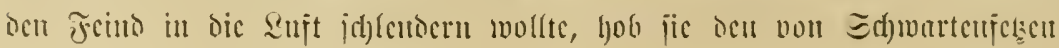




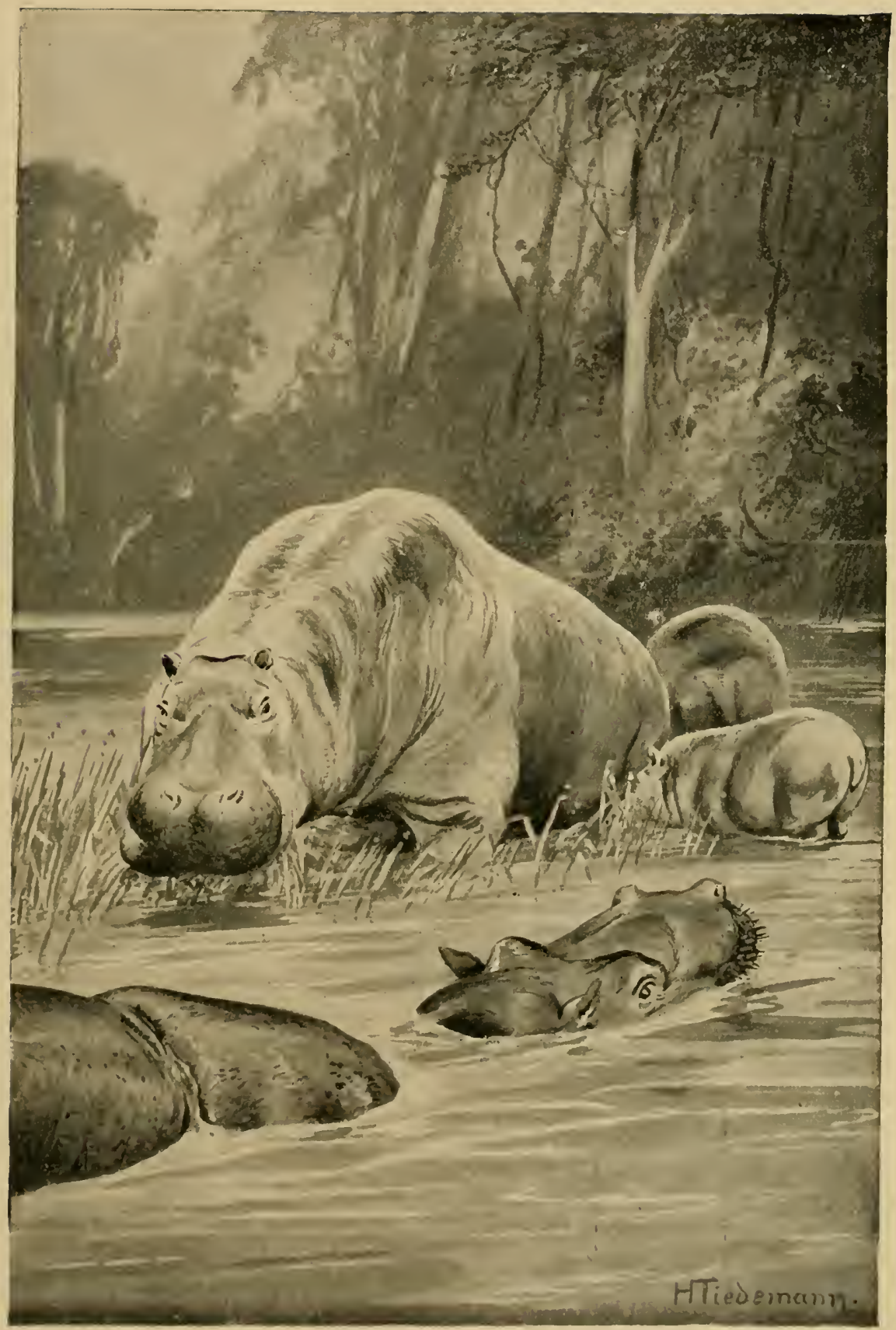

Es tat ihm leid, diejes "gemuitliche Familienleben" zeritören zu [ollen! (Evite 137.) 



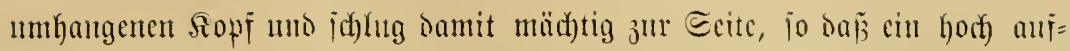

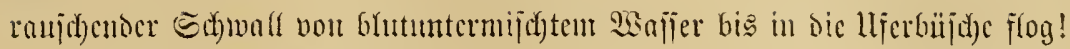

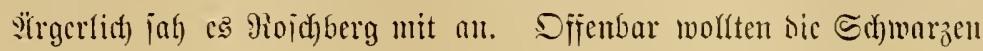

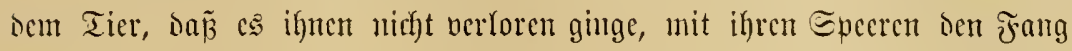

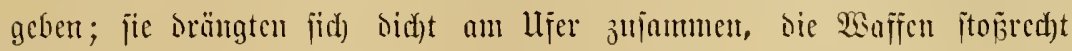

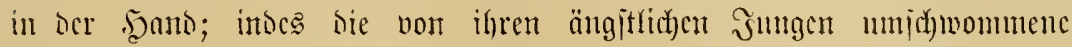

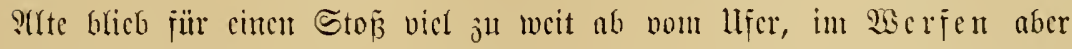

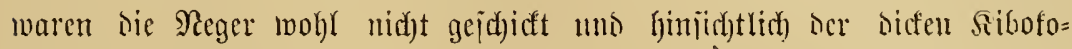

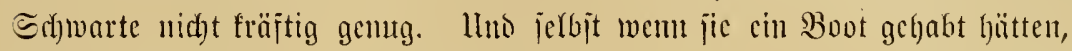

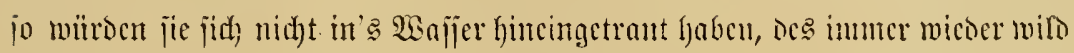
mit bem Sopj um jid) idflagenocn Tieres wegen, bic meijten and wegen

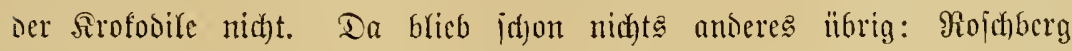

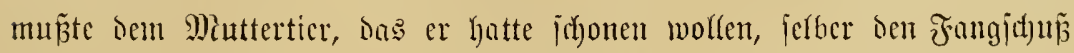

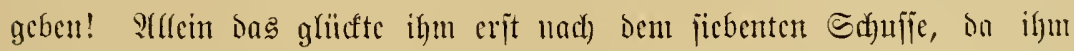

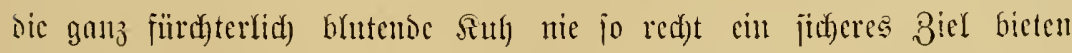
wolfte, uns der F⿱⺈

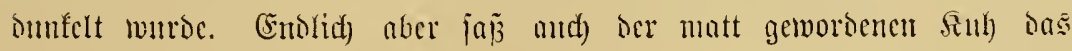

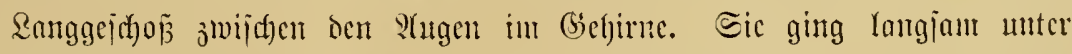

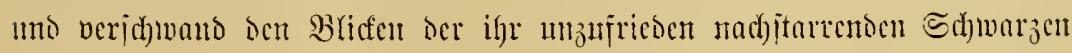

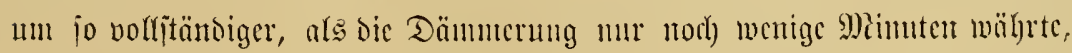

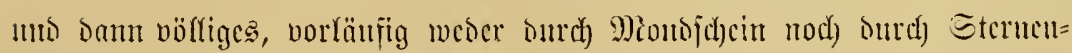

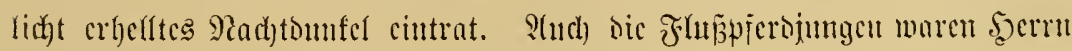

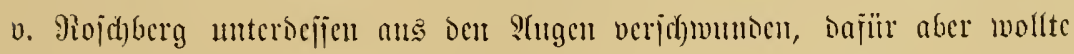

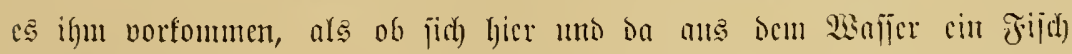

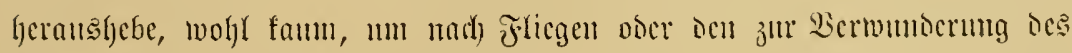

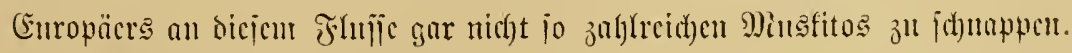

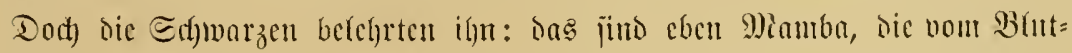

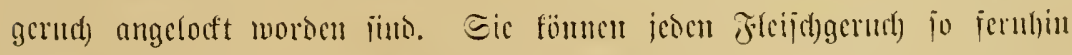

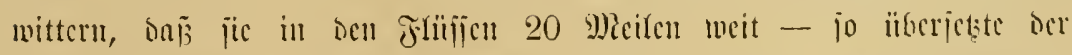

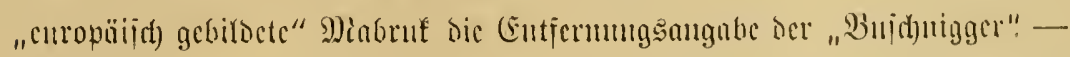

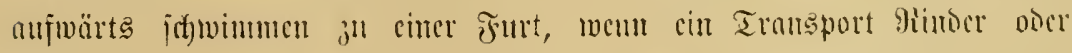
Biegen hinourdygetrieben wirt, was ja mand)mal tugctang banert.

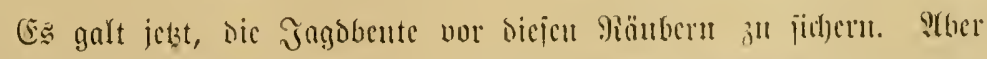

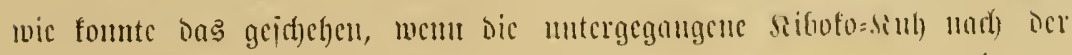




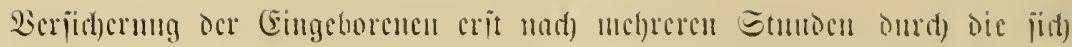

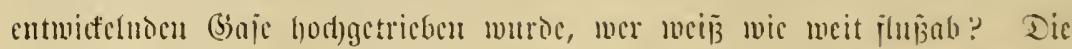

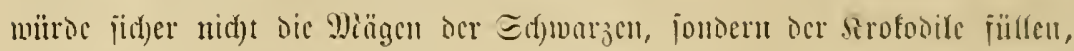

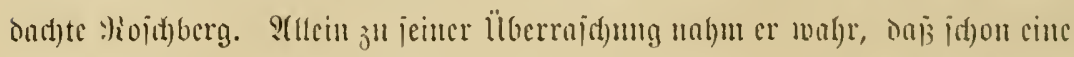

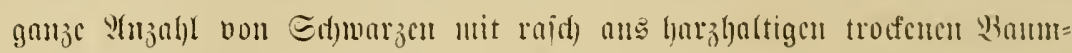

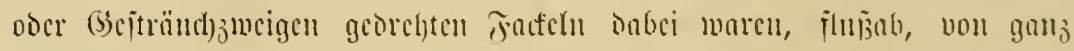

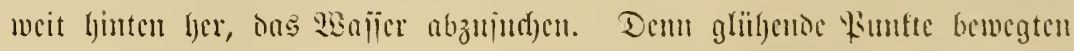

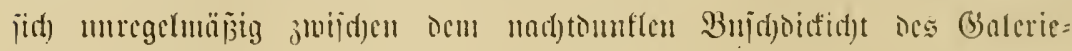

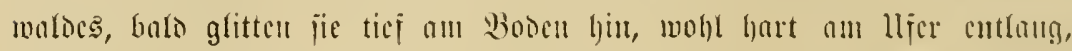

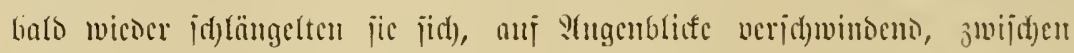

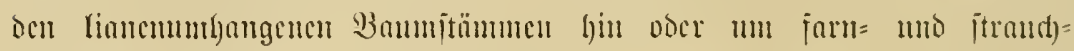

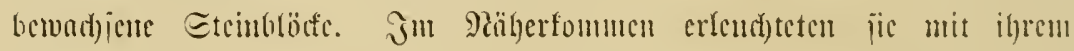

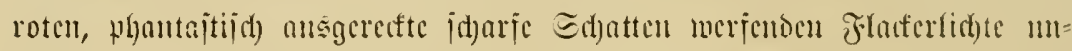

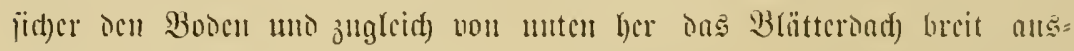

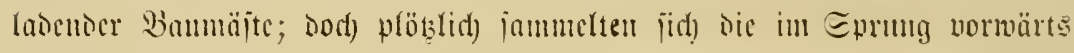

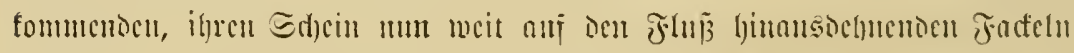

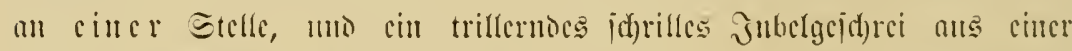

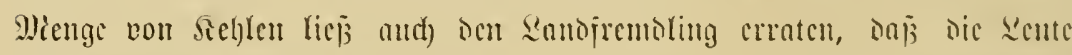

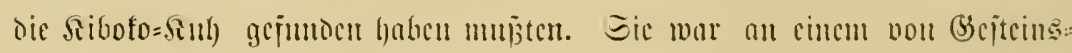
trüumern gebiloeten, fapartigen llfervorjprunge angetrichon borton, wic

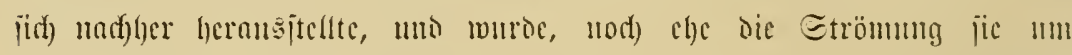

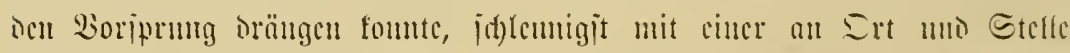

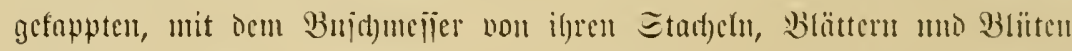
bejreiten 10 Micter langen Sinne als Ecil ditht an's llicr gejogen. Eime

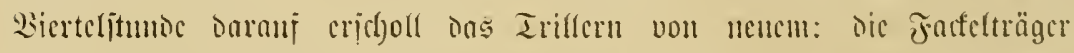

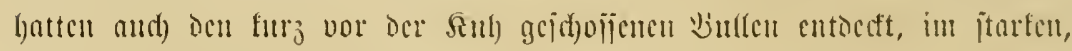

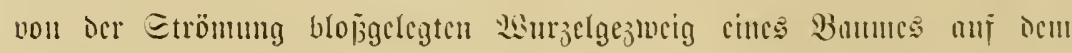

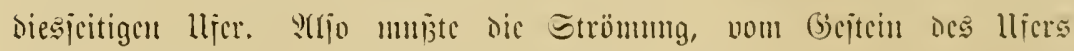

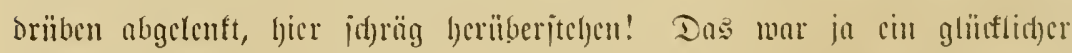

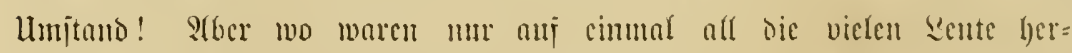

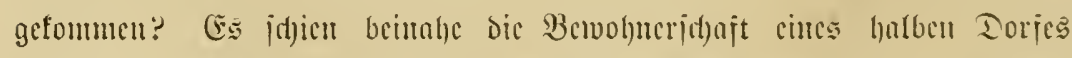

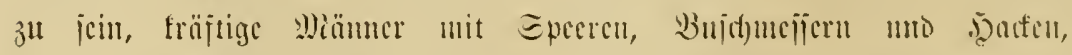

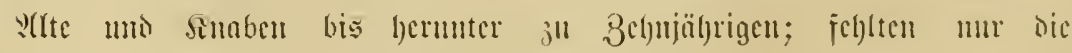

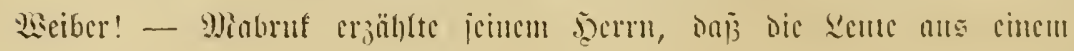




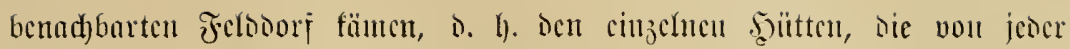

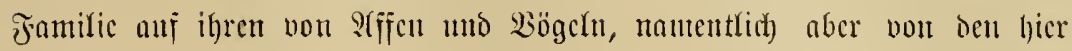

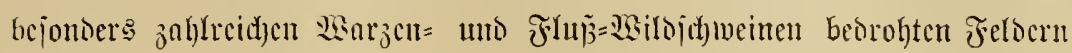
mur flüchtig für dic 3cit ber eriten (Ernte (Maisente) bergerichtet mürocu. Dic Miänner wollten bic Bente bergen helfen umb crmarteten, natïrlich),

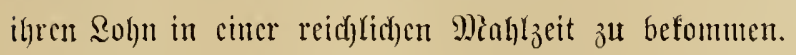

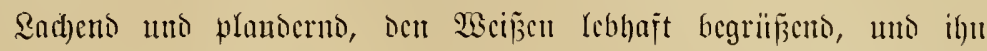
wic jeine "wcithin treffentoc bunduki" preijent - io iwenigitens veritano

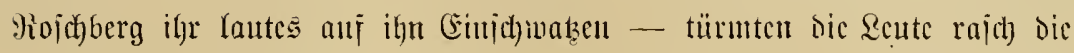

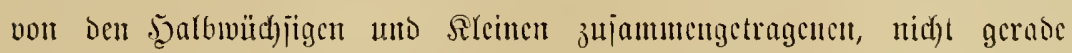

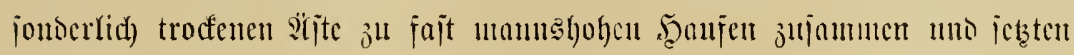

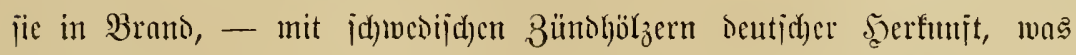

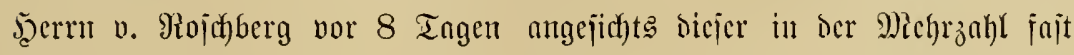

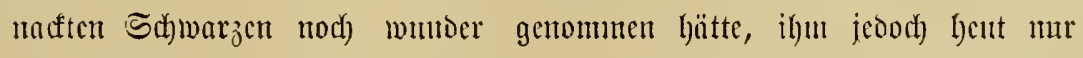
cben auffiel, jo iefre hatte er jidf idfon an oen bei sen Seeanwohnern

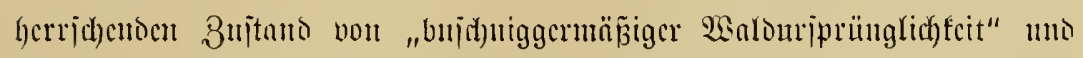

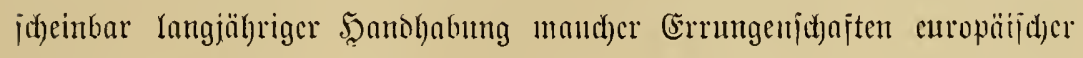
Bivilijation gewöhnt! :(h), aud Strolymatten jun Darauflegen ocs

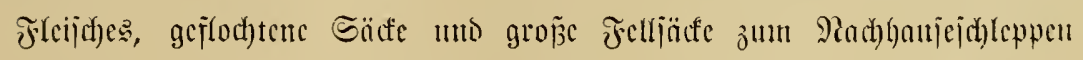
hatten jie vorjorglidy mitgebrad)! Was, jogar andt) $\mathfrak{T}$ öp je hatten dic

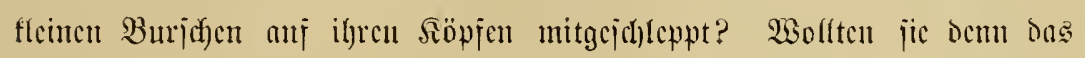

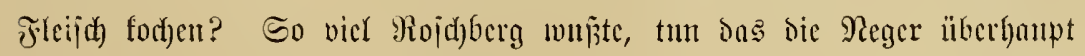
nicht, jic Graten ถas Frycijch mur.

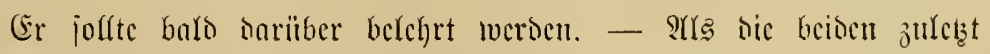

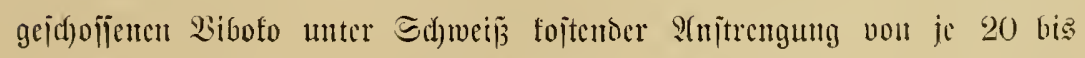
30 Mann auf́ cinc filache Etclic bicht ant Mjer gezogen maren, mobci oer Europäer auj bic Bitte ber Leute ein panrutal auf veroüatige Eteflen

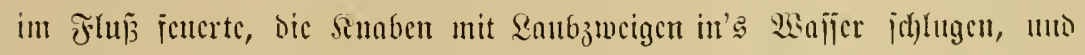

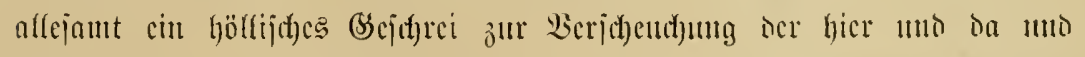

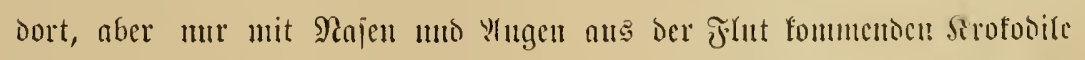

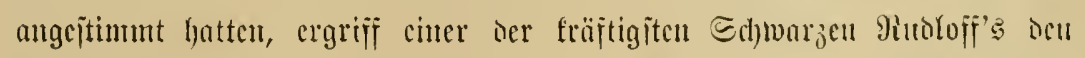

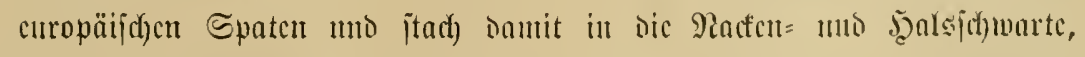

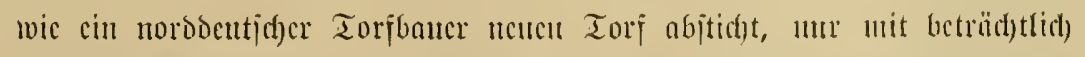

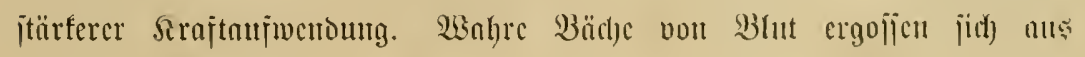




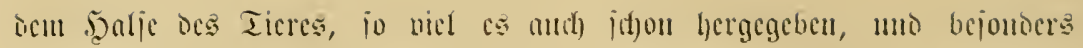

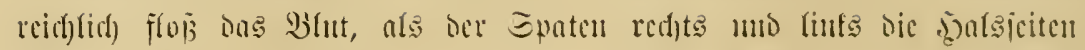

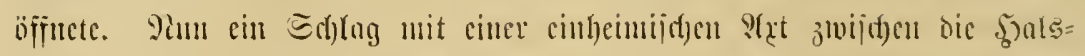

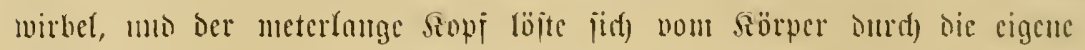

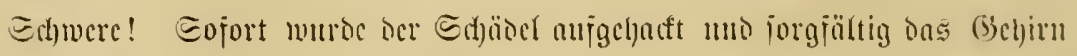

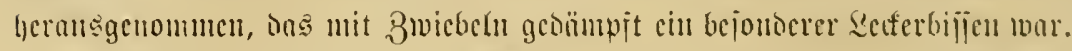

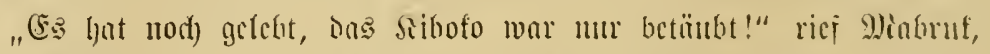
als bos (belirm ani cin jrijhes Dattelpalmenblatt getegt wurde; "id habe

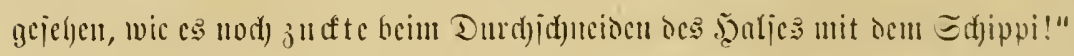

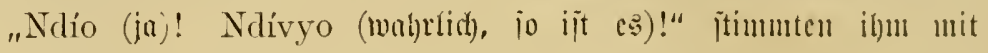

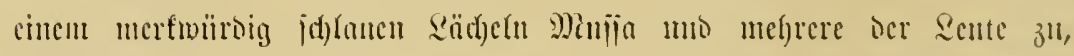

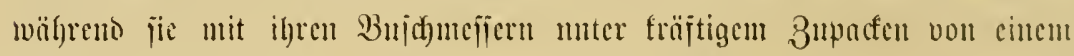

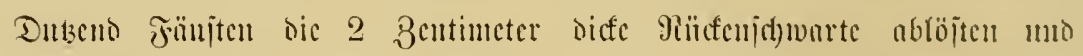

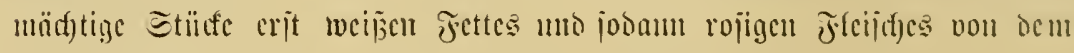

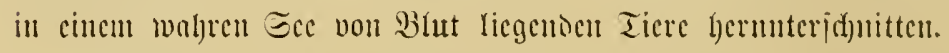

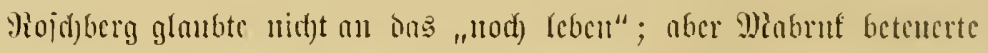

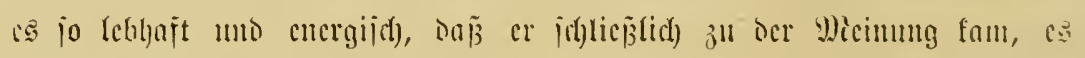

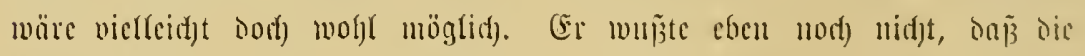

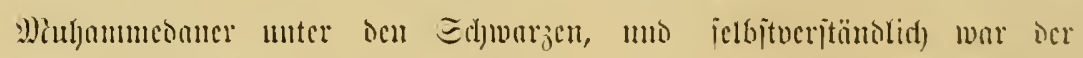

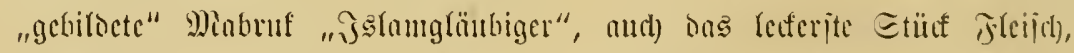

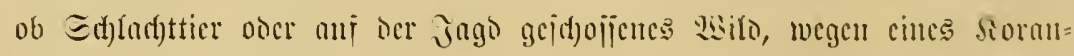
verbotes nicht geniejen bürjen, wem nidyt dos Zier dur(f) Den rituellen

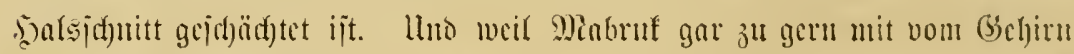

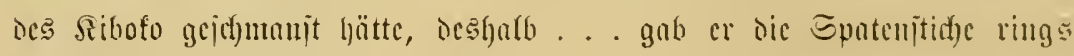

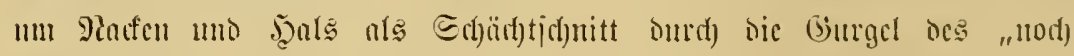
lebenocn, แur betüubt geweicnen" Ticres nus! Unt Minja wie dic

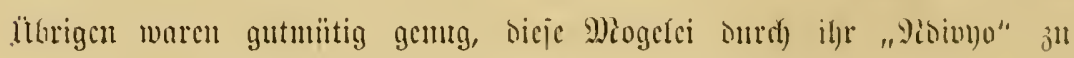

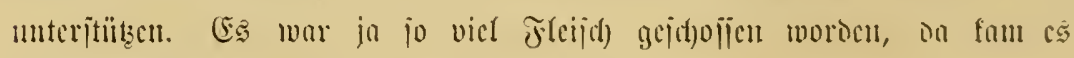
nui cincu Ejijer melht ober weniger nid)t an!

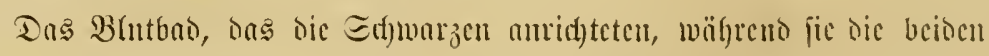

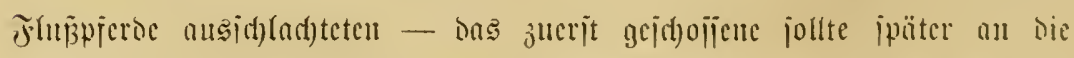

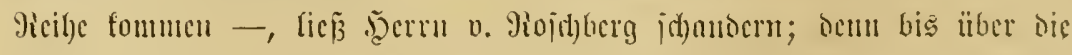

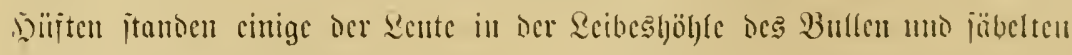

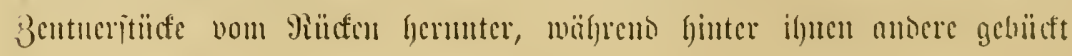


itanten uno zwijdyen den geipreizten Beinen Der Bortermänner au Dem Ticrförper herumjantitten, um affe paar Mimuten eimmal ein $10=$ bis

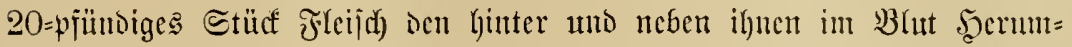

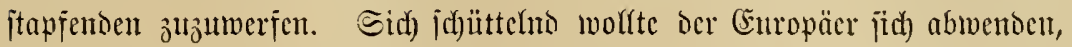

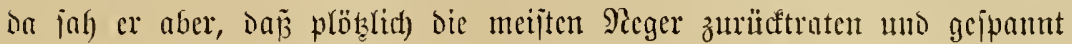
jujahen, wic cin paar ber itürfïtn Mämter cinc ungelycure, aus òcu

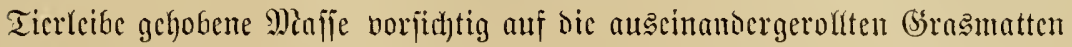

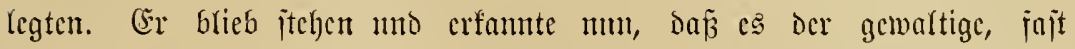
3 Micter lange Mi a gen war; den bic Mänuter heruusgetrennt hattch.

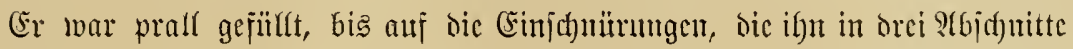
trementen - Der lebzte Teil hatte bie Form cines langen 3ulinocrs -, umb als er mut aufgeid)nitten wurbe, quofl einc grünftche, bcim Flacter=

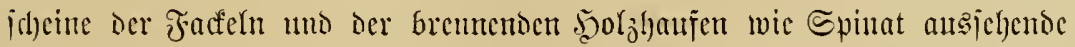
Brcintajie Daraus hervor, Die nod) unverdaute, aus ben zartejten Blättchen

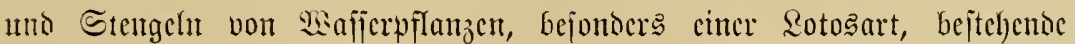

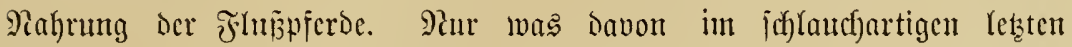

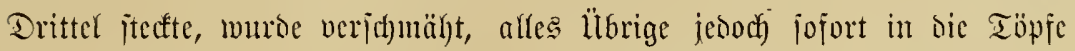

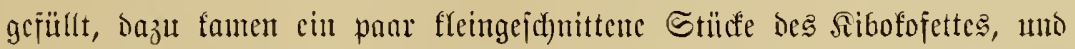

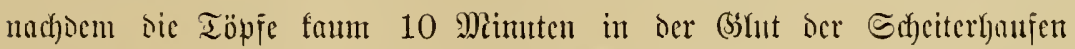

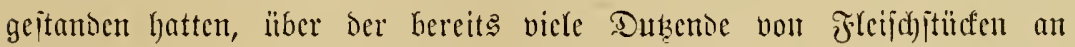

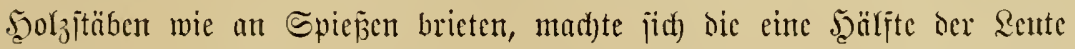
Darüber her, wäbrento bic antere Şälfte gerabe den Mangen dos jweiten

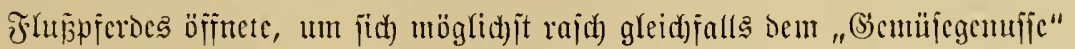

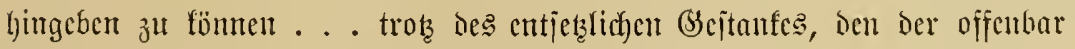
rajd) anbreunente "Spinat" oder aber Das prutzelnoe Feijt cutwicfelte!

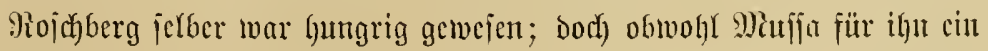

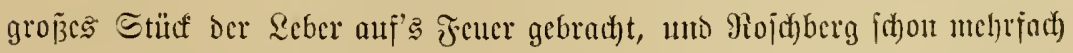

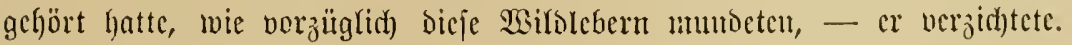

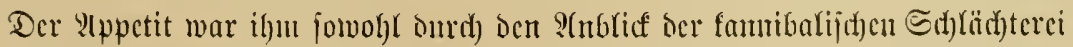

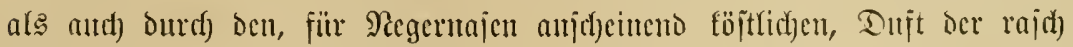

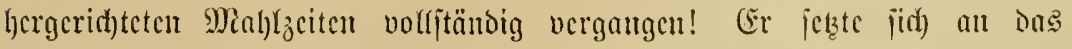

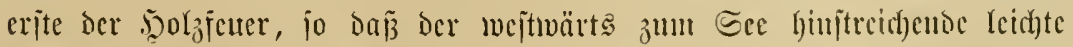

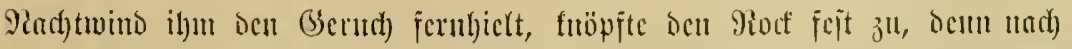

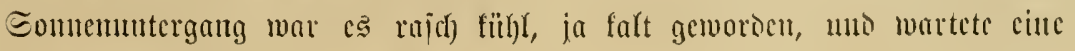




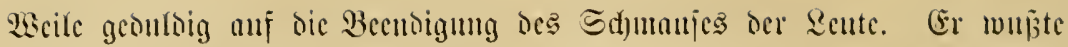

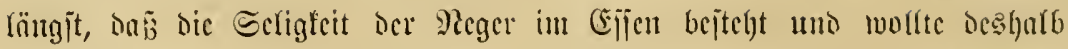

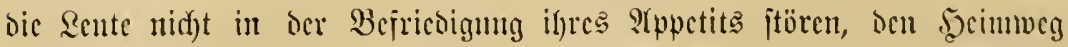

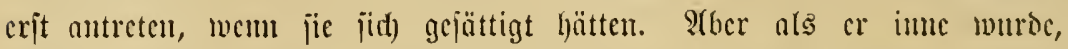
oñ

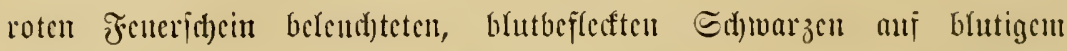

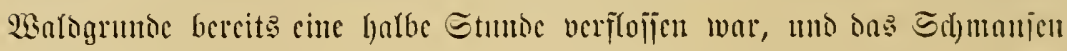

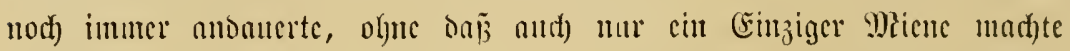

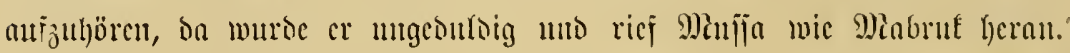
"Wic lange mird tem bas nod) bautern, bis dic Serte ba fatt jüto, und mir aufbred)en fömucu?"

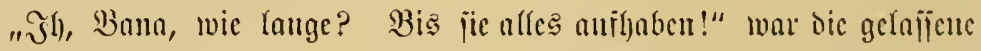
S(ntwort.

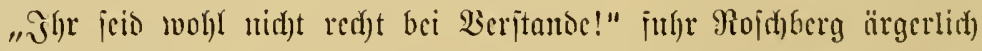
auf. "Da töunte man ja wobly gar acht Tage anj ben jecimweg warten!

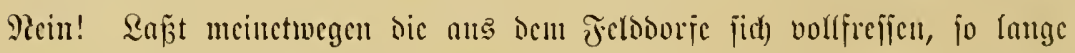
jie wollen; plakzen jie, Daum platzen jie; wir murjd)ieren aber jeszt nb!"

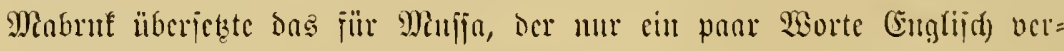

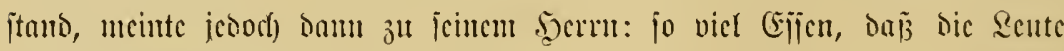

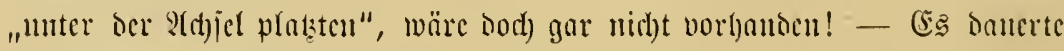

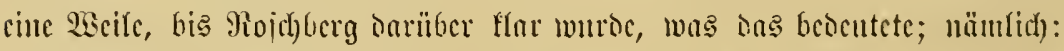

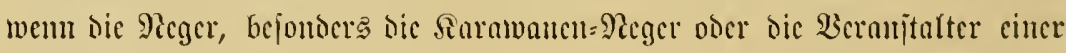

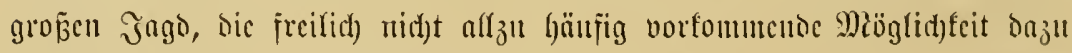

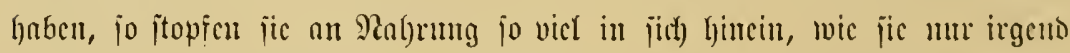

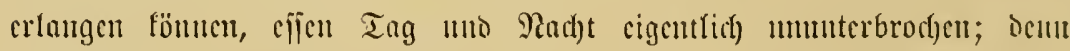

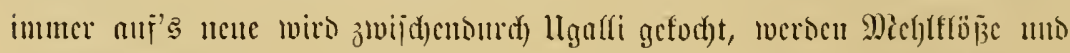

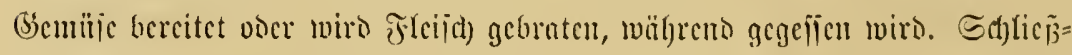

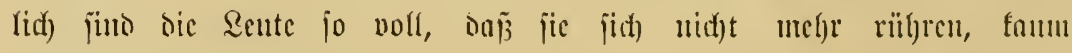

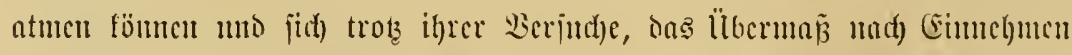

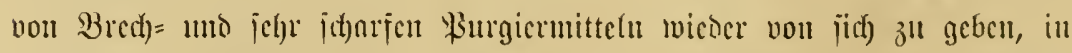

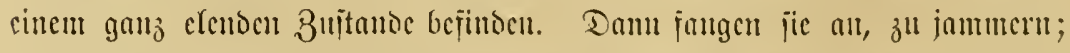

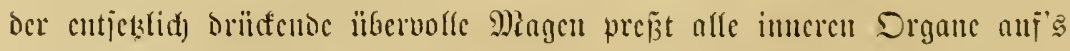

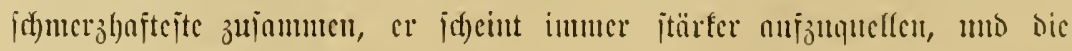

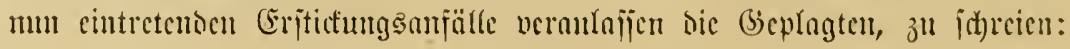




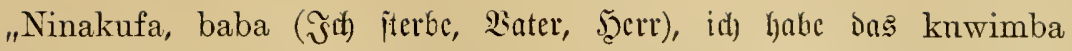

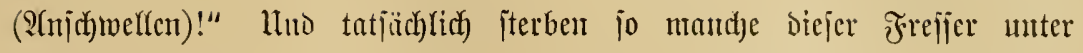
greulichen Dualen, wälgreno ihnen unverdaute Speijemafjen aus Mamo uno Darm atestreten. Bon ihnen jagen die Sabrarzen: fie plaşen unter

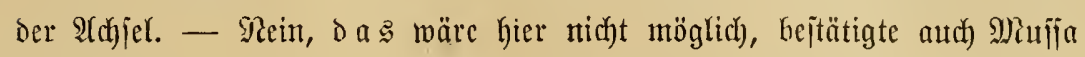
ganz ernifthaft utach biejer S(uscinanderjetzung; jelbjt wenn bie Seute jich

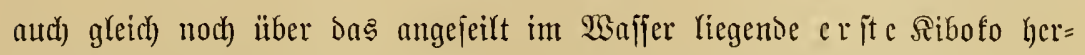
madyten, jie friegten alles auf, ohne Schaden z̆u nehmen.

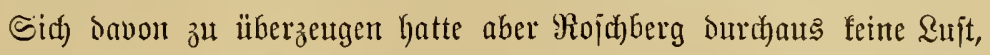
Denn wenn auth) nicht gerabe acht Tage 3eit bazu gefört haben würde, vor morgen mittag würden bie Reute nach) Malija's (Erf(ärnng bod) nicht

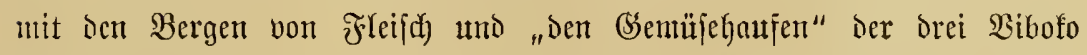

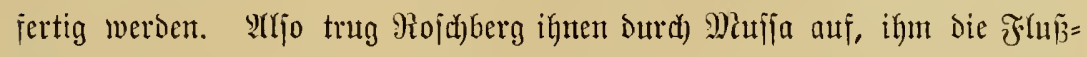

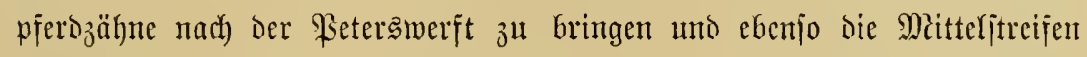
ber Sd)warte längs Der Wirbcljäule. Dentn mur aus dicjen Teilen laffen

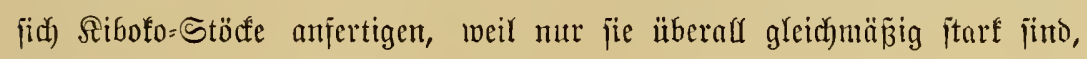
fcine dïmmen "Faltenjtelfen" haben.

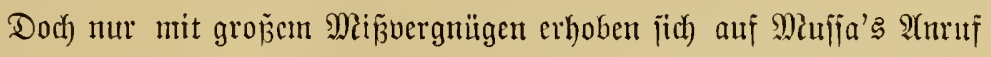

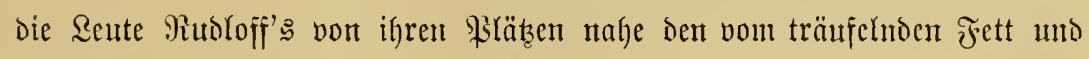

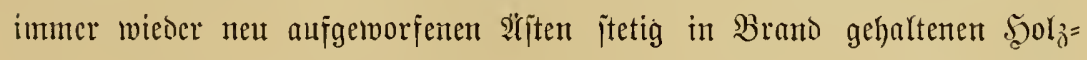
jeutern. Jetzt jorften jie joffon fort?! Das war ja cin graujamer Scerr,

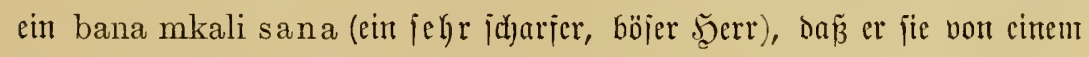
noch) jo reidylichen Mahle aufitelyen hiḉs!

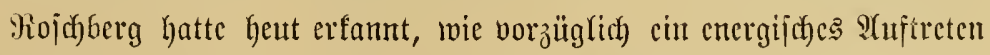
wirtt, uno fo donnerte er denn juarf gegen die Bögermoen los, gleidfuicl,

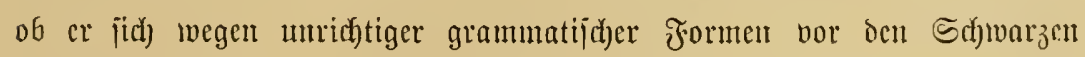

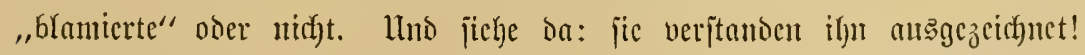

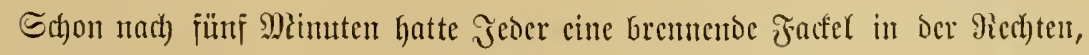
ein parr gejerveffafeln in ber Rinfen, und nad vielitimmigen "kwa heri,

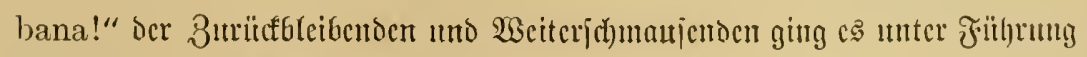
Muija's au Mjer cuttautg f̈lı̃̋ab.

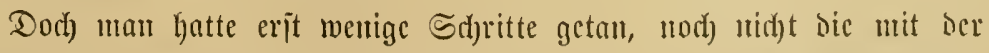

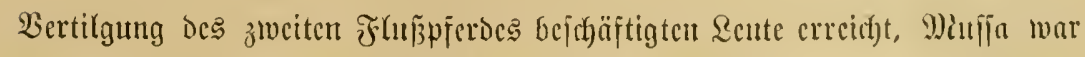

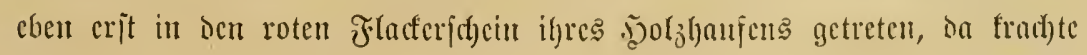




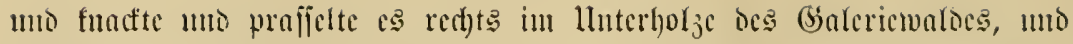

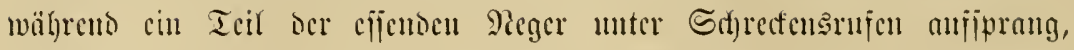
anoere aber wic critaret bor Entietzen hocfen blicben, rajte mit waber Eif jugsgcidyminsigfeit cill ung

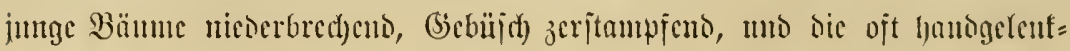

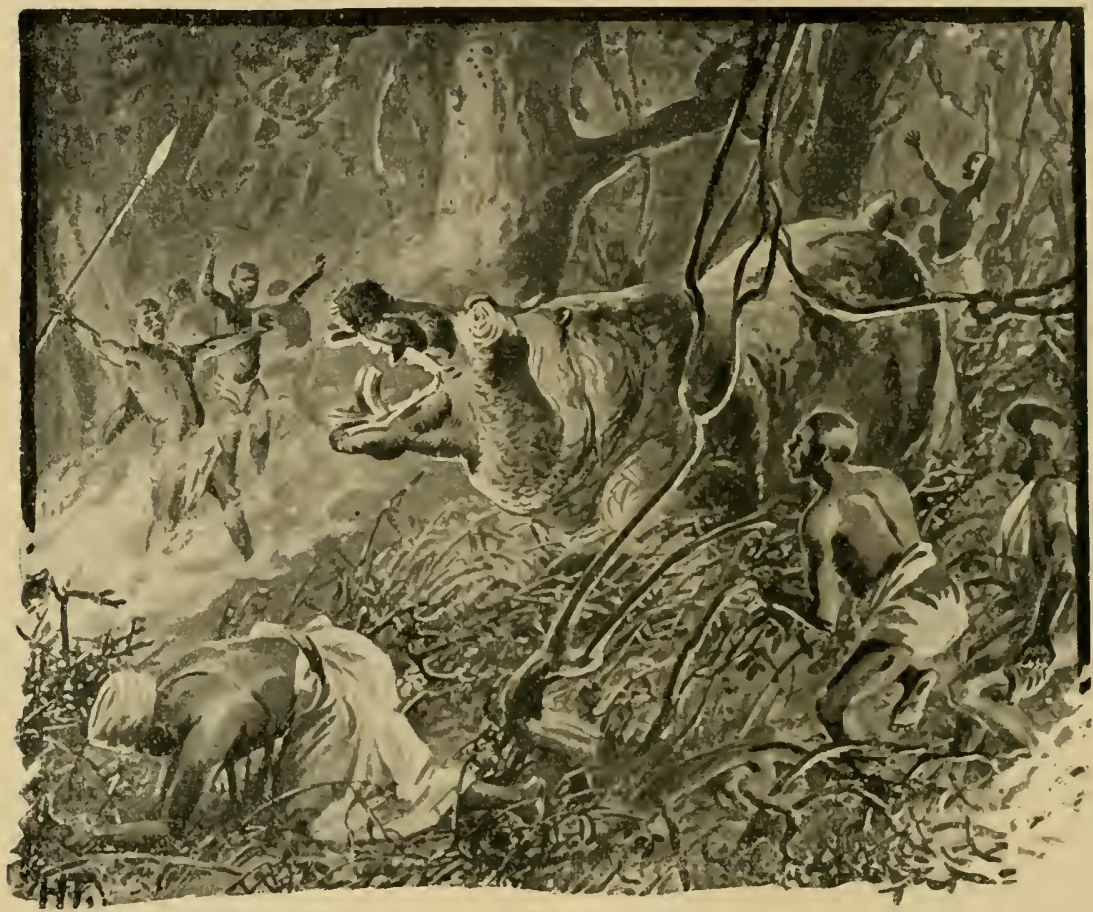

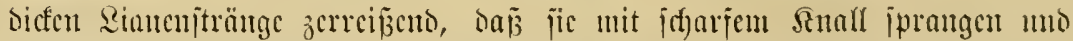

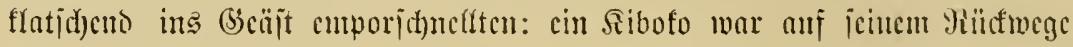

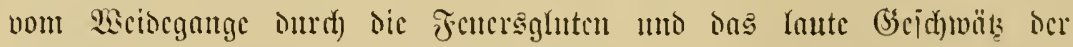

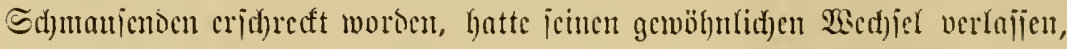

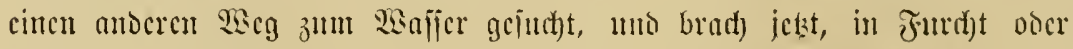

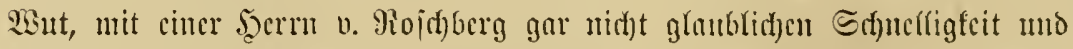

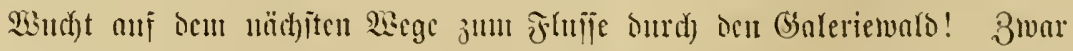
id)reffte cs vor ben hicr an bicjer Etelle uncrwartet angetrofifenen feucr=

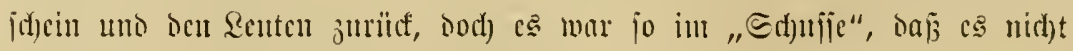

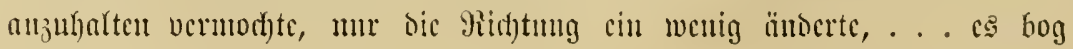




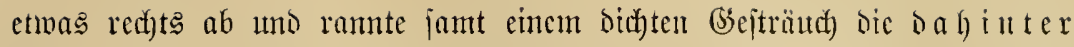

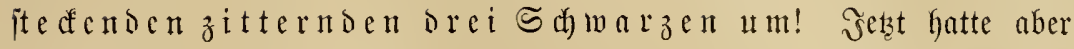

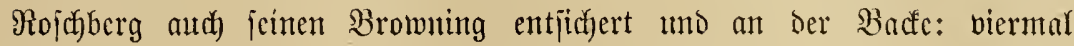

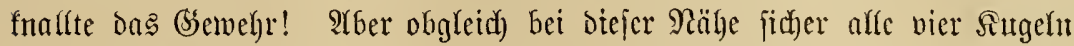

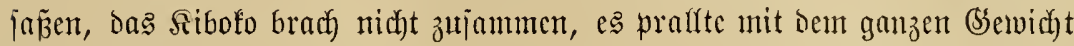
feincs ungeheurell Reibes gegen cinen itarfen $\mathfrak{B a u m}$, den es im Eroreich locferte, jod)lug mit jeinen mäd)tigen fopje einen ber eben ungerannten,

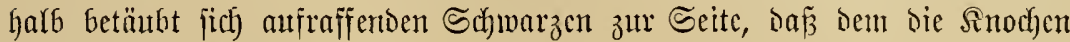

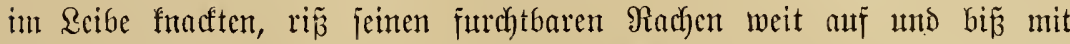
jeinen gemaltigen, frumm mo jujief in ocn Riejern jteffenten Scauern eutem

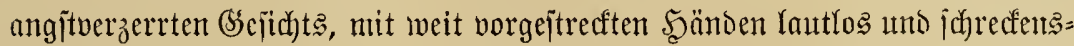
itarr itehen gebliebenen jungen Burjhen Reib und Bruftforb ourdi)! Der geflente Schrei des lunglücflithen hatte mur eine Sefumbe geoantert; in der näafjiten lag eine zerquetichte uno zerbifijene bhutende Majie mit Mienjach= fopf uno =Beinen am Boden, uno unter fürchterlichem brülfendem Brrmacm jtürz̧te jich bas nun bon vier Steflen aus blutübarriejelte Ulngetünt in bie hody aufflatidenoen 2 eflen!

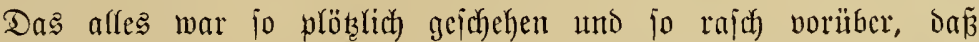

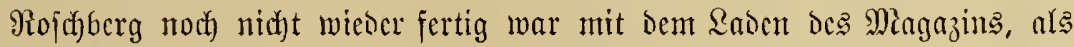

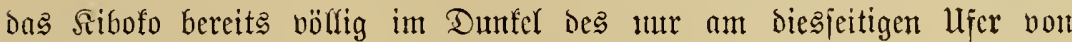

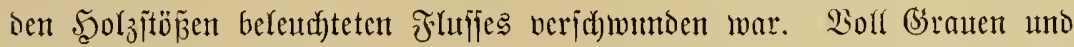
Schredf blicfte ber junge Ertropäer auf die bon Dem mütenoen Tiere "angenommenen" Ilnglüeffichen: jwei waren tot, ein Dritter jo jermalunt

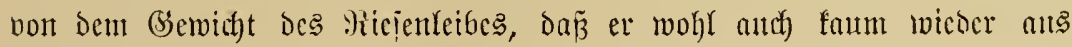

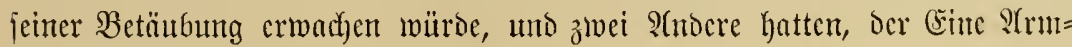
unt Der S(ndere BBcinbrït)e Davongetrngen!

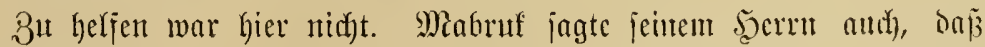

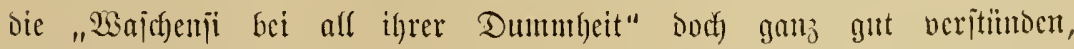

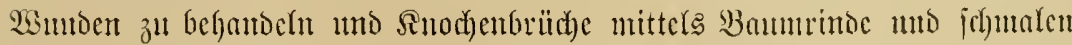

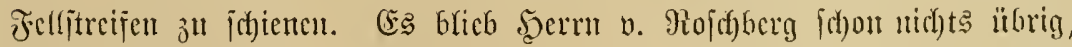

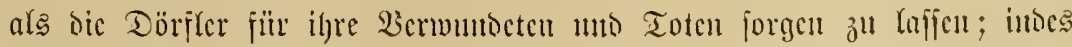
molfte er ifnen, weil er auprichtiges Mritleio mit bell fo jull Silfaden

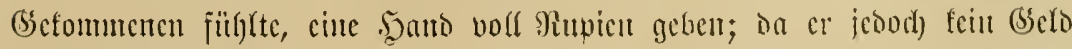

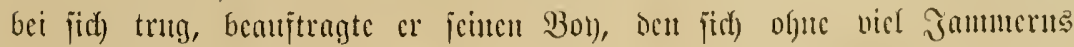




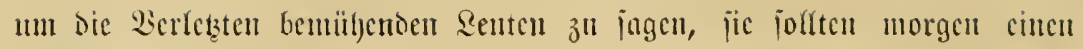

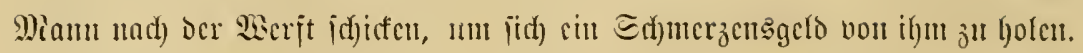

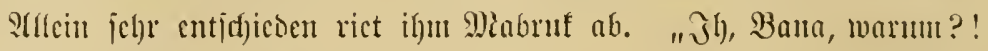

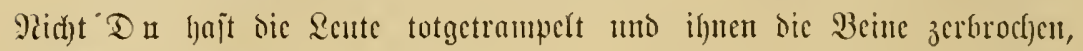

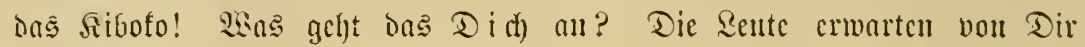

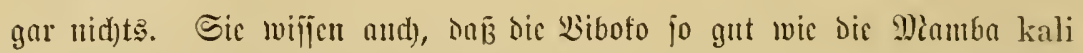

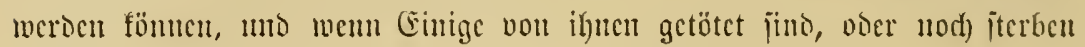

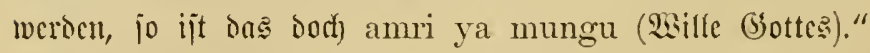

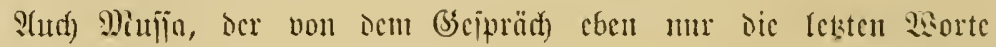

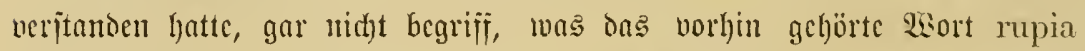

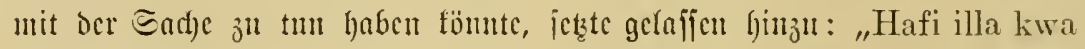

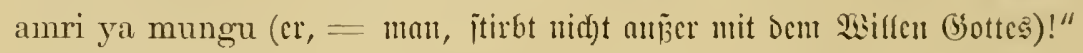
ein Epridf)wort, das sen fatalijtij(t)en Picgern jefre geläıfitg ijt. Uno mirf=

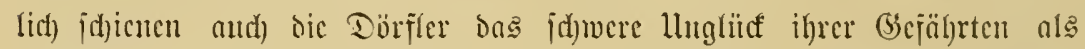

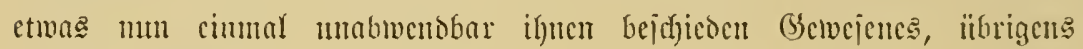

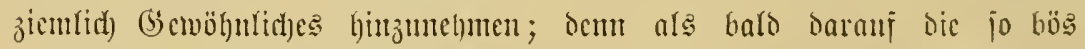

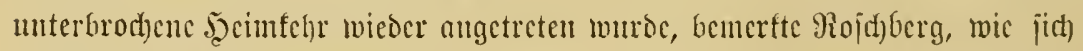

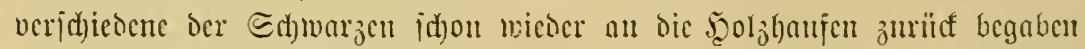
แno

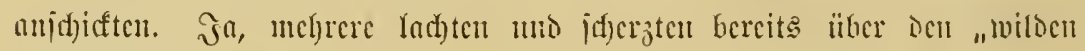
Fcino" mo madytel unter Fand)en uno Sirniten bas pluupe secramrajen uto Ropfifd) (endorn ocs Sibofo mad).

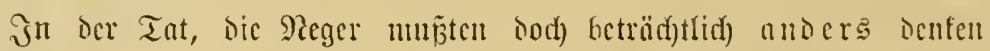

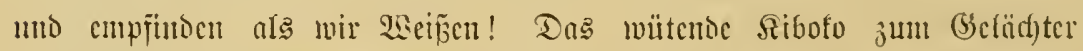
Der Übrigen nad)junadjen, währento cben vou ocn Epfern Des Ticres die

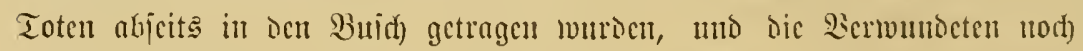

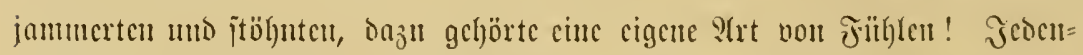

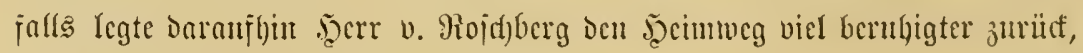
als cr vor furzent nod) geglaubt batte!

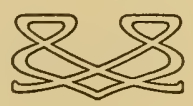




\section{Sechstes Kapitel.}

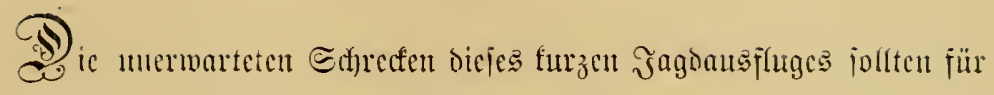

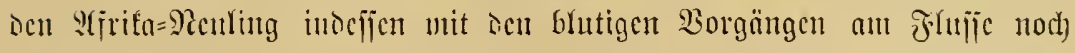

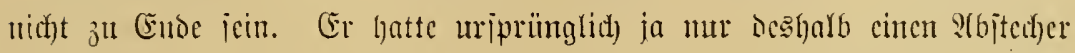

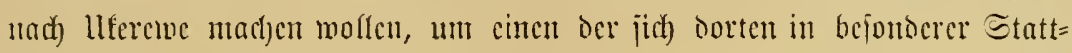

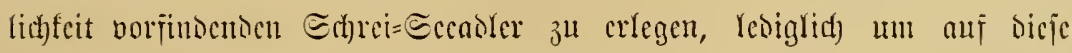

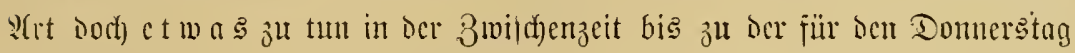
angefündigten, in jeinen Reijeplan anf die cine ober andere 2 secije cine

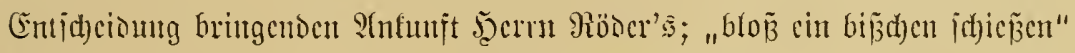
hatte er unollen, wie er heut bei jid) meinte, halb zum 3eituertreib, halb un ciner Jagtrophäe wiffen, tmo mum mus̄te er erfennen, wie rid)tig bas

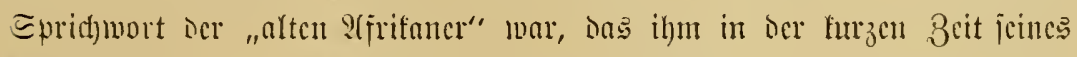

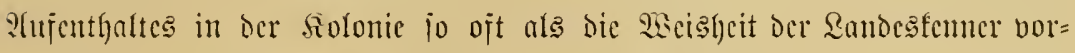

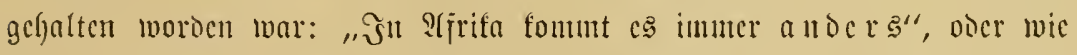

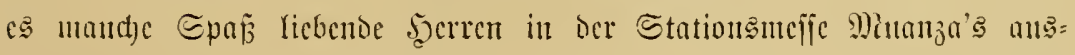

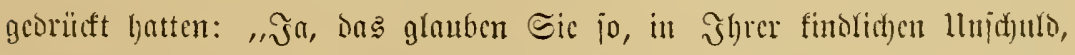
verchrter Syerr; aber: eritens foumt es anocrs, zocitens als unu

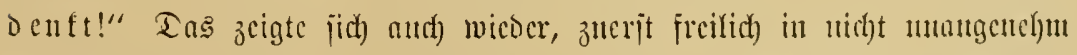

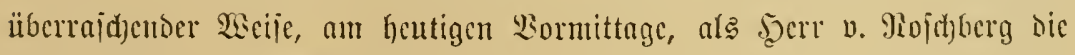

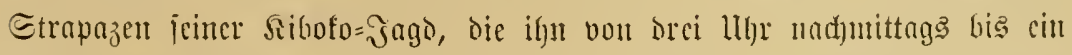

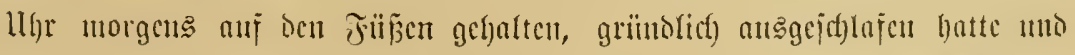

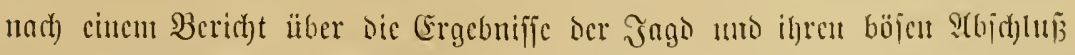

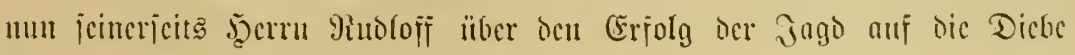
unto den Entansmürocr anejtragte.

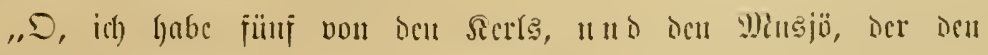
Maunangua geipecrt hat!" 


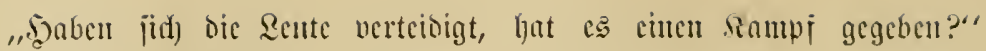

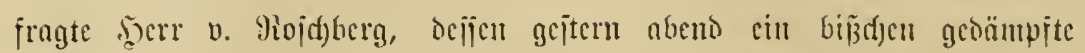

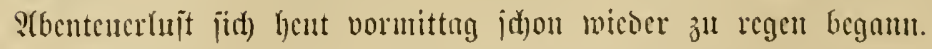

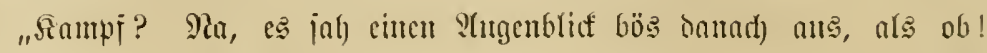

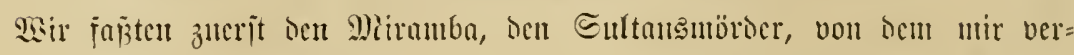

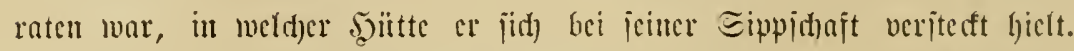

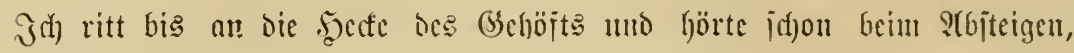

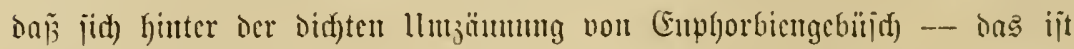

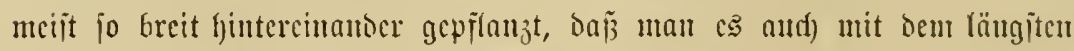

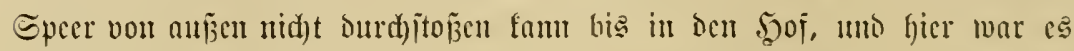

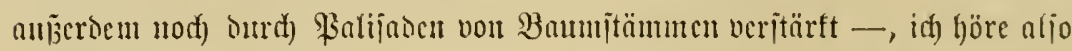

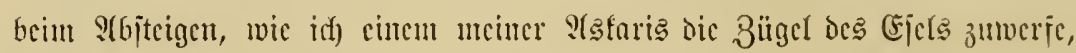

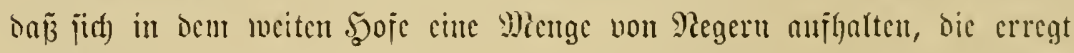

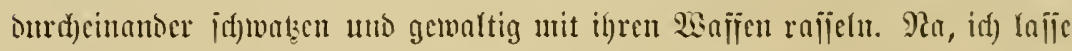
aber mit cincm (semelyrfolben gegent bas enge, verrammelte 5̧oftor in Zaum

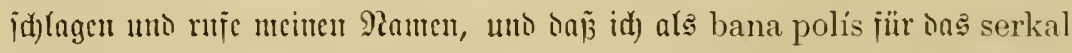

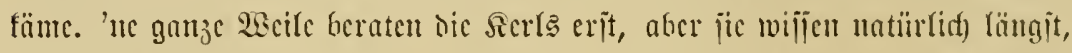

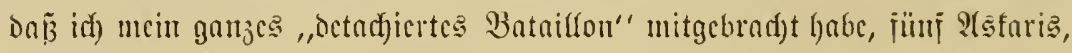

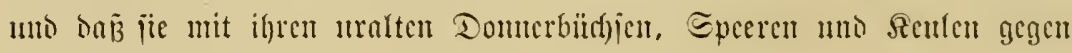

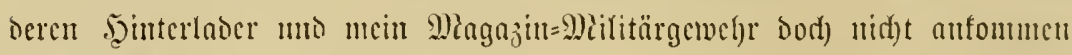

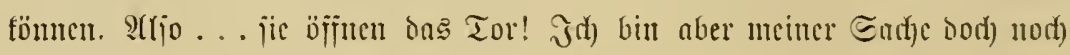

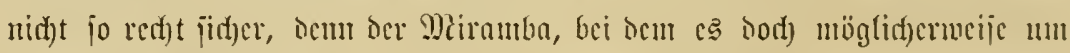

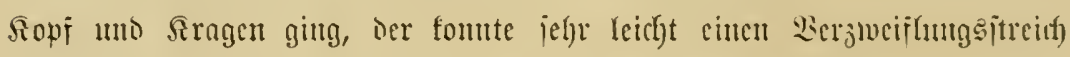

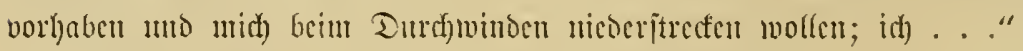

. Turd)wintocn?" jragte jein Gajt verittünonislos.

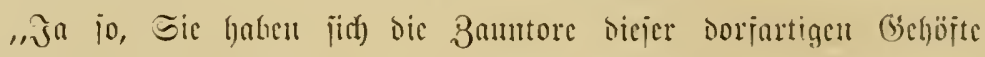

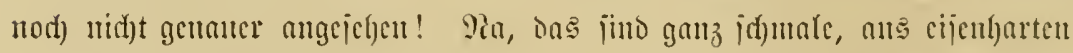
frummen Baumitüumen hergeîteflte Tore in der verpalijabicrten Ëuphorficn=

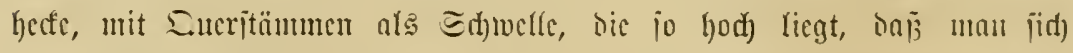
ganj วu|

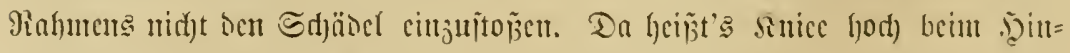
überiteigen ïber bie Edjuelle, unt Dberförper nad) vorn, io Daj man jidt) fajt wic'll zujammenflappentos Tajuenutejer norfoumut! Peotabene: Der

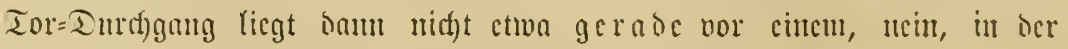




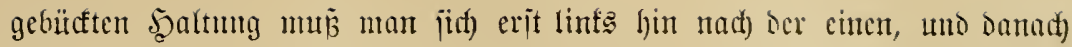
halb rechtem mad) Der anderen Seite voridjicben, rithtig burd)minden aljo!

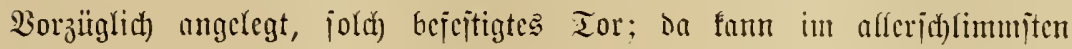
Falle immer uur ein ?(ngreifer nach bem anocren ben Berjud madhen,

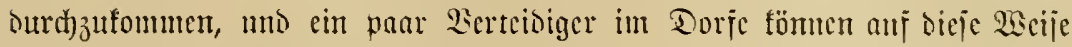
jehr hequem mit aflen jertig merden!"

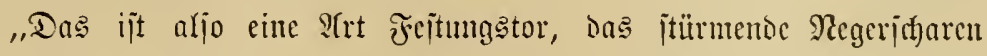

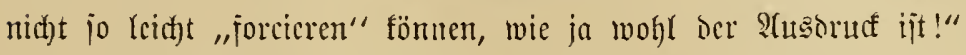

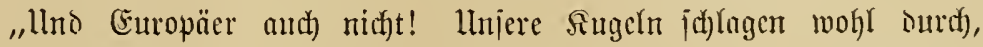
aber jie jeridfmettern Das Soolz nidht. Sogar Branaten haben frülyer,

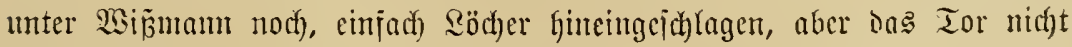

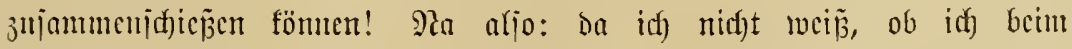

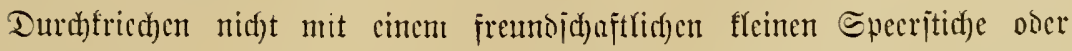
Seulenichlage anj ben Sopj empjangen merden müroc, lajī idf) juerit beu

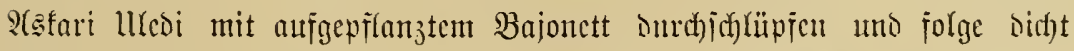
hinter ihm mit vorgehaltenem Revolver. Es geht intejifen alfes gut, uno

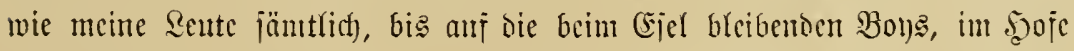

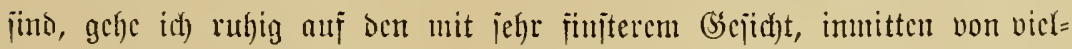

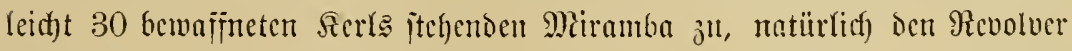

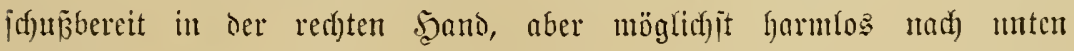

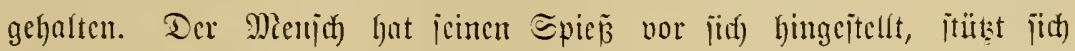

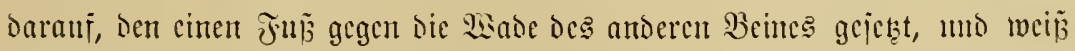
ganz offenbar nidht red)t, was er cigentlid) anjangen jolf. Das madte

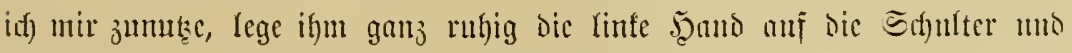

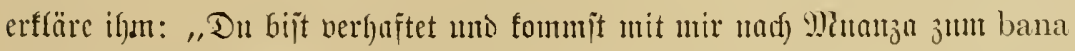
shauri (Gerid)taljerril)". Da geht cine jonderbare Bemegnng durd) Dic

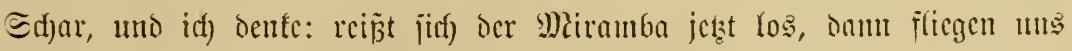

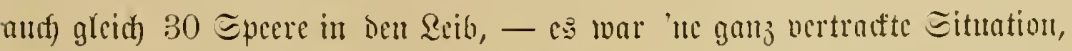

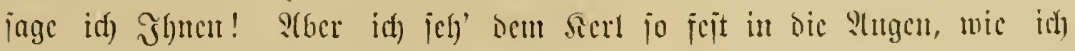

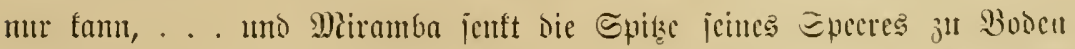

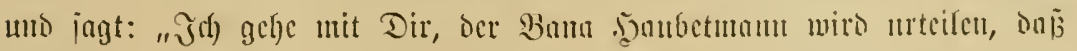
idf) midf) mit Siedst gegen ben Mianungua Ejante gewehrt bnte."

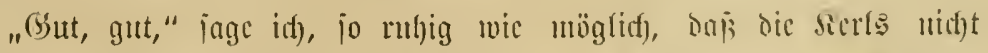

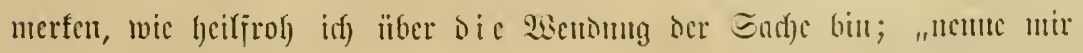




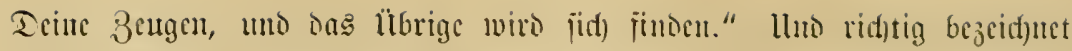
er mir mif der Etelle jïnf 3 cugen, nämlid): Die a nocren Iabafo iebc,

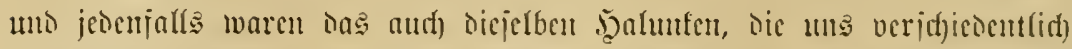

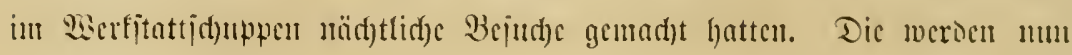

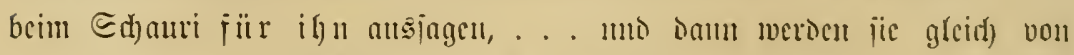

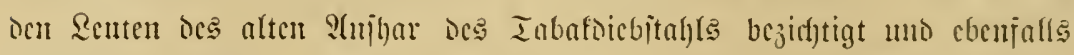
abgeurtcilt merocu! Bejer founte utur das ja gar nid)t waijen als io!" "Uno Sie haben jie alle mitgebradyt?"

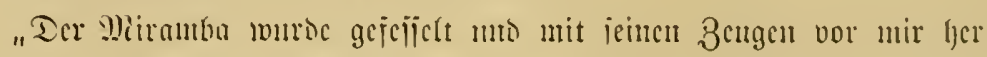

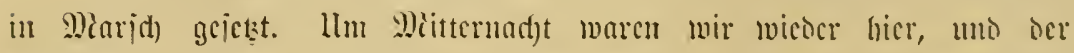
Eid)ergeit halfer gabe id) Den Miaum unt Die übrige Dicbsgejellidajt

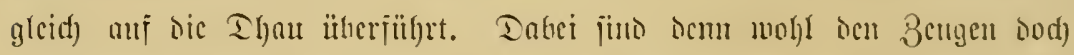

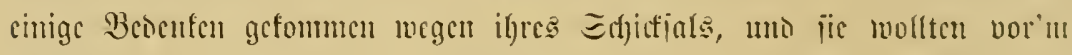

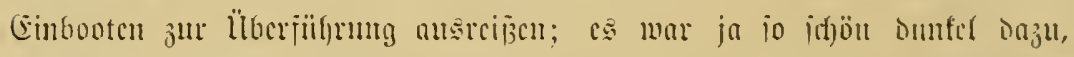

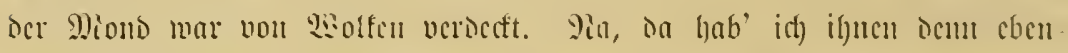

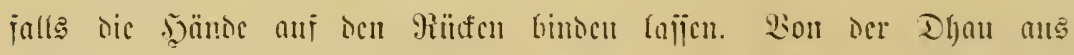
rișficren jie's num nid)t, int ien Ece jul ipringen, wem jic jidf aud)

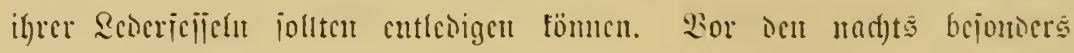

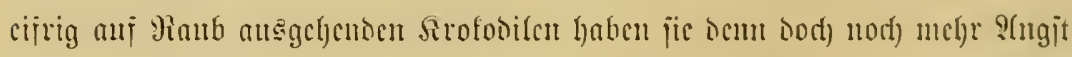

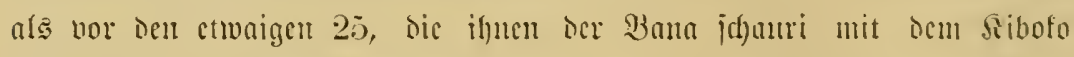

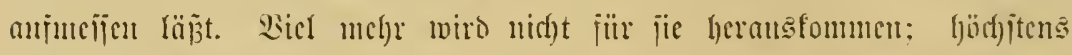

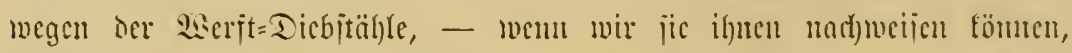

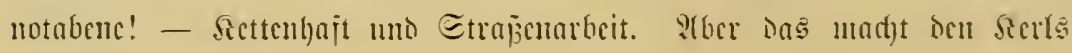
ja nid)t vicl aแร."

"Llno bas wiro mit beu Enttansmörber tocritn?"

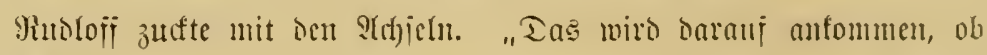
Die Ead)e medyr nad) hicjigem Piegerred)t ober melfe nad) Den crit alf=

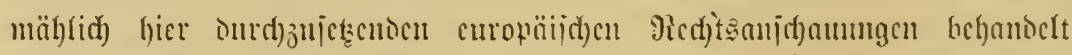

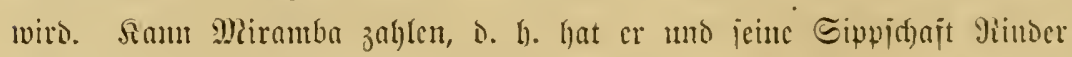

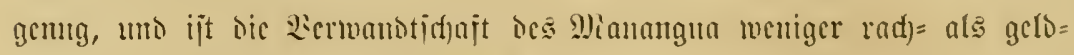

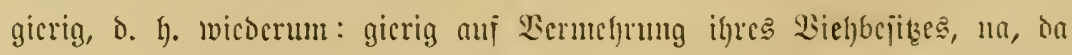

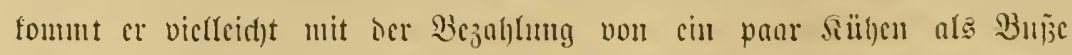

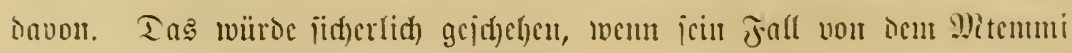
abgenrtcilt wirtic." 


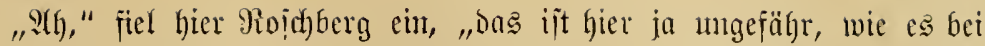

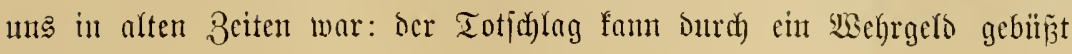
werien!"

"So? Pa, hicr ijt bas nodh Sitte. Ilno jidyerlidy würọe ber 9)itemut alfes anfficten, ba

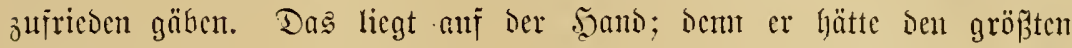

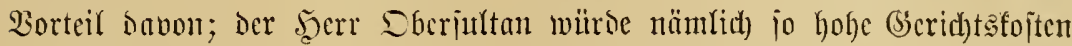

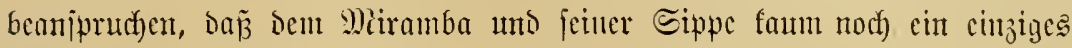

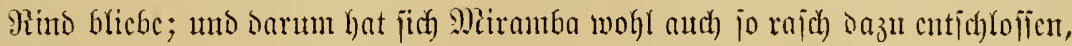

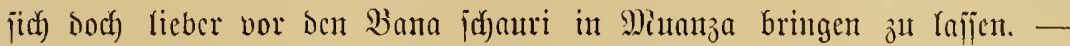

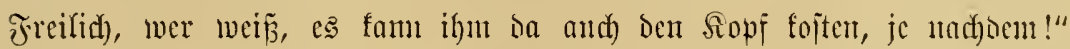

Die Dhau wartcte mur auf günjtigen Wimt, und als ber unt bie

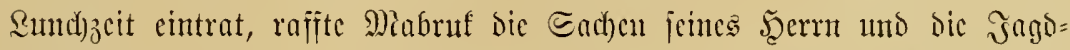
trophäen jujammen, bie Sirofobiljdywanjipize unt bie gegen slittag abge=

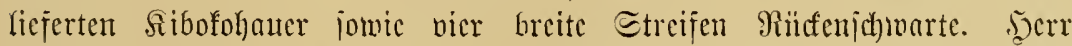

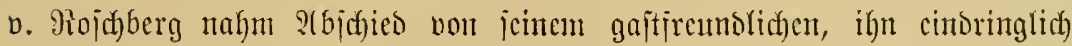

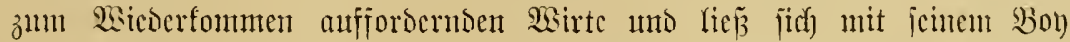

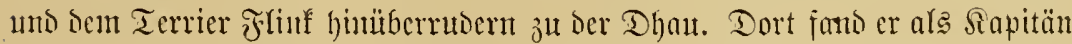
Den jchon in ber Werfitütte gejechenen ältlichen, als nakhoza am ganzen Sce

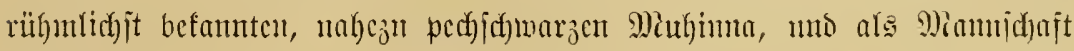
viefleidyt ein Dutsent Picger vor, erjichtlich ans verjudicocnen Etämmen. Die 2 amyammeji unter ihnen Gatten meijtens nod) bie frcilid) mehr mo utchr

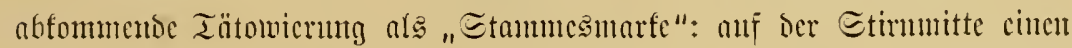
ober mehrere tiç̧blanc, jomei bis brei Miffimeter brcite, nom Stimban bis zur Najenmurzel laufente Strid)e uno ebenjo blauc, burd) Eimrifumg

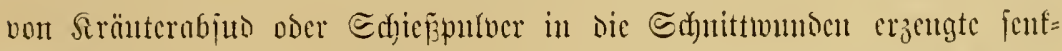

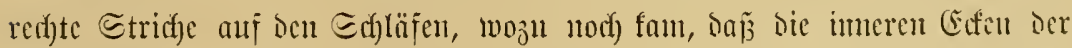
mittleren Eshncibezägne des Sborfiejers weggeidhligen waren; Dagegen

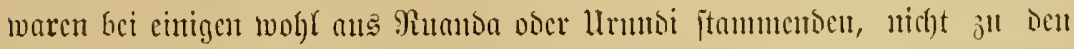

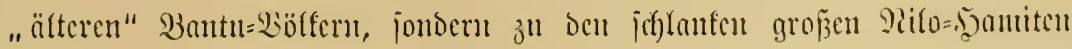

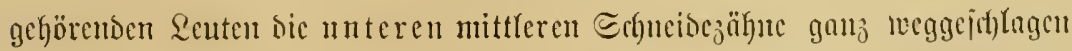

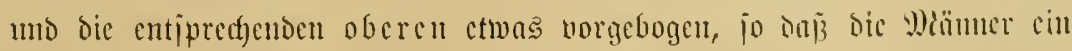

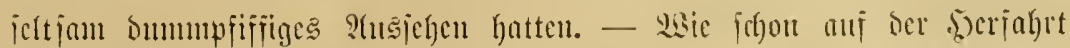

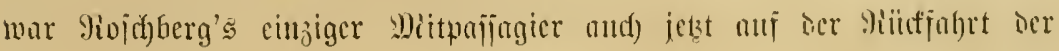




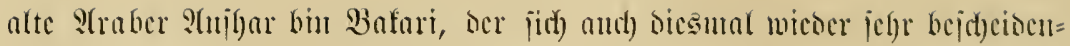

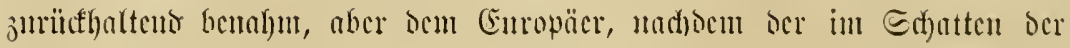

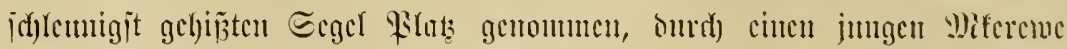

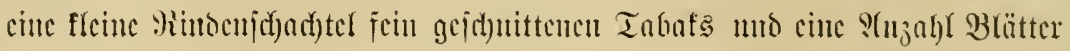

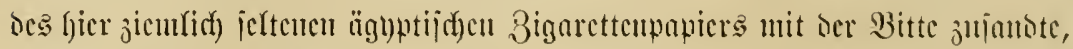

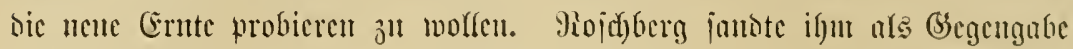

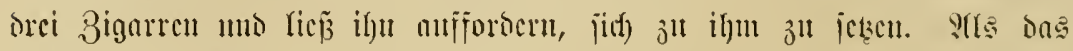

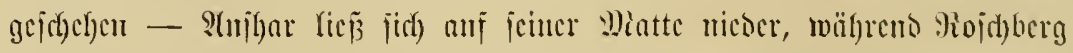

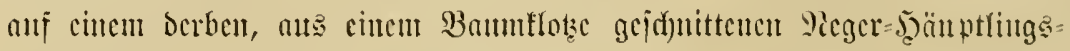
jull)le ja

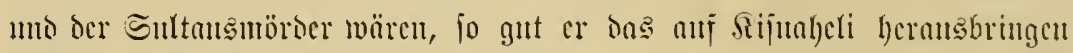

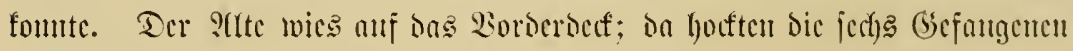

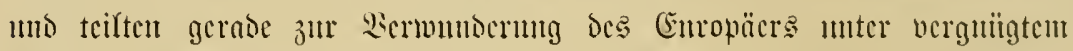

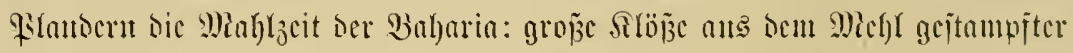

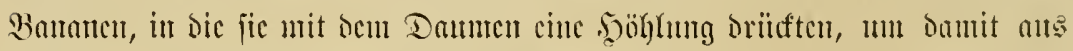

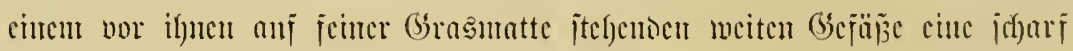

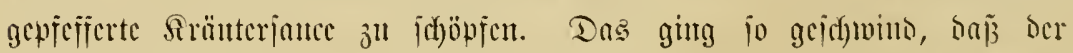

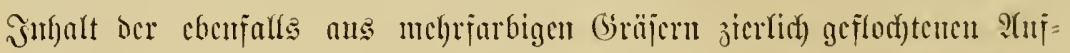

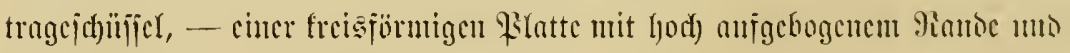

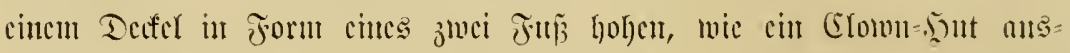

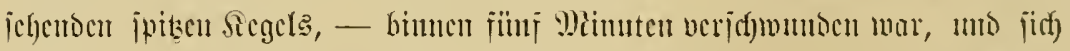

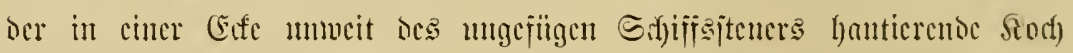
becilen mur

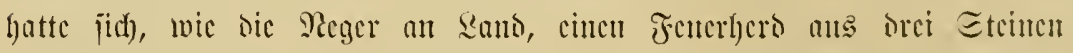

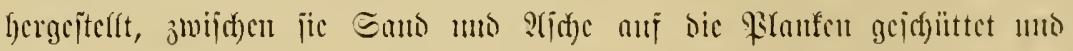

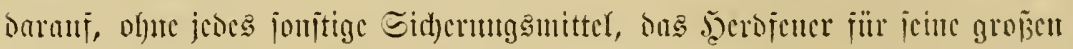

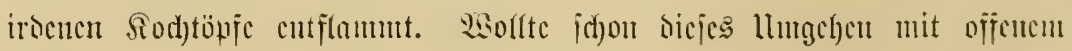

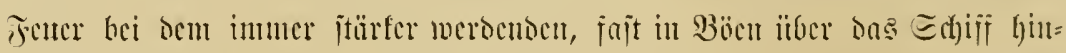

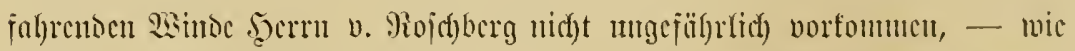

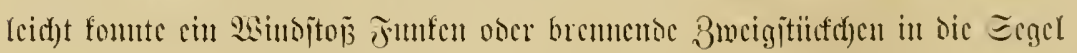

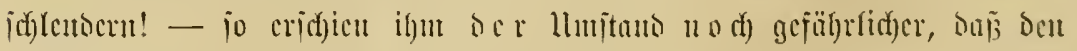

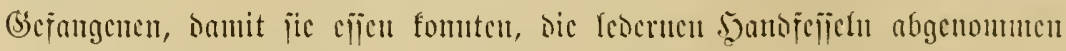

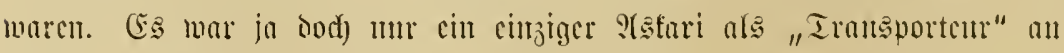

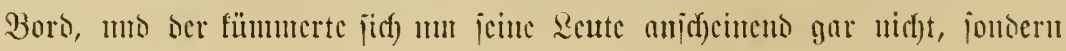




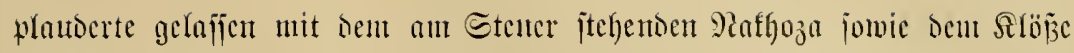

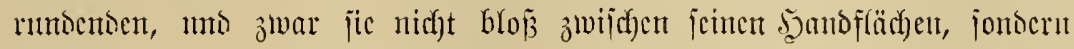

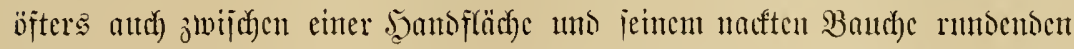

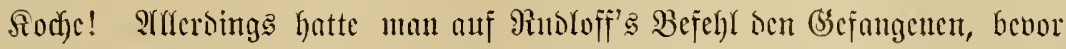

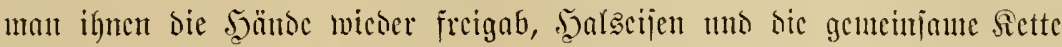

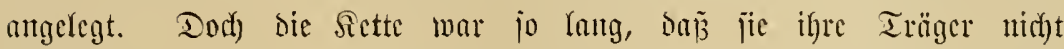

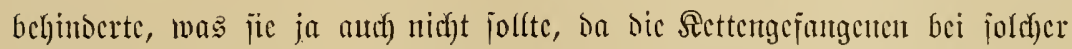

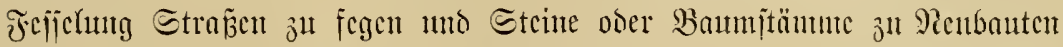
heranjuj hleppen lyaben. Sisem dic Sierle worlten, jo founten jic bic jwijhen

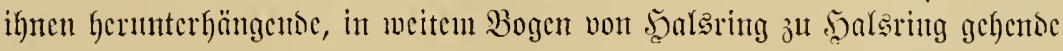

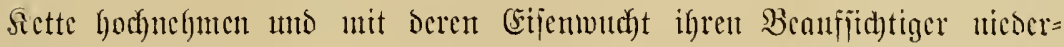

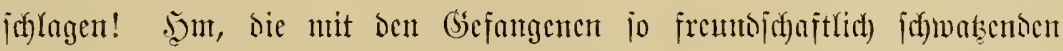

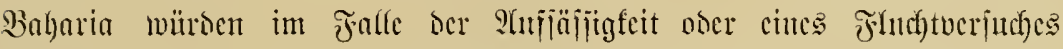

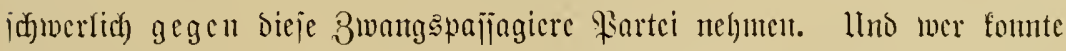

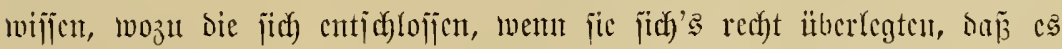

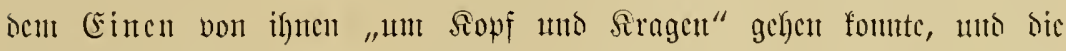

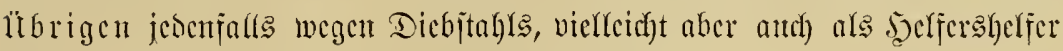
bei bem Eultansutordo bejtraft weroen würben!

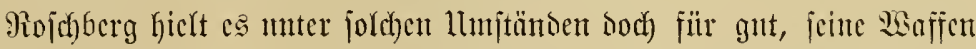

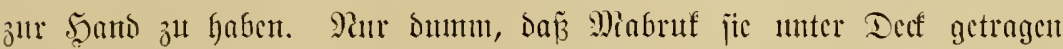

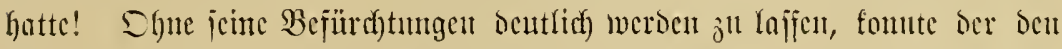

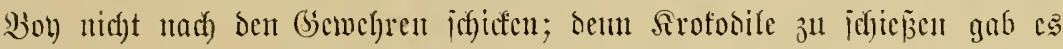

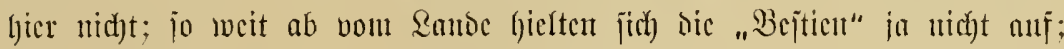

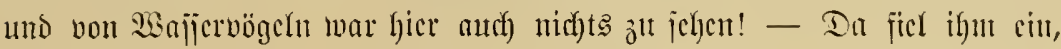

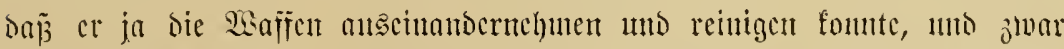

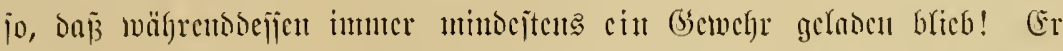

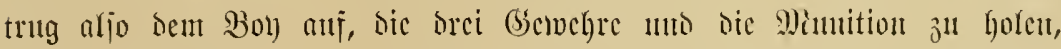

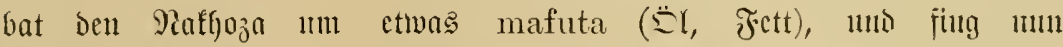

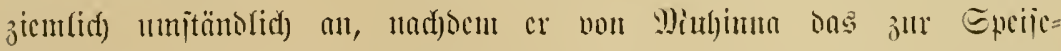

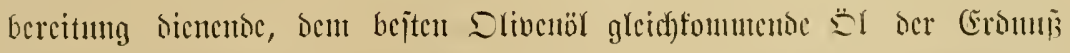

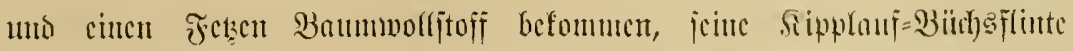

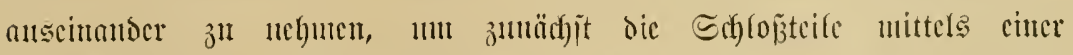

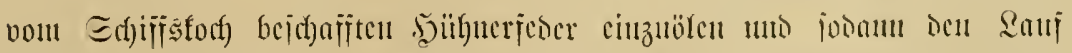

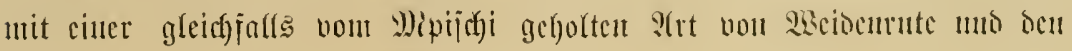




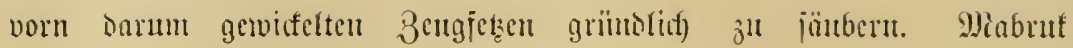

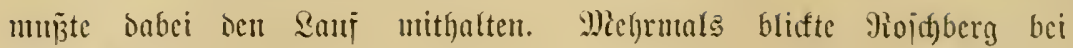

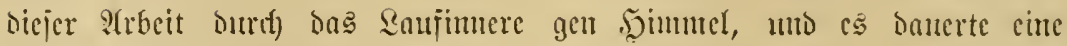

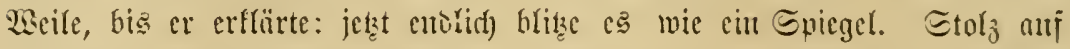
Die gejtern crjt geleruten 2iofabelu "Epiegel" utmo "blant jein" jetzete er

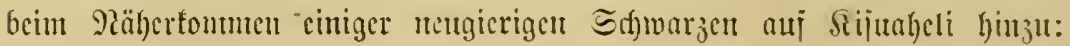
.Bunduki ana katua kwa kióo." (Es gätte zwar in a mı nidft a na

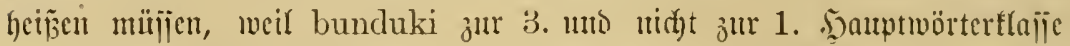
gehört, un๖ anjtatt .,kwa" Gätte cr „cha“ jagent miijīen, ıcil kioo, Epiegel,

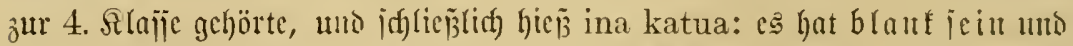

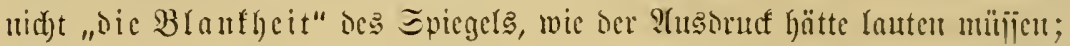
aber Davout alynte jeer v. Rojd) ferg bei aller lltberzeugutg vou Dent taujeno Fallen umo Edylingen des Sijuaheli nidyts. Err war jroh, daj er Den

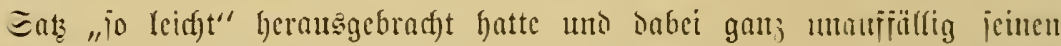

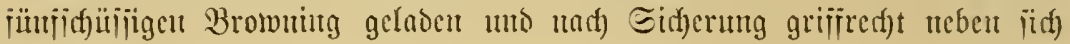
gelegt hatte!

(Er hatte intoejen nod) nidgt ben Doppelfanj ber Büidjsflinte wieder cingehaft, als er idfon bejorgte, cinc groje llufhugheit mit jeinem geidheiten

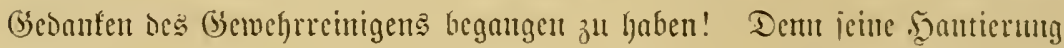

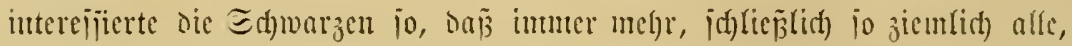

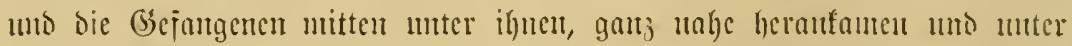

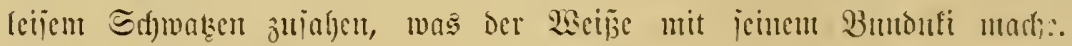

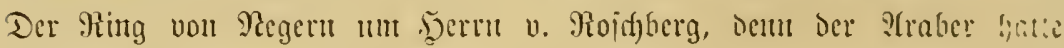

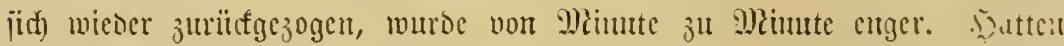

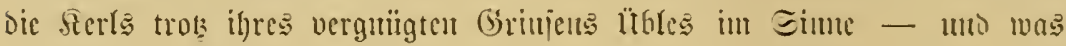

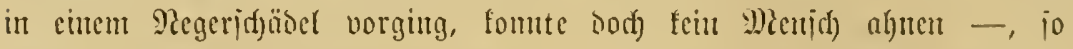

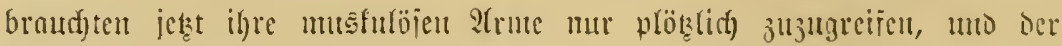

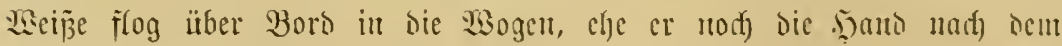

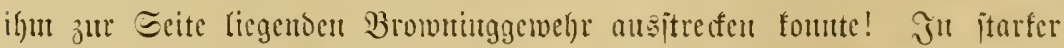

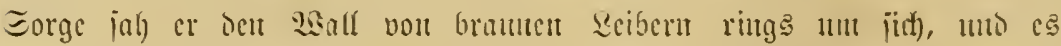

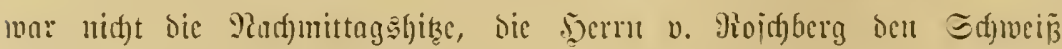

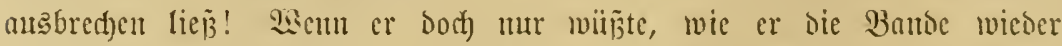

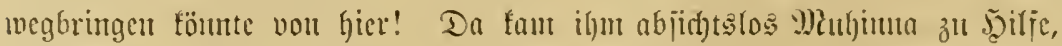

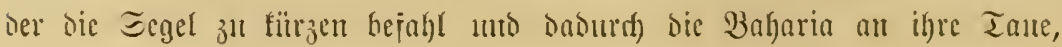


unb bie (Gefangenen burd) einen cnergijd)en 3uruf ber Miantidaft aus

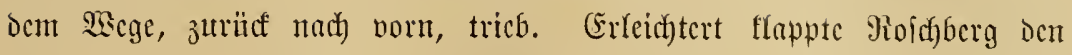

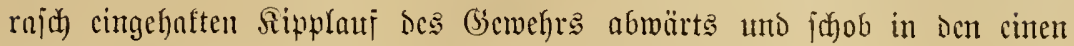
Qauj cine Sugel=, in Dent ansecn eine gojtenpatronte.

"श̂th, Bana," meinte Miabruf, Dem bas Raden ja nidht verborgen

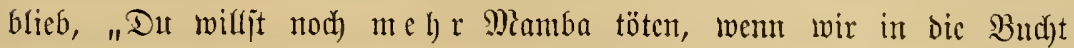

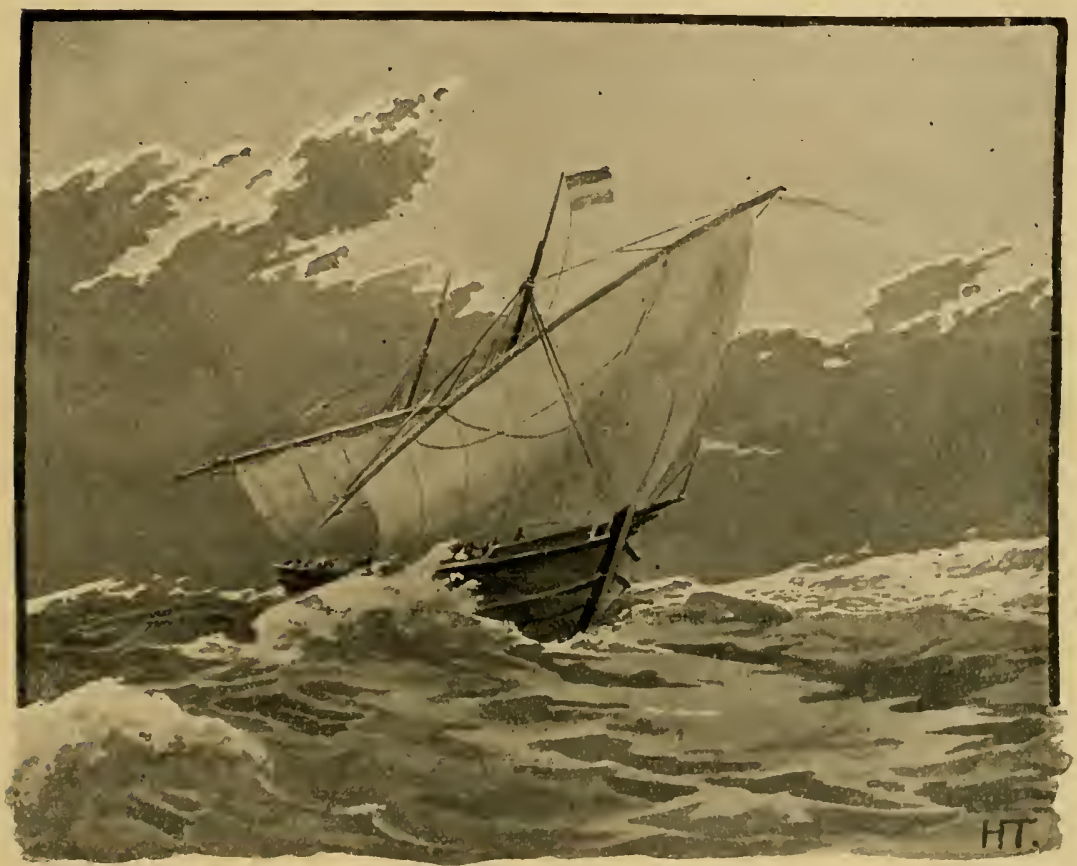

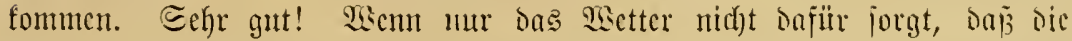

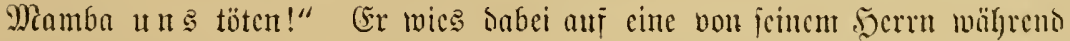

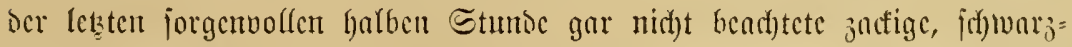

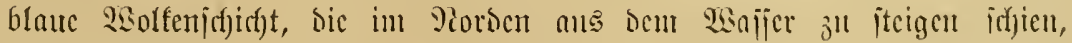

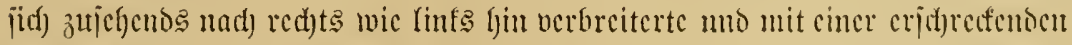

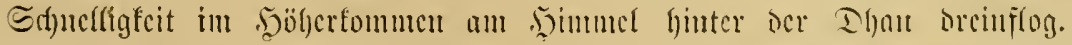

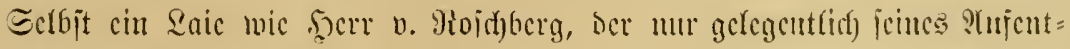

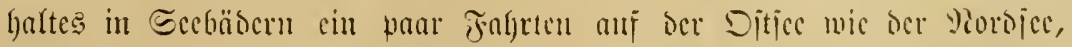

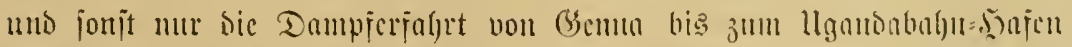

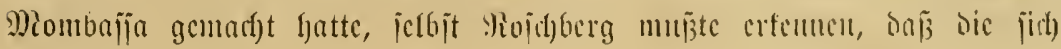




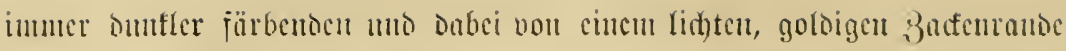

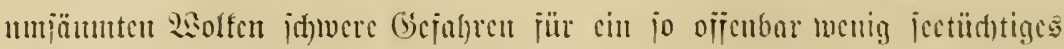

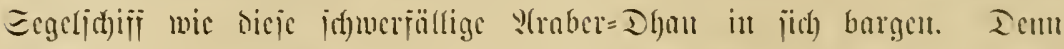

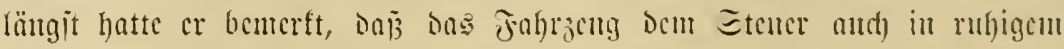

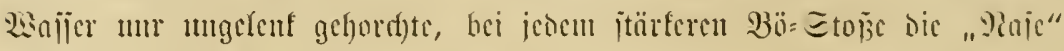

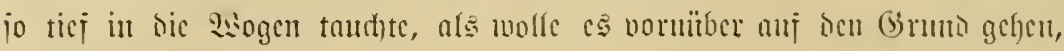

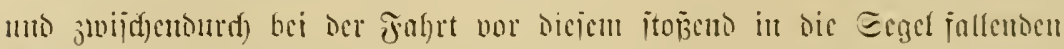

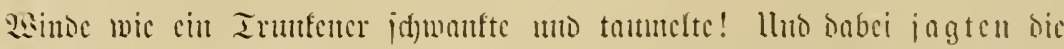

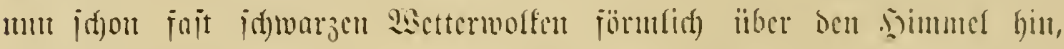

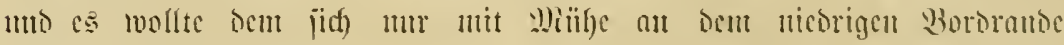

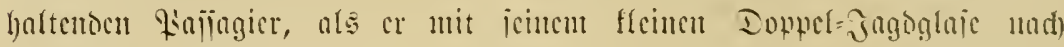

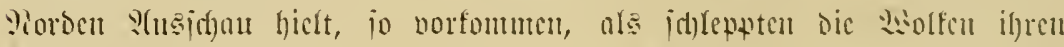

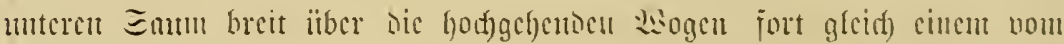

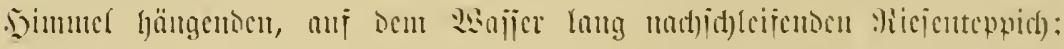

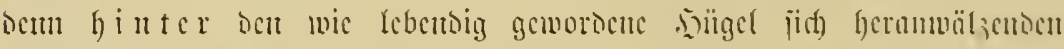

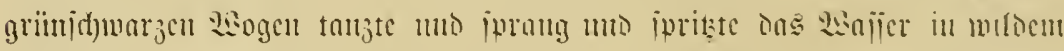
Imunlt, als ob joeben cine idfmere Rajt onariber meggegangen wöre.

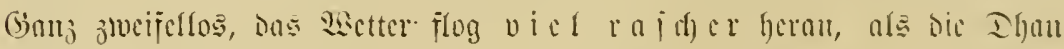

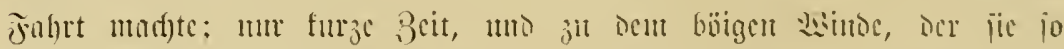

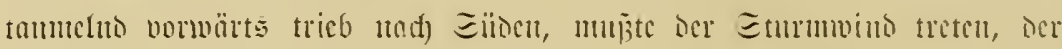

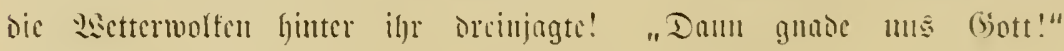

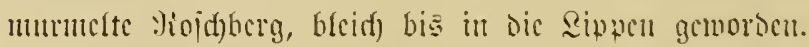

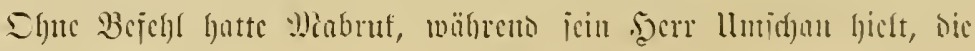
Gewebre in cinte halb muter, halb ïher Iedf liegento ffecite, idfuppenartige

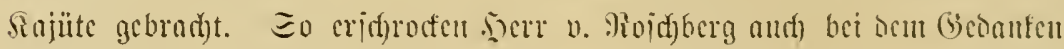
war, baj er mu sen etma aujiäijig mertenden Bejangenen gegenïber

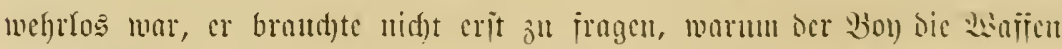

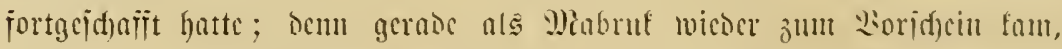

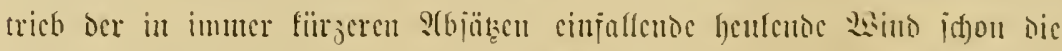

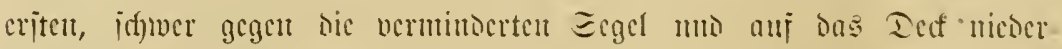

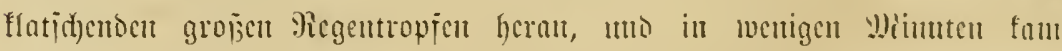

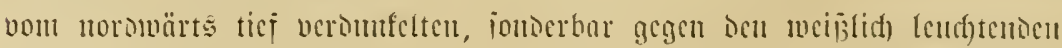
Eïben abjedfenden s)

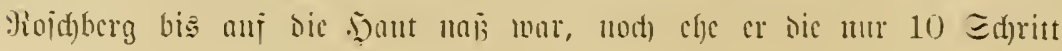




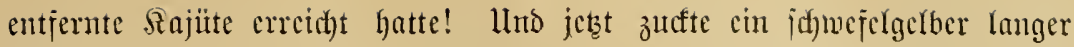

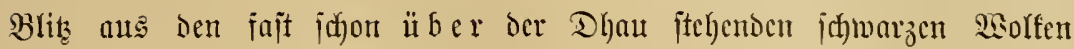

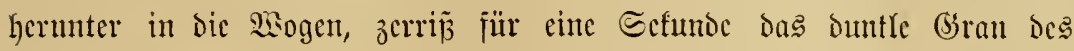
bidjt herunterrauj(henden, alfes unjid)tbar mad)enten Fiegens, ber bic Sselt ringsum wie mit eitem grauen Eacfe verbängte, es folgte cin geffenter, ohrbctäubender finall und bam cin Sinattcrn bes Donners, bas jï) jünf,

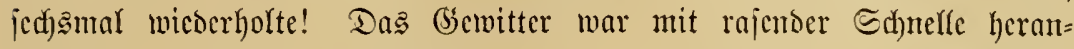

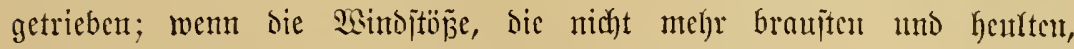

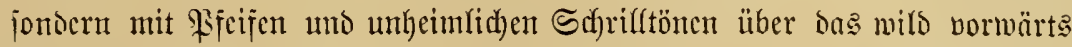

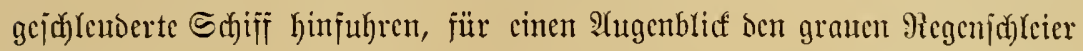
zerfetsten, bann jah ber nod) nie in cinem joldyen S(ujrufhe ber Patur

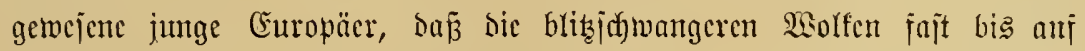

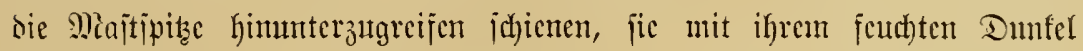

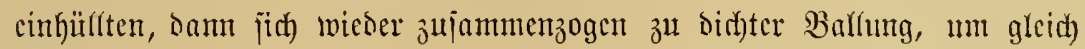
banadh von neuem wie mit gierigen 3ungen hcrunterjulecfen gegen bas nom Eturmminoc wic ein Spielball bon cinem sagonfanm in bas näcbjtc Tal gejulcuderte Edjifi. Эn breiten Edhmaden flog hinter frifjelndem

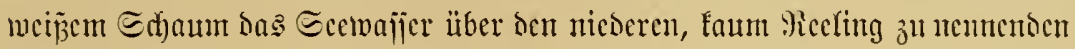
Bororant, balo auf oer cinen, bals auf ber anteren Eeite; Denn jo tief bas plumpe Fafracug eben nod) nad) Eteucrboro himïber gelegen hatte,

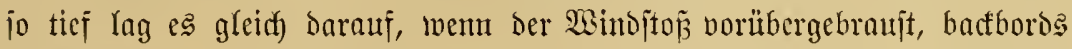
im Echifi. Sirafjelno uno trommelno traf babei ber giegen bic Dhan, Deren

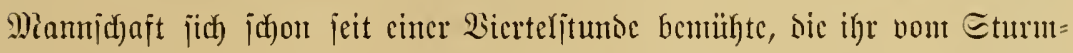

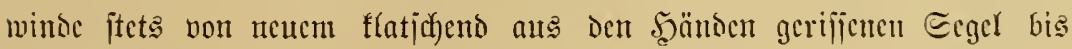

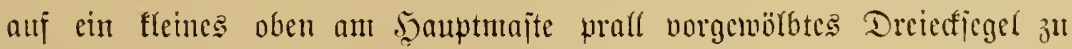

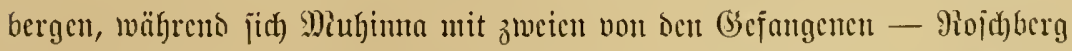
hatte gar nicht bcobact)tet, oañ die Beisen losgefettet wurben - aus Reibes=

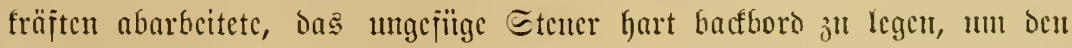

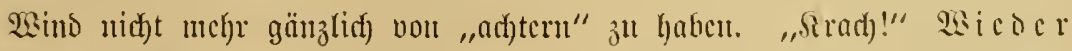

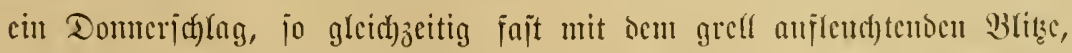

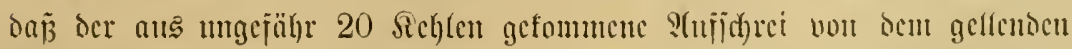

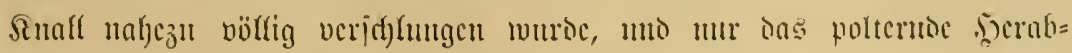

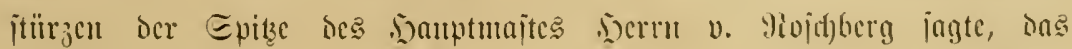


Etuld)

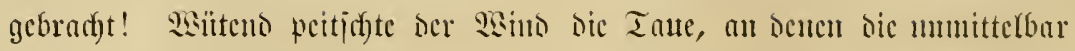

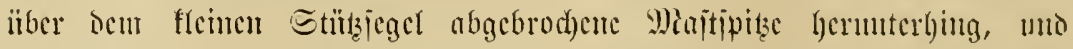

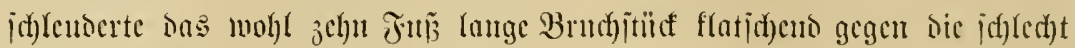

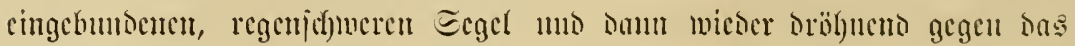
J̨or

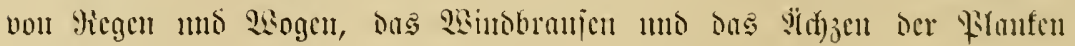

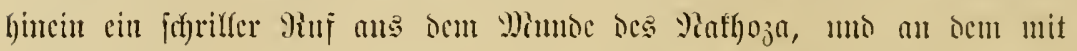

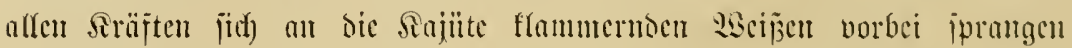

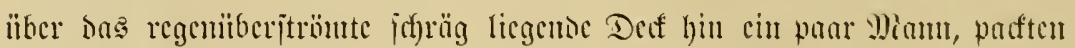

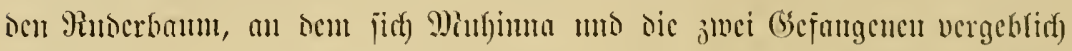

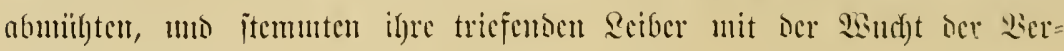

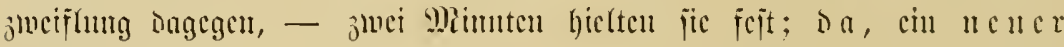

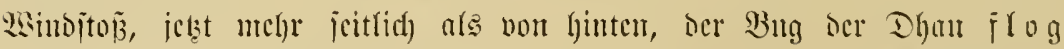

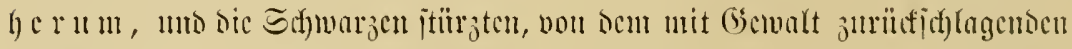

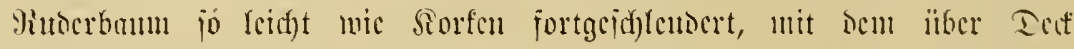

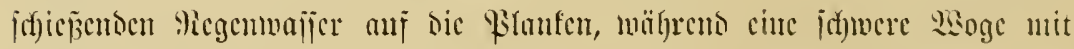

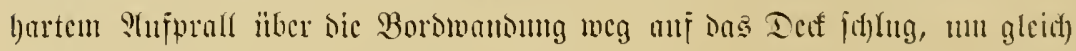

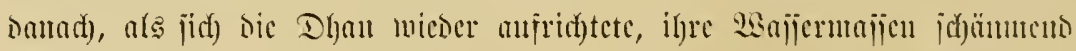

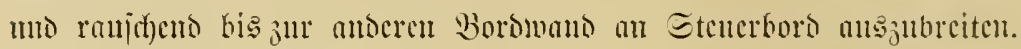

"Elhamdu lillah (Gclobt jei (Sott!)" ricj Minhimun in bicjeu

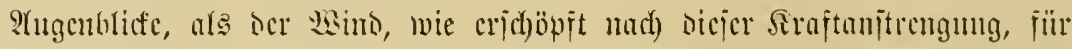

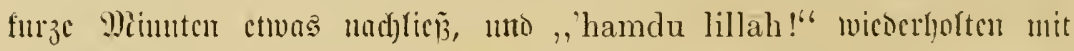

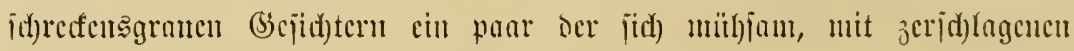

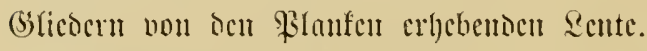

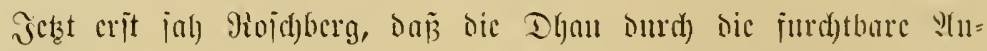

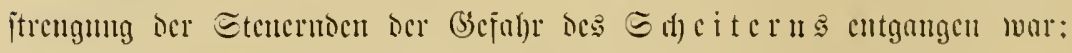

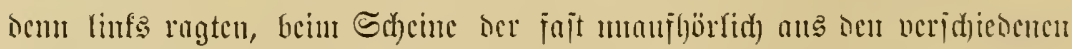

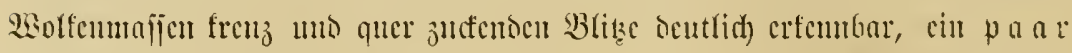

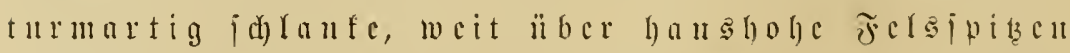
¡d)rofi a

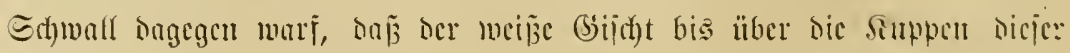

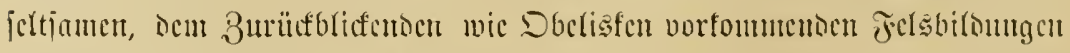

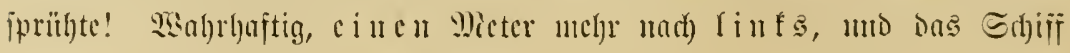




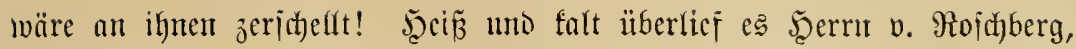

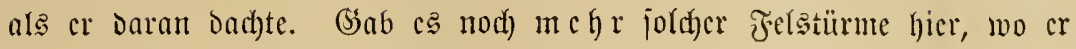
jidi) im freien Fahrwaficr des ozeanweiten Riejenjecs glaubte? Soer war

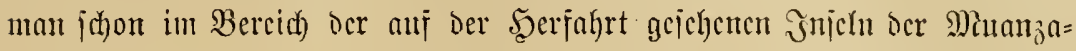
Bucht? Das war aber Doch jezzt, wo noch nicht sic Şälfite ber Fahracit zurüuffellegt war, eigentlich) gar nich)t Dcutbar; trotzbem ber Sturntwinto Das

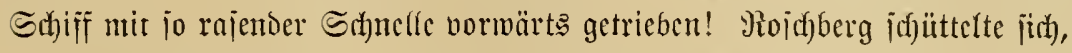

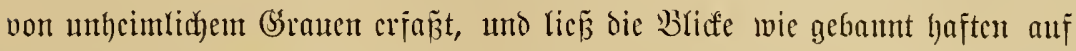
Den itcilen, von ber hoch hiutaufflatichenten, jöäuntenton Brandung untoịten

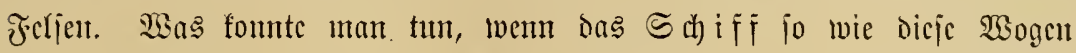

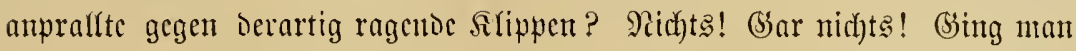

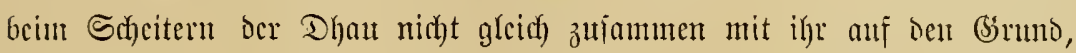
jo war man bod berloren! Saer fonnte sem in sicjen 23ogengange fid Durd) Schlwinmen ju retten verjuffen? Unt wohin, jelfjt wem es den

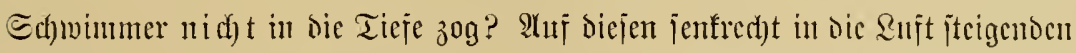
Felstürmen fonnte niemano $\mathfrak{F} u \tilde{\beta}$ fafifer; wer nidft jerichuettert murbe,

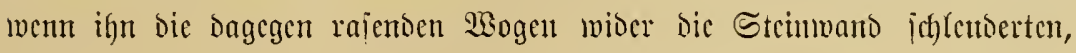
ocn rifien jic beim 3 urï ofjinfen wiescr mit jict) weg!

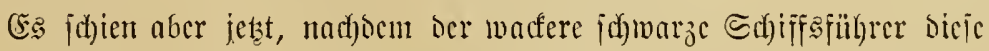
cutfestiche (Sicjafr durch Ssciftesgegenwart geraic im milociten Tumulte des Sturutes bejiegt hatte, als habc das lluwetter icine Sitüfte crijhöpjt;

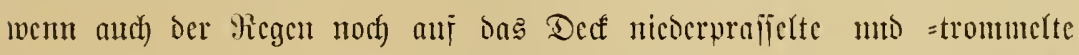

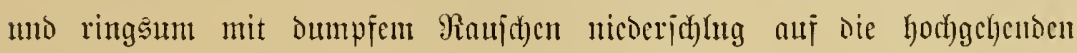

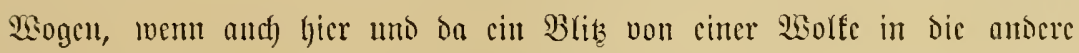

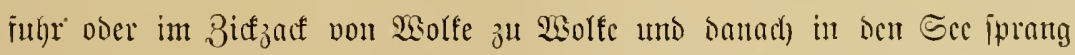

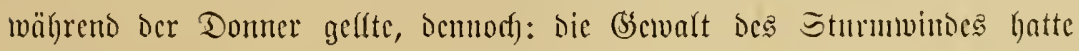

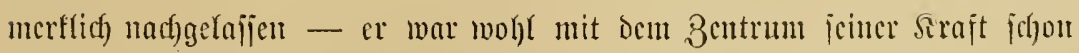
weiter nach Güben gebranit, ber vorher fo hefle seimmel sorten war ia

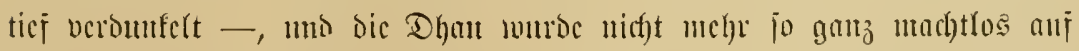

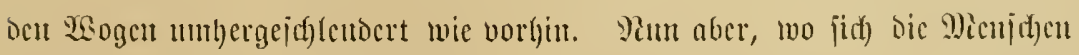

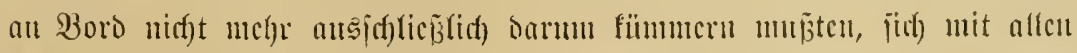

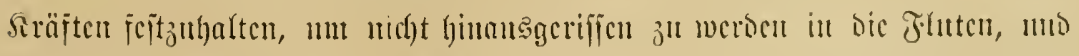

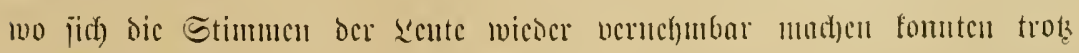

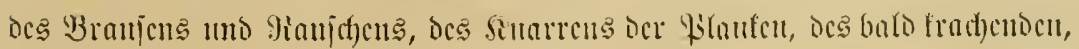


balo Dumpien Eeflagens Der weggebrod)enen Miajtipize gegen Miajt uno heruntergelaffencs Segel, mun hob cin Jamumern mo Stölnen an,

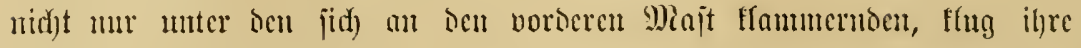

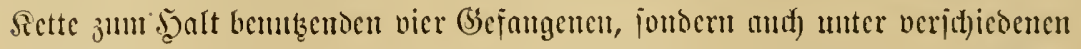

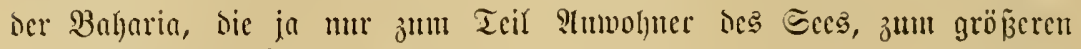
Teil Bimenläntor waren. Wiuhima fïmuerte jid) indes nid)t un ihre

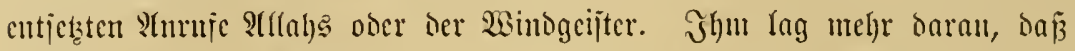

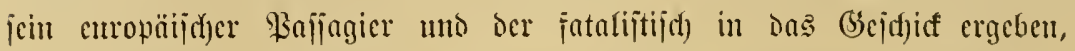

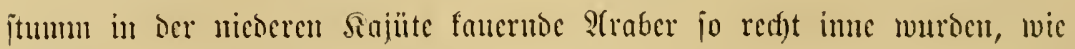

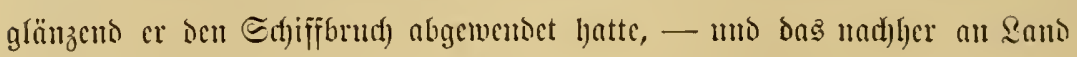
auj Der Etation mic iun Drte Minanza zu jeinem Mullume erzählten!

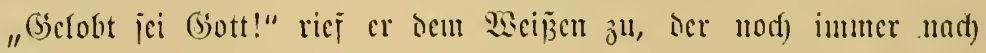

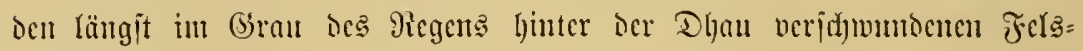
tïrmen Umidfau bielt, "cr bat แms gerettet; wo mur eime Şanobreit

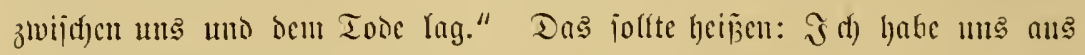

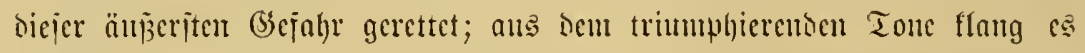

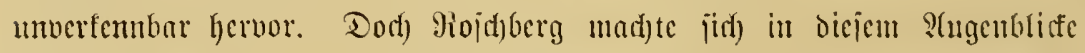

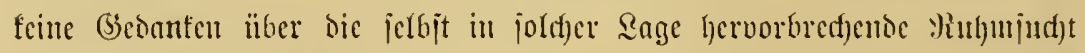

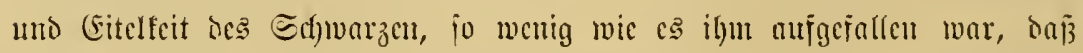
bie joujt doch) jo getajien an beu Tod Dentenden, ihn als amri ya mungu himelymenden Neger da vorn an Majt jdjicr verzucijelt taten, obwohl man boud) Der (Sejaljr entroment war. Doer w $\Perp \tilde{j}$ te $n$ jie etma, Daj nod)

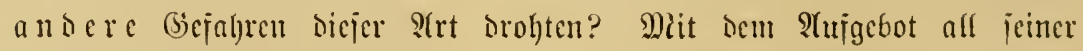

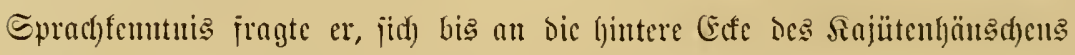

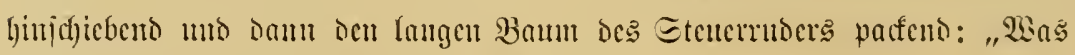
war bas? Sdjon cine Jnjcl nor Miuanza?"

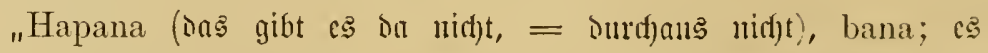
maren erīt die pinnacle-rocks." (Er naunte bic von ben Deutjd)en als "Majtipiken" bezeidfueten Silippen mit ihrem englijd)en 2Ramen, Turmipitzen=

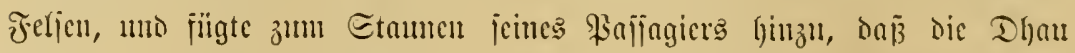

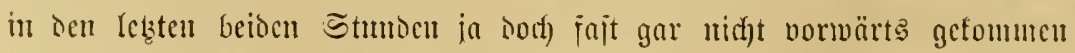

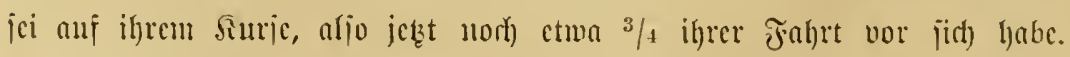

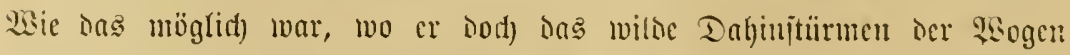

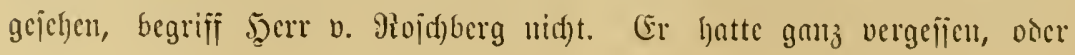




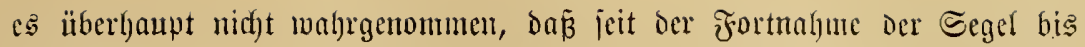
auf das Kleinc, nur eben als Stütze bienende, Der Stnmmint wohl dic Wogen geljoben uno gejentt, aber die Dhau uicht über Die Wogen

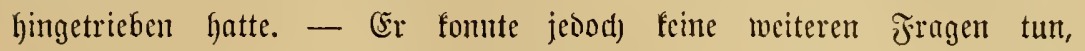

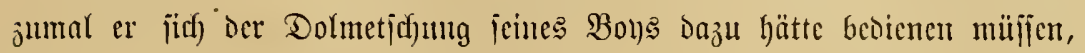

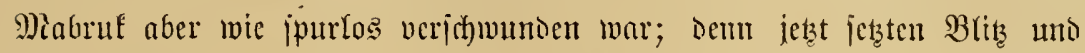

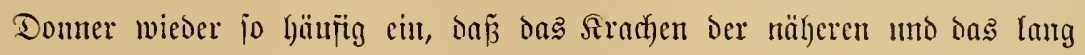

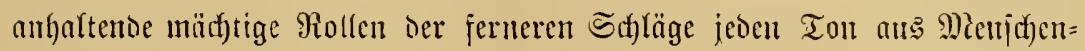

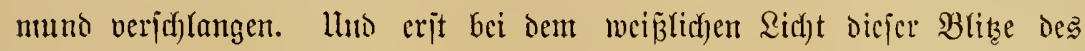

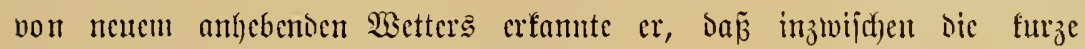

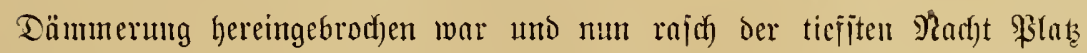

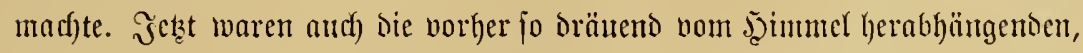
imuter auf's nette in iffwercu Mafjen vom braulenten Sturme heran=

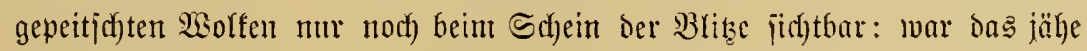

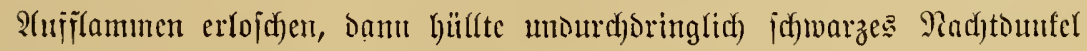
ङ

Miuthinna, der unnittelbar neben Yojdyberg Den Steuerbaum um=

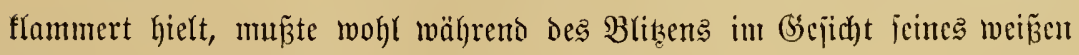
Baijagiers defijen Sorge erfannt hahen. Denn er idhrie ifnt in's Shr:

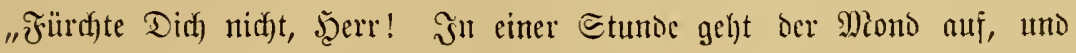

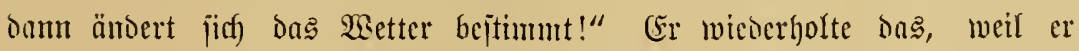
jitc) idfon won ber geringen אijuaheli=\{enntnis Jiojd)berg's überjeugt hatte, gleicf) Danach) in jeltjan gurgelntoem (Englijd).

Rod) eine Stunoe in joldher Racht, in Toben cines (Selvitters,

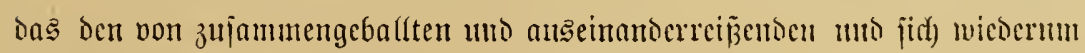
ballendon $\mathfrak{W o l f e n ~ u ̈ b e r i t u ̈ r m e t e n ~ S ̧ i m m e l ~ m i t ~ m i l o e m ~ S i r a c h e n ~ j u ~ i p a l t e n , ~}$

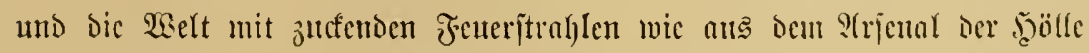

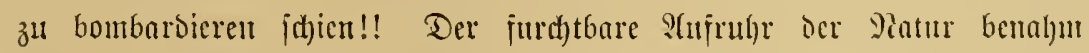

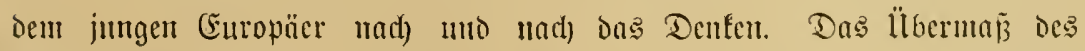

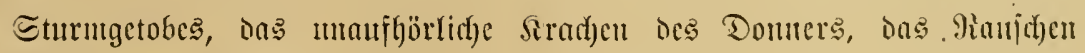

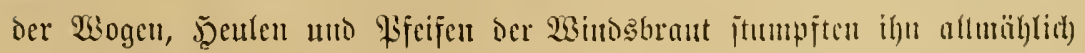

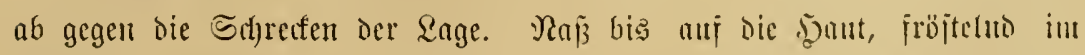

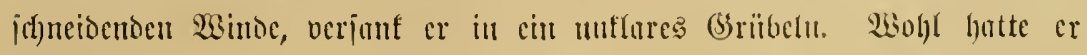

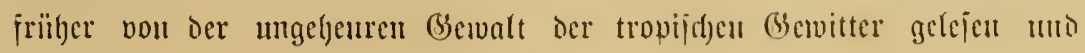




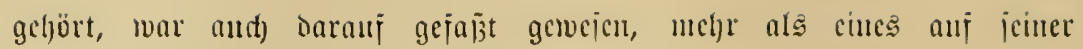
Solonialreije ïber ji(d) ergchen lajien zu miijien; ood) or hatte jid) jold)

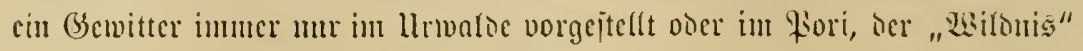

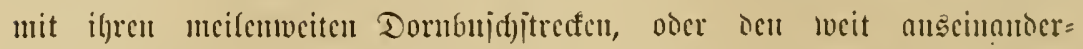

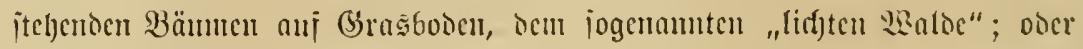
er lyatte bas wistter im (Bsijte gejebch, wie co mit jagentom Bsemölf

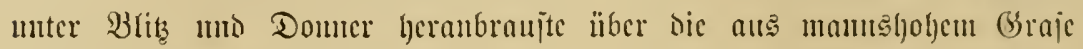
aujragenton Serïppelafazien unto bie größzeren oder fleincren "Banu=

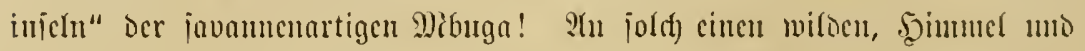

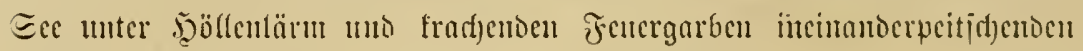
Srtan auf ocm 然ajicr aber batte er uic gesacht!

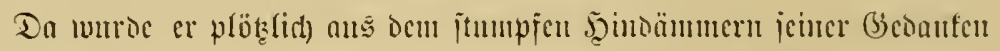

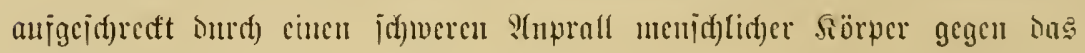

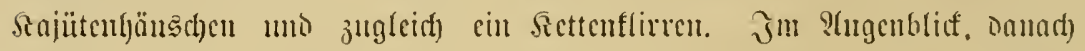

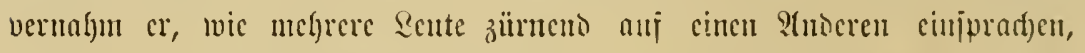

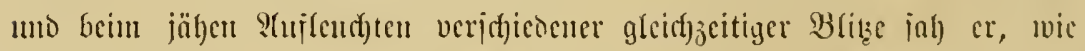
ber vorberite ber gegen bie Siajütemwand geworfenen Settengejangenen

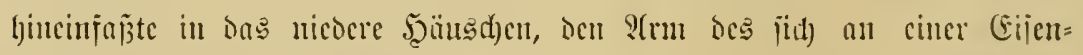

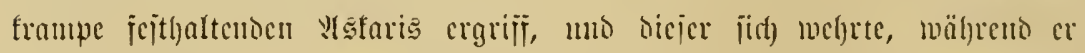
von "bunduki" uno "piga risasi (cridfiejenen)" redete, oder vicfuchr bas

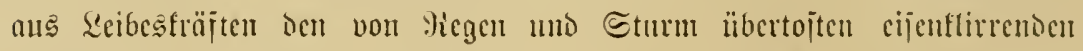

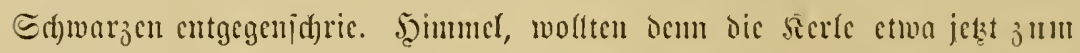

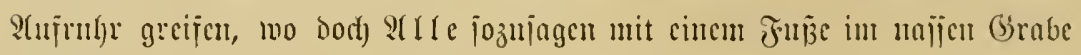

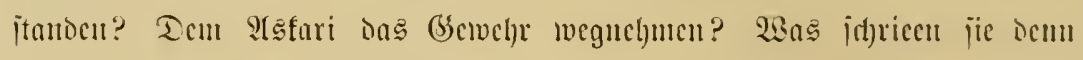
alle vier von uawa (getötet werocn)? SBaren jic verrü̈ft gevoorticu, onj

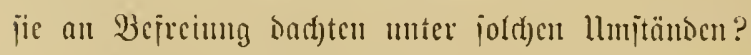

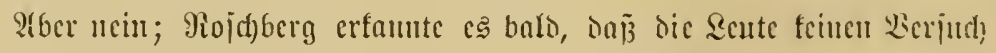

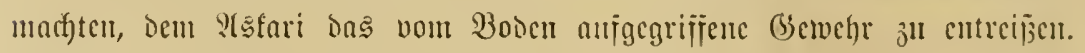

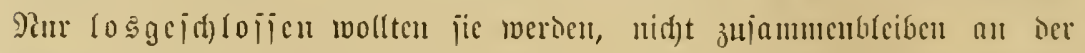

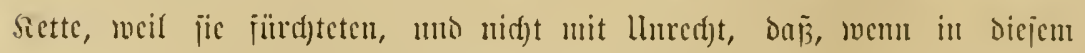

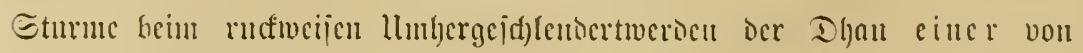

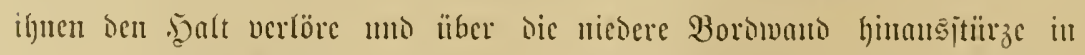

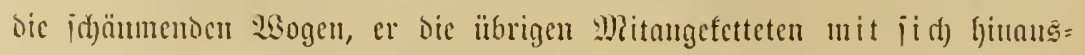

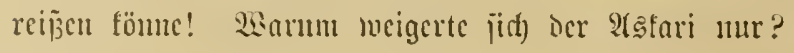


Dic Bscjangenen hatten ihn aus Der offenen, nidjt vicl mehr als

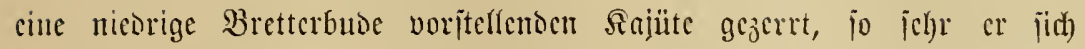

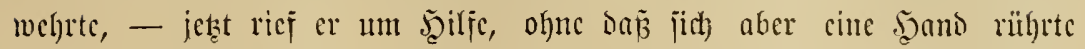

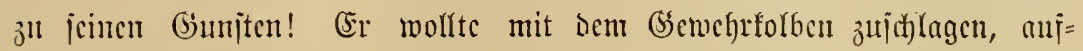

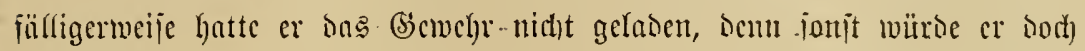

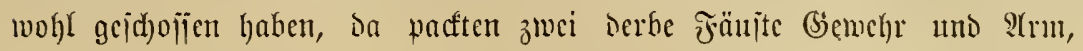

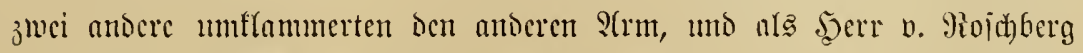

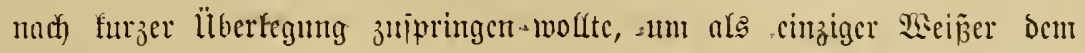

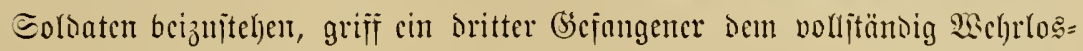
gemadhten in sie Tajd)cu. STh, jie wollter ihm dic S

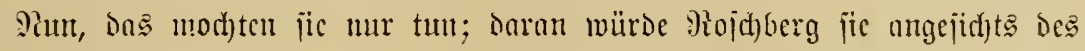
tohentien Stutmes uno ocr llmmöglichfeit jür fie, lebentig von oer Dhau

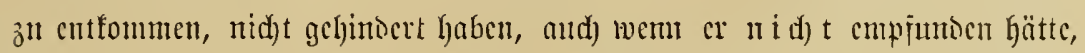

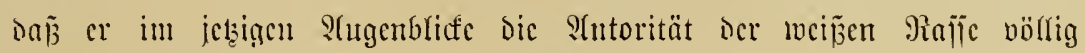

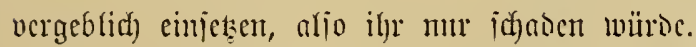

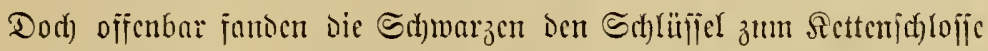

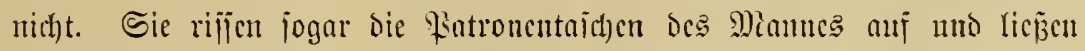

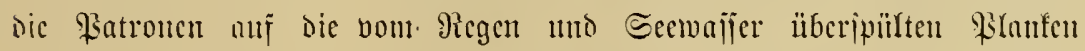

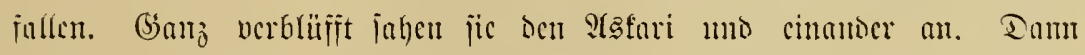

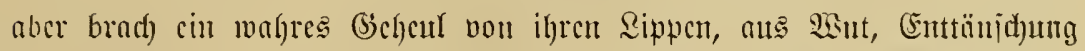

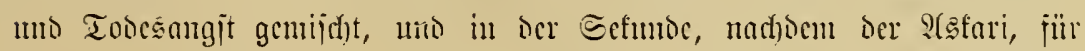

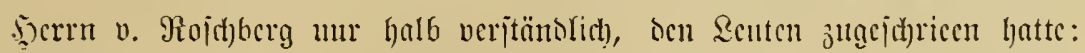

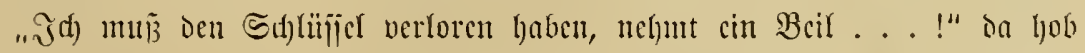

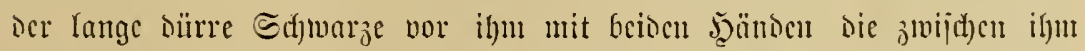

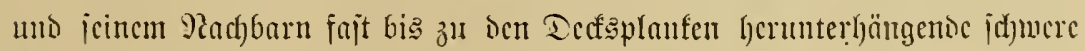

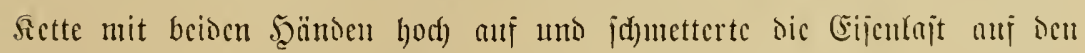

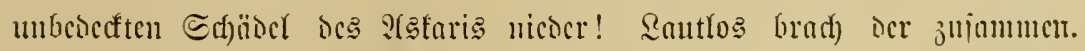

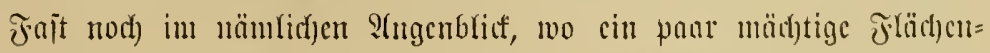

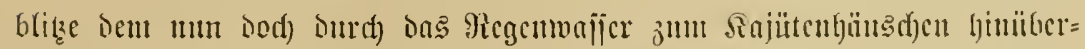

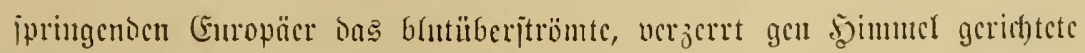

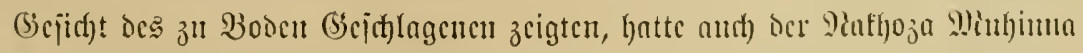
it)on orei jecuer angeffammert im Etern ber Shan funcrnocn Zente an's

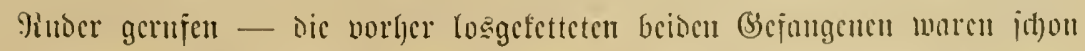

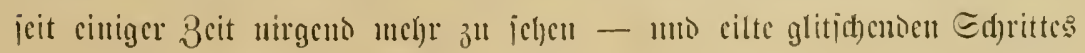




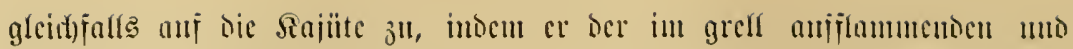

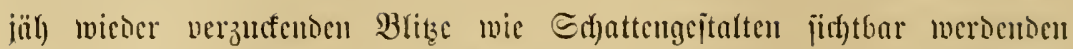

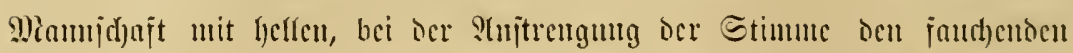

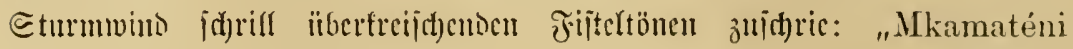

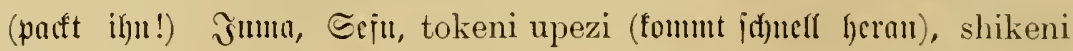

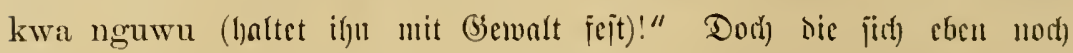

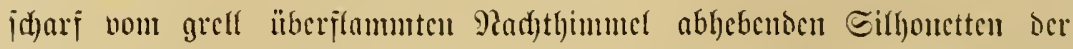

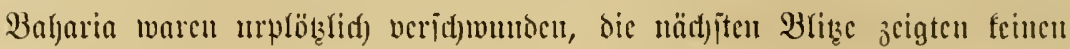
melyr vou Der Mamuid)aft, wenigitens ui(t)t j̈̈̈r bas ungcid)ulte S(urge bes

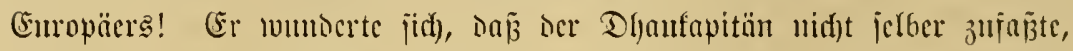

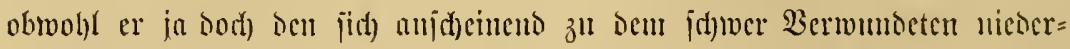

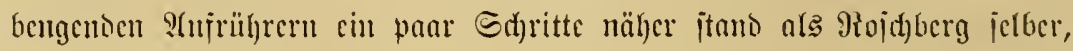

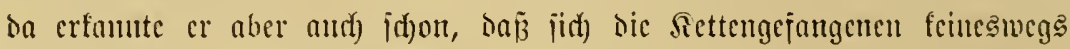
ctwa bejorgt um bas mijitöbuente Spjer Der rajchen Tat fïmunerten,

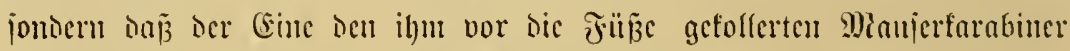

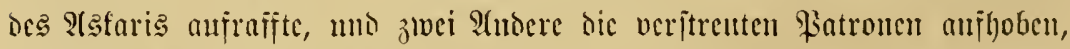

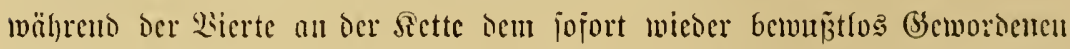

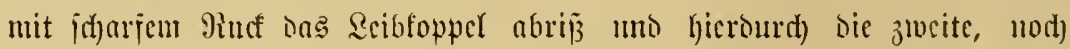

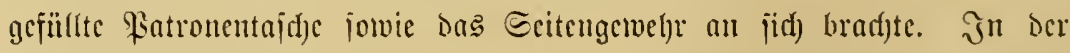

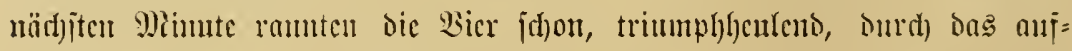

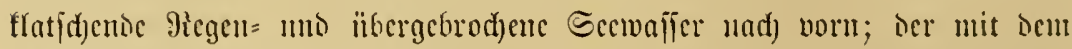

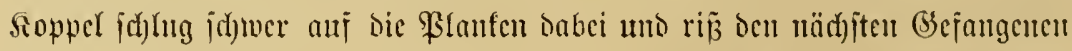
halb mit jid) nicier, weil dic Dhau cben bactbords von cincr Sisoge io

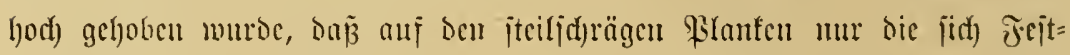

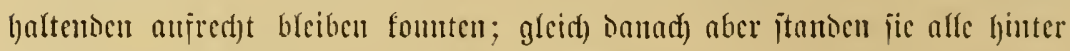
Dem vorderjten Miajte, man förte ihre Sictten flirren, als jic tounit ben Majt als şalt unicl)Langen, uno cinen STugenblicf ppäter nertal)men dic

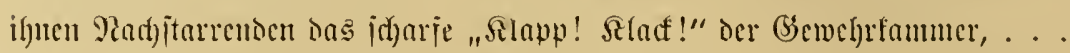

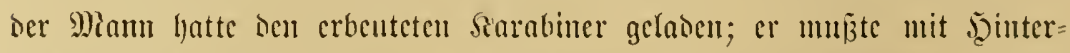
labcrgewel)en vertrant iem, war viclteid)t cin chemaliger S(sfuri ober hatte

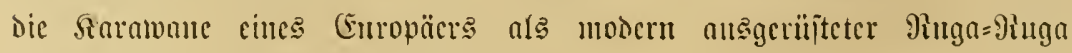
(ફ̧ilfsfricger, \&antafued)t) begleitet!

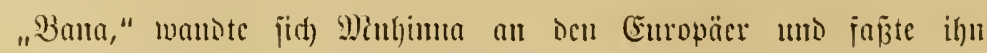

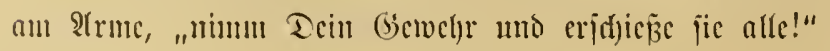




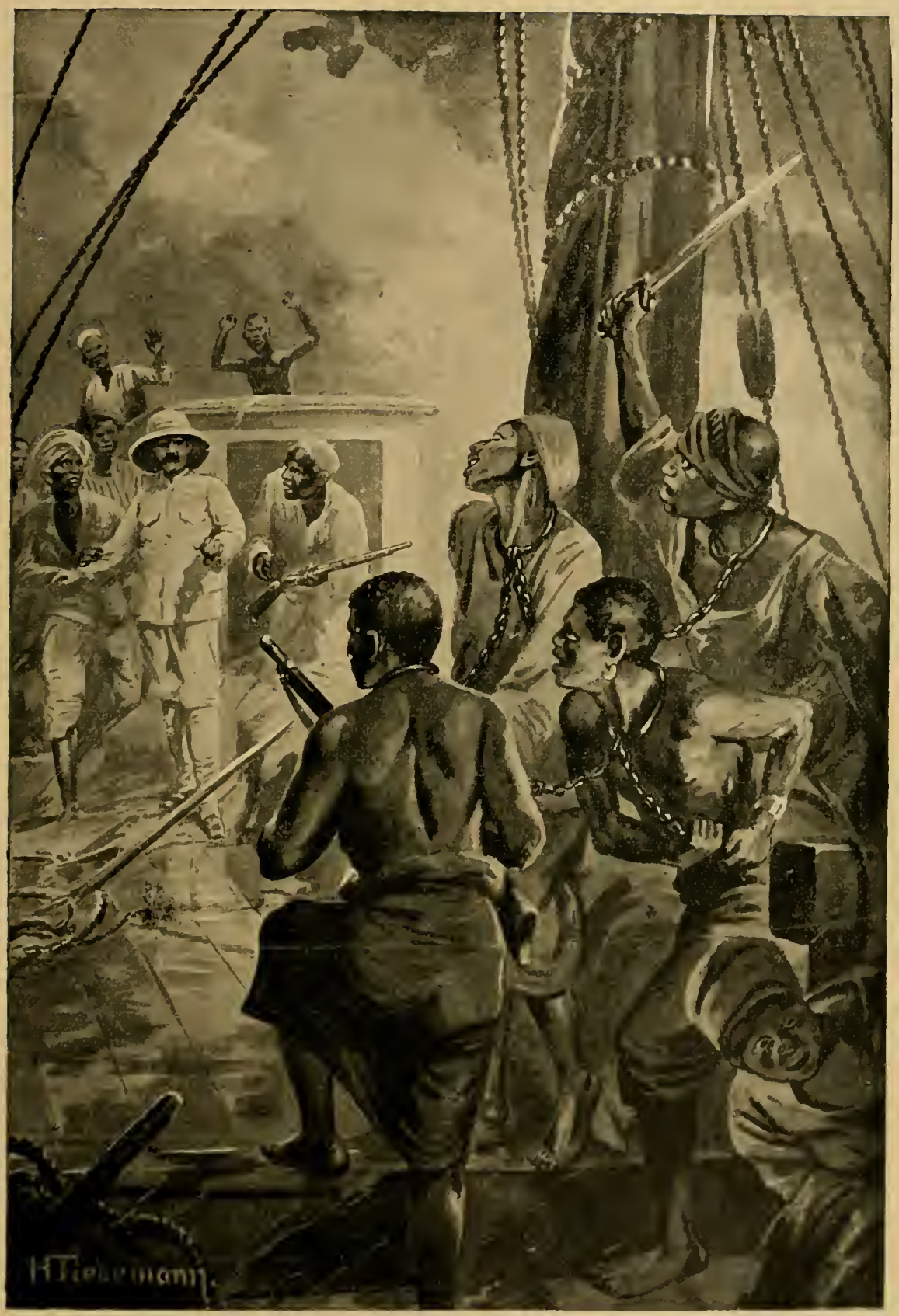

"Bana," wandte lich Muhinna an den Europäer und fajłe ihn aln Arme, „nimm Dein Gewehr und er[chiejse lie alle!"

(ङcite 168.) 

Betroffen jubr Pojd)berg herum; Dod) che er nod) jull cince Stutwort

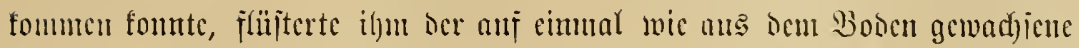

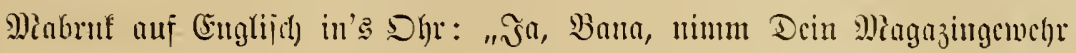

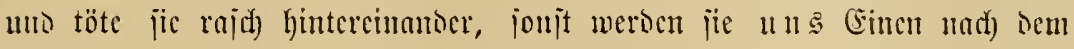

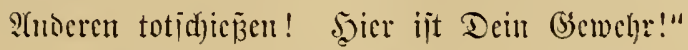

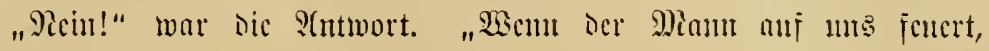

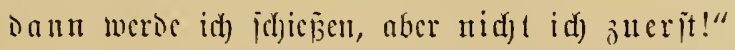

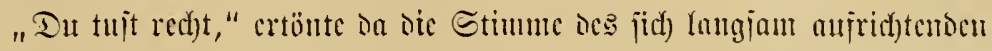
Trabers aus Dem Duntel, "Doch) att)te Darauf, ment wir an bic Borinich foumen, of jie ucriut)en wertien, jich bes Beibootes jut bemäthtigent.

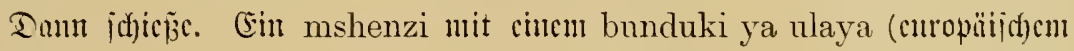

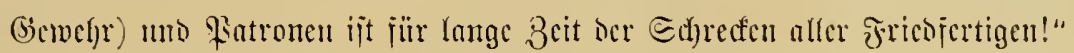

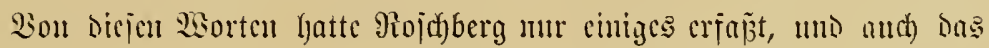
mebr erraten al: veritanten, uno Juabrut hali sicsmal nicht nus: ber jonjt mit bem Dofmetjd)en jo flinf vorgebenoc, weil jid) gern widftig mad)enoc

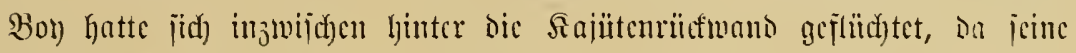

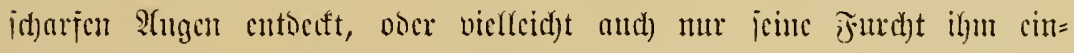

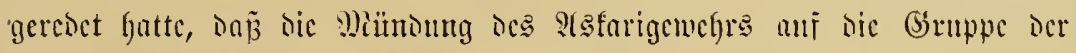
vor Der Türöf̈̈nutg Stehenoen gerid)tet wärc.

"Das Beifoot?!" unurte Miuthimua ärgertid). "Das ijt lüngit vom

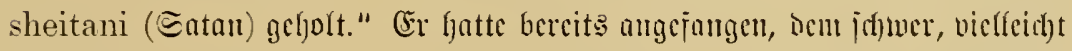

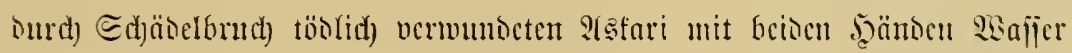

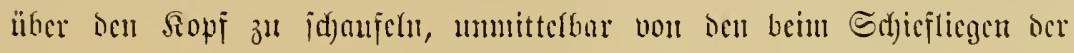

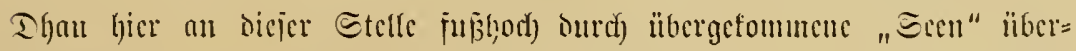

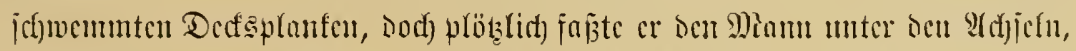

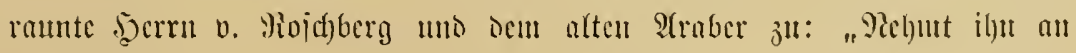

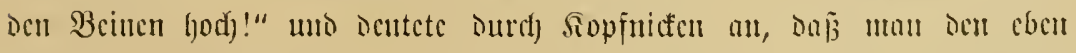

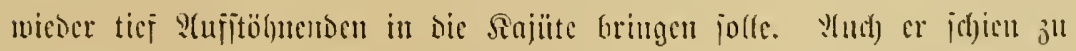

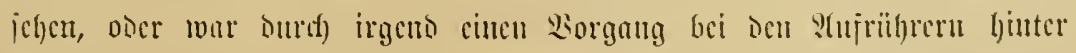

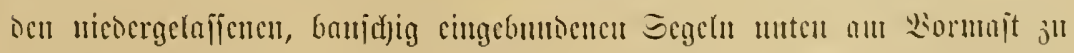

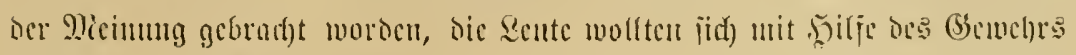

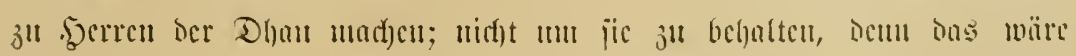

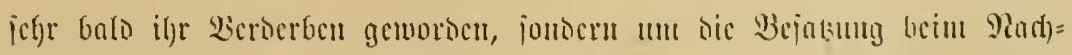

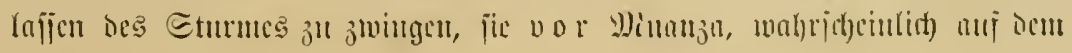


jenieitigen, wejtfid)en lijer ocs Eccs zu lanten. - Eo rajd) es anging,

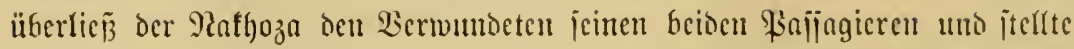

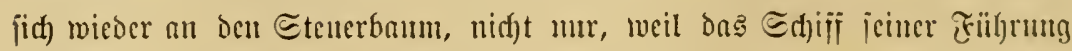

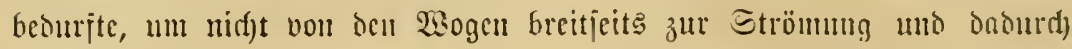

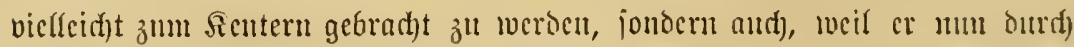
dic Rajüte wenigitens etwas vor Den beiürd)teten S(jüjïen ies Mienterers

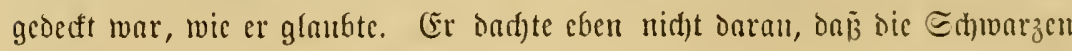
vom Bormajte her jeinen Stopi über Dem Şüttentadfe jefyen founten, aud) nur nötig hatten, geradcans in dic offene Sajäute ž feucrn, um ihn mit

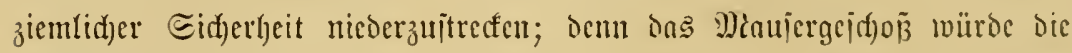

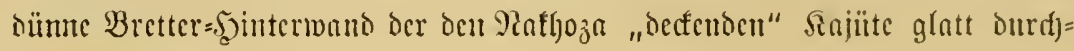
id)lagen ljabent.

Dod) norläurig badfent bic Sente noch an fecine weitere Gicualtat.

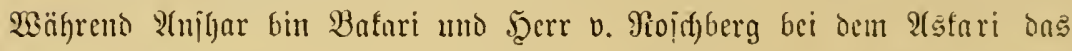

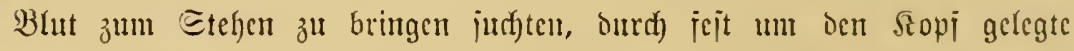

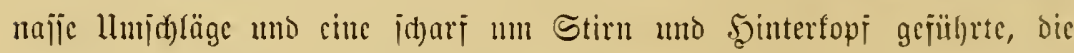

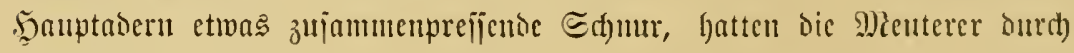
energijd)en, das Braujen uno Raujden des Sturmes ïbertönenden 3 แru

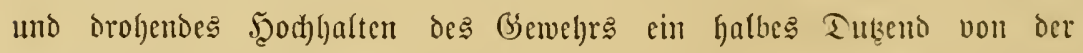

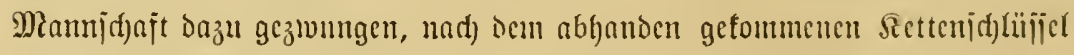
zแ juchen. Atber bas war ein ganz vergeblides Bemülyen, obwobl jeşt

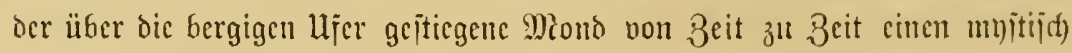

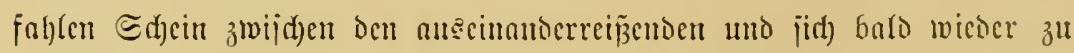

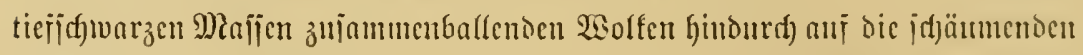
Wogen wari uno gelegentfid) and) einen unbejtimmten 2 idftiftreifen

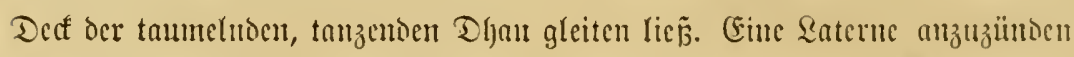

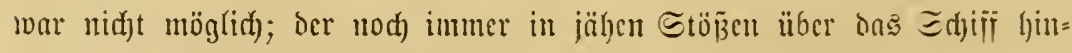

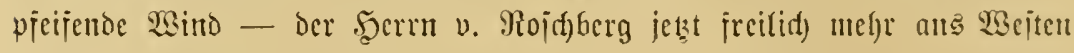

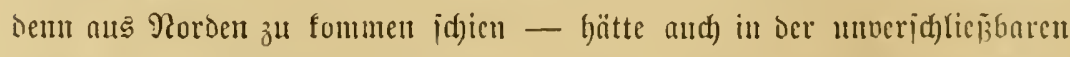

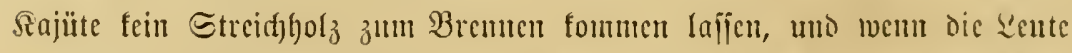
eS jelbjt jertiggebracht bättcu, dic Saterne unter Decf im nicberen Sabe=

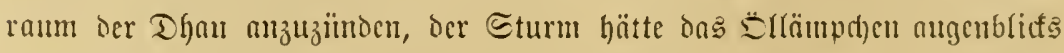
aušgelöj(f)t, jobalo Der Miann mit ocr Eaterne aus dem \&ut au Eecf gejticgen märe, uno bätte jefr wahrid)cinlid), io gewaltig tobte er nod) 
immer, aud) Die Edjeiben oer Ratcme“ jertrümmert, obwohl jie eine euro: päijhe, Durd) ein Drabtgitter verwahrte Etallfaterme mar.

"ङo bringt ein Beir!" id)rieen cmolid) bie Rettengejungenen.

Piach Iangem Endyen erflärte ein Baharia: audid dic Beife, alfe

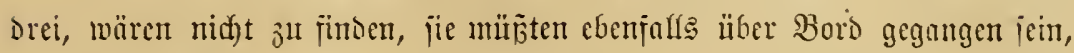

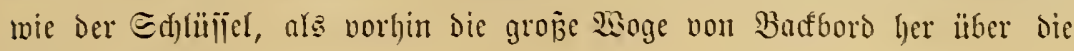
Dhau weggeititiant jei.

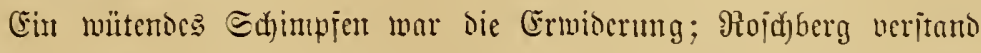
es nicht, ufwohl chen bic $30 ̈$ rajd) abiflante, und bas Shr biejes jajtelle

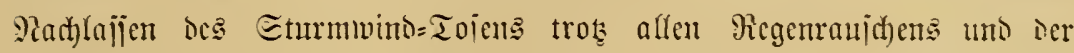

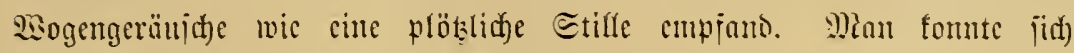
aber wohl Denfen, was bie Sicrle ia am Majte jeţt ber Miamidajt uno bcjonters ifrem Füfhrer, möglidfermeije auth ben Piajiagicren anorohten, jumal ber eine ber Gejangenen mit ben ans ocr Edjeide gezogenen, best Psfaris aud) als Bajonett biententon Seitengewelyr wild

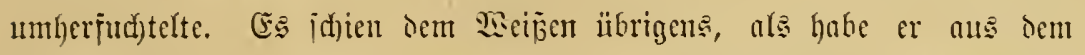
Mhunde ber Reute bie siorte ñgambo hii, Das bicsjeitige llier, nernommen.

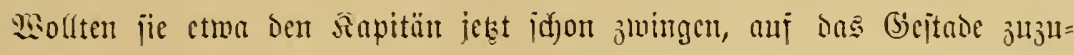

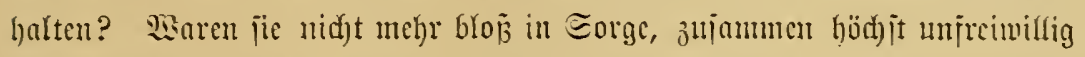
über Bord ju Fliegen, jombern beabjichtigten jic, wenn on linfs Sorinjeln

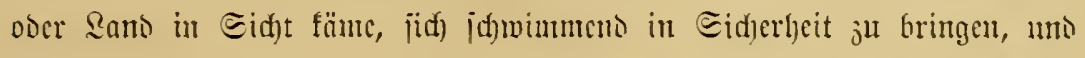
verlangten jie deshalb num nod) encrgijd)er als vorhin, daj ihre Rette

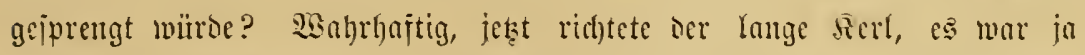

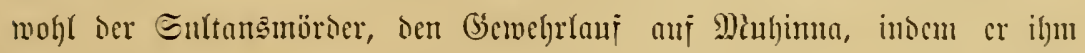

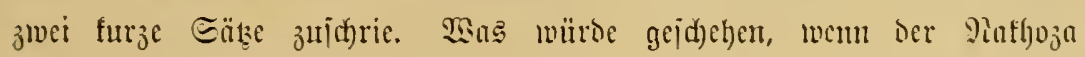
diejen Bejeble "jeiner (bejangenen" nidht nadyfommen fomte, wie es bei

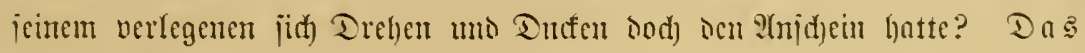

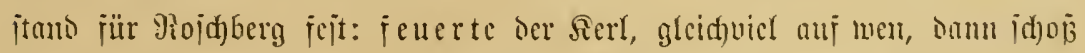

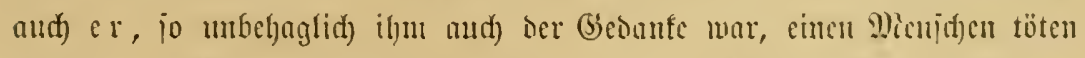

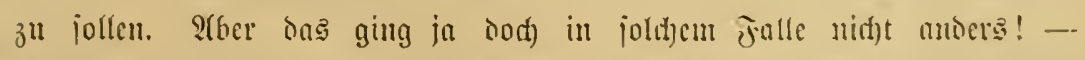
Rojdjberg hatte bas vou Mabruf an die Smmemuans ocr sajüte gelelmte

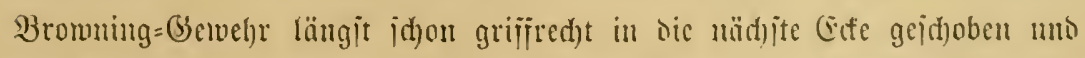

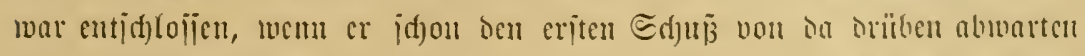

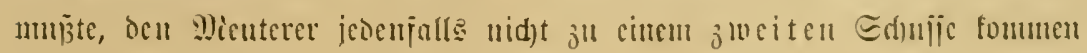




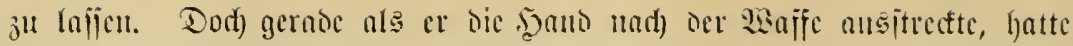

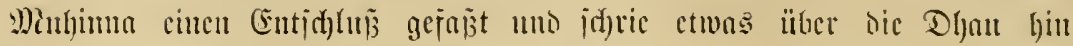

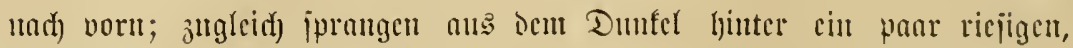

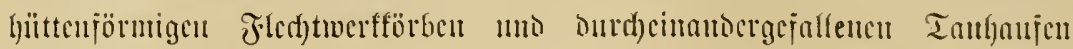

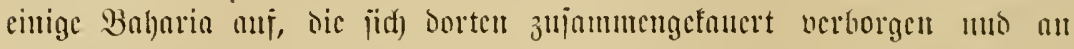
Den Şalteitriffen ber Siörbe iejtgeflammert hatten. Sic verid)undoen in

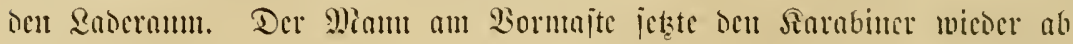

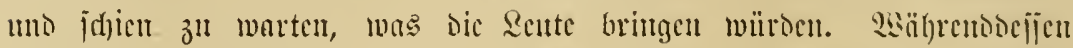

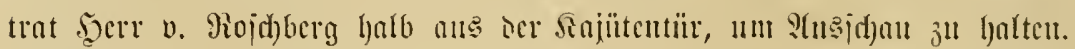

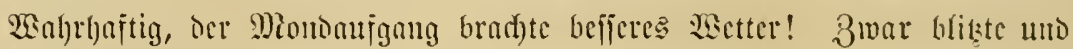

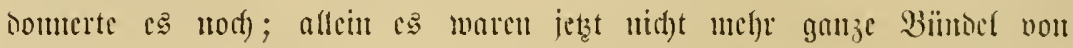

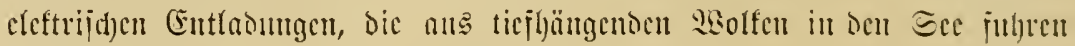

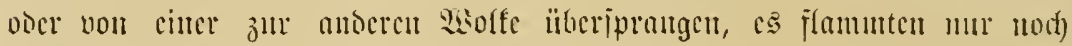
cinjelute, von greflem Suttern gefolgte 8utumgen auf; zwar rollte ocr

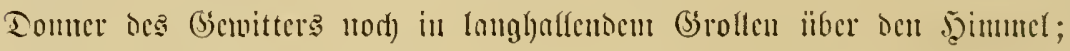
intejien bicjes gemaltige Roffen - "als ob die Giötter Segel idjöhen im

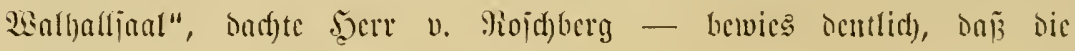

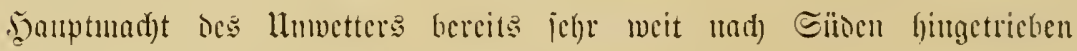

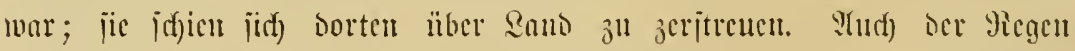

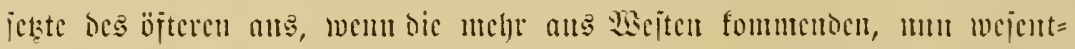

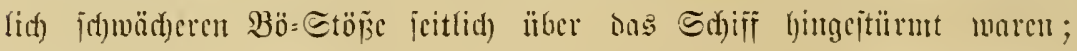

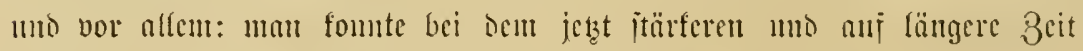

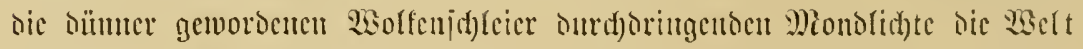

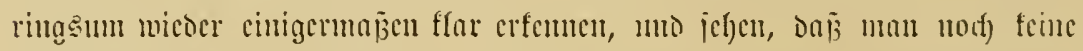

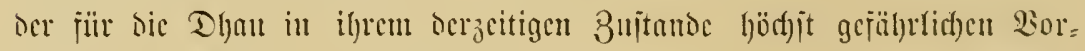

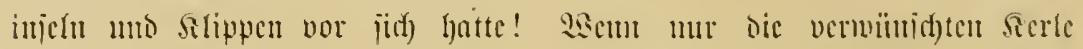
uidht on

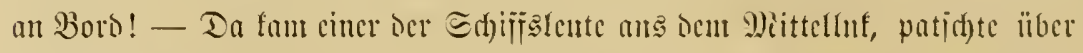

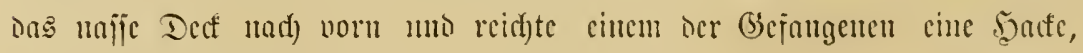

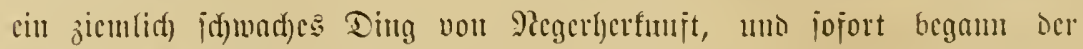

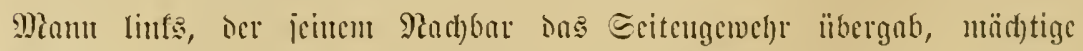
Ect)läge nuf bic halb um ocn Majt gejpamte sette ju jül)ten. Dod) jo

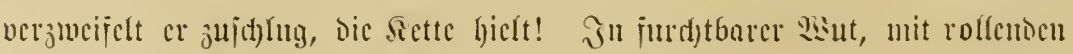

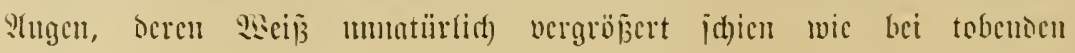


2angnjinnigen, jufricen die Bier num wieder ïber Decf hin, von neuem mit bem (Semelgr, bem Eeitengemegr uno mun audf mit ber Deacfe brohems,

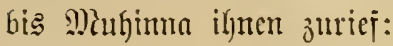

"Hebu (alio gut tem), idy tue es! sienn aber bie Dhau idyeitert, werbet igr mo mir afle onbci ertrinfen!" Das überjekzte ocm Emropüer

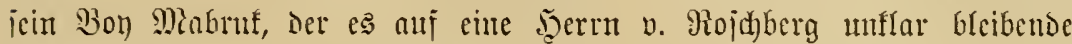

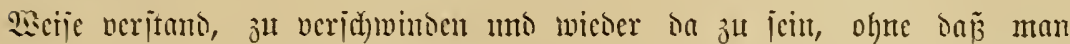
ihn weggeben oder fommen jah. Lno nod) eimmal raunte der Maffoja

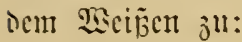

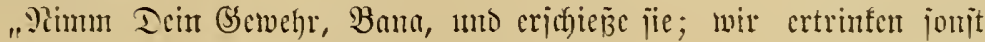
alle, went id midh jeţt oen Jnjeln mähere!"

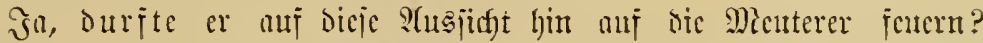

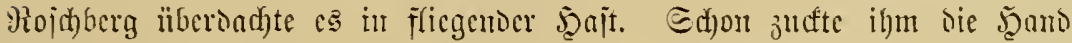
jajt oljne jeinen

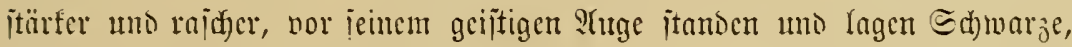

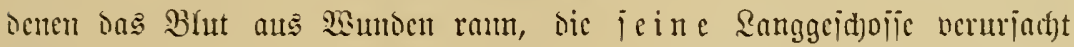

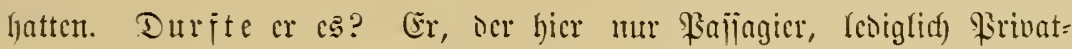
mann mar, tem bie Bicjangenen nid)t umteritelft waren, Der feiner

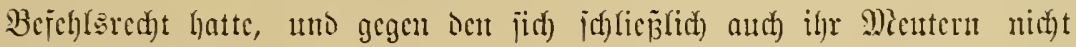

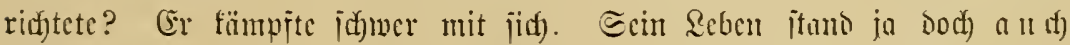
auj bem Epicle, - wenn Minhimu recht fatte, wenn es jum Edjcitcrn

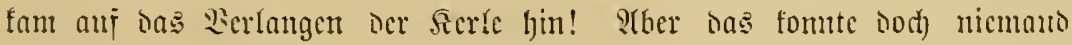

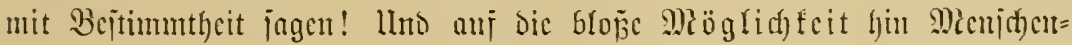
leben opfern, wenn es aud) bas \&echen von anjiäijigen Bscjangenen uno ङdymarzen war . . ?! Mcin!

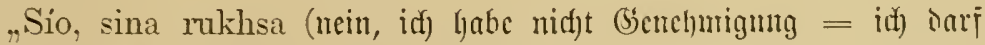
ni(f)t)!" brach)te er gepres̄et ïber die Sippen.

Mit einem gemunmelten, halb jornigen, ljalb verïd)tlidfen „mpumbafu!"

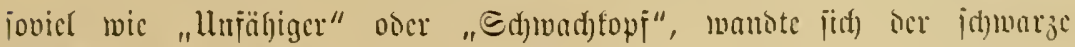

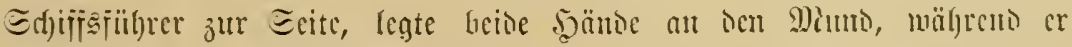

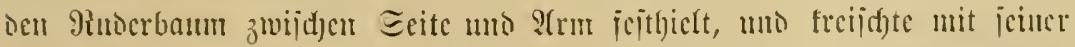

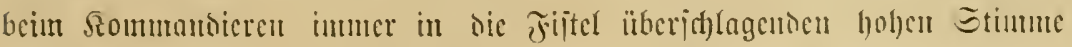

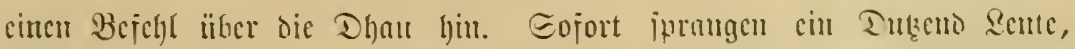

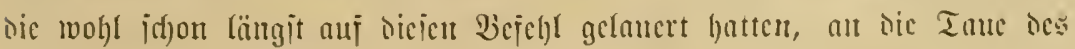


Şauptmajtes, mit cin panr fräftigen Miejierbjeben war die Serbindung

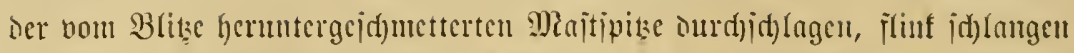
Die Sente cinige Edflaufen umb Sutete in bie gefappten Tauc, mo nad)

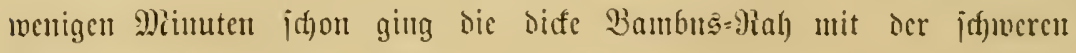
Majie des regentricjenten Eegcls tnarrend mo idfurreno in dic 5öbse.

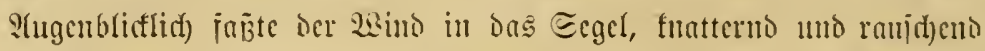

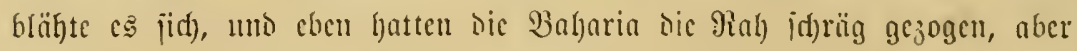

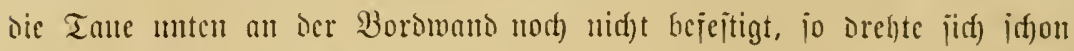

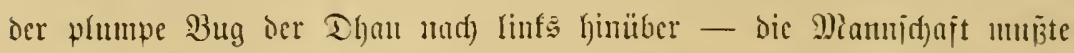

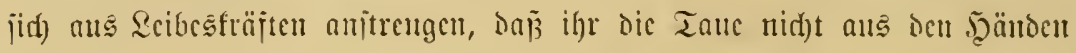

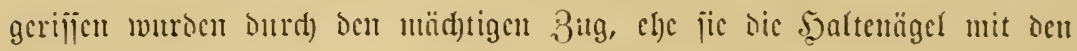

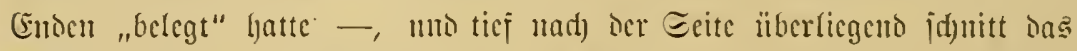

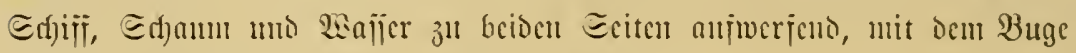

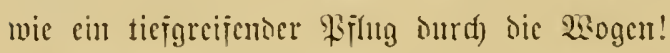

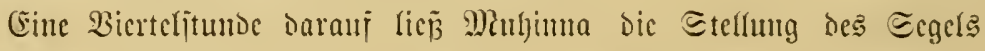

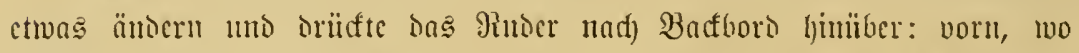

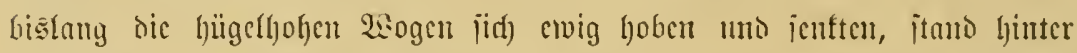

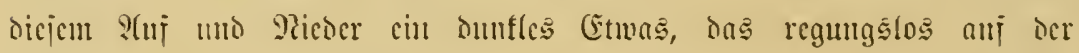

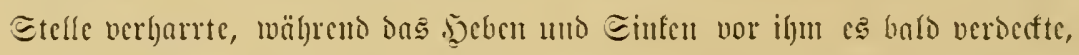
Guld wiederum jeigte. Bon banger Eorge erjuñt, ietzte Siojdyberg iein Jagoglas an bic ?tugen. S(lio rid)tig, ba war bie er ite ber vou fnorrigen

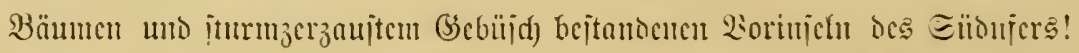

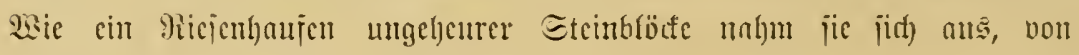
GSigantent)äuticn tort jujammengeworjen.

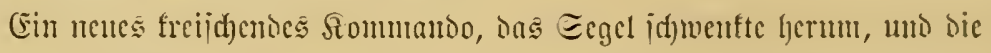

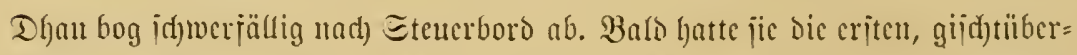

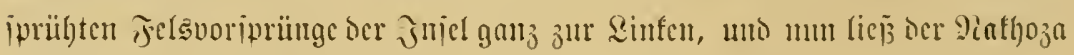

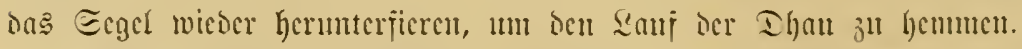

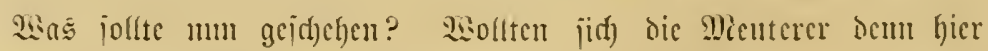

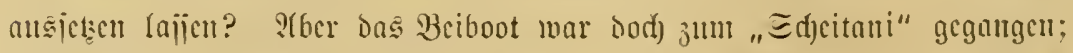

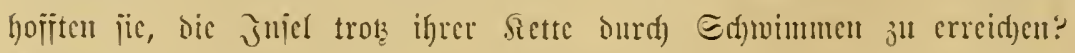
Wiegr als 150 Whicter maren es ja wohl faum . . .

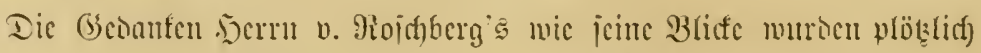

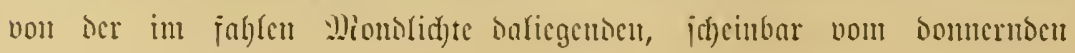




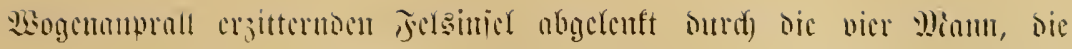

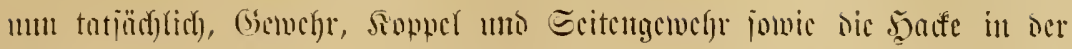

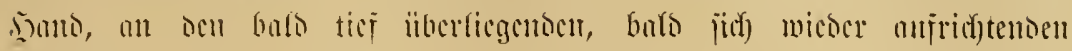

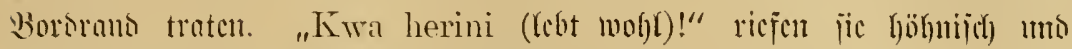

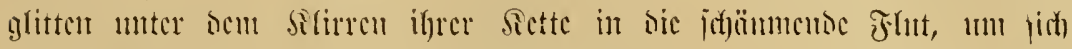

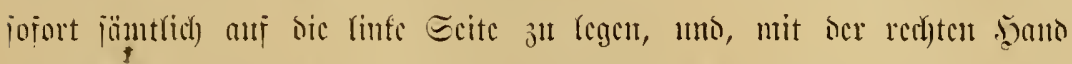

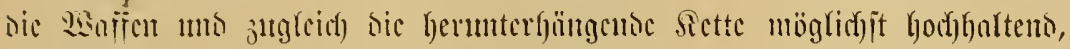

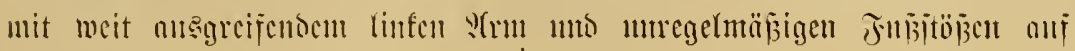

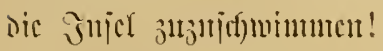

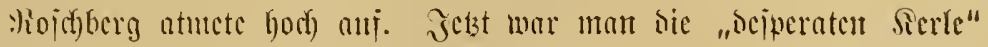

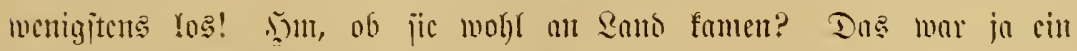

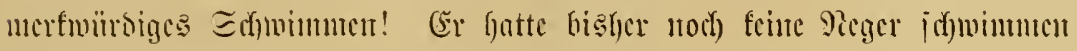

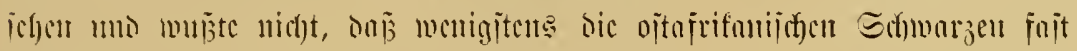

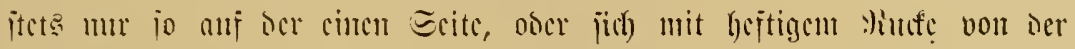

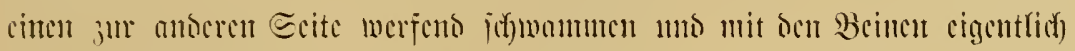

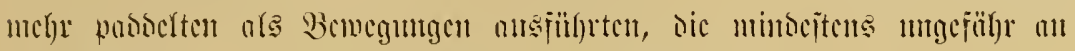

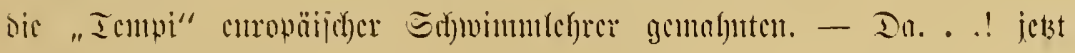

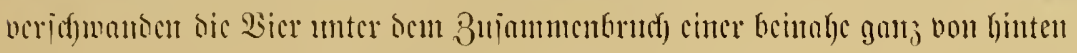

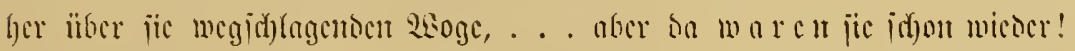

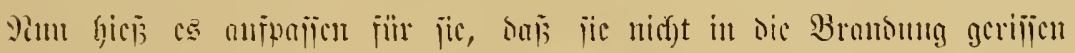

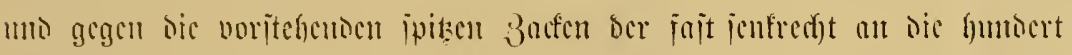

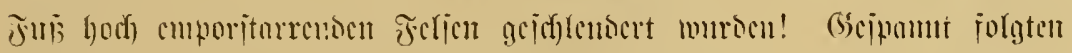

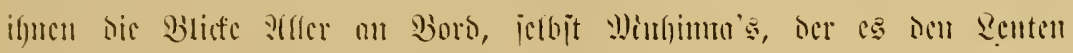

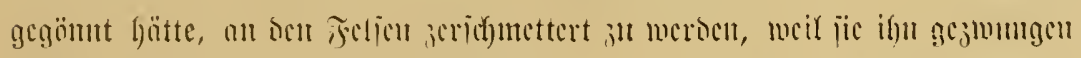

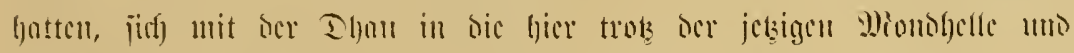

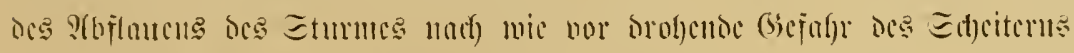

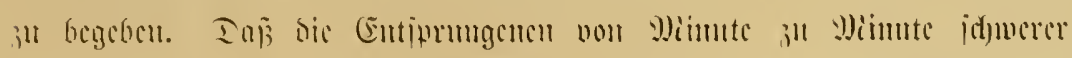

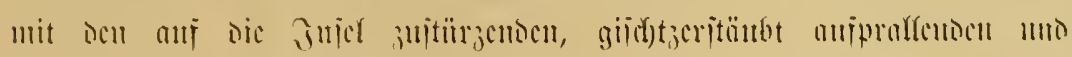

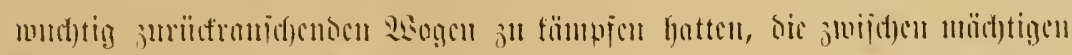

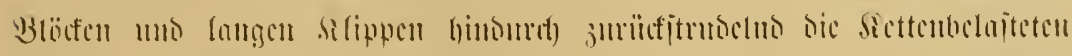

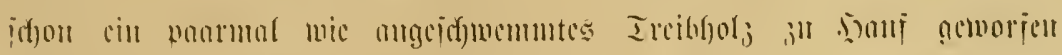

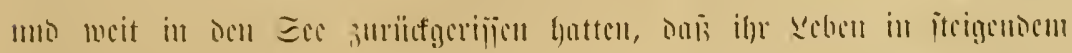

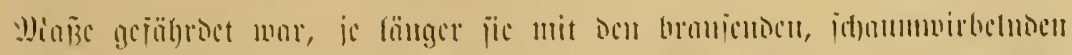

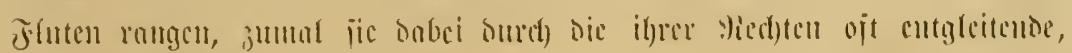




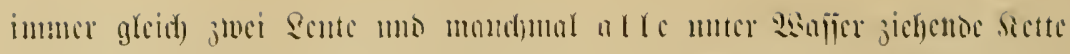

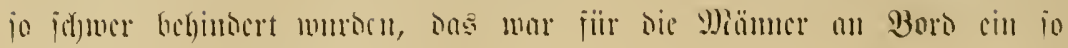

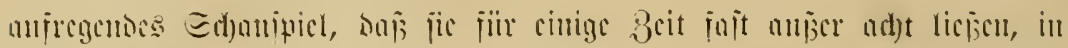

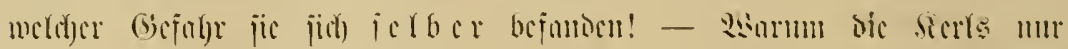

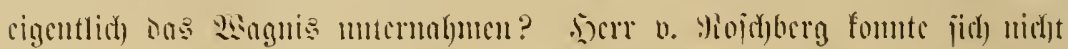

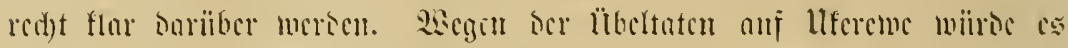

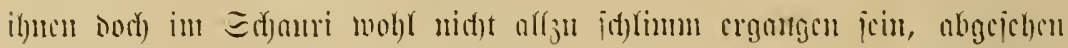

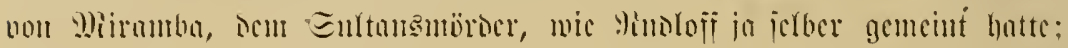

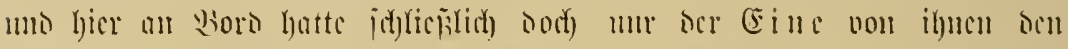

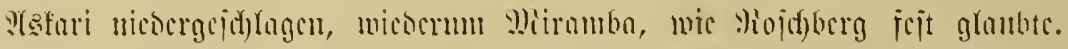

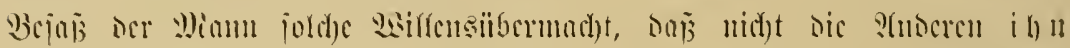

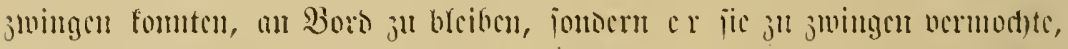

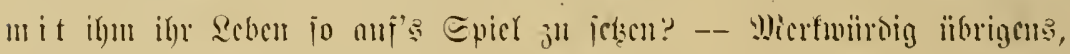

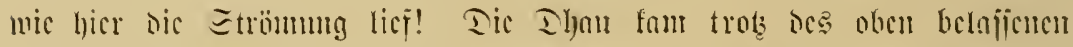

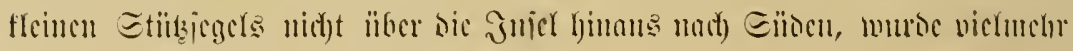

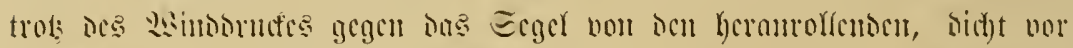

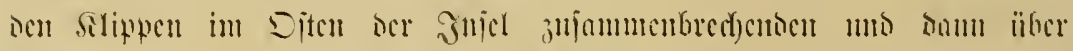

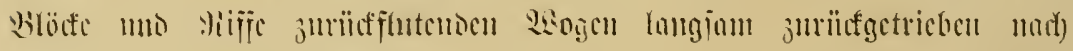

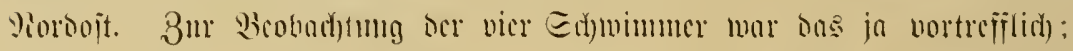

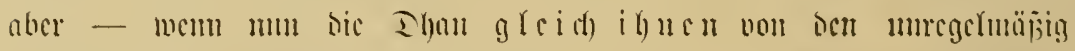

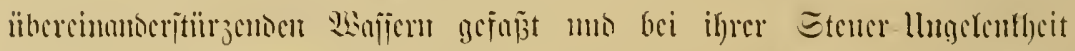

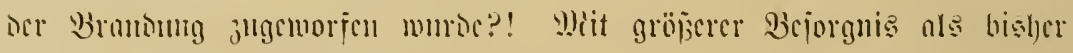

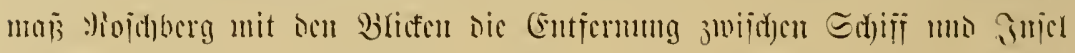

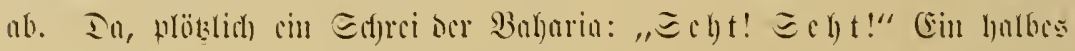

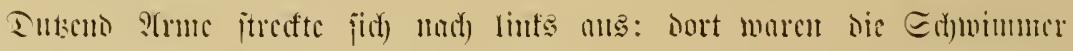
gegen ciur wobl jün bis jectse Fui

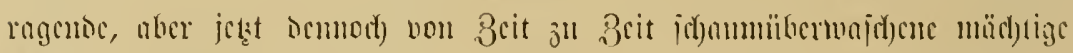

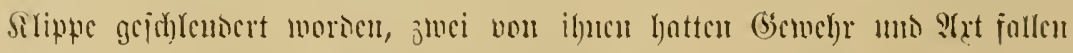

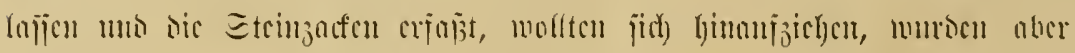

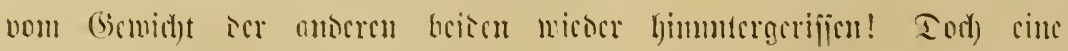

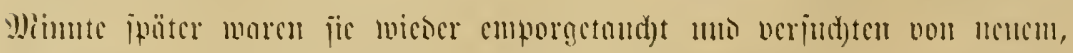

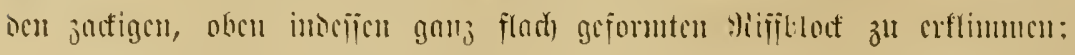

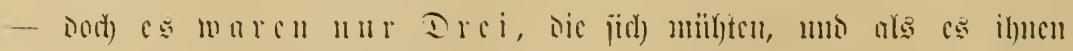

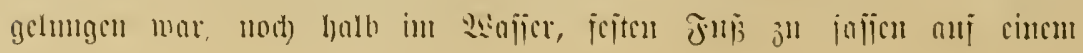




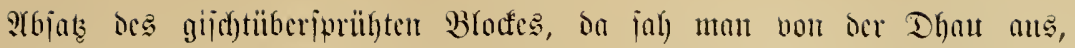

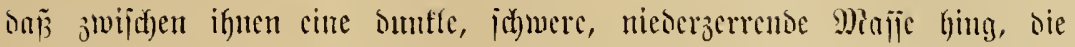

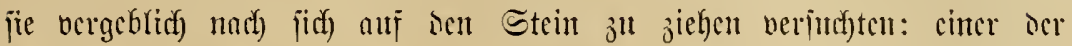
mittleren Reute war tot, entmeder ertrunfen ober bon Der Brantung

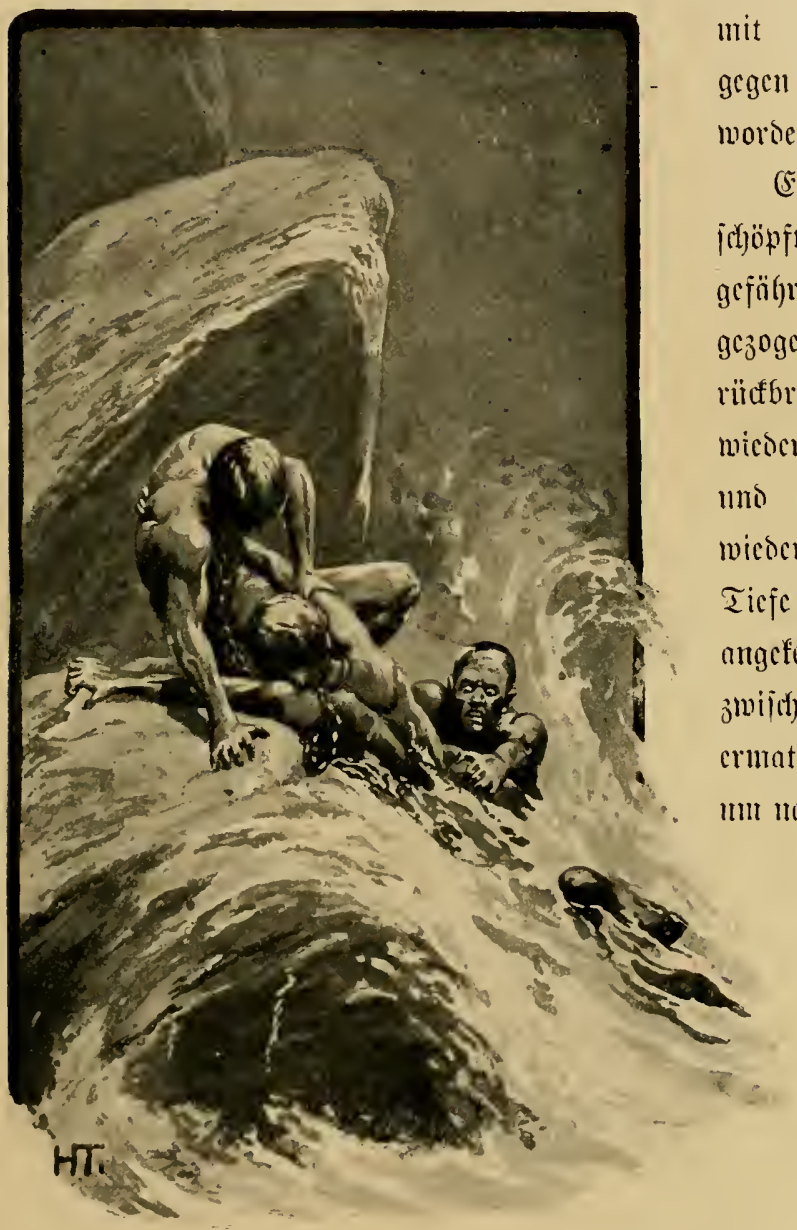

mit icm Siopf boran gegen oen Blocf gejichlogen worterr!

(Endrich hatten die (5i: ichöpften ocut toten F(ut)t= gefïgrten jo meit hernuf = gejogen, buj iljn dic rïcforantento 2 koge nicht micoer perefte, mich)t ilym Imo dis mort) Refention wicoce mit jict) in bic Ticfe reišnen fonnte. Ten angefetteten Ecidynam jwij(f)en ji(t), bouften jie crmattet anf bem Felien, mun mad) cincr fianje jum S(temilljöpfen fle= hentrich) ljimïber ju rujeu jur Dhan:

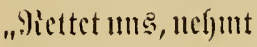

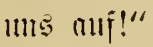

Der Tote war mohl ber Miuml, ber bell ?affari

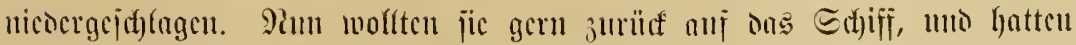
vor dem bana shauri feine S(ngit uchr: anf ien Toten bütten jie a fle Ect)uld icficben fömten!

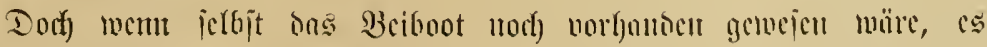

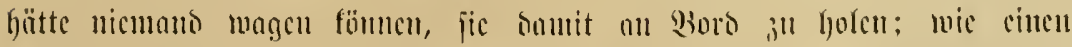

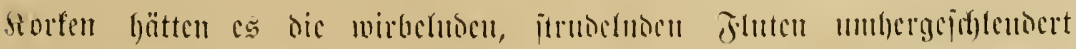




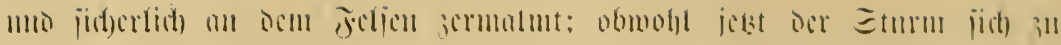

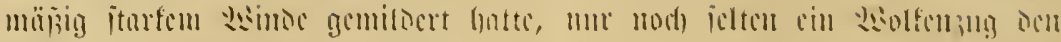

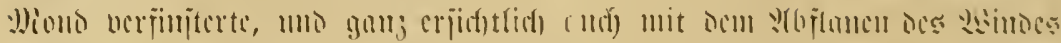

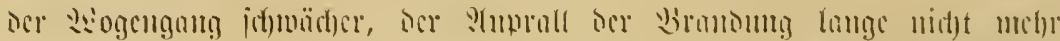

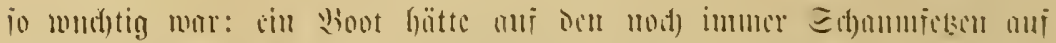

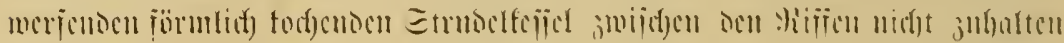
fömen, mo menu ce jefbit cin c i ic la

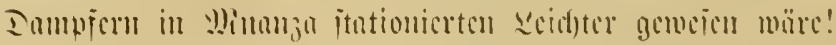

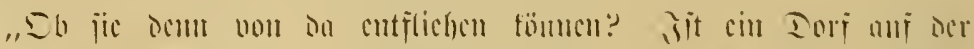

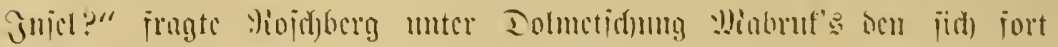

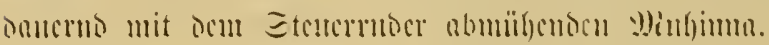

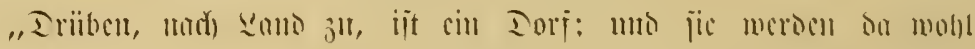

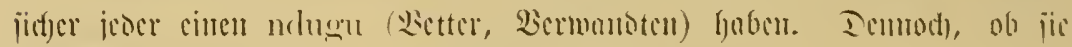
Bonontommen fömncu? . . Inshallah (mic bott milf)!"

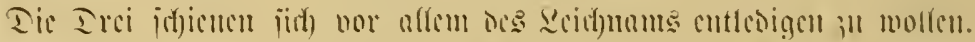

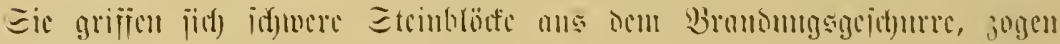

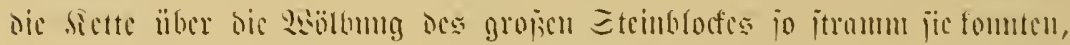

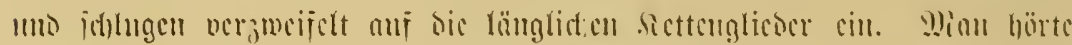

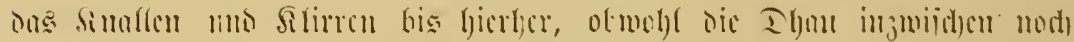

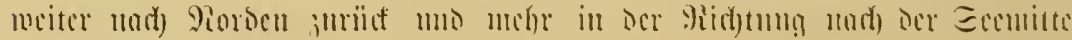

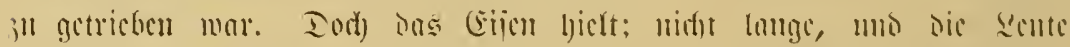

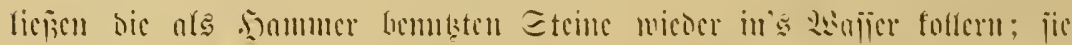

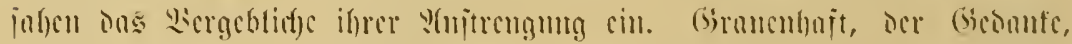

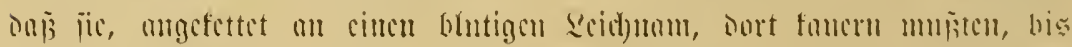

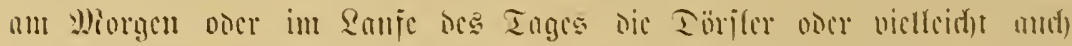

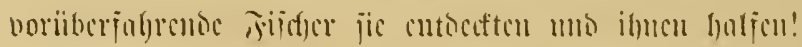

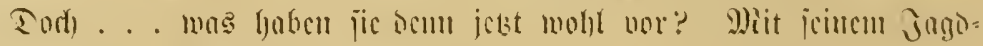

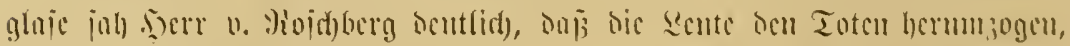

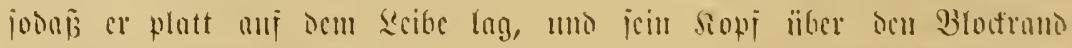
bimmaterfung in

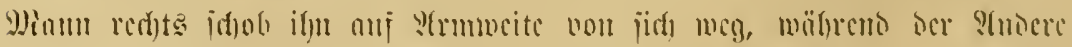

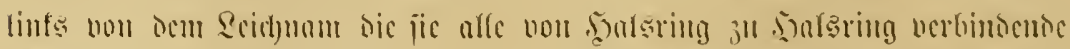

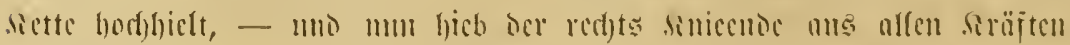

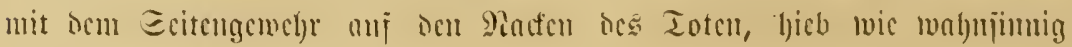




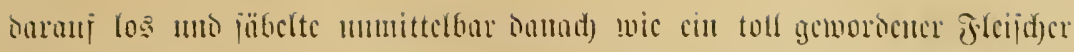

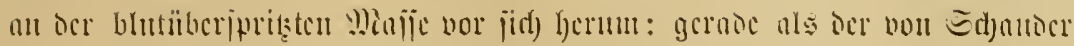

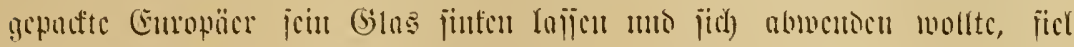

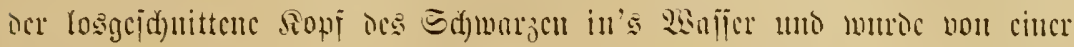

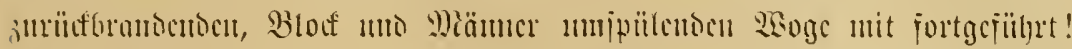

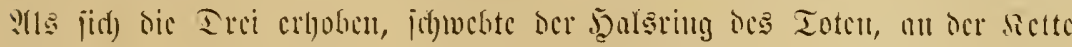

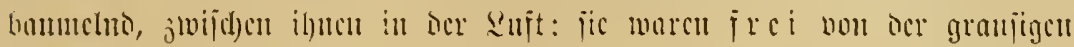

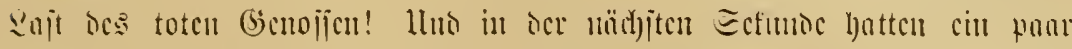

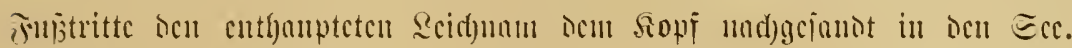

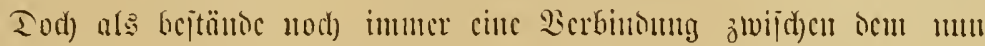

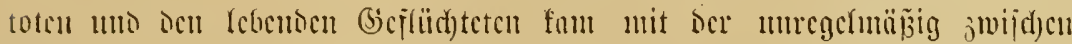

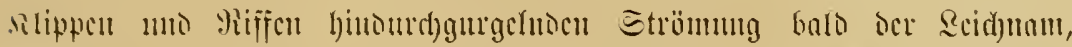

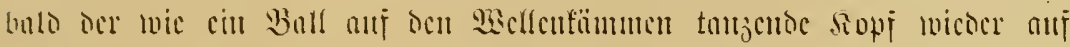

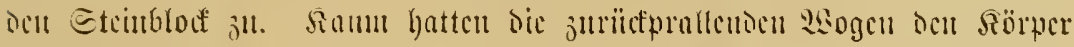

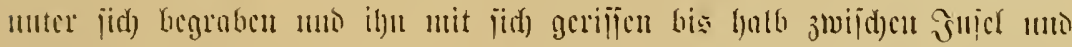

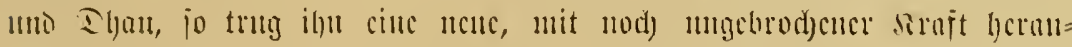

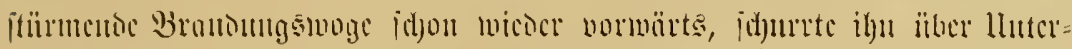

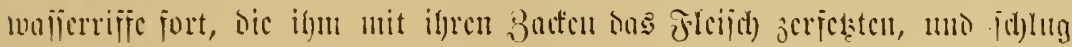

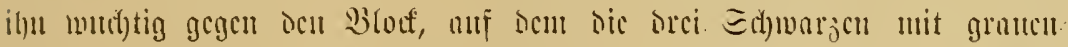

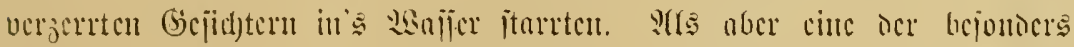

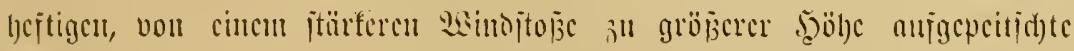

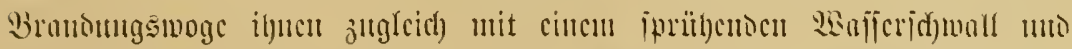

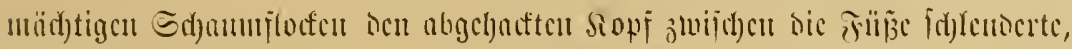

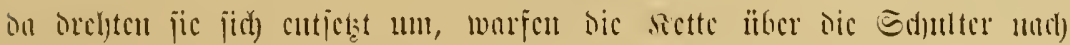

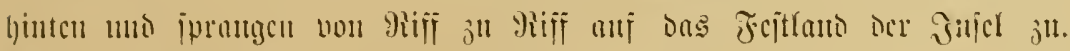

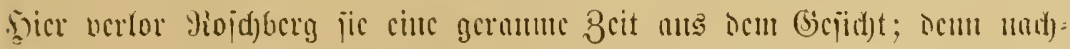

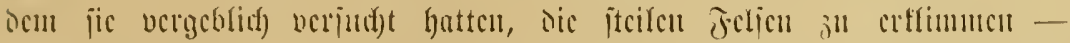

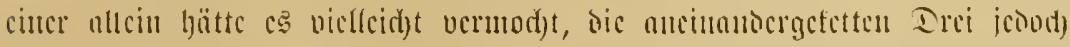

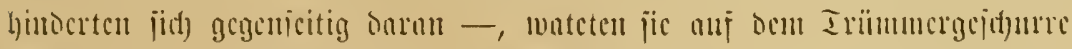

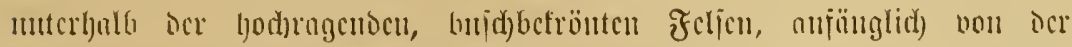

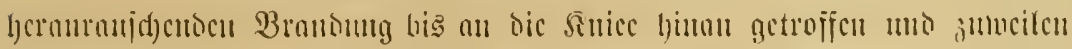

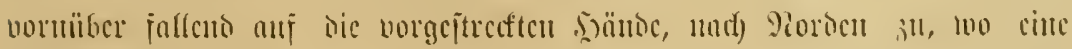

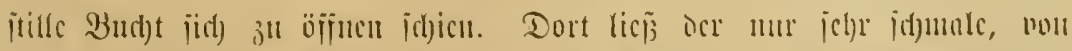

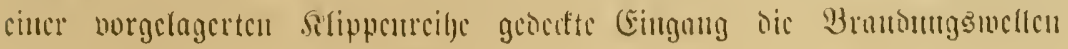




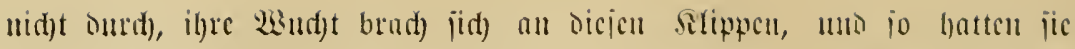

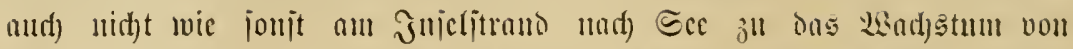

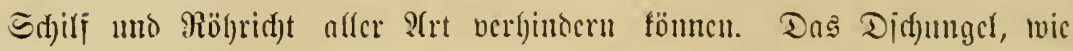
Die bidfe Eumpjocgetation ljer ojt genamut murbe, war im Gegenteif

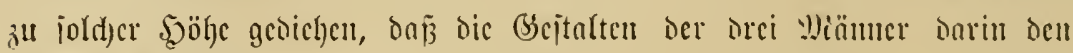

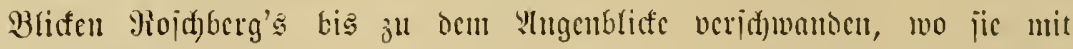

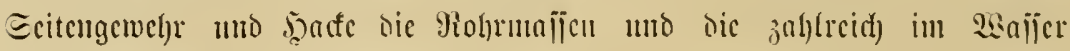

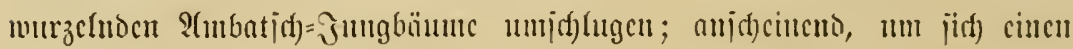

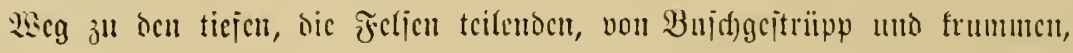
fnorrigen Bäumen beitantocuen $\Xi$ d) (utd)ten jull bahtucu.

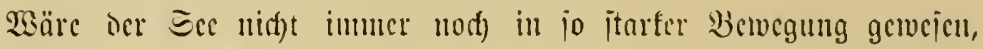

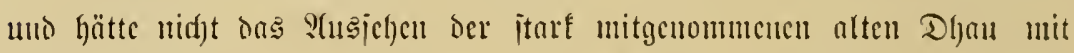

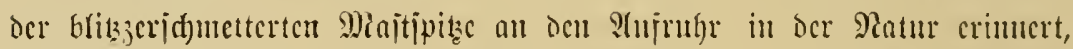

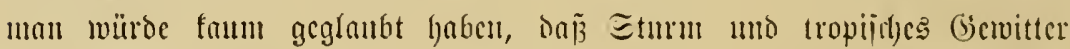

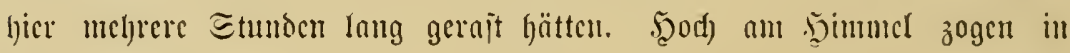

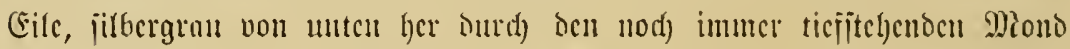

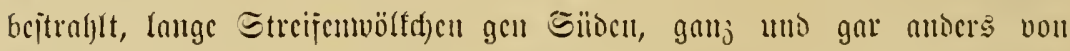

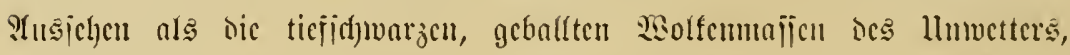

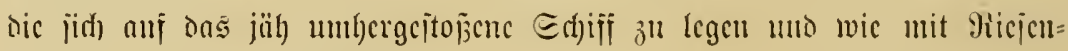

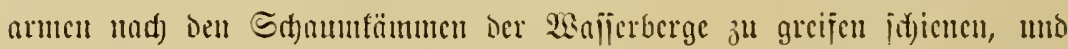
jait taghell war bald bic 2 ad)t von Dem an flaren Firmament langiam

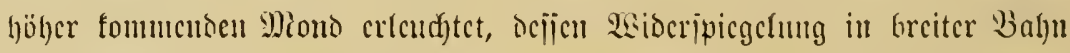

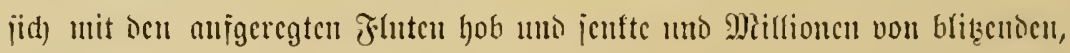

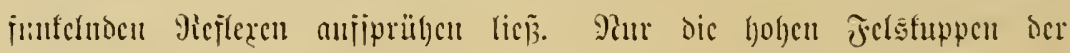

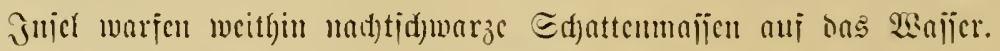

"Elhamdu lillah (Bjott jei Danf)!" murmefte ocr jiff) in cine sicte

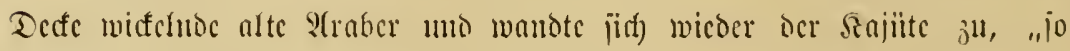

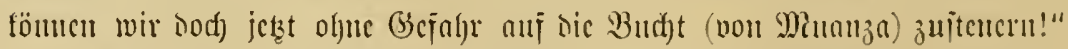

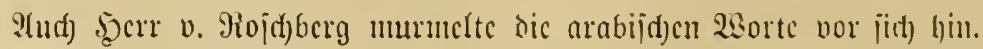

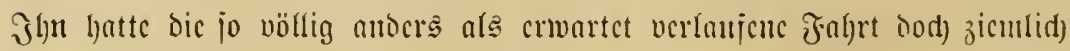

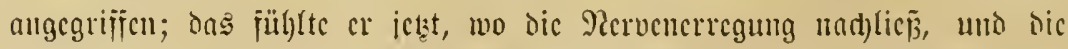

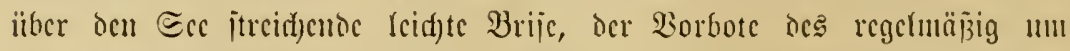

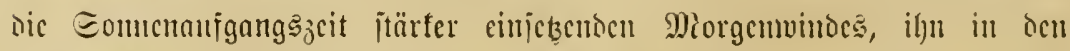

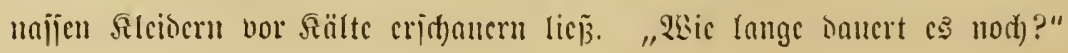




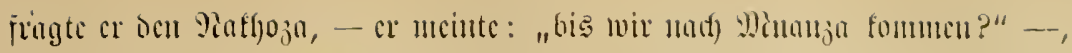

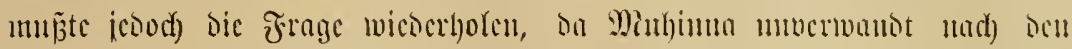

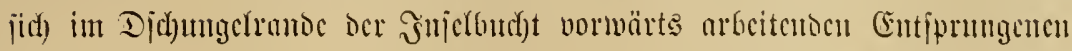

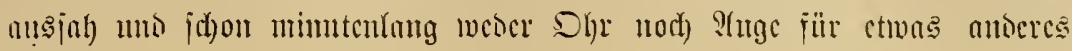
jull ljaben jujict.

"Sía ya tatu (in ocr orittcu Stmmoc), inshallah!" mar bic nich)t

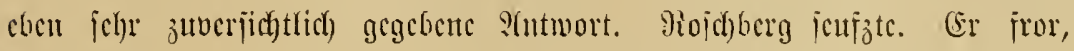

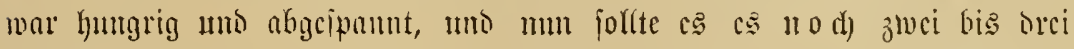

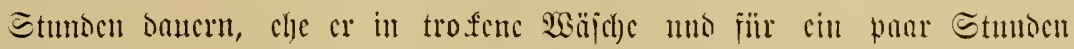
in's Bett fnut. "Inshallah", frmmute cr vor fitch hin, wic er chen bus

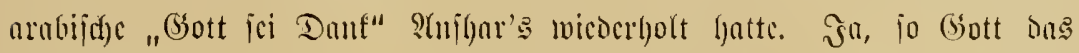

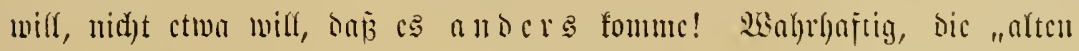

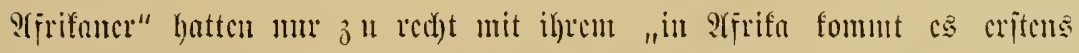

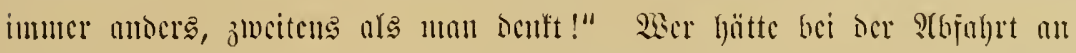

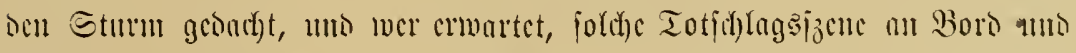

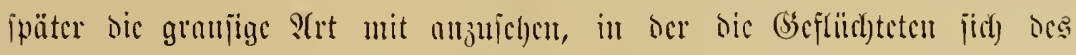

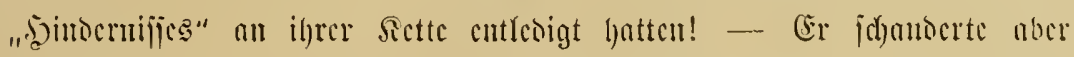

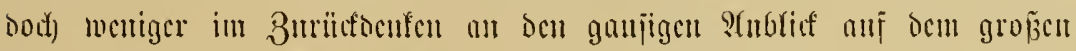

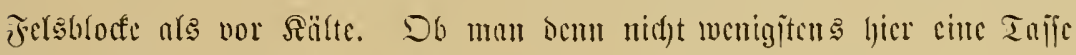
bcišcn Siffecs fricgen töuntc?

Mabut iprad) mit dem Babaria, ber jidt) baro nad) ber s(bjablet

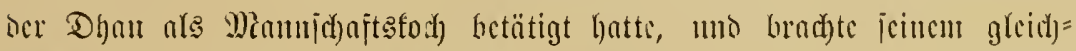

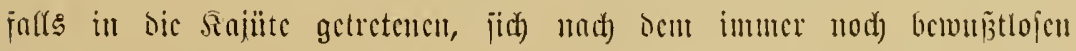

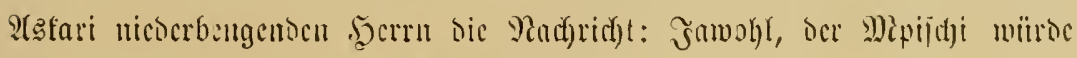

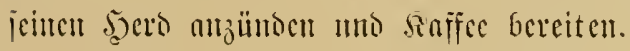

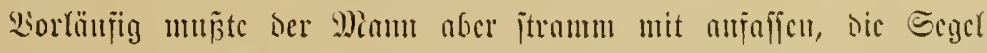

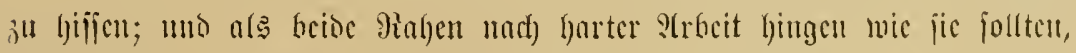

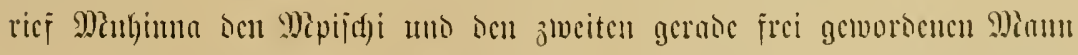

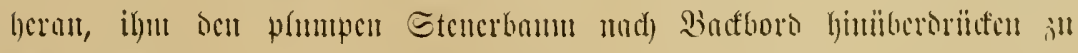

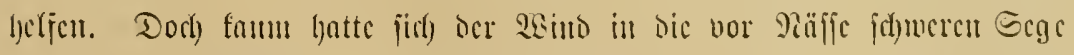

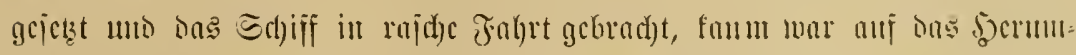

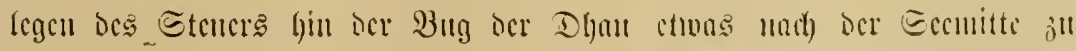

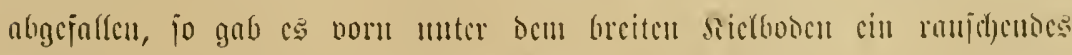

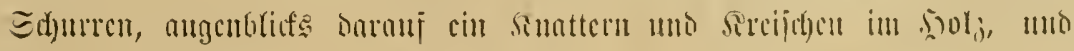




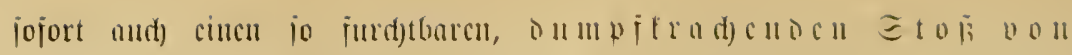

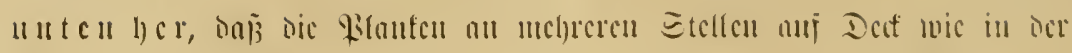

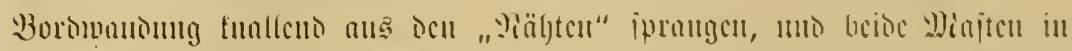

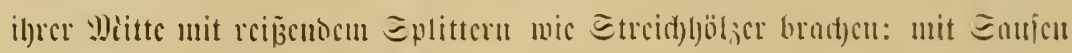

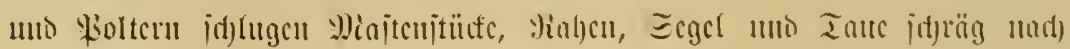

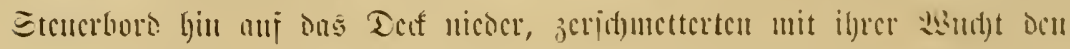

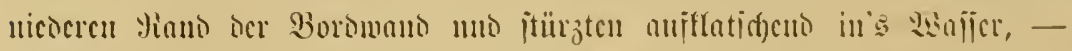
dic Dhau mar anj cinct untcriccijd)en Slipwe anjgcrant!

Ste dic won ocu bejtigen Etoje nicocrgemoricucu Babaria unter

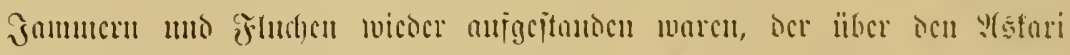

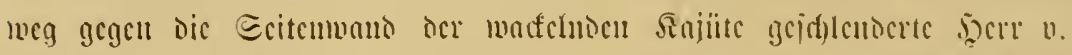

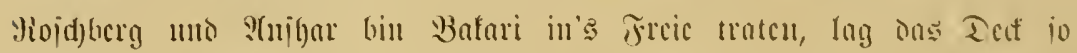
id)rüg und) Etcucrbort

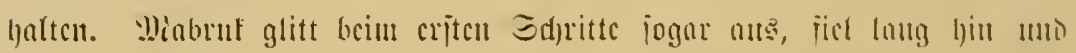

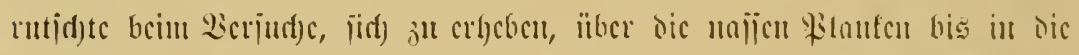

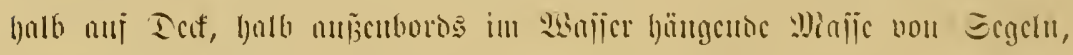

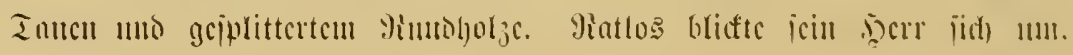

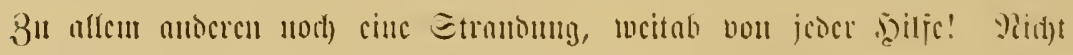

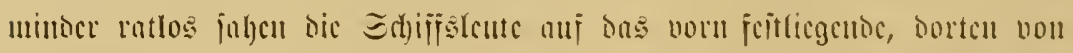

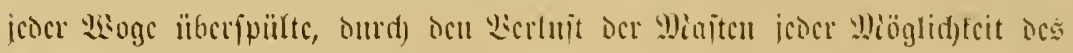

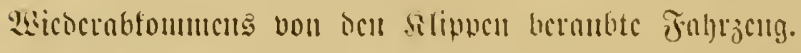

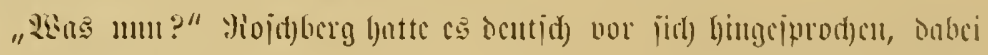

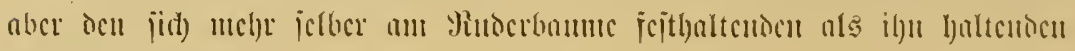
Miuljuma nugcicl)cu.

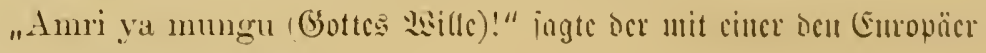
ill Born friugcuicu Piulsc.

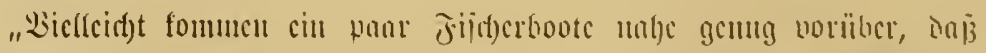

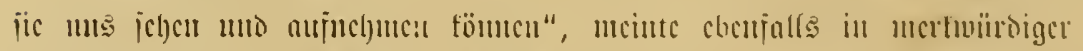

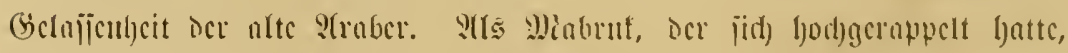

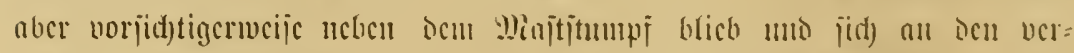

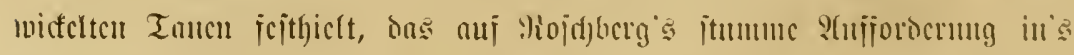

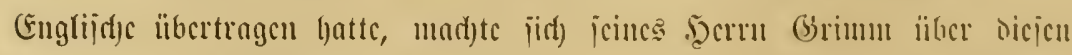

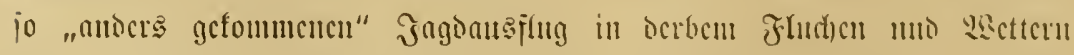

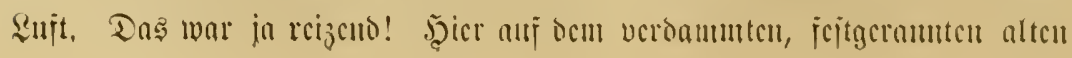




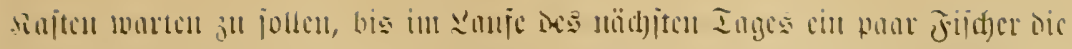

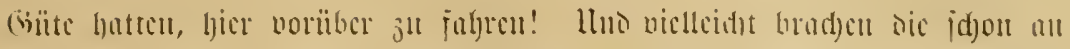

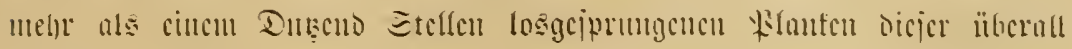

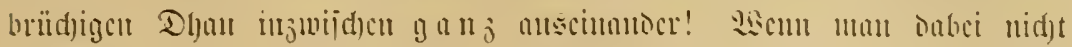

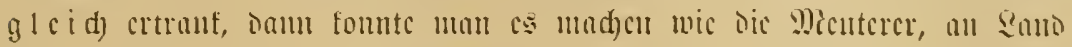

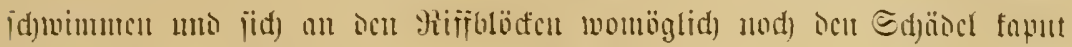

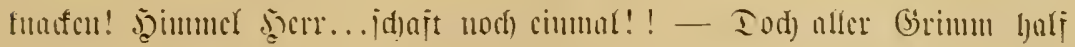

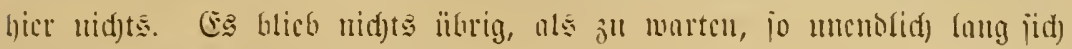
und) Dic Bait ju ochneu idfiett.

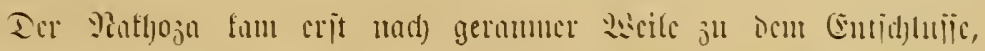

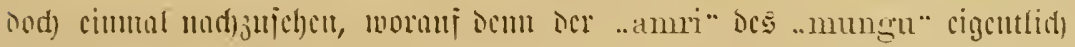

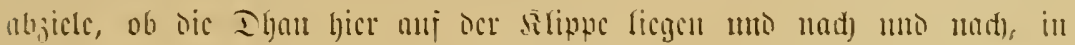

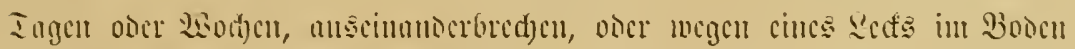

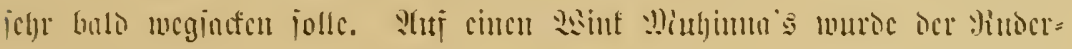

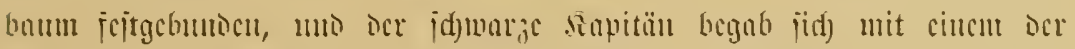

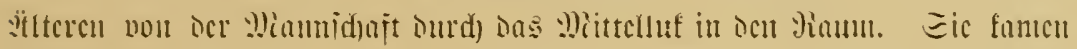

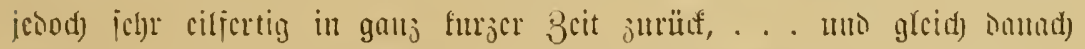

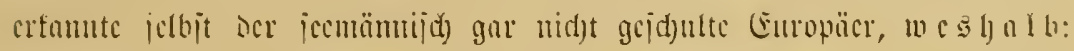

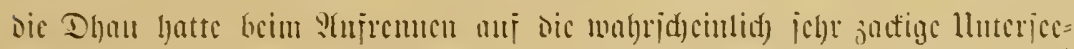

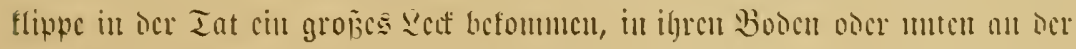

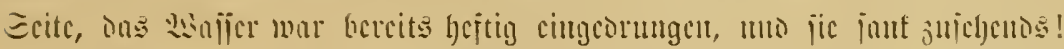
"

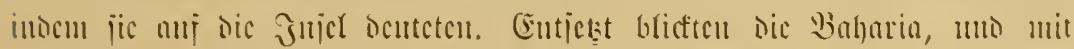

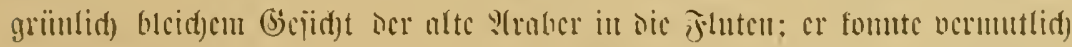

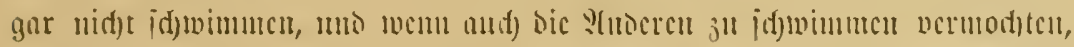

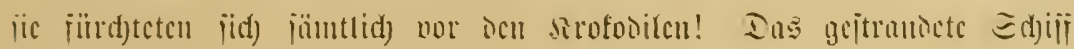

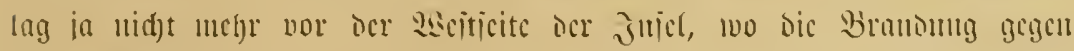

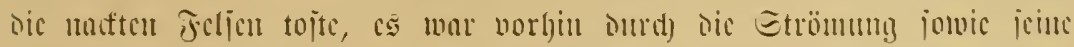

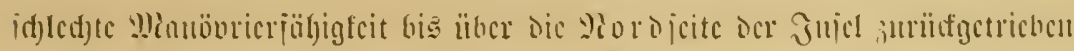

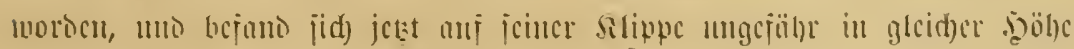

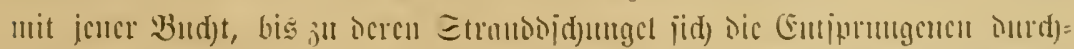

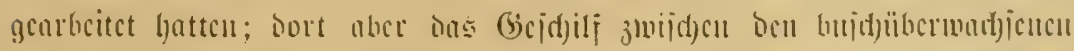

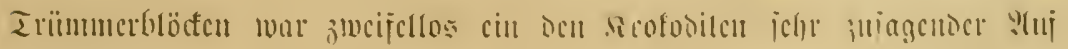

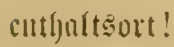




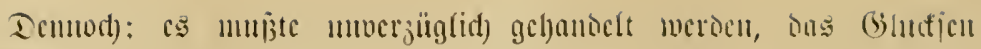

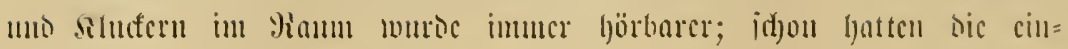

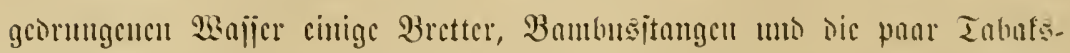
balleu 9(nif)ar's jum Treiben gebrad)t - jonjtige Sadung loutte bic Dhau ia nidyt, jic ging mit Etcinballajt und) Mitnanza, - unt bercits jeit

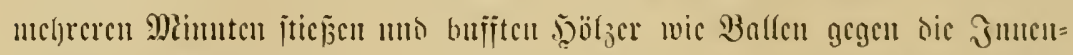

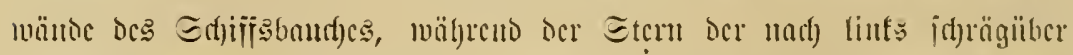

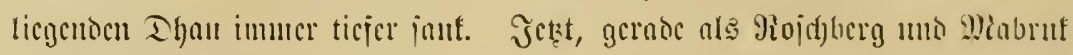

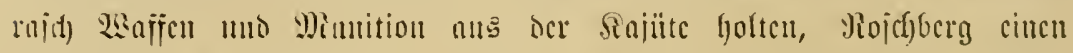
betaucrnoen Blicf anj icine verloren gef)enten Jugotrophäun wari, babci

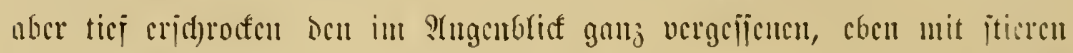

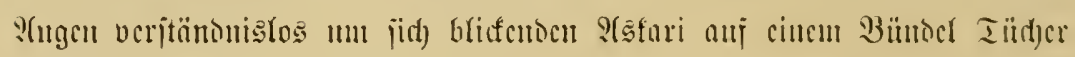

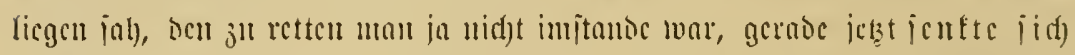

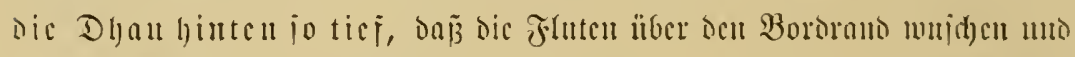

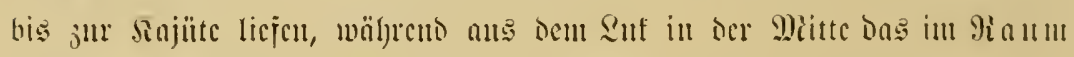

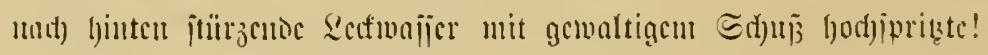

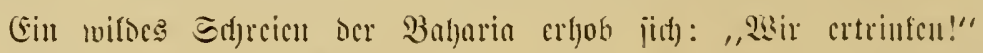
"Dic Shau geht unter!" S(lle glitten, itolperten, rutid)ten uad) dem jajt

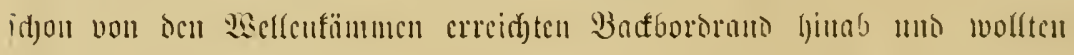

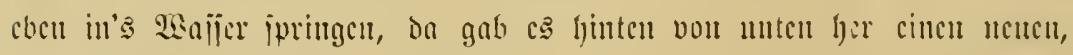

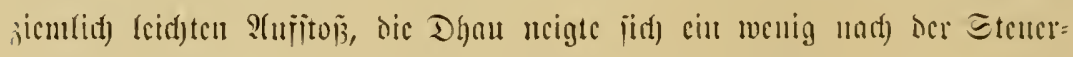

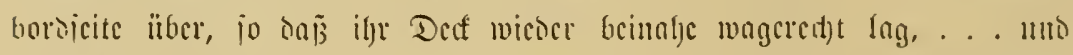

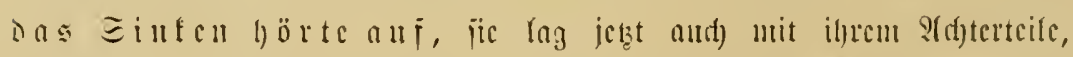

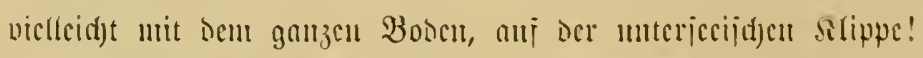

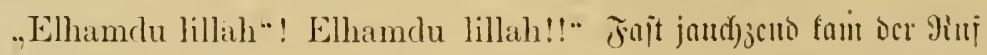

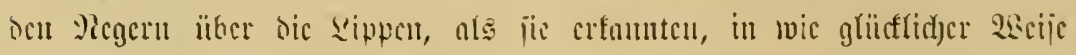

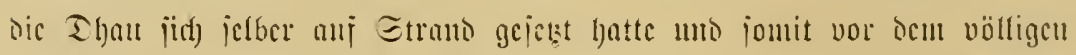

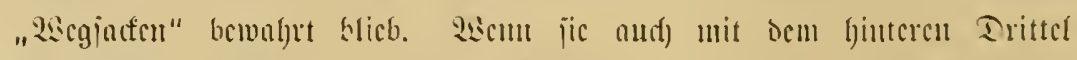

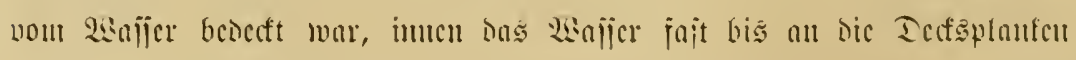

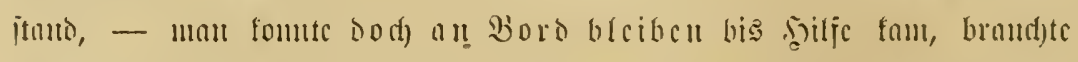

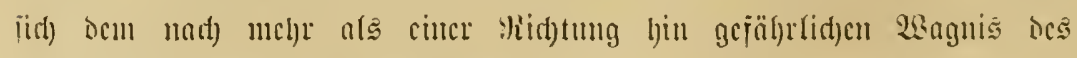

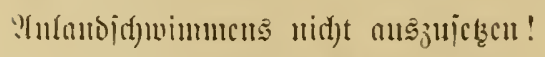

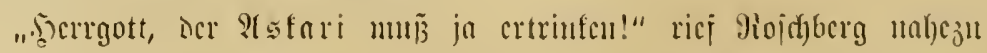

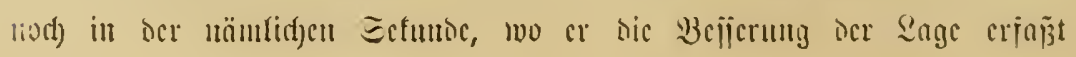


hattc. "Hapa. baharia, toëni askari (hicrber, Mantoicu, holt ocn

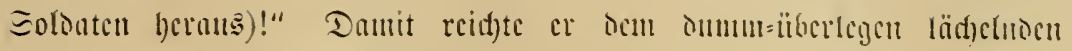

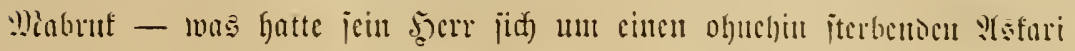

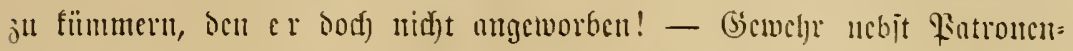

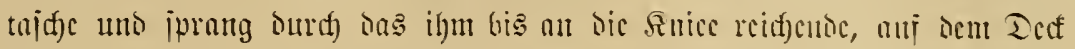

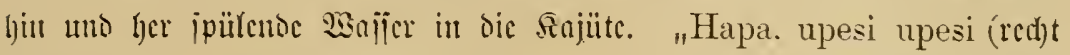

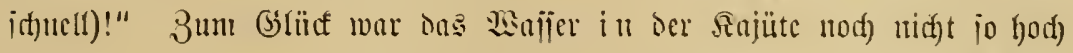

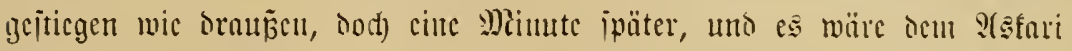

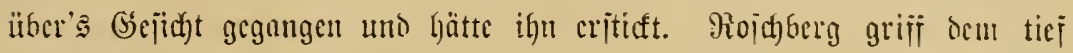

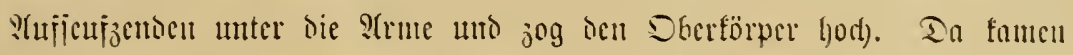

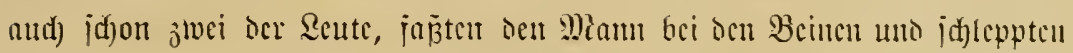

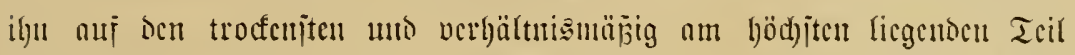

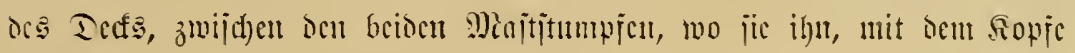
ctwus erljöht, auj ocn Segellyaujen legten.

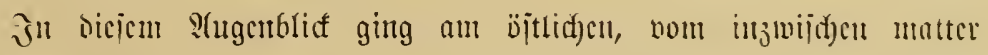

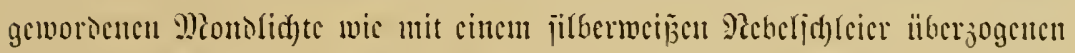
Dimunel dic Some auj. Es wal, als of jic die ganje 2 selt int flammen

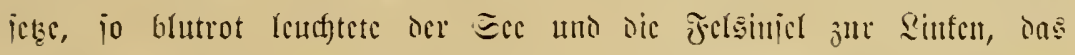

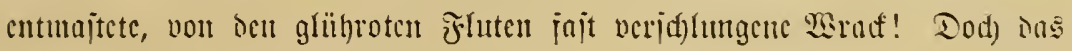
Baucte nur menige Mrinuten; je höher dic Eomu iticg, icjto golniger

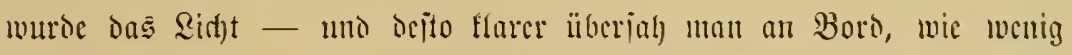

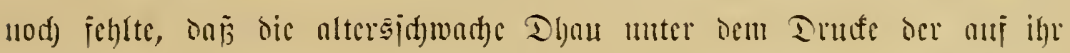
lajtenoen unt von inuen her gegen iffe viclfach geiprungenen filatfen

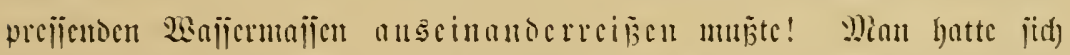
id)on geborgen geglanbt, jo Innge bis Fiid)er unit ibjen Booten berbeifonmen ImI0 dic Gejtrantocten aujuchmen fümuten, batte laut gejubelt mo Gott

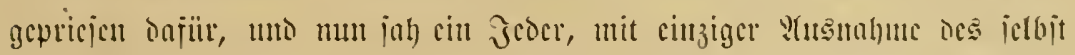

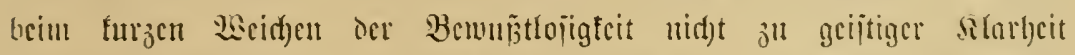

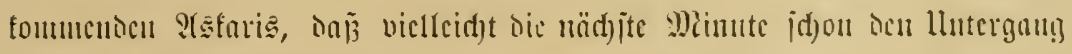

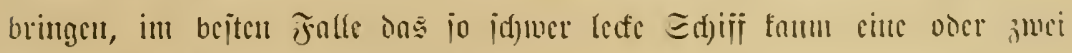
Etumicn nod) 3แjammentyalten fomute!

Dod) cin idfectfidserer : Stublict nod) jollte ocu angitwolt lluther=

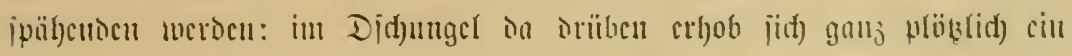

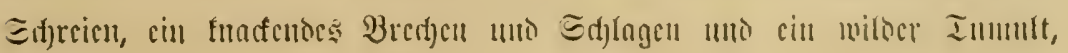




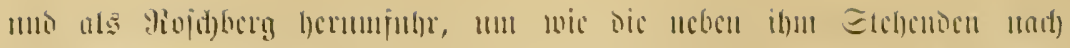

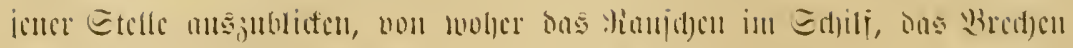

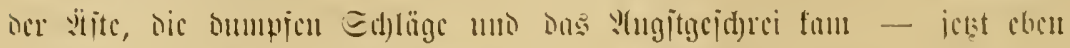

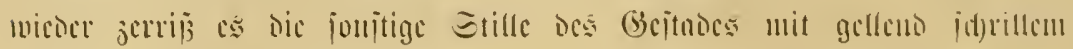

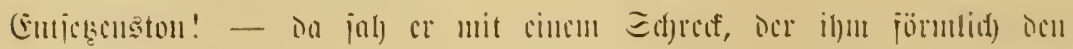

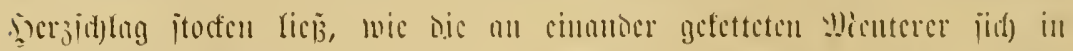

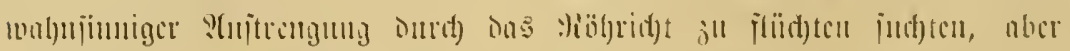

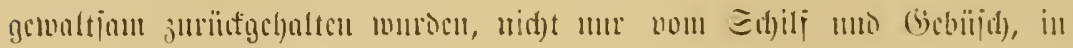

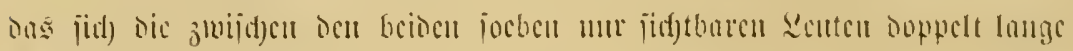

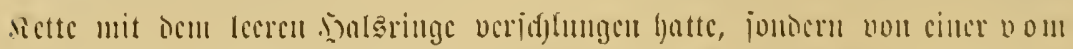

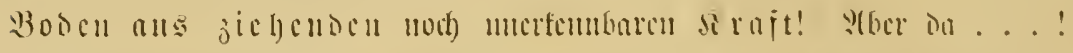

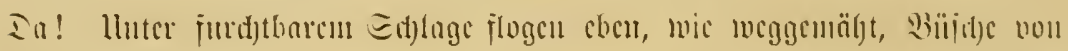

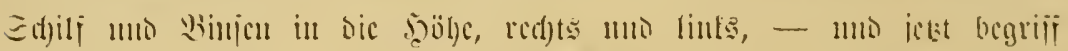

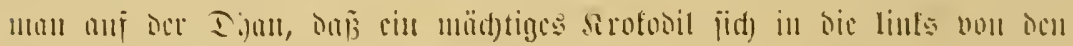

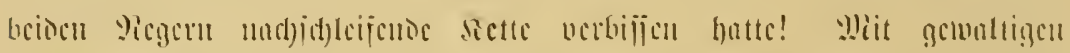

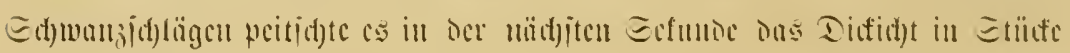

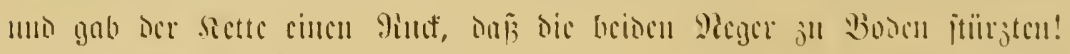

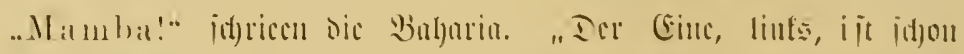

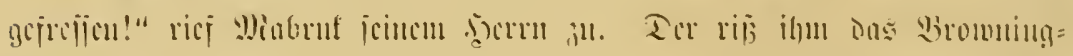

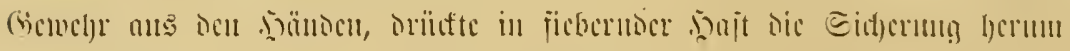

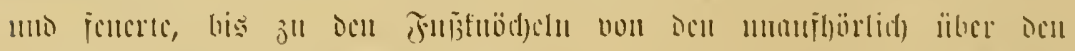

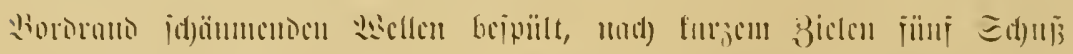

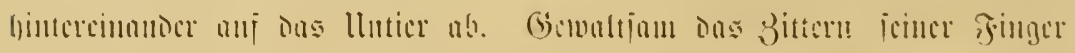

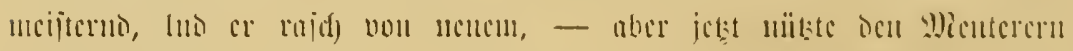

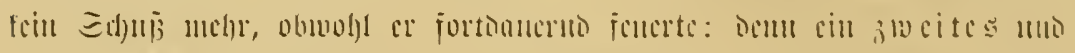

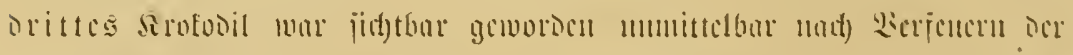

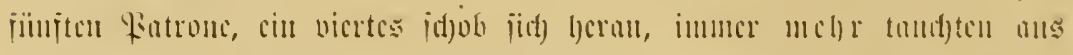

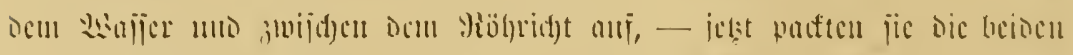

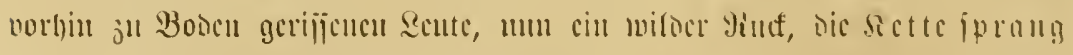

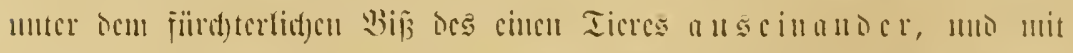

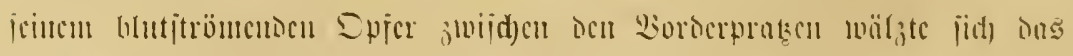

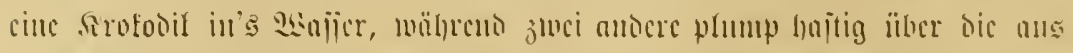

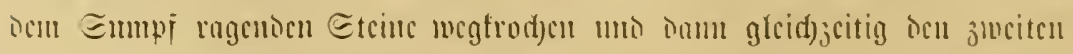

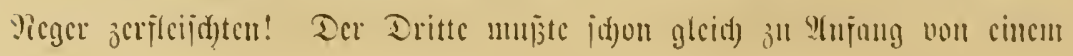




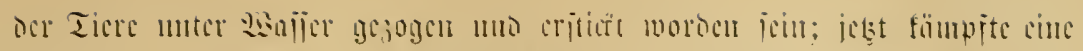

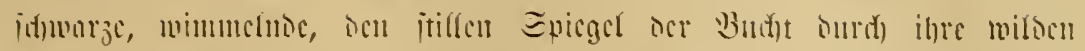

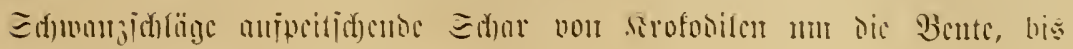

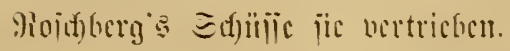

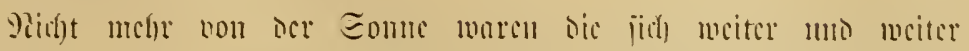

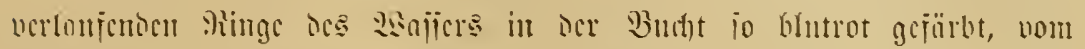

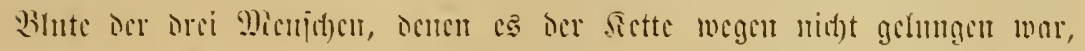

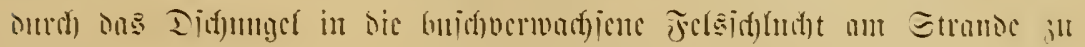

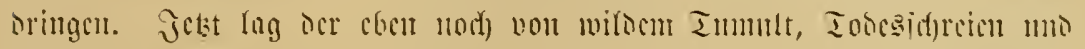

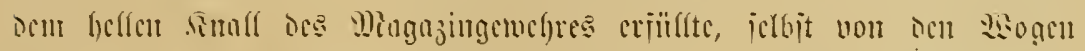

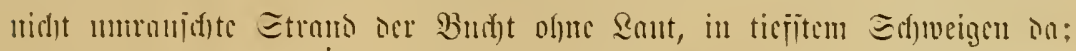

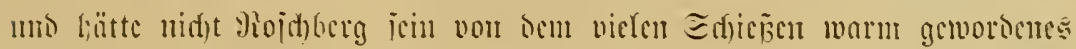

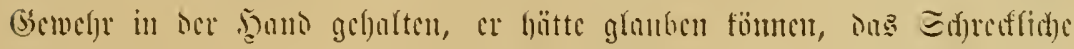

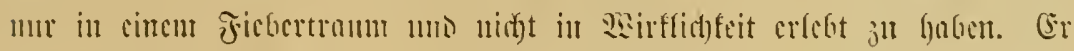

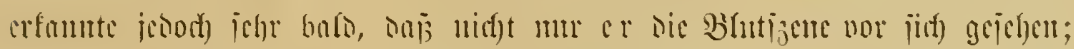

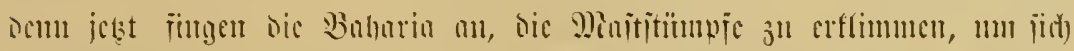

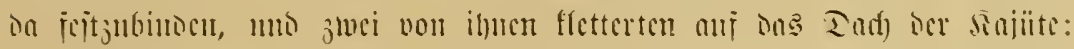

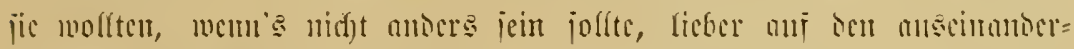

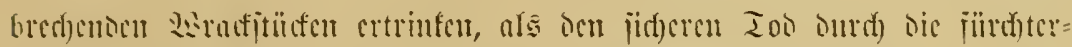

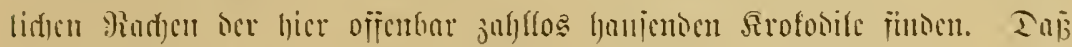

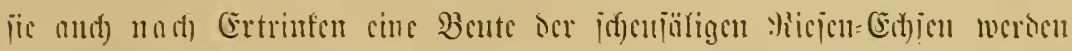

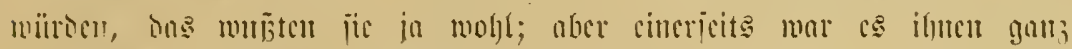

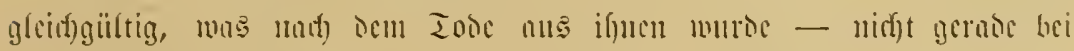

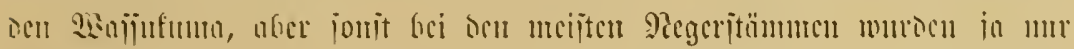

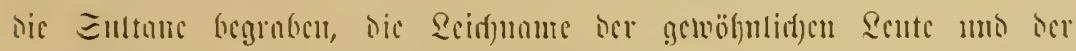

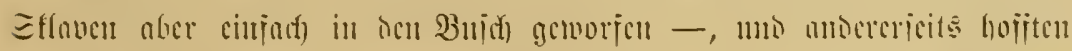

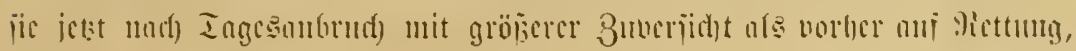

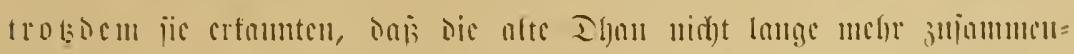

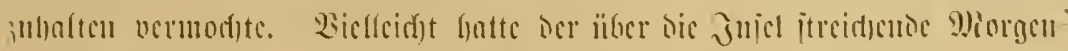

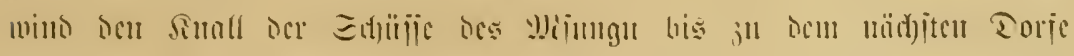

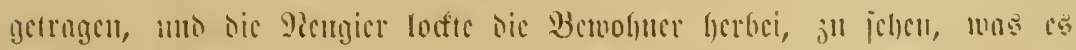

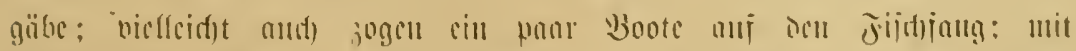

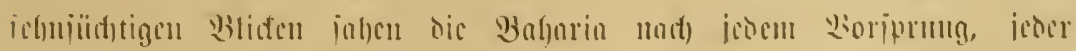

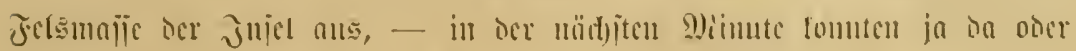




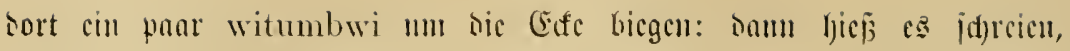

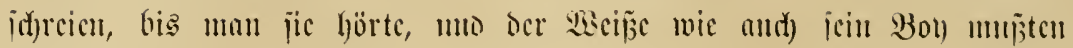

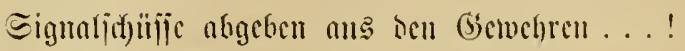

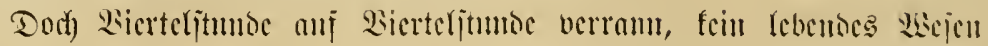

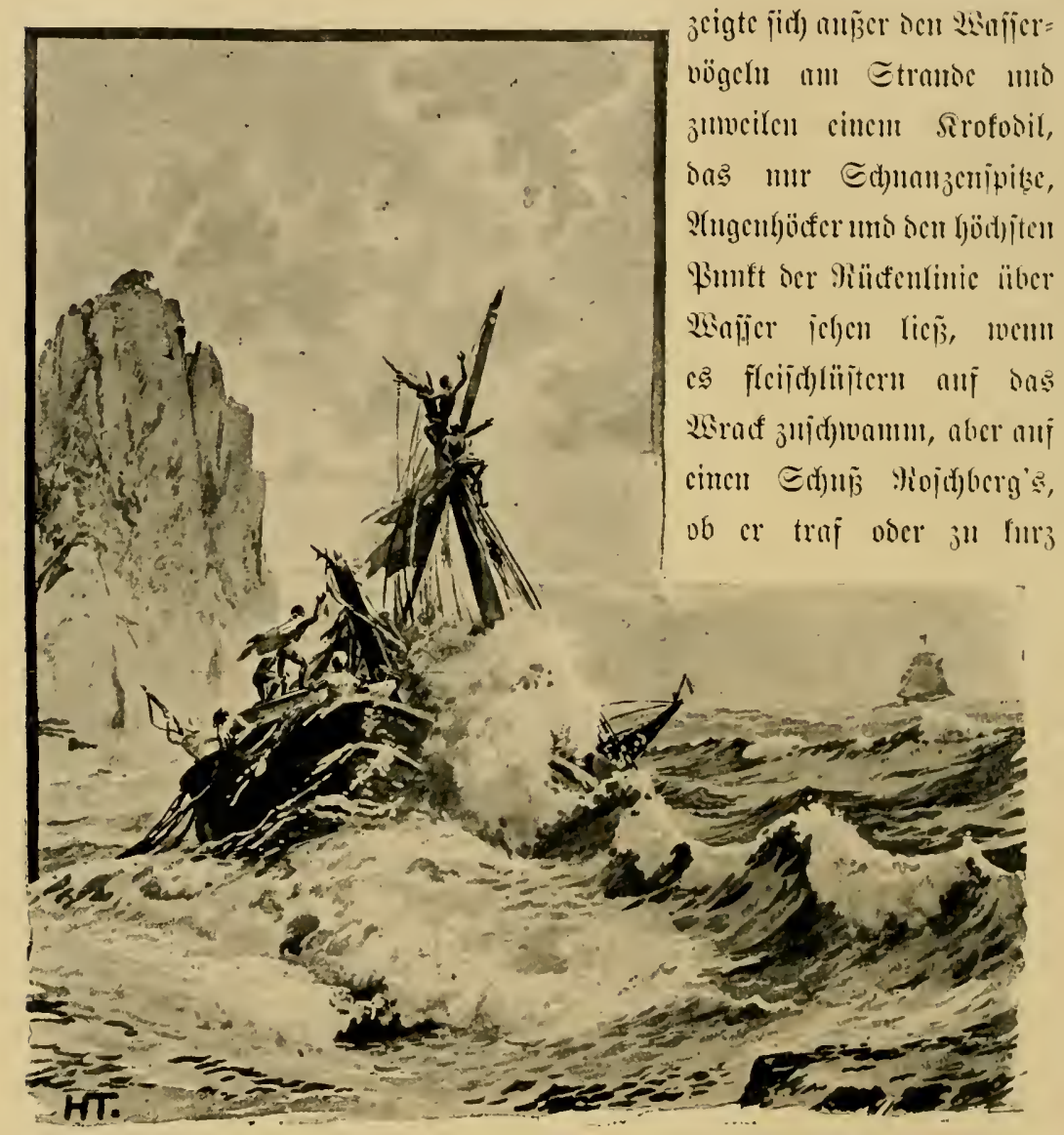

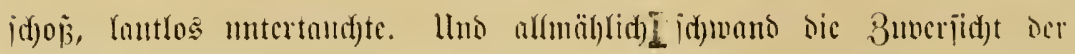
Babaria. 3luar manterten ifje B̧lide nod) immer non fels 311 Jels:

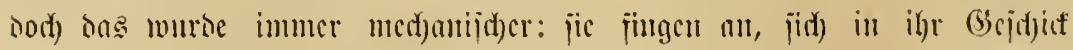

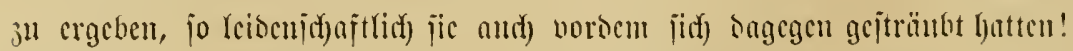

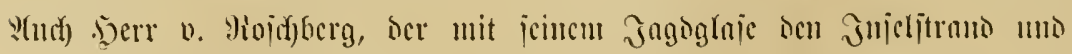

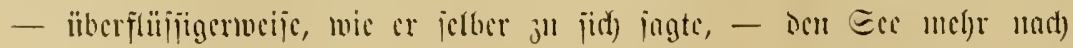

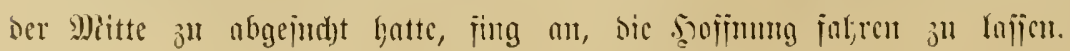




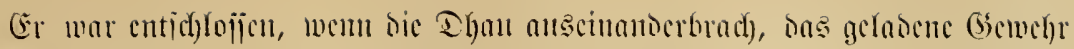

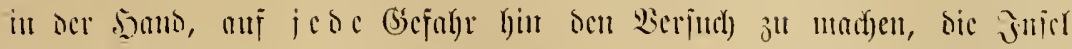

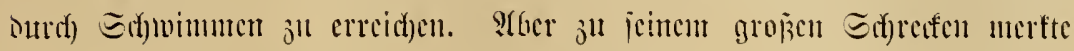

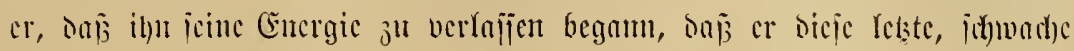

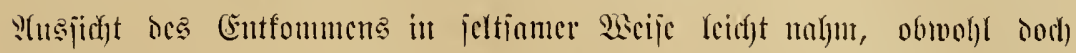

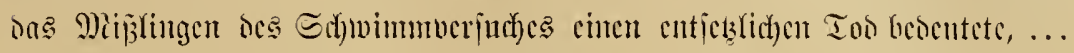

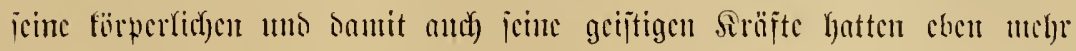

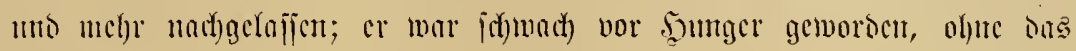

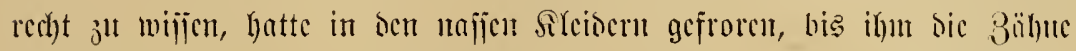

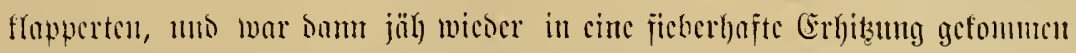

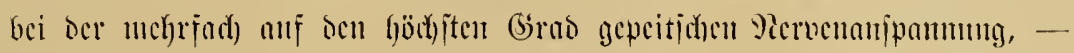

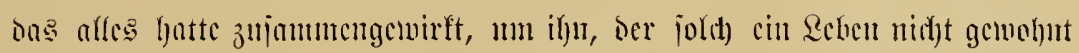

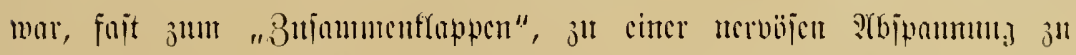

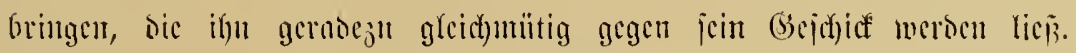

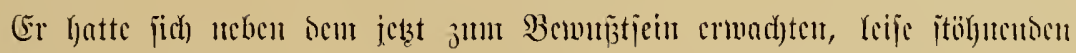

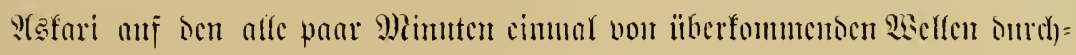

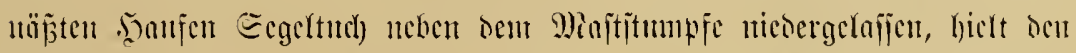

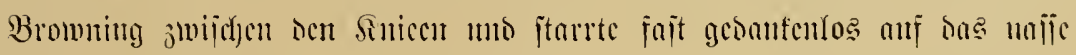

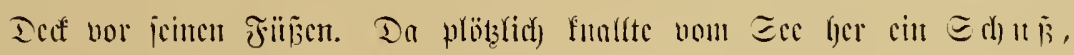

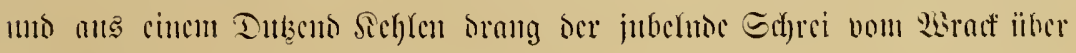
bas 2 soffer hin: "Hapa! Hapa!“

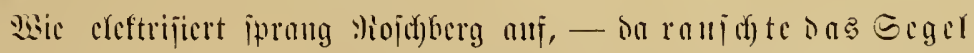

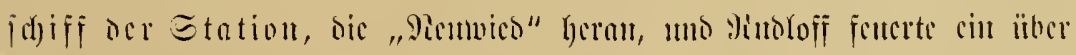

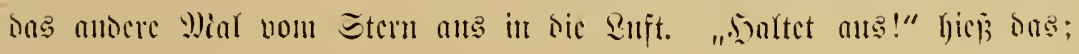
"wir foumencu, end jull holen!"

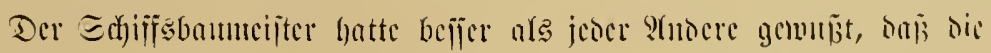

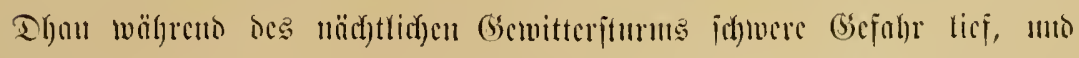

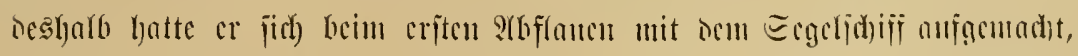

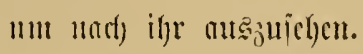

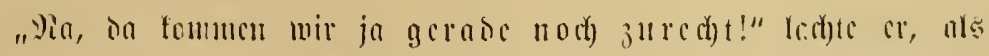

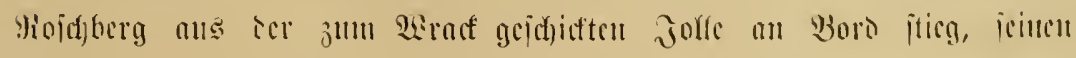

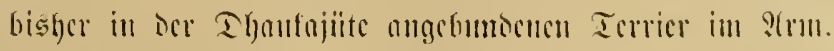

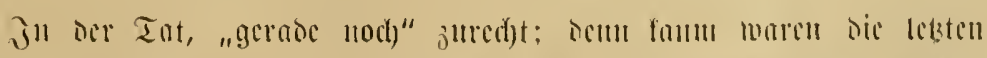

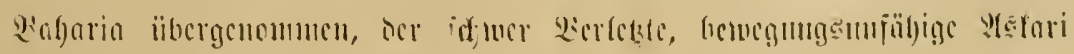




\section{$-192$}

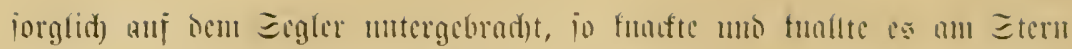

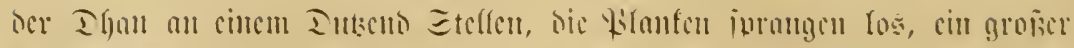

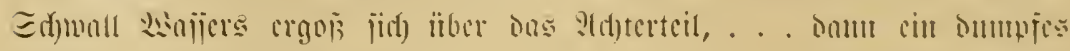

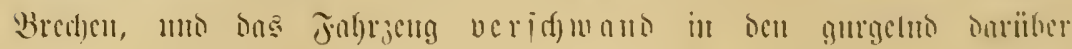

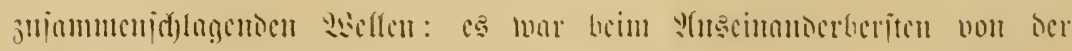

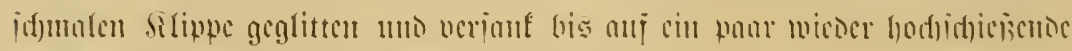

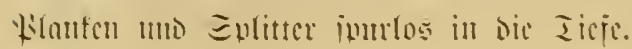

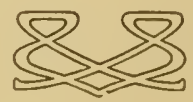




\section{Siebentes Kapitel.}

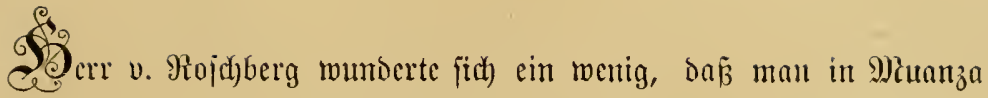

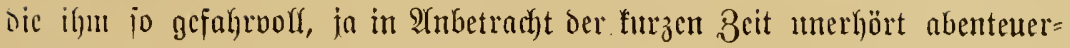

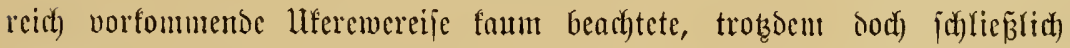
aud) bie Ctation sarunter zu leisen hatte. Denn nich)t mur hatte fie dabei

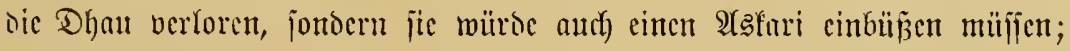

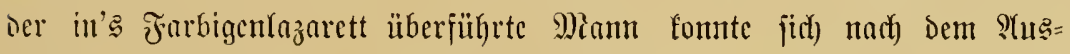

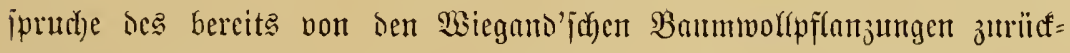

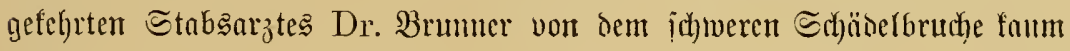
wieder erholen; er batte eben ju jeinem lunglücf nidjt ien typiid)ent

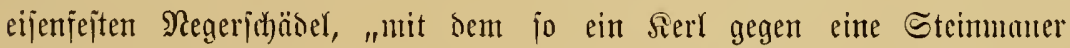
remen fann und elher ter Mianer als jeinem Sdjühel cin Roch beibringt", wie Brumer in icherzhafter l̈hertreibung iagte. Daj nie Bjefangengenommenen

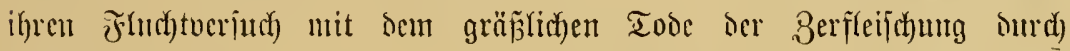

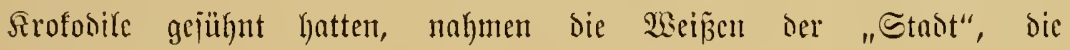
Difizizere twic die Raufleute, mit cinem Shafelzudfen hir. "Da hat cben Datutmam Fromme einc fleime Erfeid)terumg beim Echauri", meinte Sberfeutnant Strömer gefajfen, "umo bic Sache hat vieffeicht andh) ionjt

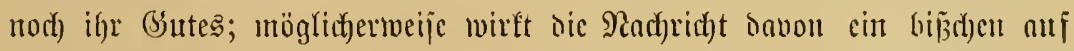
dic Wafereme cin, jo dor bic Dicbïtühle bei ber Werjt mo beim Sultans= tabaf bes braven Bana ?fmihar etwas jeftener werion". Esiter ter mocren

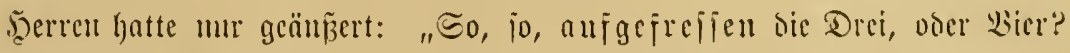

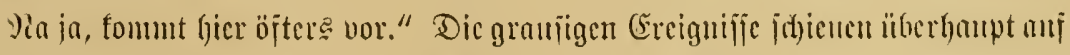

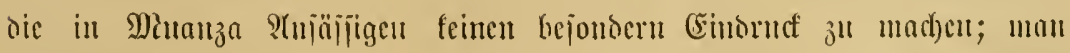

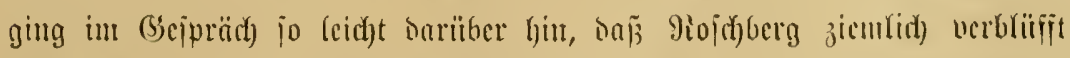

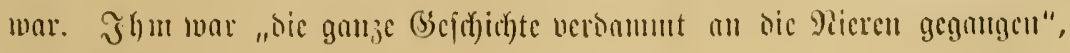




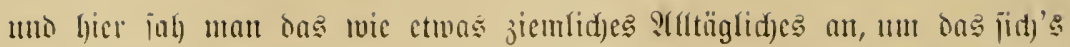

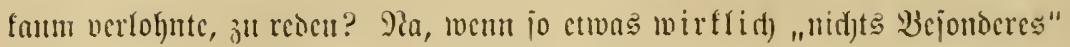

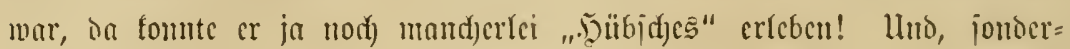
bar! (Er jïhlte ç jelber: Dic Epaumung, mit ber er bis vor furjent nod)

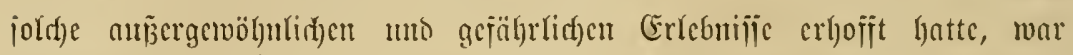

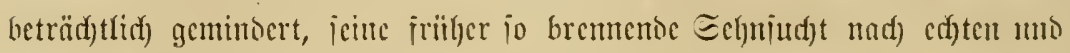
red)ten ?(bentcuern war id)on uad) bicjem crîten, anfünglid) gar nid)t mit

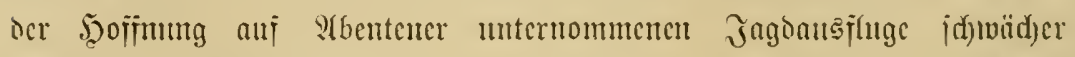

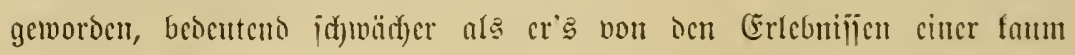
breitägigen (Entjermung uns ber Etaot f̈̈r möglid) gehalten rjätte!

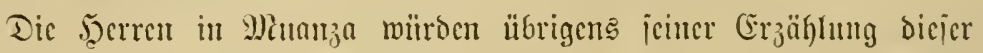

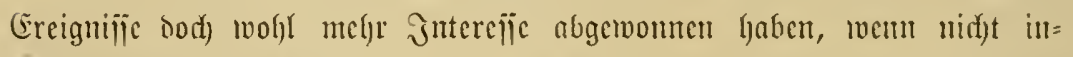

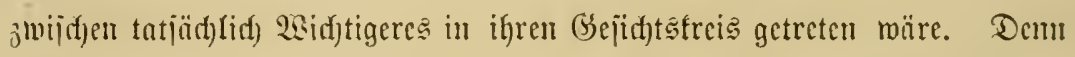
nid)t gerabe unerwartet, aber bod) fïr ien ?ngenblicf überraidsend war in

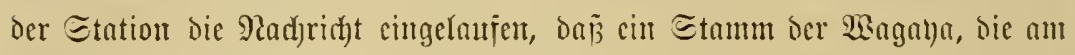

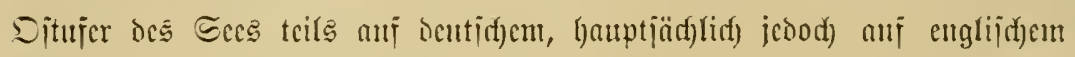

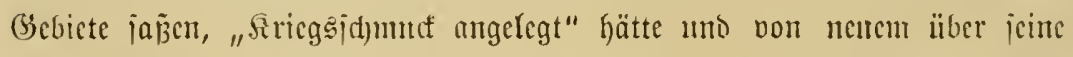

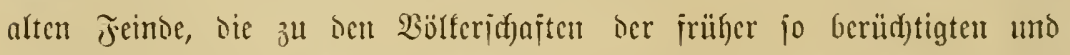
gejürd)teten Miajiai gehörigen 2safenye, hergejallen wäre. (Fs jei glcid) von ocr mur cinte idjwat)e Bejakntg aujweijenden (Sirenjitation Edjirati -

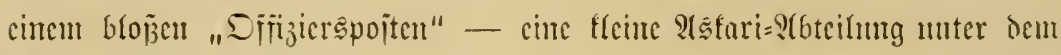

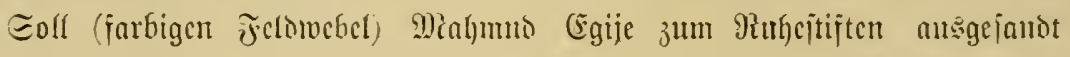

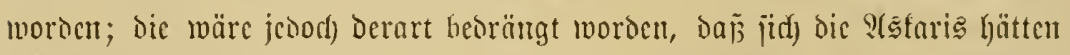

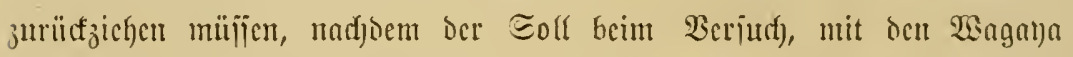

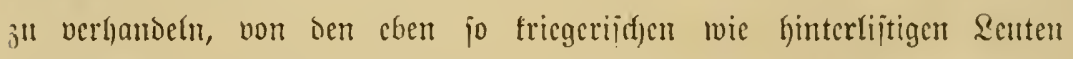
rücflings von jeinem Ricitejel heruntergejtod)en war. - Die Eilboten mit Diejer Wieloung waren geitern abeno cingetrofien; heut wurbe in ber Boma cine Silfsexpcrition julanmengeitellt, uno morgen jd)on jollte dic erite

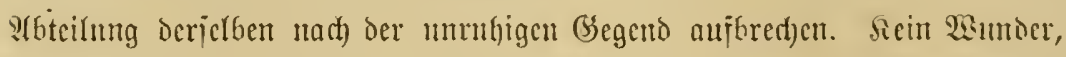
menn namentlid) bic jüngeren Sifiziscre, die jï(d) währent des anjtrengenton uno anf bie Sancr io eintönig (angweiligen Stationsoienites nad) friege=

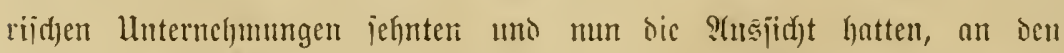
F̌eint 3n fommen, nidht vicl Juterejic jür sic "al(tü̈glid)en (Beid)id)ten" zeigten, dic incm Dienlinge io anjregento vorgetommen maren. 


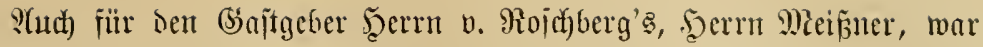
cinte Pieuigfeit cingetroffen, umo jwar mit ber Boit, bic alle 14 Tuge

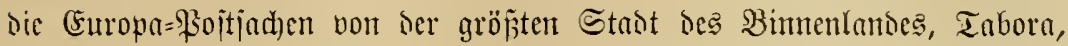
abgolte. Dortfin murben die von ten Reichspojtsompfern ben Sëüiten=

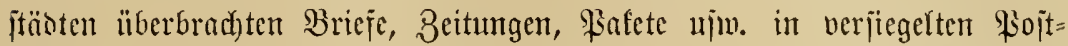

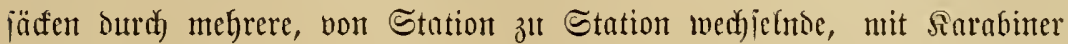
uno Seitengewehr bewafijnete, ant dor STrmbinte mit iem mejïinguen \$ojthorn

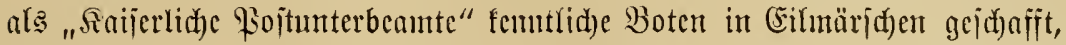

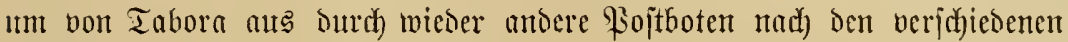

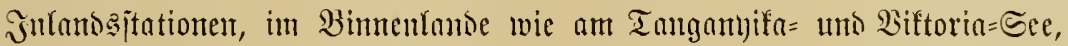
ourdf) prionte Boten aud) nad) ien Miijionts=ভtationen, beförsert $3^{\text {th }}$ merien. Dieje Rente, \$ojotangeitelfte wie Miijionszöglinge, waren bam

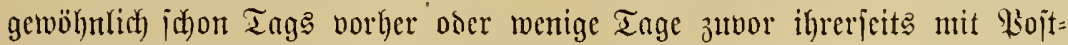

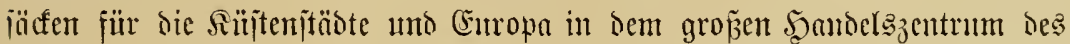
Jmern eingetroffen. Sie warteten in Tabora, bis bie "Siijtenpoit" lam,

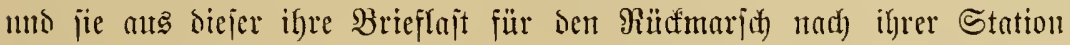
jutgeteilt erhielter. Das mar of́t eine gewidhtige Rajt; hatte Dod) Tabora im

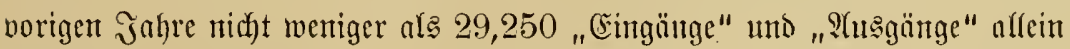

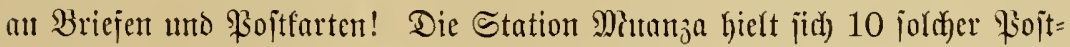

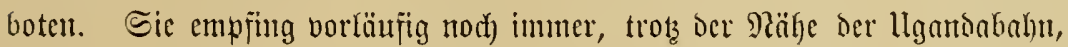
bie erit fünjtig zur Sojtbeförocrung benutst werden jollte, bie Sojt ber

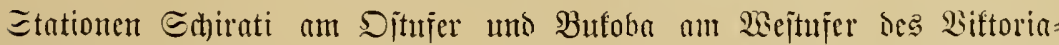

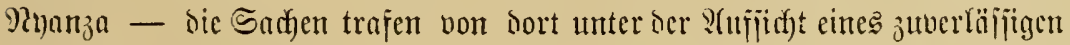
SEtaris auf Ruderbooten ein, die, von ausgejucteten Babaria besient, mur vier Tage für bie meite Fabrt braud)ten -, ums ser \$sojtmeijter, zแrjeit Unterofijzier Miencfe, jertigte baum dic gejanten Bricfictajten der orei Eeejtationen nach) Tabora ab, um nad) giü(ffel)r der Sojotboten wou

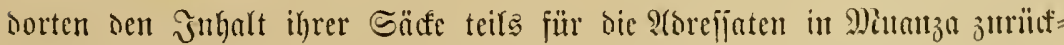

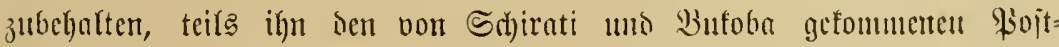

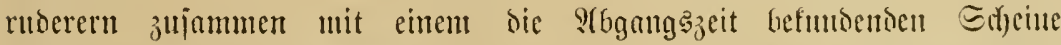

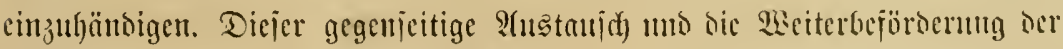

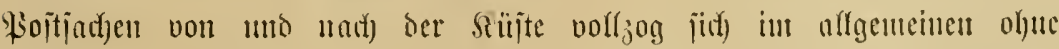

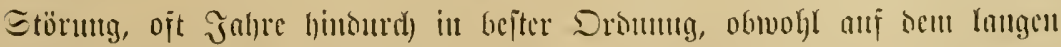
Wege von den Bimnenien bis nad) Dar=es=julanu cinte ganje Minge 
Etationen lagen. Jene Etution bieft chen ifye cigenen Pojthoten, itets

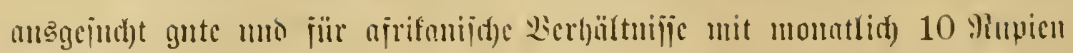

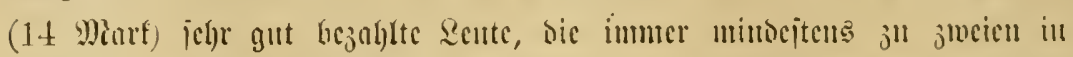

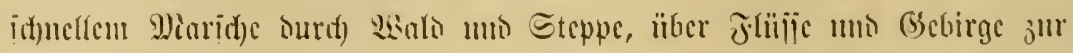

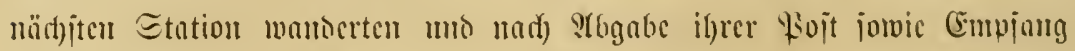

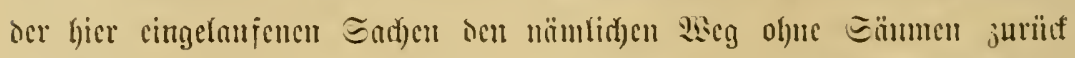

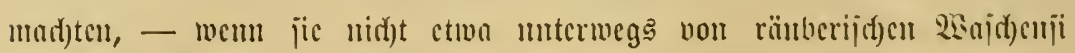

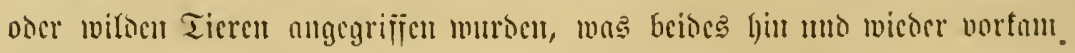

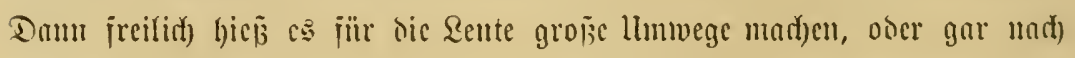

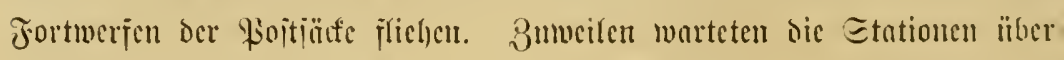

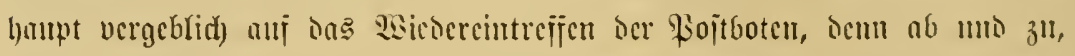

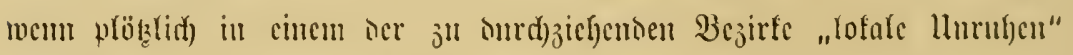

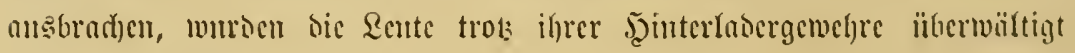

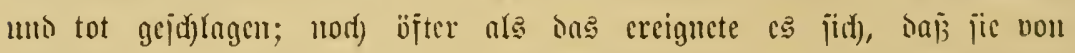

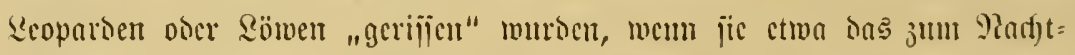

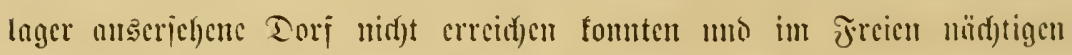

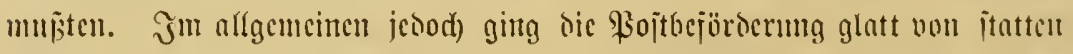

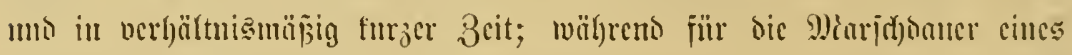

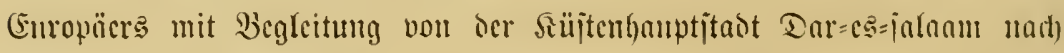

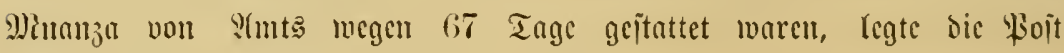
Sicje Etrecfe in 32 bis 35 Ingen zurïn.f.

Mit sicjer gejtern in Minanja ïfer Tafora eingetrofifenen \$ojt mu

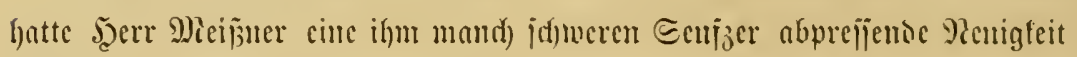

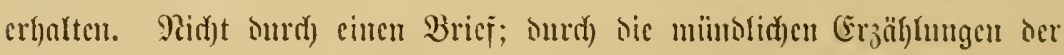

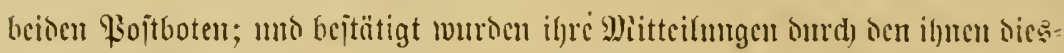
mal aus bejonteren Griünoen beigegebenen, erniten, jef)r zunerläjïgen Sintifiro:

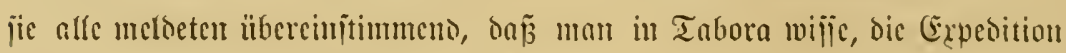
oes ndugu mdogo wa bwana Méssina jei von jel)r wilocn sajaj)enji

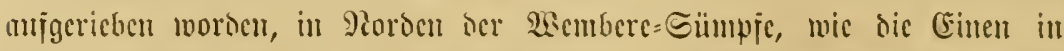

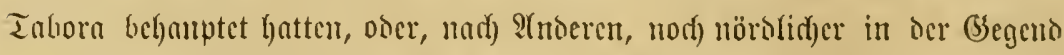

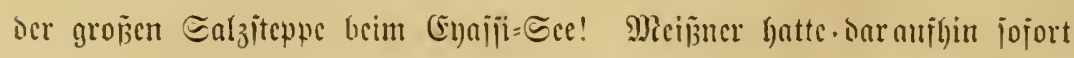

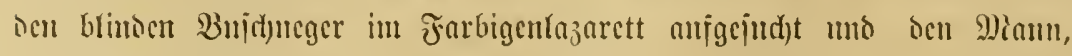

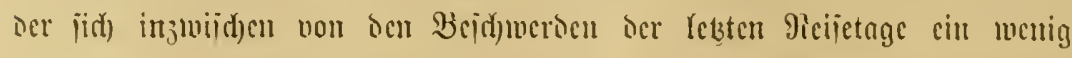
erholt batte, in geijtig etwas weriger wirrem 3njtante norgejumben. 


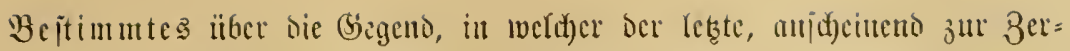

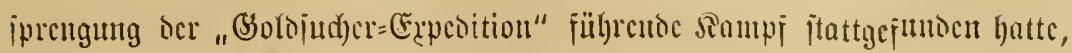

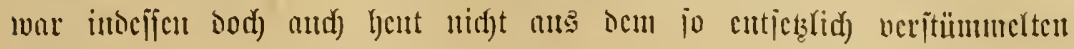

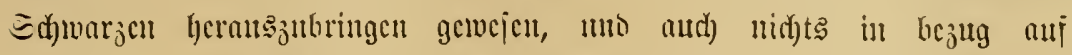

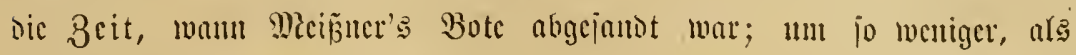

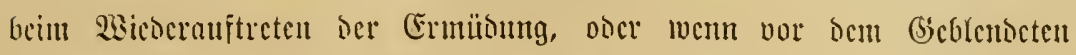

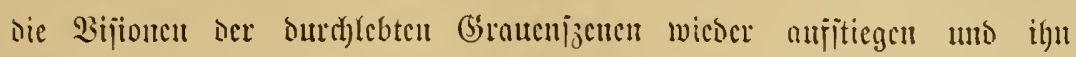
übcrmanten, jofort dic ficbernoe s(ngit ifhu jebe Erimucrung an alfes

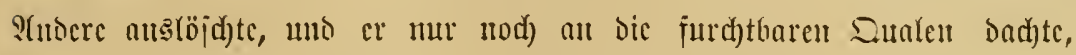

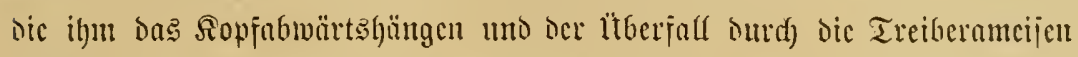

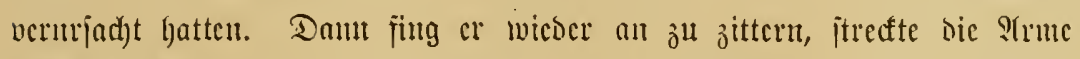

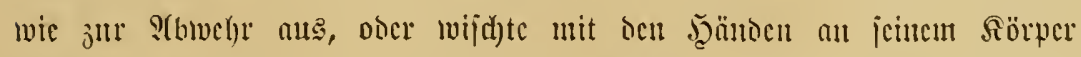
cntlang uno jtöhnte "Die Siaju! Dic Siaju!" D a

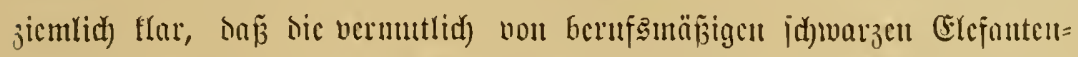

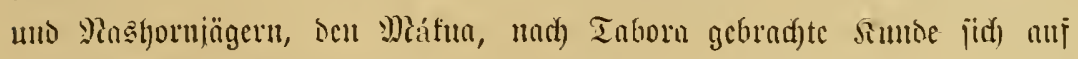

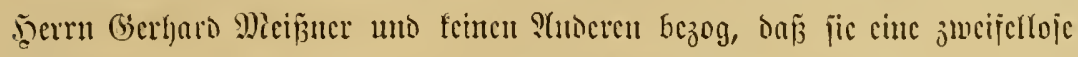

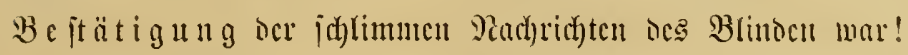

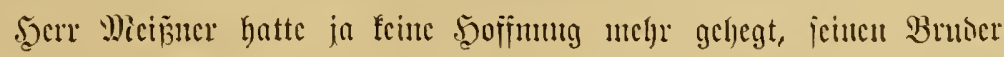

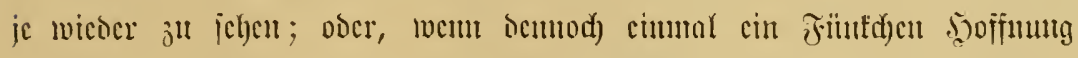

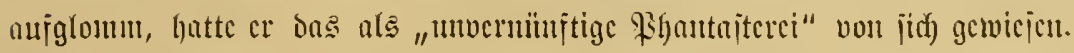

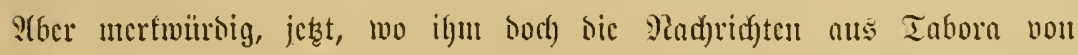

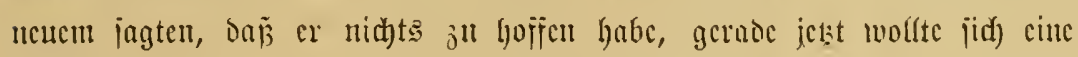

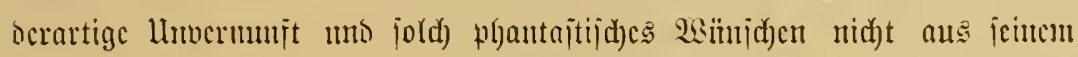

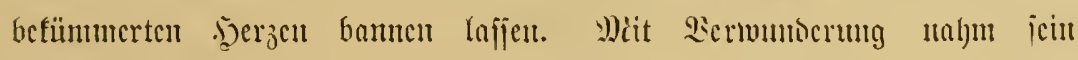

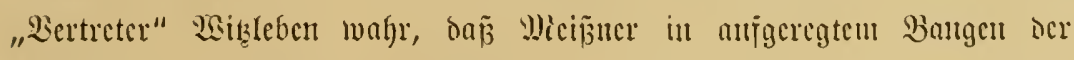

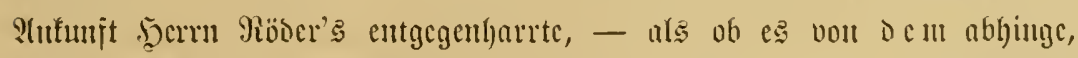

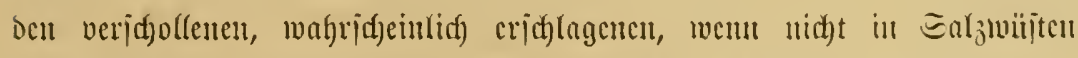

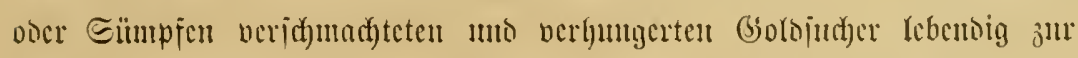

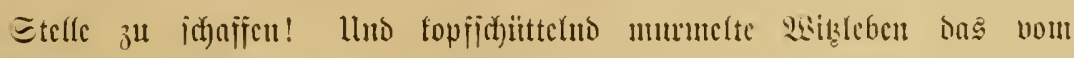

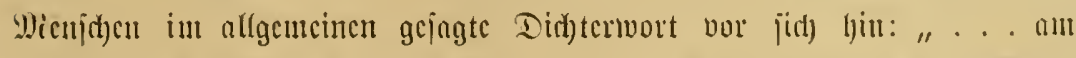

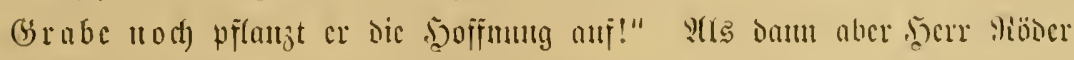

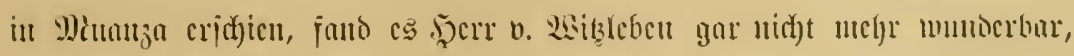

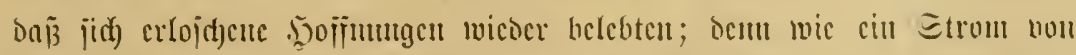

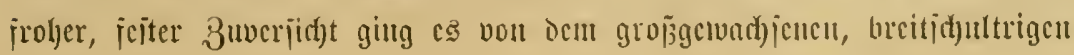




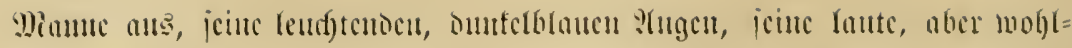

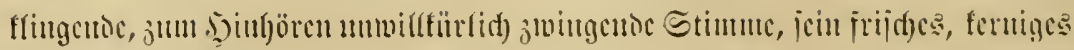

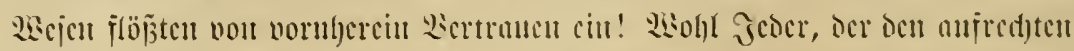

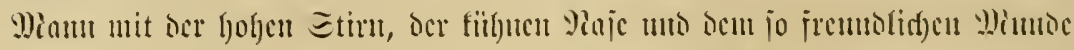

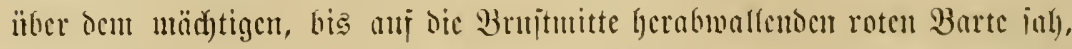

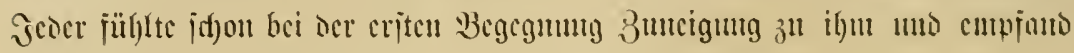

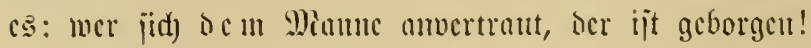

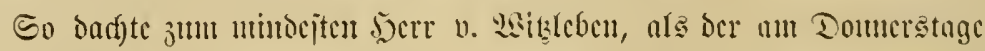

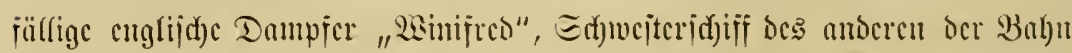

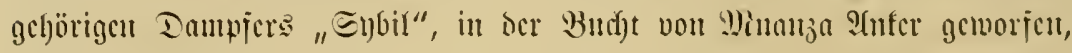

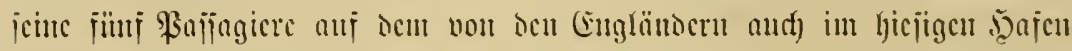
gel)aftenen cijernen Recidyter an Sauto bejörocrt hatte, mo "Der Rotbart"

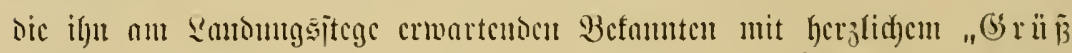

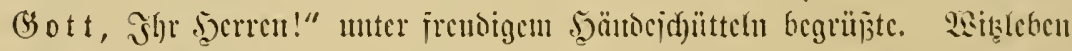

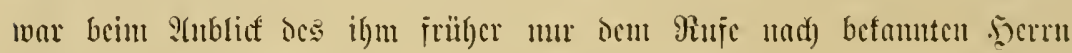

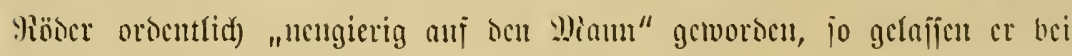

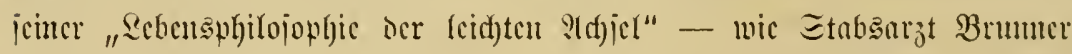

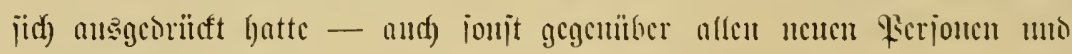

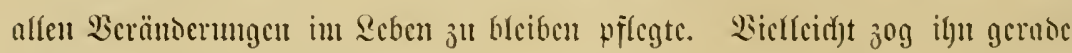

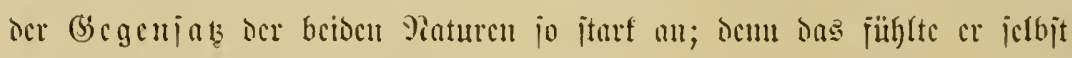

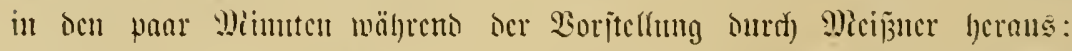

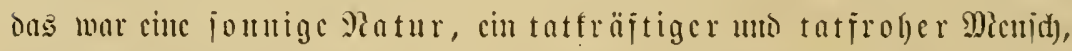

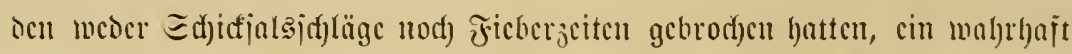

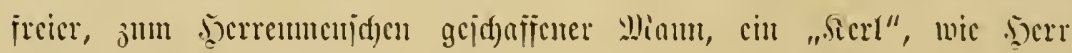

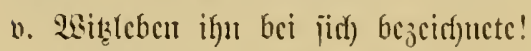

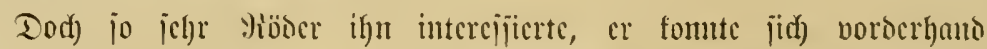

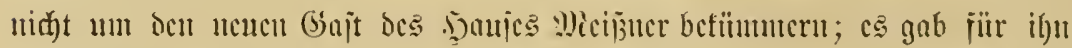

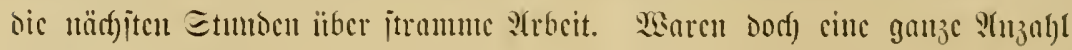

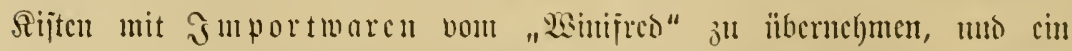

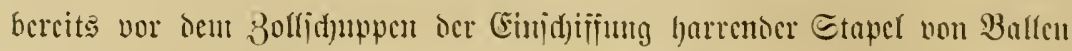

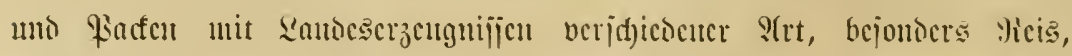

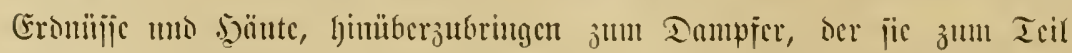

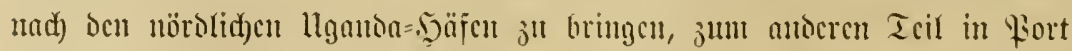

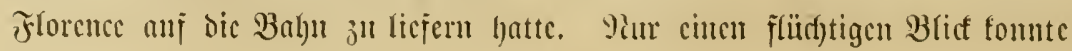




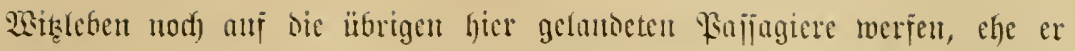
mit jeinen Edywarjen bic Strbeit begum. Die mit bem Dampie

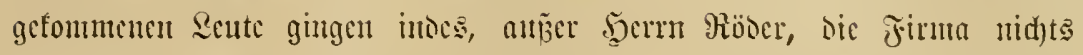

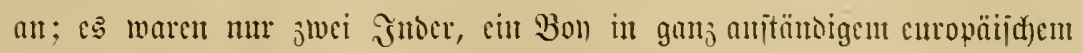

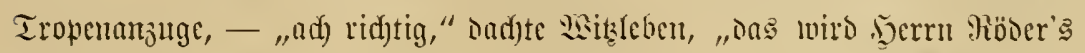

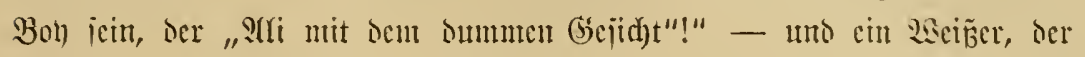

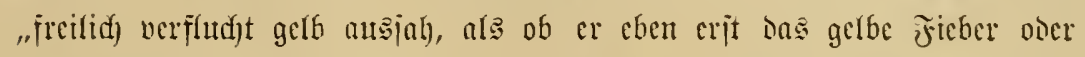

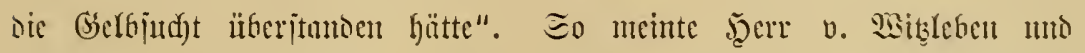

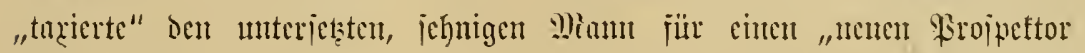

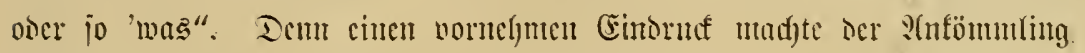
troks jeines neuen, guten Iropenanjuges nid)t gerade; er joh mefl als

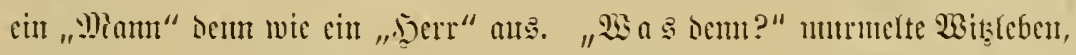

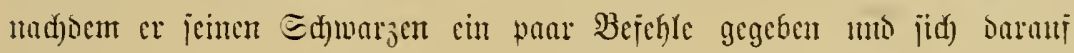

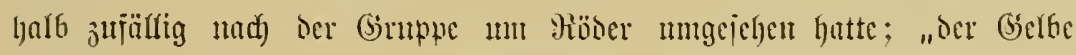

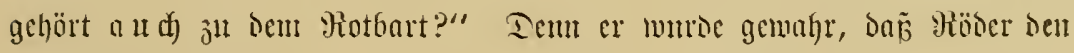

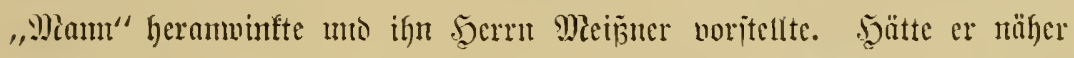

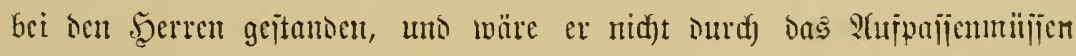

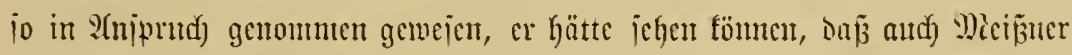
oen Fremoen nermuntert mo jogar mit cinem gemijien E(f)reufen als cinen

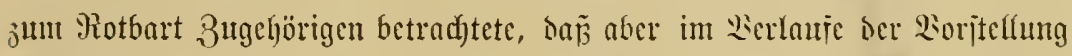

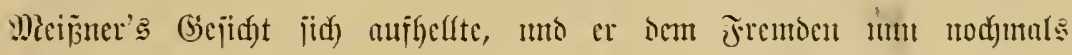

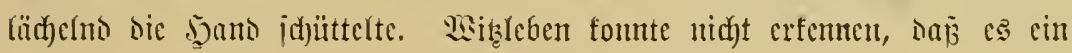

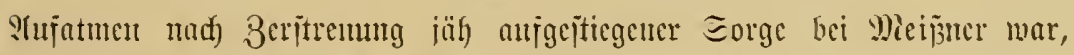

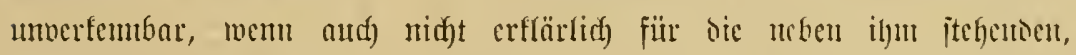

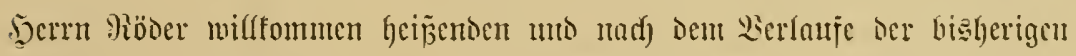
*eije fragenden Difijiere tmo bie Chejs ober Wertreter ber "meißjen firmen",

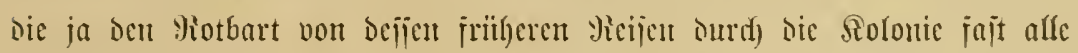

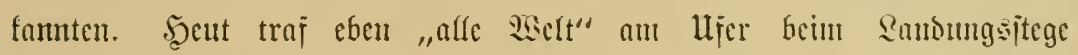

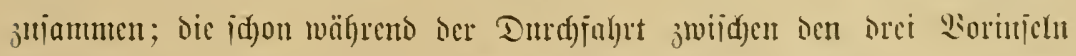

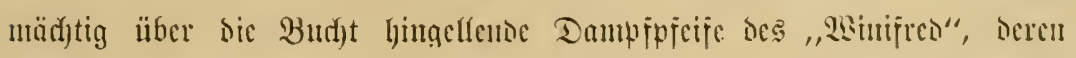

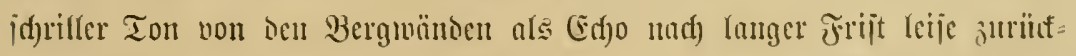

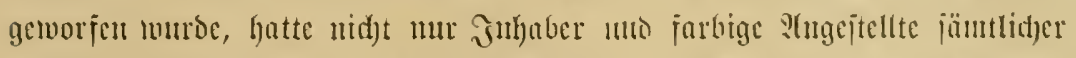

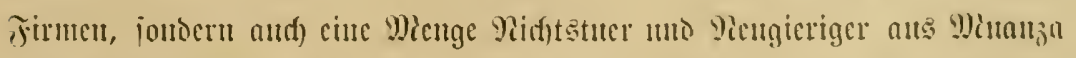
jun Sandungsplaze gernjen, - Die Dampiernuturt lvar lier nod) cine 


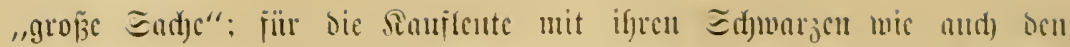

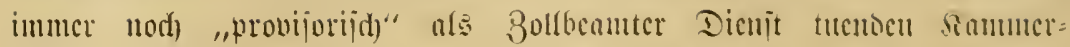

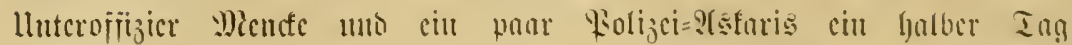

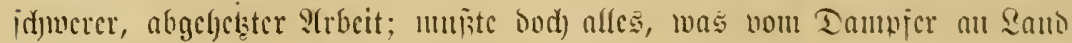

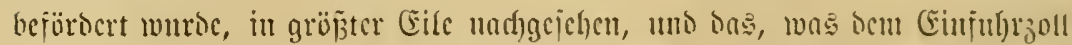

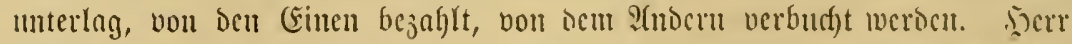

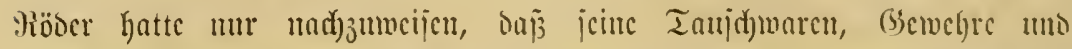

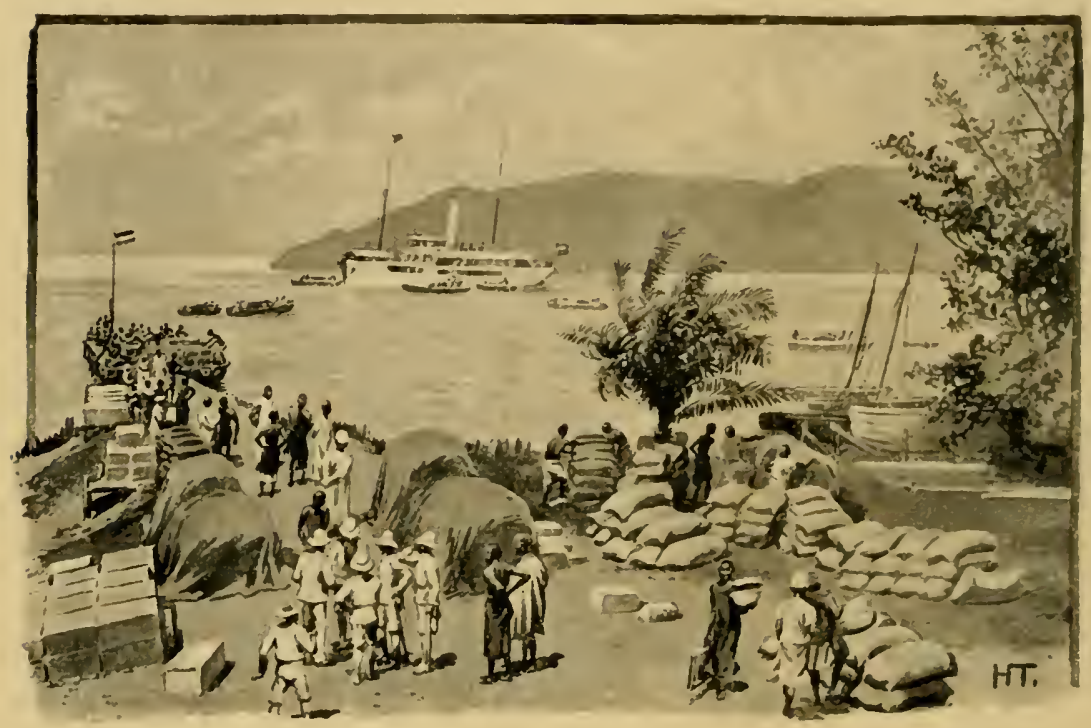

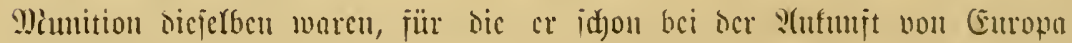

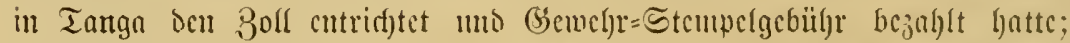

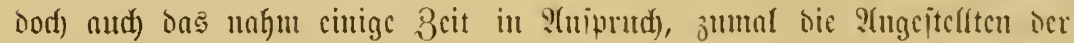

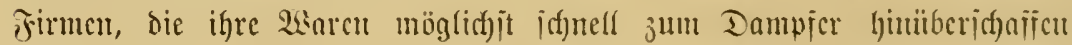

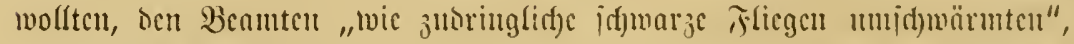

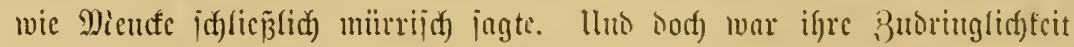
ichr begreiflicf). Cic woflten jo rajd) wic un möglid) abgejertigt werden,

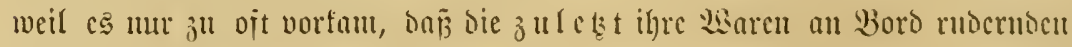

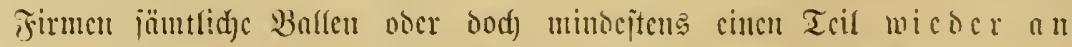

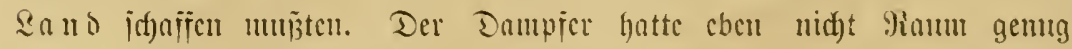

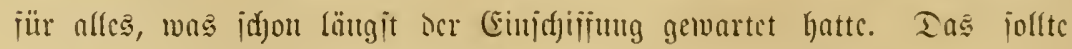

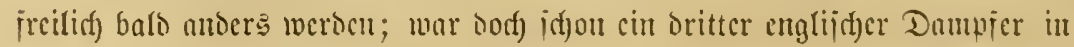




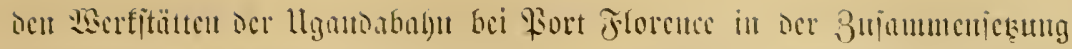

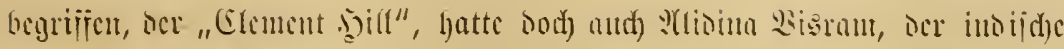

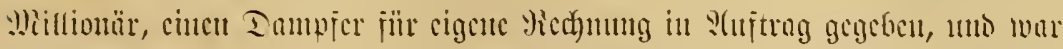

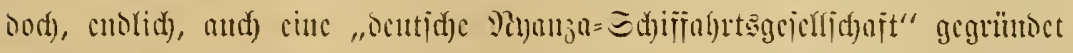

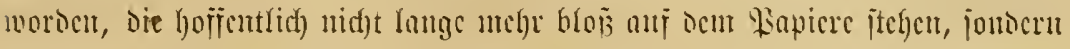

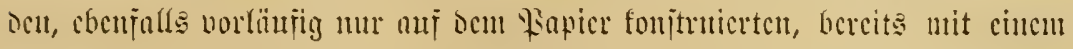

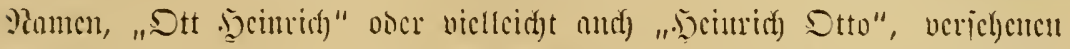

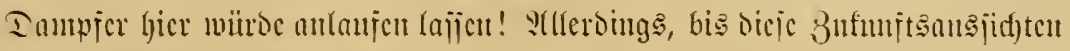

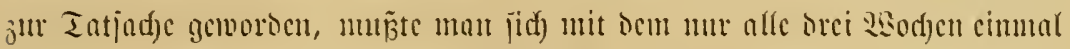

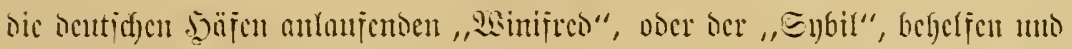

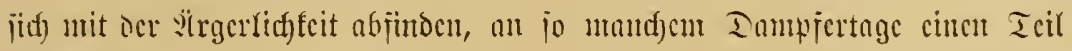

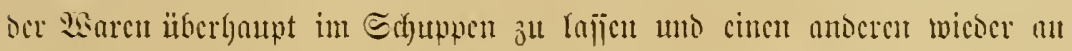

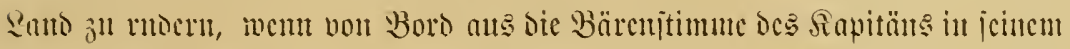

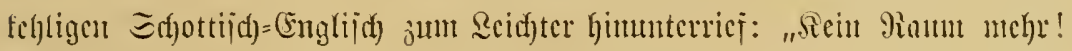

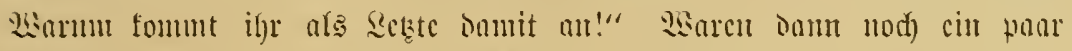

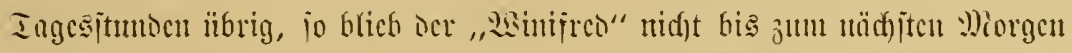

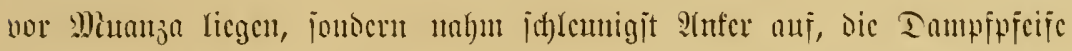

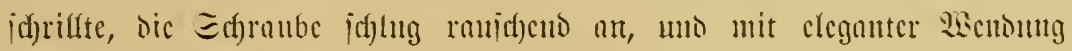

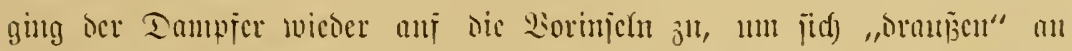

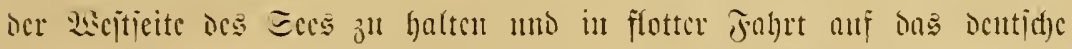

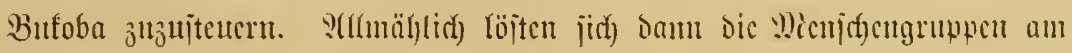

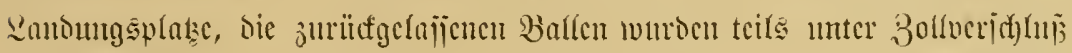
gebradyt, tcile in bic Echuppen ocr betrefifenocn Firma jultütfgetragen,

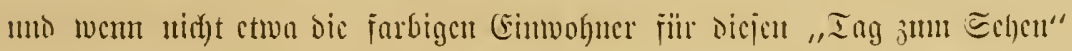

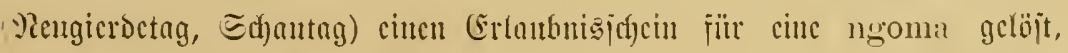

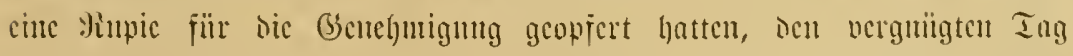

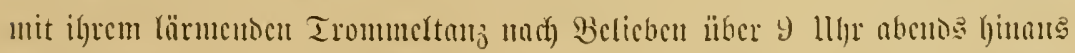

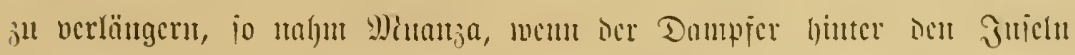

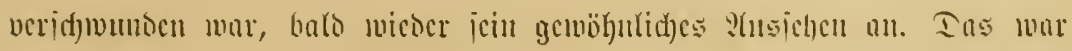

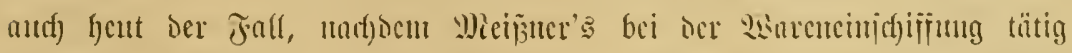

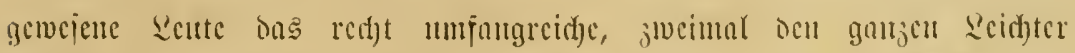

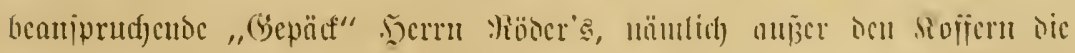

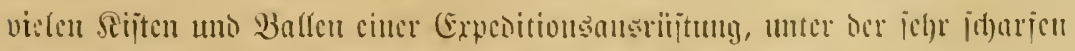

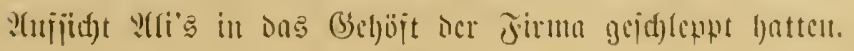




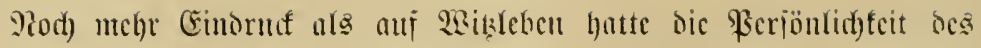

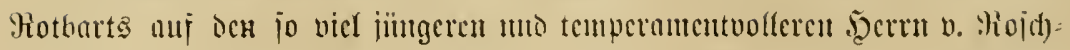

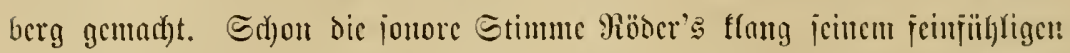

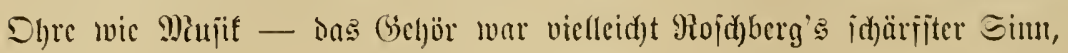

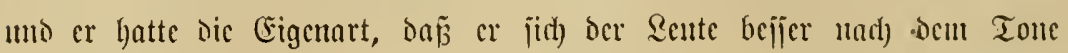
ihrer Stimue mo igrer ganjen Spred)weije als nadh Den (Bejid)tşjügen

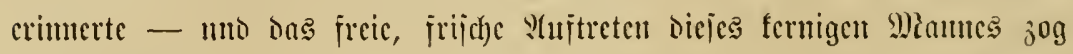

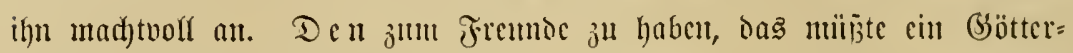

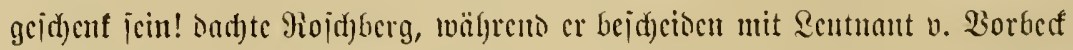

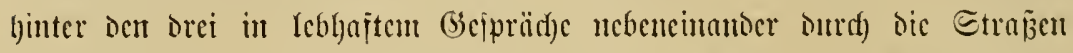

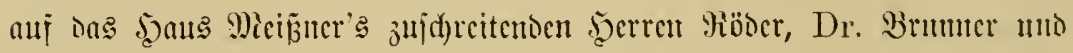

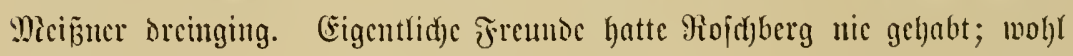
hatte cr jo Wiand)en anf ber Sdjule wie ipäterbin "Freuto" gcununt;

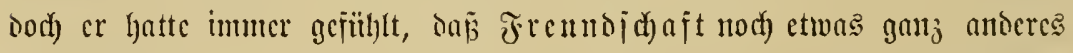

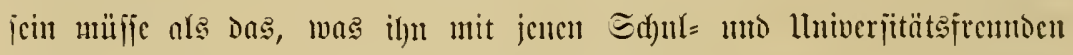
verbunto, ctwas viel jëöheres, cin jitlles Einanocrvertrancen uno jelbjtuer=

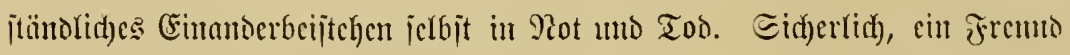

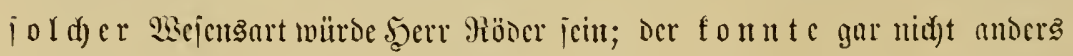

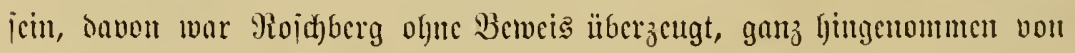

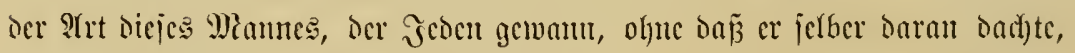

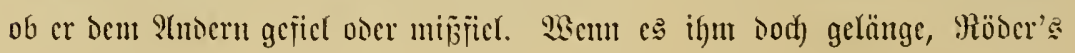

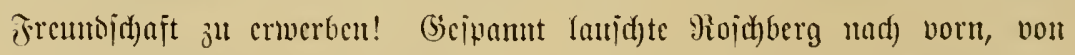

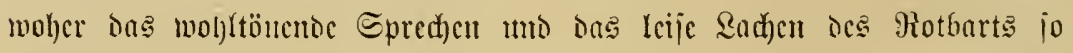
crquiffent an Das Shr bes jumgen Maumes draug. Er hörte faum, da

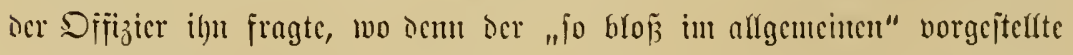
andere meize Siajfagier geblicben jei? Der Deerr Straj̈berger, oder Etrap̧burger? Dod) aud) Reutnant b. Sorbect war balo mit jeinen

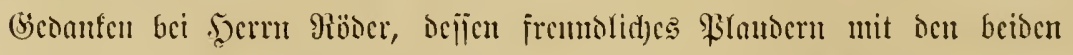

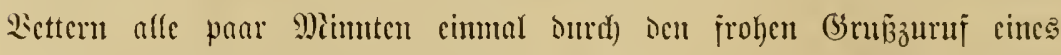

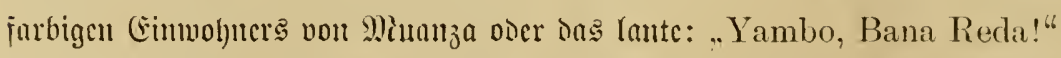

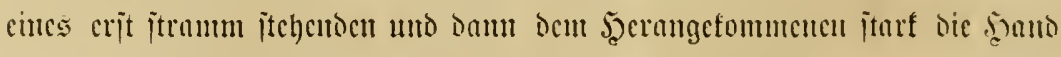

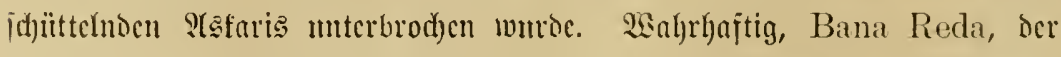

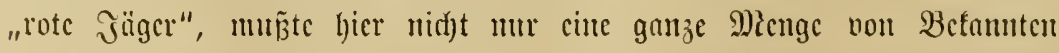

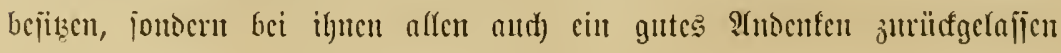




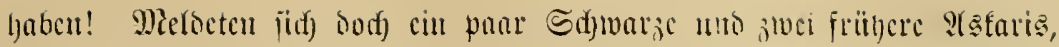

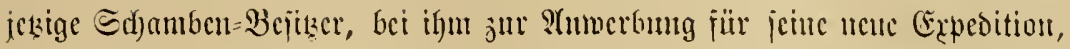

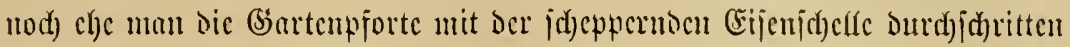

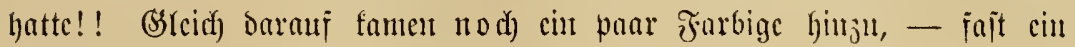

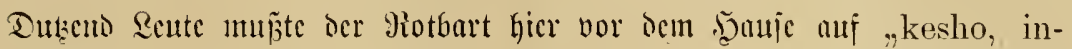
shallah (morgen, jo Gott wifl)!" bejd)eison, ehe ber mit ciniger gepäct=

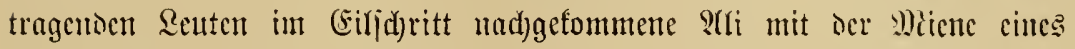

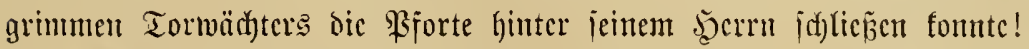

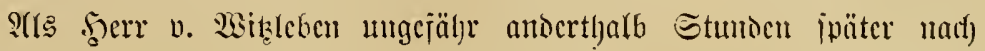

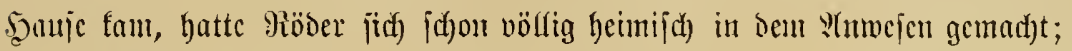

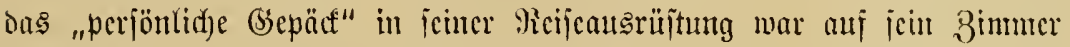

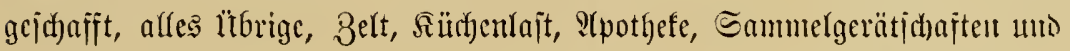

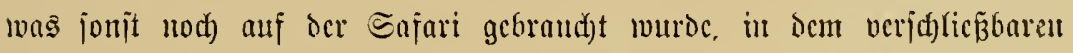

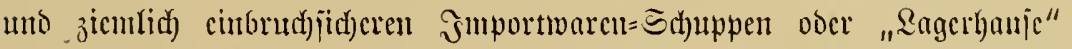

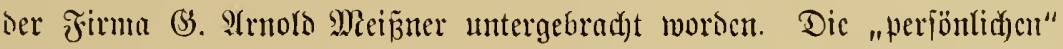

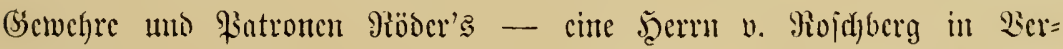

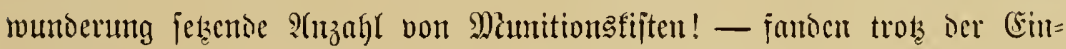

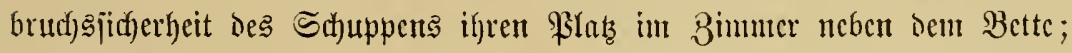

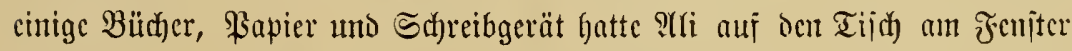
gejtelft, die jujammenjaltbare Gummibadcwame jeines 5̧crm unter bas

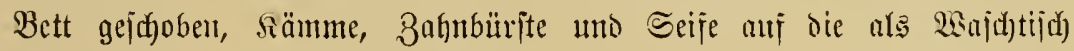

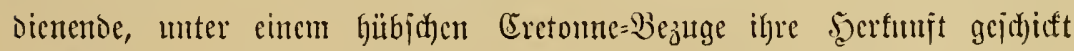

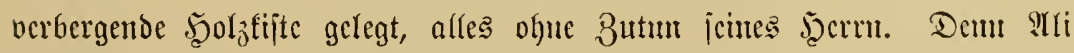

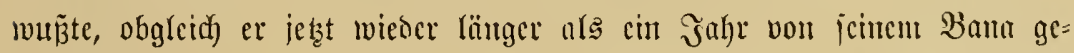
trennt gelebt hatte, in Deficn nad) beitimunter Dromung gepacten Eifen=

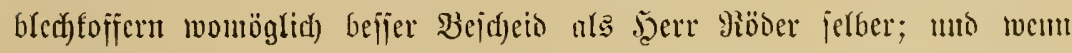

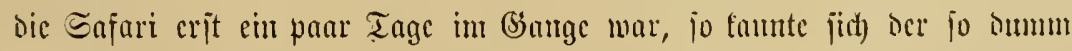

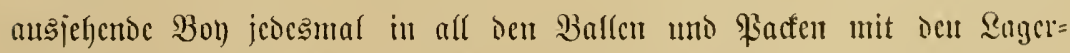

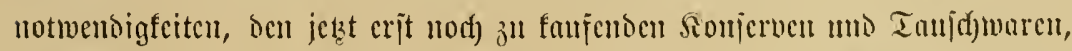

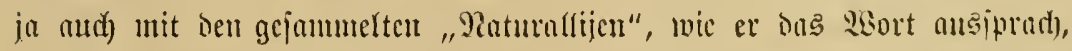

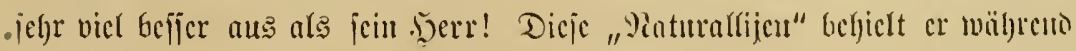

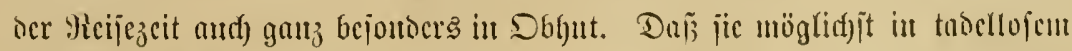

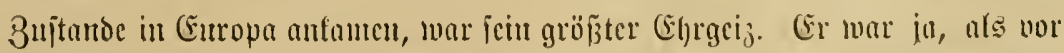

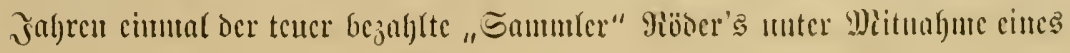




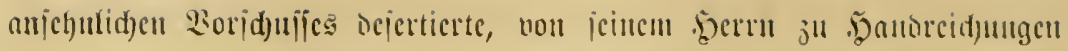

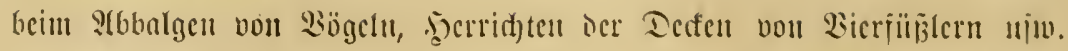

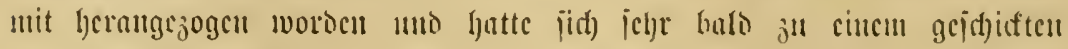

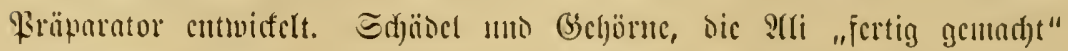

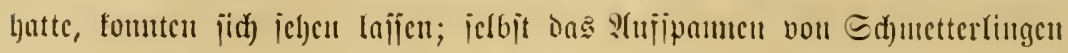

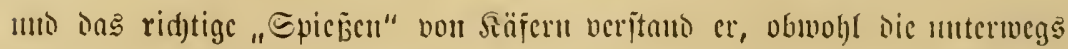

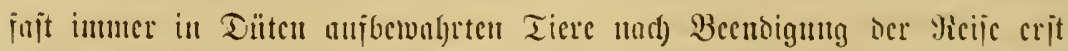

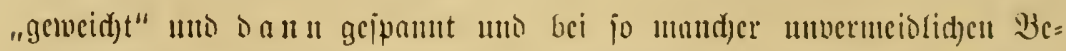

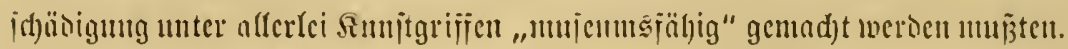

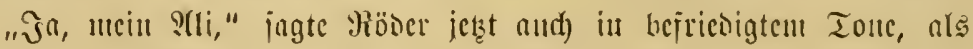
mau jid) furz nad) Sonucumutergang in bem heut "beinabe fejtlid) jtrablen=

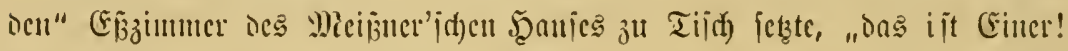

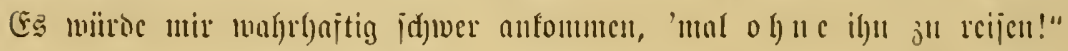

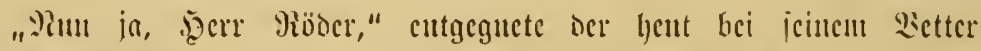

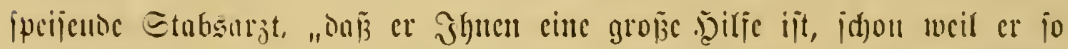

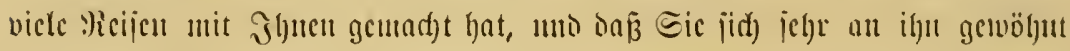

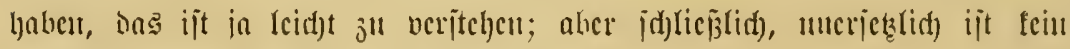

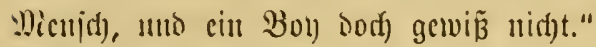

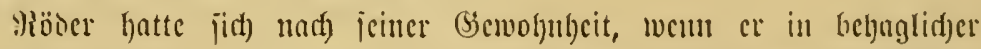

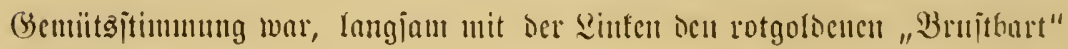

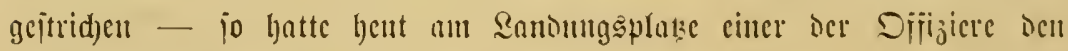

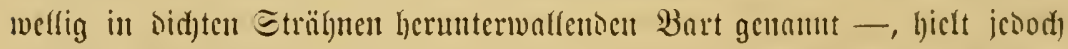

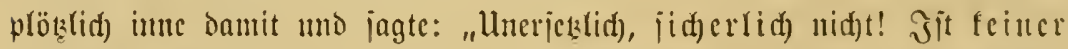
vou แns. S(ber wem id) aud) einen Boy friegte, oer meinem P(li gleid)=

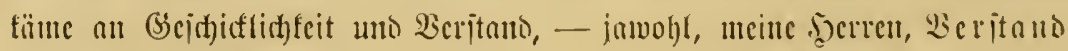

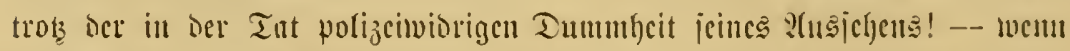

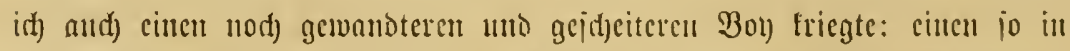

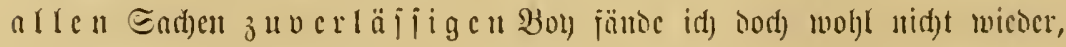

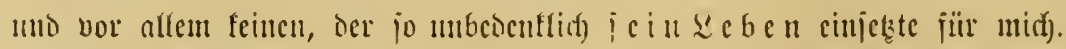
Das hat s(li melfe als cinmal, ad) was, das hat cr wohl cin Dutectio

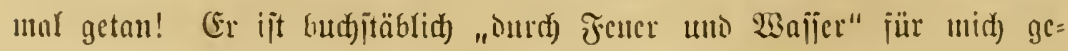

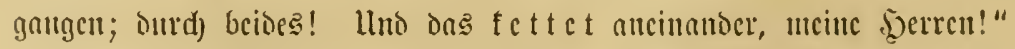

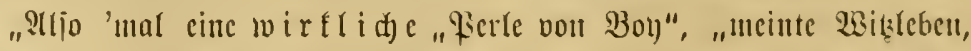

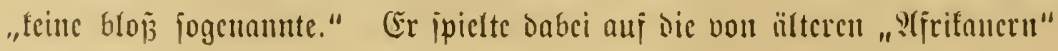




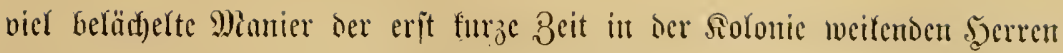

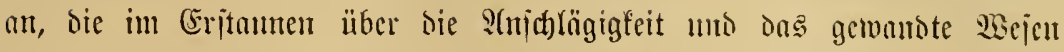

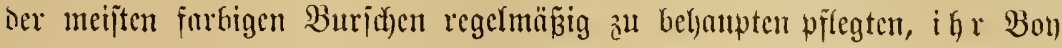

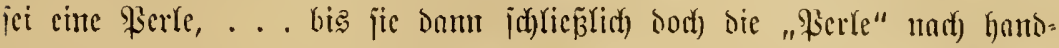

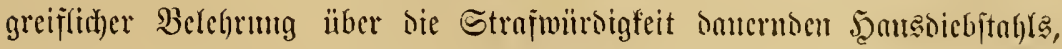

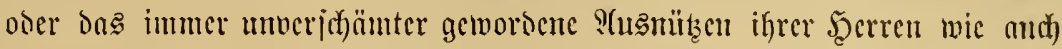

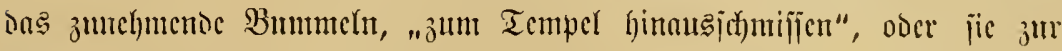
Bejtrajung zum Bana Schmri in bic Boma jobiften! "Freifich, Dumm=

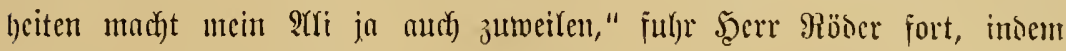

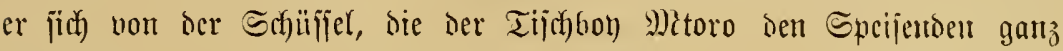

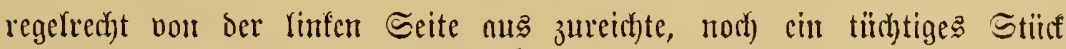

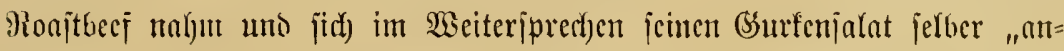

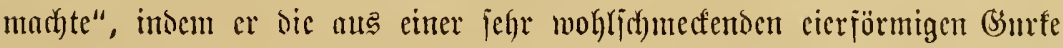

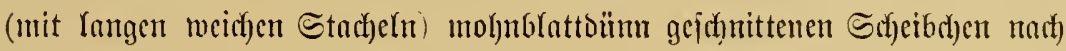

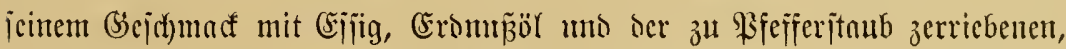

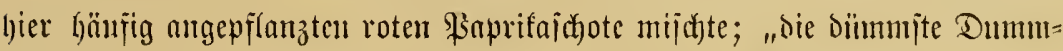

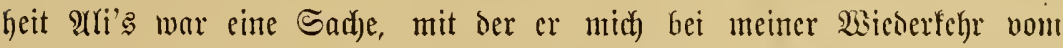

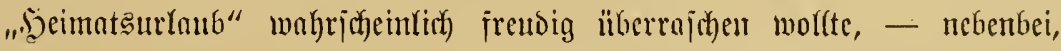

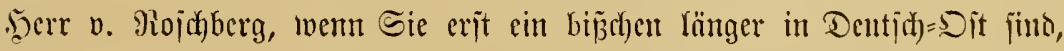

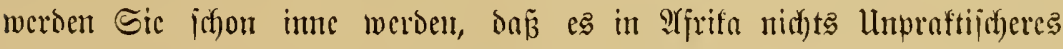

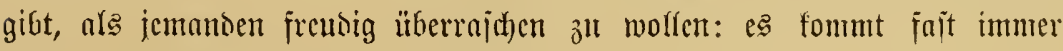
mir etmas redft 2̈rgerlidjes dabei hernus ..."

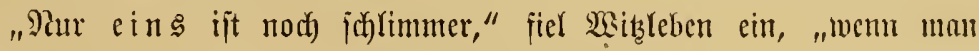
nämlich jel ber "freutig überrajot" merden forle!"

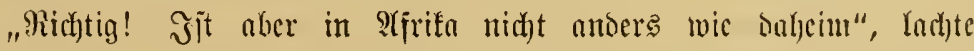

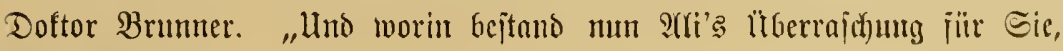
Sherr :iöder?"

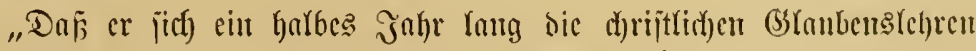

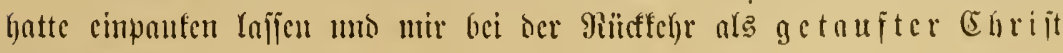
cutgegentrat."

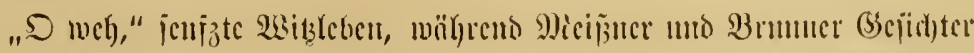

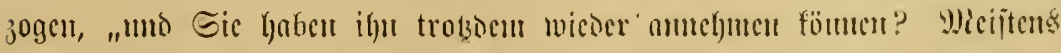

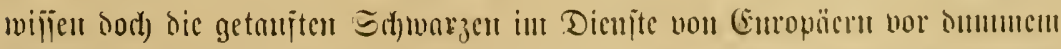

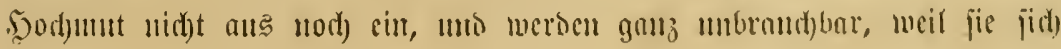




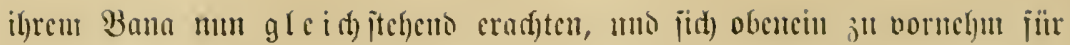

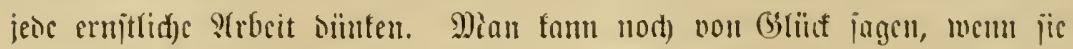

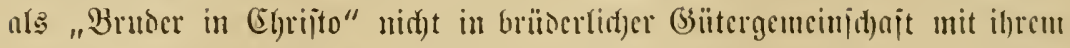

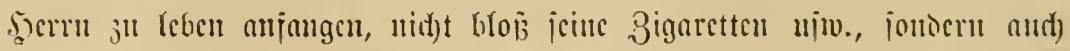

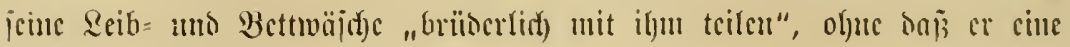
:(l)nutitg davon hat."

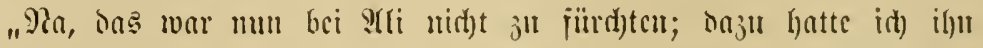

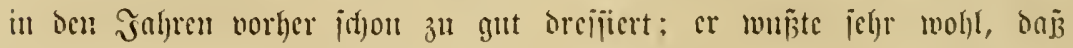

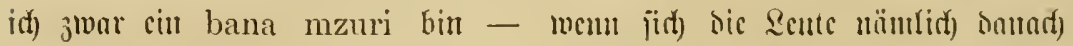

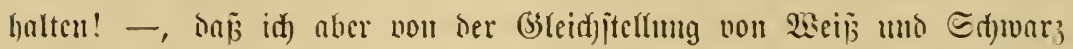

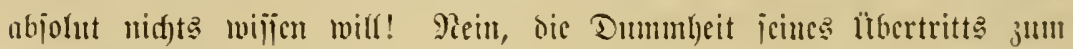

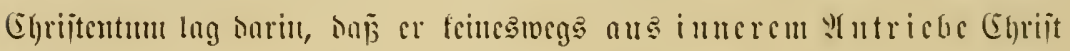

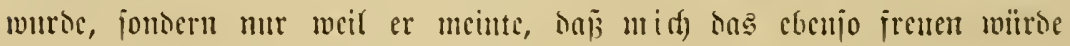

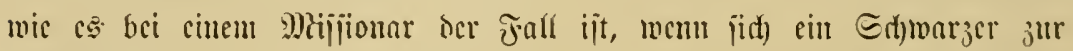
Befebrumg meloct. Ecin nencs (shrijtentum war meciucu S(li nümlid) im

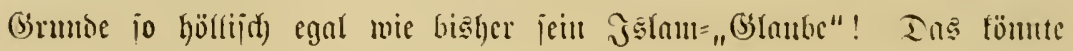

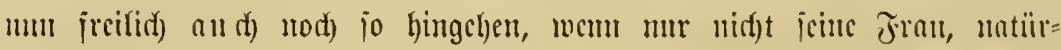

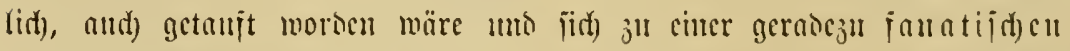

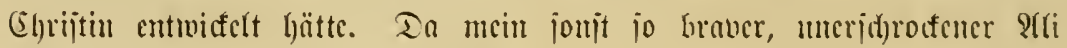

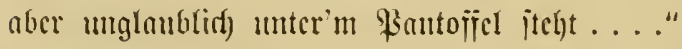

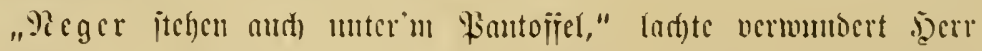

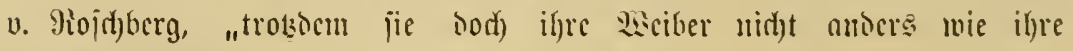
linitior fanjen?!"

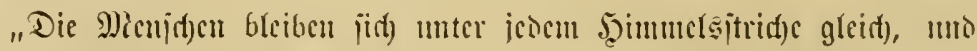

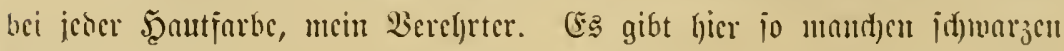

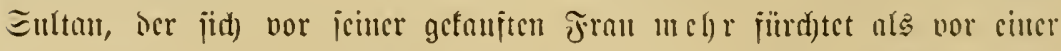

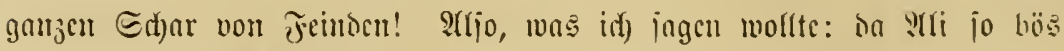

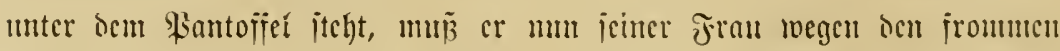

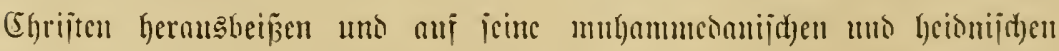

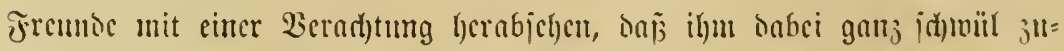

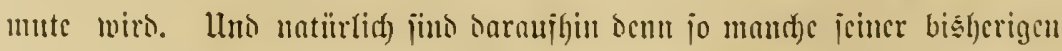

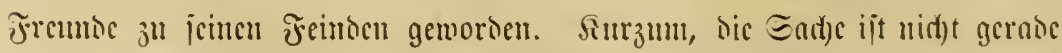

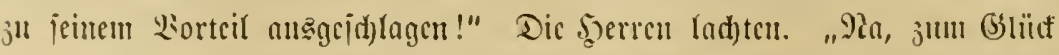

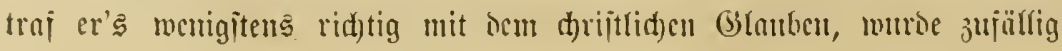




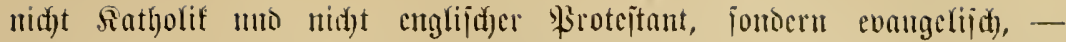

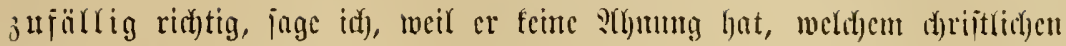
Befemtnifïe id angehöre."

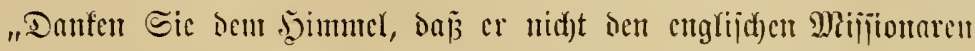

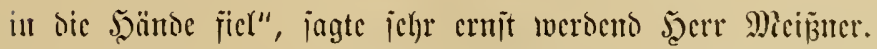

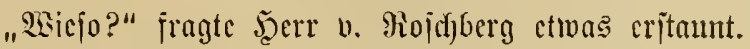

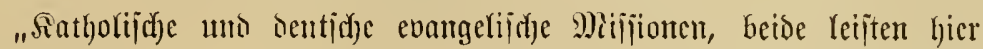

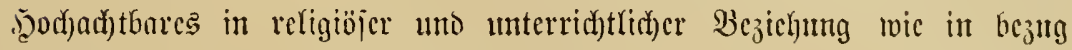

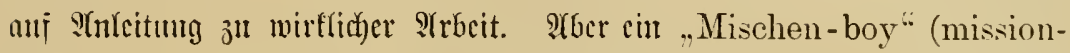

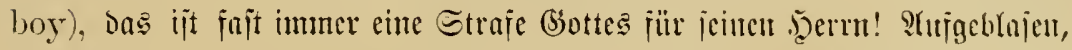

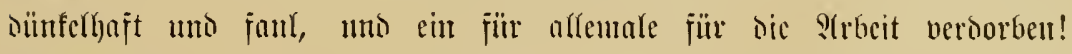

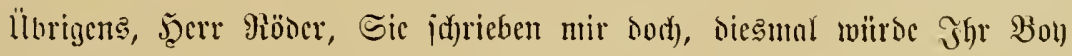
jeine sarioi mitbringen?"

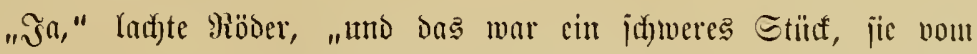

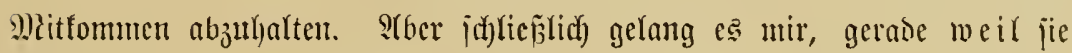

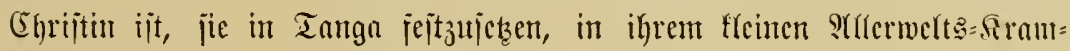

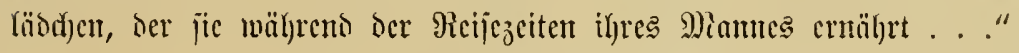

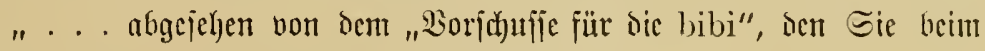
Meijeantritt hergeben mitfien", fiel Miciß̄ner ein.

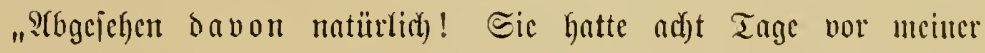

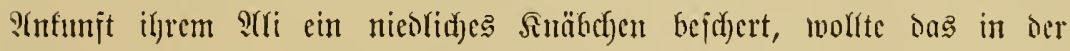

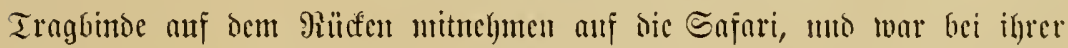

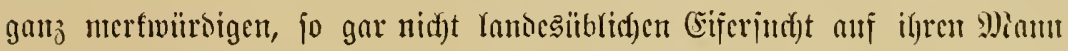

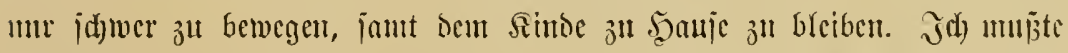

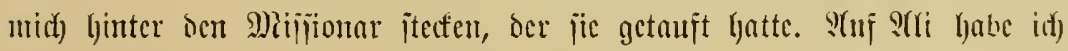

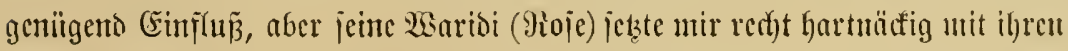

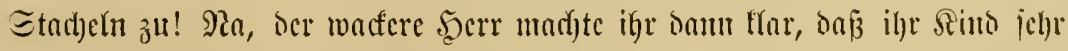

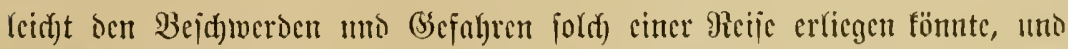

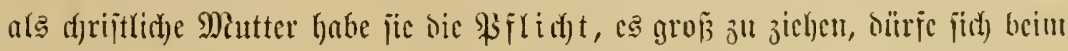

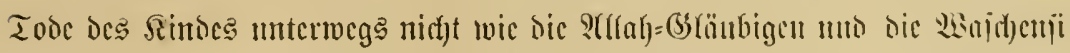

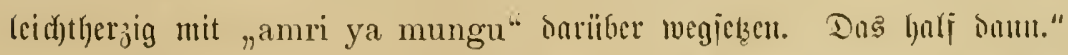

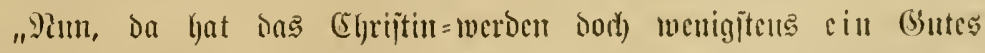

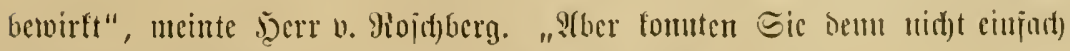

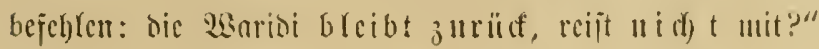




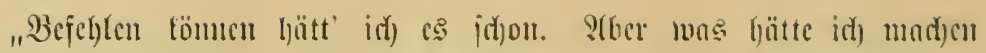

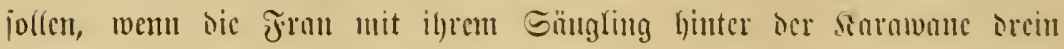

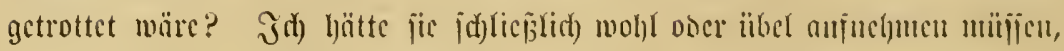

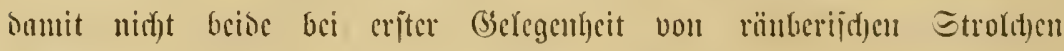

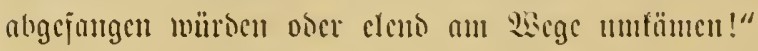

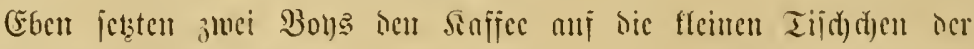

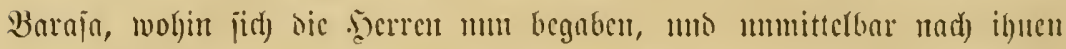

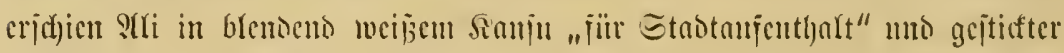

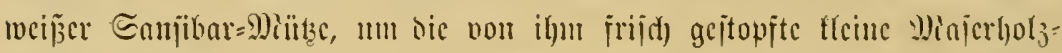

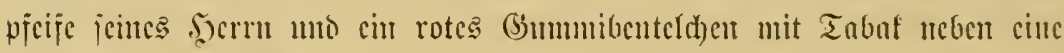

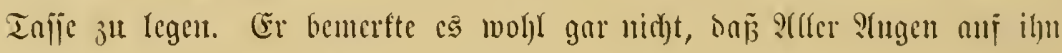

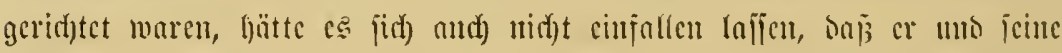

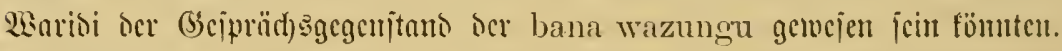

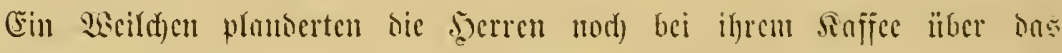

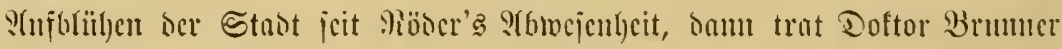

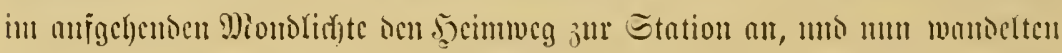

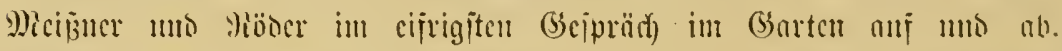

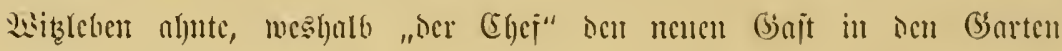

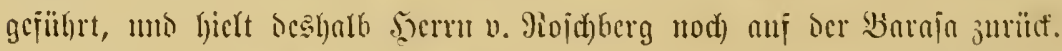

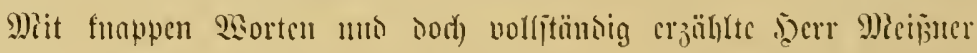

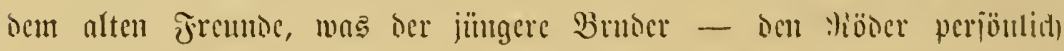

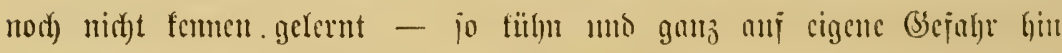

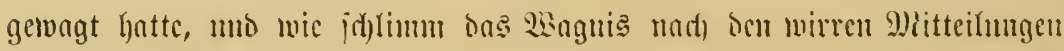

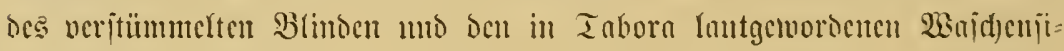

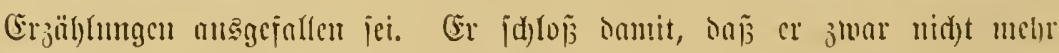

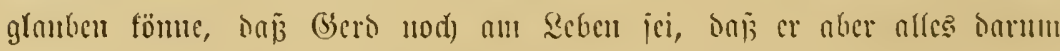

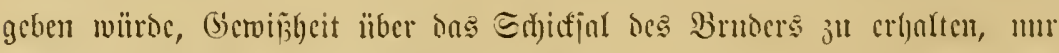

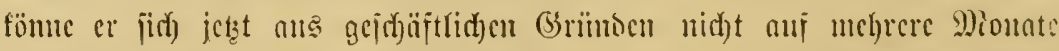

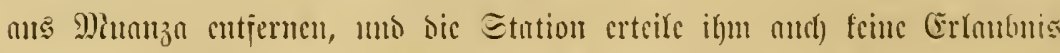

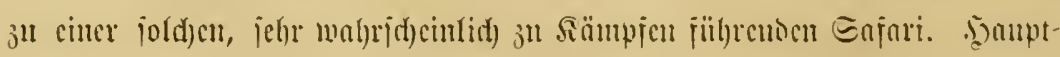

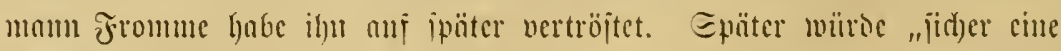
Beitrafung Der Seute erjolgen". Jn, ipüter!!

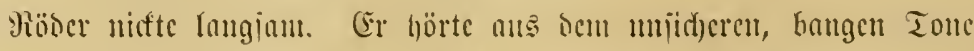

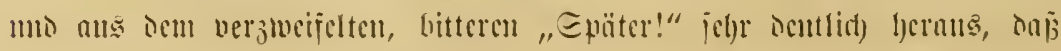




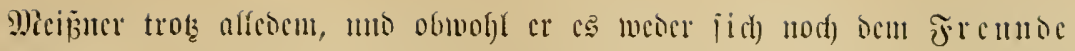

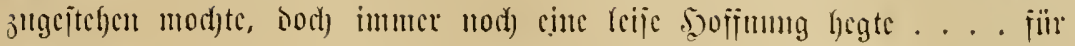

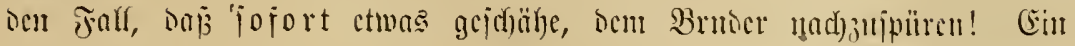

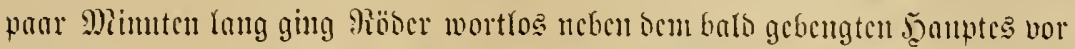
jitc) anf ocn (Barten= uncg blicfentom, balo

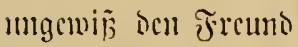
anjelyenocn fimlumante her. Daum blicb cr

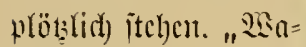
rum jagen Cic cs แid)t runo hctans, Qlcijßucr?! 巨int wir แแล jo fremo, ถก) Eic cs cutumetor nidjt "risficren", oocr jins

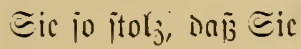
jict) vor cincr $\mathrm{P}(\mathrm{f}(\mathrm{cl})=$

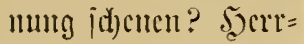
gott, Slamt, cE jtcft Shuta ja bod) im (Ścjid)t geict)ricben,

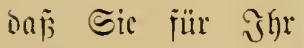
\&eben gern möc)ten, i d) jolle cinjpriugen!"

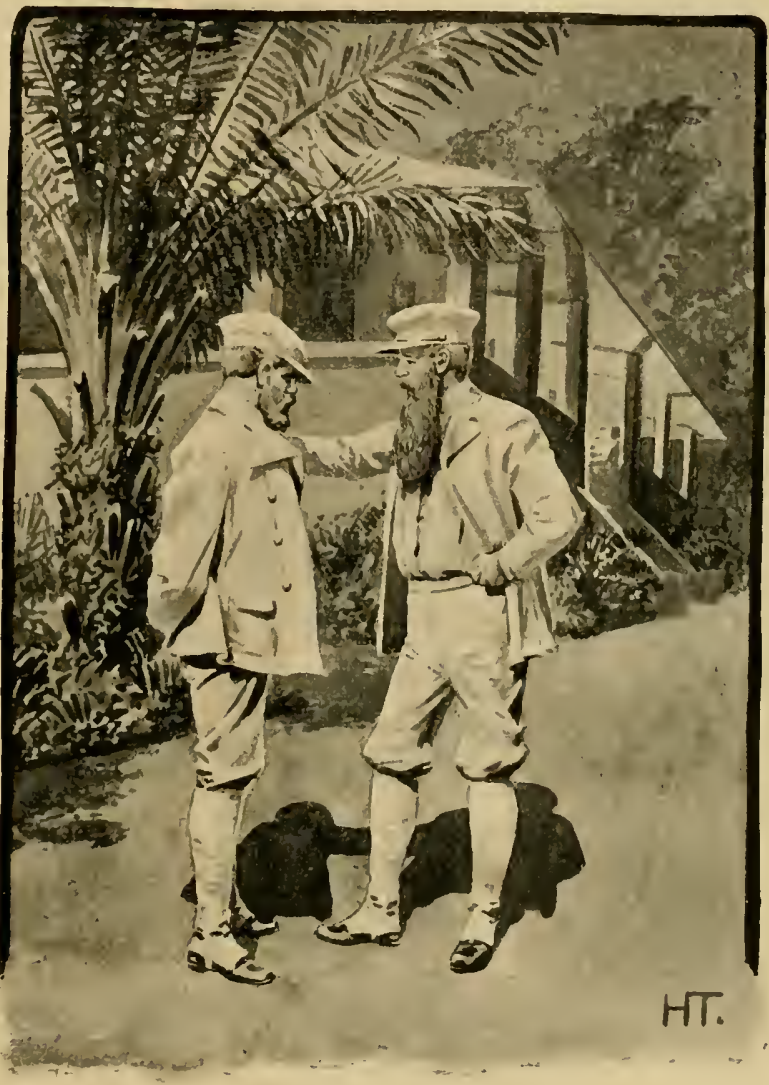
Er batte bem Freunte

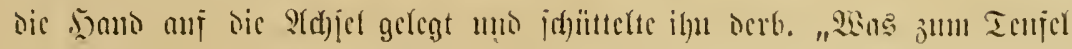
jagcn Eic mir bas nidft?!"

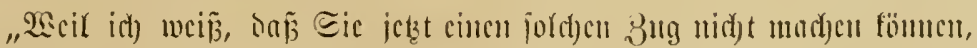

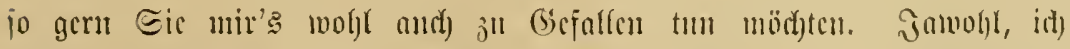

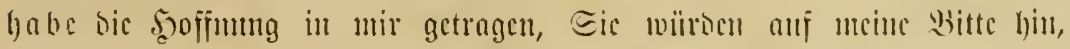

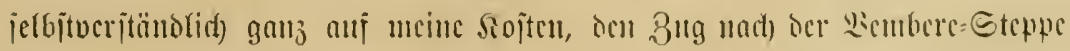

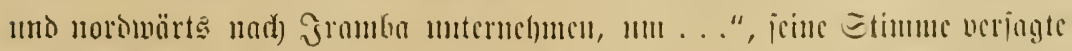

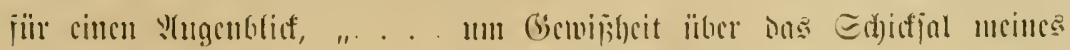




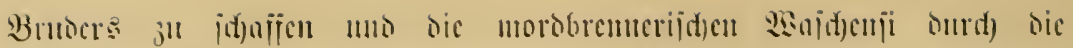

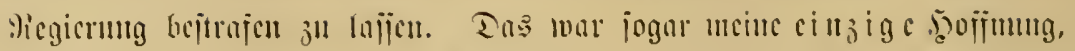

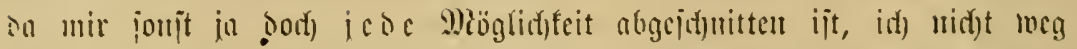

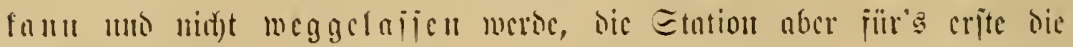

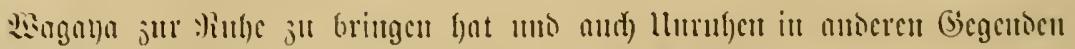

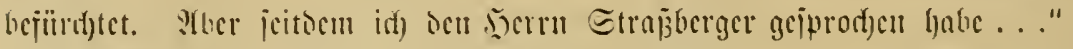

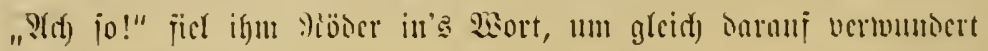

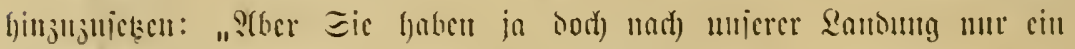

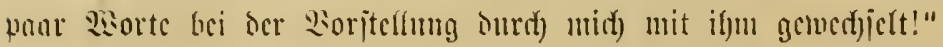

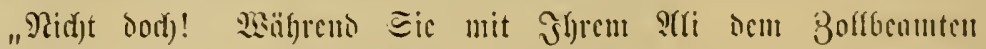
แtad)micicu, mas Sic bercits in Iangn veritenert bütten, iptrat) id) mit

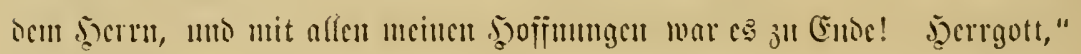

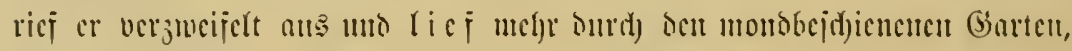

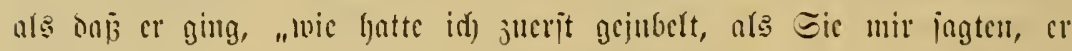

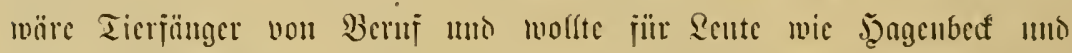
Dic 3oologijd)en Gärten ojtujrifunijd)es Grojüwilo lebentig cinjangen, -

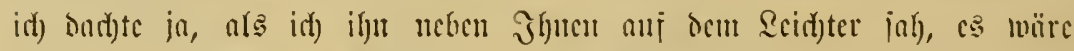

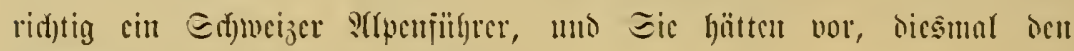
Bumenjori ju bejulugen mit ifun!"

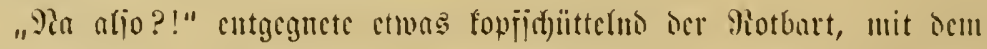

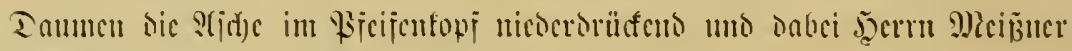
jiculid) vermumbert anjid)nuent.

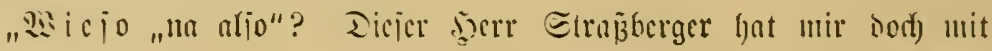
hördjt jujrictener Miene jojort erzählt, saj Sic ifm veriprod)en hafen,

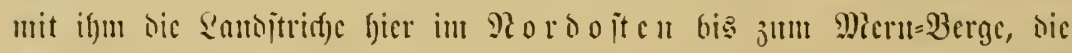

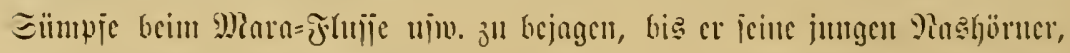

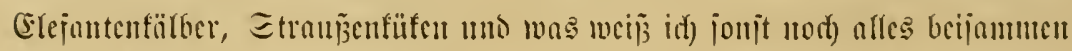

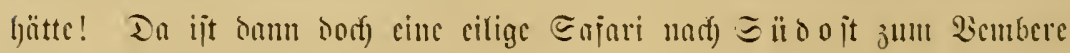
a แ

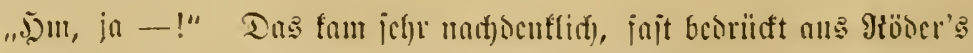

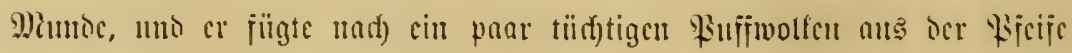

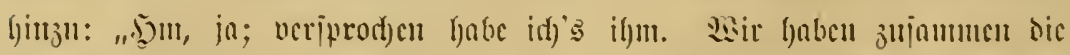

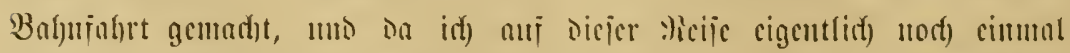

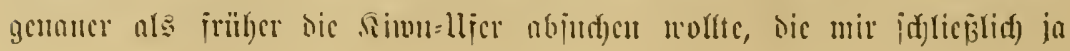




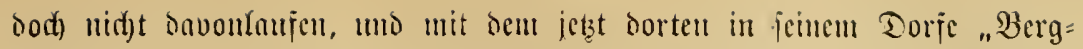

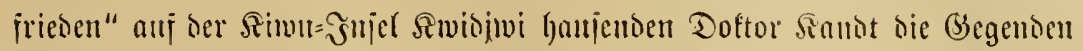

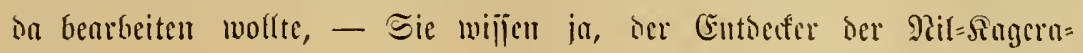

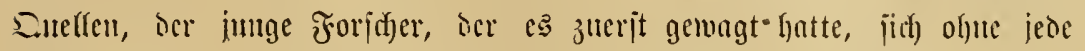

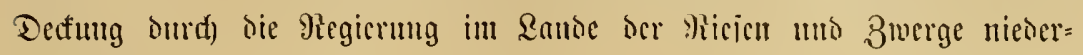
zulafifen ..."

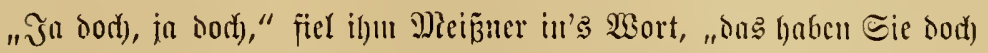

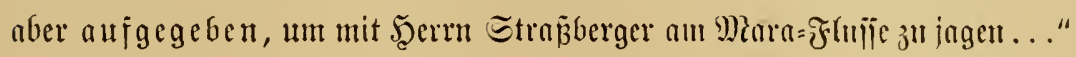

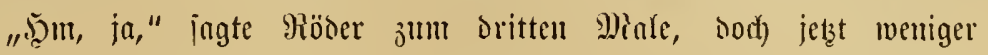

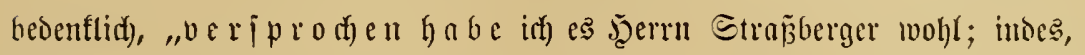

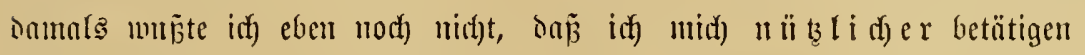

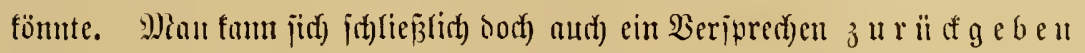

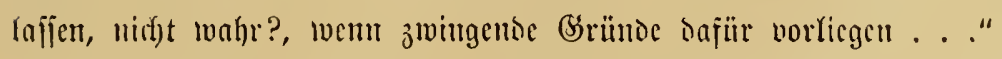

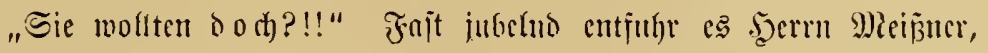

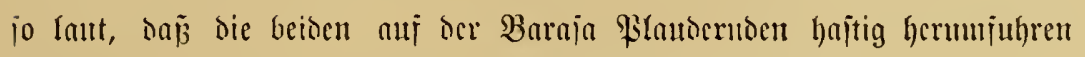
umo nad) den unten ill Gorten Stehenteibenden ansblicten.

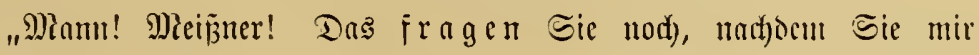
bargelegt haben, tañ jou it niema noch eine Frage iein, jo wie wir mit einanocr itehen? llns

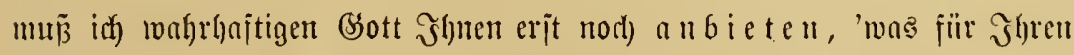

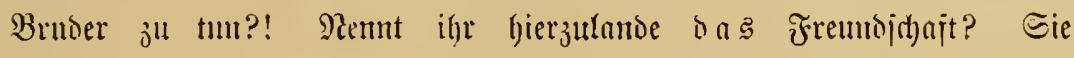

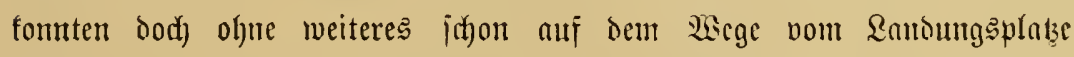

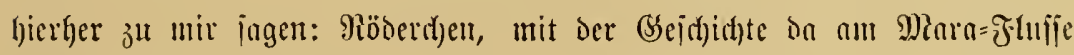

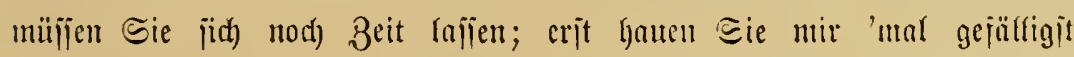

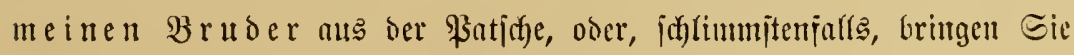
die Serle, die ifn ermordet haben, in (Eijen nad) ber Boma!"

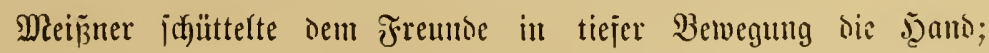

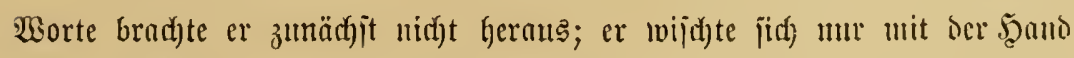

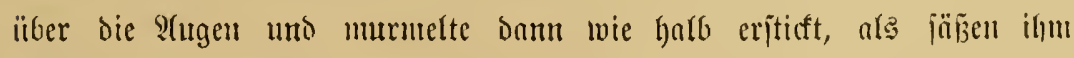

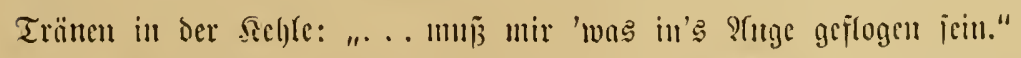

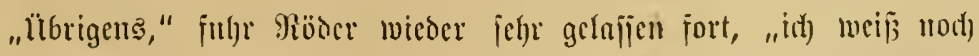

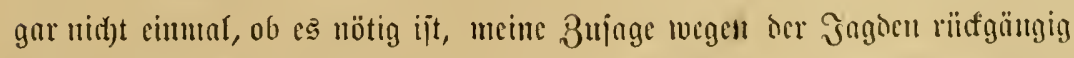

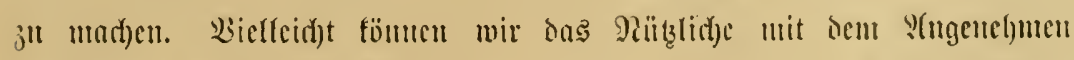

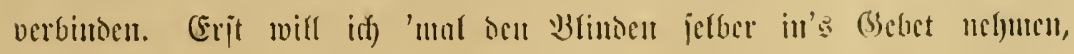




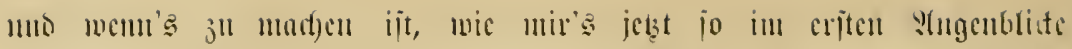

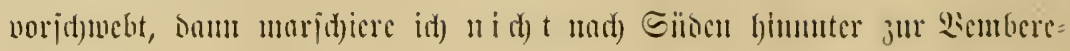

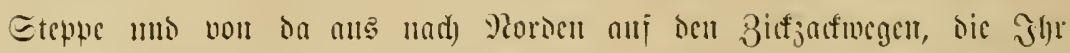

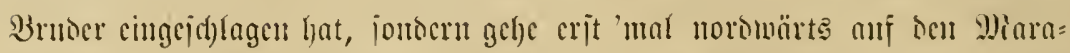

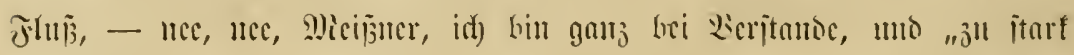

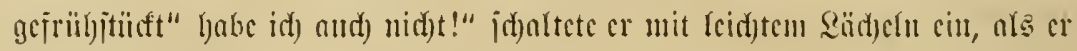

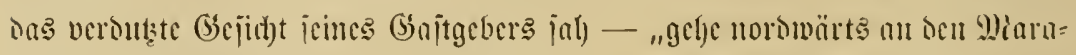

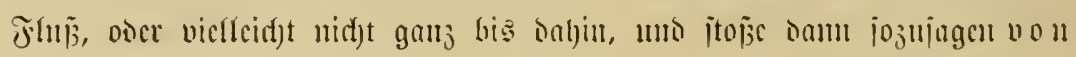

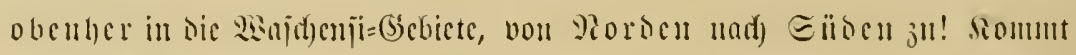

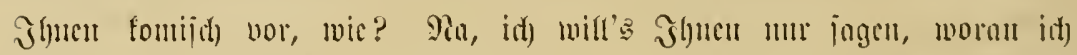

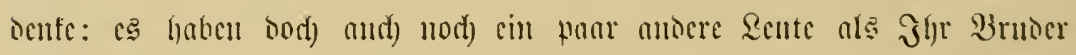

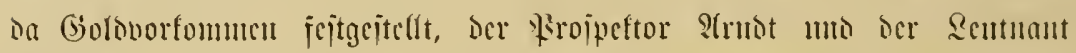

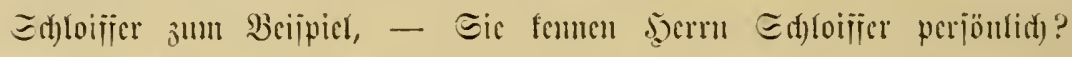

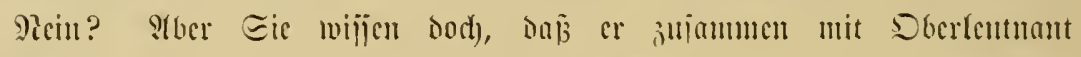

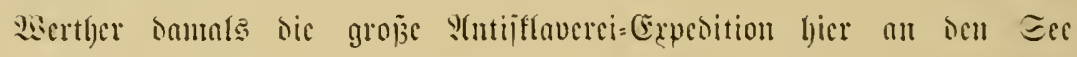

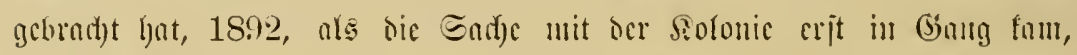

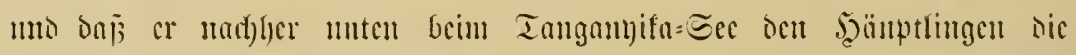

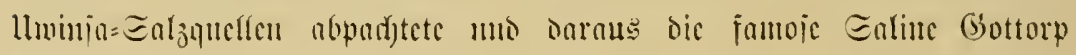

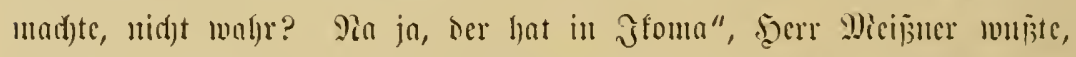

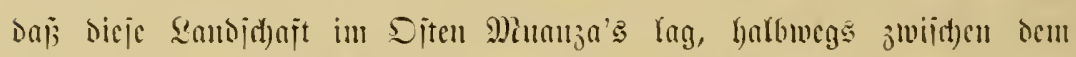

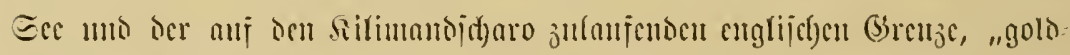

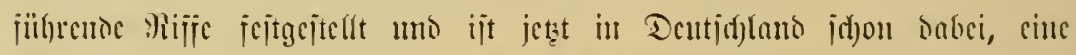

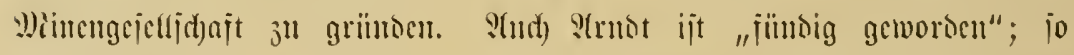

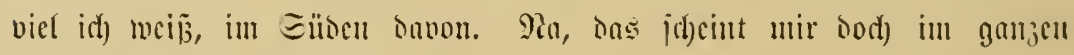

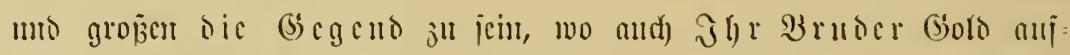

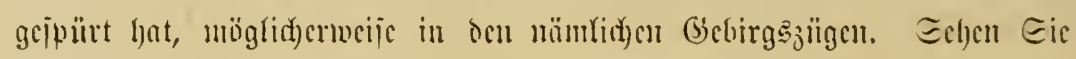
j c ţ $\mathrm{t}$ ?

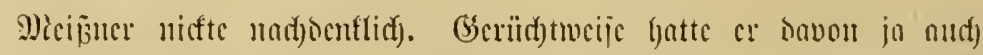

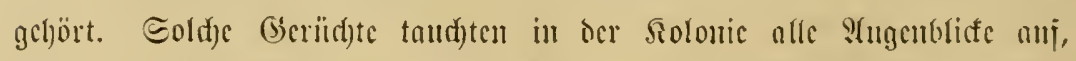

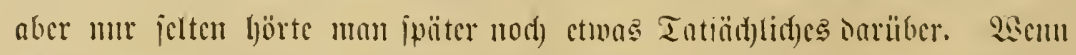

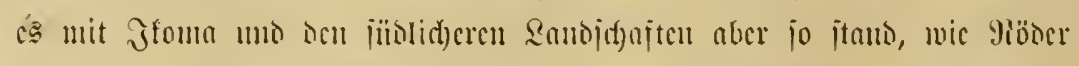

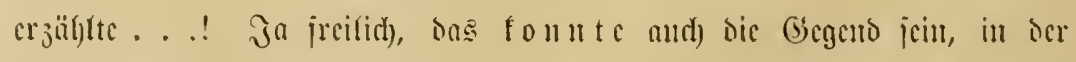

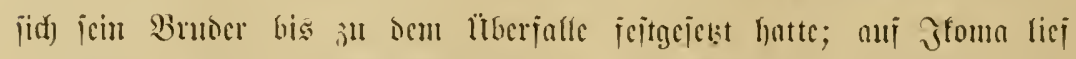

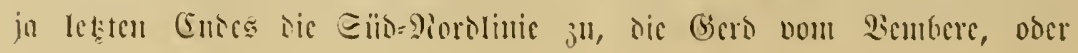


von ben Sambidaften Turu umb Jramba aus mach Porben jul hatte

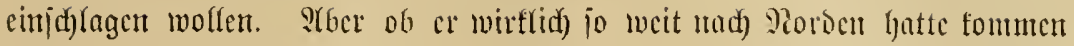

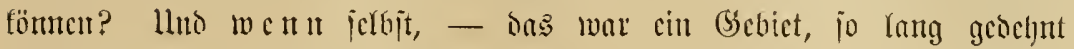

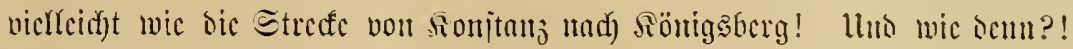

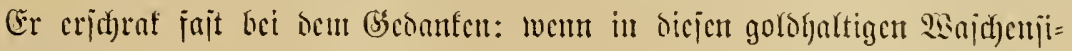

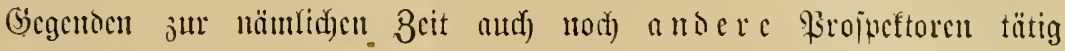

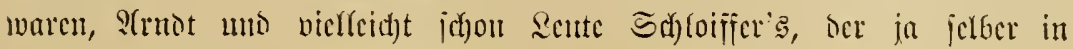
Europa jein joffte, went überhaupt borten (Solojudyer mit ifren jarbigen

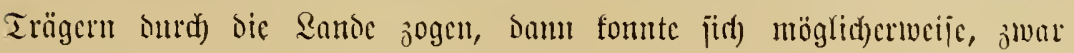
nid)t die Mefoung bes Brinton, wohl nber was bie Poitthoten an

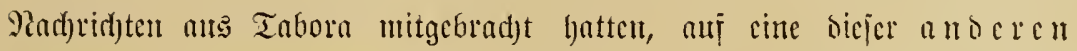

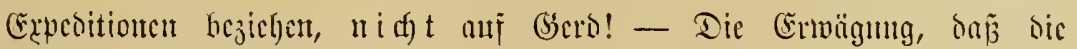

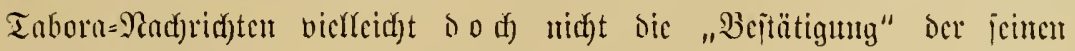

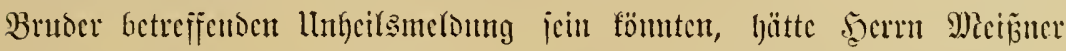

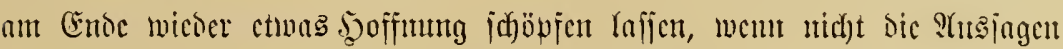

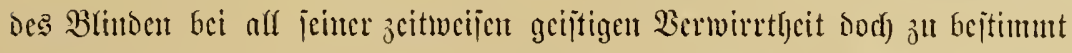

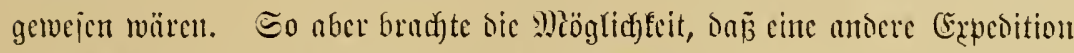

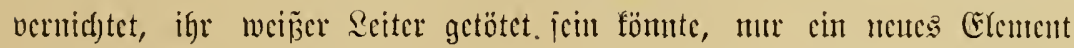

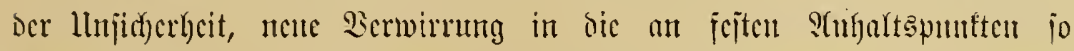

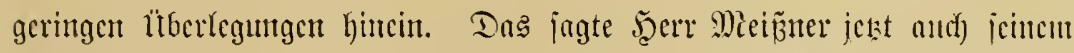

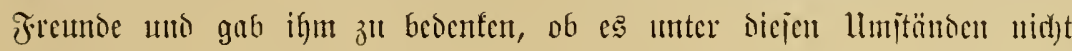
Dod) bas Geratenjte jein wïrte, den 2 seg Gerb's bolt Sï

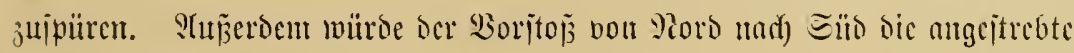

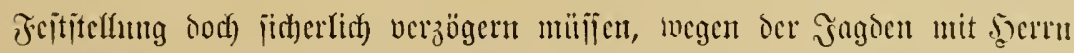

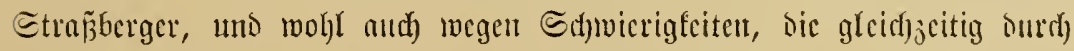

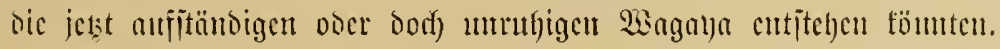

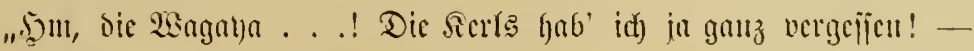

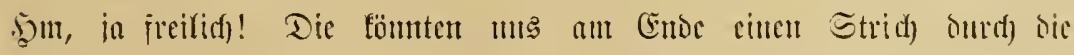

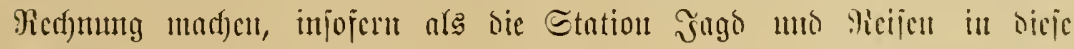

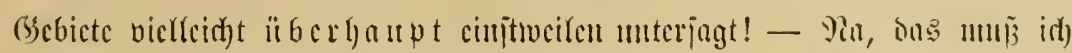

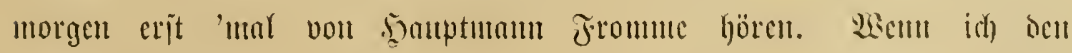
mshenzi kipofu gejprod)en lyabe, uno mir cinigcrmajen flar darïber

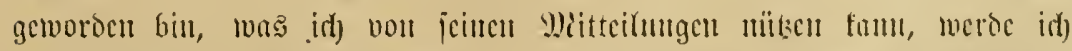

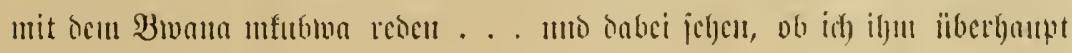




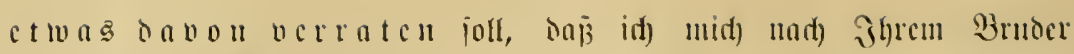

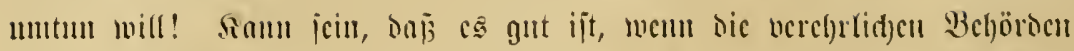

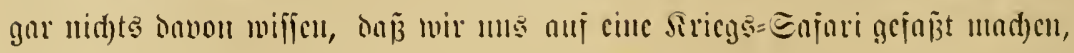
sic jic jelber juzeit nid)t muterne.jmen fömen mo Priuntlenten nid)t gejtatten wïrocn! - Seber Davon Inorgen meldr, utein Befter. Segen

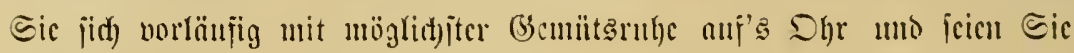

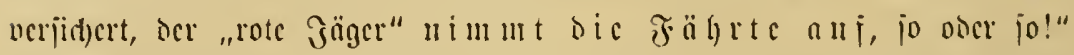

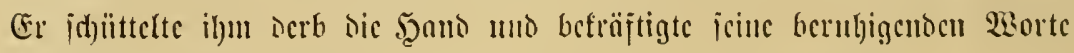

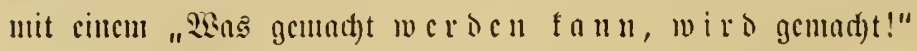

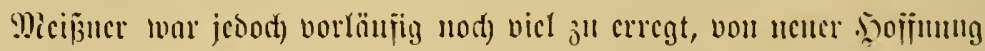

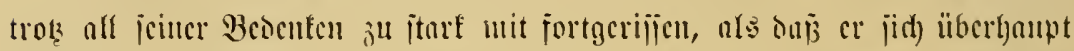

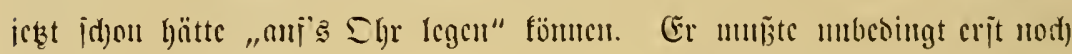

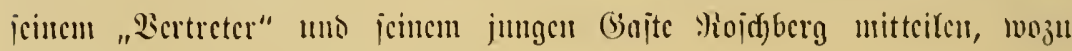

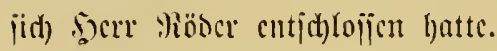

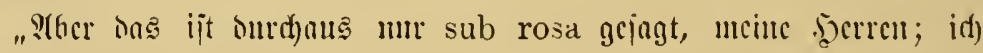

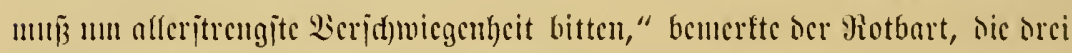

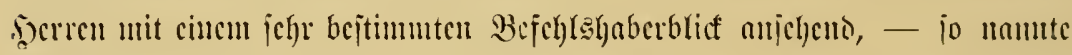

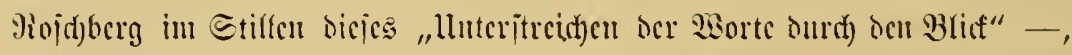

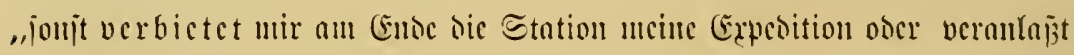

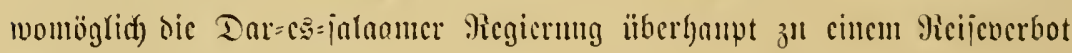

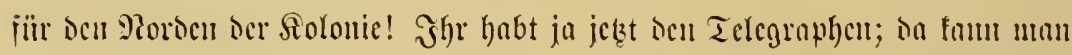

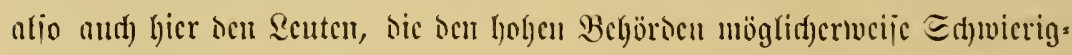

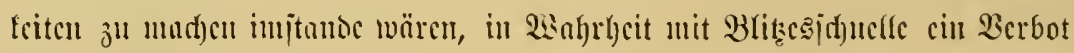

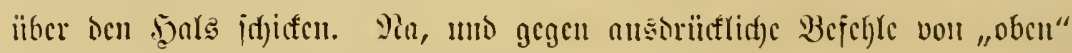

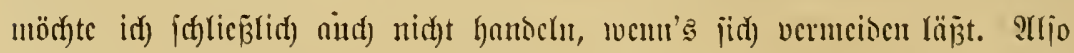

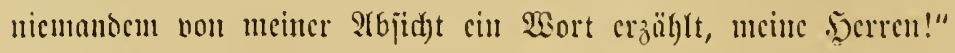

Serrn v. Rojhberg crifticu bie Gelegenbeit gïnjtił, ocm neucu

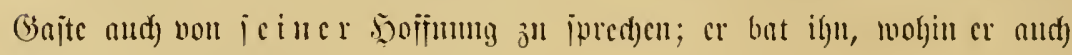
gch), if)n mitjuแchmen.

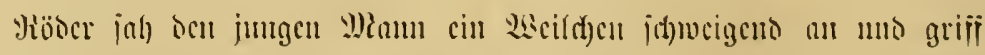

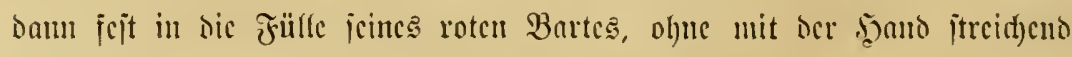

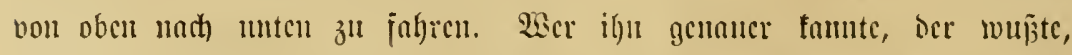

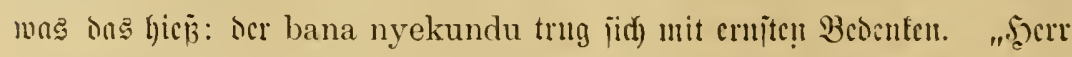

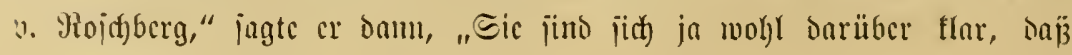




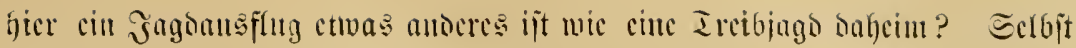
menn mir's mur unt Ticren, nid)t aud) mit Micujd)en ju tun befoumen,

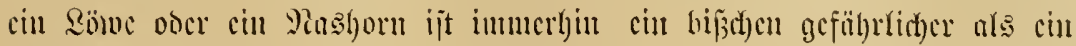

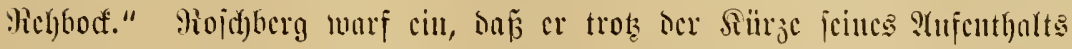

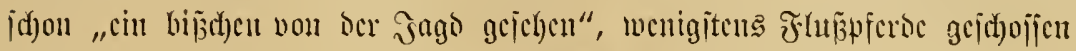

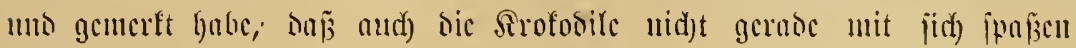

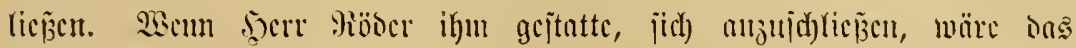

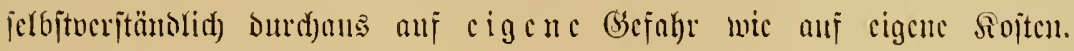

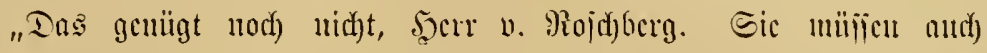

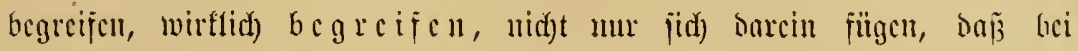

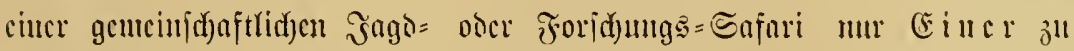

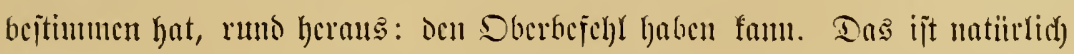

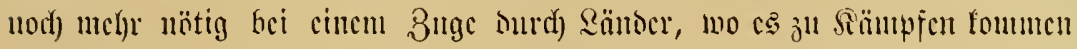
fanı. S(ber, men Sic jid) utir untesingt unterjtef(en moffen, mir aud)

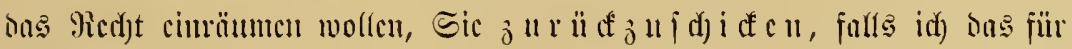

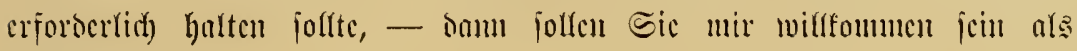
Heijegenojic."

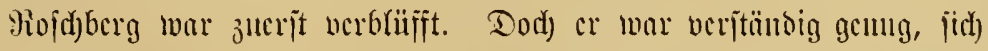

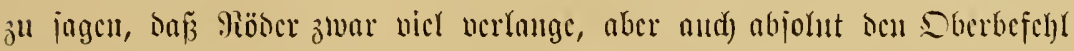

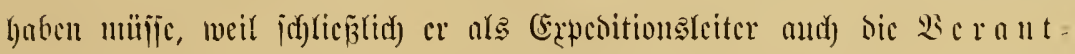

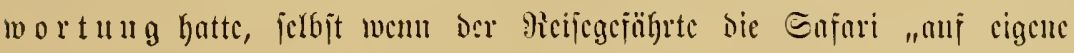

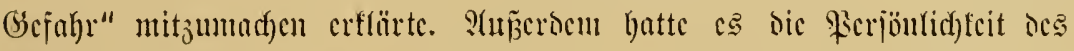

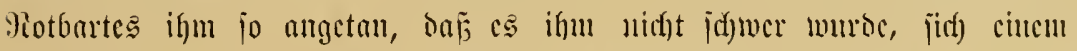

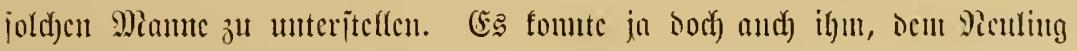

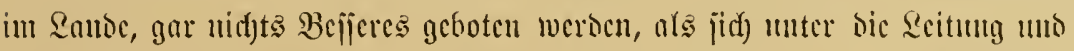

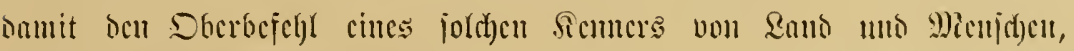

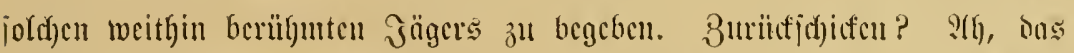

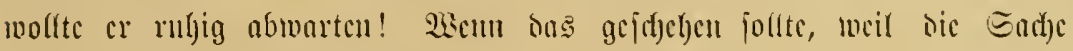

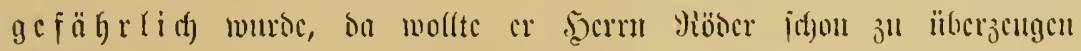

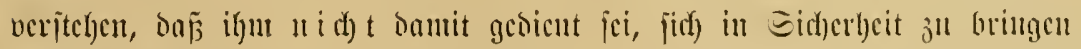

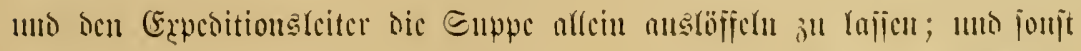

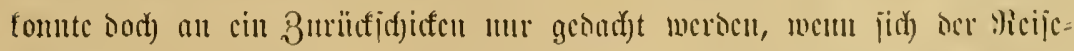

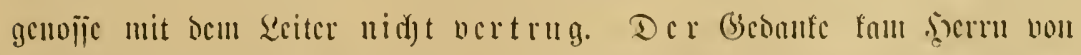

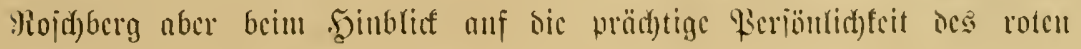




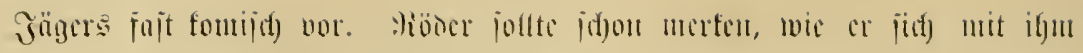

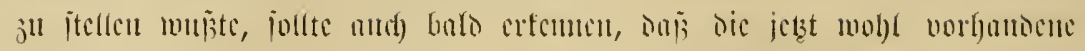

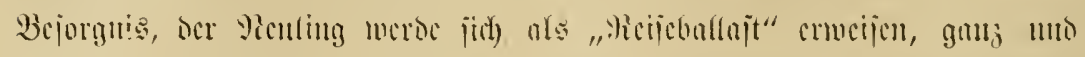

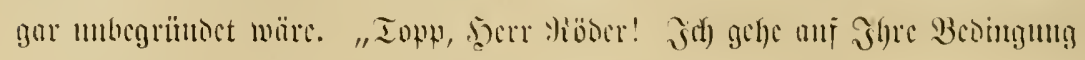

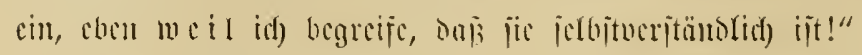

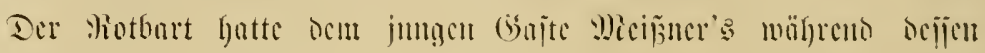

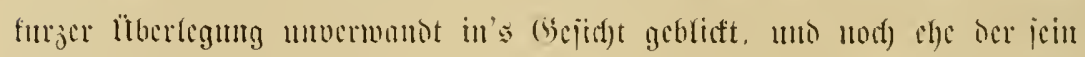

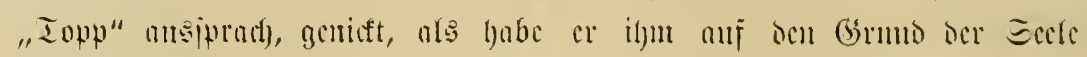

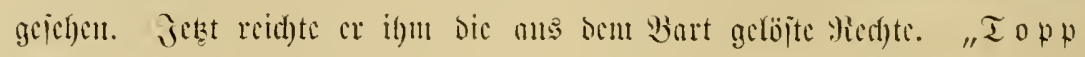

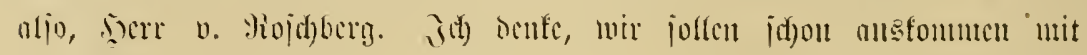
cimutior." 


\section{Achtes Kapitel.}

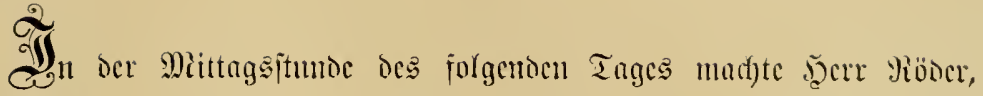

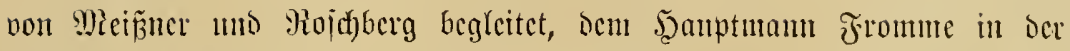
Bouna jeine Stupwartung. Sbertentnant Strömer war jefon gleidh nach)

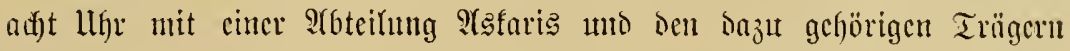

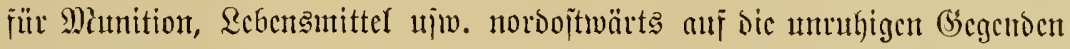

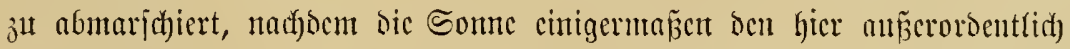

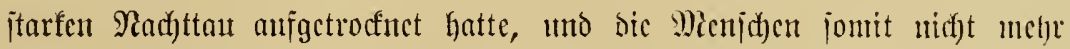

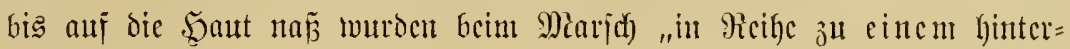

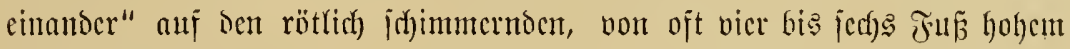
Brraje gejäumten 2 egen. Dorh Der bana mkubwa wat trokzocm erịt

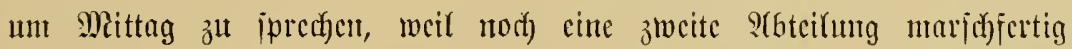

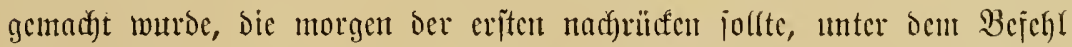

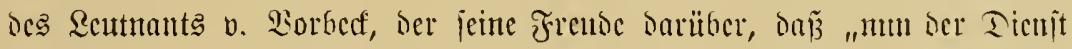
Dod) endlich 'mal ajrifanija) werben wïrbe", gar nicht ju verbergen tradfete.

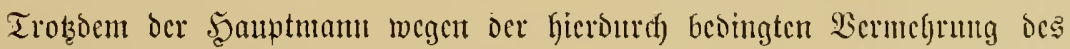
Dicuites jtarf in Pripruty genommen butroc, empfing er bic .jerten bod),

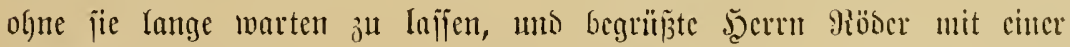

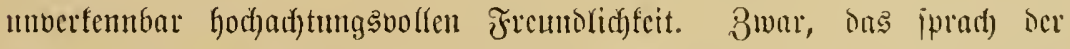

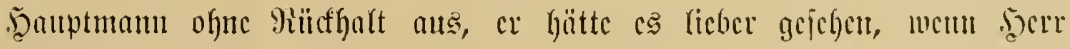

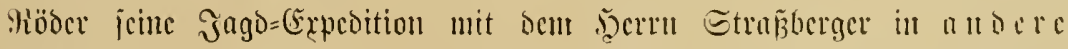

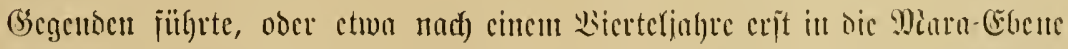

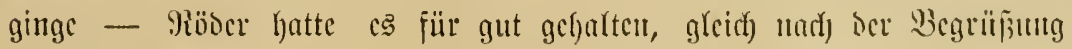

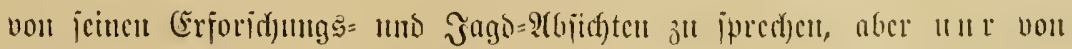

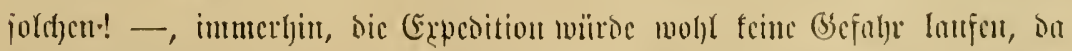

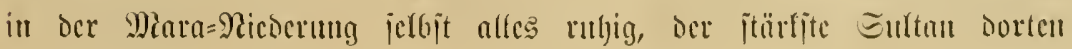




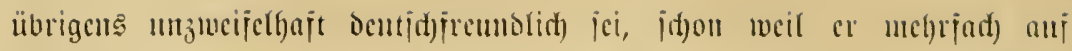

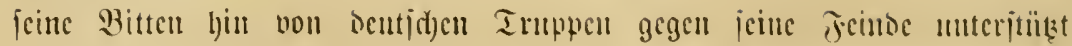

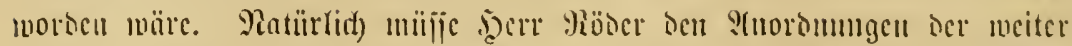

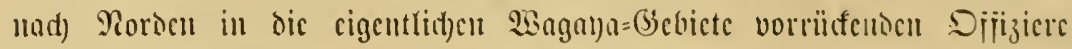

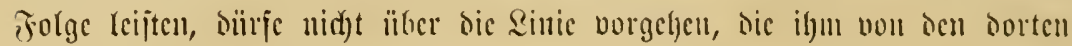

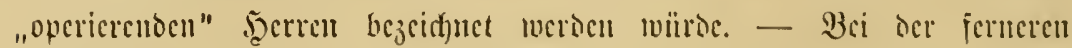

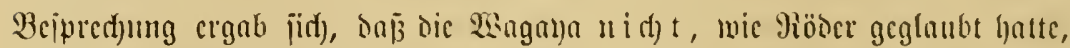

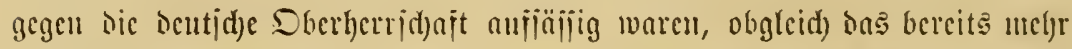

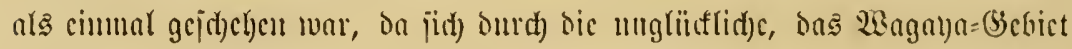

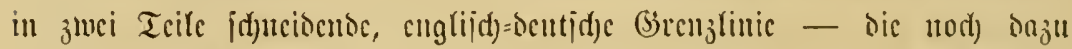

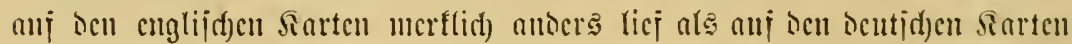

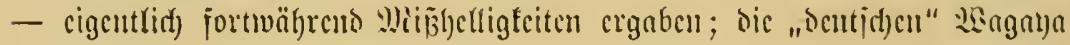

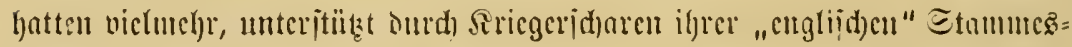

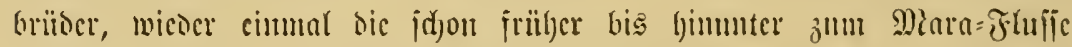

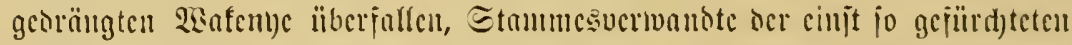
Maijai; rocnigitens cunige ber nörolid) vom Maara belegenen Dörice hatten

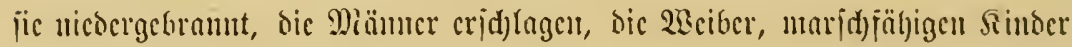

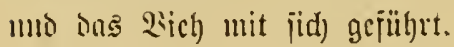

"Som," meinte Möscl ba, "sam but aljo je(bjt bic Dod) red)t

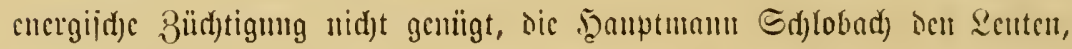
id) glaube 1901, hat zuteil merten laijen!" Er fügte fïr ben mit ien

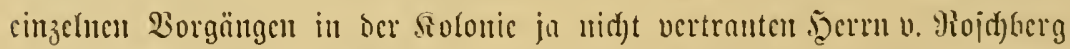

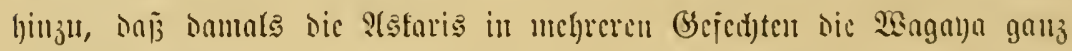

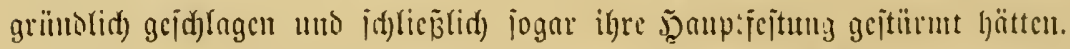

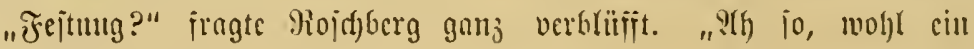
verpaliadicrtes Dori! “

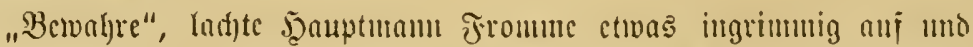

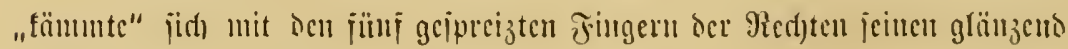

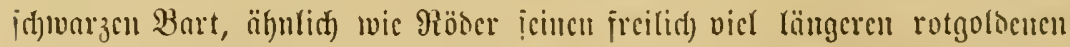

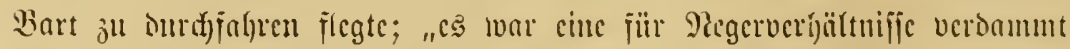
gut uno jtarf augelegte reguläre Fejtung, bicjes Siporosiva, uno cin

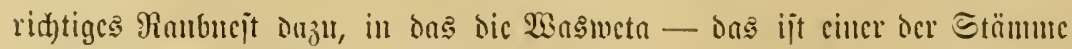

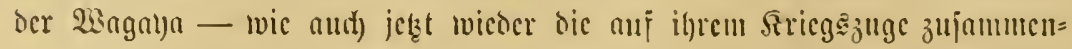

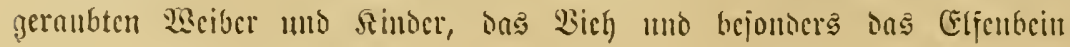


ihrer unterlegenen Fscinoc fdjleppten, notabene, wemn fic bic Befangenen 3mingen founten, die Stelfen zll nerraten, wo tos Elforbein vergraben

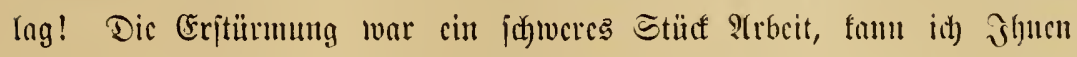
jagen, - id) hab' jic nümlid) mitgemad)t! Bon Rialijuon feinc Redc; bajïr aber cin 700 Micter Langes uno bieflecidyt 500 Meter breites :Hed)tect

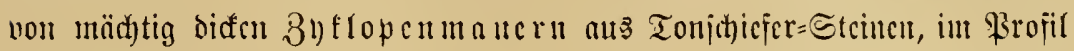

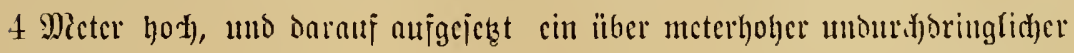
Dornocrhau! - Bollen jufriesen fein, lvena jidj's nid)t aut) ickzt wicocr

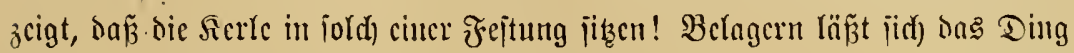

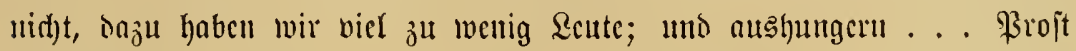

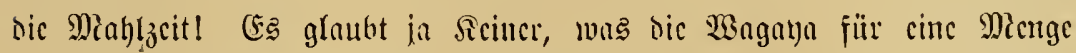

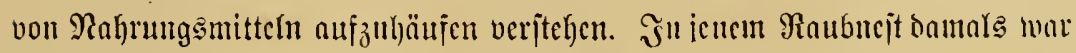
io viel Mitamn, Miwile und Miais aufgebäujt, vom Bieh ganz nбgcjchcn,

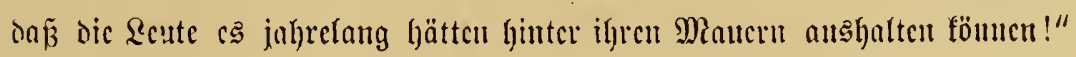

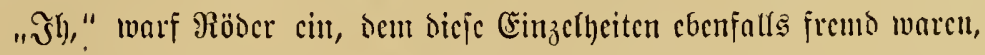
"Das war ja Daun wic bei ben $\mathfrak{B a g o g o}$ frühycr, - llgogo, ફ̧crr v.

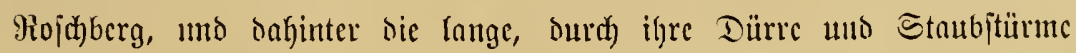
hcrüd)tigte mgunda mkali, jめ)(imme $\mathfrak{B u ̈ i t e ~ n u f ~ D e u t i d ) , ~ U l g o g o ~ l i e g t ~}$ ctwa in der Mitte der Solonic, zwifiden Mipuapua uno Tabora. STls dic

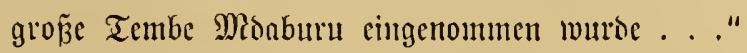

"Misaburı?" fragte Şauptmann Fromme ein wenig jubcifelus,

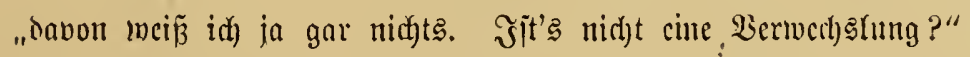

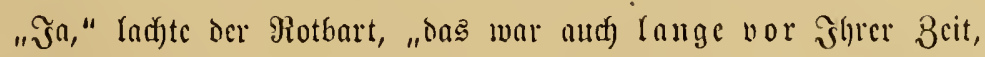

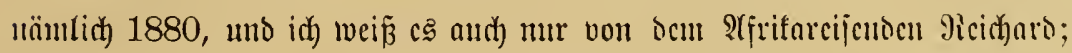

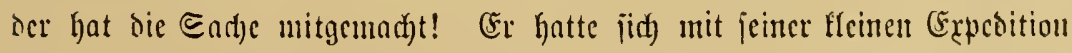

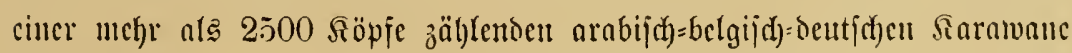

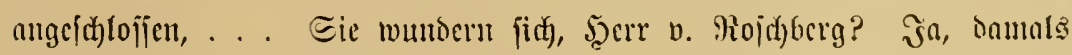

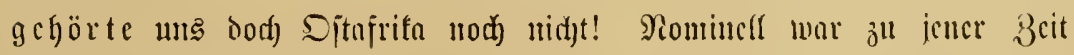

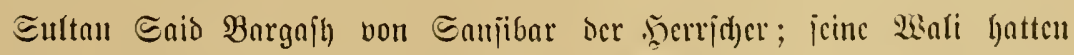

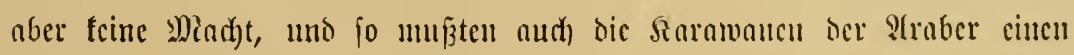

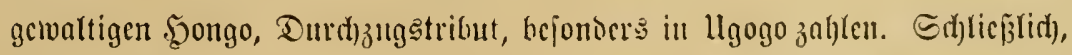
als bic Erprefifungen z" arg untroen, unterjtïtżte Enio Bargafh ciucu

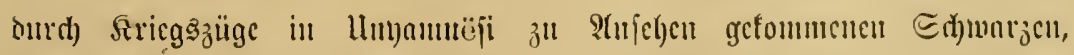

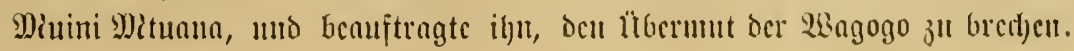




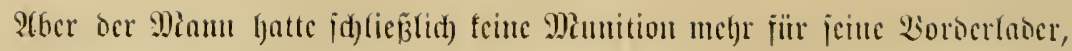
founte aud feine faufen, unto jo bat er bic vorbiut erwöbute gemijate

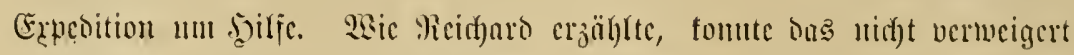

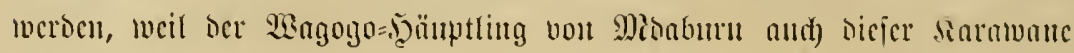
ocll 2 seg veriperte. Sumz mo gut, dic riepige Tembe - bas ijt cill

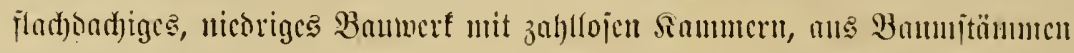

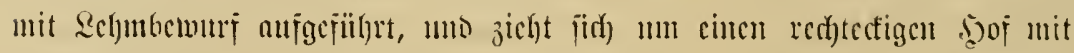

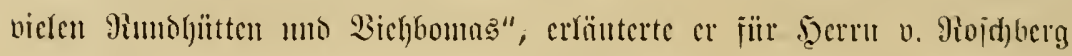
- "dicje 300 Micter brcite uno 400 Mieter Iantge Iembe mit Brnaber,

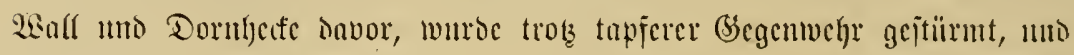

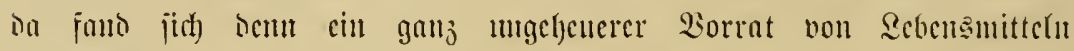
a!tigcitupelt! Dic $2^{1 / 2}$ Taujeno Sente icr vereitigten siaramanen lebten

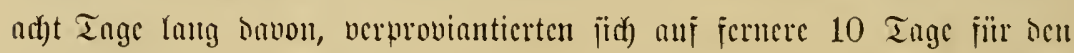
Miarid) butch die Migumo mfali, vou allen Sciten itröuten nus ocn

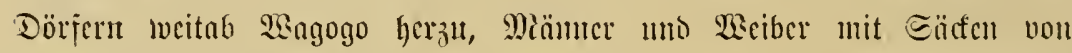
Rintocrfellen umo Traglörbell, 14 Tage fang jeoen Tag viele humtort

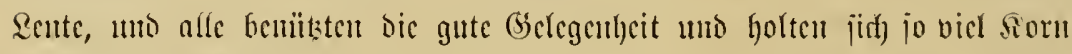

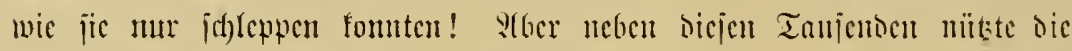

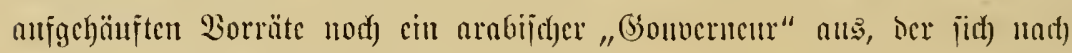

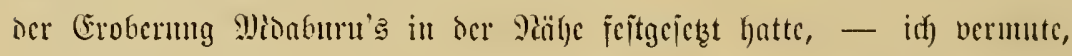

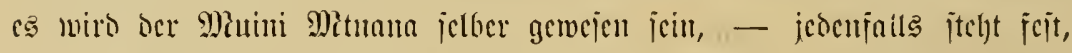

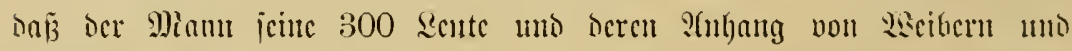

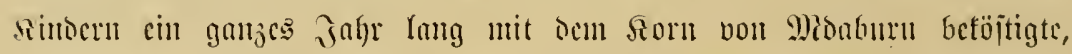

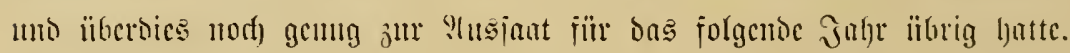

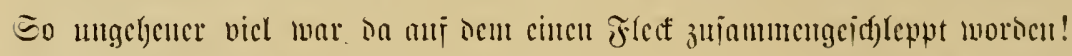

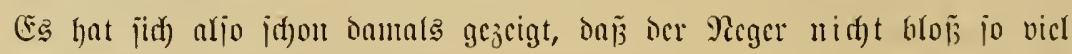

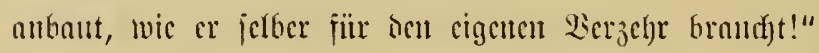

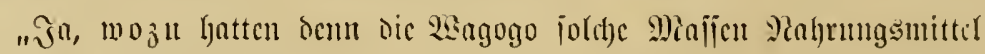

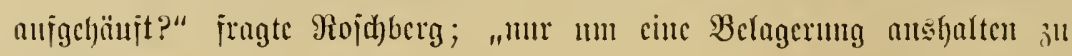
Łöแnen? ?"

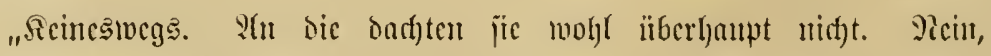

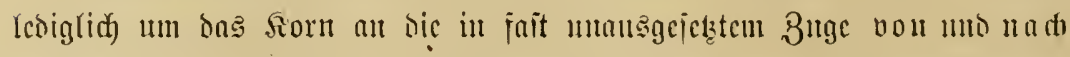

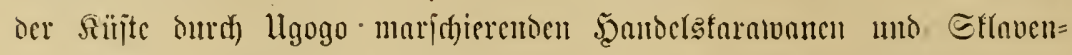

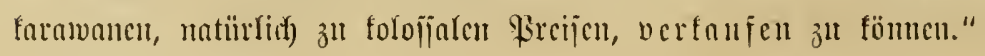




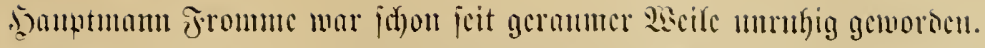

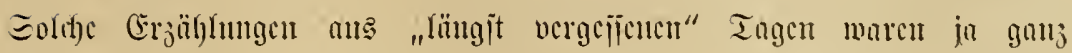

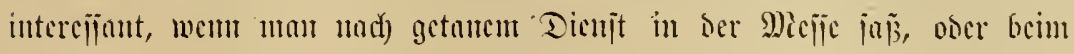

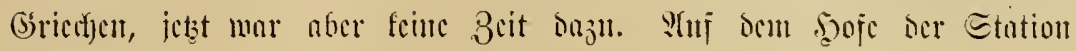

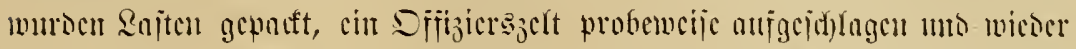

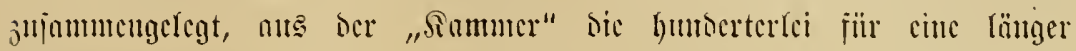

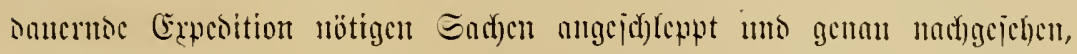

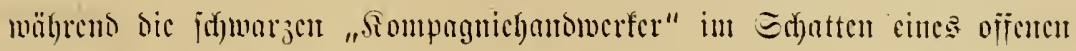

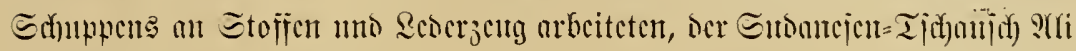

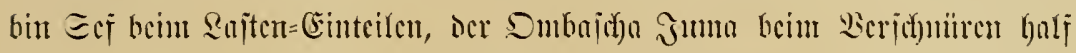

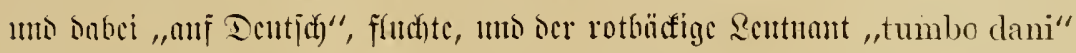

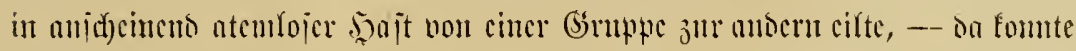

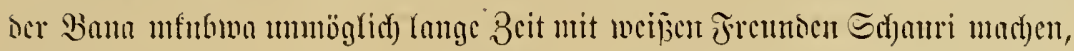

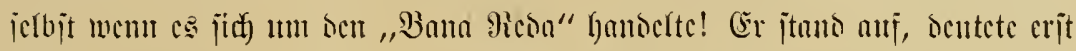

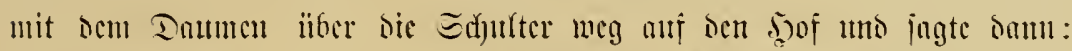
,

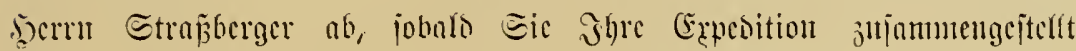

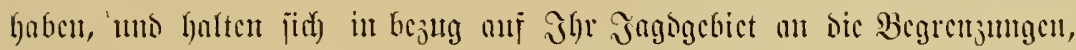

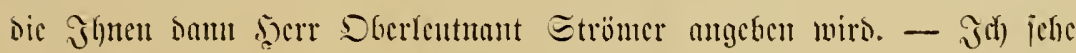

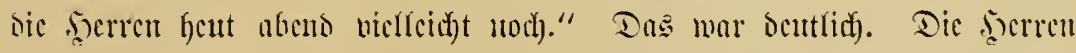

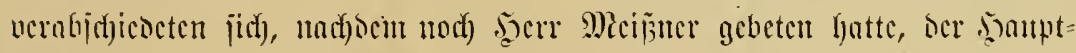

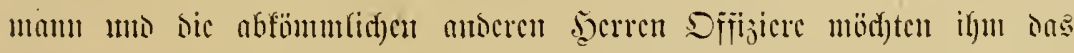

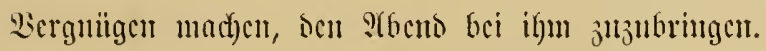

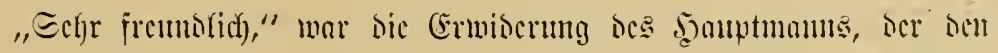

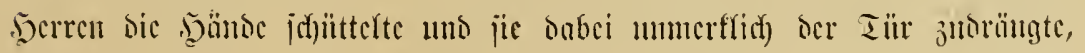

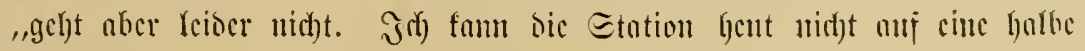

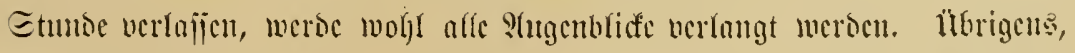

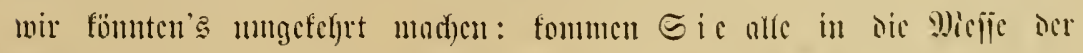

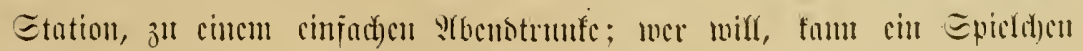

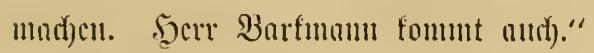

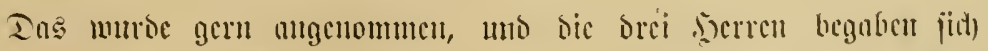

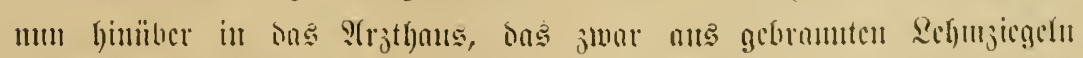

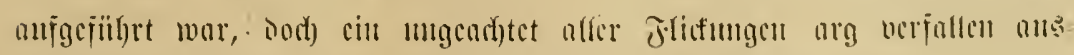

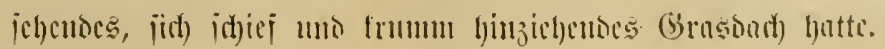




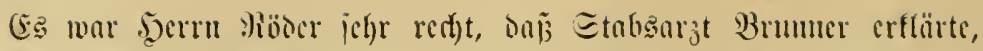

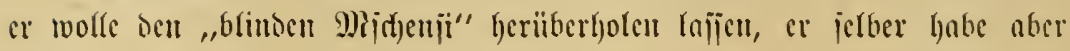

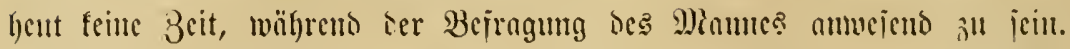

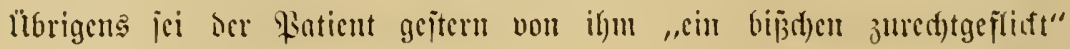

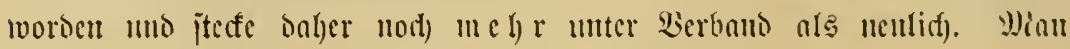

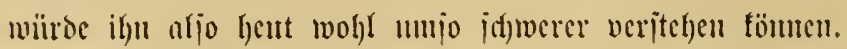

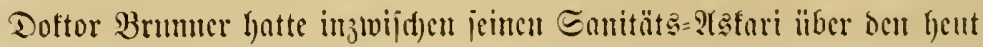

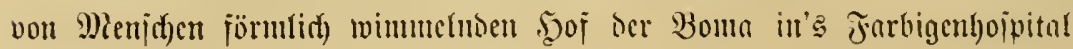

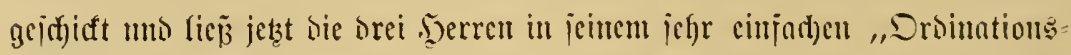
jimmer" allein. Sie hatten nid)t lantge ju warten.

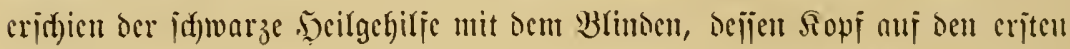
SHblicf wie eine ganj non Binoen mo Bandagen umbüllte Sutugel aแsjah),

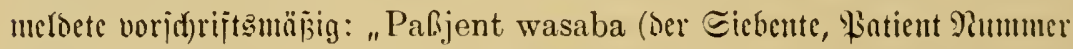

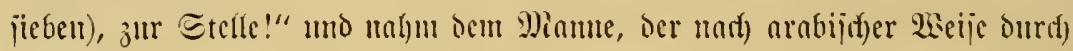

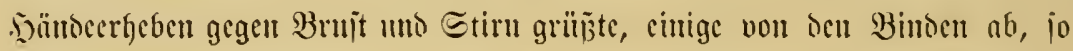

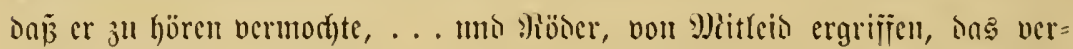

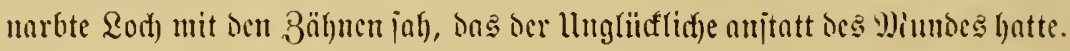

,Sicr ijt cin Freumo von mir unt meinem Brntor, Barnfu," rescte

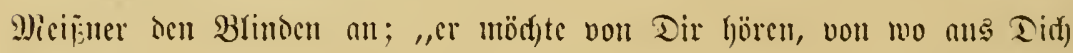
Dein berr ju mir gejants hat. Dul hajt jiffer jeffon vout dem bana ndevu nyekundu gehört."

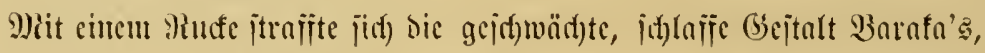

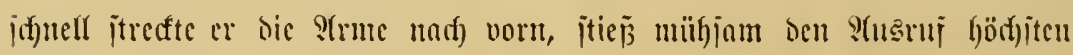

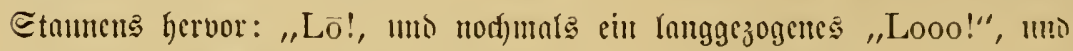

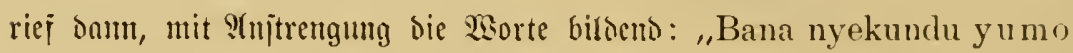
(ijt er hier trin, im 3iumuer, ber rote berr)?"

"Ndivyo (ja walgrfid)), id) bin hier orin, ben ihr ben roten ş)errn nemnt!" erwinerte ?iöder.

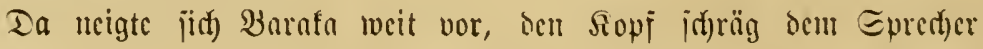
3tgewant, wic um mit bem cinen Shre befjer bören j" fömen, แแ⿰

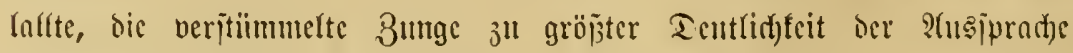

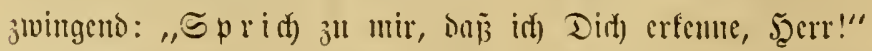

Einigermaßzen eritumut

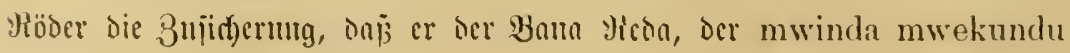




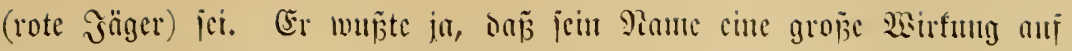

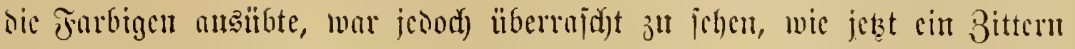

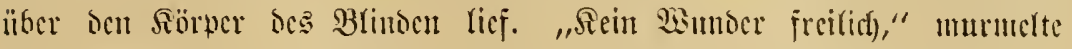

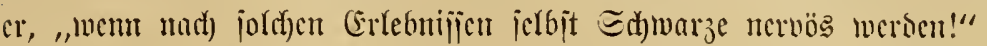

Mit vorgencigtem Sherförper, jufiebenoen Trittes fum ser llnglïct=

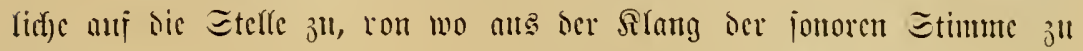

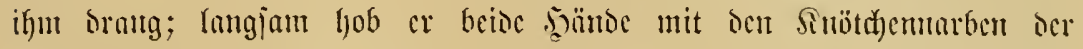
Einju=Bijic mo ton veritimmelten Fingern, uno bat faum veritündlid):

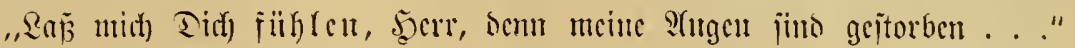
"Sionm, fühlye, Burafa!"

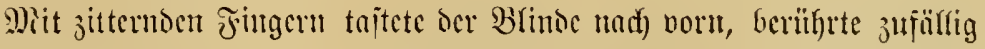

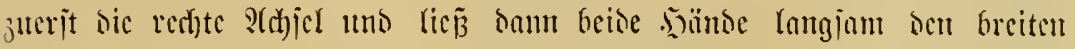

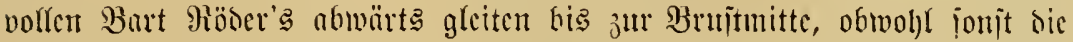

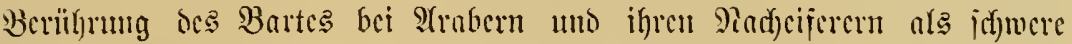
Bercisigung verpönt ijt, bann neigte er jich), filj̈te sen Entum bes Bartes,

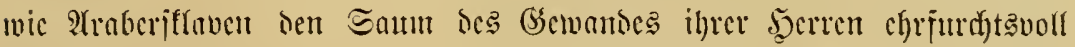

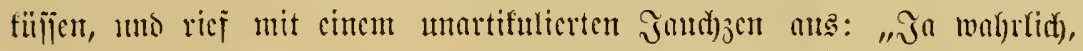
bei Shut, ocr Teint Tage lang madyen möge, D a bijt c s, mein Bann

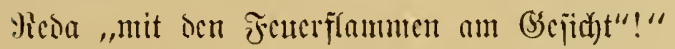

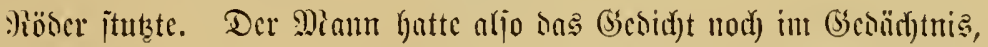

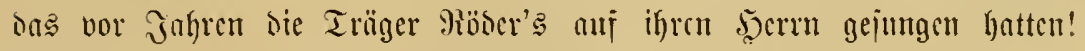
War biejer llnglïeffiche vief(cidf)t bereinjt mit ifhut gereijt?

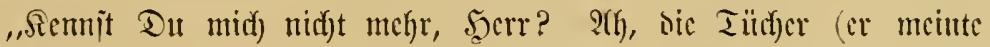

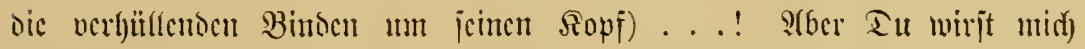

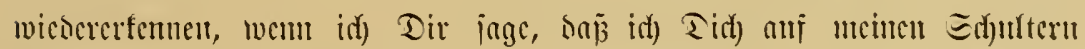
burd) ben lltanga getragen babe, unt wir beise fajt von bem sirofosil gejrejīeı morten wären!"

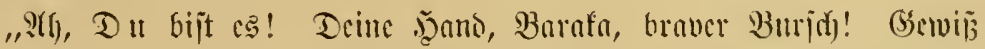

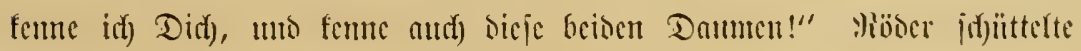

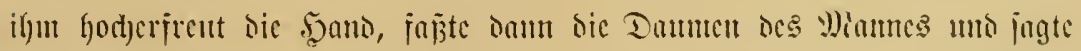

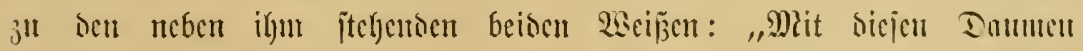

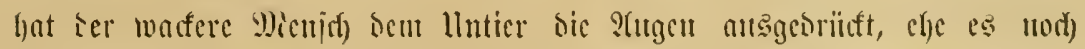

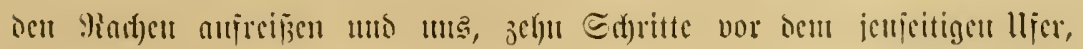

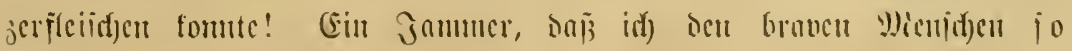




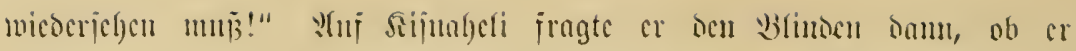

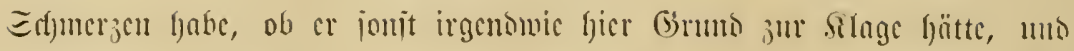

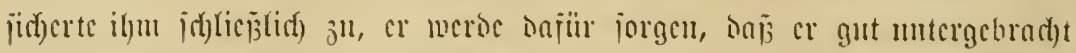

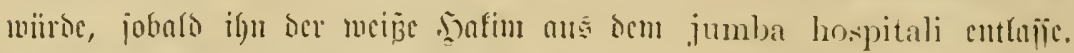

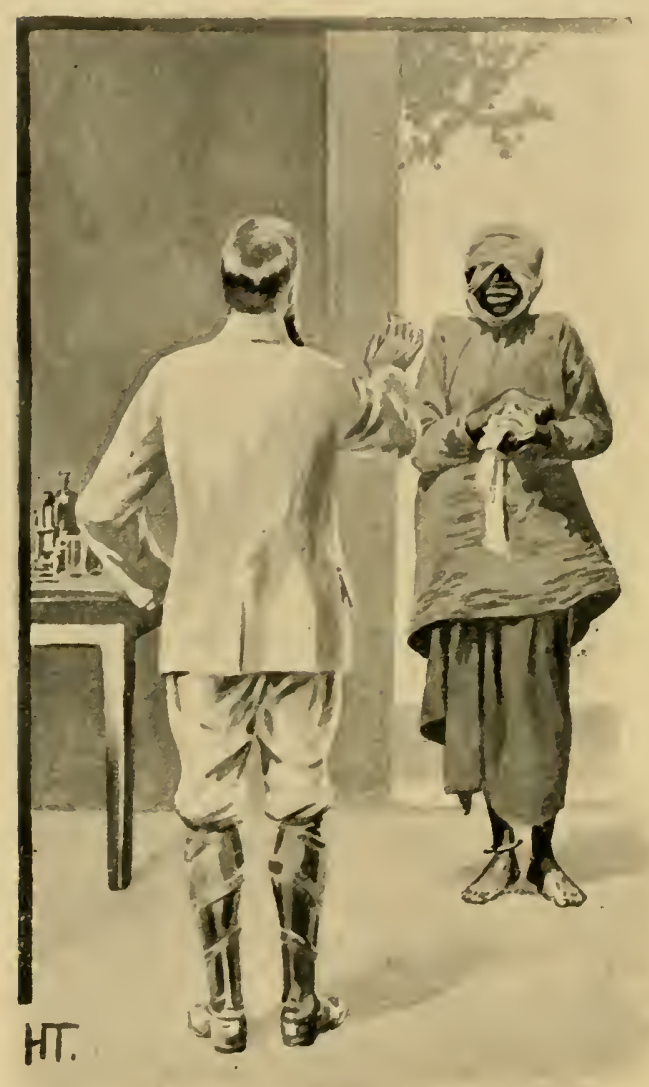

Iody Buarafo idjüttelte ten Sopf. "9imm mit) mit Dir", hat cr, "mem Du Drine Eajari antrittit." (Er brad) plöbsidid) ab; ifm jiel molyl cint, Daj ar jelst,

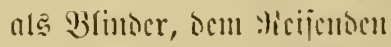
feme Siculite feijten fömuc, metse: nle Irïger nod) im

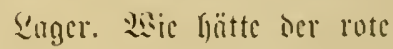
Jäger ifjn alio mitucf)ucu fönucu! Gianj traurig licis

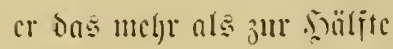

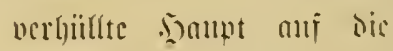
Wrujt juffus. Iort in= jmijot)en batten WiciB̈mer แmb giöser ciuten Błlidf $g c=$ medjelt, umo saranifyin jagte scr :hothart jull jenbigen Ïtherrajd)ung of "Du jorljt mit mir reijcu, Barafa! Dod) böre, wa

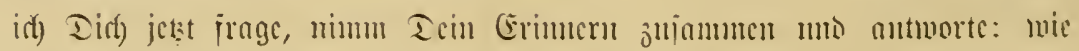

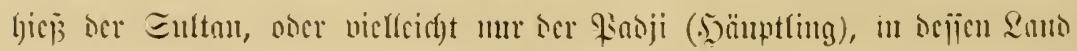

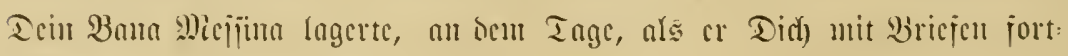
idjicfte jul icintem Buntucr!"

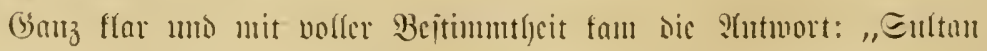
Milofonic, won : : aisa."

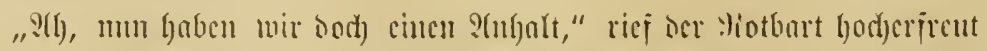

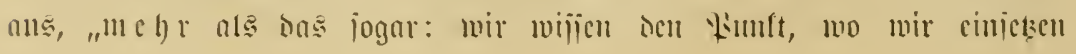




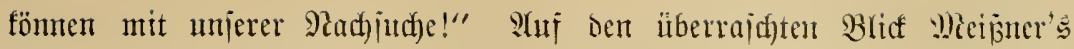

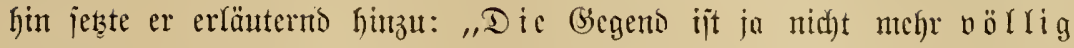
unbefant; bie Mibuga Yaisa hat Sentnant serther wentigitens an ifrem

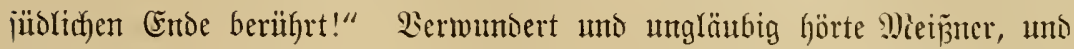

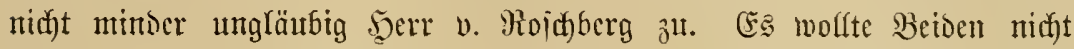

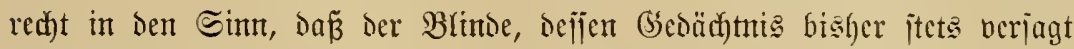
hatte, mun auf einmal imitande jein jollte, eine bejtimmte, braudfbare

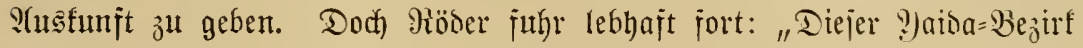

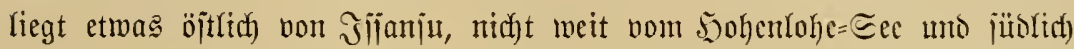
vom grop̃en (Enajît=

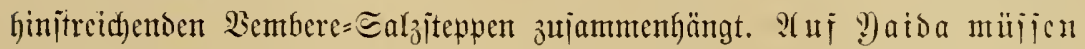
wir unter alfen Umitänden zu marjhieren, ob wir bie Sache mm von Poroen her angreifen, ober ob wir von Tabora aus norobijtlidf

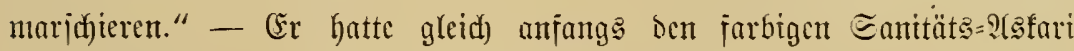

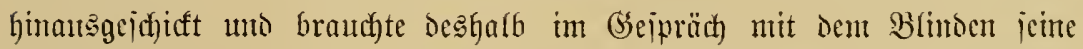

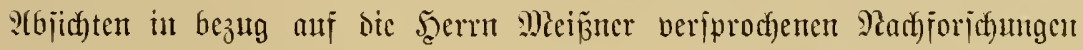

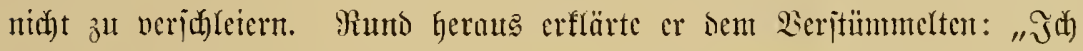
nehme Dich mit auf bie Safari; wem's nidyt anters geht, anj cimem Fiel ober einem Iragitulfl; benn Du jollit une helfen, Deinen Bana Meijina ausfintsig zu madjen, oner, falls er nidft mehr lebt, jolljt Du

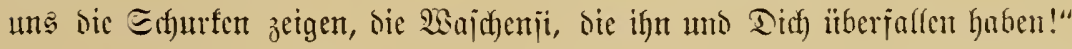

Das hätte er lieber nidft jo unvermittelt jagen jollen; senn bie Freutse regte Barafa jo auj, baj jidf) jeine (sedanfen wicoer vermirrtert.

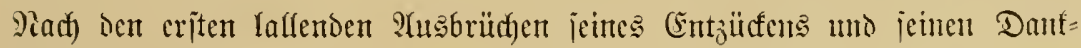

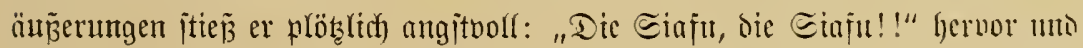
machte bie abrwehrenden, wegitreifenoen Bewegungen mit ben beänon, wic

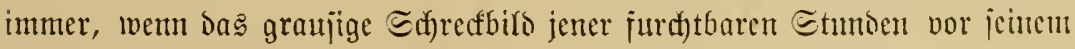
geijtigen $\mathfrak{H}$ uge auftaud)te.

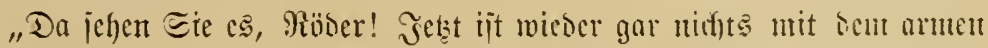

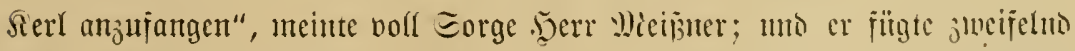

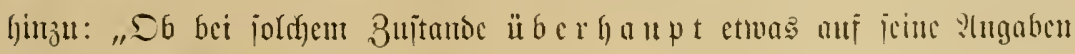
von vorfin ju gebcu iit?!"

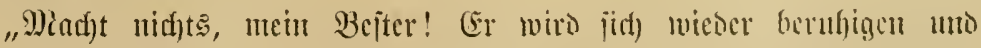

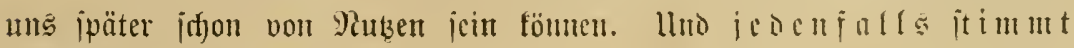




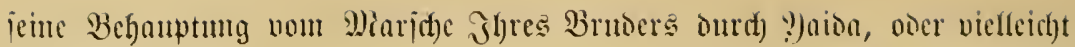

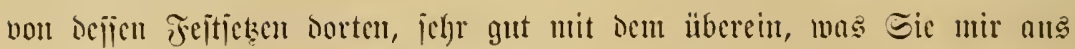

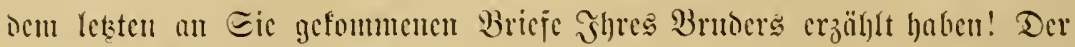

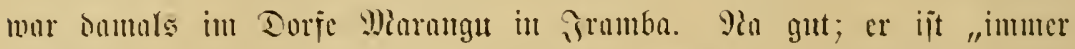

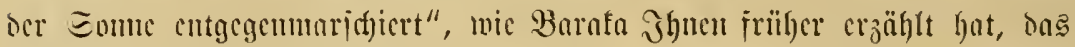

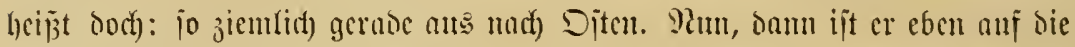

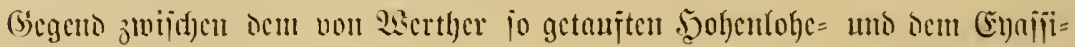

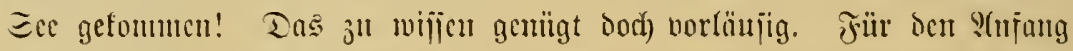

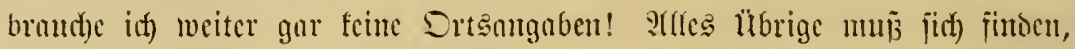
wenn mir bic Eecn erreidyt baben, - ober möglidyerweije idjon früher,

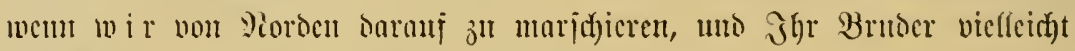
non ?:aida nod) meiter nörblid) hat jichen fömmen!"

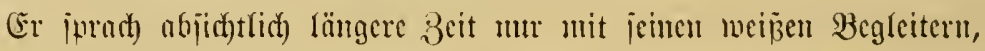

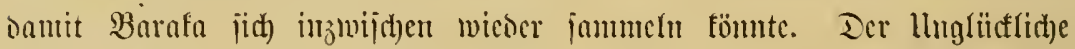

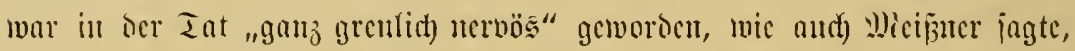
war aljo in cincm 3ujtunde, sen man bei Pegern foum jemals aud mur

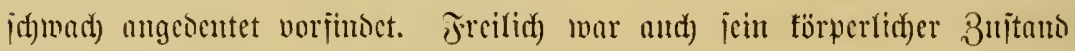

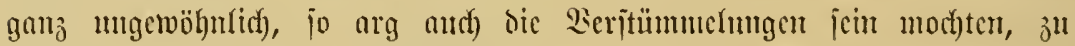
Denen granjame Sultune uno Effunenjäger manthmal ifre Spfer veromumt

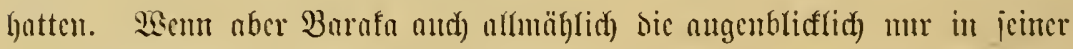
erregten Sibantajie ïber ihn herfaflemben Siaju zu verjucudfen imptande

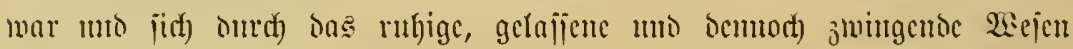

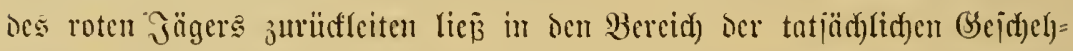

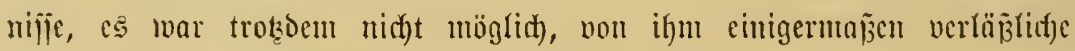
3 c it angahen zu erlangen. So menig wic jrüher gegenüber ocm .jauptman!

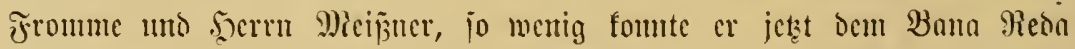

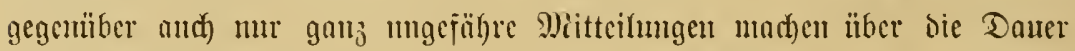
jeines Stujenthaltes bei den ihm befreumbeten Dörflern, bie ihn gepflegt, bis iie if)n mit einter gelegentlid) but(t)jichenton (Eingeborenentaramane

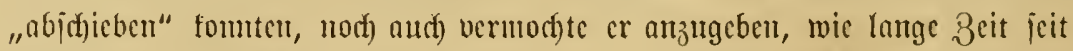

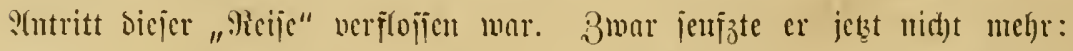

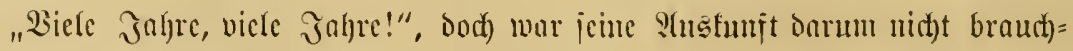

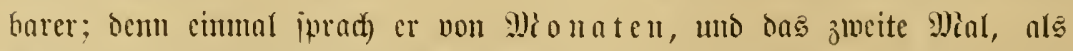

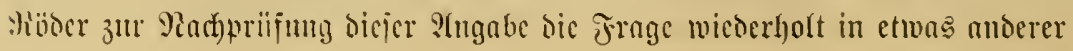




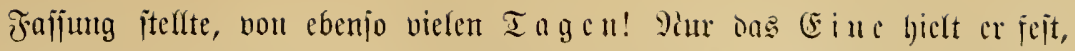

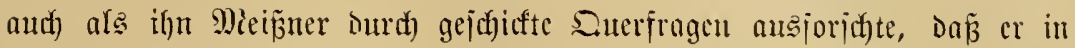
Mitale's (Dorî) juma mbili jugebradyt habe, was „ở

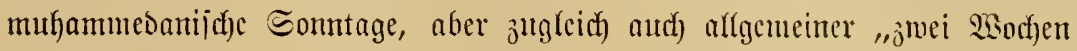

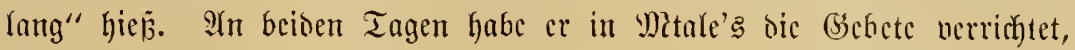
erä̈hlte Barafo, uno jïd) vorker volt eintm ndugu bes temmi bie

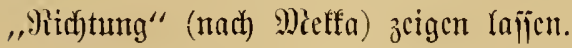

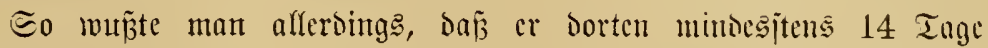
jugebrad)t hatte, vermodhte inses trotzocul bie Zeit jeit sem litberjalle autit)

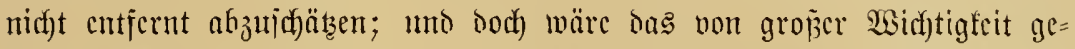
wcjen, weil man bam wenigjtens mıçähr bätte autredfuen fömtn, wic

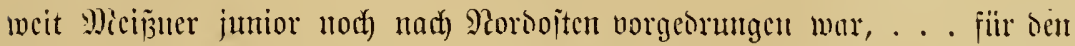

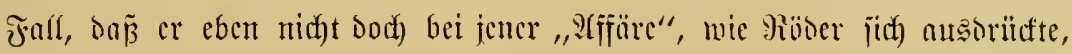
jein $\mathfrak{L} e$ ben hatte lajjen müijen!

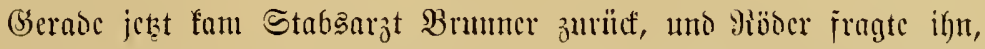

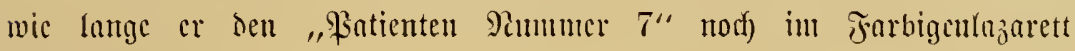
behalten werde.

"Sioumet barunf an, was idf) noct) mit ifm unathen faum. Dic flcinc

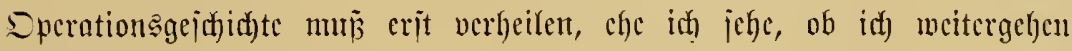
fann bumit. W a 1 u $u$ bent? ?"

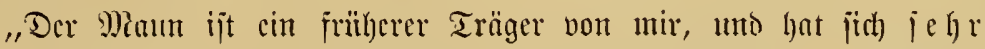

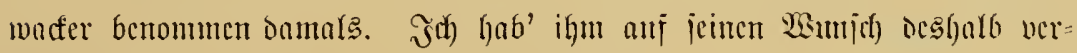
iprochen, ifn mitzınchuen nuі meine Sajari."

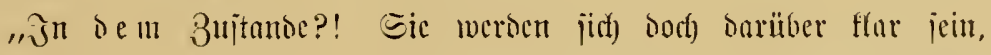

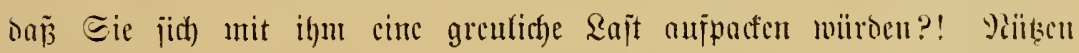

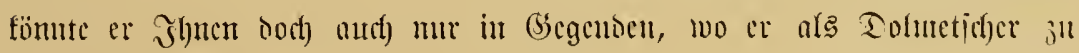
hruudf)elt väre."

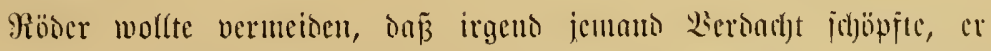

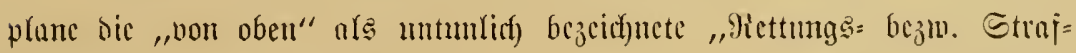

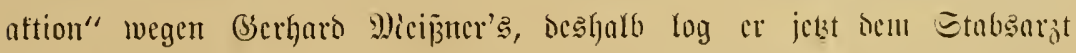

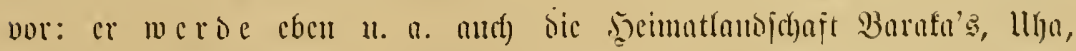

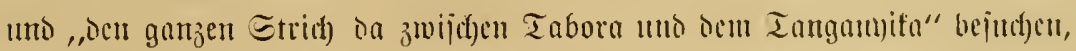

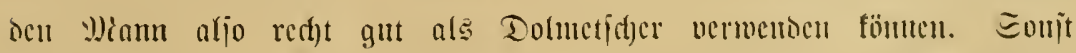

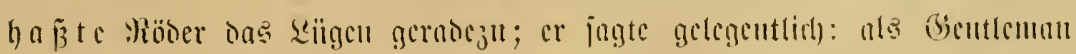




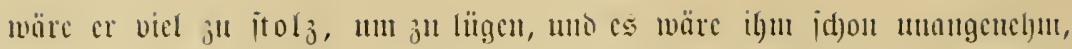

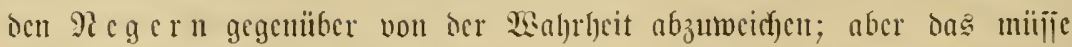

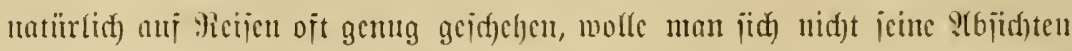

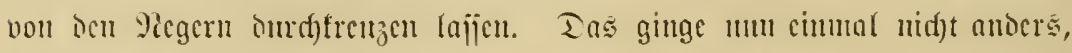

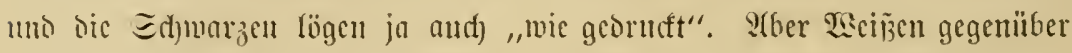

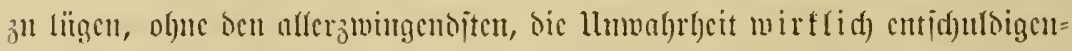

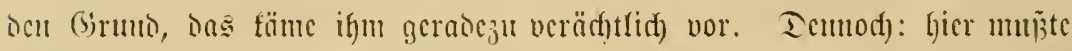

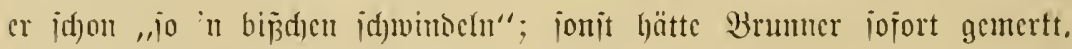

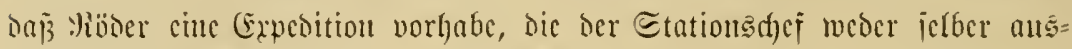

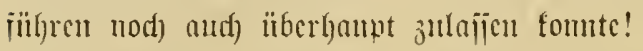

,il(d) io," meinte ice Etabsarzt, ocr jid) glcid) 3n Begim Des

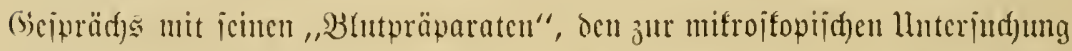

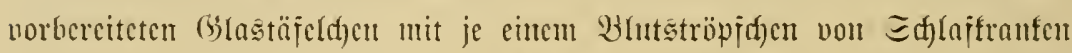
wic and non mefreren Tieren ju id)affen gemtad)t hatte, "Eic wolfen ihn

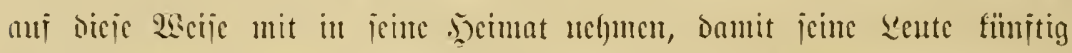
für ilyn jorgen tömnen. Eehr gut; id)lagen ba gleid) zmei Fłliegen mit

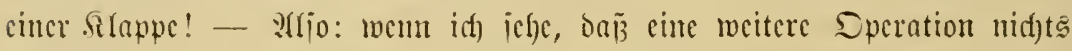

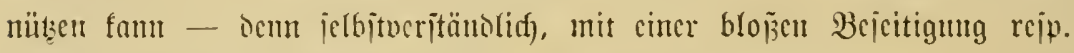

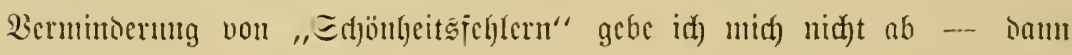
fömmen Sie i.gn, jagen wir "mul: in ad)t bis jehn Zagen mit jid) nelumen."

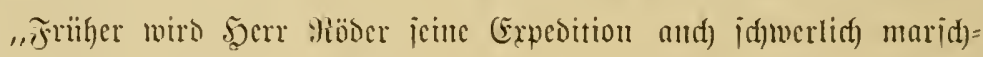

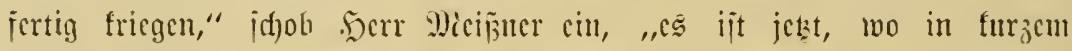

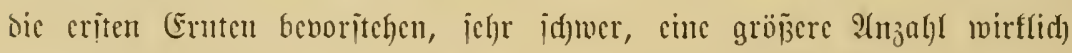
braudfbarer secute jür joldfe :ieifen von utchreren Mionaten julaumen: jubefommen."

Brumer jẩ ichon ïber jein Miffrojfop gebeugt, uno hörte faum

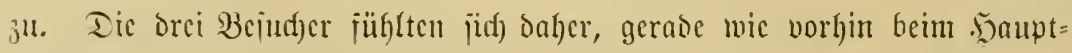

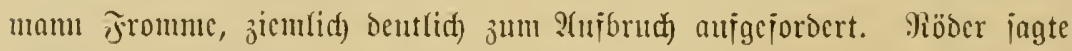
Deshalb dem Blinten, er merde in ocn jolgenden Iagen nad) ifm ieflen,

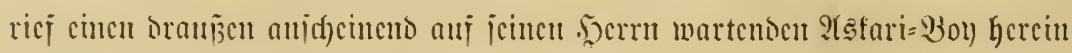

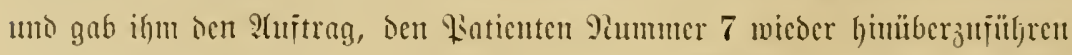
in's Farbigenlazarett; Danad) nahmen dic Drei :(fjchico vom Etabsarzte.

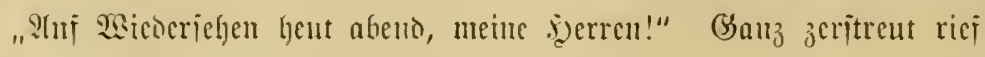

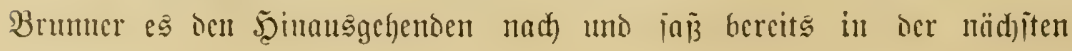




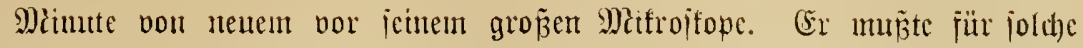
uno andere Unterjudhungen cben heut wie gejtern jedc jreie Minute zwijchen

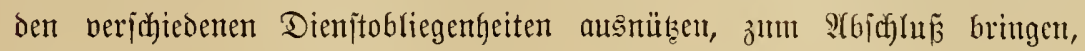

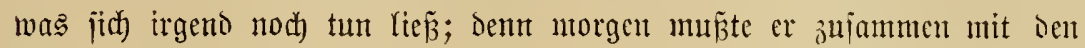

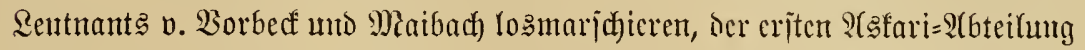

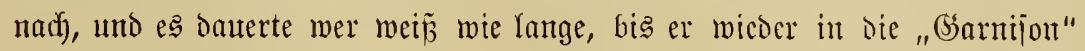

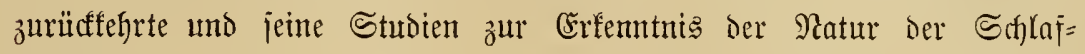

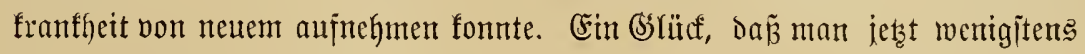

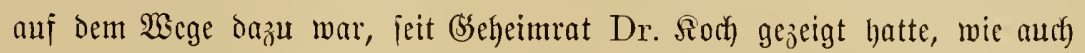
Dieje in llganda jo verheereno aujgetretene Sianfheit ähnlich dem Malaria= jieber ourdy den Stich einer in Seegebüjh rebenden Misfitoart erzeugt

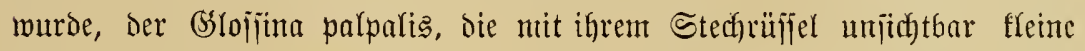
Rebemeien, "Trypanojoment", in das Błht bes (Scitochenen bringt. Mian

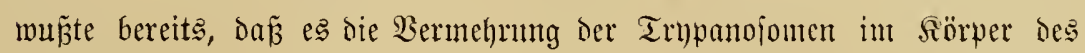

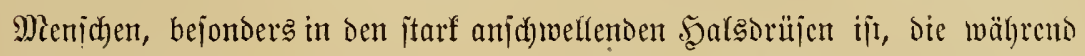
der Dauer fajt eines Jahres alfe bie juthecflichen Situntheitsericheinumgen

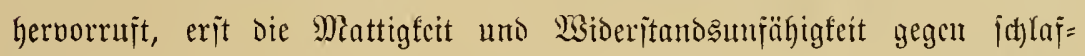
ähnliches Şindämmern, dann die entję̧liche Yrbmagerung bis zum Sfelett,

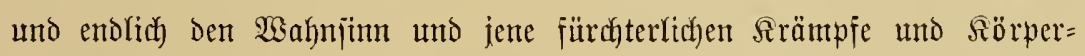
berorefungen, die das Sterben zu einer mausjprechlidyen Sual machen.

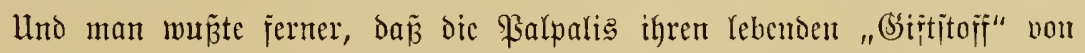

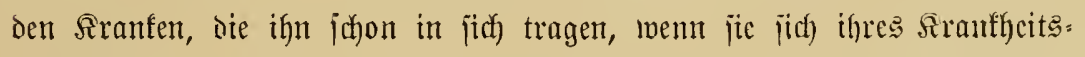

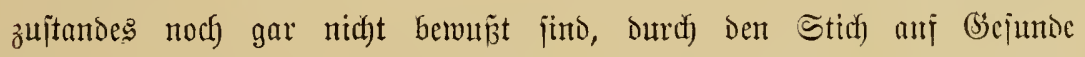
überimpft. Do(f) man war ratlos gemeien bisher gegenitber bem 2uftreten Der Sirantfeit an Srten, an benen nachweislich nic cin Shylaftranter

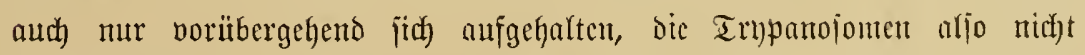

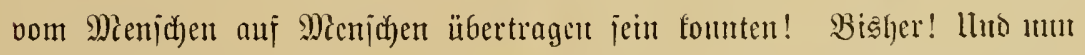

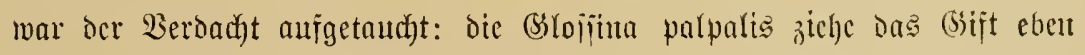

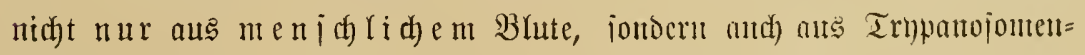
criülftem Tierblute! Dag mit voller Sidherheit feitłütellen, bic hanpt=

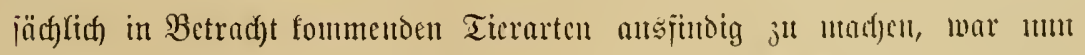

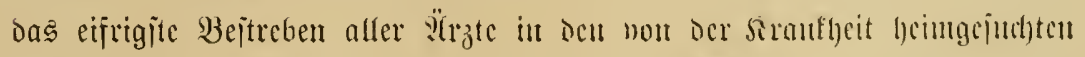

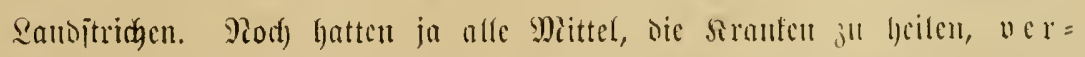

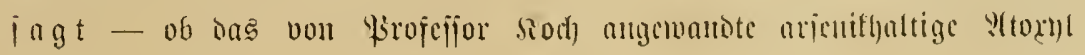




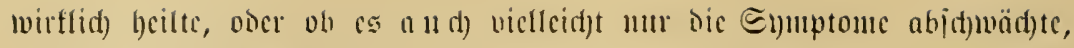

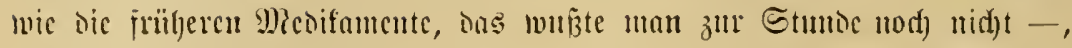

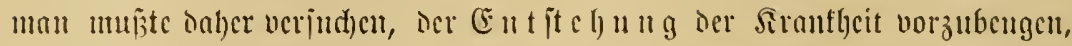
vielfeid)t durdh Siernidjtunt

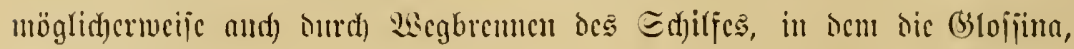

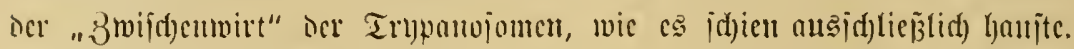

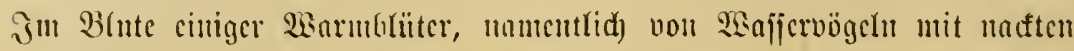

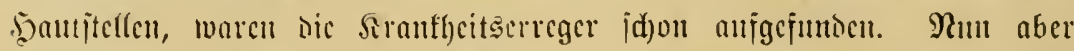

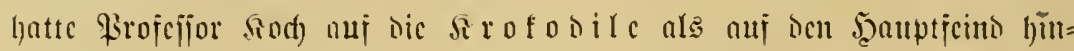

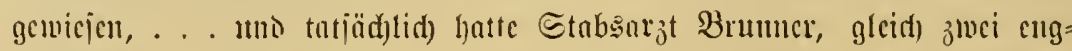

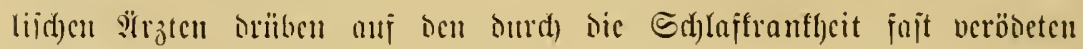

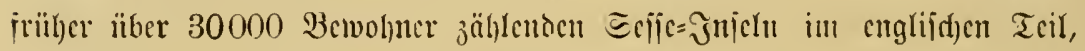

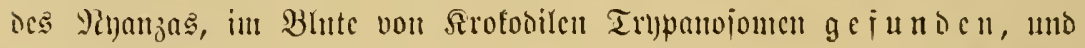
cs galt mun nad)zuncijen, ob sas mur zufärtig war, ooce ob wirflid) bic

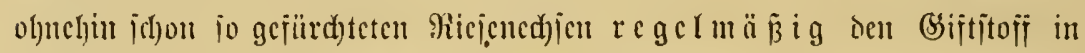

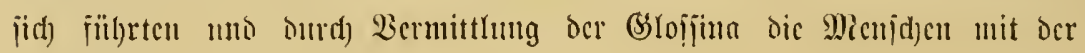
entjetzlid)en Eendic anjtecten.

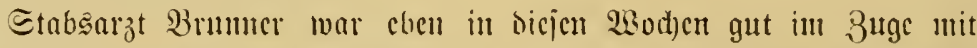

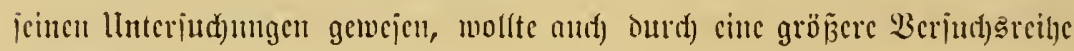

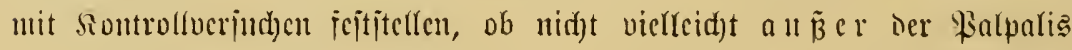

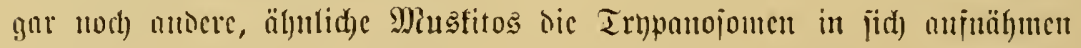

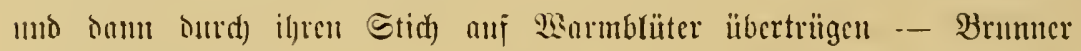

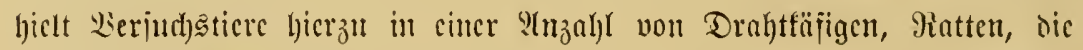

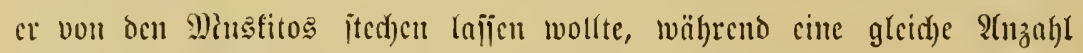

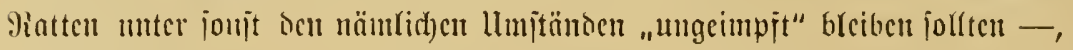

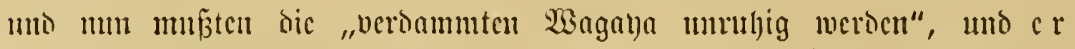

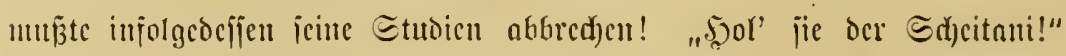

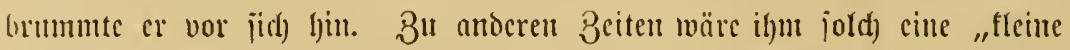

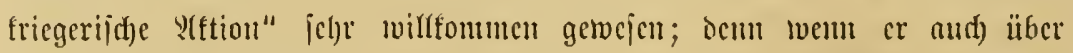

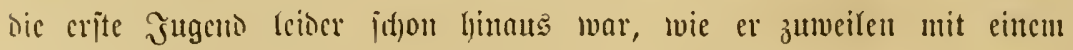

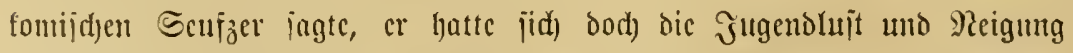

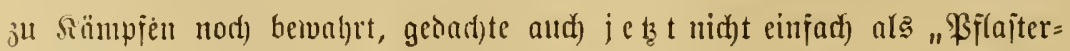

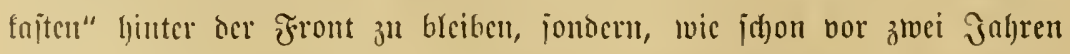

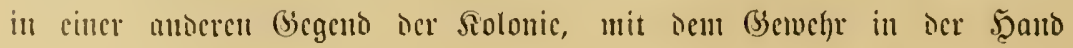




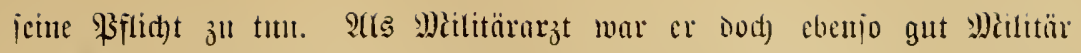

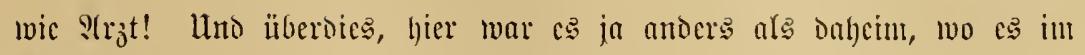

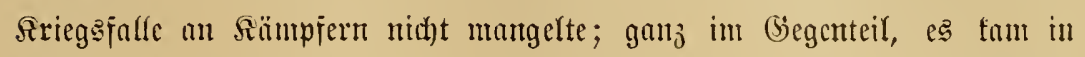

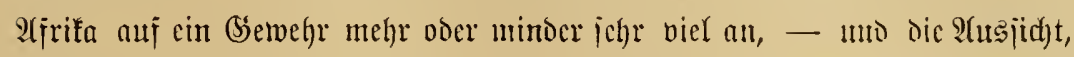

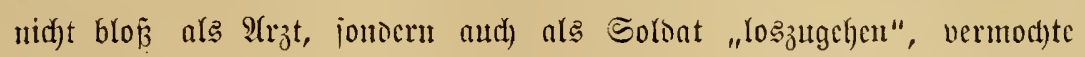

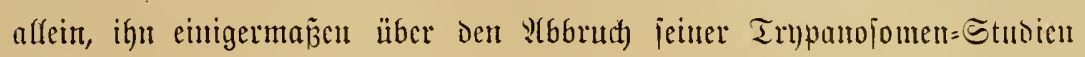
子u tröiten.

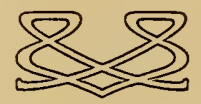




\section{Meuntes Kapitel.}

⿷匚⿳丨コ丨

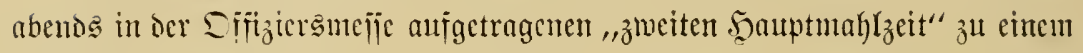

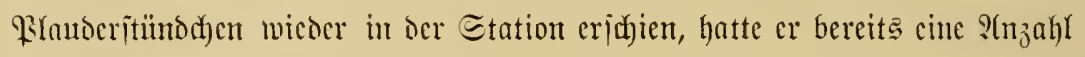
non Boten in dic jogen. Wororte unt ntächjten Dörfer entjants, um Träger

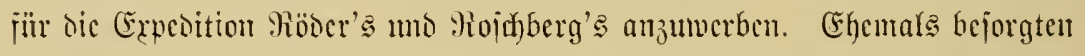

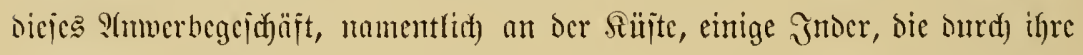
fangjährigen Berbiunomgen imjtanto waren, oft in gamz furzer Zcit viele

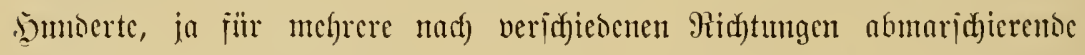
Sarmomen jogar Taujente von Senten zujammenzubringen. Pantentlid)

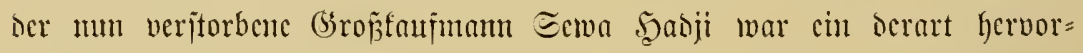

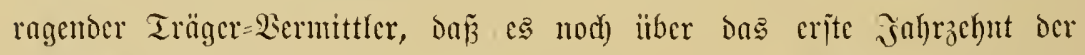

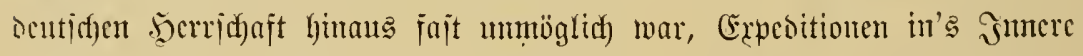

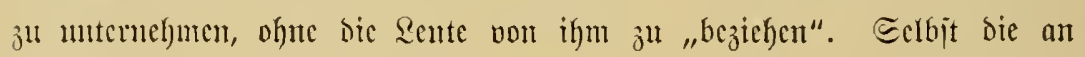

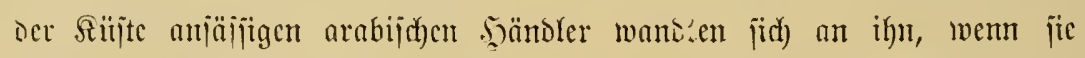

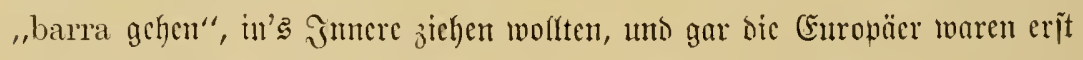

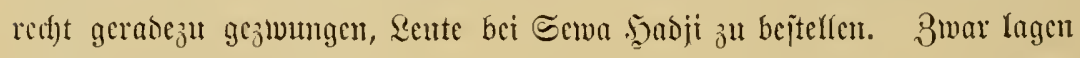

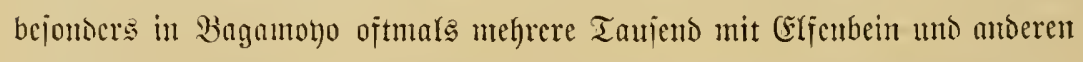

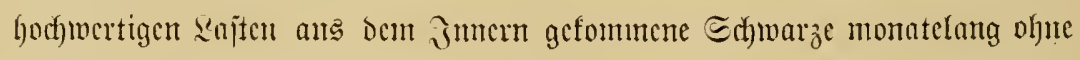

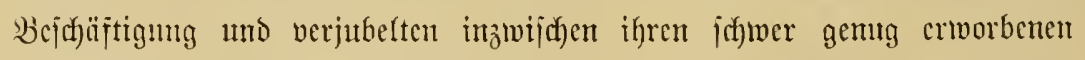

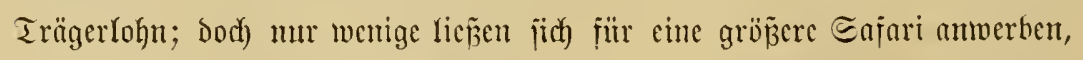
went nidft Sema bajoji der sierber war, - er veritanto es cben burd)

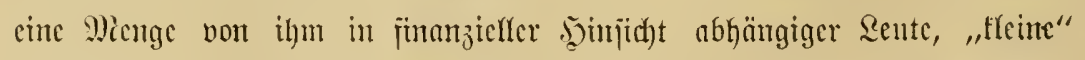

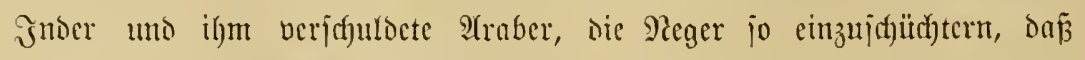
ite anf ,ic ine" Sarawanen= Buianmeniteflung warteten! Drohte ihnen

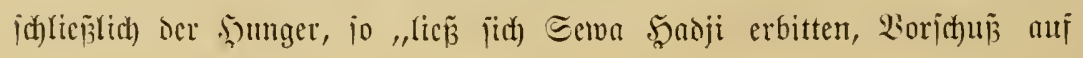




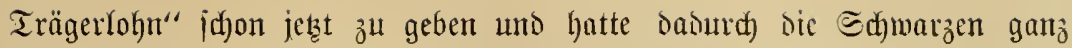
umb gar in ber Şano! - Er hatte übrigens audi) jeine guten Seiten,

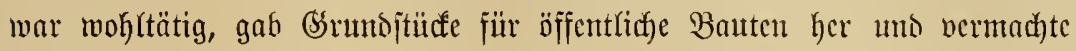

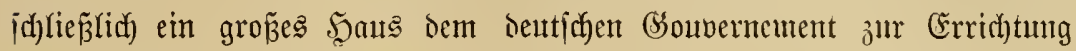

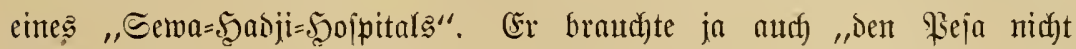
drcimal umzutrehen, ehe er thn ausgab", verbiente er bod) an oen Irägern jo viel, gewöhnlidy an jedem Mann je nady ber Reijedaner 50 bis 80 Rupien, Daj̃ er allein aus dem Trägergejuäfte Mitlionär gemorben war.

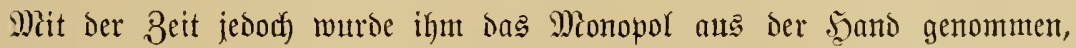
obgleich er Der einzige Bermittler twar, der für bas ridytige Crintreffen

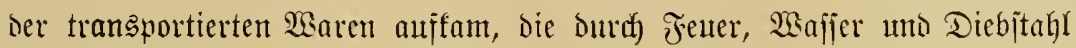

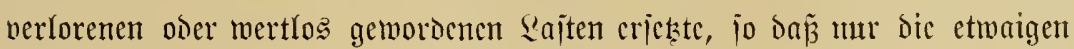

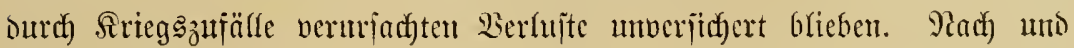

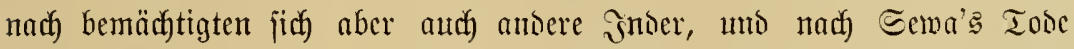

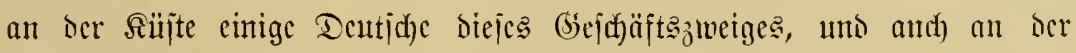

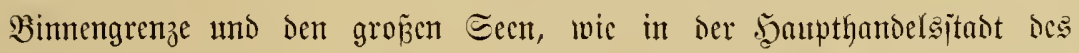

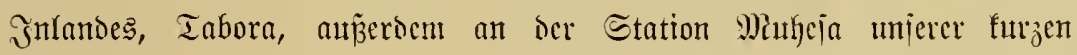
llambara=Bahn, hatten fidh veridjiescne Europäer mit ber ?(umerbung von Trägern abgegeben, in größztem Mañ̄tabe Der Engländer Stofes in Miuanza, der als Mitijionar an den Eee gefommen war, es baum aber

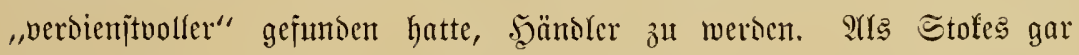

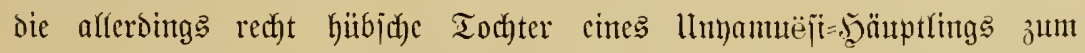
Schrecten der 2 seipen ber Siolonic in aller Form gchciratet hatte, mar er itets in Der Lage, in fürzejter Friït mehrere Iaujeno Iräger zujaumen=

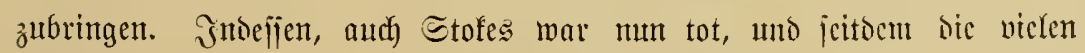

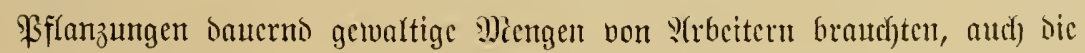

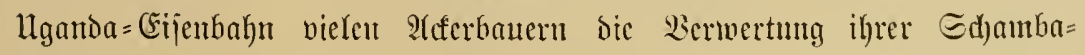
Ernten, den Biehbejitzern ben Liertauf ber Felle, ben, „Bienenjügern" ien

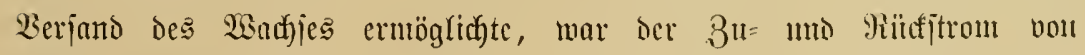

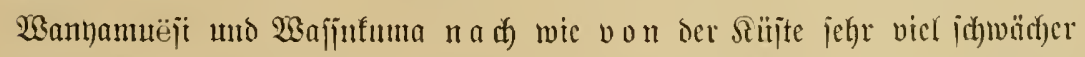

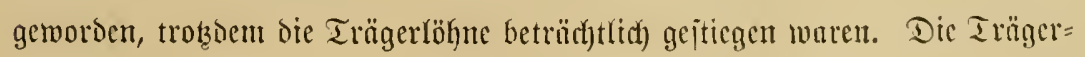

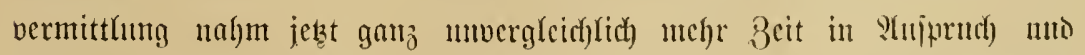

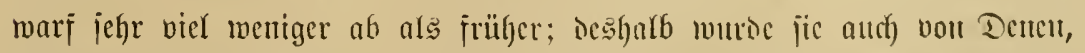

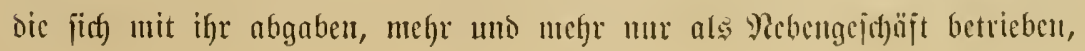




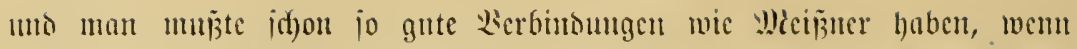

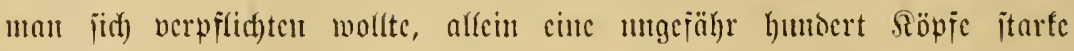

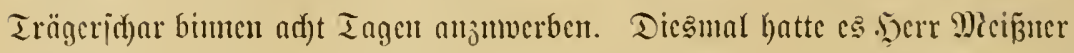

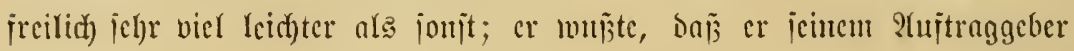

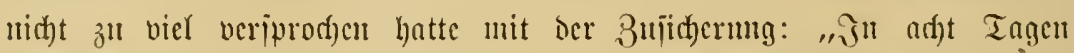

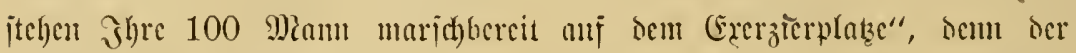
Plant Möbcr, bic S(usjicht, mit icm bana ndevu nyekundu ju reijeı,

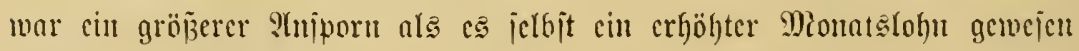

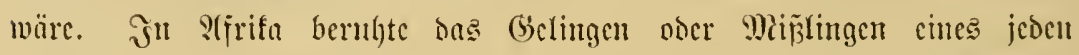

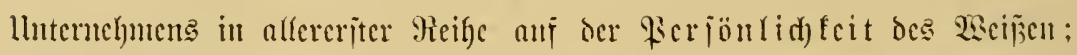
war er helicbt, io hatte er jefre vicl rajeder als jeder Stmocre jeine Seute beijammen, hatte jelten ïber jic jul Elagen anj Der :leije, mo bejiegte bic

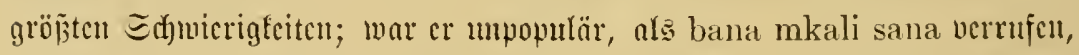
jo liefen igm womöglid) Dreiviertel ier \&eute jefon in ocn eriten Tagen

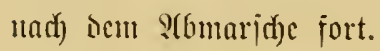

Davou ipradyen und) dic Sifiziere, als jic jidt) mit ihren (bäjten

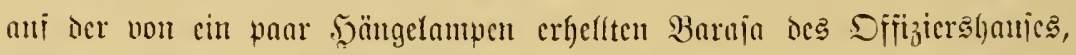
unter Den weit vorjpringenoen Strohoadje, an cincm langen, unit weip̌ent

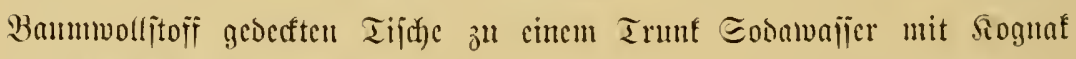

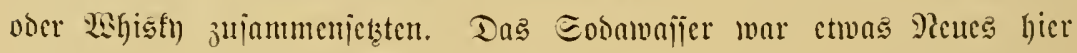

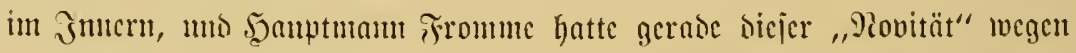
jomoht Den bana mnene, Den, "Dicfen .5errn" Bartmanu non ier D. O. A. G.,

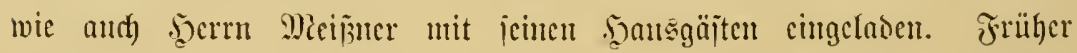

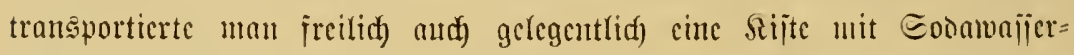

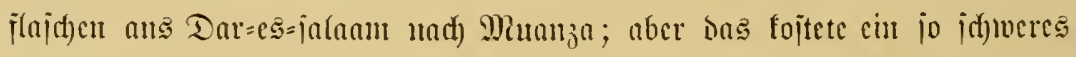

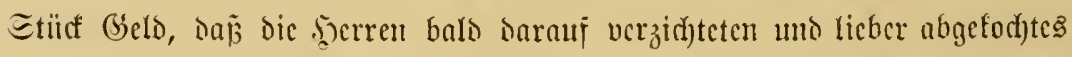

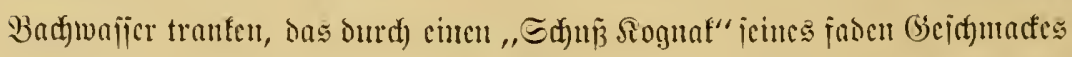

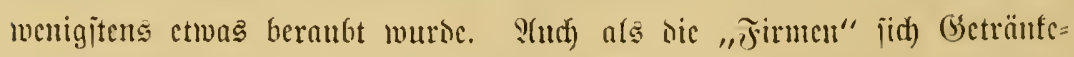

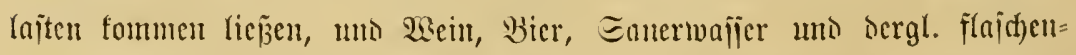

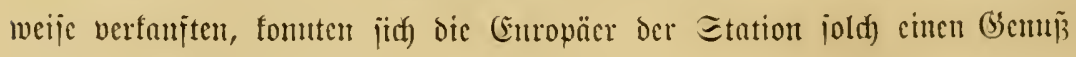
mur an Feittngen leijten; Derm bie nur $1 / 4$ Siter entfaltente flaid)e Sauerwafjer fojtete immer nod) 3 Miark, Bicr jogar 4 Miarf 20 \$iemuige Dic Flajd)e, uno ein Ieid)ter Mojelwein 7 Mart. Dent wenn autd) bie

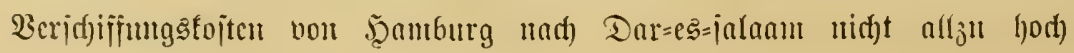


waren - die 1 Kubifuteter groß̉e Sijte wurie jür 40 Miart bejördert --

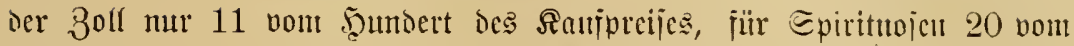

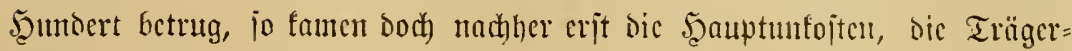

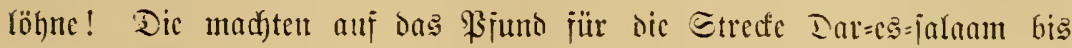

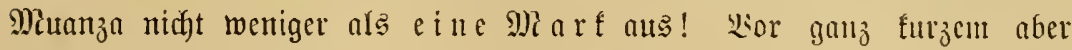
war eime Erfindung gemacht worden, bic für bic Stationen im Эumern, vor allem für ihre Siranfell, - uno Sranfe gibt cs bort immer! - cin wahrer Segen werden fomte: dic jogen. "Sodorflajchen", die Şampturaun

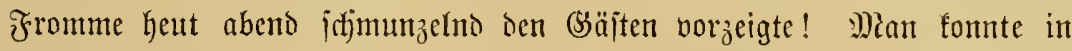
ihnten vermittels natürlicher Sohlenjäure, die man jïh) ans (Europa in

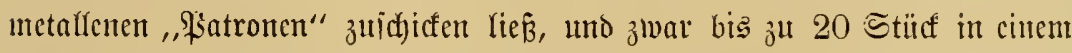
Doppelbrieje, jedes (Setränf fohlemiüurchaltig herītellen, aljo aush ons fadc

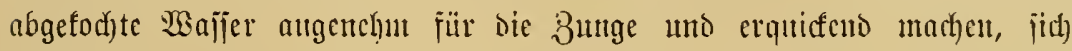
jogar einen wirffich "fithlen Trumt" bejchaffen, wenn man bie Flajche

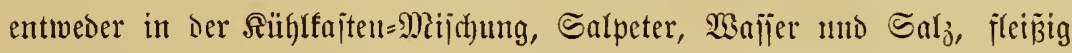
idjmenfte, ober bie Flajd)e mit najjen Tüdhern umwicfelte, jie an cineu

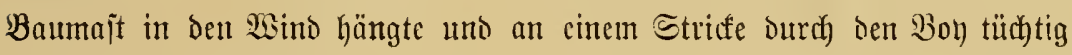
hin uno her betwegen ließ̄. Schr erjreut über sicje Peuterung rechnete

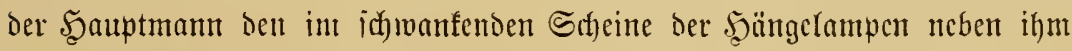

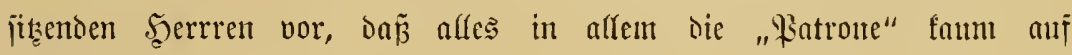
30 Piennige zu itehen fäme.

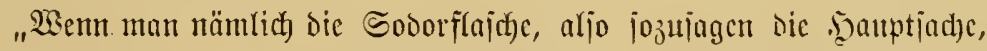
nicht mitrechnet", jeste ber Biotbart hinzu. Er trant cincn Schluct dicjes

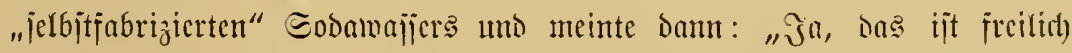
etroas anderes als umjer Wâjer auj Der Sajari, bas man - idj) jage

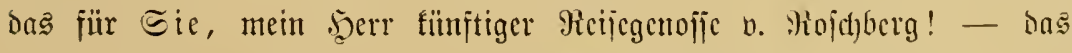

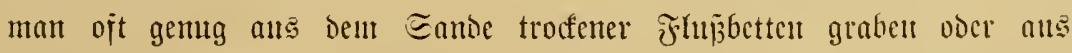

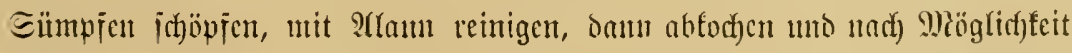

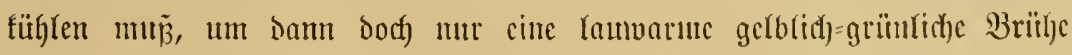

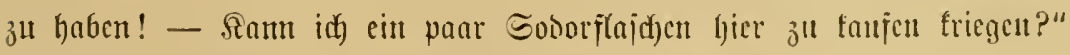

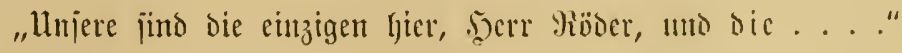

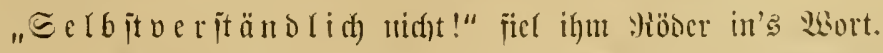

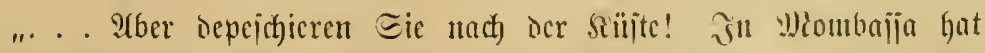

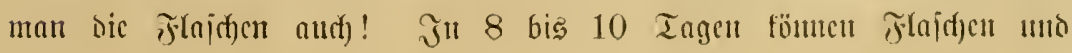




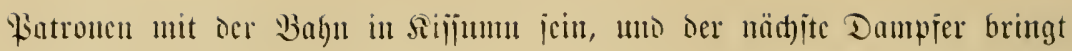
jie Э̧nen mit!"

"Dann hoffe idf) bercits in unjerem Sagorevier ju jecil, oder ridjtiger

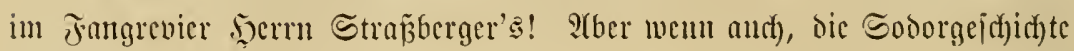
gejällt mir! 2aid)t wahr, şerr Micijuer, Eic beitcllen mir cin halbce

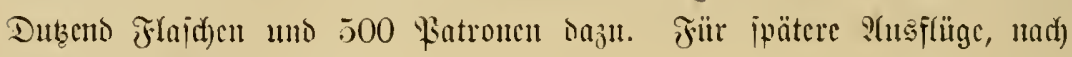
meincr Pï̈ffebr hicrher."

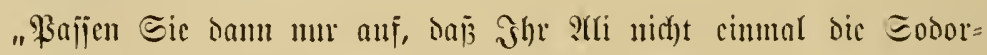

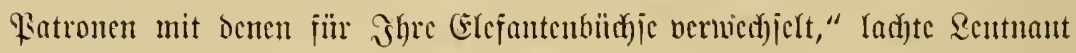
v. Miaibad), der von den itarfen Pnjtrengungen diejes Tages jo mübc

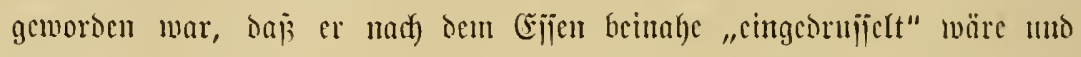

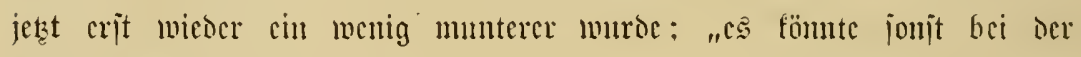

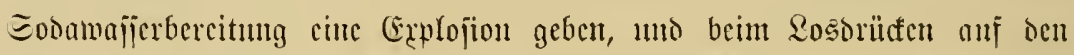
tembo cincn Berjager iu gefälyrlidyjten ?agcubficfe."

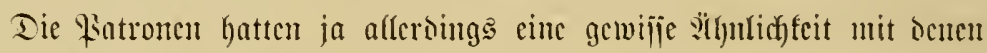

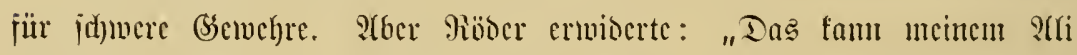

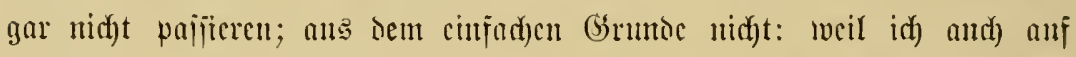

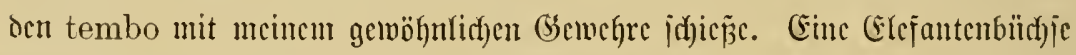
habe idt) ïberhaunt mu bei meiner crijten Mecije benutst!"

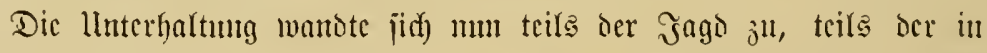

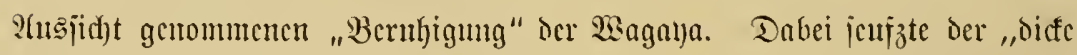
f̧)

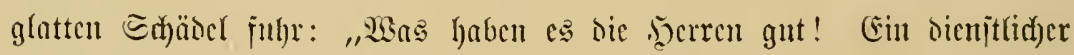

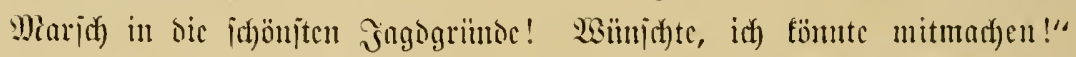

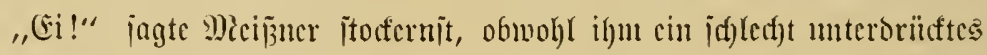

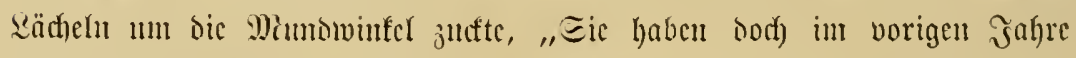

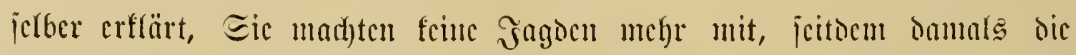

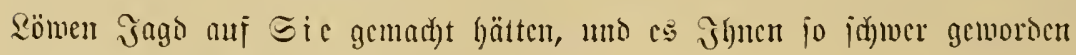

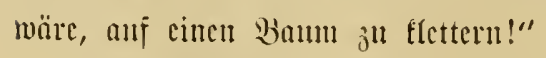

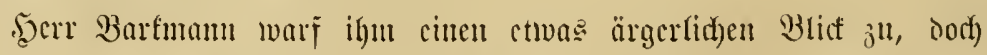

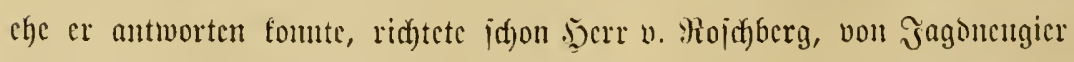

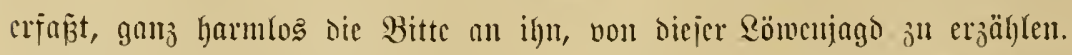

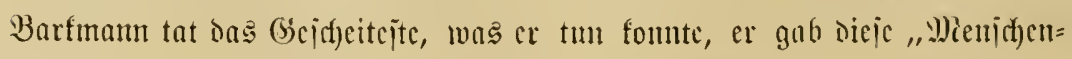

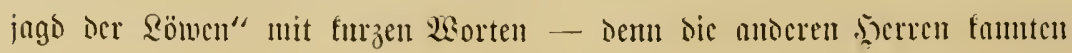




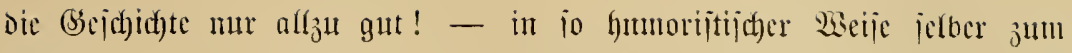

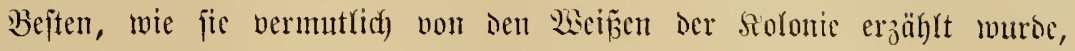

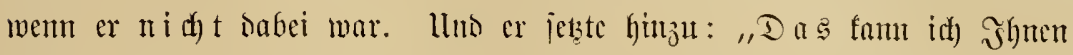

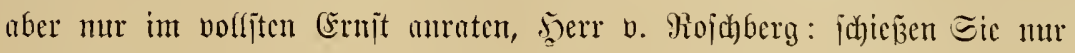
au 2 öwen, went Sic juvor cinen Baum crflettert haben!"

Dic Seerren lachten über ben Ernjt itürfer als über bie Eelbjtironic

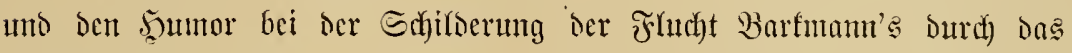
Dorngebüich und jeiner Belagerung burdh jwei unter bem glüaflid) crreichten Baum 年oito fajfente Röwer.

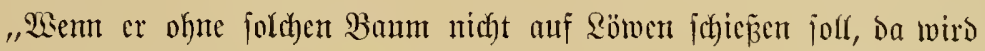
cr micht viele simba in jeine S(h)ußjlijte eintragen fömnen," meinte Röober.

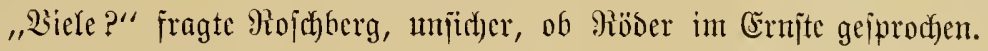

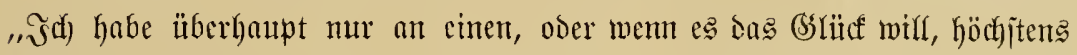

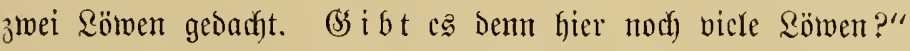

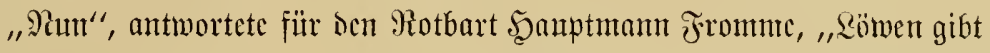
es in Deutjich= Dit noch gemug, mehr als uns lieb jüno; auth Leoparden. Jdh

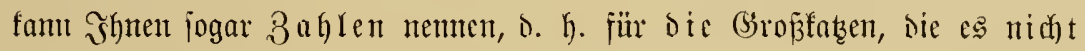

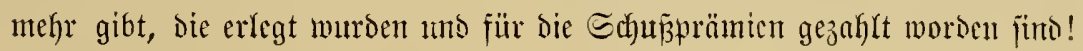

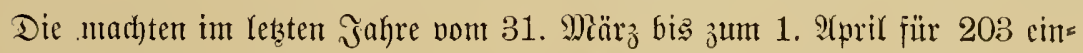
geliejerte Römen uno 791 Seoparden gernote 11000 giupien aus. Llno im Juhre vorher murden jogar 13904 Rapien atşgczahlt. Selbjtucritämolidt) fino noch fehr viel megr sömen uno Reoparden erlegt morden. (5s fam eben nicht jeder jahwarze Jüger, ser cinen Simba itrecft, bas Fell anj cinte

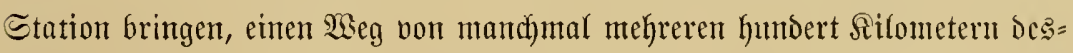
megen mad)en, jo gern er bas Schujgelo einjtridfe. Ilno nod) wentiger faum

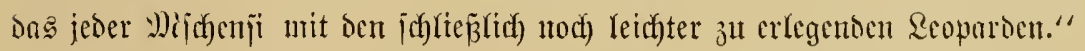

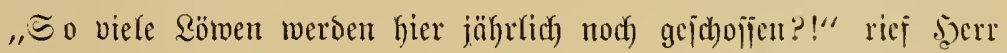

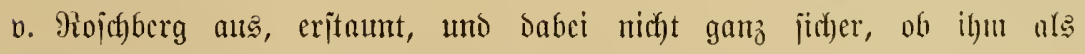

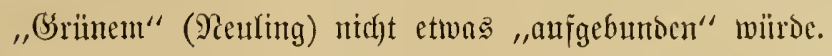

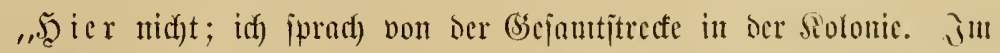

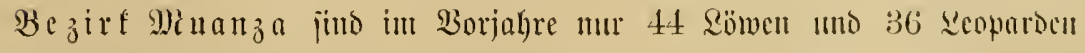

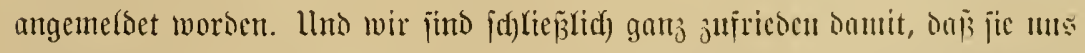

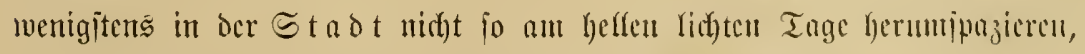
wie es bor gar nidft lange in Dar=es=falan borgefoumen ijt. ..." 


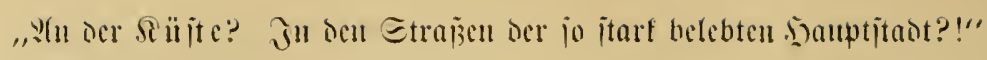
lachte Nojobberg maglüubiy.

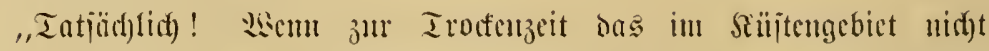

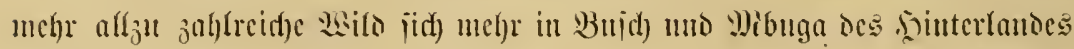
juritufjicht, bam jutt)en mumentlid) ïltere, nidgt mel)r jo red)t fräjtige

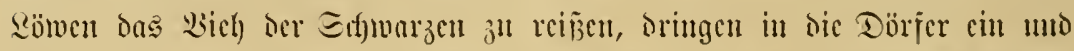

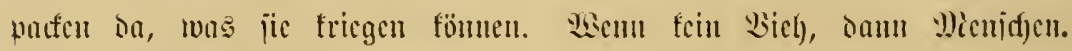
Das Dorj Rijiafi hat joga berlegt merben miijien, weil dic \&öwenplage gar zu ief)r ïberlyano genonumen hatte! $2 a$, mio cbenjo wic in ben

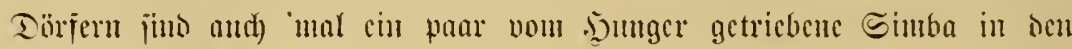

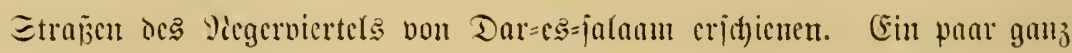
alte, flapperige ïbrigens, Denen die હefjmarzen jefr baro mit Spiejen mo Sìutteln och Gorans gemach) habch."

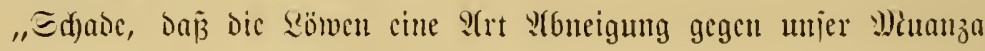
ju haben jđjcinen," hemerfte mit Ieid)ter Jronte Stabsarzt Brumuer, ber

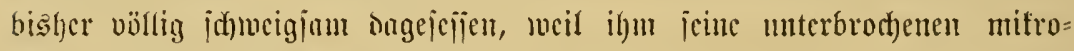
ifoprijden Etubicu im Siopịe lycrumgingen; ,mär' bod) nidht jo übel, mem mun hicr geleyentlict) vou ber Baraja aı einen Röwen jtrecten fömte."

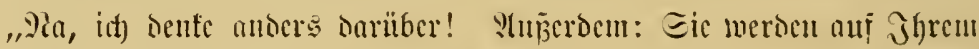

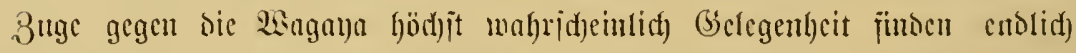

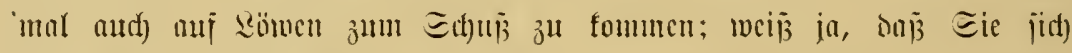

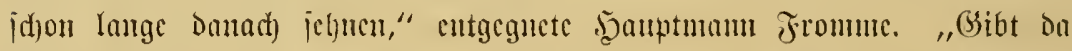

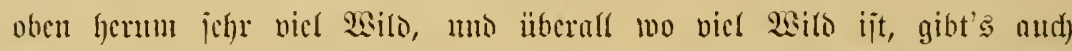
Manbticre genug. Wsenn hicr um dic Stution nicht jeit ungejühr 15 Juhren

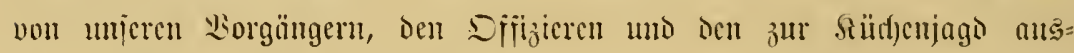

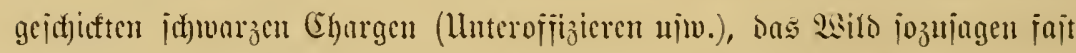

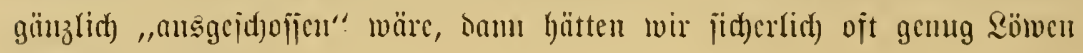
in nüch)iter Pä̈he."

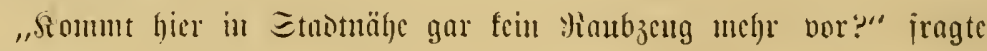
Miojabcrg.

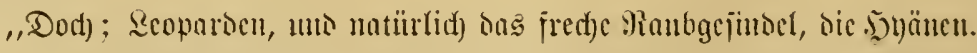
Der Ścoparten megen baben sie Farbigen ifye Ziegen=Bomas jogar didyt bei

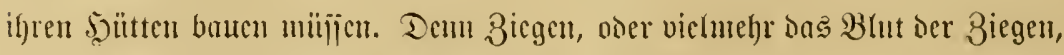
แüfïen こic mijen, ijt cinc Rieblingsipcijc crīten Banges fïr bie Reoparden." 


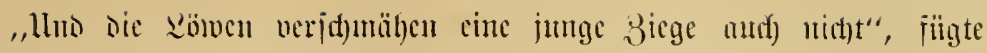

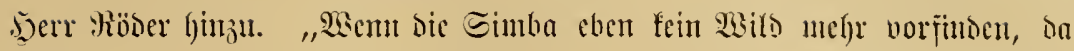

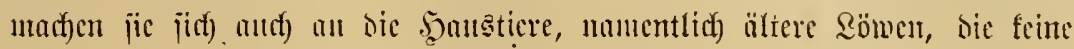

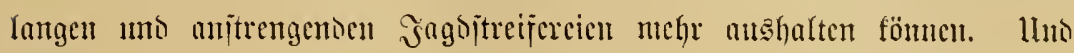

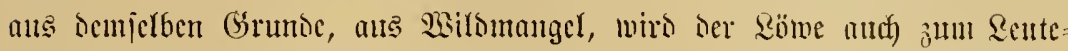
jrefīcr, man-eater, wic man's memt."

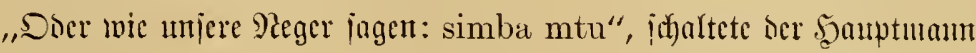

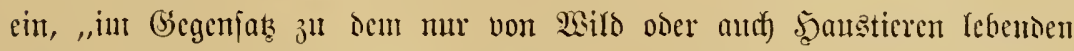

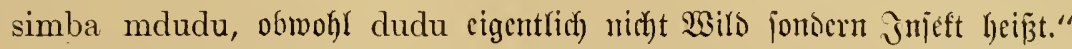

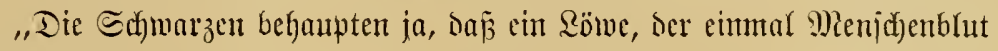

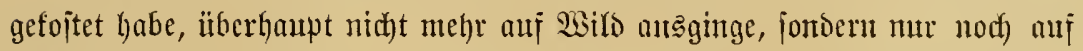

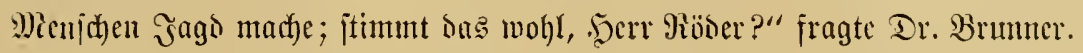
"Ïtbertreibung, wenigitene nach meiner (Frjahrung. Patürlid, wenu

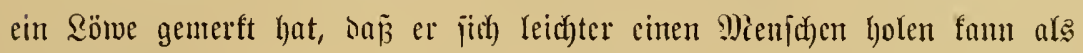

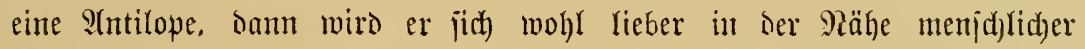

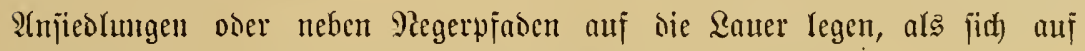

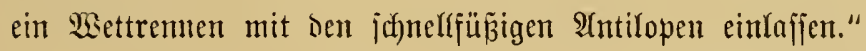

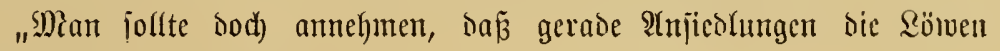
abjd)recften", meinte Rojaberg.

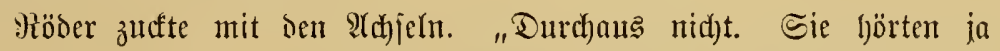

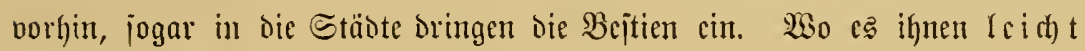

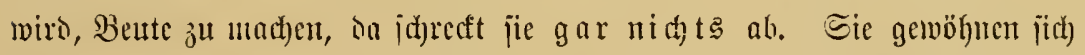
jowohl an bic vor eincr Drtjajt auf Ben Felion arbeitenton vielen Menjach, als aud) an Das lautejte 2 eben und Treiben. Sogar an Den Trubel beiu Bau Der. Ugunta=(Eijenbahn haben jic jith gewöhnt unt jü

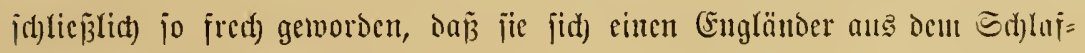
wagen herausgelolt lyaben."

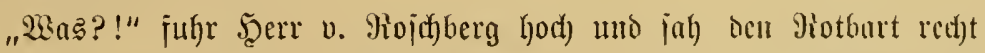

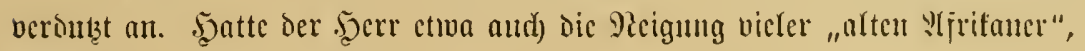
jeden Peuling mit crnjthaft erzähltem Эägerlatein "'reinjulegen"? Dam

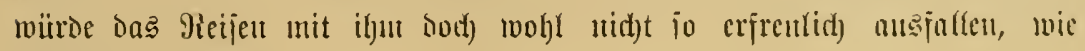
Rojd)berg erfoijte.

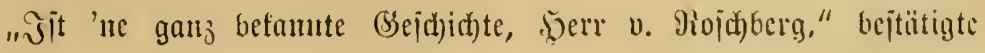

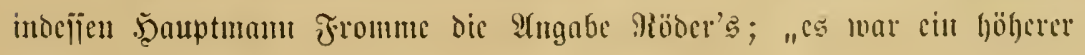


Babnbeanter, Mir. Ninall, der bubci jull Tode fam; tatjächlid) alio haben

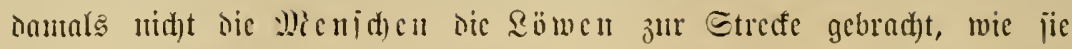

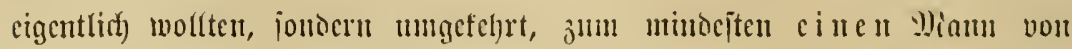

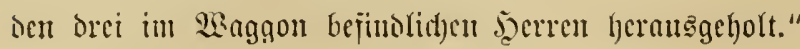

"Yloce bas ijt ja doch rein unglaublid)!"

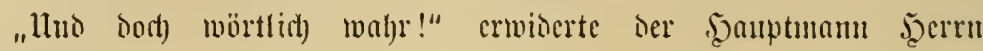
v. Roj(t)berg.

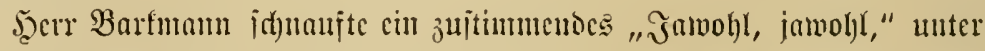

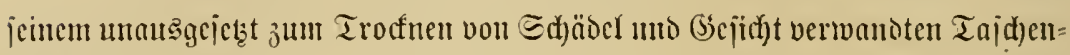

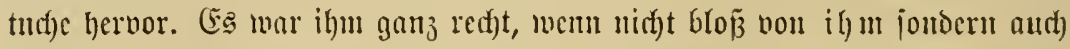

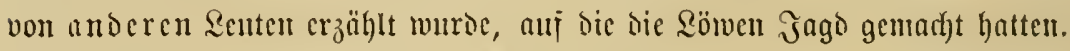
"Tas pajijerte auf Der Station Sima, Mieile 255 Der Uganda=Bahn."

"Wirflid)? Waie mar Dem dic Gad)e? S, erzählen Eic Dody!"

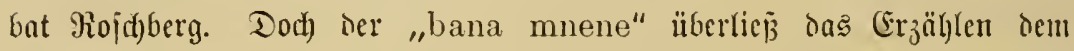

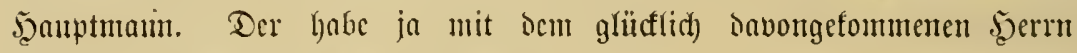
Şübner ans Ribmeji jelber gejprod)en.

Der şauptmanı hatte jid) cben cine lange 3igarette gedreljt -

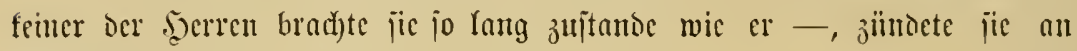

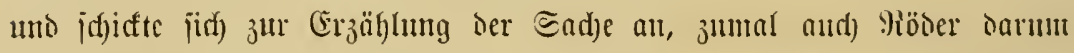
hat. Der jagte, ilym wäre ja "bie (Sejejtidjte in cincm halben Dukento

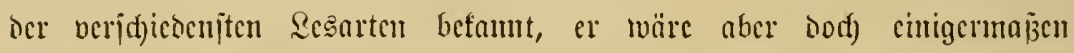

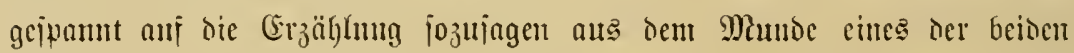

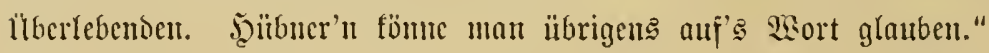

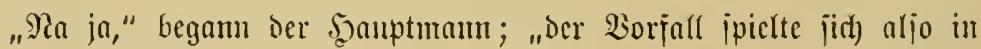

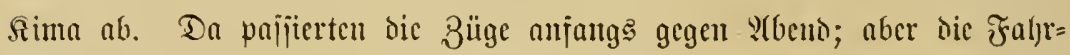

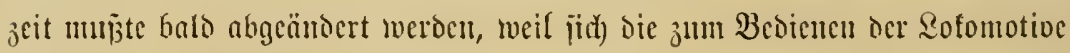

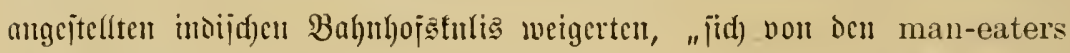
zแm S(bendbrot veripeijen วu lafïcn", wic jic jagten. Das founte man

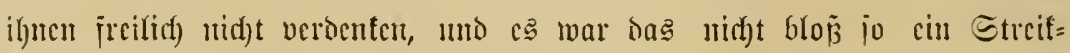
Sormants, wic dic Jnocr ign alle Tage in neucr Form vorbract)ten.

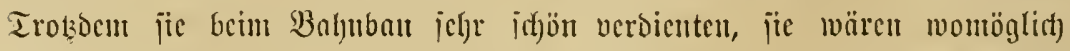
afle Davongefaufel, wem man jie nidf)t Daran verhintort hätte. :(m Fieber

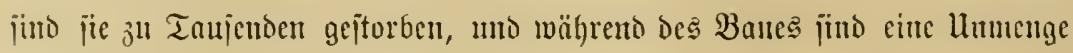

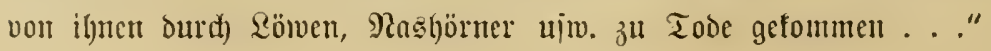




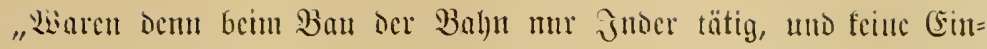
getborenen?" Fragte Rojhberg.

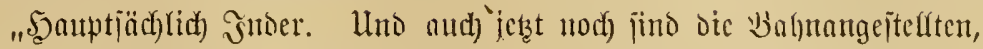

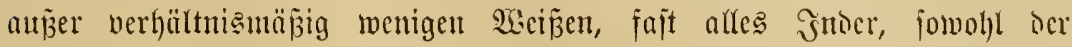

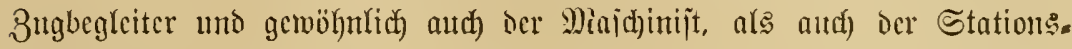
voriteher, Der babu, wic er genant wirt, was eigentlich) "Erhrift= funoiger" hci仿t."

"Ja", über die vielen Эntoer in Sierjonal habe idh mid) bei ser Falyrt

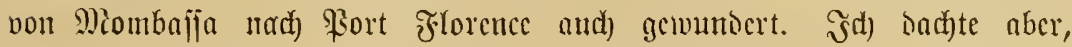
ju Den Errbarbeiten umo Dergleid)en hätte man beim Bau bic Dortigen S(t)warjen genommen."

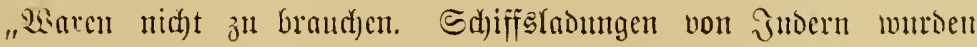
heribergelyolt, und immer neue Shiffsladungen, benu die armen ferls

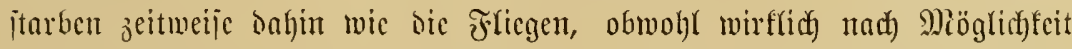

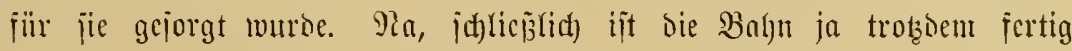

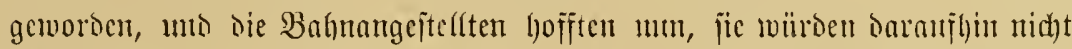

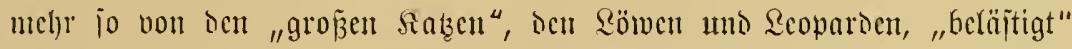
mertien, jumal ja in ber grof̧en Etcppe von 2airobi neben ocr Babn cin Niejengebiet als sisforejervation heitimmt wurbc. Na, Sic bcioc,

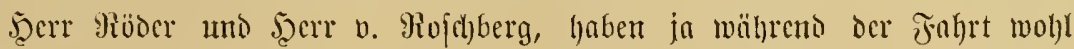

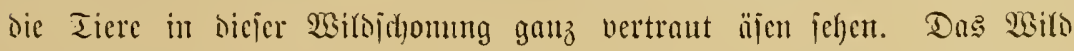

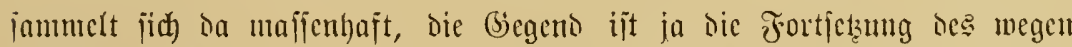

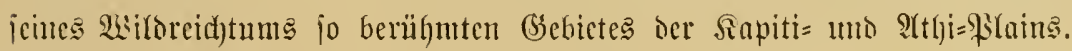
Pa jüön! Man glanbte mu allgemein, weil in ocr Refervation fein

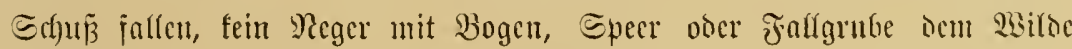

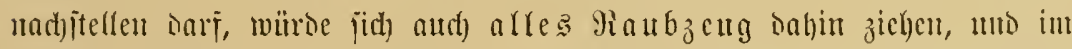

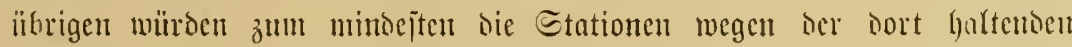

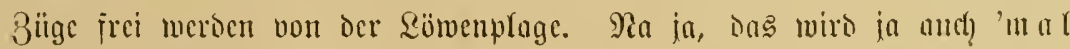
tommen; natürlict); aber vorläıtfig ijt bavon wentig 311 ipiiren, obmobl

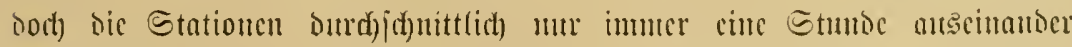

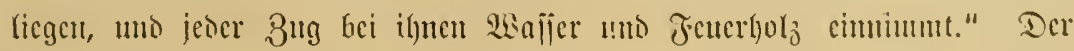

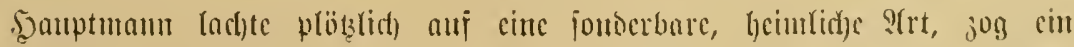

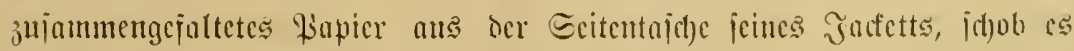

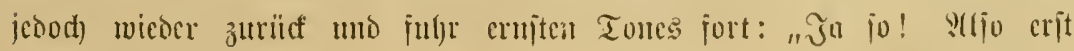




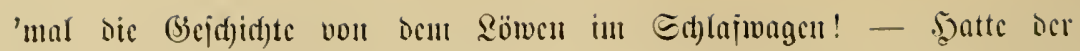

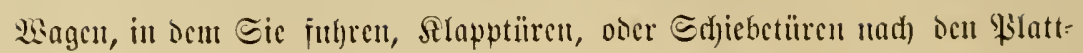

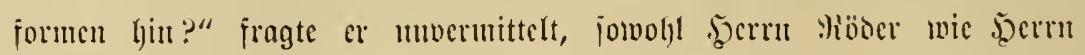
v. Rojdtherg anblidento.

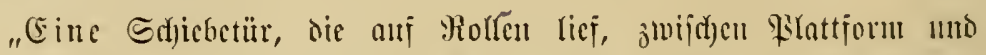

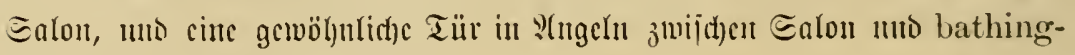
room", gab Röser zแll ?tutuwort.

Noidfberg wurde cin menig rot. Da war ar volfe 48 Ellmitu lang in fold) cinem, igut Dod) fremocu, Hach imoijd)en Minter gebanten

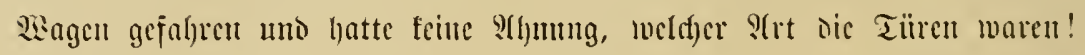

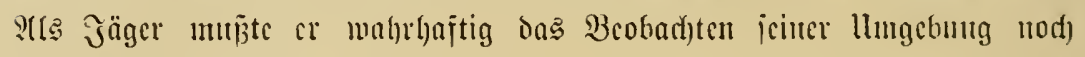
ganz altocrs leritu!

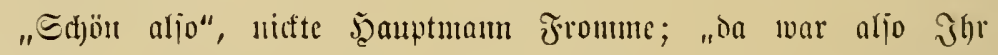

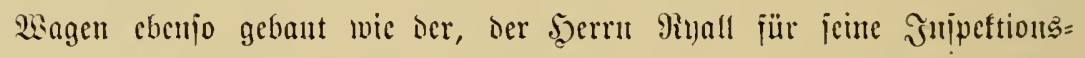

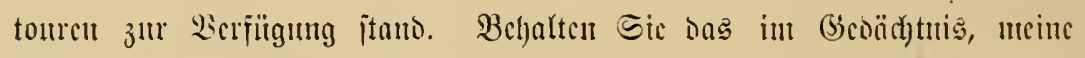

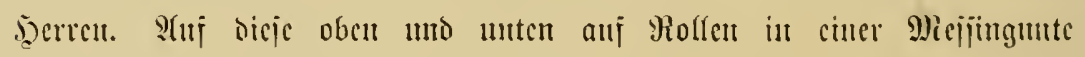

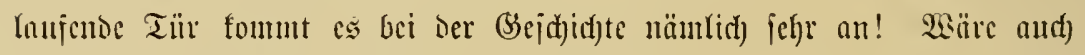

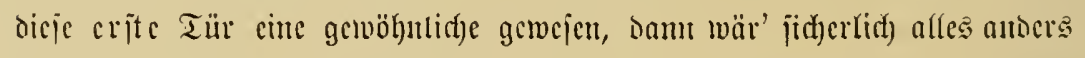
gefomment. Trljo wie gejagt, der $Z^{\text {ntg }}$ fam immer abentos jo itwas nad) 7 uhr bei Der Station Sima an, und die jeit Sintritt ber Dunferheit in Der llmgebung im Dornengeitrïpp oder unter riefigen wralten :fajicn=

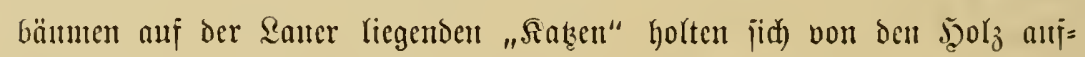
labenden umb die Rofomotive tränfendon indijchen fiulis fo oft cincu weg,

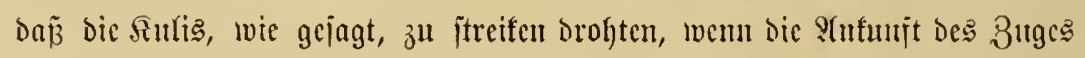

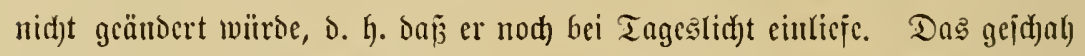
Denu un and); die Suris uno der $\mathfrak{B a b u}$ zogen jid) dann nad) S(bjertigung

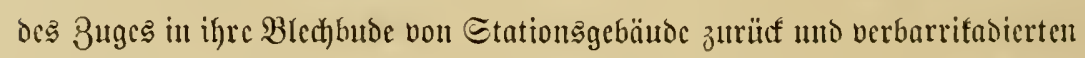

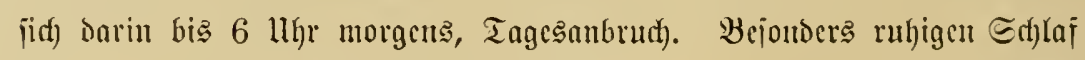

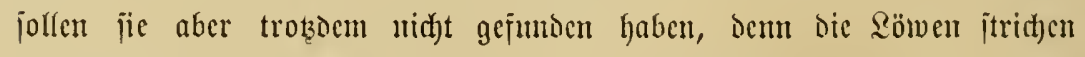
um dic Bube hermu uno briflten ben armen Ferts dic Shren voll. (5s

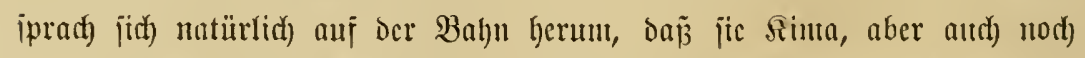
andere bicjer fleiuen Etationen, förmlid) unter Belagerung hiclten, uno

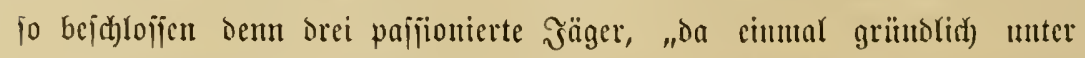

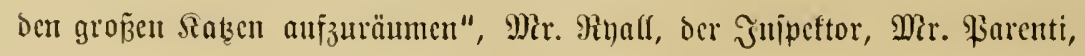




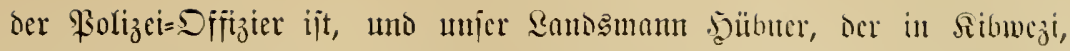
ta in oer Bahngegent, anjäjïtg ijt. Dic oret fulfren aljo, mit Siod) แmo Bots, nadh Rima. Riyall's Schlaịwagen wurto dorten vom 3uge abgchängt

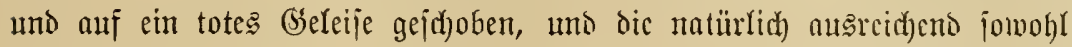
mit \$roviant wie mit guten Bepetiergeluefren und Minnition ansgeriijteten Serren warteten geipannt der Römen, dic da fommen follten. Haer oer

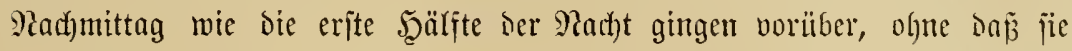
etwas von den Simba ju jehen bofamen. Sic batten bas breite offene Seitenjenjter auf ber linfen Seite se

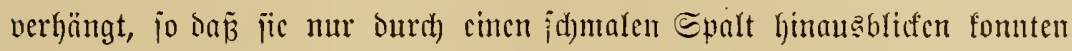

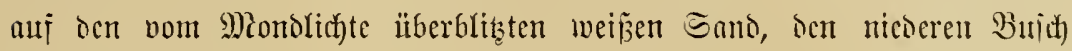

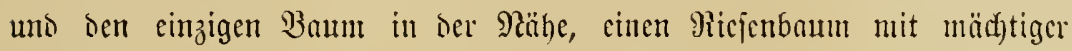
Srone, bie einen breiten Schatten auf bas helfe Bselänte mari, etwa 100 Schritte vom (beleile entjerut. Die unter iem Doppclidache bes

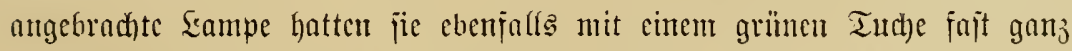
verhüllt. Dic jutr Benienung gehörigen Seute, aljo Der Sioch utto noch cin Эnocr und die fatwarjen Bous, durften nebenan im Badcraume mo

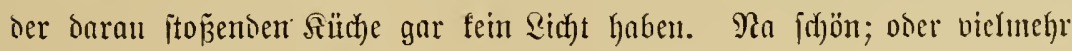

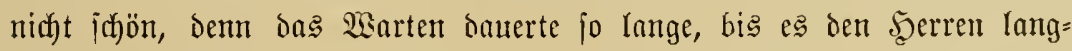

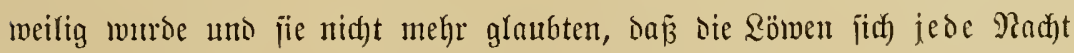
nuj ocm Beleije und rings um nie Bude herumtricben, obmofl cs ifnen der Babu hoch uno teucr jugejichert hatte, bevor or jidc) mit jeinen Reuten

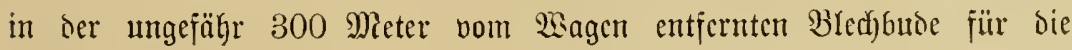

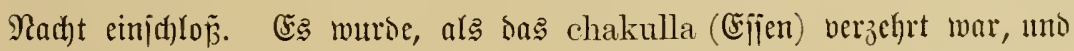
bie Römen jid) nod) immer nidgt jehen und nicht einmal hören liejßen,

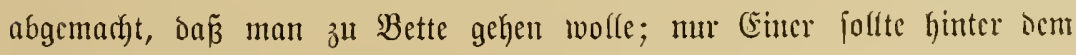

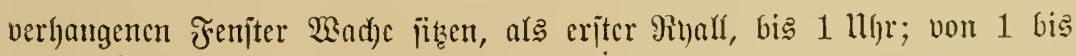

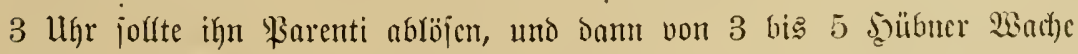

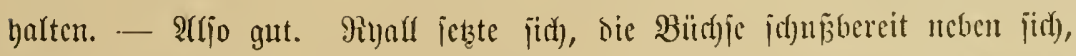
nuj die Politerbant auf ber linfen Scite, mit ocm Rïtfen gegen bie Suter=

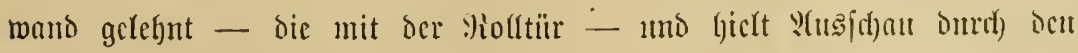

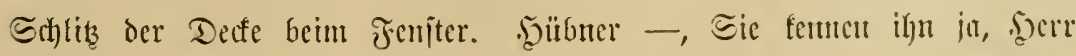

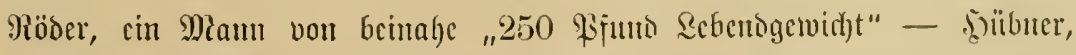

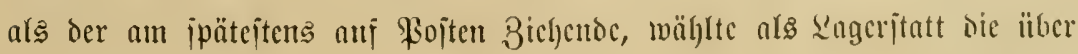




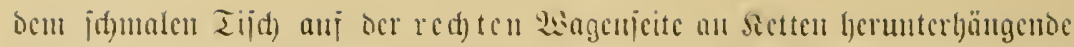

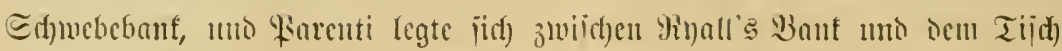

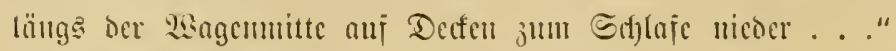

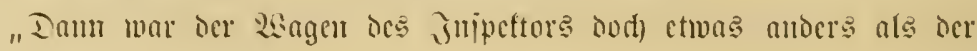
micrige", meinte viöder.

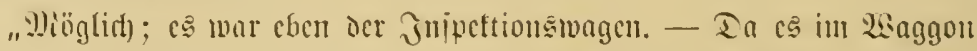

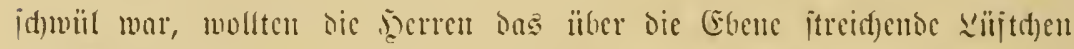

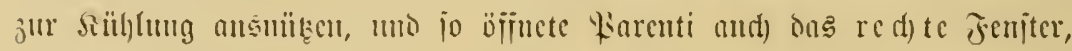

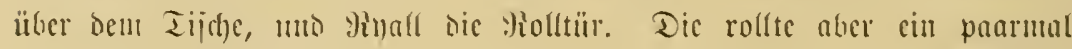

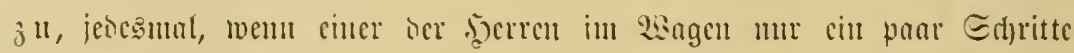

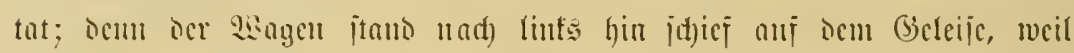

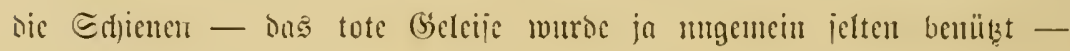

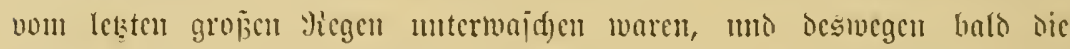

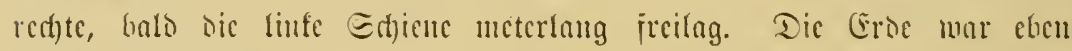

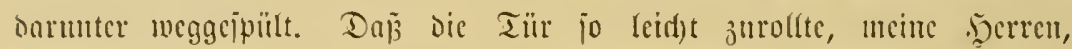
behalten Sic gejülligit glcidj)alls im (sebäd)tnis! Sasm dic Irei im

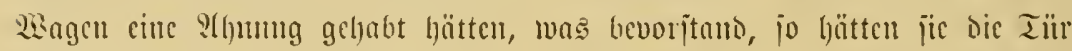

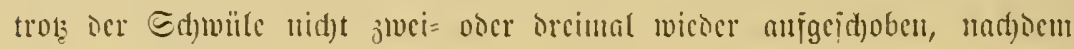
jie jugerollt war, jontern jie im (bicgenteil jo jejt wie möglida verrammelt!

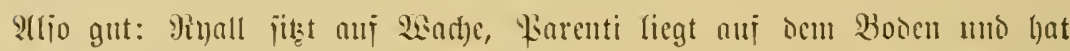

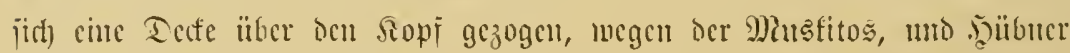

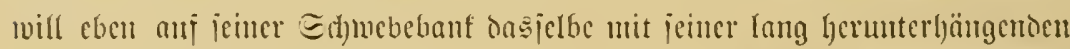

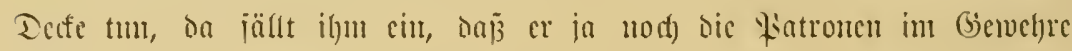

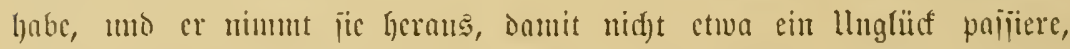

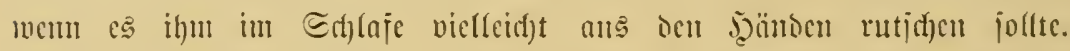

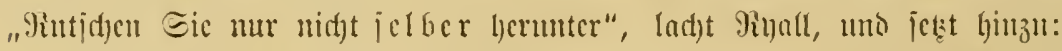

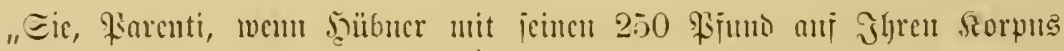
nicocrplumpit von da oben, dam friegen Eic bloj fcinen Edjreft mo

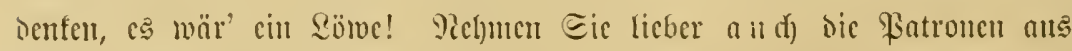

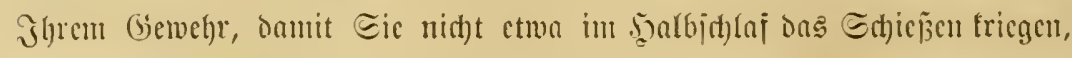

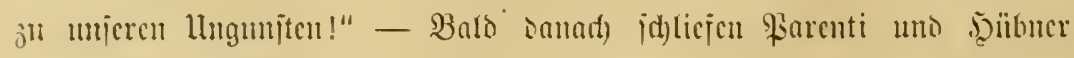

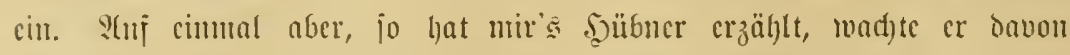

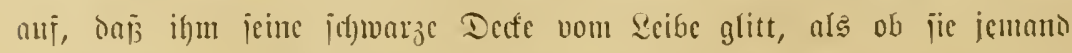

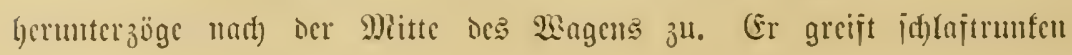




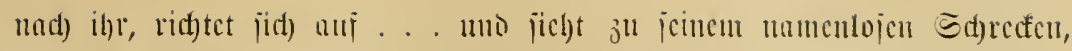

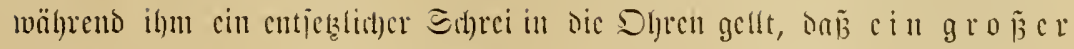

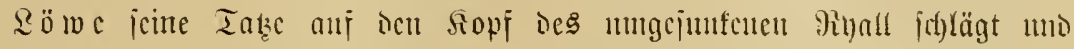
ifn mit fürthterfict)em Bijic in bic linfe Ecite partt! Bugleid) aber

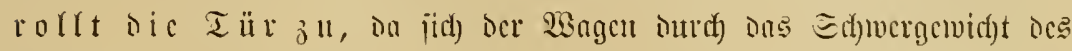

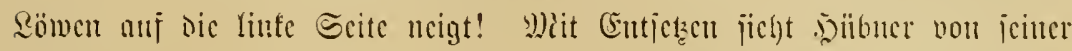

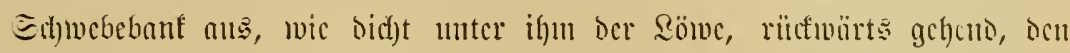

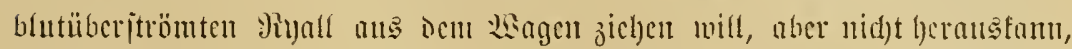

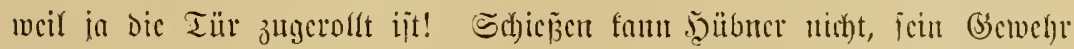

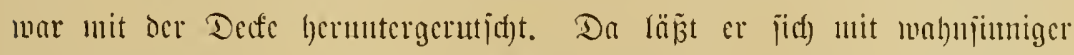

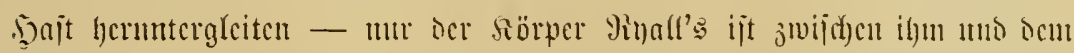

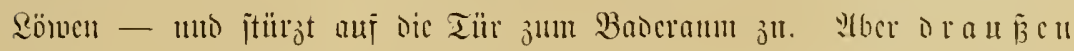

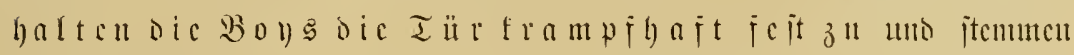
iid) mit aller (Scmalt Dagegen, Da jie glunben, cill Söme wolle jidt) $3^{\text {th }}$

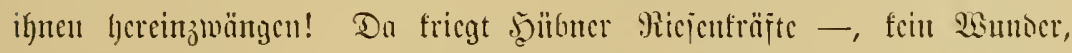

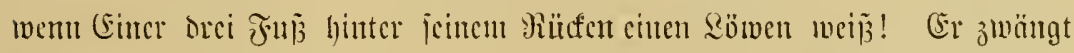

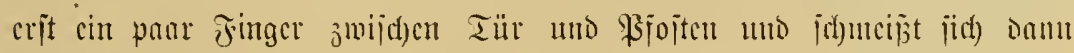

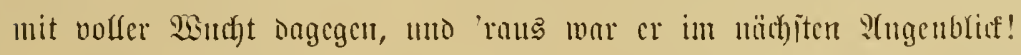

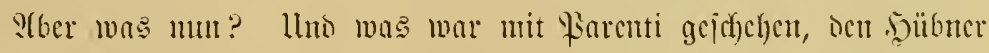

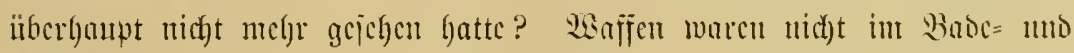

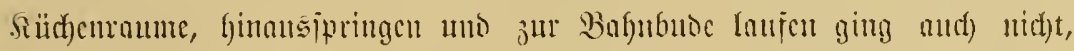

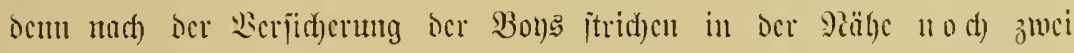

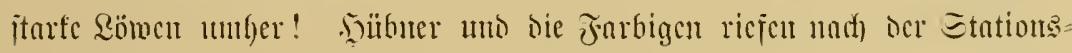

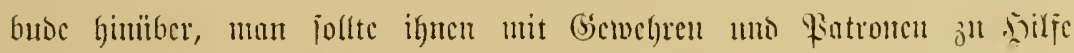

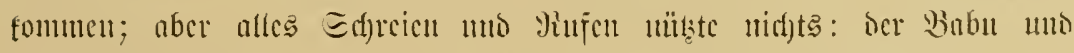

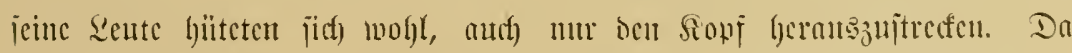

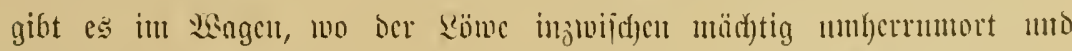

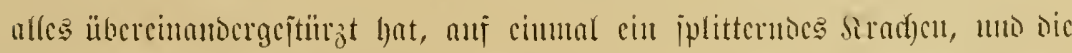

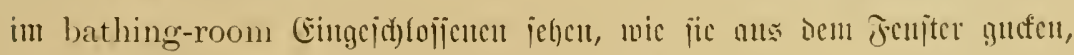

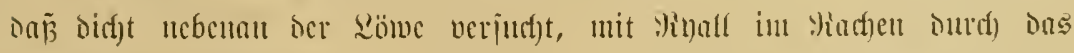
breite linte Entonjeniter in's Freic jull ipringen. (Er fomm nber nid)t

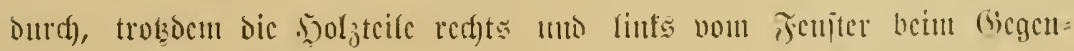

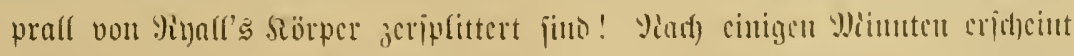

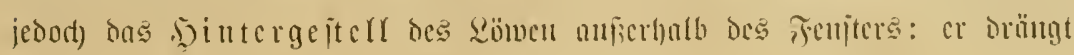




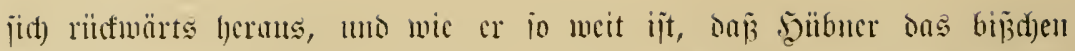
Sopfütühe ju jehent friegt, gibt's nod) 'mal cin Eplittern mo Sinafen, -

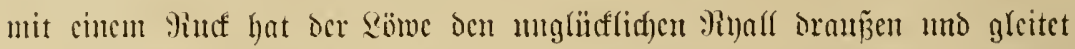

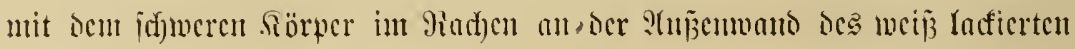

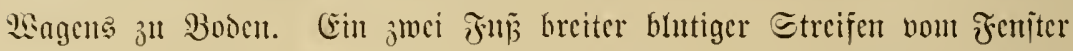

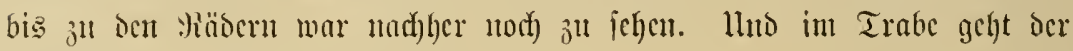
man-eater mit Dor Bentc Dabou!"

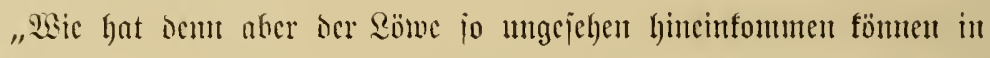

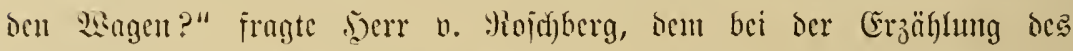

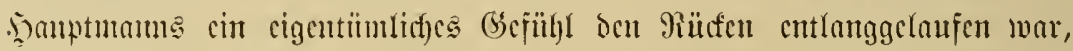

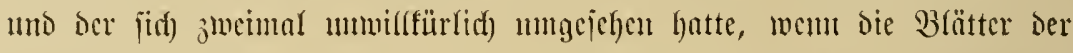
jungen Farmen im Etationsgarten ctmas jtärfer rauld ten im 2lad)twinte.

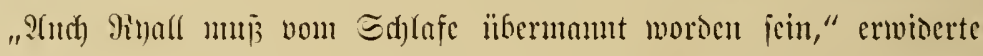
Fï̈ser mitutt Frounune's, ocr cben wiesor jwei Bigarettenblätter ancinanocr=

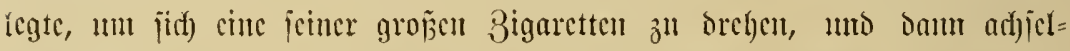

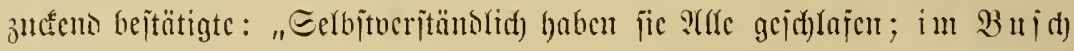
mär' ifnen bne natürlid) nidft pajjiert; abcr in igren Eijenbabnunagen, ba biclten jic jidh fïr cbenjo jid)er wie in cincr Boma."

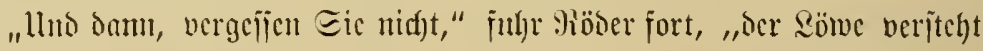
cs wohl und hejier als jede andere siatse, jid) bollfommen lantlos berant=

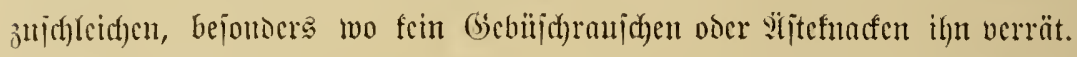

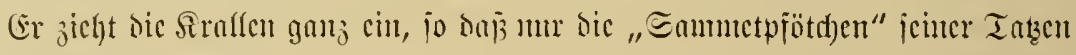
Den Bosen berülyrem. Llno on ocr Boben meidger Eano war, jo ijt's fein

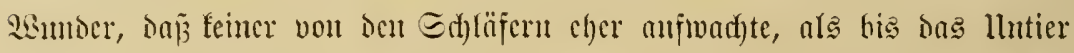

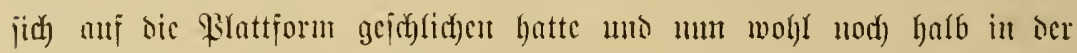

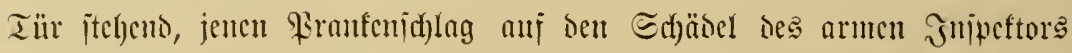

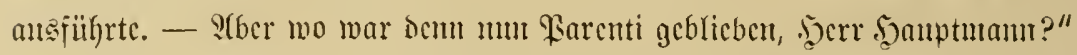

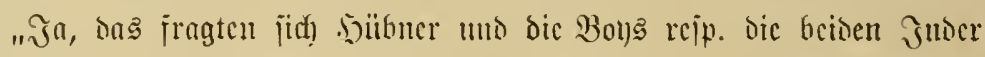

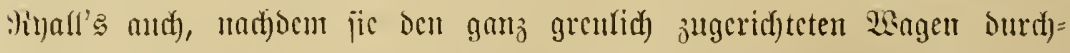

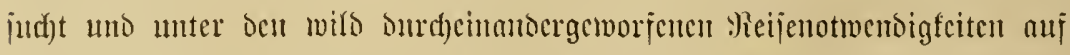

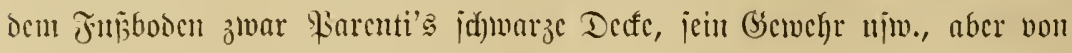
ifm jelber midyts gefumocn hatten."

"Эd) vermute," fiel hier Ecutnant v. Borbecf cin, "jic swerocu wohl dic Durd)judumg ocs \$gagens crit 'mal hübid) gelaffen uno vor aflem dic 


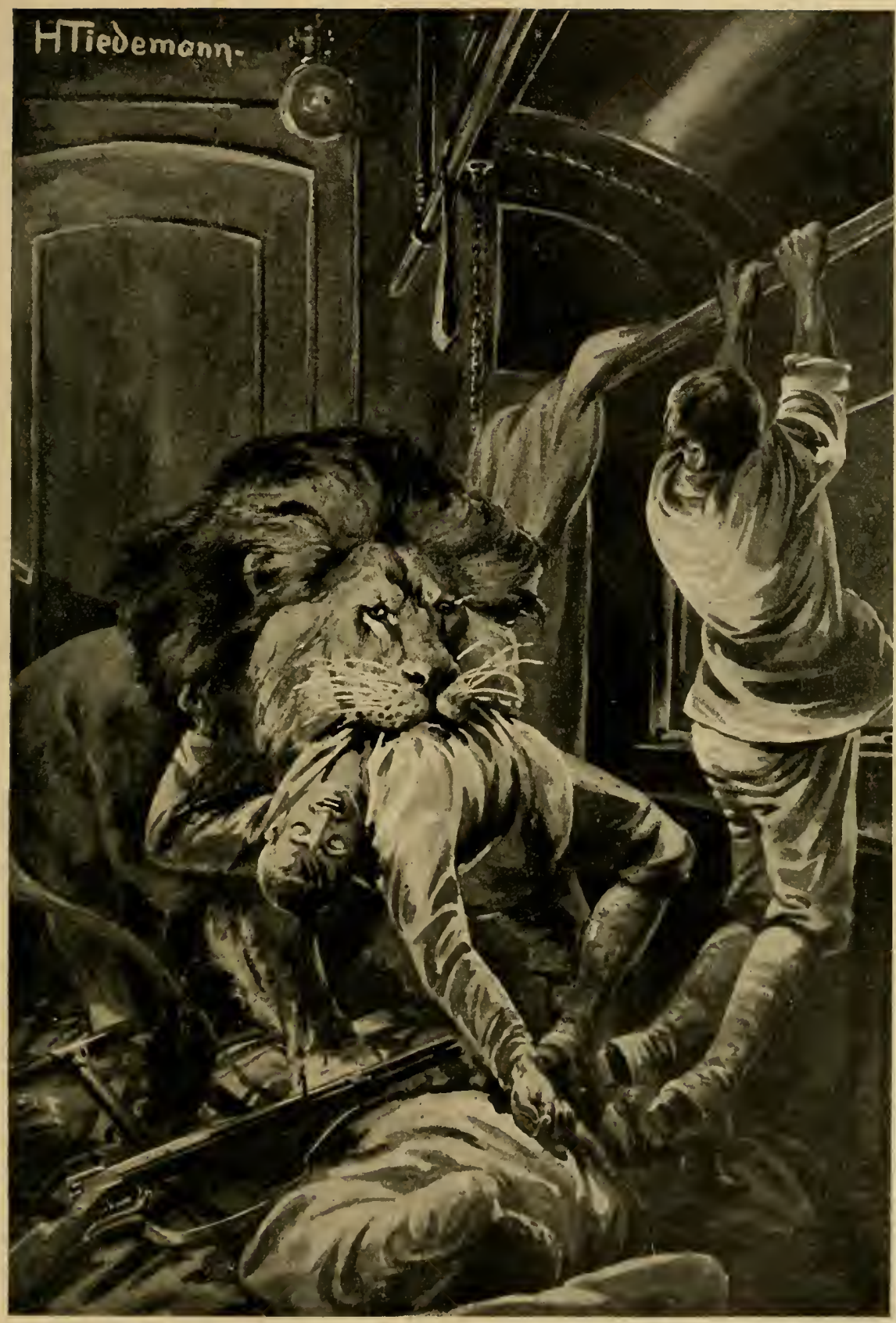

„Da läjst er (ich) mit wabnfinniger hajt heruntergleiten, - nur der körper Ryall's ift zwiłchen ihm und dem Löwen."

(Scite 245.) 



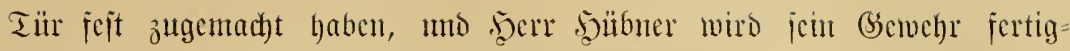
gemacht haben. (Es jollten ja bod) noch mefrece \&ömen unt Den 2Gaggon heruntgeichlichen jein."

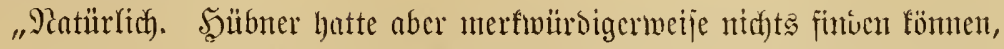
was jum Feitthinten ocr Tür jo recht gecigntet war unt hat beshalb, wic

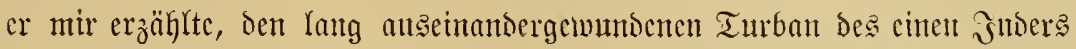

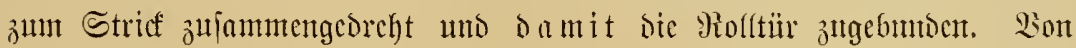
den Söwen mar aber nichts mehr ju jehen. Llno o o d) waren fie nod) it Der शähc. Demn auf́ cimmal antwortete auf bas Riufen ber Mä̈nner: "Barenti! Reben Sic nody? Rarenti, wo funs Sie!?" cine Stunme ate Dem ctwa 100 Micter cutfernten Bujuc: "j)

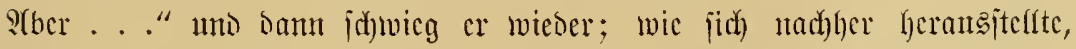
weil er "ntdyt gern ourd) jein Rufen bic 2ufmerfianteit ber Röwen auf (iich) lenten mollte".

"Parenti ijt arjo gut bavongefommen?" Fragte Böser.

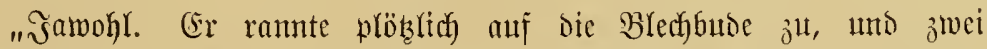

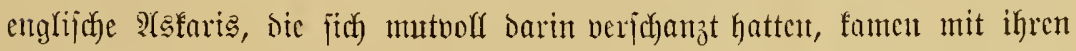

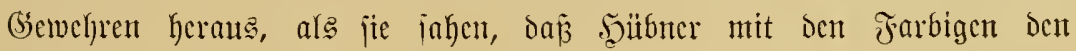

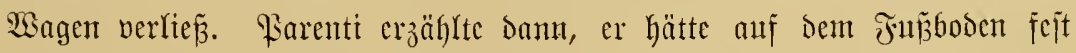

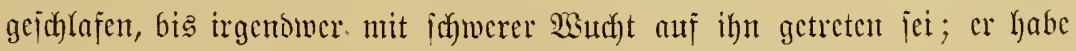

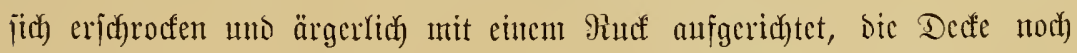
Galb über Dem Sopi, und jei Dabei zu jeinem Serferefen mit jeiner Naje dem über ifm jtehenten sömen gegen oen Baud gefahren! Das Ticr

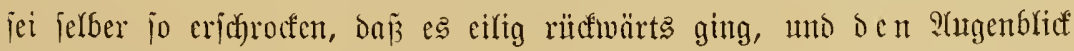
habe er wahrgenommen, um ïher Dem Tijch weg "mit cinem bect)tiprunge", wic ex jagte, burth Das offene rechte Fenjter in's Freic jut foumen. Dent

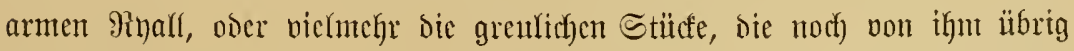
maren, fantien bic berren an antoren Miorgen bei ber Madjfutbe ctma cine halbe Stumbe von ber Bahn im Bujch."

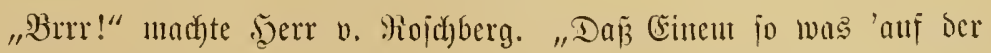

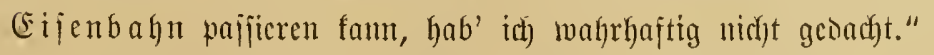

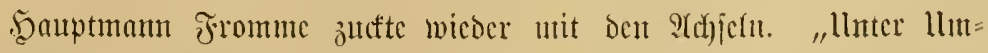

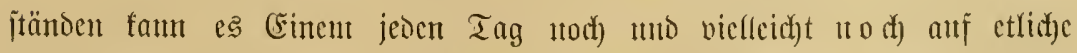

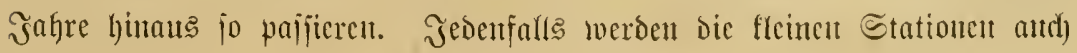




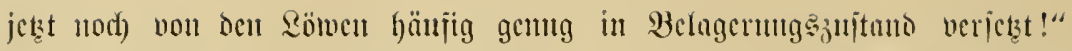

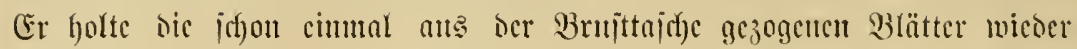

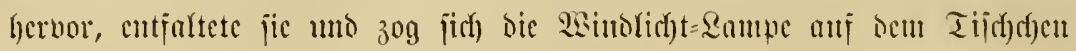

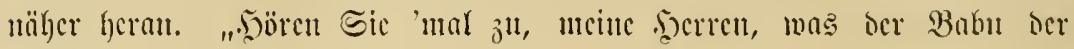
Etation Eimba...."

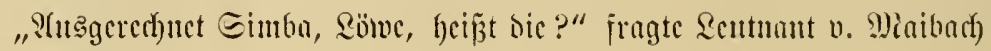
ctruas àmcif̣lno.

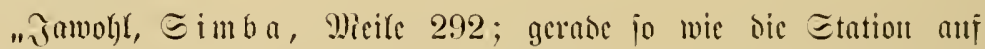
Micile 255: Sima, Miccrfasc, hcip̈t! Der Babu telegraphicet nljo an ben Bctricbsbircftor ber Bahn, in ?(prif vorigen Jabres - o warten Sic

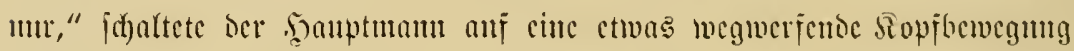

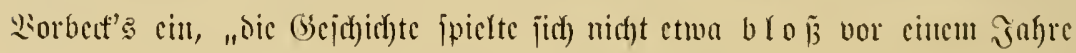

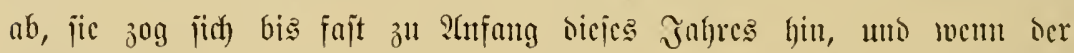

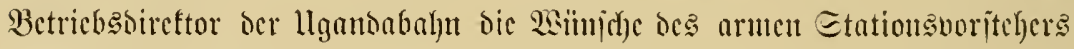

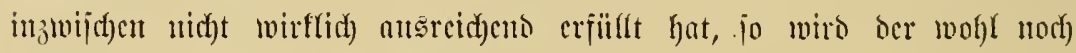
heutigentags joldye Dienjttelegramme non Etapel laijen! - 9 (lio, dą Telegramun lautct: "To the traffic-manager, Nairobi: A lion is troubling tco much since three nights, lying on verandah and trying to get into stationroom. Please send proper cartridges for Snider-rifle first train for protection. $\mathrm{Blank}$ cartridges are

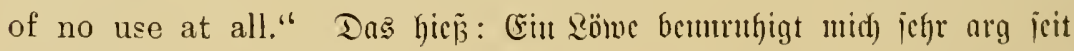
orei 2ä̈d)ten. Er liegt anf ber 2ieranoa mo verjudyt, in's Etationts= burcan ju fommen. Bitte idjidfen Eic mir $\mathfrak{r} i \mathfrak{d}$ tige \$atrouten fïr ciu Eniber=(becwebr, Damit id) mich) vertcibigen faum; umo zwar mit ocm

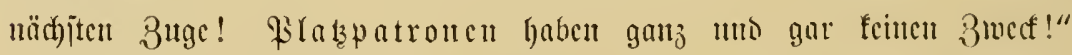

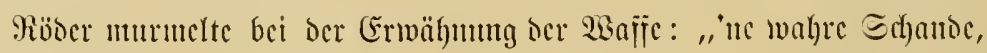

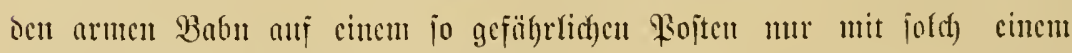

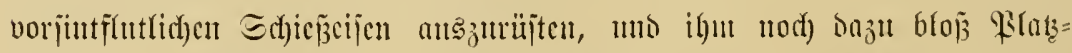

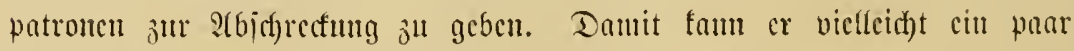

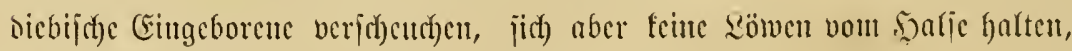
bic von jeiucr Baraja aus int's Burcau wollen!"

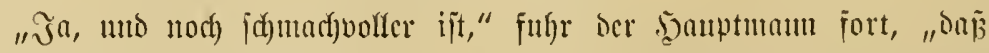

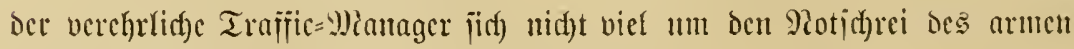

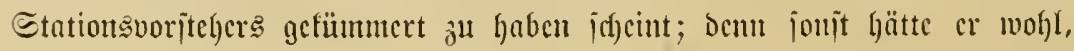


anjtatt bem Manme bloz bie erbetenen "rid)tigen" \$atronen ju idjicfen was er offenbar aber nidyt 'mal getan hat! - gleid) bajür jorgen müijjen,

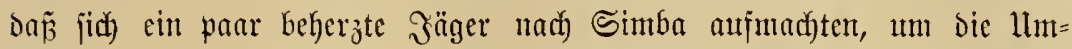
gegeno ein menig von jold)en umerwïmjhten Stationsbejudhern zu jäubern.

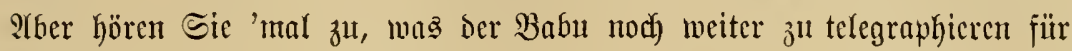
nötig fant: "Urgent! To the traffic-manager. August 17, 1.45 a. m." Der ફ̧auptmam jtofte beim Borlejen. "Ante meridiem?" murmelte er żveifelno, "3/42 llyr bormittags? Das wäre ja bod $n a d j t s$, mo bie Züge waren bod) auf Berlangen ber ftreif=brohenten Sutlis fo gelegt

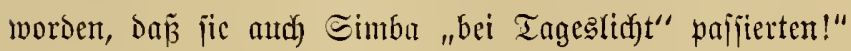

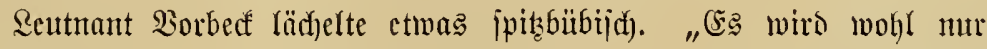

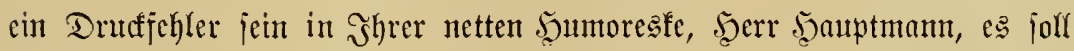

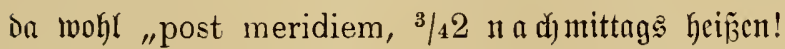

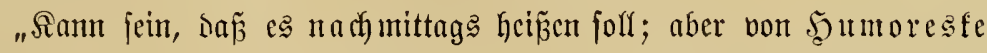

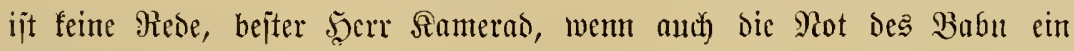

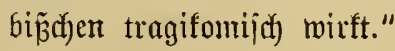

"Wer hat Jłhnen denn eigentlich) die Telegramme gegeben, bie boch

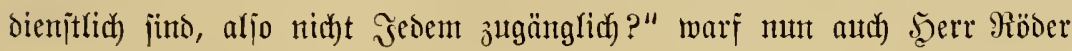
ein wenig zweifelnto ein.

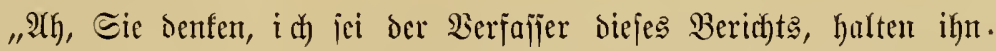

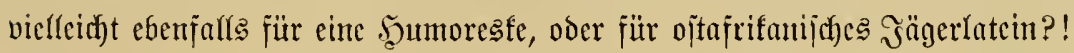

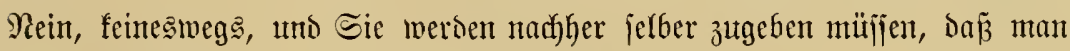

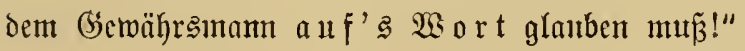

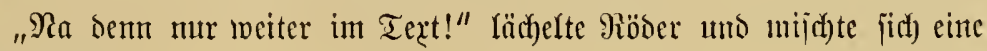
Bitronen= $\varsigma_{0 d a}$.

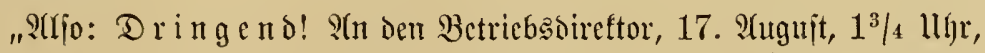

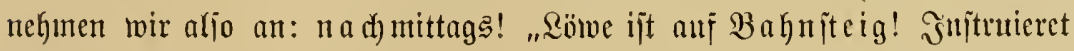
3ug= und Rofonotiojüfrer, laugjan uno olgne auj meit Signal zu warten,

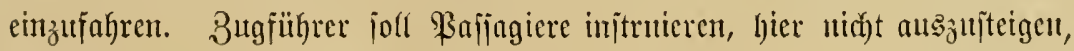

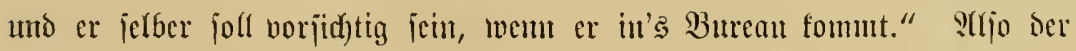
gute Miann war wieder einmal bout cincr humgrigen Siatze bclagert. . ."

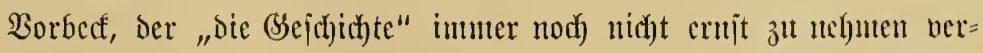

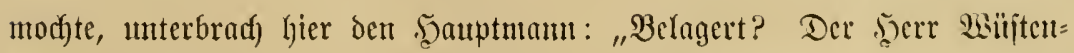

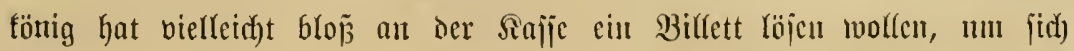




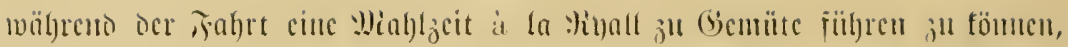
menn ctwa ber signgen bicsmal nid) t abgefängt umo anf cin totes Gelciic geiffoben wïric, wic santals in Simta."

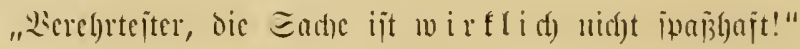

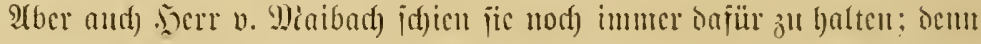

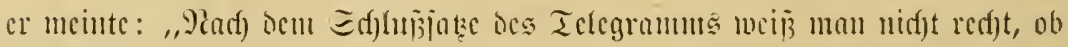

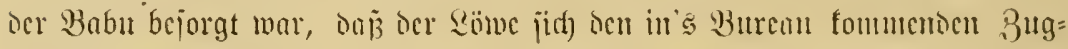

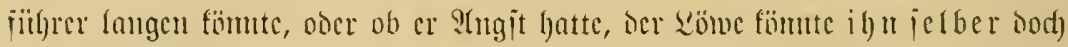
am Ënoe nod) zll pacten friegen, mem! dic Burcautïr geöfinct wïric!“

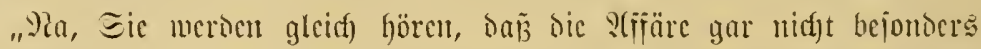

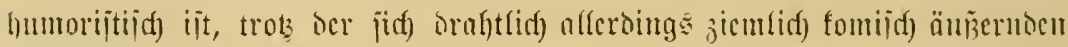

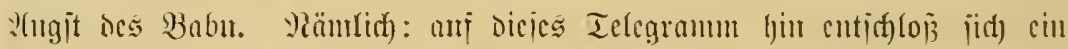

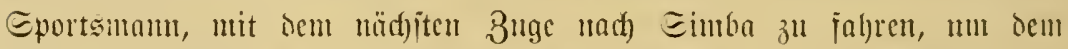

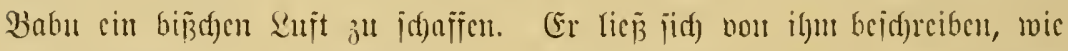

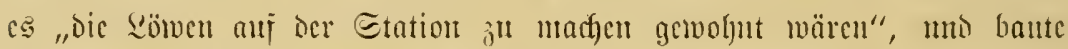

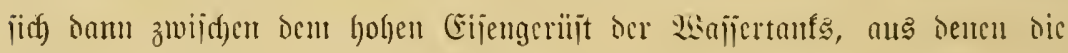

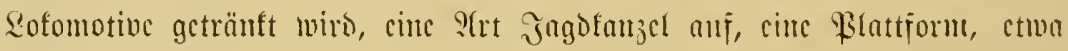

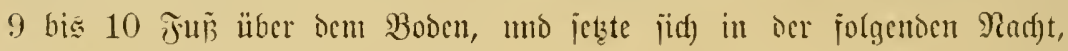
bei jüunjtem Solfunonde, da an."

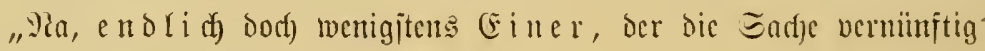
anrï̈ngt!" murmelte Röbcr.

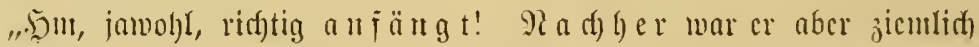

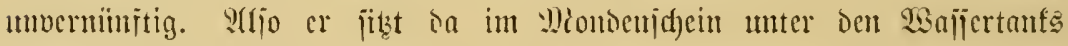

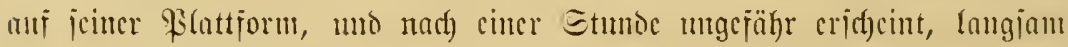
mitten zwijhen oen Edjienen auj das Tanfgerüjt zugeheno, cine jehr

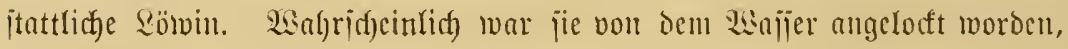

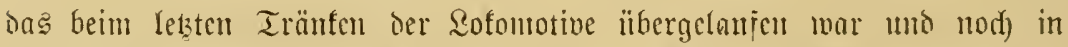

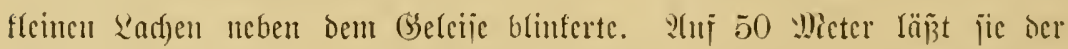
Jäger heranfommen, er hatte mohl guten 2 sino, jo dũ mitterte, uno Dam legt el jic mit ciner tõo Cordit=Siggel um."

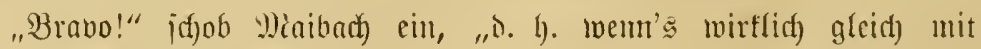
Ber eriten Singel geid)ab!"

"Crtwas ipäter fommen gleich) o $\mathfrak{w c i}$ simba dume an, - 1 in $\|$ n=

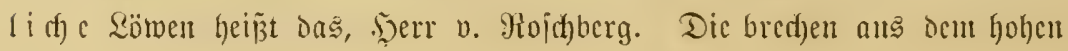




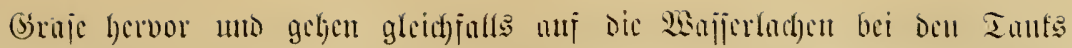

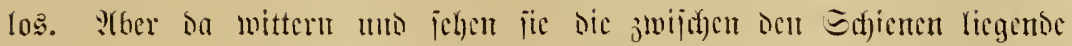

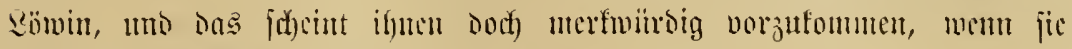

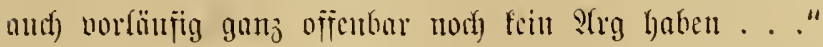

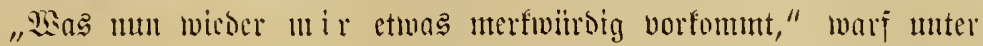

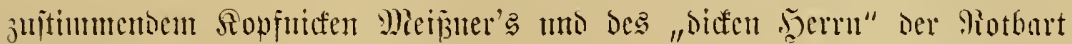
cin. "Dic frion warn boch hïb)itmafricheinlich bereits man-eaters,

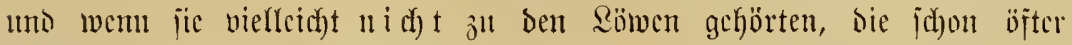

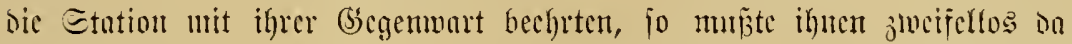

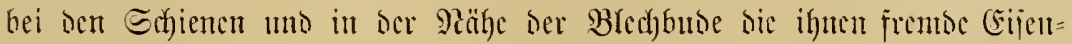

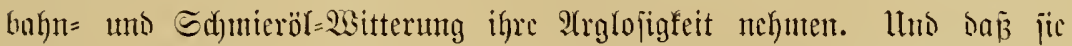

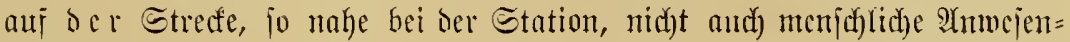
beit gewittert baben jollten, menu auth) nul bie Epuren ber bei Wnfunft

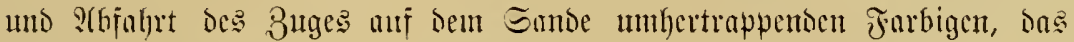
nummt micf) efenjo munter! 9(ber bitte, wic jeigte fict) benn, daj bic Röncu nod) feill PIrg hatten?"

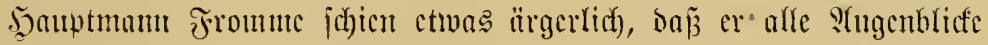

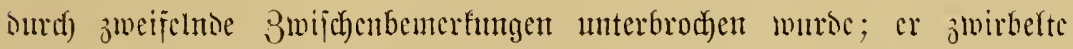

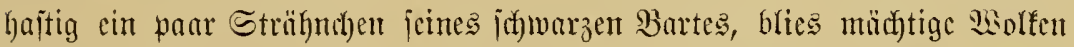
3igarettenraudses nad) oben, fing aber bann rubig mit feincm belicbten

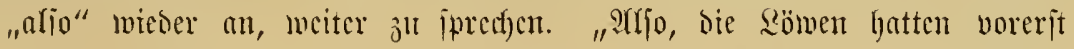

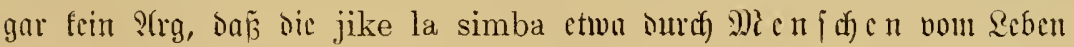

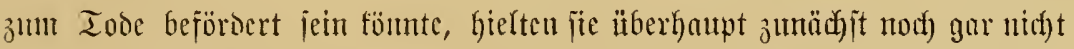

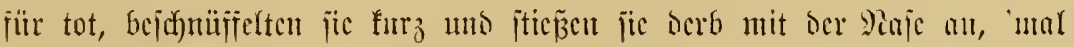
hicr, 'mal ba, als ob jic jie mujocten mollten. gelang . . ."

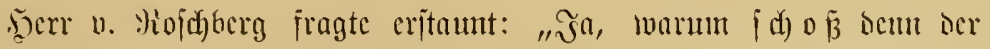

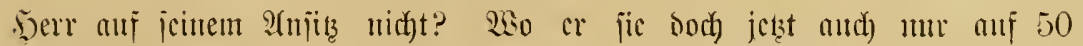

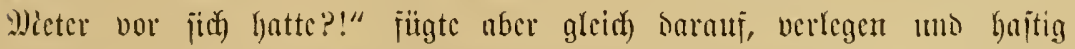

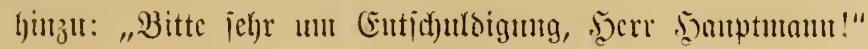

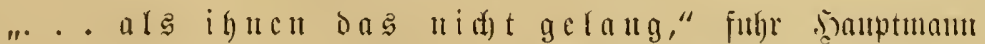

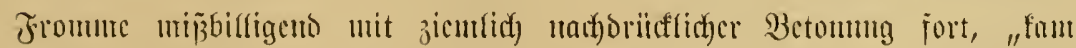

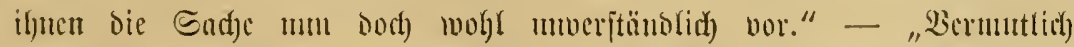

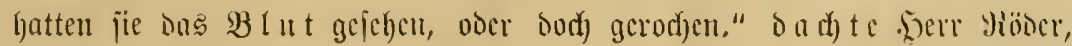




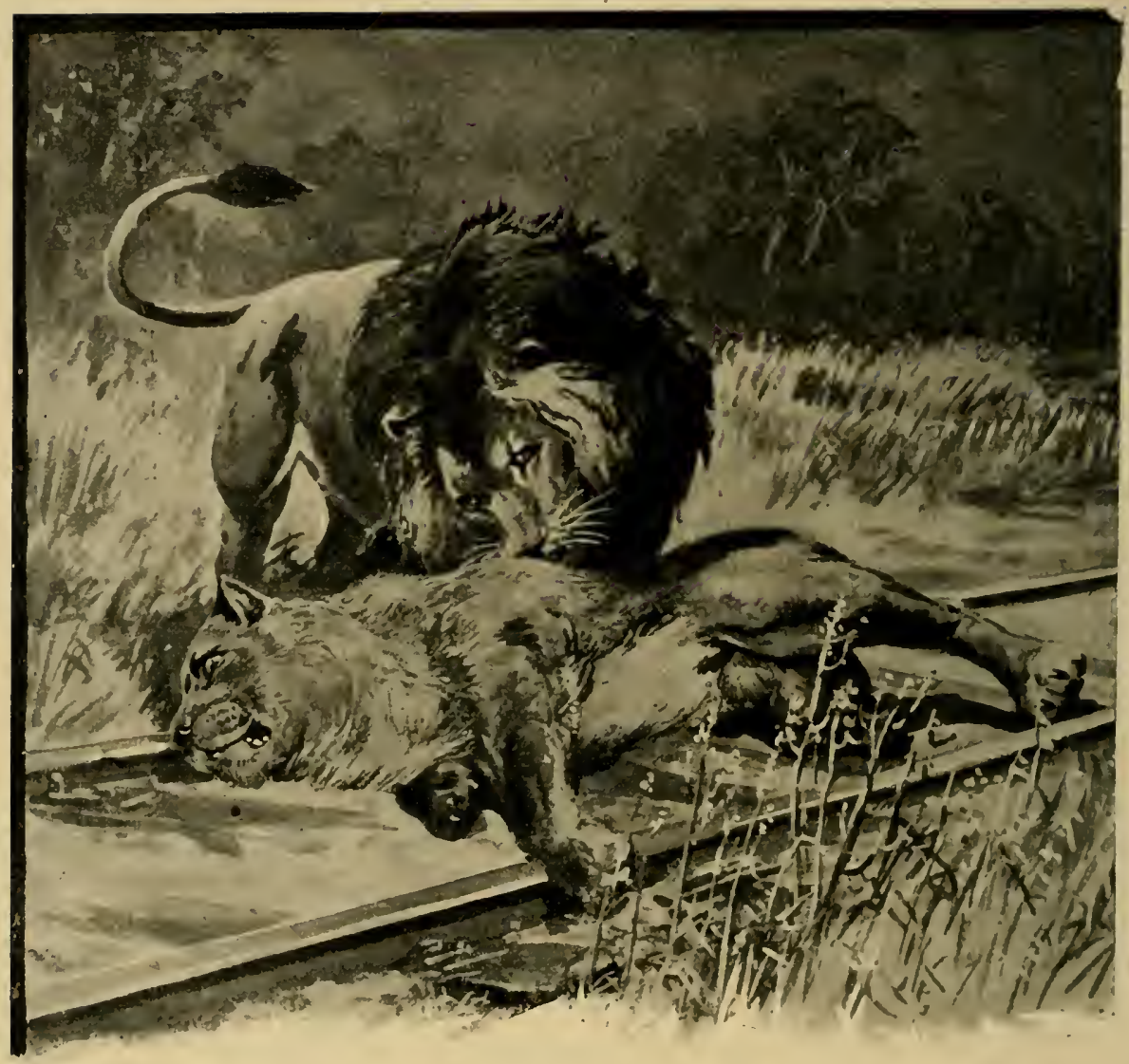

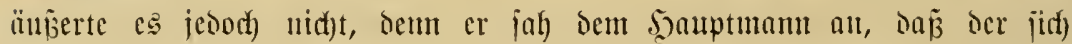

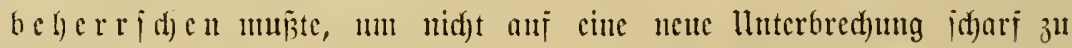

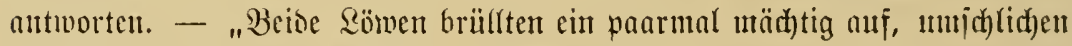
bann bic jike unter Simieln und Simurren, pacten jic an mo jerrten

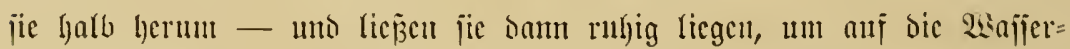

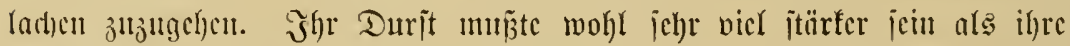

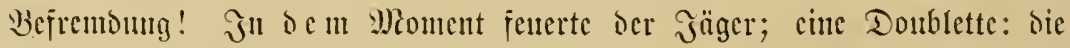
eine Sugel itre of te Den vorderiten Qömen in Feuer, bie jueite aber

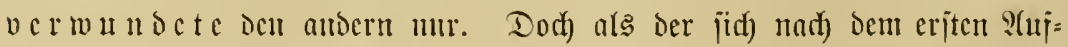
brüflen lautlos wicoer in das bohe (siras jutrüffgezogen hattc, jal) ber

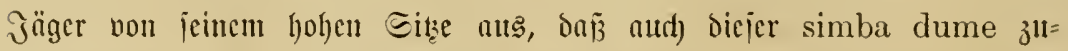

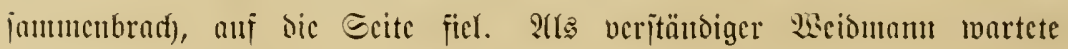




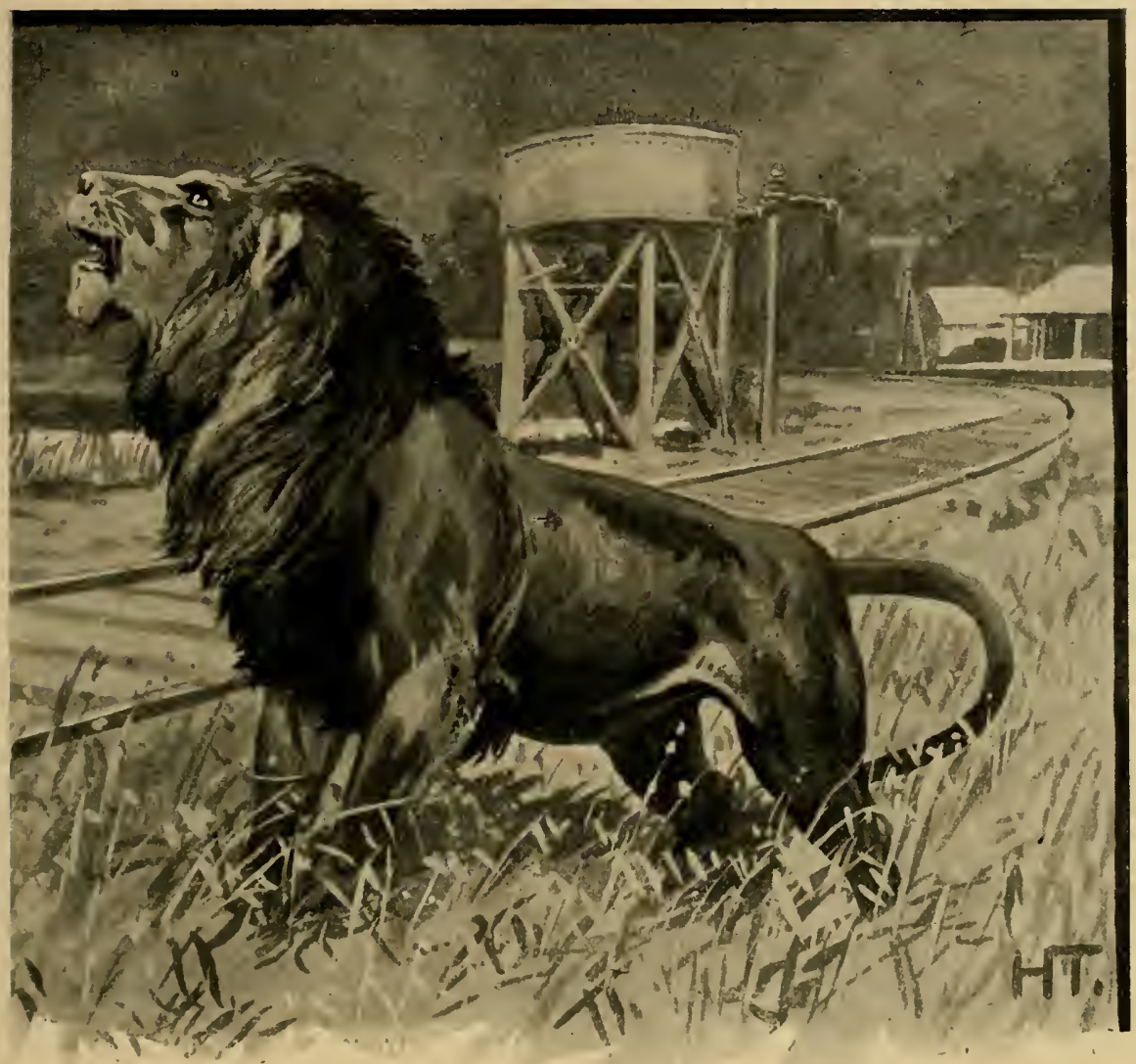

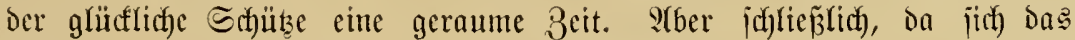
Tier im Braje nidht rïlyrte, nahm er an, es jei zu Enoc. Int mut fam jein Ctücf llmbermunt: anjtatt ocm sömen von oben her norb eine jidfere

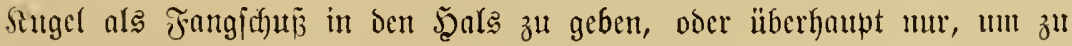
jelyen, ob bas zier noch irgentwie barauf rengiere, fichert er fein (Sienelyr uno jteigt herunter. Bielleidht, weil er jpäter banit renommicren wollte:

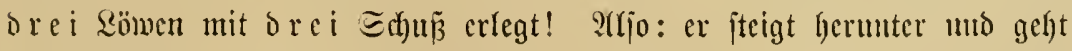
auj den söwen zu. Der wiro aber wicoer hod unt mimmt den Эäger an! Bwar feuert oer ím nod) eine Singel fwijhen dic Sïppen,

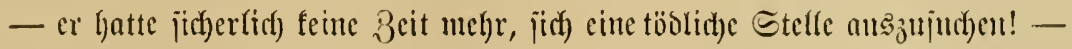
aber on jpringt bie Weĩtic aud jofjon von neucu gegen ign an, pact ben

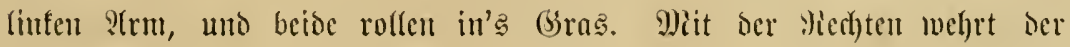




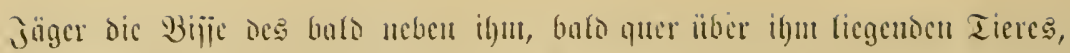

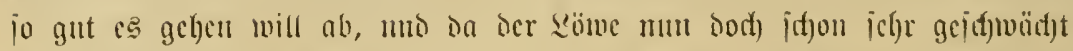

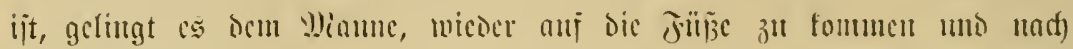

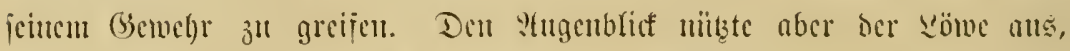

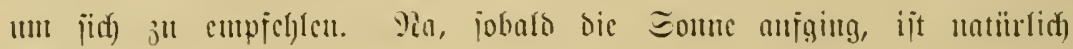

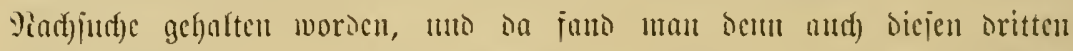

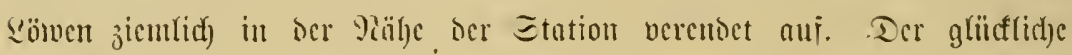

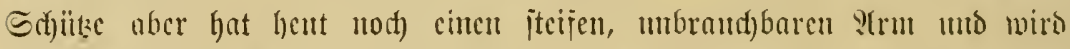

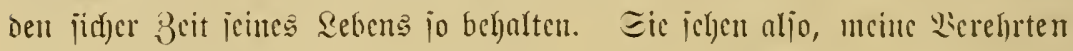

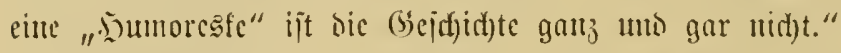

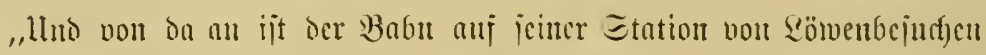

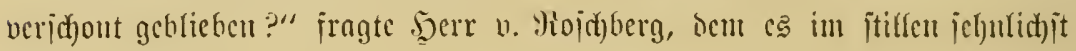

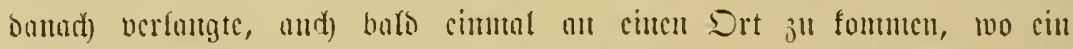

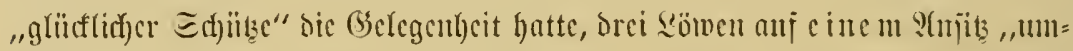

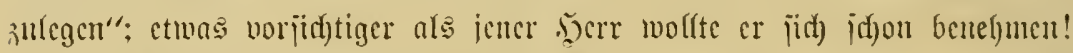

"Qierichout geblichen: Sören Sie zu, was Der Babu an Den

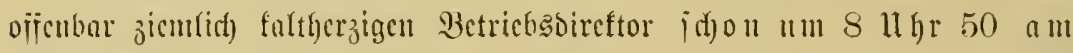
ieflen Wiorgen telegrapfierte, uadfoem un 7 llgr Ber oritte Söme auj

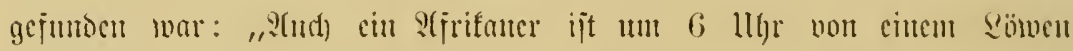

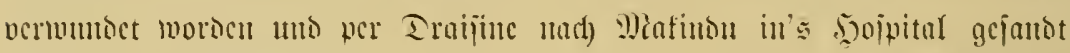
morben. Betricbsireftor, bitte, be it im m t Fatronen fer Siijtenjug Viuncro 4 jenten." Damit war ciner ber Züge gemeint, bic von ser

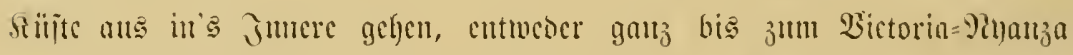
oner wenigitens biz ju den Bentralwerfitätten ier Babu bei Pinirobi."

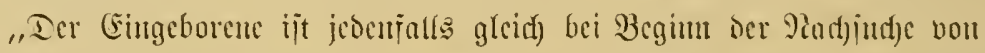

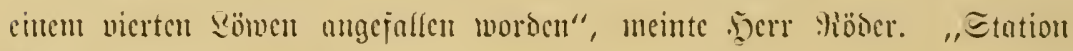
Eimbr ja)cint ja wirffich) ser reine Eammelpumft jïr bic Sömen ocr llgumba= Bahn ju jein."

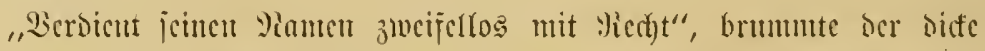

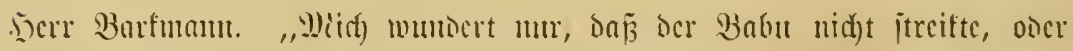

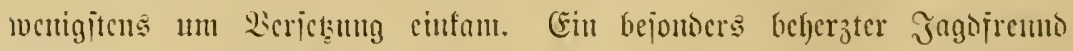
j(f)cint cr bod) ni(d)t jut jein."

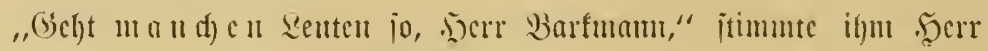

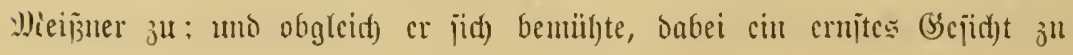




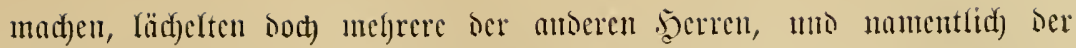
jïh heut abcus faum am (Sejpräd) betciligente Doftor Brumnce, fo „infan",

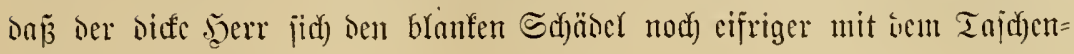
turje rieb als worker.

"Beher3t ober midft," hob Şauptunann Fromme hervor, "was fonnte

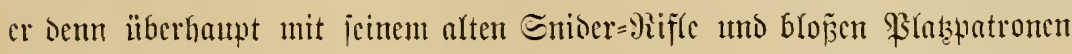
gegen Römen ausrid)ten? Da hätte er woh)l mit cinem cinfachen Neger=

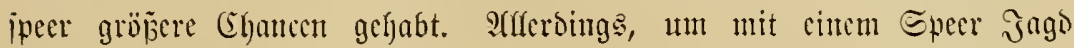

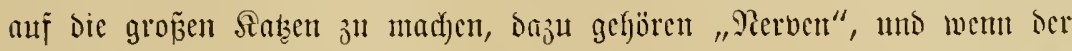
Miann je gute Perven gehabt hat, jo jins fie ifm bei sen \&ömenbejuthen

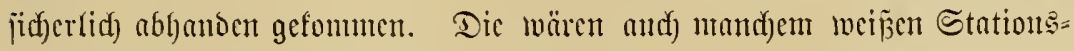
vorjtelyer jul viel geworoen! Es ging ja immer fo meiter bamit! Der arme Serl muste ja nod) an jelben S(bens, umo zmar siesmal "Ẹ̃tra=

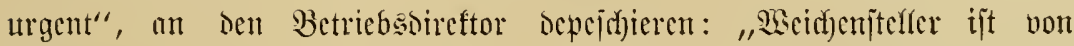

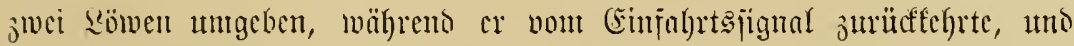

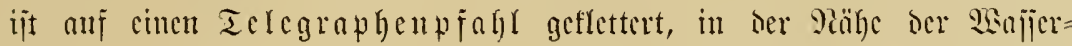

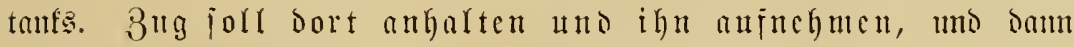
cimfuhren. Betricbesbireftor, bitte sic nötigen Edr)ritte cinzuleiten."

,'me angenebme Eituation für ocn \$seidfeniteller," meinte 2entuant Miaibad), "הa oben angeflamumert an bem Telegraphenpiahl, mo nuter

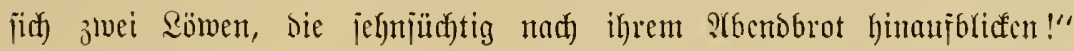

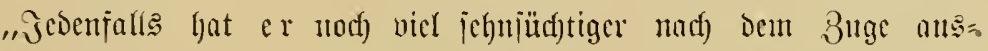

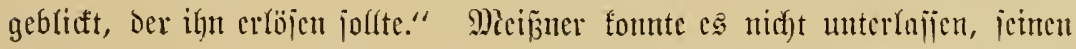
Sonfurrenten Barfmam cin wenig ju necfen unt jeţte beshalb hinju: "Da mag es jidt) jelbjt auf cinem $\mathfrak{B}$ a unc belyaglidfer marten lajfen, bis

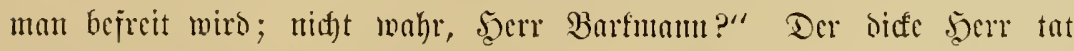

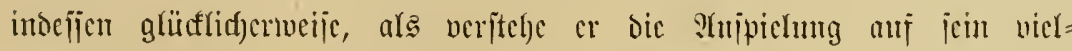

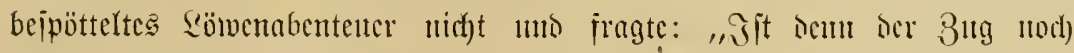
rechtzeitig gefommen? Doer founte jidf) der Wiann ba oben nidft jo lange halten, viedleid)t jtundenlang?"

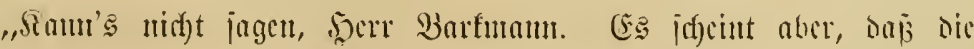

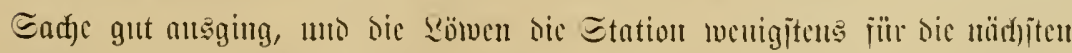

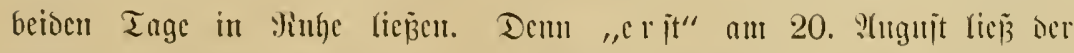

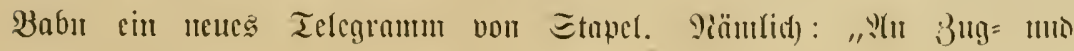




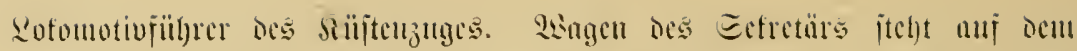

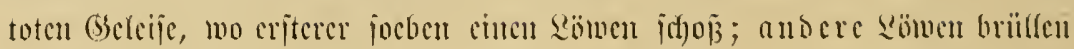

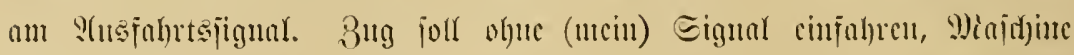

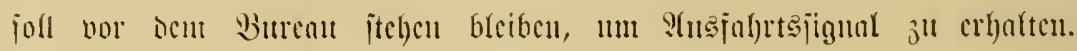

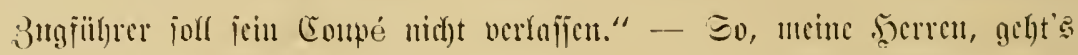

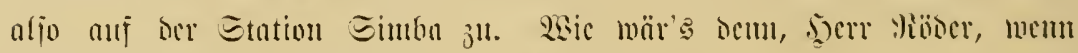

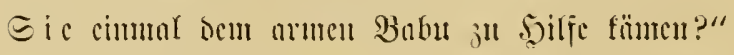

Der Giotbart antwortete mitht gleid). Er batte bie $23(i d f$ anf Das

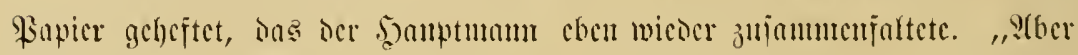

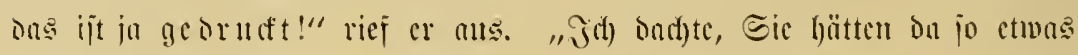

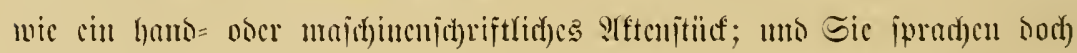

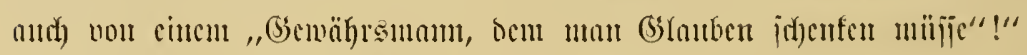

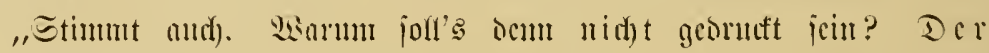

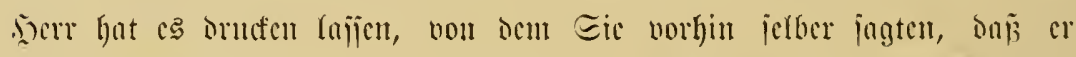

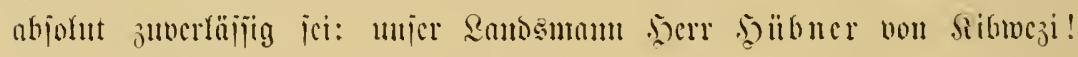

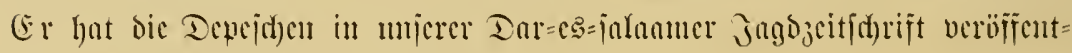

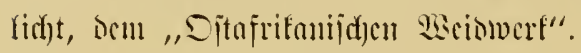

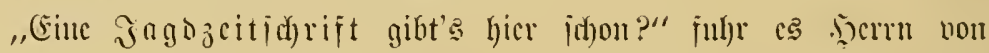
Fojuberg in werbliifftem Ionc bernas.

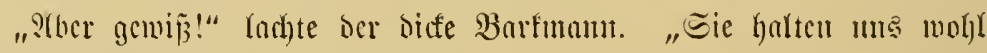

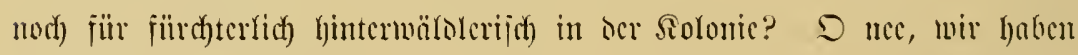

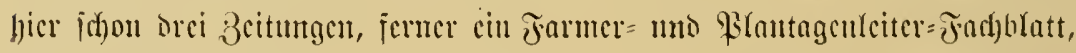

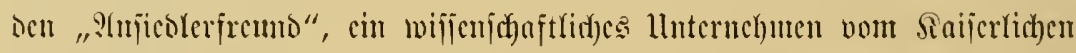

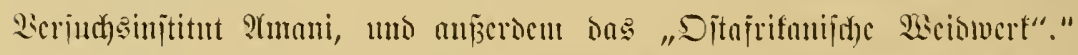

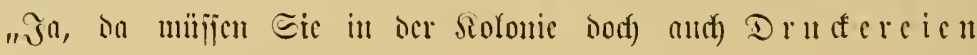
baben . . .?!"

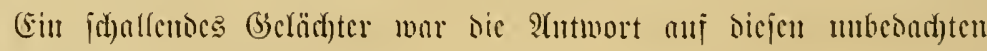

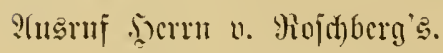

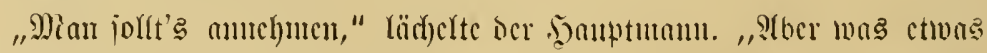
meniger jelbijtecritüntolid) ijt, bas ijt dic Tatjadye, baj mujere 3citumgen umo

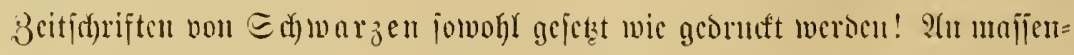

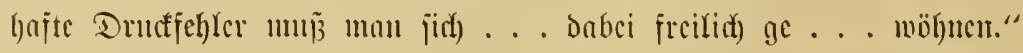

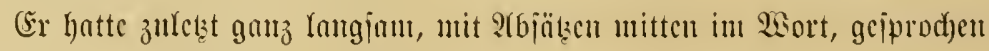

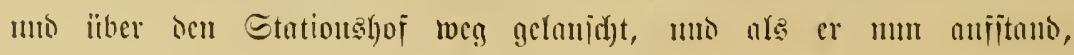




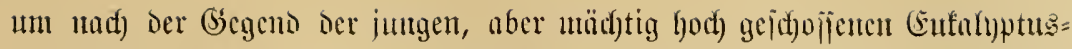

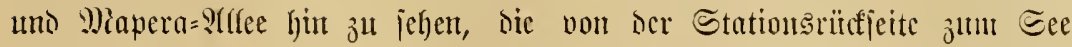
führt, iprangen auth bie anteren beerren hod) unto lauldchten borthin in

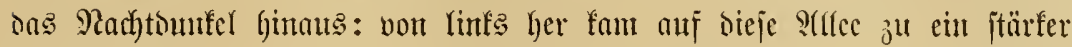
uno itürfer ammad)jentor Särm von Memjchenitummen, als verfolgten viele Seute bon bem jüngit erĭt in einer ber bielen Talöfifmungen angelegten "neuen Eingeforenendorf" auts cinen Flithtenden; Şseiberid)reie gelften

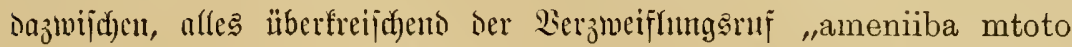
wangu (er hat mir mein Sint geraubt)!“, und jeç̧t bröhnte Dumpf ein

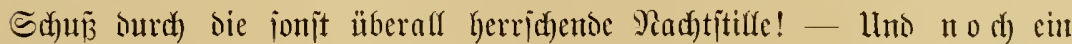
Sdu) Edjitoerhauje mur̄te gefeuert haben!

Dajtig iprang Seutnant v. Sorbesf vom Etemiocfel Der Baraja in Den Baumgarten und licf zum Tore, fhon von weitem ben Fojten amrufent: „Askari! Zuma! Kunáni (\$ojten! was ijt to Yos)? Kwa nini umepiga bunduki (warum hajt Du gejd)offen)?!"

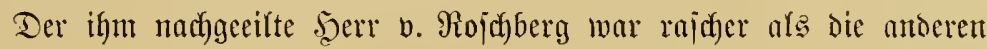

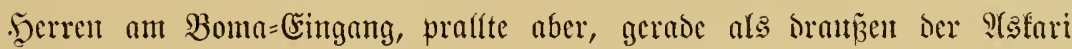

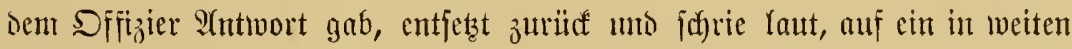
Sprüngen burd) bas Tor, über den weg uto bie niedrigen Stafete ber

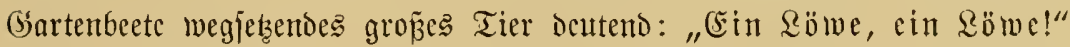

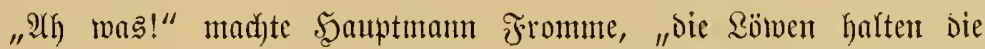
Boma bork nicht für eine (Sijenbahnitation! Jjer treibt's feinen in sie

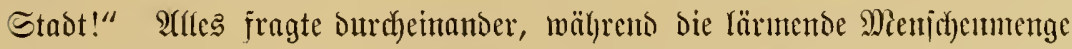
mit ber imuner nod) gelleno (d)reienden Frau jenjeite der Seitemmtanter

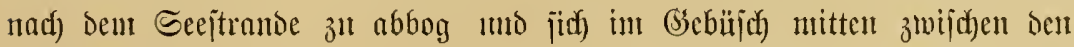
gewaltigen Stcinblöcfen verteilte. Rutr unbeutlich) flangen bie Stinunen nod) herïber; bafür wurbe es aber im Statioutsget)öft felfor rajd) Yehigaft; Demu aus dem Unterofïizierhauje, dem Farbigenlazarett, Dem Sï̈rfengebüntoe,

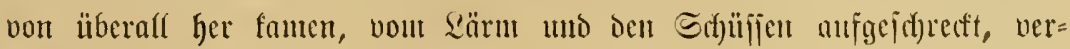
mutubert jith unjegende Reute.

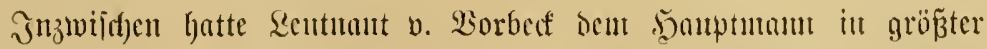

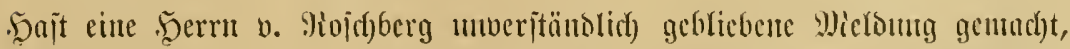

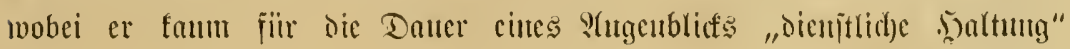




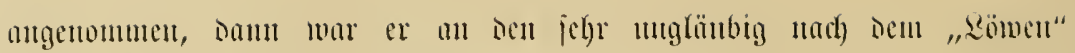

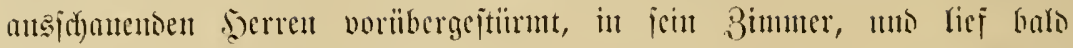

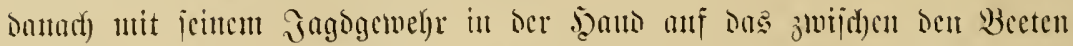

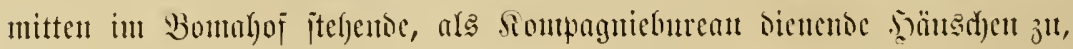

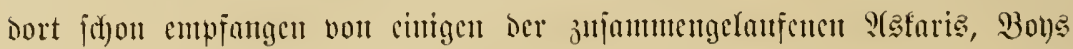

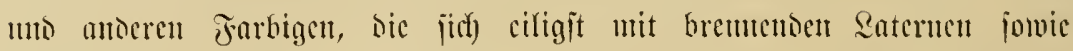

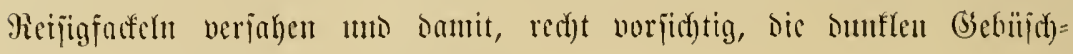
partien Des jogogartens ableututeten.

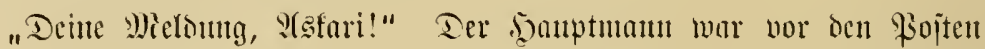
getretes, ber längit neu gelaben hatte

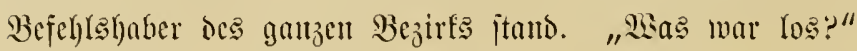

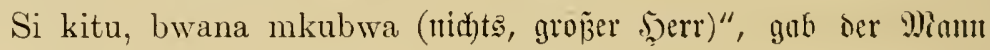
gleid)gülttigen Tones jurituf, "chui tu (bloj cin 2 eopuro)."

"llno ocr Serl hat vorbcigeplempert ..." Ein brïllentes (bejd)rei ber mit Fuafelu nom Stgfariborfe anf bie Boma uno bunu gegen bas

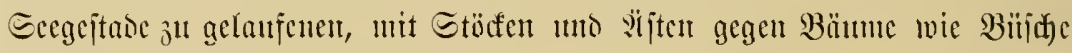

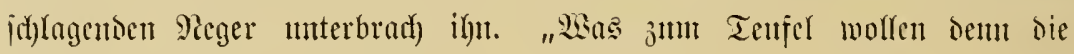
Serta mir Da? !" ricf er an?.

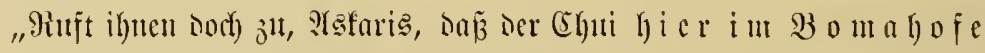

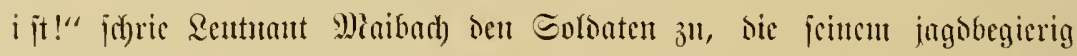

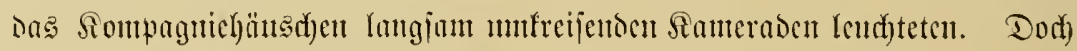

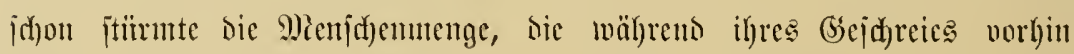
furze 3eit vor eincm bujdybemadjencu Bloct beobad)tent balt gemad)t

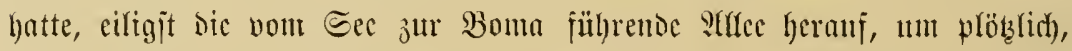
wie angemurzelt, jtehen zit bleiben utto in bie frone cines ber ftarf belaubten,

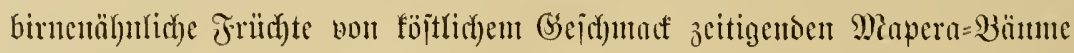

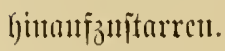

"Yuko! Yuko (oorten ijt er)!" idyrie cill dïrrer S(y)warzer, Der,

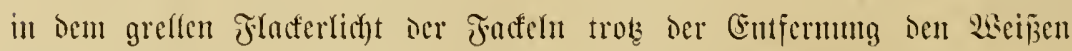

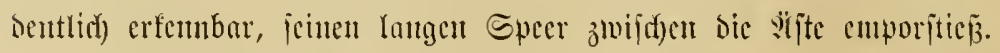

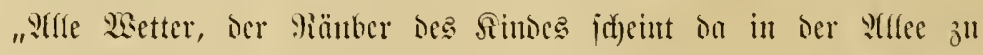

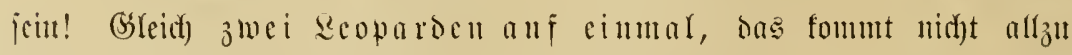

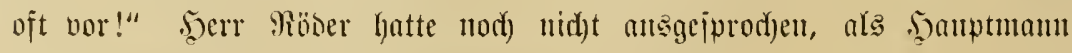
Fromute idfon ocu Qentum Miaibact) anfforderte: 


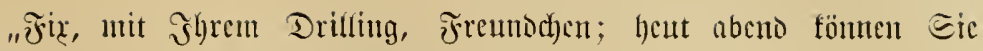

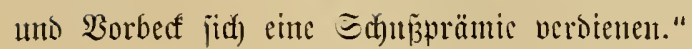

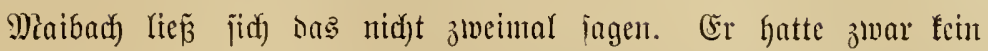

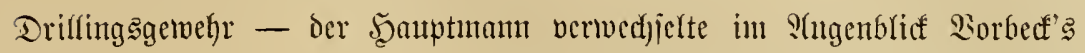

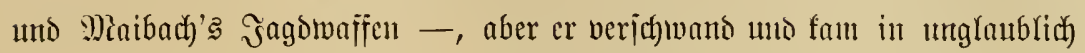

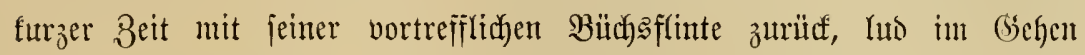

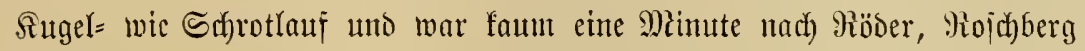

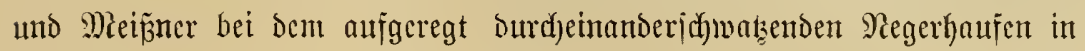
Der $\mathfrak{U l l e e}$.

"Ninamwóna (idf) fehe ifat)!" freijute cin nur im Radytgewanto,

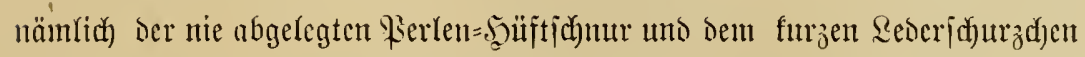
vor dem Miapern itchendes Weib uno wies nady ober. "Pale, bana (ba, Şerr), juu, mtini (oben, alf Dem Baum!)“

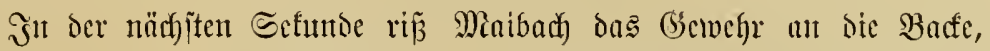

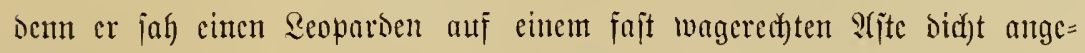
idymiegt liegen, zlour nahež vom Raubgezmeig verborgen, Dod) für Den

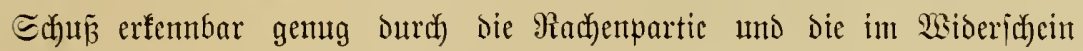

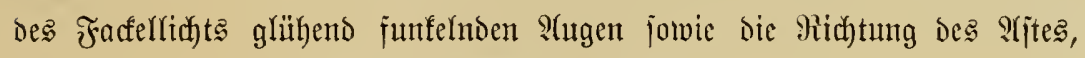
auf dem der Dumfelflectige gelbe Sïrper ruhte.

"Töte aber mein Rint nidht!" flehte bic Frau, bie mit auggebreitctent

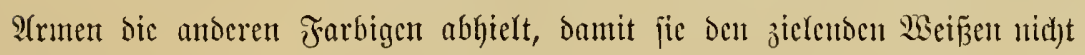
itören jollten.

Maibact) jeţte iiberrajd)t ab uno fah bie Fraut cbenjo berwumbert an, wie ifn bic Mienjidnnmenge anjtarte, sie beim Warten anf jeinen

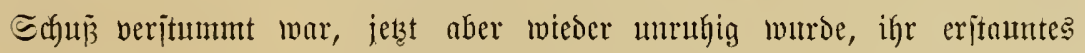

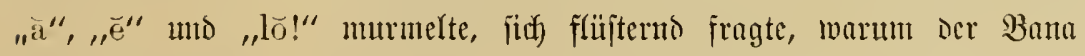

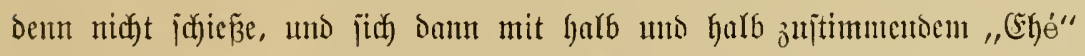

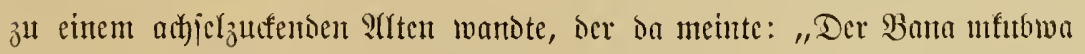

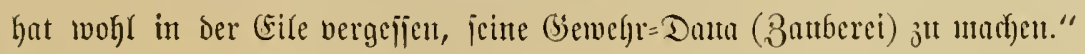

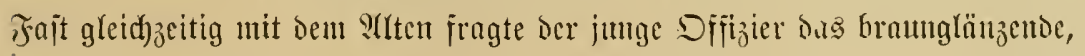

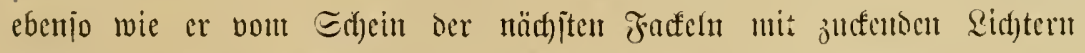

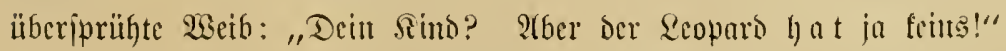

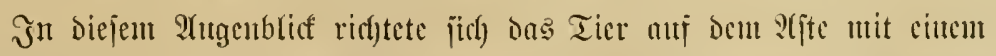

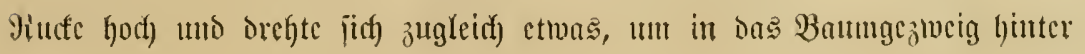




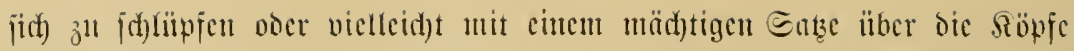

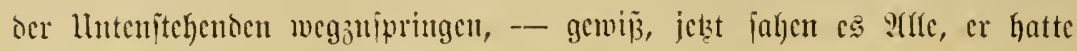

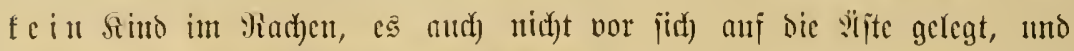

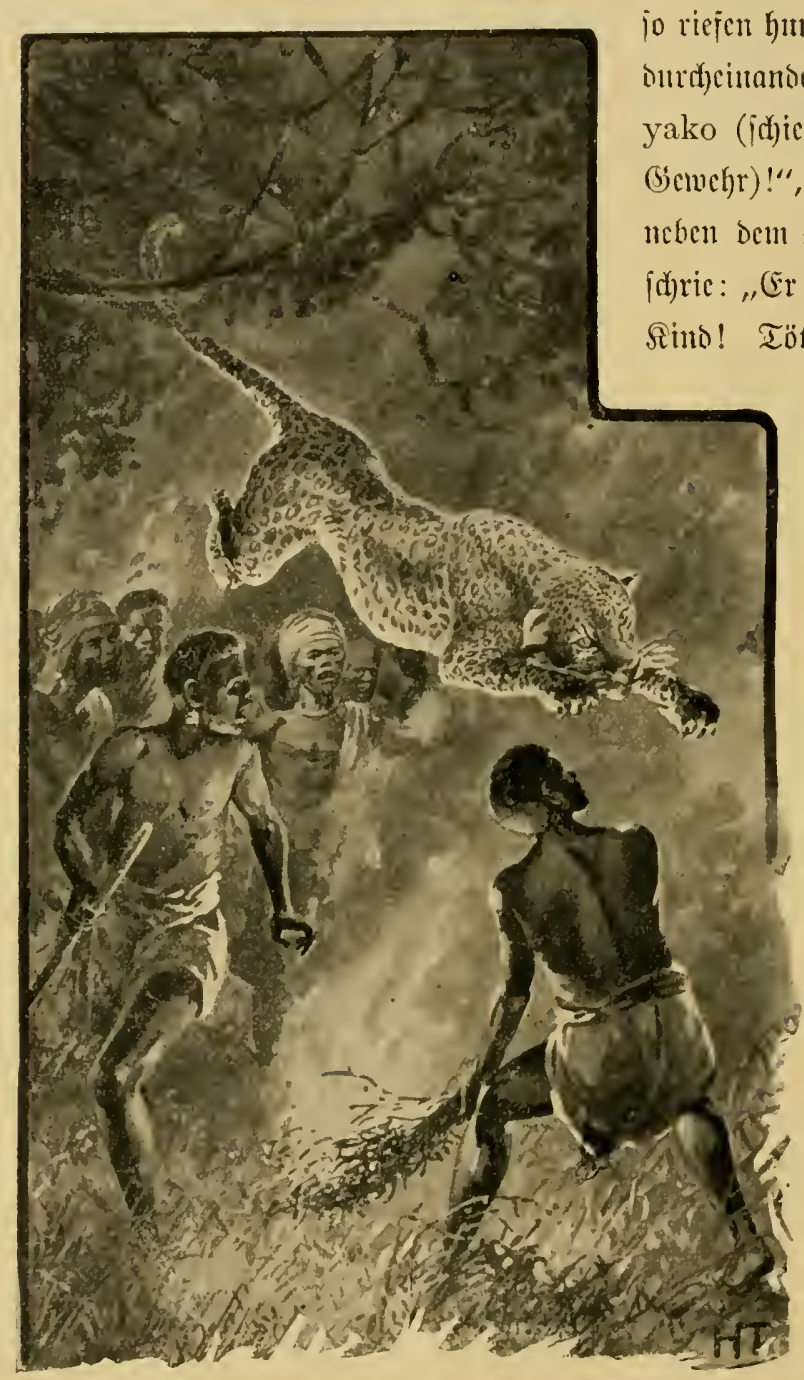

jo riejen humbert Etimunen rajad Dutrtyeitanter: „Piga bunduki

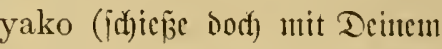
(Gemetr)!", währent das פscib neben dem Difizier gellento auf= id)ric: "Er hat es beritecft, mein Sinto! Töte iłnt, töte ihn!“

Jetz̧t Dutufte jidx) ber Scopard, in meitem Bogenfidunelfte er jidi) iiber bie eridgrocten zujammenfahrenten Meger fort, bod) eche nod) bas giauj(c)en des entlajtet hod):

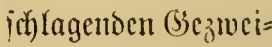
ges aufhörte, bevor Das Tier nod) auj der Eroc den eriten Satz in's (scbiilid) hincin tum formte, Doumerte Miaibade's (ธ)น $u \tilde{B}$, นmo von eimem .jagel grober Poiten in Bautd) und Şinteridyentel getroffen, mälzte jït)

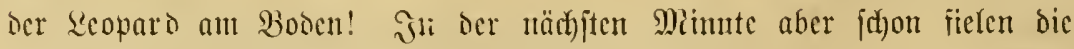
Ed)marzen mit Epeeren uno juberen Sinitteln über ihn her, trotz Miai=

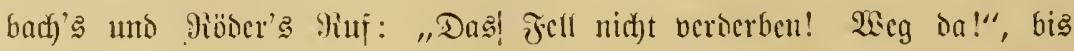

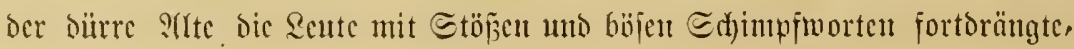


jeinen Epeer hob mo mit cincu fo fruftuollen Stoje, wic utun ihn ocm

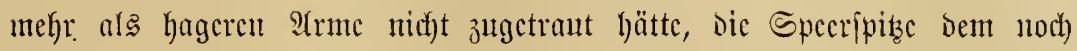

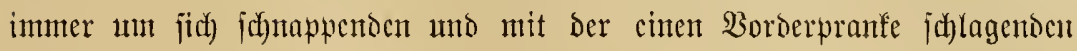

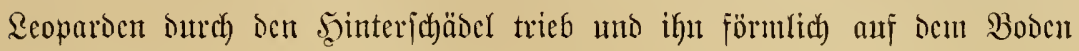
fiptnabelte.

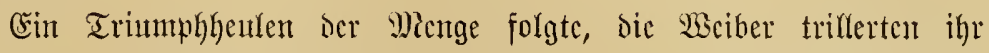

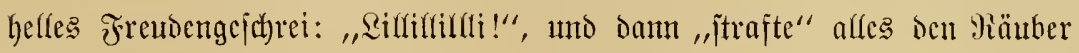

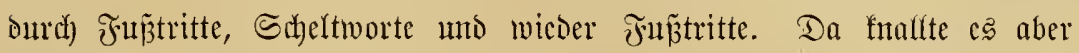
vou Bomahofe har, eimmal - jweimal! Uno nod) cinntal!

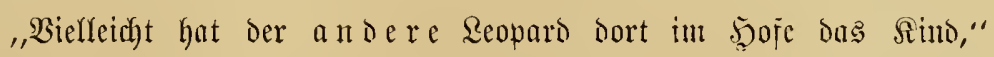
mcinte ciner ocr STefaris ju bem bcraubten $\mathfrak{W e i b e , ~ d a s ~ a n d a u t e m o ~ m i t ~}$ Füßzen uno Fäuften uno wie in Sprudel hervorqueflenden Seffimpfrcoen, ciner Jurric gleid), gegen Den erlegten (Chui raf̣te uno fobon ganj mit jeinem Bhute bejpriţ̧ war.

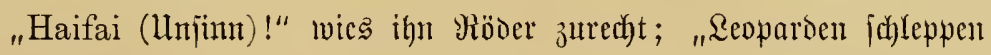

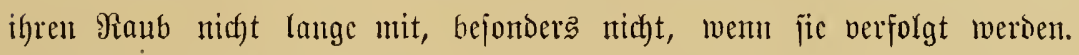

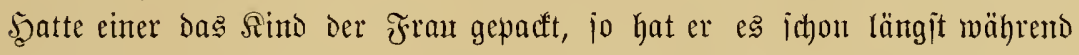

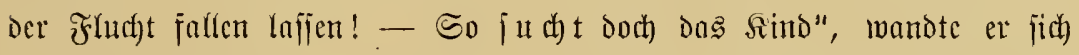
an dic Mentge, die unr jögerno von oen toten Reoparden ablieş, als Reutnant Maibach Zweien gebot, bas Tier bei Den jeinterläufen hoch zu heben uno frei vor ihm herunterbängen zu laffen, samit er sie (S)röf̧c Des zu feiner Freude ganz ungemöhntich itattlichen Chui beffer crfenten fönte; "Yeuchtet trod) Den $\mathfrak{W e g}$ ab, Den igr hinter Doul Tier her genommen habt; haltet cuch doch hicr nidht ntit all joldycu Dummbeiten auf, wapumbafu (ínr Iröpfe)!"

"Ih, mtoto (ci richtig, das Sint)," untruclten cin paar Seutc, "dus

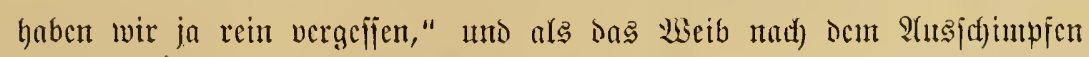

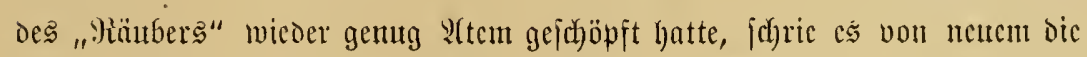

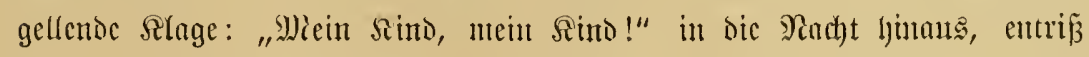

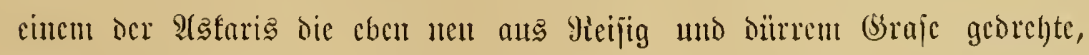

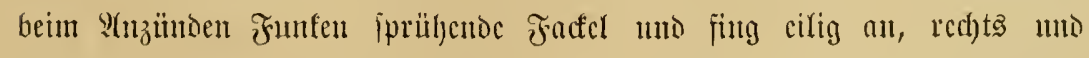

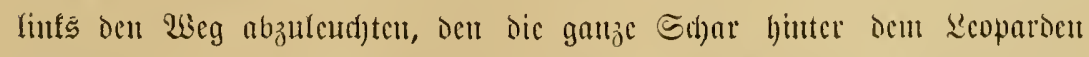

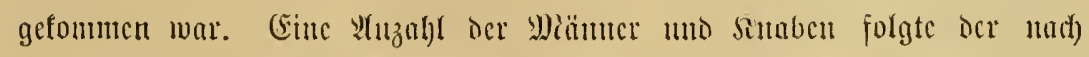
ifrem Sinte juthenton Sintter audf); Dic meijten aber zogen Giuter den 


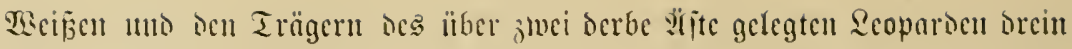

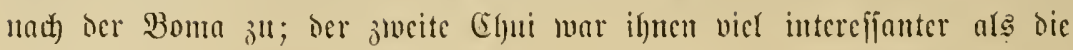

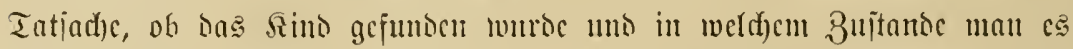

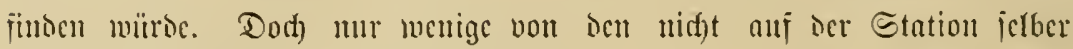

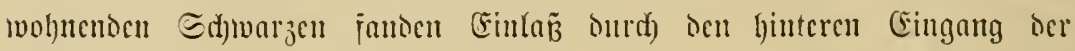

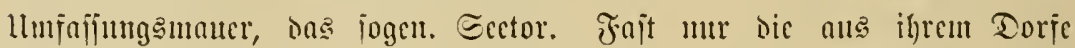

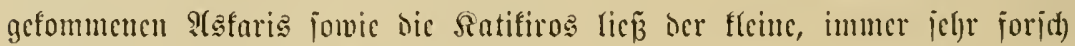
anftretende Smbajd)a Snma bincin - "joidt" iprad) er jelber dos von

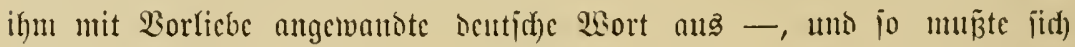

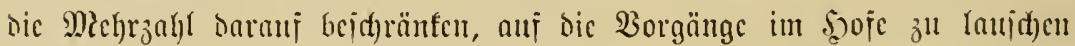
uno ifre Meinumgen ausjutnuid)en, bis cincr oer Sirizicrbous zu ifnen trat, unt um jïd) wid)tig ju mad)ch, jagte:

"Tunaje, tunaje (wir haben ihrn)! (seht unr fort, uno legt cuct)

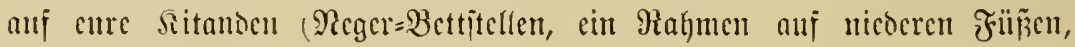
unit federndon Fajeritricfen beipannt). (beht mur; hicr gibt's nichts mebr ju iehen."

Es gab jesoch balo nod) ctwas ju jeheut uno jür den Doftor Brumucr

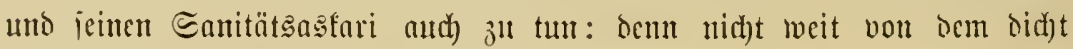
bei cincr Şütte erridjteten fleinen Biegenfrale, den bic Secoparisen un=

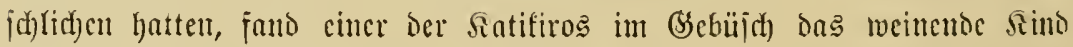

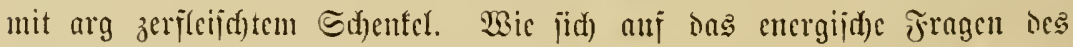

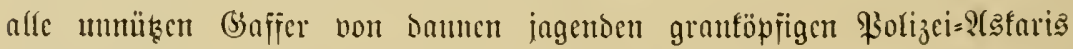

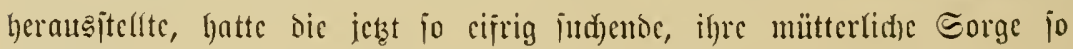

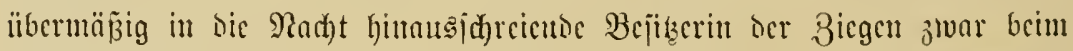

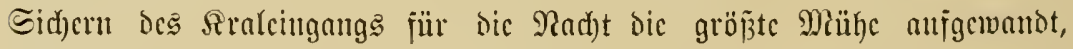
Dautit ifren Biegen nidhts pafjieren tönnc, aber babci gau ifre neben ocn

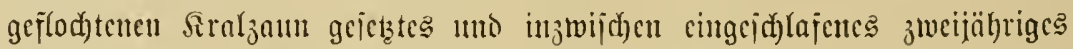

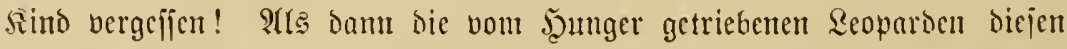

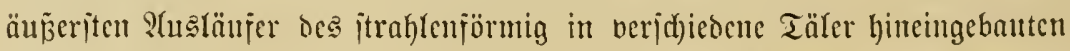
Ortes umjulfidyen uno iefre bald den Ziegenjtall neben oen Yckęten,

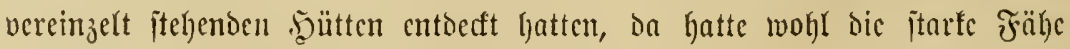

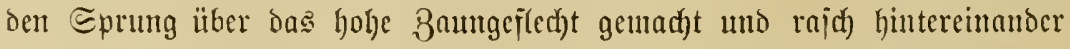

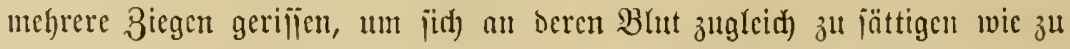

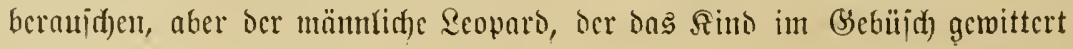




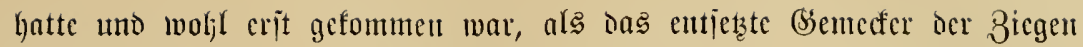
bie Şüttenbewohner aufjocfte, ber chui dume hatte fofort dic ihm jo bequem liegenioe $B$ cute in dent Fang genomuten und war vor der bente=

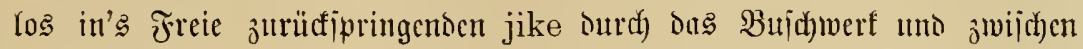

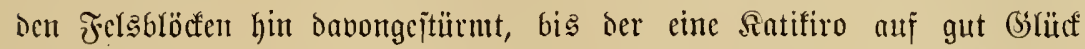

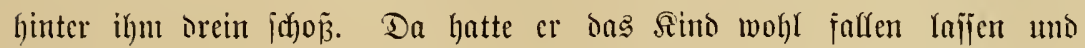

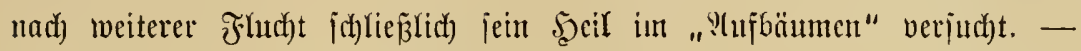
So flärte jich) die "dumme (sejphichtc" auj, wie jie der Stabsarat ärger=

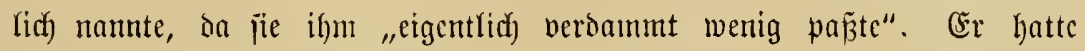
heut, wie alle Weiñen der Station, "îtarf herammïifien", war jehr mïbe, uno hatte morgen vormittag Sen Marich mit der zweiten ?tbteilung vor.

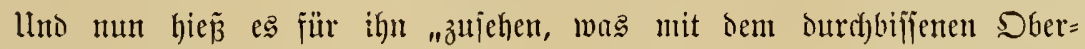
ichenfel" anzujangen war.

Dod) er ging flinf an bie 2rrbeit, unto die in igrem \$irauterabendo

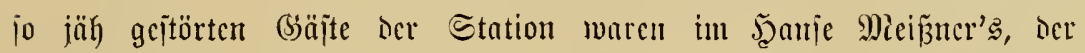

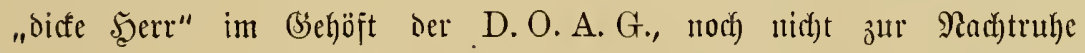
gefommen, da war das Sind ichon, genäl)t, geichient unto banougicrt, als

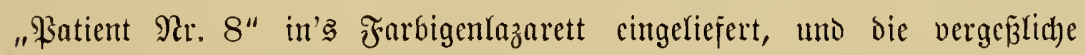
Meutter mit Dem Bejehl nach Şaụe gej(hicft morden, jich ınorgen früh beim

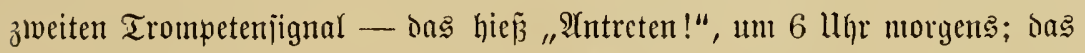
erite Signal um $5^{1 / 2} \mathfrak{a h r}$ war bas "Wecfen" - im $\mathfrak{L a}_{j}$ arett wieder ein= zufinden uno dem Mitoto jein 巨hafulla zu geben. Denn bas 3weijährige

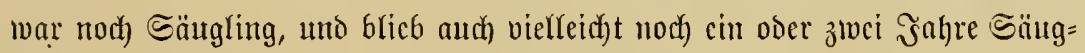

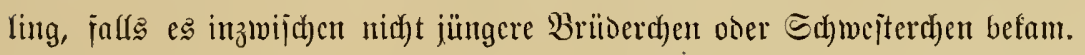

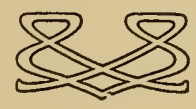




\section{Zehntes Kapitel.}

a. plake mit dem Flaggemuajte bor bem ricjigen Baume bedeuteno meniger iolsatijodes Reben uno Treiben, wenu auch bie jonitigen ?trbeiten ber

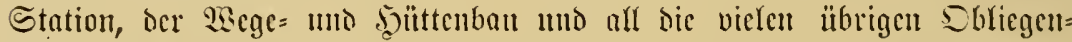
heiten unter 5jeranjichung mchrerer humbert idywarzer "Stcuerarbeiter" uneingeid)ränt weiterbetrichen wurben. Fïr ben Eeiter ber Station mo

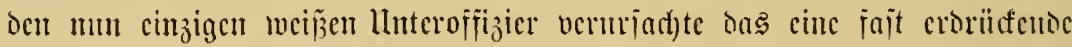

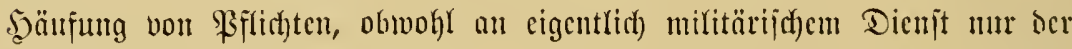

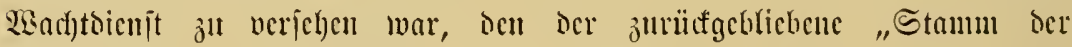
Sompagnic" - 14 S(sfaris - in hergebrad)ter sicije jtramu uno piüttrid) tat, uno im ïhrigen mur die "jüngiten", jullezt cingeitellten

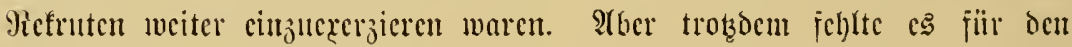

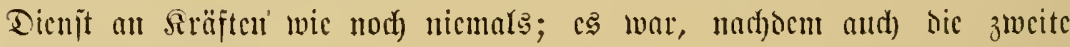

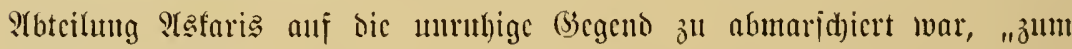

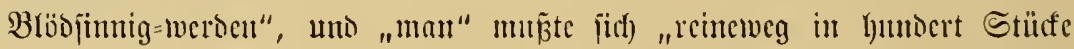
jerrciß̄en", bamit alles wenigitens notoüritig flappte, wie llnteroffizizer

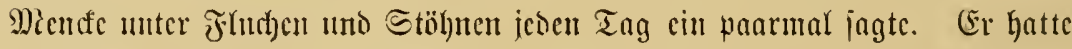

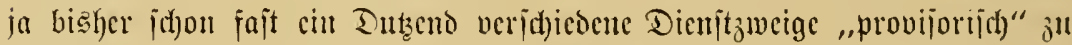
veriehen gelbabt, jekst aber lagen alle \$iflid)ten jant uno jonters anf den

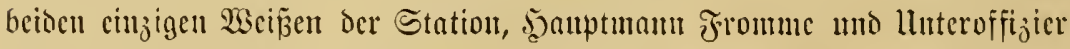

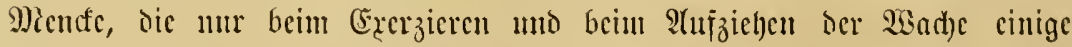

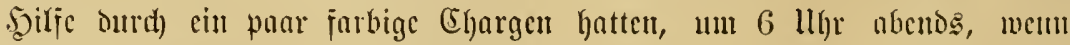

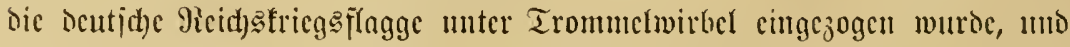

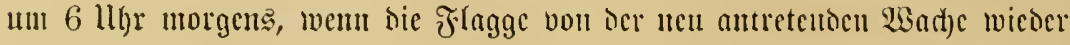
geliā̄t unurde. 
Excerziert murde übrigens non nun an auth auf Dem fid zum (bsejtade der Bubt hinżehenten flachen, einer Wieje ähnlidyen (belänte hinter bem

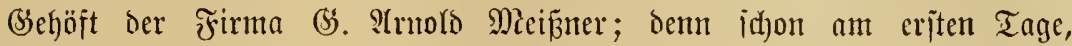
nachdem Seerr Meiß̄ner $\mathfrak{S e r b e r ~ f u ̈ r ~ d e n t ~ b a n a ~ m k u b w a ~ R e d a , ~ D e n ~ b a n a ~}$ ndevu nyekundu, in bie Dörfer auggejdjicft hatte, waren aud) die erijten Seute, teil trgsentfernung Yiegenden Dörfern angetommen, um jich als Träger, noch lieber freilich als $\mathfrak{U}$ safaris für die msafara des berithunten roten Jä̈gerß

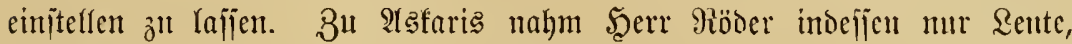

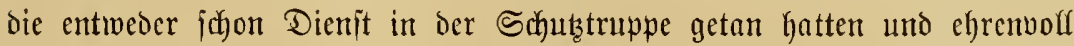

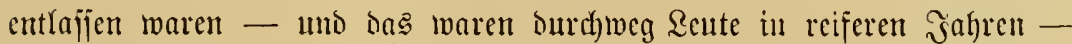

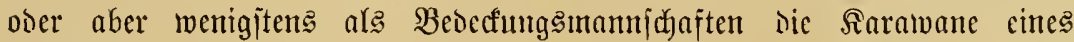

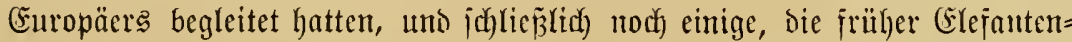
jäger von Beruf gewejen, deejen Beruf ichoch hatten aufgeben mitijen, meil es nahgerade in lifufuma nid)t aflju viele Tembo mehr gab. Dieje ehe=

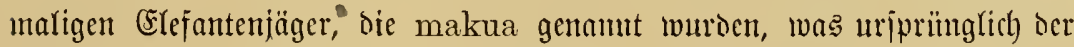
Rame eines auf Erefantenjagoen bejonders erfolgreidyen Stammes war,

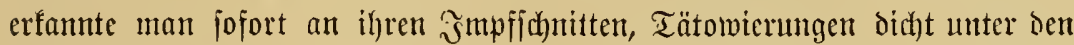
Augen, am Unterarm uno zwijhen Daumen uno 3eigefinger. Sn bic jrijhen $\mathfrak{B}$ unden sicjer Schnitte hatte ein Zauberioftor, ber zugleid) ein

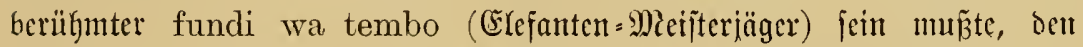

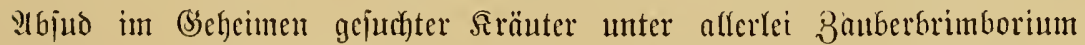

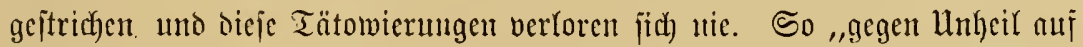

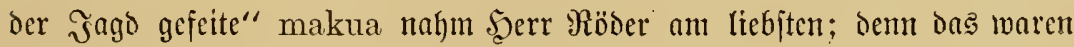

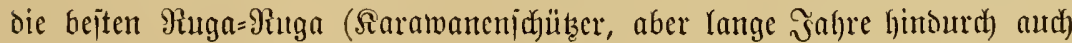

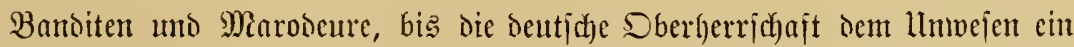

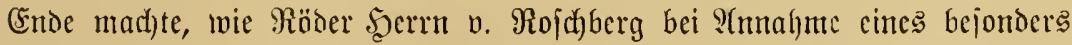

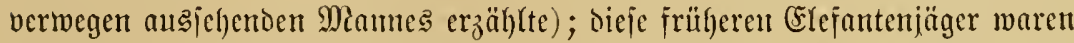
cben mehr als alle $\mathfrak{A n t h e r e n ~ a n ~ S t r a p a z e n , ~ D u r i ̂ t ~ u n o ~ S ̧ u r g e r ~ g e t w o ̈ h n t , ~ u n o ~}$ nicht minoer baran, faltblütig jeocr (SSejahr entgegenzujehen uno mit rajd)em

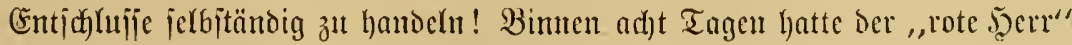
aแล den von ịenem Rufe autgelocten Reuten ${ }^{3} / 4$ ier nötigen Träger uno bie

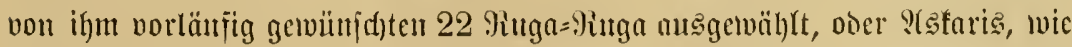

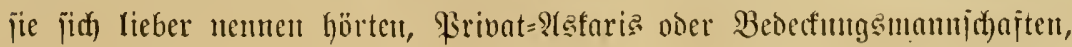




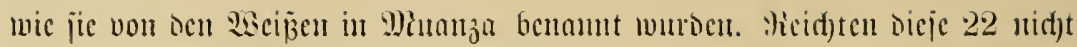

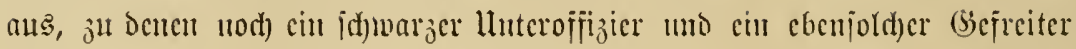

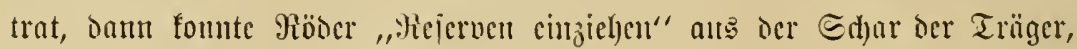
uno jid)erlich unterwege nete Iräger jür bie ïberzä̈llig gemordencn \&ajten unwerbeu. - CEs ging alles flotter, als Röner jelber gedadyt hatte; er wartete autd) nid)t lange, ionocrn f̈̈ng idfon, ehe cr nod) alfe Seute ju= janmuten hatte, mit jeinter jid) täglid) vermehrenden Elcuten Truppe an, ice

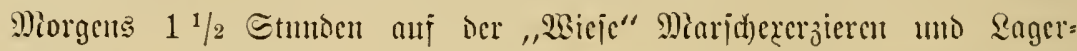

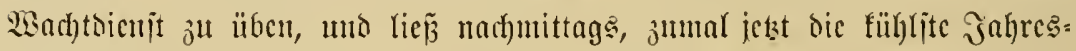
jeit war, jeine freilid) nod) nid)t cingeffeiocten ?(staris jwoci Stumoen

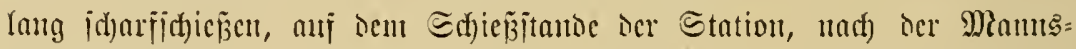

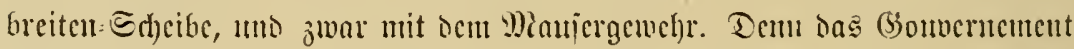

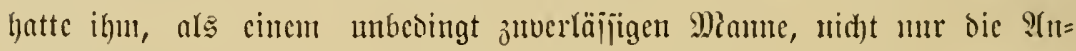

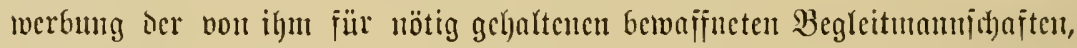
Ђ. h. ", I:

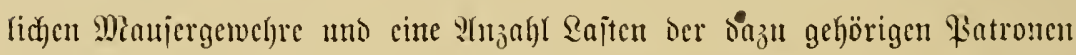

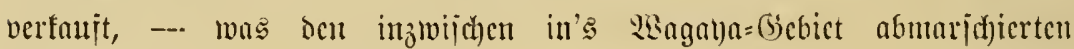

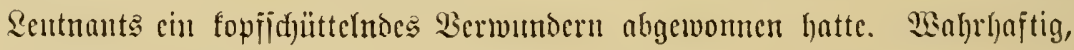

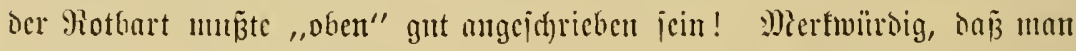

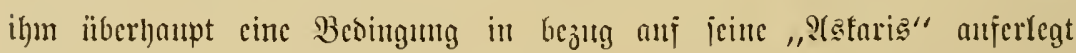

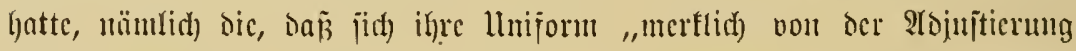

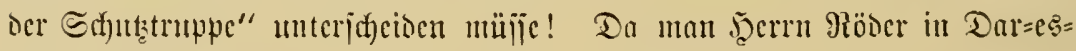
ialanm ichon (becwelyre uno Ratronen, Reibfoppel mit saran hängentom,

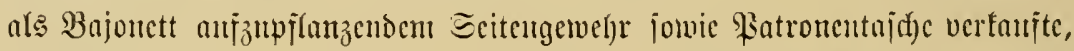
fo bätte man ihm bod) cinjact) aud) nod) dic fafijarbencu S(sfari=llniformen

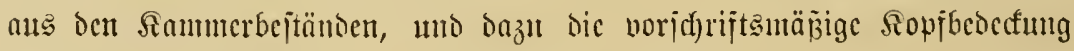

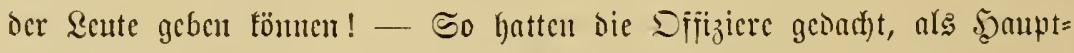

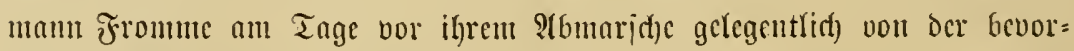
itchenoen (Fintleioung Der Röser'id)en Reute geiprod)en hatte, mo jo untrrte

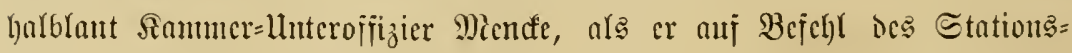

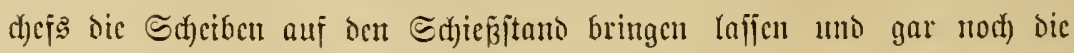

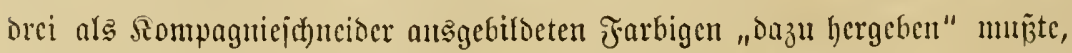

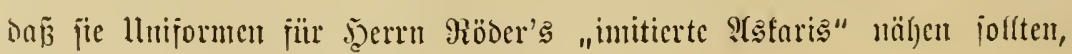
anjtatt in ocr Front Dienjt zu tum! 


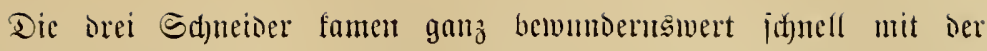

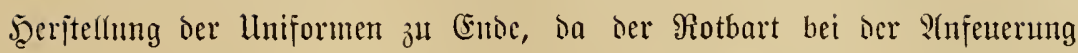

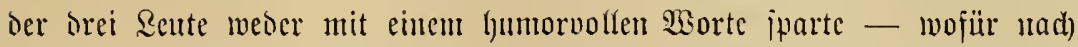

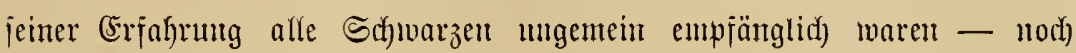

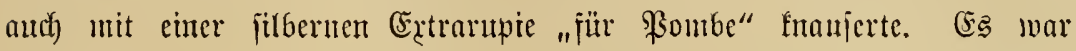

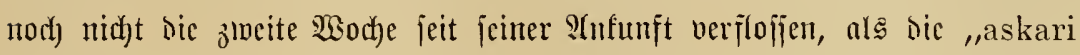

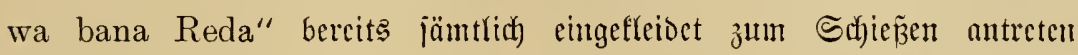

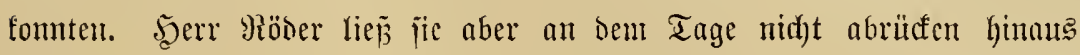

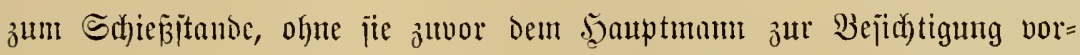
geftelft zu ljaben. Der follte jehen, wie die "Bedingung" erfüllt war.

Die Reute waren in jwei (sficsern angetreten mill itanden, nach) der

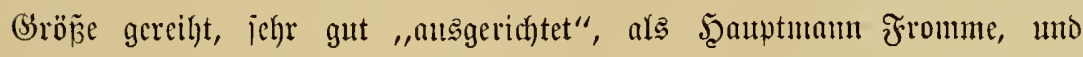
hinter ifm ber noch imuner etwos mürrịch breinblicfento lnteroffizier,

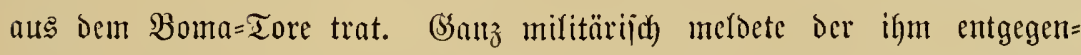
gehente Rotbart: „22 Mann Rarananenbedectung und jimei farbige Ehargen

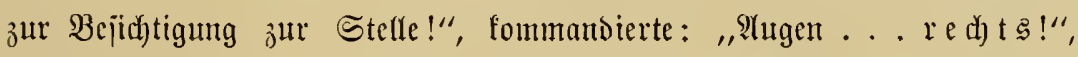

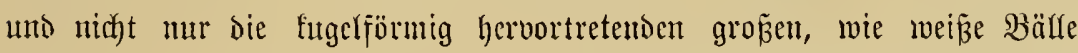

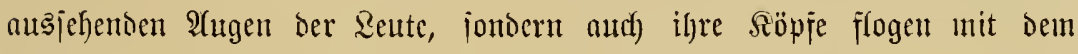

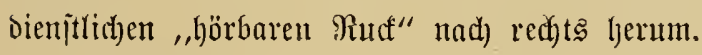

"Morjen, watu wa bana Reda!"

"'n morjen, bana hauptmann!"“ fam ter Giruz zurücf. (Fr

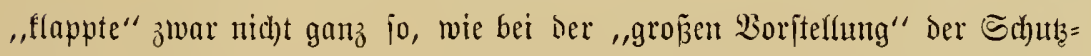

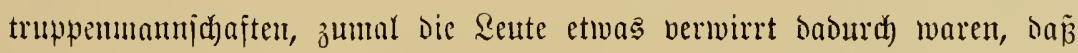

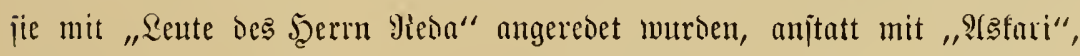
wic jie erwartet hatten; immerhin zeigte jid 's jufon in biejer erjten Minnte,

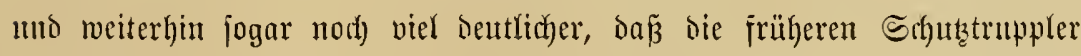

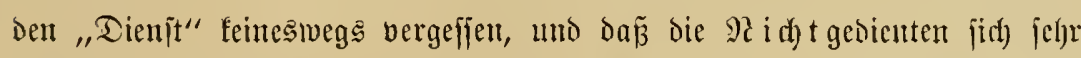

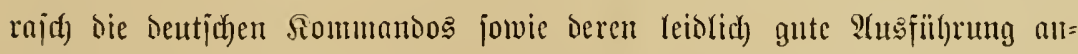

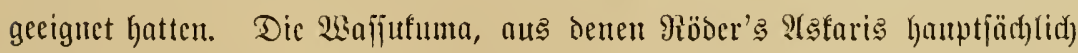

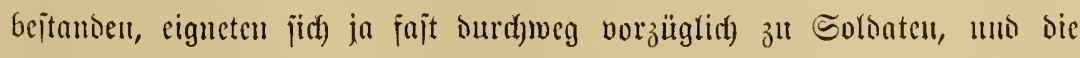

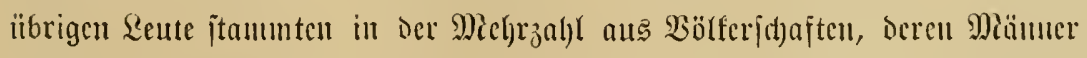
gerabezu geborene Eoldaten waren; Feldjoldoten allerings; in ocr "Stille"

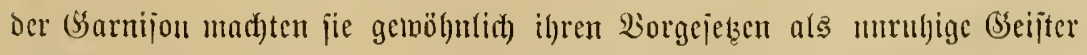
un jo mehr zu jhafifen, je ansgezcidfucter jie jidf) ani cinten siriegszuge 


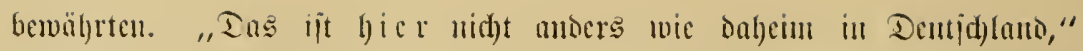

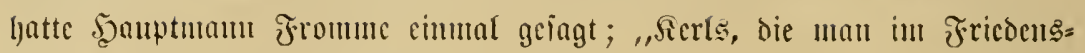

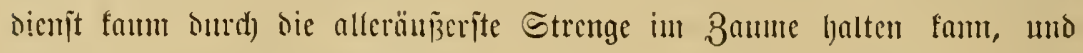
dic trok aller Etrajen fortwährent ïber dic Strünge joflagen, dic jims

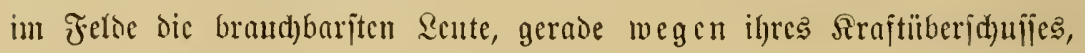
Der fie in der Garmijon jul afferfunto Afllotria treibt."

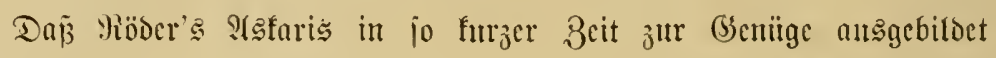
werisen fonnten, war natür(ich nidyt mur auf igre joldatijdye Esignung uno

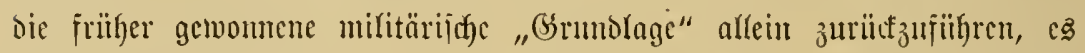

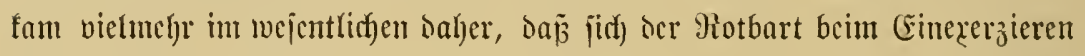

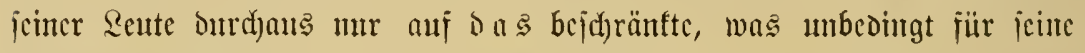

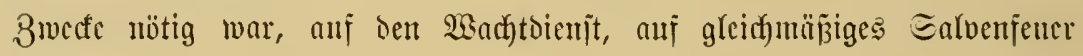

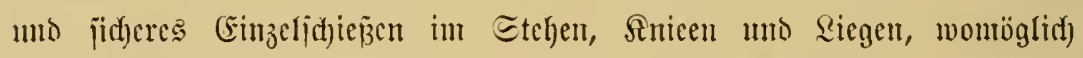

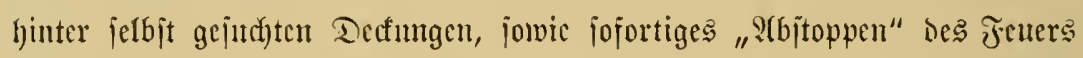
auj das Signal eincr Trifferpifife hin; und daun übte er nod) bejonocrs Den Eturmangrifi auj ถas Sommanod: "Batailfon: . . mar $j \mathfrak{d}$ ! --

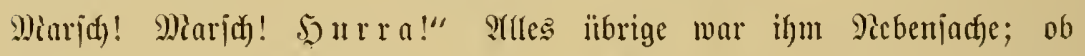

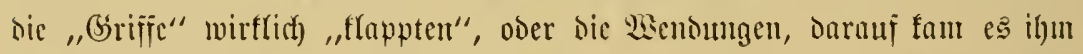
nidyt an. Desmegen batten bem and bie meijten feiner S(staris mux

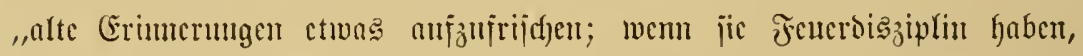
bin id) j(d)on zujricocn. Barabemarị mo jonjtige Drilfgej(d)idften gibt's bei uns nicft!" Das hatte er bercits beim 2tnjang Des Excrzierens z"

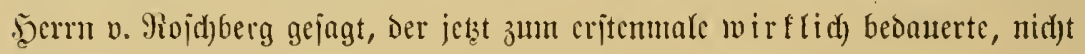
jein Jahr abgesicnt zal haben, mo ber hier gar ju gern mit „eingetreten"

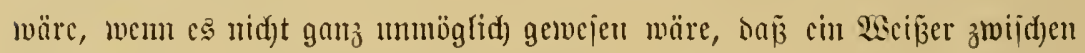
Farbigen als ifhen (Stleid)gejtellter cxerzicrte uno bei ocn nid)t ansblcibenten "S(f)wuppern" gerade jo idfari angefahren, ja im Eifer angej(hnauzt

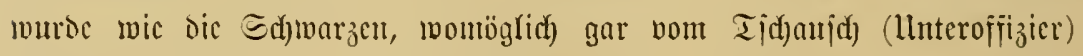
צ(bould)er Farrag oder deut Dmbajd)a Ulesd! Das ging ganz uno gar

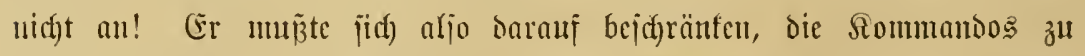

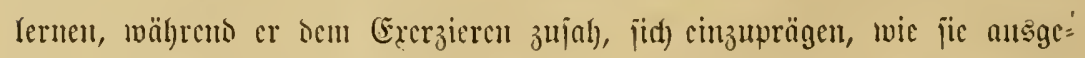

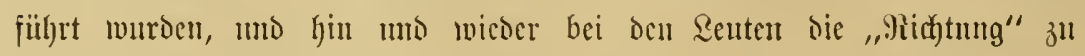

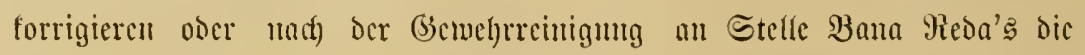

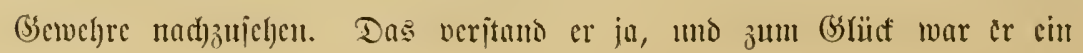




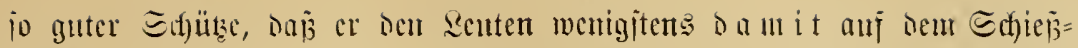

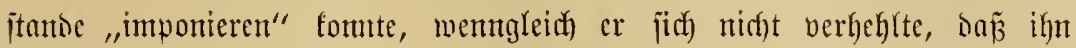

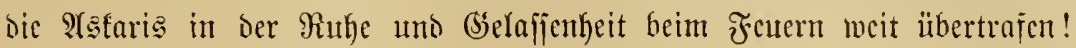

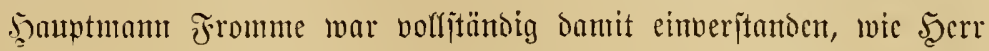
Röber bie "Bebingung" erfüllt hatte; bie watu wa bana Reda fornten ja freilich vor ben Jiegern inmer nod) jür faiferlidfe S(y)uztuppen= astaris gehalten merben; aber bas wäre auth) wohl nidyt zu berhithoern gemejen, wenn man jic in dic allerieltiamjten llniformen geitecft bätte;

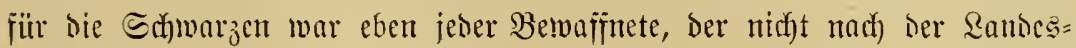
jitte mehr ober mentiger un hefleibet ging, ein I(sfari. (Es gentitgte jchod),

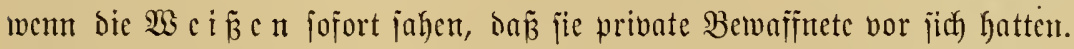

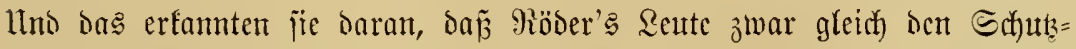
trupplern Safiuniformen uno von Den Sinieen abwörts blaue Beimwiffel

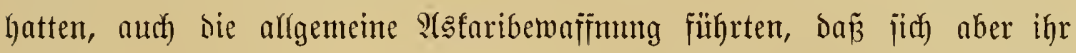

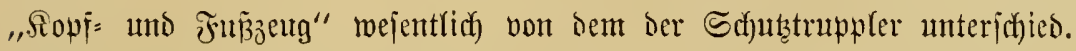
Shitatt bes ats Strohgeflech)t in Topfform hergejteflten, mit Safi über=

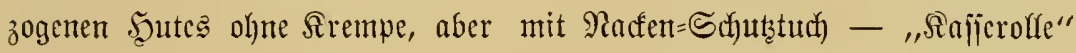
hatte es .jerr v. Fojhberg bei jidh genannt, als cr bieje Sopfbedectung

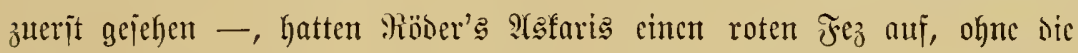

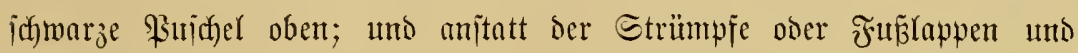

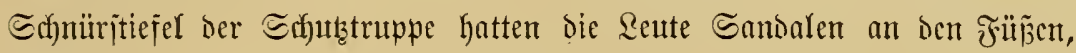
mas ifnen norf biel licher war, als bie Etiejel. Denn an Srahte oncr Stiefel gemöhnten jith bie Sdywarzen nur jehr idfwer, - ,abgejchen

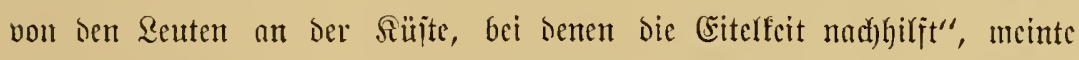

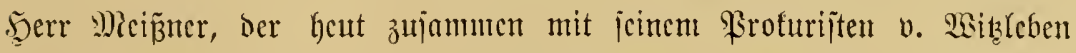
ani beu Platze vor Der Boma erichicnen mar, um chenfalls ber Borĩtellumg

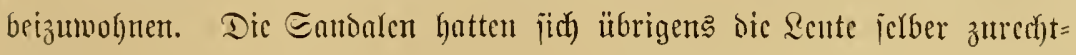

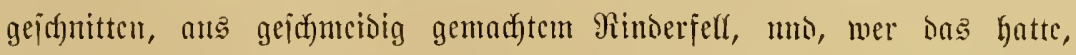

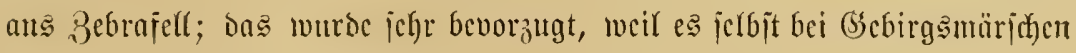
mur nach) längerem (Scbrauthe vom icharjen (Sicitcin burdblöd)ert wart.

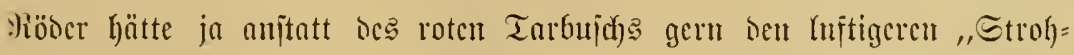

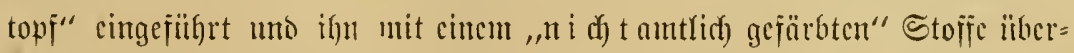

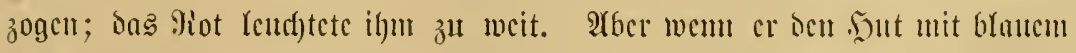

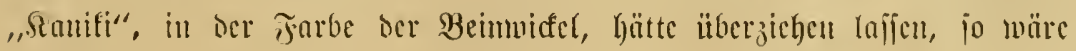




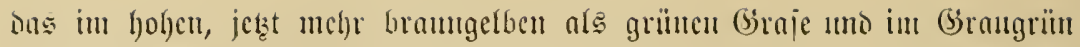

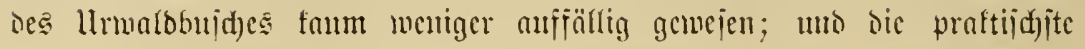

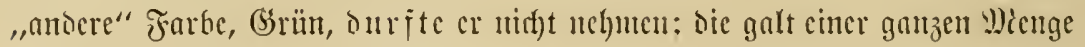

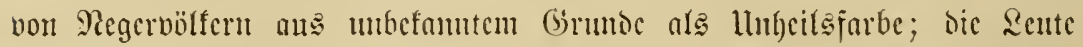

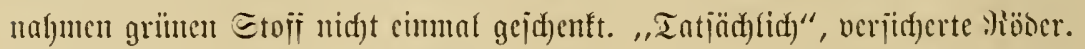

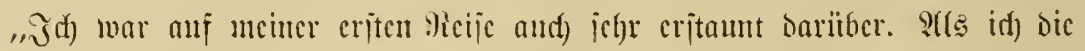

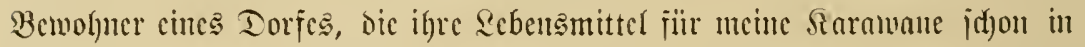
(Ǵlašperlen bezalylt befoumen batten, jü̈ gutes Berhalten nod) bejonters

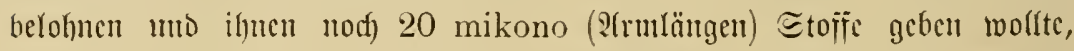
zumal jie gerabe un Etoffe einoringlicf)jt bettelten, ba haben jie jull meinem

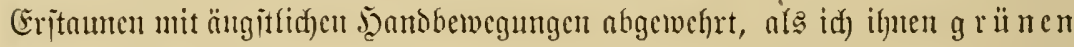

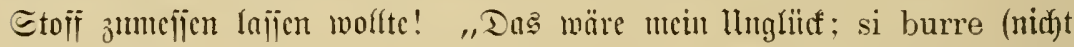
'mal umjonit)!" hatte ihr näuptling ausgcrujen. Seit der Beit jühre idf) iiberhanpt fcinerlei Tanjhyware non grüner Farbe ntchr mit."

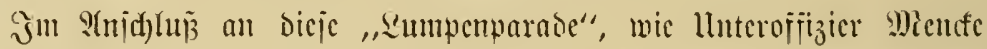

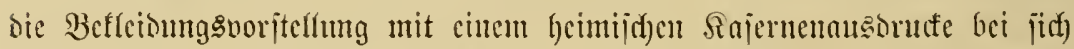

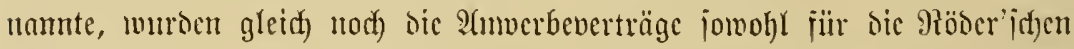
Tsfaris wic and) fïr bic von Mieiñuer zufanmentgebrachten uno jeßzt von

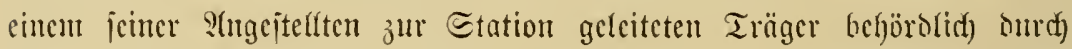
Etempclanjorucf bejtätigt, was Der Etationstajic cin flcints Eimmmed)en

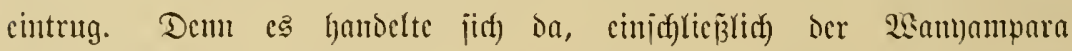

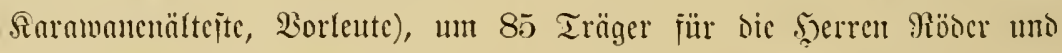

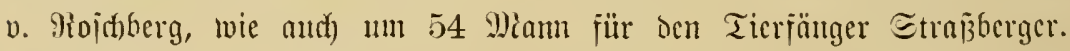

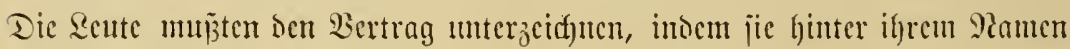

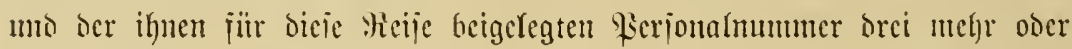

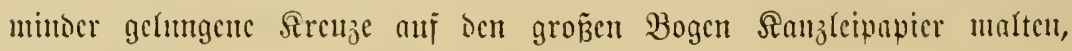

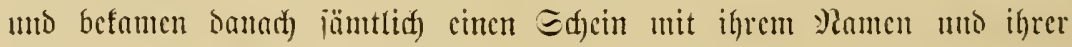

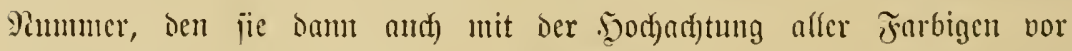

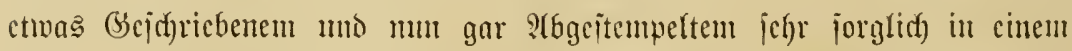

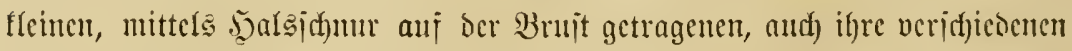

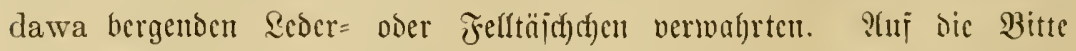
Jerm Piöber's blieb aud) Şauptmaun fromme jugegen, um ber Ead)e

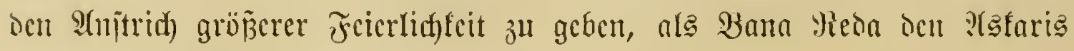
wie ben nad) Wiöglidfect in georoneten Heifen angetretenen Trügern bie 


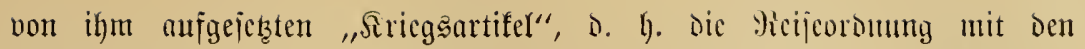

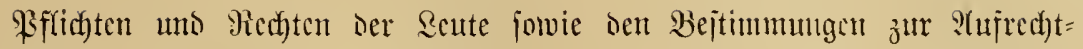
haltung ber Diszziplin auf Miarid) unt im Rnger vorlas. Dus geid)ah

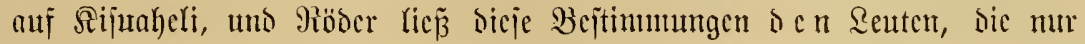
Sifijufuma, cinen ziemlich jtarf davon abweichenton Dialeft, veritanden,

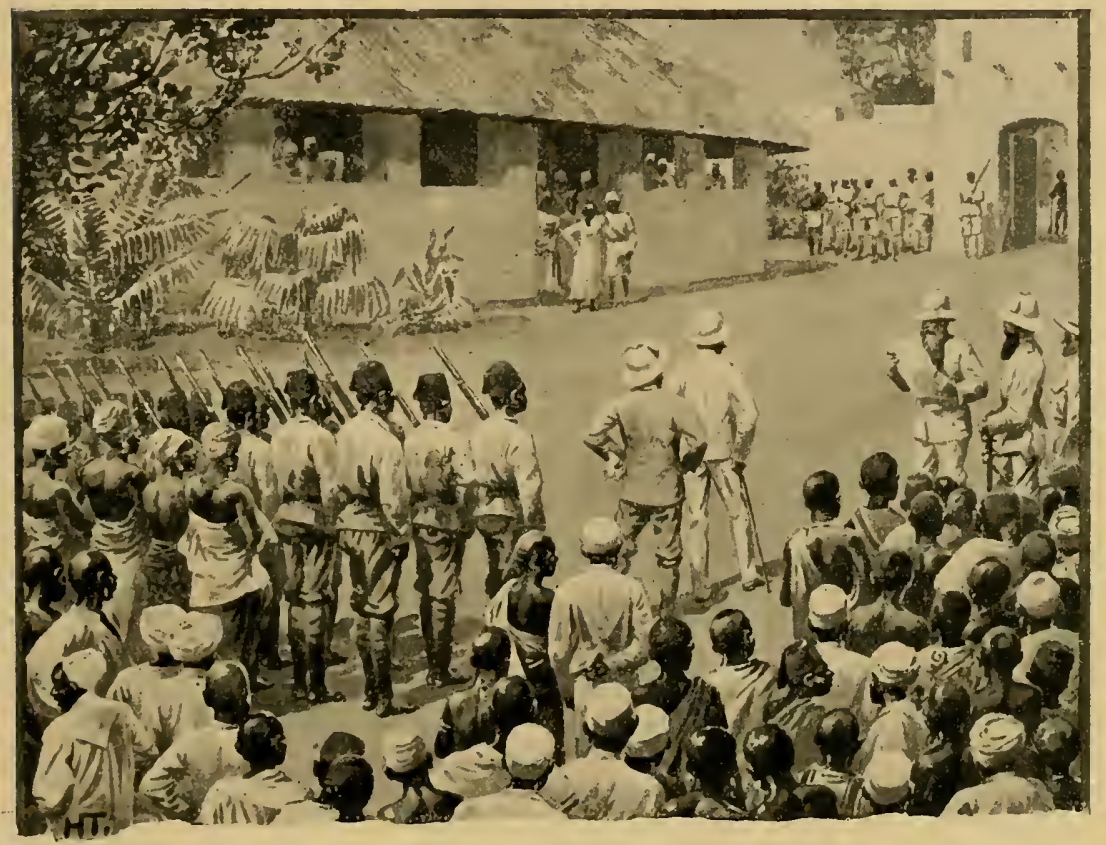

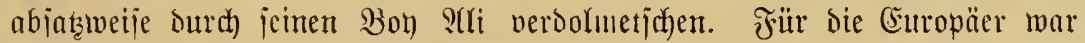

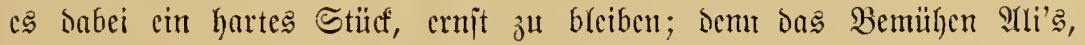

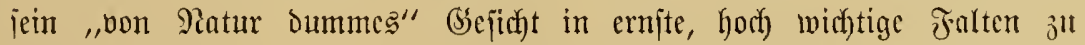

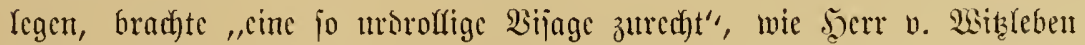

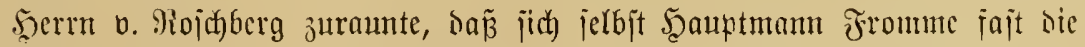

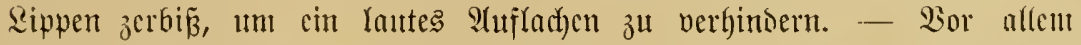

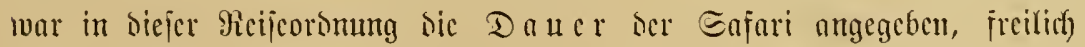

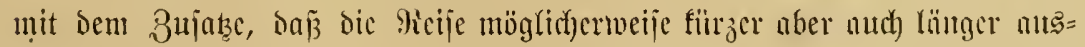

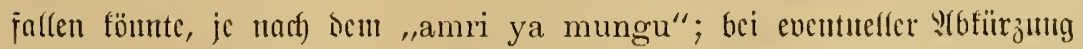

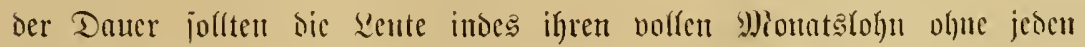

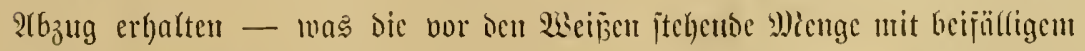

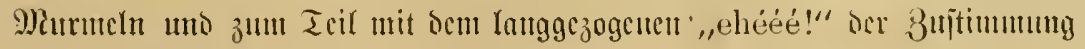




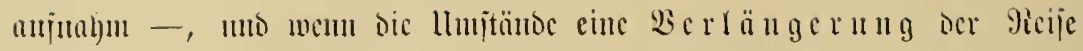
criorberters, foflte fïr jeocu and) nur angefangeneu Mionat cill volfer

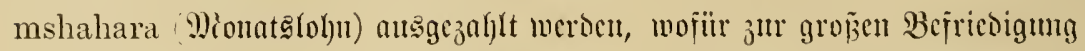

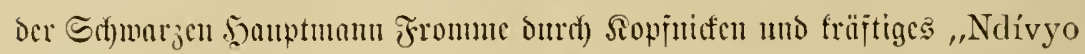

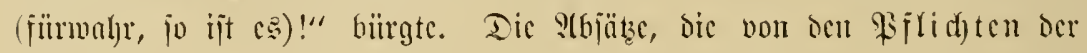

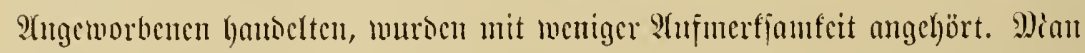

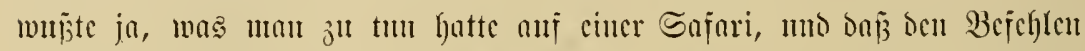

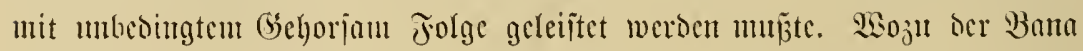

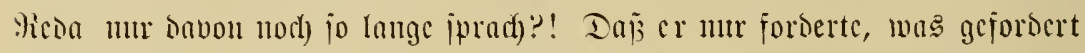

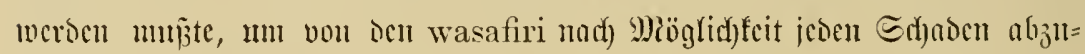
menocn - jofern ocm chen nicht der amri ya mungu entgegenitano -,

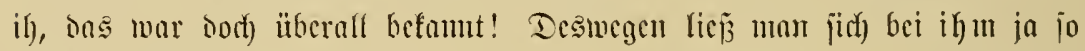
ich) viel fiefer ammerben als bei jedem anderen mzungu! - llub mu bic

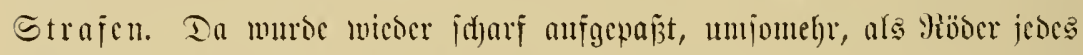

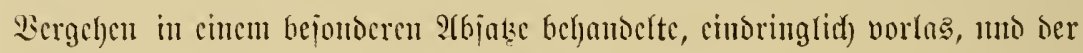

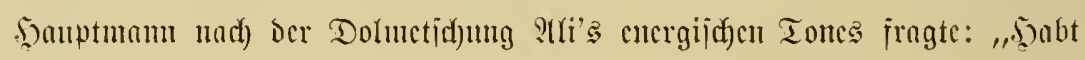
ifre veritanocn?" - Dejerteure folften an bic Sette gelegt uno, ,Der näcf)iten

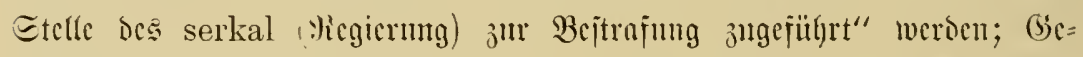
horjamsverweigcrungen, Diebjtähle an fiaramancngnt, ober giüubcrcicn in Den Iorfictaften ber Fingeborencu mürocn mit bem maneno ya fimbo,

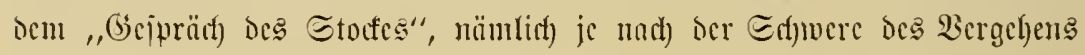

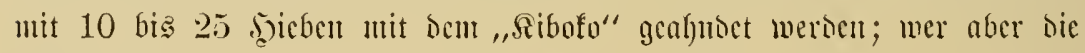

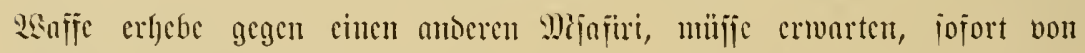

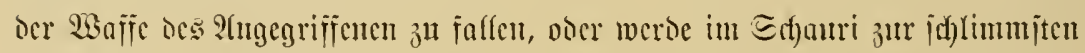
Strnfe bermeteilt weroen! -- Sb damit cin Tobesurteil geneint mar oder

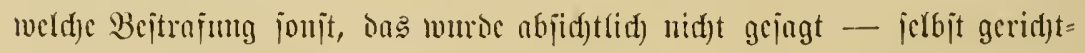

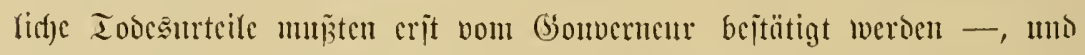

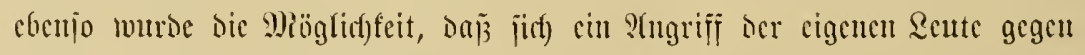

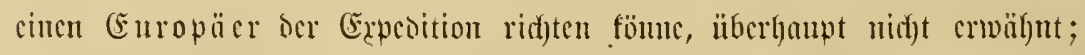
auf joldhe Gedanfen jollten bic Reute gar nidgt erît gebracht merden.

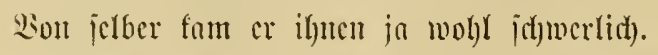

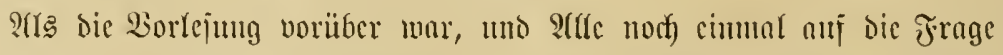

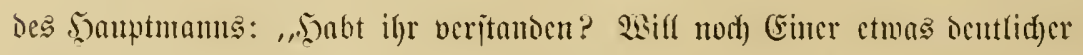

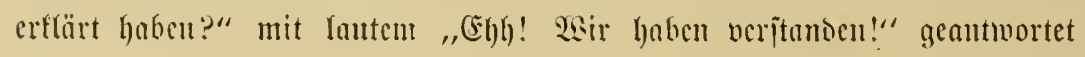




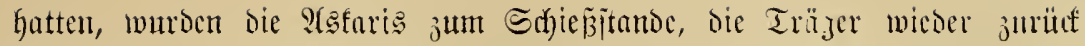

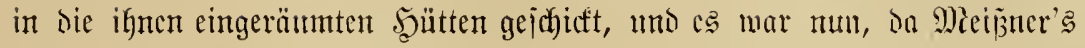
Seute zufammen mit don Wanuanpara Der Träger bie Sajten in ange= ftrengter SYrbeit bircits vorritänotg cingetcilt unto marichjertig verpact hatten, fo weit alfes jertig jur ?threije. "So wcit", nämlich bis auf

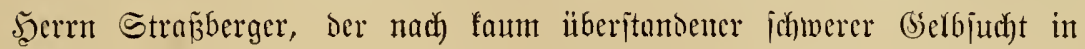
Meuarza angefommen war, jeb̧t von heftigem Fieber gejüütelt auj jeinem

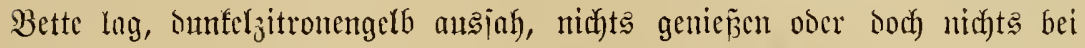
jiic) befalten fonnte, uno ocnnoch mit jturrföpfiger Saartnäcfigfeit sarauf

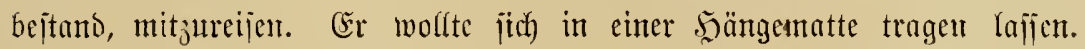
$\Im_{\mathfrak{n}}$ orci bis vier Tagen wäre er f̧hon wieder auf ben Beinen. Das

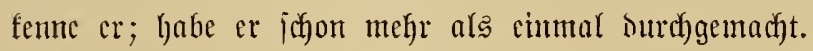

stlein am jelben Yhend nody delirierte er, fannte niemanten, mo

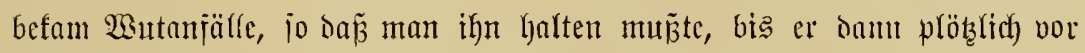

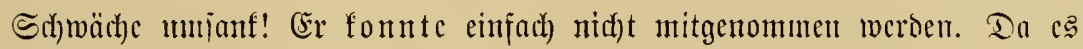
aber nad) mand)er Şinji(h)t nicht gnt war, bie für ilyn angeworbentu Träget

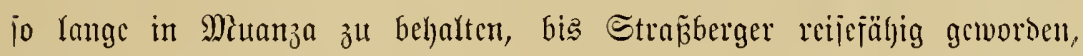

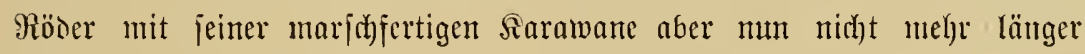
warten fonnte, jo murde bejchlojijen, ilgn hier zu lajjen, jeboch jeine Rente

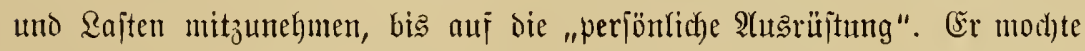

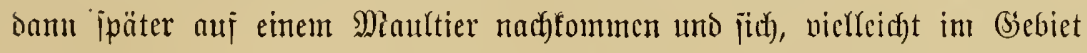

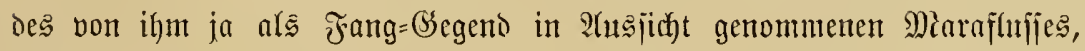
mit Der Şauptfaramane vereinigen.

马u einem gemütlichen $2(6 j$ j) berg nach) Den für ihn nicht geringen S(njtrengungen ocr \&ajten=2ertcilung biejer letzten Tage veriprochen hatte, fam es an aber nidb)

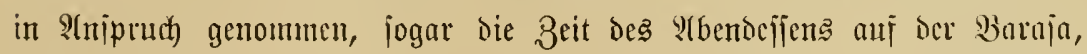
obwohl Nofithberg idjon von Mrittag an mindeitens alfe Stmmos cimmal

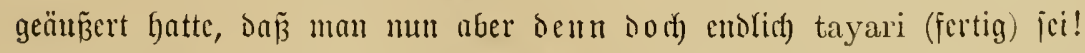

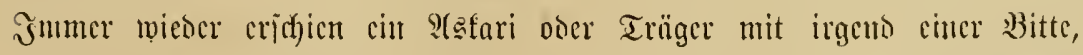

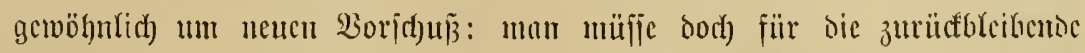

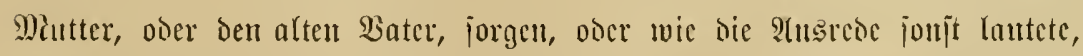

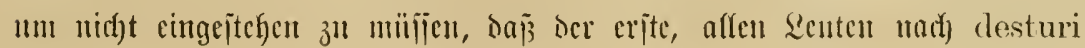




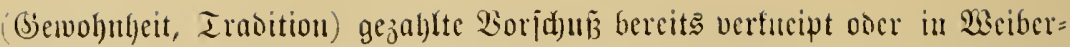

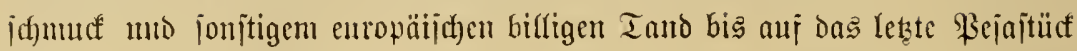
vertan jei. Dic 2lutwort bes Giotbarts lvar Daun: "Bringe mir Deinen

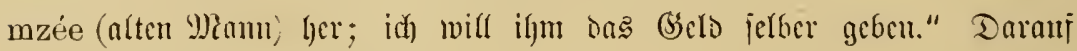

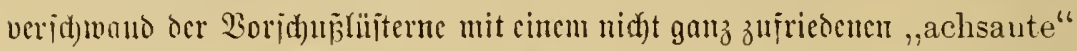

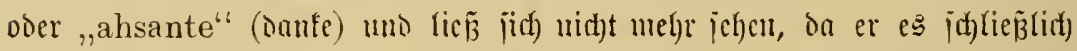
ood) nicht wagte, irgeno cinen beficbigen alten Manm als jeinen 2 ater vor=

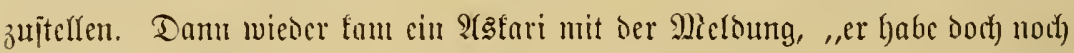
ein $2 \mathfrak{s c i b}$ befommen", bas jür ihn foct)en uno jeine perï̈nliche Sajt tragen

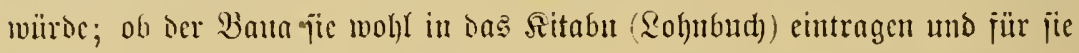

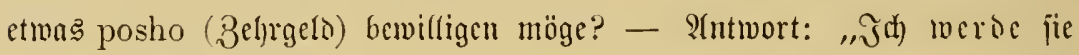

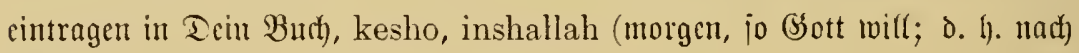
Micimung oer Schwarzen: vielleidyt morgen, ober ein andermal, oder aud) gar ni(b) ); falfs Tu jic uid)t uad) Dem erīten Rageraujenthalt zun sheitani gcjagt hajt. Posho kwa mwanamke hapana, Zehrgelo für Madaufen is

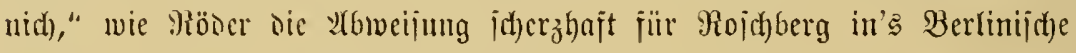
übertrug. Socr es crijdien ein Mamampara mit eimer Frage oder einem

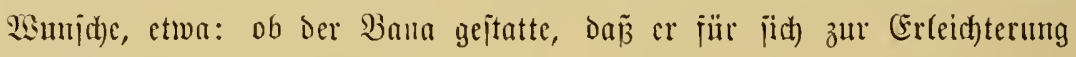
bes Marjat)es einen (Fjel faujen bürje, ber jehr billig angeboten würbe? -I(ntwort: "אanje ifn Dir, mein Bbuter! Warum jolltejt Du gehen, wenu Du reiten famit?! Sanje ihn Dir, wcm Du bas Geld baju hajt!"

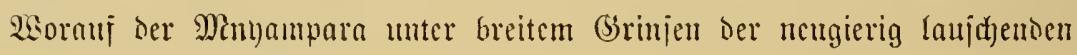
Botjs uno der übrigen amejenden Farbigen iehr "bedeppert" abzog.

"Pajjer Sie aū, Serr v. Rojd)berg," jagte ocr Rotbart, "trotzom wir dod) heut idgon jedem (Finzelnen jeine Snjt zugetcilt uno probeweije auf den Bucfel oder deı Schädel haheıt nehuen lajien: morgen vor bcu

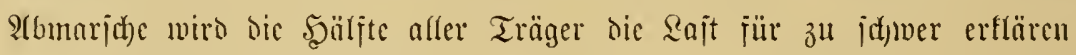

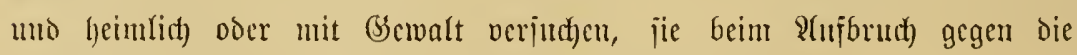

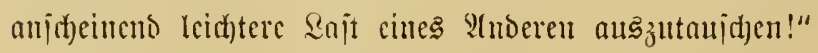

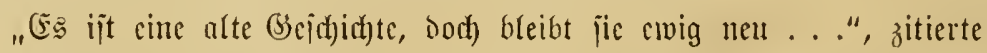

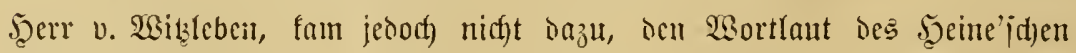

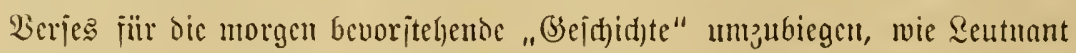

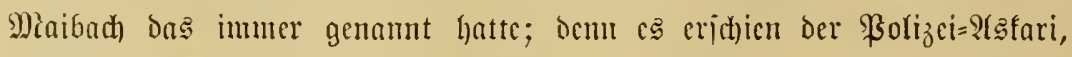

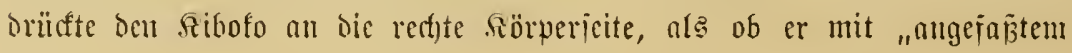




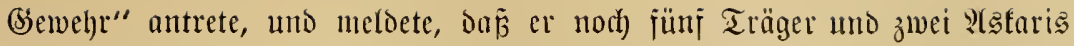

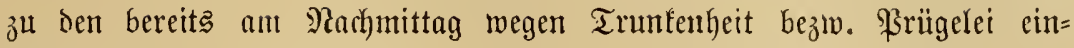
gejperten Reuten geiteft habe; uno ihm unmittelbar auf bern Fuñe folgte eilenden Gintges der Santtäts=?(afari mit ber anjangs von den bei Tijd)e

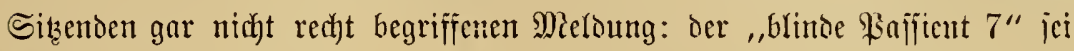
chen heimlid erjedoffen borden, mit einem Siftefeile!

Was war bas?! Röder jetzte bie Faujt hart auf ien Tiich und

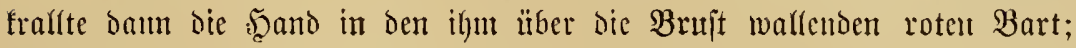
jein J̨im arbeitete fieberbaft, aber feine Miusfer zufte, mähreno cr dem

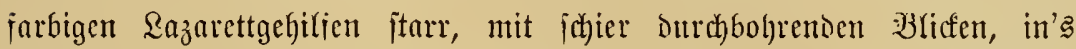

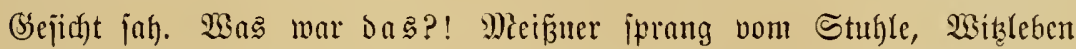
rief: "Erzähle genauer! W3er hat geịchofijen? War ber mshenzi kipofu gleich) tot?", und bie auf bas 2lbtragen ber Teller wartenden Bons im Şintergrunde glokgten Den litberbringer fo unerwarteter unt fo unbehaglicher

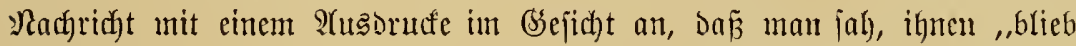
oer Beritano jtehen", uno jie hatten nur bie ounfle Empfintung: weenn in Lazarett, inuerbalb der Boma, Einer fo heimlich burd) cinen (sijtpfeil

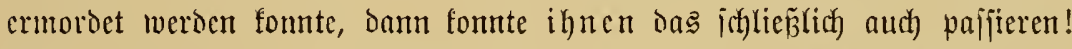
Şicr, in Muanza, im Sduuţe des Serfal, trok der vielen 2tafaris, uno obmohl der bana shauri jede Worhe jweimal (Bjericht abhiclt in Der

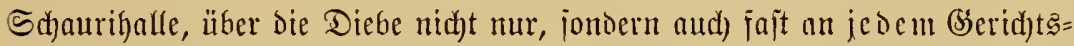
tage über Rindermörder und andere (Siffmijher?!

atber nod) ehe jidh dic erite Berblüffung der übrigen s(uncjenden

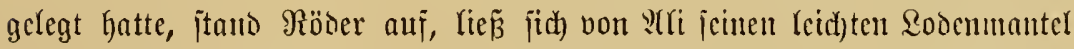

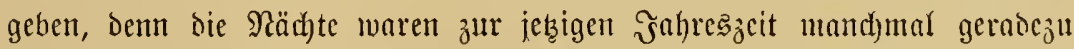

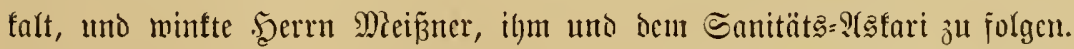

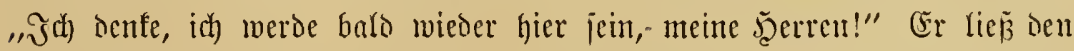
Polizijten ohne Slntwort auf Defien Meloung abtreten -- Die Betrunfenen waren ifm jetzt gonj gleichgültig - un fragte anf dem $\mathfrak{S}_{\mathrm{c} g \mathrm{ge}}$ ju Station

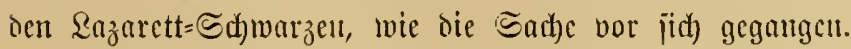

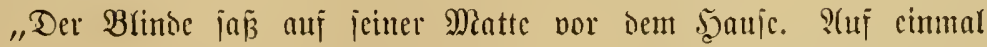

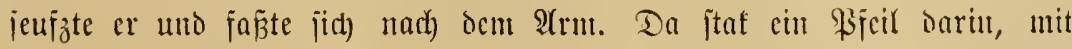

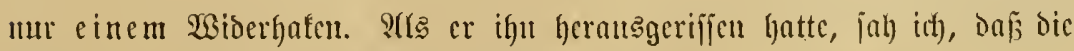
Spiz̨e mit ichwarzem Dicfiajt bejamiert war." 
"Soajt du fojort dic şumbe ansgeiogen?"

"Das tat ber Fajijicnt 7 gleid) jelber!"

"Ifl, er war aljo nidht jofort tot!" rief etwas crleid)tert Şerr Micipurer alls.

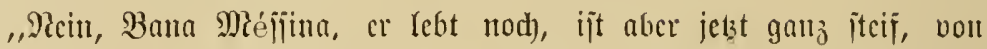
icu Beinen herauj bis zur Brujt. (Er atmet fajt nidht mel)r, uno bod)

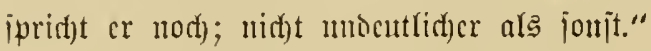

"Sott jei Danf", murmelte Röber, "da wirt das Pifeilgift wohl

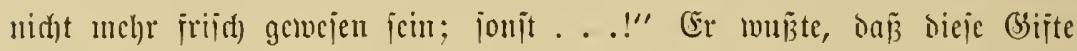

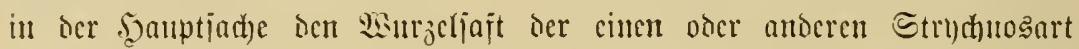

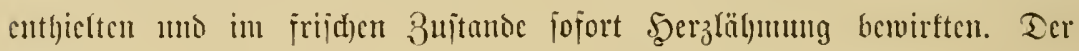
Blinse war alio vielfeidft nod) zu retter. S(ber jelbjt bamn founte er ifhn morgen uid)t mit anj bic Sajari nehmen! ?(tnd) nid)t in ber für ibn bergeridfteten Irnge, cincm Felojtuhle mit Funjorett, an zlvei Stangen bejeitigt, dic von jwei Senten abmedjielno auj dic Sdjultern genommen merion joflten.

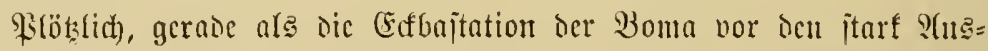

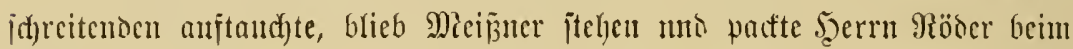

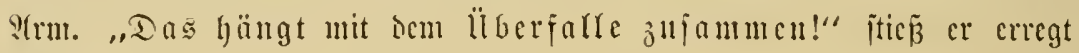
berbor.

Der Motbart gab ruthig zurüct: "Eelbjtueritünolich. Das soar

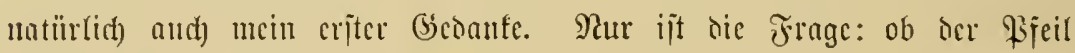
von cincm periönlidyen Feindo Barafa's atşging, ober . . ob ocr Bfeir dicjen Mijdenji, Barafa oder wen jonjt, vergindern jolite, uns auj bic

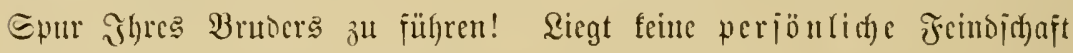

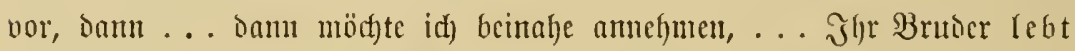

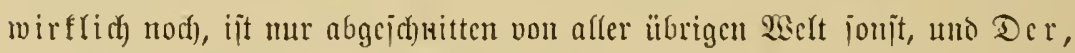

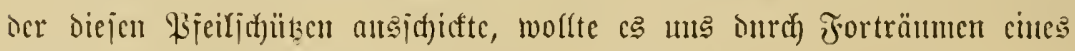

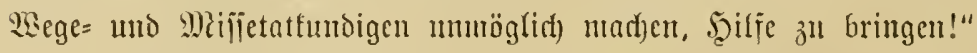

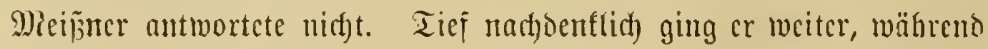

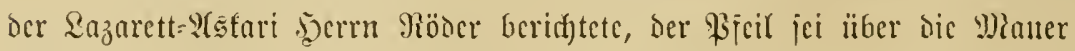
gefommen, er müjīe in den (Beäjt cines jiemlid) weit davon ab jitchenden Baumes von der Echne geidjnellt worden jein. Ein idfon vorber $a b=$ geidjoljener jei vorheigegangen uno habe im Bosen neben ocm \$atienten 


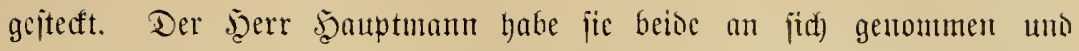
ihn als Boten auggejdidt, jobalo der \$atient auf jeine Ritanoa gelegt morden war.

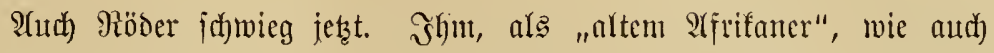

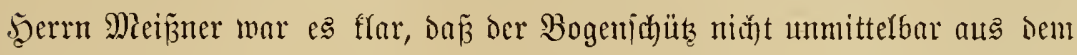

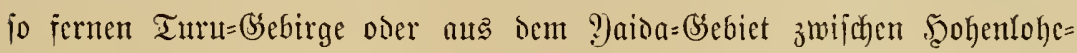
uno (Enajïi= See hierhergefandt fein mürde, um bie Tat auszuiühren. Das

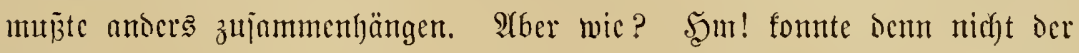
Sultan, iser ben armen Barafa baunle hatte jo graujam abjoladaten Iafien wollen, fofort einen jeiner "iकhwarzen Błuthunde" auj bie Spur gejetzt haben,

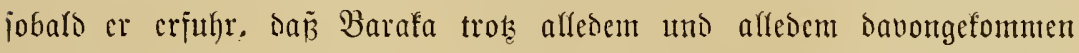

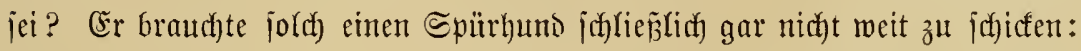
hierzulande fannte man Stajettenbotidyajten io gut wie in Europa, fajt jeder Neger hatte in anderen Sanditrithen einen ndugu (Berwandten), ber mit einem ifm ühergebenen $\mathfrak{A}$ ujtrage, ment fidf's lohntte, meiterzog, bis er den nächjten ihm für jeine 3wecte paffenden ndugu traf̣! So fonnte auch ber Miordauftrag von cine me "ficheren" Mann zum antern gebracht worben jein, namentlich) wenn etma jür die S(ușïhyrung eine kejonders gute Belolymung,

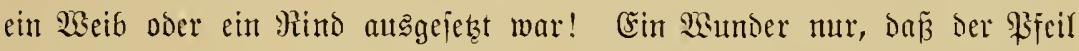

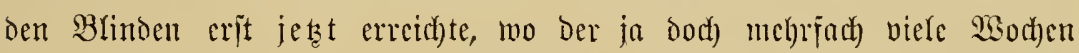
lang in veridjedenen Dörfern wumbfranf gelegen! S(ber freilid), Barafa

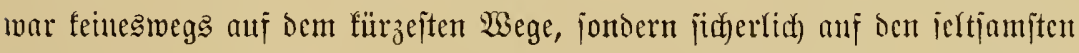
Umwegen hierher gelangt, da er ja immer auf gute Menjonen, Sflaubents=

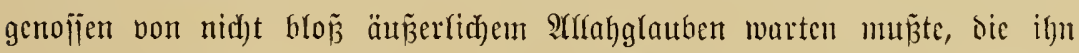
"um Brotteswillen" mitnahmen auj ihrer Micije, einte jo bejdwerlide Rnjt

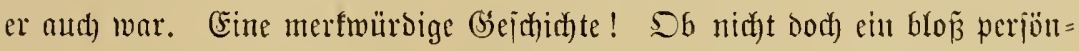

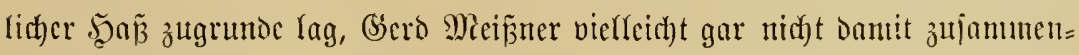

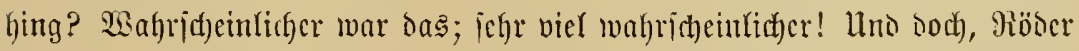

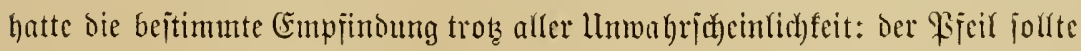
indireft bem 2 eben ocs fülnen Brofpeftors cin Ende madyen!

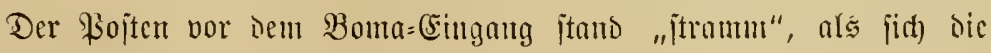

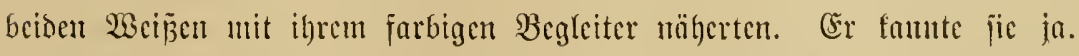

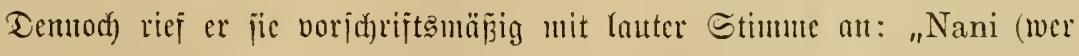

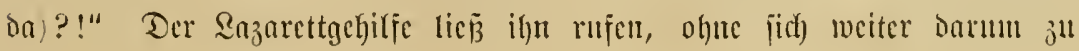




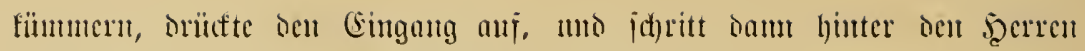

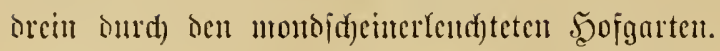

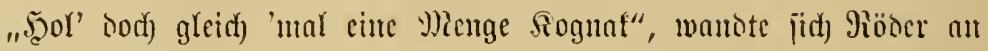

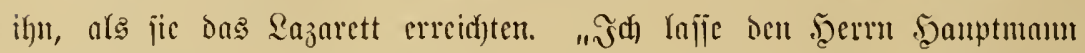

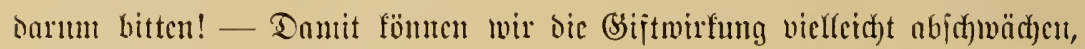
wic bein Srhlnugengift," meinte er ju Şerrn Mieis̄ner. "Jeocufalla hilft es, die .̧.

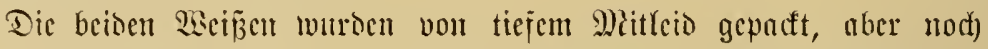

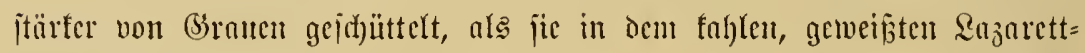

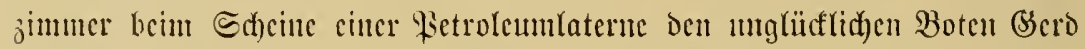

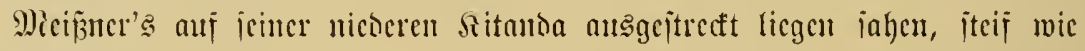

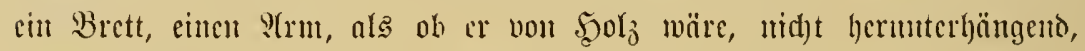

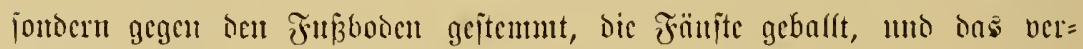
ïtünmelte (sicjicht, defien verhüllente Tït)er abgenonmen waren mo defïen

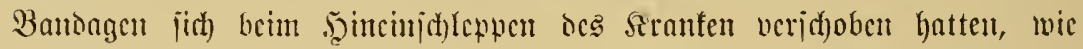

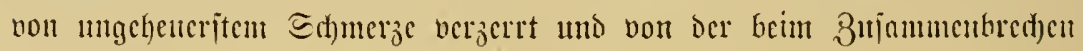
des Mlannes miescr anfgegangenen fleincu Dperationsmunde mit હtreifan

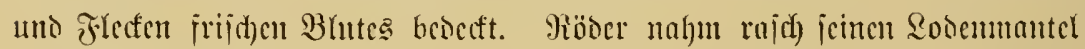
ab uno woffte ihn alif ben cincn im Bimmer vorhandonen Etuht wer jen,

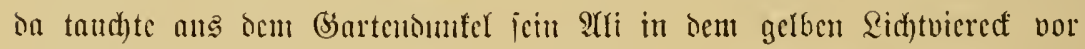

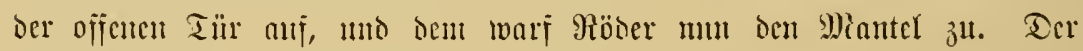

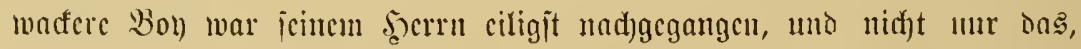

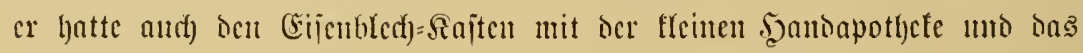

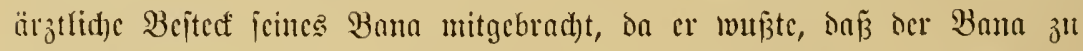

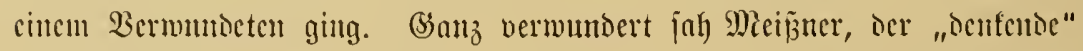

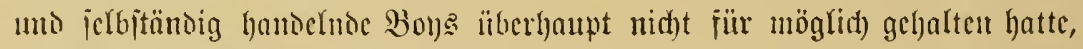

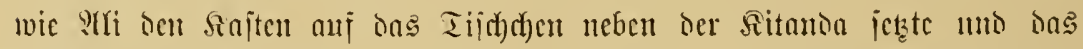

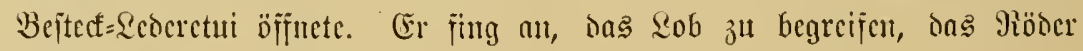

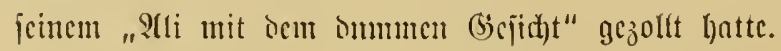

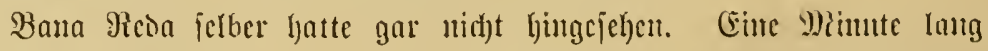

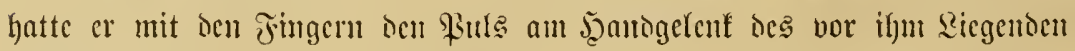

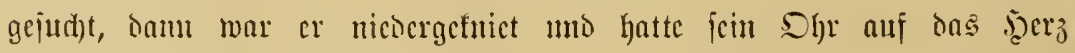

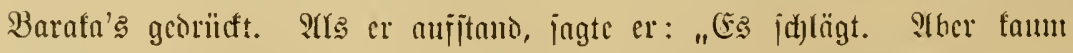
30 mal in oer Minute! 厄o' luas habe inf nod) gar midjt crlebt." 
Jn biejem Augenblicfe trat Şauptmann Fromme über die Schwelle, uno hinter ihm fam ber $2 a z a r e t t=2(3 f a r i$ mit Der Sognafflafthe uno einem (şäschen. "Jit wohl nichts zu machen?" fragte der Siffizier nach furzer

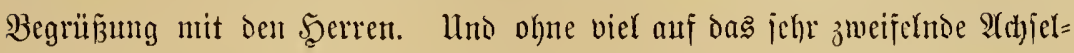

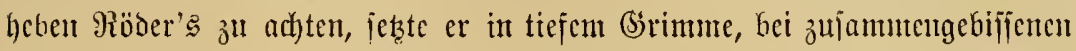

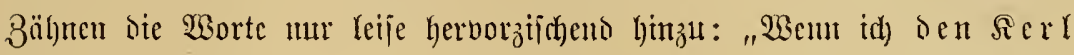

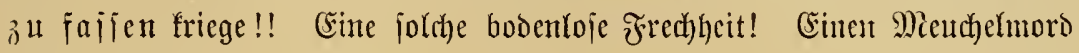
in ber હtation zu begehen!"

Dic beiden Seerren begriffen Den Born Des Stations=(Sheje jel)r gut. Für thu war bas eben nidht nur cin Meuchelmord, ober gar bloź bas

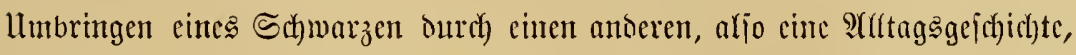

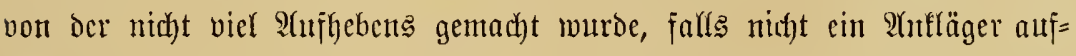

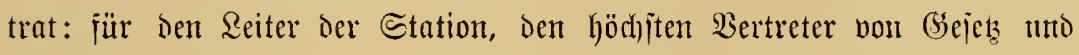

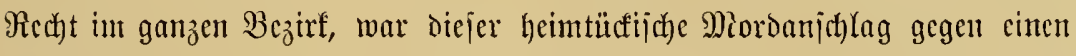

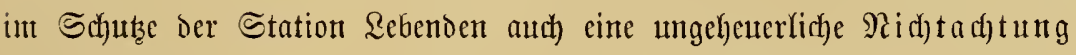

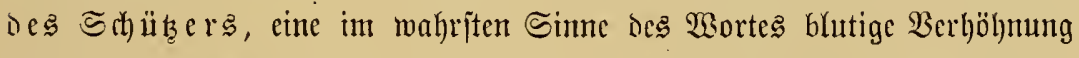
Der beutichen DGergerridaft! Dañ nidht bie Berhöhnung beabjictigt war, lediglich der Mord, das minterte weder die Entrïitumg bes Şauptman!s

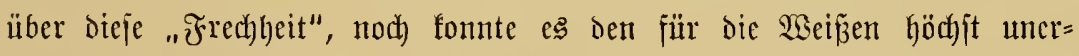

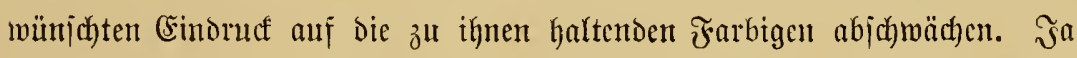

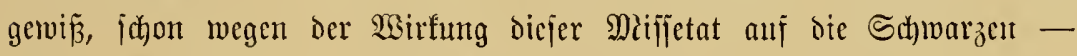

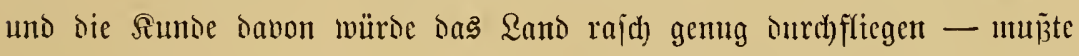

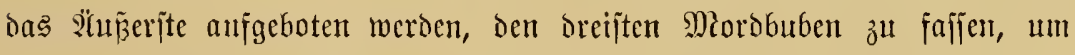

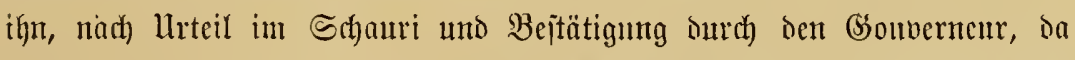
drüben an dem grof̌en Baume auf Dem Excrzicrplatze vor allem Bolfec ourch) ben Strang Ginzurichten!

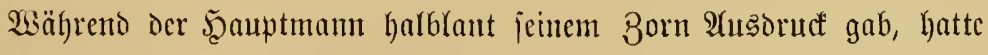

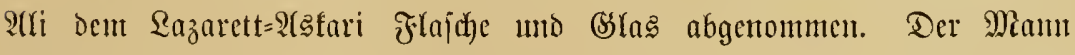

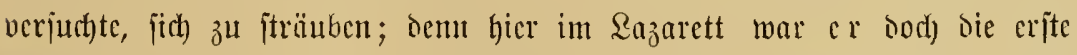
Perion, mo nicht der "onmunte Bol) Des fremoen 2(rjtes vout Bivil"! (5s l)alf il)m jeood) nid)ts; gegen :(ri's janften 83wang faut er ju jeinter

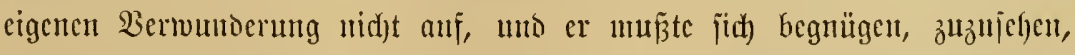

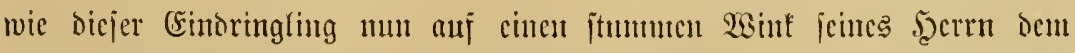

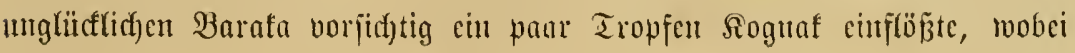




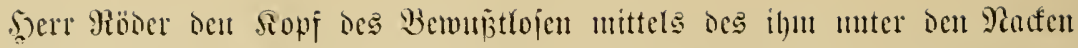

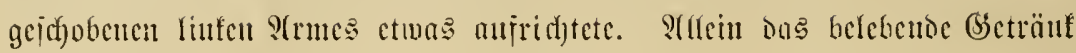
murde von Barafa nidht himuntergejd)luft; es liej vielmebr aus oer linten

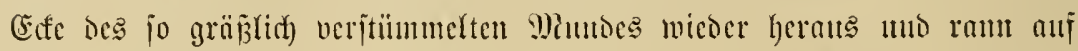

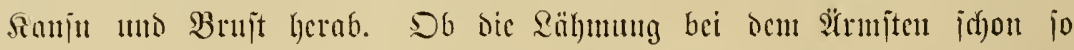

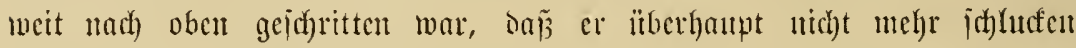
fonntc? - Csinen mur Bemuñtlojen ober jidf) etwa in geijtiger llnflar=

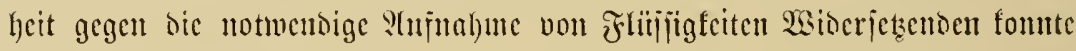

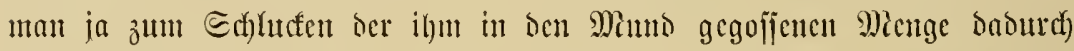

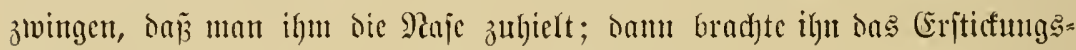

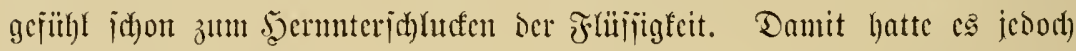

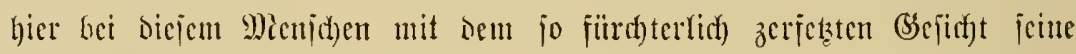
Schwierigfeiten; Barafa hatte ja feitre Naje melyr, mur ein won Doftor

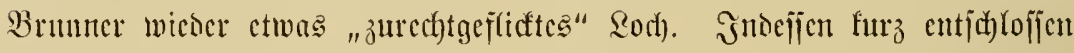

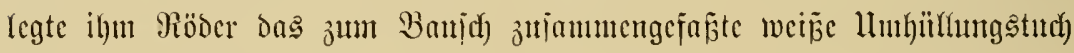

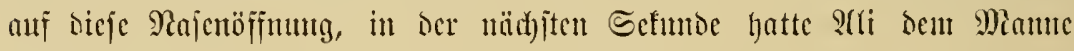

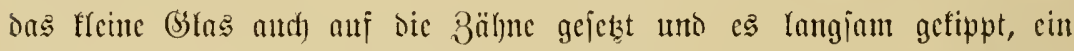

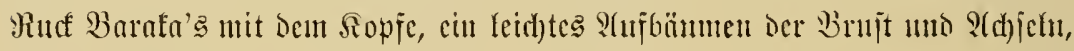

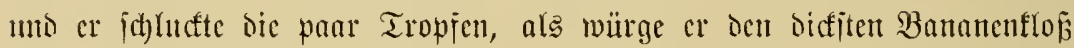
aui cinmal himunter! Er itöhnte mit raulyem B̧urgelton, währeno die

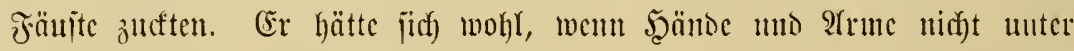

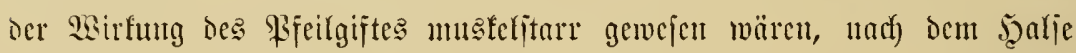

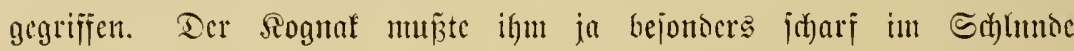
bremen, weil er als Befolger des Soranocrbotes nicht an Brantutwein

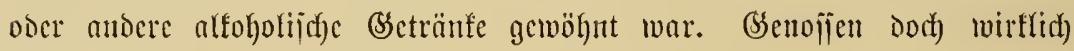
(S)fänbige unter oen Ed)warzen nich)t cinmal Fombe, jondern mur Togna,

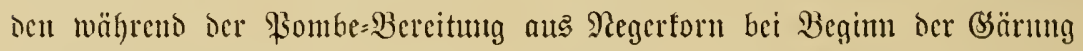
entitehenoen jü̈̈lichen Dünnbrei, ocr noch faum cine Spur Q(ffohol entbält. -

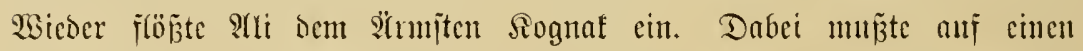

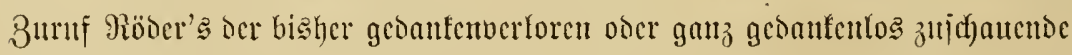

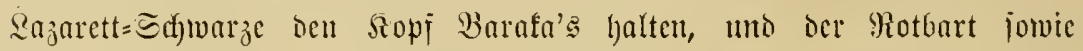
Jamptmant Fromme uno Micin̈ner beobad)teten ocn Reisenton. Defīen zerfreffene unt fnotig vernarbte Shagenfioce, bie jeither hatb bie blutrot aus=

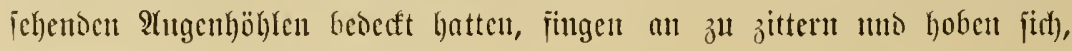




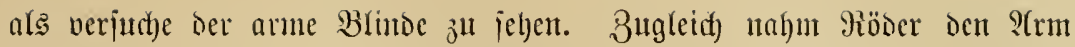

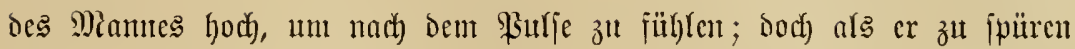

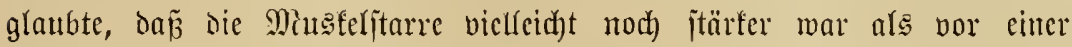

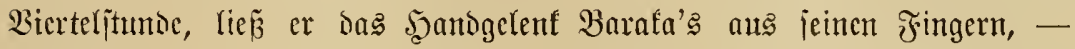

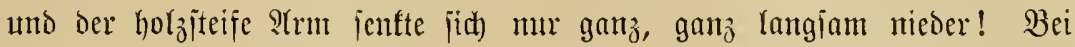

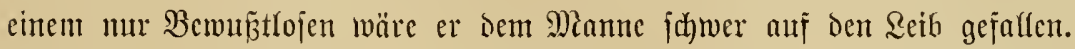

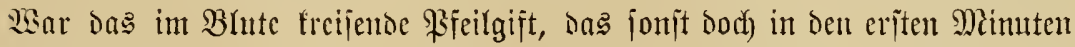

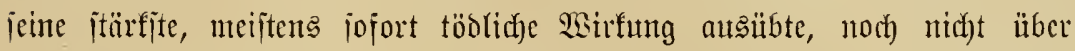

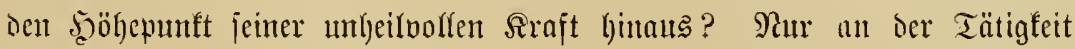

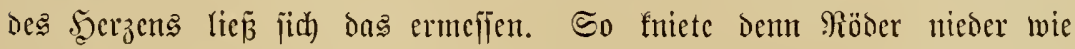

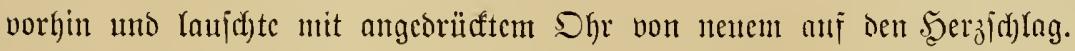
"D," rief er nach zwei, Den Umittehenten unglaublich lang vortommenoen

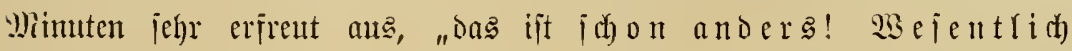

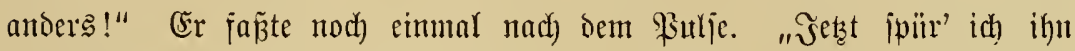

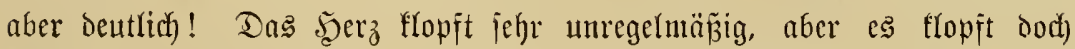

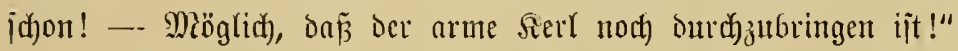

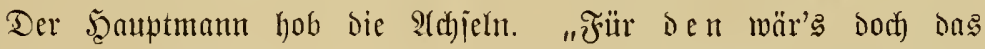

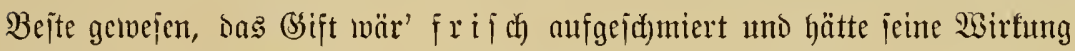
bereits getan. Was fann ifm das Rebent in biejem 3uitande demn fein?!“

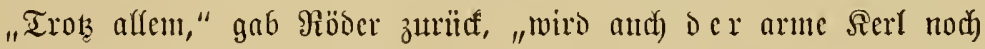
germe lebon, wenn ifgm zut reben nodh ferner bejchiedon jein jollte. So eleno ein Mienja) Daran jein mag, er flammert jidt) Dennod) an's 2 chen bis zuแ lek̨ten Îtemzuge."

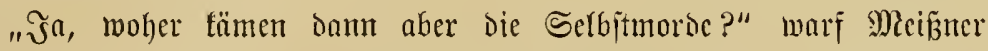

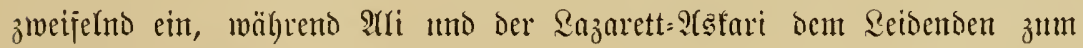

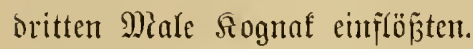

"Die Selbijtunorde? Sind Ergefnifie der llbertultur, uno ..."

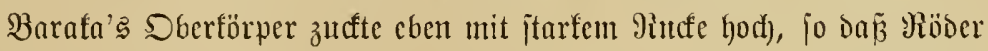

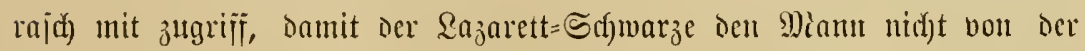

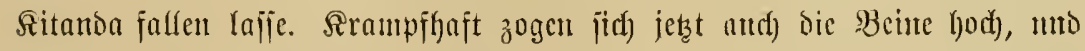

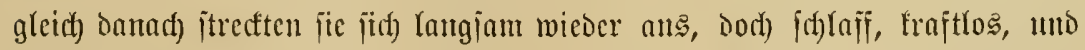

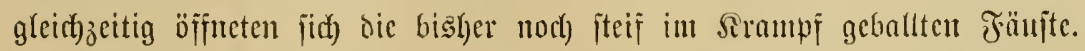

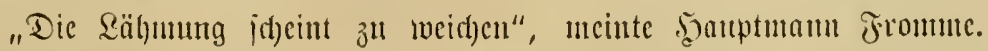

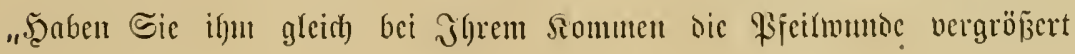




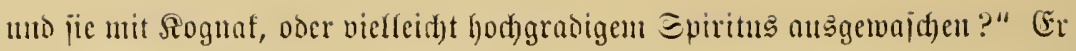

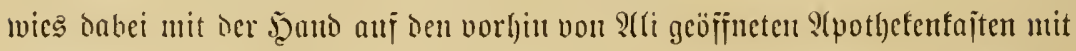

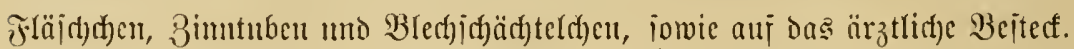

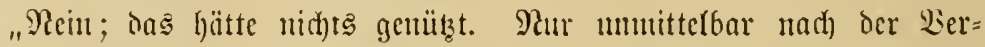
muntonng hätten wir anj bieje 2 cije Erjolg loben fönnen. T(ber id bitte,

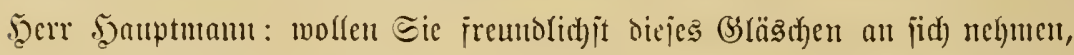

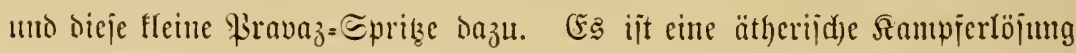

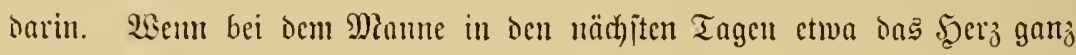
3 verjagen broht, trok öfterer Sognafgaben, dann bitte idf), ihm eime halbe Epritze voll von der Söimng unter bie Dant ju injizieren. Ter Stabsarajt ijt ia nicht meht da; idh jelber fam mit all den vielen Renten

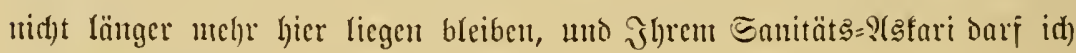
sic Bsejdidgte molst nidgt aunertrauten."

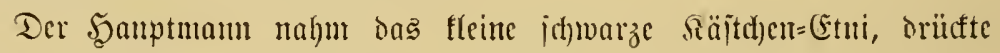

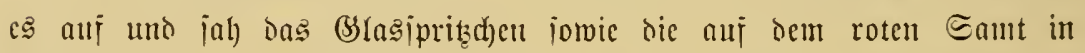
Nuten liegenden, ocr Eprize aujüntecfenten beioen Şohlnabeln cinen 2ugenblicf an. Daum nicfte er. Er hatte ja jo. Iange ofne $\mathfrak{A}$ rat auts=

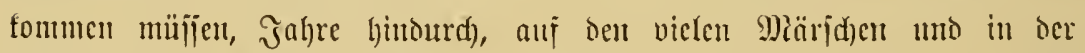

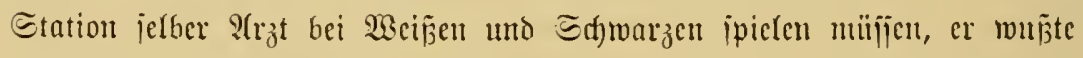

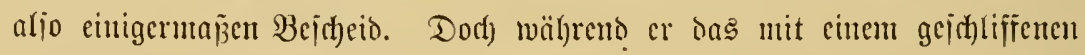

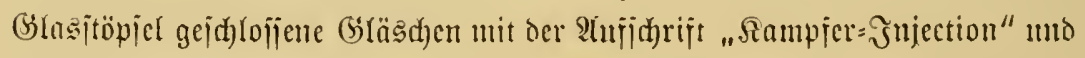

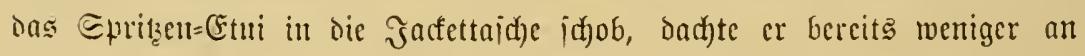

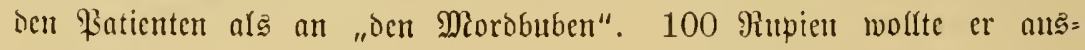
iekzen für $\mathfrak{D e n}$, Der den jrect)en Menj(j)en vor ihn als bana shauri liejerte!

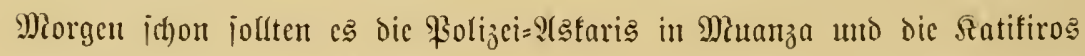

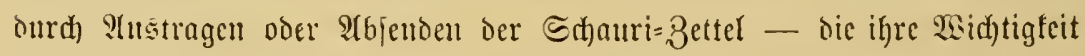

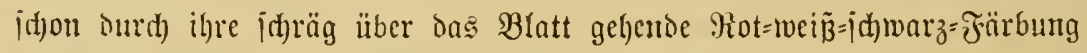

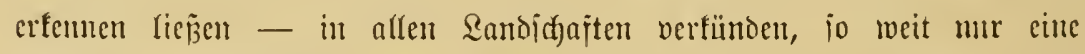
Berbindung herzulteflen war! S(ber freilid), wenn jid) der Serl nidht etwa jelber verriet, war nid)ts j̆ll hoffen. Jrgentoweldhe Epuren von ih)m waren nicht aufgejutben worben, auf̃er dell afgeriffenen ziveigen am Baumte. Der Saututuan hatte jofort, als ilym Mieloung gemad)t und die betoen Hifeile überbrad)t worben, mit einem balben Duţend laternen=

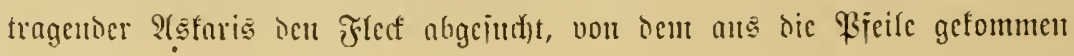




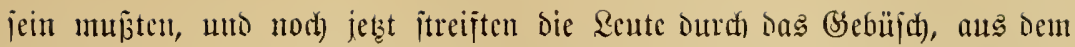

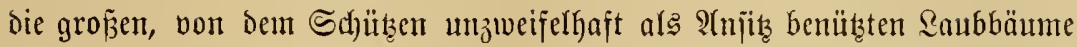

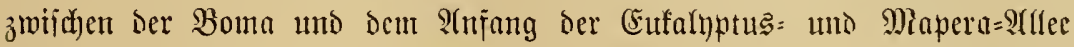
aufragten. 22ürde auch nid)tz helfen! Daran zweifelte der Stations=

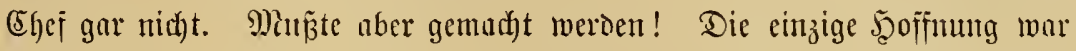

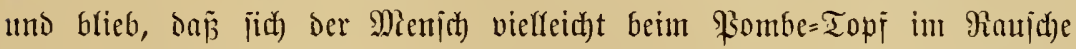

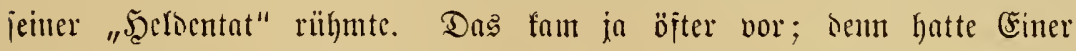
jeinen Feint "зut Stredfe gebrad)t", fo fonnte er häufig genug ieinen

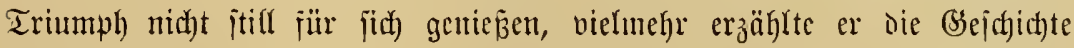
weitichlveifig jeinen Dorf = ober Reijegenoijen uno ipielte jie ifnen unter

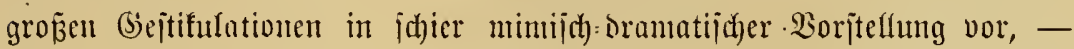
"i o lag ing aus, jo jührt' id) meine filntge", würde wohl f̧err v. Wibz= leben den bicfen Hrahler Faljtaff zitiert haben. - 2 ber wenn es jidh hier nun etwa bo(t) nidht un Die Meuthelung eines perfönliden Feindes

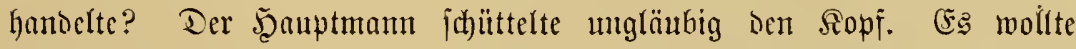

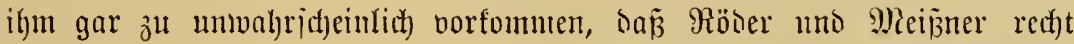

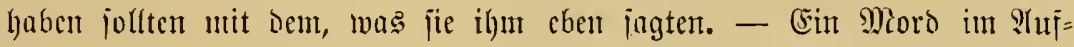
-trag, - jehr wohl möglid); aber faum benfbar, baj biejer (sififtejeil jo=

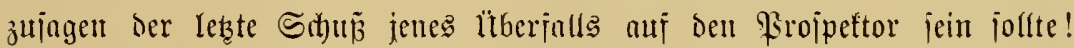
Freilid, jreifid): wenn man jith erinnerte, wie ein nid)t minder meit

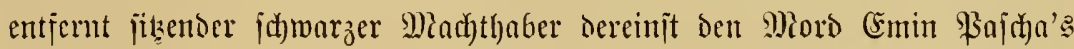

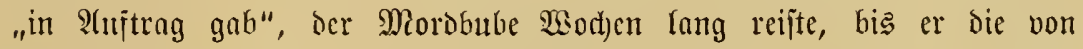

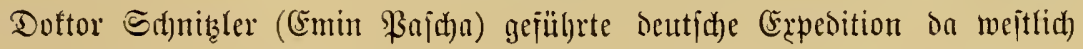

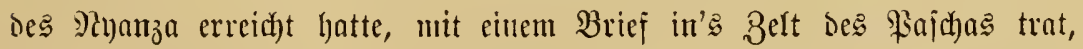
ibm nach lltherrcichung Der Schriftrolle uno ber Frage: "Sannit Dut

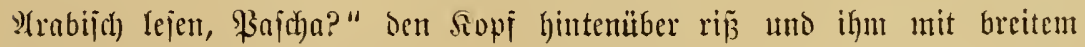

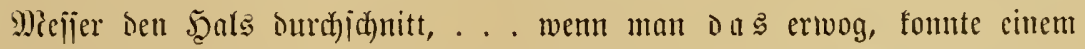

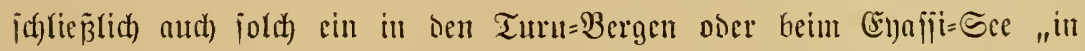

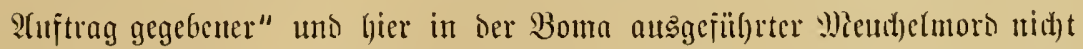
mefr ganz uno gar umbalyricheintid) vorfommen! Bcioe Erciguifife lyïten

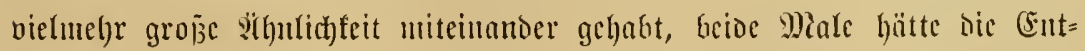

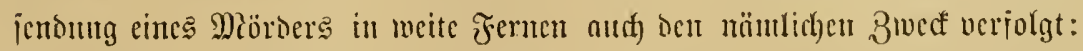

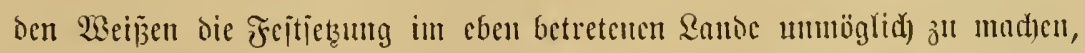

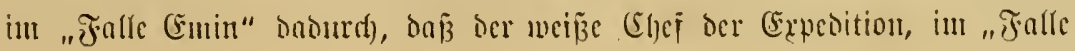




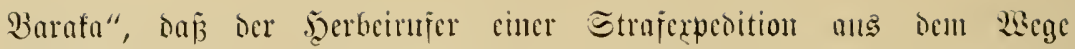
geräunt wurde!

Das alles war bem நanptmann bimucu wenigen Scfumben burd)

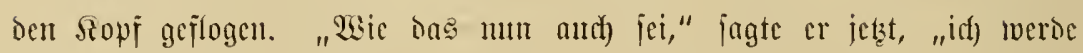

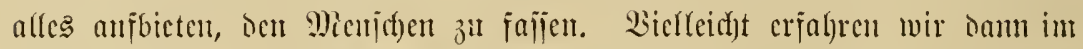

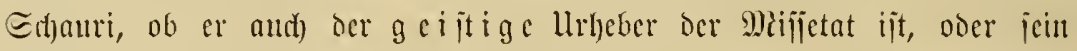

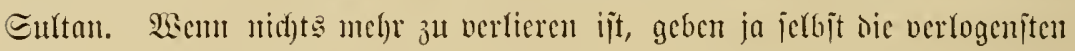

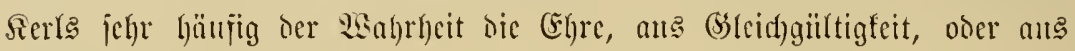
\$rall(jud)t, ic nad)oemr."

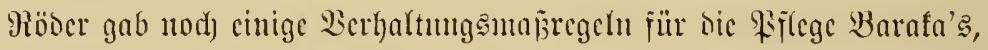
bevor cr jid) jum (beben anjefidfte. Seine auj Stubium bernhention, auf

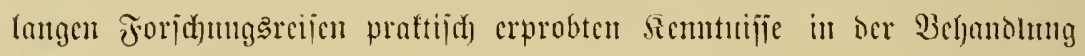

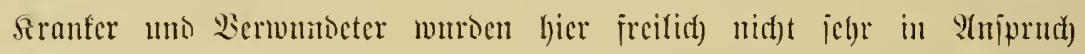

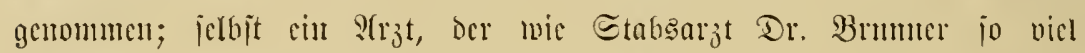

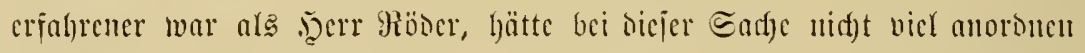

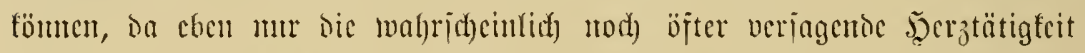

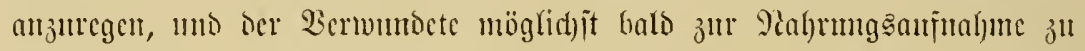
3twingen war. Stles ïbrige mus̃te man oer itarfen Patur Barafa's. ïberlafijen, unt abwarten, ob jeine Sebengfrajt ïber bas cingeormingene

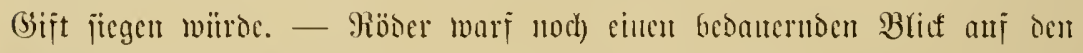

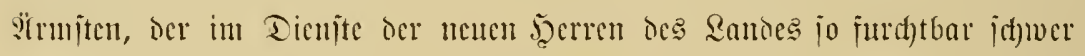

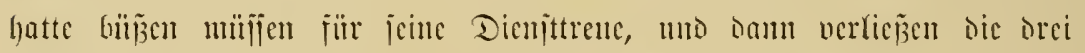

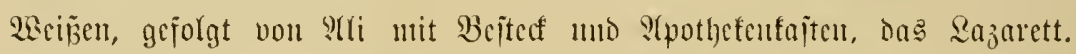

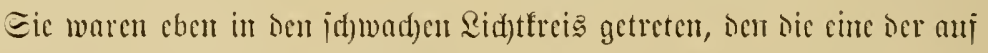

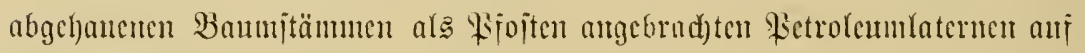

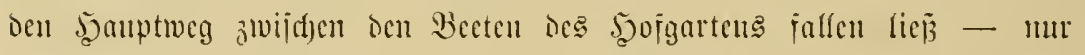
cine sor Raternen braunte, bem fïr die übrigen feblte es an 3ylintorn,

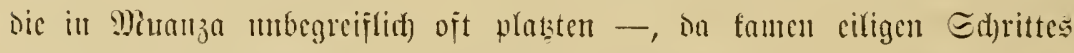
die vom Etations=(Chej mit nod)maliger 2Rad)juche betrauten 2(sfuris auf

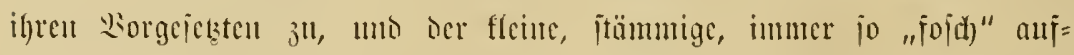

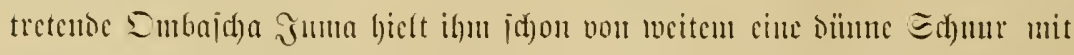

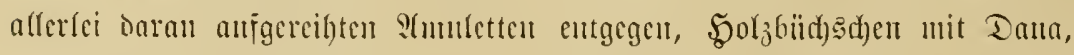

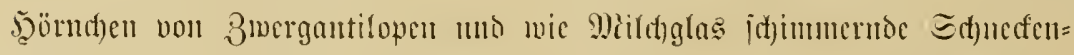

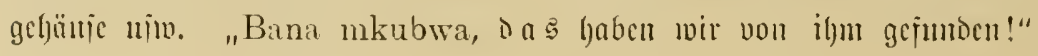




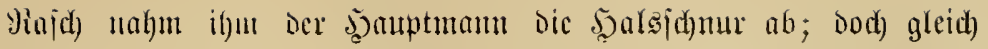

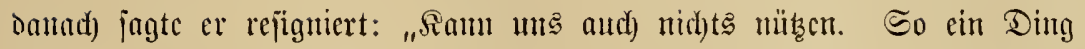
tragen unzählige Sabwarze; nur bei wernigen Stämunen ijt das nidyt üblich. - 230 habt igr's gejunoct??"

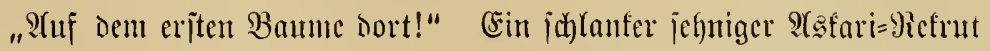
rief cs mit unverfenufurem Stofze aus und zeigte dabci ïber sie Mlancr fort auj cinen breitäitigen Baum, deffen Sipficl man von hicr aus cben nod) jah, oder, da ja bie jiath nad) Der gewiejenen ßichtung

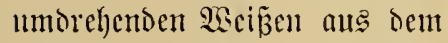
Sidftfreije in's Duntel blicften, cigentlid) melyr mur ahnen als

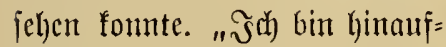
geflettert auf Den Baum, vout dem zueci gefnicfte 3weige her= unterbingen, und es mar richtig der Baum, auj dent er gejefien. Sieh ljicr, bana mkubwa haupmann: die Dauaịhnur ijt il)ut gerififent, a(s er jict) nact) dem S(f)uffe gefdumino hat har= unterglciten lajijen, unt jie ijt lä̈ngen geblieben im didbten Beäit!"

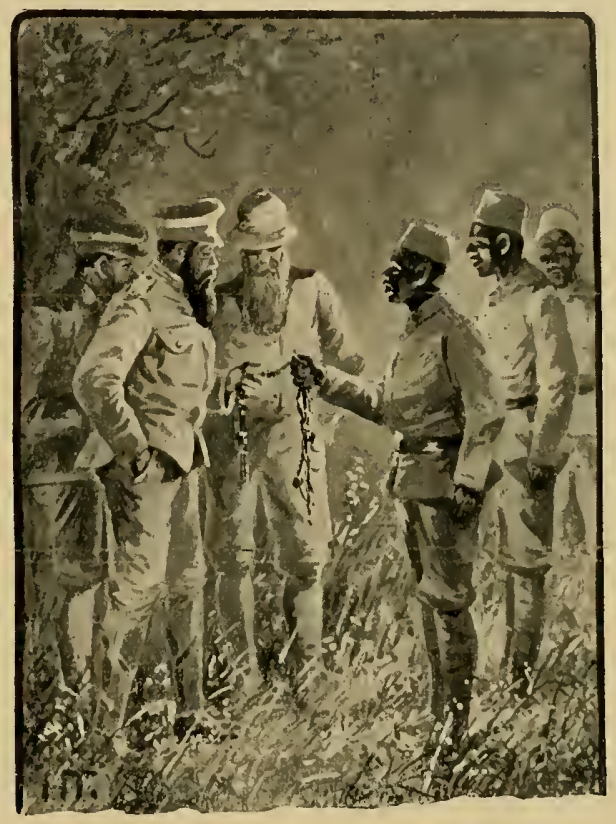

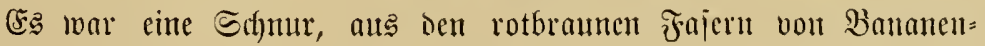

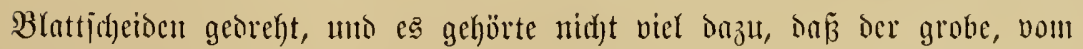

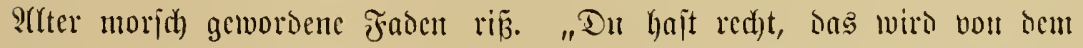

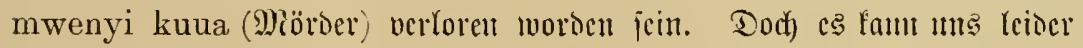
nirft auf dic Spur bringen."

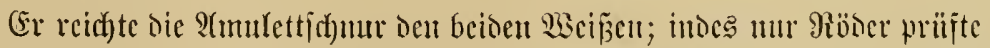

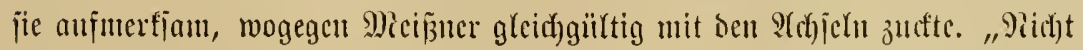
anf Die Epur bringen?" jagte ier Motbart Dabei langjam. "Das will urir bod) noch nidht io ausgemarht vorfommen. Schen Sic cimmal hicr, meine

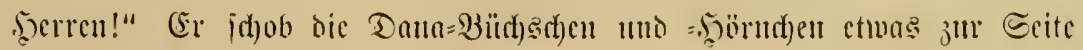




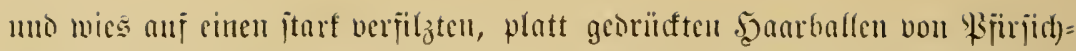

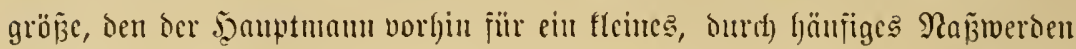

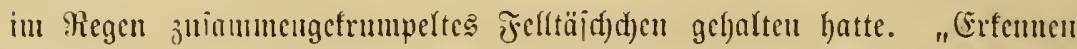

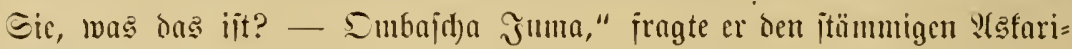
Gejreiten auf Sijunheli, "was i jt Das, uno lver trägt Das allcin?"

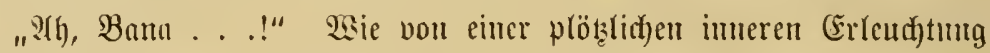

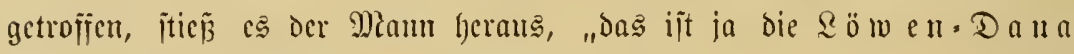

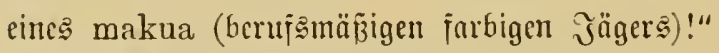

"Kweli (ridtig), Smbajda! - Eie haben beine joldye "bejondere" dawa moht nowh nitht gejehen, meine Socren? Pam ja, jie ijt ziemlid) elten, . . . aber gerabe oeshalb wirb jic uns vielleidte um jo eher ben Miann finden lajicn, der jie verloren lyat!“ Der J̧auptmann jah

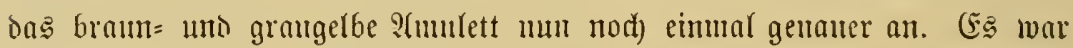
in ber Tat nichts anderes als eine verfillzte simba=5̃arlocfe, wie Röier

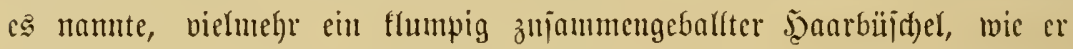

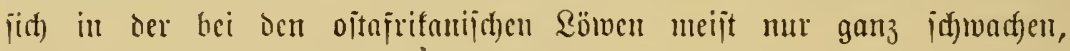

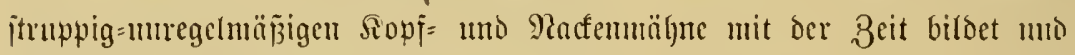
cutweder, jobalo das janar abjtirbt, von jelfer abjällt, oder aber vou dem Eimba cingebiinjt wirs, wem er beim Sagen surd) deu B̉ujd, viefleidft aud) im Sampf mit anteren હimbas um bic Römin währent der :iamzzeit

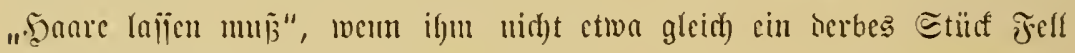

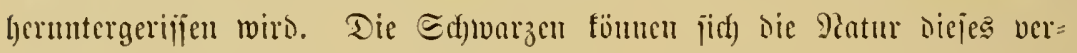
filjten Balleus nidf)t red)t crf(ären; mand)e behaupten, ber \&öwe werje ihn nus - wic bie grop̃en Manbuöget bas "Bcwölle" —, Da jie nber

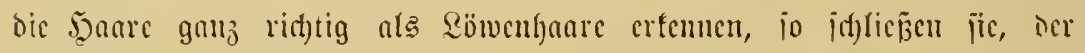

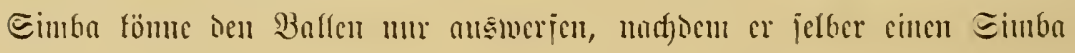
bejicgt uro gejrejjen; habe er das getan, oier auth mu einen Teil des Bejiegten zermatnut umb verị)lungen, baum habe er fidh samit and bie

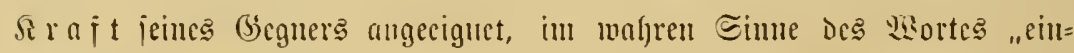

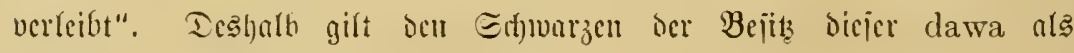
bejombers fraft = uno ingoglüfforiugctro!

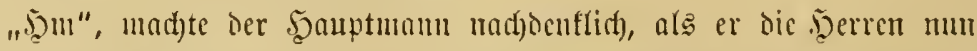

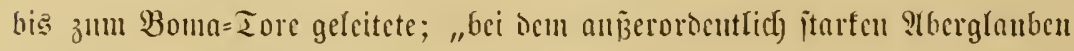

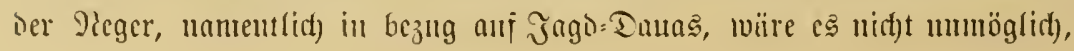


Dan franze madte ..."

"Das ijt jogar bejto wahricheinlicher", fiel ifnn ocr Motbart int's

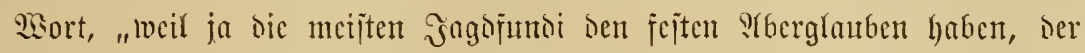

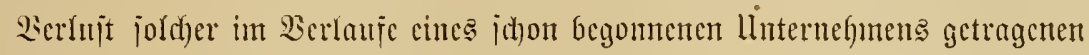
Daun bringe som 2erlicter ocn $\mathfrak{z}_{0} \delta$, falls cr jein Unternelymen nidyt jofort aujgibt uno geinfehrt, ebenjo jifher oen Tob, afs wenn igm

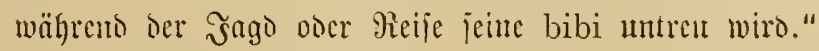

"Den Tod fönnte ifm diejer Berlujt allerdings bringen," Der

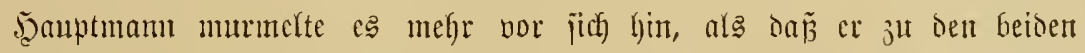

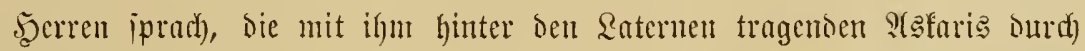
Den (bartent gingen; "ment er nümlich) in bicjen Tagen wirffich bantach)

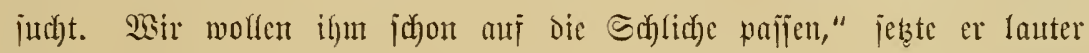

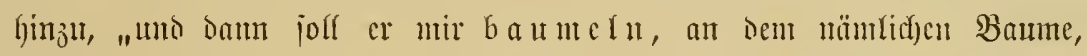
von bem berunter er fred)erweije jeine Sififtpjeile in bic llmpreoung der Etntion gejubofien hat!"

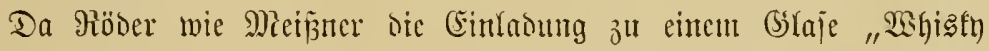

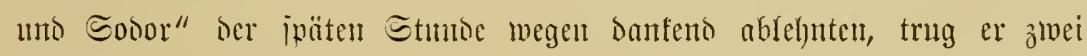

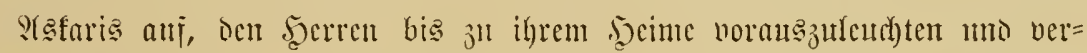

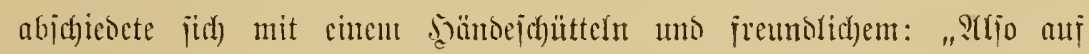

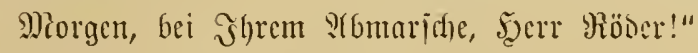

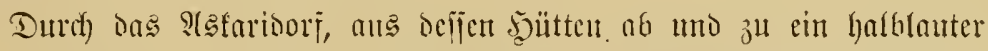

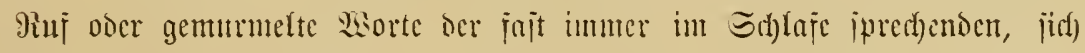

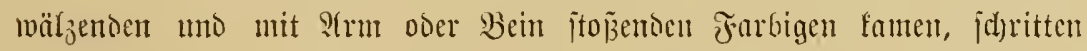

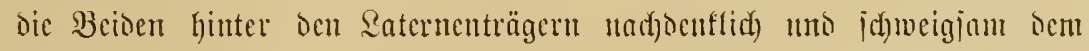

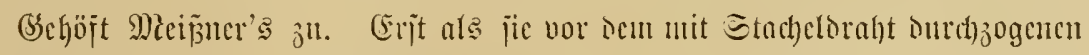

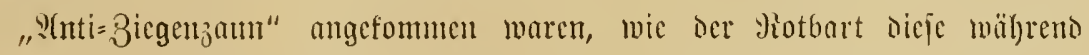

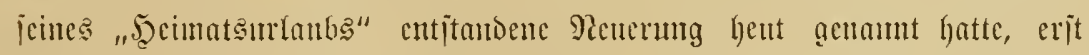

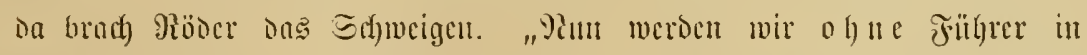

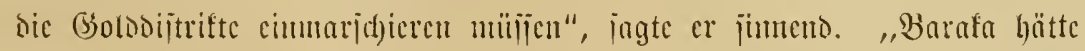

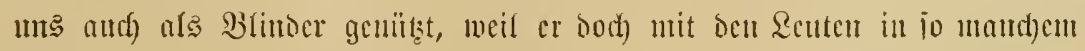

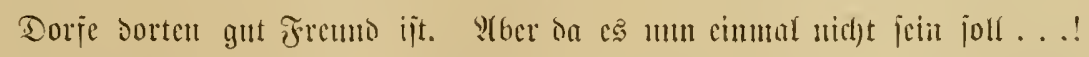

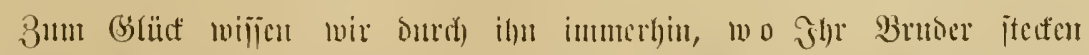

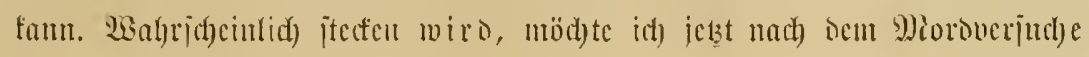


aIt Barafa mit größzerer Sidjerheit jagen, als id on so vorker gewugt

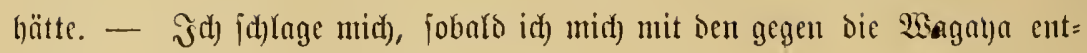
jandten Dffizieren in Serbindung geielzt und mir von ifnen bie Brenze jür unjere Mara=Jagoen habe bezeidfuen Kajjen, ohne weiteren Shufenthalt "ieit=

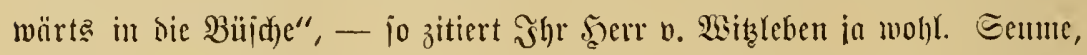

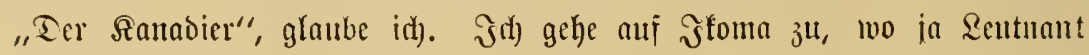
Sd)loiffer "fïndig geworden" feit foll, uri bon to ans gerabenwegs oder

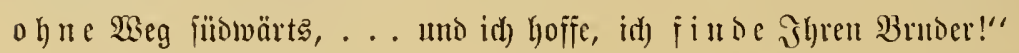

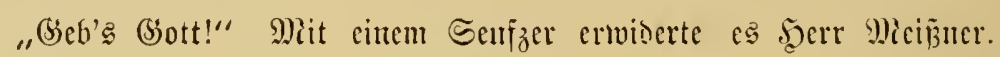
Sein (Bemüt war jeit Dem Miorianjafl auj Barafa nod) mely bebrïft

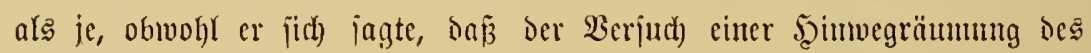

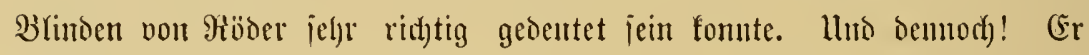

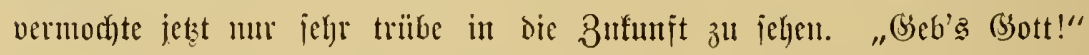

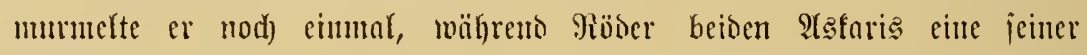

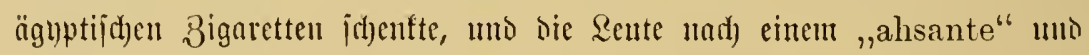
"kwa herini" (Danfe, lebt mohl)!" feh)rt mad)tert.

Die eijerme Sdjelle über ber 3 amutül idjepperte lant durth die jitlfe

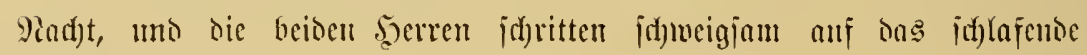
รุณนร วแ. 


\section{Elftes Kapitel.}

S( 9 uhr am nächiten Bormittage itano die msafara ya bana

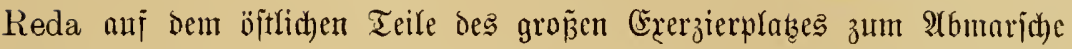
bercit, bic Träger in orei langen Reihen vor ihren auf Dem Boden liegenden

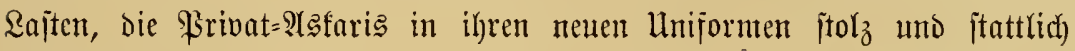
10 Schritte dovor; Yinfes bavon hieften bie Marltier= uno Ejelwärter mit

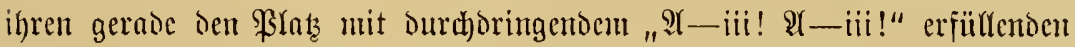
Pĩlegebejohlcuen, uno hinter den Trägerreihen mar Der Troj̉ verjammelt, bie Weiber Der Aafarta uno wapagazi, ungçähr 40, manche mit cinem

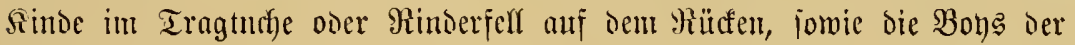
Solonten uno der 8 Wamuampara; es waren mit bem vor ber frout in möglidyit friegerija) ftolzer Şaltung ftehenoen Tichauja Farrag und dem Subajda llledi in ganjen 209 \$erionen, olyne die fimber. Dic 54,

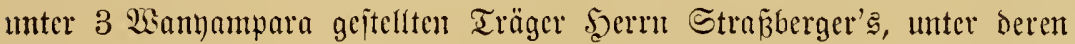

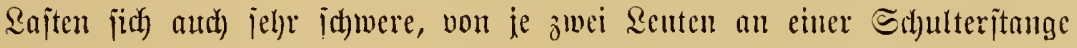

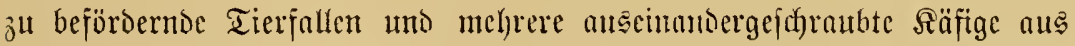

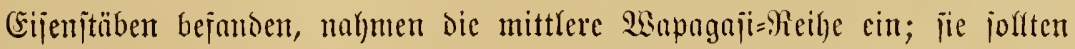

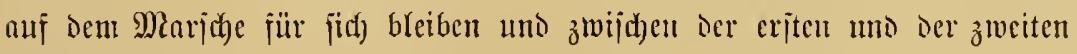

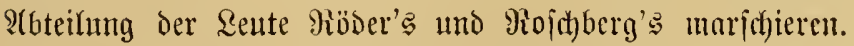

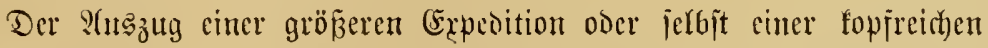

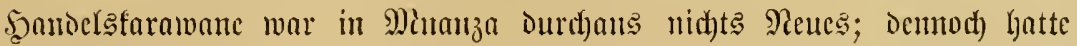
Der ljeut bevorjtehenoc S(bmarich oer Mijajara bes roten Jügers viel jurbiges

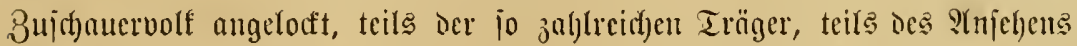

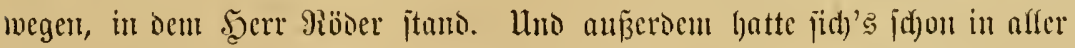
Frülye herumgeiprod)en, onß

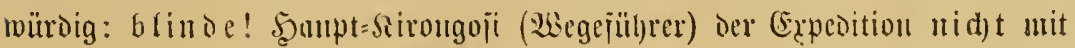




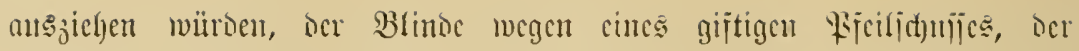
mzungu, weil inm in Der chakulla oocr in ocr pombe ya ulaya Bijt beigebrad)t worten iciu joffte. Sb cr wirflid) 3urïdblicb uns jterben muñte? Dier ob cr in ocr wawu wa kuchukulia (Wiatten=Tragbaf)re) tramsportict

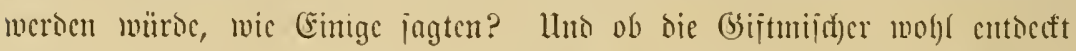

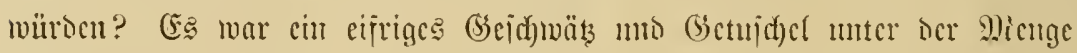

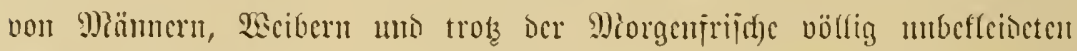

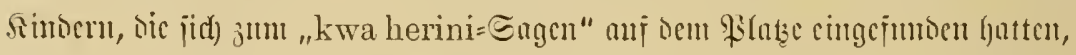

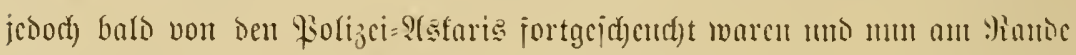

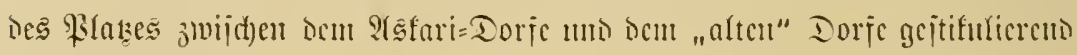

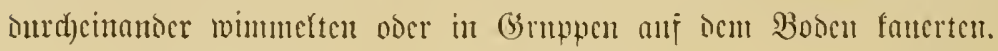

Rä̈rgit war alles bercit, man fomtc aujbect)en, zumal ber y)iorgentau

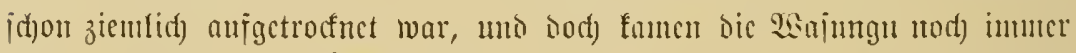

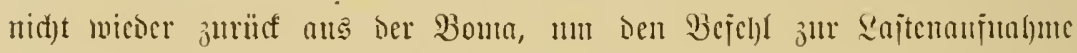

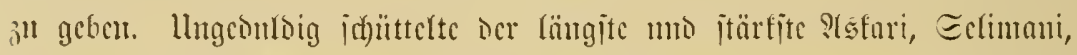

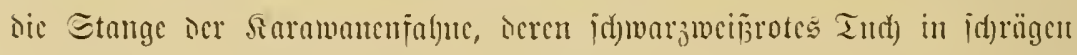

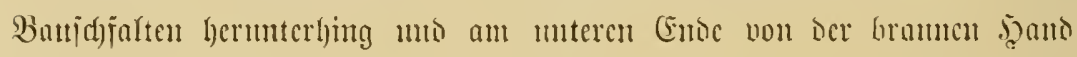

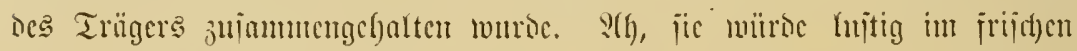
Morgemminto flattern, wemt mur erit ter bana nyekundu tom linf erid)allen lajien molte, anj tocu jie s(lle marteten, das jreusige Haya safari

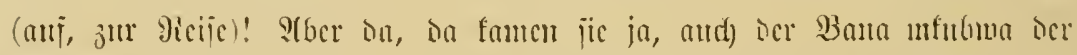

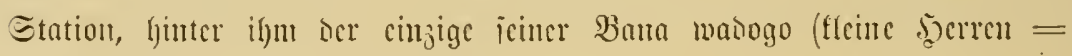
llnteroffizicre, ber nod) hier war!

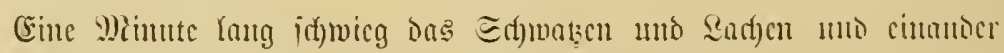

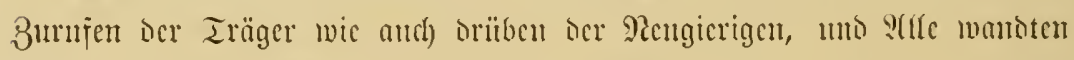

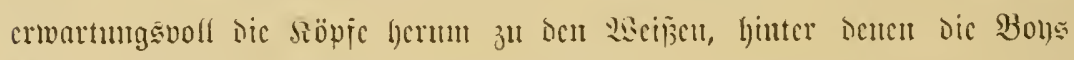

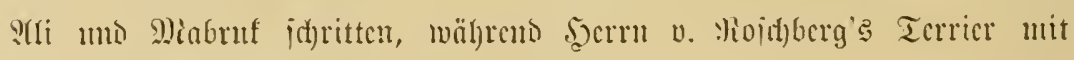

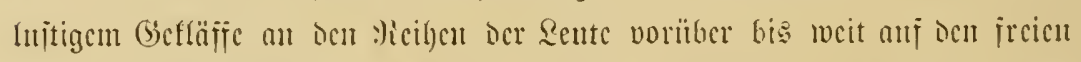

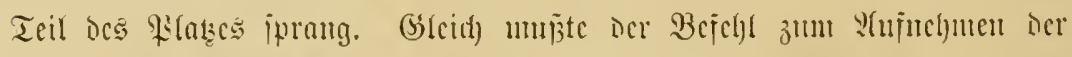

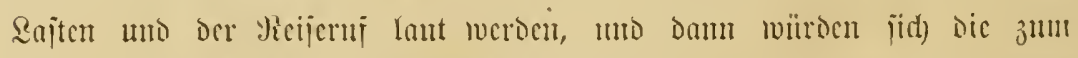

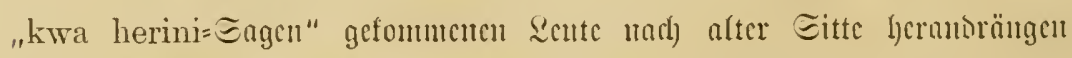

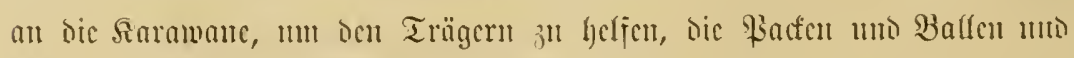

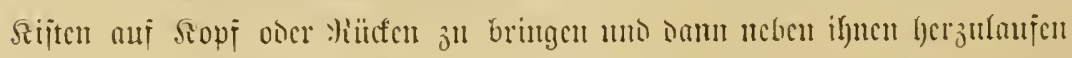

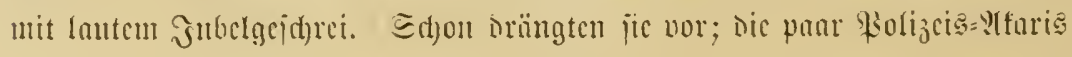


wollten jie aber nach Becichl thod) nitgt heranlajien, und jo gab es am

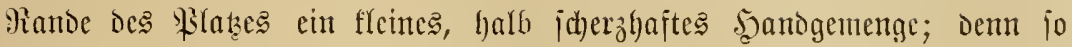
red)t ernit nafmen es bie Bolizijten jelfer nidyt mit dem gegen bie desturi

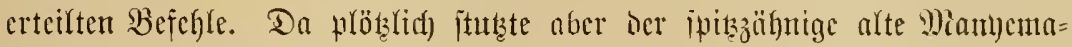

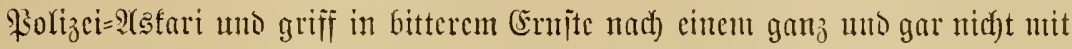

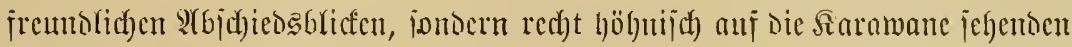

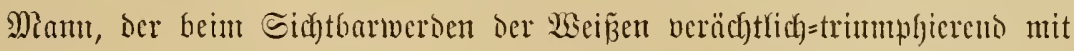

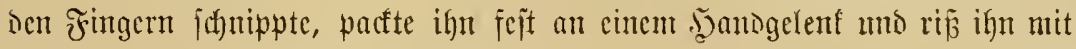
icharfen Jiutefe alls ber Menge heraus.

"romm', Du flylimmer mshenzi, zum bana mkubwa!" horrichte

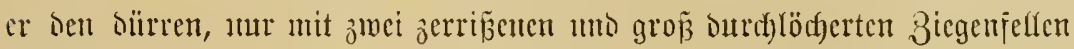
befleiseten, aber am rechten Sberarme wic am Reibe mit ciner Menge von

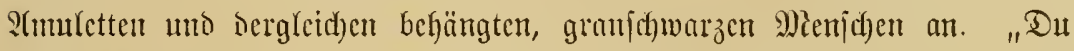

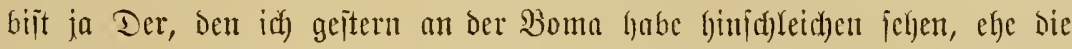

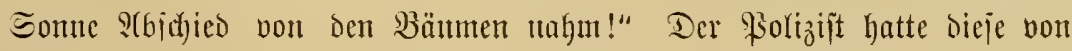

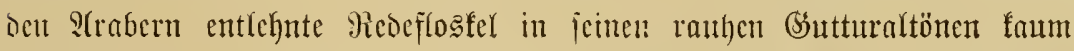

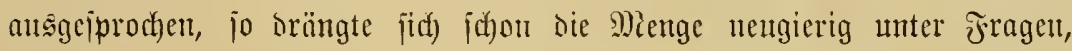

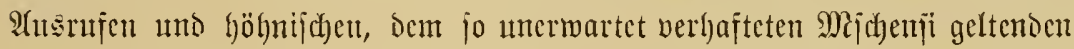
Ah's, Eh's uno Lo's an ifn heran, jo dañ er dic Sente, namentlidf) cin

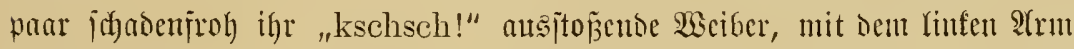

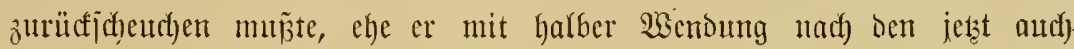
herüberichenden Siaramanenleuten hinwinfen unı nad) llnteritüßung rufen

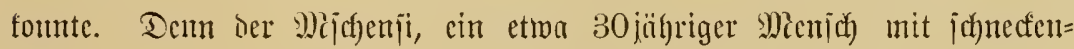

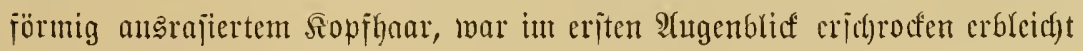

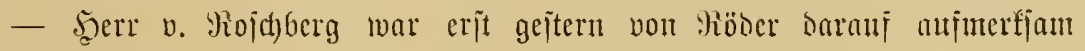

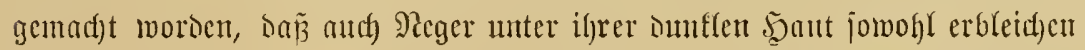

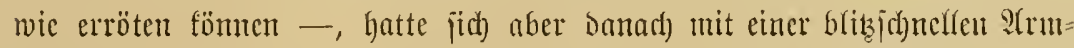

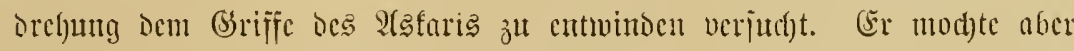

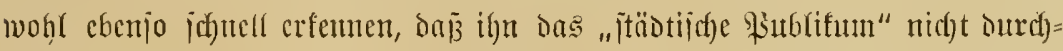

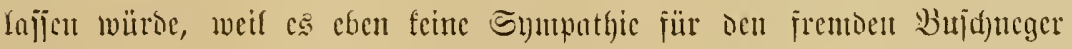

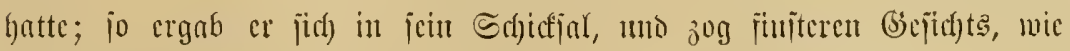

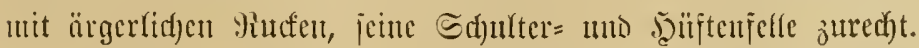

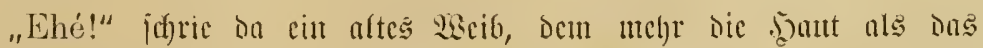

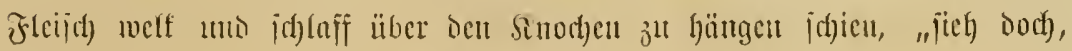


Tafari, er hat ctmas fortgeworfat, was er mohl gejtohlen hat!“ Sic trat

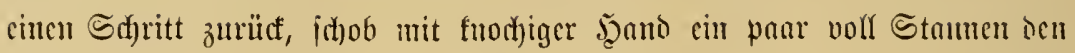

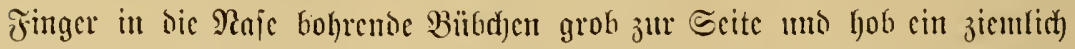

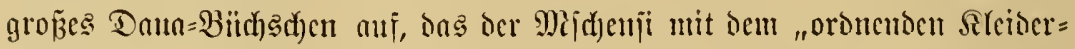

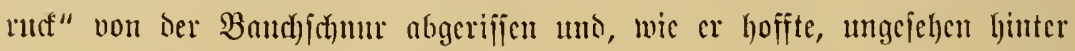

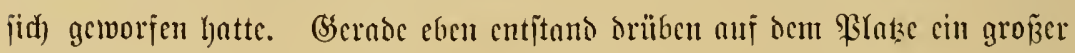
Särm uno ein, alferdings nur fdecinbarer, Bintwarr, oenn auf cin Zeid)en tes

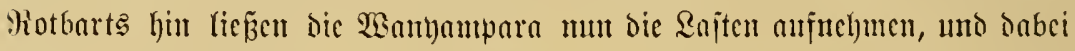

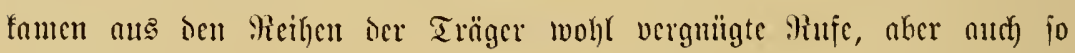
manche Bantworte, cs gab hicr und on cin Sedränge mo Bscichicbe, meil umgend)tet affer Borid)riften, Punericrung ber Träger wie Fadén mo der

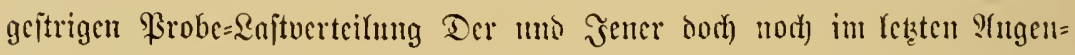
blidfe cinem finutraden Den Yeidhter als die cigene Snit geglaubten Ballen

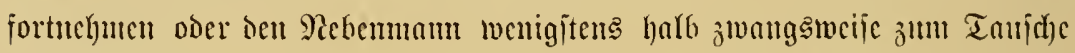

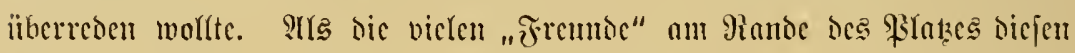

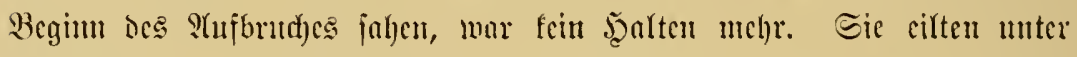

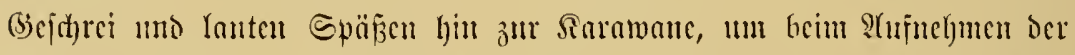

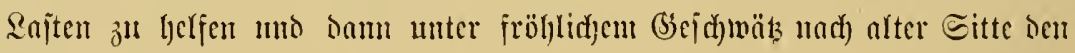

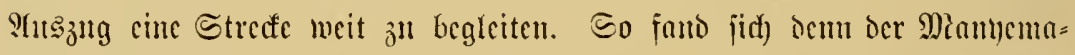
Folizijt plöbzlich alfein mit jeincm 2erhajteten - man hatte orïben jemen

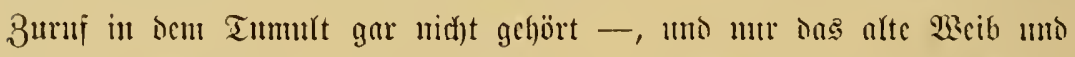
bic paar neugierigen Sinder waren ttm dic Beiben. Sas benütste Der

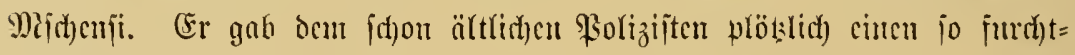

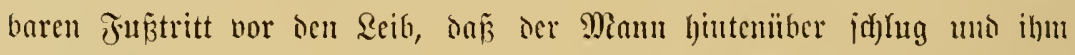
fïr Mrimten sic Ruft verging! Doch) gernoc jein Buboocnitürzen fiel cinigen

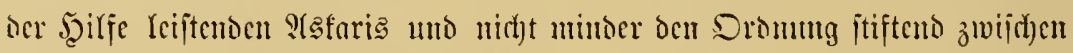

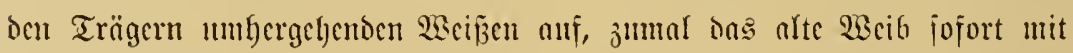

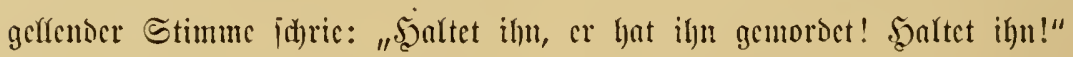

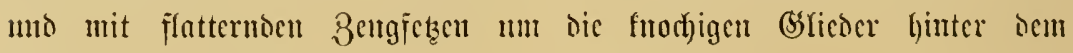
Flïr(t)tenocn orcin ftïnute.

Er. fam midyt weit. Nidgt mur bic anderen bciscu, mur mit Esiten=

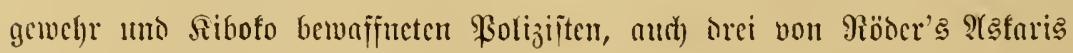
hatten anf Befehr ihres Bana Reda fidfon bie 2icrfolgung anfgenommen,

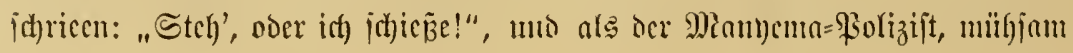


atmend und mit idfuerzerzertem (sejidyt aufitano, fnaflte aud idfon das (Scmebr eines breitbeinig zum Bielen itehen gebliebeucu 2(sfaris; von hinten in ben Sberichenfel getroffen, fnicfte ber Mejchenji zujantunen! In Der

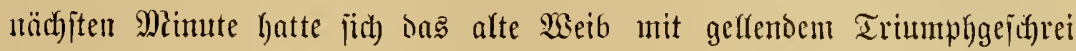
über ifn geworfen, unfrallte ifyn mit ber Sinfen bic Selle uno bielt ifn jo auf Dem $\mathfrak{B}$ bon feit, indem es mit der fnodjigen redhten Faujt, fein

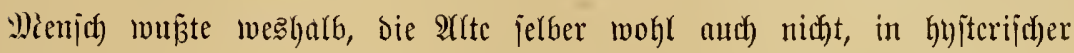

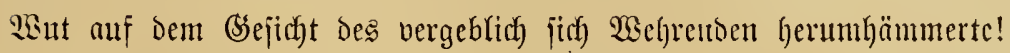

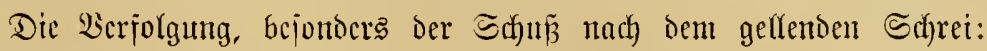
"Er hat iln gemordet!" und bas verrücte (beheul bes alten $\mathfrak{B e i b c s}$ hatten

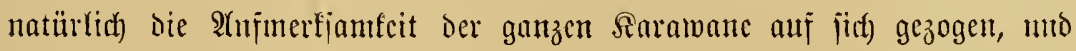
obwohl feiner von den Reuten wiffen fonute, um was es jidt) Dabei lyanoclte, ging es bod) wic ein Rauffeuter burdh bie Mentge: "Sie haben ihn, ben (Siftmörocr!" Trobzocm bie Sanyampara ben Trägcrn, bie iljre Saften

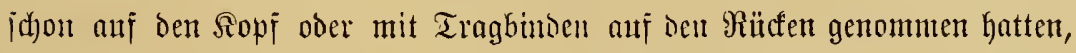
zujd)rieen, jie jollten jie uid) $t$ weeder auf ocn Bosen gleiten lajfen, obgleid) jie

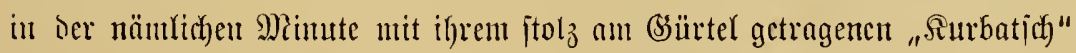

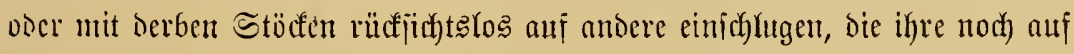

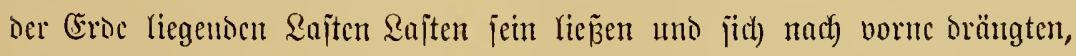

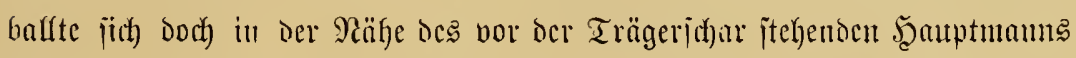

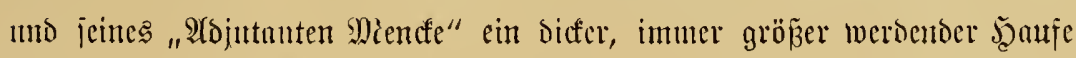

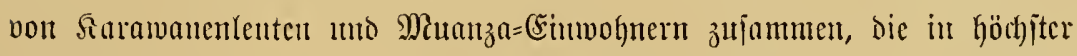
Peugier zujahen, wic der Gintente, jtarf blutende Midfenje von den Rolizijten

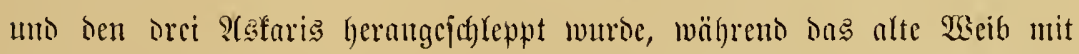

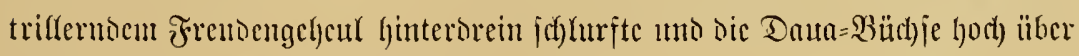
ihren Sopic nadf) allen Seiten hin zeigtc.

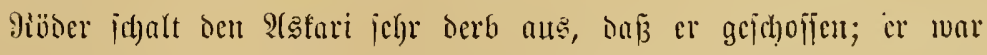

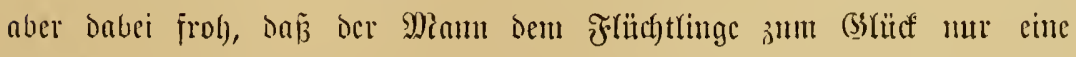

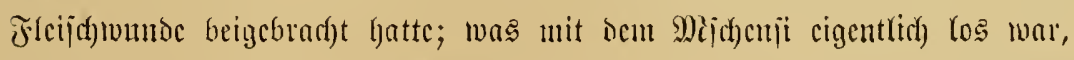

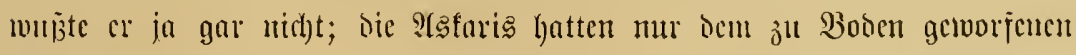

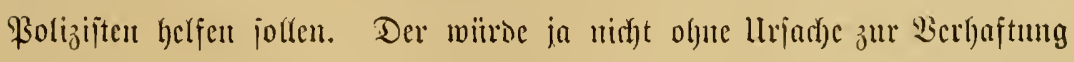
Des Manucs gejuritten jein! Wenn's blóz cin Dieb war, wie jelzet cinige

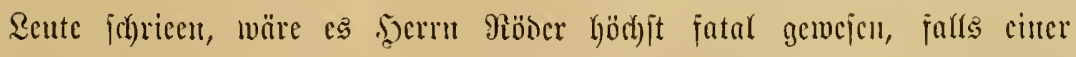

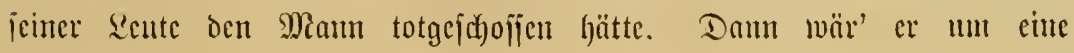




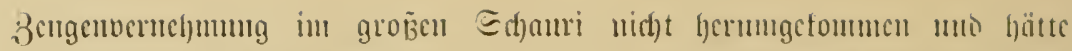

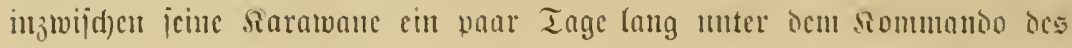

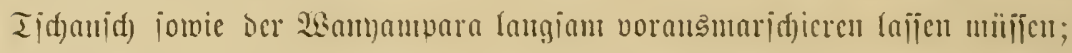

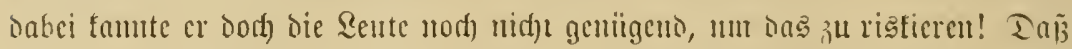

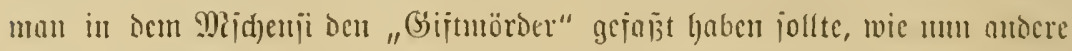

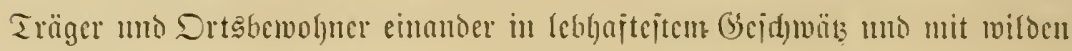
(3cjtitufationen crjählten, Daran glaubte cr uich)t. Eo Dumm, jisf) bent

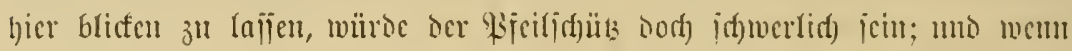

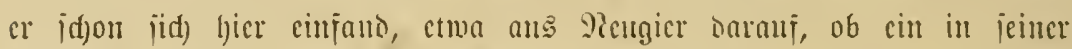

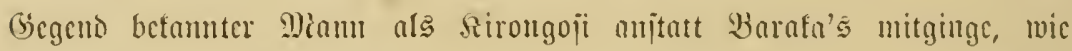

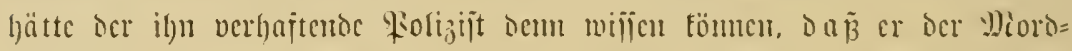

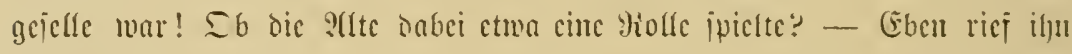

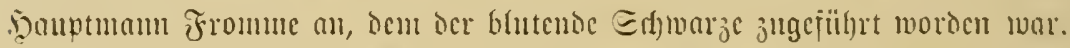

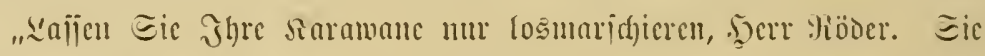

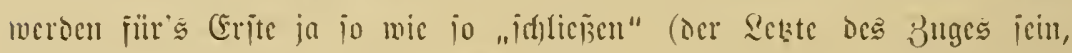

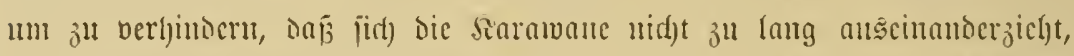

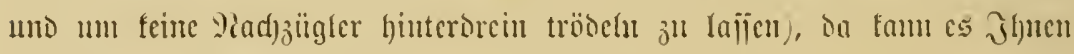

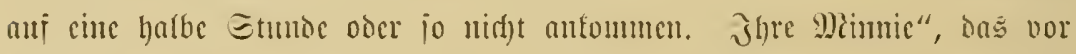

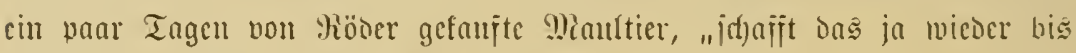

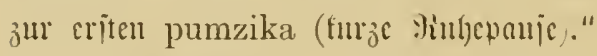

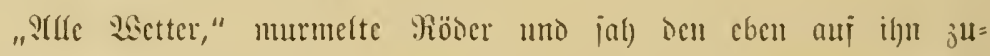
tretenden Fojofberg ungewiẽ an, "was habe id) Dem mur mit Dem Sert

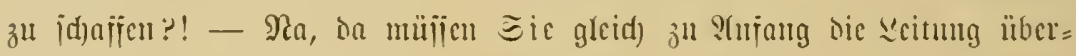

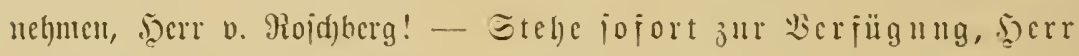
(̧) auptmann! - Tidanjd) Farrag!"

"Bana?!"

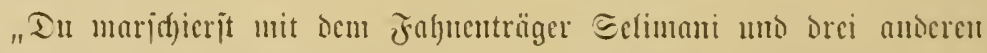

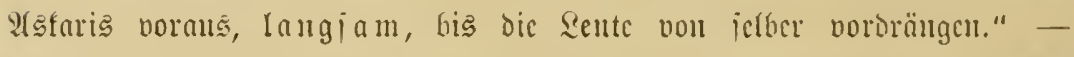
(Er blicte auj bic crite Eeite cines id)malen, immer grififect)t in ocr luten

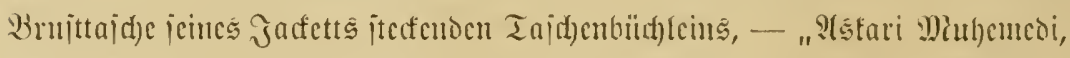

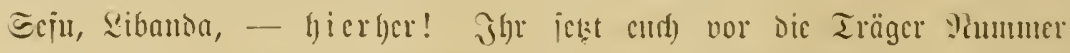
86, 8т nim.! Die da hinten juts's, mit den Eijenjtangen in ihrem

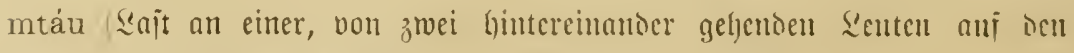
Edulteru getragenen Etange). - wa ijt Der Embaidja?" 


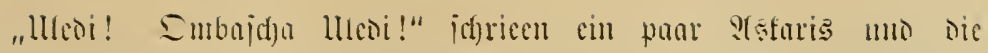

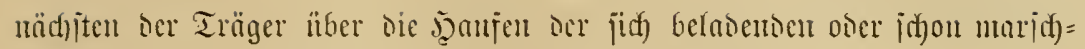
bereit mit ien "Etaitrerunien" plandernocn s.apagaji.

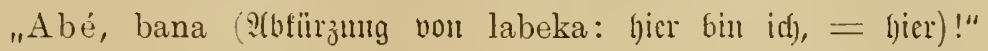
frciichte jujt mit Fijtelitmure oer Sicrujene mo jprang langfeinig, mit

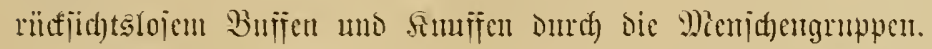

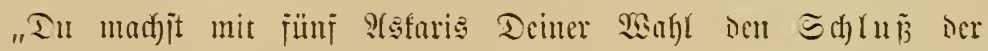

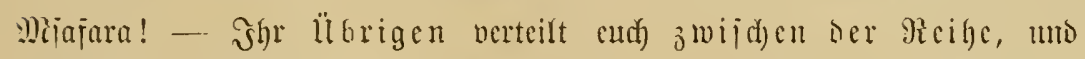

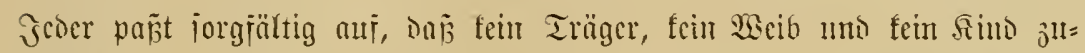

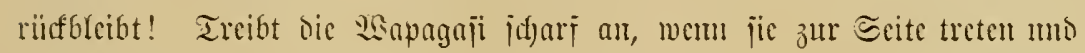

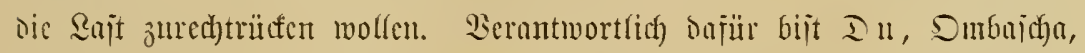

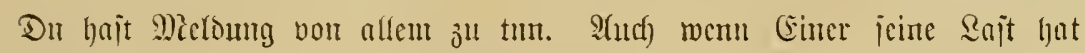
jallen lajicn; tamit mir nadjieljen fömnen, ob jï caputti ijt."

"Hewallah, bana (arabijd)e Bejahung: jebl wohl, jecre)!"

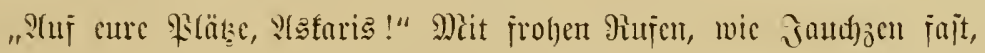

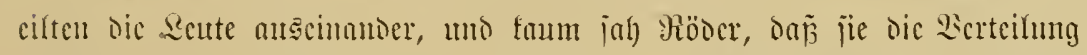

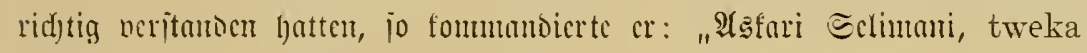
bendera yako (hific, nimm Deine Fahne hod)!"

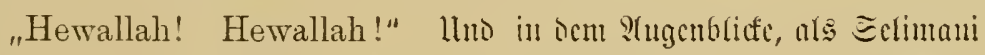

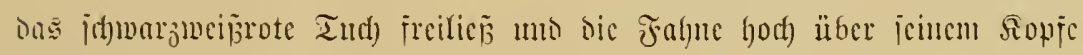

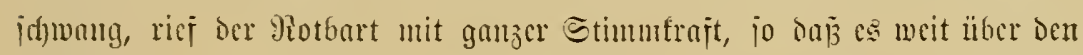

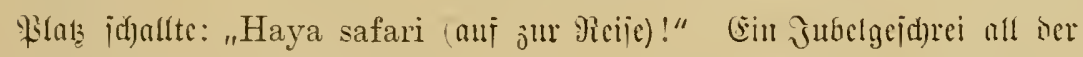
Träger uno igrer Fremnoc antmortete ihnn: "Haya safarj!“, cin Bargumu=

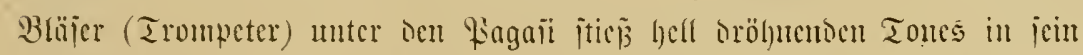

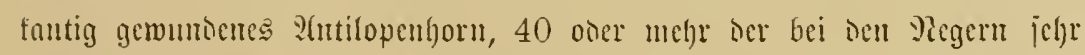

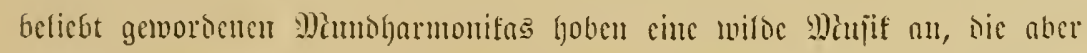

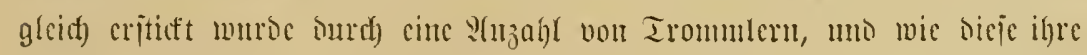
länglid)en, jü̆artigen Pegertrommelu nicht mur mit Den Fingern, fonnern aud) mit Etö(fen bearbciteten, io trummelten gleid)jeitig und) Die meipten

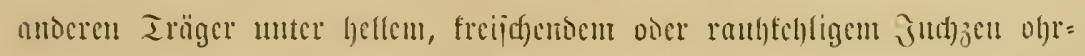

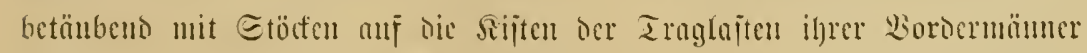

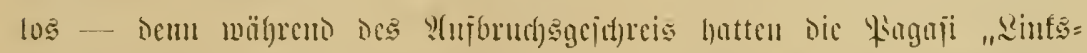

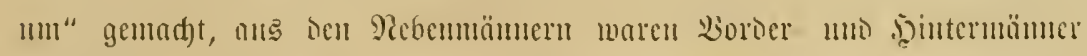

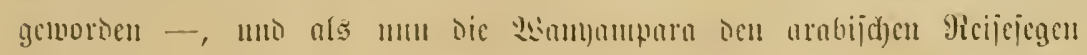


"Bismillah! Bismillah (im Pamen (Gottes)!" riejen, da iekzte jid)

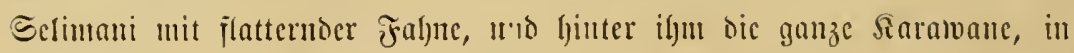

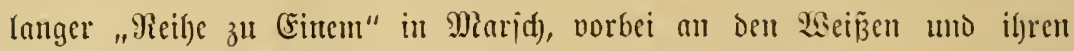
Bot) jomic den Rolizijten mit oem ehen vom Eanitätsastari bchantolten verbajteten Mijhenji! „Kwa heri, bana mkubwa!" idrieen die (Einen

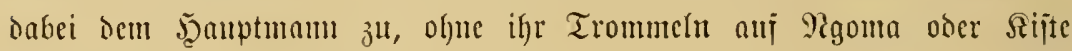
cinzuitellen, „kwa herini, watu wote (lebt wohl, all ihr Leute!") ricjen

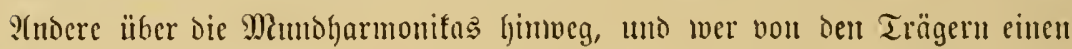
Borderlaser zugeteilt befommen lyatte, ifgwenfte ihn wie die simuampara

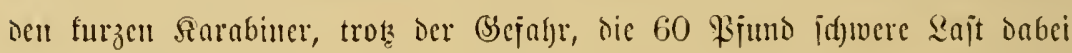

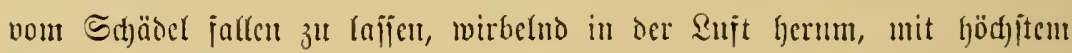

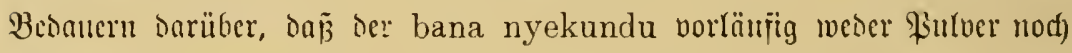

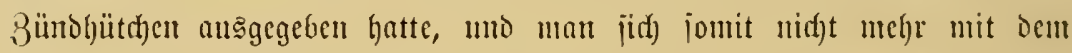
ïber alles beliebten Sicweljrtnallen vergnïgen founte wie in jrül)eren Beiten beim Sintritt Der Dicije!

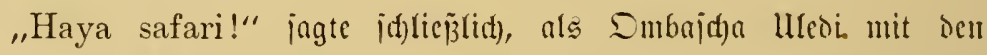

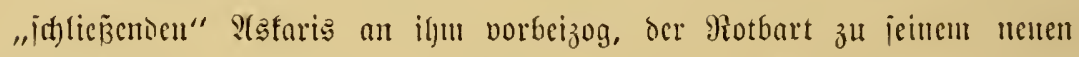

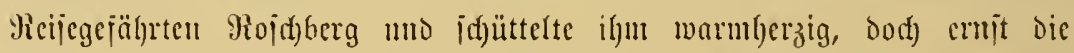

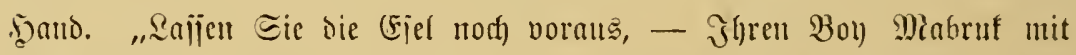

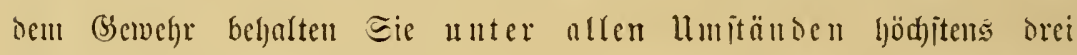
Sd)ritte hinter ober vor jid)! - - ङo, mo mun Bismillah, mit Gjott,

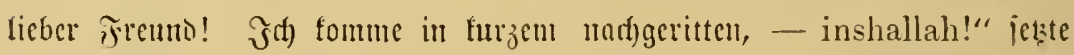

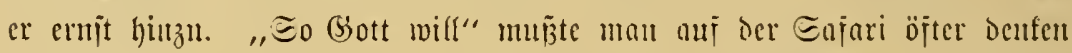

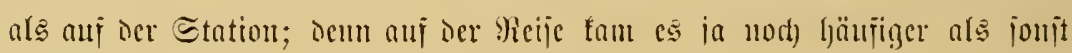
"aldocer", je Had) Dem "amri ya mungu".

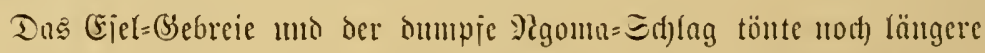

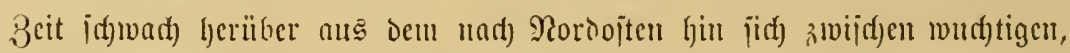

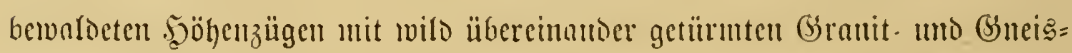

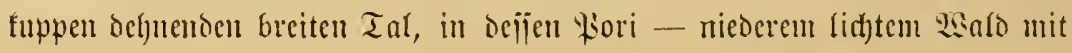

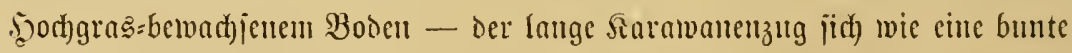

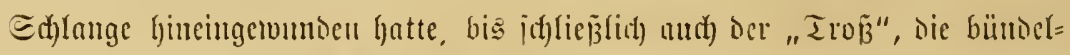

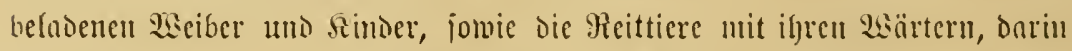

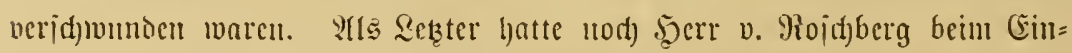

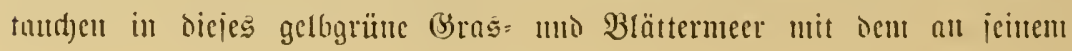




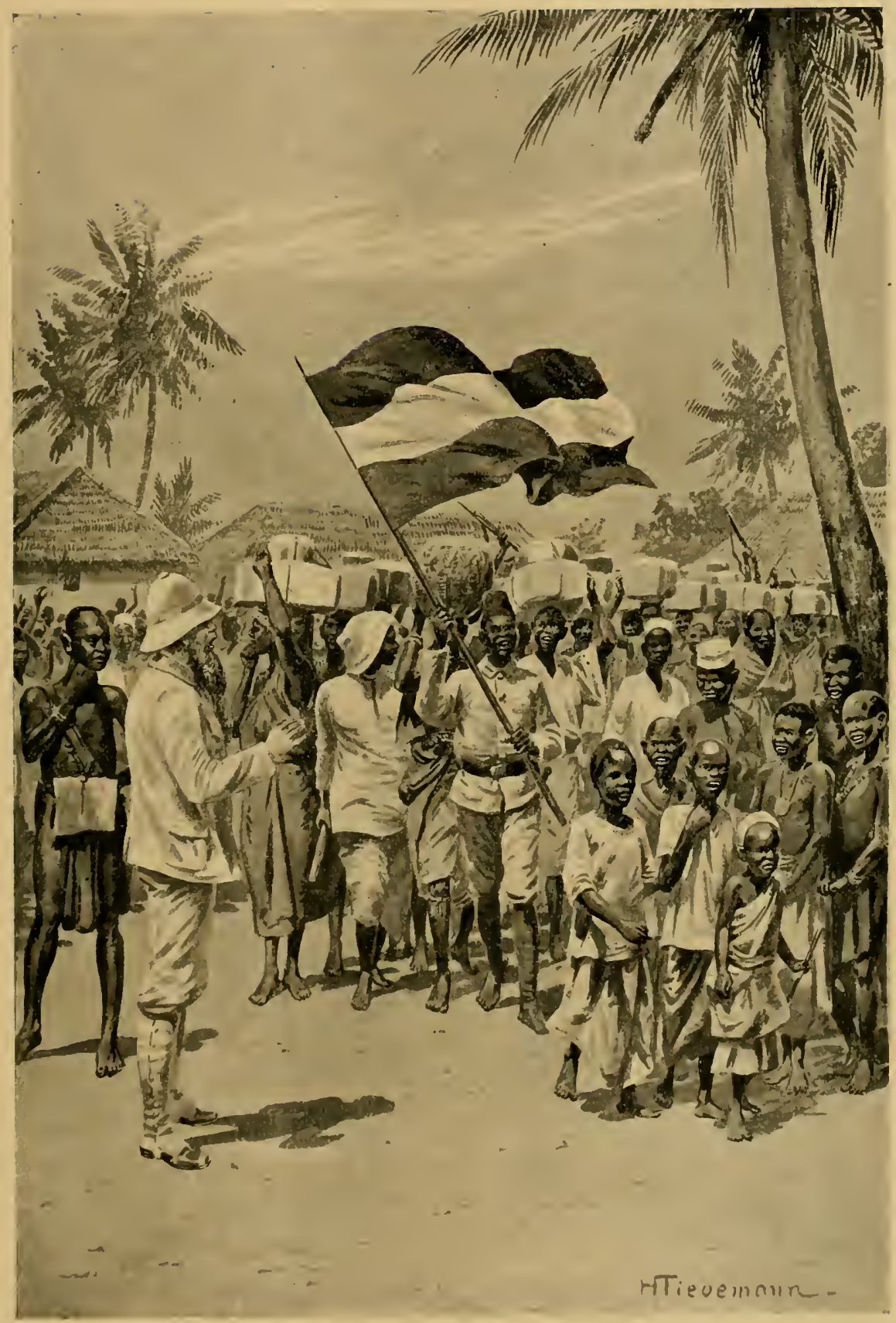

..Haya safari! (Huf zur Reife!)"

(Erite 297.) 



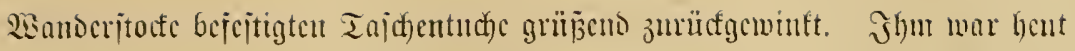

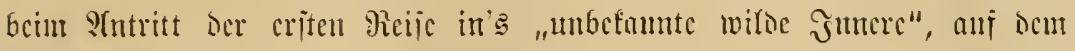

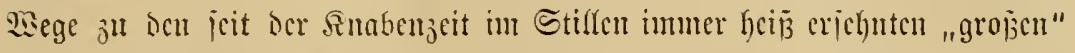

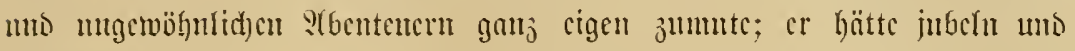

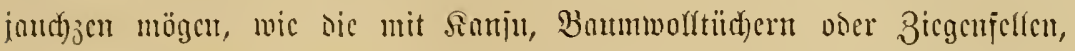
mit cincr halben Rimbshaut obcr rotbramtem Stofi ans geflopiter Feigen=

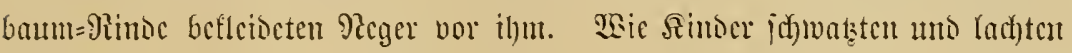

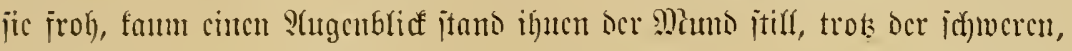

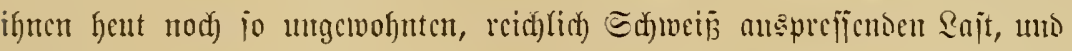
nid)t an wenigiten vergnïgt, ganz jorglos ihres Dajeins froh waren bic

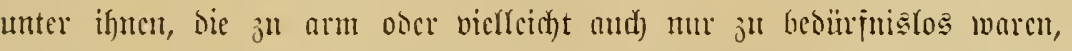

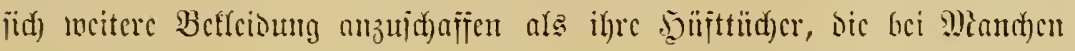

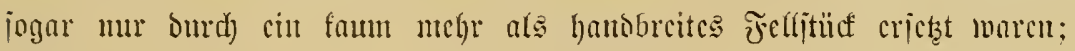

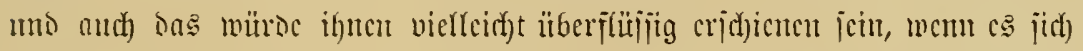

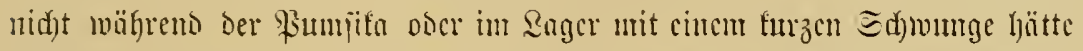

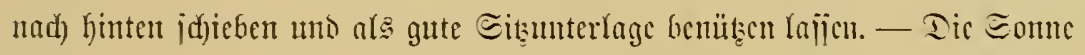

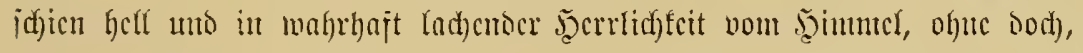

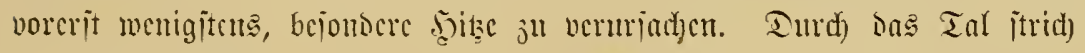

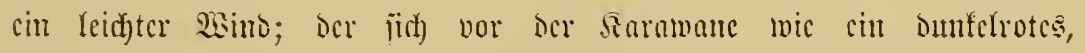

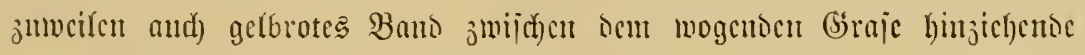

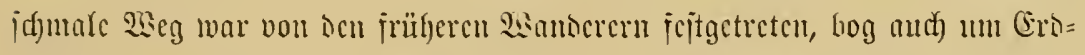

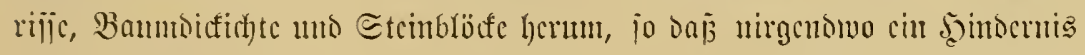

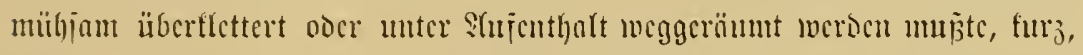

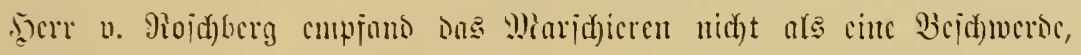

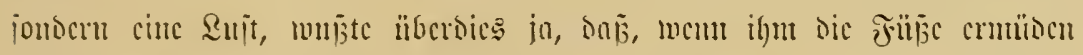

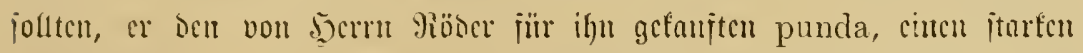

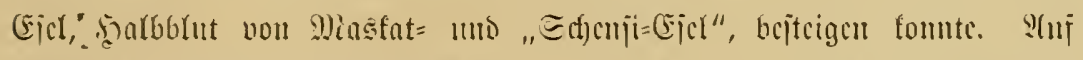

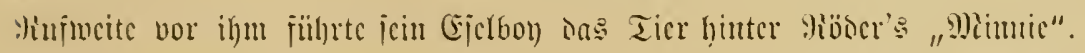

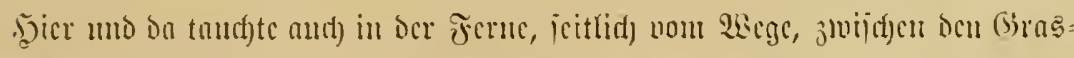

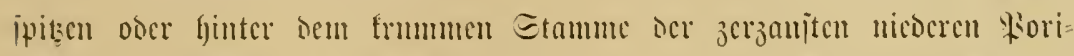

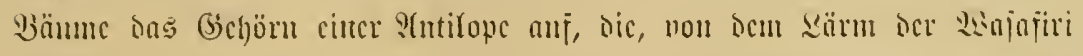

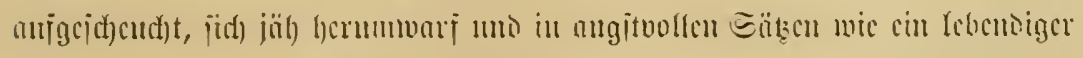

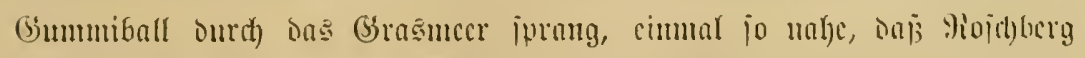

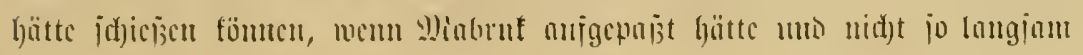




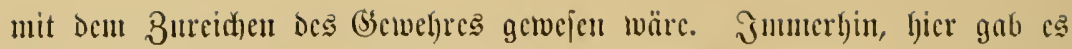

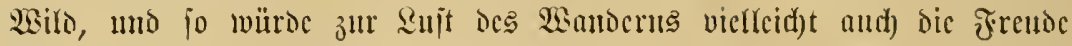

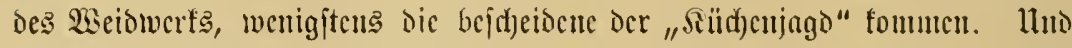

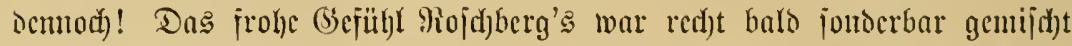

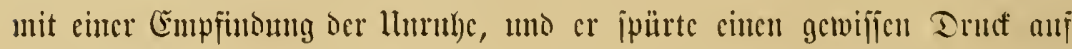

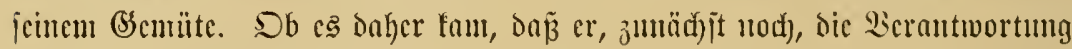
für fo vicle Mienidyen hatte, er, Der nod) nidft gelerut hatte, im voraus 3 แ crfennen, was Schaden bringen tonnte, ber jid) nod) gauz unt gar anf bic

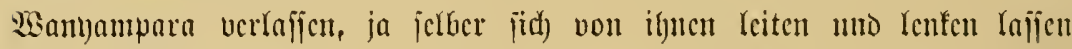

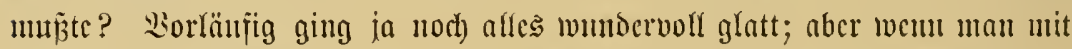

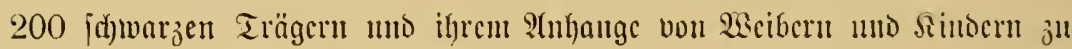

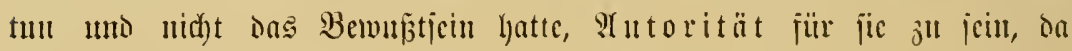
fomte in jeocr Mimute eill unerwarteter Bwijd)enfalf cintreten, vor Dem man

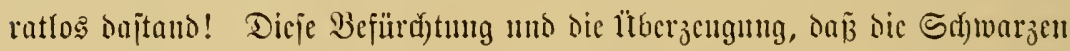

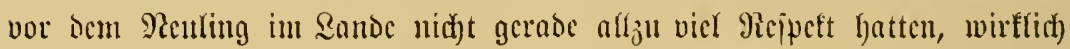

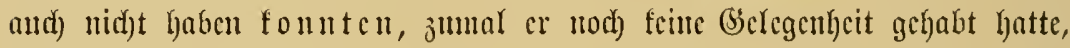

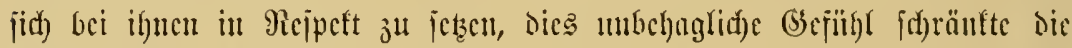

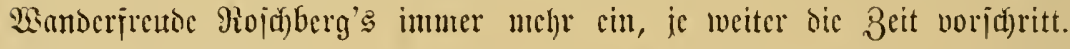

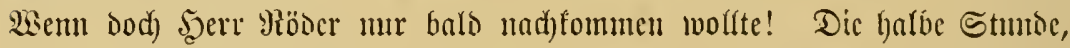

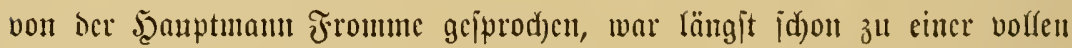

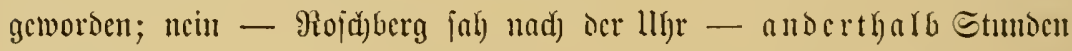

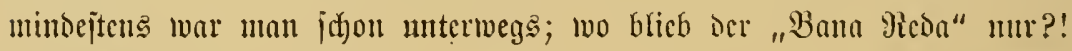

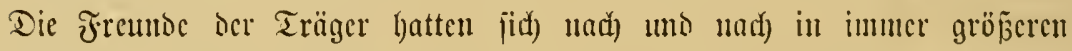

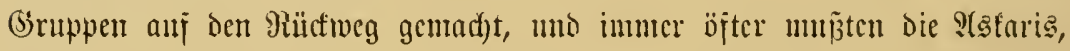
Gier uno da uno dort in bem langen 3nge, cinzelne Träger mit berbem

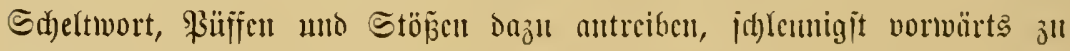
marjuieren, semu nad) der eriten halben Stumbe idjon fing es an, daj

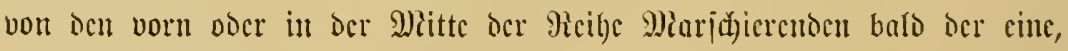
bald der antore neben cincm Baume jeinc mzigo oder mtumba ju \$3oden

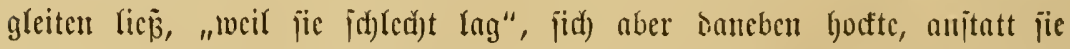
jojort mit ફ̧ilfe cines Samernden jïh) bequemer wicber auj Siopj odcr

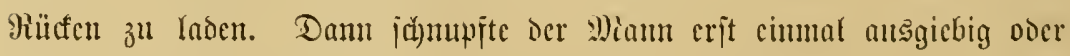

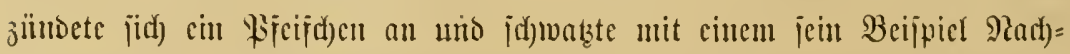

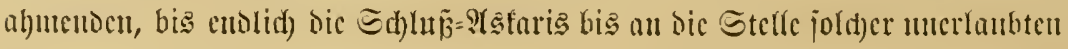




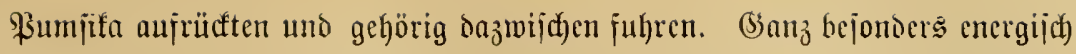

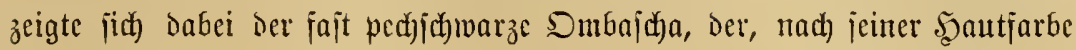
zu urteilen, fein reiner Nijutuma mar - bann wäre er viel heller gemejen -,

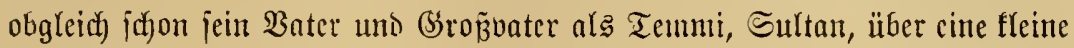
ujiufuma=2nnojd)ajt geherrid)t hatten; fein Bater jo lange, bis ihm jein

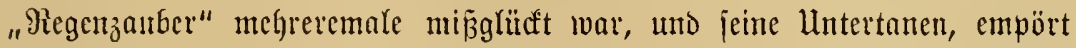
ivegen jeiner Shnmadyt über Den Hegen, ihn narh einer bejonders argen Dürre bavonjagten. Diejer (Exjultansjohn trat ljier jo anşerordentlid energijd) auj,

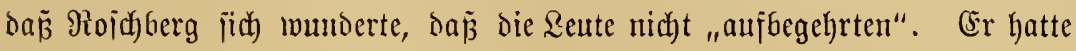

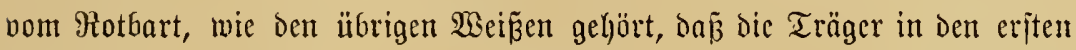
Tagen noch nicht red)t "im Zuge" wären, wešljal( auch) feine rechte Marjd)=

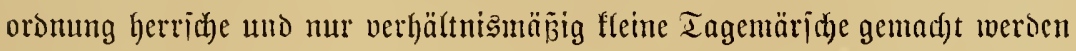

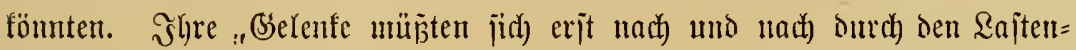

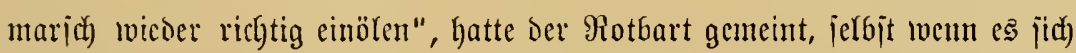

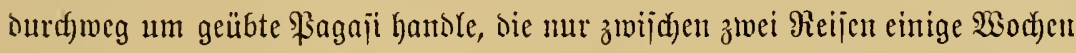

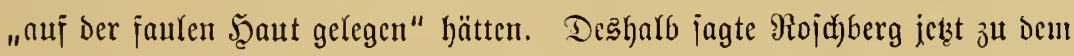
mit einem iturfen, elajtija)en Stocfe auj eine Bruppe Burüdfebliebener ein=

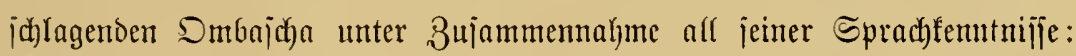
"Sajlage die Reute nidyt; jie merden bald nachfommen, wenn fie jid cin menig geruht haben."

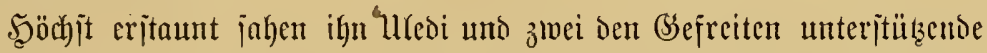

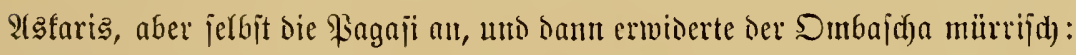
"Wie Du befichlit, Bana. Ther dann befiehl auth, Daż entweser mit bicjen hier zugleich aud) afl bic Sente da vorn \$iumjifa mad)en, ober aber la $\tilde{\beta}$ alle 2afaris hierber zurüdrujen. Eonjt werjen sie unbeaufjichtigten @d)lingel

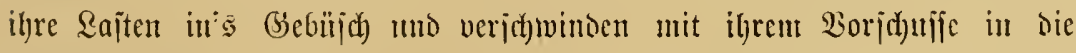
nädjiten Dörfer. Uno Dn birjt mit mur cin paar Trägern in's erjte Rnger

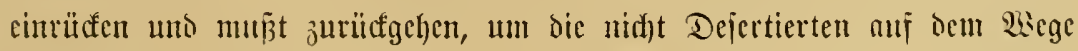
einzujammeln!"

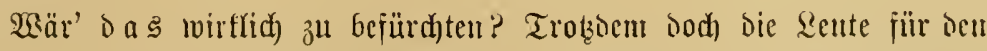
Rotbart jo begeijtert waren? Rojd)berg befam cinen orbentlid)en Schect.

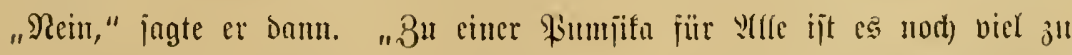
zeitig. Haya safari!" ermunterte er die cinanoer veridsunizte Blicfe

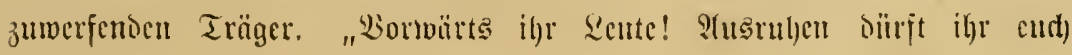




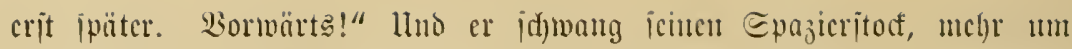

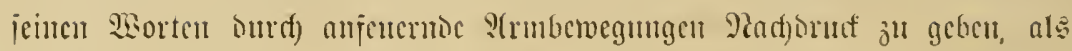

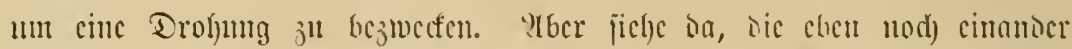

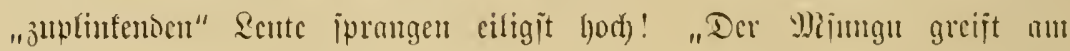

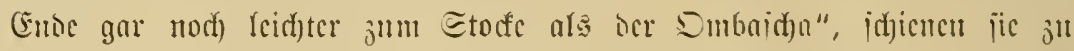

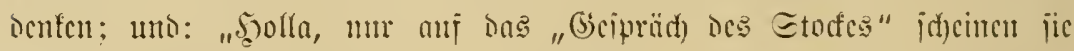

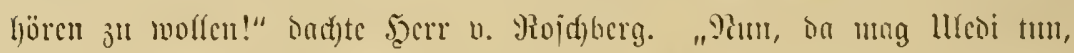

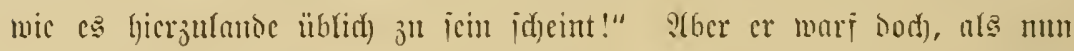

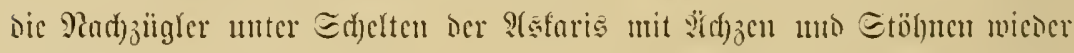

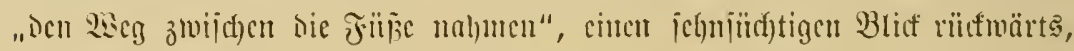

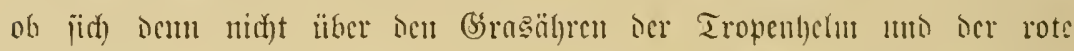
Bart Riöscr's chllid) linter ben "Daflohrigen" Sioptc des Mianlticres jeigen molle?

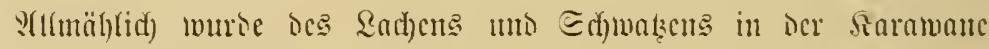

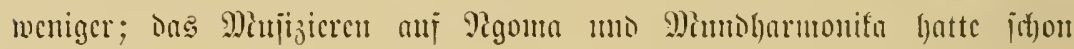
längit anjgchört. Zwar Der Sacg lwar hier immer nod) gnt, biel beifer,

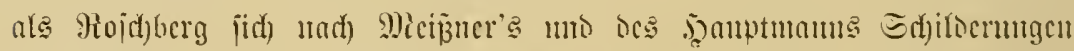

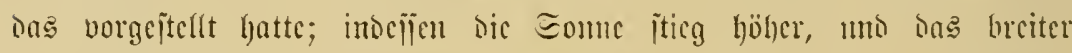

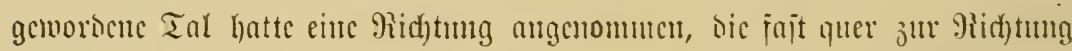
bes simbes licj, jo baj er von ben bewalseten Bernen abgejangen murbe

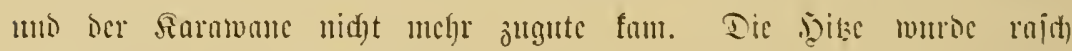

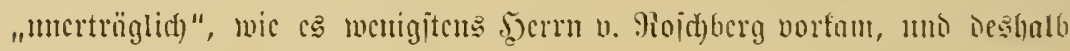

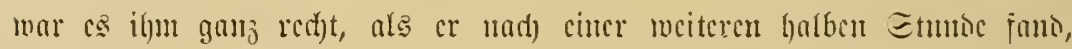

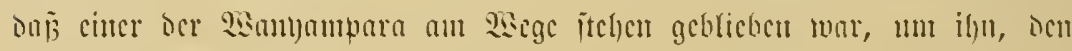

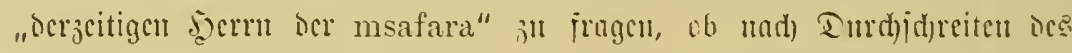

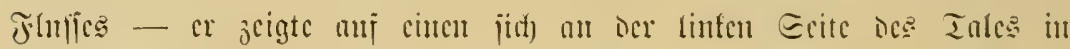

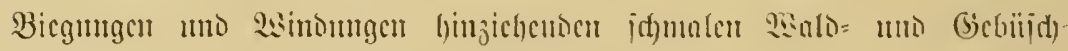

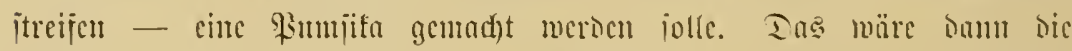

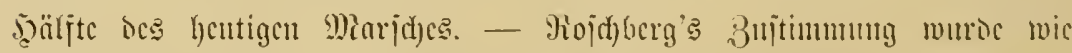

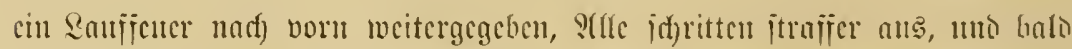

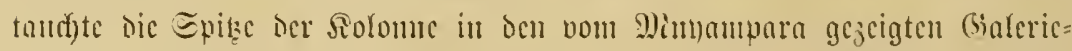

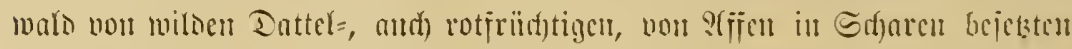

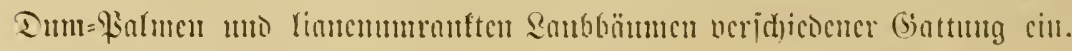
Jmuttem Dicju mu j(d)malcu 


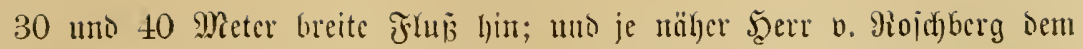

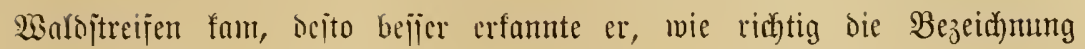

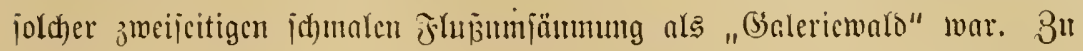

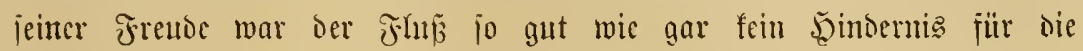

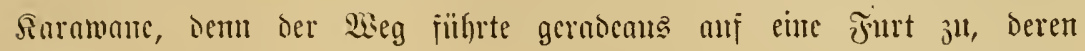

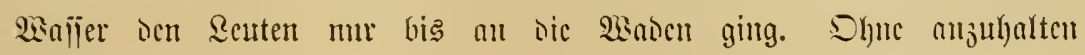

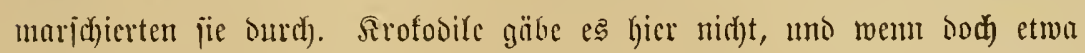
weldye borfanoon jein jollten, jo folten jie ja niemals Mienichen aus cinex

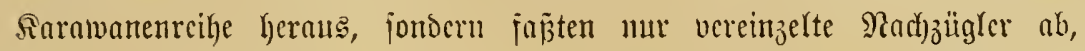

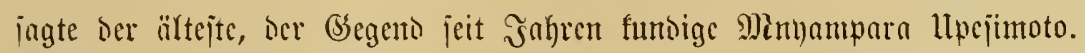

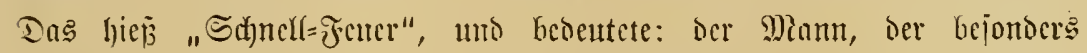

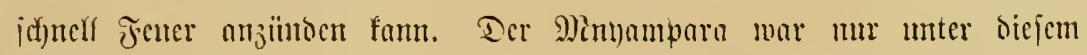

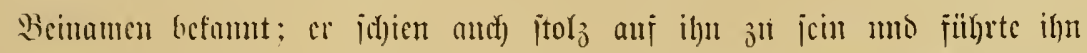

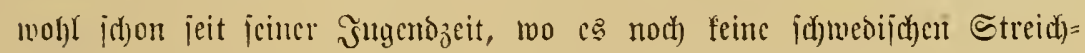

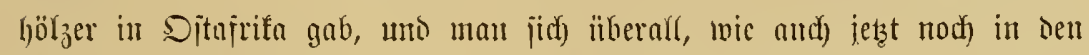

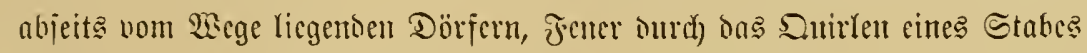

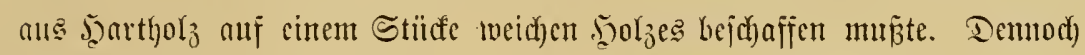

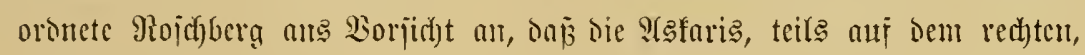

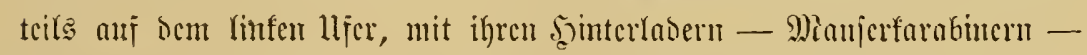

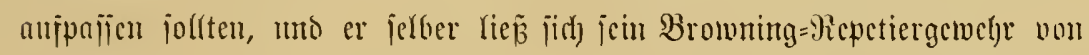
Miabruf żureid)en, Imı von cinem mit Mioos uno mädigen S(olerjarnen

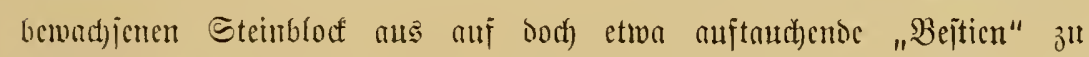

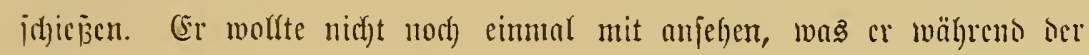

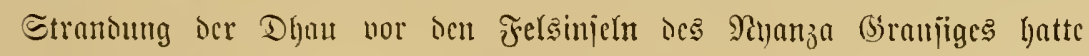
crlehen mitijen!

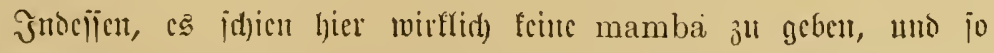

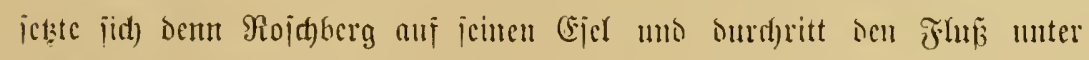
ocm lanten Bejdyrei ber fein Tier norwärts jerrenden Leste, als and) dic

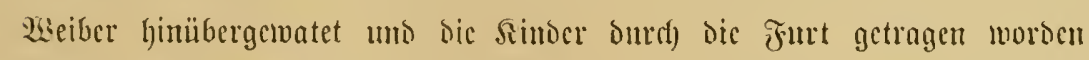

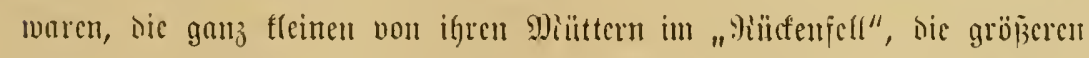

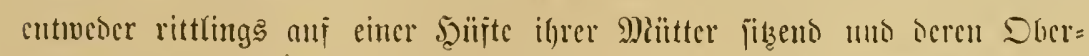

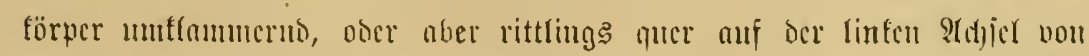

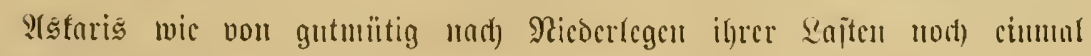
bcrïhergetoumenen Trägcru. 


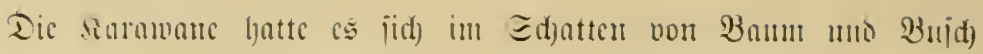
faum bequen geutudt, io hörte mall aus oer ferne jwei rajd) ljuter=

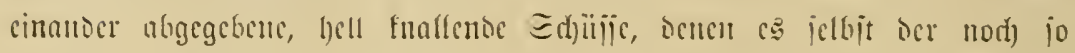

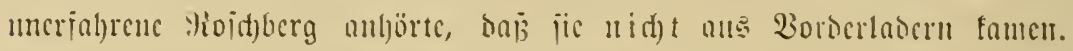

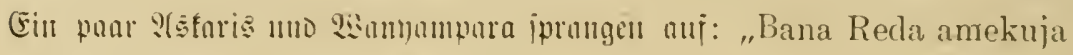

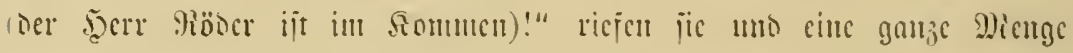

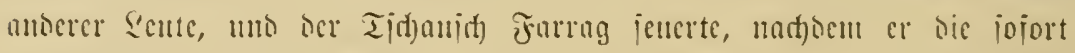

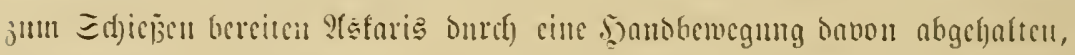

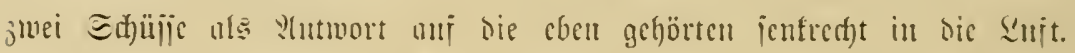

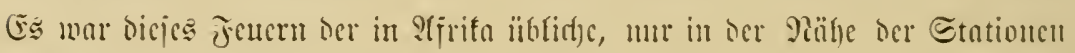

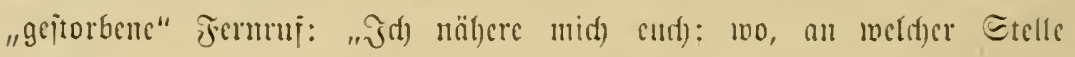
jetio ifre" unt die Bentad)ridytigung: "siomun hicther!"

Rad) einer Biertelitume ritt ber "rote Jäger" mü jeinem grojen,

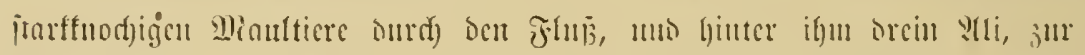

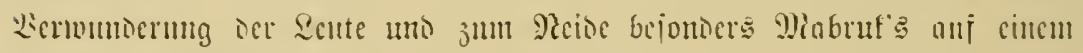

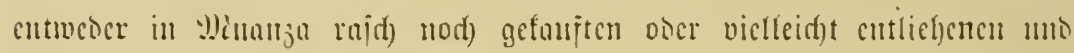
gelegentfidf) jurüafjugethenien cijef.

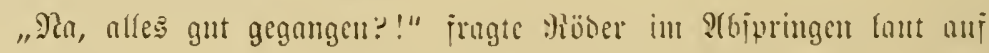

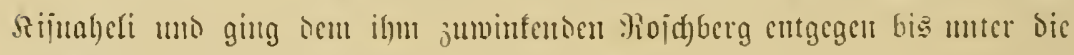

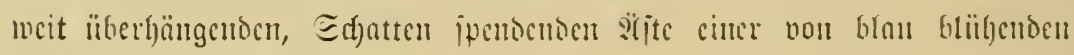

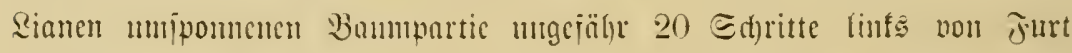

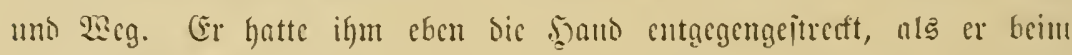

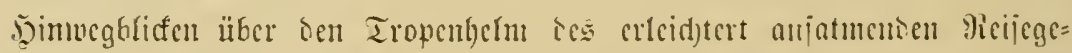

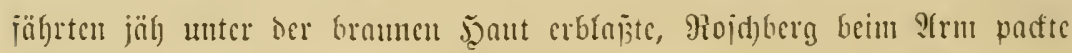

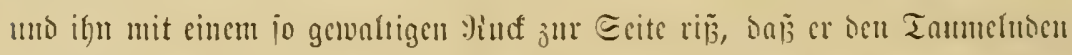

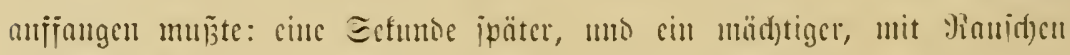

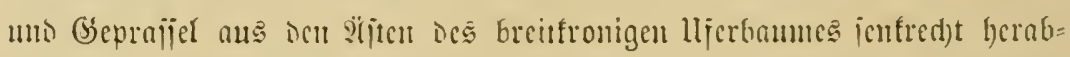

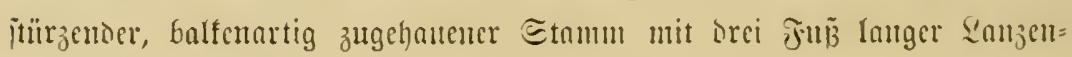

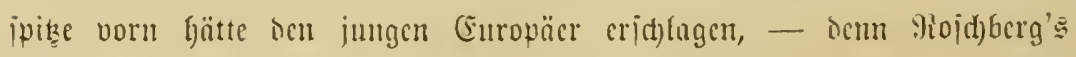

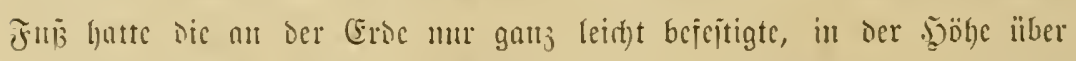

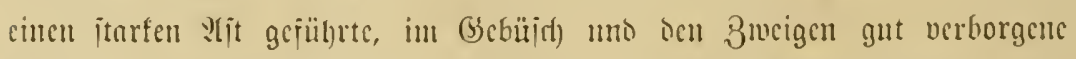

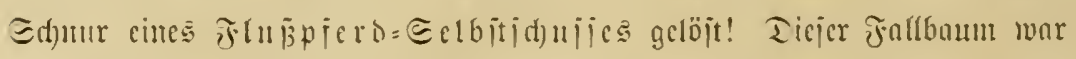

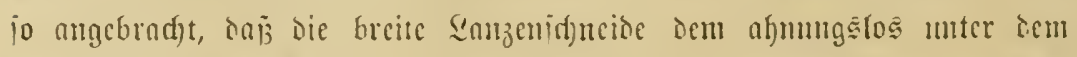

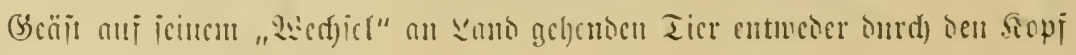




\section{$-30 i-$}

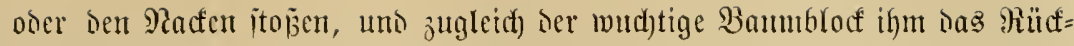

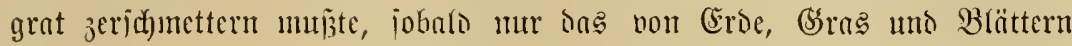

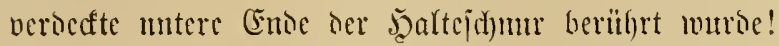

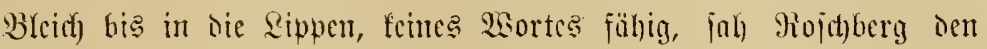

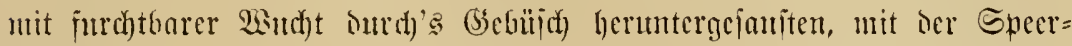

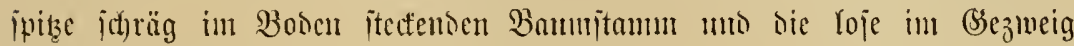
j(d) mingentie E(b)m an.

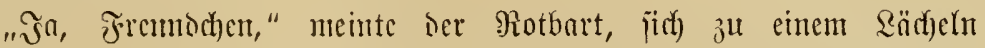

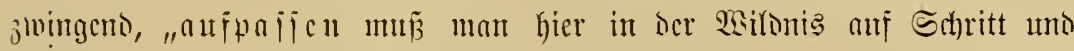
Tritt: jonit ijt man nirgenis feines Sebens jidfer! V(uf fold)e fleinen

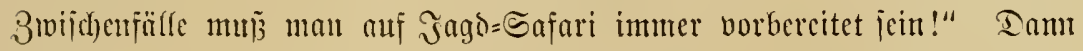
iffalt or aber socn Menuampara llpejumoto tïthtig aus. Sor hättc erit Die ganje \&ageritelle genau prïfen müfïen! - Das wurde un joblennigit

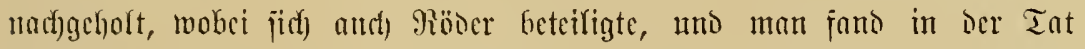

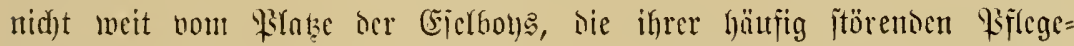

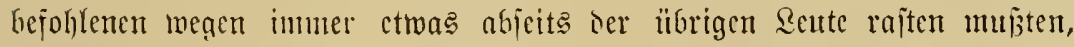

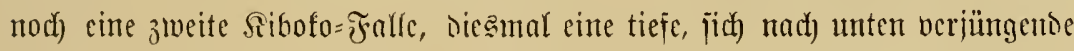
(S)rube mit cincul halben Dutzent jugeppitzer, nad) oben jtarrenter Sï̈h)le!

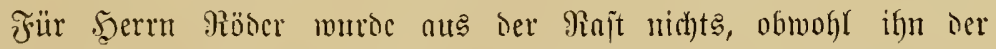

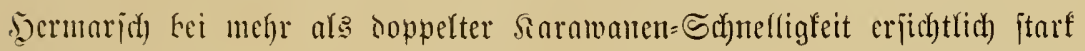

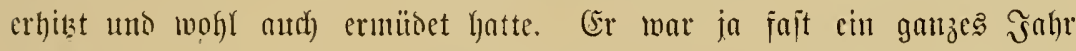
in Europa "auf Jeeimat=Urfaub" geweien, wie er gern jagte, uno jein itrapazengewöhntcr Sïrper war baburd) etmas ants ocr lifbung getomuren.

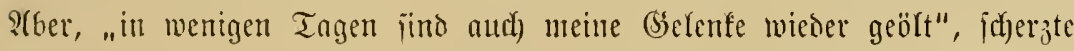

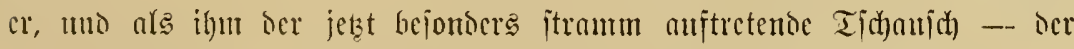

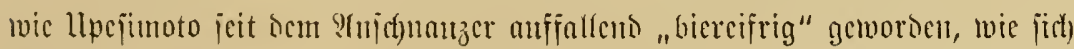

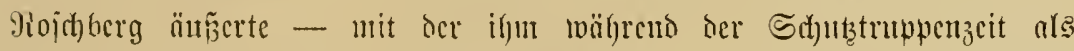
Belohnung für dos Bergen cines in (Sefed)t idhner nermundeten Difiziers

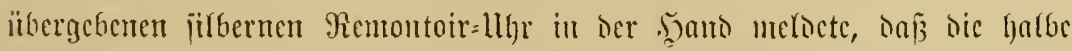

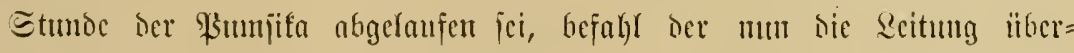

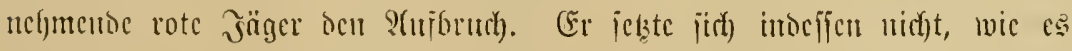

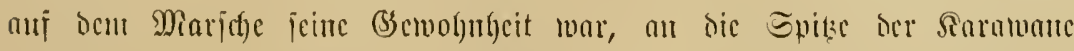

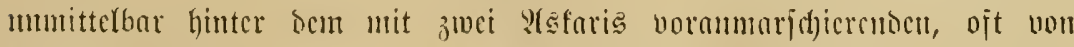

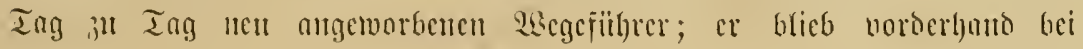




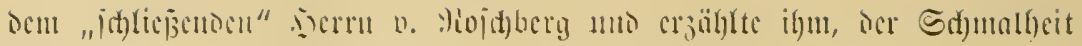

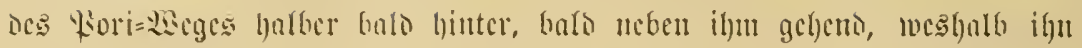

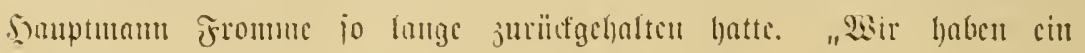

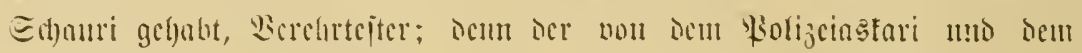

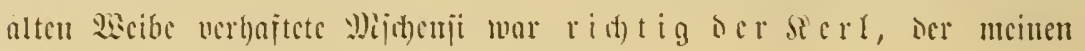
Barafa mit Gijtpicilest boj(t)olfen hatte!.”

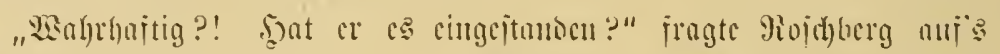

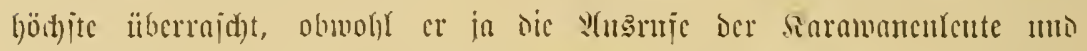

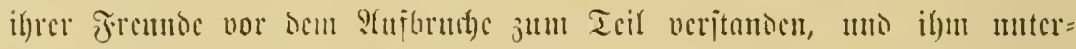

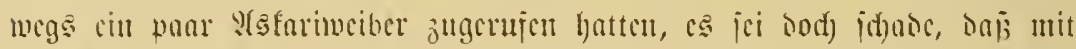
Ben S(buraride nid)t stod) gemartet wäre; jie hütten io gern nod) ien

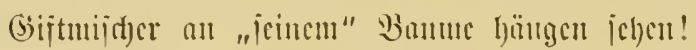

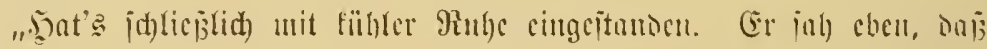

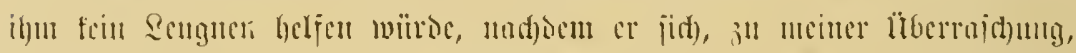

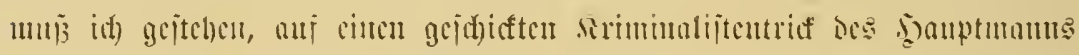

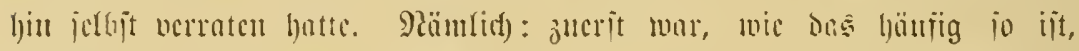

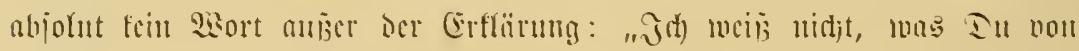

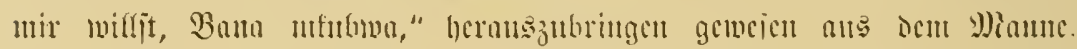

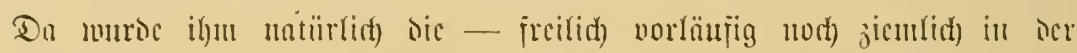

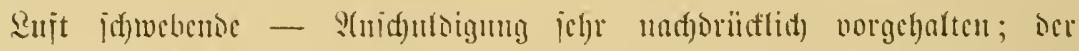

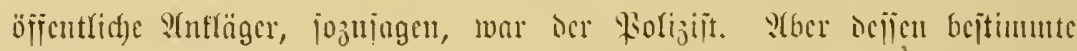

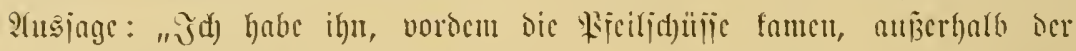

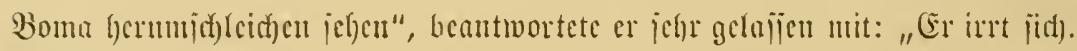

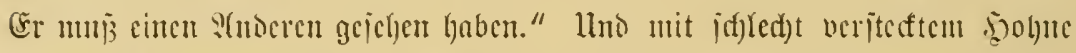

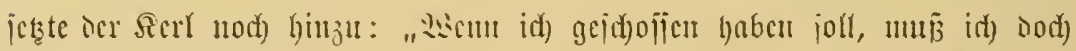

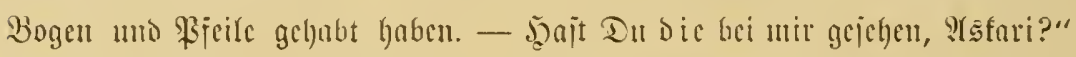

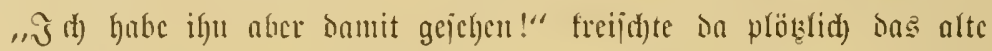

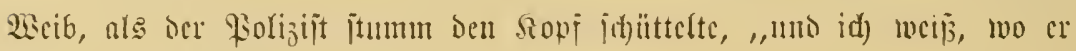
Bogen uni Fellföblyer verborgen hat!."

"Douncrwetter," ricj Siojoborg critaunt aแs, "on war cr abcr eflig

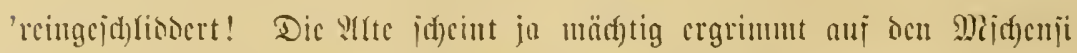

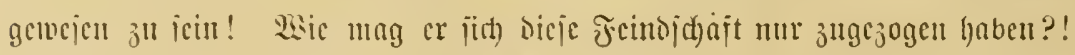

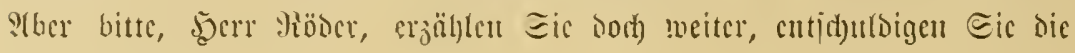
lluter(ucr)umg." 


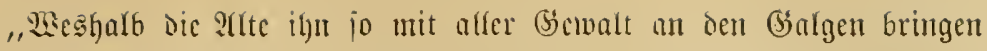

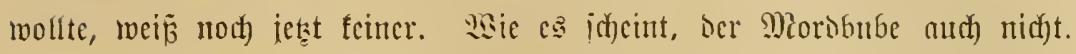
Sroenjalls bchauptete er iehr scrächtlich), er femue "Das altc Dürrbcin"

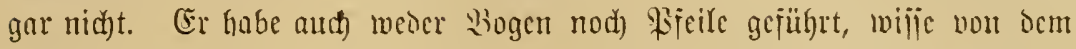

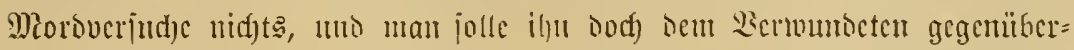

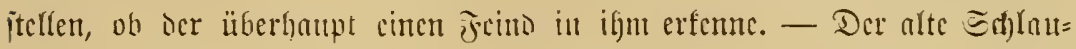

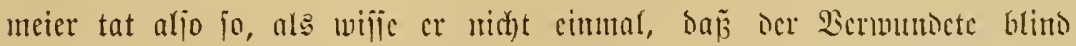
ijt! Dod) mit jolthen sinfeljügen fum er bei Dem Şanptmann nicht weit. Der mantote den litbermajulungstricf an: er zog mit einer rajdyen

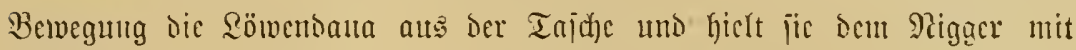

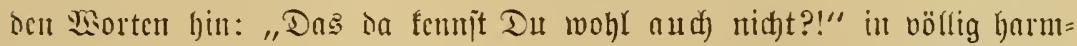

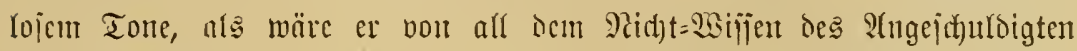
j(hon io halb uno halb überzeugt. Llno o a verga

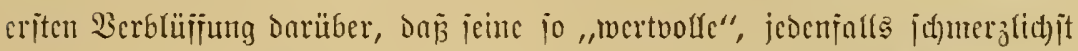

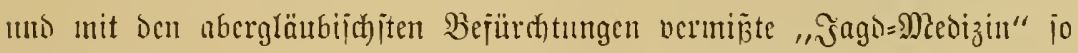

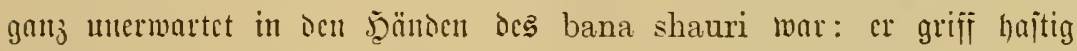

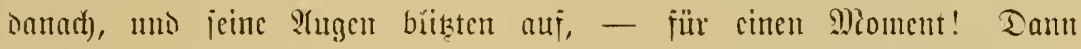

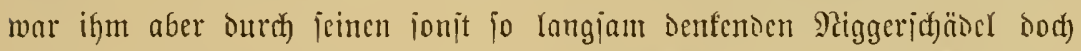

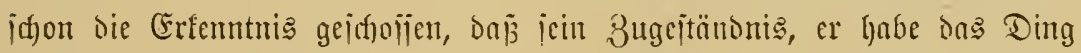

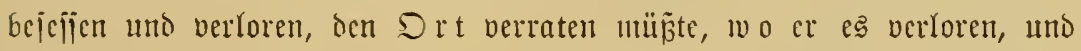

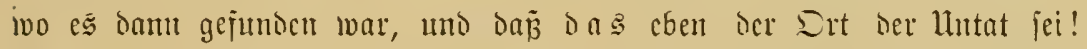

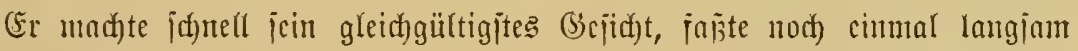
nac) Der Röwenlocfe unt ermidertc: „Pu hajt ganj recht, bwana mkubwa,

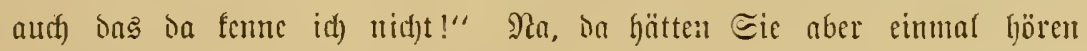

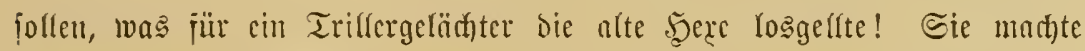

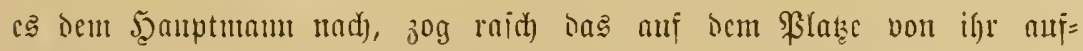

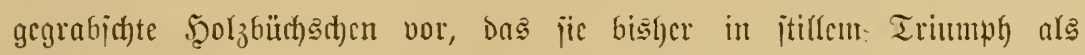

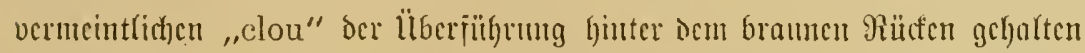

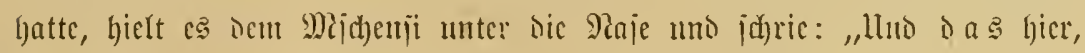

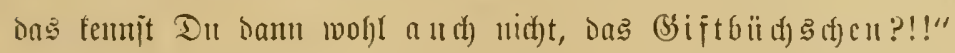

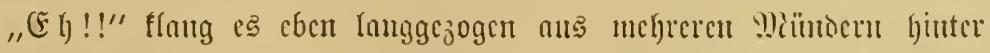

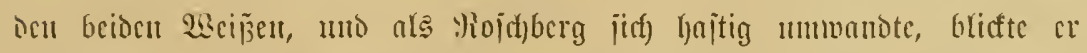

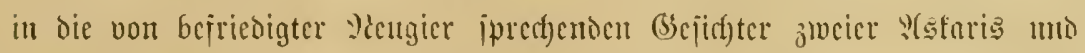

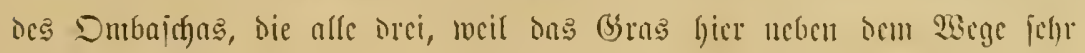


nicorig mar, neben cinnond bicht finter ben Decren Dreingegangen waren

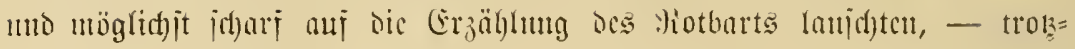

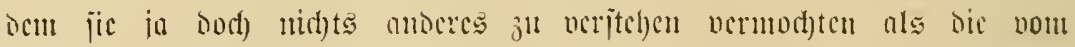

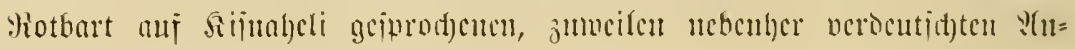

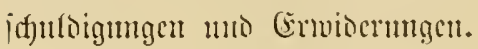

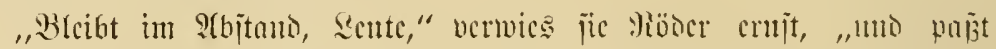

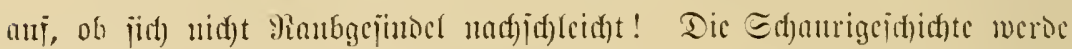

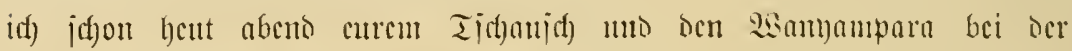

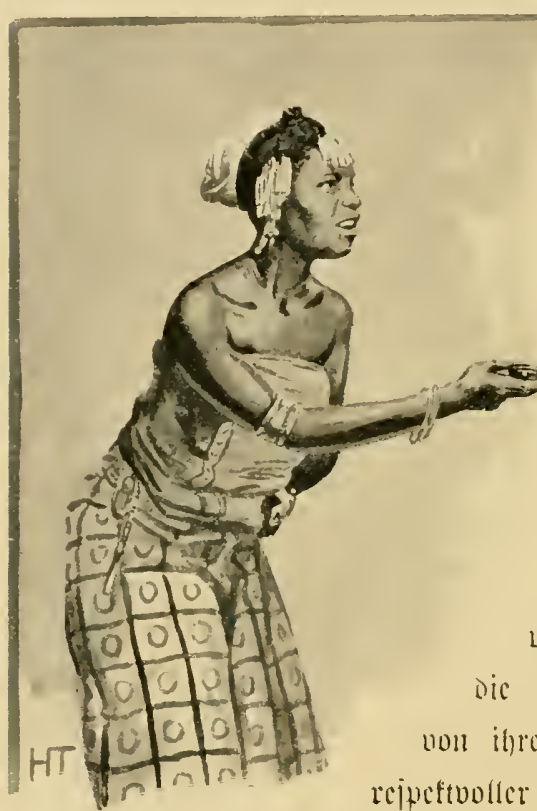

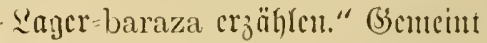

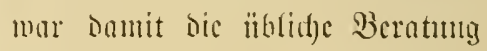
Des Sorawanculciters mit Den jarbigen :lfotcilutgsiülyrern nim.,

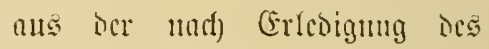
"Dicuitlid)cu" oít cin Plantoce= itïnod)en am Eagerienter murioc, bcjonocrs ant längeren Beijen,

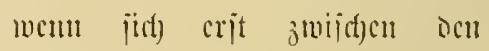

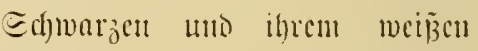
Ehci nad) gemcinjamen Etrawazcn utti Bspabren cin Bertrancte: nerhältnis heranggefildet hatte, mith oic Sente jidf jutraulict) Jints crbolten

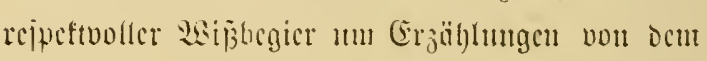

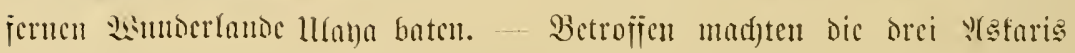

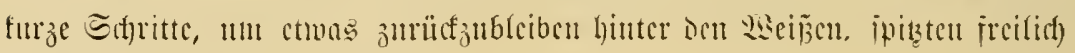
Die Dlyren um bejto mehr.

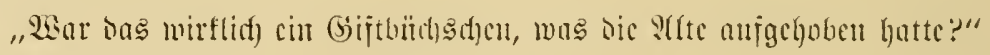
iragte Mojufberg.

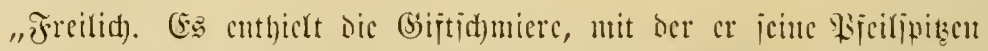
bejtrid)en hatte, uno mifïcn Sic, wic cr Donon

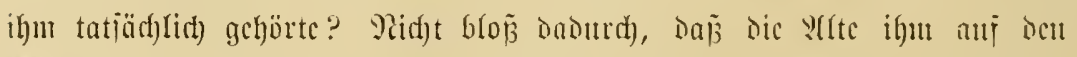

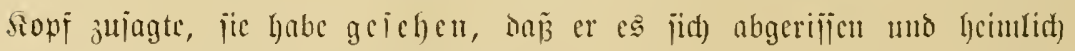

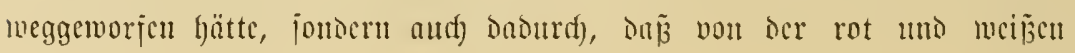


Ferlịticferei, mit ber jeine Dumabüdje oben verjiert war - Eic haben jic

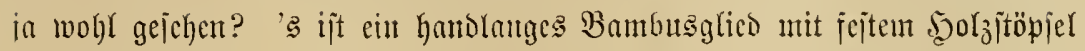

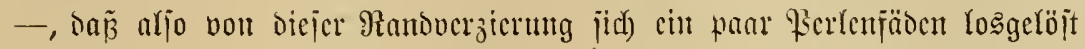

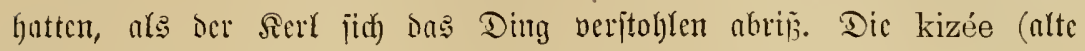

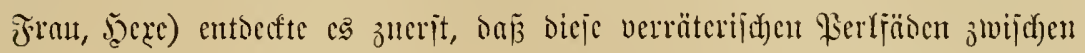

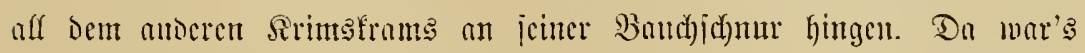
mit dem Seugnen zu Ënde. Sobals ar bas cingejelyen batte, geituno cr

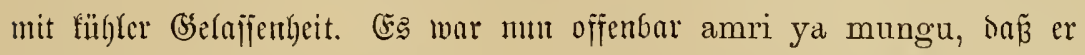

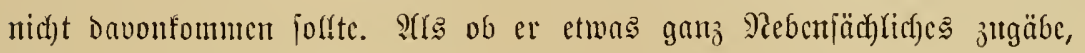

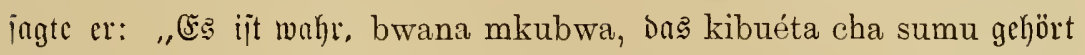
mir. SEirị es fort, bwana mkubwa; werm Du aud mur cine fleine 23mte haben jolltejt, Du fömtejt an bean sumu iterben!"

"Sondorbar", meinte Rojhberg lopfidüuttelno. "Marnt Dent Şaupt= mam davor!"

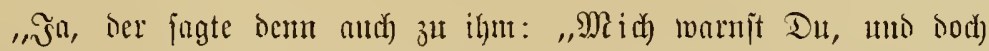

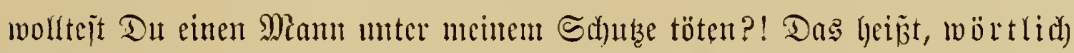
jagte cr: einen Mann, ocr jeţt mein mtoto (Sino) geworisen ijt unto in meiner Boma lebt."

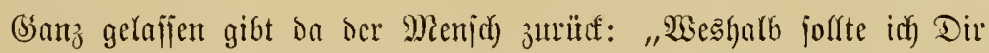
llblcs wollen? Barafa ijt ein P(ntorer."

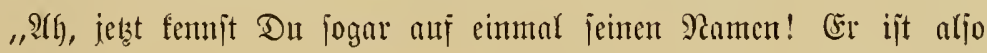
Dein Freinto?"

Mit Ropfichïtteln erwinert el ruhig: "La (Necin)!“

"Sজarum wofftejt Du ihn trobzoem töten?" Darauj befan nun jreilict) Der Şauptmann feinc antore S(ntwort als: "(E⿱

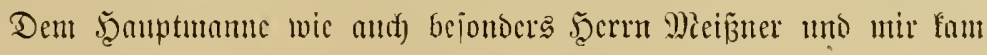

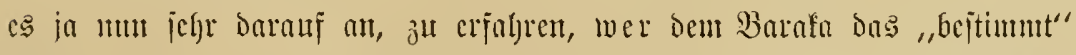

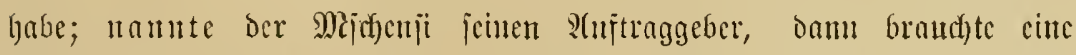
Pettungsexpedition feine Bcit mit alferlei vergeblichen Meärichen ju verticren,

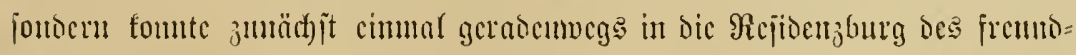

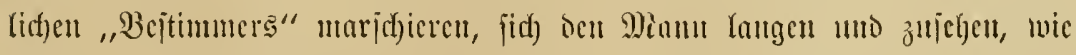

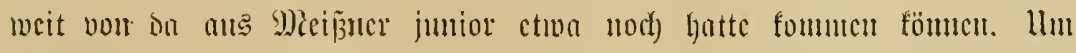

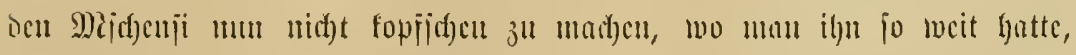
Daß̃ er verblïmt von Dent ?ajtrage jum Töten Barafa's iprad), ging ocr 


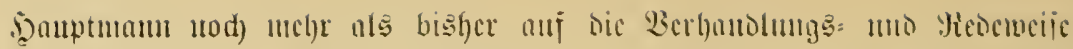

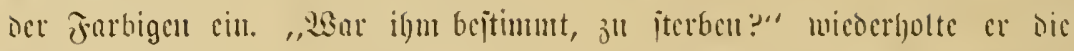

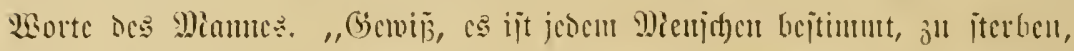

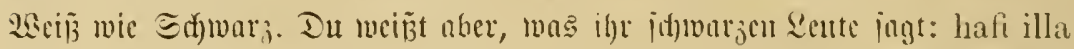

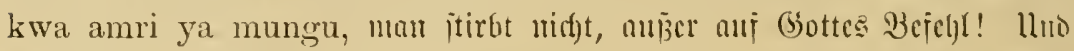
(Bott hatte eben befohlen, Barafa jolfe no d) nid) t jerben, obluobl Du ingit, es jei ifum bejtimut gemcjul, - hajafa bado (er ijt no dh nid) gejtorben)! Dod) mun ijt ca Dir bejtumnt, jul iterbon."

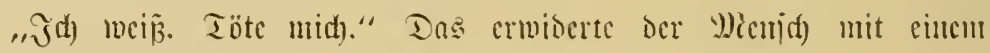

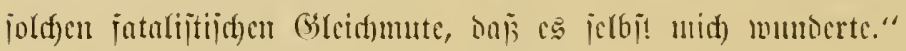

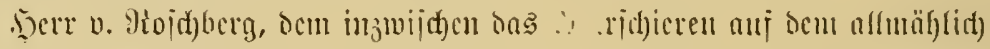

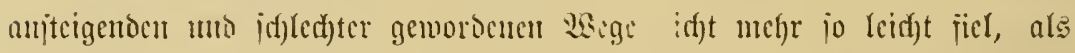

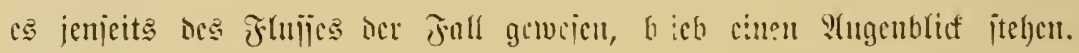

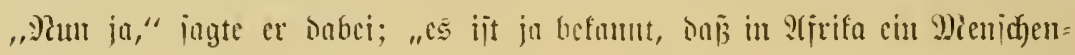
leben nict)t vicl gilt."

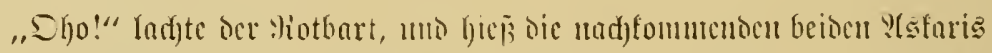

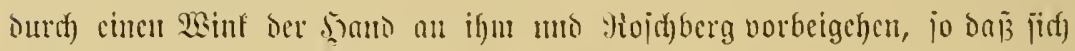

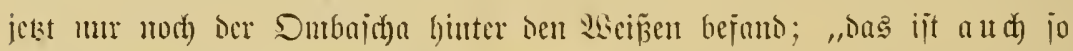

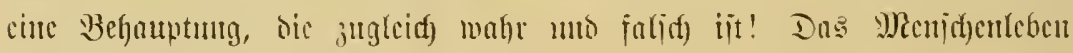

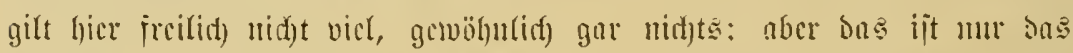

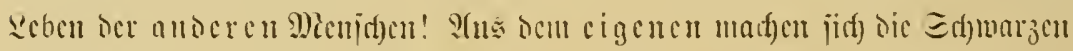

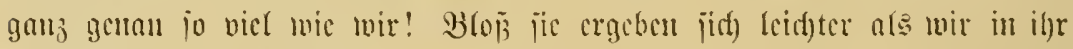

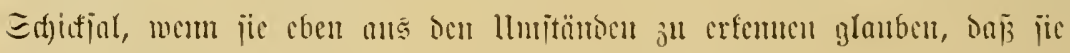

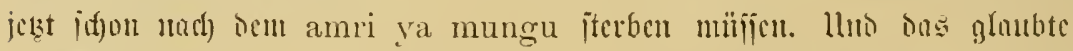

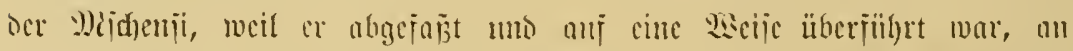

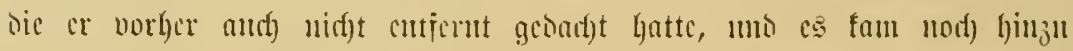

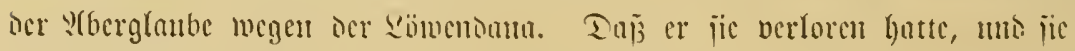

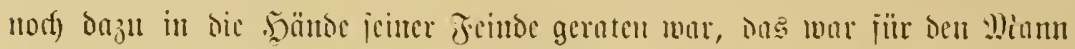

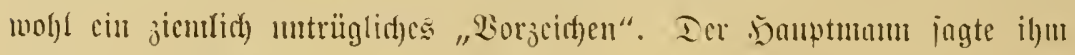

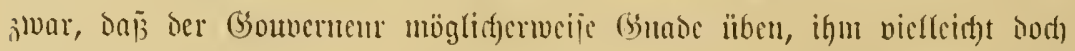

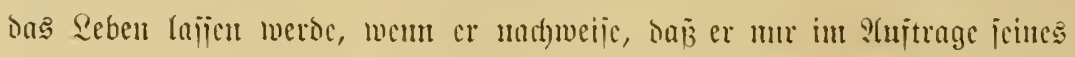
Derm, vidleidjt jeintes Enltans, gebantolt bätte. Der Biann idject aber an

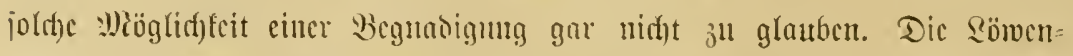

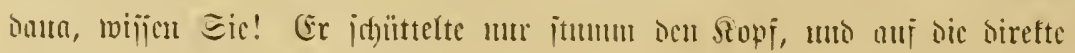




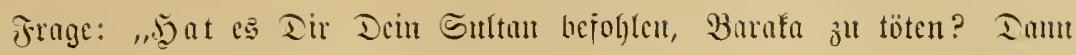

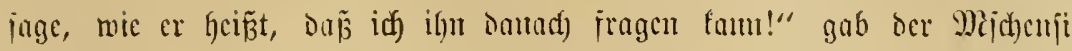
nur sic S(ntmort: .:Sitaambia, nijapolazimishwa!" Das heip̃st: idf) merite

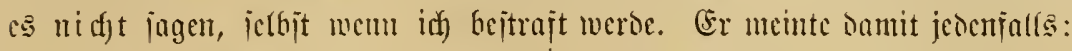

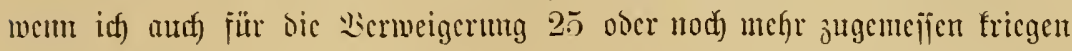

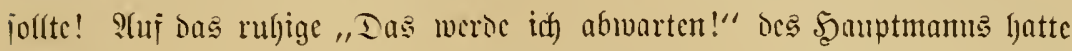

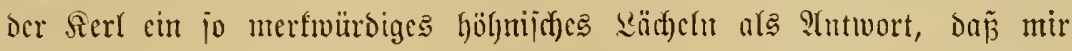

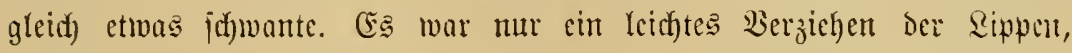
oer Sauptmann hatte cs gar nticht bemerft unt fah mich vermumbert an,

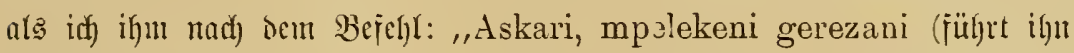
in's (Sefüngnis ab)!" zuraunte: "Safjen Eic ihn idhari belwad)en; er hat ctrwas vor!" - Na, es jeigte jid) ja balo, was! : Wir fahen gerade nach, ob inn die \$olizei=2(staris in oner Mauerbaftion aud jo berjorgt hätten,

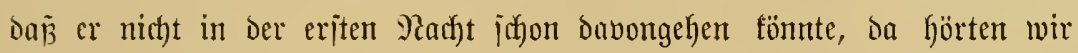

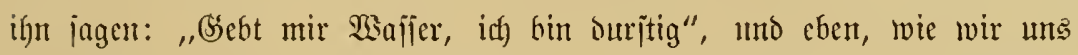
umwanton, um zu gefen, reichte ifm Der einte Polizijt die mit \$sajjer

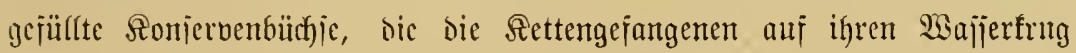

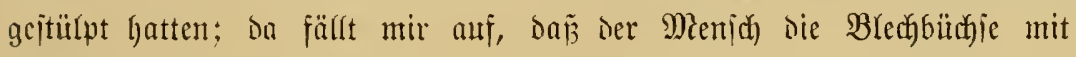
beioen ફ̧änden crgreift, - jehen Sic, io, als ljätte er dabei etwas ver=

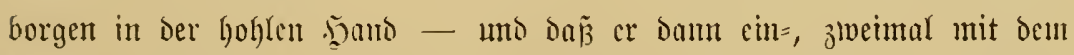

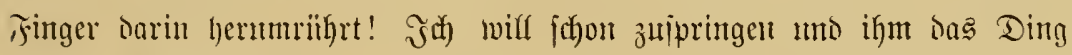

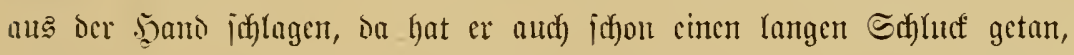

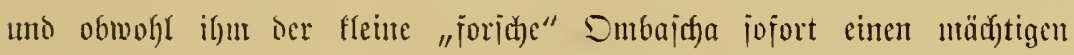

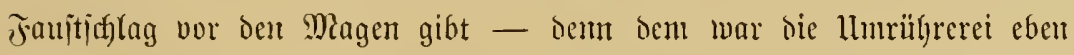
aud) anjgejaflen! - , es erjolgt fein litbergehen, uno nach) ciner Bicrtel= itunde war ber Miam tot!"

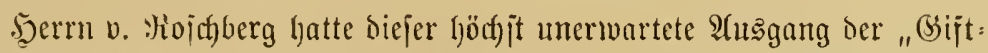

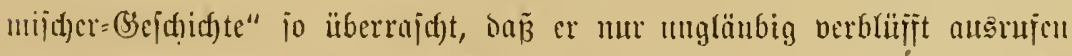

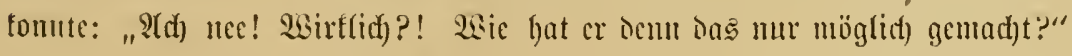
"Unter jeinen viclen Dauas mar eben ante) cinte, die ifjn fïr den

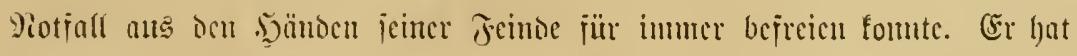
jiit) mithin ni(t) t żmingen (ajien umo feimen Sultun nid)t verraten. -

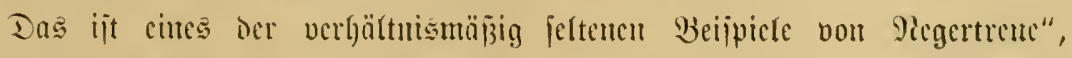

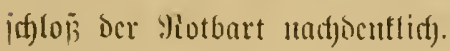




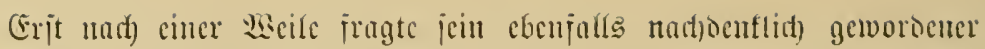

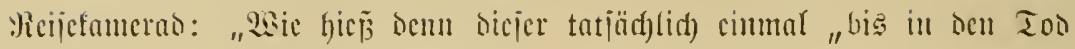
verjd)wiegent" Mijdenji cigentlidf?"

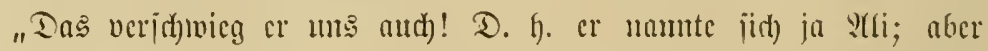

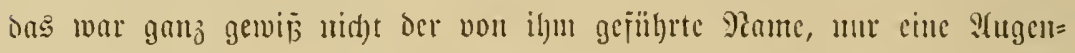
blicts=Cringebung; er war unjweiferfajt fompletter becioc, nidbt cimmal

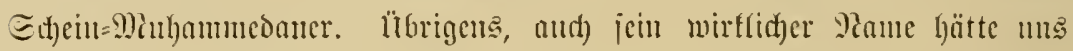

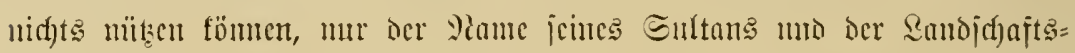

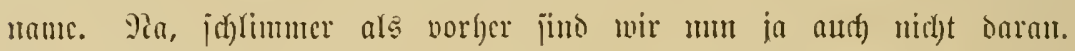

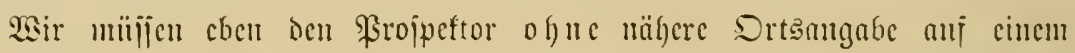

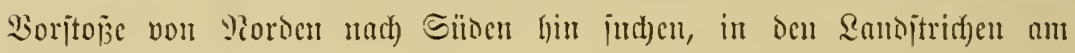
(Enajït=

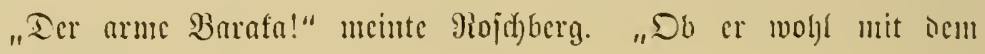
¿eben davonfommen wird?"

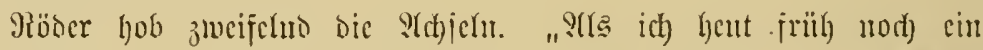

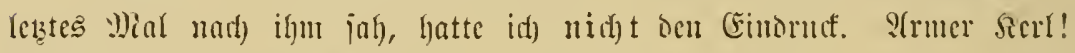

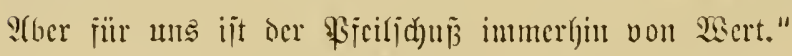

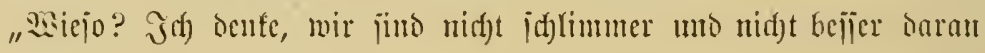
ałร vorher, jagten Sic nicht jo?"

"Nidgt jolimumer; befier injojern, als iff mit mehr l̈lberjengung vom Seben Mecip̈ner's auj bie Suche gehen werde. 然äre er tot, io bätte

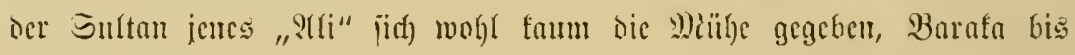

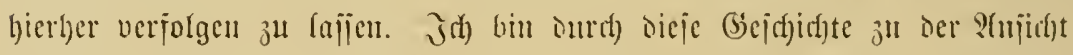

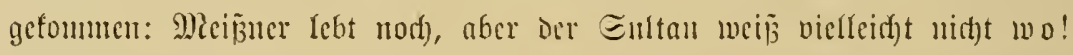

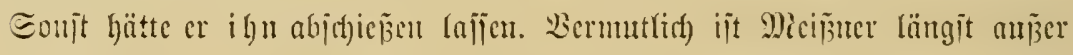

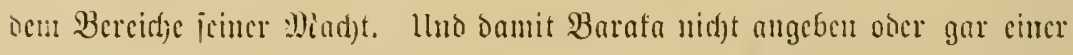
Iruppenabteilung jeigen föme, wo bie bamalige Miorobremmerei geichel)en

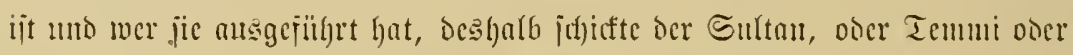

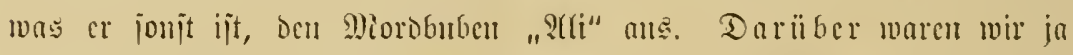

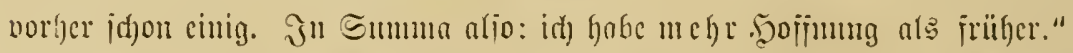

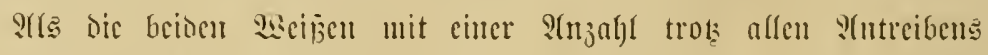
juriitifgeblicberer Iräger das erite Sagerbori erreichten, jtunt bereits

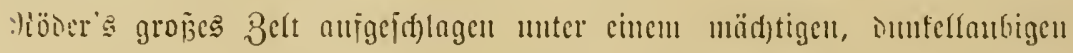

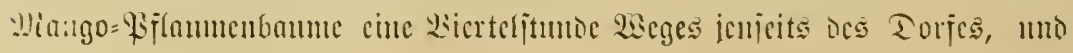




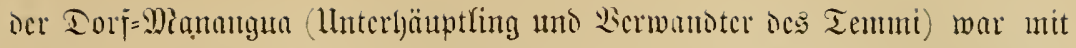

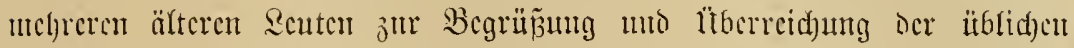

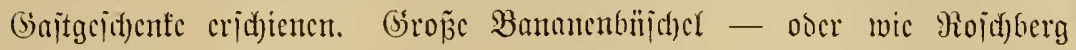
jugte: Bananentrauthen -, jefre vicle Miaisfolben, cine Zicge und orci

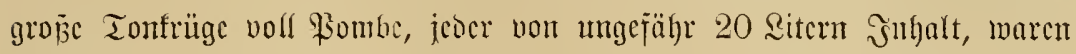

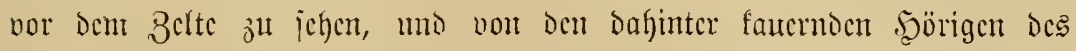

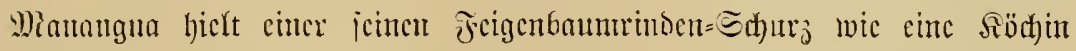

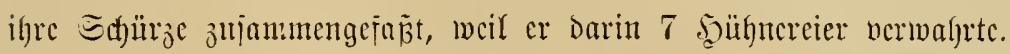

Decre v. Rojefberg traj jiemlich ermitoet von biejem criten Tages=

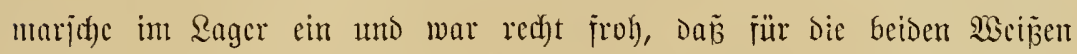
jobou alfes hergeridytet war, dic an Der Eptizc ber fangausgcdehnten

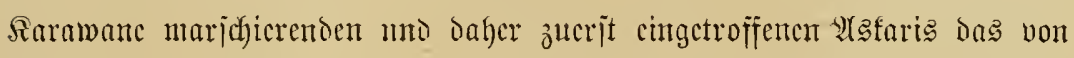

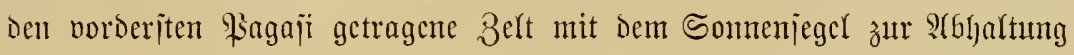

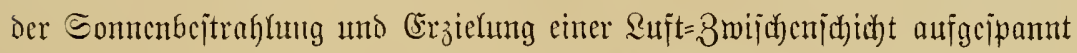

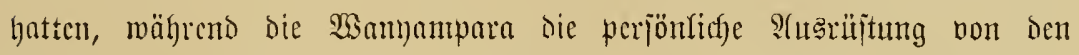
übrigen \&ajten gejondert hatten legen Iajjen. Die Irägerlajten mit Iauj(h)= waren, Iicrjallen uị. wurben auj ciner fibon öjter non pajijerenden Saramauten gcbrauthten Unterfage von Stämmen etmas erhöht übcr Dent Croboden gelagert, bamit es bie alles zeriefilenton Termiten uno anocre

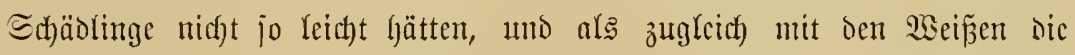
lez̧ten Raiten im Rager eintrajen, murocu waijerbid)te Stoff̈bahmen über

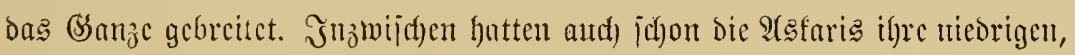

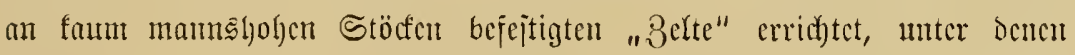
jic nur Yiegen, höd)jtens ljocten fonnten, umb bie Träger waren babci, mit

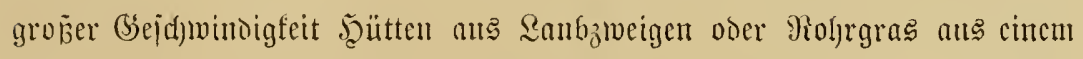

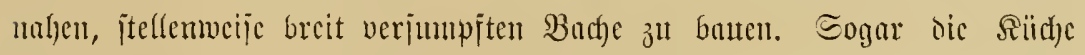
jür Die Europäcr war bercits von bcm branten, fïr niddt gerabe geringen Sohn von Röocr angeworbencu mpishi zujammen mit Den mpishi-mtoto

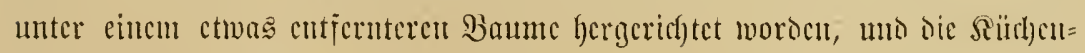

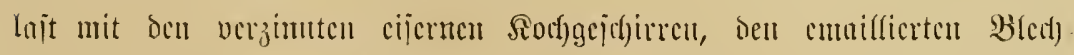

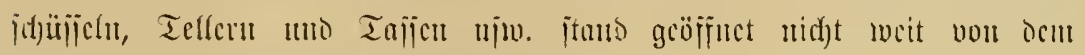

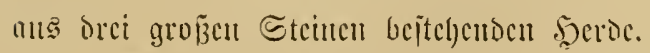

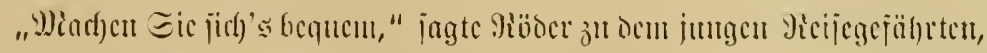

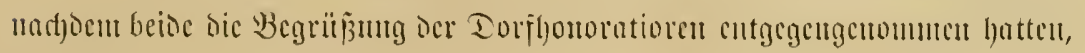




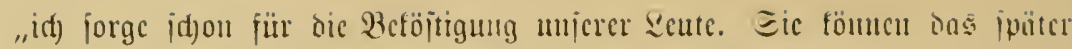

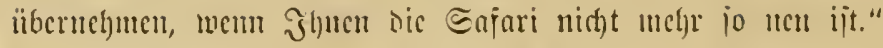

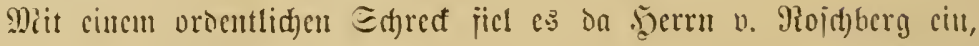

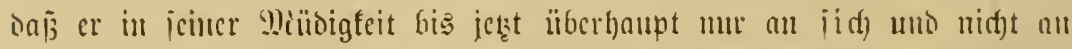

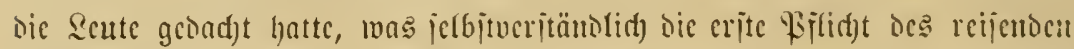
Mijungu war. „Plein, ucist, bitte, Inijen Eic mid) mithelicu, oncr bod)

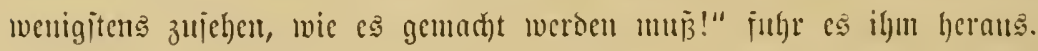

"Pas trop de zèle (utid)t zu viel (Eifcr), Lierchrtejter," lüchelte

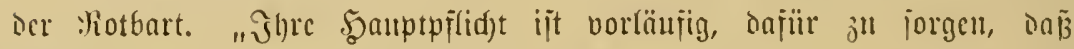

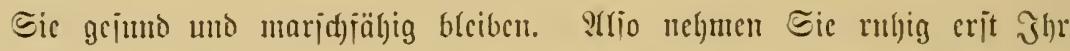

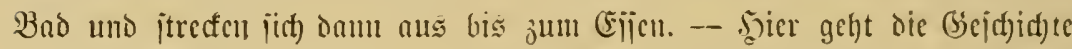
ja aud) nod) ganj glatt. Das Dorj ijt an Nicije=Reierungen gewölynt.

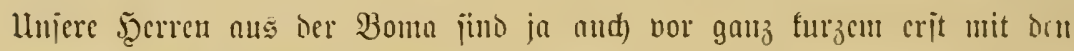

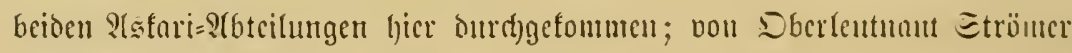

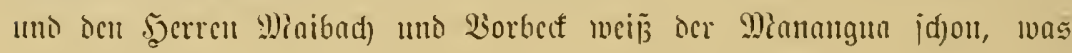

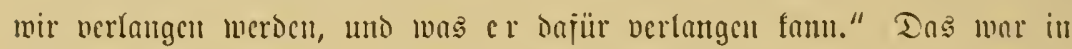
oce Tat jutrefifent, umb weil das Torf wohthabento mar, die Seute reidge Ernten hatten, jo wurde das für die viclen Mecuidgen criorderliche Whis:

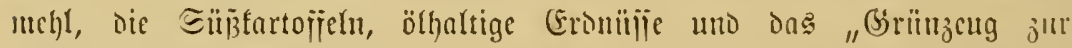
(Simüjejance", wie Röder jagte, viel id)neller herbcigeidsajit uno vertcils,

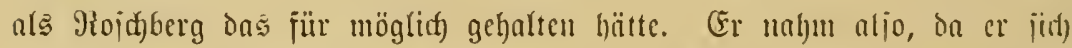

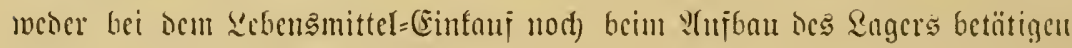

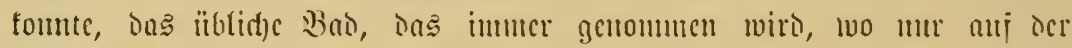
Reije irgeno 2 ajier genug vorhanoen ijt - er itellte jid) in jecu zmjaumen=

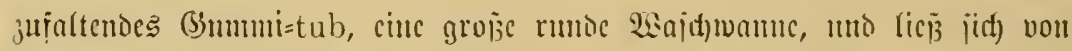

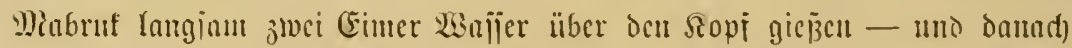

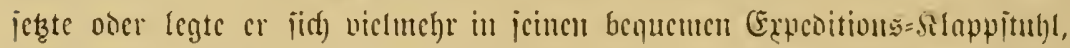
ipiclte mit jeincm trok des langen, in jein uno Derjagen mindejtens

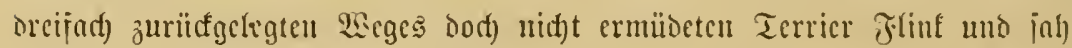

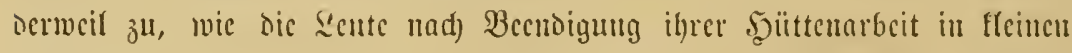

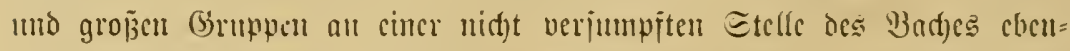

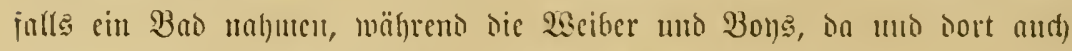

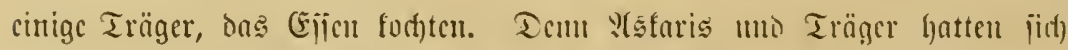

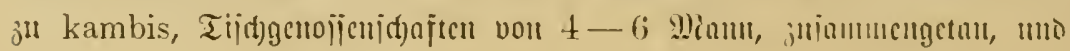




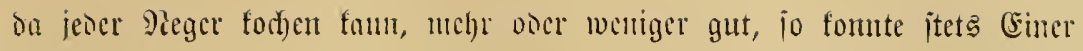
für bie Sï̈chc jorgen, während bie Stnderen vom Rambi ihren fonjtigen

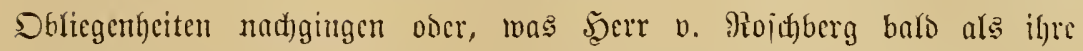

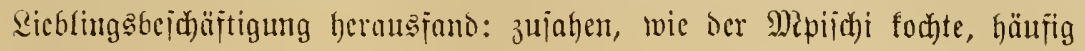
foiteren unto ilyr (S)utad)ten abgaben.

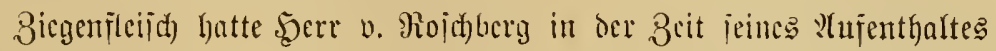
in Mitanja ja idyon mefrifach borgejebst betommen, jescsmal in ciner anderen

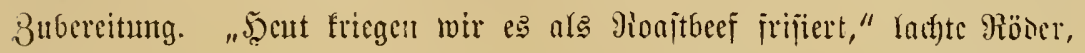

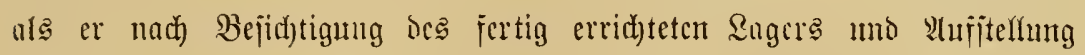
mehrerer \$ojten - „gegen allju fingeriertige Dorjbemohner!“ - hinter

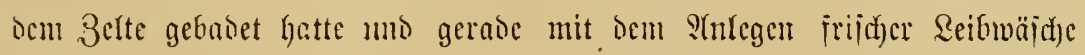

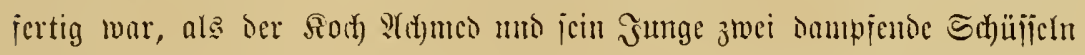

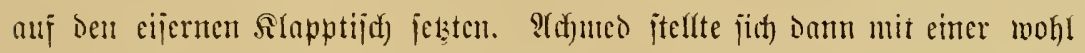

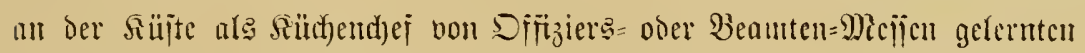
Berbengung neben Den Belteingang uno ricj Ben Bann zu: "Chakulla tayari (bas (sijen iīt jertig)!" Dann verictuvand er mit jeinem Mitoto,

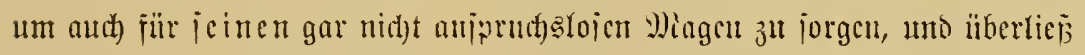

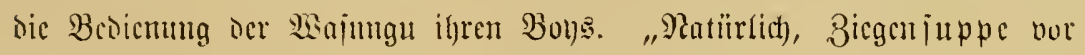

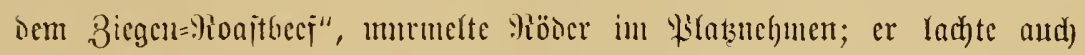

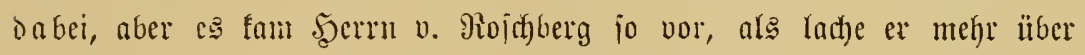

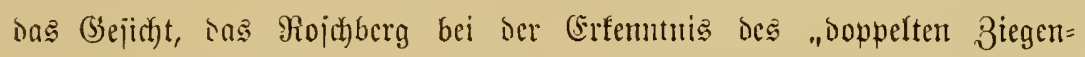

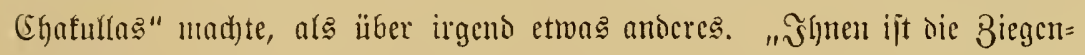

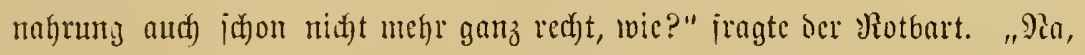
vorläufig geht's ja noch)! 2(d)meo bringt uns heut nor ocm "beef." dic Biegenbouillon wenigitents à la jardinière, wie ocr Dentiche jo ichön jagt,

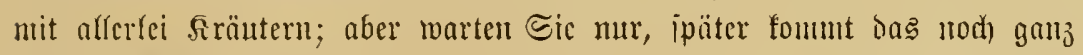
unders! Wem Eie crït 'mal ein paar Wochen lantg icben Tag Biegenfleijd) und nidft Eprud) cinitimmen:

\author{
"3iege junt unto Biege alt, \\ 3icge warm uno Biege falt, \\ 3 3iege zäbe, Biege hart: \\ Icr Teuicl hol' die gauze wirt!"
}

Piun (ad)te and) Siojd)bery; aber ctwas jaucr-jiij; bei iem (Scinanten

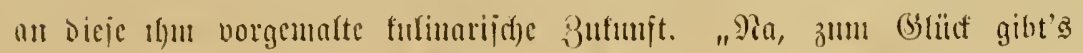




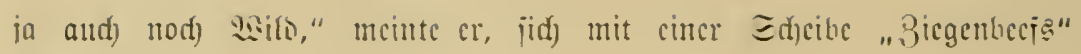
bebicuctio.

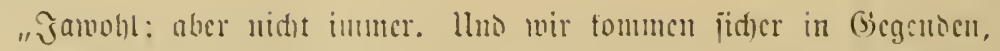

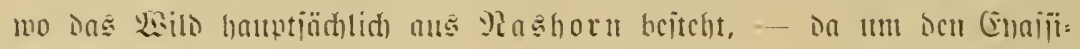
Eec herum."

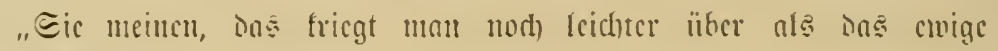
3icgenilleijch?"

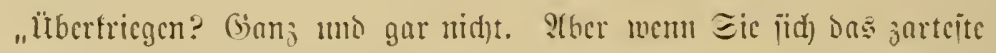

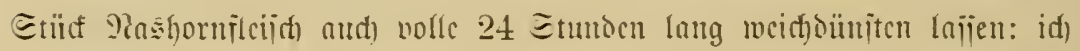

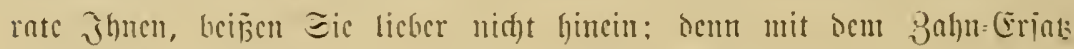

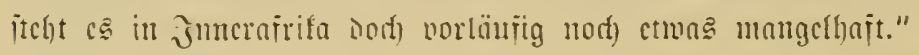

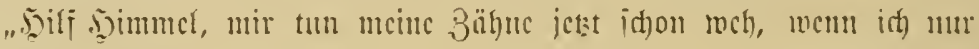
an io ctmas onfe! !

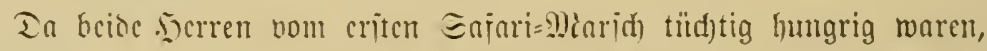

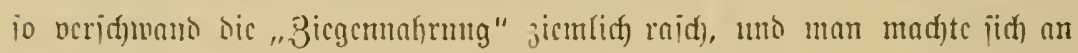

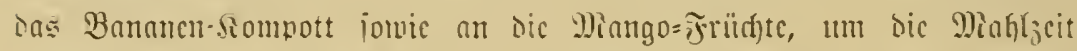

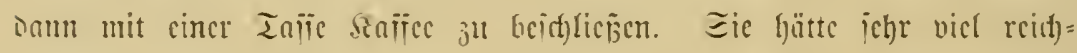

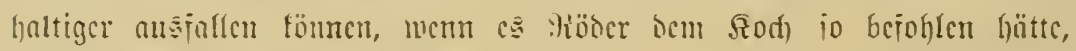

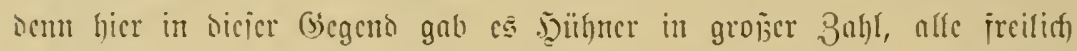

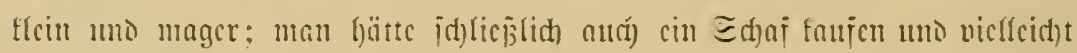

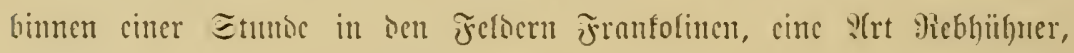

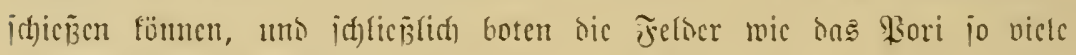

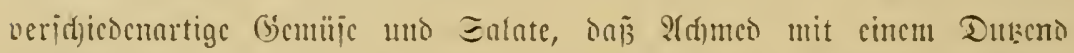

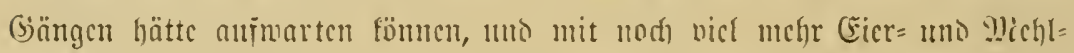

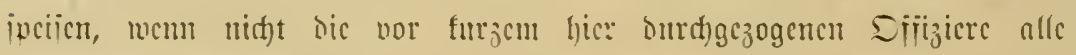

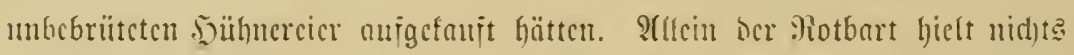

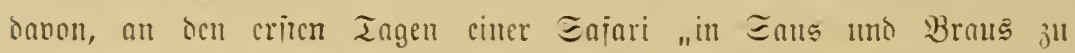

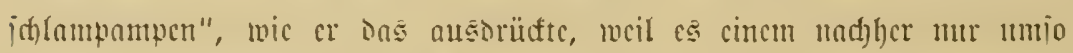

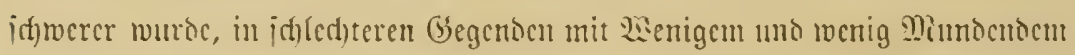

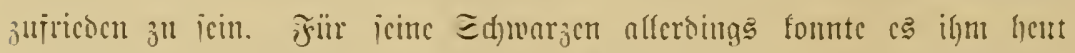

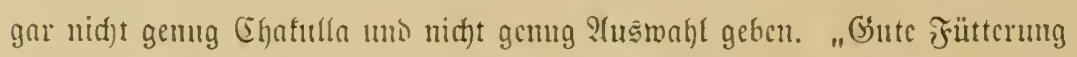

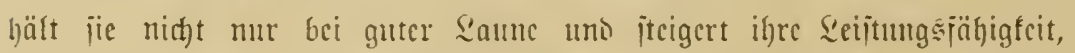

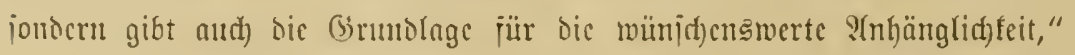

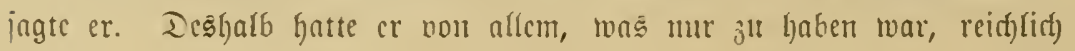


gefnuit - hier hatte er hcim Srtacher logar noch Silberrupien in 3ahlung geben tömten, mälgrenb bic meijten anderen Dörfiler nur Feiaitücfe und,

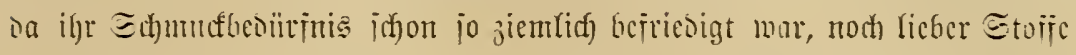

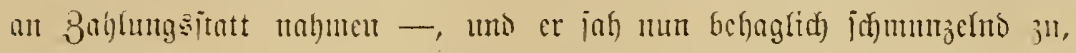

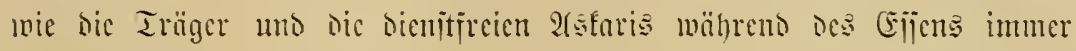
weiter fod)ten, die Cinen ugalli, ben lie mit ben Jingern blibgeidjwint

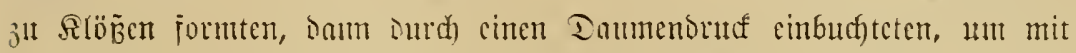

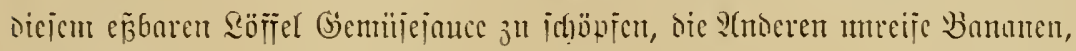

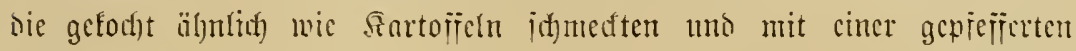

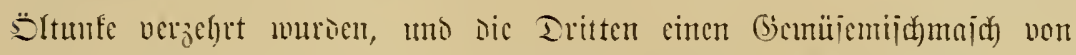
aflerlei Grï̈ mit zerjtampiten ölfaltigen Erromiljen. Dicies forben uno

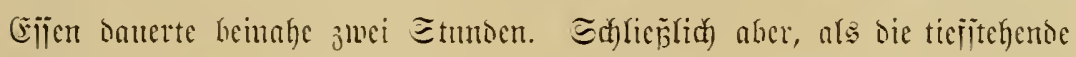

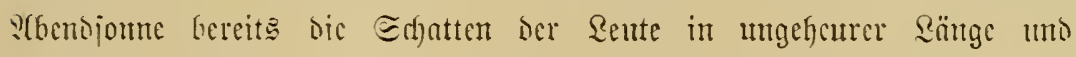

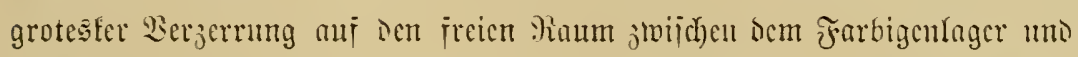

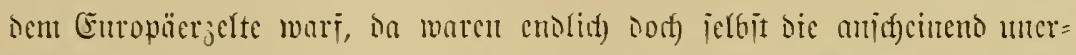

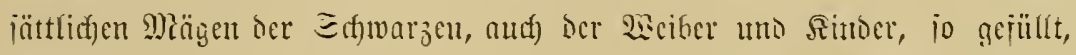

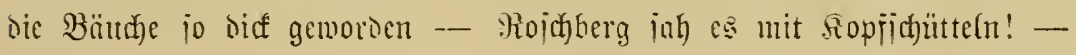

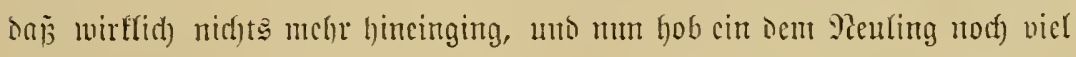

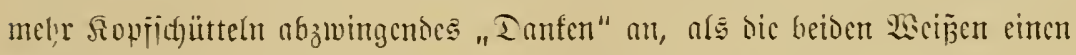

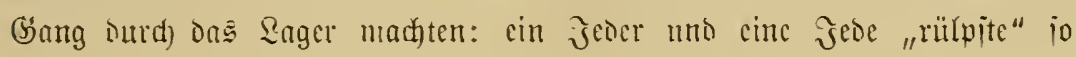

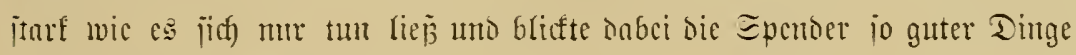
mit vergnügtem Grinjen an!

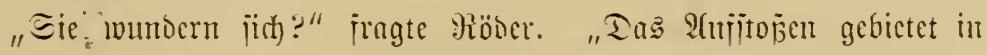

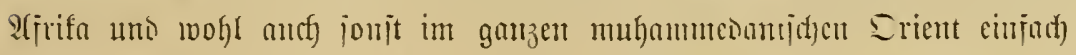

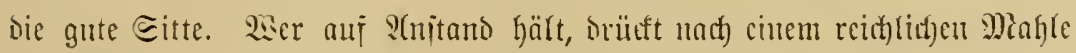
jeinen Sanf burd) "tie Epradje scs Magens" aus. Stnoere Sünder, antere Eittcu, beiter Jrenno!"

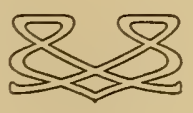




\section{Zwölftes Kapitel.}

息

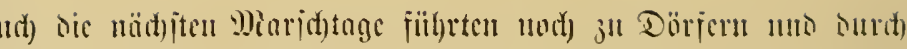

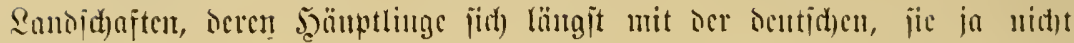

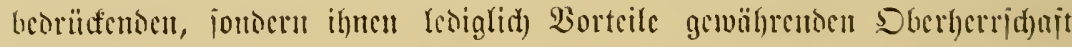

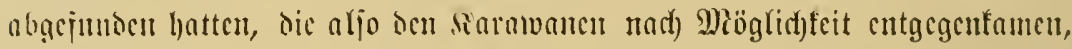

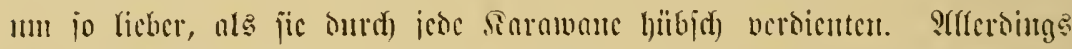

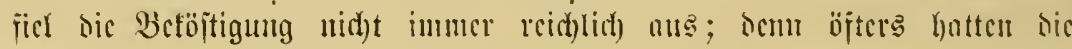

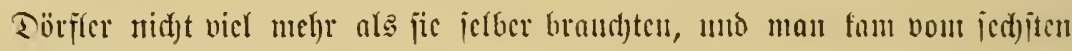

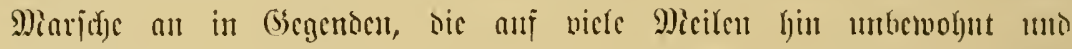

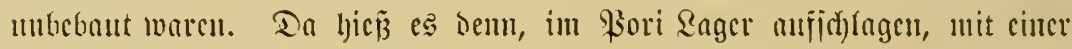

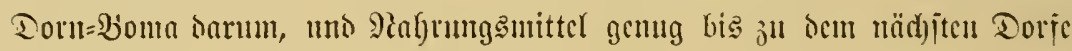

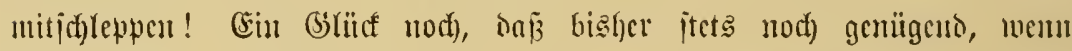
aud) cben nur genügento cinjufanjen war! Gumerhin mujte von ba an

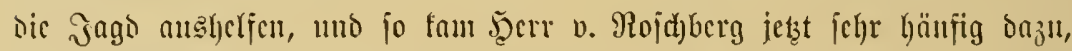

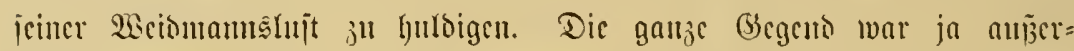

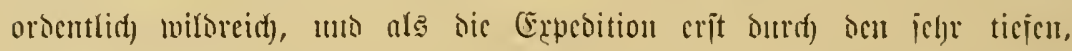

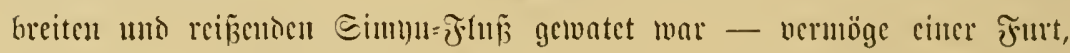

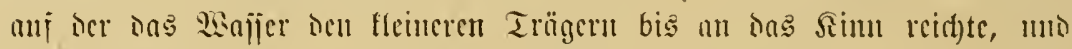

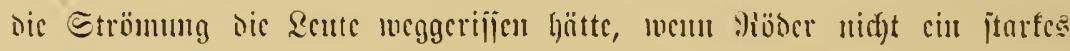

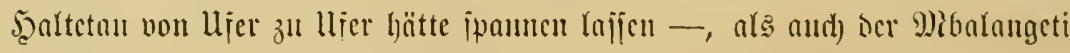

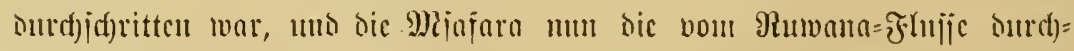

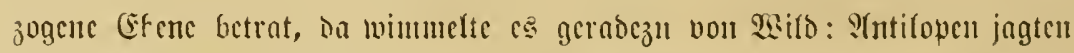

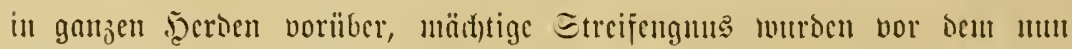
an ber Epitze marjojictenten jungen Europäer flïd)tig, uno ju jeincu

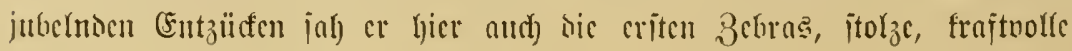


Tiere, gegen bie aud) bie beitgehaltenen in den joologijden Ssärten mur Rümmerlinge waren! Scine mit zittermer J̧and abgegebenen Sdjüffe

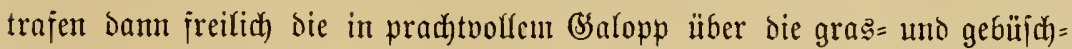

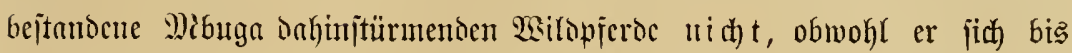

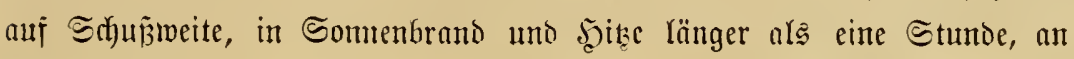

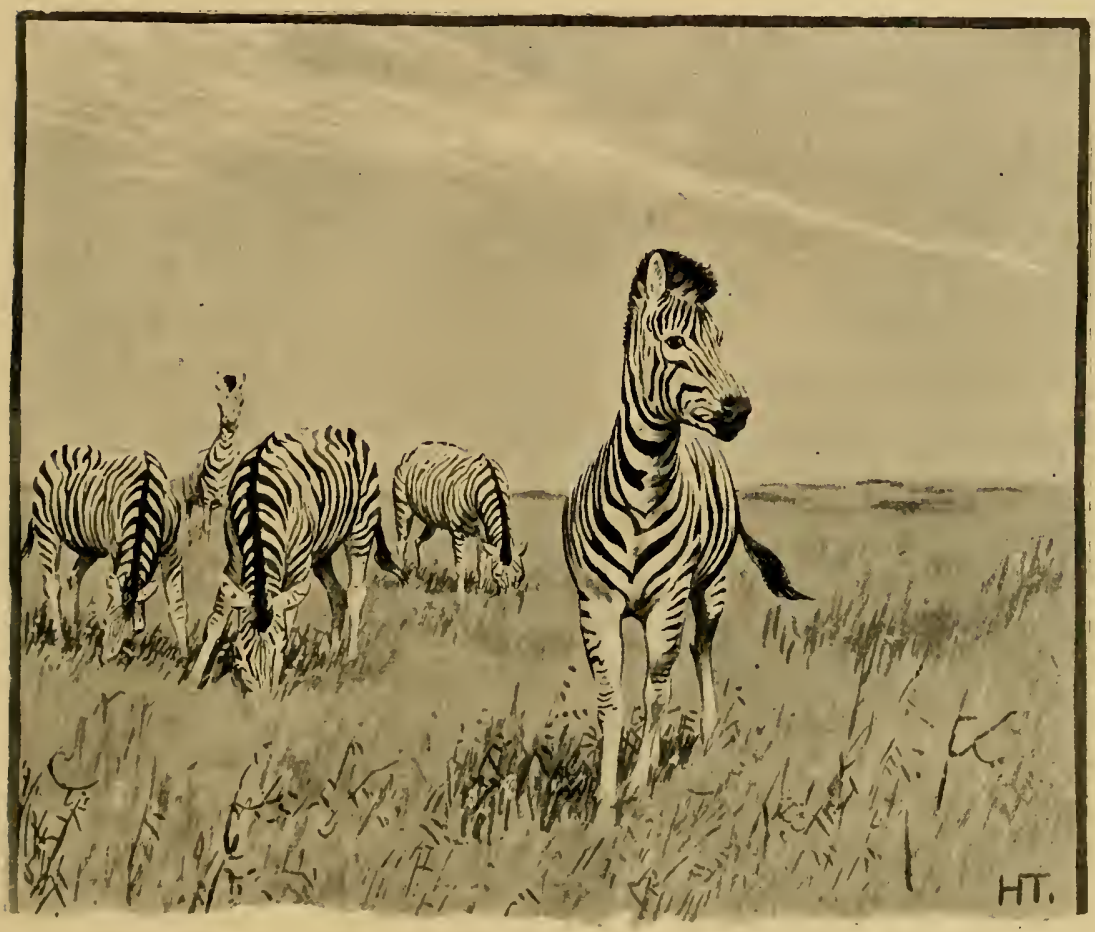

die rubig äjenoen Zebras angejdlichen hatte, immer gegen ben 2 ino uno

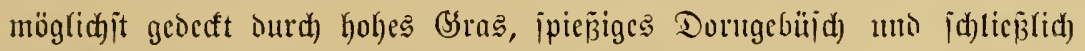
eine Sruppe flad)froniger Sd)irmafajien: Der alte Şengit, Der immer cin pare "\$fcroelängen" vor Den vier anderen Zebras herjog und jwijhen

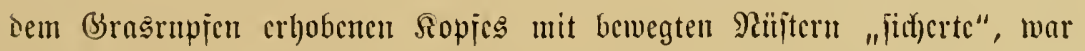

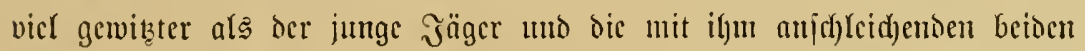

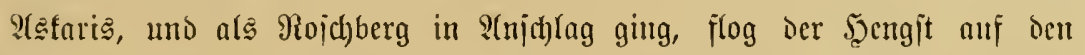
Sinterhufen bermu, und wic Der Sturmmind brauten Die Tiere über dic

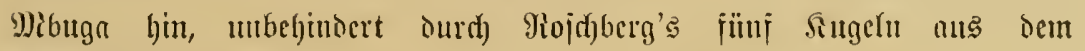
Repeticrgemehr! 


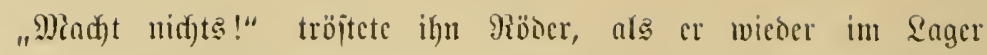

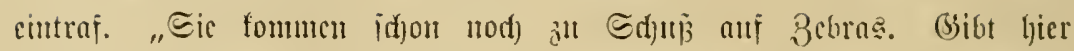

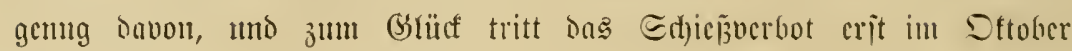
in Rinft."

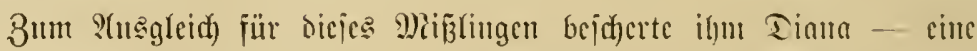

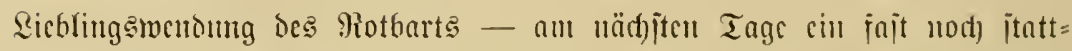

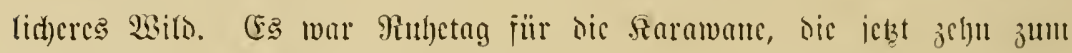

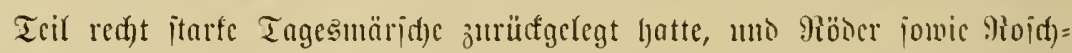

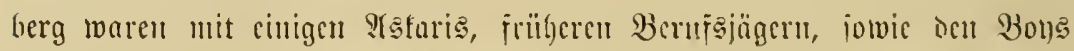

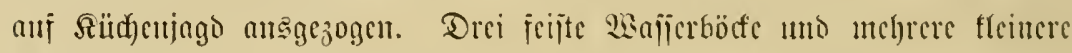
Plntilopen waren bercite erlegt, on iprang, eben als Roichberg mit inen

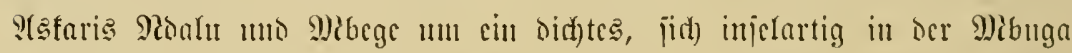

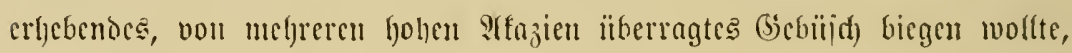
cine mäd)tige gappen-?(ntilope mit herrlid)em, jujt meterlangem, idjön

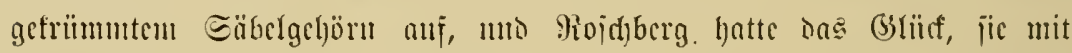

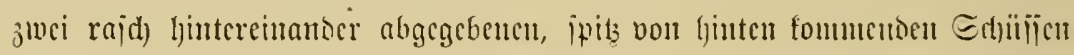

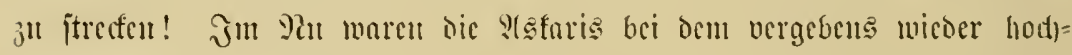

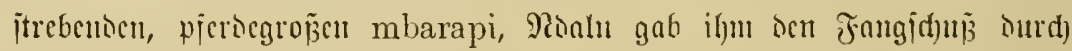

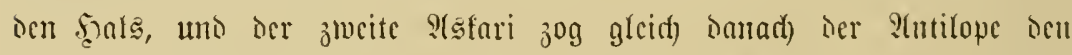

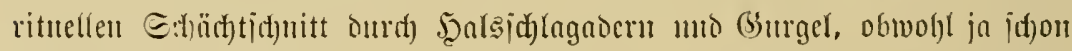

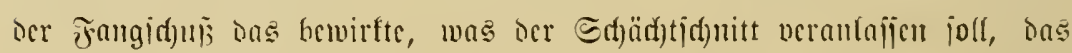

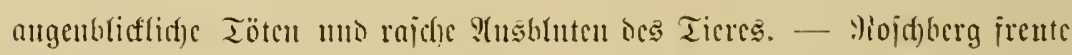

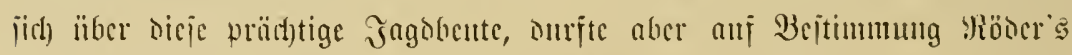

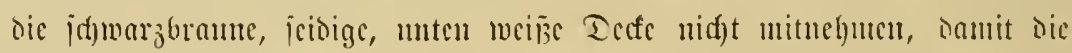

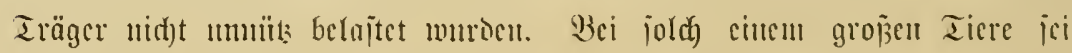

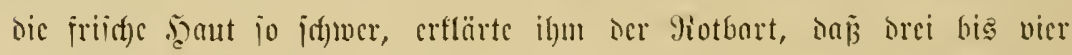

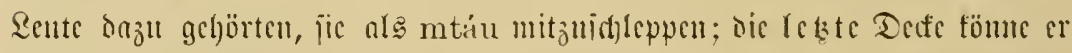

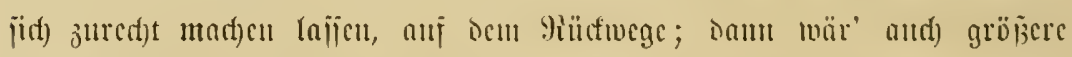

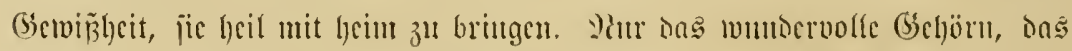

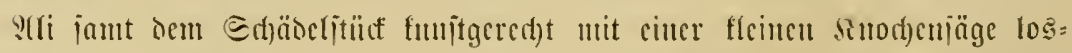

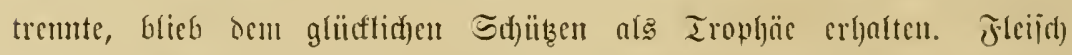

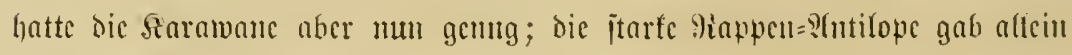

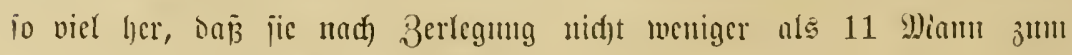
Iransport int's Enger beaniprutdete. 


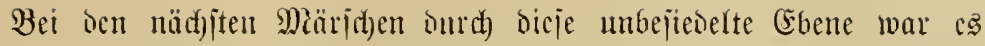

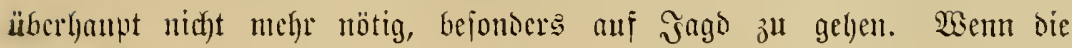

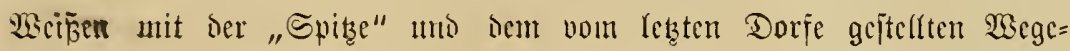

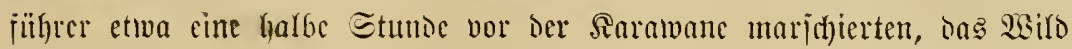

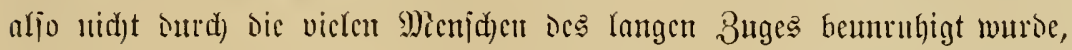

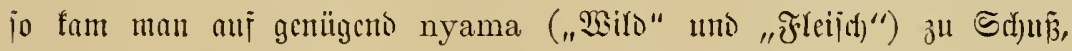

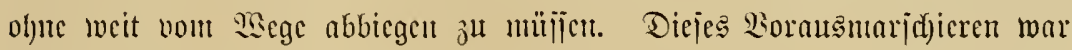

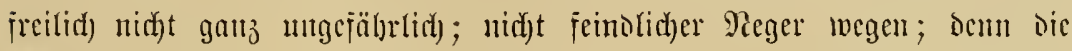

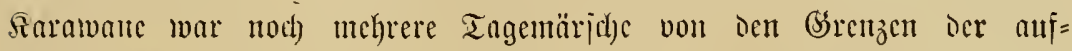

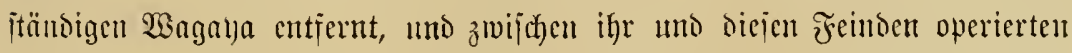

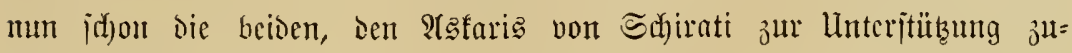

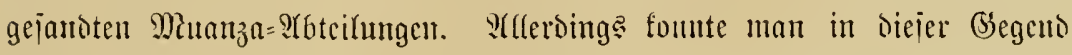
bereits auj verciujelte, von Noriojten lyer vorgedrungente raublujtige

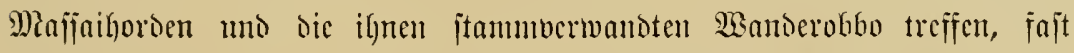

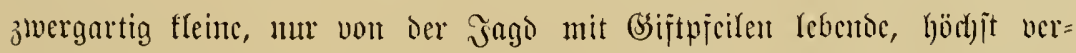

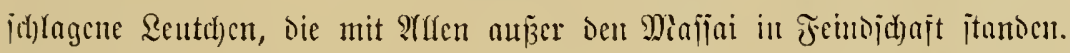

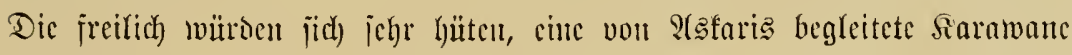
am bellen lidjten Tage aujugreifen, Das wup̈te man, uno ju Giftpfeil=

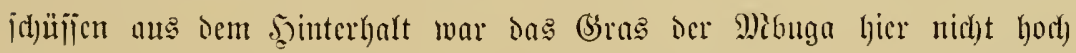
genug; Dic Schützen wären balo nicoergejtrectt gewcjen! Die Sicjahr,

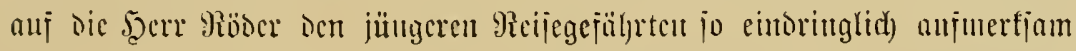

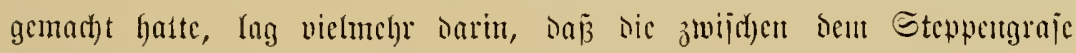
auj gerade um juß̈brciten

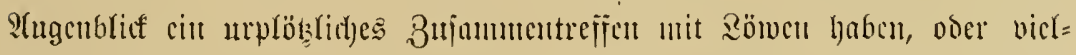

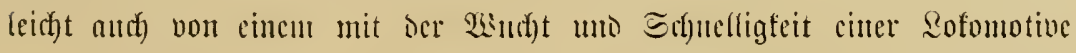

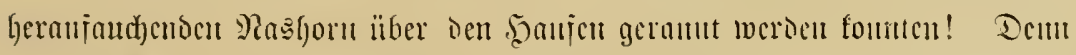

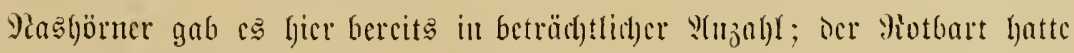

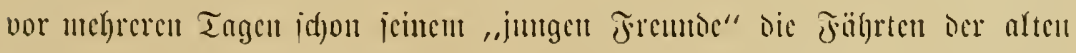

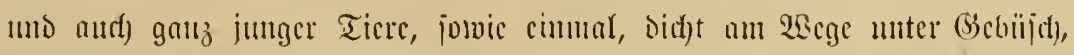

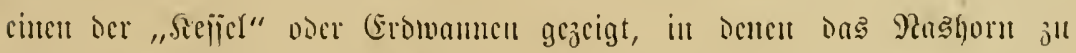

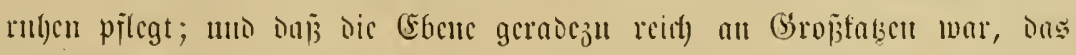
bewicien nicht mur bie hier unt ba gejundenen l̈berrejte vout gand bor

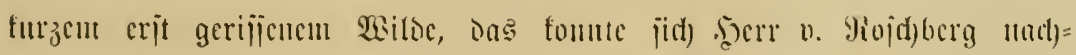

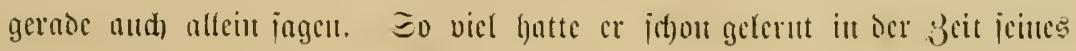




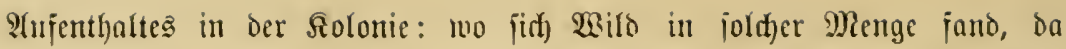
fehlte es aud) nidyt an den natürlidyen Feinton bes 2 sillos, vor allem nidjt an Römen! - (Es dauerte jreilid) nod) einige Beit, ehe er bie „periönlidge Befanntichaft" mit den simba mad)te, von denen er io viel uno jo 2tbentenerlides gehört hatte. Dajür befam er jedod) bei jeines erīten Begegnung mit Römen gleid) mehr ju jehen als ifm lieb war!

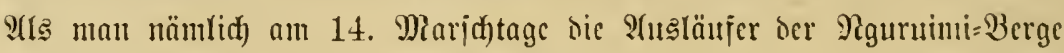
ïberquert batte uns jidh im Miaridje surd) eine breite, aber bon cinzeliten

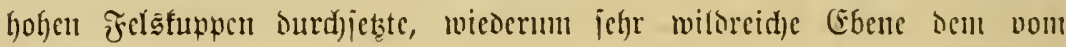

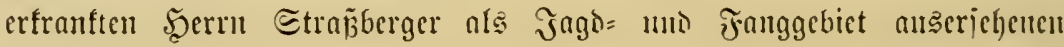

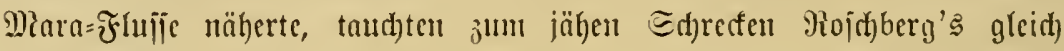
or с i Röwen unter cinem gebüjđunzogenen, von cin paar Bécrn bejeßsten

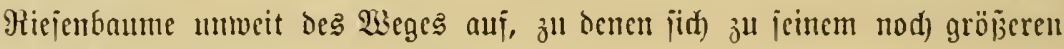
厄d)reden auj bns murrente (sebrïlt bes einen Simba hin noth weitere

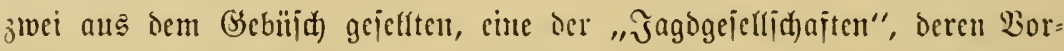

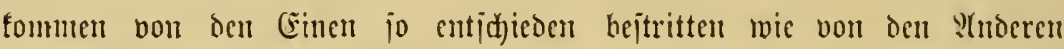
behauptet murde! Ta war aljo jold cin gemcinjau jidg bas 2 sild ju=

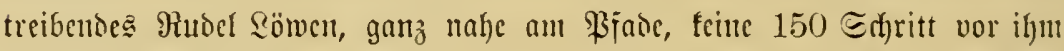

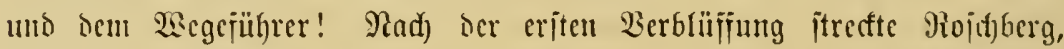
ohne jidh unzubrehen, weil er tien Blidf nidgt von den mit ifren Ed)weijen die Flanfen idflagenten sömen wenten wolfte, den ted)ten S(rm halb nad) hinten aus, um jid) von dem (semely und Mitnition tregenden Boy die Büd)ic jureidfen ju lajien. Stlein er grifi in bie \&ujt, Miabrut war

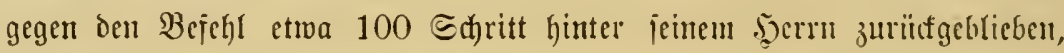

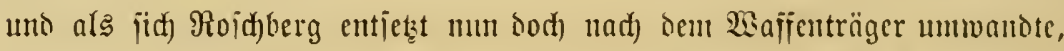
jah er, wie der jid) eben in's etwa idulterhohe Gras ducte, (Bemegr unt Patronentajdyen ginlegte unto, nad) der Berweguntg der Brashatme ju

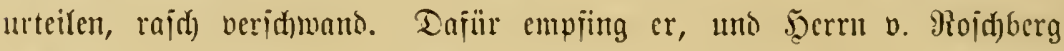
erflang das in jemer angenblicfidyen Berwirnung wic bie tröittentie Etimune

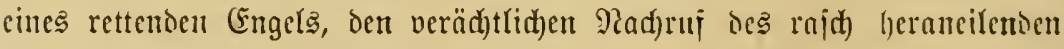

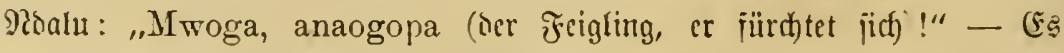

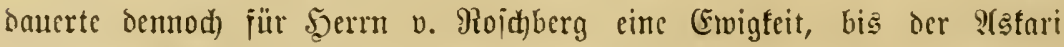
heranfam, denn bie bisher offenbar unidhlüjïg gewejenen Sömen, bie jweiffllos unter den Bamme mit einer Miahlzeit bejdäftigt gewejen waren, 


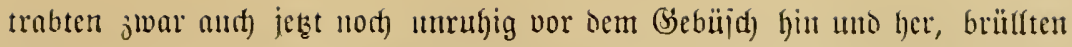

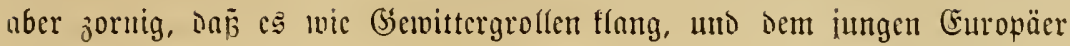
unterljarb ocs Miagens ganj jettjant wurde. Čin paar Sprünge nur, uno

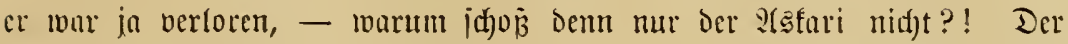
Maun jah Doch, baj er waffenlos war, uno der jitternoe Wegefüfgrer nur

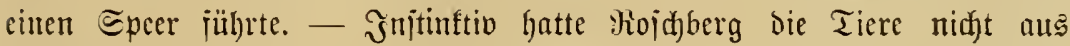
bem Shage gelajīn, uni tat bas aud) weiter, obgleidh ifm flar wurbe, wic lädherlich dic dabein jo ojt gelciene Behauptung bar, ocr , fejte menjafliche Bricf jwinge ielbit den Rönig der Tiere". Freilid), eben

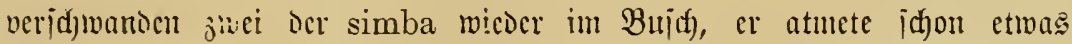
jreier, da famen aber dic bciden Röminnent wieder aus dem Diffidjt hernus,

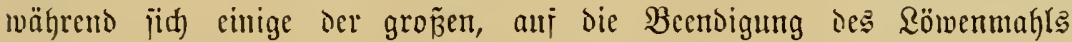
wartenten (seirr mit flatjdendem frlügelid)lage erlybben, um balo auf anderen ïjten wieder aujjubaumen.

"Behe langjan zutüt, Bann, und hole Dein Giemehr!" raunte ifm

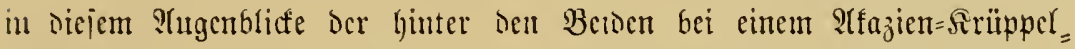
baume baft machento ?edolu ju, ber jur Bermunderung des Europäers

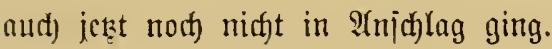

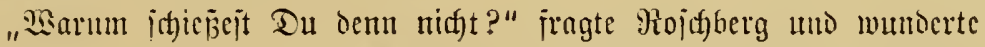

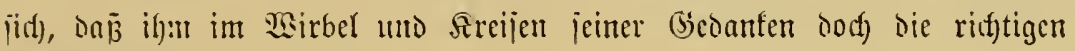
Siijualeli= 3 ofabeln einfielen.

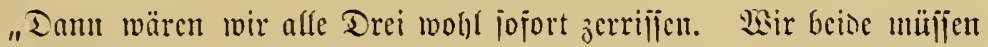

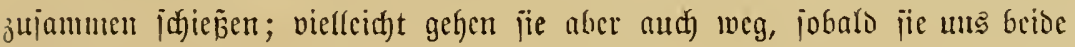
in Bereitjant jehen."

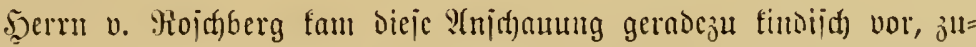

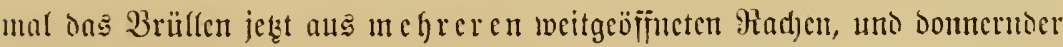
nod) als vorijin, heriibertönte, wäfrens in ber Mitte die cine mähnenloje Sömin, unt ganz linfs der nädjite, ofjenbar alte aber ricjerijtarfe Sö̈ve

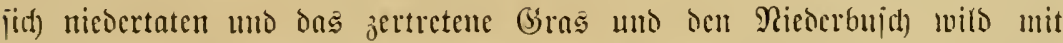

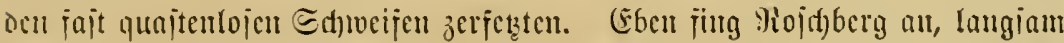

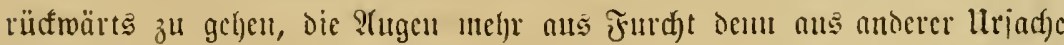

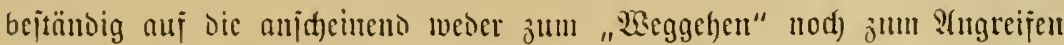

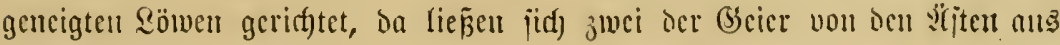

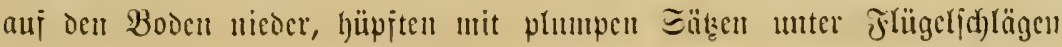




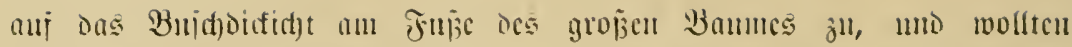

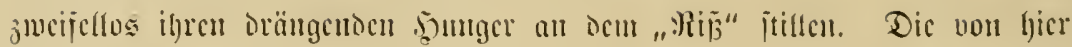

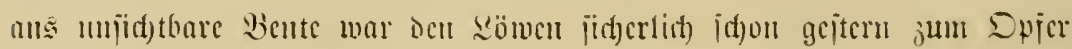

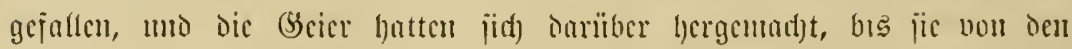

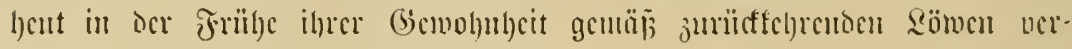

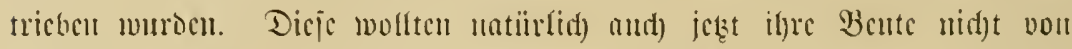

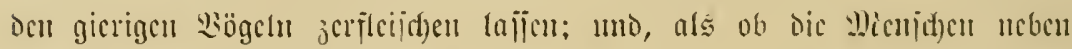

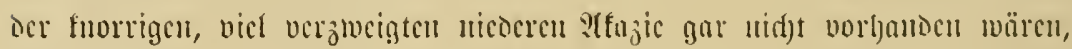

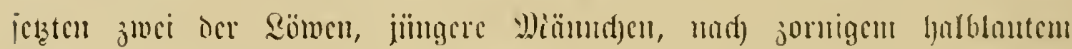

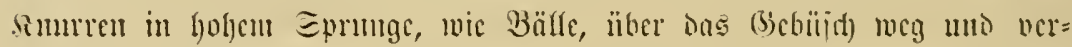

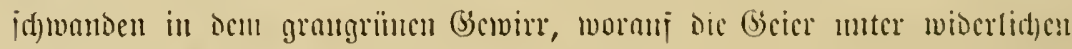

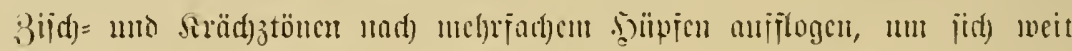

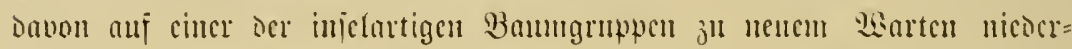
วulẫ̆cu.

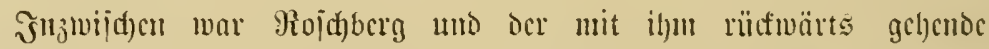

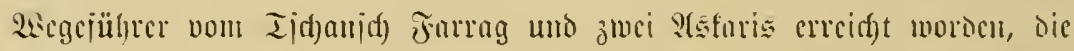

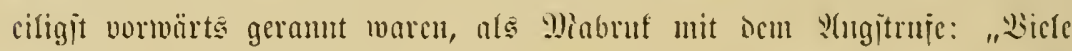
Eimba! Eie übcrjallen dic Scute vorn!" an iluten vorbcigeitürmt war,

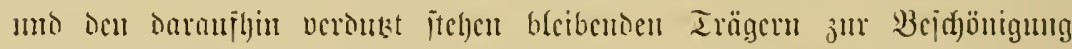

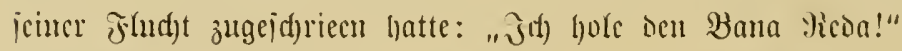

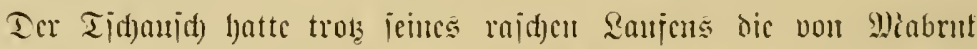
in's (Sras gelegte Browning=\$icpetictbüd)ic Niojd)herg's entoceft, jic mo

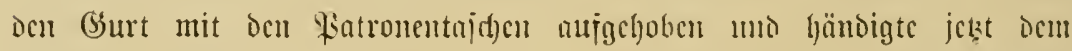

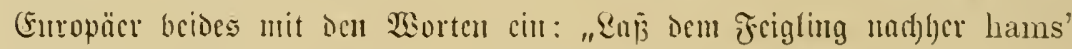
inshri (arabija) = khamsa u 'asherin: 25) gebcu, Bana!"

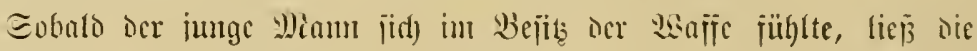

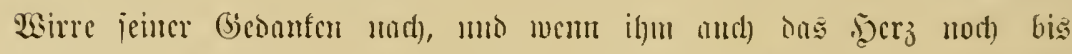

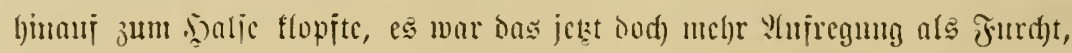

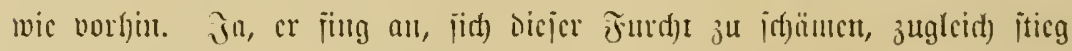

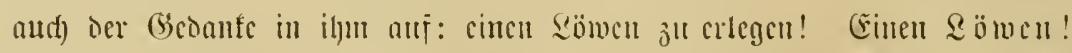

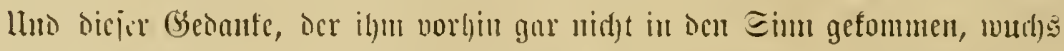
iid) raid) 3 "

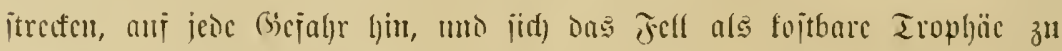

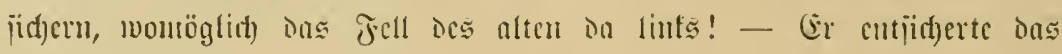




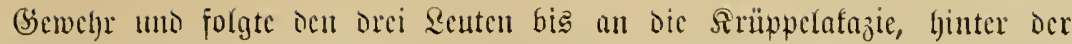
Poalu nod) imuter reglos jtano und dic num wicocr ju jüuf gin uno ber

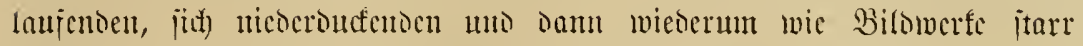

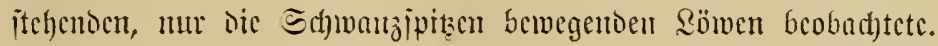

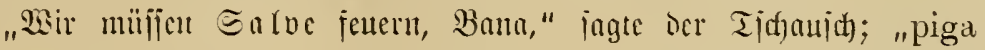

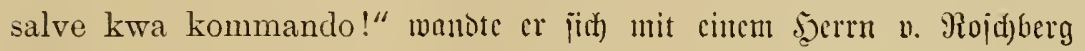

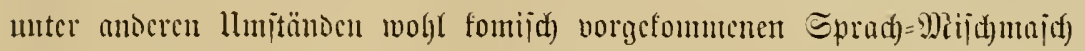

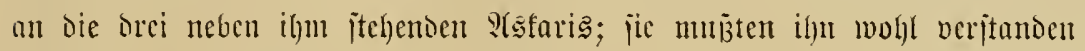
baben, Denn jie bliften halb und bem lintes neben jie getretencn Curopäer, als crwarteten jie wic beim Sxerzicren mter Röber bas Sommanod "Regt

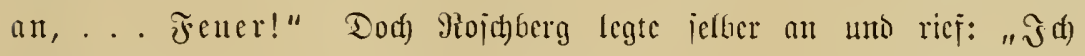

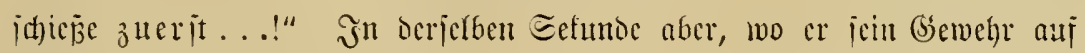
oen alten Simba lints ridftete, idnellte der cmpor uno jprang mit cin

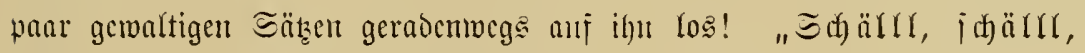
id) älrr!“ fnallte bas Repctiergemelgr oreimal bintercinander helfen Toues, ...

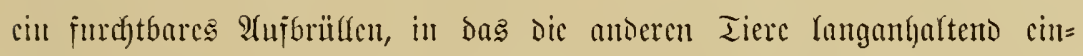

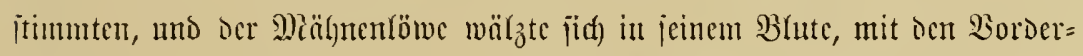

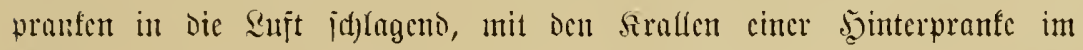

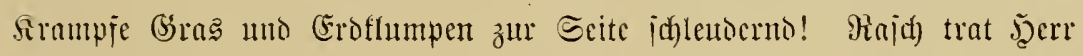

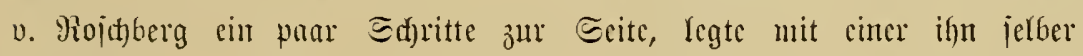

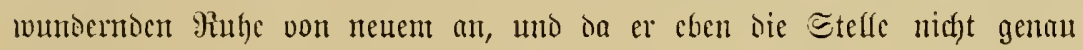

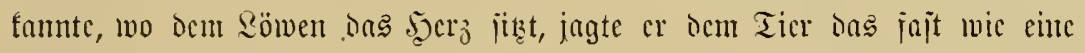

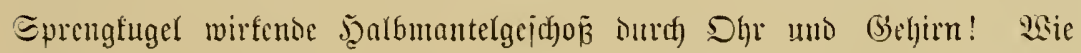

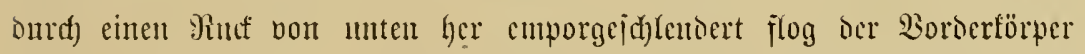

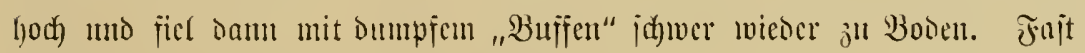

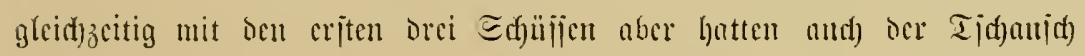

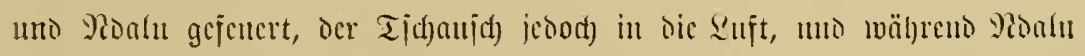

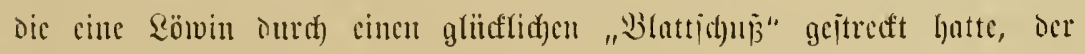

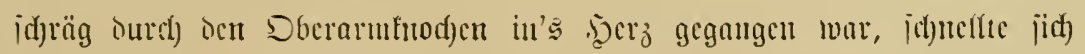

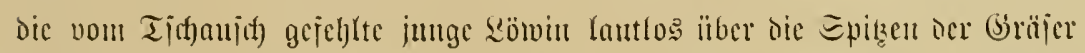

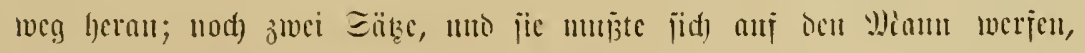

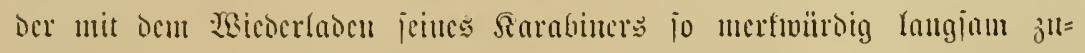

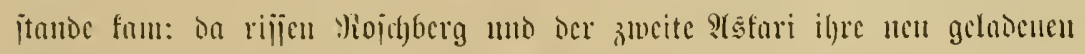
(Scuchre an Die Bacfe, jajt cin Toppelfuall, mto ummitteibor vor Dem 


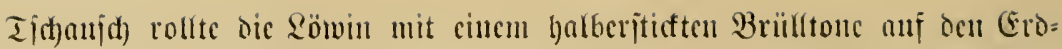

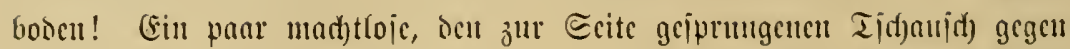

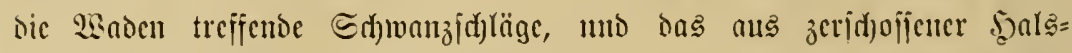

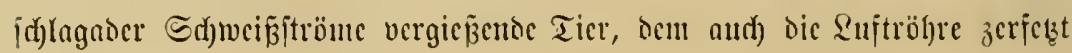
war, criticfte binnen cincr Miunte!

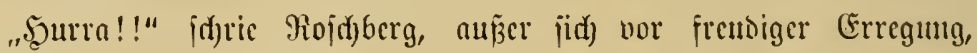
uno jujwenfte jeinen Tropenlyelm in dic \&uft, "orei \&öwen anf eimmal!"

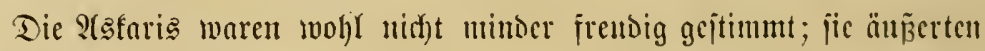

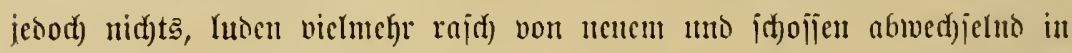

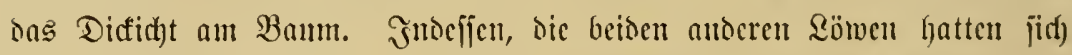

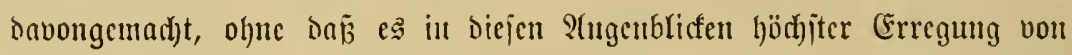
cinem der vier Säger bemerft worden wäre; mut bie Gicier hatten darauf

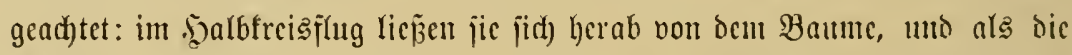

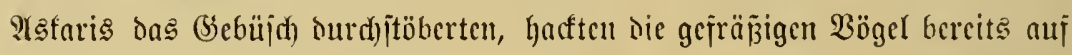
cincr von den Röwen gerifienen Bebrajtute ums cinent vielleid)t halbjährigen

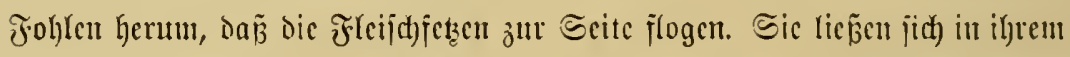

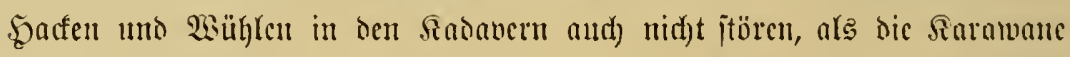

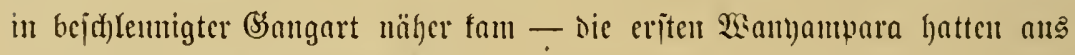

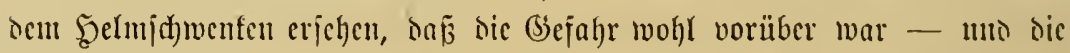

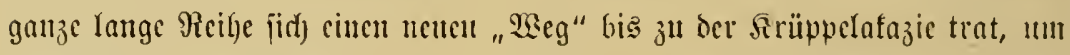
wenigitens im Borübcrjichen cincn Blicf anj bic erlegten Simba jull verịn.

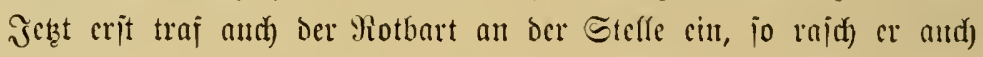

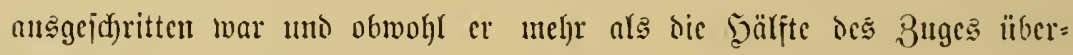
holt hatte. „Bravo, Freundd)en! Gratulicre julu critten Simba! Doer

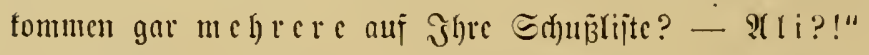

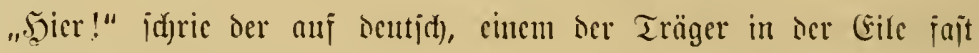

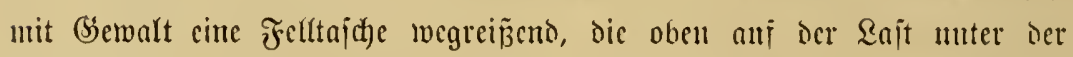

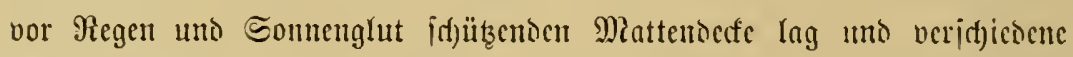

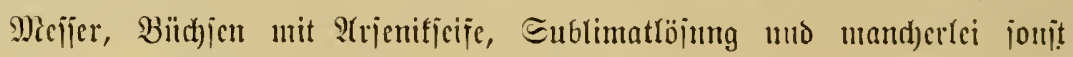
jum Tierpräparieren 2otwenbigce entfjiclt

"Nimm Dir ein panr Reute uno jtrcife den alten simba uno ba Die junge jike ab!"

"Sasa hivi (jojort)!" crmiocrte der Bol) utno j(f)wang dic Felltajd)e zum

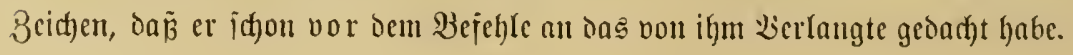




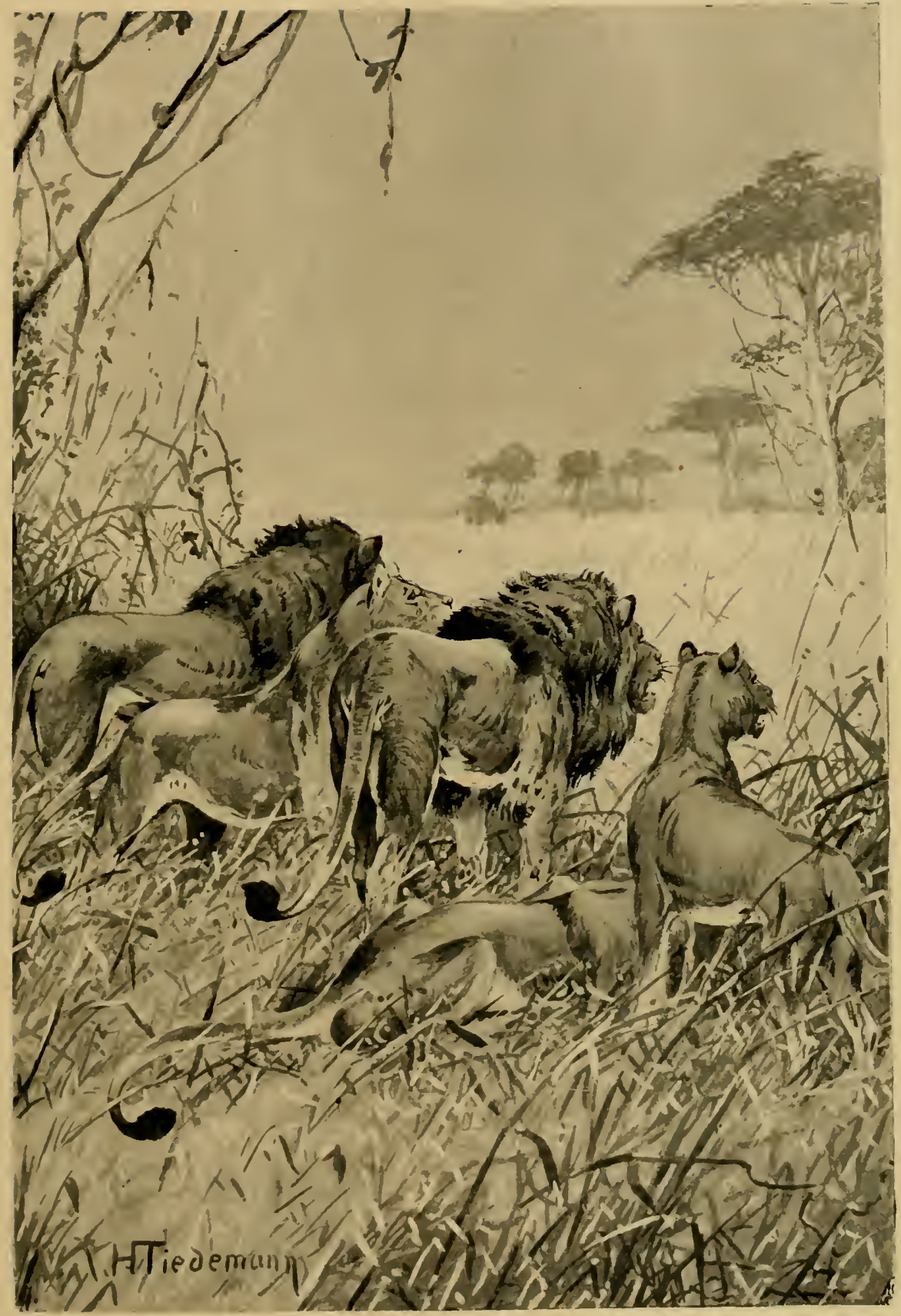

ndalu (tand noch immer reglos und beobachtete die Cöwell. (Evite 327.) 



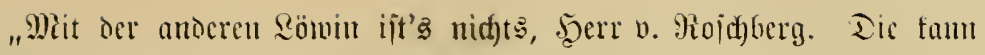
ifre Decfe rufig behalten! Selnn Sie 'mal: fie ijt total räudig!".

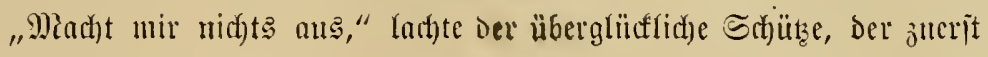
faum jugehört hatte und jetzt ipielent mit oen Fingern durdh bic bei

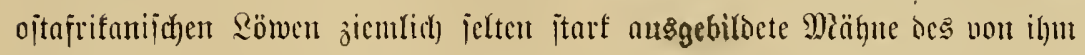
juerit geitrecten Mänudfens fuhr ; "bic tommt ni(b) auf meine Pied)unng!"

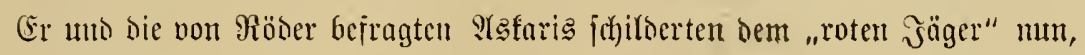

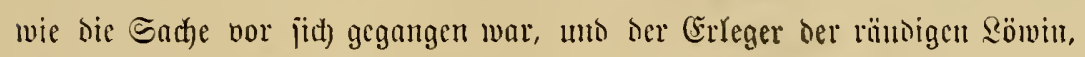
Beren Miüfen wie Semoen alleriings gerabeju efelfajt ansjahen, fragte

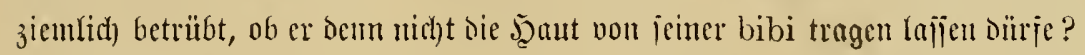

Piöber flopite ifm lathent auj die Sellulter. "Dan bie bibi und

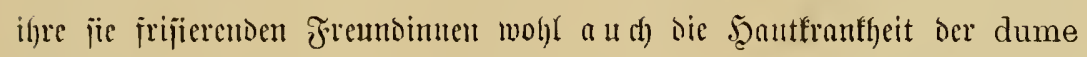
friegen jollen? Mee, is nich, lieber Mamm," jügte ar ieinen Rijutalycli=

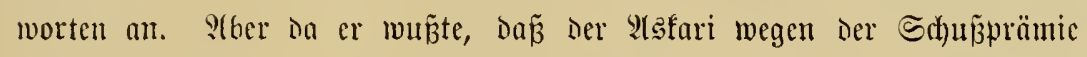
traucrte, die ihm verforen ging, Inem or nidht auf ber Etation bas Felf abliejern funmte, er und) ben Eijer jeiner Reute lieber anjpornte als Dämp广te, io jagte er: "Éfucise dem Tier Srallen mo Schmanz ab, Irti tann Dir ten mit jeiner sabuni ya liga (Gifitieife) abreiben. Nenn das

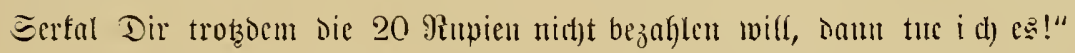
„Ahsante, ahsante, bana," erwioterte Der Mann erjreut milo madfte ïid) ïher dic Sömin her.

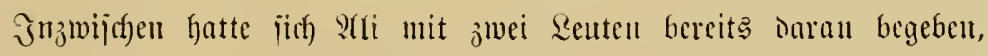
Deren Sajten anj andere zu verteifeu, mo als cr mit il)uen au's : 1 bjtreijen

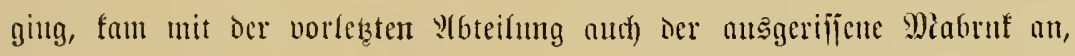

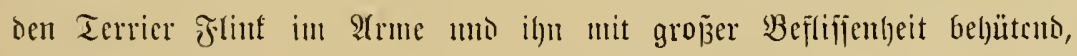

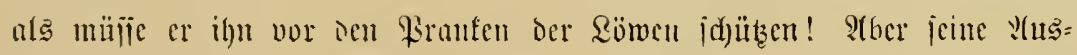

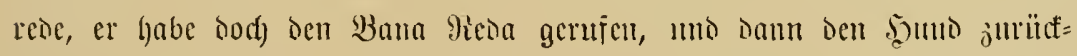
gehalten, Der immerzu bätte voripringen wollen, nübte ifm nid)ts. Sein Buna war ourt) den llngehorjam uno die Feigheit gerabeju in Sebens= gejahr getomuten, wie ifhut jekzt erit bieder io recht flar mutrie, umb er

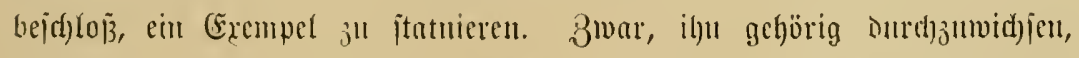

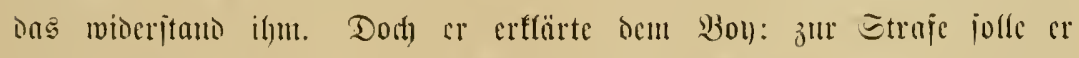

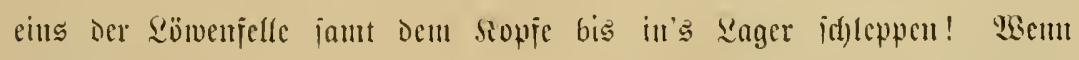

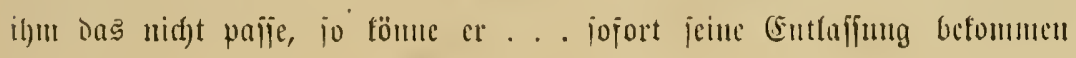


mo jid) "nad) ந̧aule trolfen". Damit der Burid)e jedoch grïnolid)

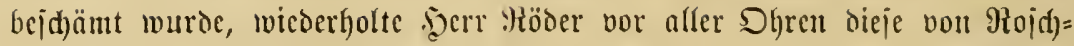

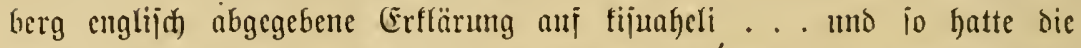

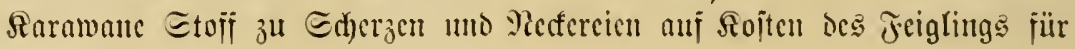
mefrere Tage!

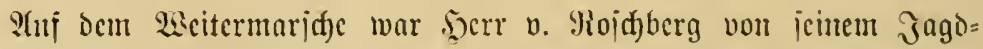

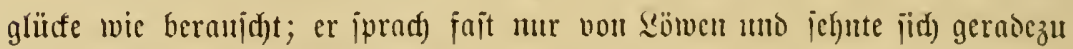
ciosnid)ajtlid) nact) cinem zweiten Bnjammentrefien mit cinem Eimba.

"Ea geht nid)t immer io glimpflid) ab, Bicrehrtejter," warnte ifhn

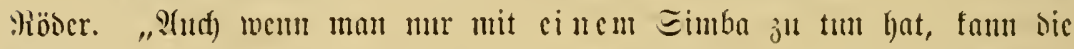
Eact)e böje gemig ansfallen! Jat will Jhnen bic Frenbe an sem (Frjofge mugrtid) nidft trüben; aber Eic haben bei J̧rem 3njammentrefien mit

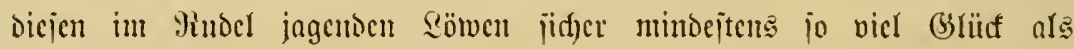
Beiduicf gehabt! Wären bie Röwen ni d) t i a t t bis obculfin getwejen, dic (Scjđjidfte hätte Dod) red)t ïbel ablaujen fönten."

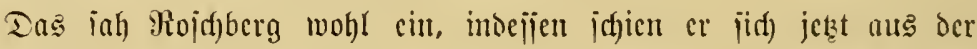

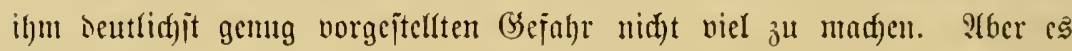

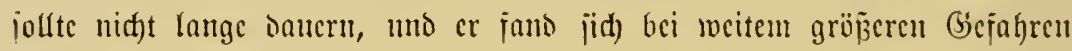
gegeniiber !

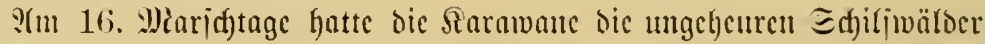

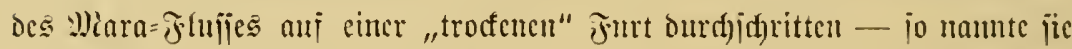
ber Siroutgoii, obwohl bic Reute vor oer Furt unter ien ungehcueriten

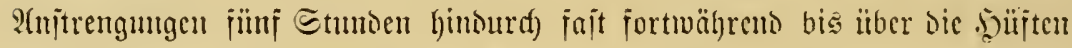

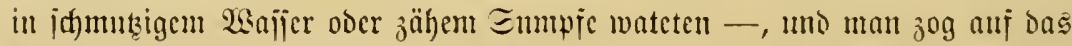

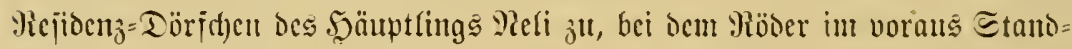
quarticr zu nehmen bejdylojien hatte. Bei biejem über cine flcine Sambja)ajt Des llfenue=(Ǧcbietes herrid)enten "Eultan", Der jid) ieit jefher ala juner= läjifiger Freuno ber Dentid)en bewicien hatte, jollten dic Sente uno Saiten

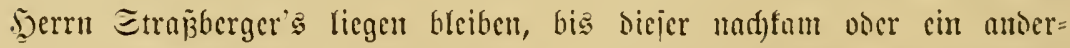

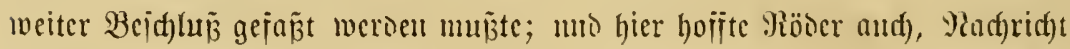

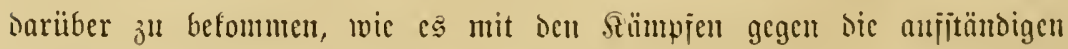

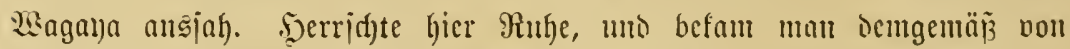

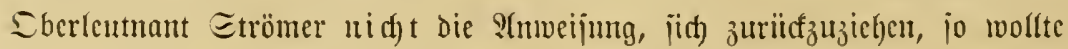
or hier begimen zu jagen; ocm er hatte auj Bitte ocr Boologiingen 


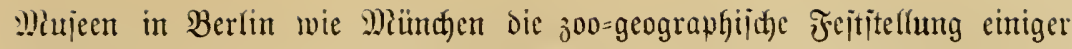
jeftenen Tieve vor; Dann jedoch beabjintigte cr, mit Der un Straß̄berger's

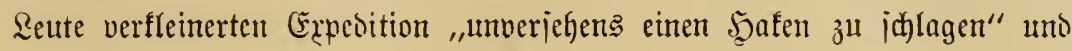

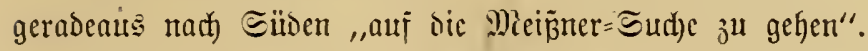

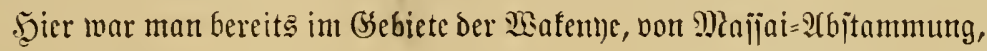
Derielben Wafente, die idjon ein paarmal von ber Edulthtruppe aus

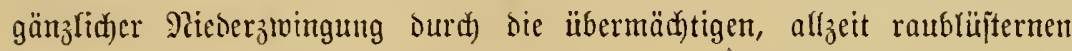
Bagana bejreit morien waren, - auj den jerrijjenen, idfludytenreidfen Bergen, bie fich nom Mlara=Flujie, oder wie er mit ieinem Majijainamen

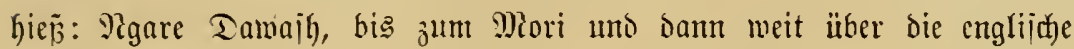

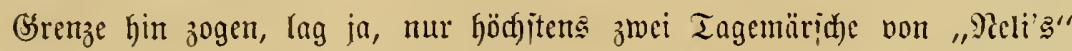
entiernt, bie vor etliden Jahren von ben Deutidyen eritürmte fyflopijhe

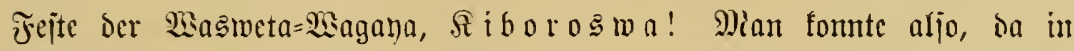

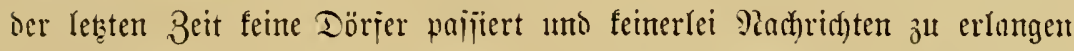
getwejen maren, gar nidjt wijien, ob bic Sarawane nicht ant (Ende jid)on

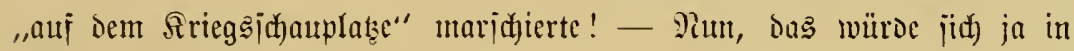
Peli's zeigen müjïen!

Der nlte bürre Enltan empüng die Expedition mit ungeheuthelter

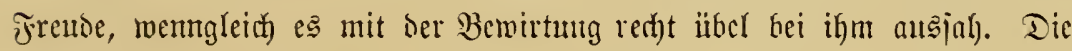
Tösiler hatten mur Bananen unt bie geringere, iehr grobe uno holjfajer= reidhe Eorte Bataten ju verfaujen, uno bejap̃en jonjt unr äuß̌erjt fnapp an Mais uno Şirje, was jie jelfer brauthten. Denn nidyt mur mar ber Ertrag Der vorigen Crutte von ben Wagana geraubt, cin Teil Der Maämet

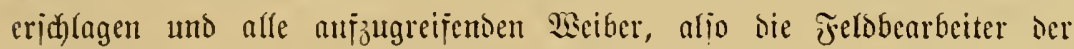
Wafenne, von ben Eiegern jortgciügrt worden, jontern es waren and)

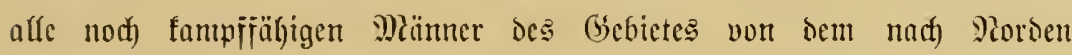
gezogenen B̉ana mfubrua Eiteruer (Oberleutuant Strümer) aujgeboten

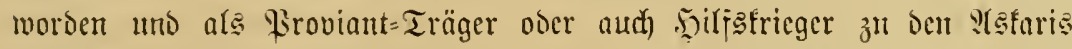
des. Bana mfubwa abgegangen! (Fin Teil jammle jiff nod) im Dorji

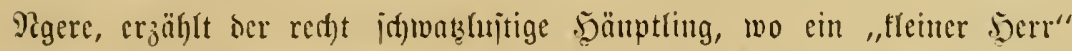

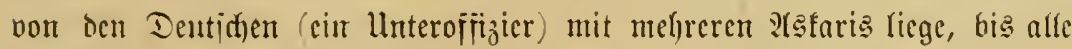
Rrieger beijanmen wären. Dam maridjiere er mit ben Dillistricgern

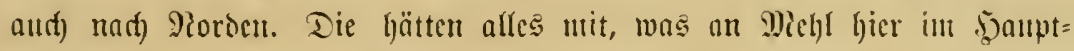
borie und jeinen anderen Dörịcrn vorfanden geweien wäre. Wiedft cinntal 


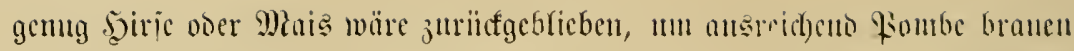
zu fömen! :

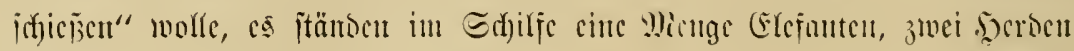
von jujammen woht 30 Tieren!

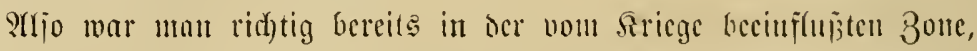

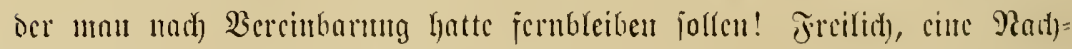

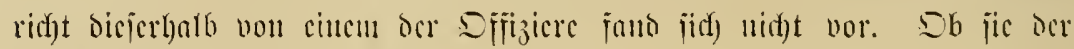
Ilnterofijizicr in Sigere vielleid)t hatte?

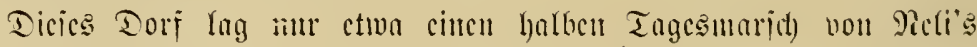
entfernt unt murbe non cincu feincr Sölune "regiert". Huter alfen llm=

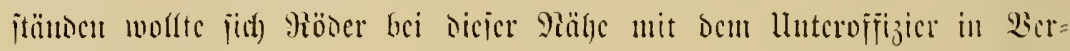

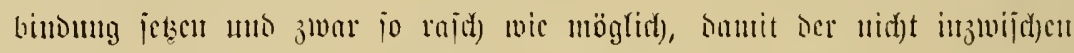

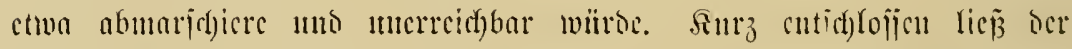

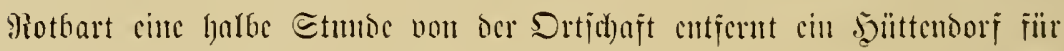

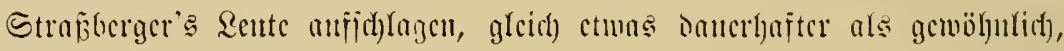

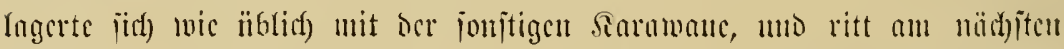

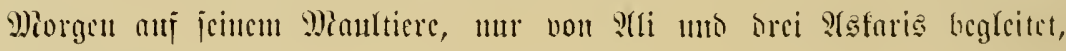
nact) Mrgere.

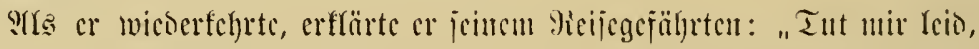

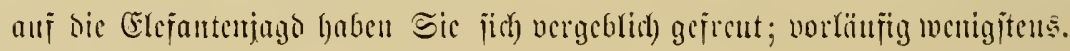

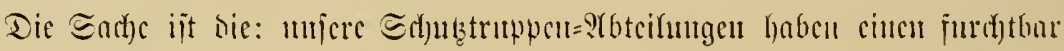

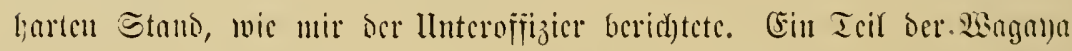

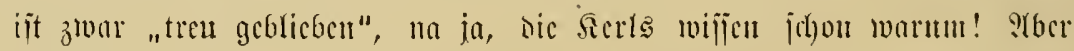

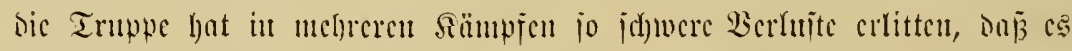

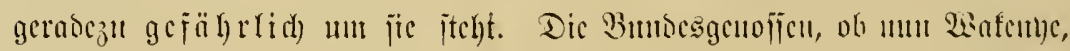

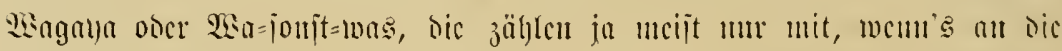

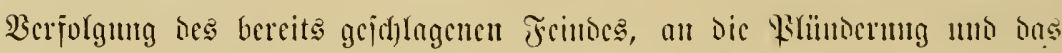

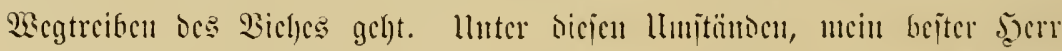

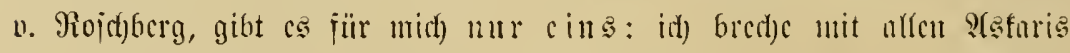

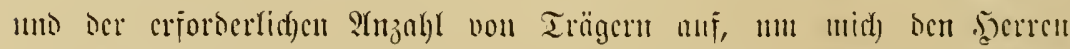

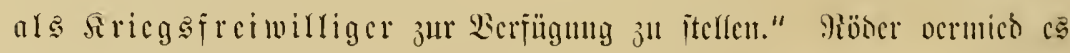

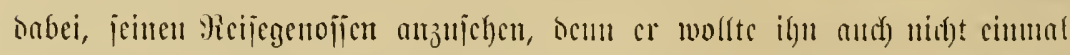

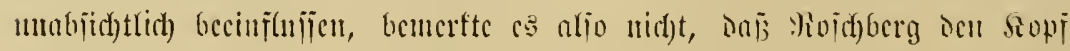

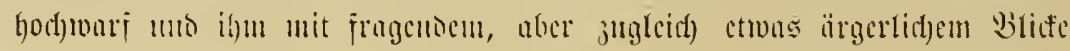




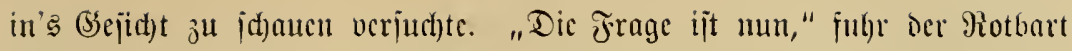

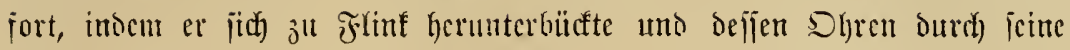

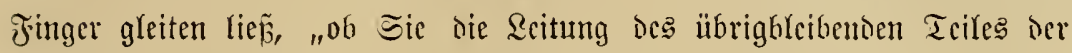

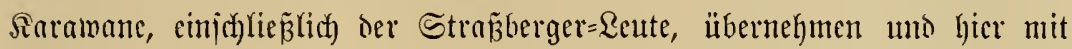
ilynen jagen wolfen, ober ob Sic verjuchen wolfen, mit unjeren überzälyligen

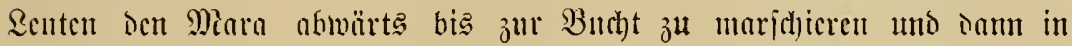

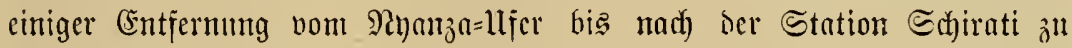

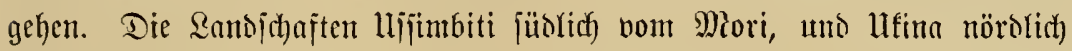

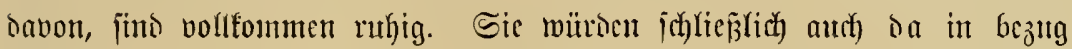
auf dic Эago ..."

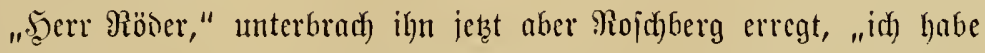
nicht ben Borjutg, von Slunen längere Beit gefaunt jul iein. So viel aber

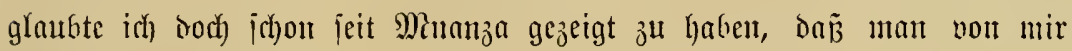

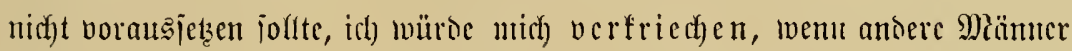

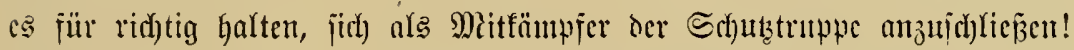

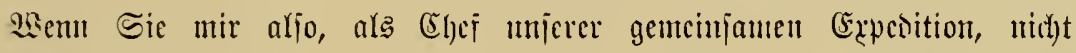

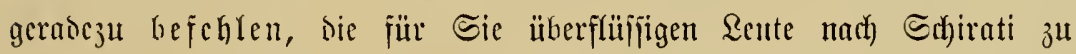

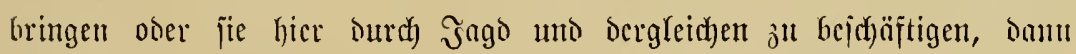

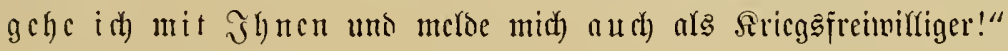

Röbcr itamo auf uno reid)te ifm die Şand. "NRchmen Sie mir dic

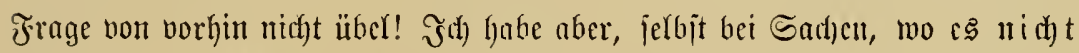

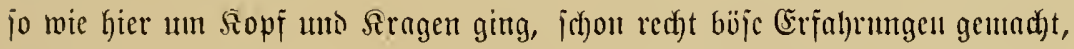
gernie, wo idf) es jehr wenig erwartete. - (5)nt! Marjoficren Sie mit!

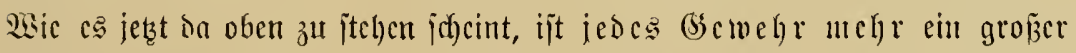
Seminn für bie Truppe. Die für Strẩberger angeworbenen Träger uno

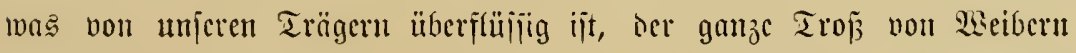
uno Sinbern, bleibt bis auj weiteres bier unter Bem bcichl bes ältejten

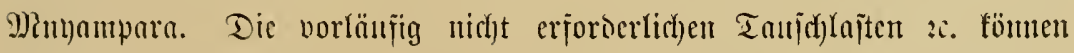

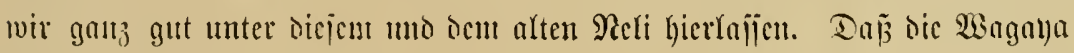

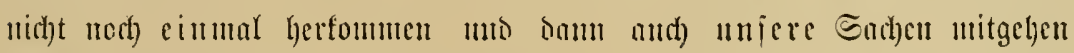

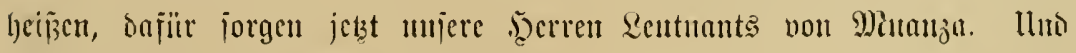
wir wollen igueu helfen."

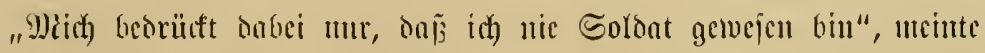

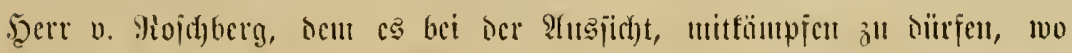




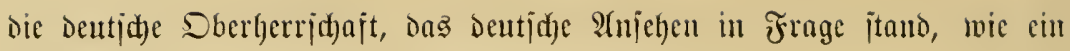
Strom von Frentie Durd) Die Brfieder riejelte.

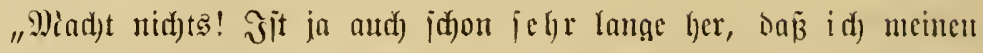
Miangel an miltitärifd)en Semutuiffen als Pejervelentuant zeigen founte,"

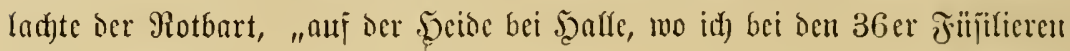

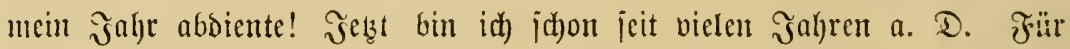

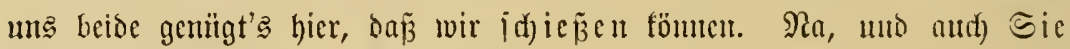

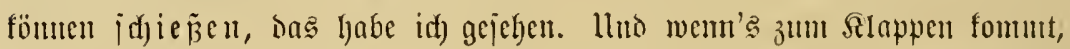

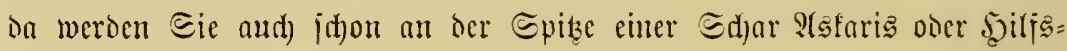

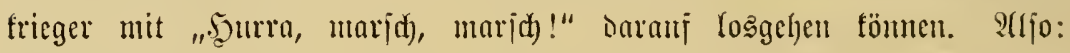

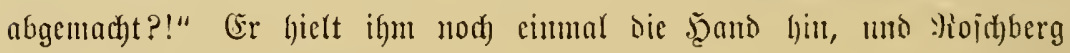
id)lug berzhaft cin: "20(bgema d)t!"

3mei Tage ipäter zogen dic 20 S(eftaris unter Tidjanjid) Farrag umo

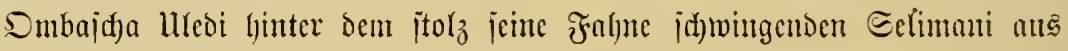

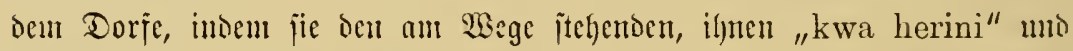

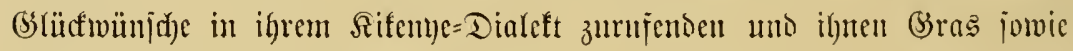
grüne 3meiglein zmwerienten (Ënwohnern entgegenj(d)ricen: "Wir werien eure Feinte bejiegen!" Die etma 50 Träger, Die Röter ausgewählt hatte, iff)wangen ihre (Setwehre in bie \&ujt und jubelten lant: "Sasa watu wa

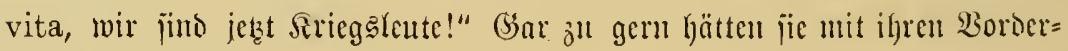
fatern ein Dutzenomal in bie \&ujt gefuallt - mit Mianjerfarabinern wie

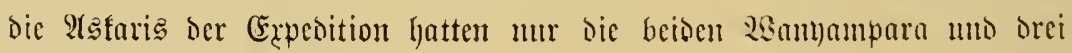

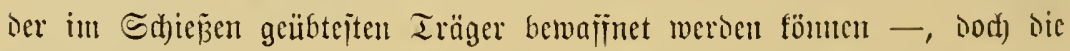
23ajungu hatten den Reuten flar gemad)t, daj bas Fulver idjon in Den nädjten Iagen weit befjer 3 gebrand)en jein wïrie, und jo verübten bic

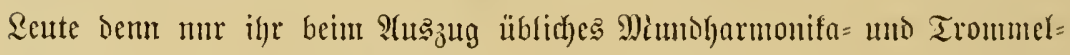

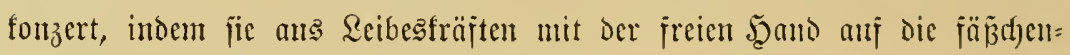

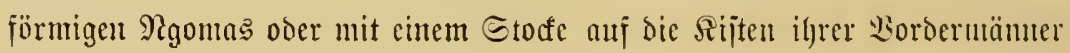
losidhlugen. Der Troz war auj das umungänglichjte bejd)ränft; alle

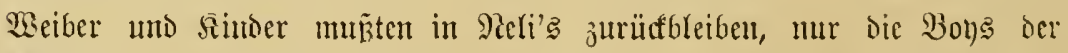
I(sfaris durften mit; bie hinderten eben nidht, nahmen den Soldaten in

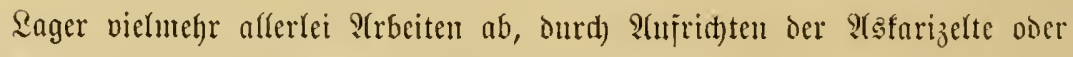

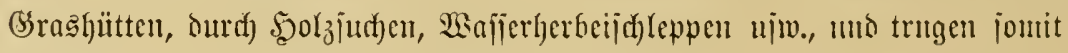
baju bei, "Die Truppe jederzeit jajlugjertig zu lulten", wie fidi) Der 


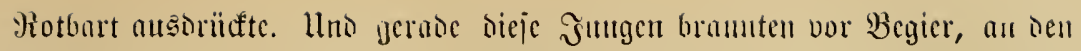
Feino ju tomuncu, womöglid) mitzufechten; fic wofltell ja afle, durdh)weg,

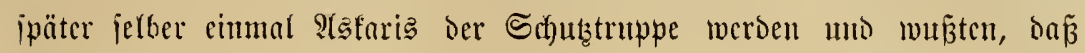
ifuen bas leid)ter werden würbe, wenn jie dam id)on bas Solontenlyant=

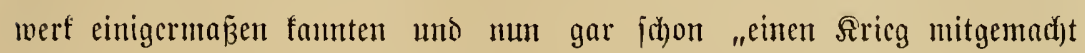

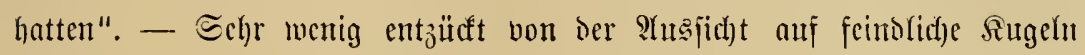

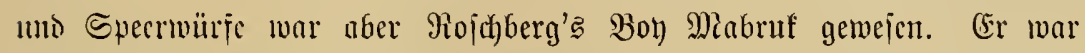

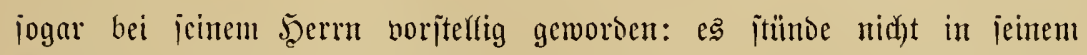

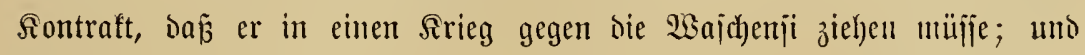
da bei cincr joldyen Unlujt nicht viel (Shutes, wohl aber jelgr vicl sïrger

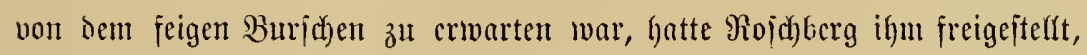

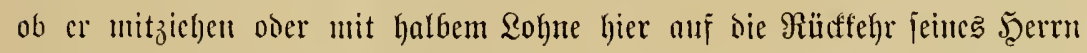

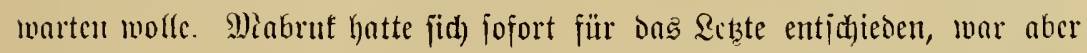

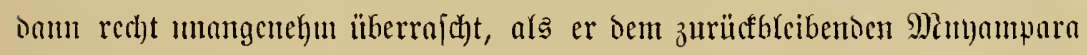
Upejiutoto afs Bol) jügetwiejen murie.

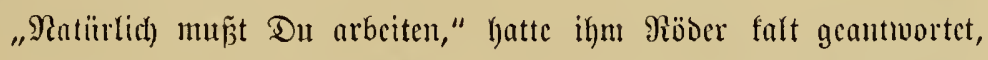
als ar jïtl) beshalb an den (5xpeditionsleiter wandte; "glaubit Du, ber

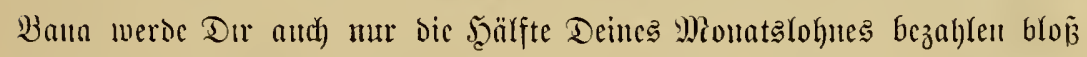
für's tembea=\$iachen (Spajicrcngehen) mo Sitharmuzieren mit den Dorí wcibcrn? Du wirit den Minnampara besienen, wic ber es verlangen

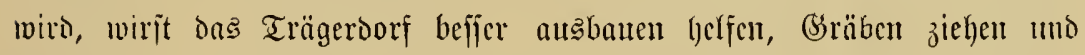
mit Dell anneren Seuten arbeiten wie bieje, bis bir jurïlffehren, ober ocr

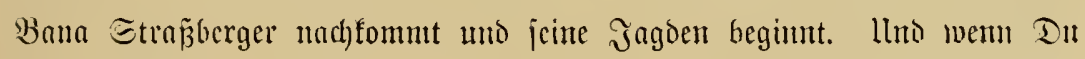

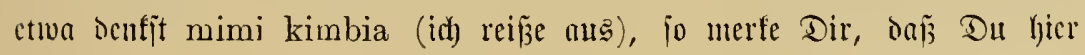

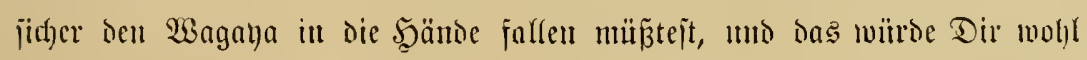
nod) weniger Bergnügen madyen als bas 2(rbeiten im Ragerborfe!"

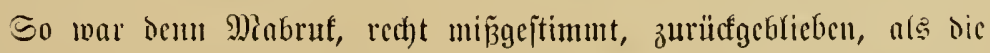

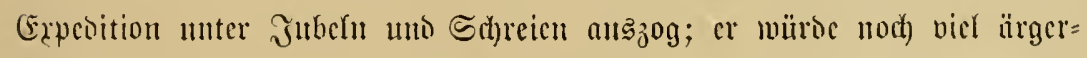

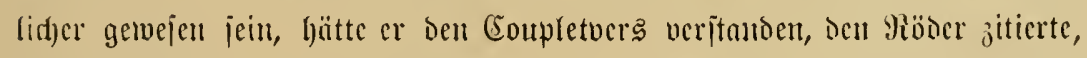

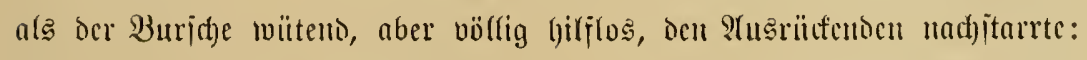

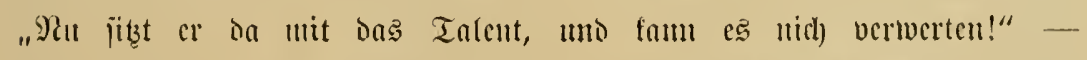

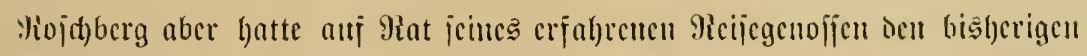

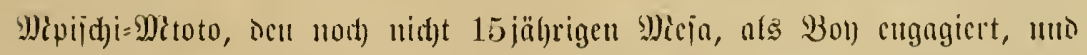

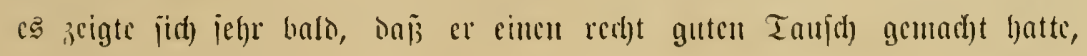




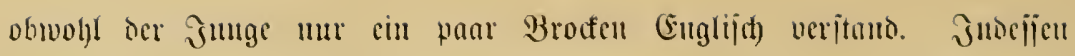
Roj(t)herg hatte jich ja auf ber Eafari jo im Rijutaheli bervolfomumet,

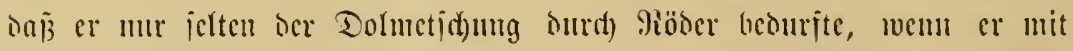

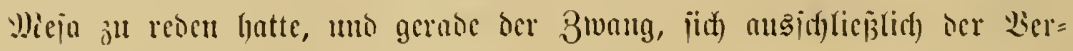

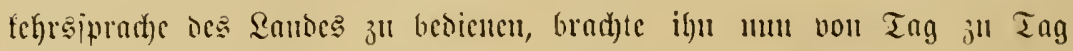

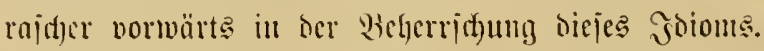

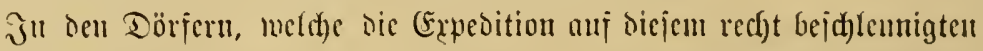

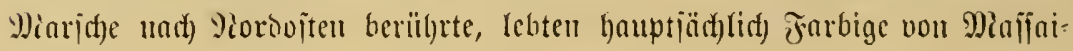

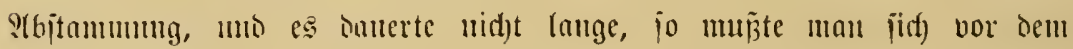

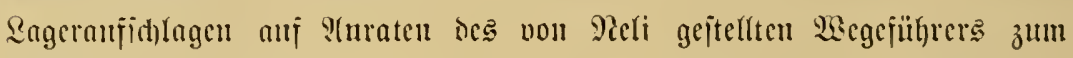

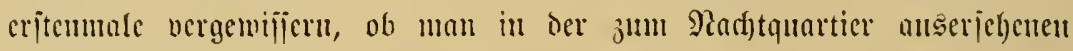

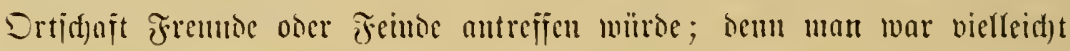

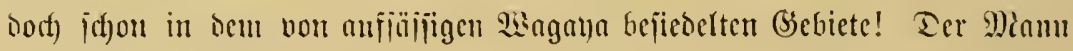
ging injolgedejien ber Epitze vorans, bis cr in ten Feldern vor der riejigen,

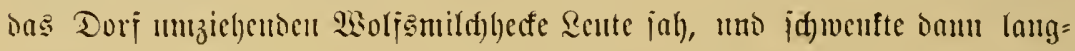
fam cinen grünen 3weig vou ofen nad) unten. (5s war bas ein bei allen

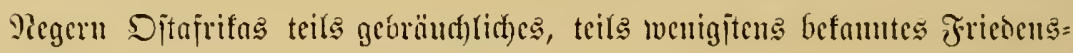
jeititent.

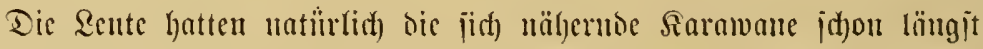
cutoeft uno jid) bis anj einige Mutige jurürfgezogen, bie lyinter einer

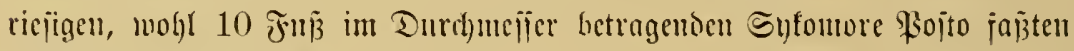

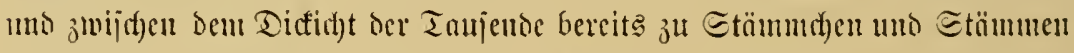

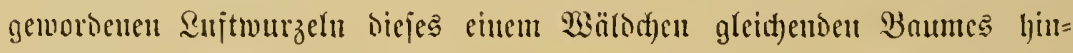

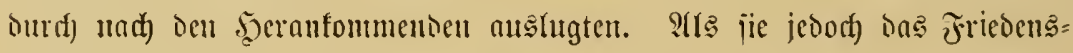

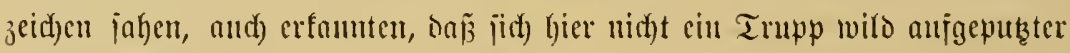

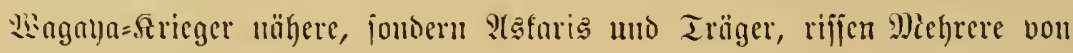

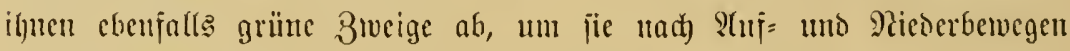

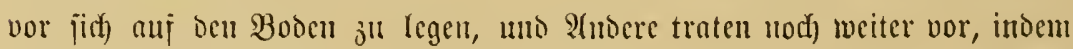

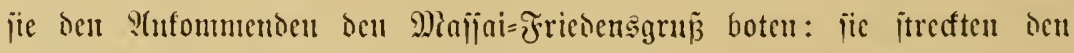

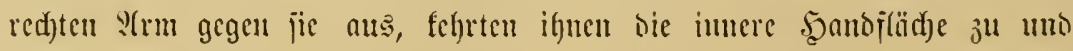

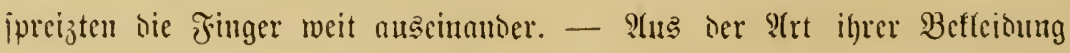

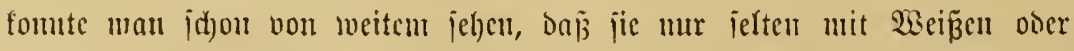

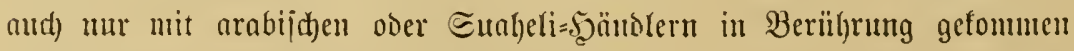
ıaren; dem dieje brauten, ja)lanfen Mämuer, bic jajt gar midts von bem 


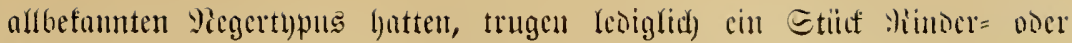

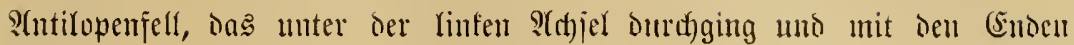

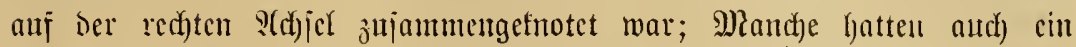

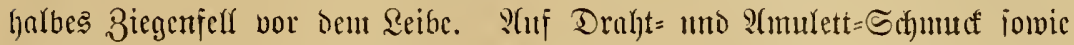

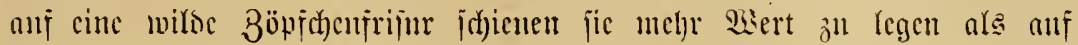
Befleioung. Shwohl ocr 2 egejülyrer cin Migana, aljo nus vermandem

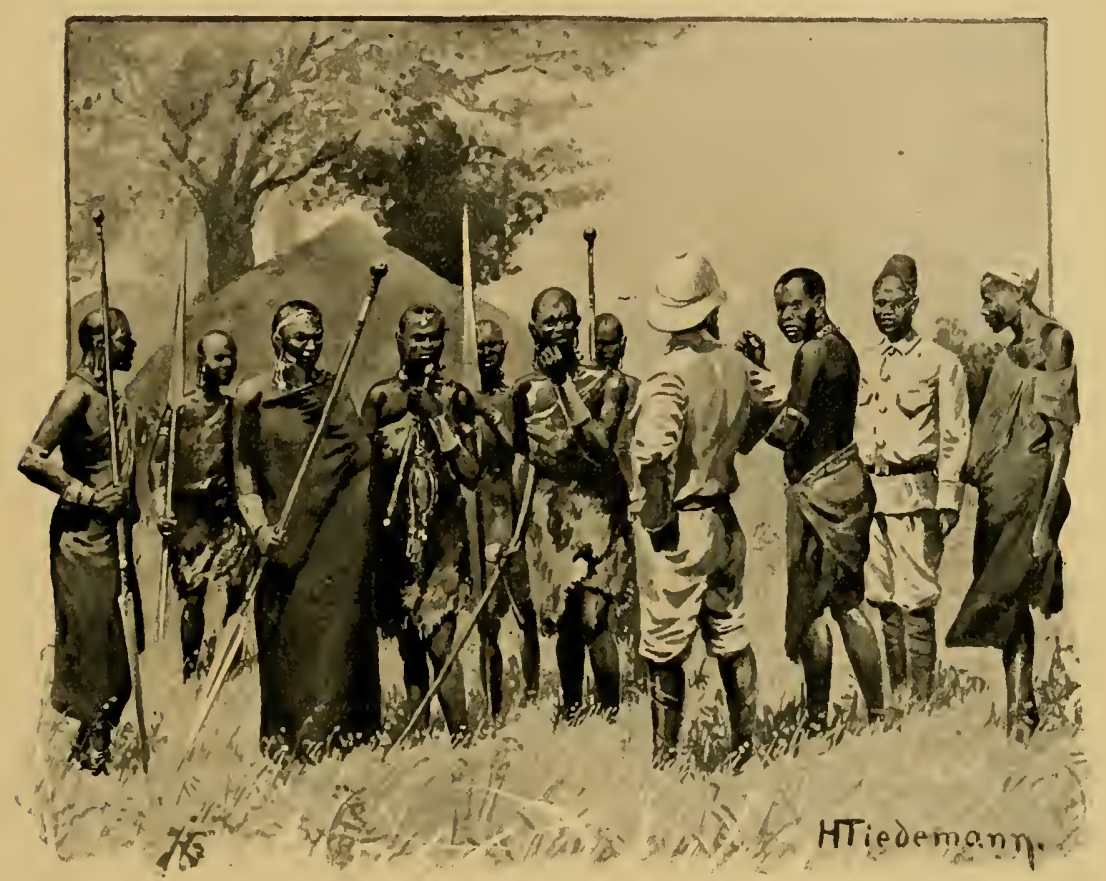

Etanme war, ging die iprachlidye Berjtäntoigung Dod) ziemlid) f(h)wer won itatten; Die Dialefte waren z"l verjeficoen, und unter ien Wiewohnern ies Dorịes founten nur wenige Mann cin paar Worte fijualycli. Der Dorf =

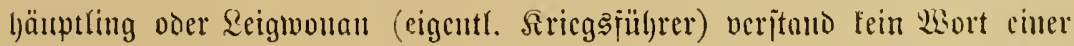
jremben Eprad)e, mo chenjomenig ocr Reibon, ocr Śanberer, oefjen Drafel=

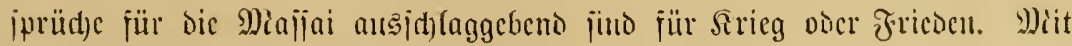

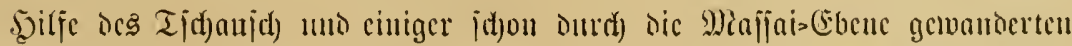

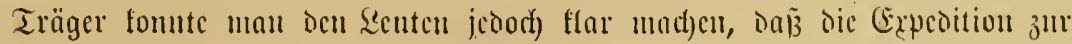

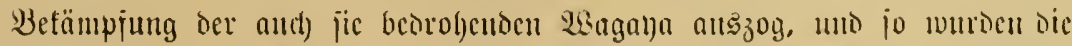

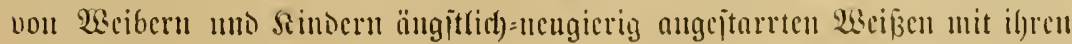


Eeuten hereitmillig mujgenommen uno verpjicgt; natïrlid) aujerthalb oce

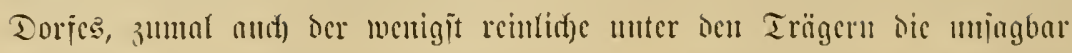

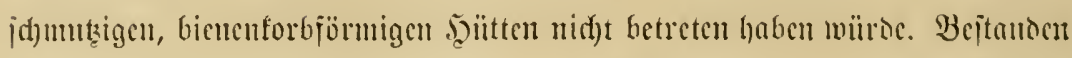

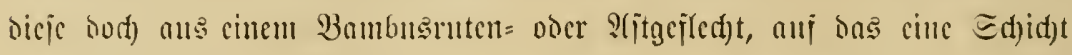

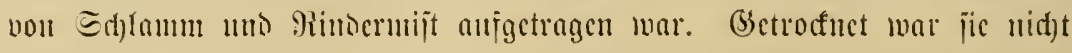

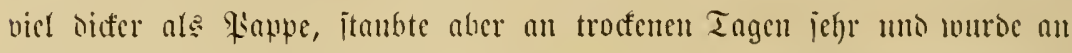

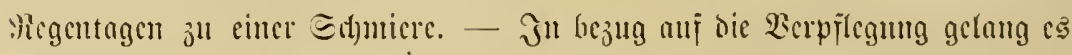

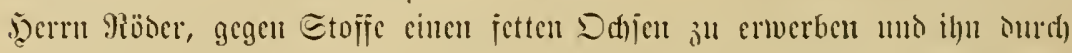

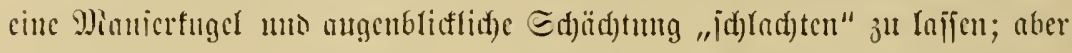

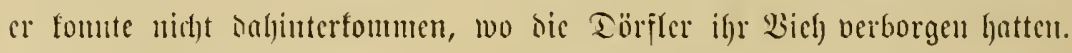

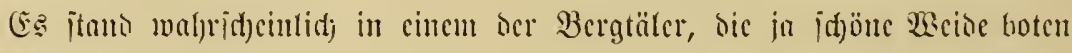
Imo geraic Deshalb bic ans Der mehr im Mordojten liegenden Miajiai=

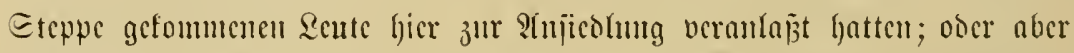
ilje .5ernen waren, in fleine Trupps geteilt, in ben Bergtwölnern, Edj)ludften

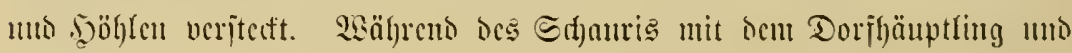

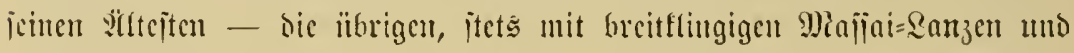

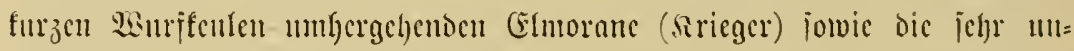

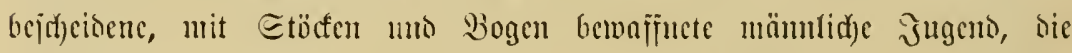

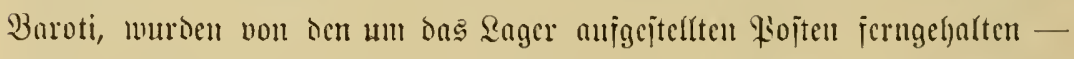

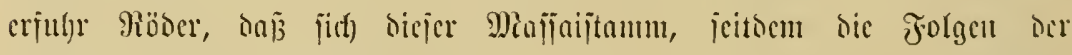

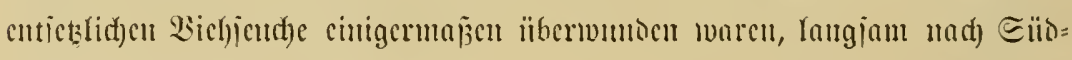

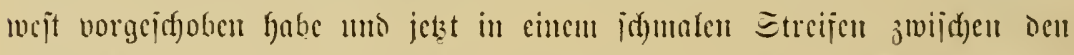

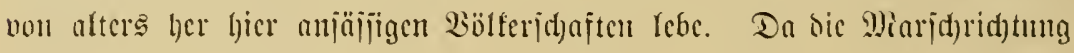

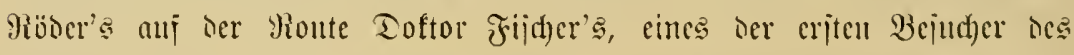

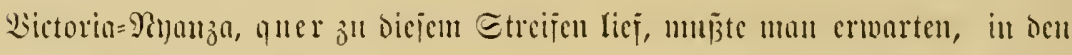

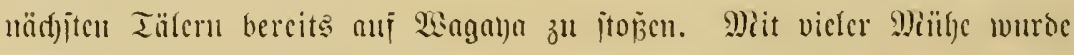

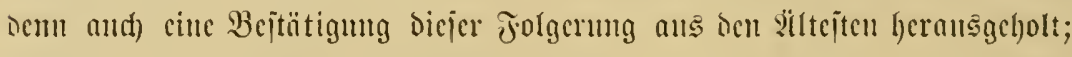

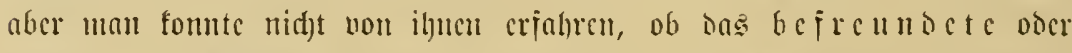

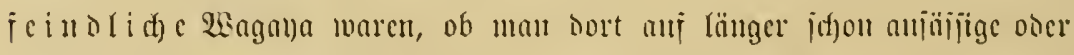

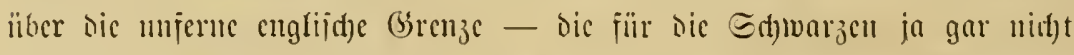

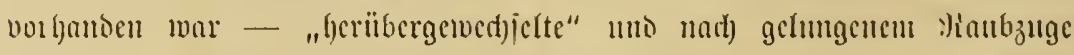

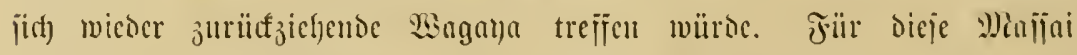

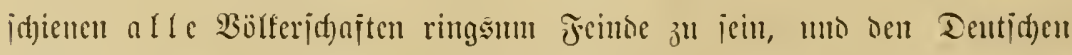

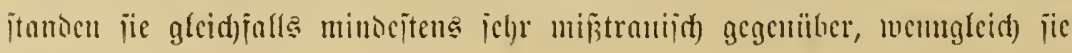


Tiöscr's Expcoition fremblid) anfgenommen hatten. Das war cben mu

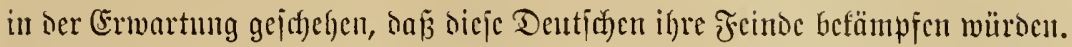

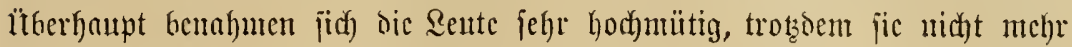

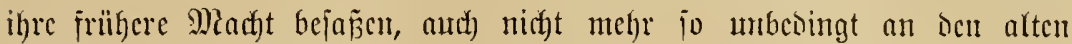
Stammes: Eigenfleiten fcithielten. Die Sirieger lehten jetst nicht mehr in

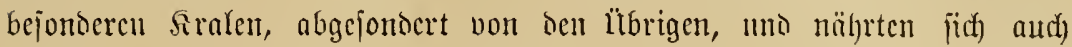

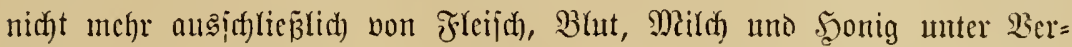

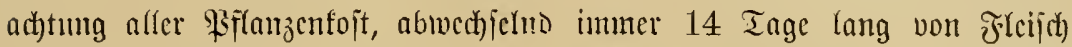
uno Bhat mebit Seonig uno Dann wicoer 14 Tage hindurch nur von Milith

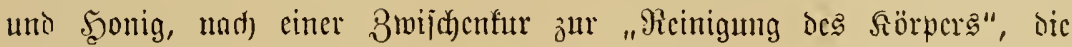

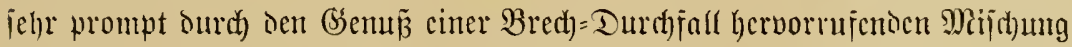

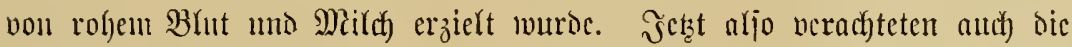

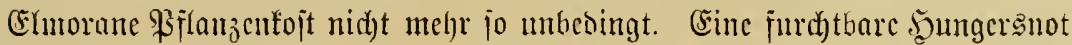

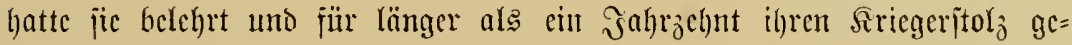
brod)en. Freilid), fie waren in un jめon mieder mehr "oben auf", als ihren Rachbarbölfern licb war! Dic ßeit ifres Elents, in ocr vicke

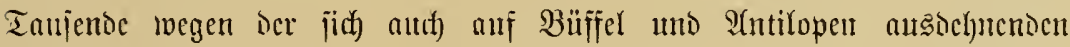
Minterjeurhe verlyungerten, uns sie l̈tberlcbenden jïh) von oem jür jic

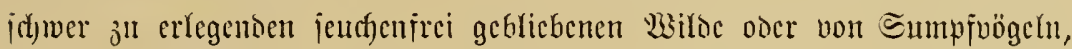

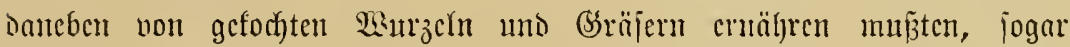

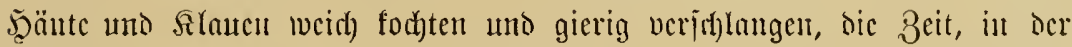

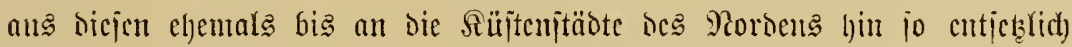

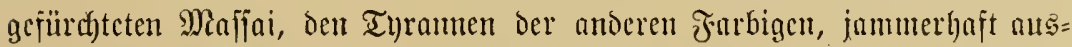
ichente Bettler, wantemie Sfclette getwornch, jic suar jeit untgefähr 15

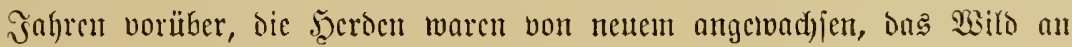

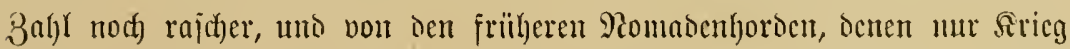

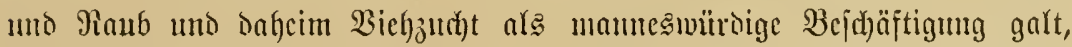

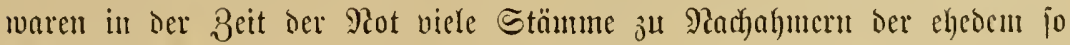

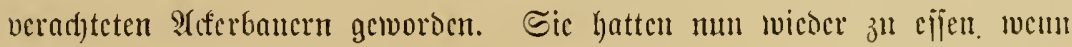

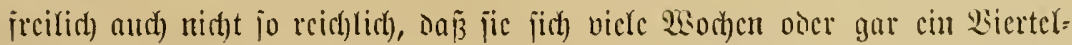

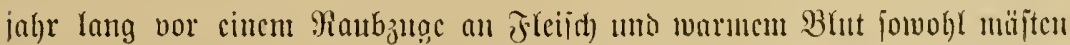

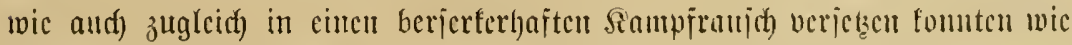

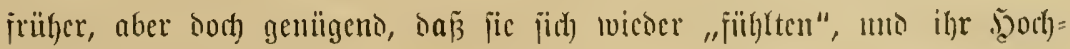

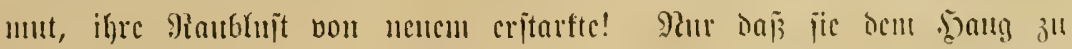




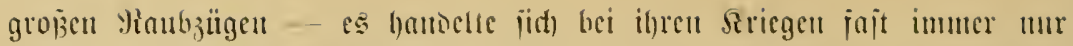

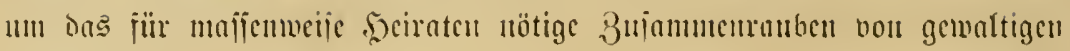

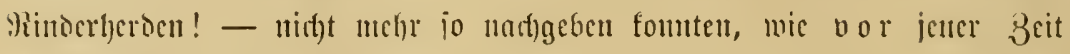

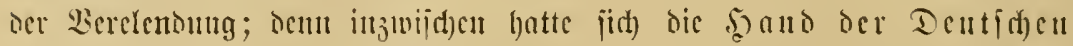

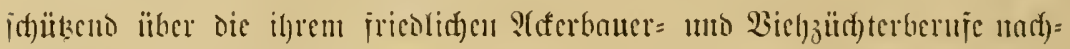

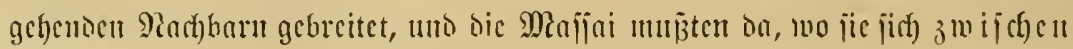

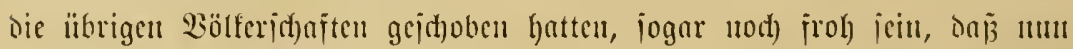

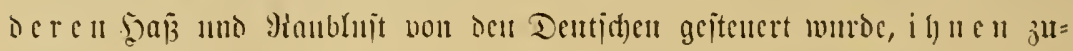
gunjten! - Tas mar mun auch) hjer ber Fall, bei den bis nahe an Den

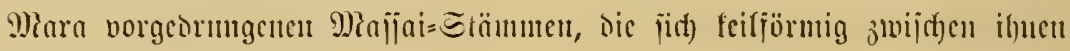

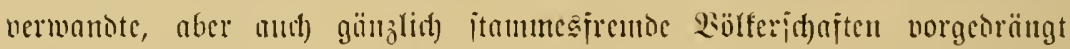

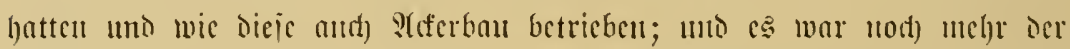

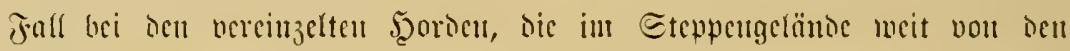

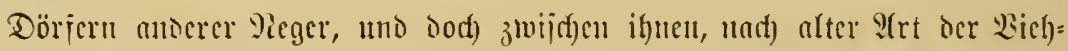

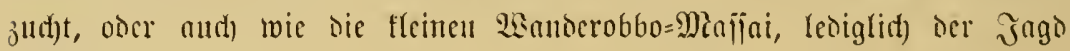
oblagen.

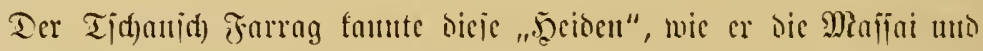

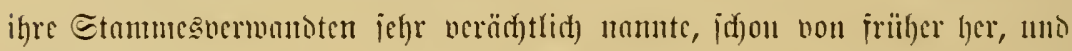

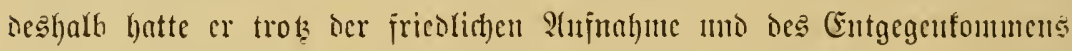

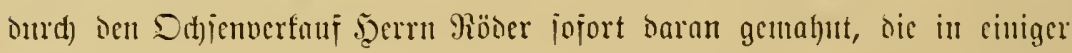

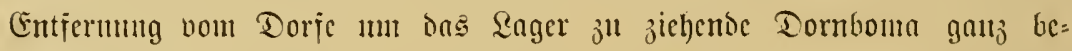

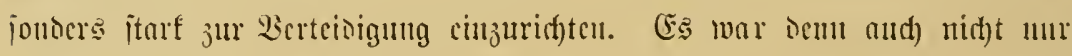

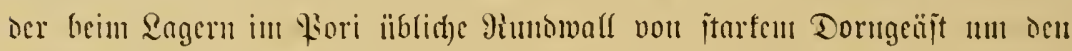

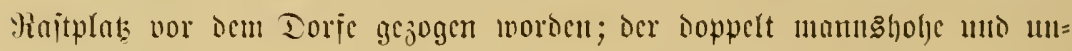

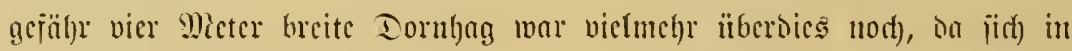

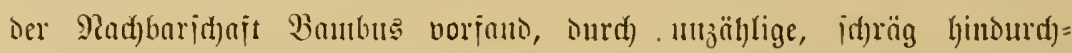

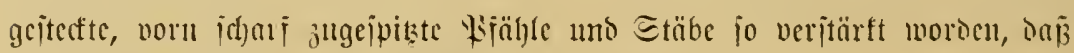
io reidgt feill feino cincu lltberifall magen fonute.

"Sise cin iggel, ber ieine Stadjeln nad) allen Eciten ipreizt, jieht uniere Boma heut ats", hatte thojdberg bei ocm lekzten gemeinjamen Rumbgange vor Eommenuntergaug ju :iöder gejagt, als er dicje bundert

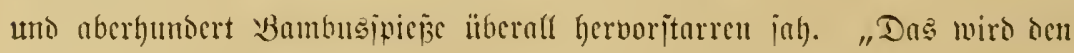

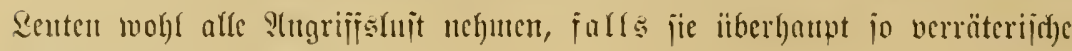
P(biid)ten haben iollen." 


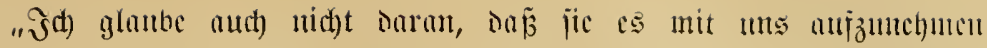

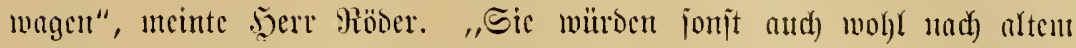

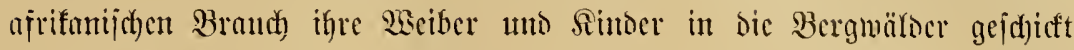

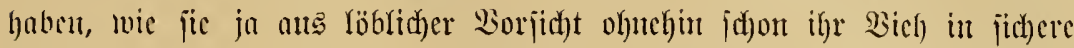

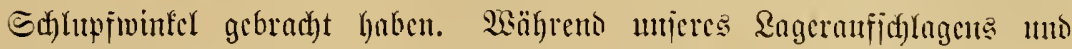

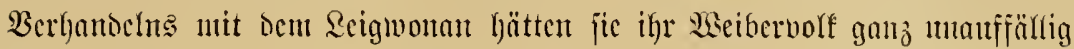
für uns entịtucn fömen. S(ber iehen Sie, on jtehen bic Dorfichöntyciten

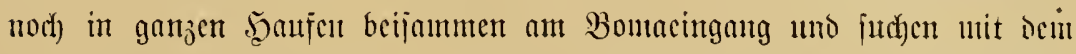

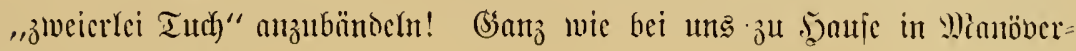
zeiten!" Iadute er.

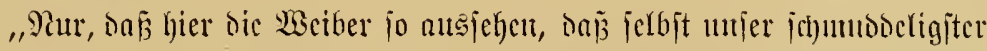

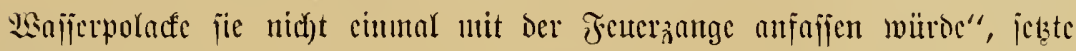

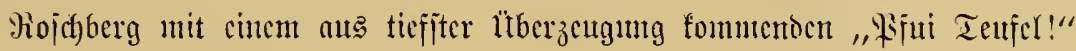

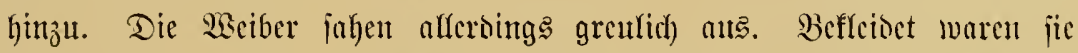

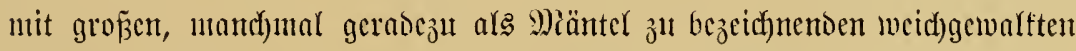

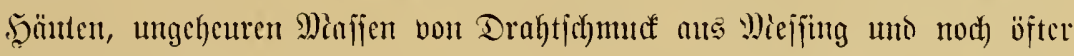

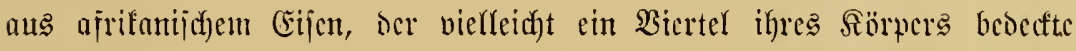

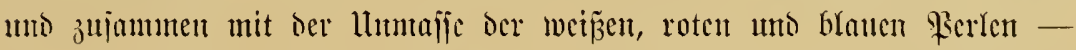

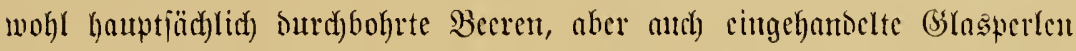
- ala cin nidht mmejentficher Teil ihrer Befleioung angcjehen werben

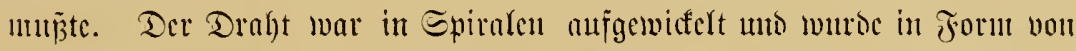

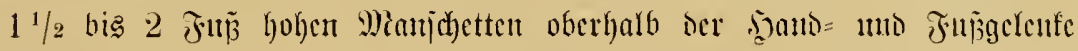

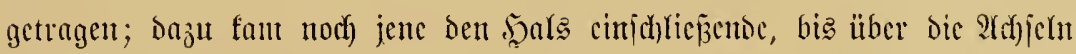

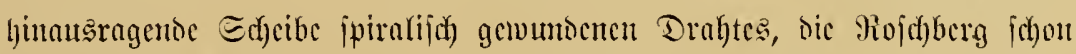

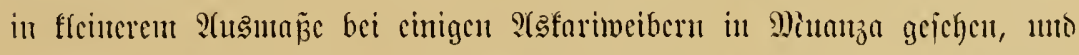

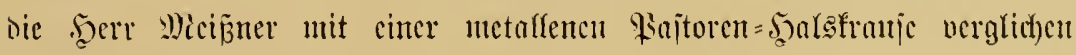

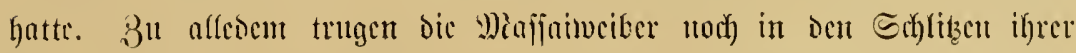

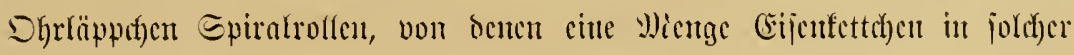

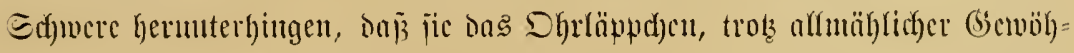

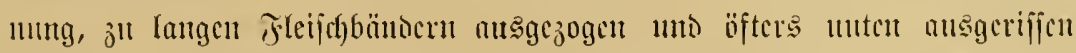

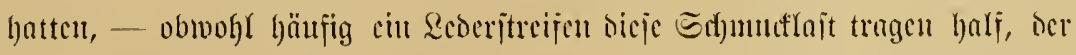

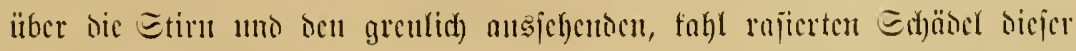

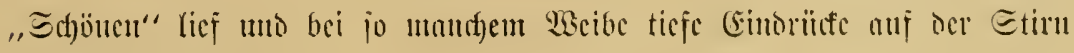
hervorgerufen hatte. 


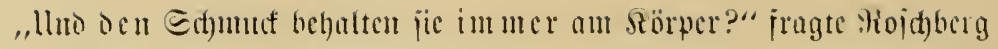

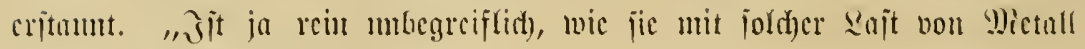
das Fero bejtellen füment!"

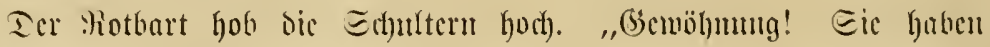

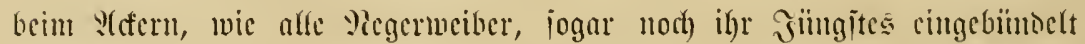

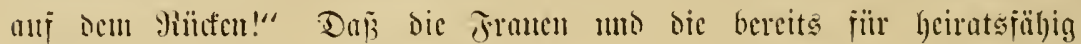

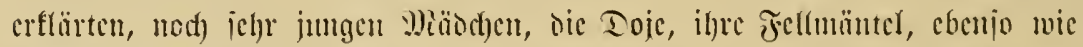
¿s : muth mit ben hejten Sengitofifen mad)en, mit ranjiger Butter cimjalbten mo

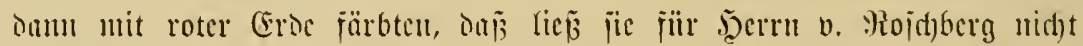

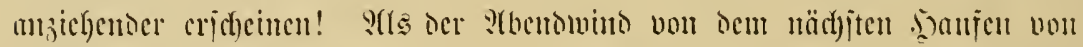

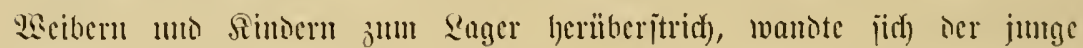
Emropäcr rajh ab. "Qketter nod) cinmal," ricf er ans, "eau de mille fleurs richt anters!"

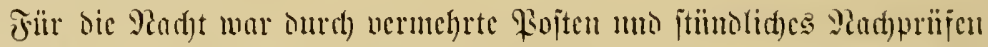

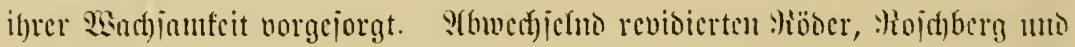

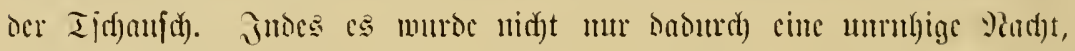

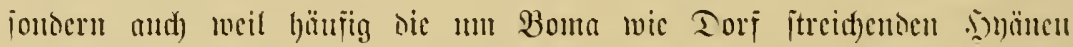

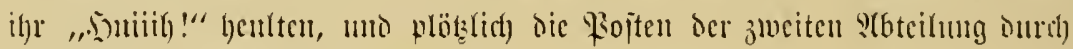
dic B̧oma nad) anjen (d) oijen!

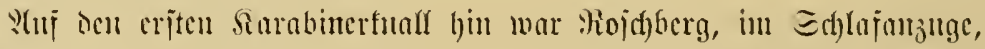

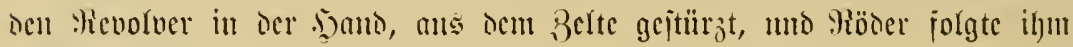
แni Dem F̂ñe.

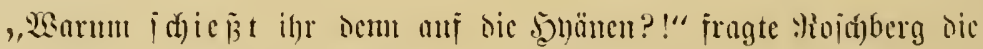

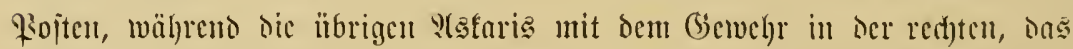

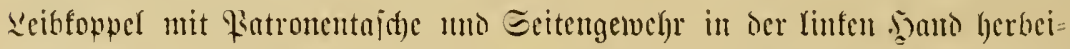
inrantgen, umo die crid)rocten แns ifren (Sras= obcr Blätterhütten hervor=

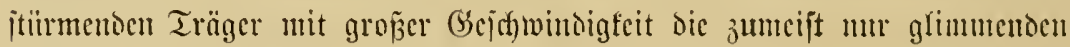

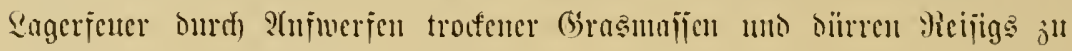
hiumelan idflagenoer sohe anjad)ten.

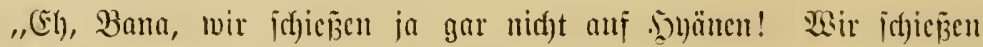

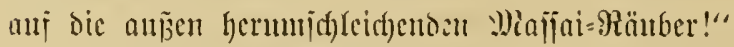

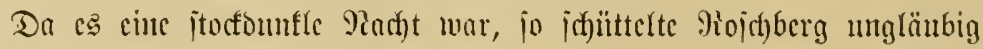

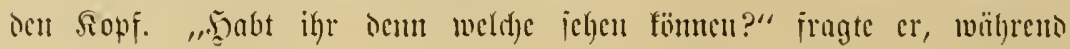




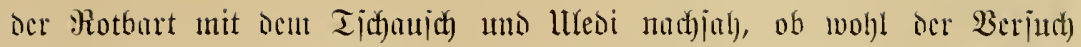
gemad)t lval, bic Dornbouta Yciie an eincr Etefle altscituntocr ju jerten

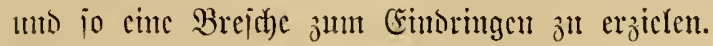

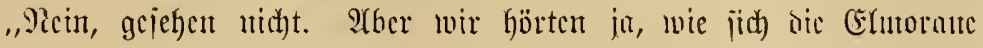

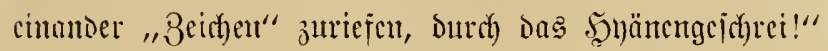

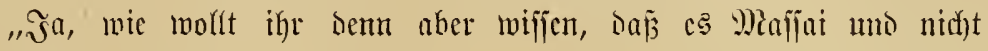

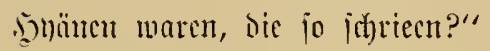

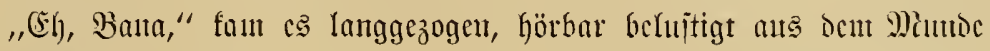

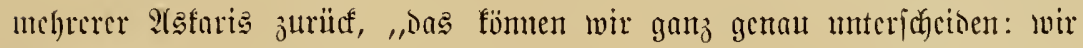
madjen bas ja in oct Padyt cbenjo!"

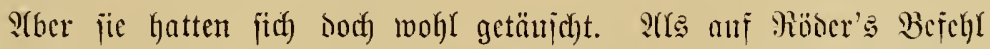

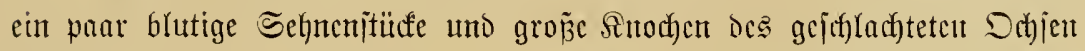

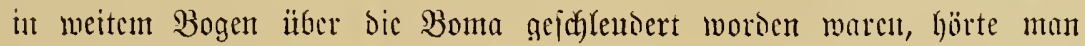

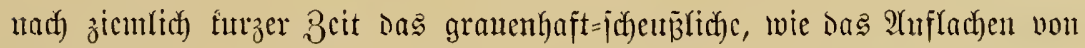

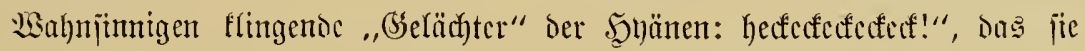
anjtatt ocs hallen .joultones ausjto

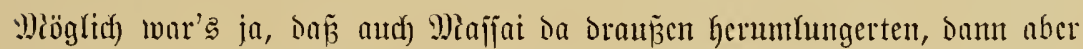

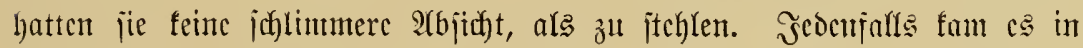

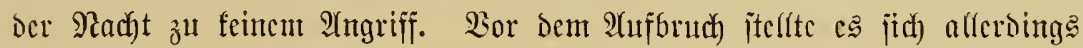

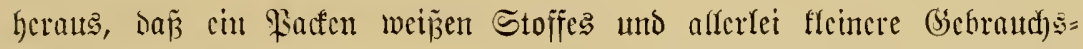
gegenitänoc geitoflen waren, - auj ganj unbegrciflidye \$seije, da ungemcit

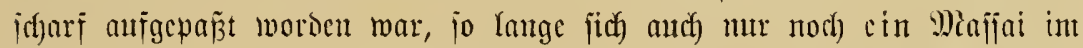

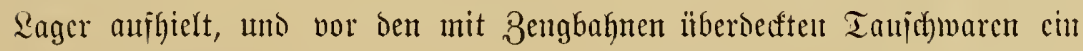

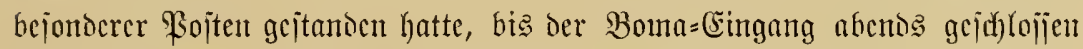

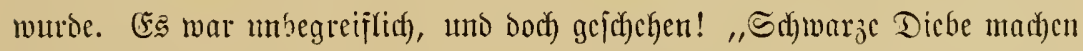

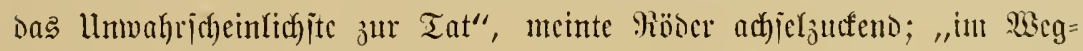

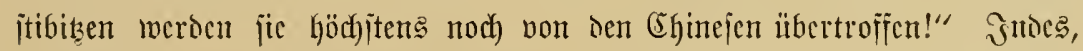
cr mollte wegen diejes Diebjtahls feine "llnterjudfung" beginnen; baju war

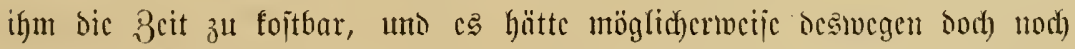

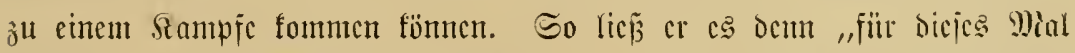

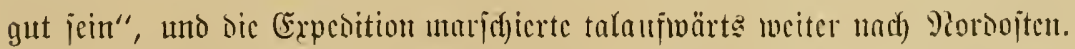

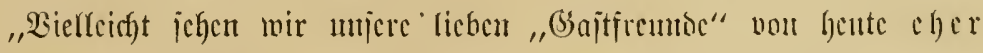

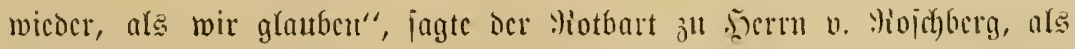

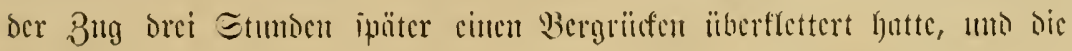




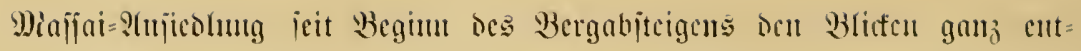

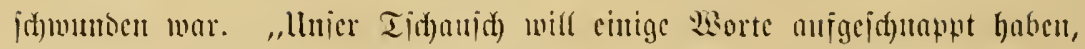

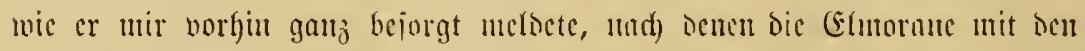

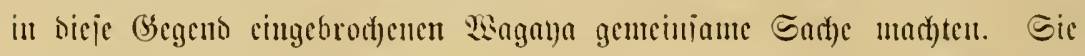
ljütten ja andf) jo viele neue blutrot gejürbte Seberitbeisen fïr ibre Edfuerter geutacht" - Mojed)berg hatte einige bavon geichen: ichr lange Edfuerter

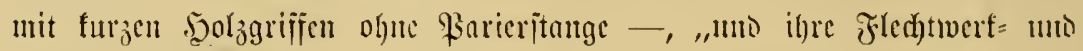

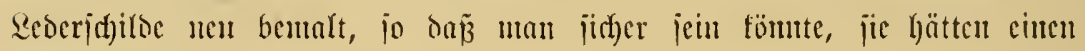
"尺ricgझjug" vor."

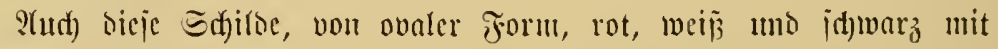

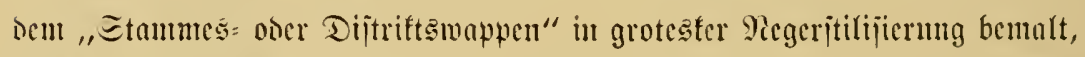

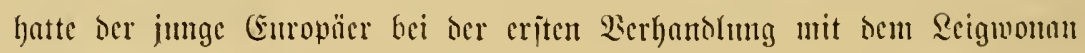

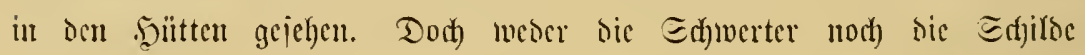
imponierten ihn, wie er jeßzt jagte. "llujere Sutgelt werden im Erriftjalle

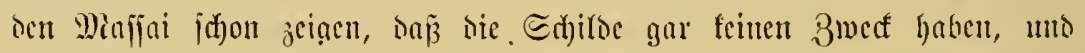

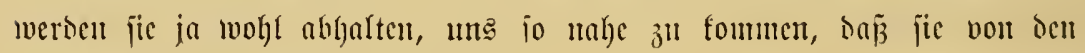
E(j)wertern (sicbraud) machen fömen."

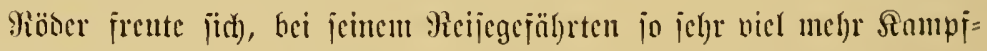
Eifer ju fintocu, nla er bei biejem, "Dod) blof ju ciner Ferienjago herïber= gefounuenen jungen sesern" vorausgejetżt hatte; er wollte bieje Frentoigfeit and) ni(f)t bäupfen, fonnte jifh jebod) nicht enthalten ju crwioern: "Das

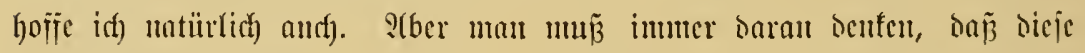

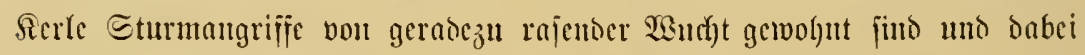

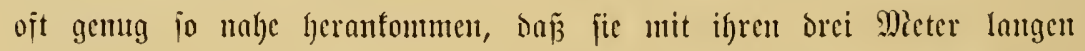

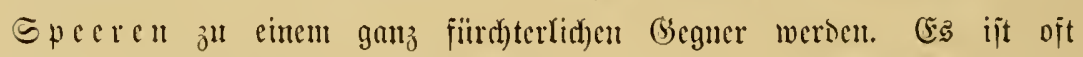

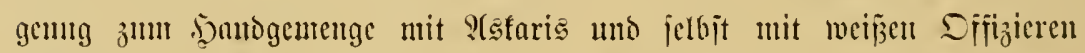

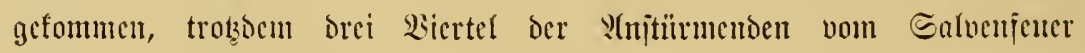

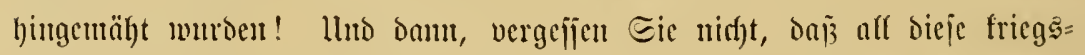

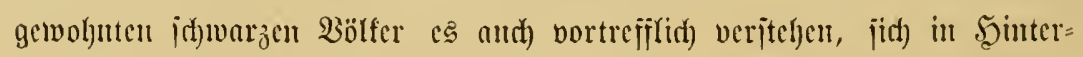
halte jul legen, uno urplözzlich) ïber eine nod) gar nidht faurpfbereite Truppe

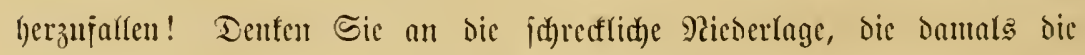
Wabehe, oder Mafiti, ocr groß̈en Expedition Zelemsfi beigebrad)t loben,

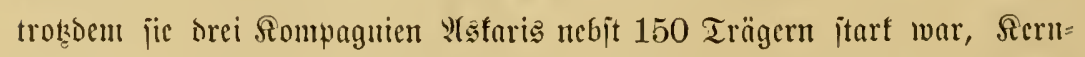
trmppen, wic wir jic nie bejfer gehaht haben, umb troz ber anf Eiefn 


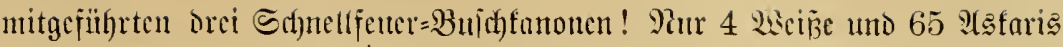

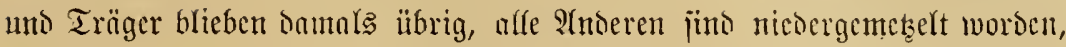
Sanonen, (Secwehre unt fo jemlich bie ganje Mantion gingen verloren,

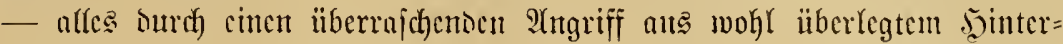
halte fyerbor!"

(F)

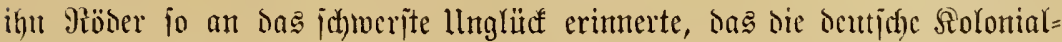
madft je getroffen; und wejentlich bejorgter ale juvor mujterte cr währeno

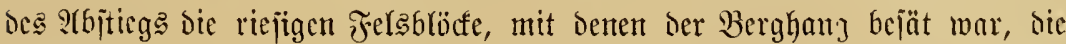

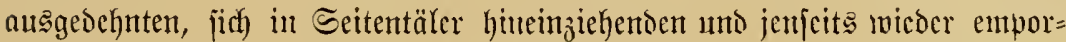
fletternoen Bufappartien, uno bie tiejen Sdyluchten, unter icren gigantijchen

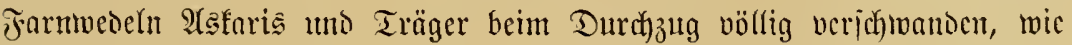

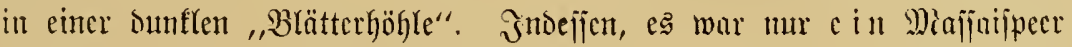

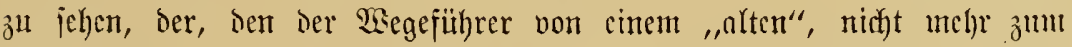
Sriegsbienite Berpflichteten geitern cingehanoclt hatte. Sas ïber hand= breite, fajt einen Meter lange zmeifhncisige Speerblatt oben an dem jwei

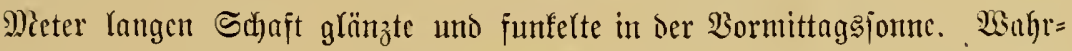
hajtig, wer joldh einen Speer zu hanthaben muftetc, war fein jul verachtenter Bsegner!

Die Splize oes Buges war nod) nidht ganz um Fuß̌e bes Berg= rücfens angefommen, als man im Tale Ronungen und neu nugclegte

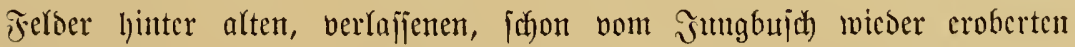
Idferitreffen mahrnahm. S(ber es waren mur ein paar vercinzelte, flühtig

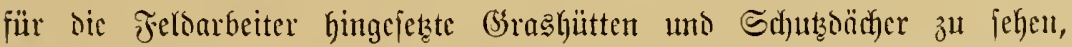

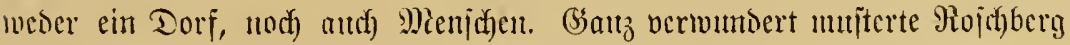
mit jeincut Jagiglaje das Tol. Da wię Rüber auj den Berghutg ienjeits des viellcicht mur zmei Stunten breiten Tala - die Bergä̈gc itraflten jömtlich) von Dem fornen D̃anptgcbirge wic Mippest, fajt paralfel,

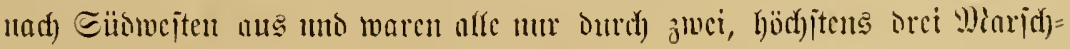

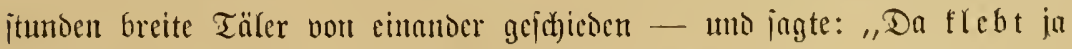
cin Dorf! llno dort hinten jeke idh nod) Jmei!"

(Erit nad) geraumer Wscile gelung (s) Sherrn b. Whojd)berg, mit jeincm

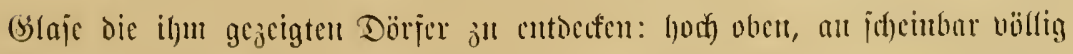

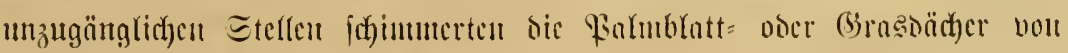




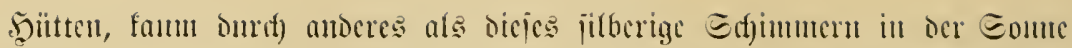

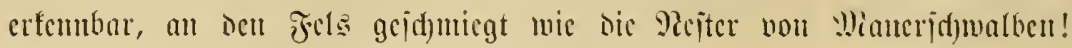

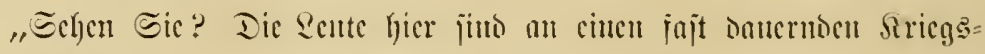
juitant gemöfnt, unto haben gefernt, menigitens jidf) periönlidf) nor ocn

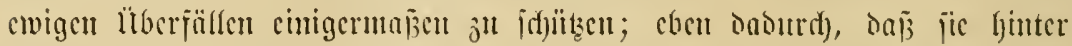

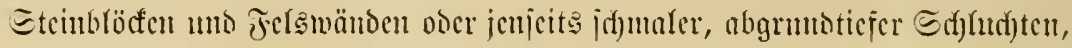
igre "Burgen" bauen. P(m Tage liegt Dann cin Baumitamm oocr viefleid)t

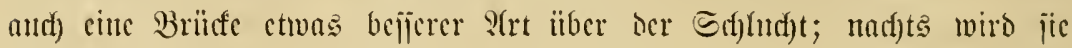
weggenommen, unt natürlict) and) bunn, wenn ber Feind in Sidft ijt.

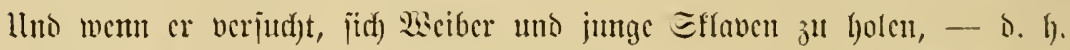

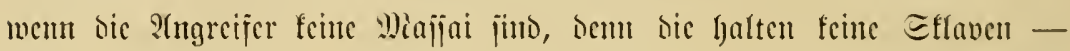

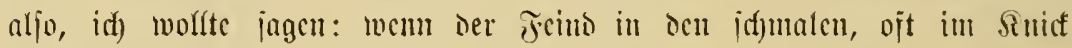

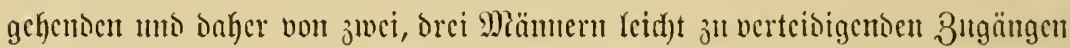
hinnui will, ober ctwa gar ohue wecg ben Berghang anfwörte flettert,

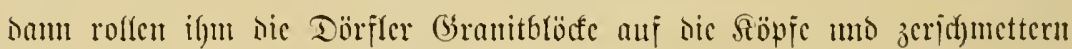

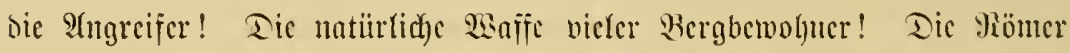

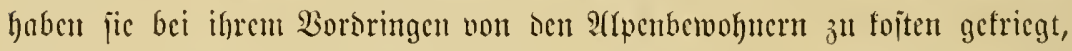

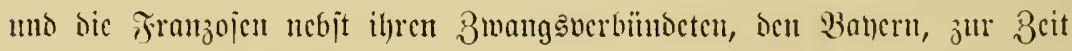

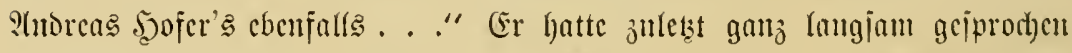

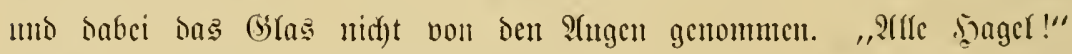

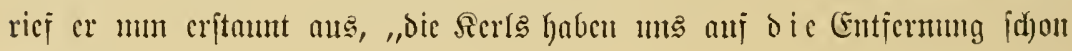
cuntocft!!"

"Wiejo?"

"Schen Sic mur genan hin, ba hinter icr cincu Felsmancr hervor, Da orïben ganz linfs, dic jo jäh in dic Ticje geht, . . f tömten Sic's

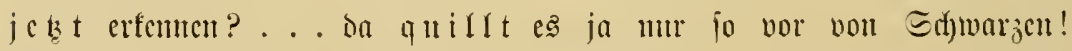

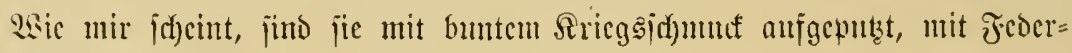
biijden . . . !"

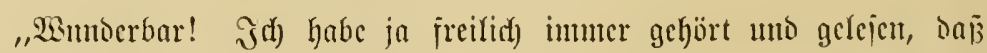

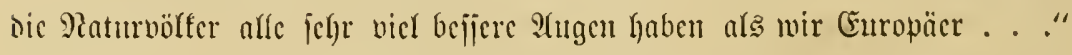

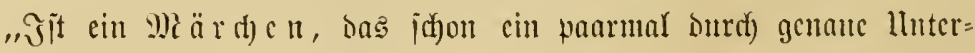

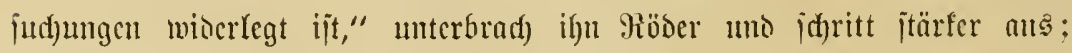

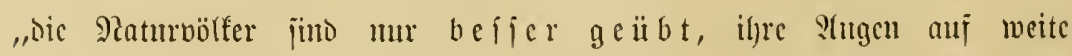
(Entfermutacu ju gcbraud) $\mathbb{c} \|$; $\delta$ a 
unt jo geübte Stugen, uns von ocm bergnejte aus ju erfennen, hat aber

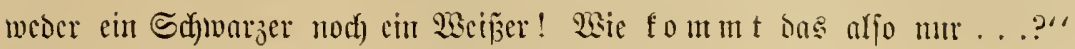
Sopfichüttelno murmelte er bas vor jich bin.

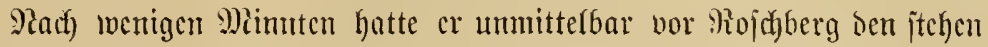

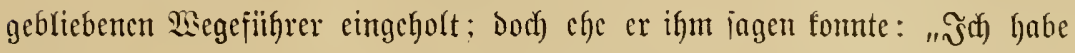

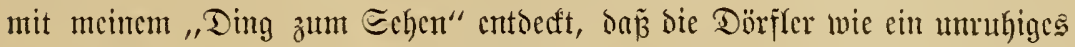

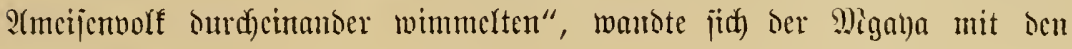
জiorten an ifn:

,Bana, dort brïben ivarten Freunte ber Deutichen aui uns, นun

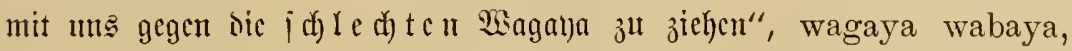

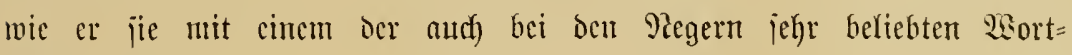
wikge nannte.

,?th, Du fennit dic Reute da?"

"Эa, idh habe da cinen ndugu ..."

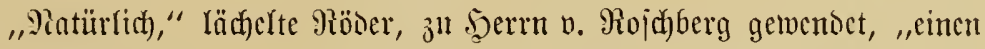

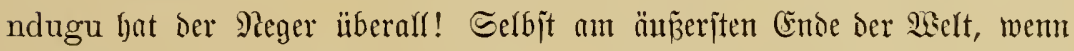
ba nidyt ein feindlidfer Stamm mohnt! - Atber hajt Du bie Leute brïben ¡ehen fönnen? Ilno wie haben fic ung als Frcumbe erfennen tömnen?" „Эh, Bana, idh jah, wic bort unten wabuyuni (bei dem mbuyu,

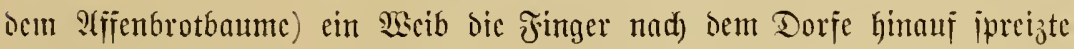
tmo Dann hier herüber jeigte!"

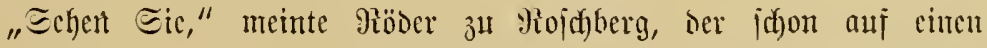

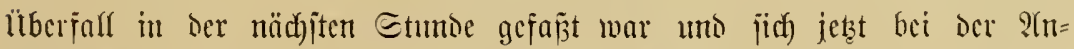
fïnsigung von Freunden troks alfen Sampfeiferes cinigermajen erleichtert

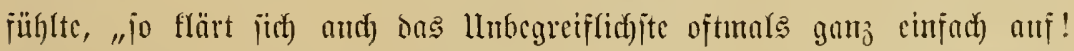

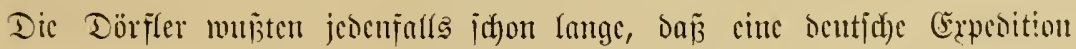

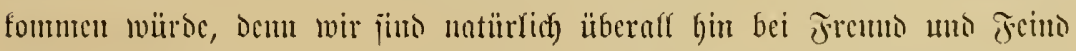

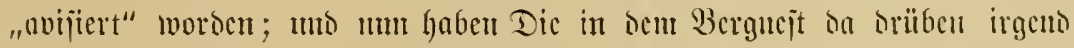

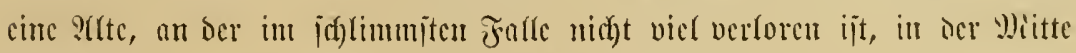

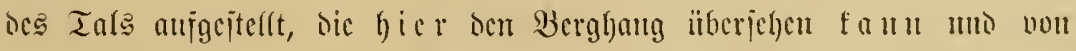
Drïbcu geichen wirs. Dic bat aljo "Jremmo" jignalipiert! - Jd) faun jie übrigens audf jekzt nod) unter oen Bonbabs nidgt jefhen!"

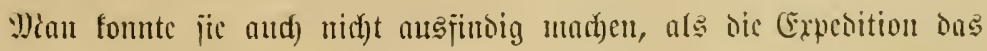

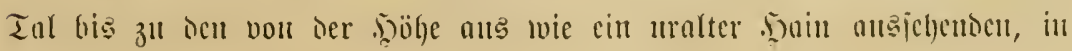




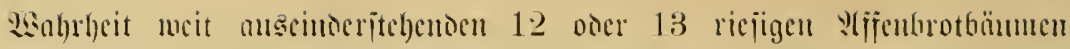
gefommen war; jie hatte es jescujalls jür gejdecter gef)alten, jïh vor den Fremoen in Sidherheit ju bringen. S(ber in ciner Der gewaltigen 5)öhlumgen,

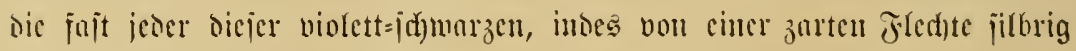
überzogenen Boabahs anjwics, gloum nod) ons Fencr, über bem jït) dic

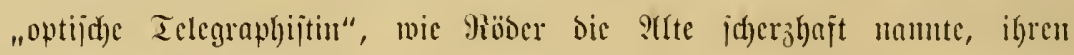
llgalli geforkt hatte. Den Topi allerbings hatte jie vorjict)tigermeije mit=

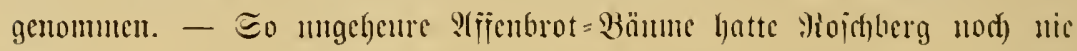
gejehen; er itunte jie an wie man Bormettricien anjtanuen wiirte; ihr

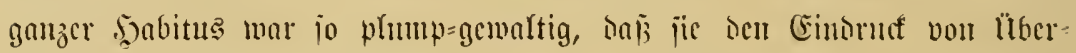

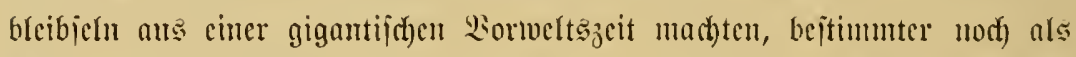
Elejant uno Fluzpjers in oer Tierwelt; mo mährent bic Ezpesition cinc Fimmifa madte, jugleid bie fajt jescr Siarawane, oftmals itmonemueit,

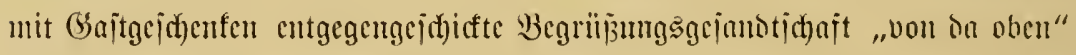

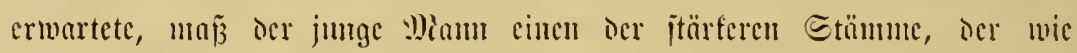

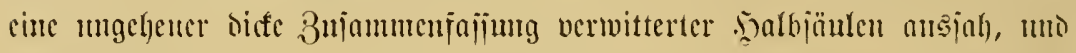

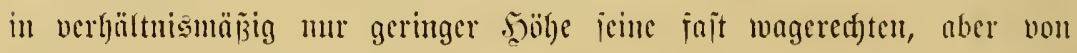

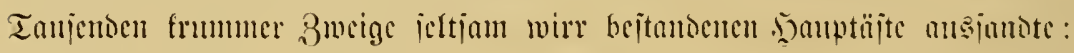

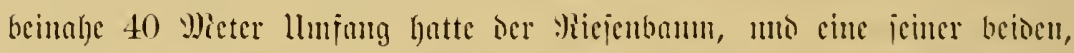

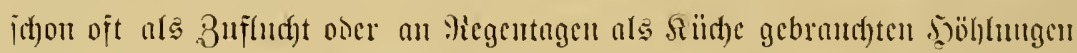

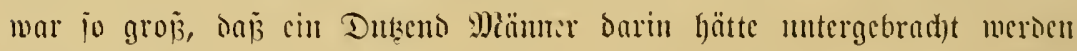
tömen. Der Baum itano trokz sicjer inneren Bermorjd)ung in volliter Sebensfraft; juar hatte er menig Blattj(t)mutef, da bic s(fifenbrotbämuc

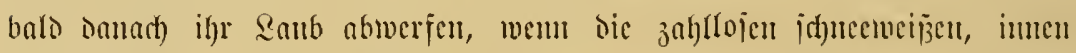
etmas rötlidben, an unjere Miatwen erimuernoen, aber 15 Bentimeter groß̈en Bliten ifn ïberzogen haben; er trug aber cine Wienge grangrïner, mit

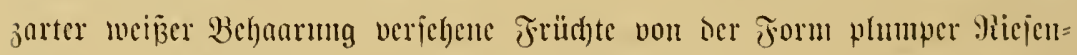

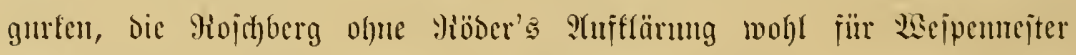

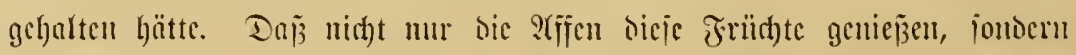

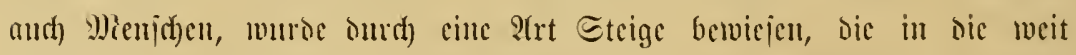

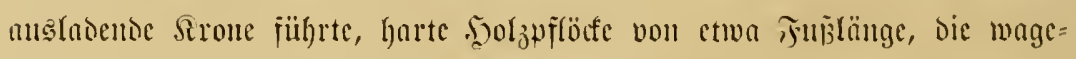

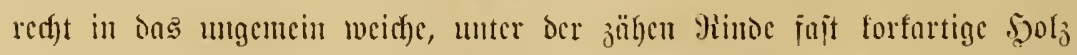

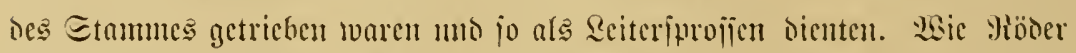

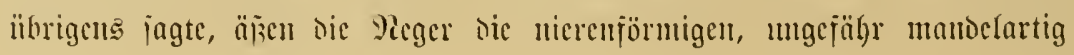




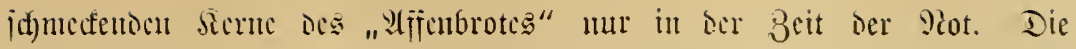
etwa 20 Sierne in dem jadyartig getcilten, mit cinem idfwammigen frud

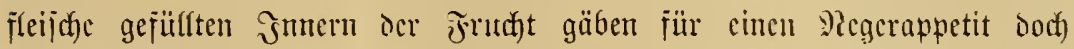

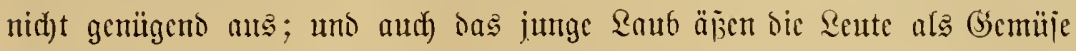
mur hunn, wenu jï nichts Befijeres hätten.

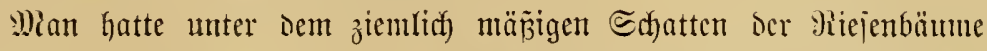
bereits cine falbe Stumbe nad) ocm Eintrefien ocr letzten Seute gerajtet - bie Expesition mar jeit dem Ahjtiege jo eng anfgejalojjen wie mur

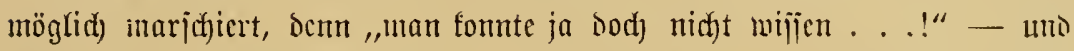

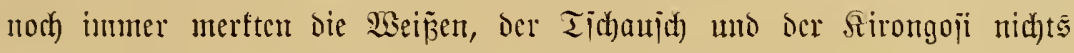

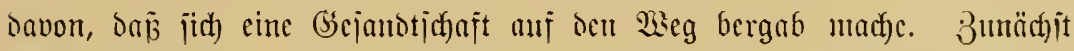

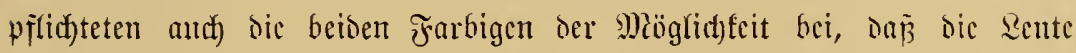

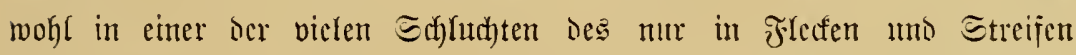

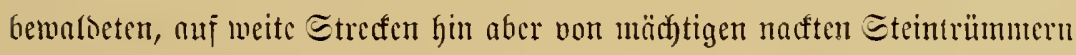
itarrenten Bergrüufens zu Ial jögen, uno man jie beshalb nidyt jefyen

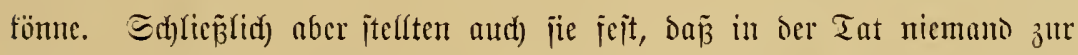

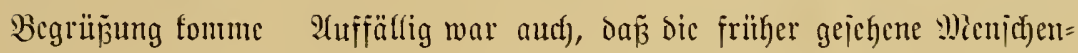

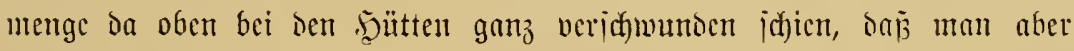
mit beur Ǵlaje hier uno da hinter flippen uno zmijhen fnorrigen Bäumen einen von iqfwanfenten Febern befrönten ounflen Sopi über cincul hraumen Dherförper hervorlugen jah.

"Sie beobadten ums", jagte ßöber. "Entweder jint jie jid) nod).

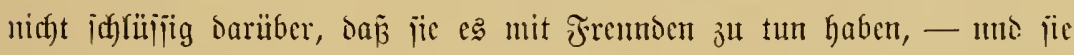

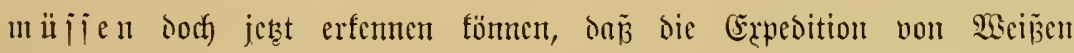
gejührt wirb! - ober aber, Dic ba oben jino trok des Plougus unjeres

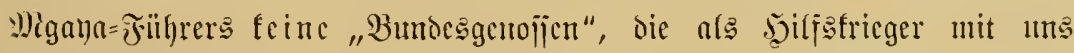

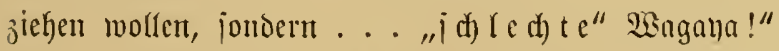

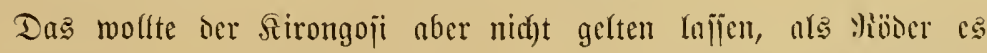
ifm vorfielt. Sein Pougn habe jo ielfer inn vorigeu Sabre mit dem Bana mfubıva vour Edjirati gegen bic Mrajjai gefümpjt!

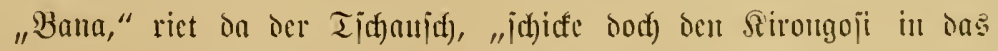
Dori Ginouf. Dann werien wir bald mijjen, woran wir jinto!"

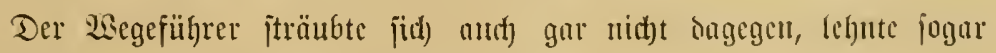

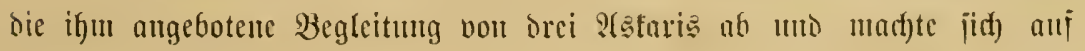




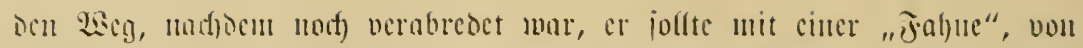
Stofï ober 3iegenifll, bermenteminfen, wem bic Secute sa oben in der

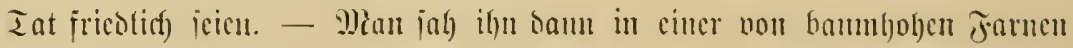

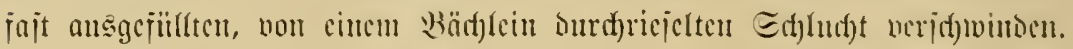

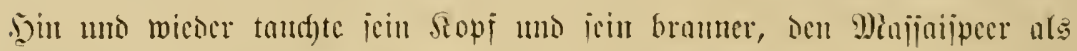

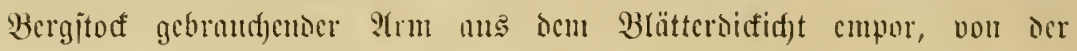

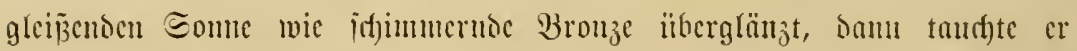

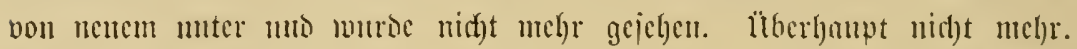

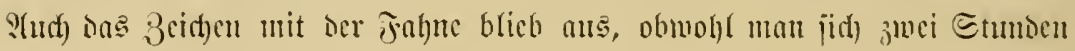
lang bie Sugen santud) ansjab!

Tic Tstaris mie die Träger waren idfon jeit längerer Bcit habon

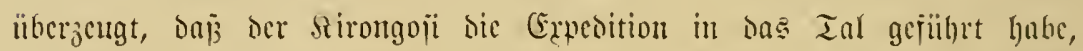

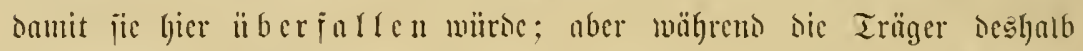

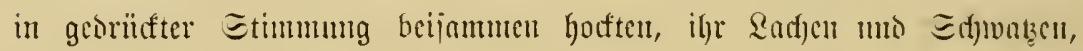

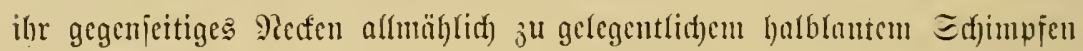
ïbcr dic washenzi wabaya (bie ichlect)ten Docisen) mursc, ermarteten

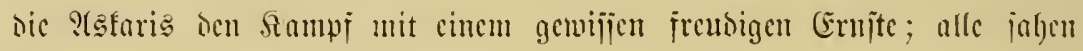

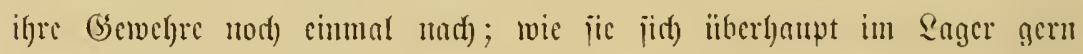

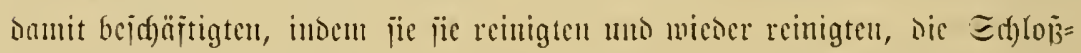

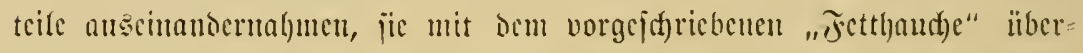

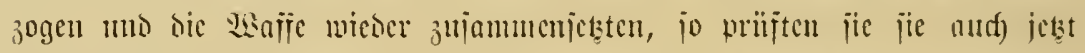
micoer, fnöpiten sic neuen, ctwas idjmer gehenten fiatronentajd)en nuj mo

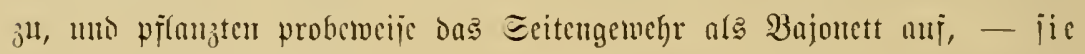

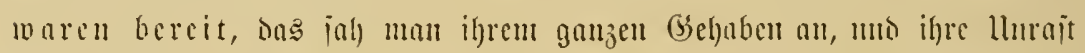

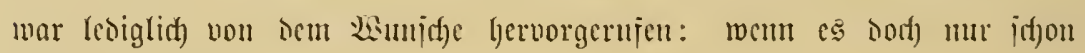
losgehen mödyte!

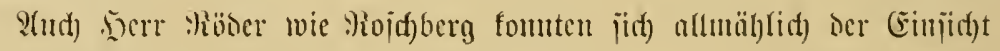

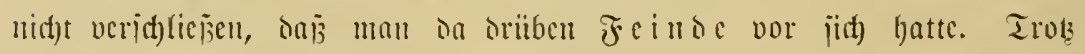

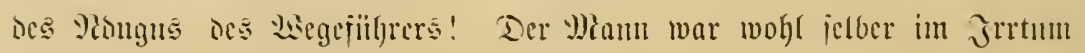
gemeich, war on oben jecusticf) empjangen, ermorset morten, oser bejten

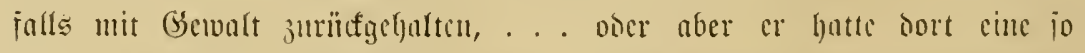

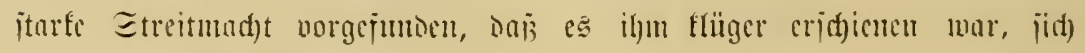

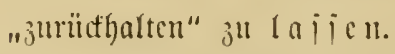

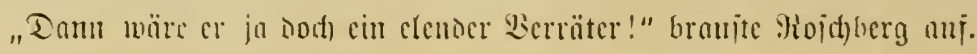




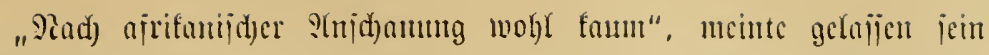

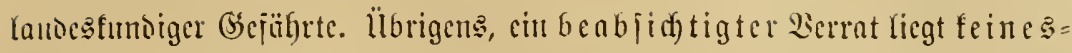

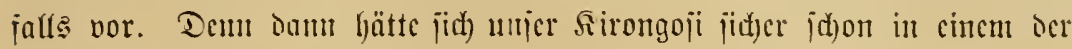

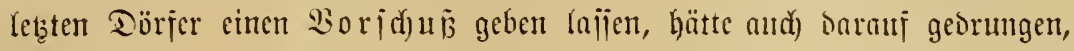

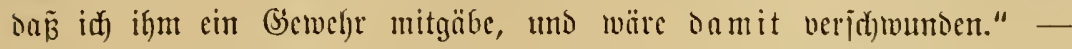

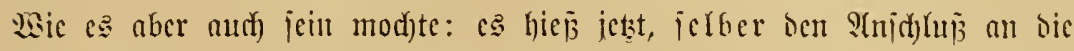

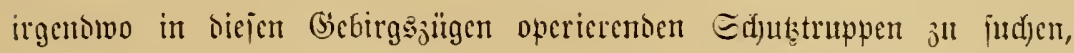

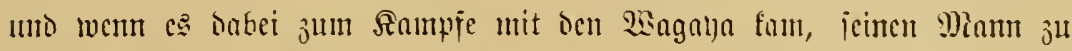

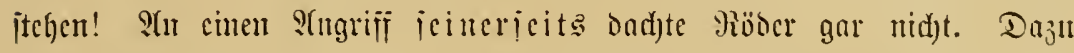

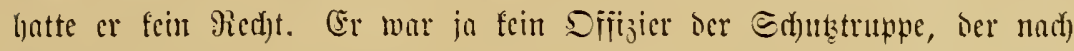
bejtem Ermelien jut entid)eioen hatte, ob cin feintblides Borgehen gegen die Eingeborenen angebrad)t mar oner nidj)t.

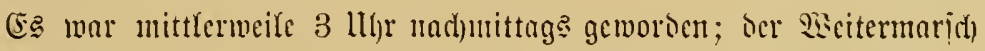

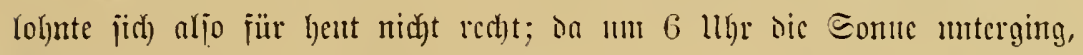

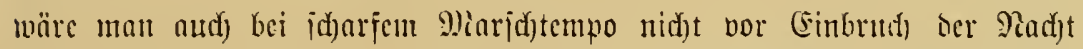

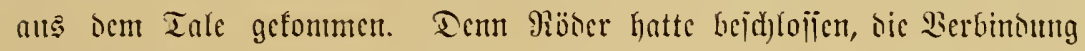

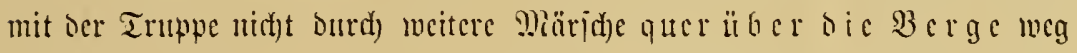

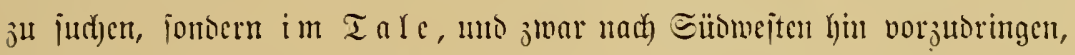

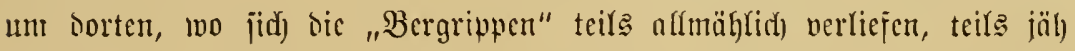
abbrad)en, juntädjt cinmal wicter in bejiedeltere (Segenten ju fommen. Er

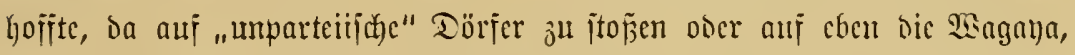
bie bon ifren "englijdycn" Stammešverwantoten beträngt waren anto bie

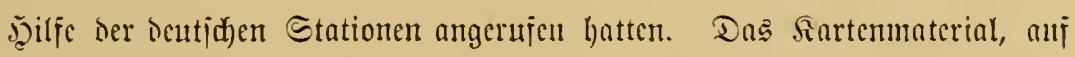
Das hin er biejes Borgclyen plante, war ireilid) adyt bie jelyn Эafre alt; bejicre Unterlagen ale dieje auj $\mathfrak{E}$ egenujmahmen von Sirizicren uno

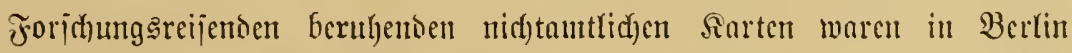

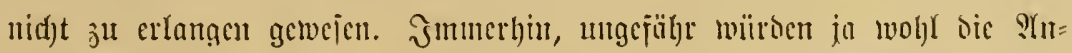

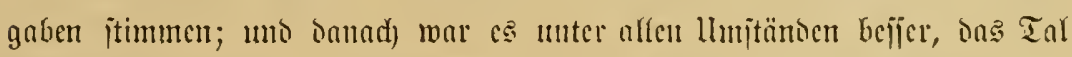

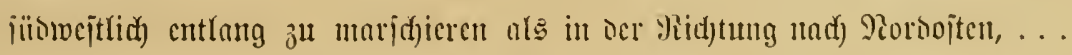

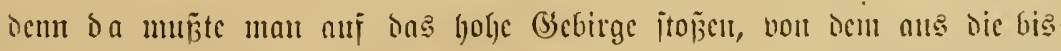

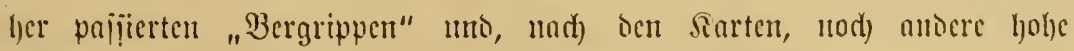
Siïfen hinter ocm Bergälige Dort orïben nutsjtrah)(ter.

"Es wiro hent nid)t meiter marj(f)iert!" tcilte ocr Ti(t)anj(t) Den

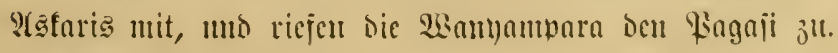




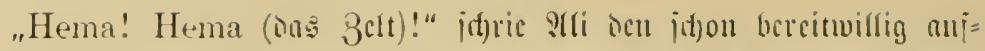

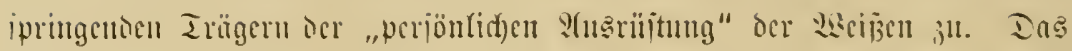

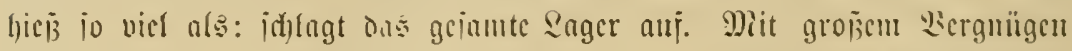

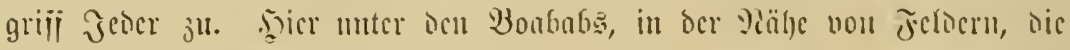

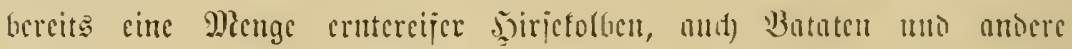

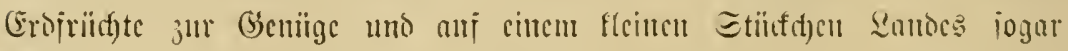

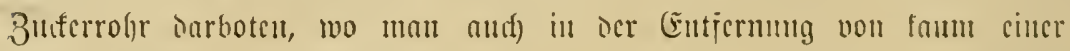

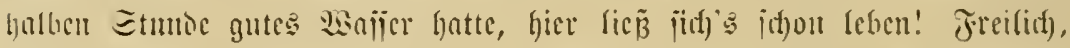

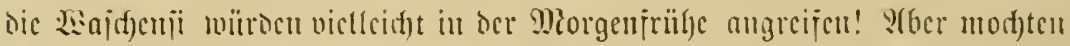

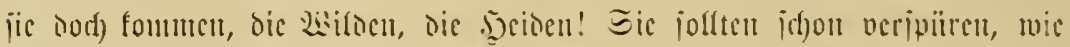

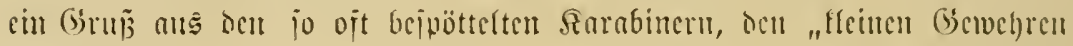
iür Sinder" tat!

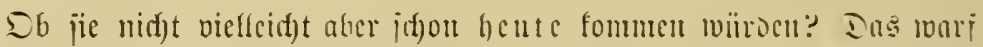

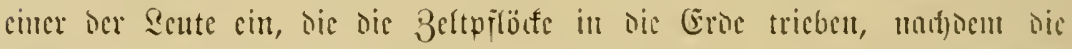

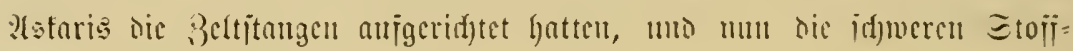
saf)nen darüber breiteten.

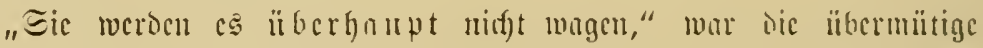
S(ntwort ies Dmbaja) luedi; "jonjt bätten jie ja idjon herunterfommen

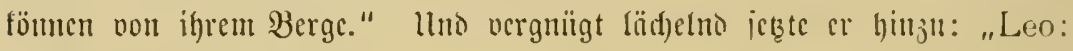
leo (hout [iit] hout,!"

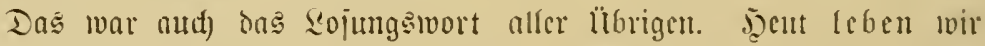

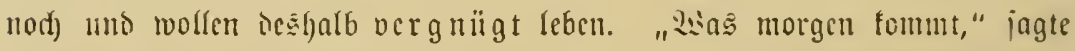

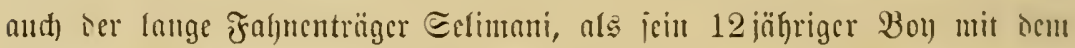

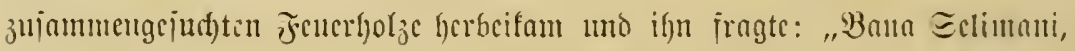

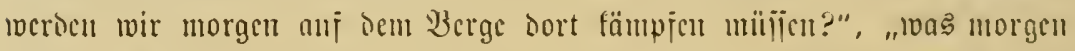

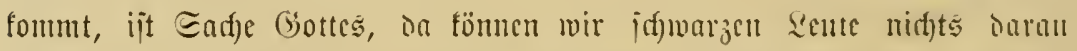

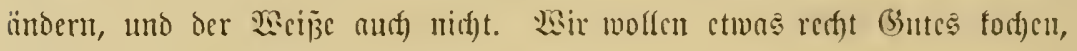
Mieri, mo redft vicl; leo: leo!"

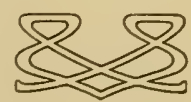




\section{Dreizehntes Kapitel.}

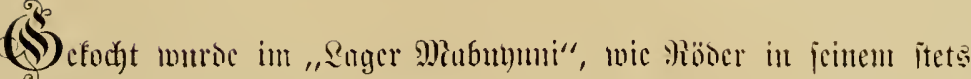

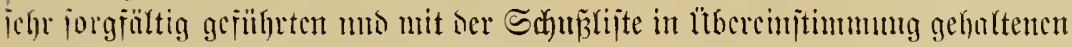

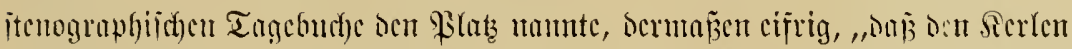

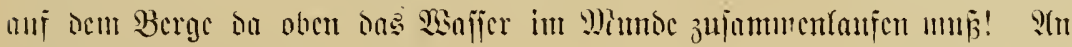

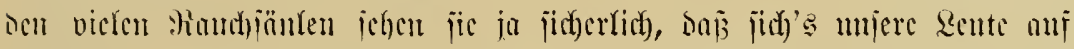

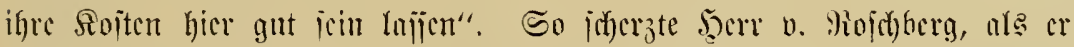

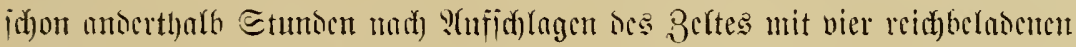

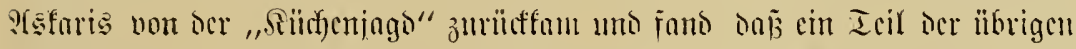

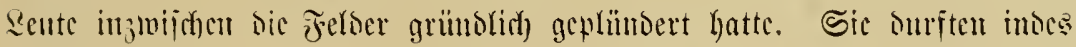

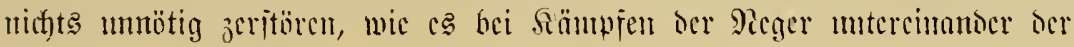

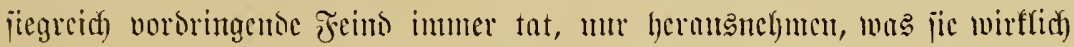

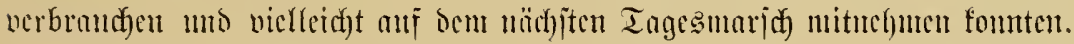

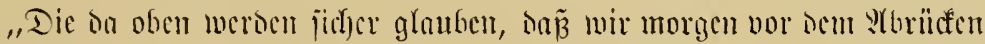

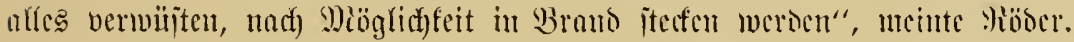

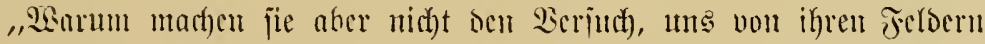

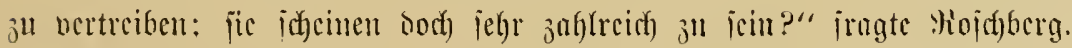

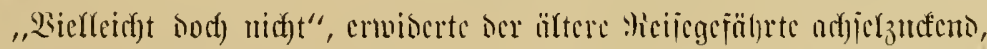

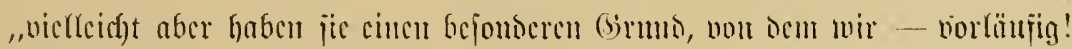

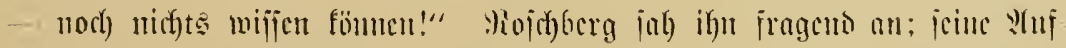

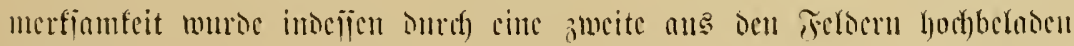

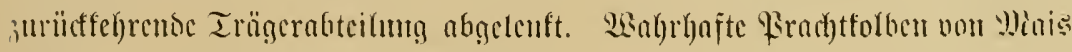

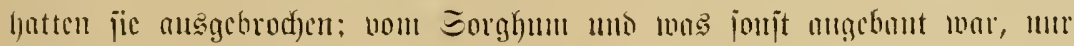

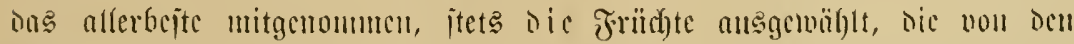

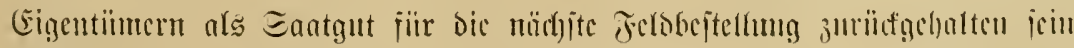

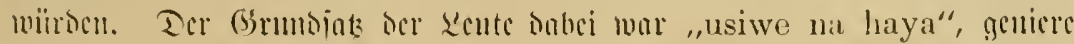




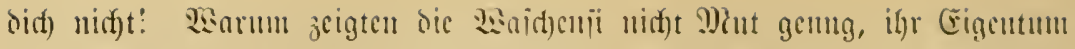

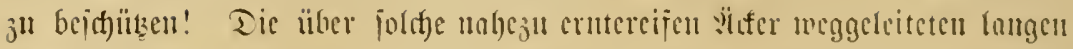

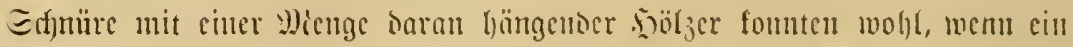

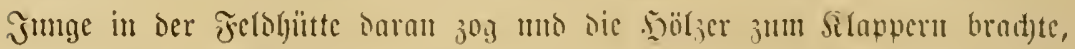

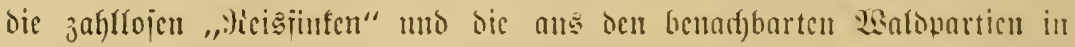

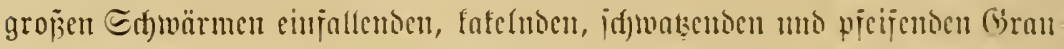

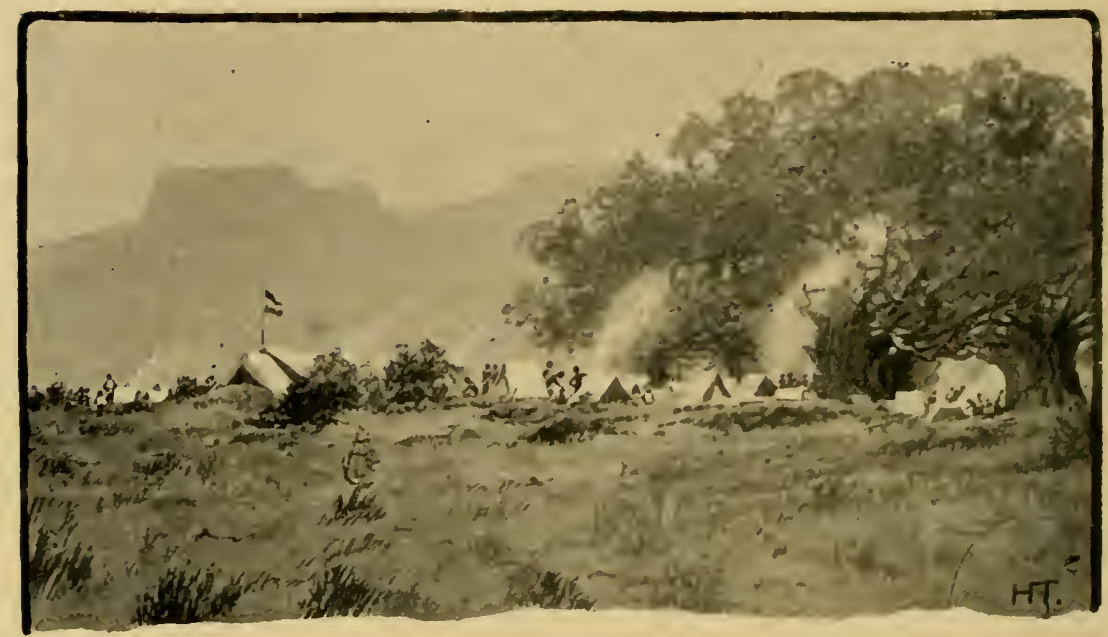

papageien abhalten, aber nicht eimmal bic vielen jogenamten, "grïnen" Dicer=

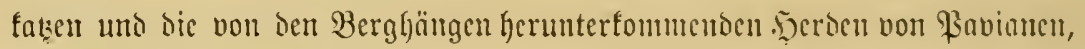

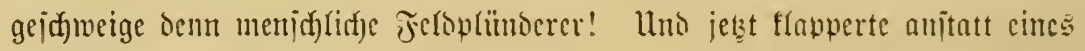

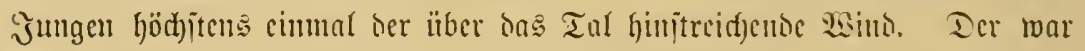

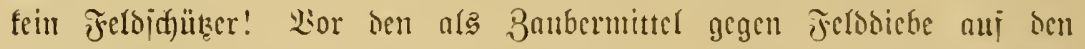
3ugangstwegen eingegrabenen Topijid)erben mo jonjtigen Dauns iffenten

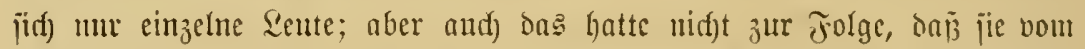

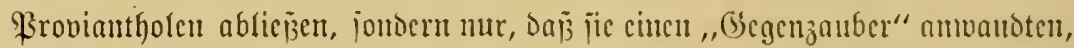
indem jie anf alle als verzanbert erfembaren Etcllen juei finger voll Michl itreuten! - Fïr Flecijd) war nad) bem furzen Jagojuge liojd)berg's mo

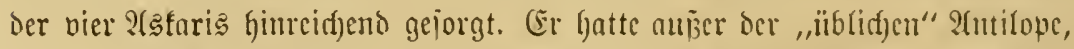

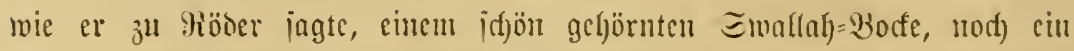

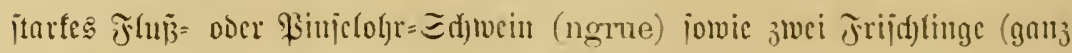

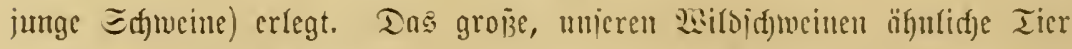
hatte cinc rötlicf)e Esf)warte mit itarten granen Borïten ohne lluterbaar; 


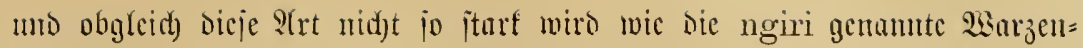

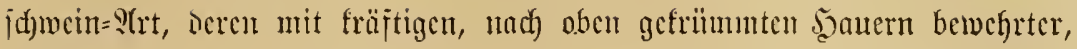

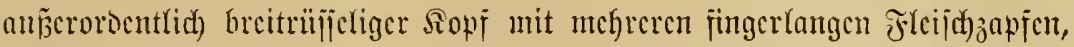

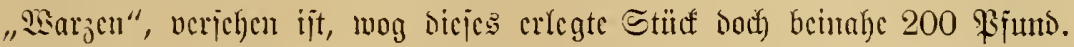

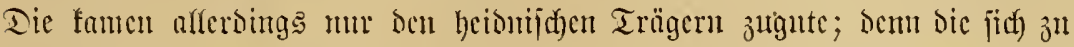

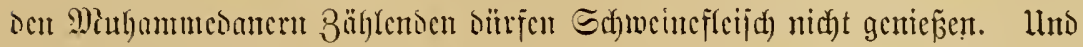

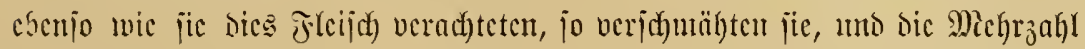

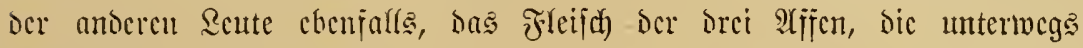

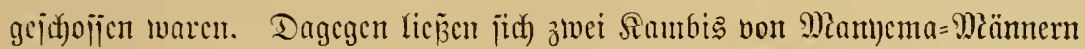

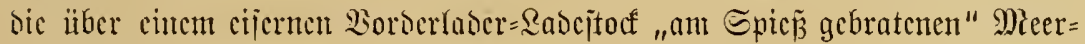

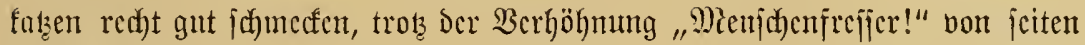

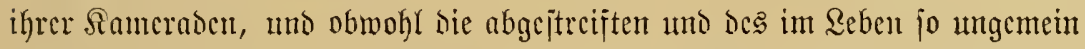
gewantot gebrauthten Iangen Sdywanzes entledigten Iffen in ber Tat abjdredfeno

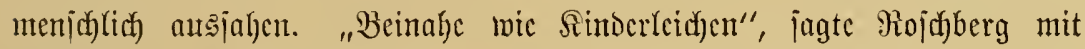

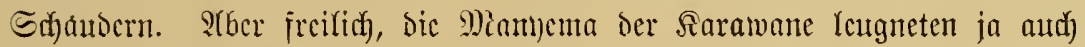
gar nicf)t, früf)er Mienj(c)en verzefyrt zu haben! Şatte bod) ciner biejer

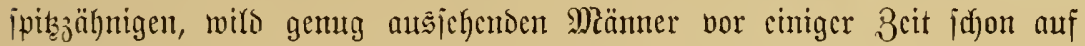

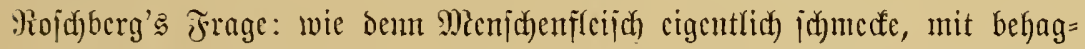
lichem Grinjen geantwortet: "tamu". Das bedcutete je Itady limjtänden

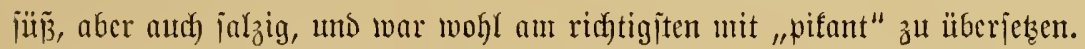

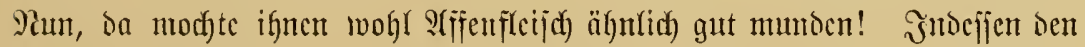

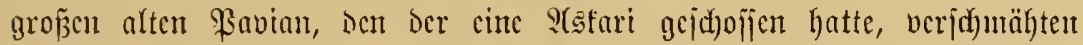

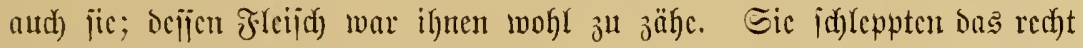

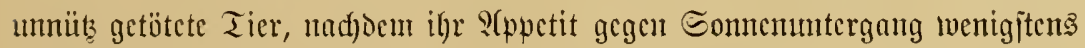

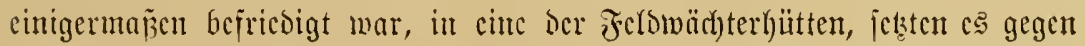

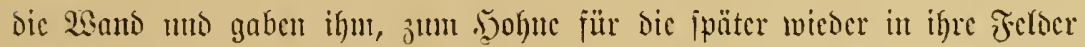

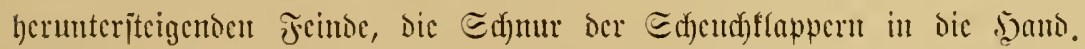

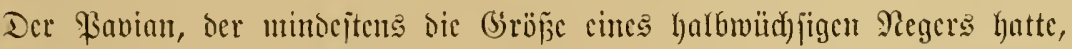

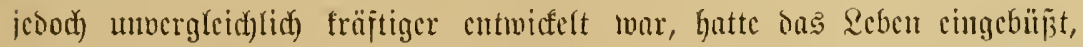

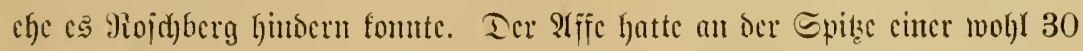

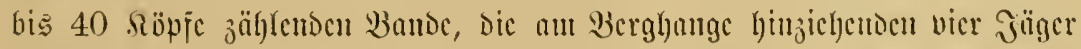

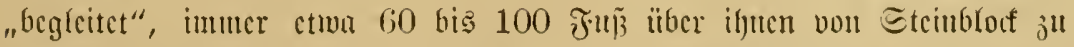

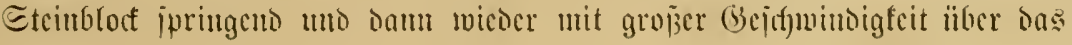




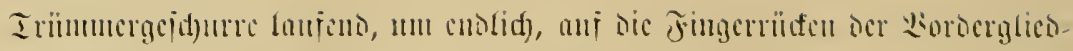

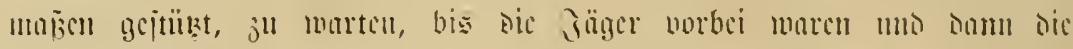

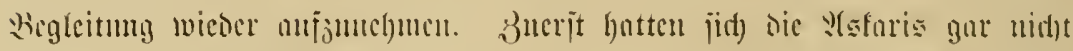

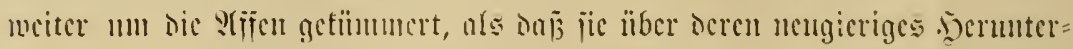

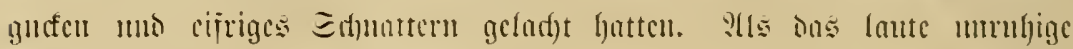

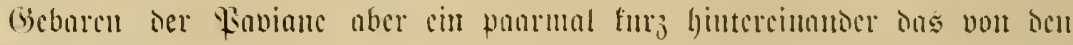

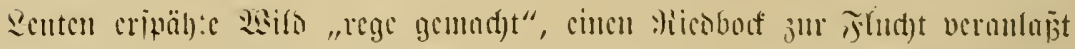

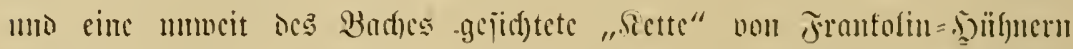

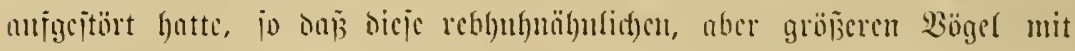

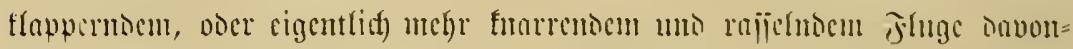

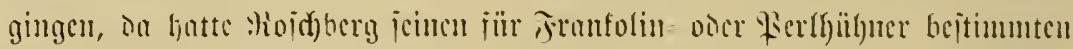

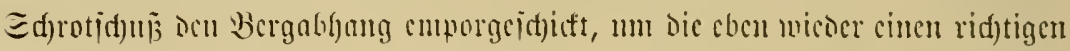

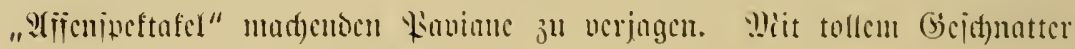

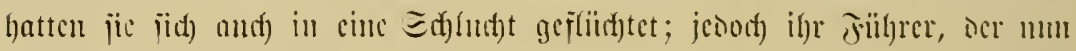

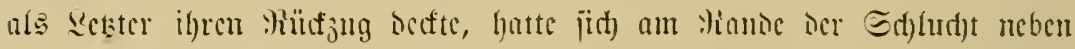

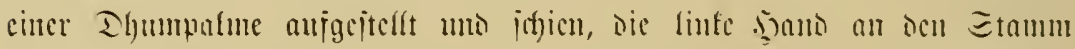

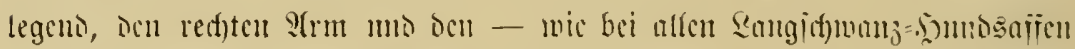

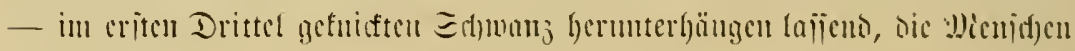

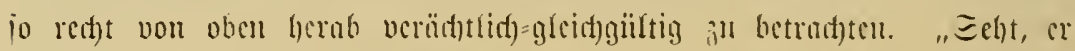

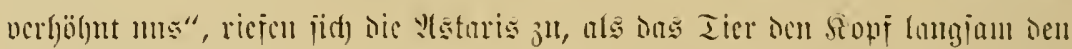
muten Borbcijichenton jumanote, ohne ieine Etellumy am Bumuc ionjt ju

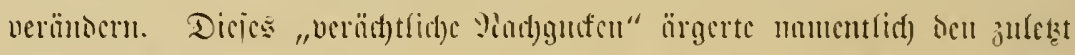

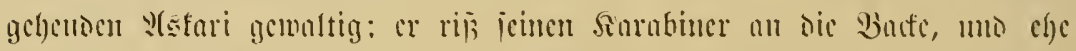

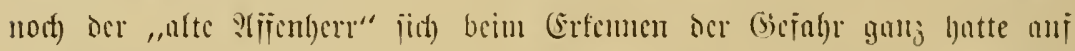

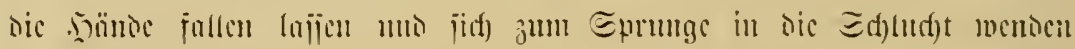

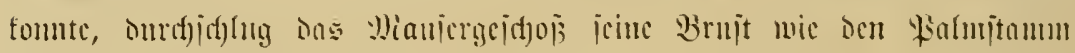

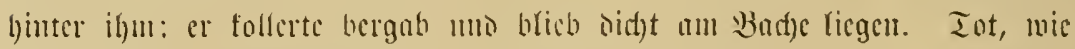

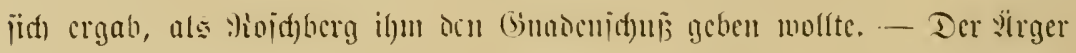

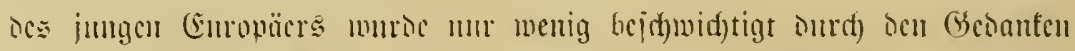

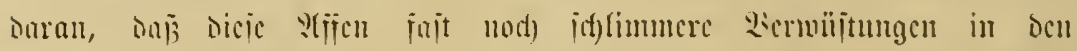

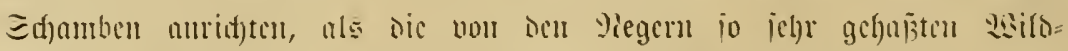

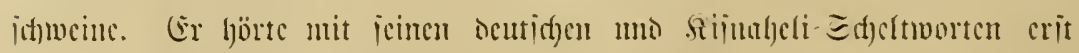

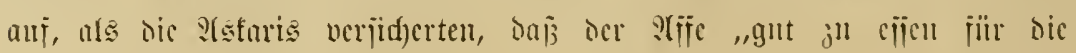

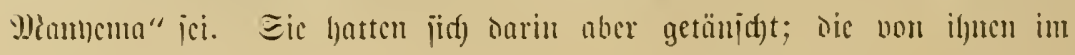




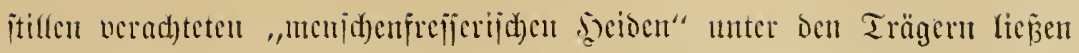

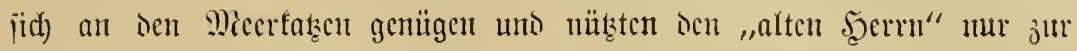

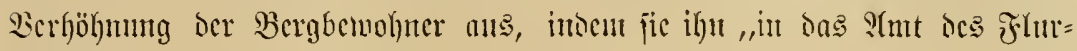
wäd)ter's cinjesten".

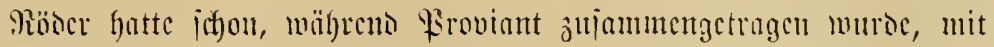

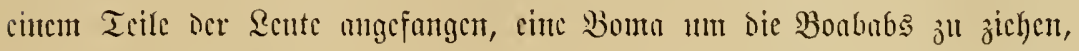

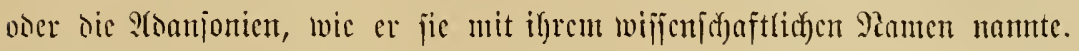

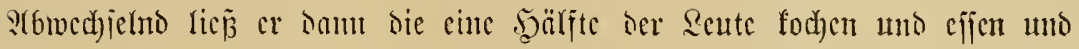
Dic andere an ber Bonta arbeiten. Es mar bas cin jomeres Stǘf Srbeit, meil bic Bäune meit auscinamieritanton, bie llmwallung aljo ausgebchnter

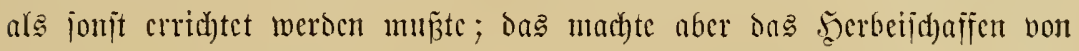

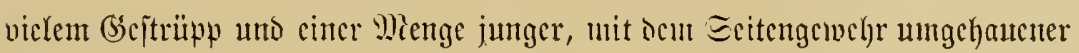
Stämme nötig; ocnn man durfte feinen ier Boababs añerfalb ocr Boma lajien; jonjt bätten fich bic Feintoc bei cincm S(ngriff jeincr ars Decfung

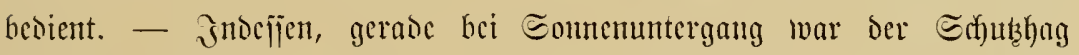

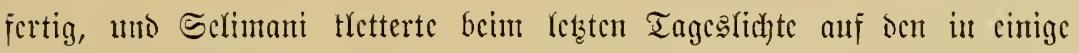

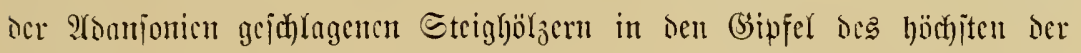

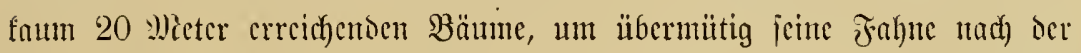

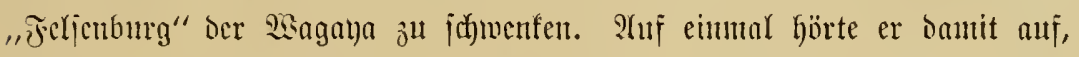

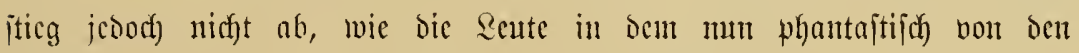
jutertoen Joeroflammen beleudeteten Sager crmartet hatten.

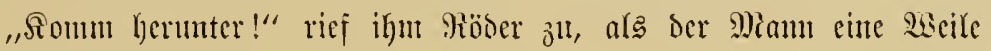
da oben ganj itill gebliefen mar.

„Bana," flang bic S(ntmort in vermundorten Tone zurüc, ,id) miff mur erit nod) weiter jehen ...."

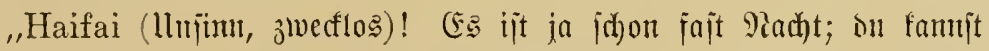

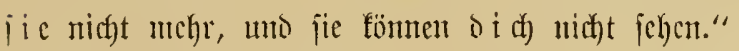

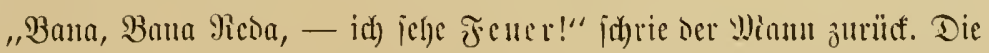
(Europäer wic bic an und in den nüdjiten Boabab hanjenden S(Efaris jprangen

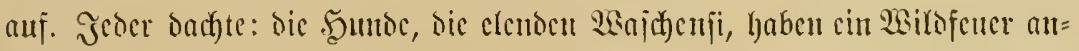

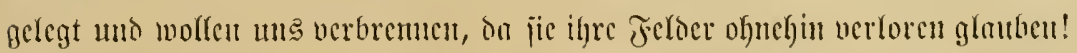

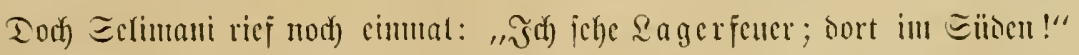

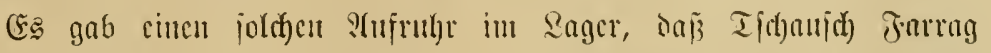

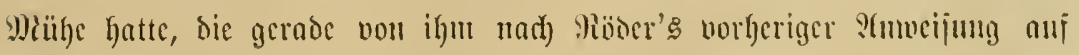




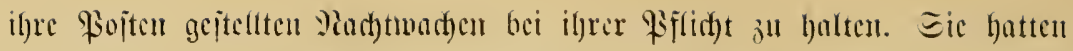

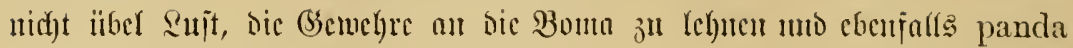
mtini (anf cinen Banm ju flettern), wie jic ju Dem lörbjt barja mit

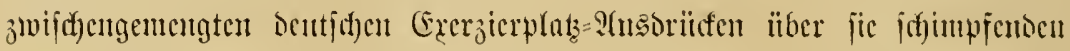

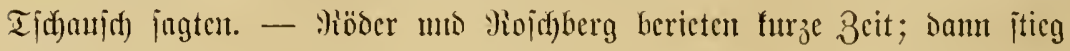

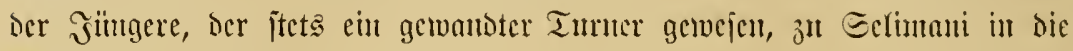

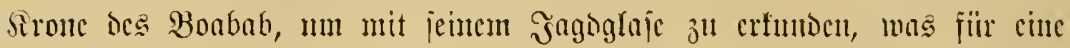

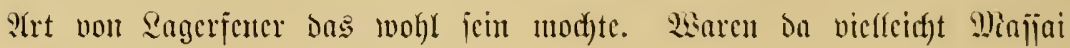

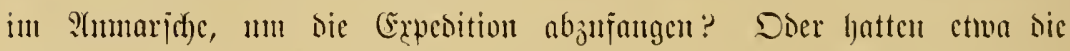

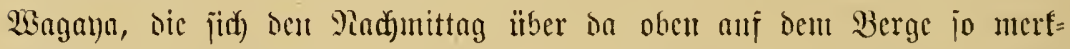

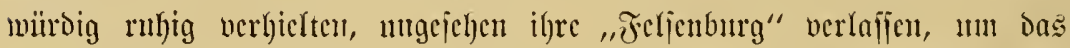

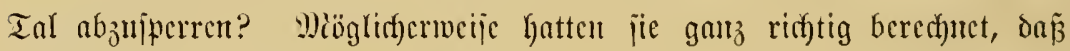

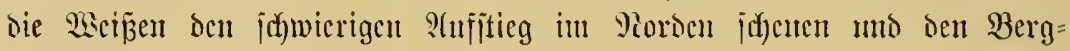

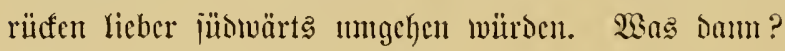

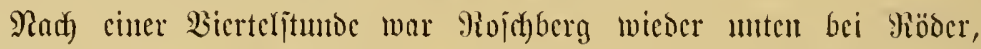

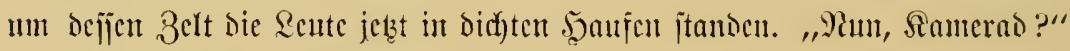

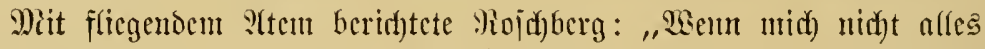
tünjidt, habe idf) bei viclen in fiveije georbneten Fencen cin obce jwei

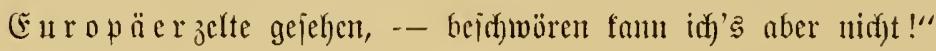

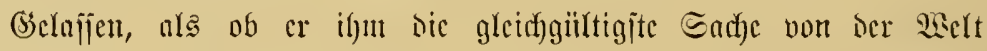

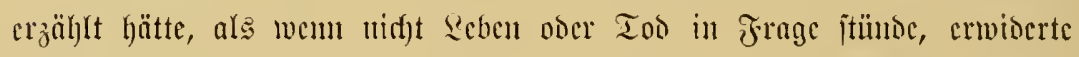

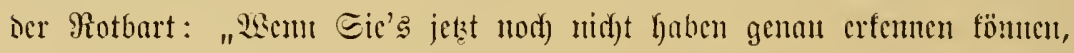
ba warten wir cben ben Miondangang ab und ichen baum nod) cimutal jt."

Der Mions ging hent aber critt und) Mitternad)t auf, mo io hatte

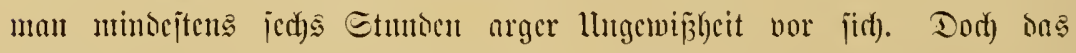

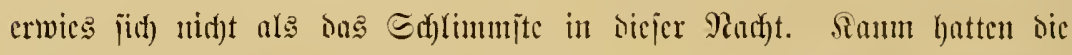

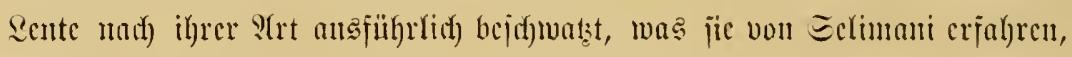

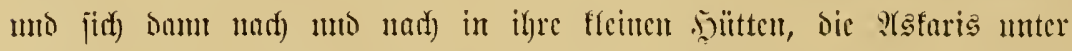

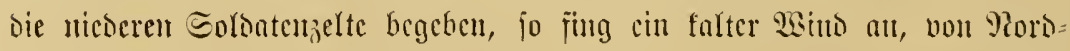

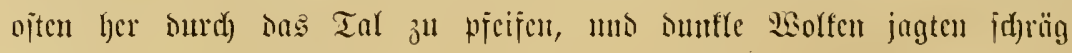
iiber bic Bergrüden iveg.

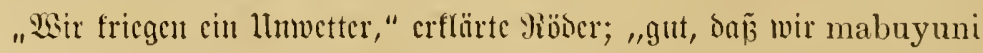

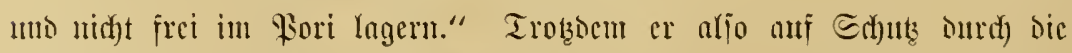

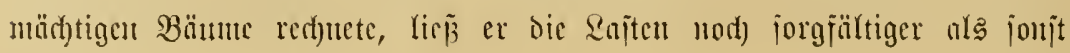


hedecten und alles mit Striffen fejt jujammenidhüren, bic Beltpflöffe von

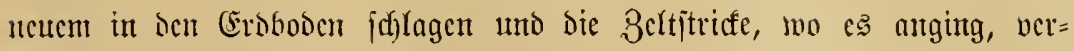
ooppeln. Das half jedoch nidht niel, Denn in furjem war ans ocm fulten

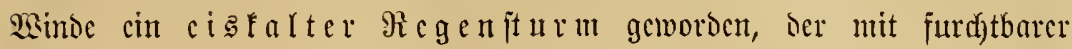

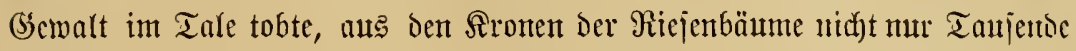
non fleinen 3weigen, jontorn auth mit heffem firachen fajt metersicfe

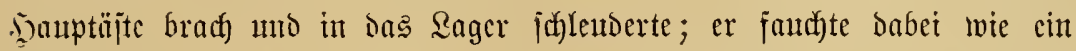
gcipcnitijd)es llnticr über bic fo mühjam erridtete Boma hin, zerrij jic

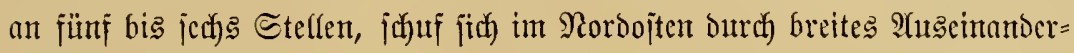

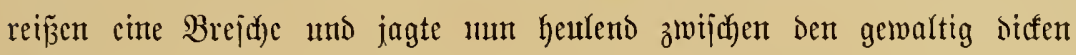
Etämmen Durch bas Lager, pacfte uno rïttelte bas Belt uno hätte $\mathfrak{E}$

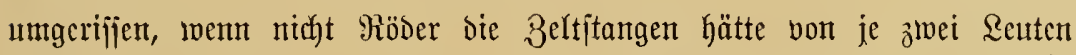

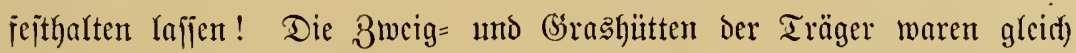
in ber eriten Biertelitumbe jerfekzt in bie Sujt gemirbelt worden, uno auth)

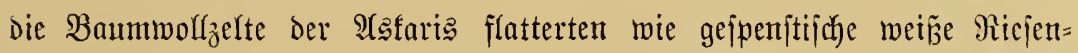
vögel dawon, wenn jie jich nicht in ben Boabab=2ijten wie in ben gigantijhen Armen von urweltfichen lingeheuern verfingen. 3itterno, wie geijtesnb= wejent, hodfen bie in ihre triefenden roten Decfen gewidelten Träger in

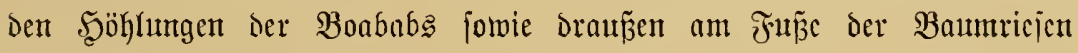

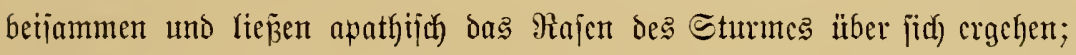

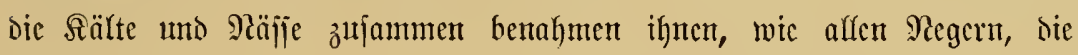
Fähigfeit zu oenfen uno machten jie willenlos. Mechanifin nur murmeltc hald hier, bals bort (Einer: "Nakufa (idi) fterbe)!", umo mem ein Cturm=

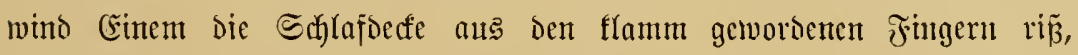
jo liefs er jie fliegen, ohne den Berfutd) jut madjen, jie wieder eitzulfangen.

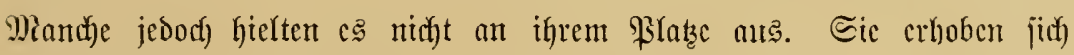
unt itolperteit oser waulten auf cinen anderen Bam ju, wu nad) fur

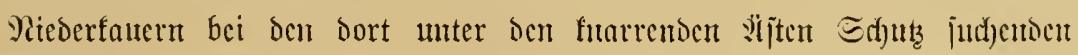
Sianteraben bon neuent, angîtgetricben, bavonjuwanfen. Sic ritten unter

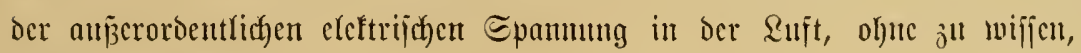
woher Dicfe $\mathfrak{A} u g i t$ faun.

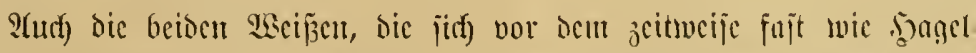
fđ)lag anjüb)

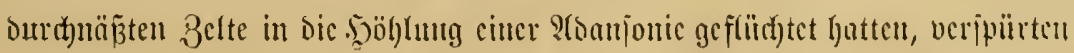




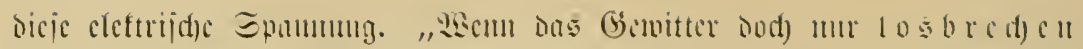

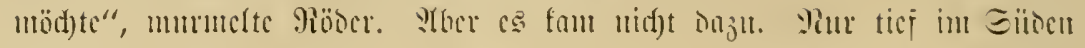

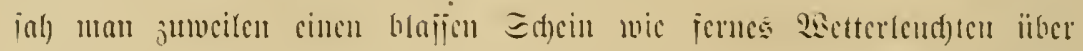

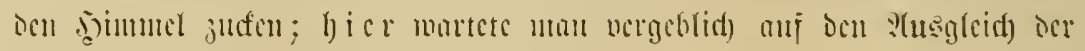
cleftrijd)en Exutumutg Durd) B(tizentlonutugen!

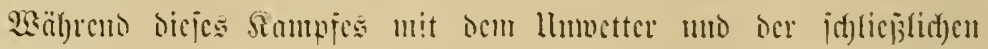

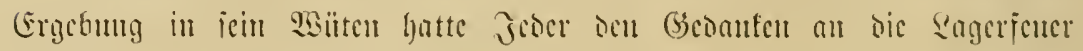

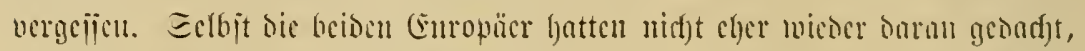

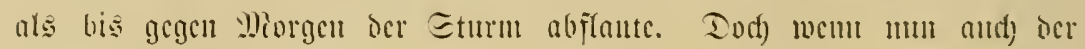

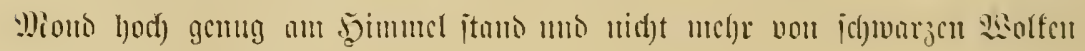

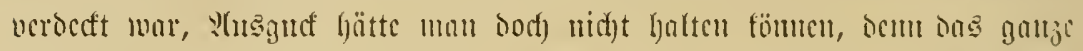

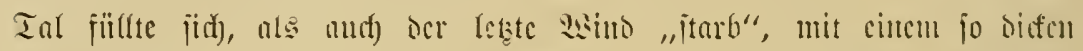

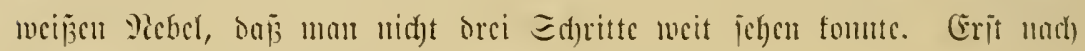

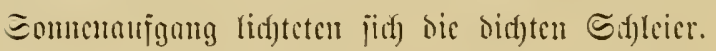

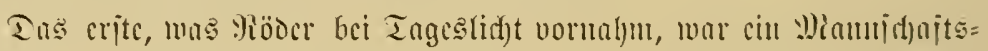

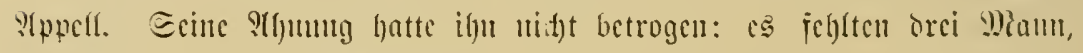

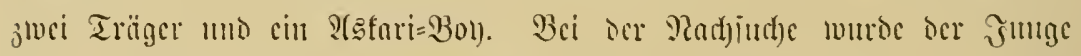

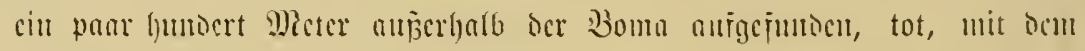

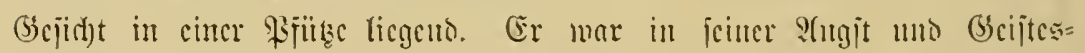

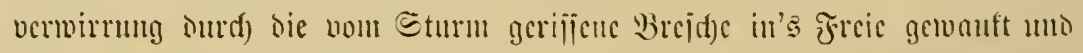

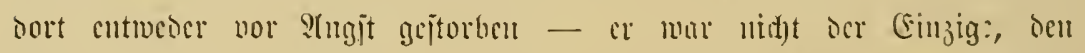

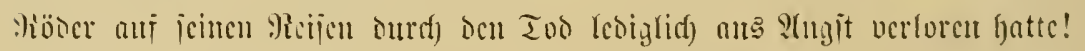

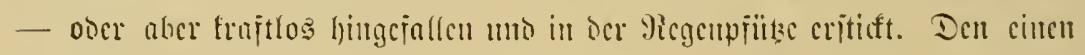

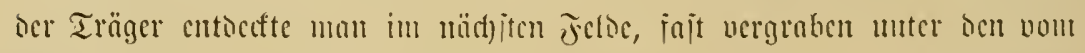

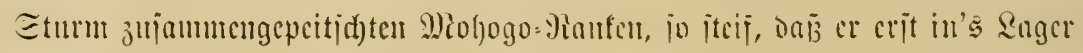

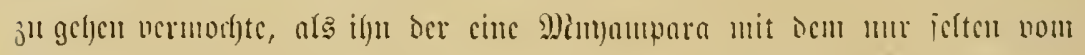

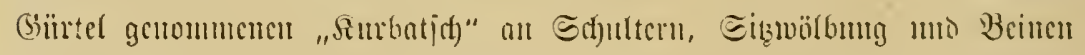

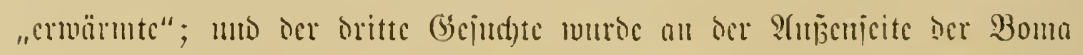

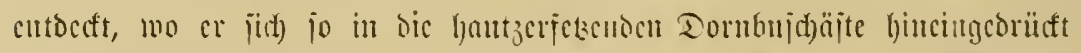

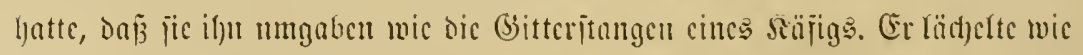

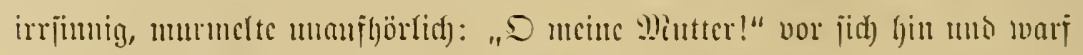

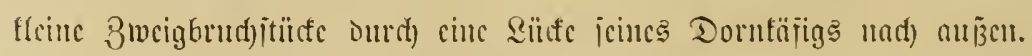

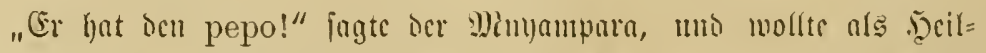

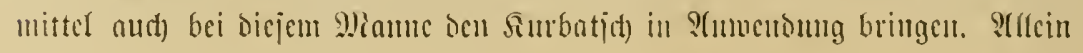




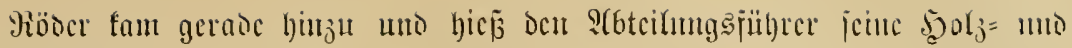

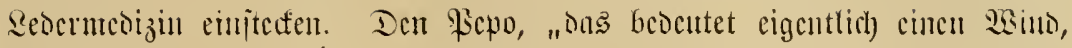

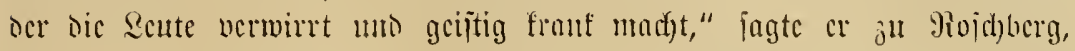

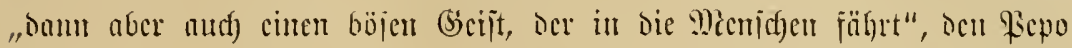

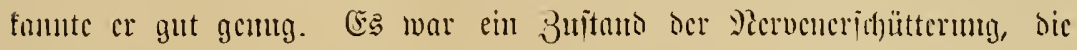

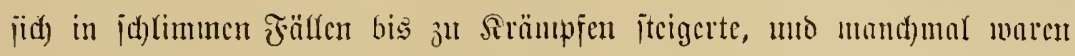
cs aud geraicz

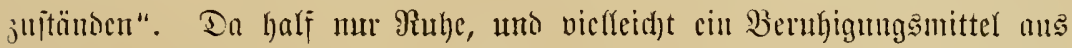

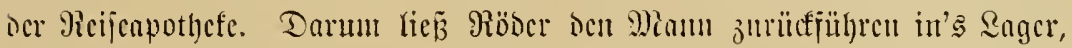

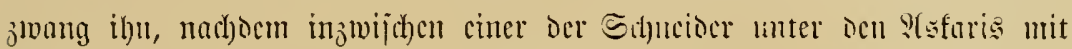

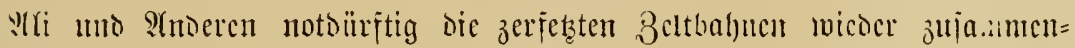
genäht batte, bei der heute bercits bor bem 2(bmarich uno nicht crit wic

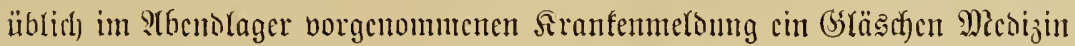

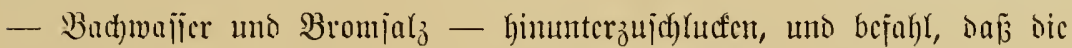

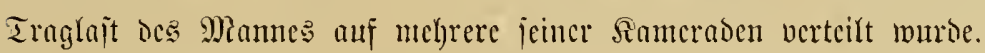

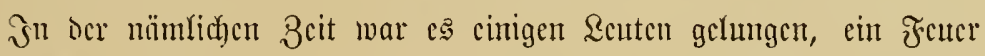
ju cutjachen, obwohl ringsum auth nidht ein einjiges Stütfit)en trodfenen

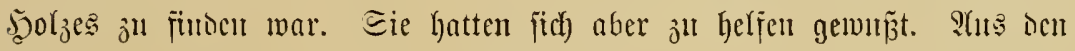

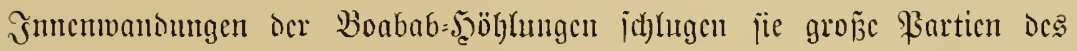
wcid)en, jajt wic Fencrichwamm glimmenden Şolzcs los, troufneten über

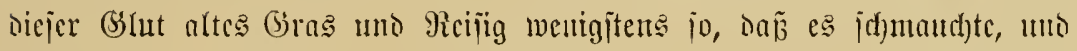

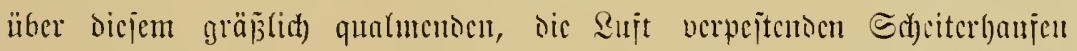

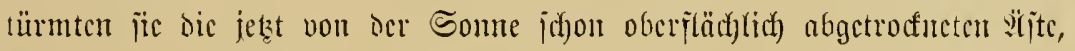

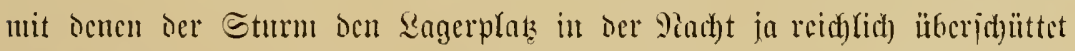
hatte. So fan allmäblich cin Ragericucr zujtanoc, an bent wenigitens jür bic all meijten mitgcnommencu Scutc ctmas bïmer llgarfi un fïl bic

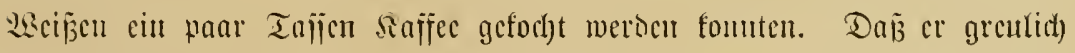

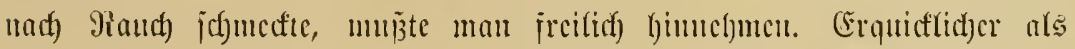

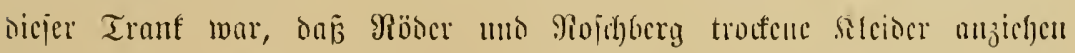

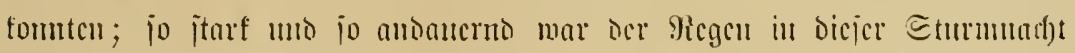

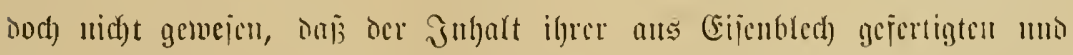

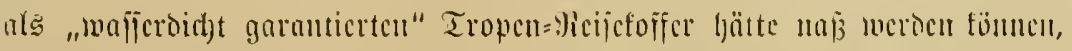

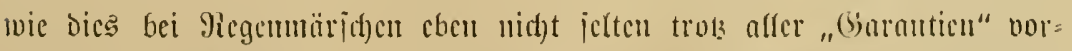

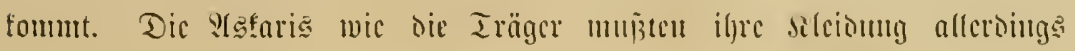




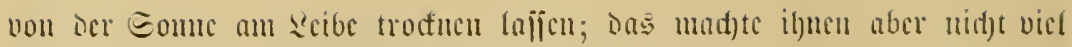

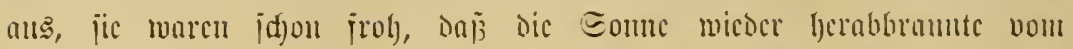

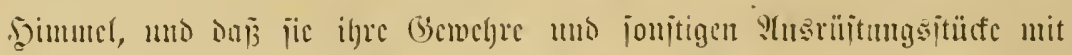

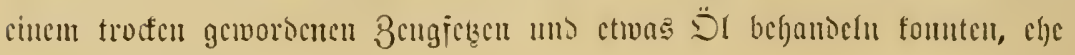
iid) Roìt bifocte.

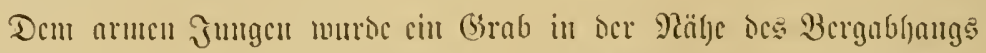

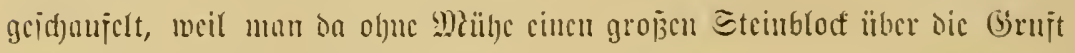

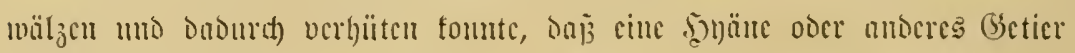

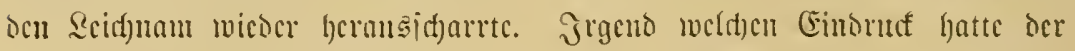

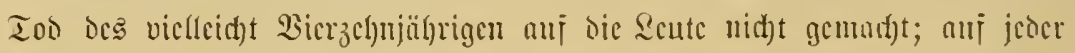

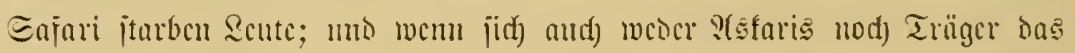

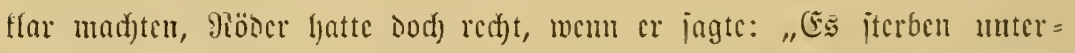

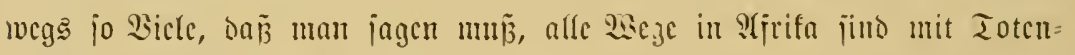

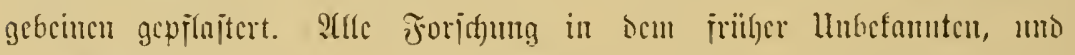
jcoe Eroberung iit ja mur möglid) geworisn Durch bie 3ahllojen, bie il)r

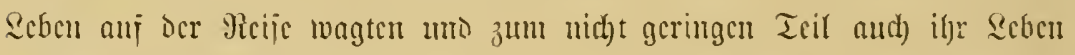

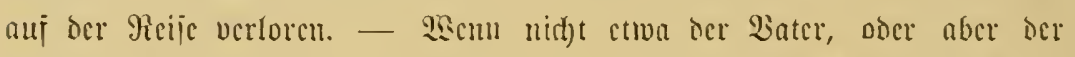
Soljn cints unternegs llutgcfoumencn in ocr gleidfen Sintamane ijt, io

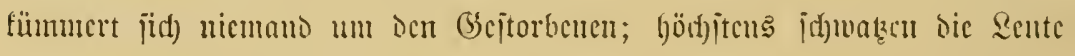
nod) im näd)jen Sager bartibcr;

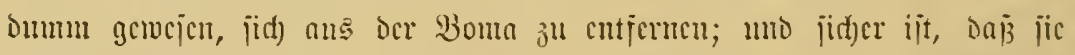

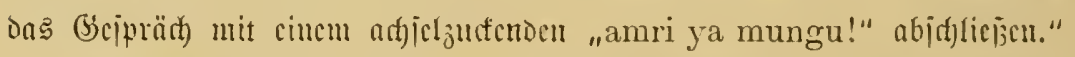

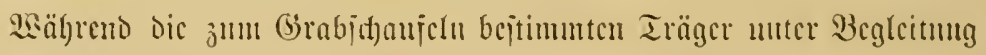

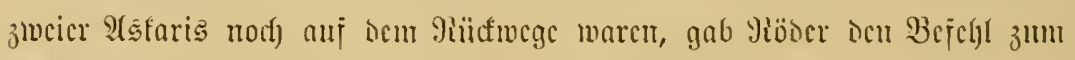

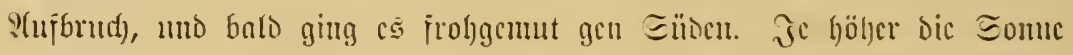

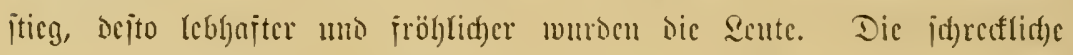

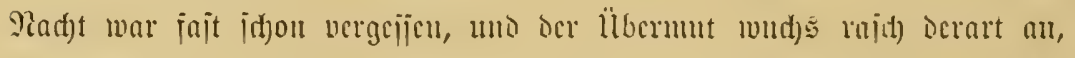

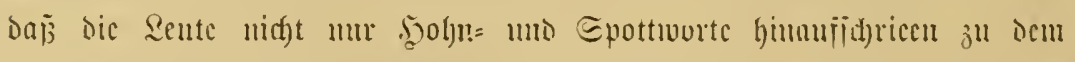

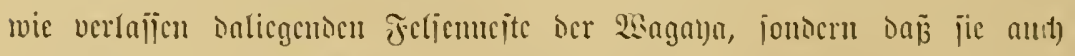

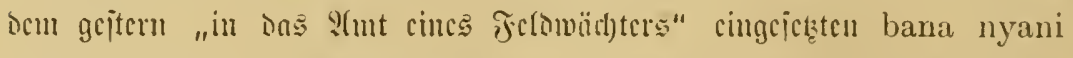

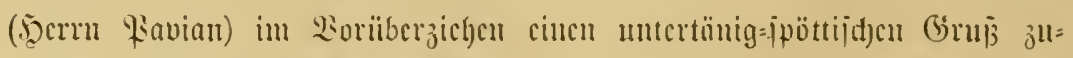

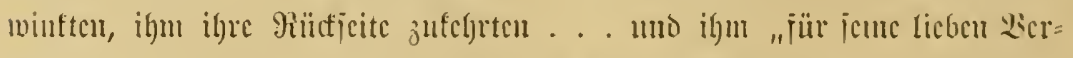
mambten da oben in oce Bergiejte" cine Ceinfadumg juricjen, Dic Tiojd)berg

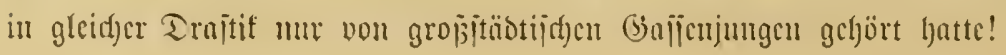




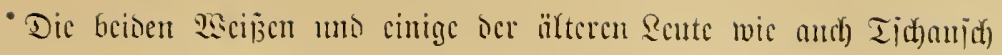

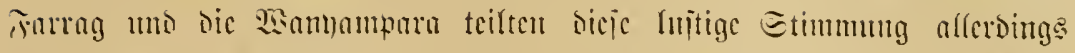

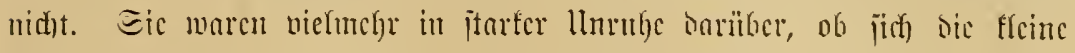

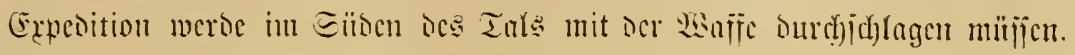

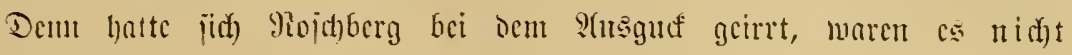

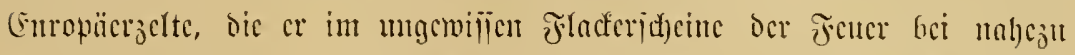

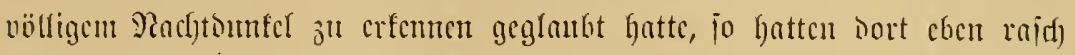

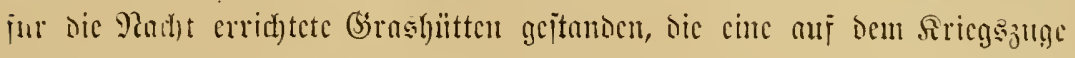
frimolide

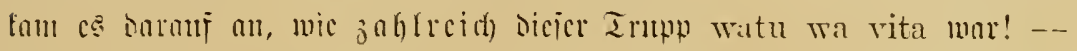

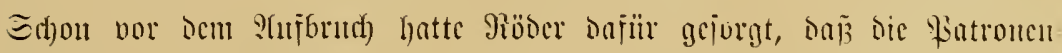

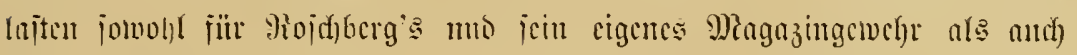

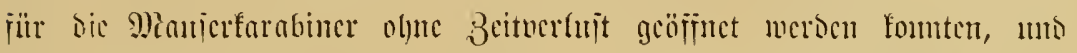

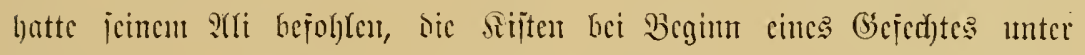

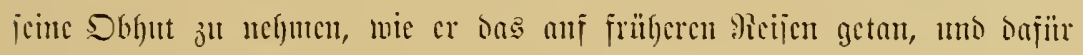

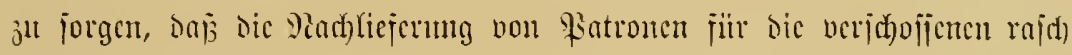

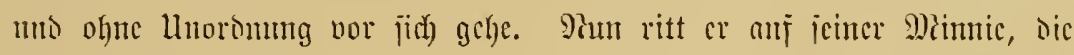

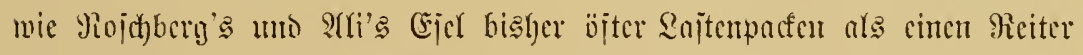

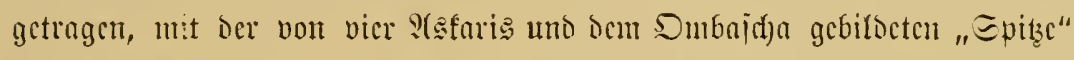

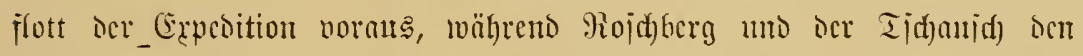

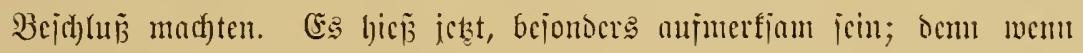

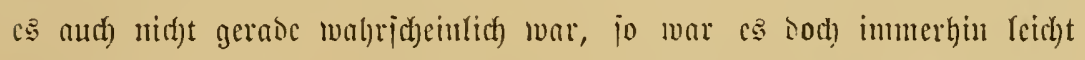

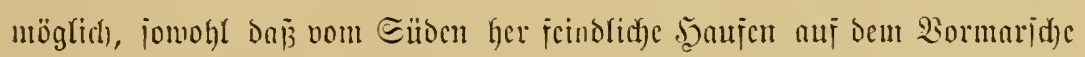
waren, als auch daj bic জeagaua ifyen Bergjitz verlajien lyatten, um ocr

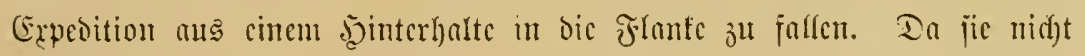

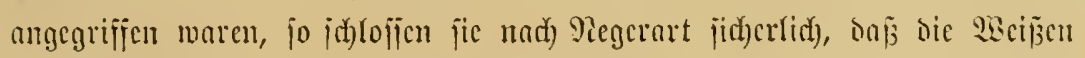

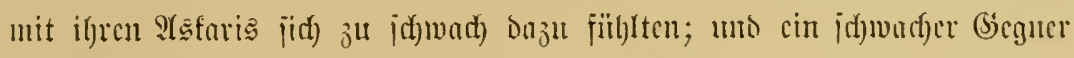
luar genau bas, was jic jitd) bünj(hten!

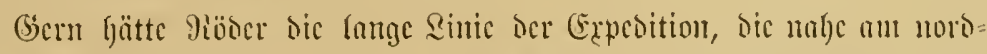

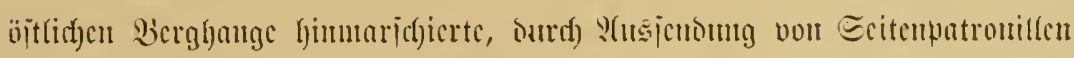

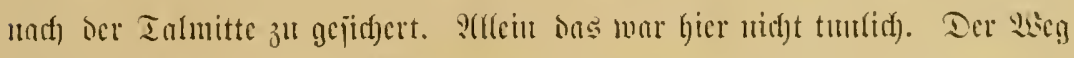

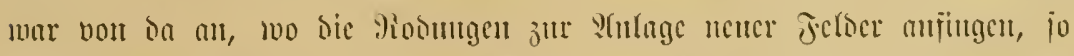

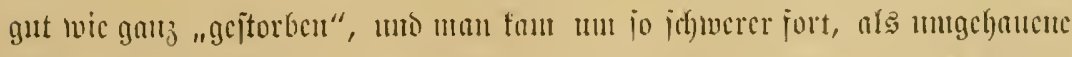

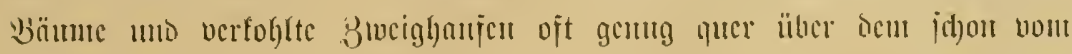




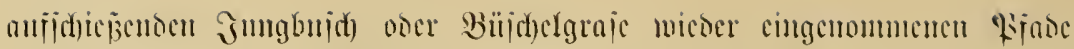

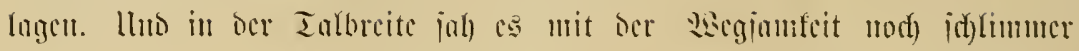

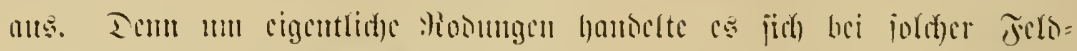

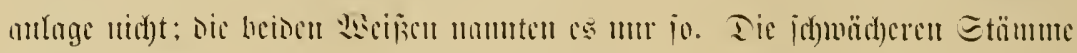

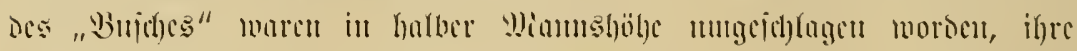

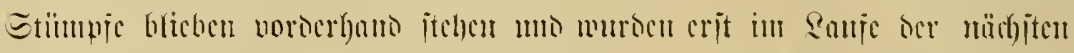

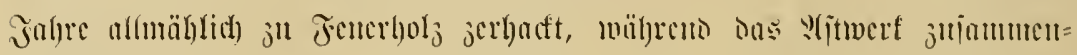

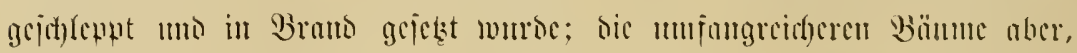

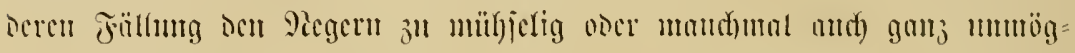

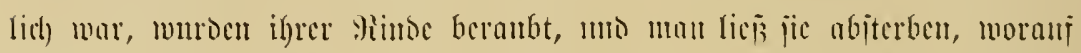

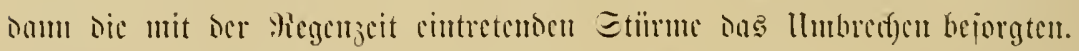

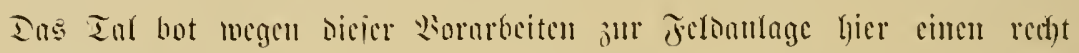

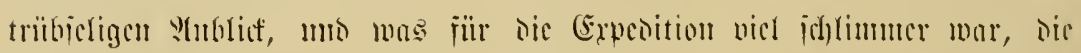

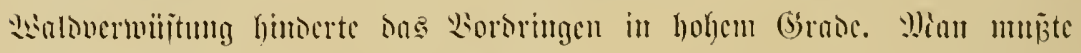

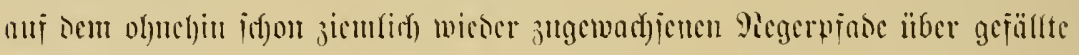

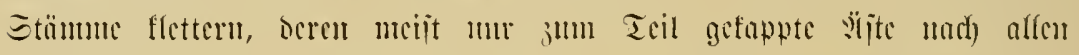

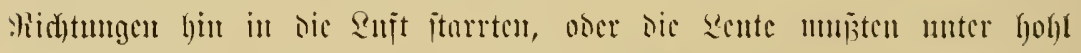

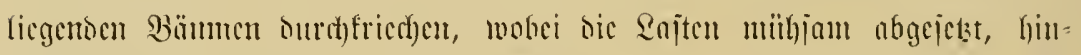

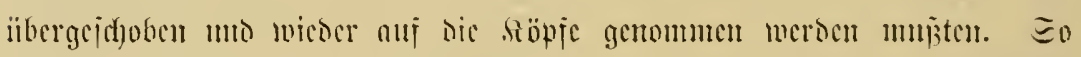

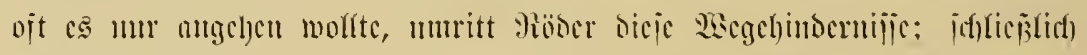

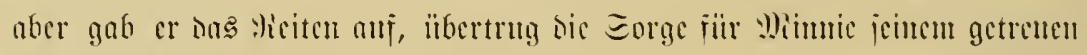

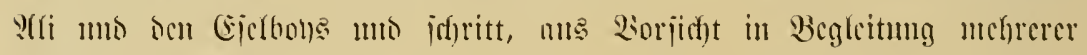

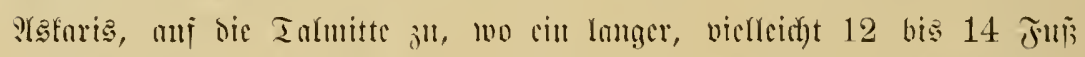

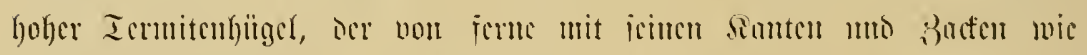

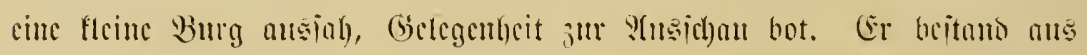

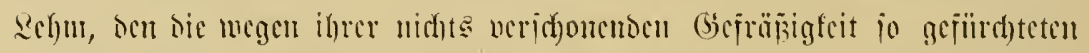

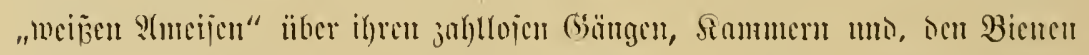

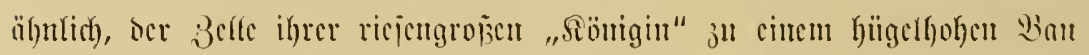

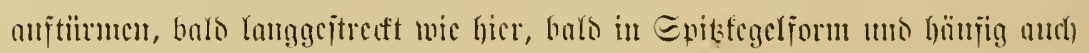

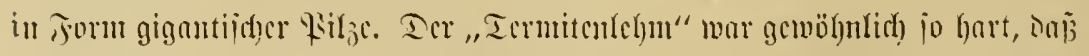

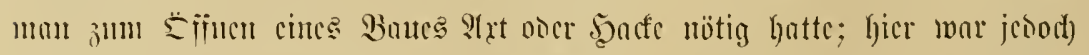

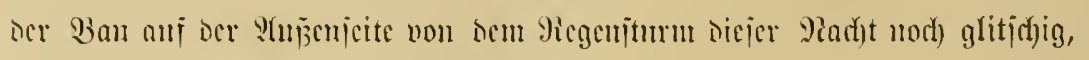

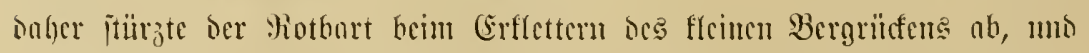

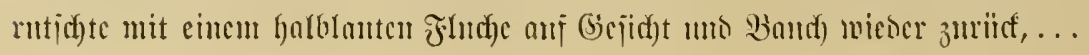




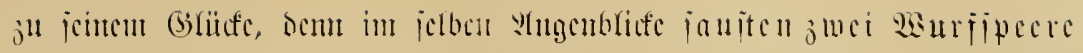

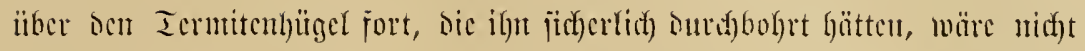

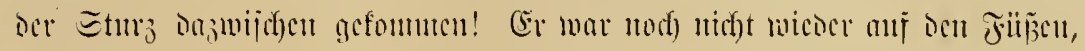

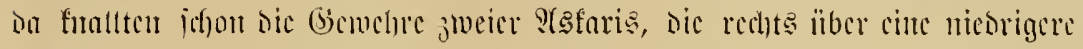

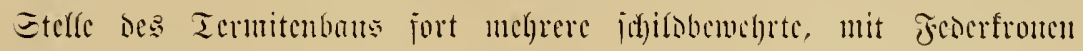

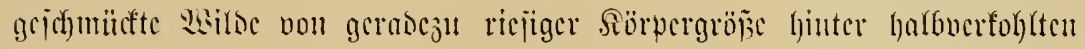

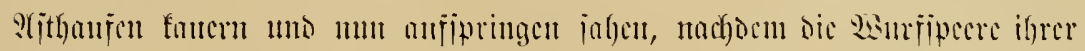

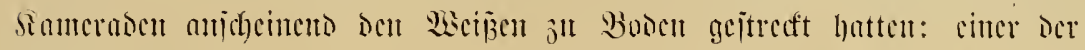

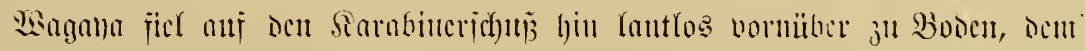

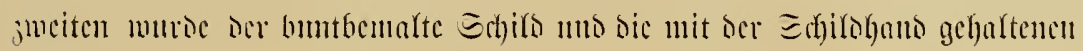

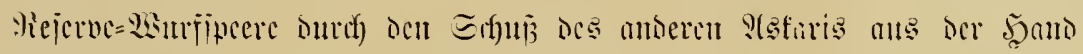

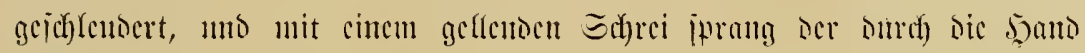

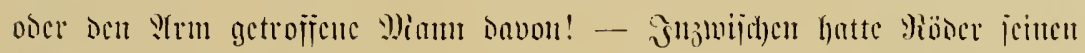

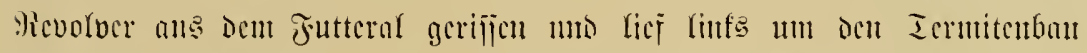

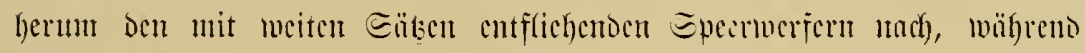

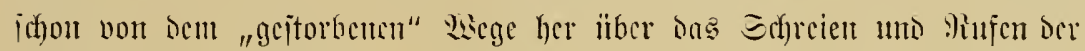

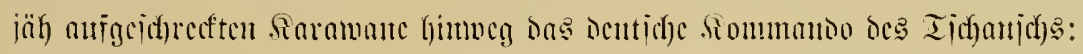

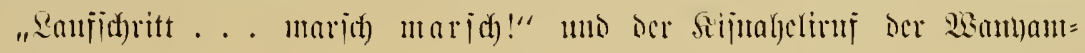
para: "Sajten niesoricken!" heritberorang. SElöblich blicben bie von 9iöber

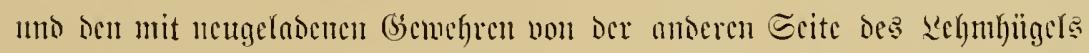

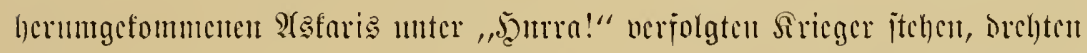

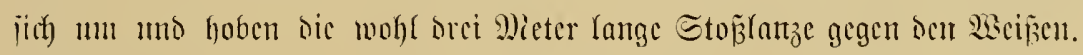

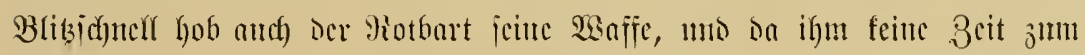

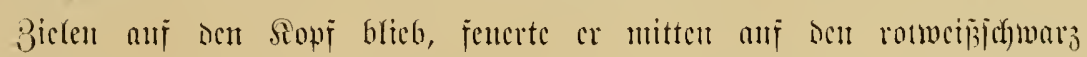

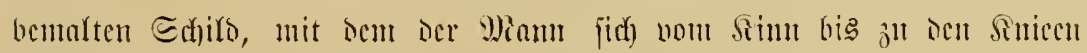
Deefte. 311 icinem Eeffred brach ocr Sirieger jedoch nicht Jujammen, jombern

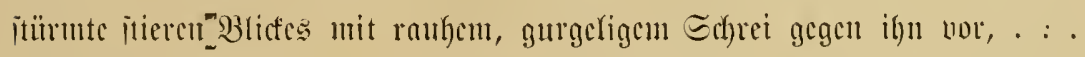

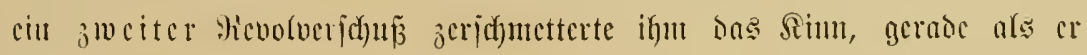

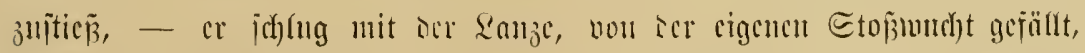

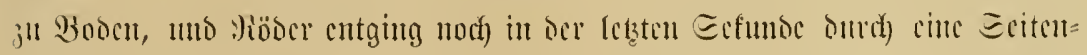

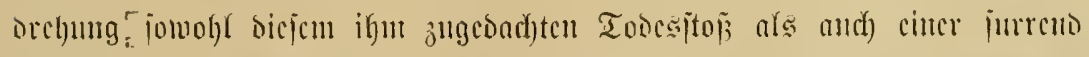

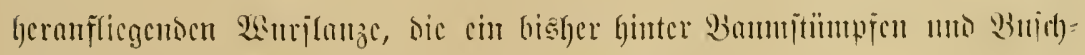
werf neritecter Wigana nach ifju idflentorte! 
Pim aber maren alfe Pafaris, bis anị bie jut Deftung oce Träger

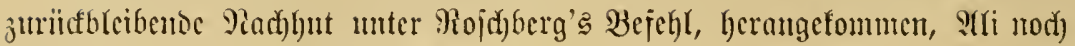

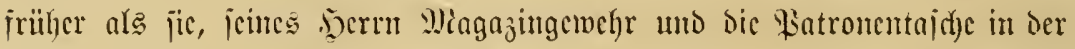

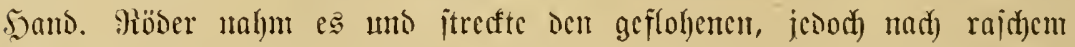

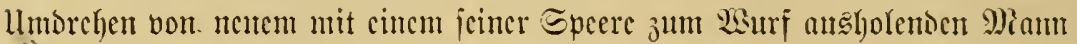

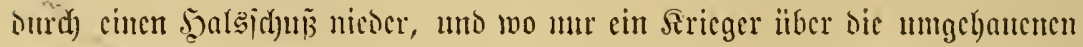

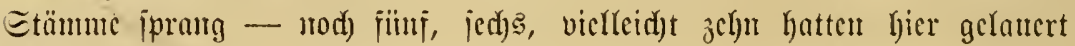

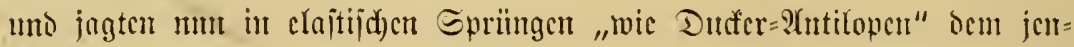

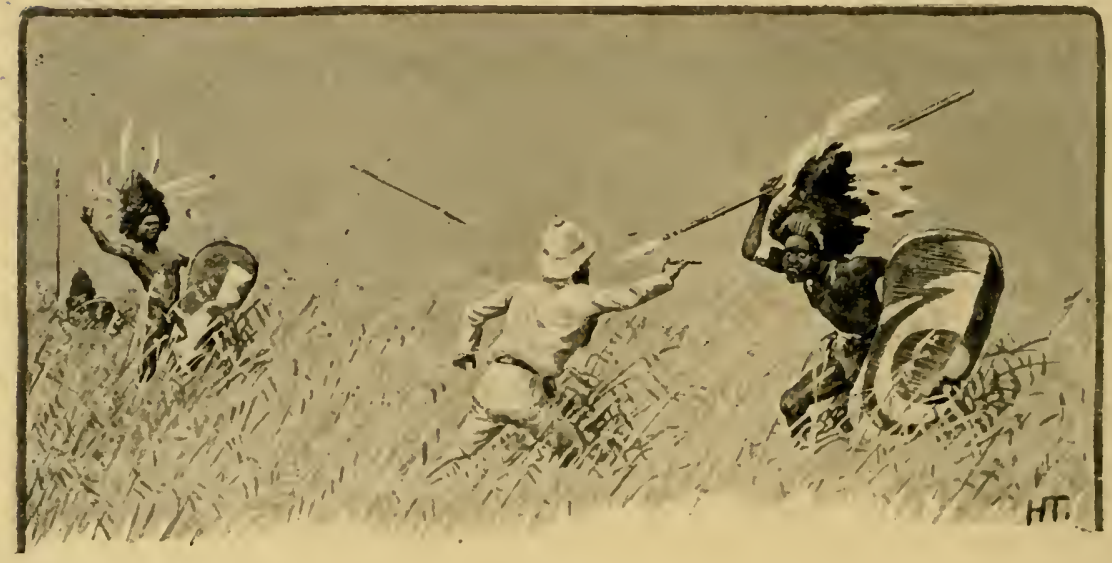

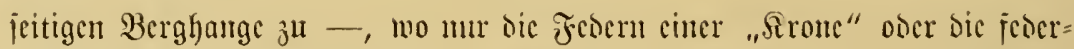

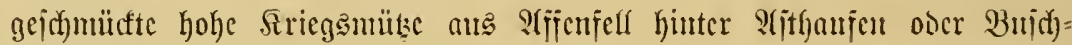

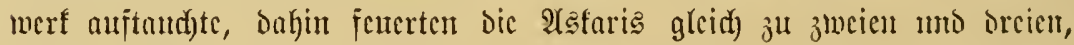

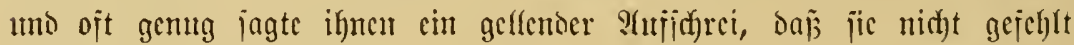
hatten!

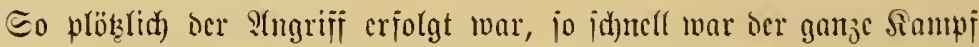

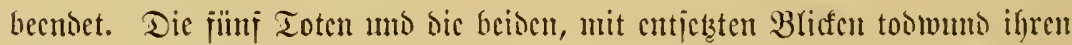

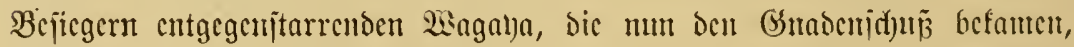
befunoten bem inzmijd)en cbenjalle herangefoumenen .5erm v. Fojd)berg

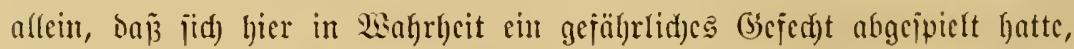
nidft bas affes mur cin wilocs Epicl crregter \$ibantajie gemejen! Dem

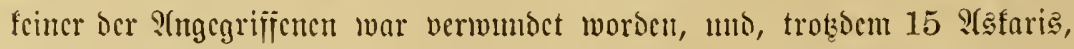

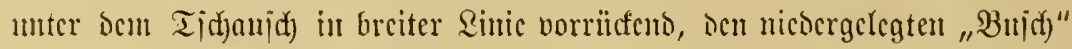

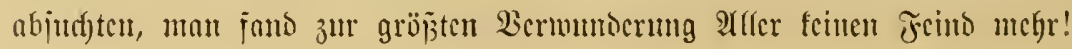


"Sie werden uns weiter unten im Tal mit ifren .̧cerhaufen erwarten,"

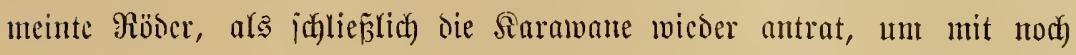

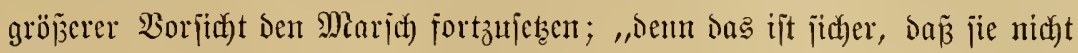
glauben, uns mit biejem fnappen Duzeno Siriegern abfangen zu fömten!

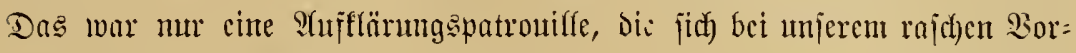

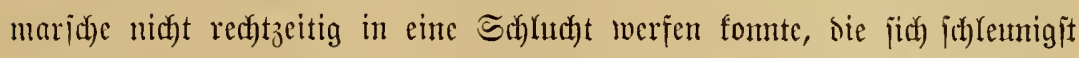

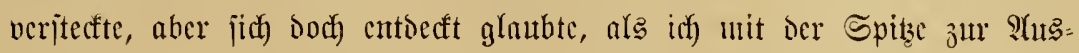
id)aut auf ocn Termitenfügel losging. - Jetst wiro's soohl gleidh emit= hafter merden!"

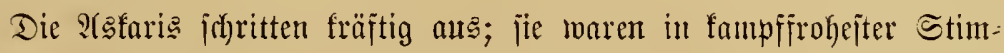
mung! Paun fomuten jic Doch endich einmal ifre gefiebten Bicmehre auf

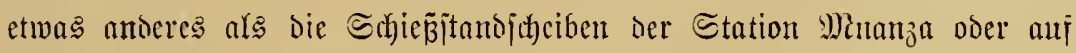

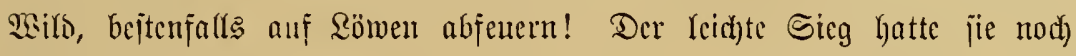

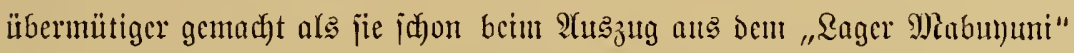
waren. Sic hatten tem eitten Toten den od) jenthanttübcrjogenen łöljernen

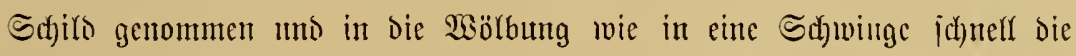
eijernen uno mejïingenen $\mathfrak{A} r ı n=$ uno Beinipiralen gemorfen, dic fie cintgen Der bepiegten Feinic unter roljen $ఠ$ d)erzen heruntergezcrrt hatten, daju cin

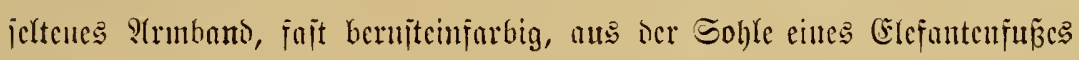

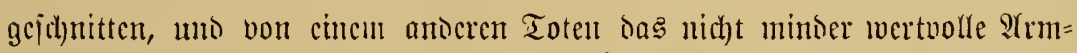

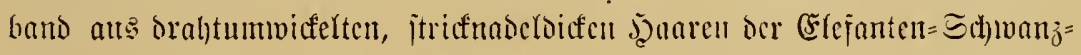

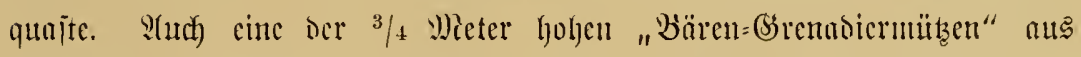

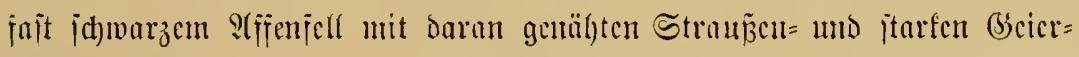

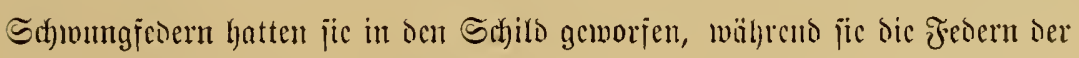

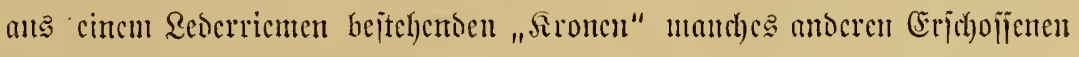

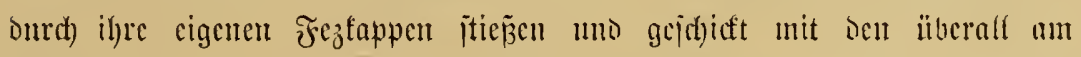
Begbuj(t) $\jmath^{\mathfrak{u}}$ fintontoen miba (frumumcu Dorncu) bejeitigten. 'Stolj

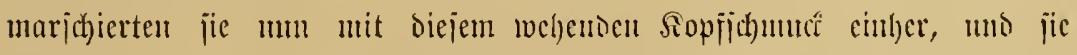

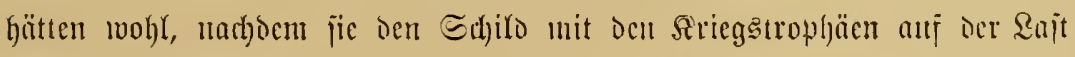
eincs Irägers jeitgebunten, am liebjten Stegreijuerje ïber ben glïeflict)en

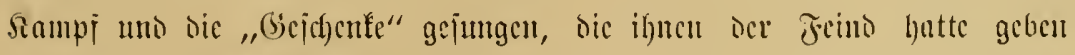

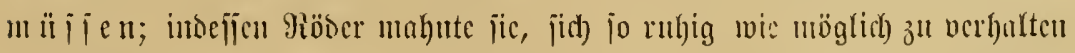

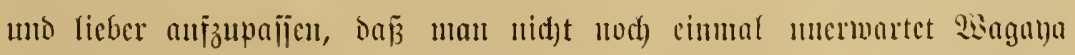

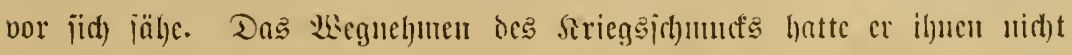




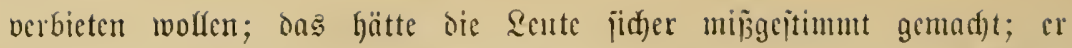
mußjte ja, uidyt menige von ihnen gätten den Toten am liebjten dic siöpje abgejd)nitten, wie bas in ben Ariegen bei ihnen babeim mohl nod) allgemein üblich war; wenn jie es hier nid)t verjudten, fo mar bas lebiglidf burnuj

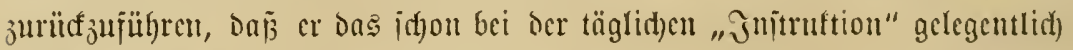
des Finexerzierens verboten hatte, umb bie Sente jidh) flar darïber waren,

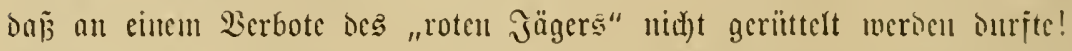

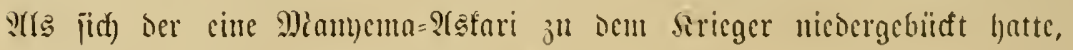

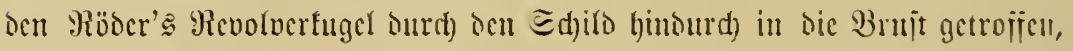

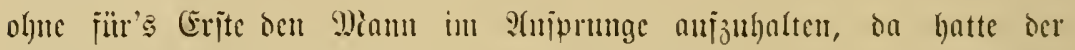

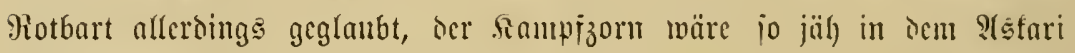

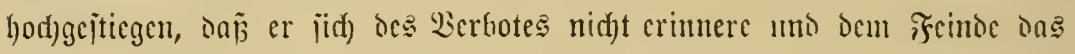

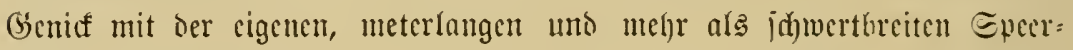
flinge surdjidflagen molle; er hatte indejien nad)her gejehen, baż Dor tote Migana, cin Micnid) wie geid)affen jum Wiodell für cincn Bildganter, แod)

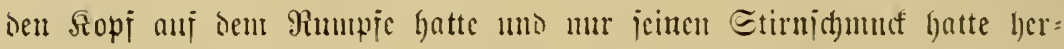

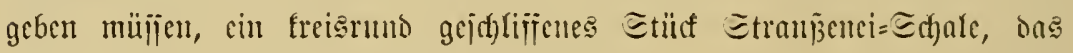

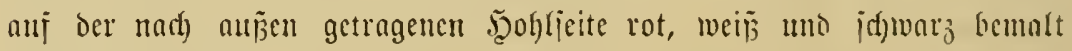

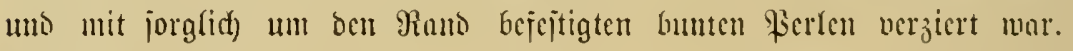
Ins gatte ifm ber Mianyema jugereid)t mit ben SEorten: "soicr, Bann Reon: Das ijt von ocm mpumbafu (Inum fopi) übrig, oer on glunbte, jeine Sericgsonau iei jtärfer als die Deine!" Dabei batte Der Miann

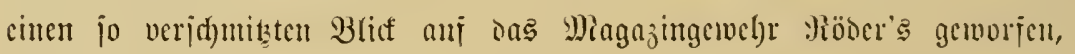

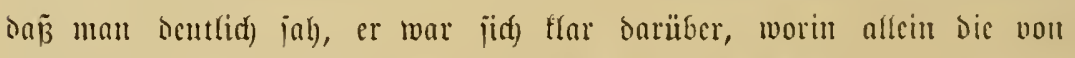
den 习egern io viel bejprod)ene jtarfe Seriegsoana ocr Europäer bejtuno!

Sie faramane mar nod) nicht cine halbe Etmoe meiter vorgeornngen,

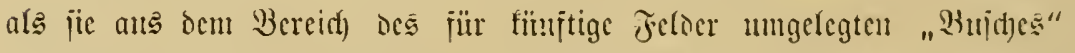

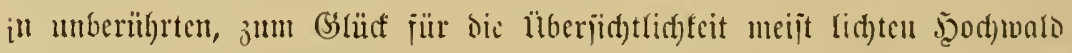
Gauptiädblid) von Minombo=B̈̈umen cintrat, beren bidgte Sronen mit ben

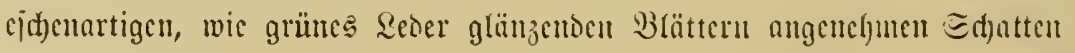

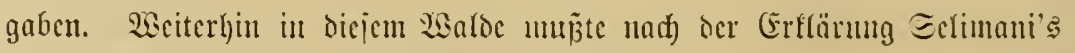

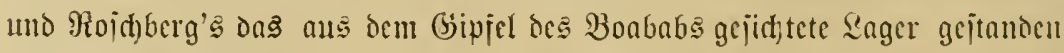
haben, oder vielleid)t nod) itehen. S(ljo doppelte 2iorijid)! Wian founte

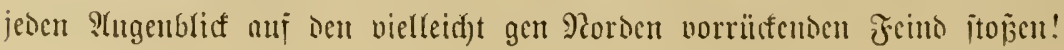




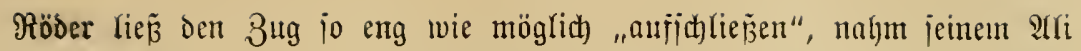

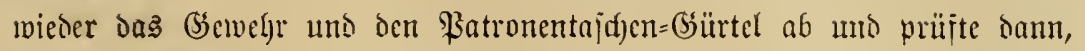

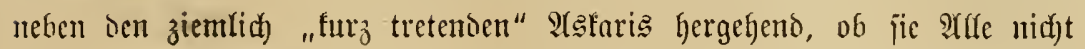
nur gelaten, jondern andf) gejichert hatten, damit nicht aus Berjefen

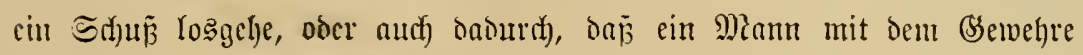

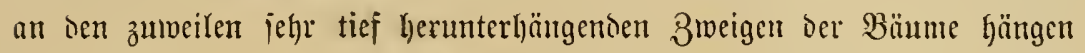
blieb. Da fnarten prözlich or üben im $\mathfrak{S}$ alde ein paar S di) üjic, - hell uno ichari, aljo jither feine aus Borderfatem!

So überrajeft Ilfe waren -- bie ganze Sarawane madyte unwill=

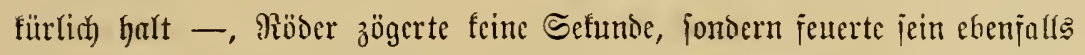

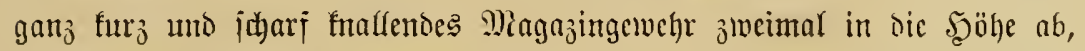
um Denen da brüben, we n anth) fier fino (suropäer!

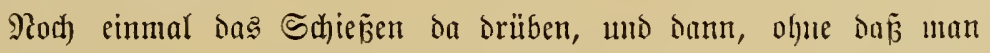

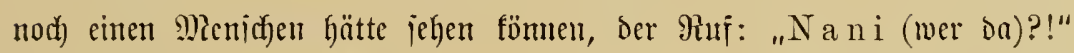

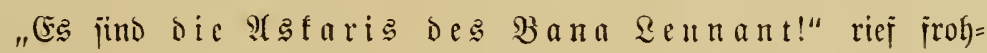
loctend ber jonjt immer jo itocfernjte Tijuajd); uno: „Es jimo Freunde!"

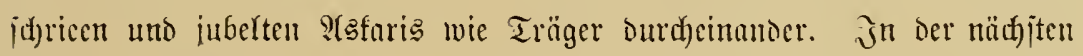

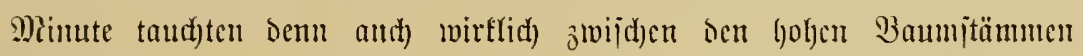

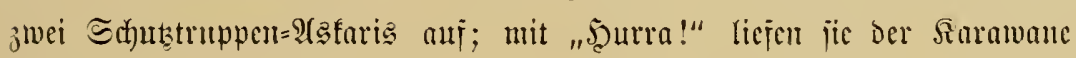
entgegen, nnfuten baun iesod), als jic ben Fotbart erfannten, "itramme

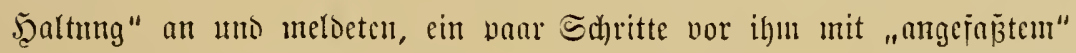
Gemebr itehen bleibeno, wie jie es fïr bent injpizierenten Sifizicr gelernt hatten: "\$atrouille der 9tbteilung bes Bana Scutuant Miaibact)!"

In ber nädjten Sefumbe war jedod) has "Dienjtlid)e" vergeljen:

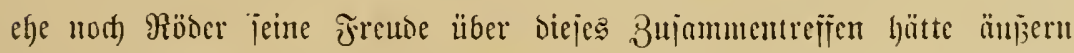
oder cine Frage tum fönuen, jubelten die beiden förurlid) nui: "Alhamdu

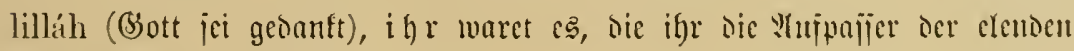
2Bajdenji verjagt habt!"

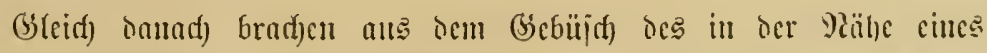

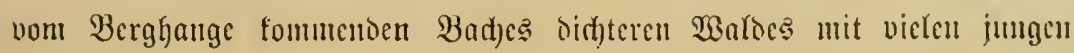
Wildoattelpalmen uno an jumprigen Stellen, ,itamutojen" Giapljapaluen

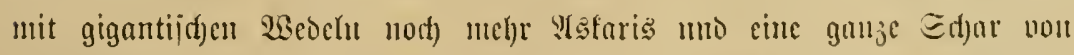

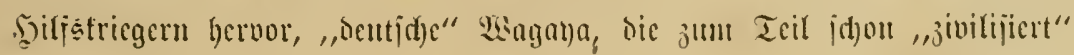


gemug waren, um trotz ifrer mit öl unto zinnoherroter crrbe greulidf)

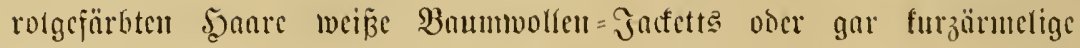

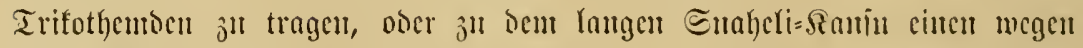

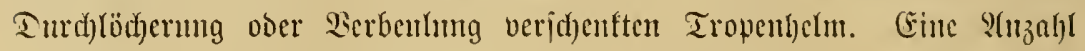

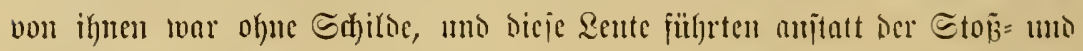

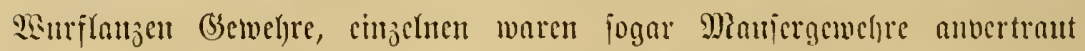

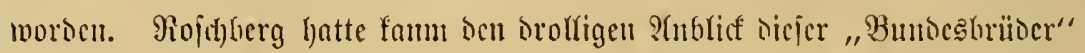

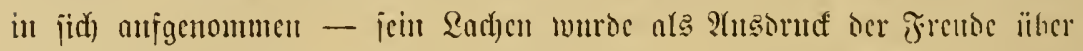

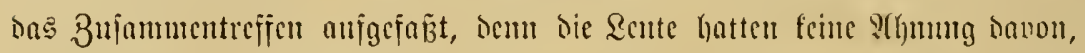

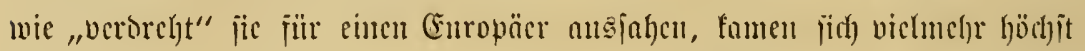

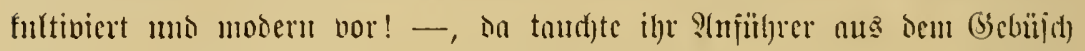

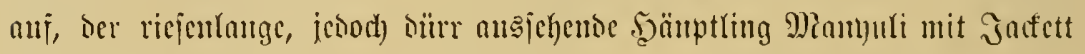

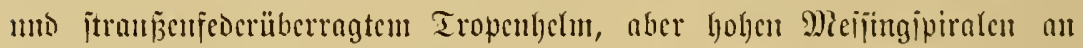

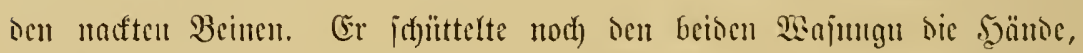

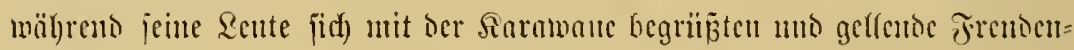

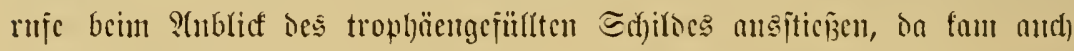

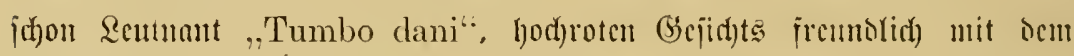

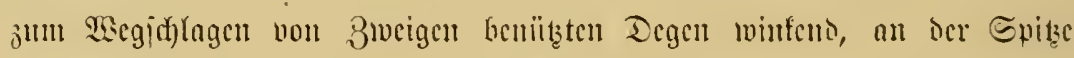

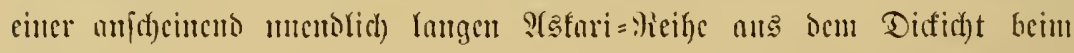

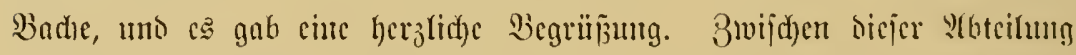

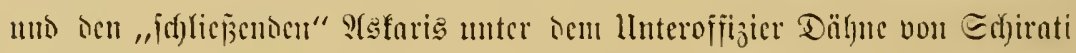

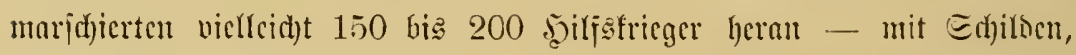

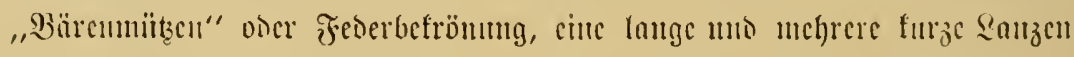

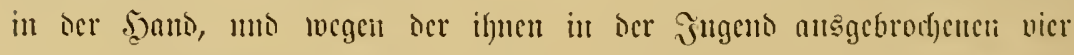

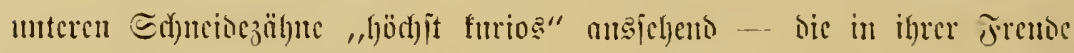

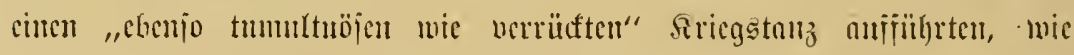

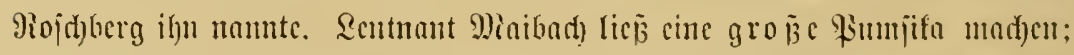
er war fd)on fritil) aufgebrod)en umo woffte nad) bem S(bforf)en umo längerer

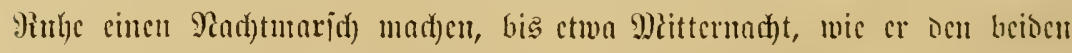

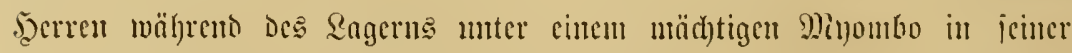

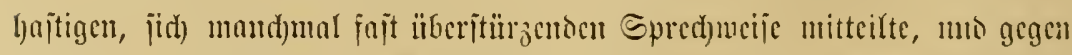

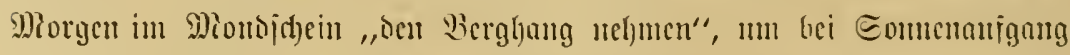
Tasweta dönye, Bas ani ocm Berge licgente beceitigte Fori Iajmetn, $3^{\text {ll }}$ itiirmen. 


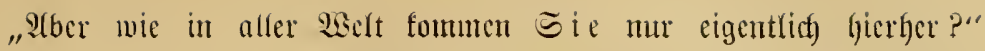

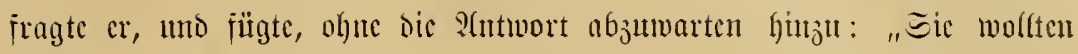

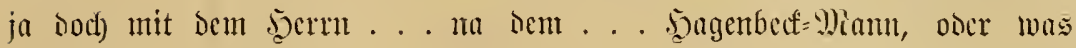

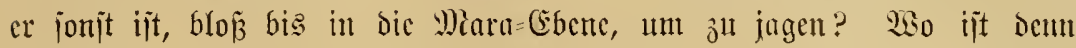

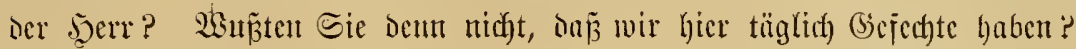

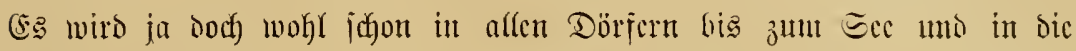

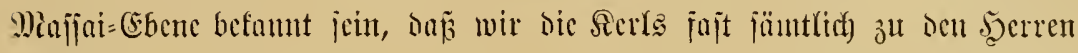
Engländern hinübergejagt hahen! Paur noch sic da obent halten jejt!

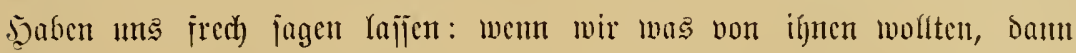

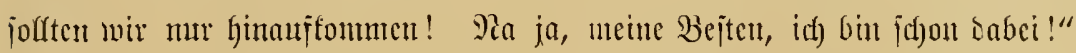

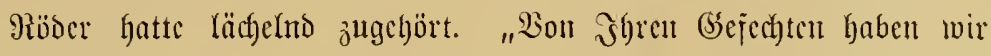

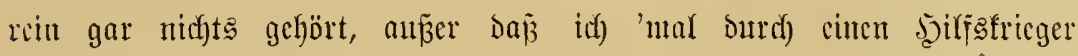

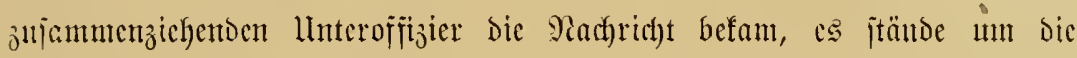

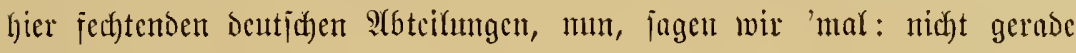
jehr gutt. Itno..."

"Э bewahre! Sit überall gerabezu glänzeno gewejen, wenn wir auch in ber erijten 8cit eine jdanobare llbermadyt vor uns hatten!“

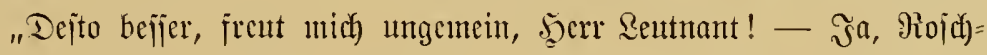

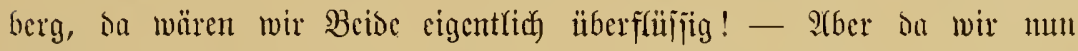

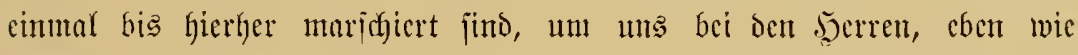

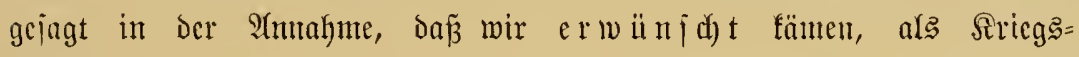
freimillige ..."

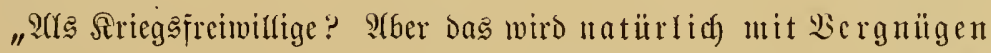
angenommen, meine Serren! Mit Bergnitgen! Jab bin ja nid)t ber

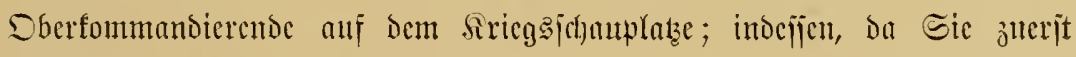

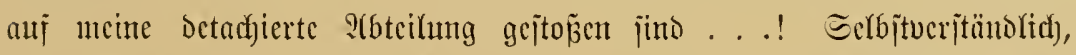

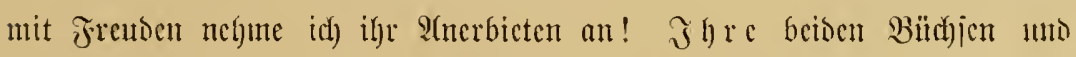

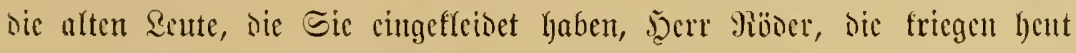
nad)t, rejpeftioe morgen jrüh, nod) ?(rbeit genug!"

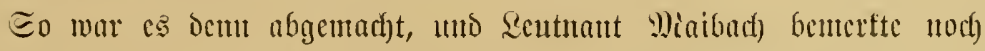

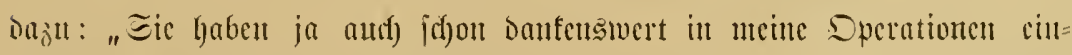

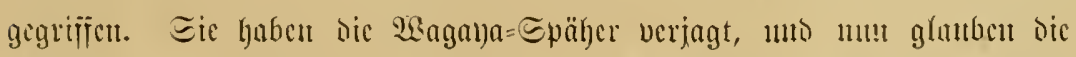

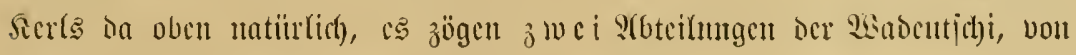
Jarden und Sitben her, ulf ihr Berguejt log!" 


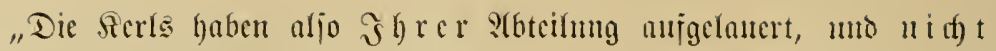

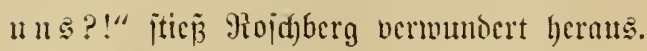

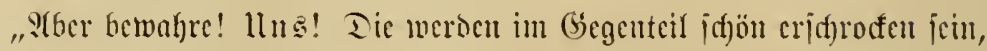

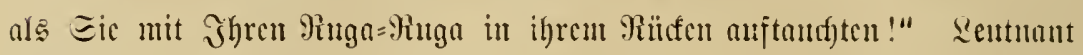

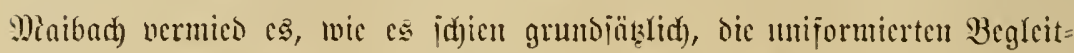

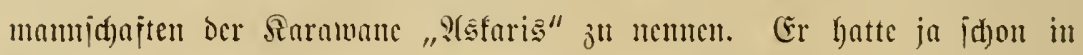

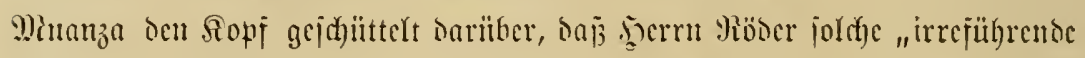

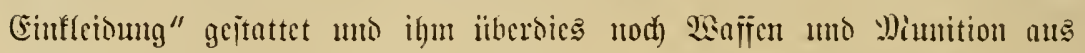
den alten Bejtänton verfaujt moroen maren. S(lz Eoldat batte er jedod)

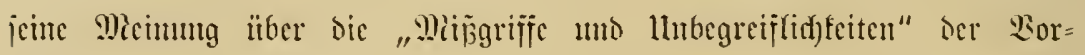

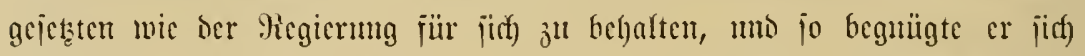

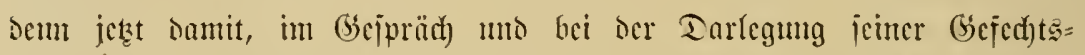

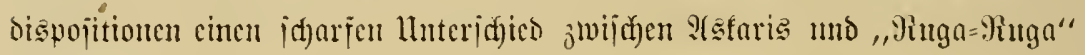
3l ma(t)en.

Ecinc Mianujdajt bejtano miprïnglide ans 81 2(sfaris, von Denen

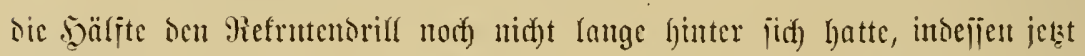

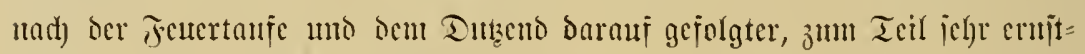

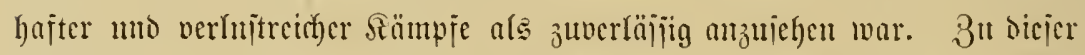
Diamnidfaft mit cinigen jarbigen Chargen mo bem llnterofijizier Dähne fam

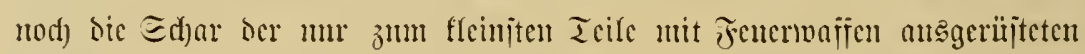

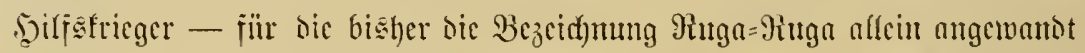

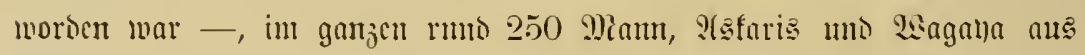

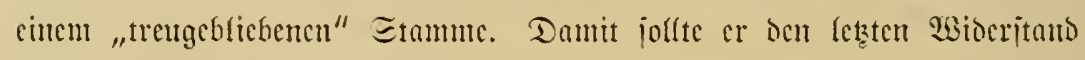
ber "idfled)ten" rengaula bred)en, mo bas waren cben bie fier auj

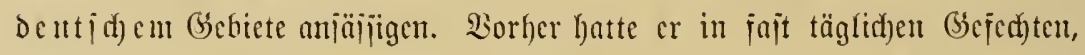

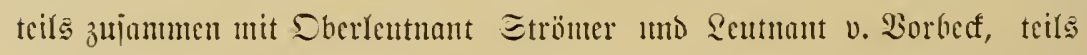

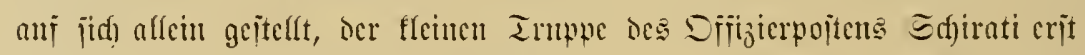

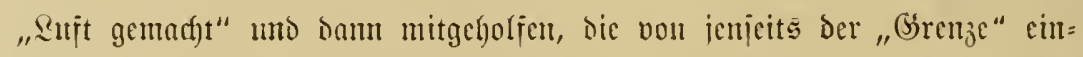

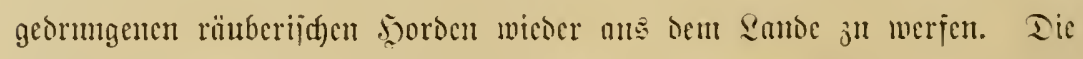

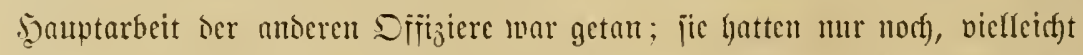

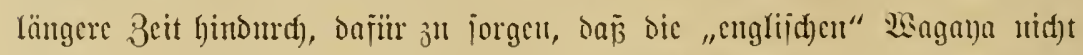

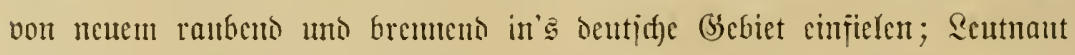

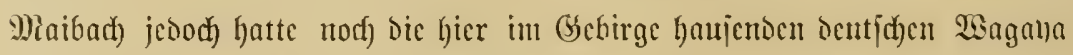
zu "bejtrajen“, bie jids anjocinento nlle in einer ihnen umeimebmbar 


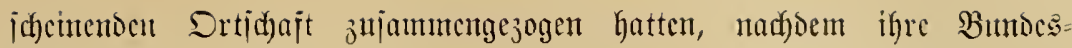
genoffen von "brïben", wie cr es ausorüufte, "mit blutigen Röpfen heim= geidficft worien maren ju Menttern". (Er frohlocfte bei bem Gsebunfen,

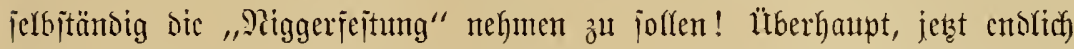

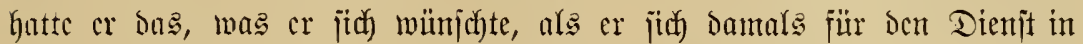

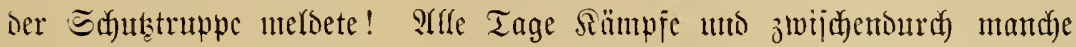

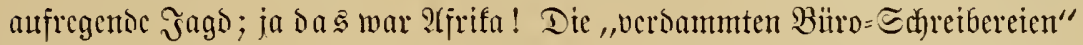

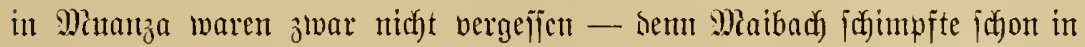

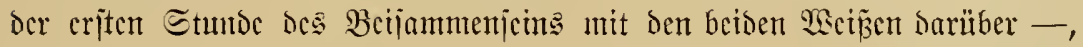

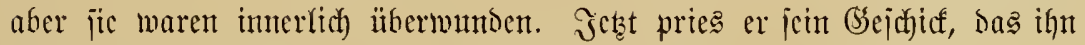
norf), „3u guter Sctit" vor eine jo widytige 2 ungabe gejtelft hatte.

Sisie bielc humbert fricgsgemohnte und jtets mit wahrem Fautis:

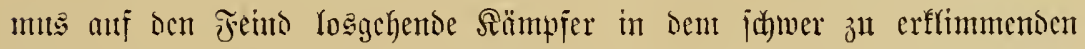

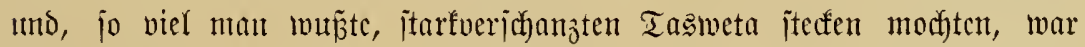

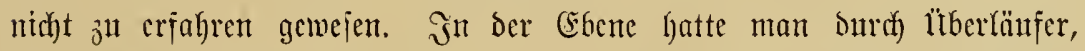

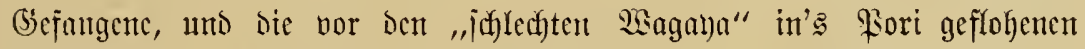
Dörficr immer Rachridgten über ben Feino befommen tönnen. Ђ̆ier im Grbirge aber mar bas anters. Spione gab ca nicht. Sisc fint in ber

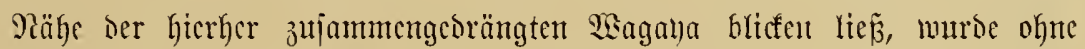

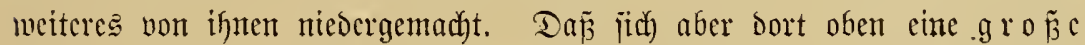
3ahl von Siregern gcjammelt hattc, bas and bicle von ihnen Fencrwaffen

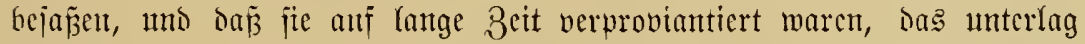

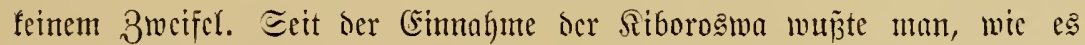
um bicje Bergicitungen itans! - Unter jolchen Ulmitünoen mar Scutnant

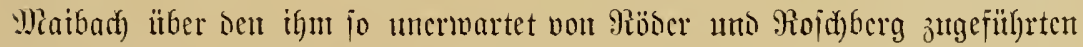

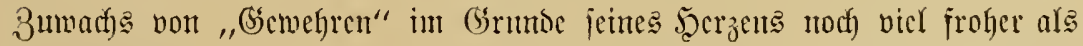

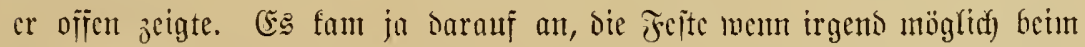

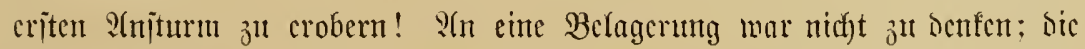

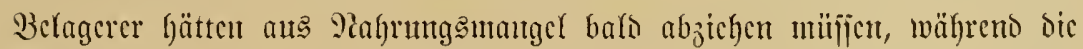

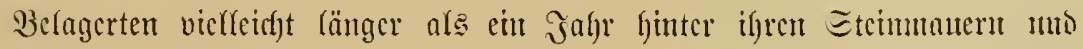

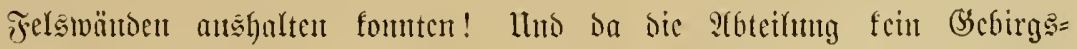

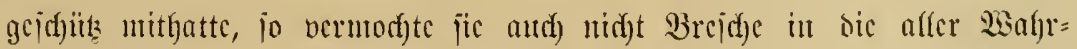

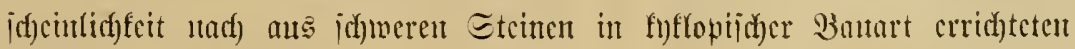

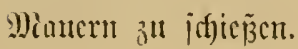




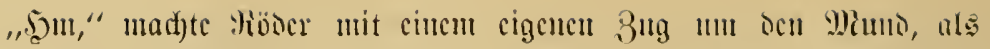

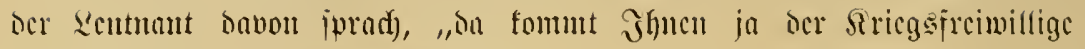
Pä̈er an Ente ichr gelegen!"

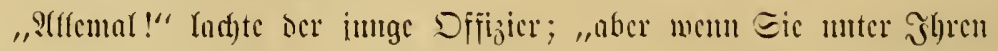
Reuten cin paar Trompeter von Jeridgo hätten uno bic Miancrn umblajen tömuten, wären Sic mir offen geituntocn no d) mi(lfounucucr!"

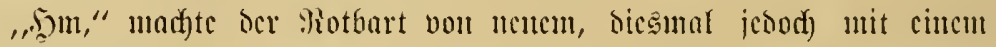

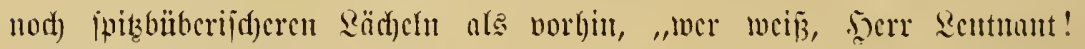
Il mblajen ja wohl gerabe nicht, aber fjicr mo on cin tübthtiges Stïaf

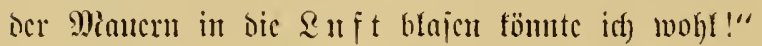

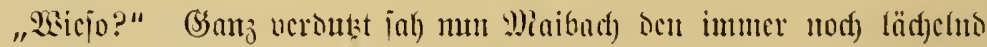

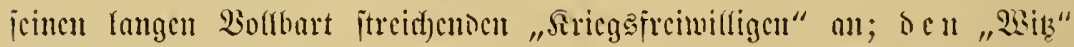

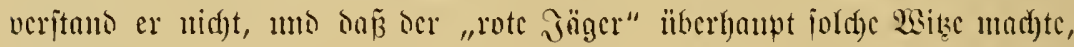
molfte nicht jo rect)t ju bem jtimunen, was ar bon bem Miame gejeljen uno

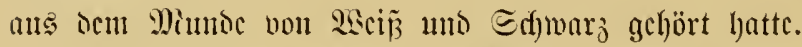

„Эd) meine, wem bie Miancen aud cbenjo jtart wic bic bon Siborosmwa icin jolften, mit meinen 30 Stïct Dunamitpatronen weribe idt)

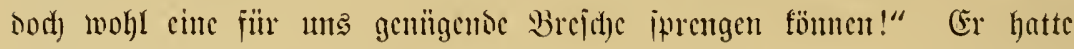
ganz glcidymütig geiprodjen, als of cr gar nid)ts lltberraichentes vorbräct)tc,

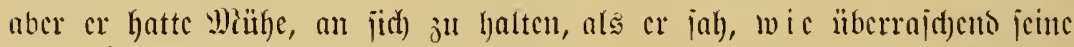
REorte wirften! Der bemegliḍc Sentnant jprung von jeincm Expenitions= Sllappitulfle anf umb jtarrte ifn wortlos an, cr, ocm bic Werte boct)

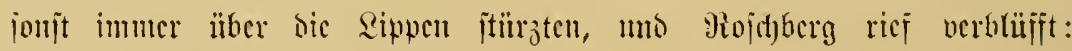

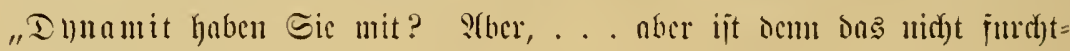
bar gefälyrlidy?!"

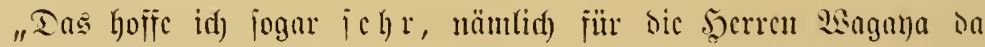

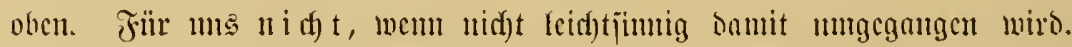

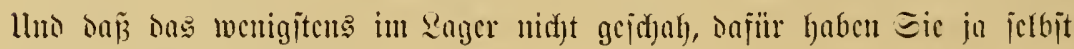
imucr hejtens mitgcjorgt!"

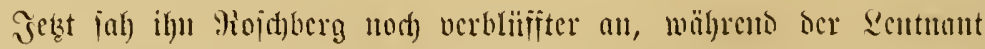

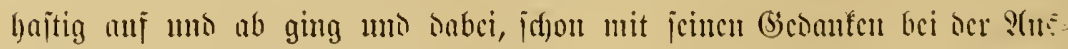

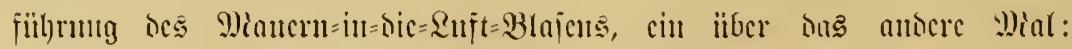

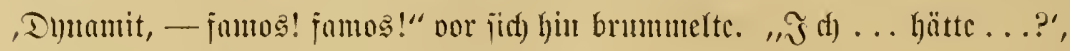
Miojd)berg bracte die Frage tumm herane. 


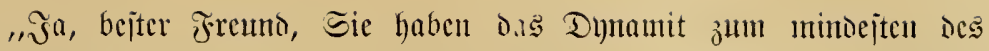
Rad)ts mit iem eiganen Seibe gegen Dicbĩtahl unt llnfugtreiben gedect; Denn Sie haben itets über Den Sprengpatronen geid)lafen!"

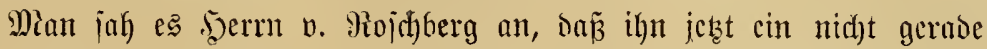

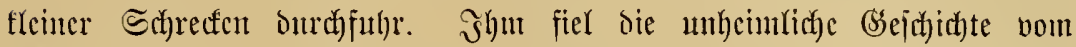

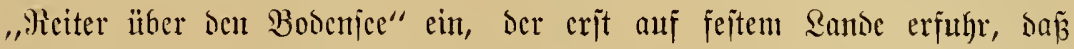

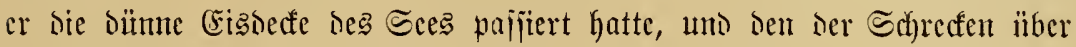

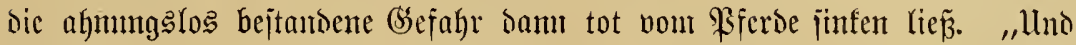

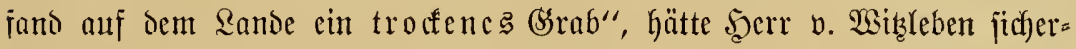

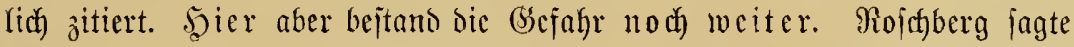

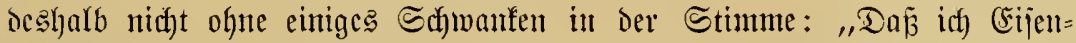
bledffijten mit ber (S)ewehrmunition unter meinem Feldobette hatte, wie

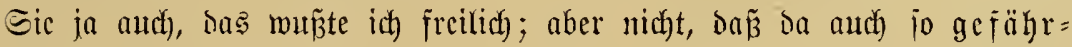

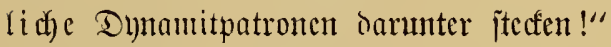

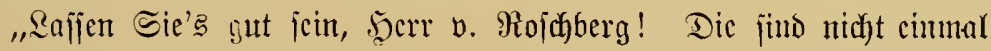

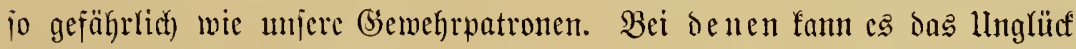

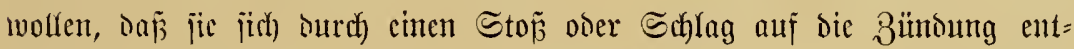
faden. Bei ocu braumen Dingern in ocn beiden nodh extrajtarf in Dejjen= Gäıte eingenühten Sijten Dy I uno II - Punumer II j̇ano übrigens unter mciucu Bettc! - da fam bic Explojion nur burd bcjontere

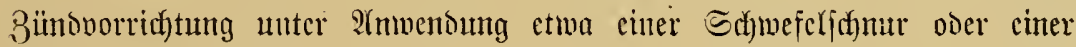

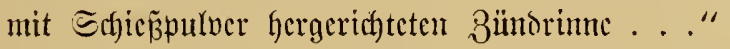

(Er brach mitten in Gakze ab, ocnn bei den cinen Pojten war cin

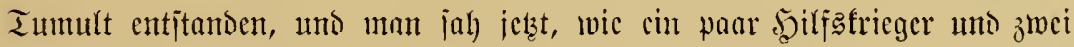

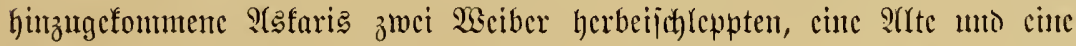

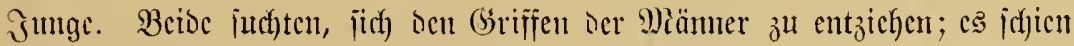

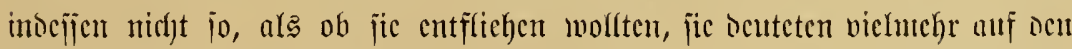

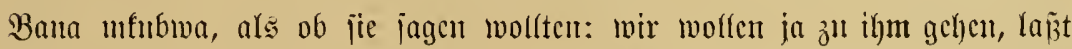

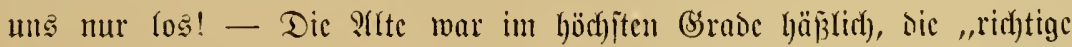

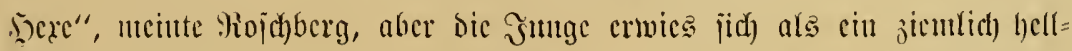

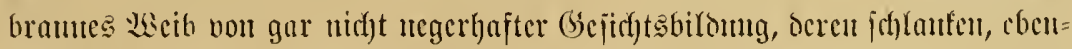
mäp̄igen Siörperfan man ocjto genuner jal), weił igr bic Sente währento

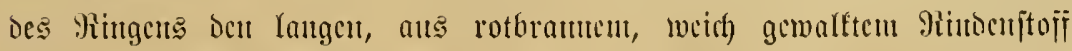

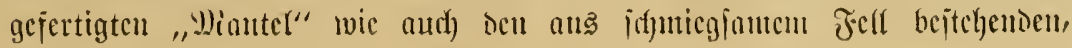




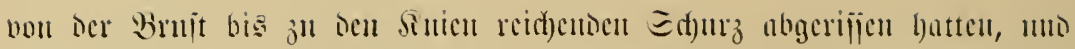

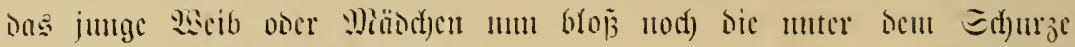
getragene bunte Fisrlenfette mo sic ïblichen Drabtipiralen an Beinen mo S(rmen an jiuf) hatte.

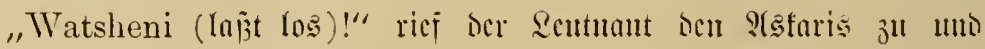

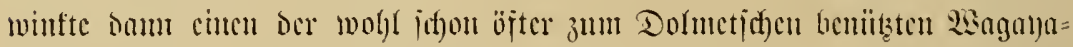
Sirteger heran. "(bebt ihr kanga mo shuka micocr!! - № babt ih)r dic sisciber gejmmon?"

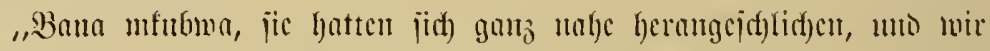

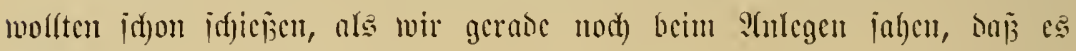
sisciber jinto."

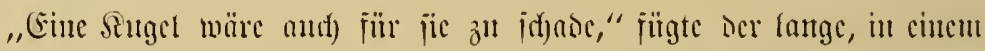

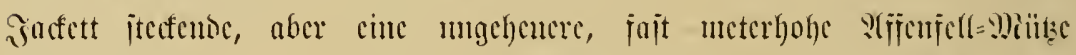

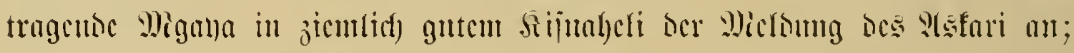

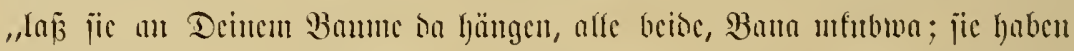

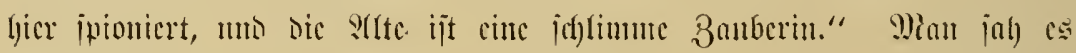

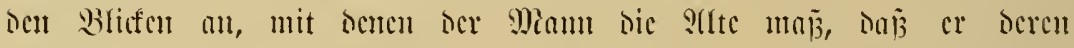

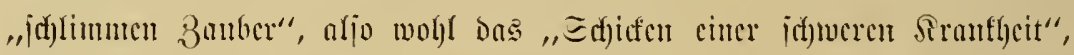

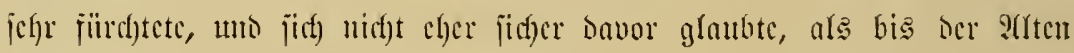

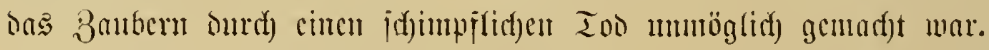

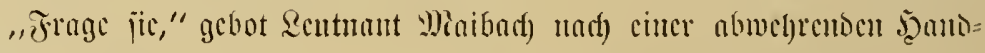

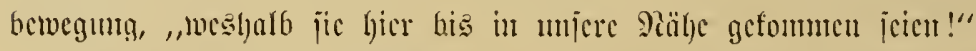

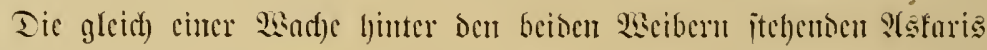

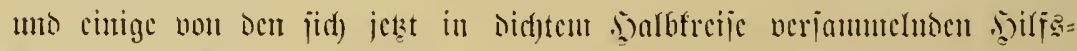

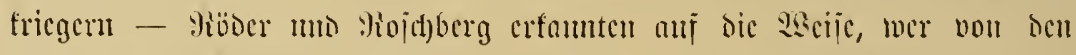

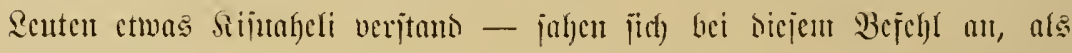

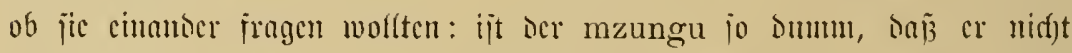

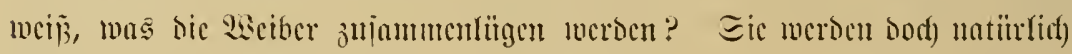

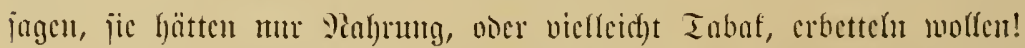

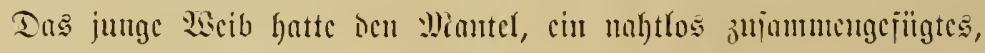

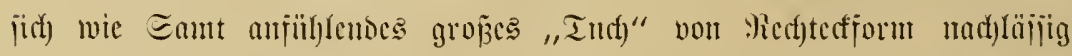

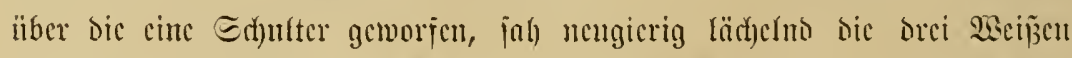

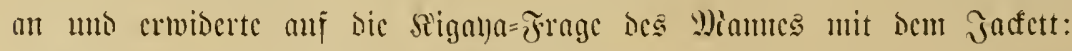

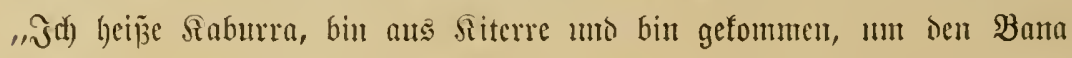




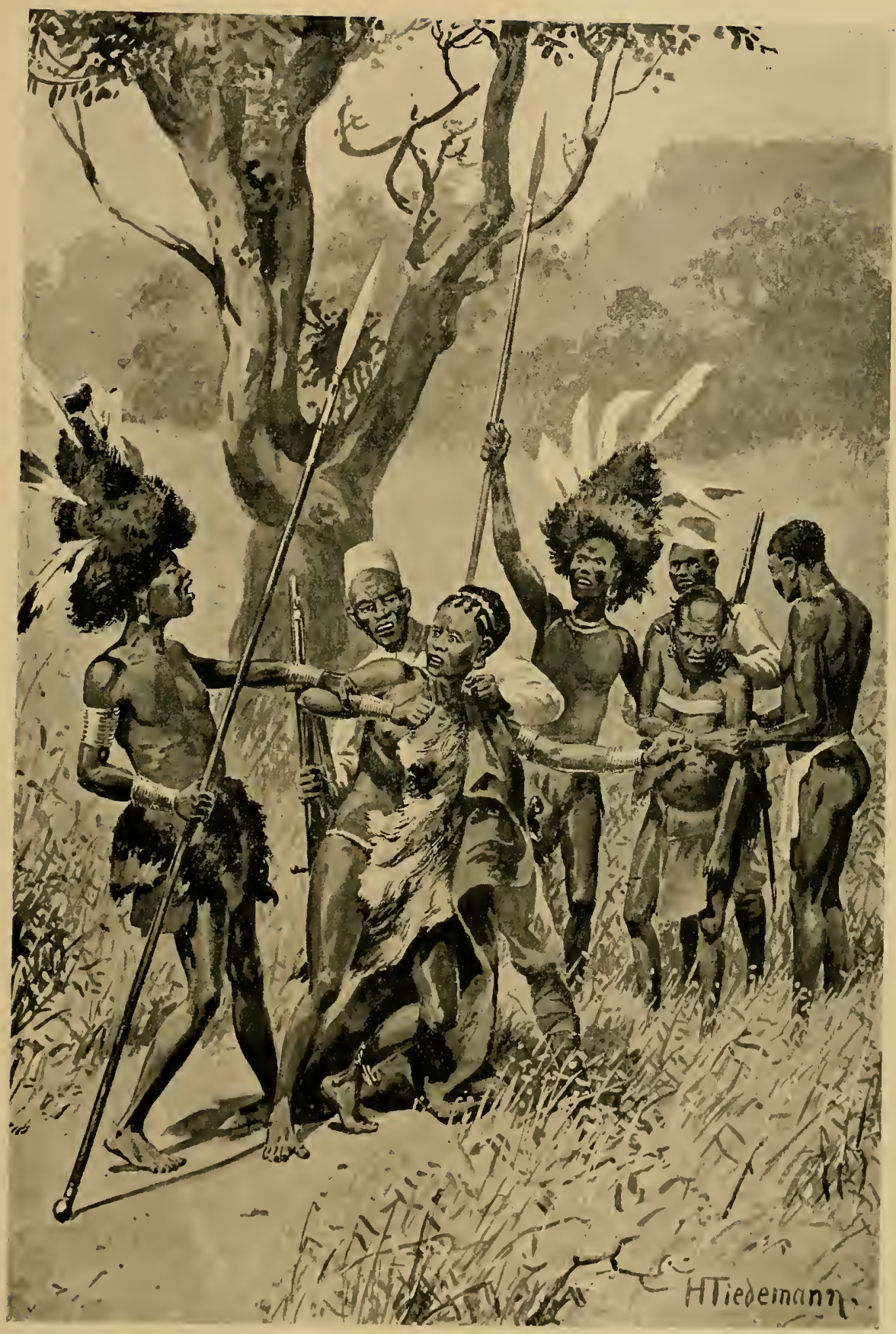

Beide fuchten, fich den Griffen der Männer zu entziehen. (Evite 377.) 



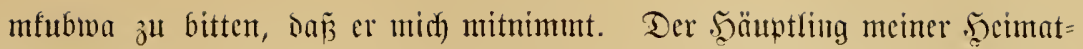

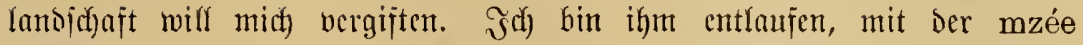

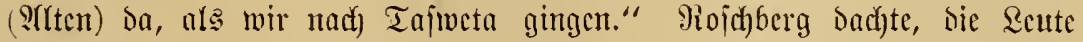
Iachten bas জscib orrauf hin mur aus Refpeft vor dent Bana mfubma

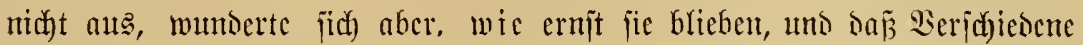

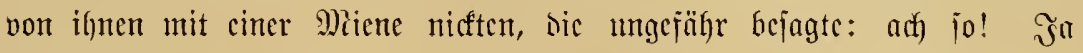
b a nn hatte fie redht !

"So", verjetzte ber Reutnant. "Der manangua", mit biejent $\mathfrak{B o r t c}$ hatte Der Migana bas Wort für Şüuptling ober Sultan übericţt, „will

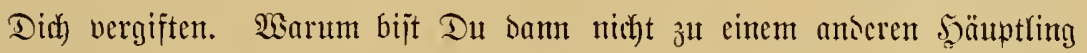
entflohen, in ein anderes Dorf?"

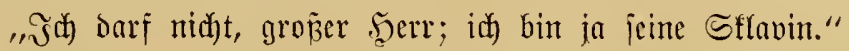

"Dann Darịit Du bod) aud nicht ju une 2 scip̃en flichen."

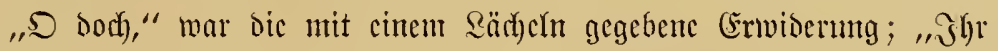

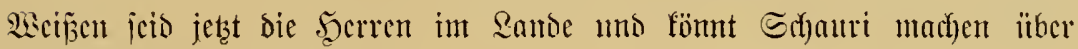

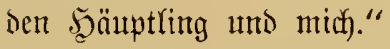

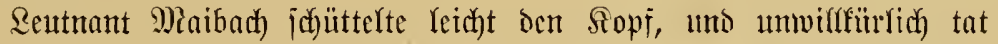

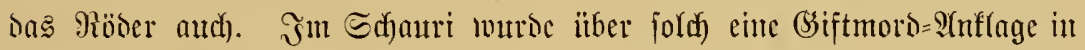
Mauatza wic unf jeser Etation bes Эnneren oft genug geurteilt; aber saum waren Siräger uno Betlagter jtets jugegen.

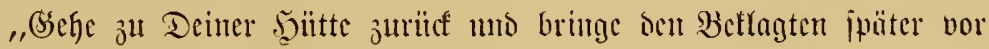
Dcn bana shauri."

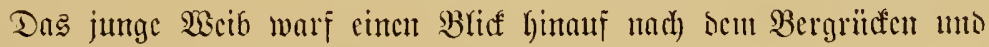
jagte: "Er wiro bas Edjauri nidyt aumelyuen."

"Dam fann idh chen nich)t urtcilen."

Ein zujtummentos „Lo!"“ uno cin ranggezogcues ,Eh" flung halb=

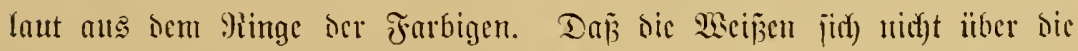

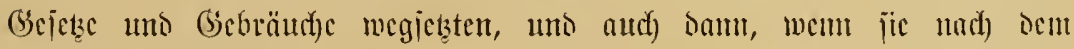

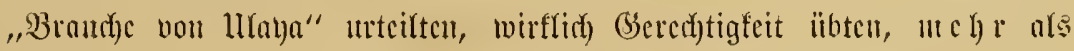

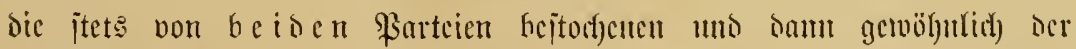

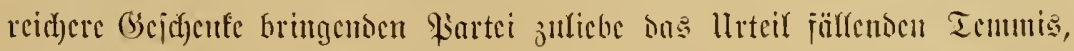

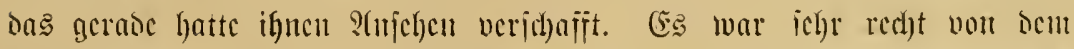

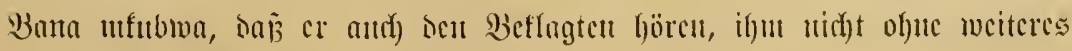
jeine Ellavin wegnclymen wollte! 


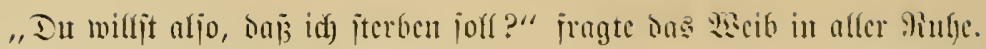

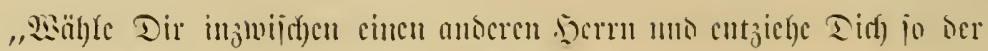

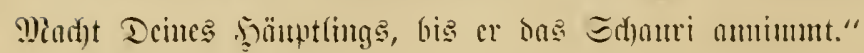

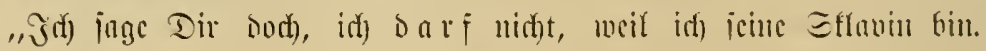

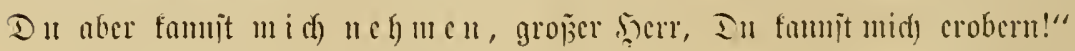

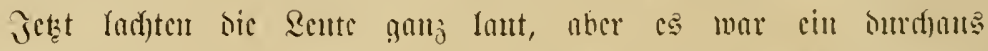

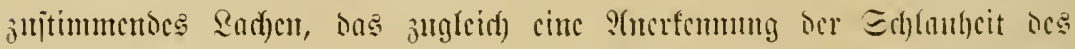

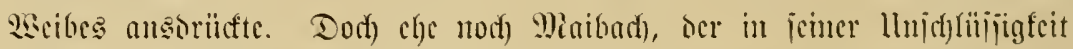

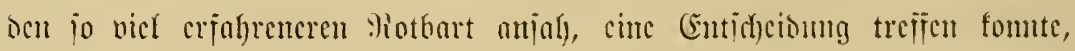

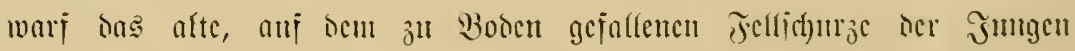

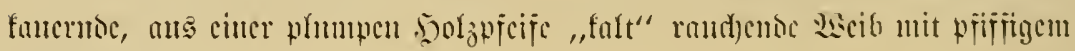
Griminen cin:

"Alnt Du famit dic Gicjangene ja bamr and jwingen, Dir Den

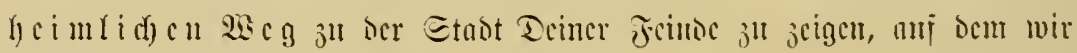
centuididen jims!"

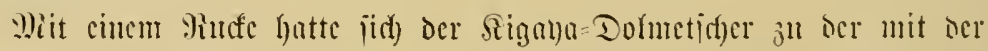

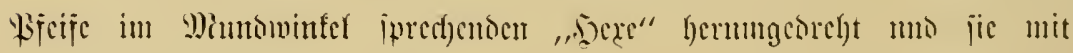

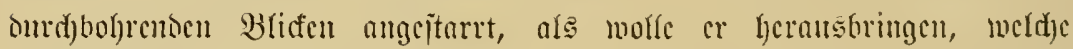

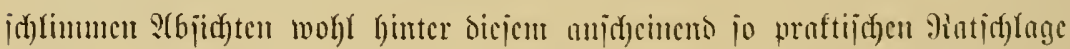

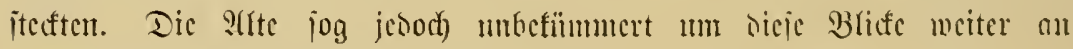
ifrer ansgebranten \&ifcife. Dann iiberictste cr igre sisorte.

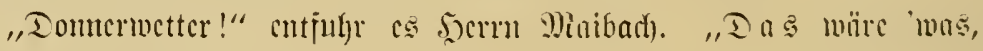
memn mir ungejehen bis vor bie Nianern fämen!"

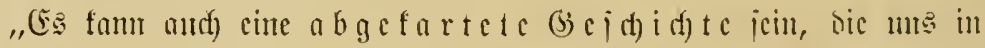

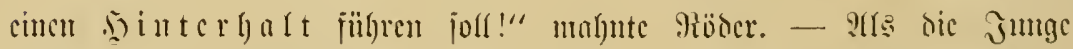

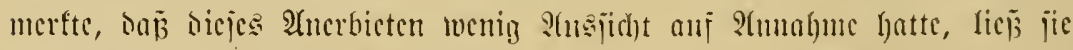

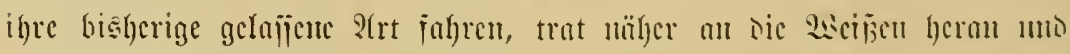

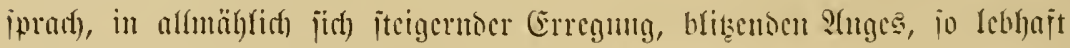

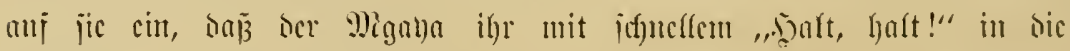

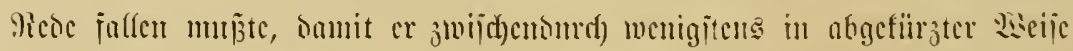

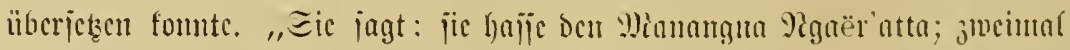

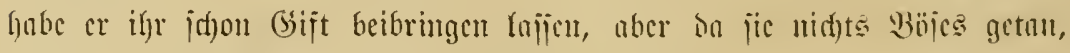

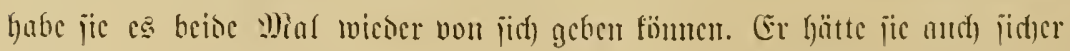

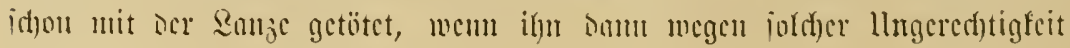




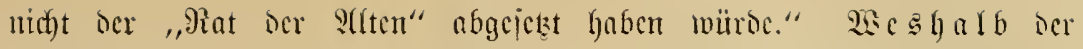

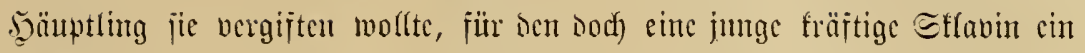

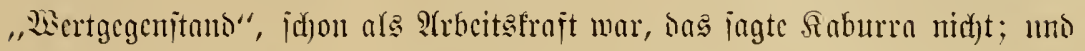

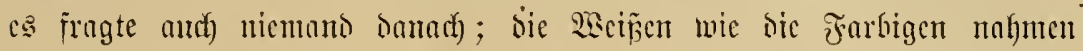

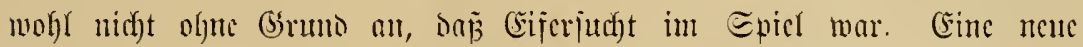

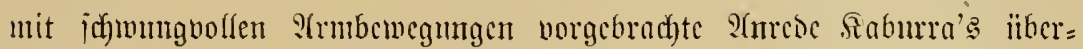

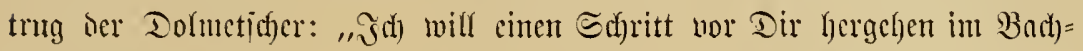

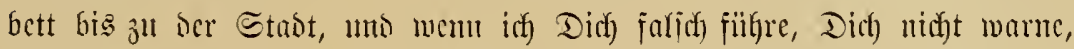
menn ich Gsejahr jehc, jo fammit bu mir Deinen furzen bunduki an sen

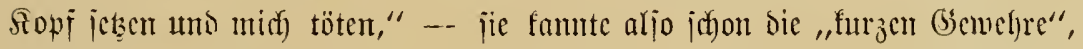

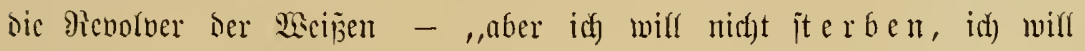

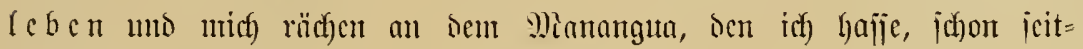
bem cr midf) gefauft hat!"

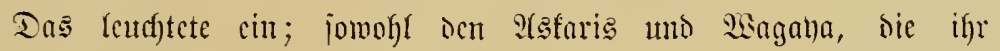

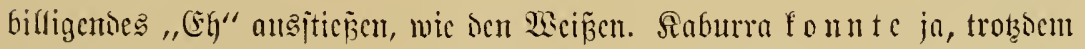
jic ïid) Derurt ale (ścijel antoot, Derrat ïben wollen unt babei hoffen, in

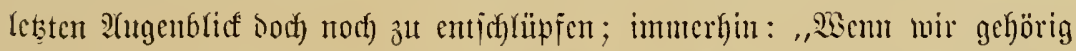

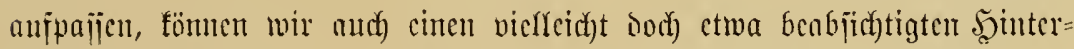
halt wermeiocn," meinte Rööer nach einigem Rachbenfen; "unt jelbit bei cincm Siampje würoen wir's in bicjem Falle nicht jo idfuer haben, als

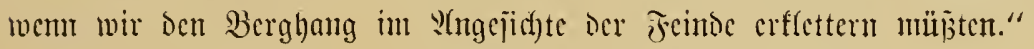

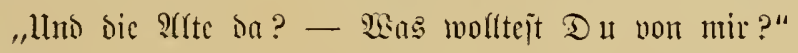

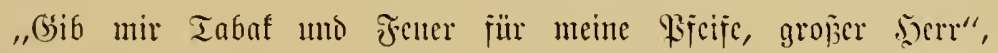

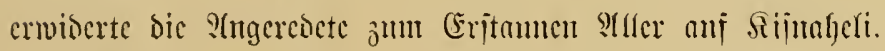

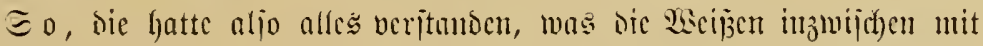
bem Dolmeticher uno sen jarbigen Efargen gejprodgen hatten! llno juerit hatte jie boch ifgren Ratichlag mur ani Sigana norgebradt, nuo jo getan, als

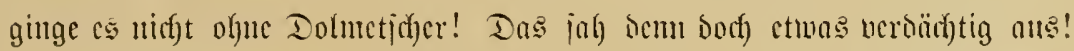

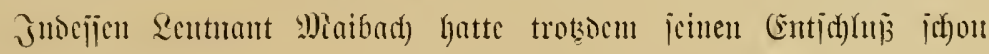

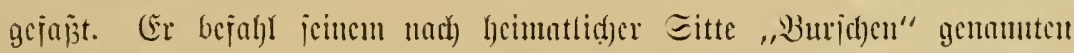

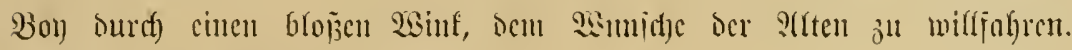
"Jlyr jeis aljo Beide entranjen!"

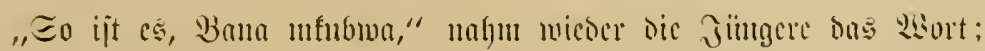

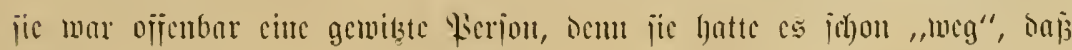


Der Difizier jie im Rager behalten würbe, unt war wieder ganz rufig geworben. "Matebe iit nit mir gegangen. Der Wanungna jürnt iffr,

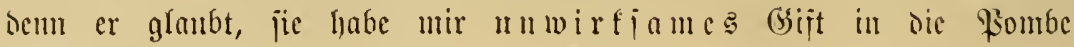
gej(j)ittet."

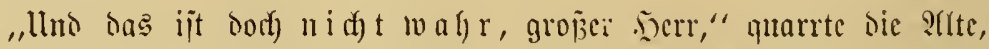
ummittelfar nachiem ber Migana gedo(metict)t hatte; "Siaburra fam ce

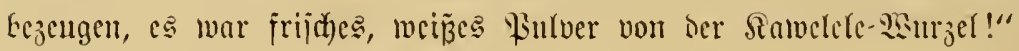

"So ijt es, groj̄er ,jocr!"”

Rojuberg fuñte jidy an bie Stim. Dantte er bus bem ridftig veritanden? Dic jlucintal bem Bsiftmoroc Enttgangente entflol) zujaumen

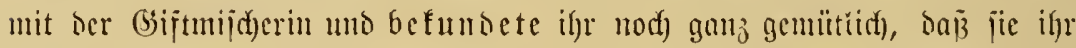
ni d) t Davongeffoljen, jontern wirfiantes (sijt eingegeben habe?! - -

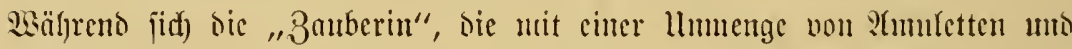

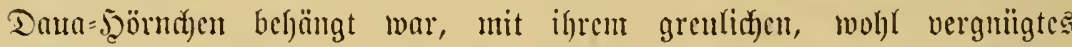

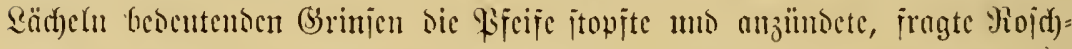
berg ien Rotbart, wie jold) cinte gemeinjante Findf)t ber beisen Iodfeinte betur nur möglidf jei?!

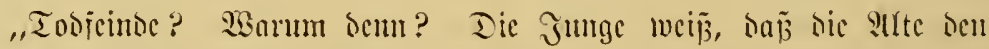

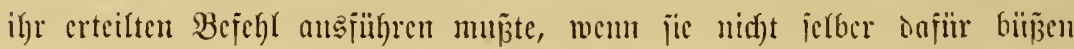

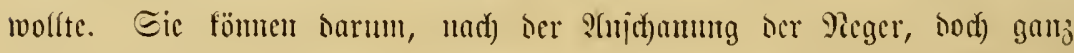
gut Freunt jein, unt nad) bergeblict)er Bergiftung and ferner gut Freumo bleiben. Llno sa jit beibe ihren liebenswïrsigen j)errn Eultan ju fïrdyten haben, jo haben jie jidf elen gemeimioni unter oen Edyuz Dejien gejtellt,

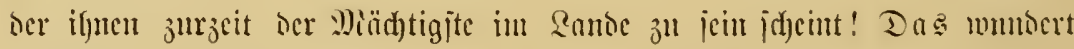

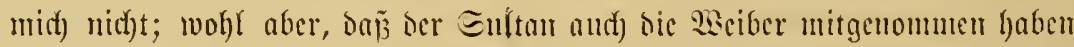
jolf, als er fich mit ben anteren .jecrfanjen in Tasmeta vercinigen wollte.

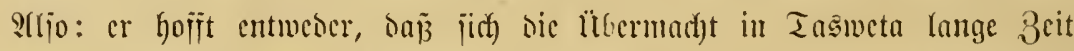

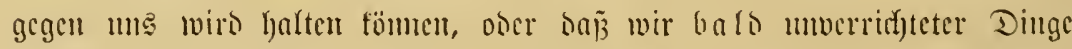

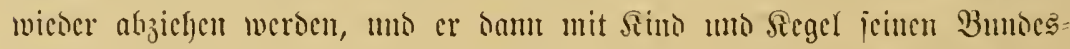
briiben, rejpeftive was nod) von ifmen iibrig ijt nuad) ocn Sï̈upjen sicjer

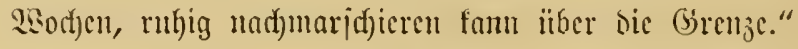

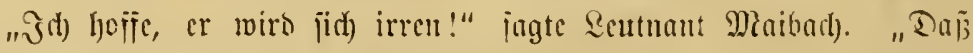

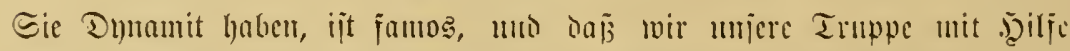

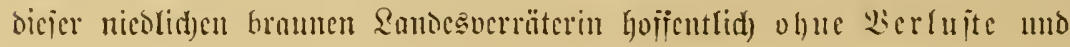




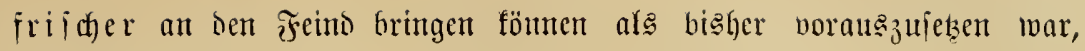
ijt mir audh nicht unlicb. - Unter offizier Dähne!"

(5r übertrug dem offenbar von Fieberaufüllen recht mitgenommenten Ilnteroffizizier bie Fürjorge für bie beiden $\mathfrak{W e i b e r ~ u n t ~ z u g l e i c h ~ D e r e n ~ i c h a ̈ r f i t e ~}$ Berwachung. "Madht (Fine etwa ben $\mathfrak{B e r j u d h}$, ju entfliehen, fo regen Sie Beide an die Fette!" Und jith aud zu ben beiden anderen Seerren wendent, jeţte er hinzu: "Eine Stumbe, nachbem wir gegeijen haben" — er jah) nach ber Hhr - "mein, gleich nach demt Efjen, marjatieren wir ab. Wir haben bann fajt noch vier Stumben bis Somnemuntergang. Das Sietter idheint gut zu bletben. Wienn wir damt bis Mitternad)t gefagert

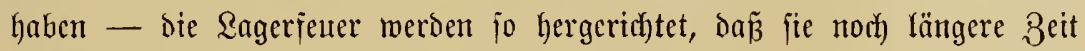
breumen, io daj etwaige Beobachter glauben müfien, wir lagerten nod), Sie jorgen Dafür, llnteroffizizer! - Dann jezen wir uns in Marich nact) Dem Bachbette, von Dem Die Raburra vorhin gejprochen hat." (Er jeţte

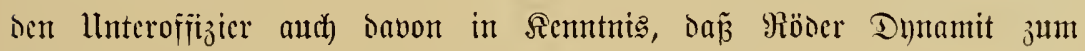
Sprengen ber Miauern zur Berfügung geiteflt hätte.

"Dynamit?" l̈̈ber bas fränfflidhe, hagere (Sejüht des llnteroffizier:

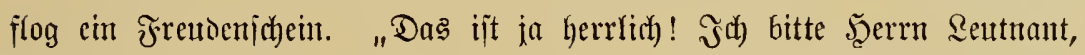

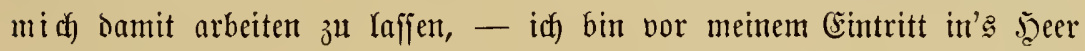

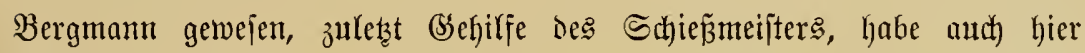

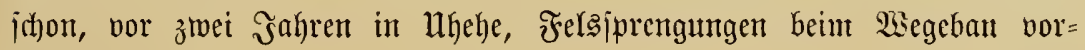
genommen!"

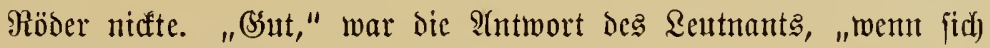
aljo Şerr Piöber bas nidht affein vorbehält -"

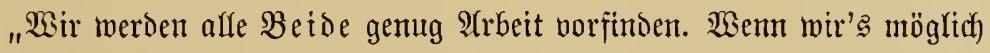
madhen fömtnen, auf zrei Seiten Brejche in bic iteinere Bomta ju regen,

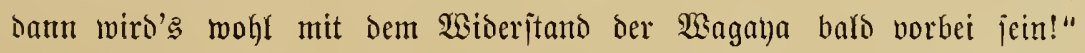

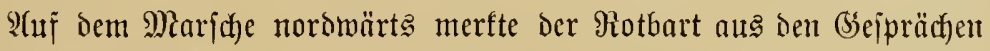

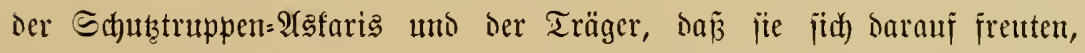

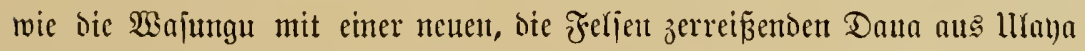
Den wagaya wabaya zu Leibe gehen wollten. Da über bie Dunamit= patronen ja mur beutid) geiprod)en worden war, aud) Päber's Rente voritent

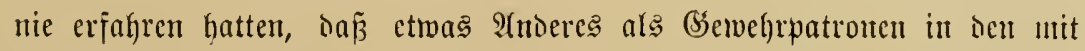

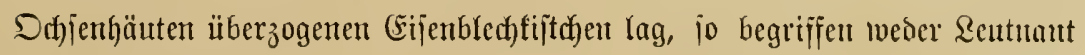




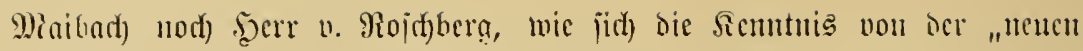

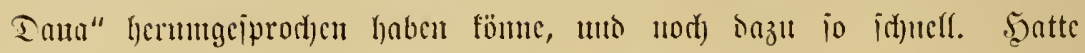

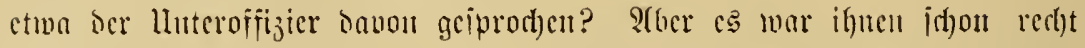

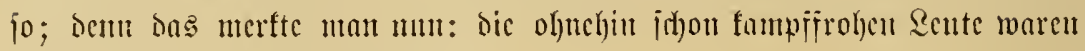
jekt jutucrijudtlicher als jeutals!

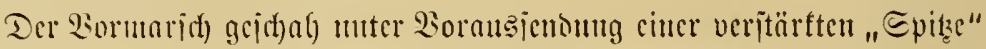

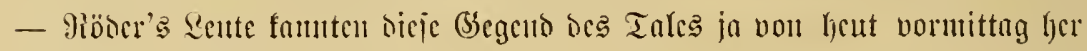

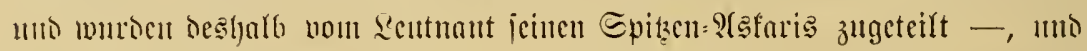
sic uöglichjt cug aujgeid)foifene Truppe murbe und) nod) burdh eine 20 Manu

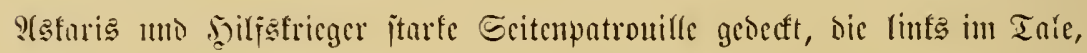

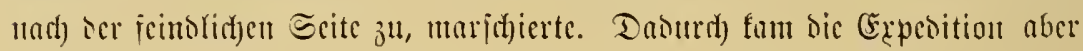

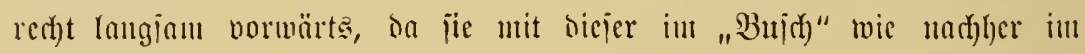

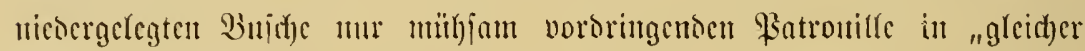

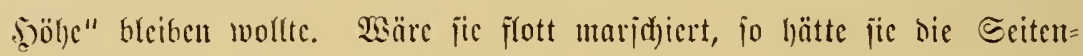

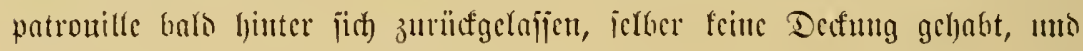

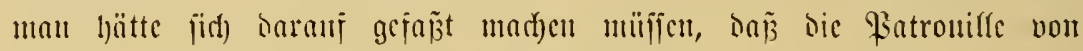

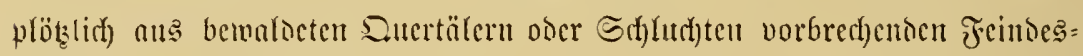
haujen in cincu Sinupi verwicfelt uno bei grofier l̈tberunad)t wohl gar

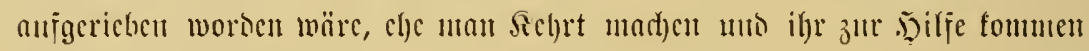
fomute! Dajis das "Gros" ocr Expedition angegriffen wurte, war nict)t

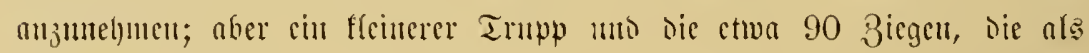

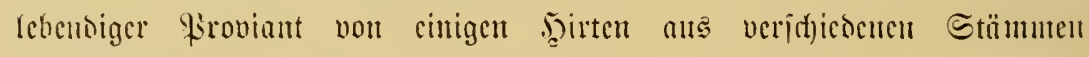

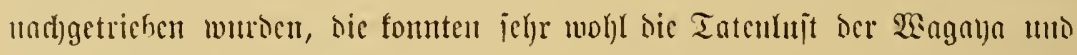

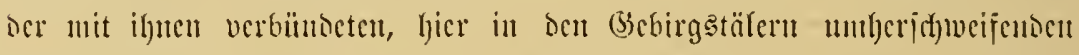

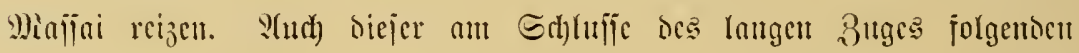

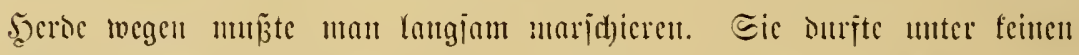
lluitüuthen verloren gehen! Deun ohwohl cille Mienge von Trügcin ic

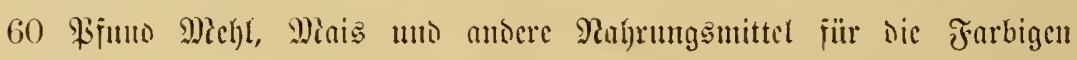

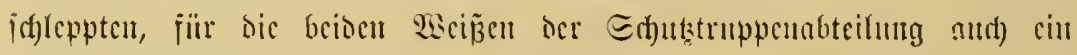

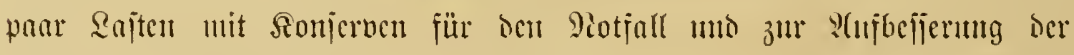

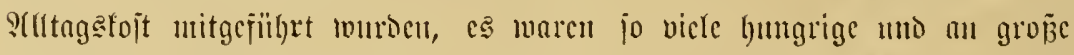

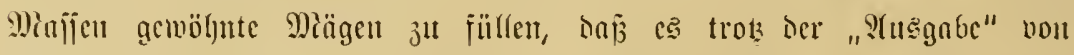

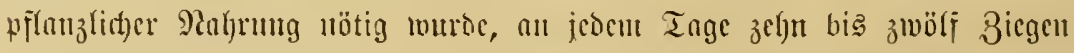

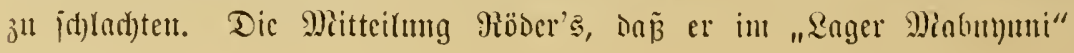




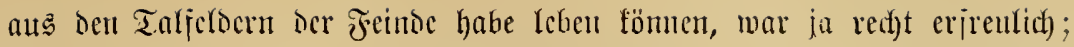

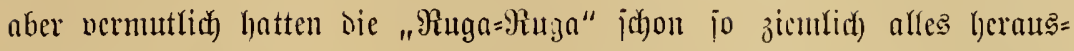
geholt, was reif war, uno jo mïrbe cs mohl bahei blciben, was Reutnant

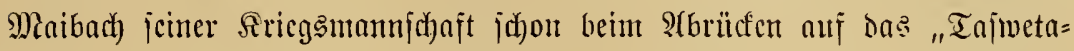

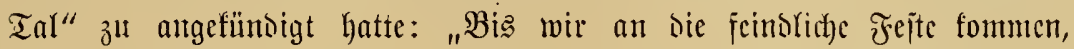

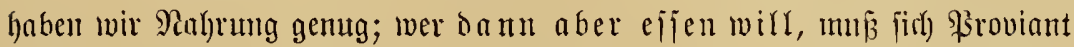
aus ocr Jefte holen! ”

Srlyon bcinalye eine Stunbe vor Somnemuntergang war bic Expedition

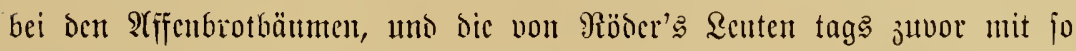

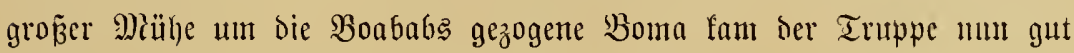

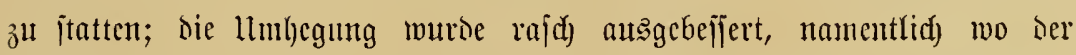
nä̈htlich) Sturm jie arg mitgenommen hatte, uno umichlof́ balo ons sager

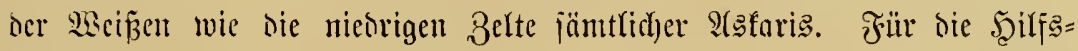

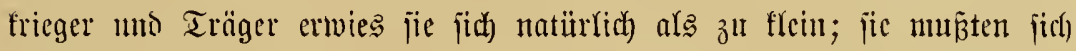

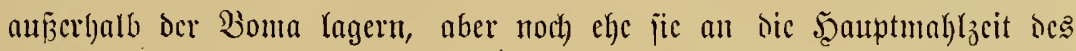

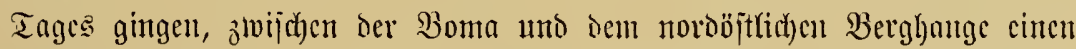
Wielffral crrichten. Die Ziegen, Röber's Miaultier mo fümtliche Sijel,

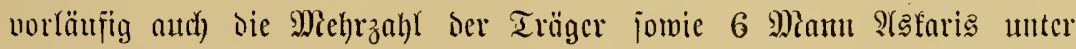

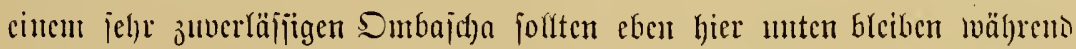

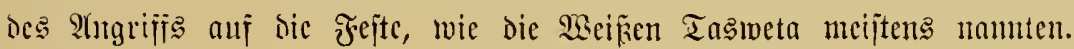

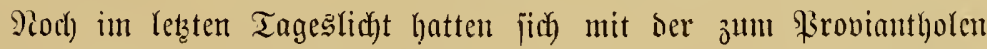
foumantoicrten Mannichajt einige von Miöber's \&enten in dic Feltser

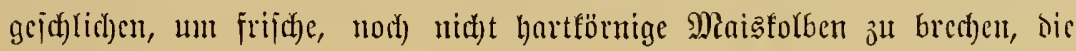

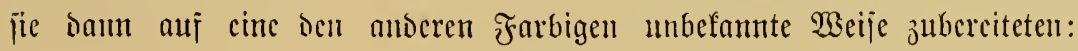

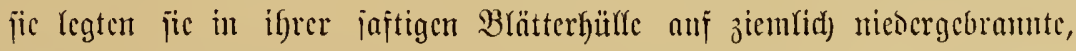

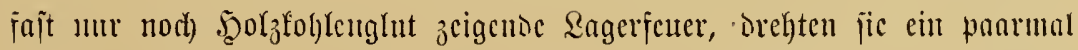
und goutten in wenigen Mimuten cin berrlich) Duftenoes, aud ben anjünglid)

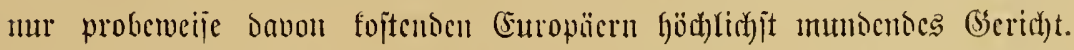

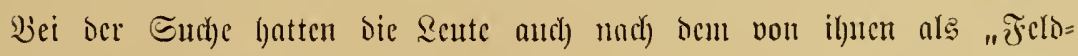

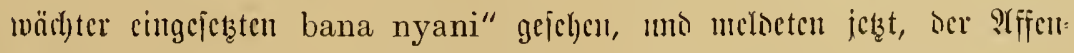

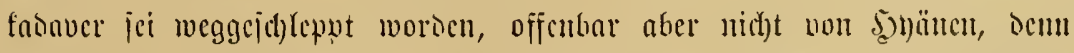

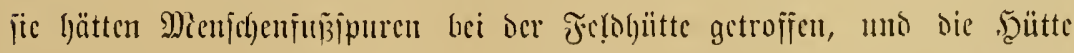

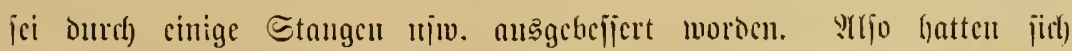

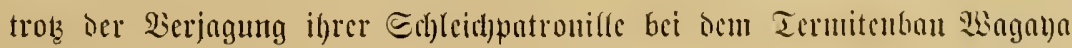




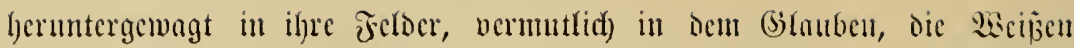
mit ifgrer farawane feien überlyaupt abgezogen! Freilids), ickst hatten jie non ihrem hohen Beobathtungspoiten her in oben auf bem Bergfamme

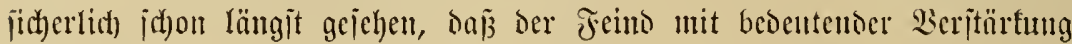
junülfgefommen war, mo paijten boppelt gut auj. Plun, jie jollten mur

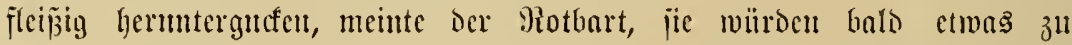

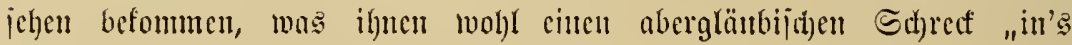
flappernoc Bebein" jagen milroe!

3ur l̈lberraj(t)utg jomohl Des Reutnants wie jeines jungen Reije= gejührten entnahm er jekzt beim Edyeine Des im Belteingange hängenden Sisinotidt)

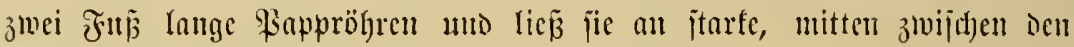
Bonbabs in bie Erose geĩtojene Stöcfe feïtbinten.

"S(h, aud) Bafeteu haben Sic mitgenommen!" rief Jiojuberg eritam aus; "von all bem hatte idh ja feine arhuming!“

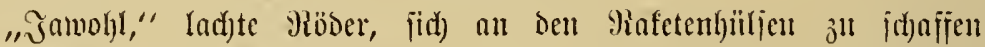

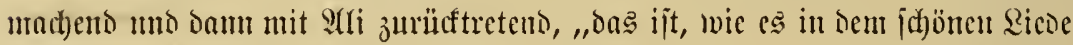
heipt: "Du fennjt mein 5)erz noch) lange lange nicht!" - "Teufel, Teupel,"

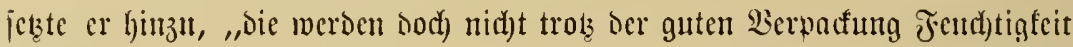
angezogen haben?!" Er hatte vorhin ein mit Bünnmajie verichcucs Stücf Fenerifhwamm an bem Scolzjtabe gericben uno es anf die Spitze einer ber

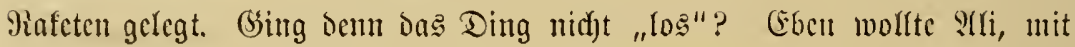

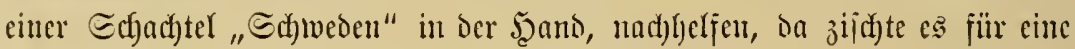

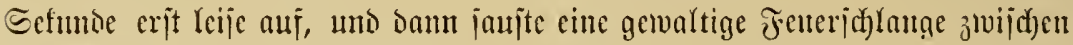

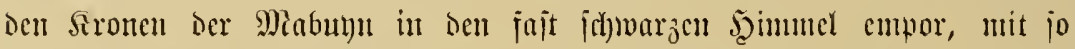

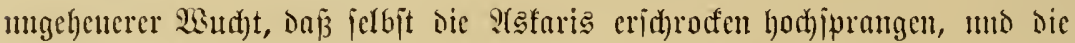

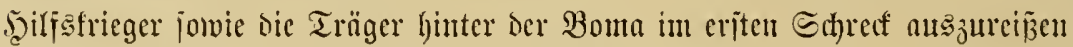

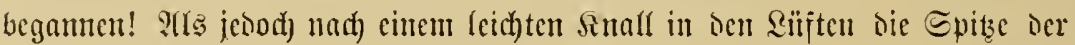

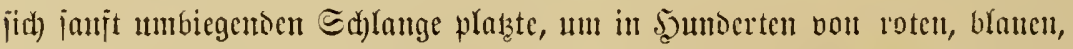

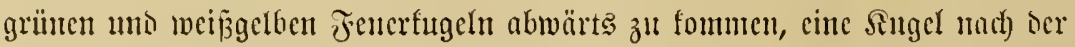
anderen jpurlos veridymant, uno gleid) Danad) bie Stifle ber Pad)t über tem

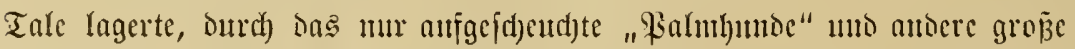
Flencruänje j(d)webenten Fluges jogen, on brad) förmlid) cin Etmm Der

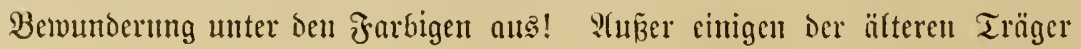




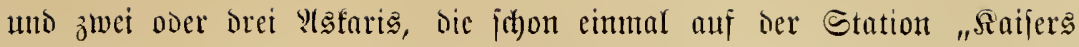

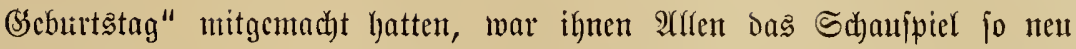

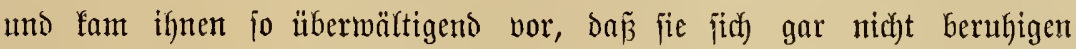

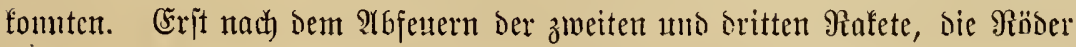

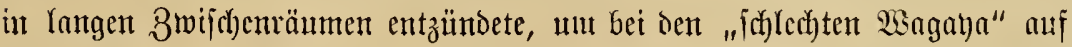

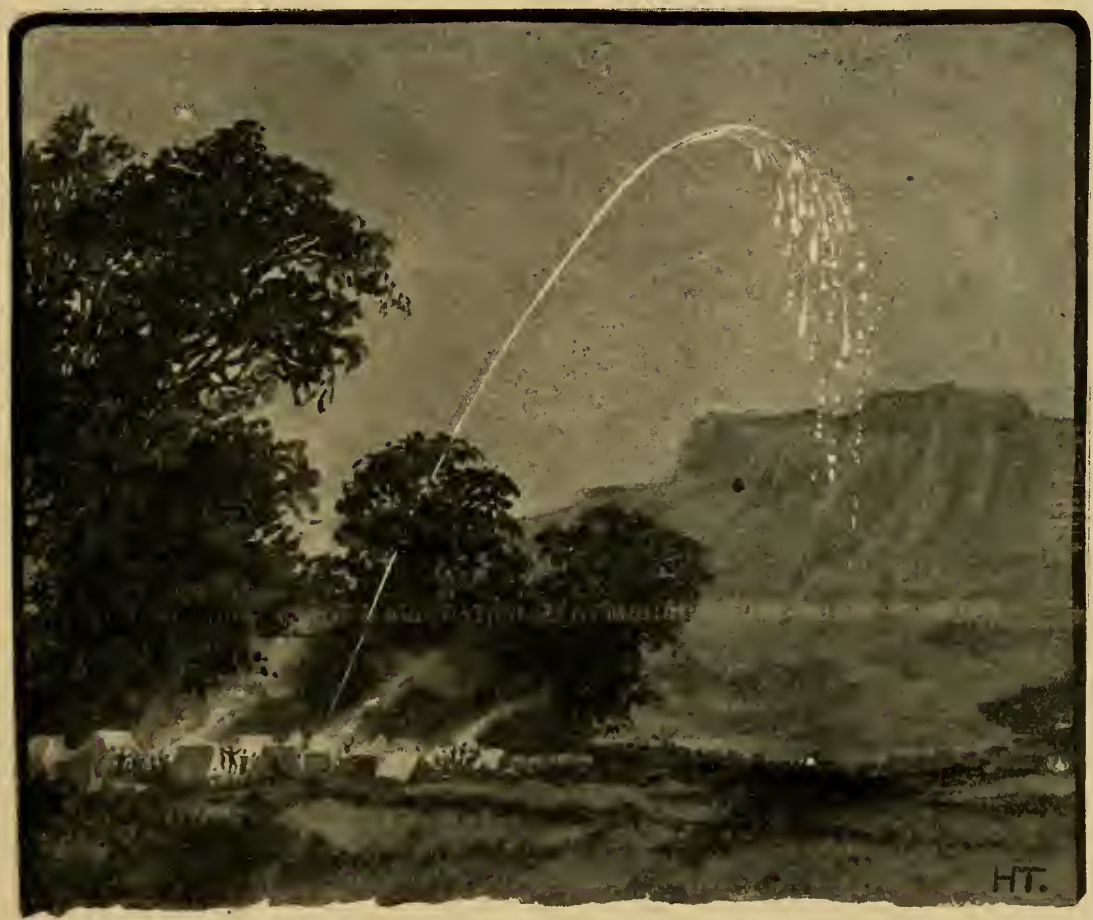

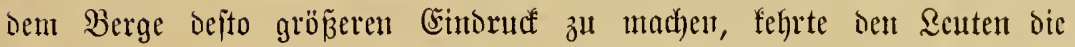

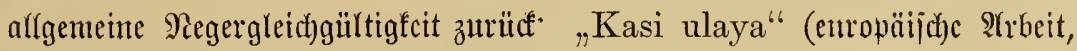
Sache), jugten jie da gelajijen. Die Europäer jitto ebent flïgere Reute als wir Sdjwarze, das weiz man ja längit; ba braudht man fid arjo nicht

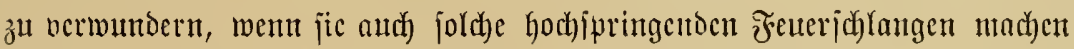
fönnen, die Feucrfugeln aแรppcien unt dann fterben!

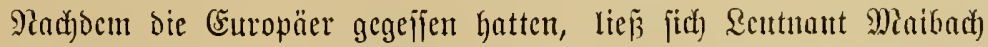

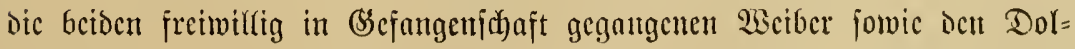
melicher noch eimmal vorführen unt hejpradh mit ifnen in Bicgentwart ocr

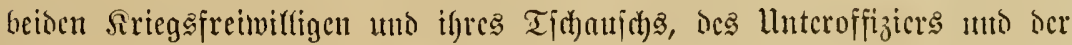




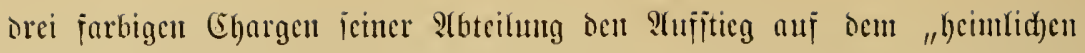

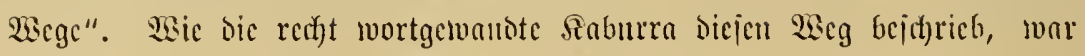

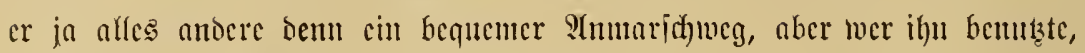

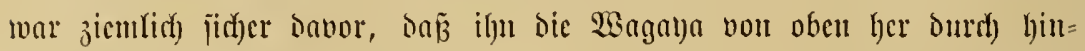

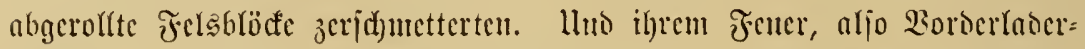
(a)

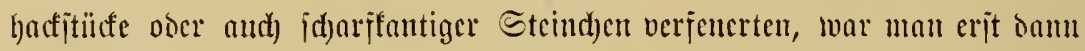

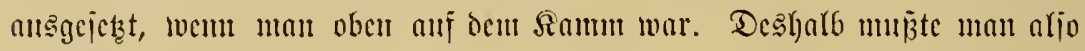

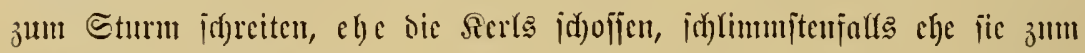

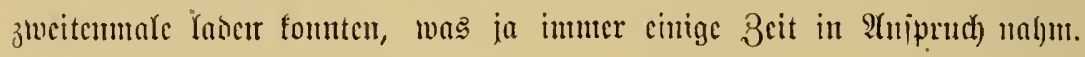

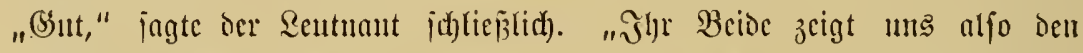

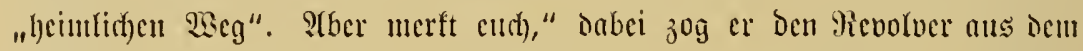

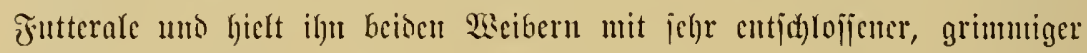

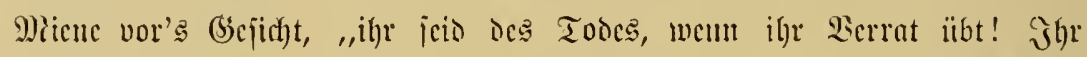

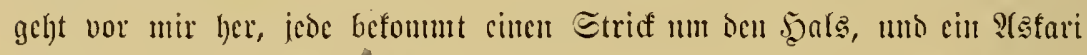

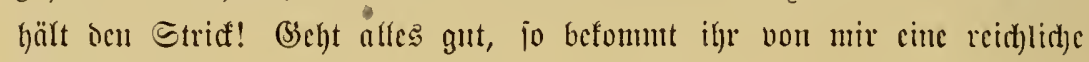
Bicloljumtg."

3ur Bermunderung Rojd)berg's waren dic Beinen ganj Domit cin=

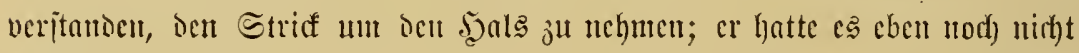

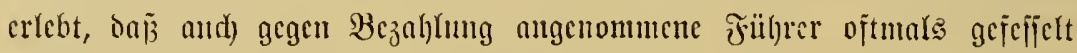

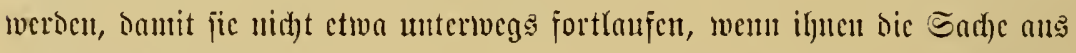

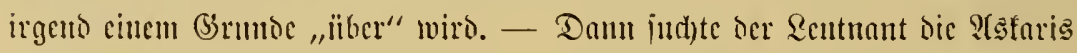

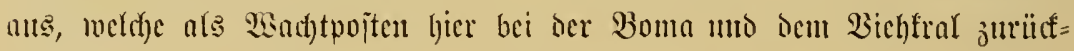

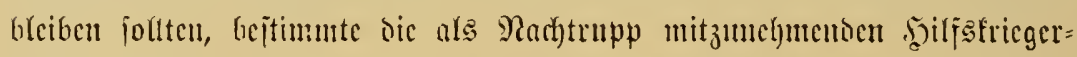

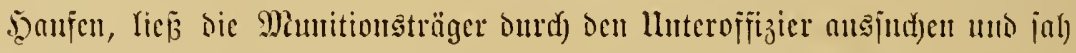

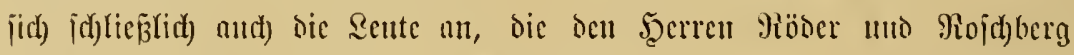

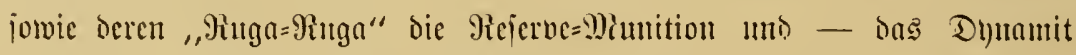

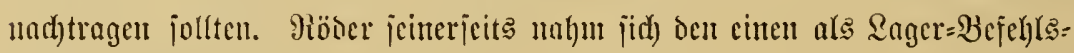

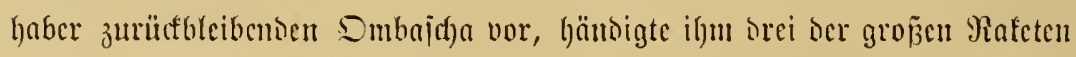

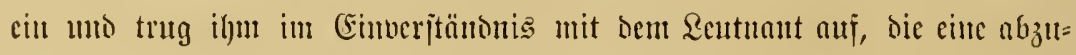

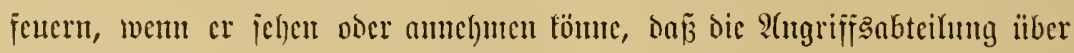

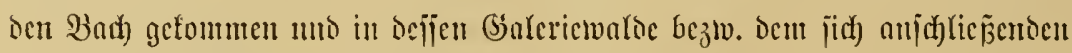

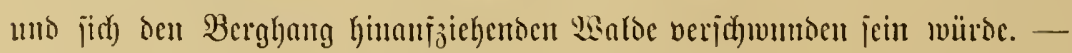

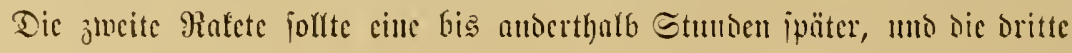




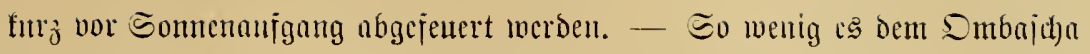
behagte, bã $\tilde{3}$ er hier, "Biegen bewarden" follte, anjtatt jïd) an dem, ,luftigen

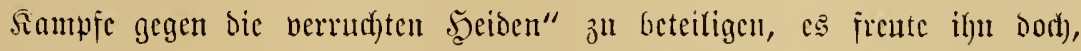

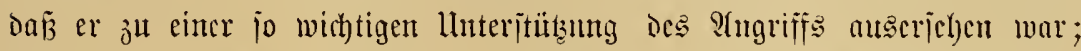

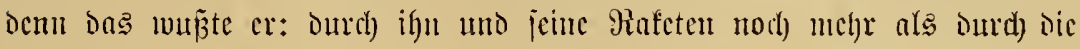
mäbrent Der ganjen Radht weiterbrementen Ragerjence würben bic "ver=

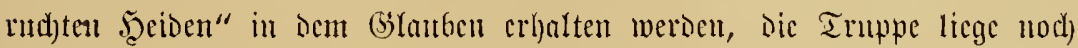
unten im Tale, mofle aljo crit bei Tagestidgt ben bumn redht gejal)rvollen

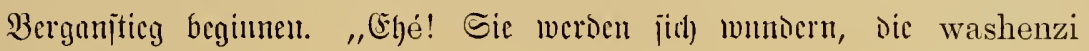
waapizo! “

Paun war alfes vorbcreitct, uno mer nicht als \$ojtcn auf Wadde

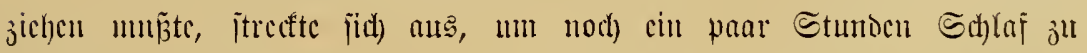

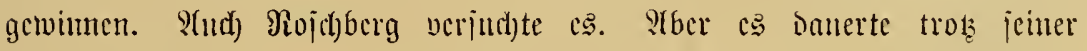

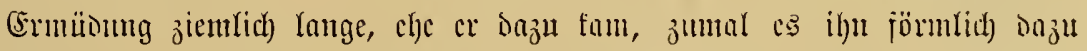

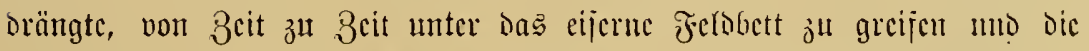

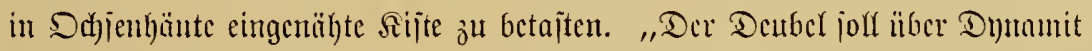

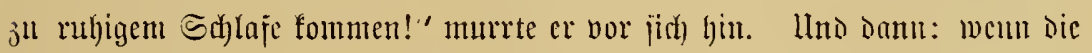

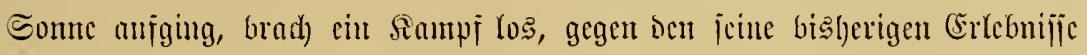
mut Rinderipiel gewejen jein fomtur. $S_{b}$ er ben Tag wohl überlebte?

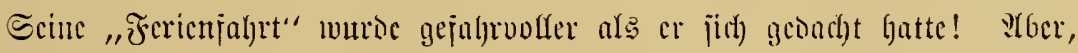

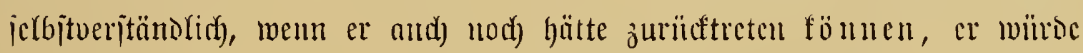

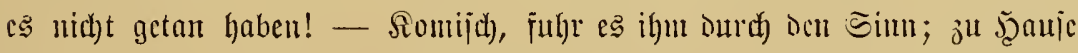

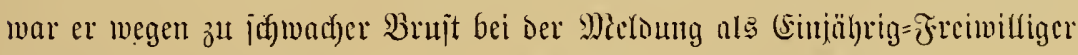

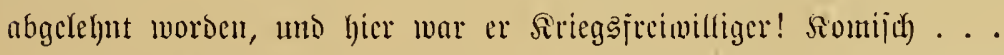

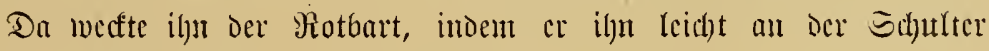

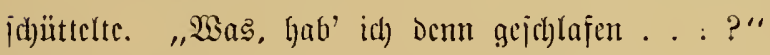

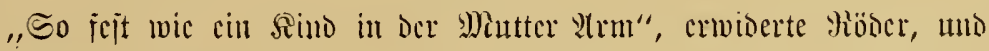

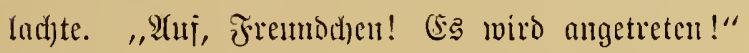

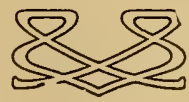




\section{Vierzehntes Kapitel.}

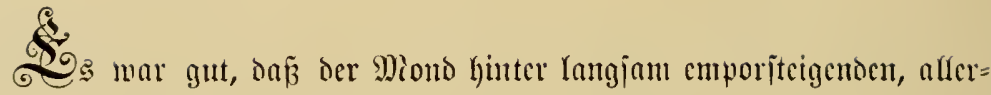

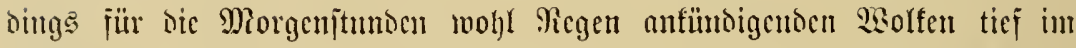

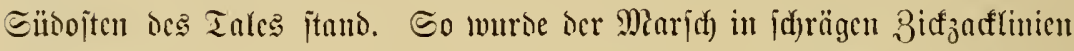

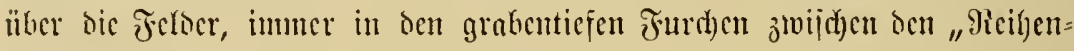

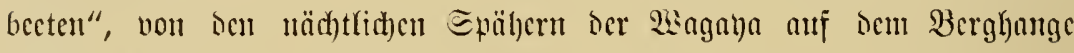

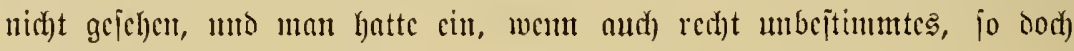

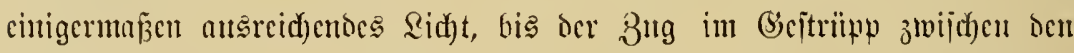

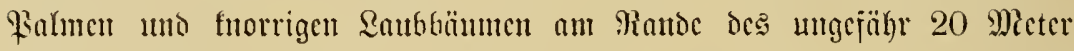

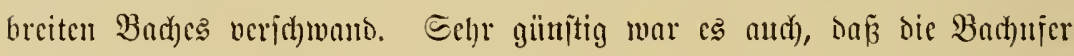
nidyt morajtig, fondern jeteinig waren; fonjt laätte man dic Durdywatung iu

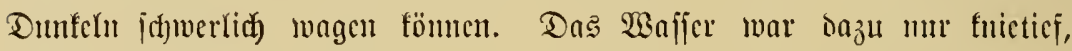

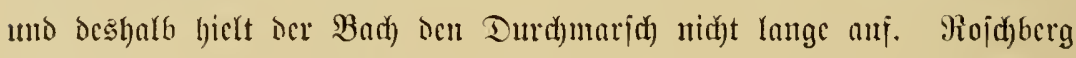
hatte jïh) von cincm jtarfen Iräger auf bie Edjultem mehmen laficn, bic

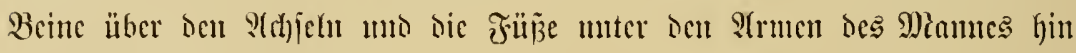
in Deffen Rücfen geflemmt, wic er es von Rentnant Miaibad) fal), docr

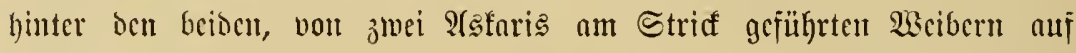

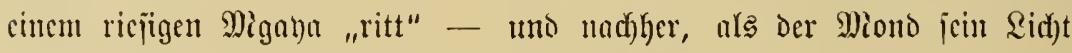
ither Berge uno Tal marf, in jeiner hajtigen 2 seije über "Den Rerl", aber

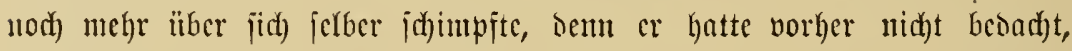

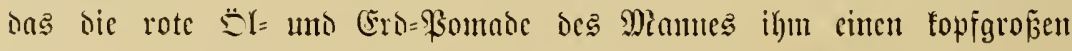

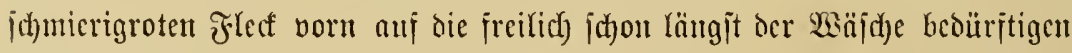

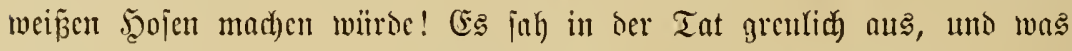
nod) unangenebmer war, alfe Farbigen, bic ben roten \$akzen vorn anf

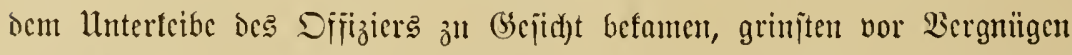
und zcigten jïh) don Reutnant gegenieitig. So etwas hei cinem Mijugu 


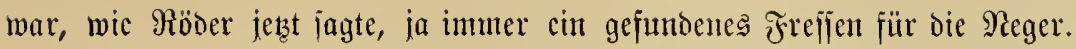

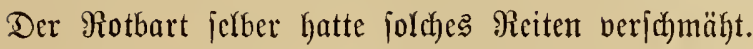

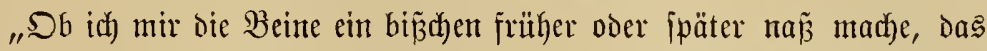

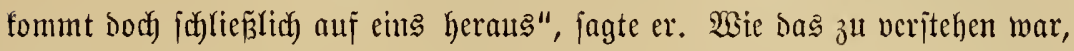

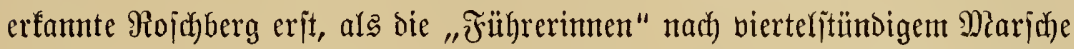
längs oes anderen Bachufers vor einer fefr jumpfigen, mit wilsem Dattel=

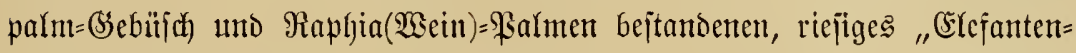
gras" aufweijenton Steffe, Der eriten Sumpfpartie, bic man bishyer angetroffen, nady rechts abbogest unt auf Den Berghang zugingen: Da befam Der Bach einen

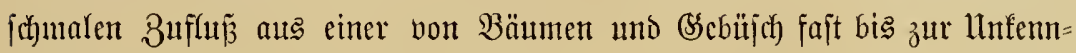

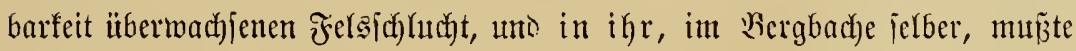
die stbteifung num aufwärts flettern; o a s war der "gehciune $\mathfrak{B e g}$ ", nicht cin trodenes Bachbett, wie ber junge Europäer angenummen l, atte!

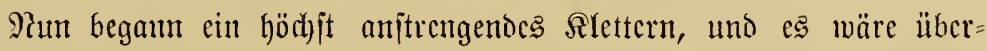

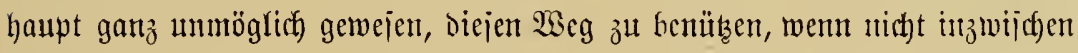

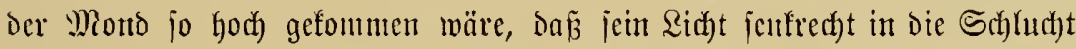

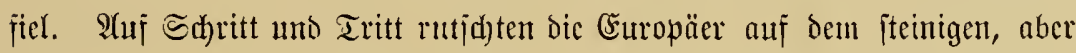

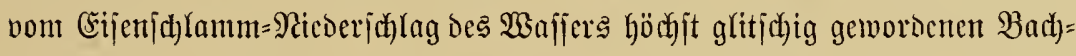

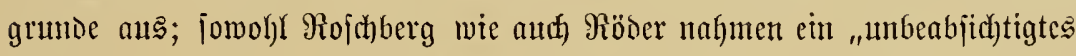

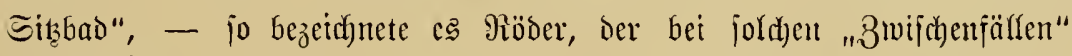
jeinen Şumor nie verlor, auth darn nicht, als biejes Falfen jwijenen bem

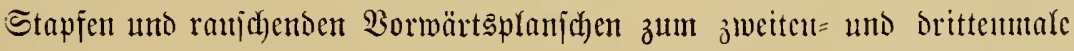
geichah, utto unangenchm häufiger noch Drohte, aber im Yelżten $\mathfrak{A}$ ugenbliaf nod) berhütet wurbe. Die Sahwarzen hatten einen viel jïhereren Sabritt, Denn Die feit ihrem Eintritt in Die Schuthtwppe an Shuffwerf gemöhnten

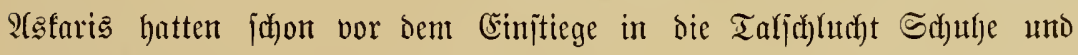
Beinwidfel abgelegt, uno Die Träger wic die Şilfaftreger trugen ïberhaupt weder Safuhe nod) ๔andalen. Dennod) nahm auth bon ifnen jo mandher ein Siz̧̧at, uno einige der mit den Munitionsfijten beladenten Träger ein "ziemlid) fomplettes Bolfbas". 3uerit griffen oa bie Reute vor unb hinter dem in's Waffer Bsejuntenen nach der Sijte; erfit went bie gejichert mar, reichte auth jemans dem Träger bic Şand jutm wiebcranfĩtelyen, tmo bie

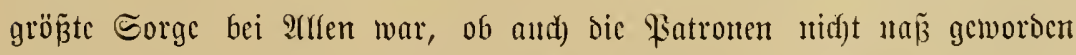

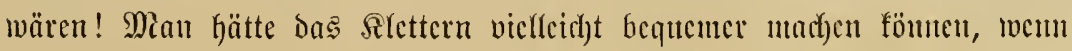




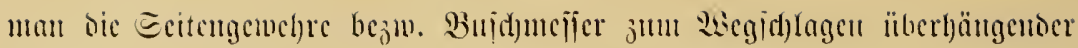

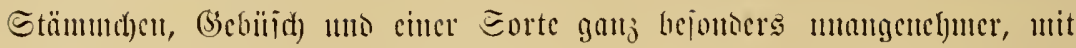

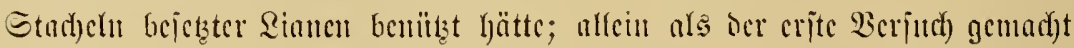

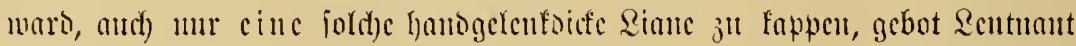

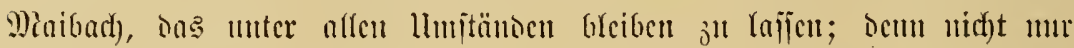

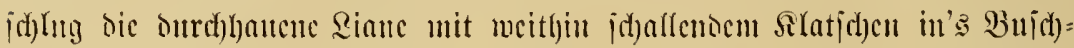

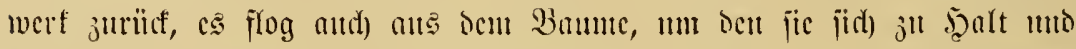

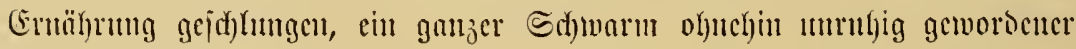

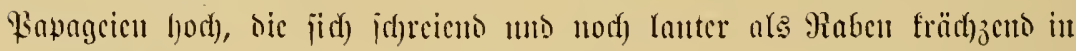

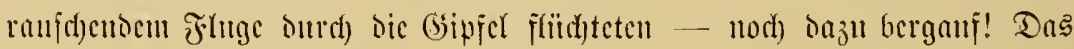

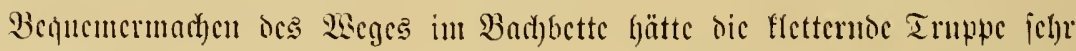

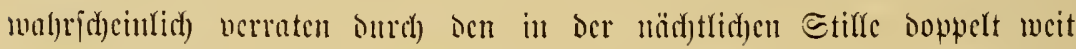

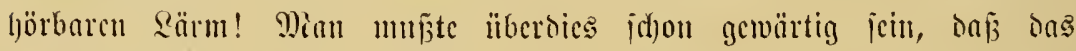

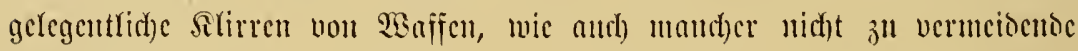

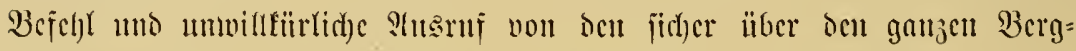

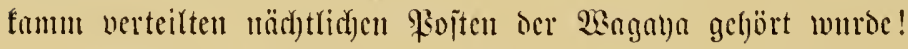

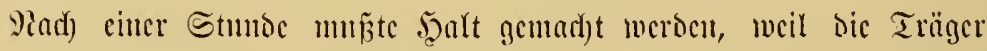

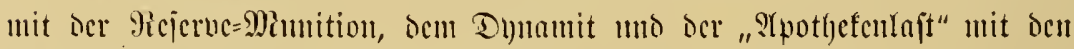
Serbanomittehn nidyt fo rajd) wic bic übrigen Sente vorwärts foumen founten.

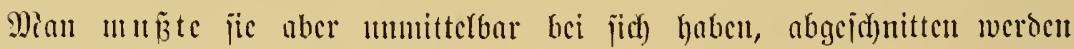

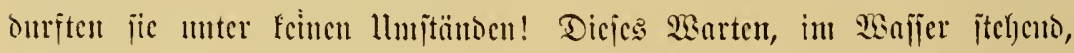

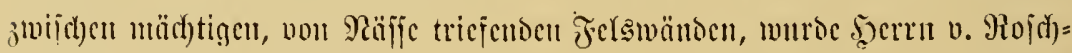

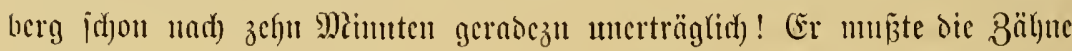

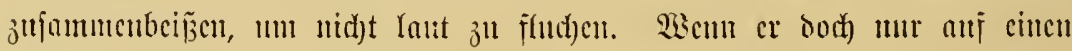

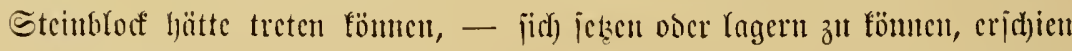

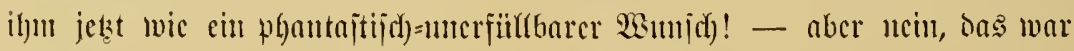

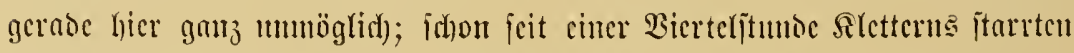

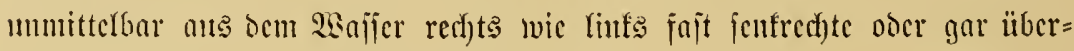
l)ängende Felīn mindejtens 50 bis 60 Fun hodh empor, au benen mur

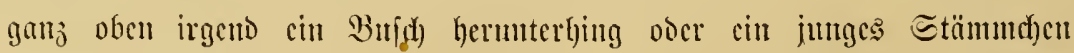

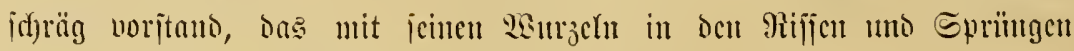

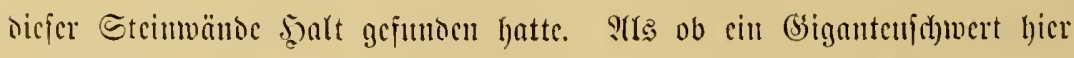

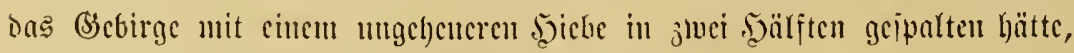

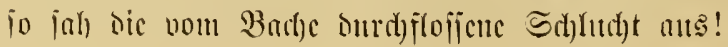




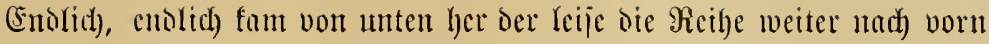

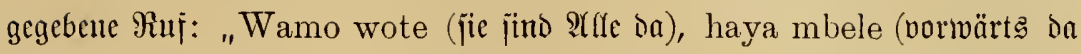

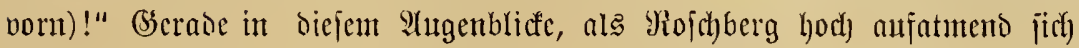

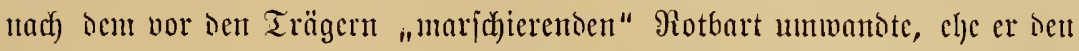

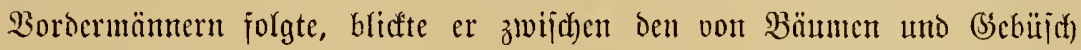

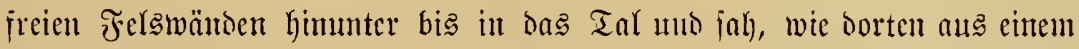

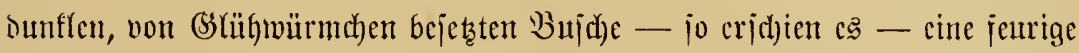

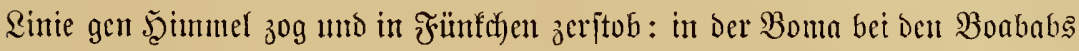
war zwiichen den Ragerfeuern die zweite Rafete losgebrannt wordon! ऽo

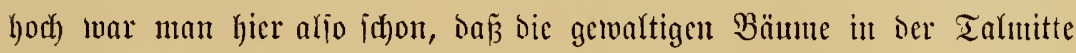
wic ein einzelnter niebriger Buich ausajahen? Th, bann founte ja bie ver=

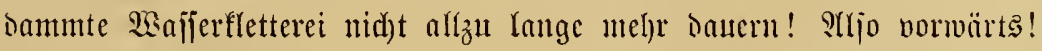

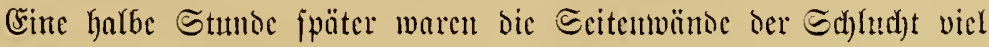

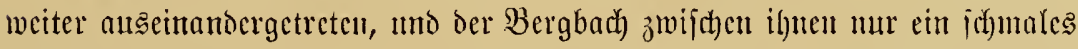

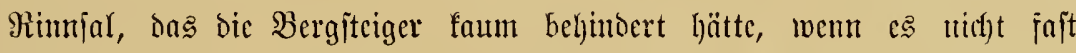
überall unter wirrem (Sebüjich dabingefloffen wäre. Roichberg hatte bei ber

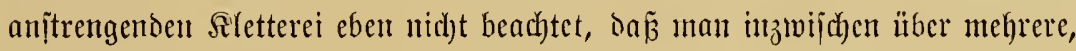

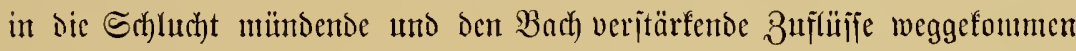

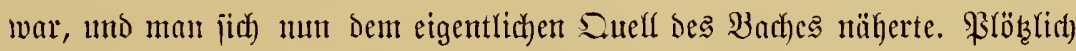
jtano bie junge 2 cgeführerin jitll, hielt durdh ein mit erfobenten 2 (rm

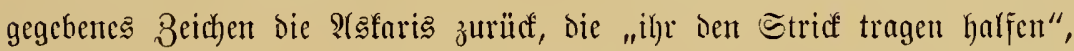

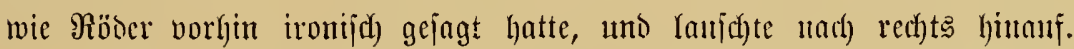

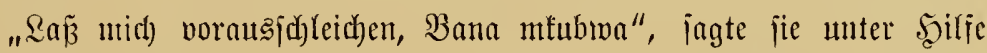

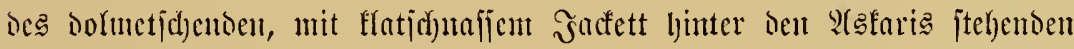
Mgaya, ała Reutnant Miaibach jo leije wic möglich bis zll ilyr vorgeorungen war. "Şicr weiter oben entipringt ocr Duelf in einem iteinernen Becfent,

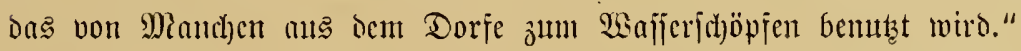

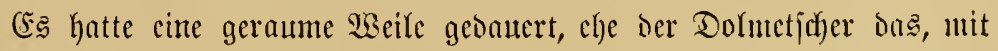

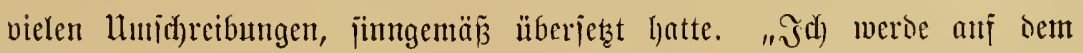
Boden friechen, und jie weroen mid) nid)t jehen, jelbjt svenn jie beim Becfen

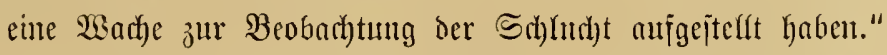

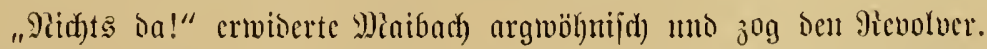

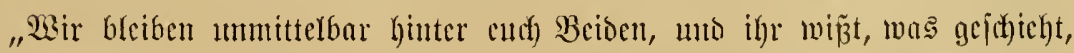

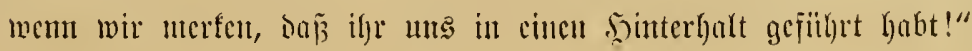




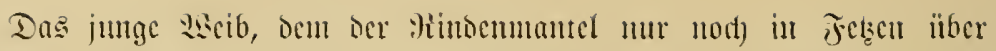

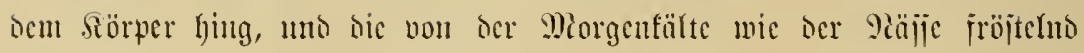

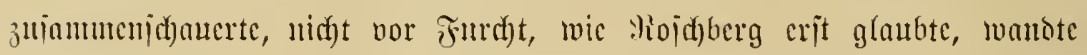

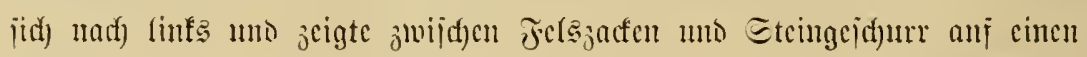

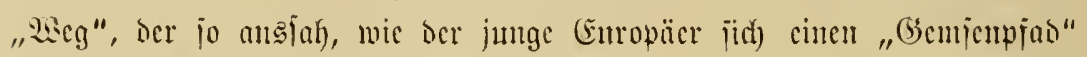

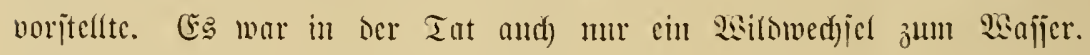
"Ian! miilīen wir torthin ansbiegen; icm fommen wir bis an bns Becfen, fo föment wir vont Dorị ans jojort gejehen merben."

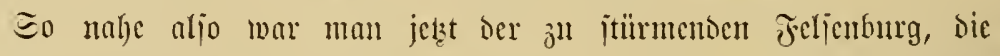
bas junge Miädd)en Dorf namle?! Dann war man eben jofon fajt unter dcu Sianu des Gefbirgstïtfens; vom Tal ans war ja ju jeljen gewejen,

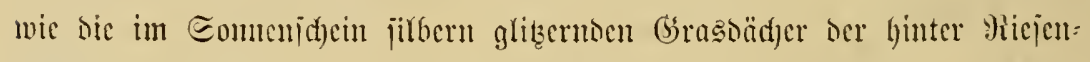

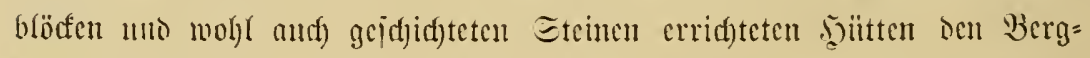

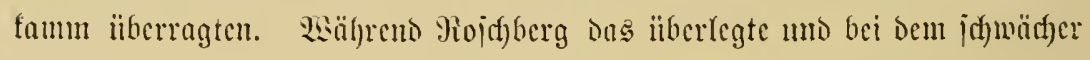

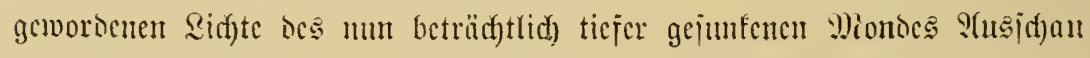

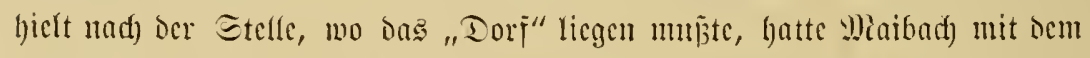

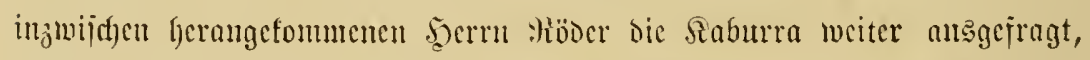

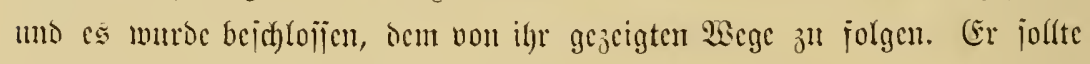

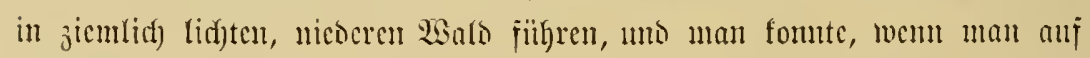

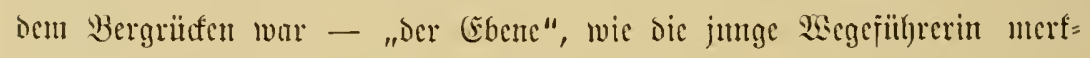
müroigcrmeije immer jugte - red)tŝum madyen uno gerabcrnweges anf bic

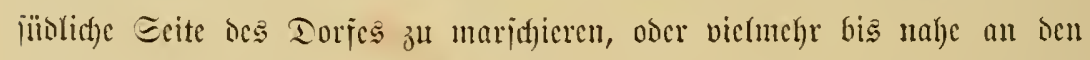

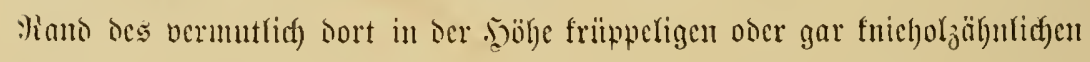

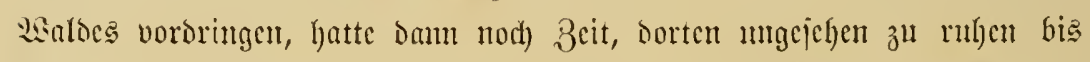

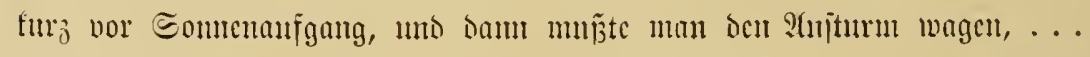

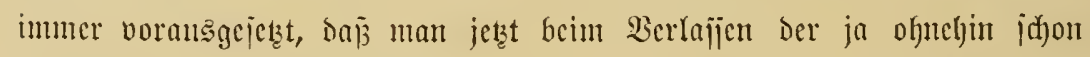
zur Wiulse geworienen Edylndyt, nicht von oben entoeft, mit Stcinblöffen

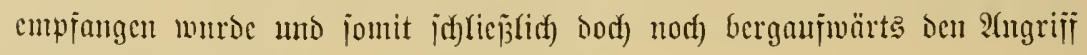
unternchmen muĩte!

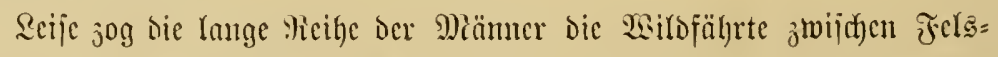

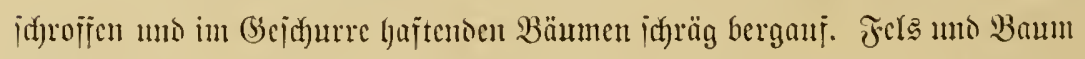

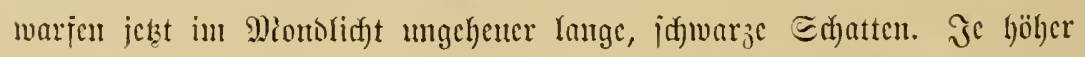

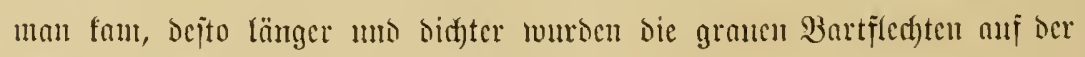

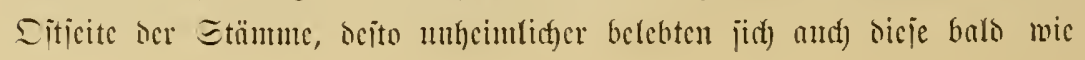


vermunute, ungejüge Ricjen, bals wie Berggnomen ausjelgenden Bäume

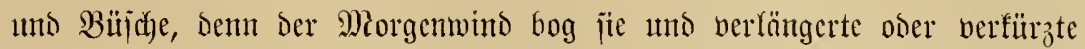

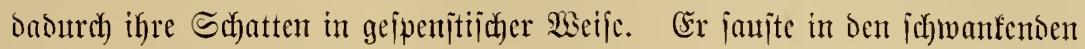

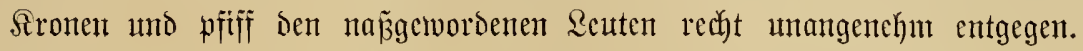
Yher es dahte wohl Jeder: befjer ber Wimb als Stcinblöcfe, die uns entgegenfliegen! Şin unt wieder iprang ein aufgejdyeuthtes Tier aut; hüpfent und rollent ftürzten bann cin paar Steme zut Tal; jonjt regte

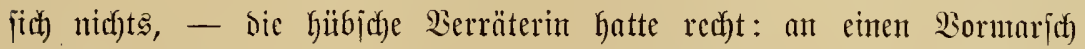

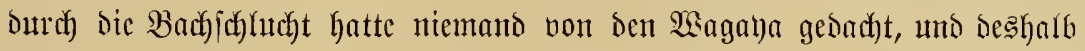

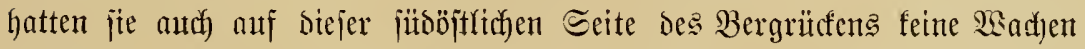

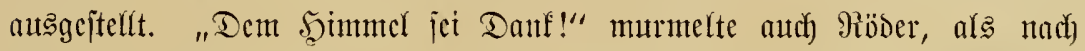

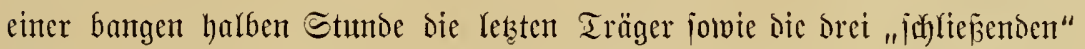

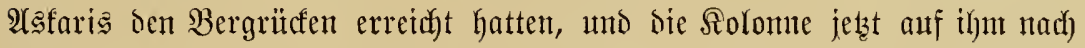

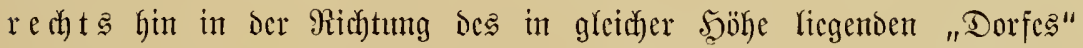

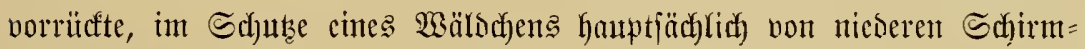
afajien, bie z'war weit auscinanderjtanden, aber suted bic flache Form igrer

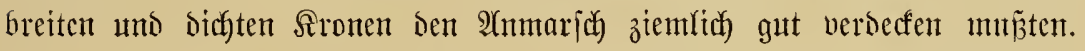

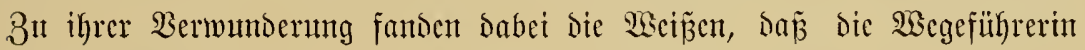
mit ihrer Bezeidfunung "Ebbene" eigentlich recht hatte. So biel man bei hem mun blajjeren Monolidjte erfennen fonnte, marjojierte man nidyt auf cinem

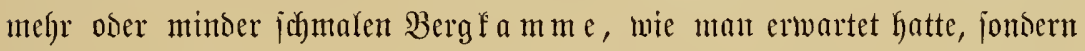
hatte ein Şod)plateau eritiegen. "Na ja," murmelte Röber mit feiner beim leijen Eprechen jo merfwürdig tiefen Stimme, "fïr bic Sartographen ijt hier noch majjentaft jut tum."

Der neben ifm durd das niedere Büfidelgras ftapfende Scutnant hatte nidyt hingefört, vielmehr mit ciniger Diühe anf ber Ulhr herats= zubringen gejutht, wie ipät es jei. "Șm," madyte er Dann, "etwas über einte Etunde fönnen wit nod) ruhen bis zum Sonnenaufgang." $\mathfrak{a}(\mathfrak{s}$ cr

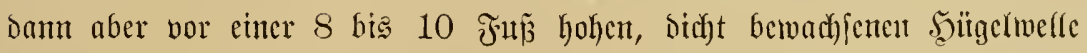

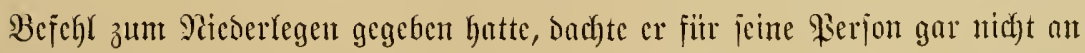

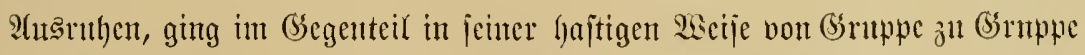

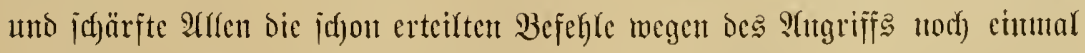

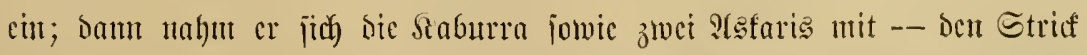

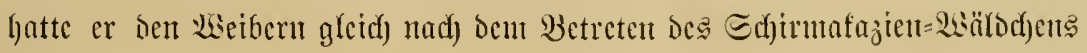




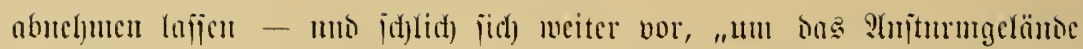

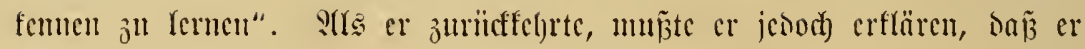
trok jeines Gilajes nichts anjer ben Epizen von Bujchwerf gejehen batte,

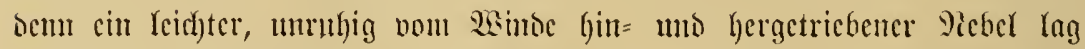

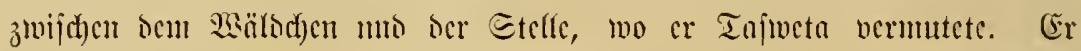

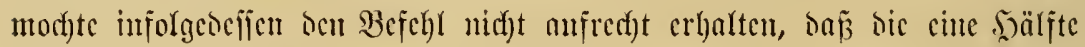

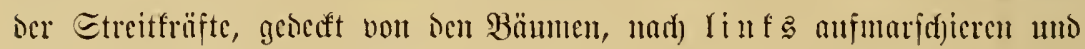
auj ons Eignalbfajen hin gegen bic nadh Sinburra's E(f)ilsermug jidf an bic hörbjte Simpe tes Berges Yehnende li ü af jeite Des "Dorfes" norbecthen

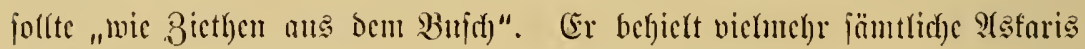

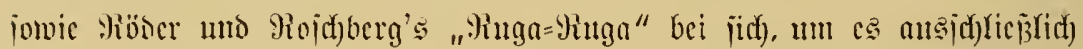

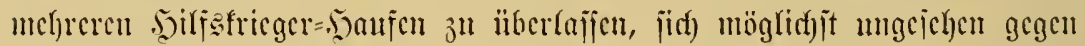

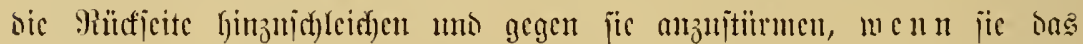

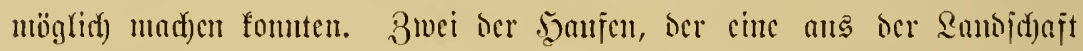

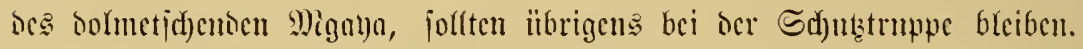

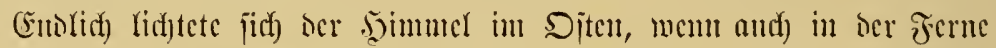

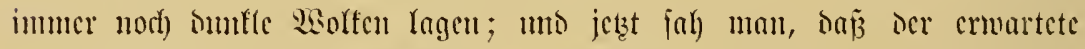

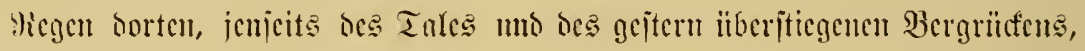

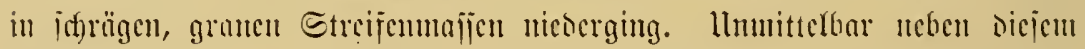

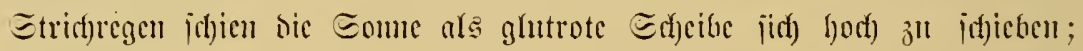

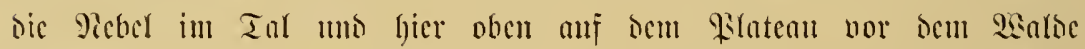

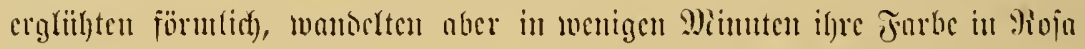

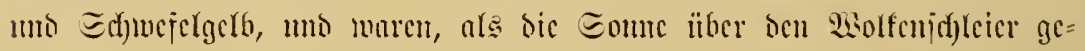

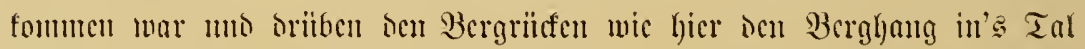

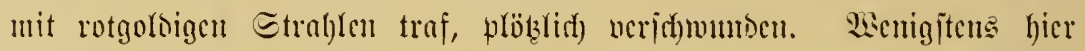

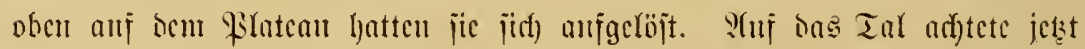

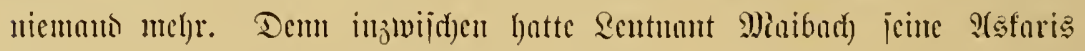

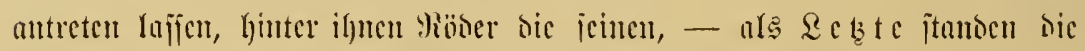

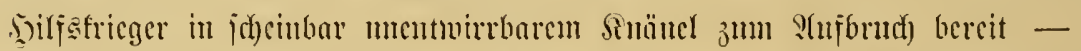

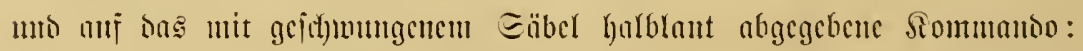

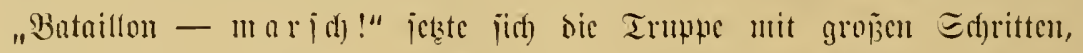

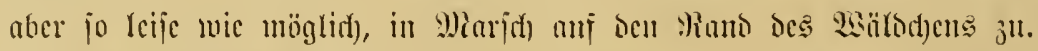

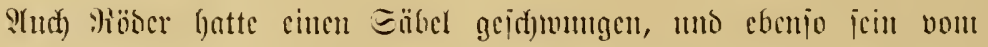

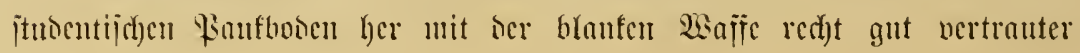




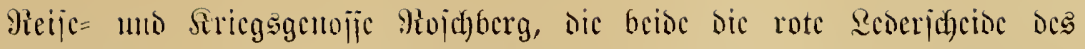
Schwertes an ifrem. Revolver=Reibrienten befejtigt hatten. Fït die

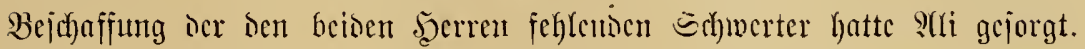

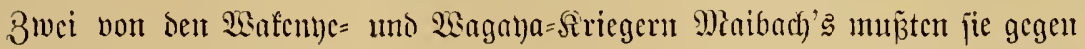
Enttichöbiguntg hergeben.

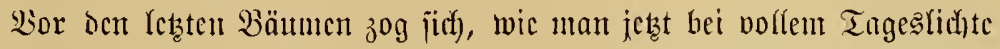

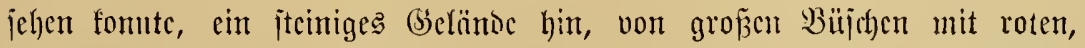

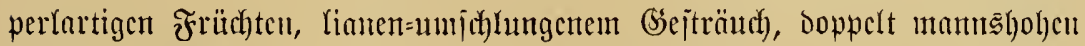

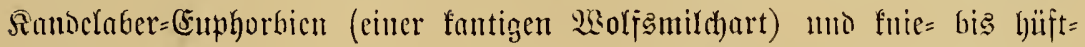

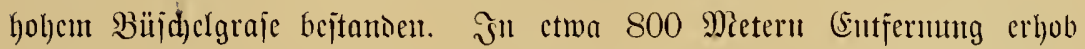

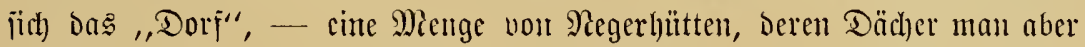
aud) jetzt nur jum Teil jah), Dent bie Mehrzahl war veriedt von riejigen, breiten Felszacten, in bie hicr bic höd)ite fuppe ics vermeintlichen

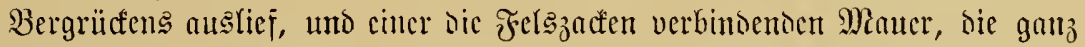

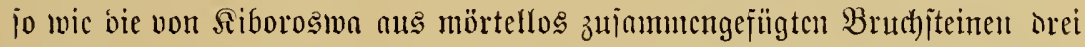

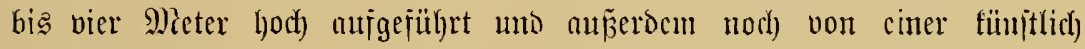
verïtärften Yebenden Dornbuj(cht)e(te metcrbod) überragt mar.

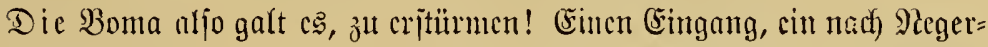

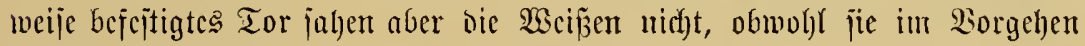

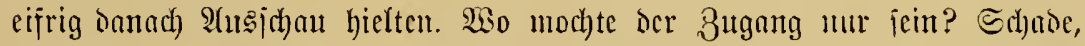

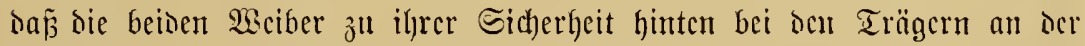
Ђä̈gchwelle gelafjen waren, jie bätten bas verjtefft angelegte Tor wohl jeigen

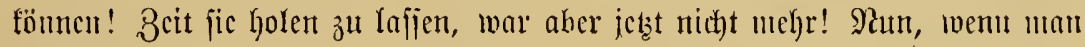

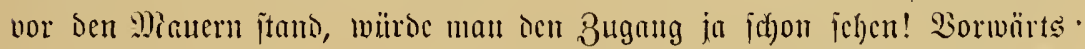

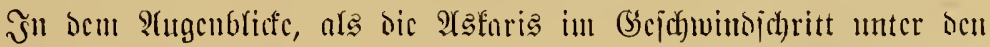

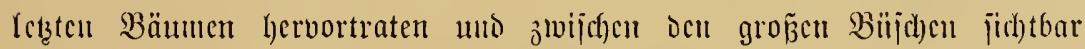

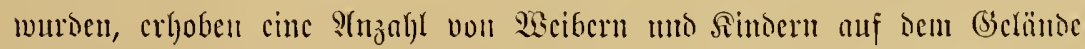

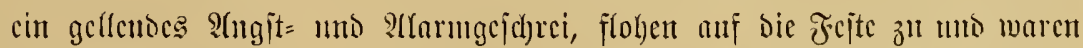

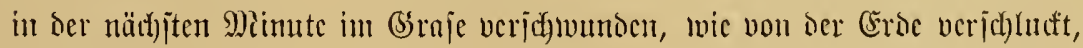

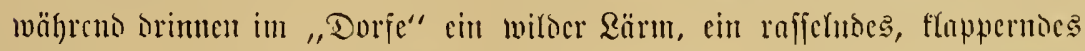

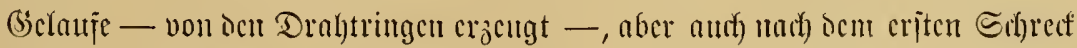

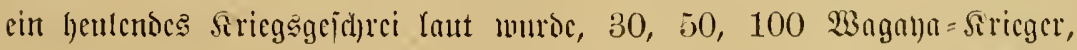

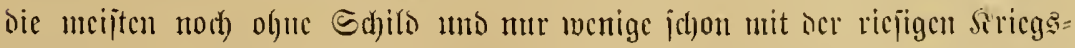
haube auj sen אopje, halben \&cibes ïber sem Dormberlyan auftanthten!

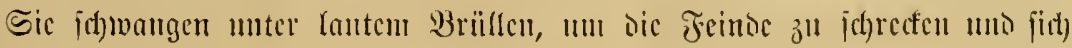




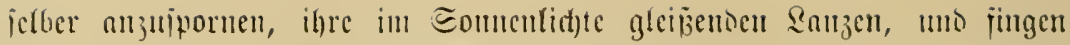

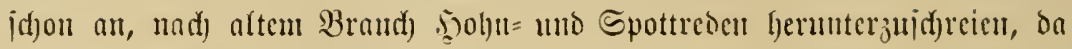
flang das Sommanto Rentmant Maibad)'s lefl burd) den Tumult:

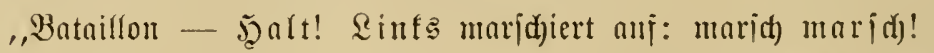
Dealt! Ricocr! Segt au . . Fener!" Mit Domnerrollen frad)te dic

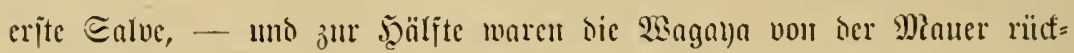

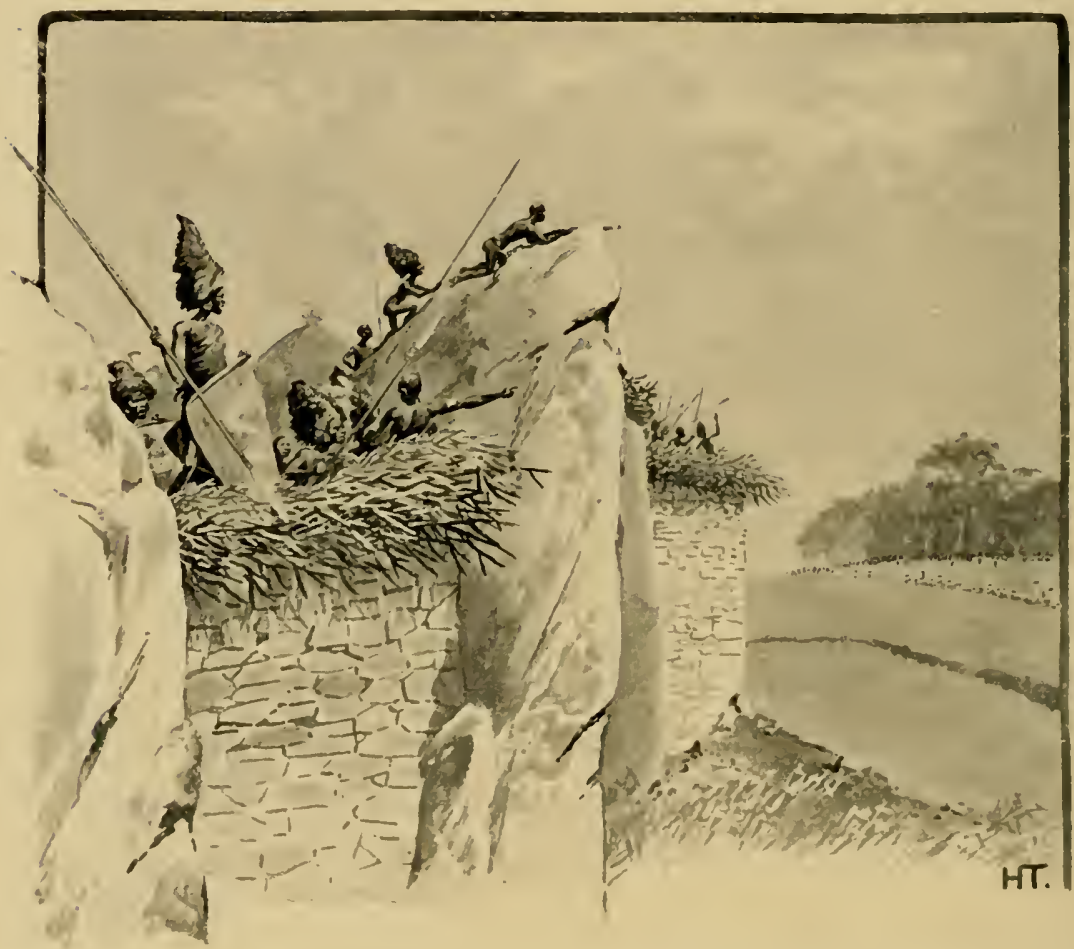

lings auf bic Röpje uno Epeere iljer Rameraden gej(h)lentert worben!

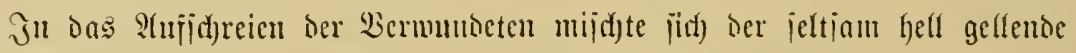

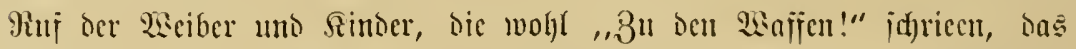
imuler aujgeregter meriente, vom Margenwinoe herïbergetragene Getöje ber

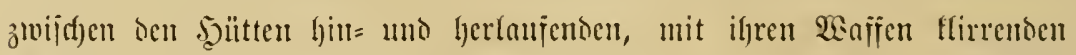

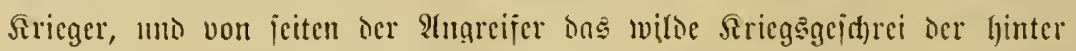

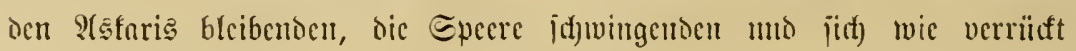

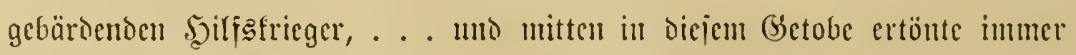
wicter ber furze finall Der mur auj Mimuten id)weigenten Sarabiner! 
"Sclaben! Eiujelieuer!" hatte Miaibad) fommantiert.

"Legt . . a an - Jeuer!" befahl zur jelben Beit rechte von ber

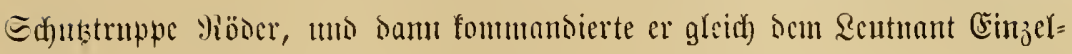
jetter, - wo jidf) nur unf ser Miauter ein Sberförper ober Sopf zeigte, So marj ifn auth eint Sitgel nieder!

Die ltherrajdyung Der Feinte war volffommen gelungen! Sie hatten

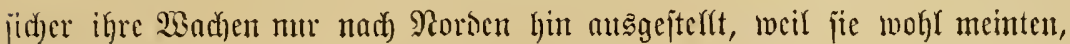

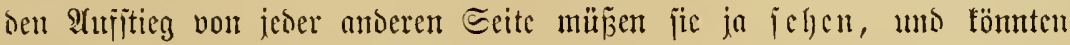
ilgn burch heruntergerolfte Steinblöffe abunchren, ehe dic wajungu mit

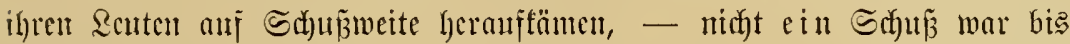
jetzt ans ocn Borberfadern Der Berteidiger gefaffen; jic lutoen wohl erjt,

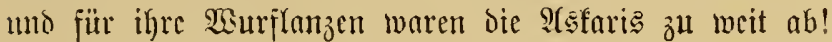

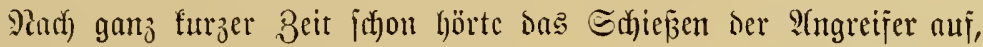

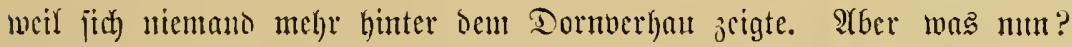
Stujtitrmen und die Mianer crffettern? Das ging nisft ofne bic furchl= bariten Werlujte. Der STijturm war auj bas Eringangstor gedaht, uno Das jah man immer nod) nifft! Sonnte bas denn io gut mastiert jein? Sidyer nidyt! Es lag woh)l anj ber Siürfiette. Eben wollte Renttunt Maibad) mit bem "criten 3uge" cine llungelyung Dafin beginnent -- Den

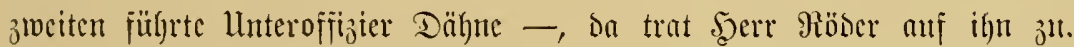

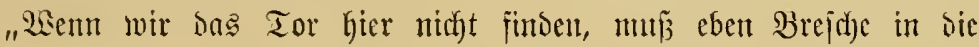
Wiauer gejprengt werden", jugte ber Jiotbart, währeno bas Schloffllappern

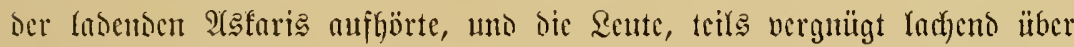

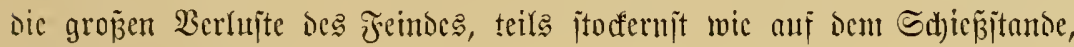
(Gewebl bet $\mathfrak{z} u \tilde{\beta}$ nahmen.

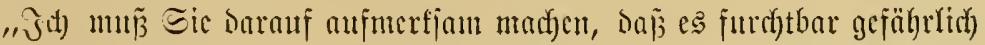
iit, jo ofne Doctung! Sic risficren Shr \&eben, unt wir haben, mem Eie auf ber Sirecte breiben, bo of feturn Pintzent bavon."

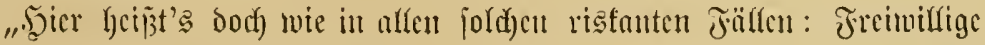

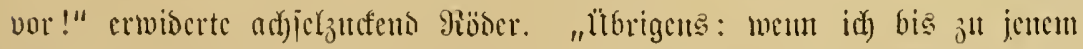

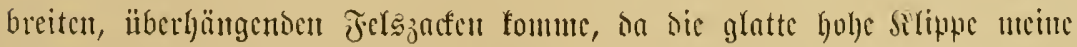

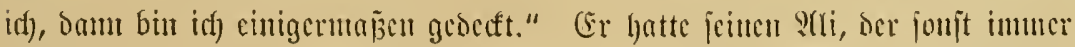

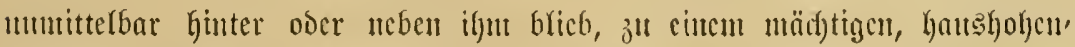

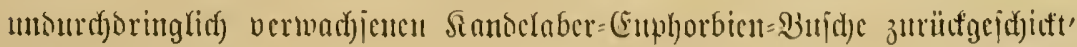




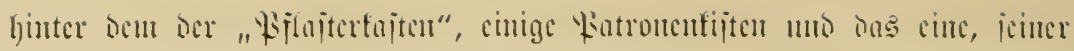

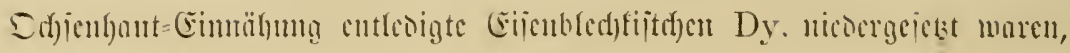

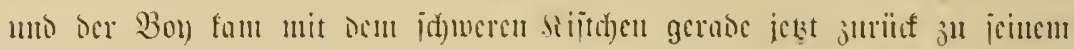

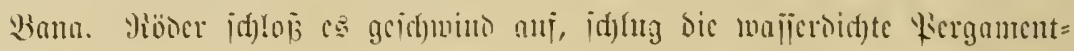

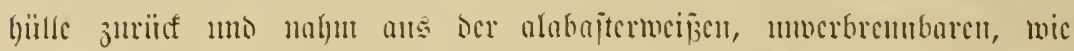

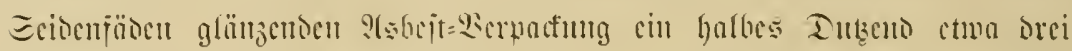

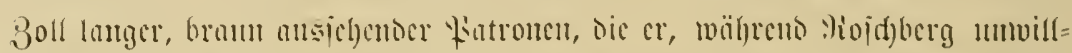

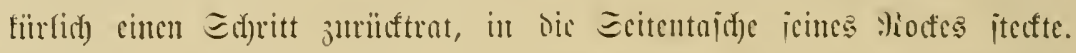

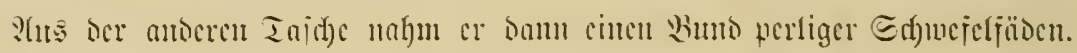

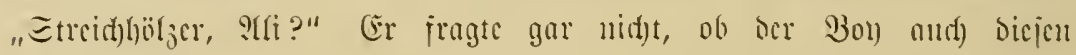

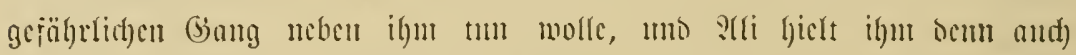

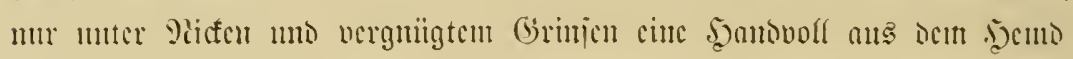

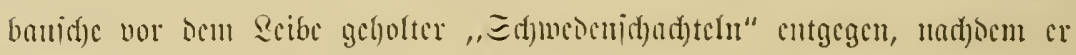
Das jugctlappte siijtchen auf Den Bodu gejtellt hottc.

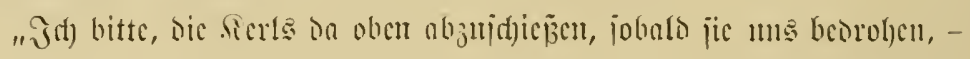
id) meroc jic anjünglith tünid)en mo jo tum, als ob id) ctmas bergat

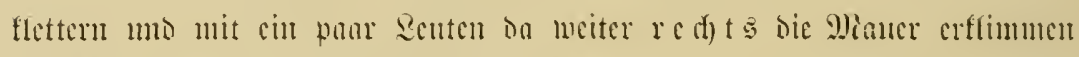
wollte, bei Den alten Diffen Wiangohäınen ba, ober waร jie jein mögen." "(s)miñ fricgern mit," ricf Der Ecumant, "Dic fömnen Eic benigjtens ctwas mit

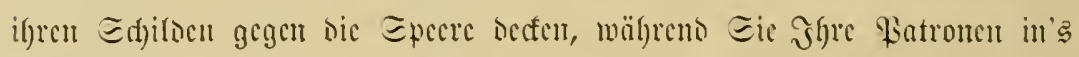

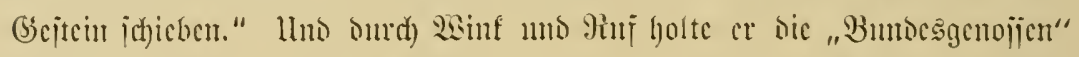

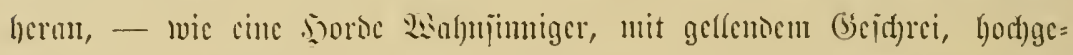

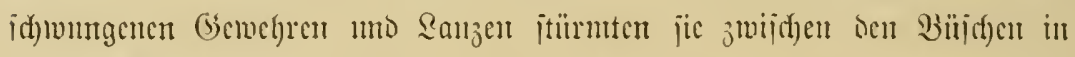

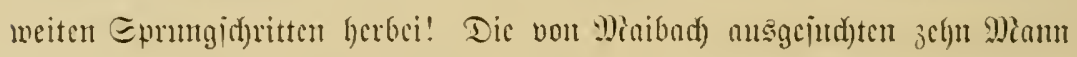

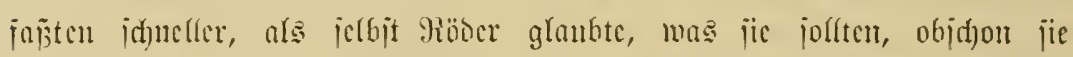

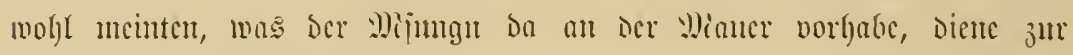
Icichteren lithorfletterung.

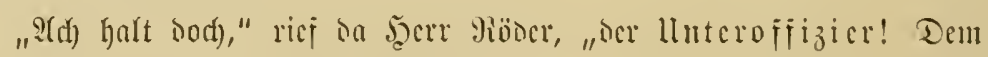
Dari idj's nicht antum, ihn jurïf(julajicu!"

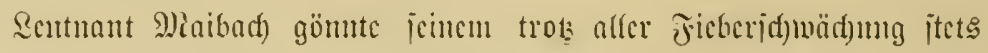

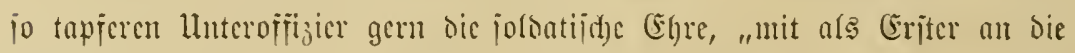

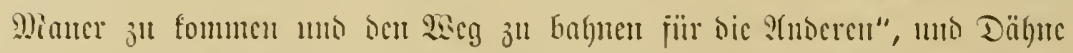

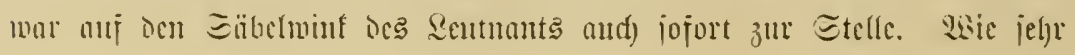


er auf jeine Betciligung beim Eprengen gered)net hatte, bas jcigte jiht) burau,

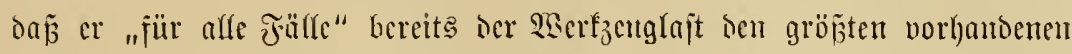

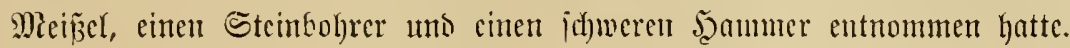

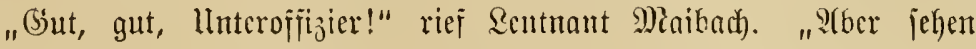

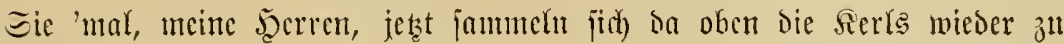

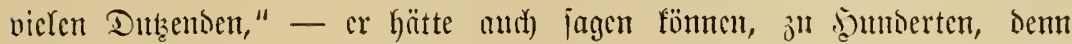

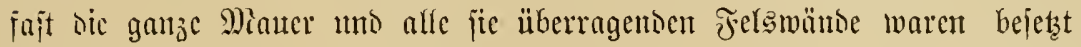

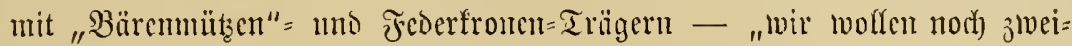
humbert Micter näher herangehen, tamit mir mit Standvijier Эhre Epreng=

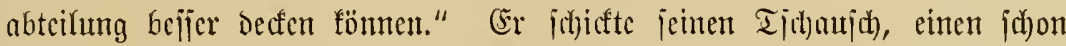

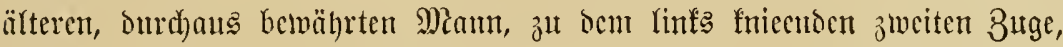
umb fommanoierte, fo wie ber bie Stefle ses Llutcroffiziers eingenommen:

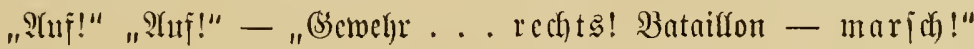

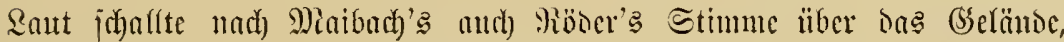

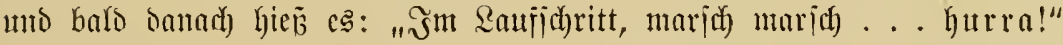

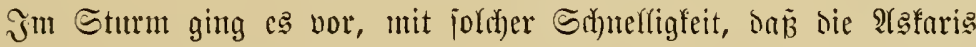

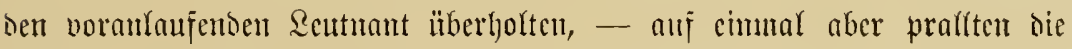

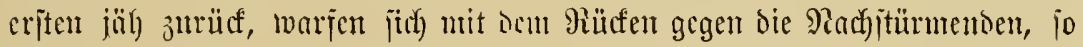

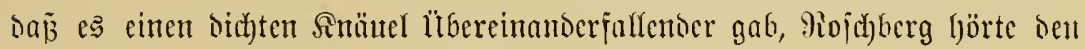

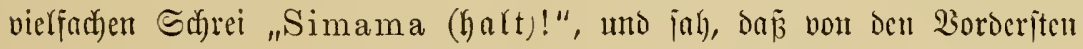
cill paar jutgriffen, wic um ihre unbegreif(it)erweije in ôn Erobodest

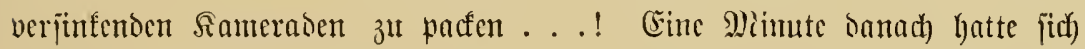

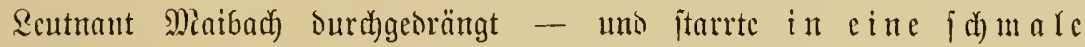

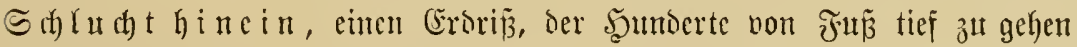
jdien! Dit Entjetsen erfannte er, und nidht mintor begriffen cs die voller

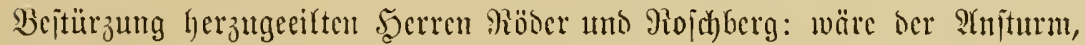
wic erĭt geplant, im Miorgengranten, vor böfligem Stufgang ber Sonne

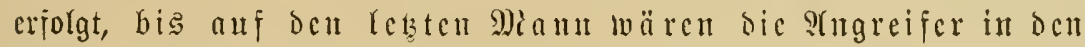
Itbgruno gcitürzt!

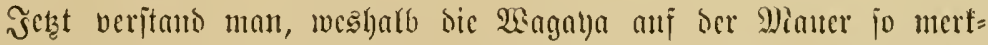
willoig unjig, ofne ihr jonjtigcs tobentes kelele, ohne bic Eanjen ju (d)wingen, herïbergeblifft hatten anf dic amitürmente Iruppe!

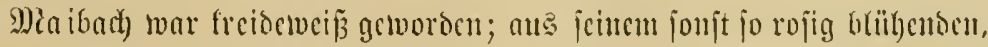

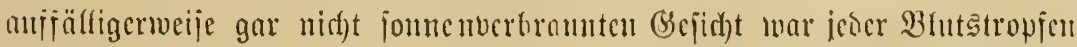


gemidyen, uno non 9iöser's Etirn perlten groje Edjweip̈tropjen, die meser

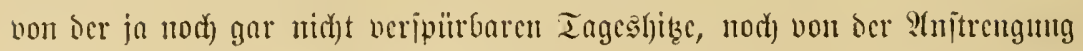

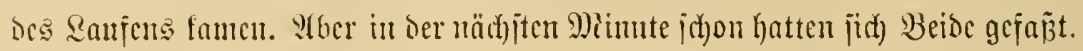

"(S)anzes Bataillon fehrt, . . marid)!" bejahl der Reutnant.

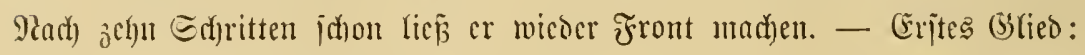

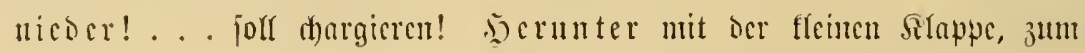

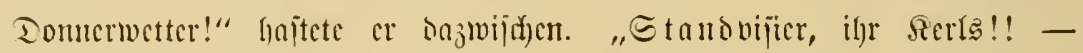

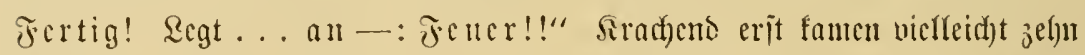

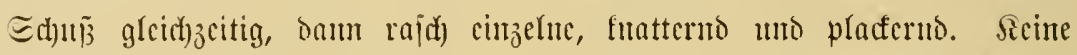

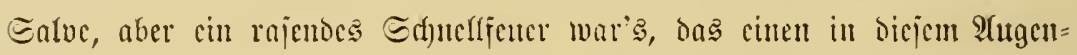
blicf ganz uncrmarteten Gejejolibagel gegen bic auj ber Miauer unb ocn Felszacten itehchocn siriegcr jantote! Eo raju mar ans ocm erhofiften

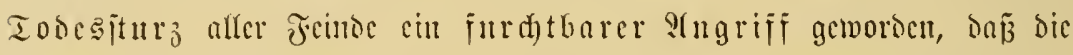
K2ngana nicht Bcjumung tmo 3cit gejumben hatten, herunterzujpringen, -

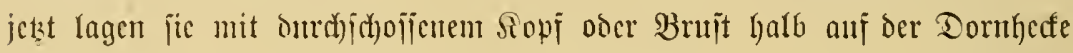

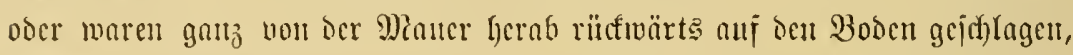

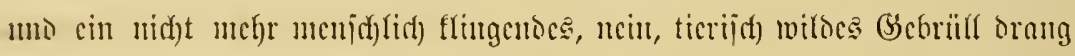

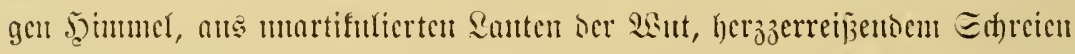

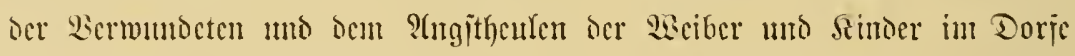

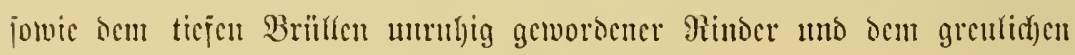

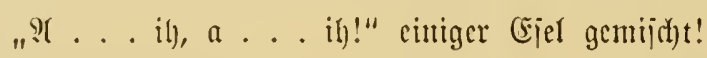

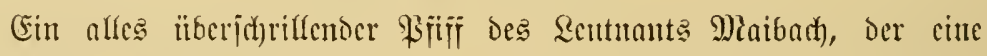

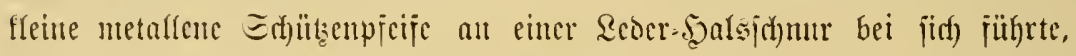
jtopite bas (Sewel)rienter jajt augenblicflid); nur nod) ber mit jold)en Bejelylen

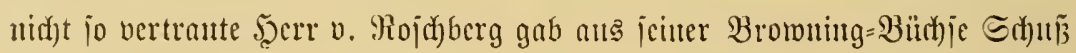

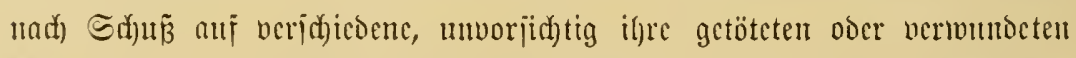

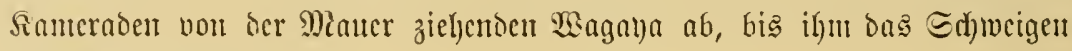
ocr frarabiner aufficl.

"Ylga!" riej in biejem ?lugentblide ber Rotbart, Der am Rante ber

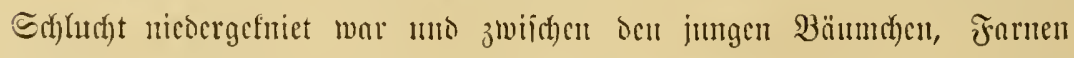

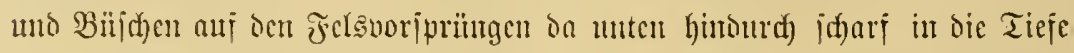

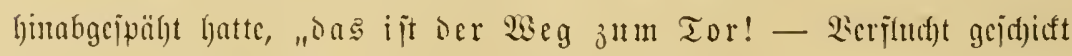

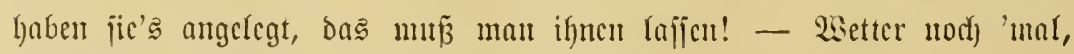
wo itecft desm aber ber (Eingang Der Edy)lucht?" 
"Die miro wohl auf der Taljeite veritecte finter ben Rlippen Des Berghangs anfangen," meinte ziemlidy ärgerlid Der junge Dffijzict.

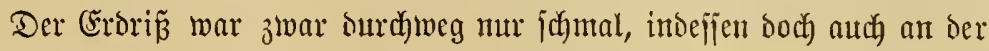

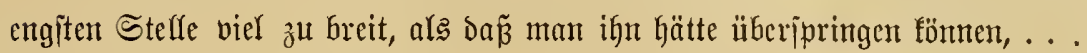
unt lange überlegen, was jonit ju tut wäre, das ging jeşt uidht an, denn

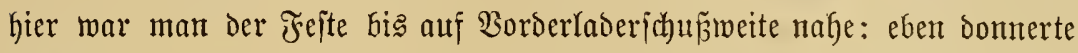

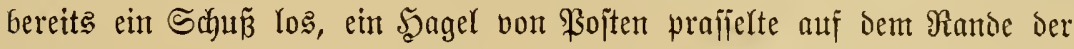

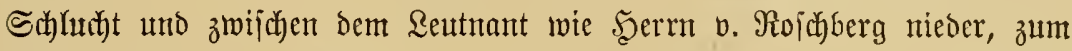

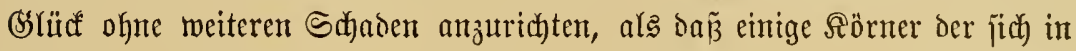
oer Ruft "trauthenförmig" ausbreitenden Bejchoñmafie dem jungen Sriegs= freimillfigen Den Tropenhelm vom Sopfe riffen und zwei ihn, Durdi) dent didfen Rorffelm abgeidlwädyt, oben an ber Stirn trafen. Röber iprang auf mo jah bejorgt nach bem jich Das in zwei bünnen Fäben über. Stirn umo Bacten riejelnde Bhut abwijdenden Reijegejöhrten. Der mar freilich zuerił crichrodfen zurülofgetaumelt, lächelte jełzt aber:

"Reine Sorge; es jinto nur Ritzhen!"

"Dann: Tafdhentuch) orauf, Ramernd, und Şclm brüber!"

"Zum Deubel noch 'n mal," brummte eben Reutnant Danibach, als

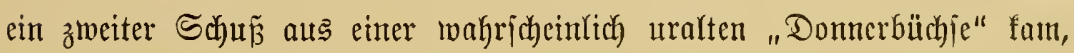
"mir müifien wahrhaftig zurü af . . oder da Gimunter!"

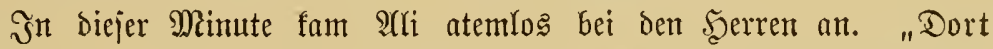
rechts die beiden fleinen Bäume geben eine $\mathfrak{B}$ rü cfe ab; jie reichen himüber, und halten, wenn wir bie Ranzen unjerer "Freunde" quer barauf binton," feuchte er, indem er auf zwei zicmlich bicht nebeneinander jtehentie junge Bäıme nahe am Bergahgang zeigte.

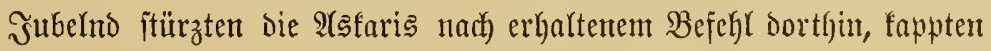
mit ihren als Bajonctt wie Şaumeijer dienenden Seitengewehren beioc Stämme und jobleppten jie zur Schludht. Dann wurben bic Yciscr gauz glattrindigen Stämme, trotżem jeţt öfter ein Schũ von ocr Maucr hac fiel und auth noch zmei bon den fojort auf dic Dornthecfe zunüffeucmocn

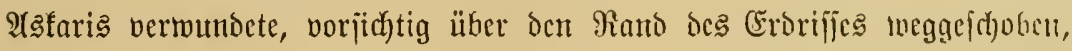

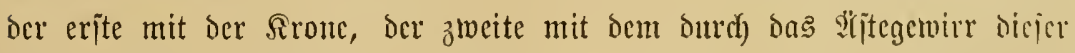

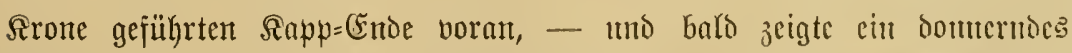

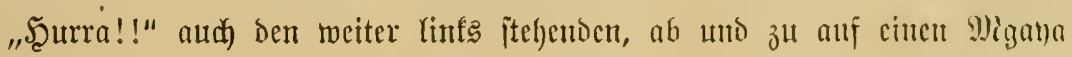




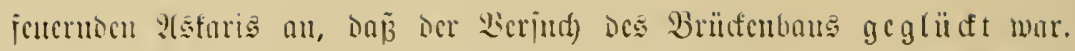

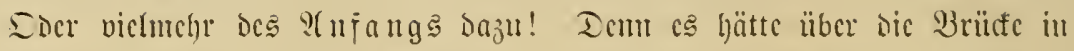

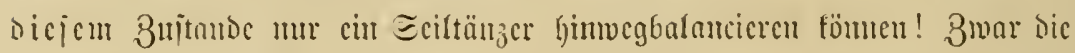
Bammfronen, Dic cine hier, die andere drüben, gahen idgon .j)alt; icdod) in

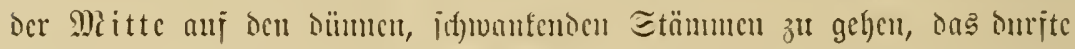

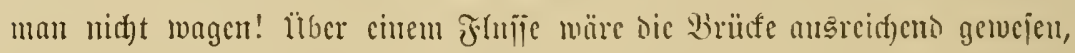
io twie jie war, cin Fall in's :

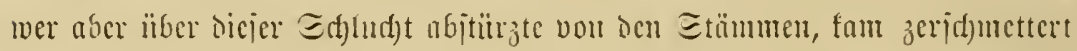

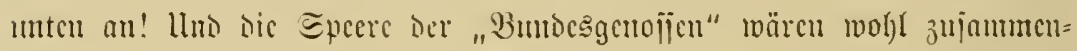
gebrod)en, went man jic mad) a(f's joce vic Soucridfwellen über bic

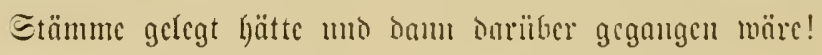

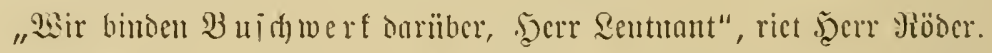

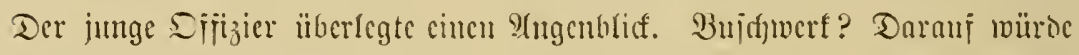

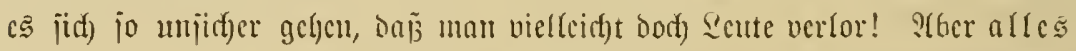

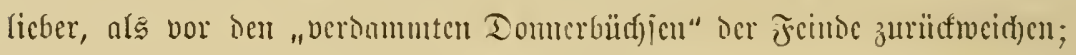

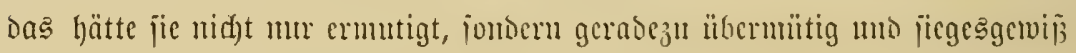

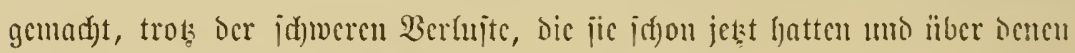

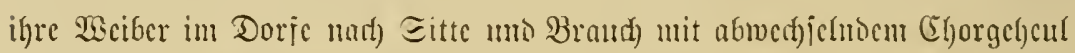
"meinten". "Gut! \&ajjen Sic Bujd)werf idflugen. Siancu zum Binbeu

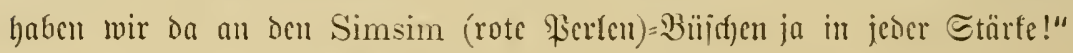

Pind) einer balben Etmme waren an Etelle von Sueristuellen bidf

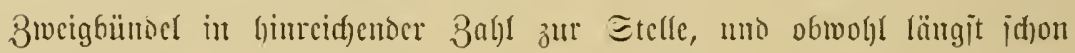

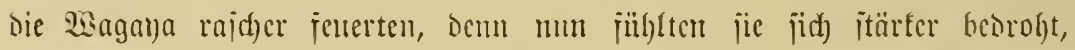

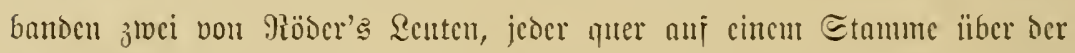

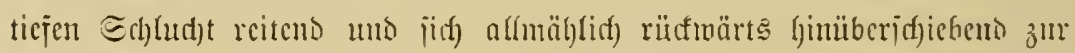

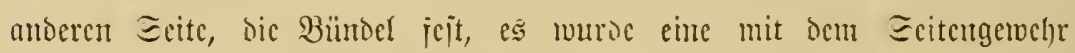

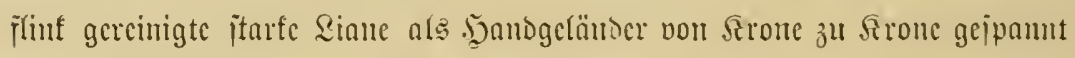

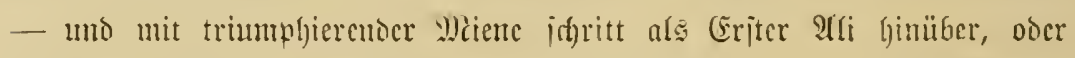

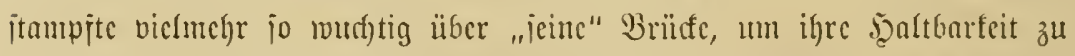

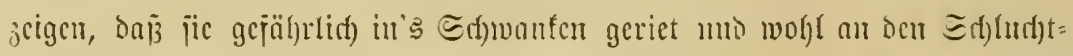

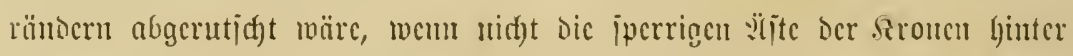

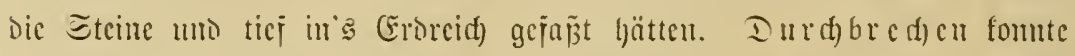

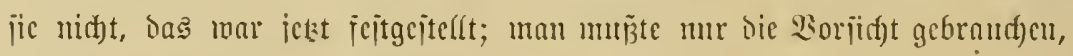

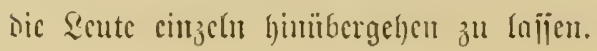




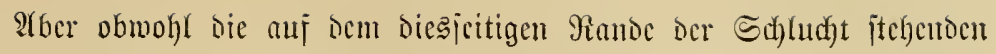

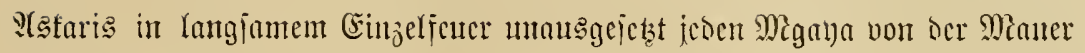

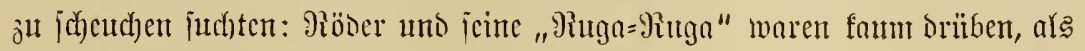

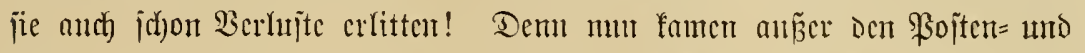

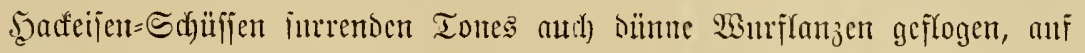

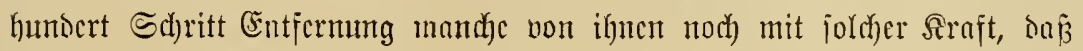

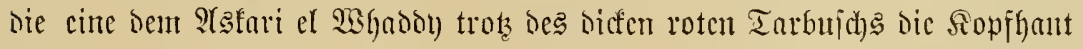

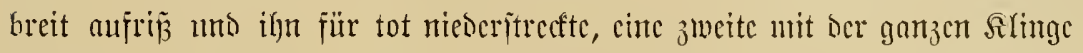

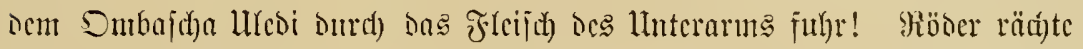
icinen Smbajcha freilich angenblidflict); che ber Specrichleutderer jidy butfent

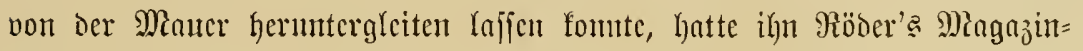

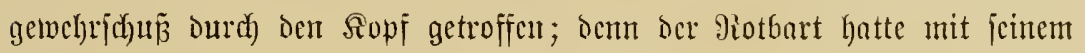

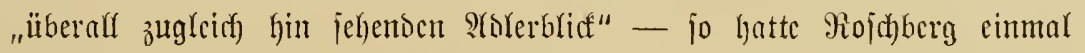

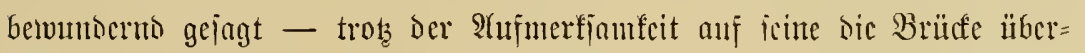

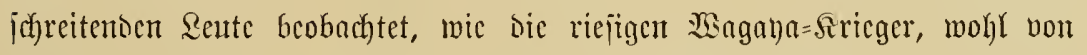
Felsblöcfen hinter Der Mauter aus, im Sprunge auf ber Miancifrone

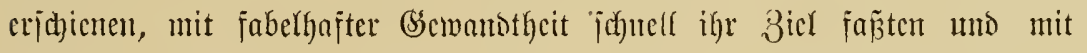

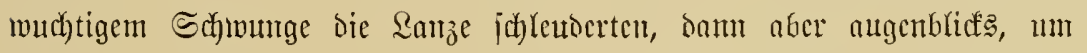

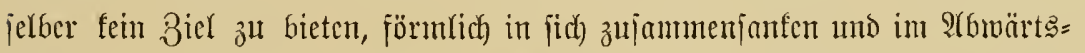
gleiten oen Bricfen entichwanden; Desharb hatte er bahin gejielt, wo der

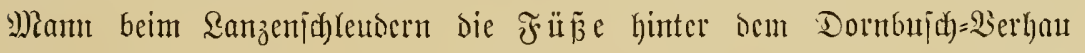
haben mus̃te. Uno aud dem Bueiten wie bent Dritten hatte or jo trotz

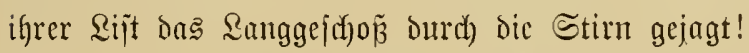

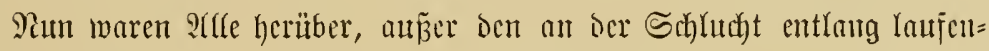
ben, nad) Dem (Eingang juthenden "Bumbesgenoficn".

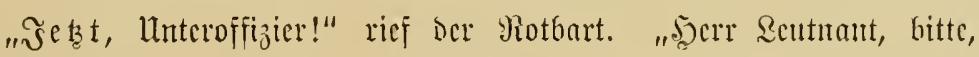
bejwäjtigen Sic, wic verabrebet, bie Sicrla, bantit jic แms für furze 3cit nuอ ben Augen verlicren."

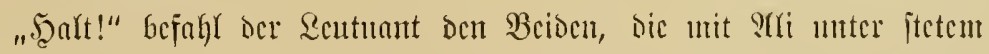

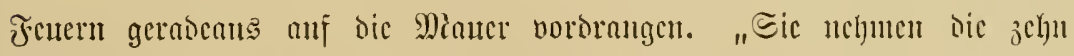

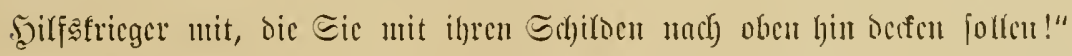

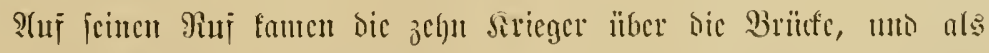

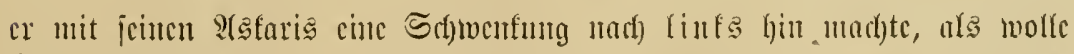

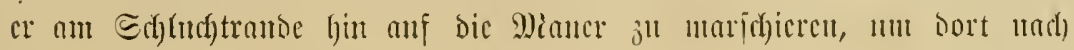




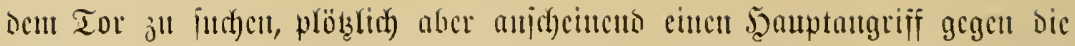

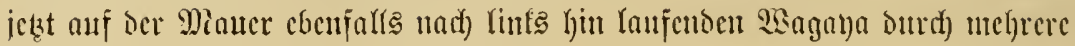
Ealven cröffutete, da cilten ber Protbart mo her lluterofijizicr in Srhnt

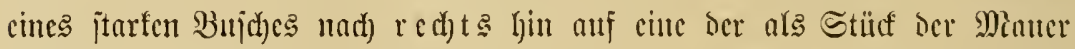
benübste breitmandige Felsflippe jn, gefolgt vou ?(ri utto den wie mit

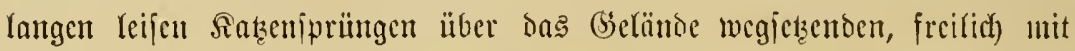

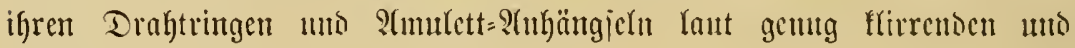
flapperndell S̨ilf̧africgern!

Shymer atmend blicbent bic wecinen hart an bie Rlippe gedrüdt

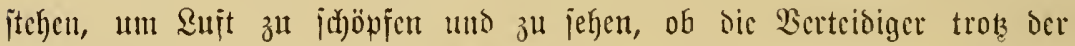

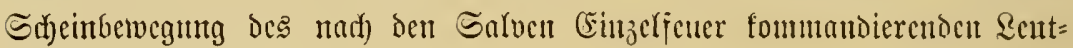
nants ihr foummen bemerft bätten.

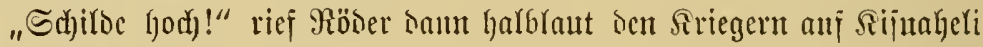

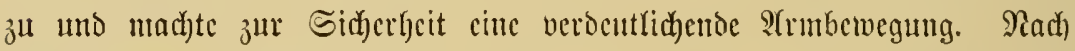
nochualigem llmjehen winfte er aber ab, jprang ein paar Micter nod) meiter nady reats vor bis an bie Mianter, trat anf einten futchohen Blocf,

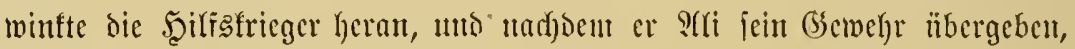

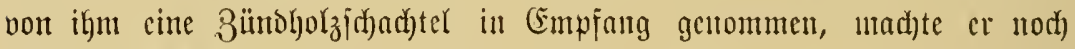
cinmal dic ?(rmbetwegung. Sojort hoben bie $\mathfrak{W a g a l ) a = F r e n t b e , ~ b i c ~ u n g e = ~}$

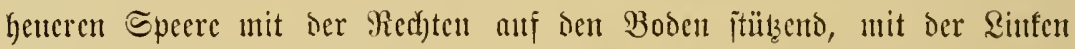

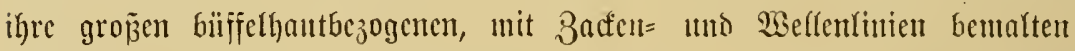

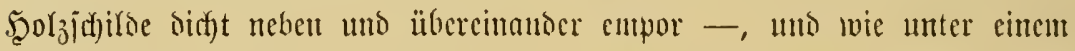

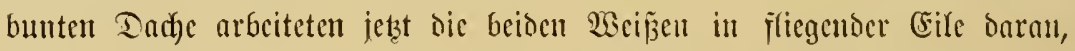

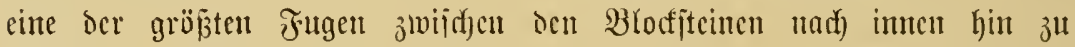
vertiefen! - Dod) nidgt lautge blieben jie untgeitört. Der Sopf cines etwa

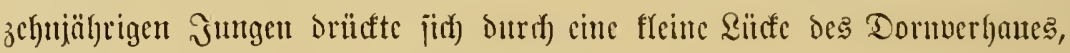

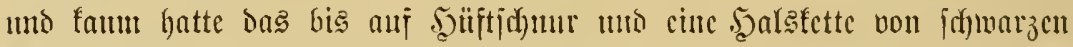

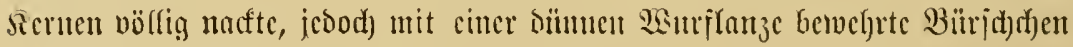

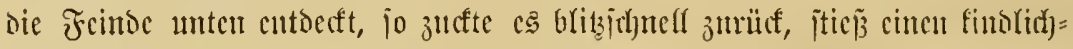

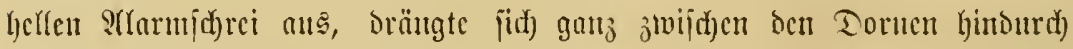

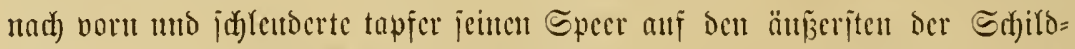

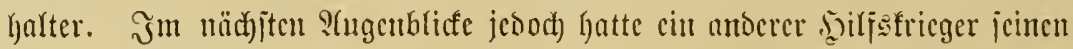

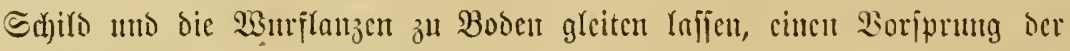

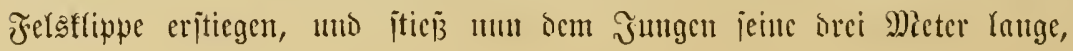




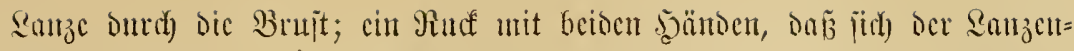
idaft bog, uno ber bluttriefende Sinnge murbe, wie cine von Sintorn auf

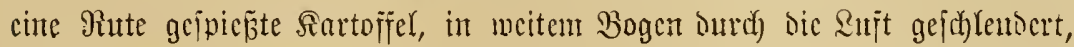

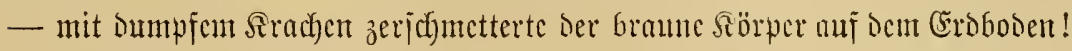

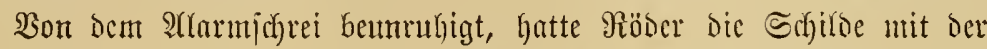

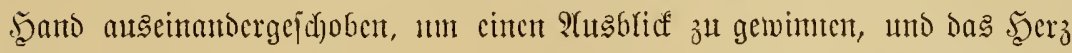
frampfte jich ifm jujammen, als er bas Simo anf bie Crobe fliegen jah!

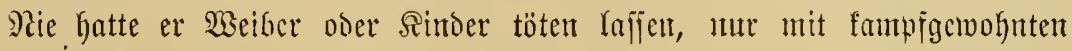

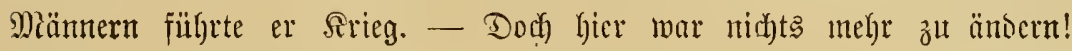
Die oft jiticrten Worte c'est la guerre, c'est l'Afrique (io ijt oer Sirieg, fo geft's in 2(jrifa zu!) flonen ifm Durch den Sinn, als cr fich wiedcr mit dem Meiñel jeiner STrbeit zunamote.

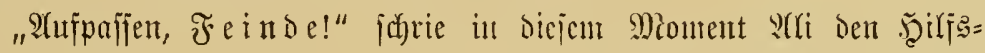

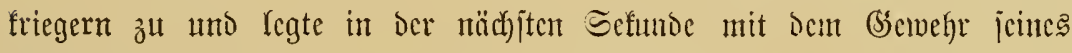

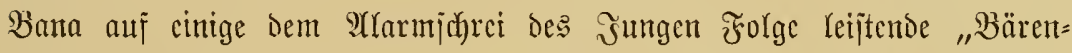

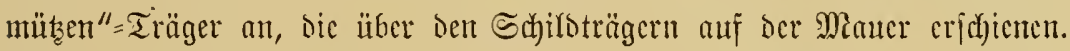

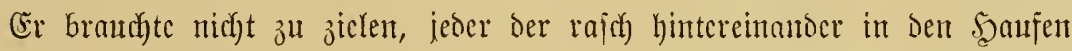

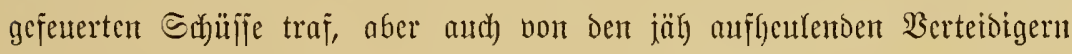

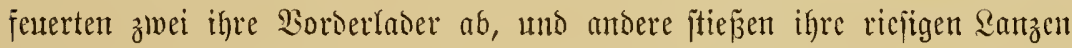

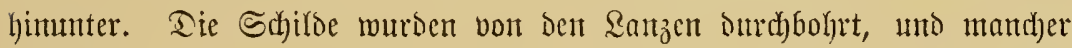

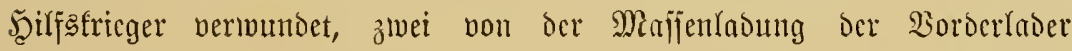

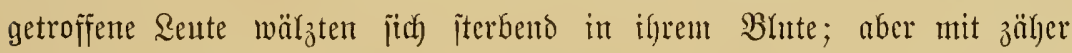
Tapferfeit jedjoben bic l̈tbrigen, vermumbet ober nid)t, bas becfento Dach

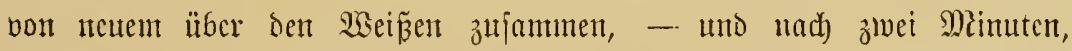

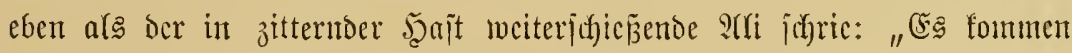

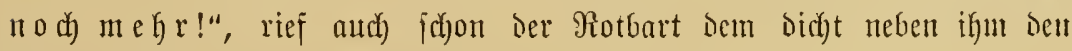
Steinboher brehenten llnteroffizier ju: "Tayari!"

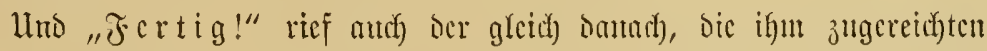

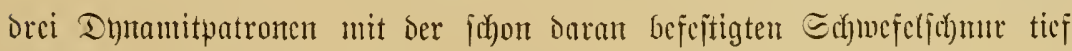

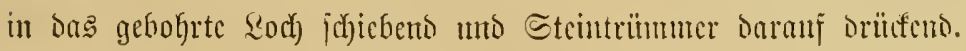

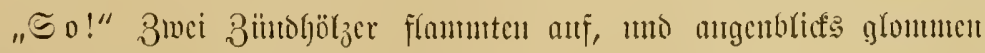

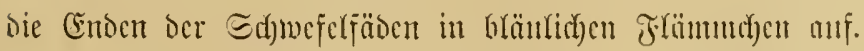

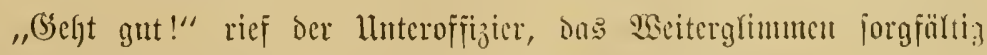
beobad)teno; unto: "Fertig; weg unt แแ $\mathfrak{s ! " ~ G e j a f l ~ g i o ̈ s e r . ~}$ 


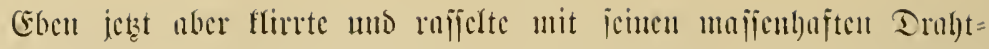

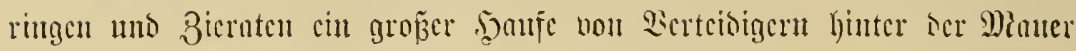

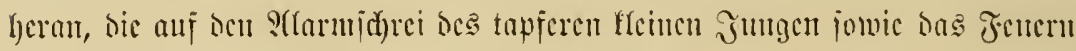

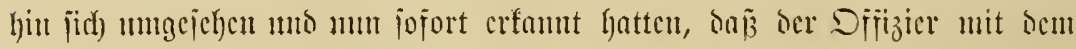

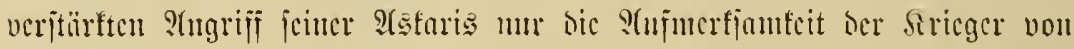

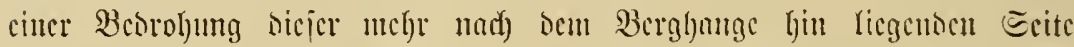

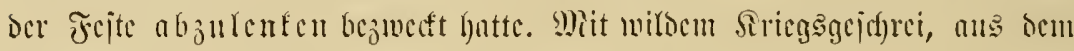

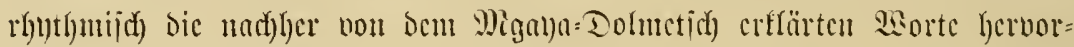

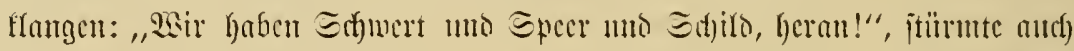

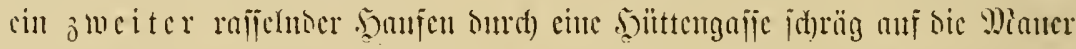

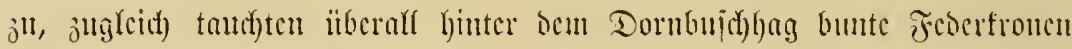

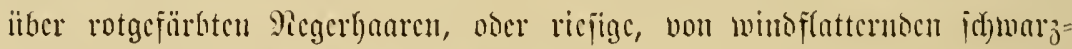

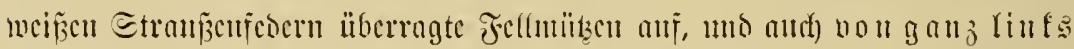

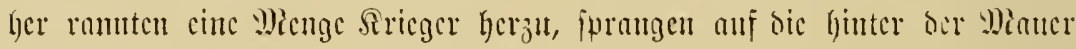

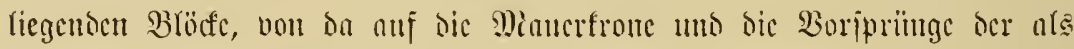

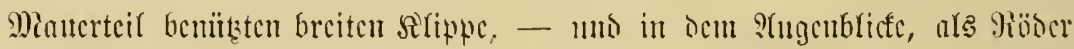

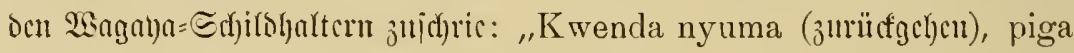
mbio kwa nguvu (remucu mit alfer Sirajt)!" ba frad)ten aud joffou

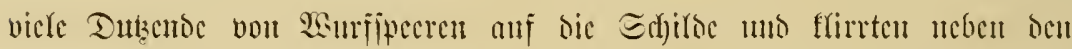

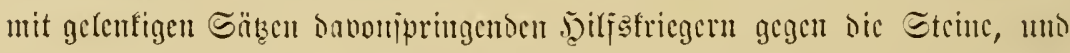

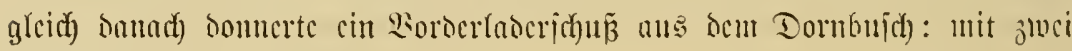

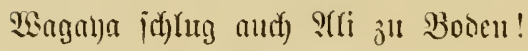

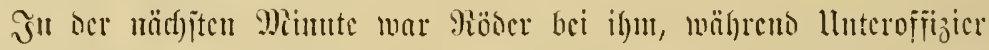
Dähne ocm firtegem nadycifte, pacte jeinen getrenen Boy mit bciscn

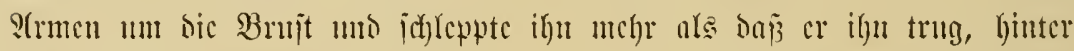

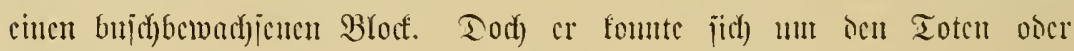

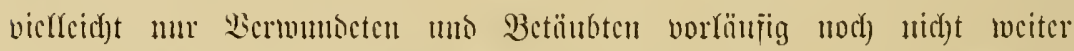

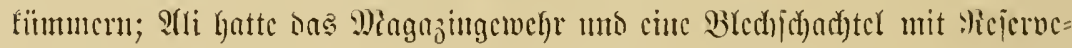
patronen fallen rajīen; bas muñte unter affen llmïtünocu banor berwalyet

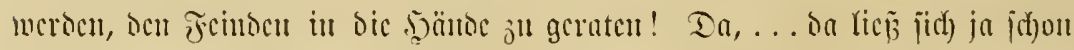

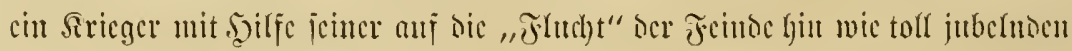

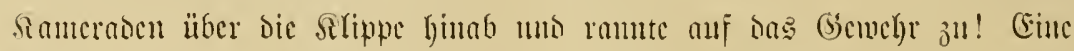

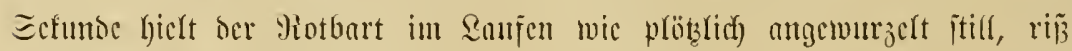

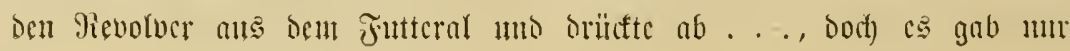




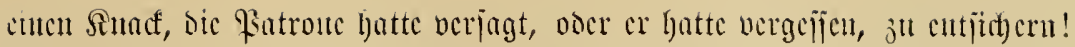

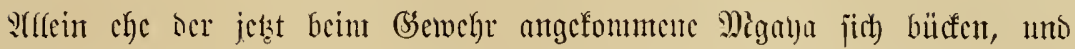

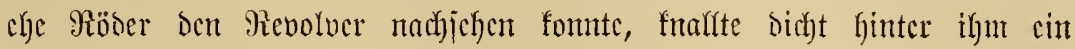

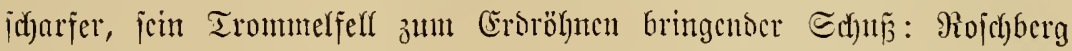
war Ginter cinent nieseren Bufich von Bromberen altgejprungen, Ginter sem licgento er umablëjïg gejenert hatte, war feinent bon ber Neauer her burch Epeere uns einen jweiten 23orderlaberidun bebrohten Beführten nad)gelanfen und Gatte ben Berfager Röbcr's wett gentarht, - mit eincm Sakze, wie bon unten emporgcidhleutert, iprang ber bon bem Browning=

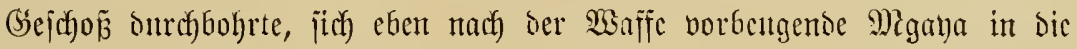

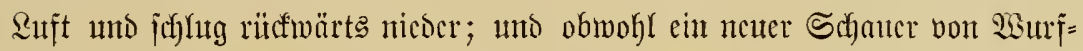

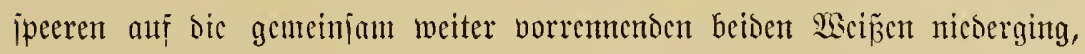
Röber babci von cinem Specrictaft cinen mudytigen Eshlag l̈ber bic

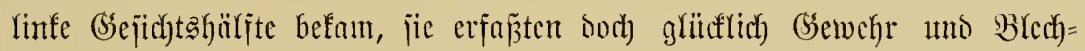

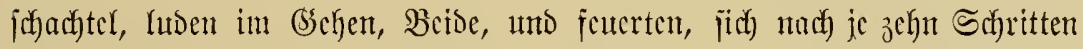

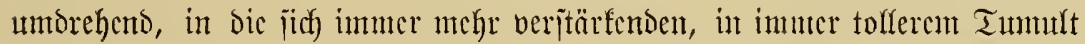
an unt auf ber Miauter zu beiocn Sciten ter Alippe jammelnoen Sirieger= majpen! Die glaubten, den Berjuth eines jie überrumpelnoen Erfletterns Der Mauer abgejdylagen zu haben uno tritmphierten jhon, - ba gab cs cincn

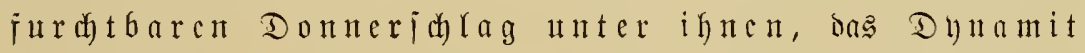

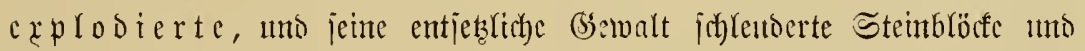

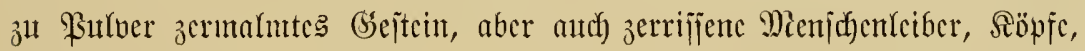

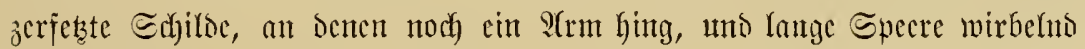
in bie \&uft, - als ob ein 2 ulfantusbruch (5roc und Felfat und afles was Darauf Lar, gen . Simmel geiprengt hätte! Uno jetzt cine z we it c Explojion bidht buncben: wie weggeblajen waren bic Menjuchunafen, als jid Stanth

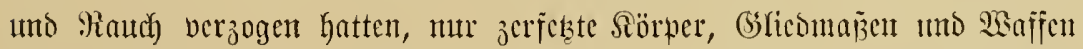

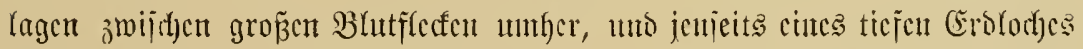

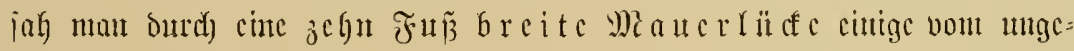

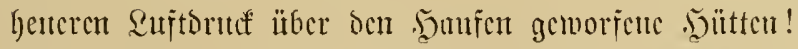

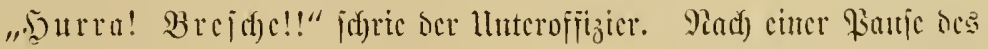

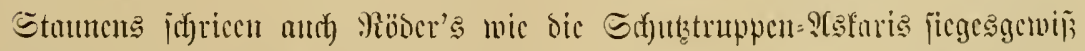

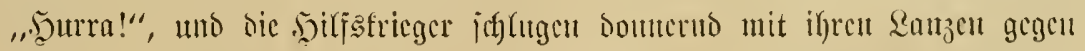

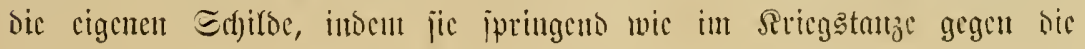




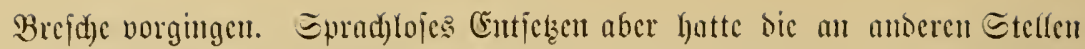

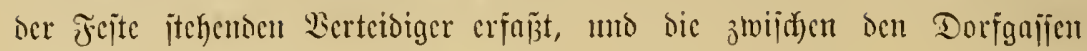

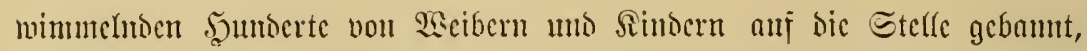
- bas Ungeheutere, Piegeabute siejer ieljenzeriplitternoen (Scwalt hatte ifor Denfen unt ifye (słlièer gelähnt!

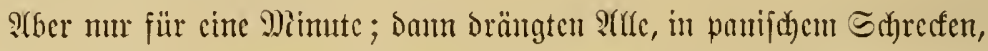

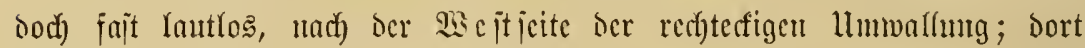

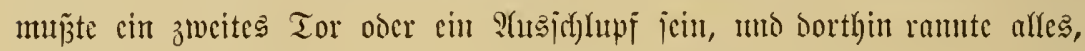
was jid) nod) anj ben Becinen halten founte, groj und flein!

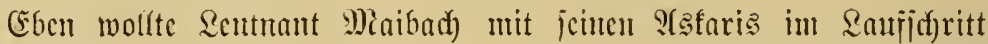
auf bic Brejhe jucilent, ba faut cin jubchnoes Echreicu von thẹ unten aus

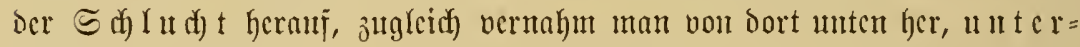

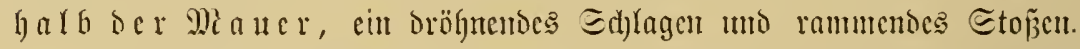

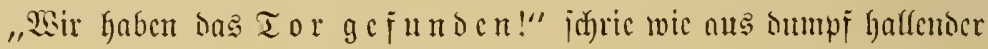

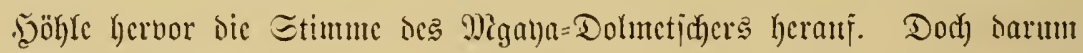

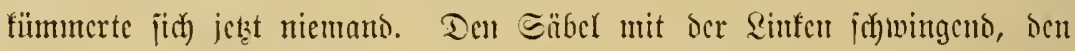
Revolver in Der Redjten cilte Sentuant Maibad) an ber Eplize jeiter

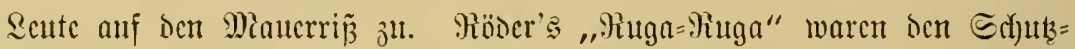

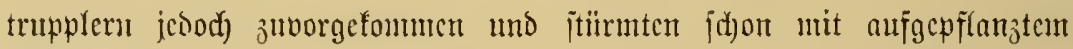
Ecitengemelgr in bas, "Dorf" hincin, -- wer jetżt noch von den Berteibigern,

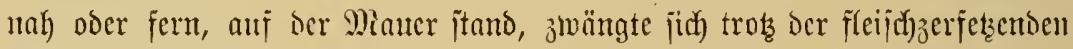

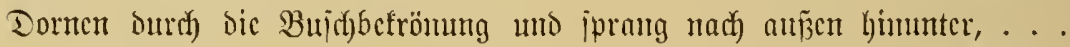

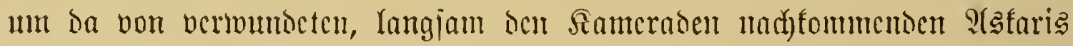

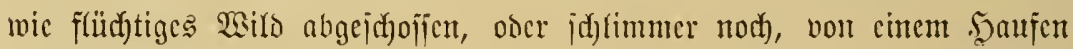
.̧ilfsefrieger mit ben Epeeren nicdergemadyt an merben!

Nur fnz̧e 3cit nod) fnallten bic Sarabiner im Dorje Ginter Den

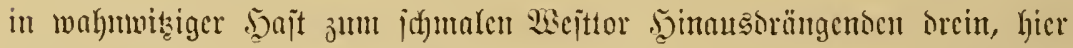

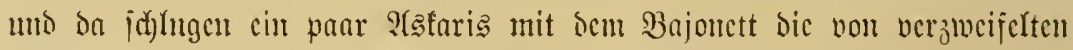

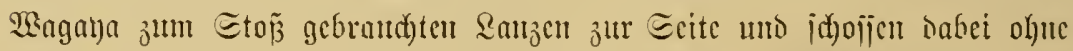

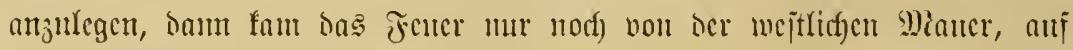

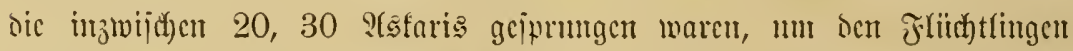

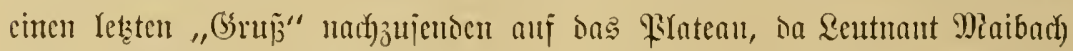

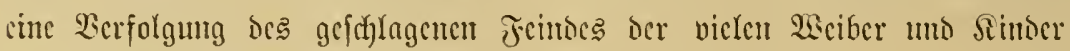
megen nidgt zugab, - is a ,Dor $\eta^{\prime \prime}$ war erobert! 


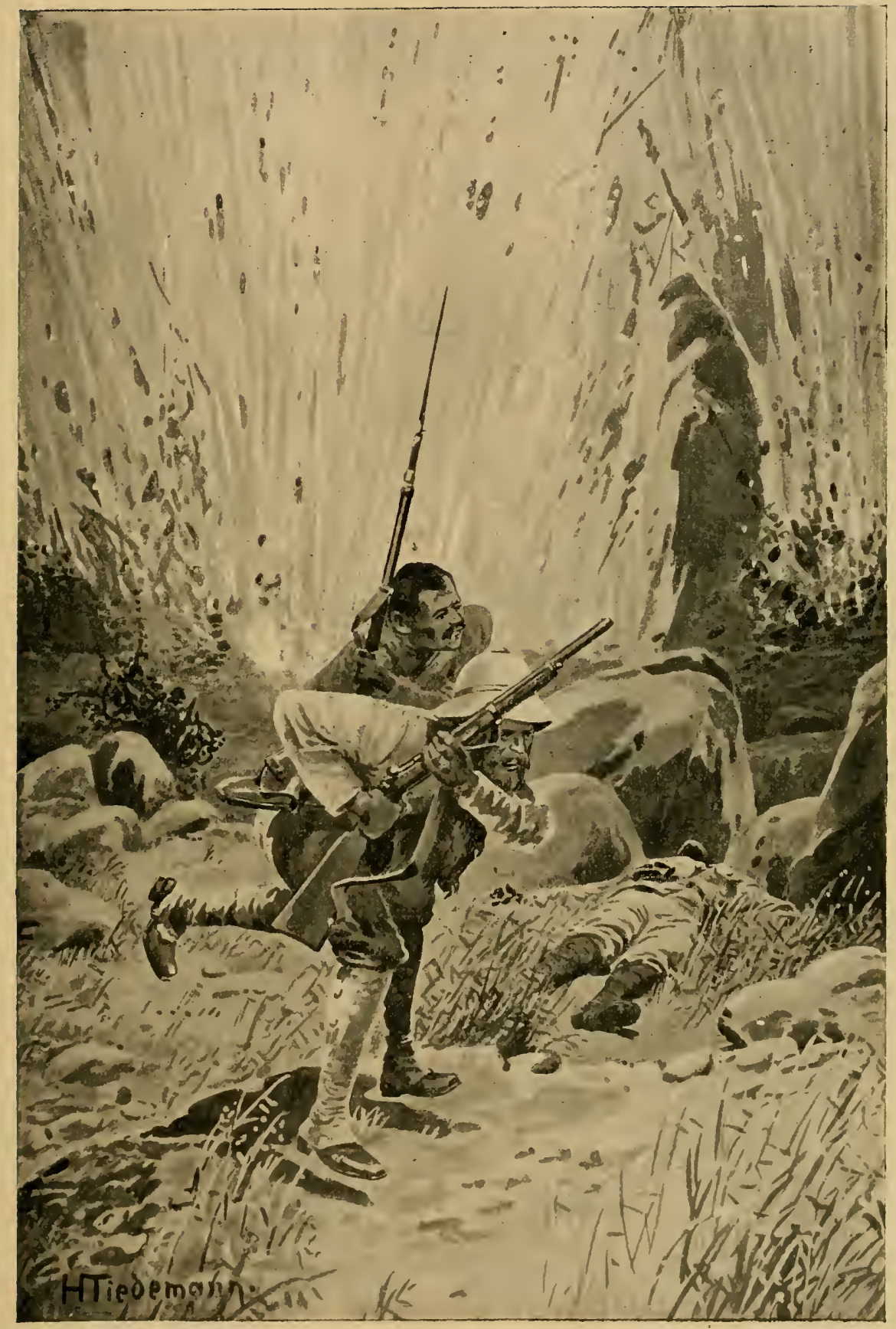

.. als ob ein Uulkanausbruch Erde und Fellen und alles was darauf war, gen bimmel ge(prengt bätte. 



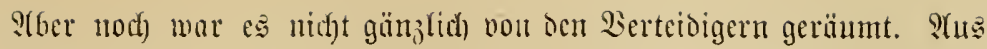

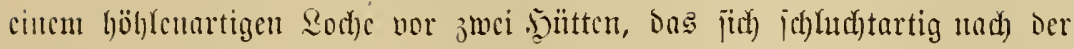

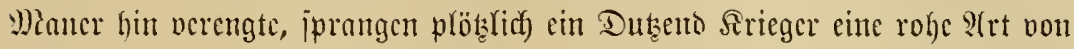

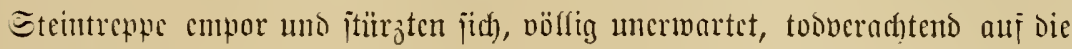
nüchiten Sisfaris, wälyeno von unten her, wo bns Splittern der einge= ichlagenen Torverrammlung aujgehört hatte, mit mildem Eicgesagebrüll dic

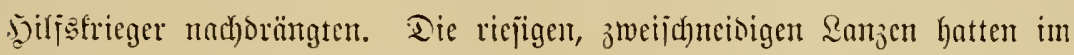

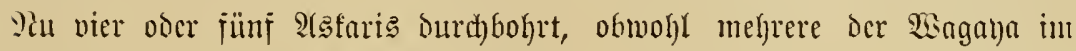
jerausipringen von Rarabincridüjjen niedergejtrecft wurben, und jidher luätten bie mit volfem Bemuẽjein ihres nahen Endes in rajender $\mathfrak{B u t}$

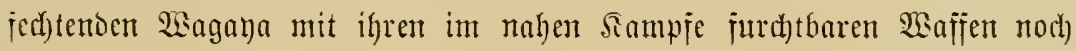

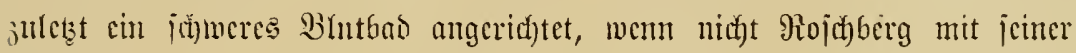

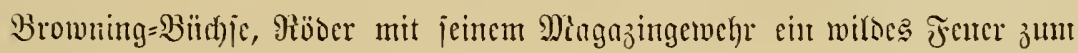

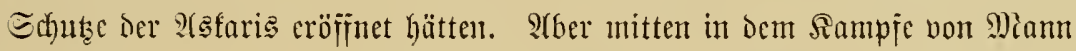
gegen Mann, Denn idyon hatten cinige 2(sfaris, aus Miangel an 3cit jum

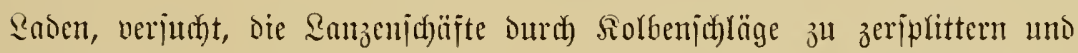

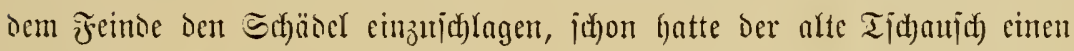
(Scgner an ser Gsurgel unt mürgte ihn, - mitten in bem 5̧anogemenge

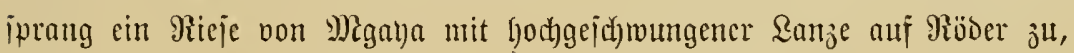

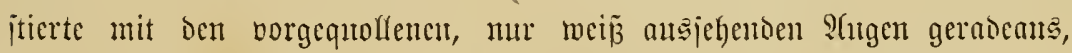

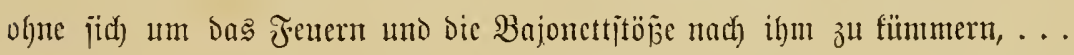

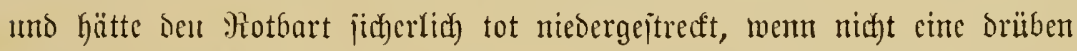

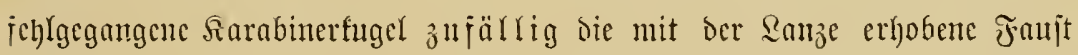

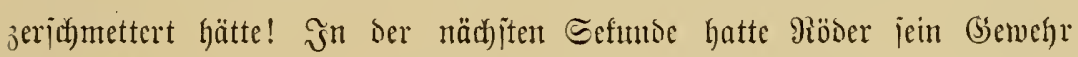
hingeworfen - es war patronenleer -, uno gerabe als ber Ricje trotż der

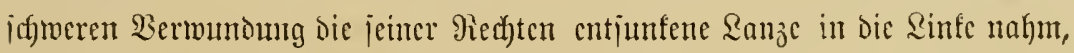

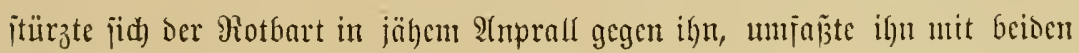
Ylemen, juchte vergeblid), ihn niederzuringen uno gab ihn beshalb endidid uit Dem Snic einen jo jurdhtbaren Etoj von unten nach oben gegen ben

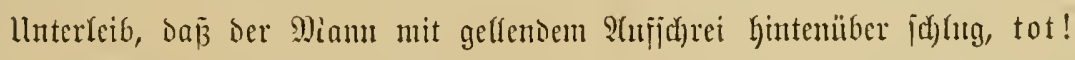

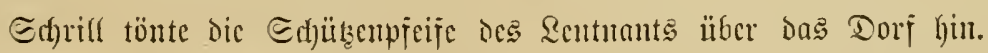
Eojort jtand das Feuern. Das Sommanoo "Intreten!" riej alle IEfaris,

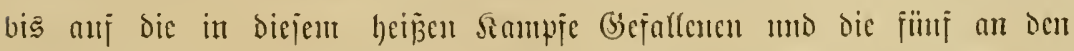

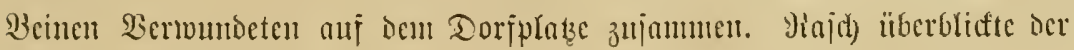




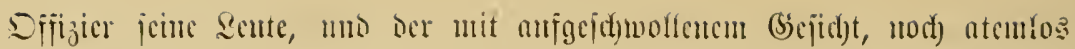

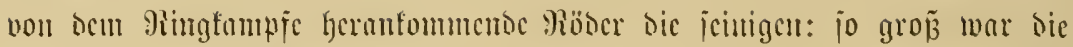
Diajihlin, io itraffe 3ucht hatte der "Drill" Den jarbigen Eofdaten cin= geprägt, baj jic jajt jo raj() in Picih) unt (Blies traten wic in Piuanja

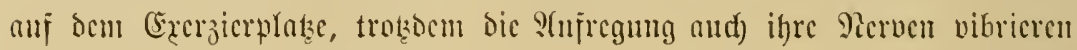

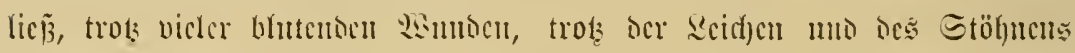

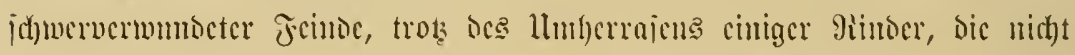

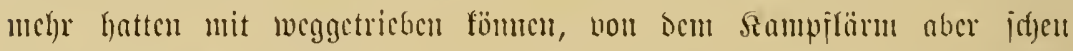

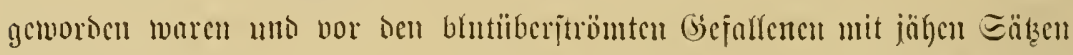

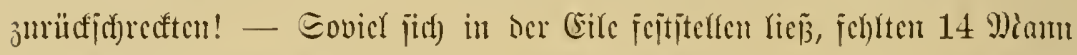

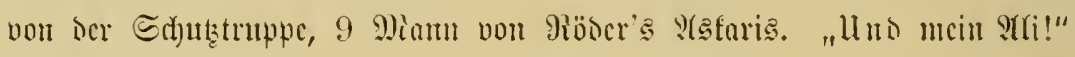

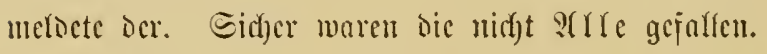

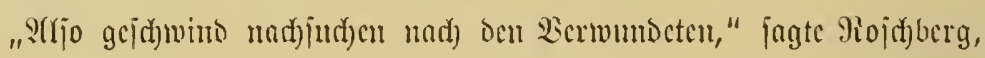

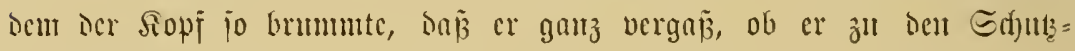
truppen=?(afaris ober zu ben Seuten ocr cigenen Expebition iprad).

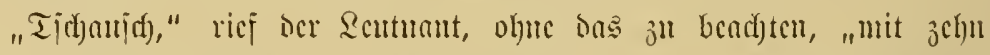

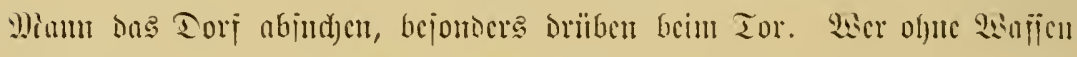

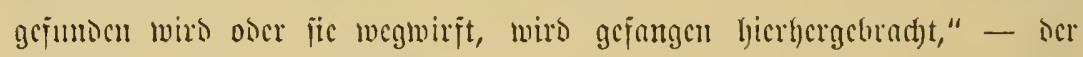

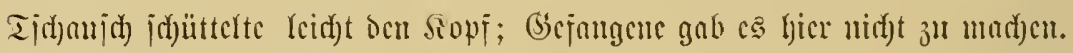

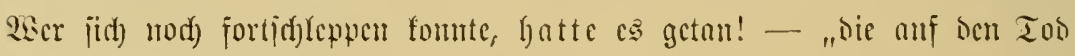

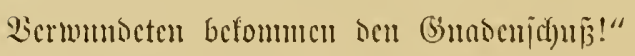

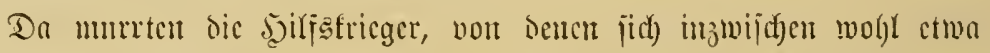

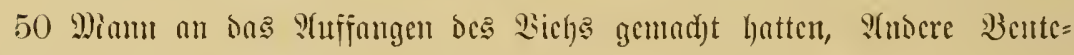

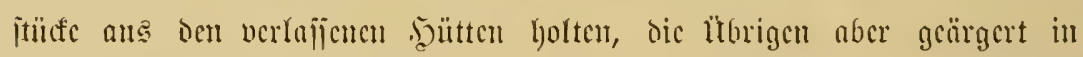

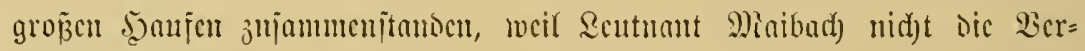

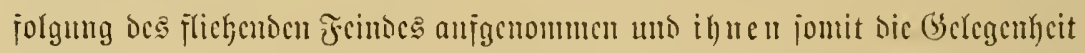

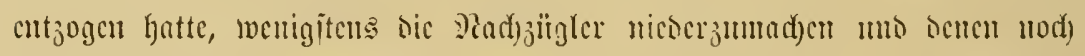

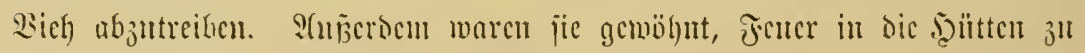

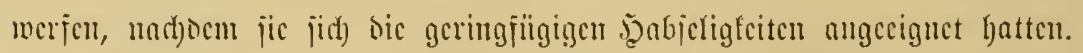

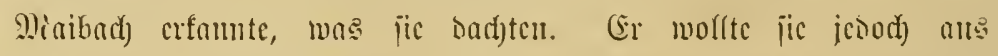

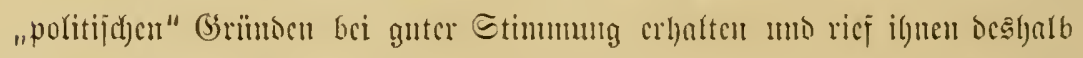

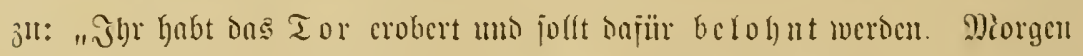

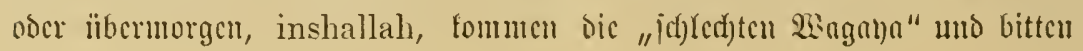


um Frieden. Die Şälfte des Strafuiehs uno jwei von den vier "Erçantenfjörneru", die jie zahlen müjīen, betomnt ihr!“

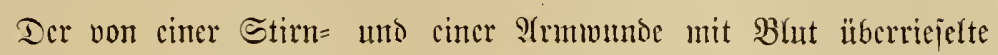

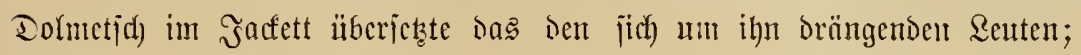

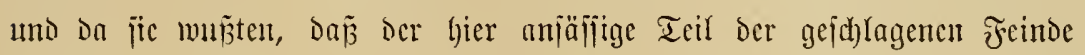
nid)t wenige Rimber wïrbe zaflen miififen, ment er nidjt jetze noch) ocr= folgt werben uno mit jeinen Berbüntoten über bic (Sirenze in Deren Rano

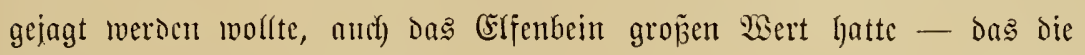

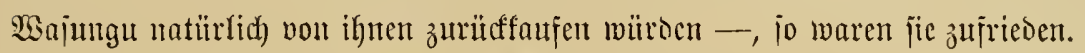

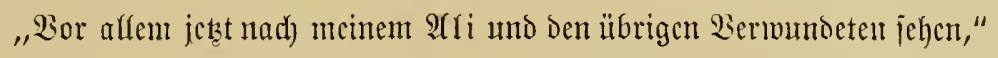

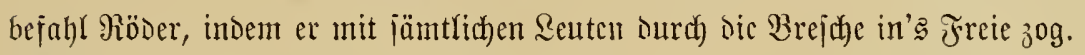

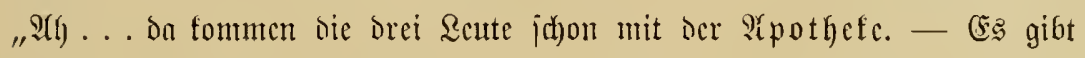

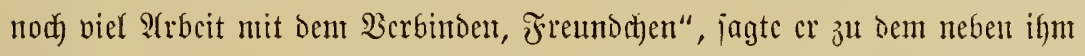
gehenden Rojhberg. "Sic fömmen dabei etwns lernen, für bie Bufunft!"

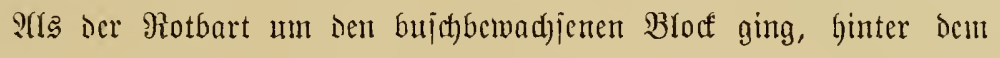
er jeiten getreuen Boly liegen gelajfen lyatte, fanto cr ihn micht melly vor.

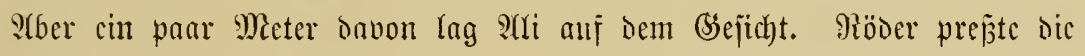
Rippen zujammen und ridgtete Den braven Burityen latb auf. Da jd)lug

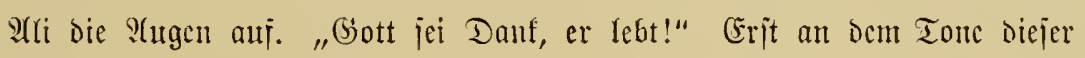

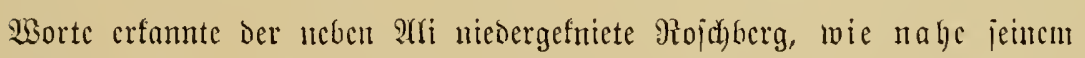

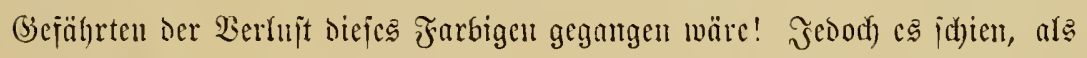
ertenne seri meder jeiten Bana, nod) wo el jid) bejano.

"Er hat cinc (bénirueridjüttermy weggefricgt," meinte nad) cintigen

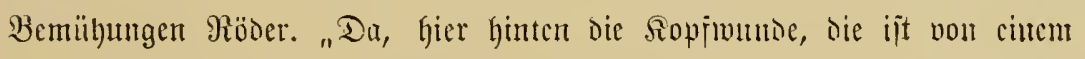

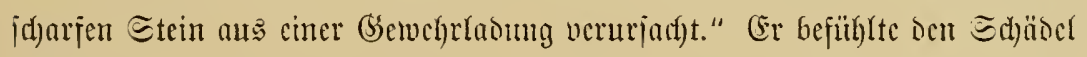

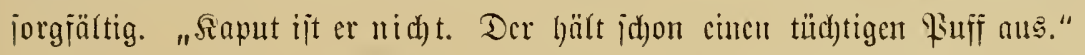

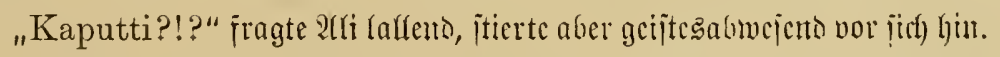

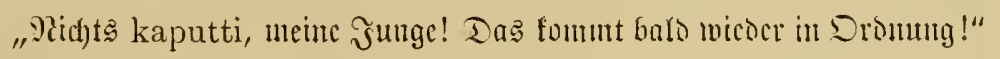

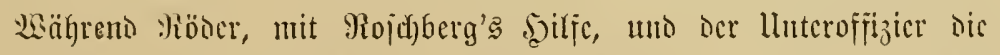

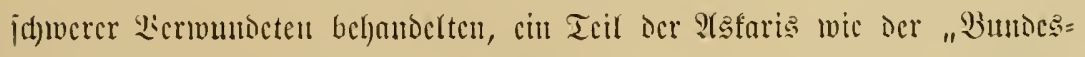

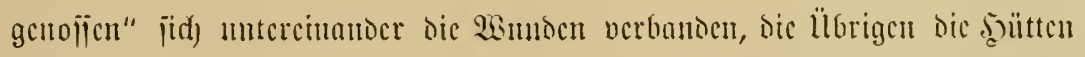

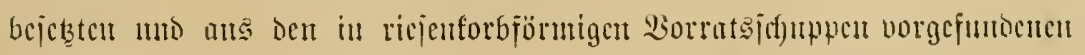

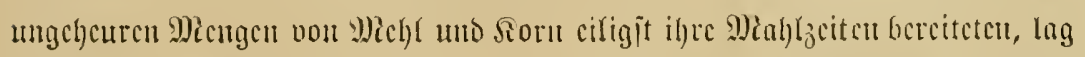

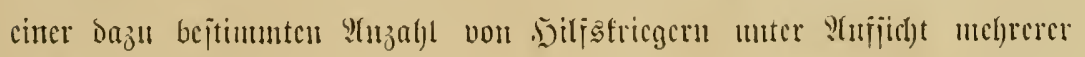




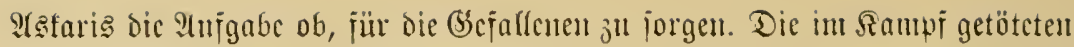

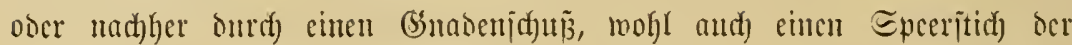
Şiljątrieger von ihren Snaten crlöpten Berteisiger ber eroberten Jejte, wic

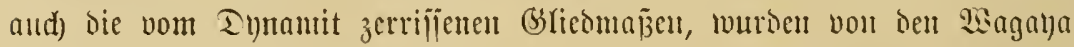

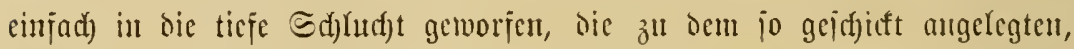

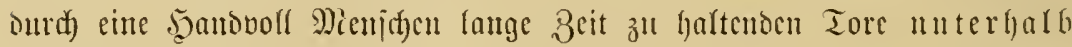

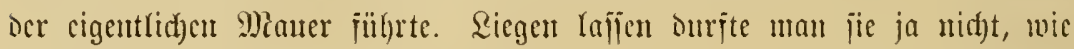
Das jonjt ̈̈blid) war, benn man mujpte ein paar Tage in ben croberten

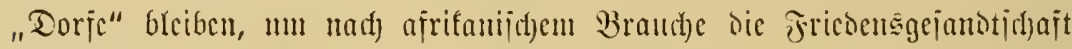

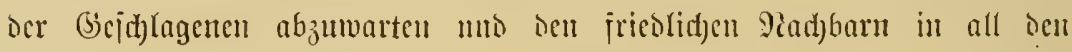

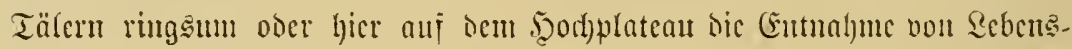

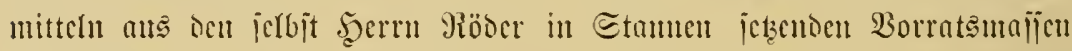

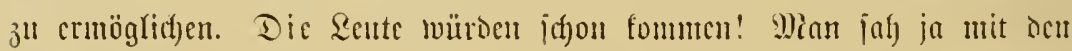

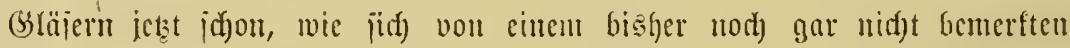

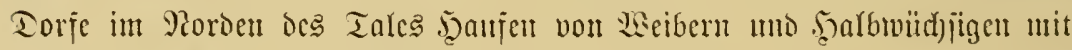
gewaltigen Rörben ocn Berghang hinaujbewegten!

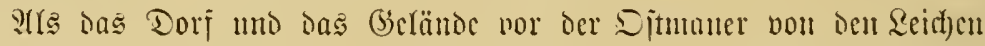
gejüubert war, hicẽ

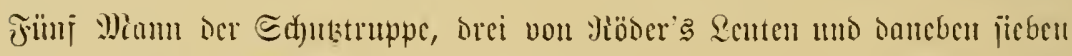

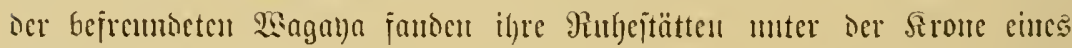
mäd)tigen Bames. Sentmant Maibad) jprad) ein paar 然orte ïber bem

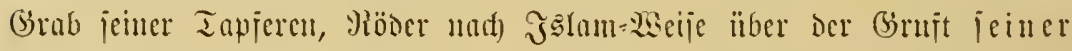

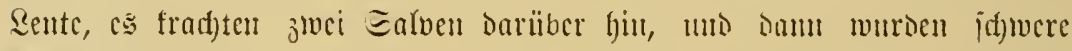

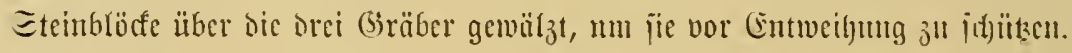

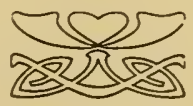




\section{Fünfzehntes Kapitel.}

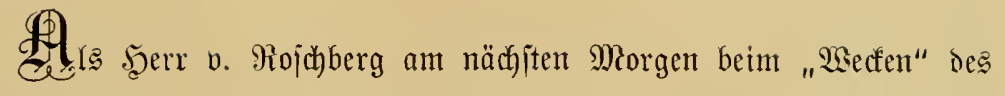

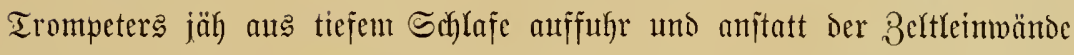
das Эomere einer Regerljütte vor jich fah, glaubte er żterĩt, er träume noch. S(ber wie jein erjtaunter Blict mun in ber sumflen, mur idjwad) von

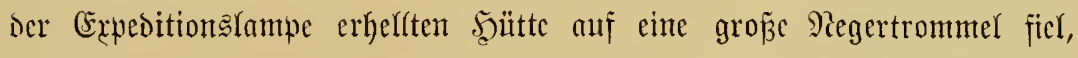
dic ringsum mit gebleichten Totenichäbeln als Zierat umb zum filappern behängt war, ba muj̃te cr binnen einer Sefunde, wo er war: in einer eroberten Feite, am Iage nach) einem fodweren, blutigen (befechte, einem

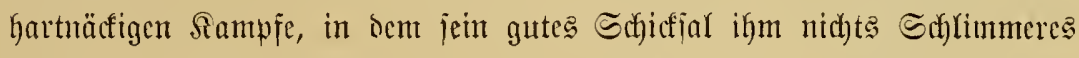

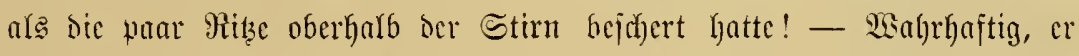
mušte nach ben itarfen 2(njtrengungen bes nädhtlichen Bergfletterns im Bachbette und ben Shrfregungen biejes (befechts, des criten wirflichent

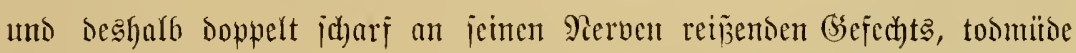

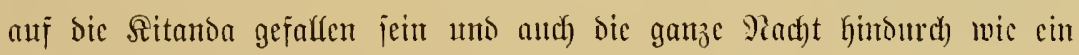

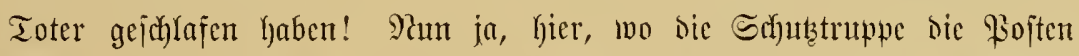

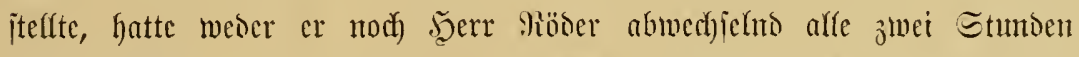
herausmiijien, unt bic Scute ju revibieren! Deshalb bicjer Daucridylaf!

Er wollte aufipringen; allein Da merfte er, Da $\tilde{\beta}$ er iteif all alfen

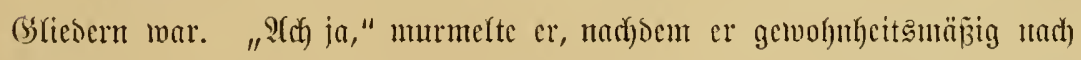

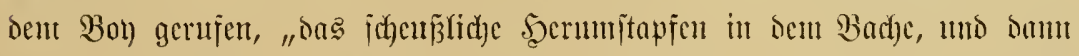

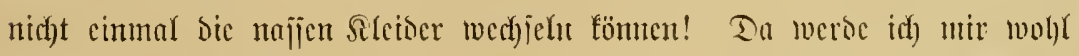

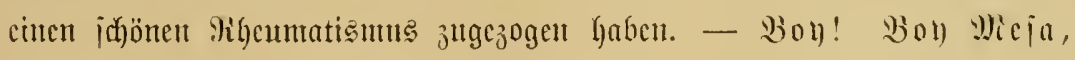

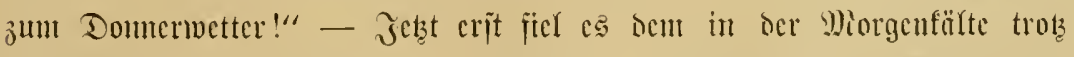

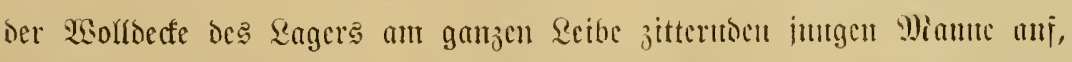

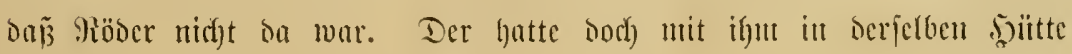


Padthtlager bezogen? Socr, . . wie mar bemu bas eigentlich geitern

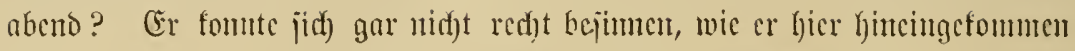

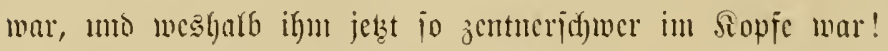

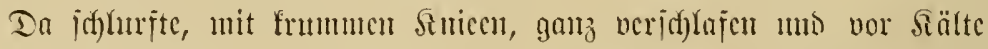

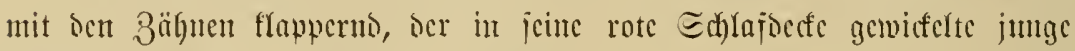

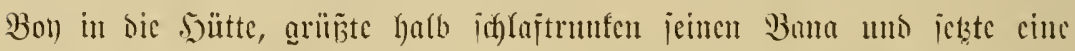

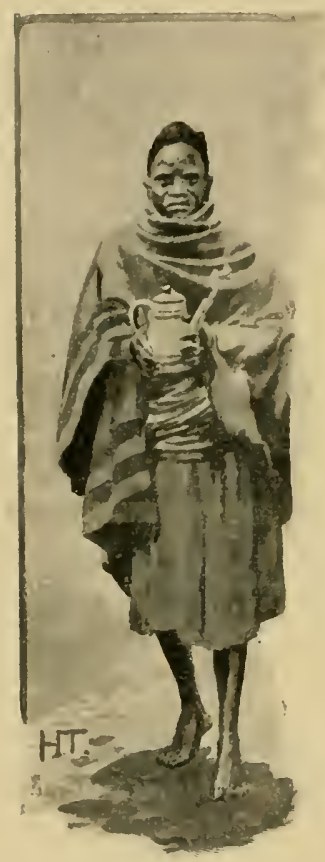

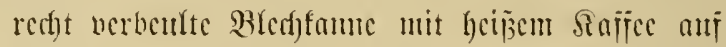

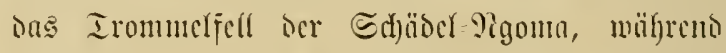

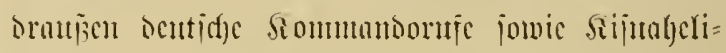

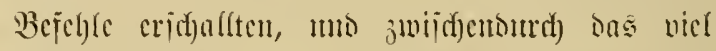

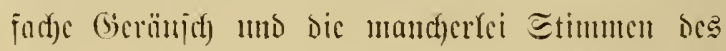

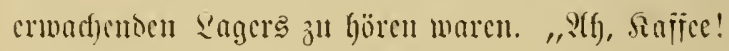
Nipe.(gib mir)." Whit Bebugen jog Bojeftberg

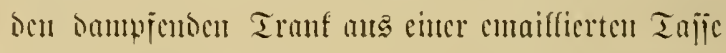

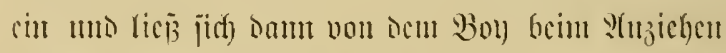

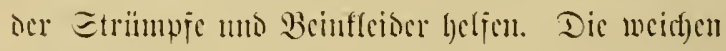

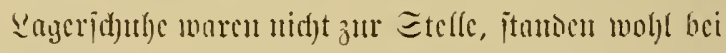
ถen ӥбrigen jurï̈(fgelajijenen End)en "mabuyuni", unter bem :(fifubrotbanme int $\mathfrak{I} a l$; aljo glcid) int bic

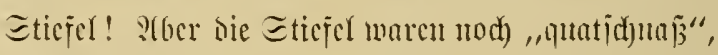
wic Niojofherg jith mit ciniger l̈tocrtreibutg ans =

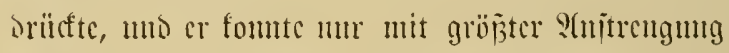

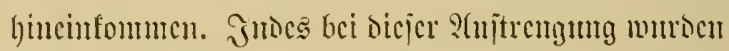

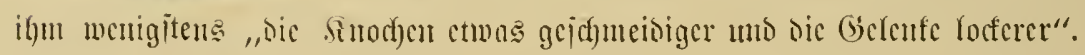

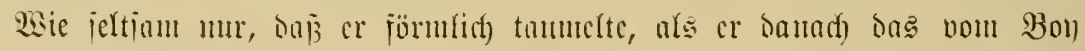

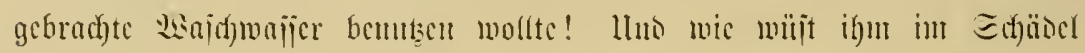

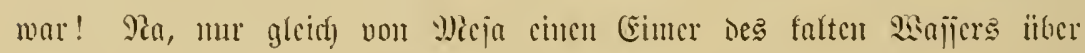

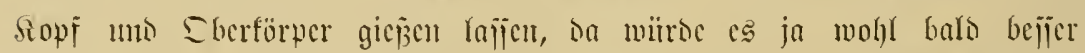

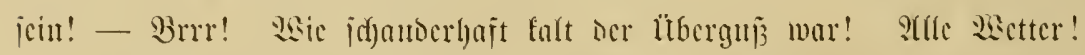

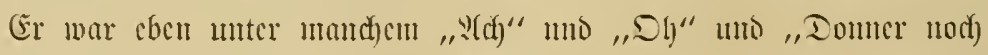

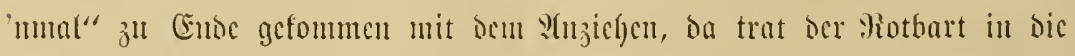

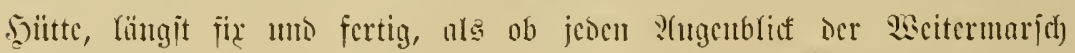

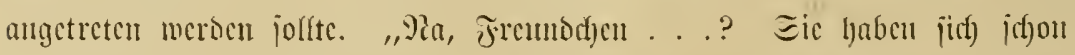

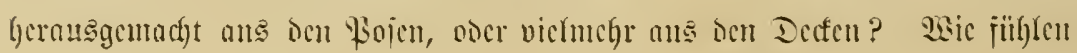




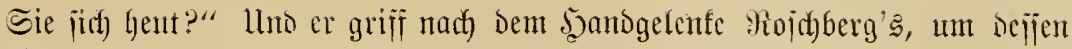

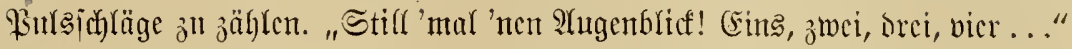
"Ja was ijt bem los mit mir? Sie tun ja gerabe, als..." „.. nla ob Sic gejtern acgen abend cinen ganz ljübichen Fieber=

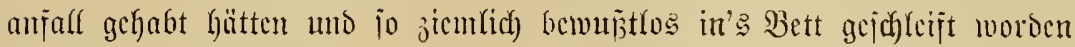

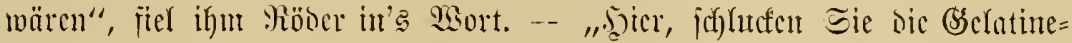
Sapjel mit Dem üblidfen (Gramm (SGinin nur gleid) mit 'uer. Ferneren Tajje

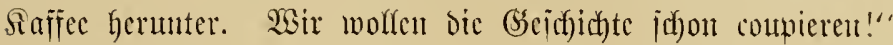

arjo b a s mar's! Fieber lyatte er gefricgt! Darum war ifm idyon gejtern nuchmittag jo jomberbar jumute gewejen, davou maren

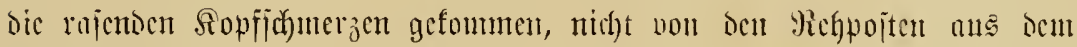
Worderlater, wie er gesacht hatte! Ficber! IIno noch baz̆l cincr der

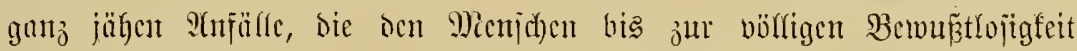
bringen!! Das flaute ja bann gegen Miorgen immer etwas ab; aber mer

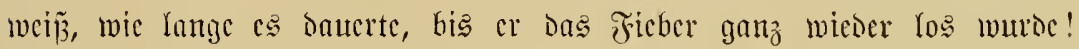

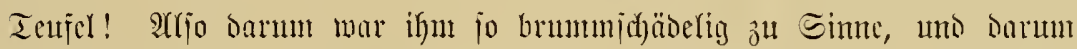
taten ifm mogl unth) bic (sflieder jo weh, als wäten jie ifm halb jerid)lagen!

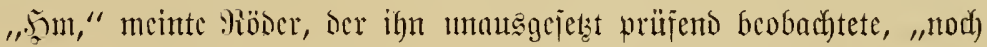

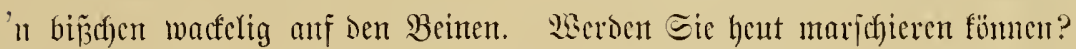

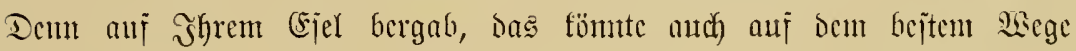
bös alı̃allen!"

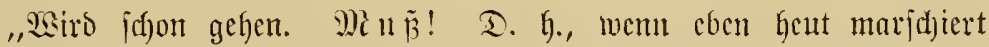

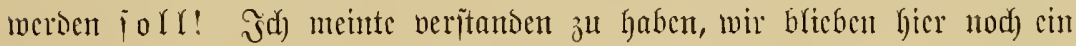

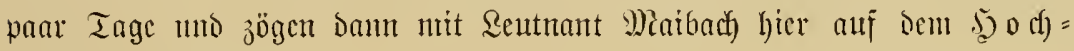
platcau meiter?"

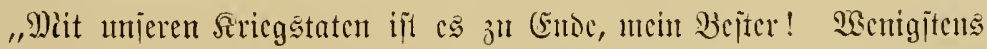

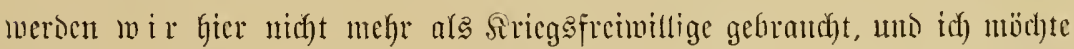
beshalb jo buld wic möglich aupbred)en."

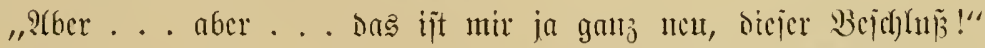

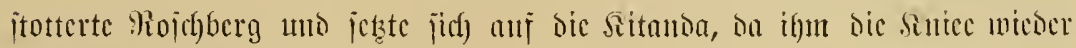
"io merfwüroig" jitterten.

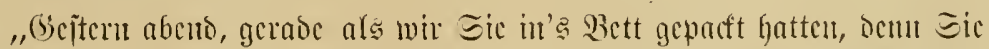

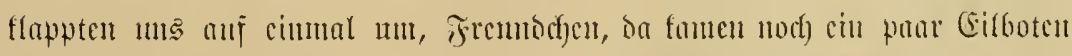

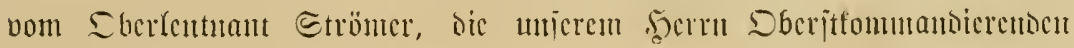




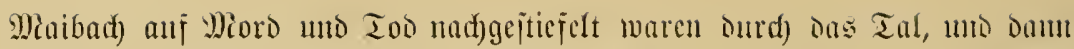

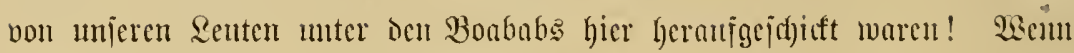

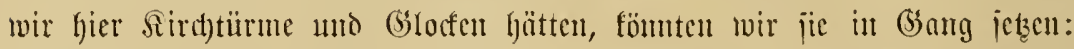

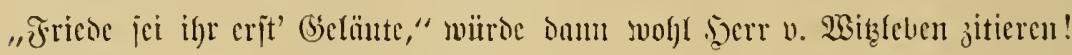

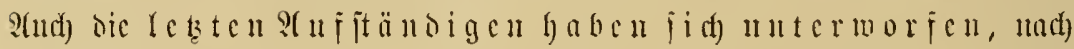

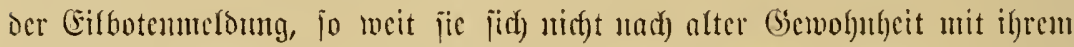

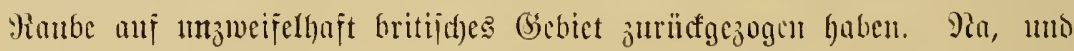

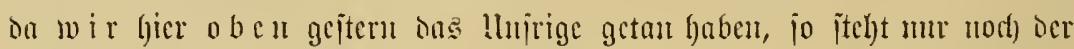

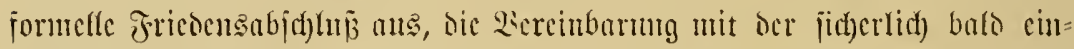

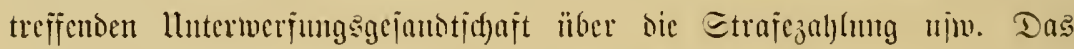

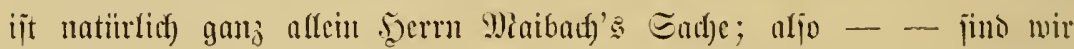
Beibe mit unjeren, "ruga-ruga" hier vollitündig überfliijiig! llno ganj offen

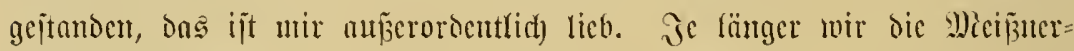

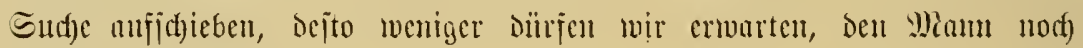
lebenoig auj̧ıјрüren!"

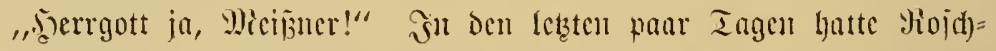

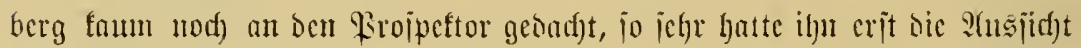

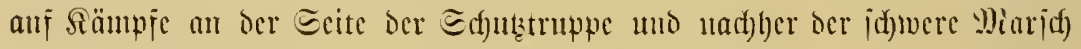
wie Der Sampi ferber aud geiftig in 9(niprud) gentomment. Ja natürlid)! Böber hatte volffommen red)t; mar man ljer nid)t nötig, danm jo raj()

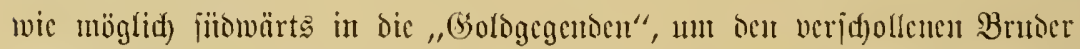

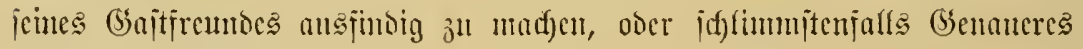

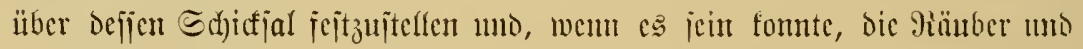

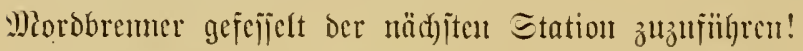

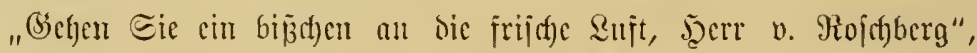

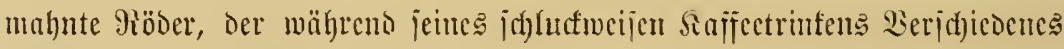

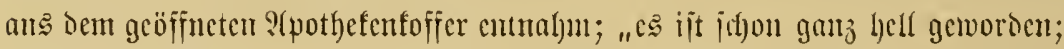

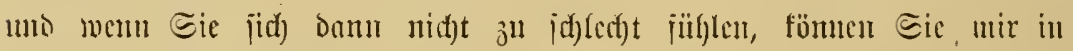
furzen bei Der Sirantenvijite helfen. S(ber mel)uen Eie erjt jelher 'ural cin paur Tajien voll jrijde Miorgenlujt. Die flärt cincın dic Rehengageijter

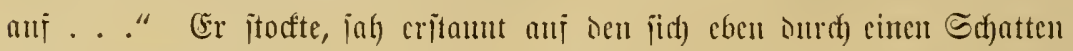

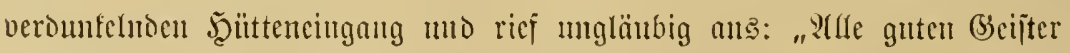

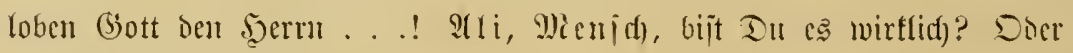

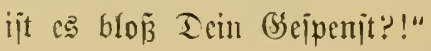




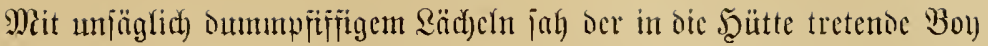

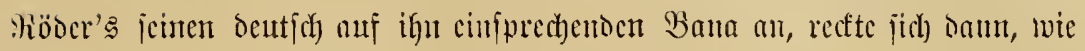

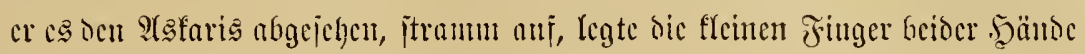

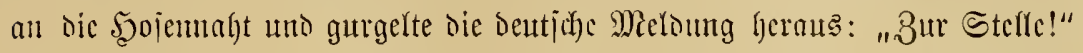

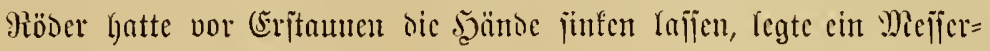

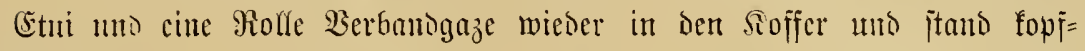

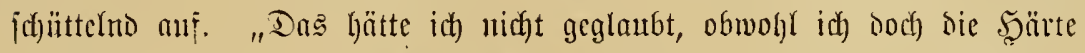

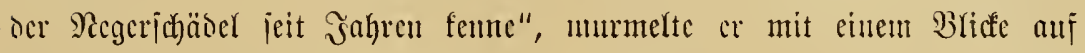

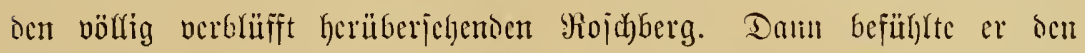

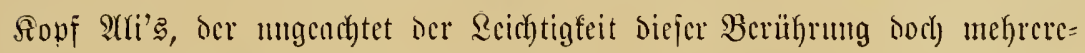

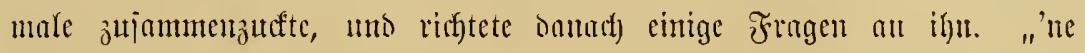

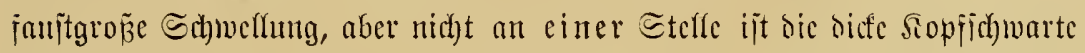

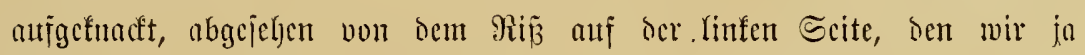

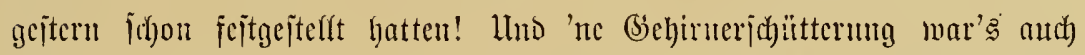

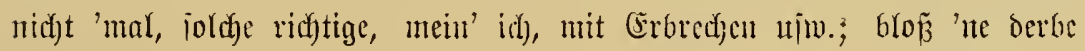
Betüubung! - Ramnjt Dut effen?" jragte cr ocn Boy auj Ríjutueli.

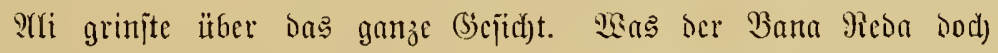
immer jür jamofe 2 siłze machte! WSartum jolfte cr benn nicht effen fömen,

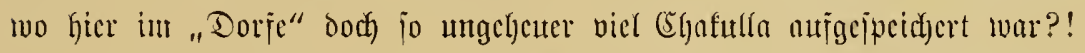

"Pla Daum ijt's gut! - Fange immer an, mit Mcija bic Sadhen

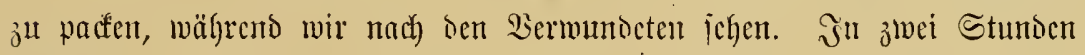
marjojieren mir in's Tal!"

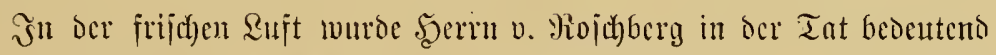
beffer; Der Drutef im Ropje hörte auf, uno dic S(h)wäd)e in oen Beinen

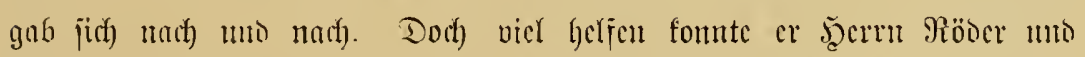

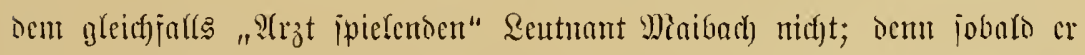

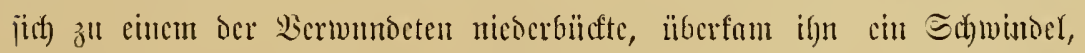

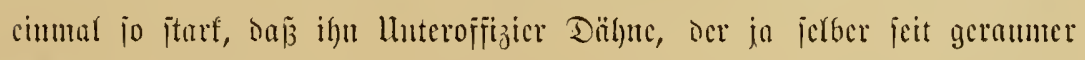

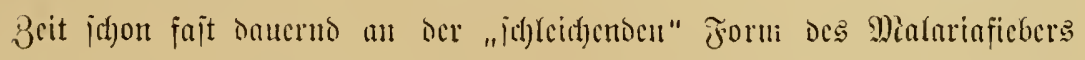

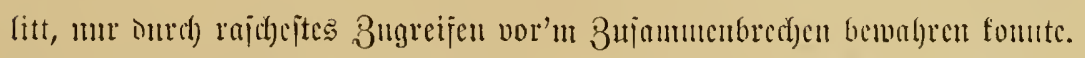

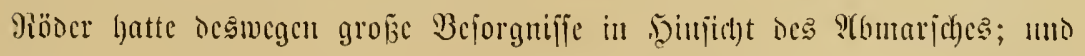

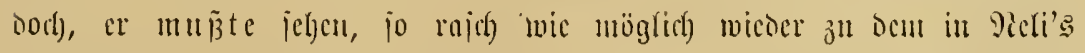

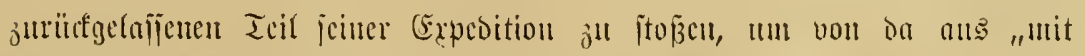
Sims uno Sicgel" Den Bormarj(l) jüomärts anjutreten! 


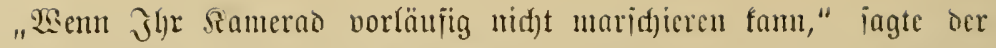
Sentmant zum Rotbart, ale bie franfenvijite vorïber war unt Der ?(rbeits:

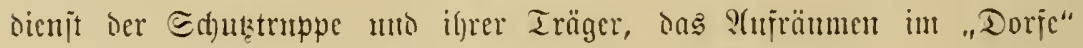

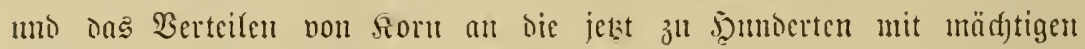

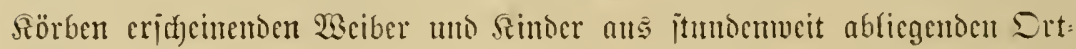

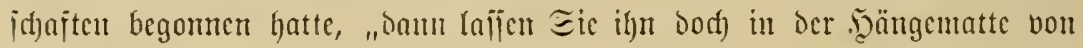

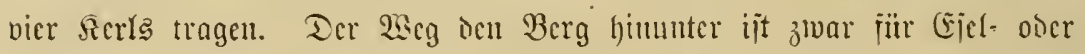

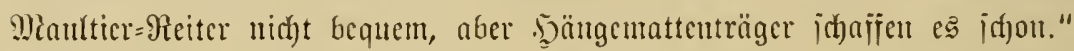
(Er hatte jich geitern vor (sinbrud) oer Dunfelfyeit oen in jricolichen Beiten bemukzten 2 seg von cin paar jidf) nad) unt nad) wiescr "untrümeftnden"

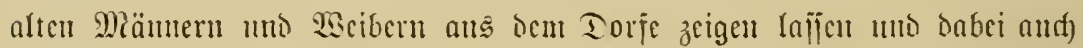

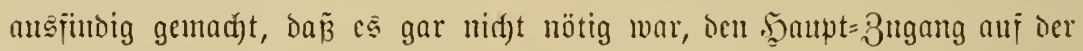

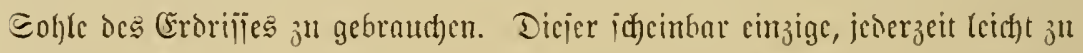

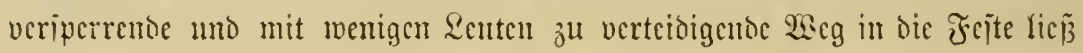

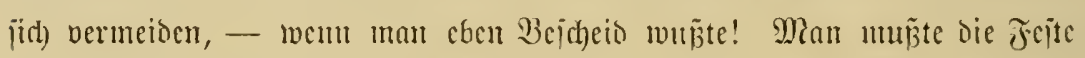

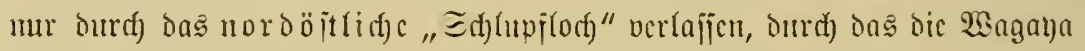

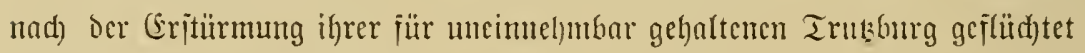
waren, uno ungeäbr cine halbe Etunde lang auf dcm von Eshirmatajicn

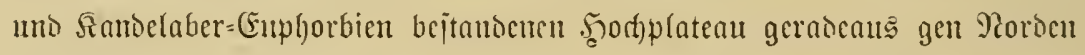
marjuieren, um bann, wic bis ïber igre fiornbeute glürffict)en "guten

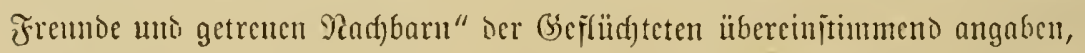
burd) cine zwar veritect liegende, aber nur furze Erflucht bergab zu ítcigen

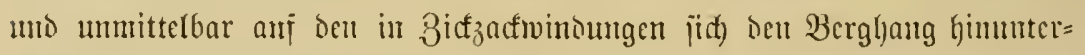

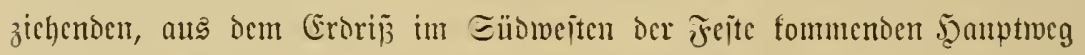

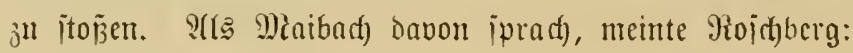

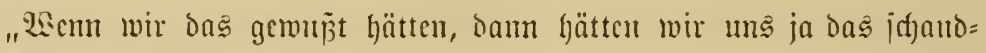
bare Slettem im Bad) eriparcn tömren!"

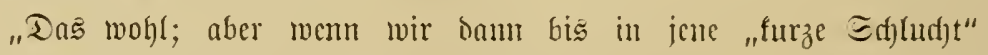

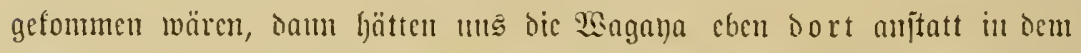

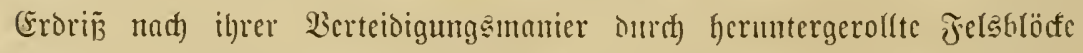

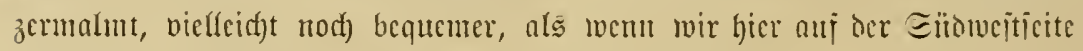

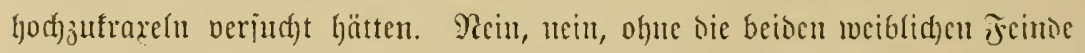

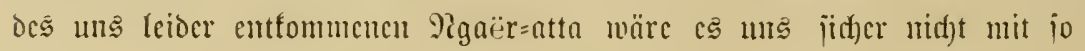

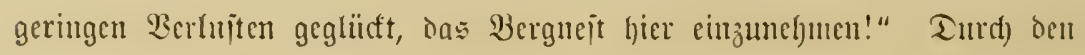




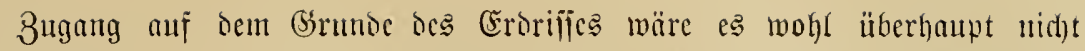
gefungen, uno der vergebliche Beriuth hätte die alferichmerīten Spjer gefoitet.

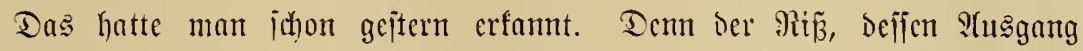

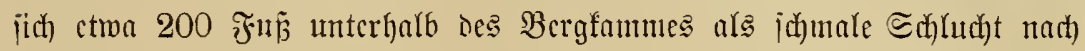
bem Tale hin öfrnetc uno jo ju cimem von hier oben aus ju überblicfenten

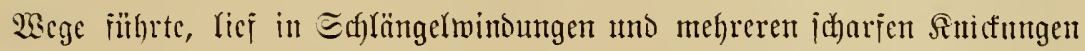

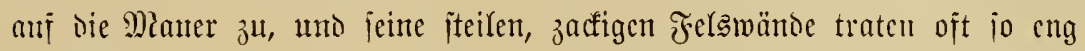

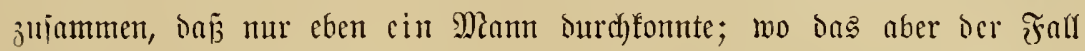
war, hätten sie Berteidiger mit ifren Iangen Speeren jeden Bordringenden abitechen, oder hinter occfention Felavoriprüngen hervor gleidh) mehrere Der einamber folgenton atngreifer auj einntal mit ifren Borderladen nieder: itrecfen fönnen, währeno die anf den breiteren Stclfen vorrü̈fenden Feinde von oben hac ourch himuntergejtoß̧ene Steinblöcfe mühelos, und ohne die Bertcibiger bejondcrs zu gejähroen, hätten vernichtet meroen fönnen. Uno

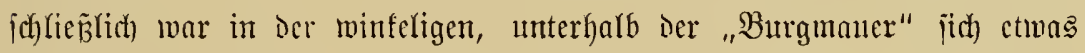
crweiternden Edhlud)t cinc Dreifache Palijabierung aus gewaltigen Baum=

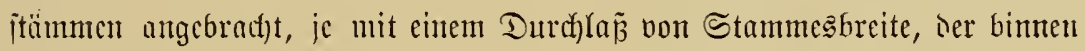

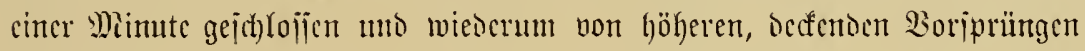

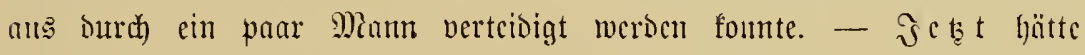

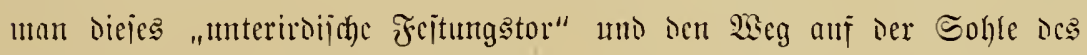

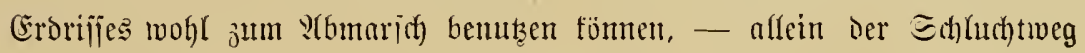
war nun beritopit Durd) Die himeingeworfencn Reid)en ber singmua. Frei

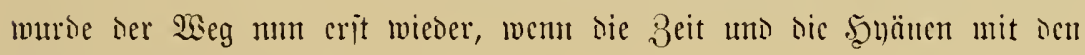
Toten aūgeräımt hatten!

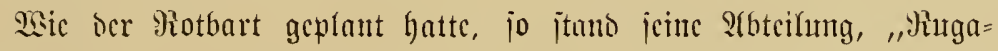

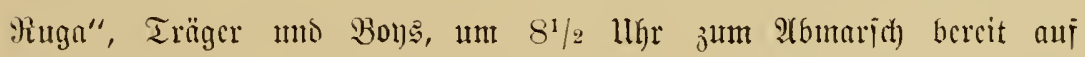

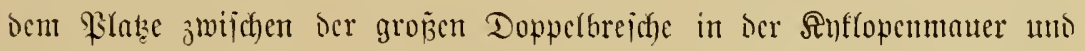

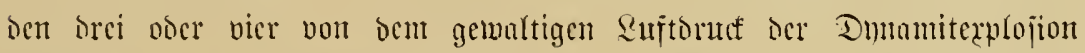

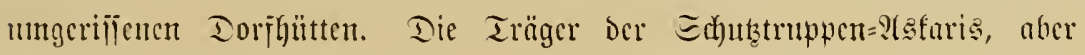

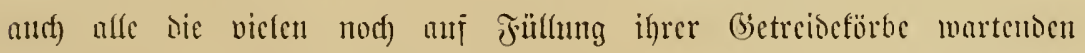

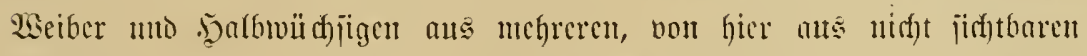

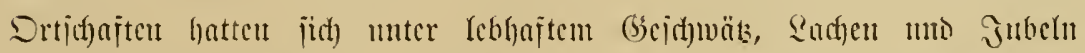
hcrangedrängt ju bem bei jeder 9(brcije ïblichen tusha mizigo (Rajten=

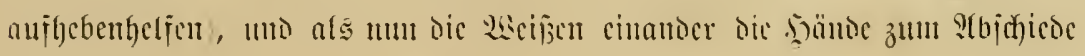




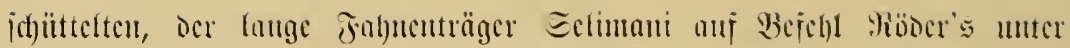

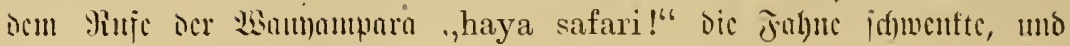

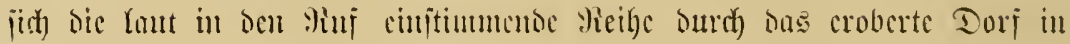

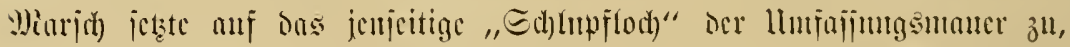

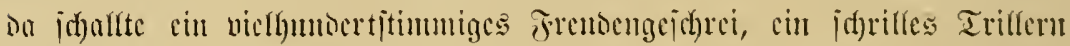

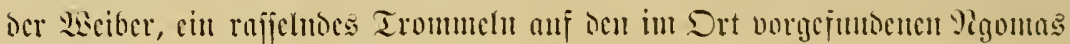

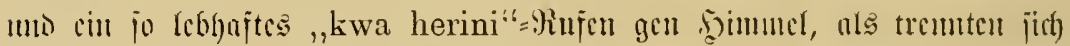

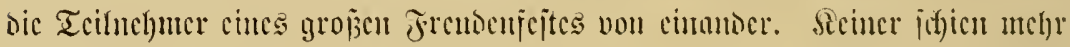

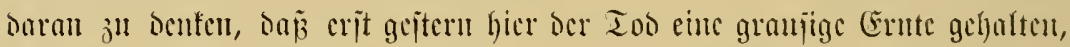

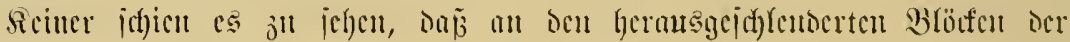

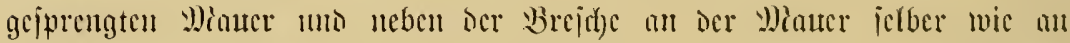

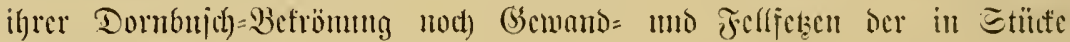

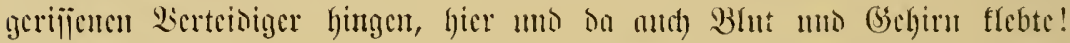

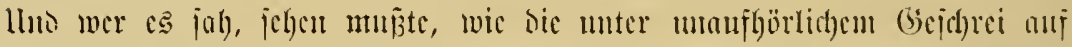

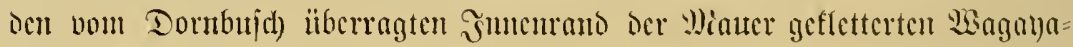

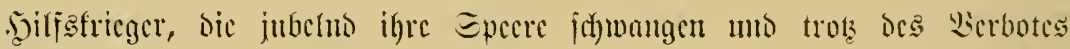

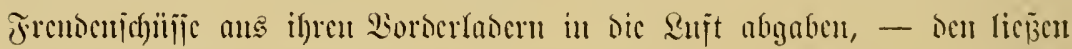

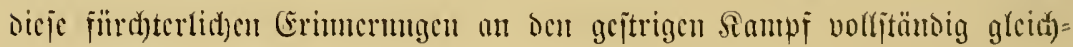

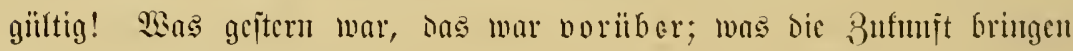

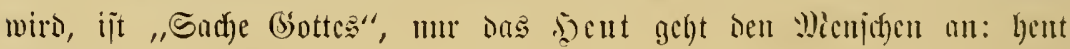
iit heut!

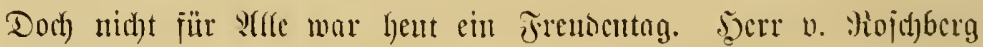

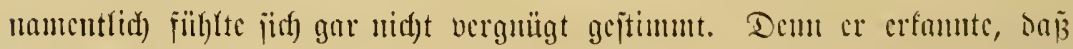

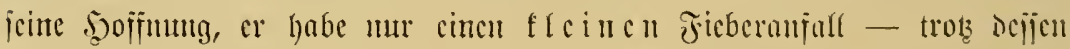

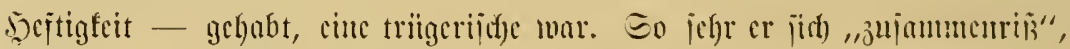

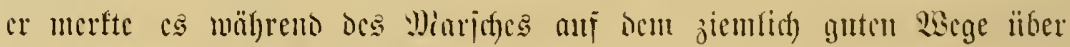

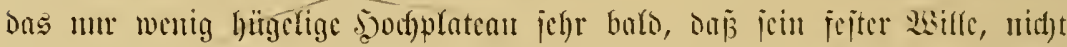

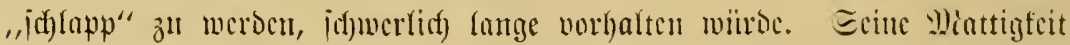

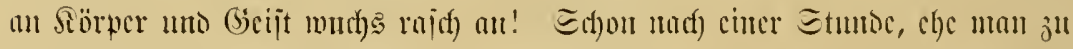

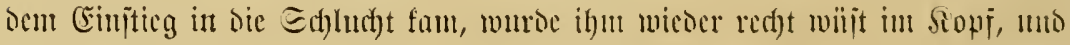

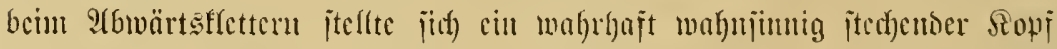

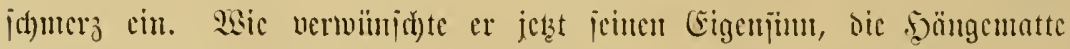

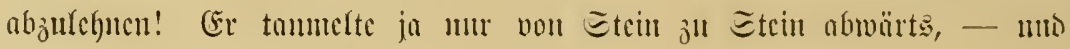

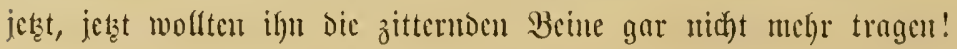




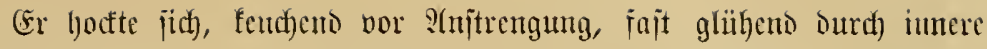

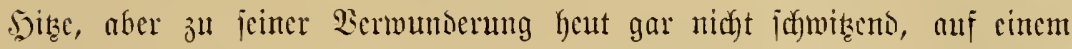
Jefsblocfe nieser utto winfte den vorüberziegenten Leuten - maren es

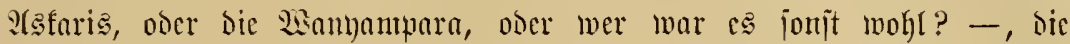
anjedeinemo bei ifym blciben uno ihm helfen wollten, ju, weiter ju gehen.

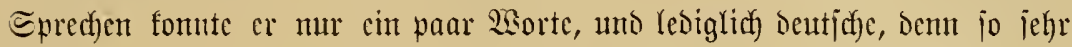

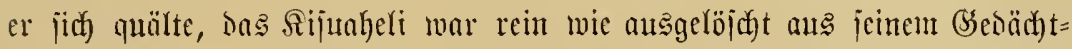

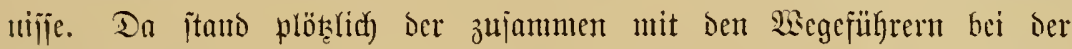

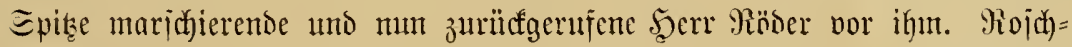

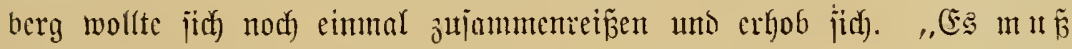

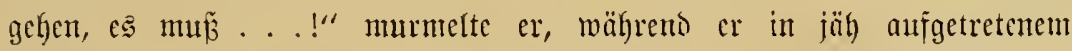
Sdjüttelfroit mit den Bähnen flapperte, "ę mirt . . vorïbergehen . ..!" Dann jebod) hatte er das (scfü̈lyl, ju fallen, immer tiejer unt ticfer zu jaflen, - uno als er wieder zum Bemusptjein fam, fano er jidf auf jeinem Bette im Beijezelte unter Den Boababs!

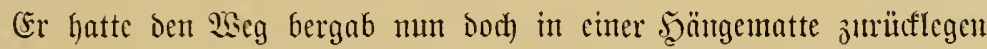

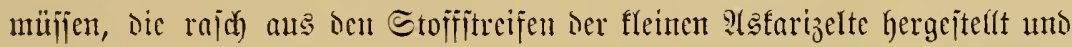
unterhalb einer langen, vorn wie hinten non je zwei hintereinantor gebenien Seuten auj den Schultern getragenen Stange befeitigt worden war. Won

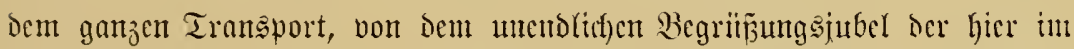
Sager jurülfgelajןenen Iräger unt Bor) hatte er gar nichte geichen umb

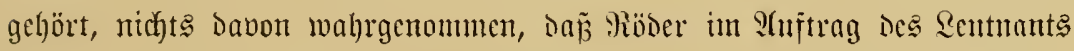

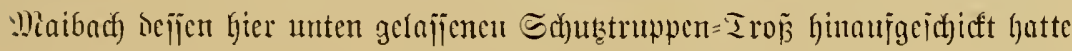

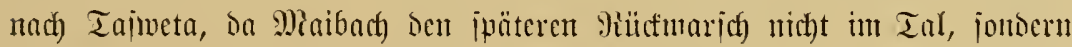
auf bem hod) unbefanten hod)platean ausiülfren mollte, unt hatte jetzt, wo

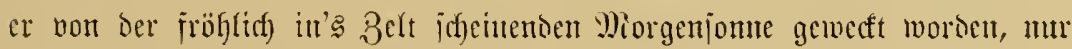

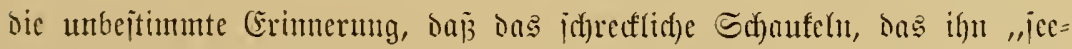

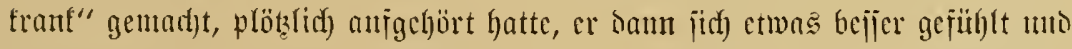

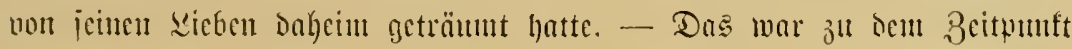
gewcien, wo icine Trïger mit ifu im, "Rager Minbummi" antgefangt muren,

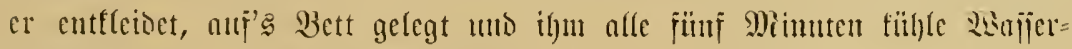

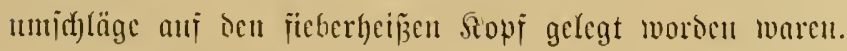

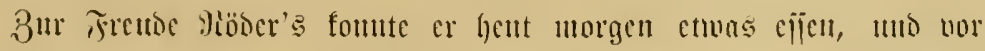
allen Dingen: das (benojiene bei jith beljalten, So fam er menigitens 


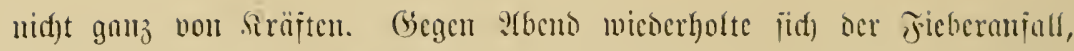

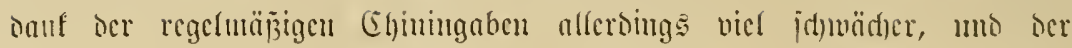

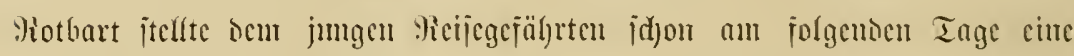

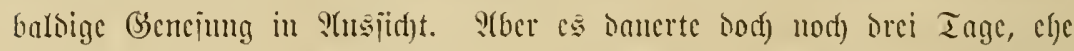

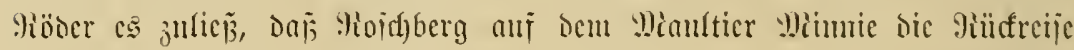

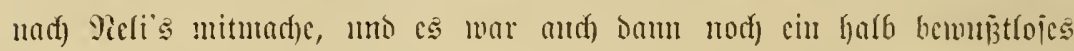

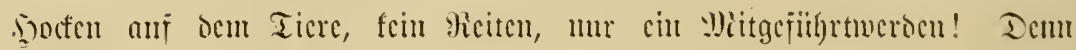

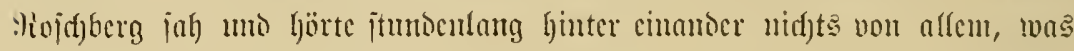

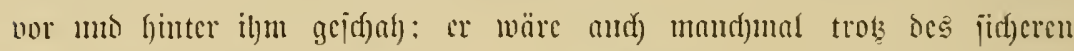

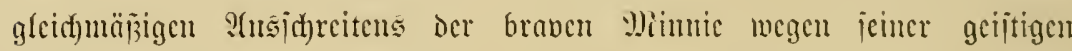

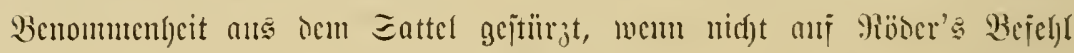

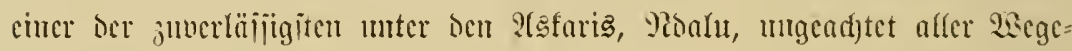
icfulerigfeiten neben Den Minultier hergegangen wäre mo Den jungen Mijungu itets jur red)ten Beit geitürst hätte.

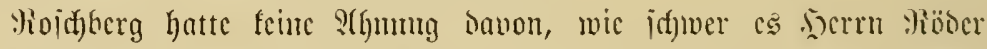
geworien, mit bem ?Intritt ier Yiüfrecije io lange anj ihn ju marten,

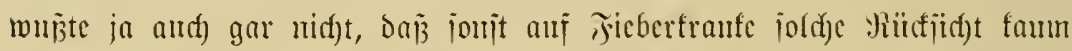
je genoumen wiro, wo ocr (Erreid)ung Des Reijejieles ourch Werjögernung

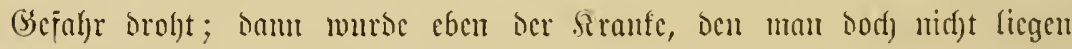
lajien founte, unter alfen Lunjtänocn in Der Sä̈rgematte getragen - uno

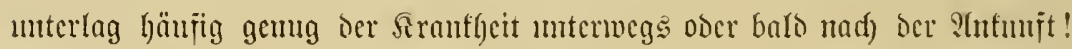
Erit jpäter murtoe es dem jutgen Meame flar, wie gerabeju väterlich ber Hotbart fïr ifh gejorgt hatte vou bem Yugenblicfe au, als cr oben

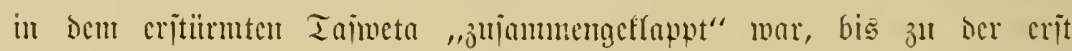

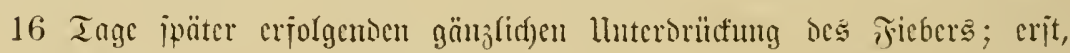

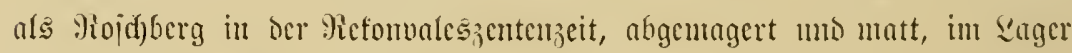

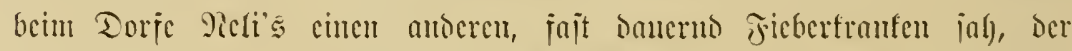

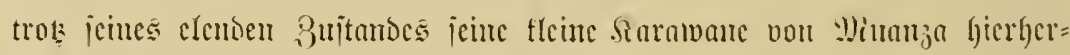

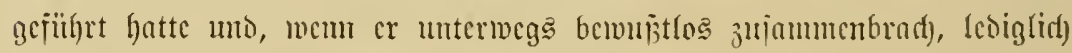

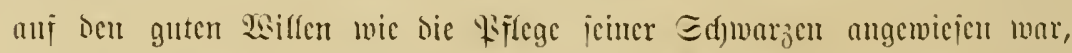

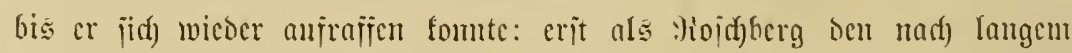

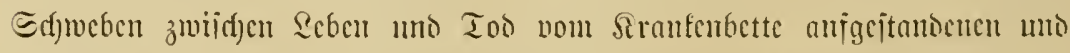

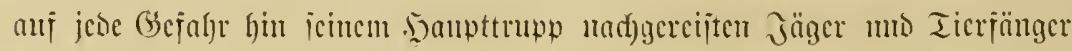

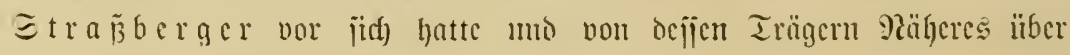


dic Sajari des Fiebcrfranfen hörtc, - o a er jt crtante cr, wic gut cr

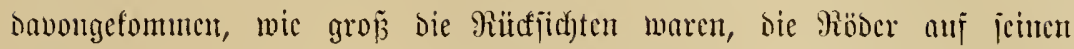
3ujtano genommen, uno wie ungemein jorglide der ign gepflegt hatte!

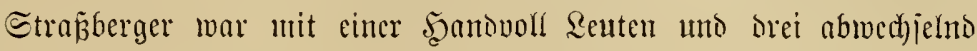
entweicr als geitticr jür ben Fiebernden oder als Fastiticr gebraudften

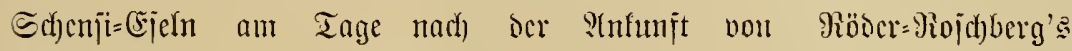
Mefari=Truppe bei Neli eingetroffen und hatte bercits aun jolgenden Miorgen

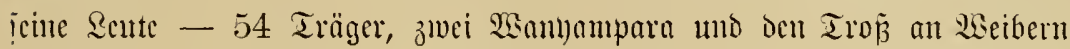

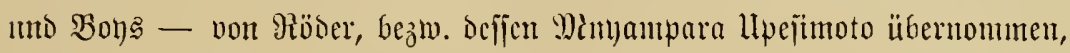

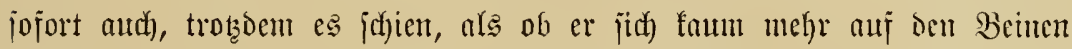

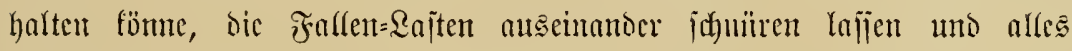

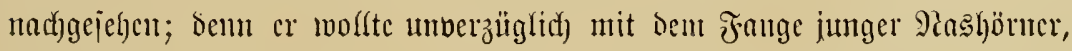
anf bic es inu cbenjo wic auf junge Sirraffen gamz bejonders anfam, in Der öjtlich des Mara=Smupjgebictcs licgenocn Steppe beginncur. Selbit

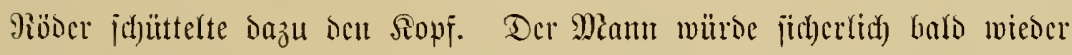
jujamunenbrechen; cr war ja nod) an feinem Tage jieberfrci gewejen,

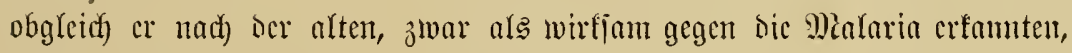

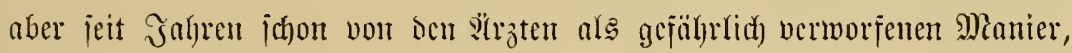

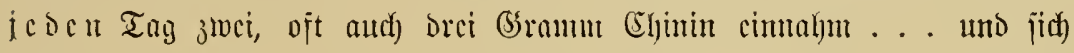

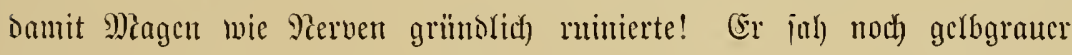
aus als in Mitanza, uno, „ljug แut jo in jeitucn fileioern. Wic cine

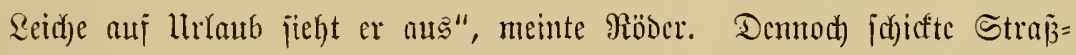

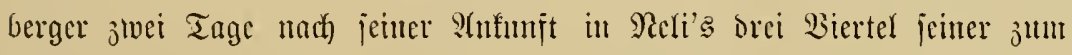

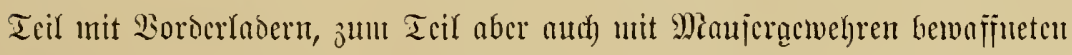
Scute unter Fïlfrung eines Solnes ocs alten Dorifhäuptlings voruts nad)

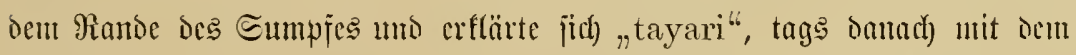

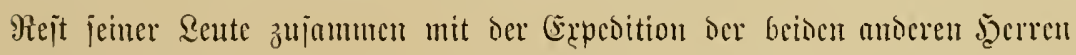
abzumarjojeren. - Bei ben langen Echauris mit Picli uno jeinen Dorí=

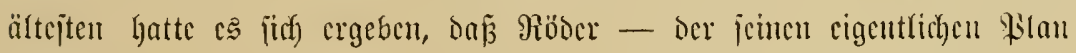

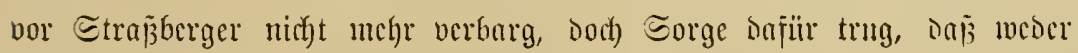

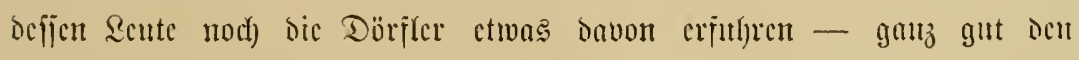

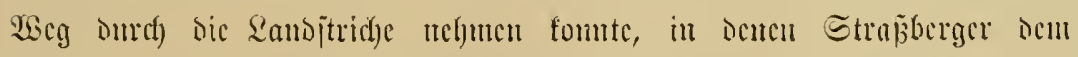
Fange oblicgen boflte; cr formte bann wenigitens in ben när)jten Tagen

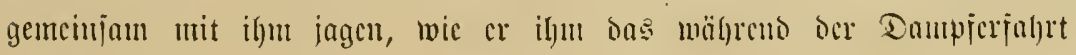




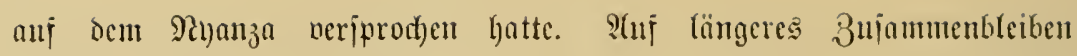

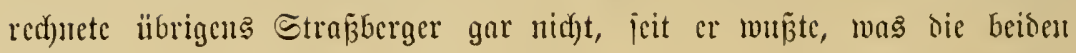

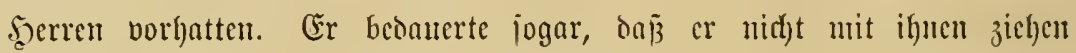
fomte. Er hätte "Den \$rojpeftor jehr gern mit herausgehaucn", jagte

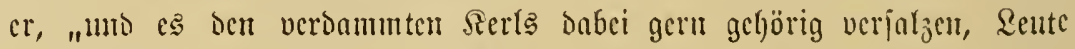
jut ïberfyallen, bie frieslidf ifyer S(rbeit nadygehen". (Er Dad)te dabei woh)l an jo mandhen bhutigen Stranj, oen er jelber ani jrüheren Picijen batte

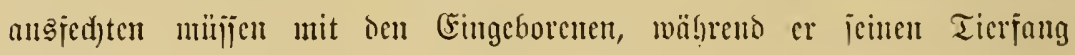

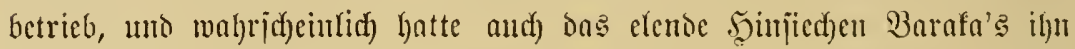

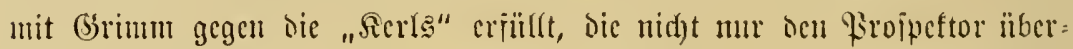

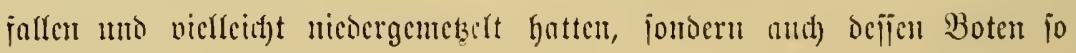

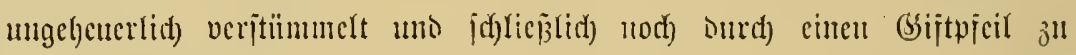
eimen unfejd)reiblid) elenoen Dajein gebrad)t hatten. Barafa hatte beim

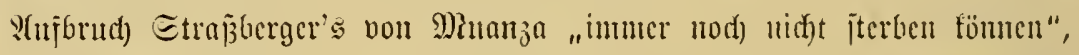

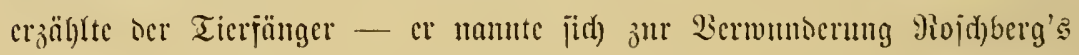
"Sammler", wemu er vou jeinem $\mathfrak{B e r n j}$ iprad) -, mi er jügte hinzu:

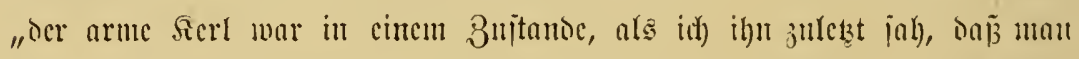

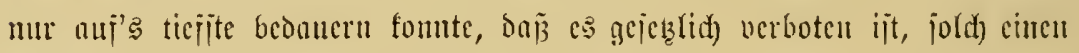

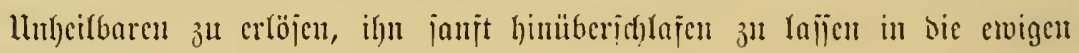
Эagogefilloc!"

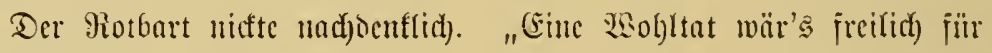
Den unglïnfeligen Barafo", meinte er. Das Thenta regte den Juritten

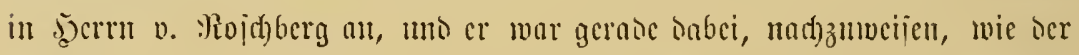

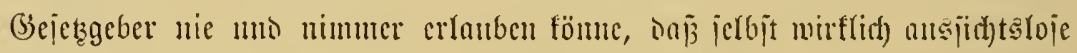

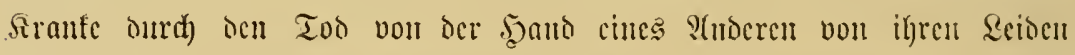

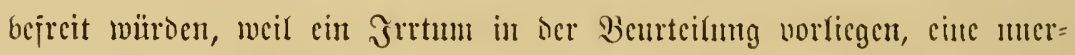

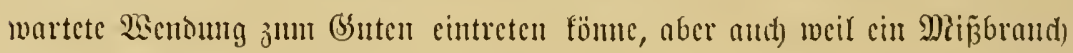

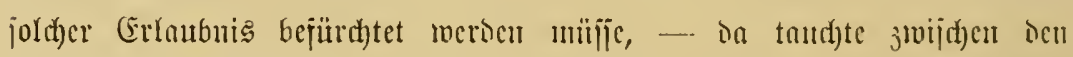

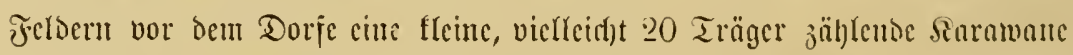
auj, bic zut litberraj(d)ung jowohl ser bei Reli’s Sagemben als aud)

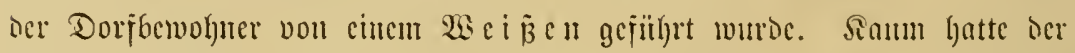

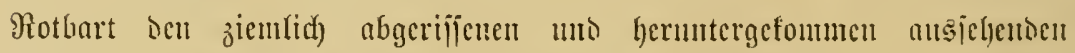

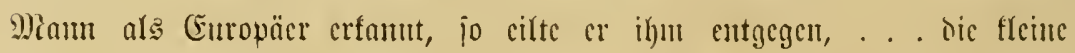

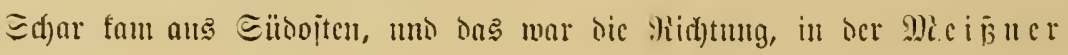




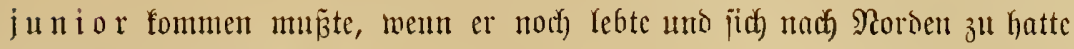
Durchichlagen fömen!

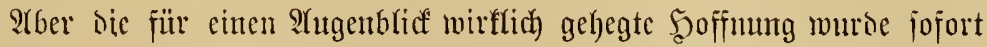
jujhanocn: Der Saratwanenteiter war wohl ein Projpctor, aber nirgt

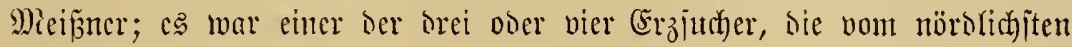
Şafen der Silifte atts nach Diten in's Jnnere gezogen waren, und an ben

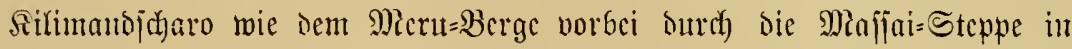

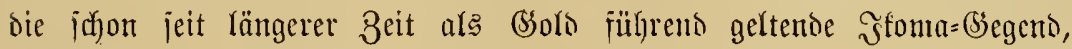

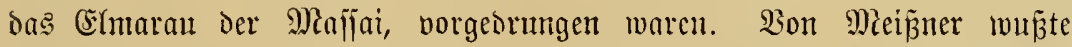
bor STnfömmling nichts, obgleich er in dent elf Monaten, tic er im Sfoma = (Selünde und reciter jüolich proppeftiereno unhyergezogen, ocs öfteren non

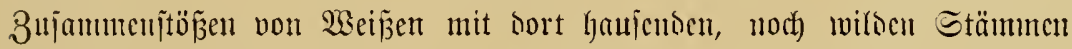

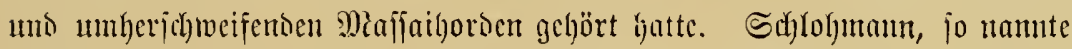
jidf) Der ctwa 40jährige, ichon leicht crgraute uno "nerwitterte" (Sorojucther, hatte jib) auth jelber gelegentlich mit oer $\mathfrak{W a f j e}$ gegen bic Eingeborencm

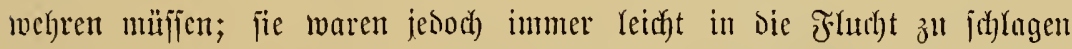

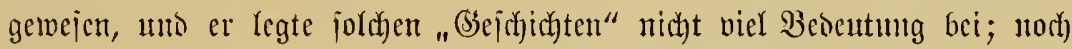

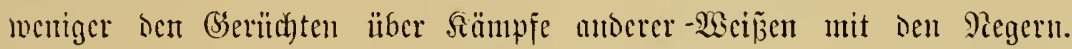

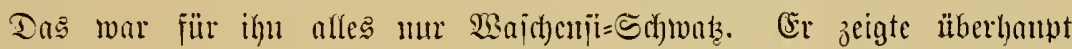

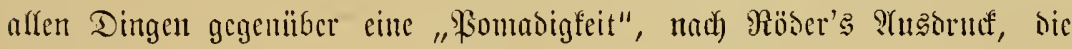

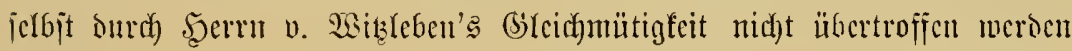

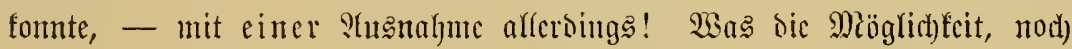

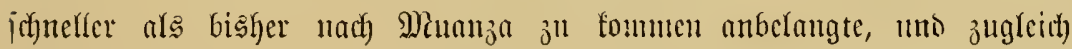

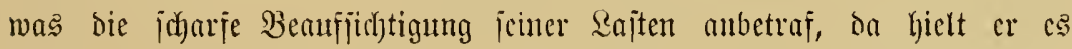

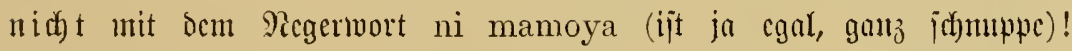

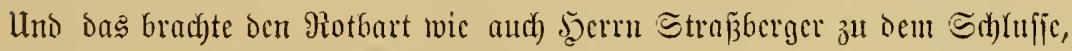

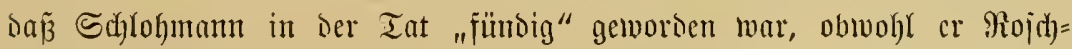
bcrg's rein menjolid Anteil nchntente Frage banad) mit eincm brummigen

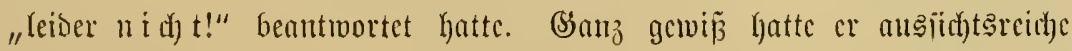
Golonorfonmen feitgeịteflt uno führte Erzproben in jeinen Rajten unt;

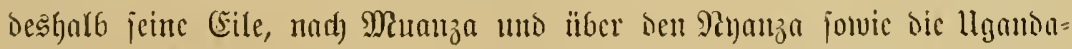

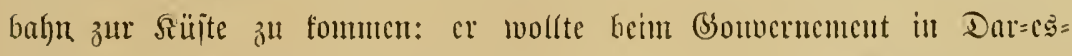

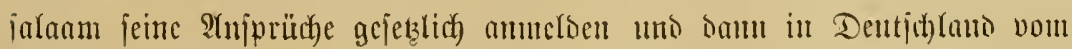

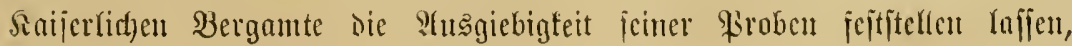




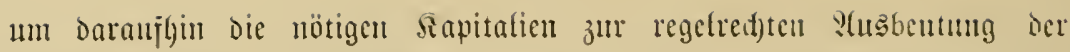

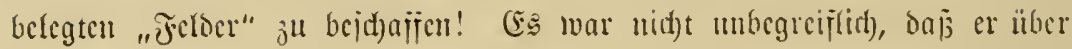

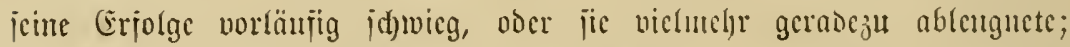

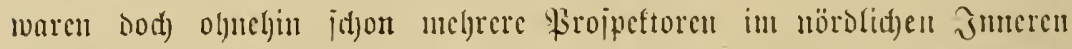
Der Solonie anj (jolo jündig geworden, war Dod) jogar Der Begrünocr

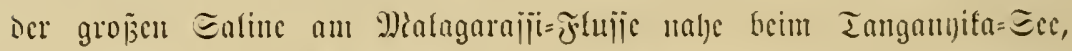

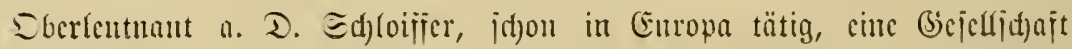

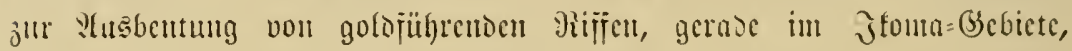
ऑ1

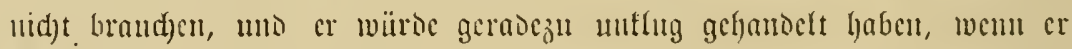

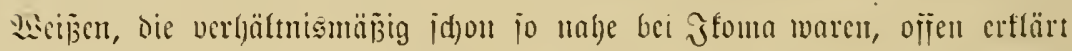

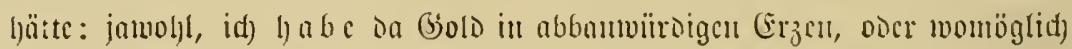
gar loje im Eande an ocr Dberfläd)c liegendes "然ajugolo", gejunten!

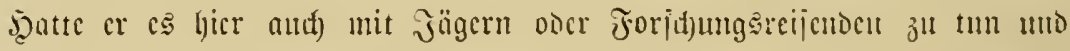

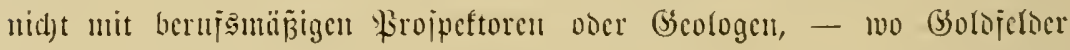
cutoest wurben, Da wari jo jientlid) Jester, ber mur bortlyin gefangen fomute, jeinen jrühecen Beruj beijeite umo murbe Gologrïber. Das l)atte jïd) in oer ganjen 2ielt io crwiejen!

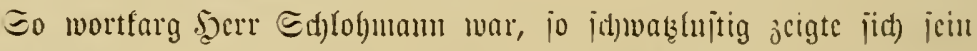

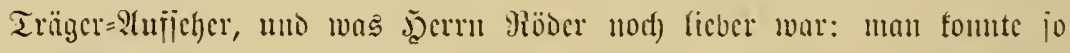

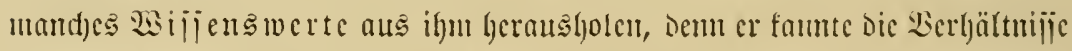

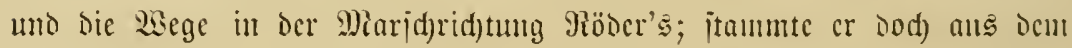

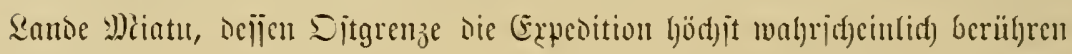

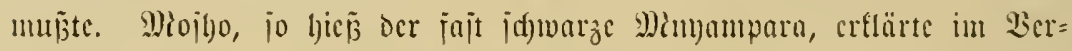

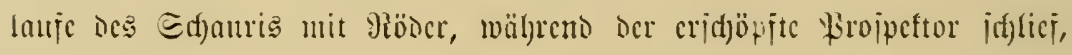

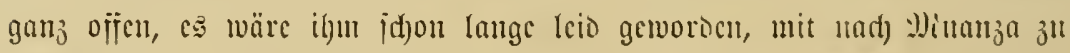

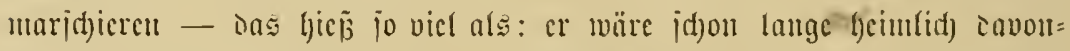

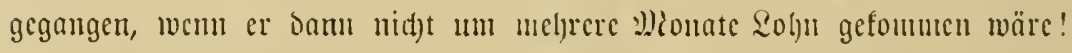
- uno er jragte mit der naiven llnverjdjämtlyeit von Reuten, Die แur

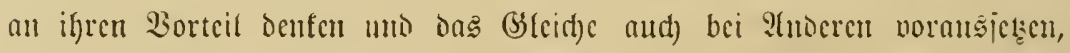
ob il) oer Bana mfubma nid)t als Memnanpara engagieren wolle? Eciu

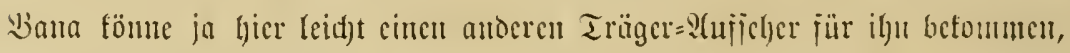

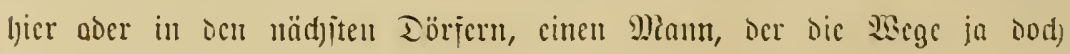
vicl bejịer temte als er, ser nod) niemals hicr getwejen jei! 


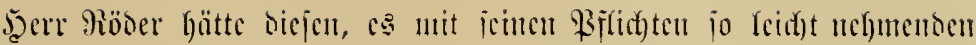

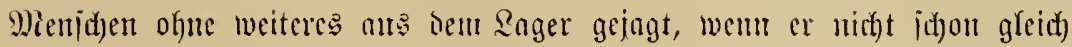

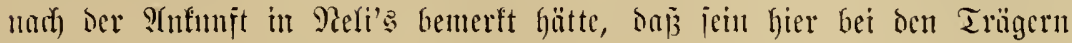

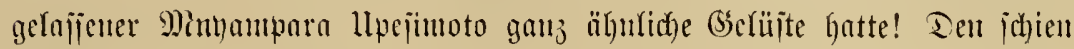

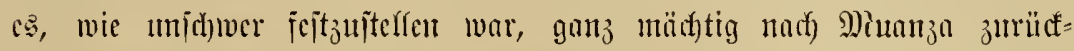

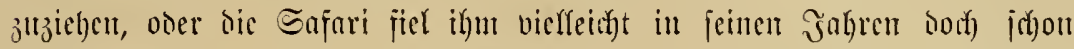

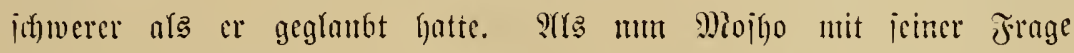

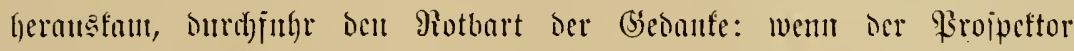
cinveritanden war, founte man die beiosn Wanjanpara ja mistnuichen!

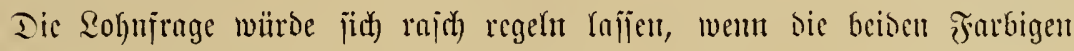
untr jonit ifgen 2 siffen befamen, unto in Butht halten worfte er Den neuten

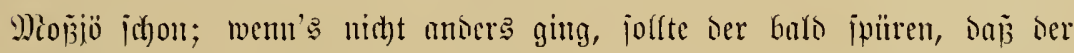

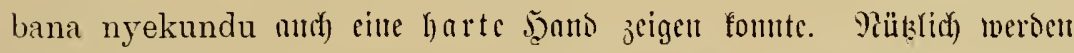

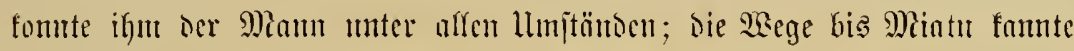

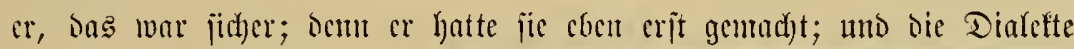
in jeinen (Ssegentoen jprast) cr wolgl auth), jutwe ober brei Dialefte beherridten ja, oder ravebrechten wenig= itens viele Rente ans bem Lülfergejutebe bort jüslidg. - Co iprad) Dent Röber mit Dem ßrojpeftor ïber Dicje Sadte, nady)= Dem der jidh ante= gcidjlajen hatte umo ats Grajt an der Minglzeit ber drei J)erren vor hell 3clte Riöber's int Eat)atten eimes alten dich) befaubten Minngobanmes teil=

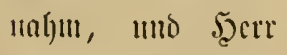

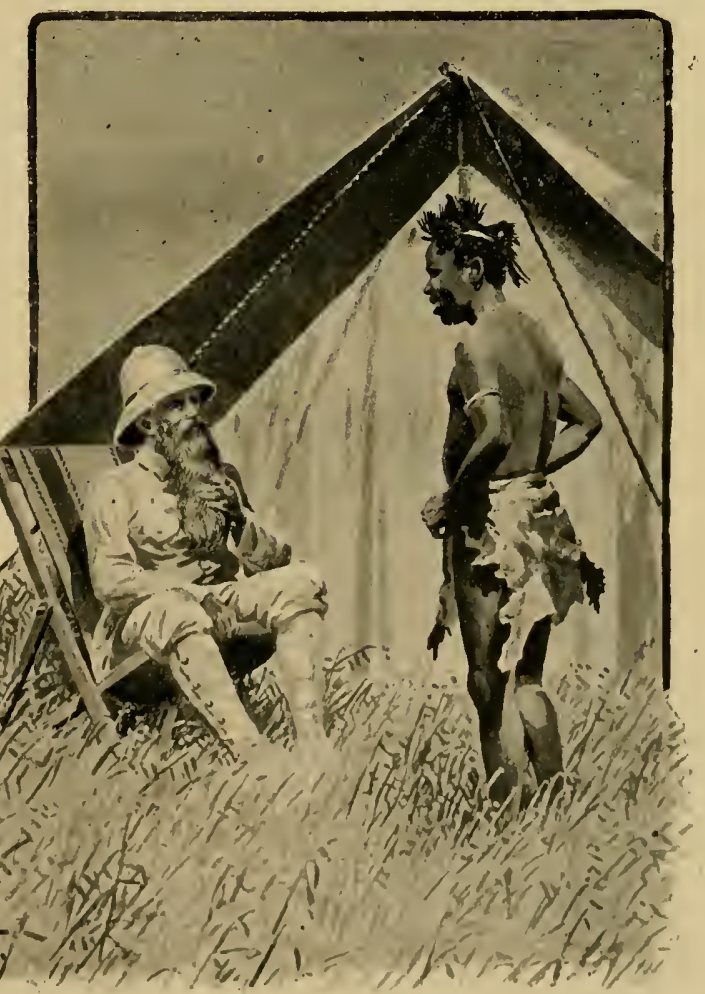




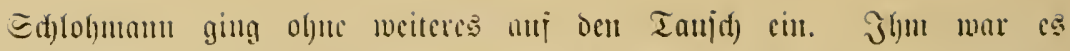
gleishgültig, wer ihm jür die "furje Strecfe" n!s Mimuampara dicute,

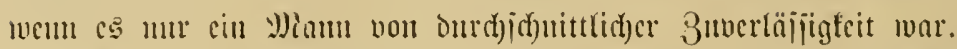

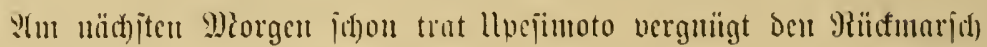

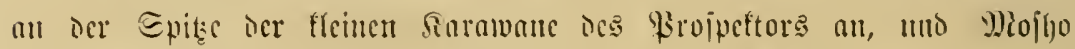

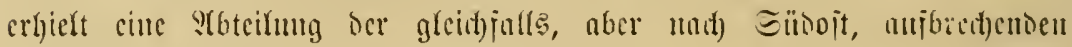

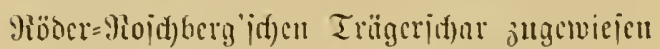

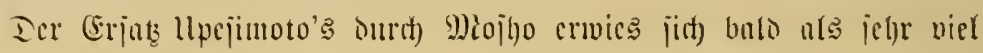

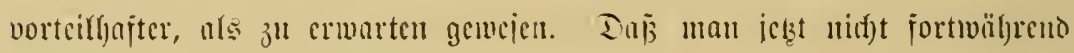

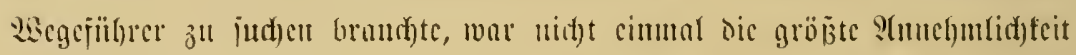

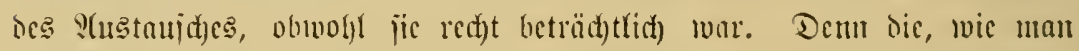

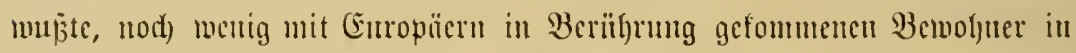
Der nuj bicle Ingemürid)e hin menj(d)

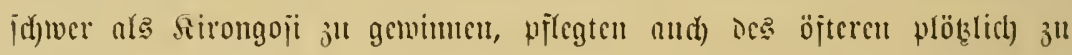

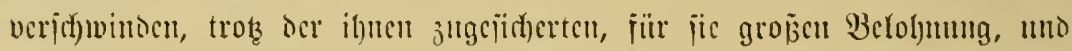

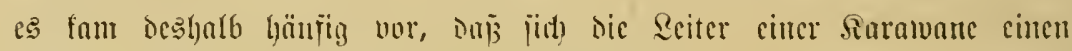

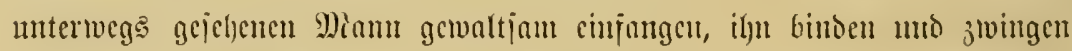

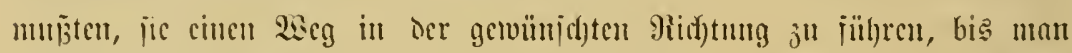

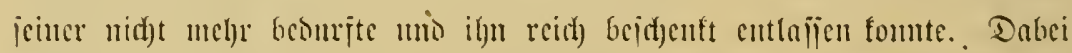

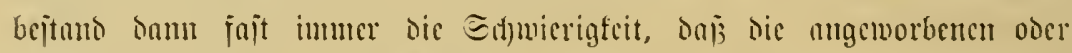

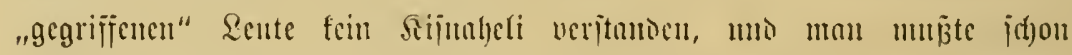

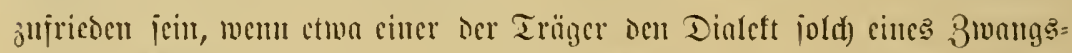

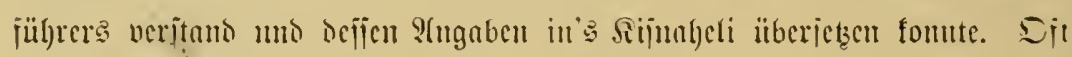

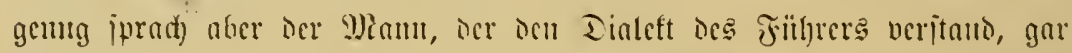

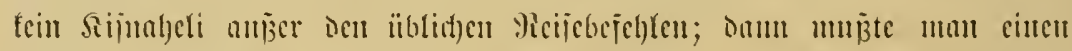
Träger juthen, ber den Dialeft Dicjes Trägers und siijuafeli veritant,

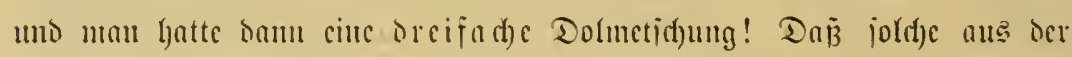

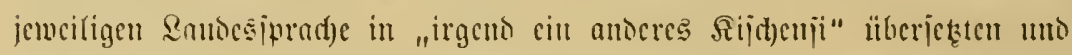

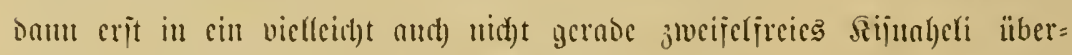
tragenen Mitteilungen on (benmigfeit mand)es nerloren, ehe fie ons Slyr

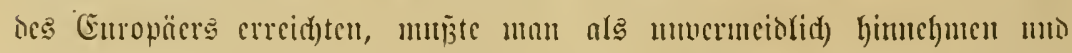

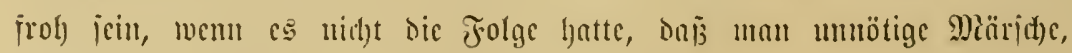
lange mio anjitrengentie llunvege mad)te ober gar lvieder zurüa muñte.

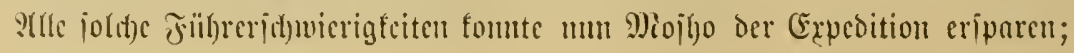




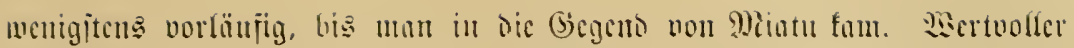

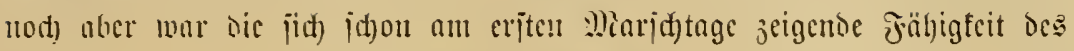

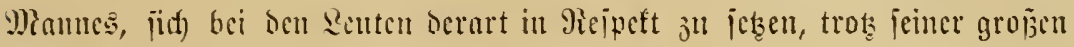

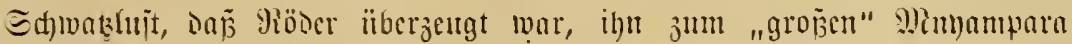

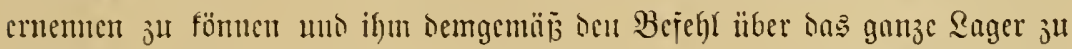

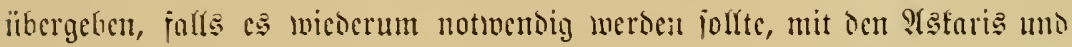

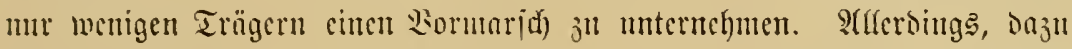

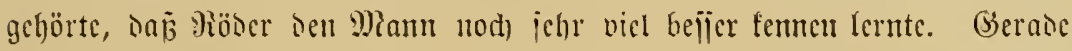

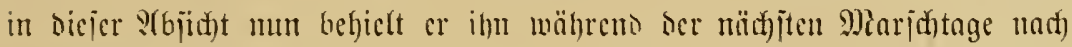

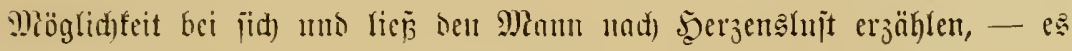

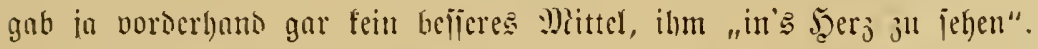

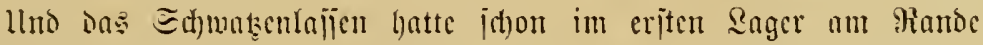

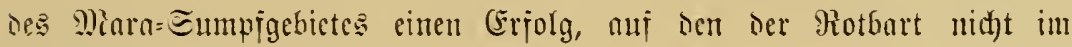
entjerntejten gerechuet hatte.

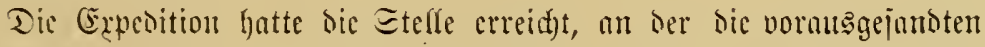

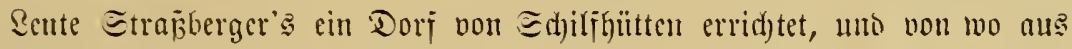

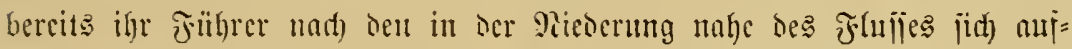

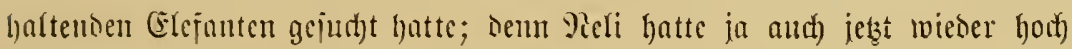

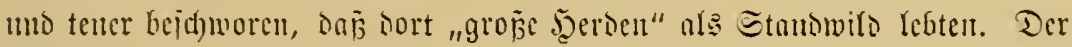

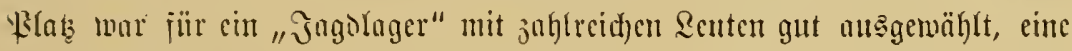
trocfene Boocnerböhung cine halbe Miaridjitunie vor Dem Begim ber ben Miara=Unterlauj anj beinen Mjern breit cinjüumenden S(h)(fï̈mpje. Freilid),

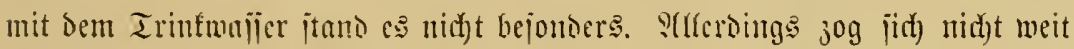

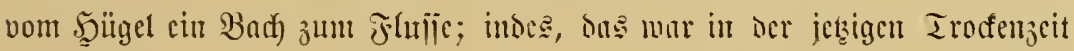
nidjt mehr als cin trocfentes Bachbett, in dem die 2 seiber un fimter

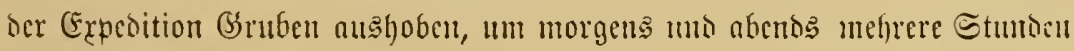

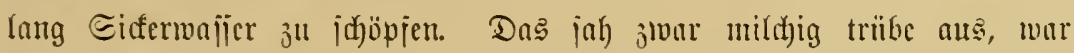
aber trinfbar, ohne baj man es mit Slaun reinigen, abfod)en uno wicier

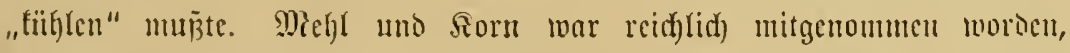

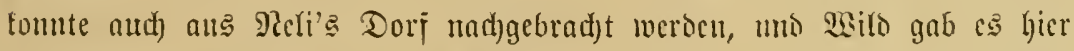

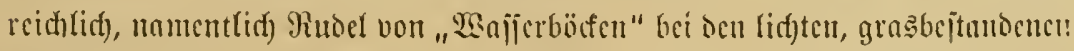

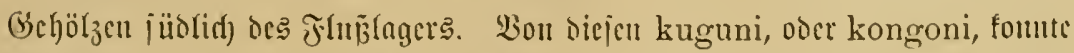

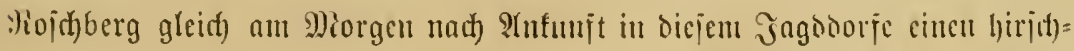

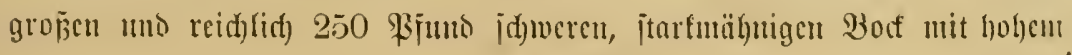




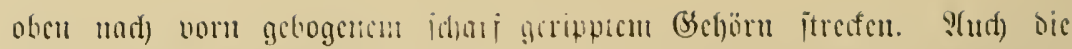

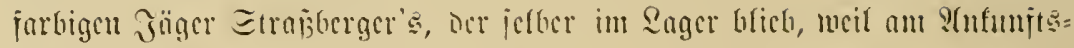

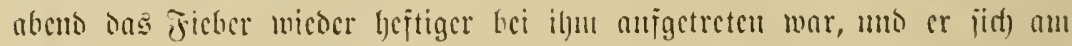

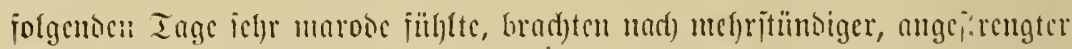

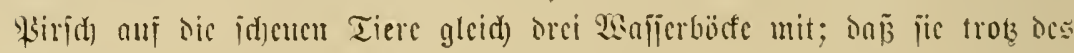

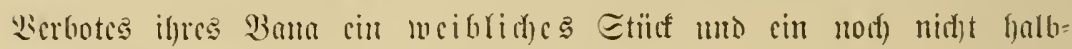

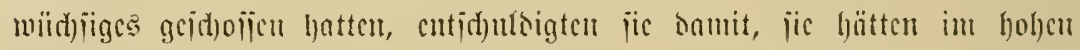

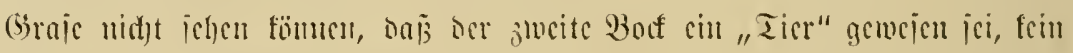

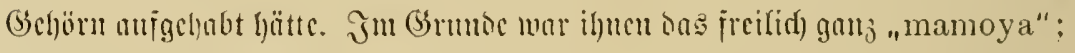

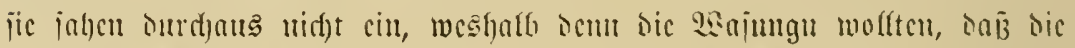

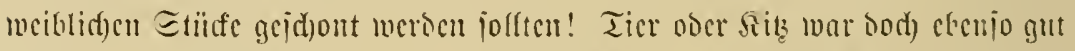

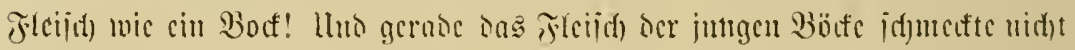

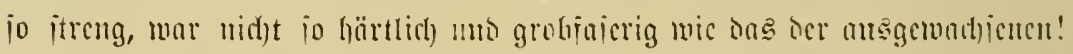

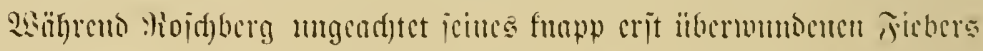

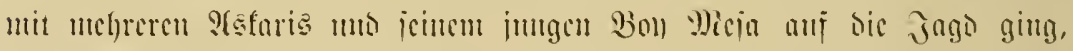

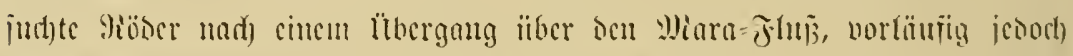

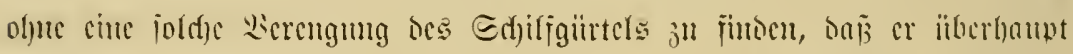

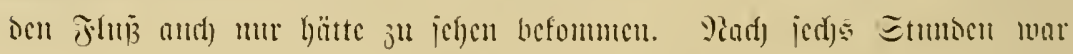

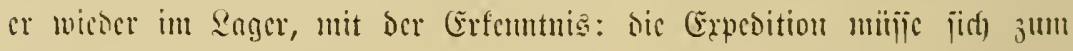

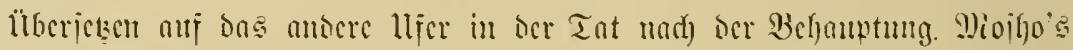
crit nod) orci Tagemäridye am Eübuifer cutangichen. Sam crit ver-

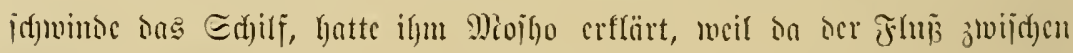

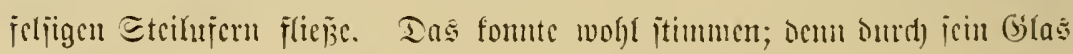

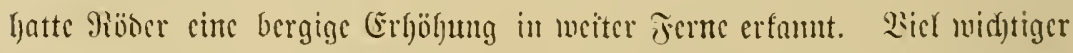

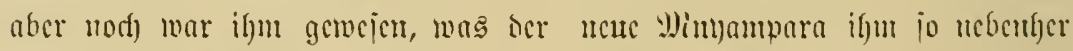

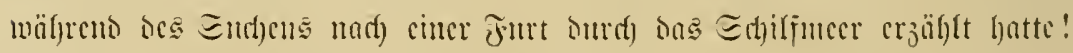
"Jd) fumt Jghen jagen," beridjtete ber Botbart jeinem mïtic, aber wegen

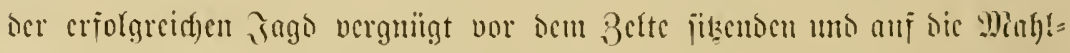

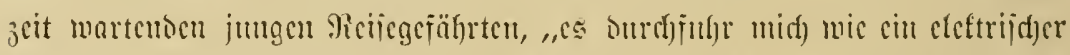

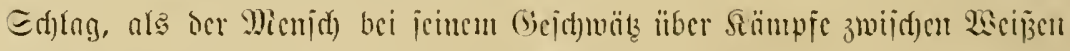
uno (Eimmolyncrn plöklid) Den Yiamen Messna naunte!"

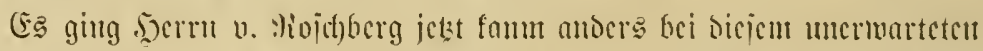

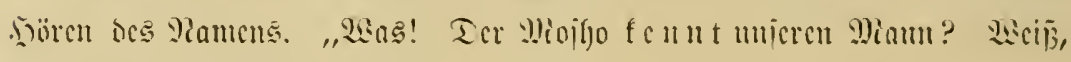

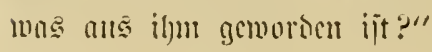




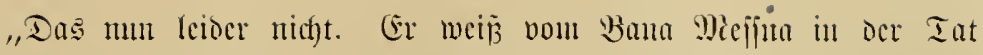

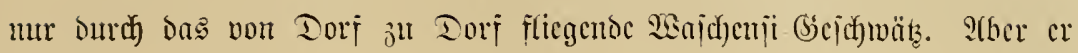

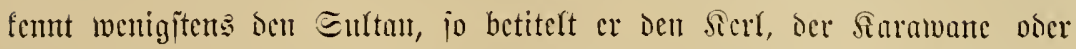

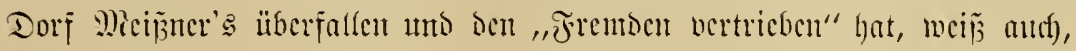

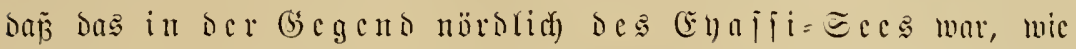
wir ia auth aus ben Bricjen umb nadher ats bem verworrenten Beridht

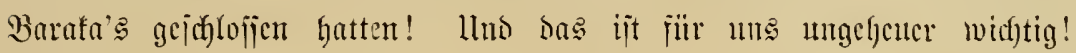

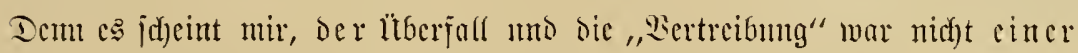

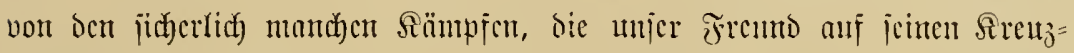

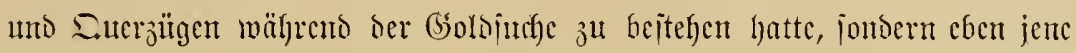

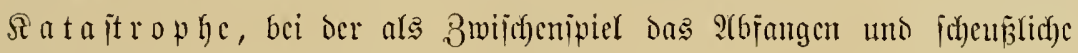
Serjtümmeln von Mieiñner's Boten vorfan!"”

So gelajien scr Rotbart erjüglt hatte, jo crregt hatte Rojojhberg jugefört. ",ltnd Miojho fennt ben Jiaubmörder, Sen Sultan oer Gegeno ?"

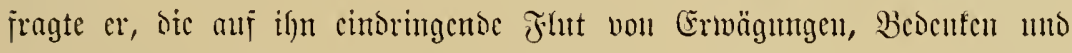
Miöglichfeiten förmlid) gewaltjam abwehrent.

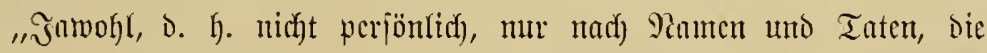

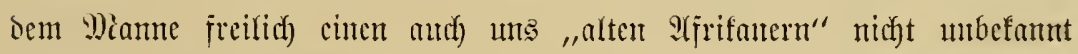

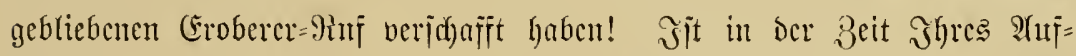

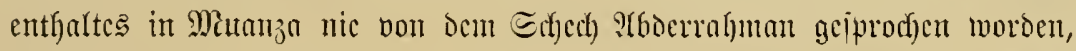

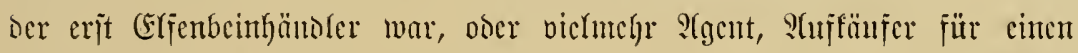

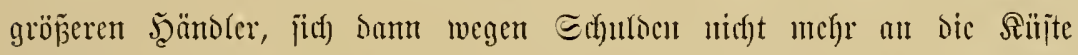

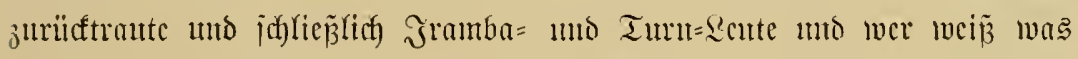
jonjt nodf) für Stammesangeljörige um jüf) judarte umo ba, inmitte॥

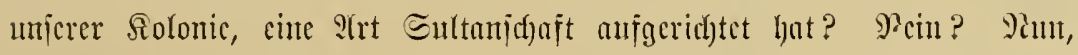

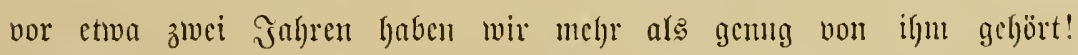

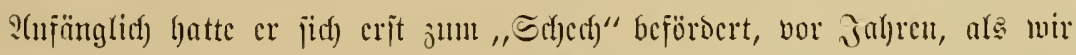
Deutiche nod) nidyt vicl über bas Sijitengebict hinnusgefoument waren;

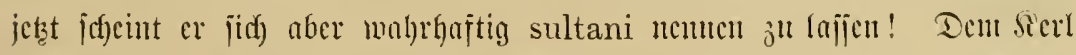

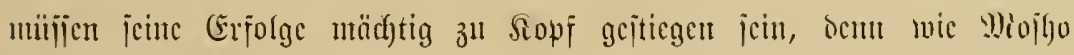

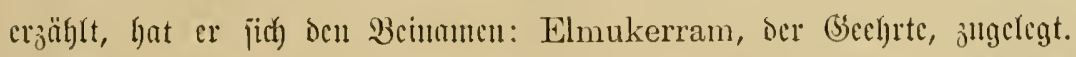

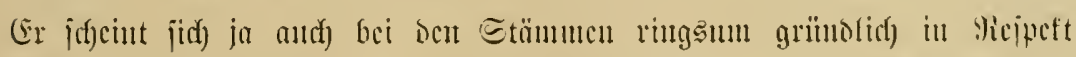

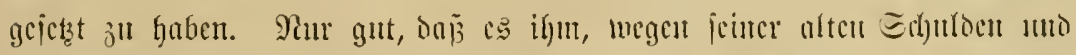

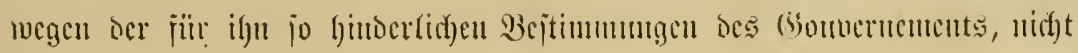




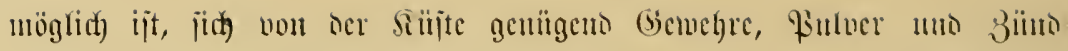

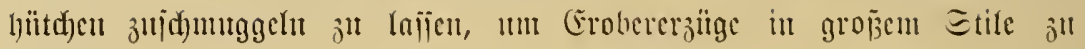
trcibelt."

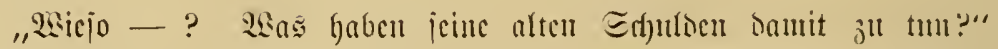

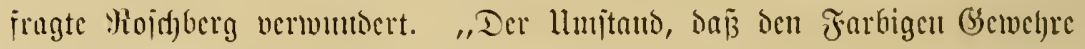

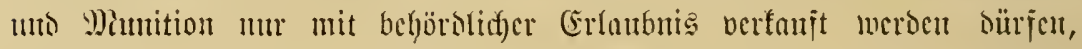

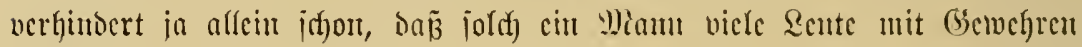
hemafinten famt."

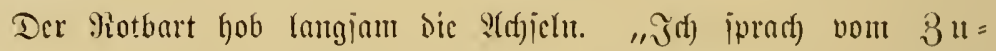

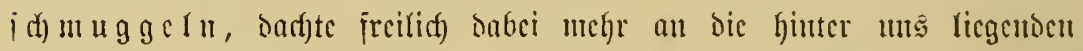

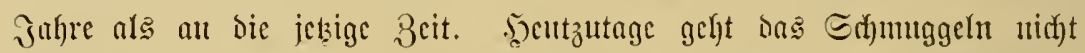
mehr jo leidyt, weder bas sjeransidnumggén von Eflaven, nad) Samibar,

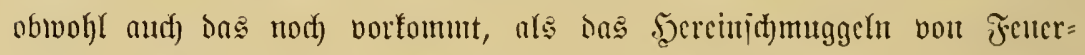
waffert. N(ber wents cs andf) ginge, dicjer Thberrahmant wïrbe fcincu

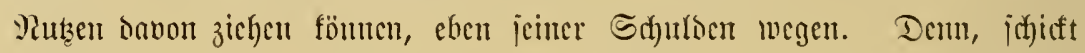

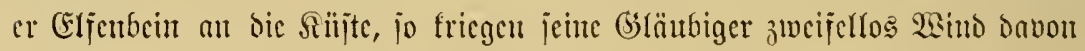

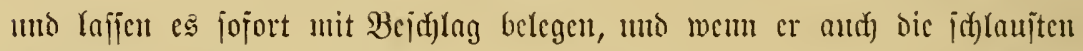

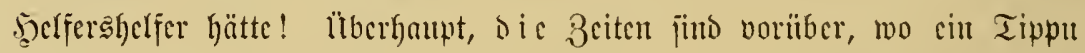
Tipp, oder vor 20 Эahren nod) cin :humaliza, mit taujeno (scivelyrträgem

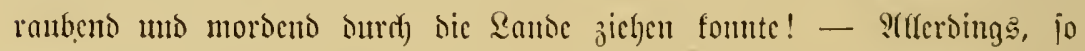
behauptet menigïtens Nioifo, an bie humbert Sirieger mit (Sewehren joll

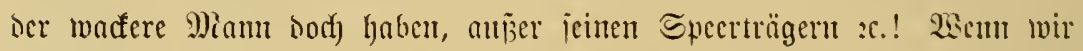

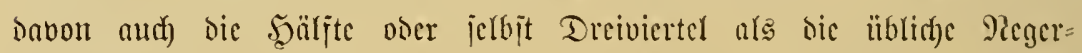

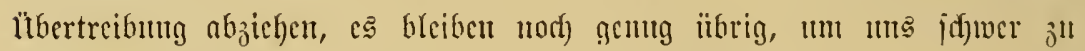
idfaffen zu mad)en, jobalo wir mit ifut jujamutenjtojen!"

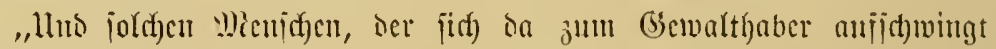
uno jogar Europäerfaramanen zn Hiberfaflen magt, ben hat das Gsoubernement

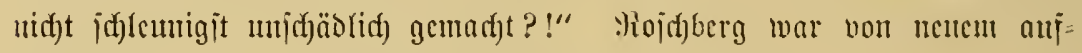
geipreutgen uno ricf aufgeregt vor bem Belte ant mo ab.

"Er treibt jein llnwejen cben in cince Ǵegent, die jebr abjeits vou

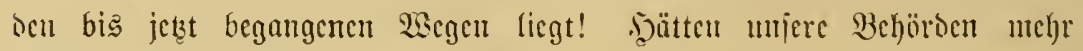

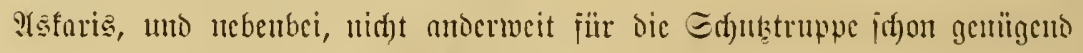

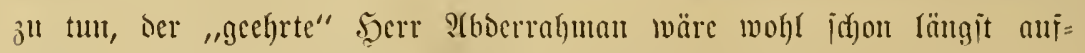

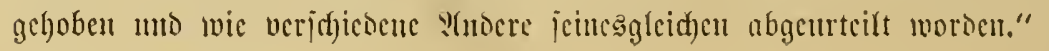




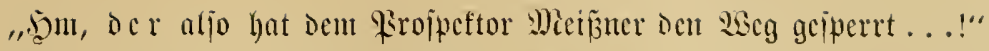
"Und der hat es fertig gebrad)t, bem Boten bes "Bertriebenen"

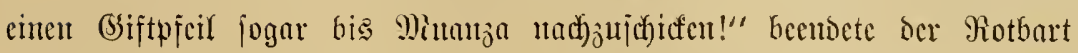

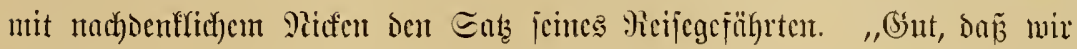

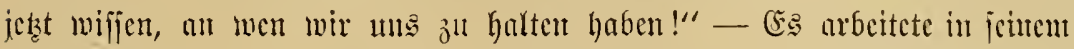

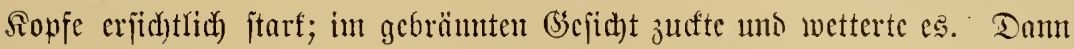

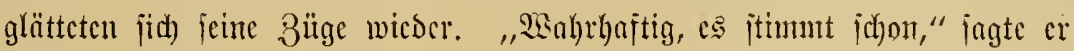
nad) ciner sieile, "in 9 (frifu foumt cs $\mathrm{i} m \mathrm{mer}$ "anders"! Da haben

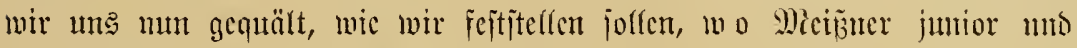
jeine Sarawane aujgerieben jein fünnte, haben ung alle ben fopj jer= brodhen, wo wir uath igm wohl ju juchen haben würocn, - uno ba fommt

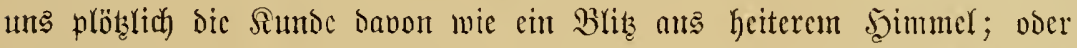
wie cin Funfipmech der Drahtlofen Iclegraphic, mus man ja hentjutage

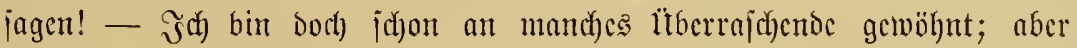

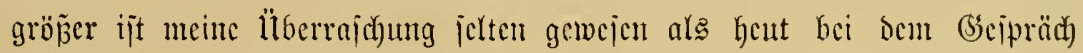
mit Dem fo unerwartet engagierten Minyanpara!"

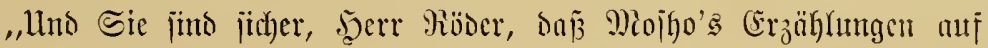
Wahrheit berufen?"

"D, $\mathfrak{O}$ i cher? etwas baranjein,... uno wir werien ja hingeben uno jujehen, wieviel!"

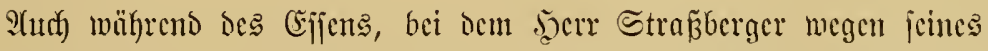

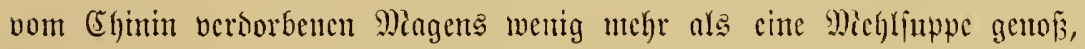

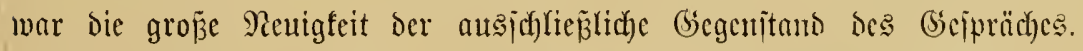
"So," meinte der faift inmer mürrifhe oder boch mindejtene jefre mortfarge

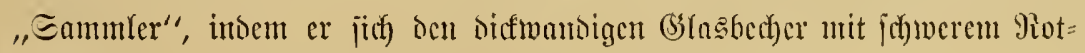
wein füflte, "Eic glnuben hem Sicrl, ocm Mioigo aljo!"

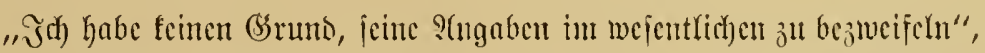

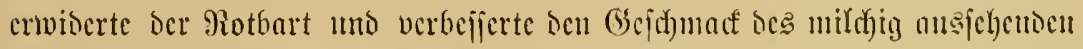

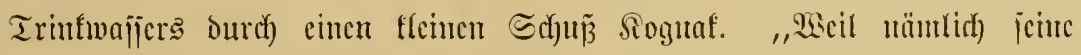

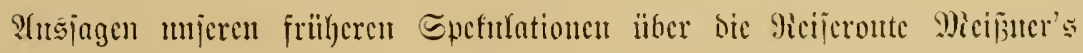

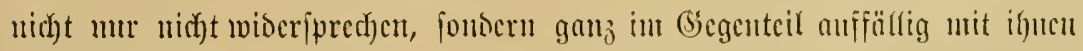

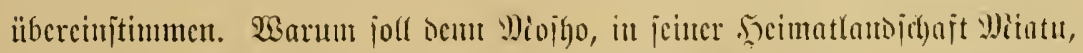

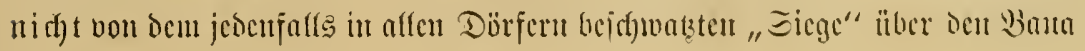




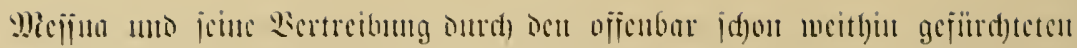

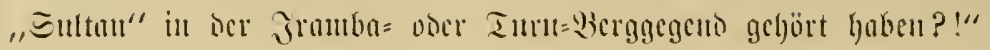

"Sinut jein, faum and) nidft jein", murrte Etrajberger. "Îenen

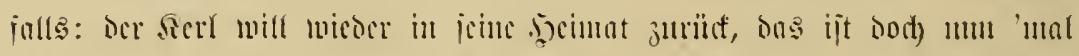

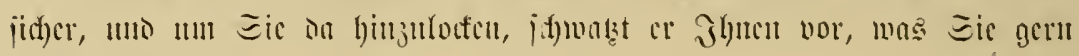
büren wotfen!"” .

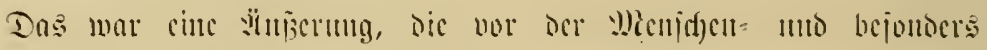

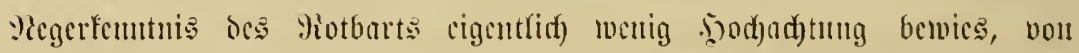

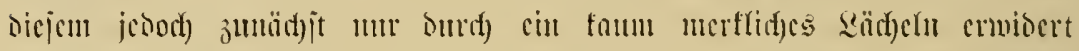

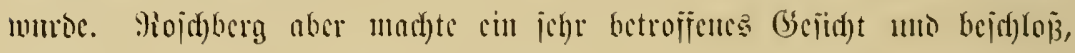

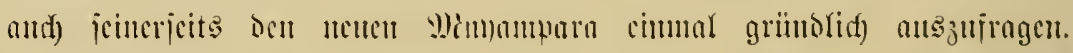

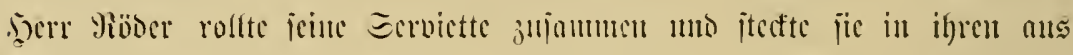

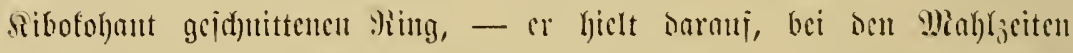

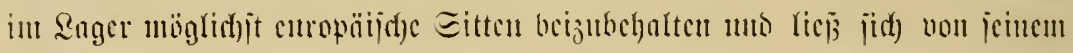

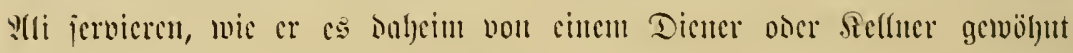
war -, bum crijt jagte er gelaijen:

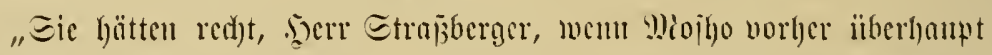

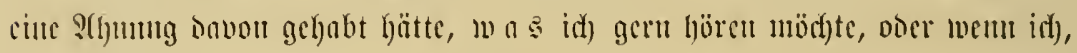

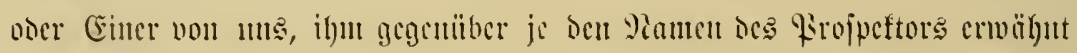

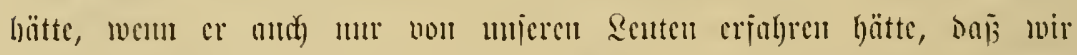

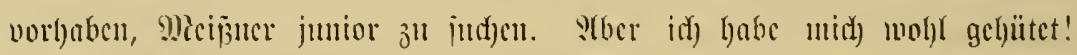

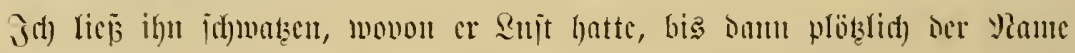

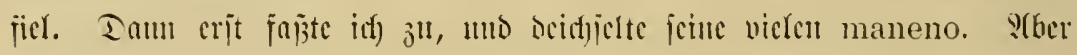

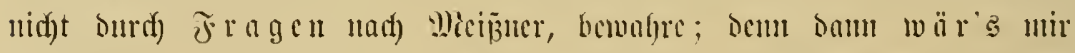

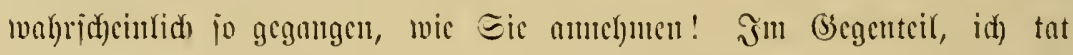

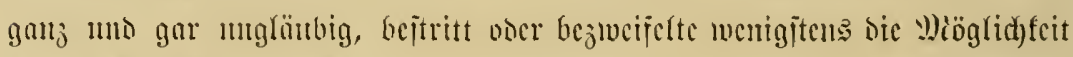

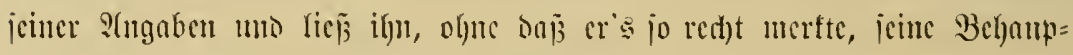

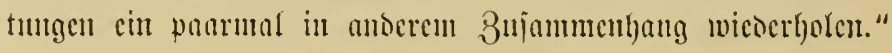

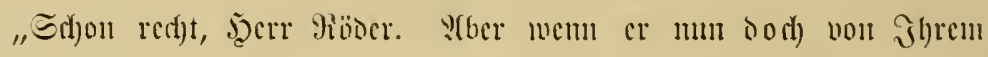

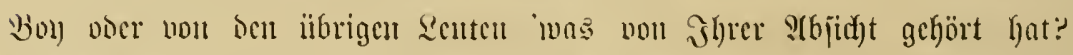

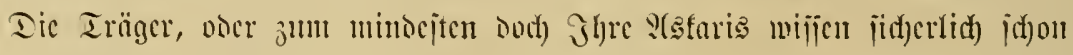
von Dinuıa ha . .."

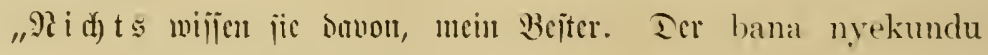
ijt soch nidgt erjt jeit gejtern in santic!" 


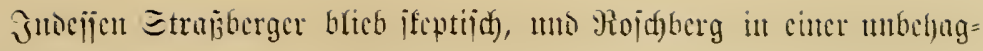

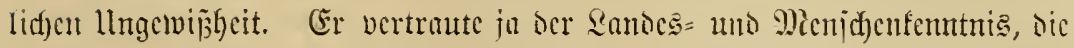
ben "roten Jäger" in ber folonte cinen jo weit reichenten Paunen veridgajit

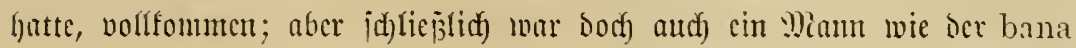
ndevu nyekundu gegen cine gelegentlid)e litbertölpelung nidj)t gejcit!

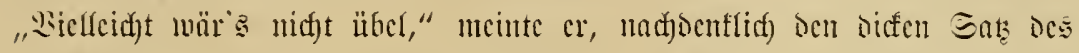

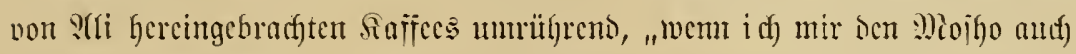
cinmal vornähme แno mir, jo rein aนs Peetgicr natür(id), bie (bicicfidfte yon

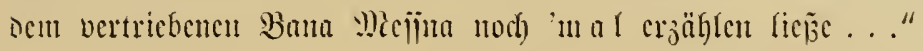

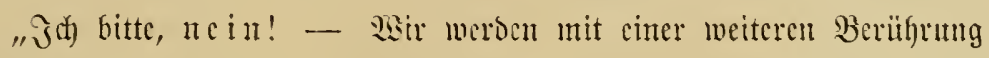

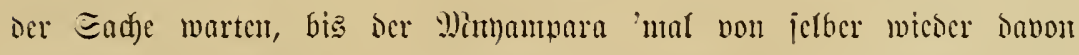

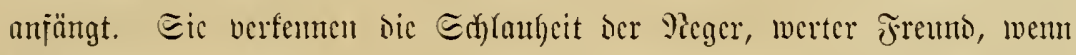
Sie glauben, baj ber Mann jid) nidyt bei ocr eriten Frage Shrerjeits jofort jagte: :Yha! Den sajungu licgt 'vas Bejonteres baran! - Ecicu

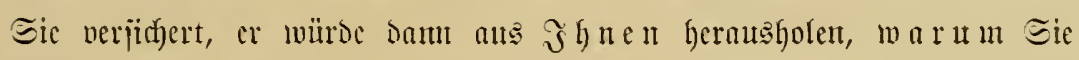

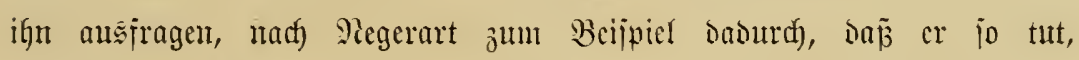
als habe er J̧he Frage nidft veritanoen. Ilno ganj abgejchen bavon,

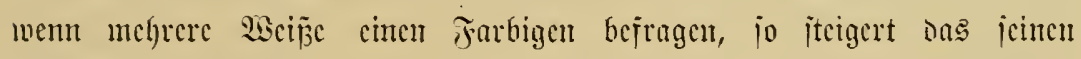

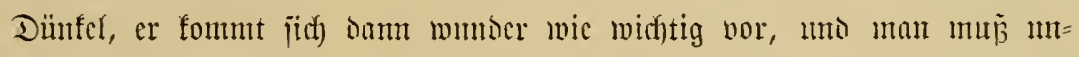

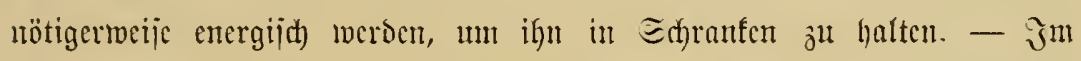

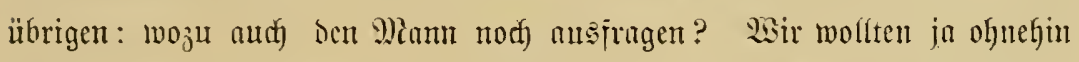
von hier aus nach Eitiocn, wenn nötig bis nady bem Doric Miarangn in

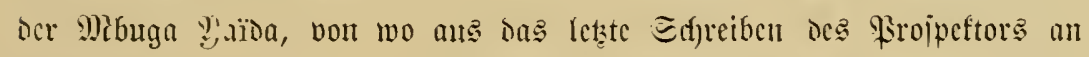
jeinen Bruter baticrt war! Db mun Dic Goldiud)er=(Expedition idfon ba

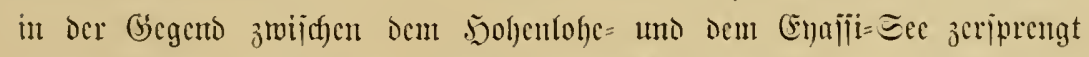

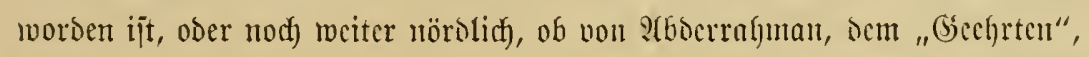

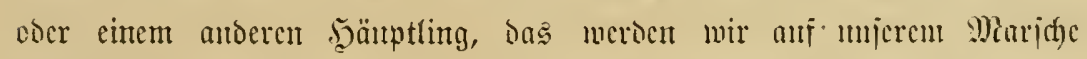

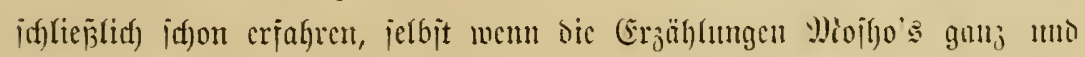

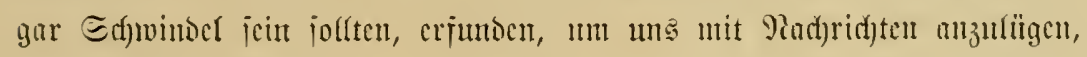
dic wir "gern hören".

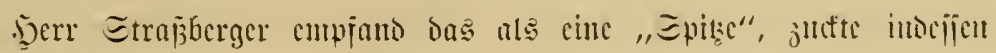

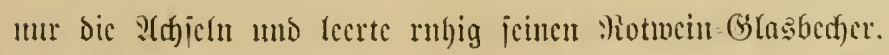

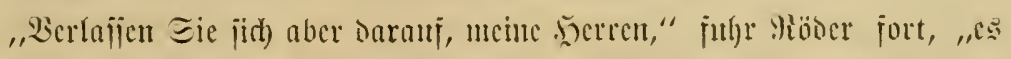

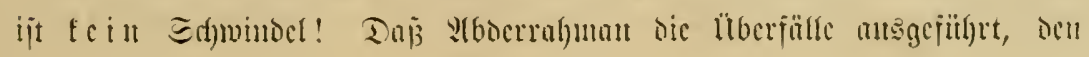




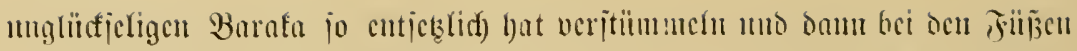

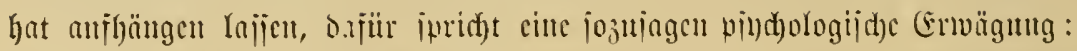

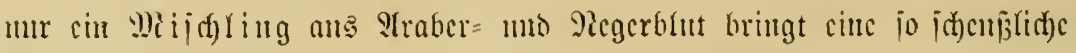

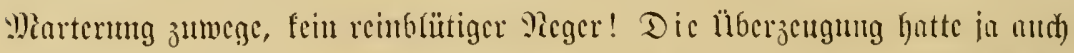

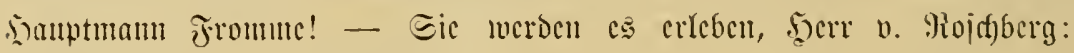

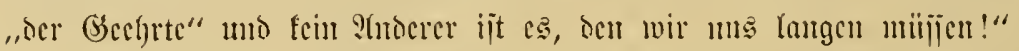

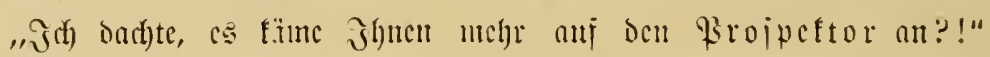

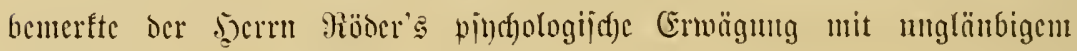
:I(t)jeljuffen nbtucnde, „Enmuler".

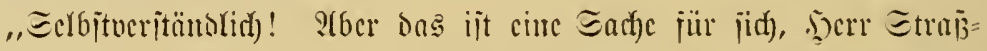
berger. 2 cbt Der Mann nod) - uno Das glaube idf eben jeit ber Gijt=

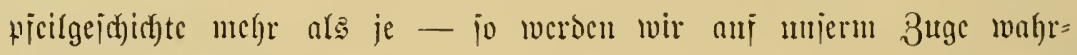

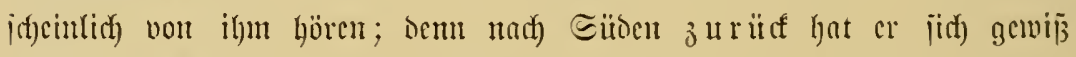

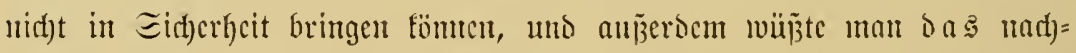
gerade längit, ïber Mipnapua-Tabora-Mitanza. Lno and) wemu cr mad)

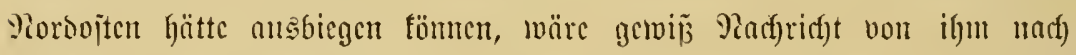

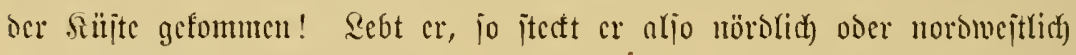
von ben Dörjern P(boerrafunan's. Uno daum bringen wir ihm Entjats. Den Miorsbremer mo Micud)chmörber vou "Suftan" abcr lauge idf mir unter alfen llmitäntocu, ob id) mu Wieiñucr junior lebendig ober mur

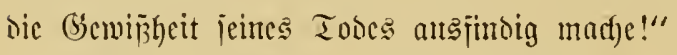

Eben entitant in bem immer iche lebfajten Eagertreifen cinc

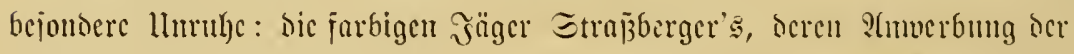

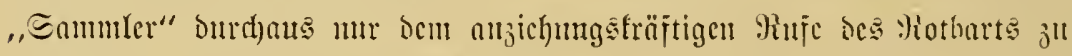

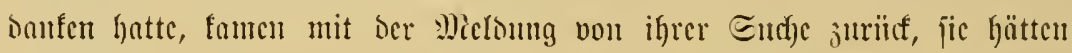

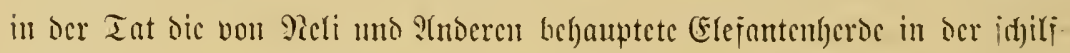

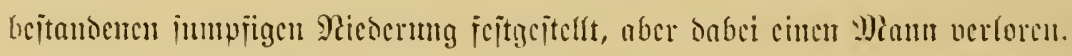

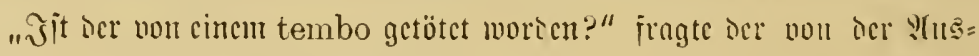

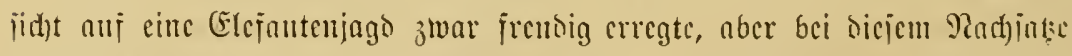

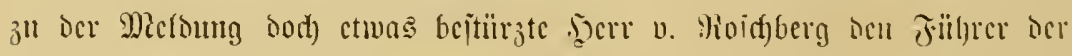

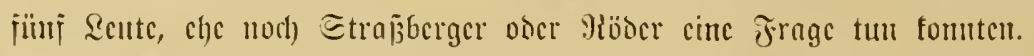

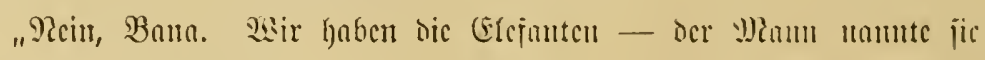
uid)t tembo ionocrn ndovu - in mu nus ocr ferme gejchcr. Turufi ijt im Eumpi criticft." 


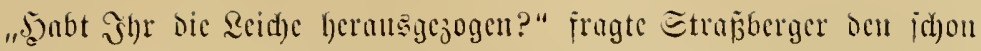

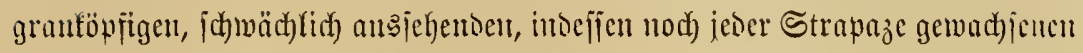

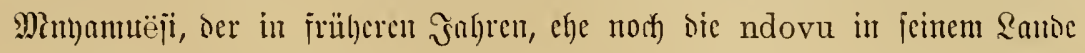
jo gut wie gan

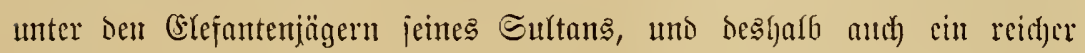
Mann gewcien war; Dem dieje Jäger brauchten ihrem Şerrn, jie maren

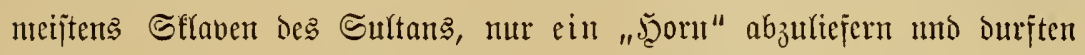

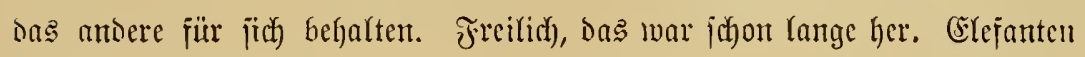
gab es im B̉ereithe jeincs "baba" nitht mehr, uno das jujammengciparte,

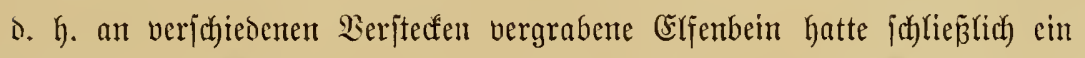

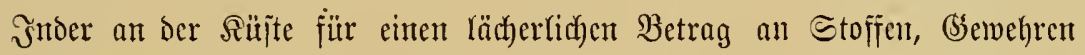
und $\mathfrak{B u f v e r n}$ an fidj ju bringen veritandon, nadjoem er ben nach alter Sitte in der Rilitemitadt als Sajt bei ilym haujenden Bejitzer monatelming mit sem Berfaufe lingezogen und igm furchtbar hohe Unterhaltsfojten, daneben now) höhere Binfen für frühere Borichïffie von bem unglanglich nicorig angejetzten Werte der Bähnte abgezogen hatte. - Sefu war daher jeit Jafren futon ein armer Mann uno ging nur auf Erejantenjago aus, wenu Europäer ihn bazu anmarben; in ser ührigen 3eit war er in jeinem Dorje Eijen=fundi, berïfmt ałs 2Ytæbeficrer "kaputti" gewordener Fluten. Or

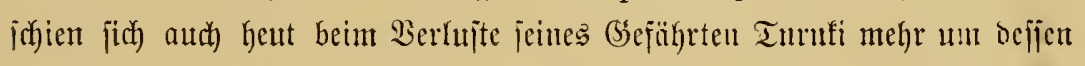
Flinte als um ocn Mann getünmert ju haben, unt bas aud für bas

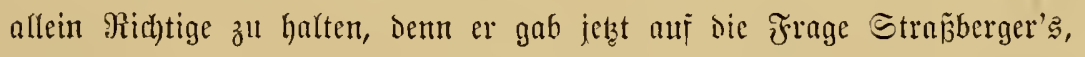
of oer in ien Sumpi Beriunfene menigitents als Seiche herausgejogen worden jei, etmas verwmidert die Erwiberung:

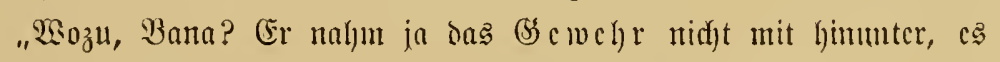
bafte an ben Echilfiwmrzeln, uto wir fonnten ce Deshalb retten."

5errn v. Roichberg frod) bei biejem nenen Cinbliaf in bas Secten=

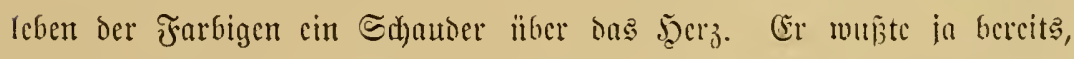

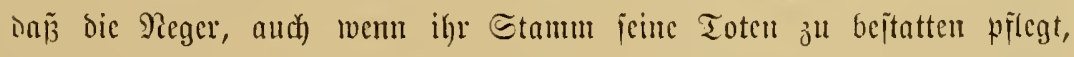

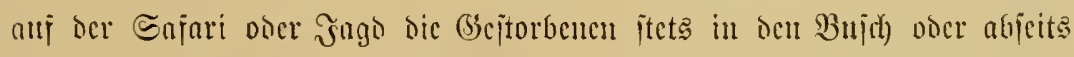

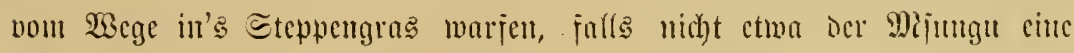
Becroigung anoroncte, Doer ber Tote ein "(Srof̧er", cin Berwanter Des

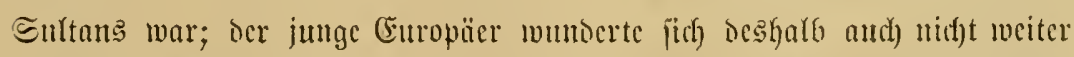

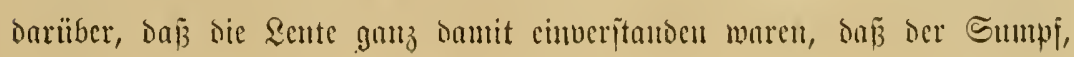


Der ibren Genojien getötet, ilm and) gleict) begraben hatte; aber baj jic

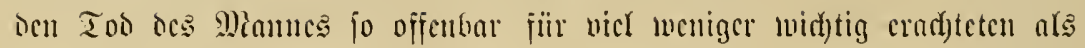

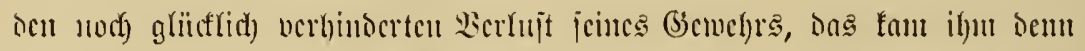

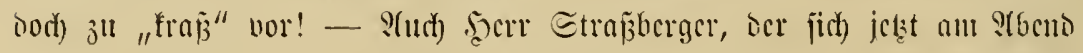

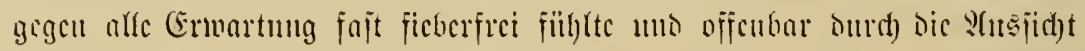

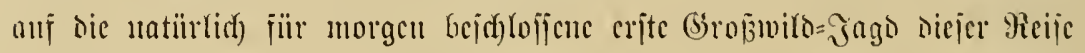

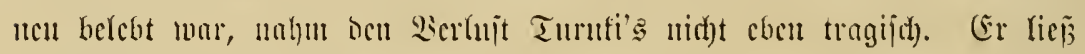

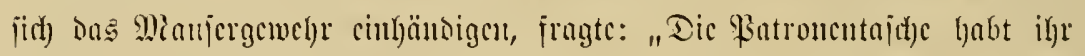

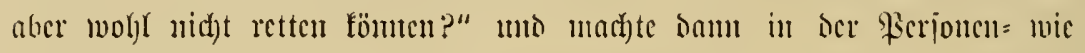
it Ber Rö[)um foumunchen.

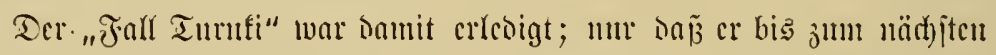

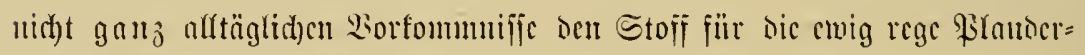

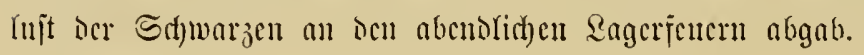

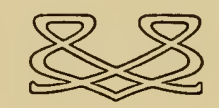




\section{Sechzehntes Kapitel.}

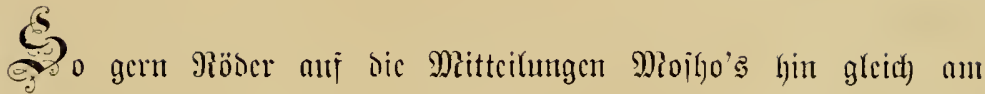
nüd)jten Tage ben Weetermarich nad) Sitocn angetreten hätte, er brathte

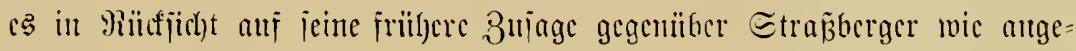

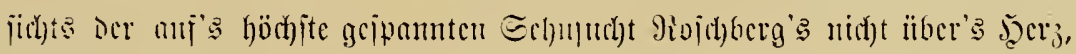

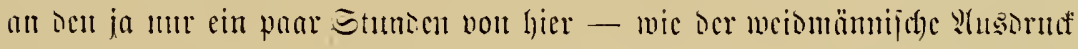

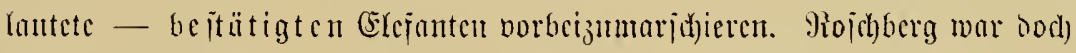

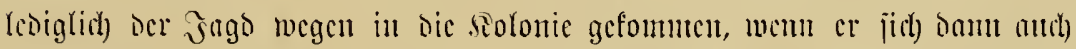

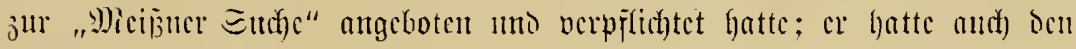

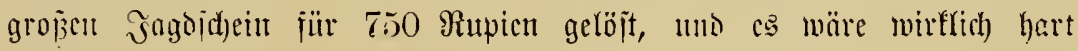

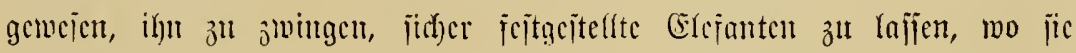

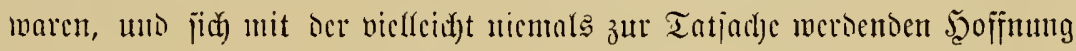

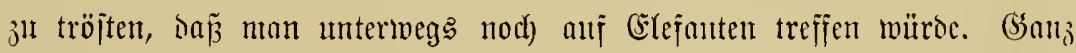
gemiñ, Eile tat not, wenn man dem \$roipcftor "Entiaz bringen" wollte;

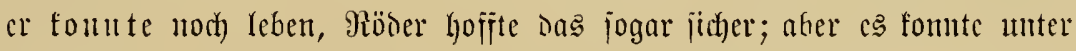
Berbältniffen jein, in ocnen womöglidb cill einzelner Tag ïber jein Dajein

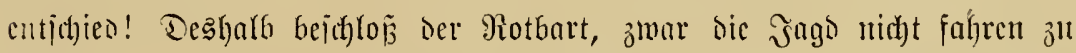

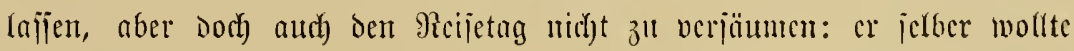

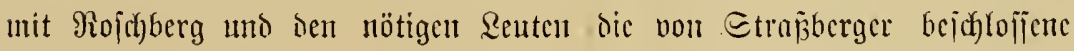
Streife ill die Sifilfniedcrung miturachen, feime Expedition jollte jesoch

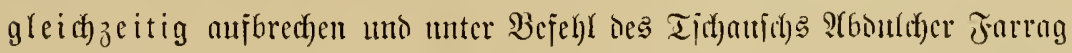

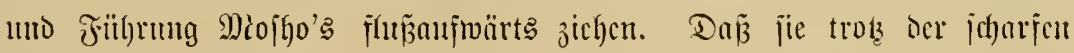

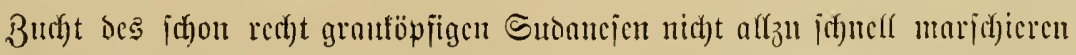

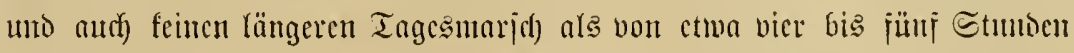

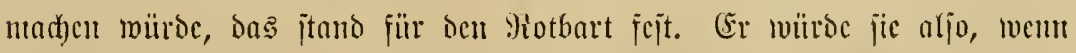

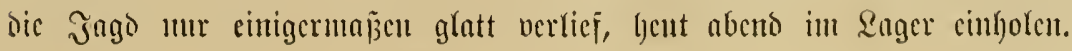




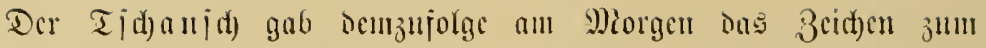

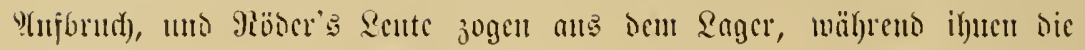

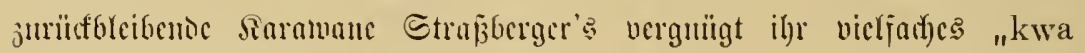

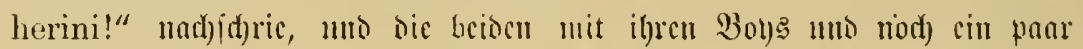

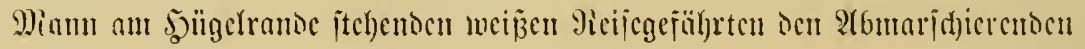
cin "ya kuonana (auj 2sisicriebcu)!” juriejen.

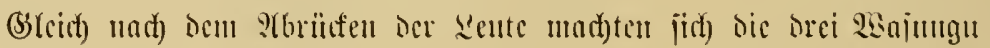

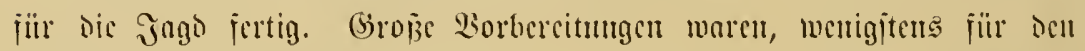

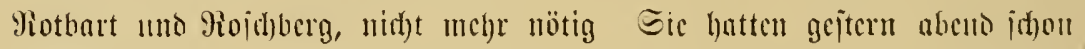

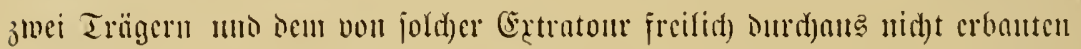

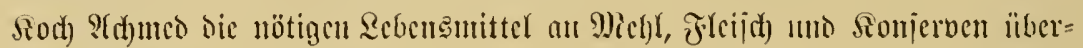

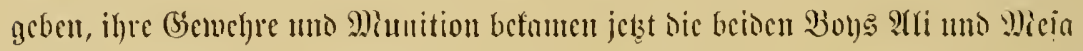

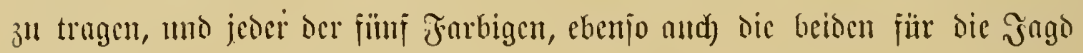

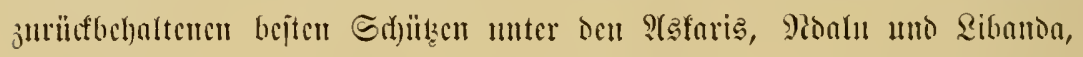

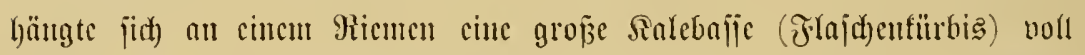

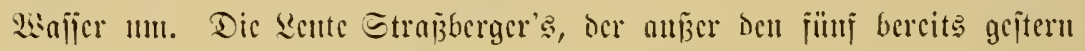

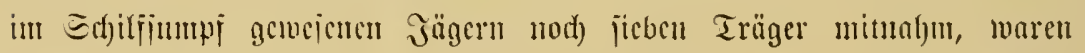

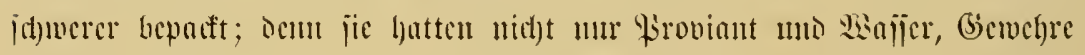

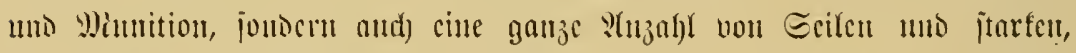

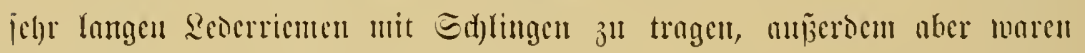
vicr Miam noth mit Dopperfajten beladen: je juei bejörberten, hinter= cinamoer gebent, mittels ciucr ïher bie linfen Sdyultern gelegten Stange - bicje nic gern ühernommene $\mathfrak{\text { Trt }}$ von Rajt wurbe mtau genunnt -

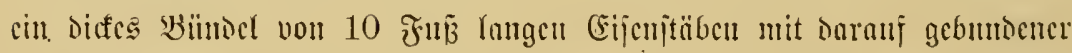

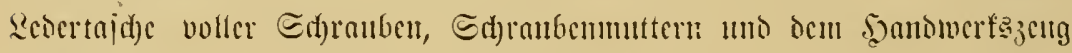

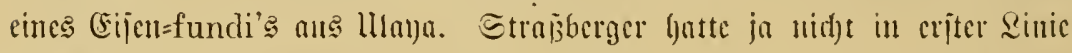

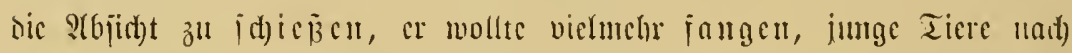

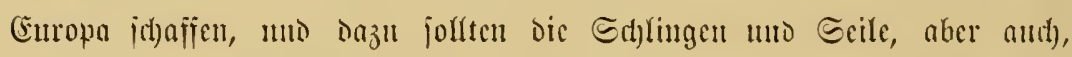

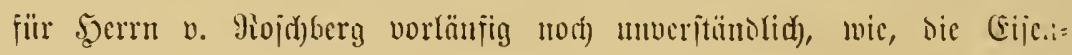
itnurgen bienen.

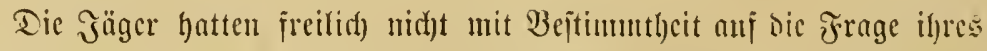

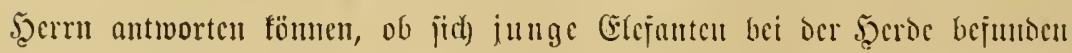

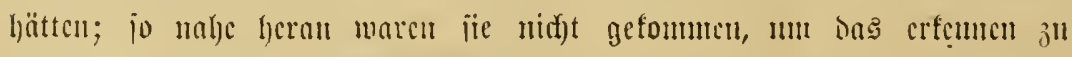

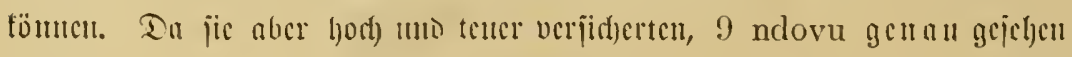




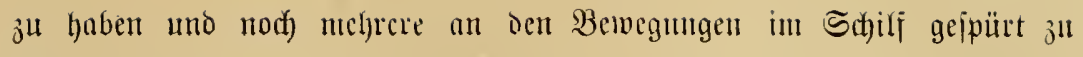

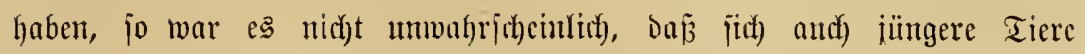

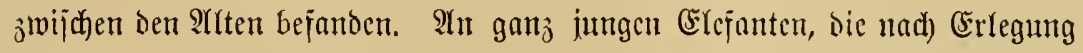

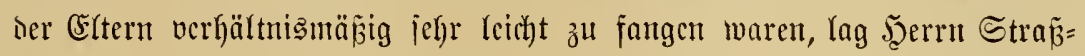

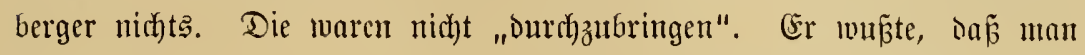

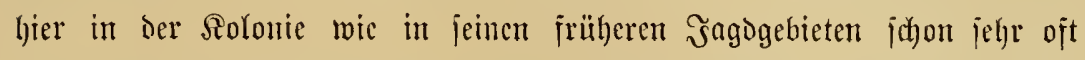

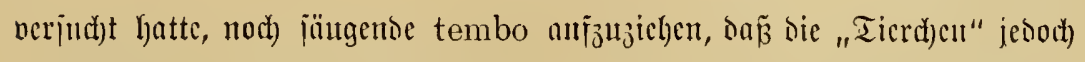

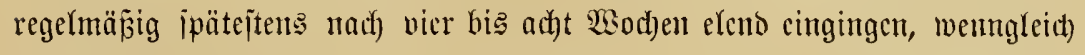

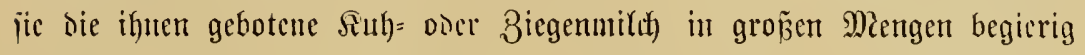

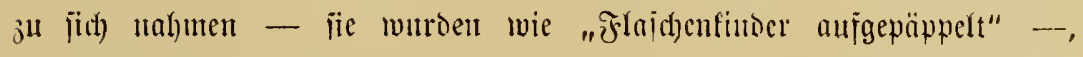

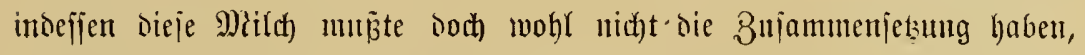

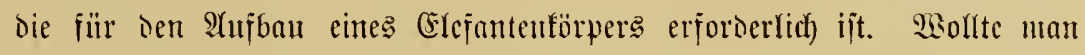

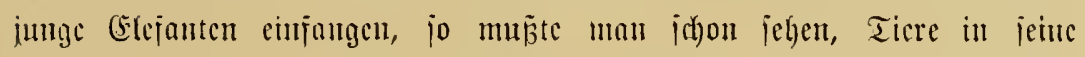

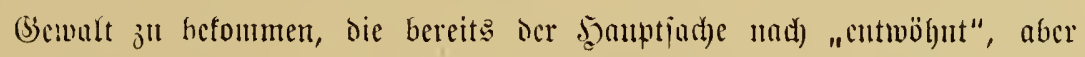

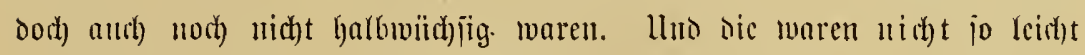
ju ïbcruältigen wie die "Babieg"!

Sobulo dic fleme Expentition auf Dem Wiaride war, ibjen es, als ob tor vom Ficber jo id)wer mitgenomurenc, gelbgran ausjebenoe uno ganj

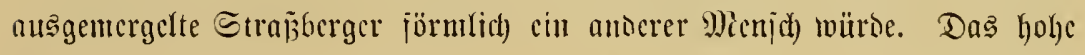

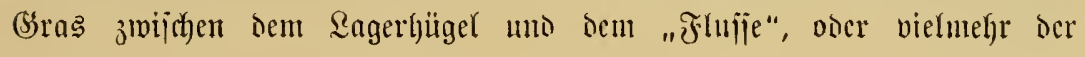

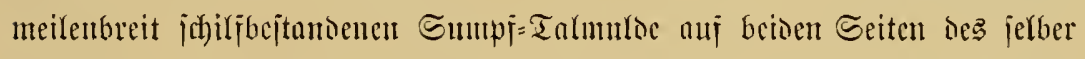

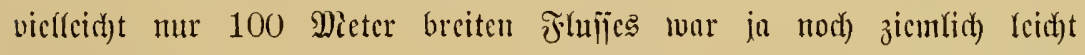

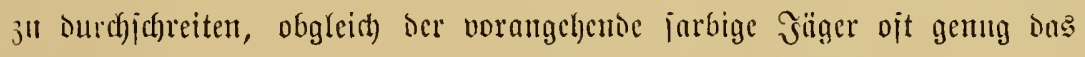

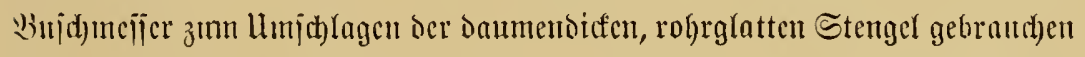
muñte. YUs dent (Sraje aber fam man eben in das inwergleid)lid) j(f)werer

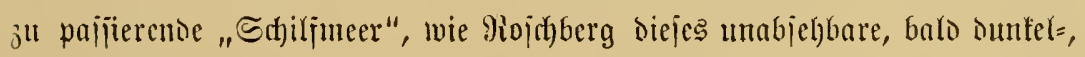
balo bellgrüne (Semoge nante, aus Dem jreilid) aud), wälyreno der erjten Stunie sics Marjuses, hier uno da einzelne verfrüppelte Saubbüume, cin

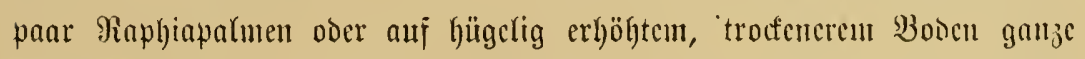

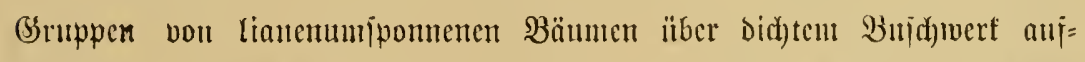

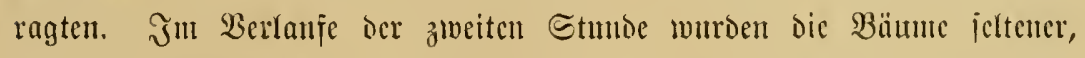

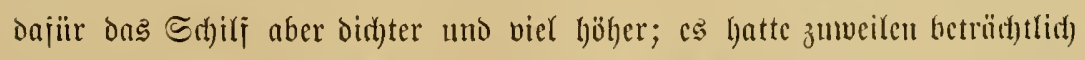

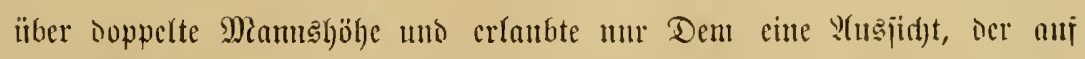

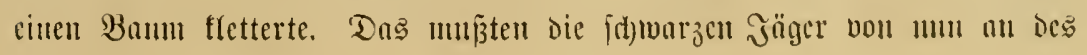




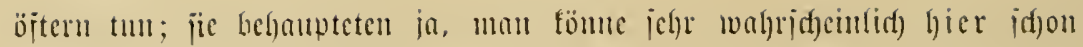

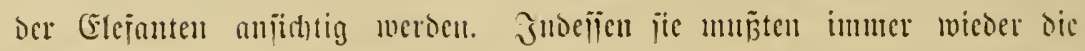

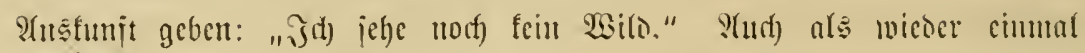

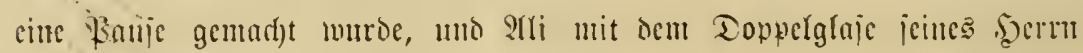

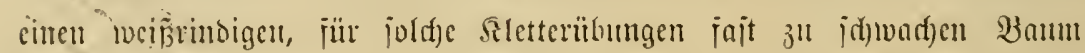

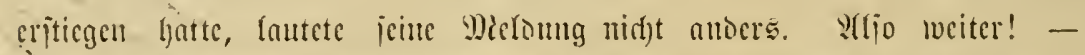

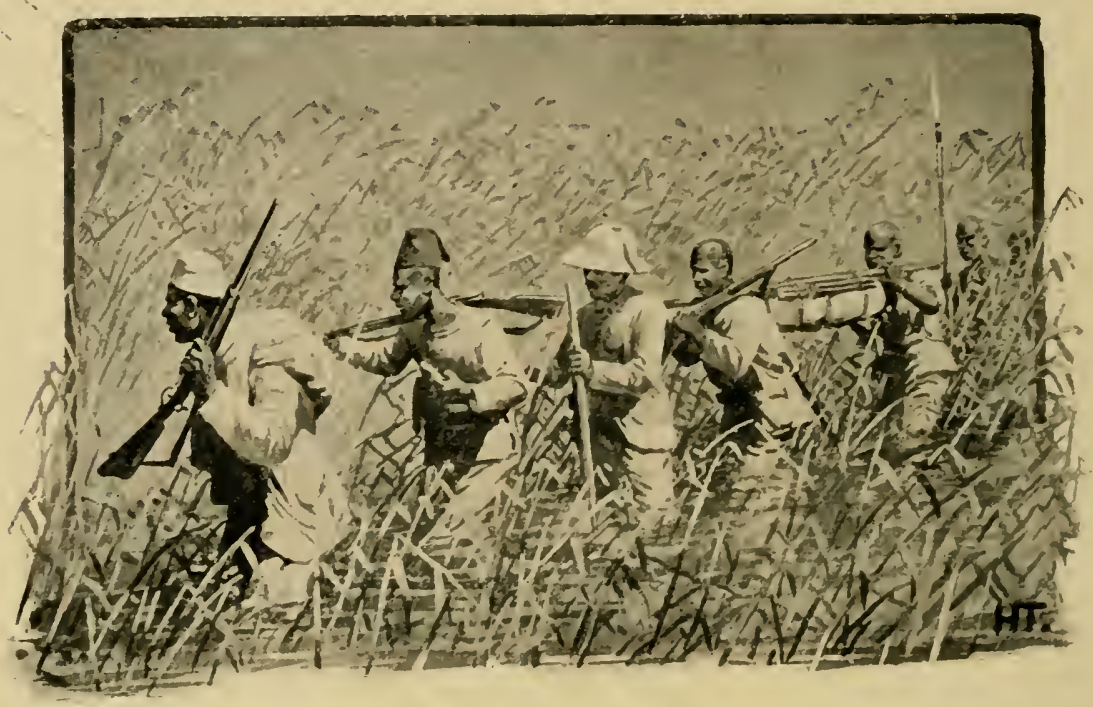

Derr v. Rojdberg jing bereits an, biejen Ririd)gang in Eumpi "einjad)

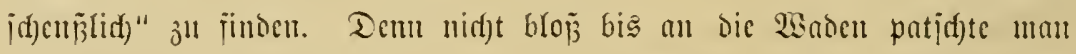
iul id)warjbraunen Mroormajier herum, jondern oit gemug aud) bis aut

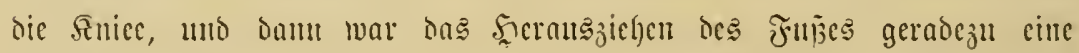

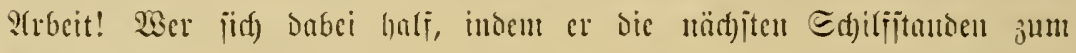

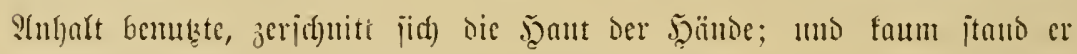

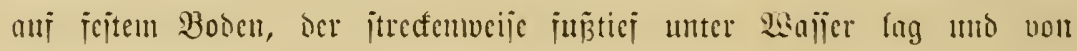

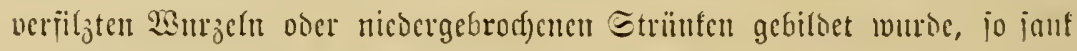
er iđgon beim nür)iten Ed)ritt nomöglid) nod) ticjer cin! Echlimm war

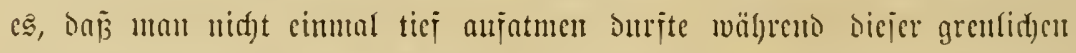

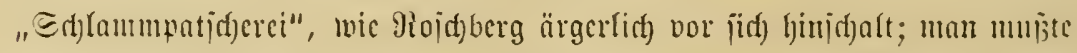

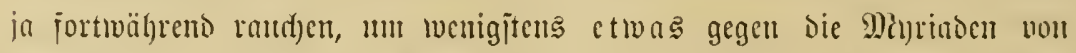
Minfitos zn tum, Dic an Zage an Der llutericite ber Edjiliblätter jajjen

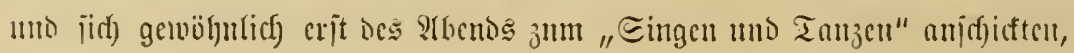




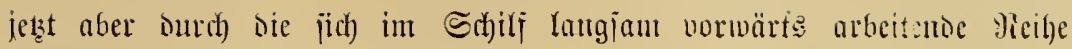
Menjuch aujgeitört murien.

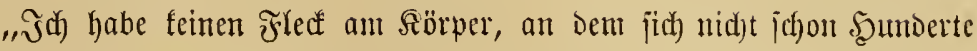

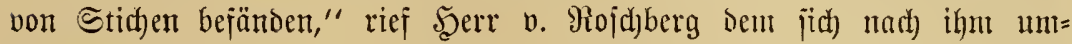
mentenden Rotbart ju und jhlug in ohnmächtiger $23_{\text {ut }}$ nit bem lüngit

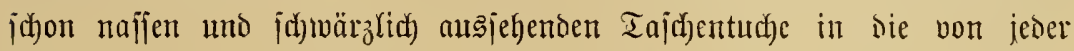

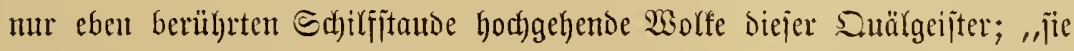

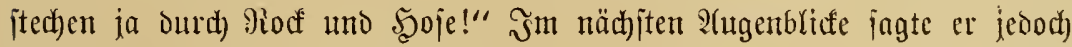

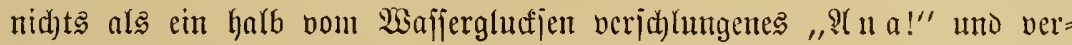

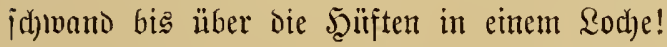

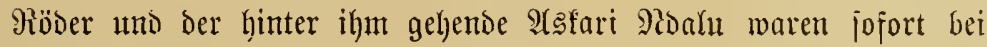

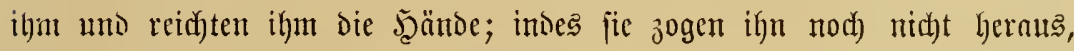
jo jornig Roj(d)berg aud) Den $2($ sfari, auf Deutj(h), anjd)rie: "Bormärts ถo(t), mą jolf Denn bas bröbjinnige Umgutfen!"

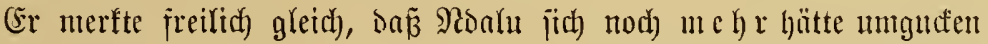
jollen; deum der asfari glitt eben mit dem einen Fuß̌e in cin gan

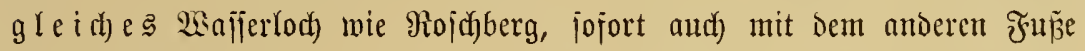

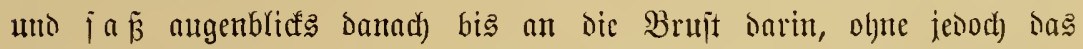
frampihajt mit ber Rinfen feítgehaltene (Siewehr uns mit ber Medhten die

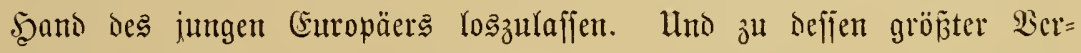

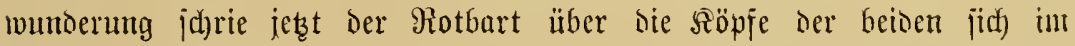
Sumpi abarbeitenden Miänner fort dem noch weiter Ginten "marja)ierenten"

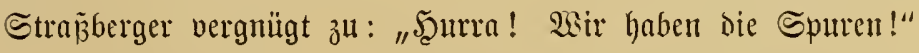

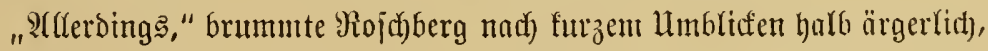

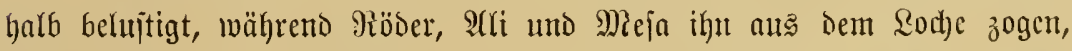

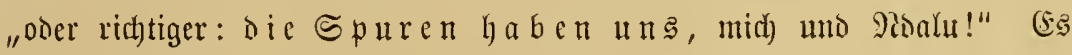

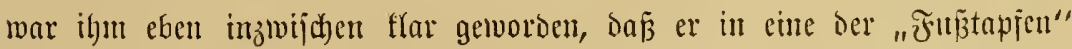

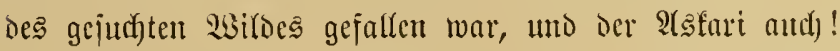

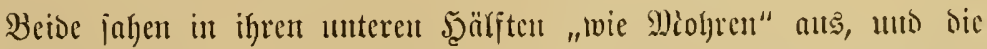

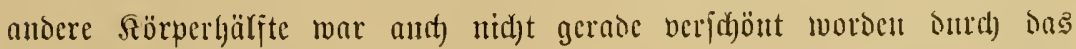
aufiprizende Sumpfwafier. Sie wurben mit cincu Bïjud junger Sathlf :

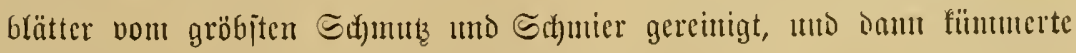
jïch) aftes uur nod) unt die Tembo= Fuīiputrent. 


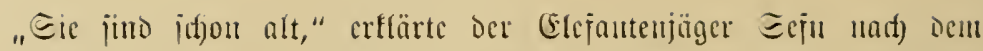

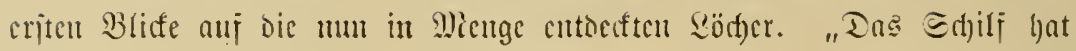

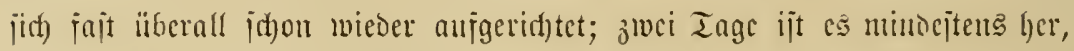

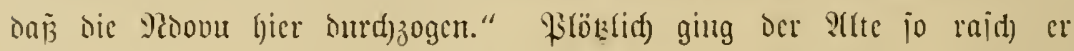

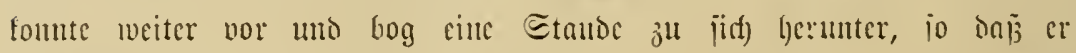

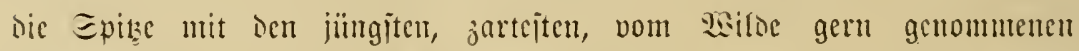
Edfiffblättera genan ichen founte, mo faum hatte cr bas diffe (Bowäd)

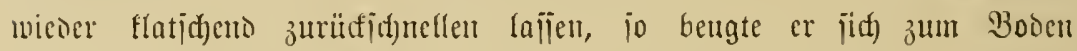

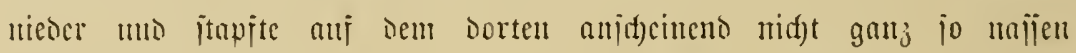

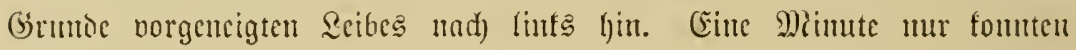

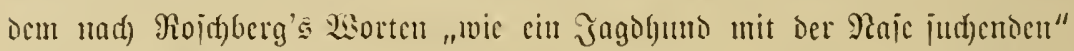

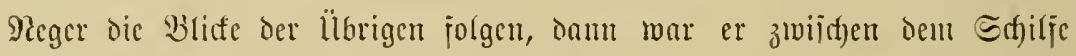

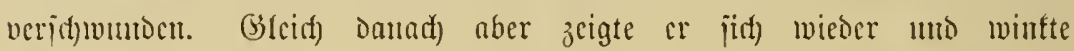

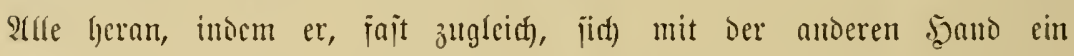

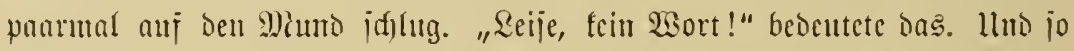

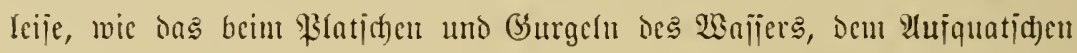

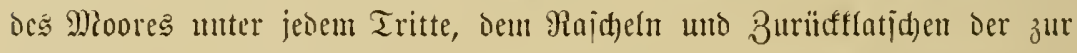

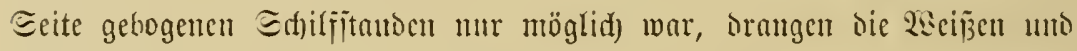
Giuter ifjuen dic Farbigen in langer Reifle ifm nad). Er hatte 'mas cuttoeft!

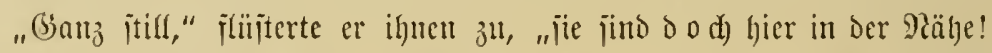

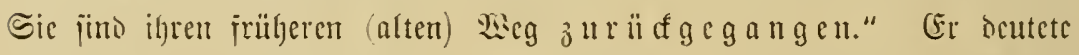
auj cincu .̧nujen grüngraner "Ranonenfugetn", wie Sloj(t)berg bic Ballen

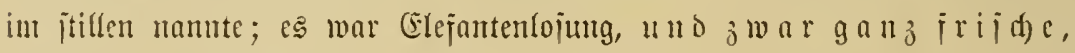

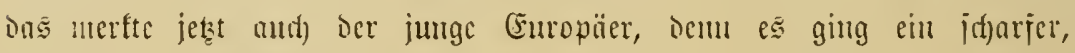
jalminfartiger (Bernd) Davon aus.

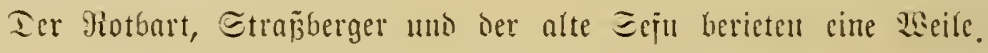

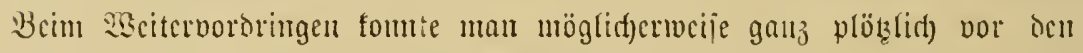
Elcjanten itchen; Denn auj 20 こdyritt Entjernung wären Dic Ticre dee

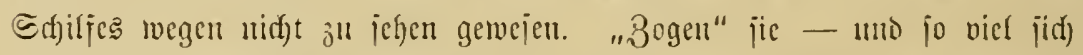

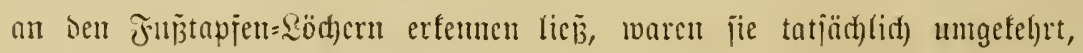

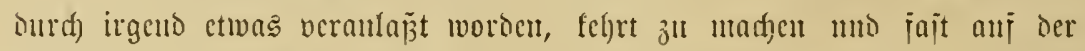

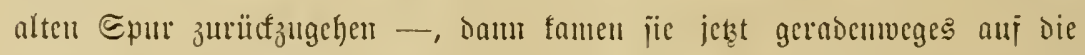

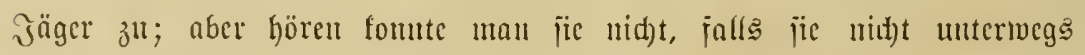

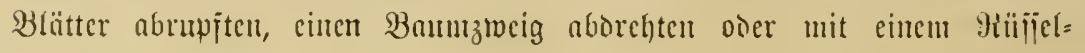


jumbunge ganje Stauten in bie \&uft warfen. "હo plump ber Elejanten=

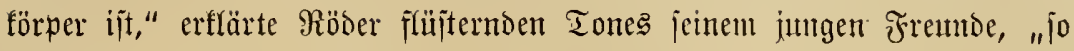
iäulendicf bie Bcine find und jo wuthtig der Tritt Des Fñ

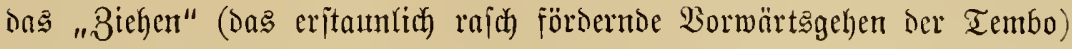
ift auf hartem Booen böllig lautlos, im Sumpfe nur burd) das $\mathfrak{\text { Utuf }}=$

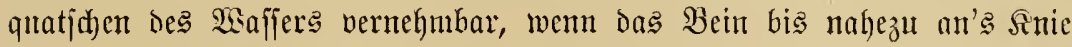
in Den Mloorboden einjinft." llm das aber ju bören, Durfte man nidht

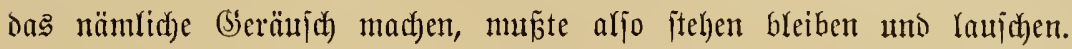

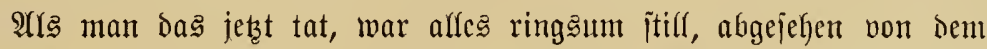
leid)ten Flattern, mandhmal fajt metallijhem leijen Alirren, bus ber mu

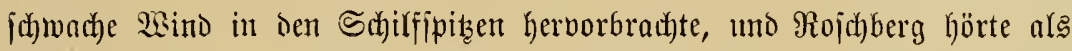
lautejten Ton ben Shlag feines aufgeregten Şerzens. Die Curopäer

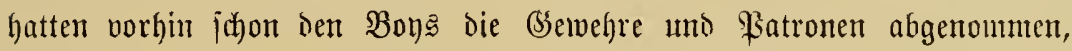
geladen uno gefichert jomie autch möghidy jt viele \$satronen griffred)t in bic Rocftaichen gejtecft; Röber jah Der Worjicht halber noch eimmal nach, ob die mit Minujerfarabinem bermafjncten jarbigen Эäger unt jeine beiden

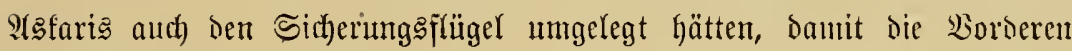
in ber Reihe "nicht etwa einen unveriehens losgehenden Sdur jwijhen

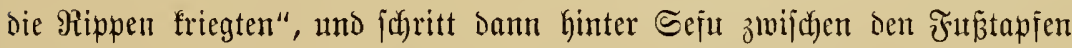
ber Tiere langaam weiter vor. Der Winto ftano günjtig, wie man am

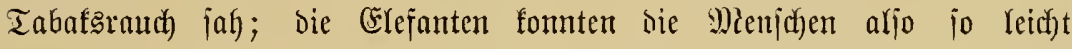
nicht wittern. YUf eimmal murde ber Grumb wieder fejter, mau betrat einc breite uno augenfdyeinfich aud) auf cine längere Strecte jidd) hin= jiehende Bodenjabelle, all Der, bielfeid)t 100 Meter meiter nach born

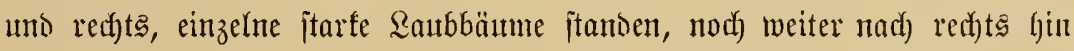

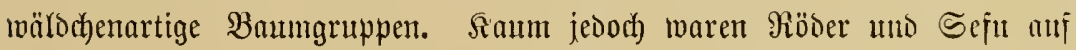

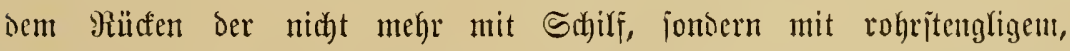

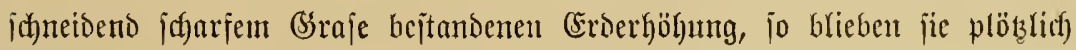

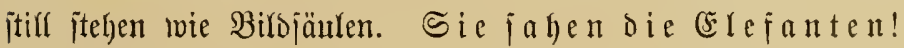

Auj Straß̧berger's rajd)en wint junfen alfe llbrigen angenblictlict)

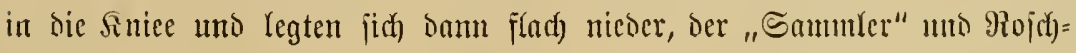

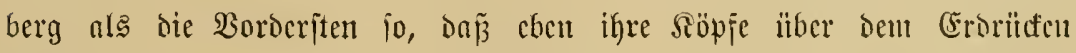

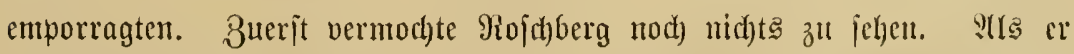

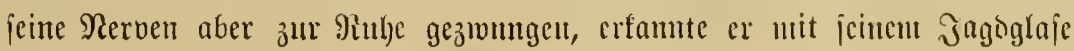




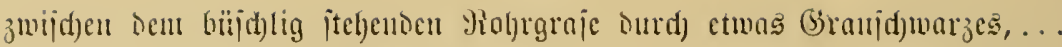

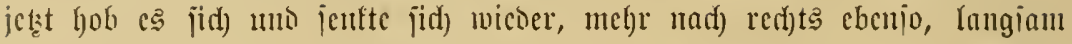

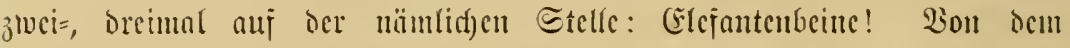
mälltigen Tier war jomit nid)ts ju jeben.

Rum wante Röbcr den fopf und winfte dantit. Man fonute nod) weiter vorgehen, dic (Élefanten hatten nod) feinen S(rgmohn gejd)öpit.

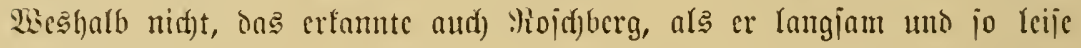
wie möglid) hinter bem Rotbart anf ber ljïgeligen (Erböhung nod) etwa

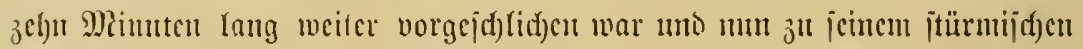
Entzücfen neben jungent Bambusgebüịc) die Elçanten jelber jah: denu von den Tieren - es waren jieben riejengewaltige, melyrere bon ihnen

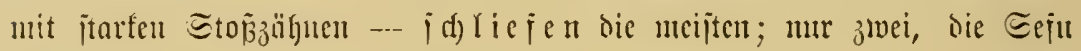
jait mur haudfento "dic 2 sächter" naunte, waren in Bewegung; bod) aud jie jtantoen mit oer Räucfieite nad) Den Эägern zu! Sic orchten von ben Bäumen vor ifren 3weige nb, itreiften die Blätter herunter und jüfrten

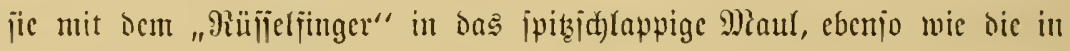

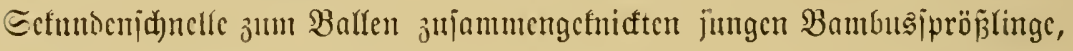

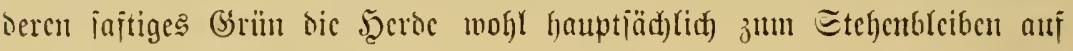
ifrem 3uge veranla $\tilde{\beta}_{\text {t }}$ hatte.

Dem jungen Ëuropäcr jefien ocr 2 (tem zu verjagen, als cr dicje

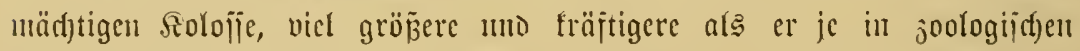
(5ärten gejeben, iı faum 800 Metern Entjernuıg vor jidf) erblicfte, uno cr woflte faum jeinen S(ugen trauten, als er wah)rnabum, baj auf bem

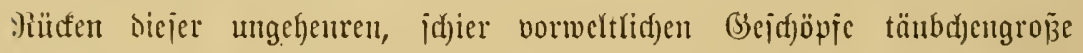
Dögel jujen, liefen uno flatterten, Madentyadfer, die Becten mto Jnjeften=

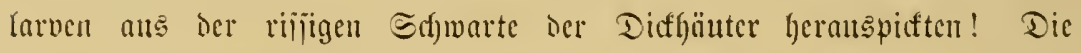
"2sïc)ter" flappten dic ungehemen Shren gelafjen nad) worn mo Iegten

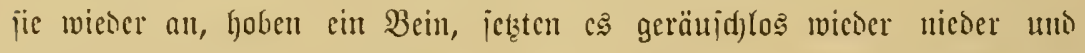

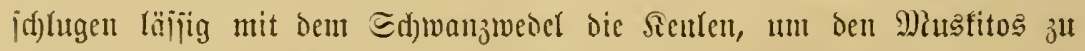
wehren; ber lange Rülïel des einen Elejanten glitt währendocijen mit ber jingerartigen (Sircifipitze an den 3weigen ocs ifn etwas beja)uttenden Baumes hin mol betajtete dic jumgen Blätter auf ifgre 3artheit, elje er

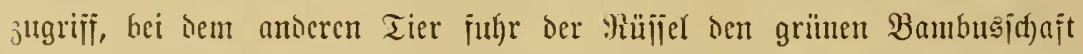
abwürts, ıแn den zwei Zoll diden Stengel damn aus bem Boden zu brehcu 


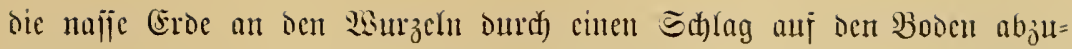

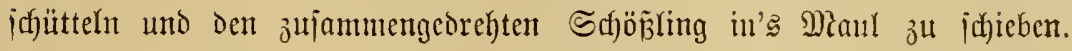
Man jah deutlid), fic wählten ifre ’ahrung jorgjan aus wic fein=

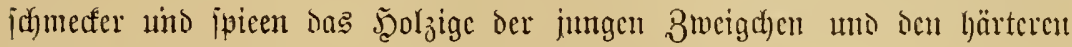

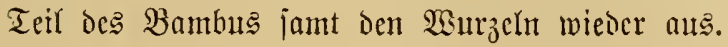

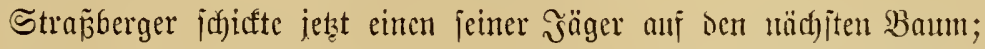

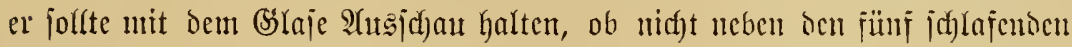

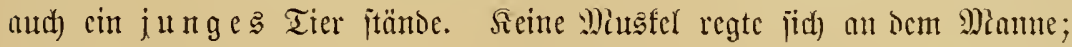

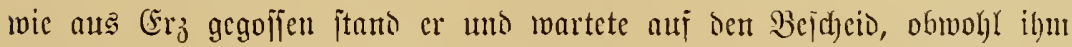

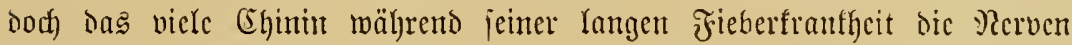

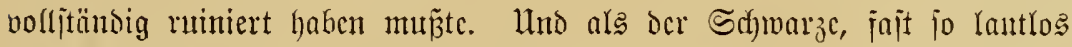
wic cine Sdjlange, vom Baum herunterglitt uno flüjterte: "Ndivyo, bana (ja wahrlich), Scerr), wengine wamo (es jüro einige ba)!", ba fragte cr

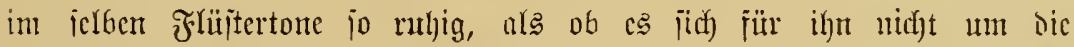

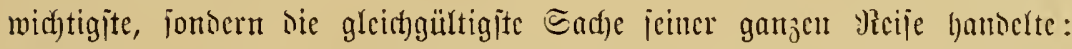
"Wangapi watoto (mie vicle Sumge)? Na ginsi gani (uno was jür

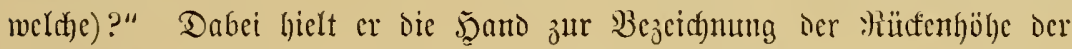
jungen Tiere erjt an jeine Brujt uno banad) un's fiun.

"Namna wawili (beibe 9 (rten); kweli (ja, in Wahrbcit)!" ickztc ber Mam raich aui bic energijathe, Bweifel oder viclutchr geradezu cin

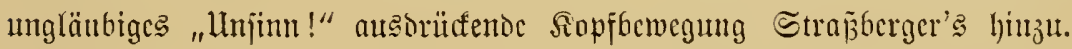

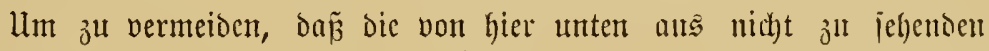

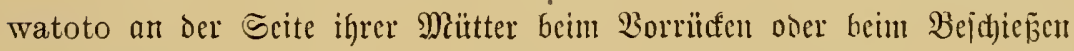

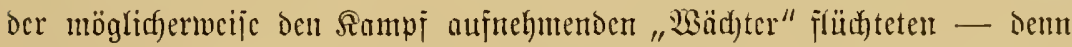
bann waren jic cin für allemal verloren, weil ja an cinc Berfolgung

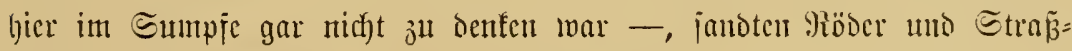

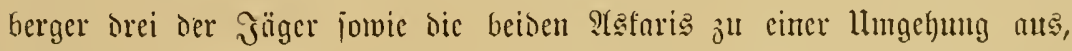

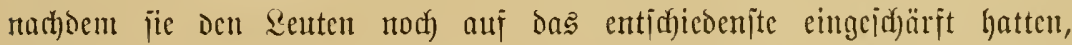

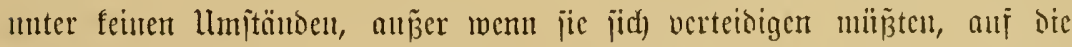

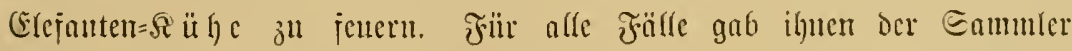
auth) nod) cin paar bon Dell Striffen umo cinc lajpartige Fangidylinge

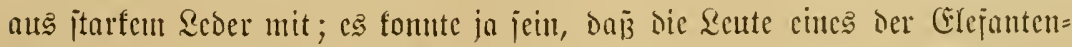

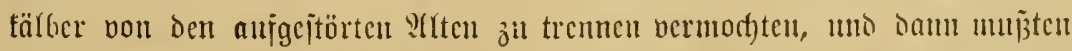

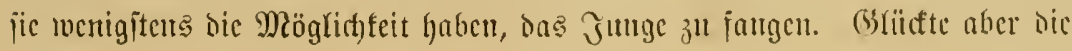




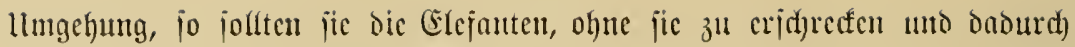

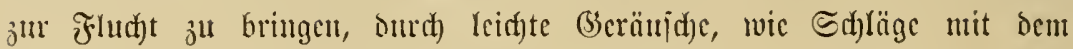

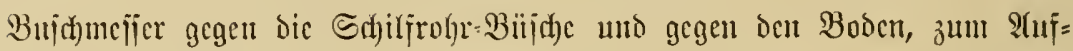

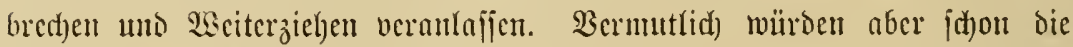

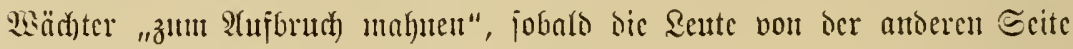

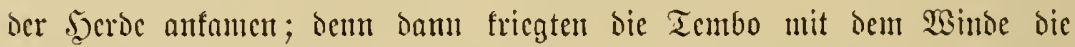

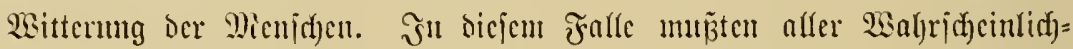
feit nach bic Tiere gerade nui dic (Erbichmelle zufomment oder did)t neben ihr vorïberwanterst.

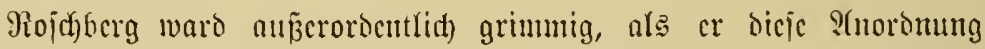

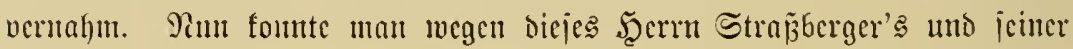

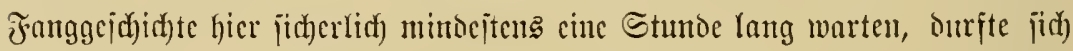

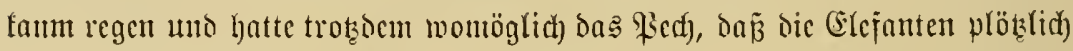
jeitwärts abgittgen, elje nod) Dic jarbigen Jäger joweit waren, baz̃ jitc bic Tiere hierher "orücfen" lonuten! Tsäre man alleis, - dic 6 bis 700

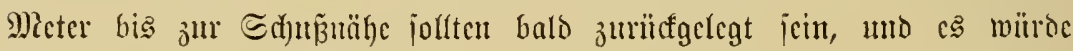

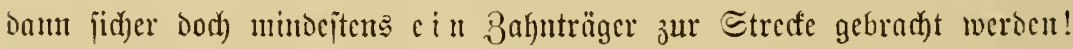

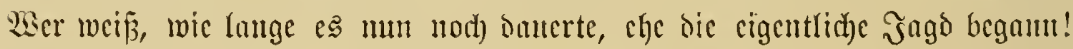

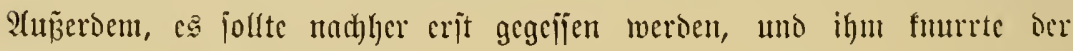
Miagen boch) jetżt idjon!

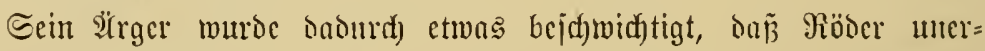
marteterweife bejtimunte, dic 3cit ocr llngehung jolltc burch) bns Frühïtücf

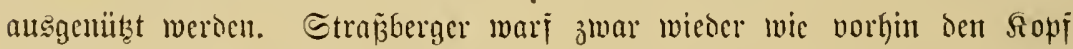

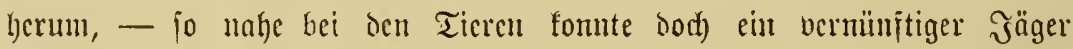

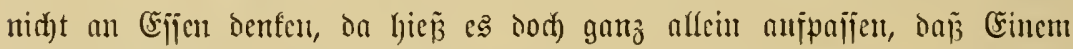
das willo nidht "durch die Sappen ging"; indes, als ber Rotbart juei ber Seute zur Bcohadtung aujgcitellt hatte, Den cinen mit oe III Jagoglaje svicderum auf bem nädjten Baunte, und den anderen nod) meiter vor, wo

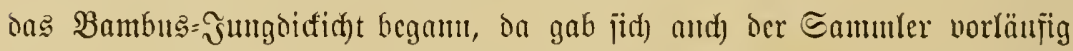

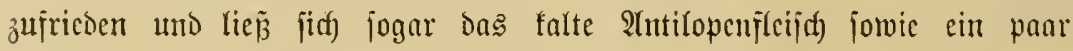
Sd)eiben $\mathfrak{B r o t}$ gut ichmeden. S(ud) jein , jo lange idjon greulid) mal= trätierter Magen" war heut wie oer ganze vom Fieber zermürbte Miann in eritauntich) veränderter Berfafiung! Freifiç, das Brot war, hicr in

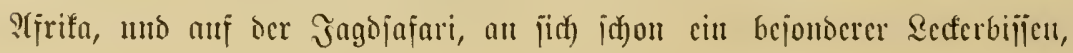


ridtiges Brot ats balb sieizen=, halb Maismebl, jrifd uto locter, bent es war nicht, wic man es früher hier allecin fante, ein vom Mepijdi

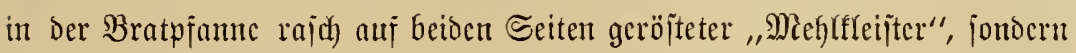
fajt curopäifiches Bäcferbrot, Defijen Teig in Ermangelung von ,Bärme",

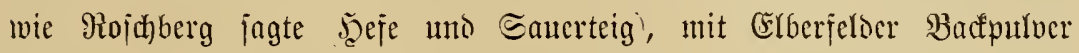

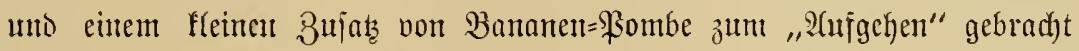
uno gejäuert war, hevor es in ben vor "Neli's" gejdicft hergeriduteten Bacfojett geichoben wortict.

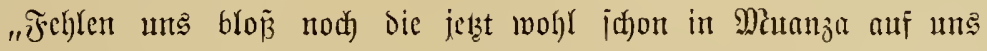

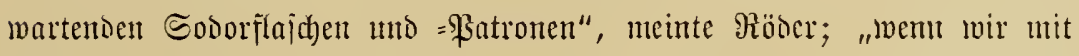

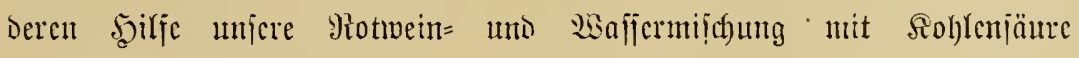
"anreichern" föunten, da würoe uns das Frübjitücf noch) mal jo gut munden!"

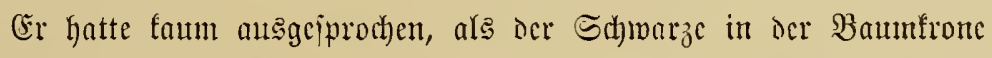

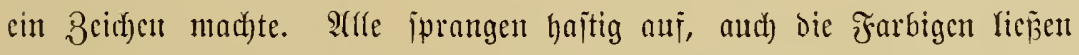

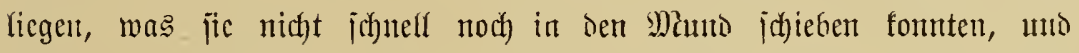
griffen $\jmath^{u}$ ien Bewwehren. Waren bie Elefanten beumuhigt worben, fingen

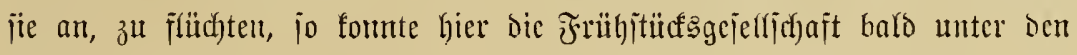
Sïulenbeinen der Tiere jerqueticht in Erraje liegen! (Ebon johlüpite aud) Der jum Bambus gejanote Mann herbci. Die Tembo muj̃ten "2sino betommen" haber, jie "witterten"!

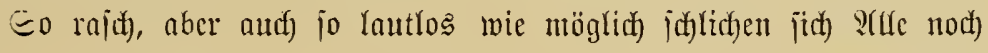

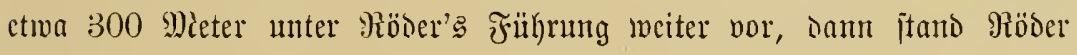
- je tz thelten jich die beiden idwwarzen Jäger recht gern hinter den

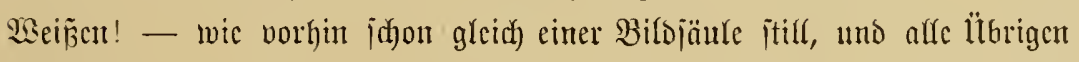

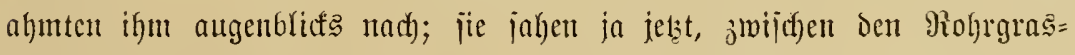

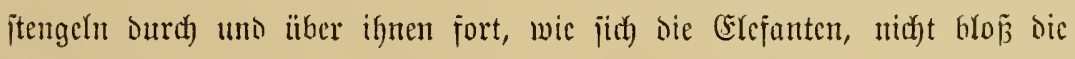

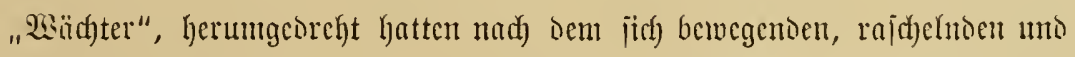

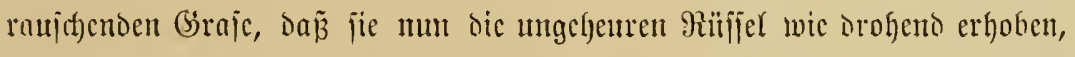

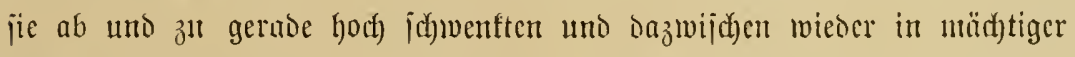

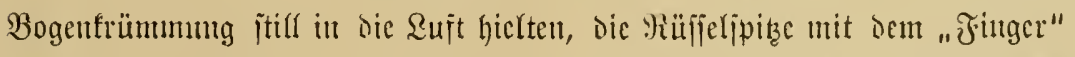
über Den rotbraunen शajenlörberu gerabcaus ocn Эägem jugementet. Dabci flappten jic bie Dhren wiener ab utur an, ofyne jidf jonjt ju rï̈)ren.

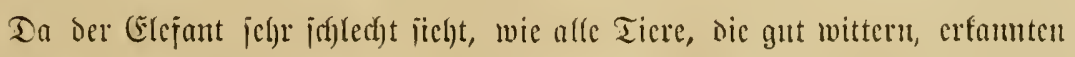

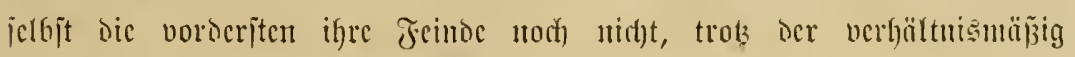




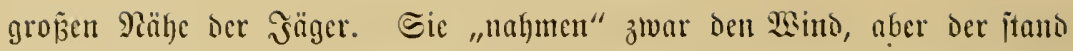

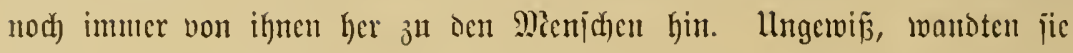

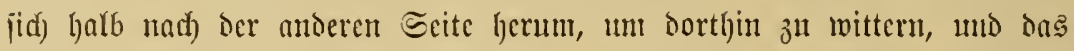
benürz̧te Röbcr, um reije nod) 200 bis 250 Meter vorjulringen, fojort aber wieder wie angenagelt jtelyen zu bleiben, ale oer eine $\mathfrak{B a ̈ a d}$ ter jith förmlich herumbarf แmo num cinen zornigen Trompetenton ausjtic $\tilde{3}$.

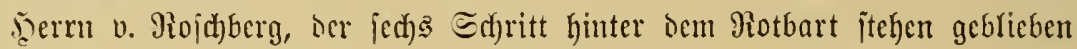

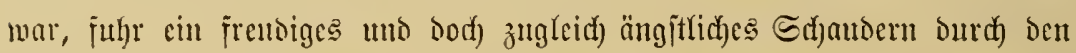
Rörper bei biejem wilben Ton. Wadfte ber Tembo angrcifen? Warum

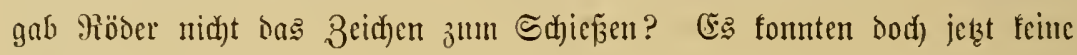
200 Micter melyr jein!

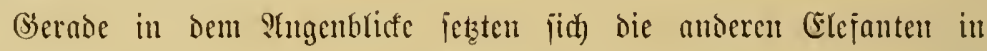

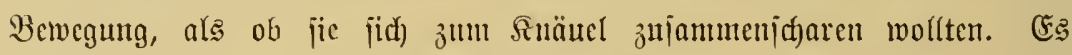
maren ein paar "Zahnfümmerlitgc" und jwei oscr brei "§ül)c", genan founte man die Tiere nid)t jüblen, Der Bambns und bahinter das Sdjili verdecten bie Siörper jum Teil, mol die abwedjiefno jwijd)en ber grauen

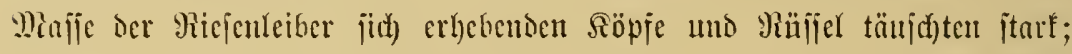

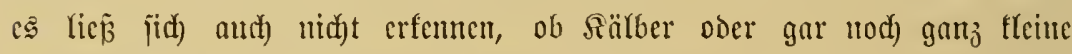
"Babics" dajwijden iteften. Difenbar hatten dicje bier oicr mefje um

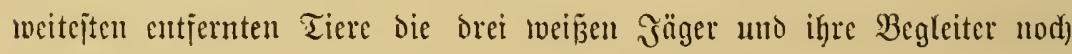

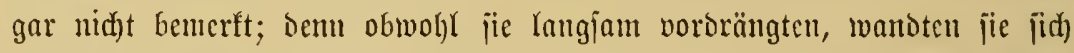

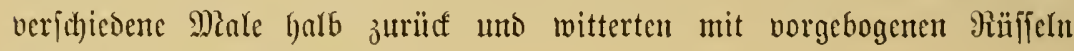
nach) Der entgegengejekzten Scite.

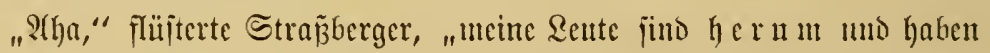

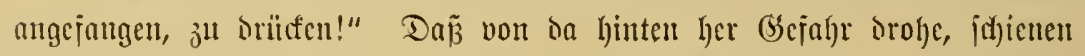

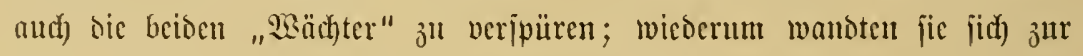
Scite wie die llbrigen, unt jingen an, nach Dortgin ju "blajen", Den langen, turz abbred)enden trompetenartigen Sd)rei auszujtopen, den jie

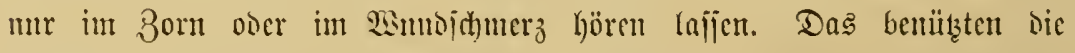

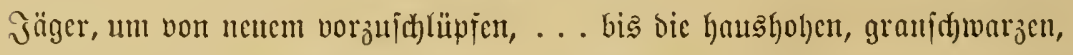
aber vom braunen Sumpjmorajt mit Riejenjlecfen bedecften Reiber faum noch 90, viclleidyt mur 80 Micter vor ihnen ans ben Mafien teils umge= brodjenen, teil(s niebergetretentu Sdjilfes aujragten. Seiber jtantien bie "然äd)ter", itarte Butllen, jeșt jo, Da $\tilde{B}$ jie sie übrigen Tiere fajt ganz 


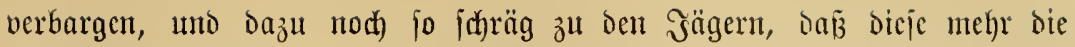
gewaltigen Şinterfeulen, uno bon bem eriten einen Teil des Leibes, als etmas von don Röpfen jahen, aljo noch immer nidht den einzig Eryolg

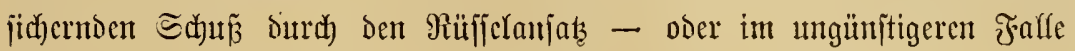
bid)t vor Den Dhrlappen - in's (Sefirn anbringen founten.

Das murde jedod) in der nächjten Minute anders! Wier oder jünj Der Tiere hatten bei biejer शähe, trotzdem jie halbabgefehrt jtanden, oenn

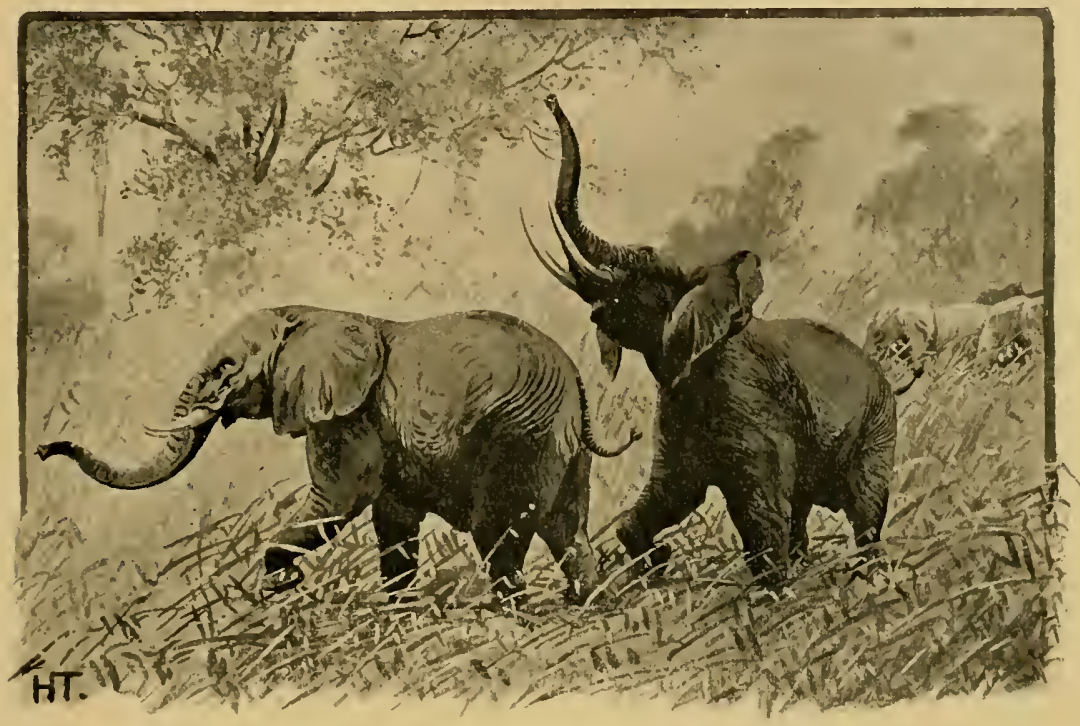

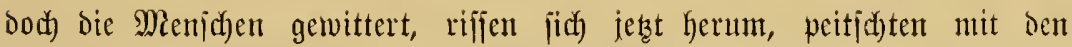

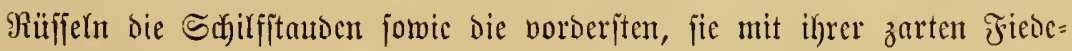
rung nod) wie ein grüner Schleier leidgt berbüllenten Bambugitengel,

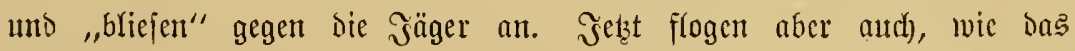

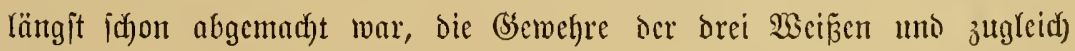

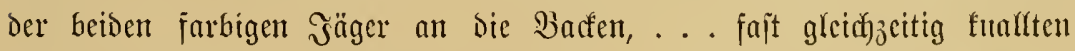

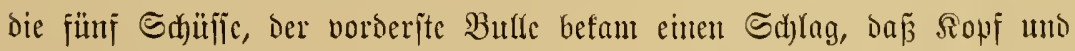

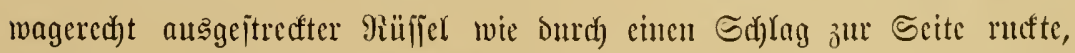
und in ben bröhnenden Wutifhec dicjes wie des umunttelbar danad) von

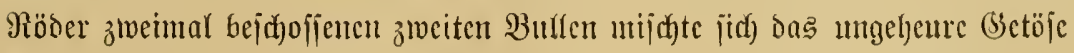

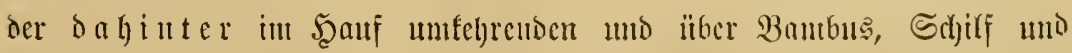

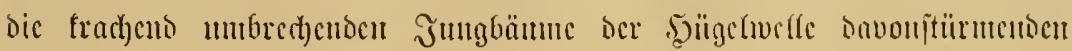




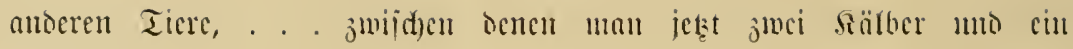
,Baby" jab!

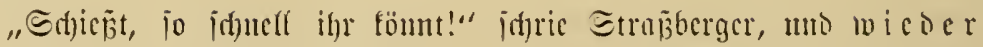

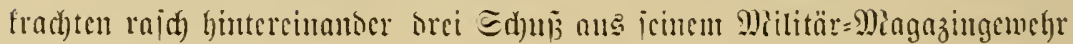
jowic bic Manjerfarabiner jeiner bcisen ङdywarjen. Er batte Dabei ani

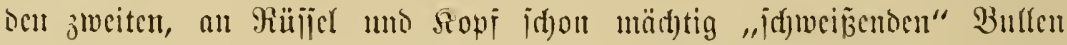

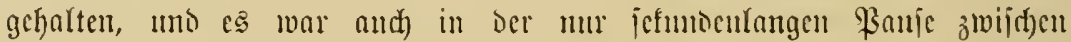

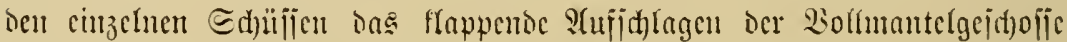

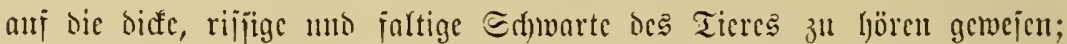

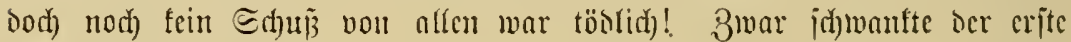

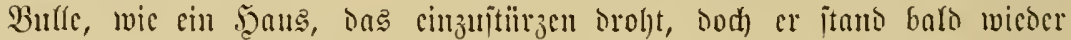

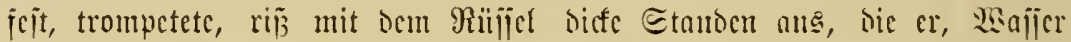

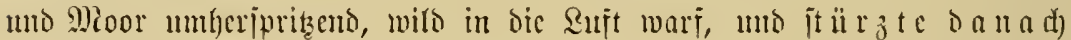

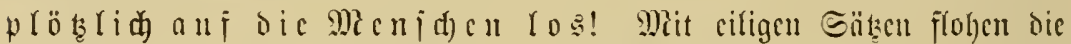

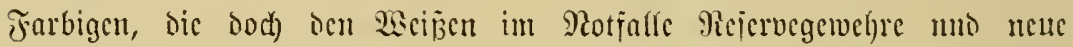

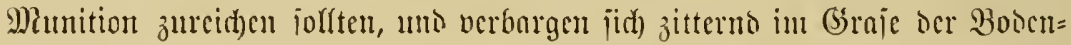
welle oò binter ben bort jtehenoen Bäumen; Röber aber trat nur eiu

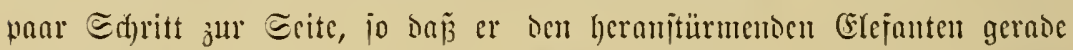

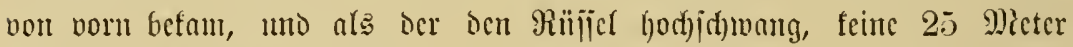
vou bem Berwegencu, fnallten zwei Edjüjīe, . . von nnten her ourd)

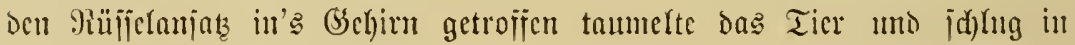

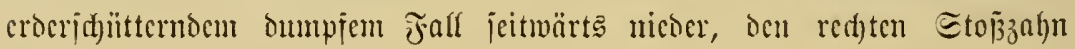
tief in Den weithin iprisenoen Miorajt grabeno.

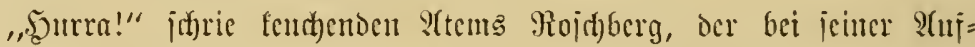

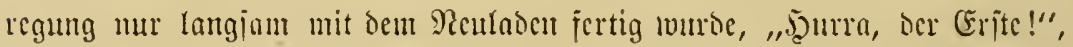

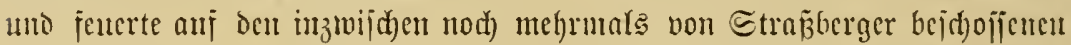

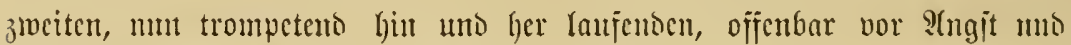

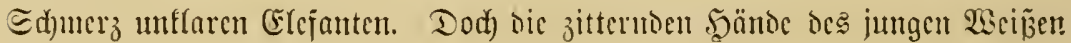

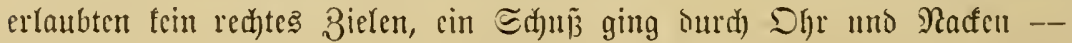

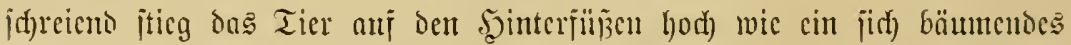

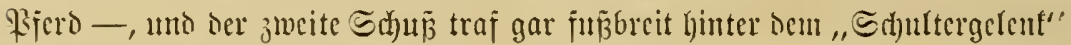
in Den Scib! Eime Mimute Darauf ftürzte jich aber and bicjer idmerz=

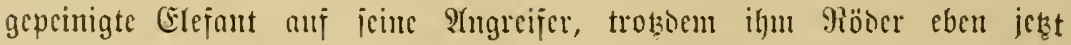

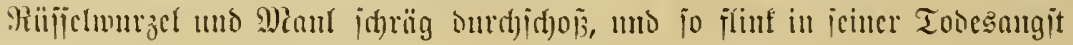




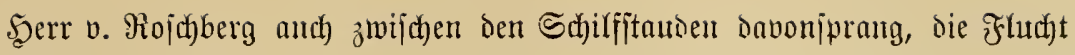
gelantg ifm nid)t: er julutg in ocm zertretenen $\mathfrak{s u j}_{\mathrm{t}}$ bon Stauden uno

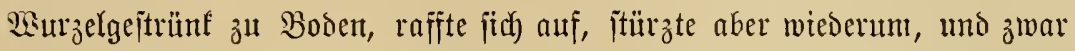

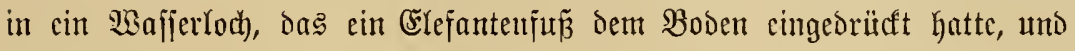
obmohl nun bie anderen beiden Weiñen jomie bie beiben jarbigen Эäger

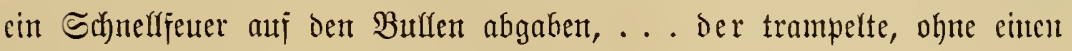
Raut von jidh zu geben, in rajender 2 sut auf dem Flecte, wo jein Feino

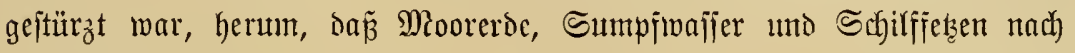
allen Seiten ipritzten!

Entịeszt waren bie übrigen Farbigen nodh meiter gef́lohen, eintige

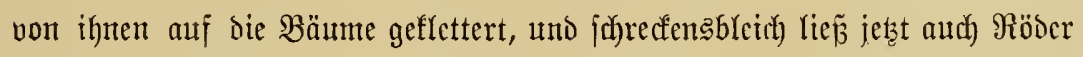

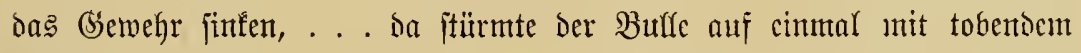
(Seräuju) Durch bas rajjelntoe, flatternde, raujchende Shilf bavon! Balo

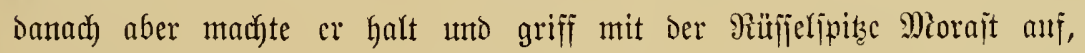

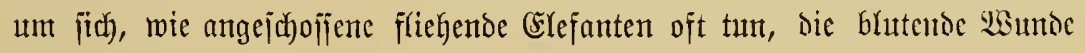

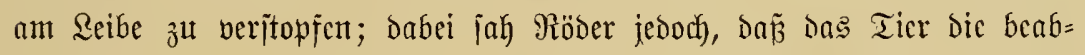
jidftigte Bewegung gar uidht ausführen, nidyt zum Reibe hinlangen fonnte, uno er begrifi, weahalb es jeinen Feino nicht mit dem Bïjijel

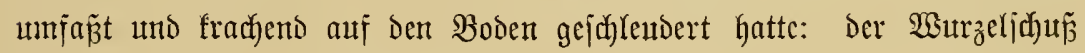

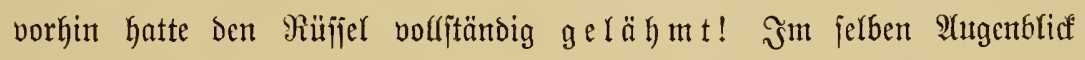

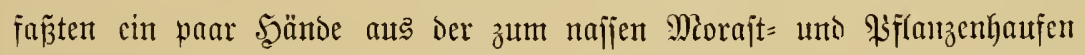
zujammengetrampelten Sumpfiftelfe hod). Wa a sent?! Mojdberg war

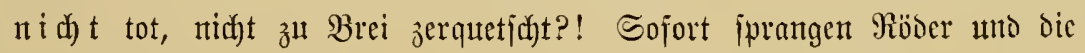
beiden farbigen Эäger borthin - - und zogen den fajt erfticften, aber wumberbarermeije nicht "z̧山 Mius zeritampjten" jonbern mit cin paar

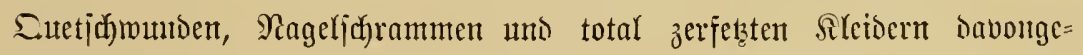

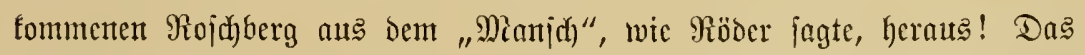

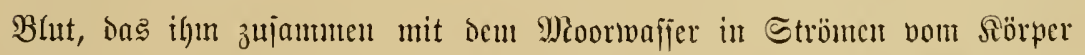

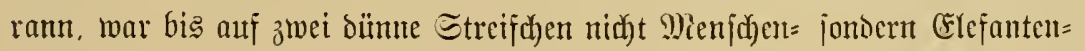

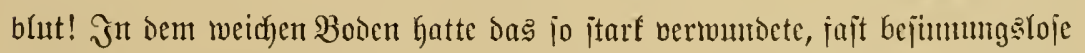

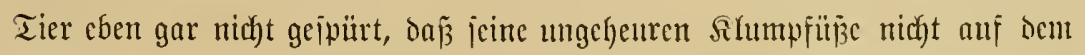
Fe i inde, jondern nur in tem "Mianfich" herumtrampelten!

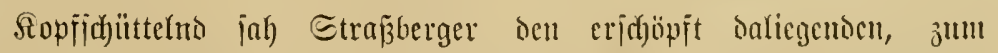

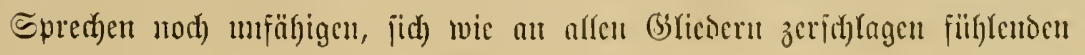




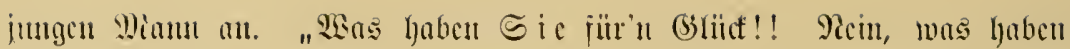

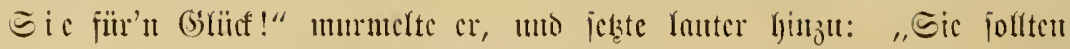

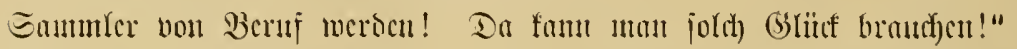

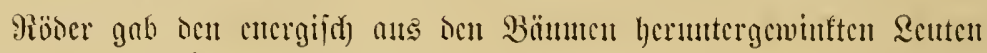

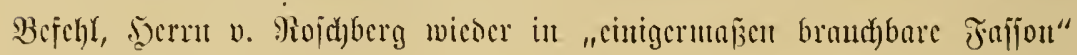

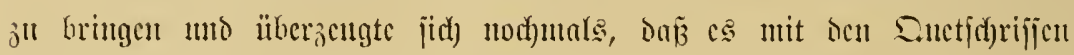

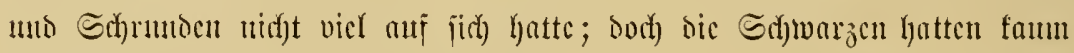

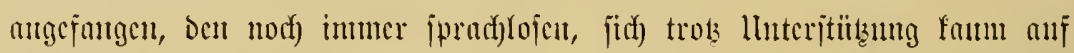
Den Beinen haltenden jungen Mann mit einem Büntoel von Sofjilfblättern

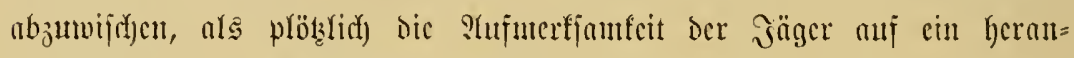

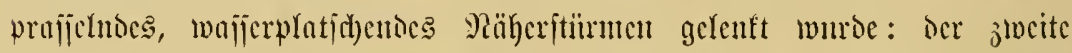

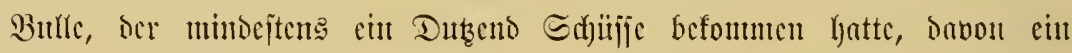

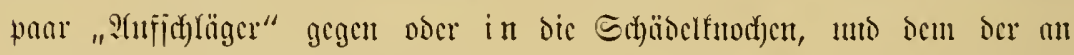

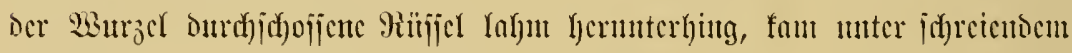

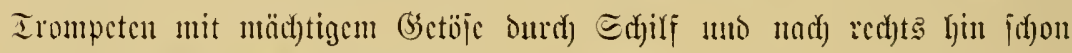

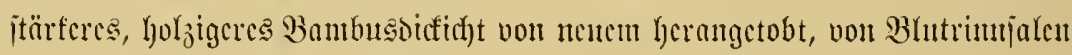

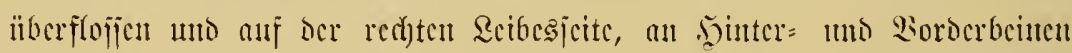
von blutigen wsuffer beflect. In fadenoüunten Strcifen tropite bas Rot

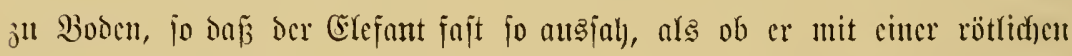

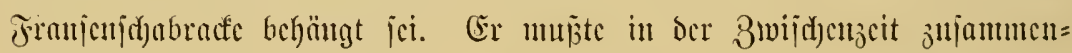

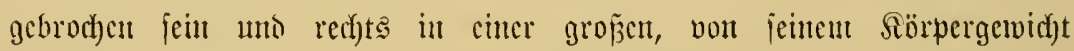

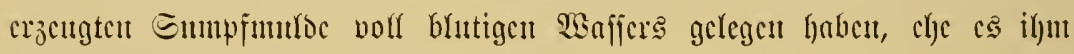
gelutgen war, wicber, "hod) ว̈H werien"!

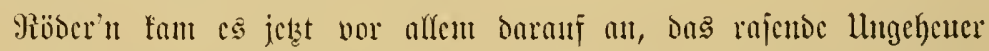

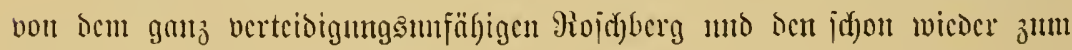

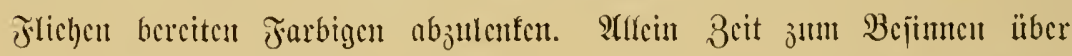

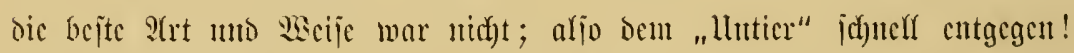

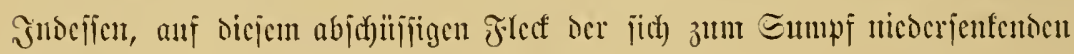

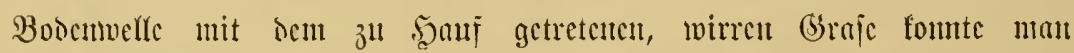

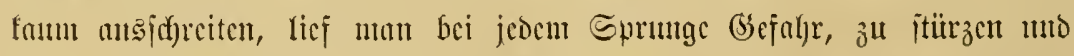

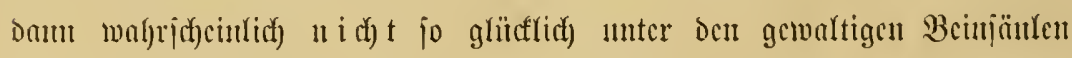

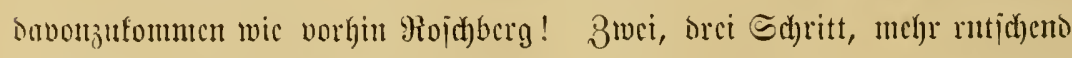

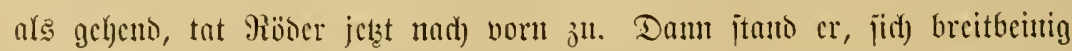

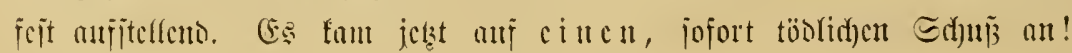




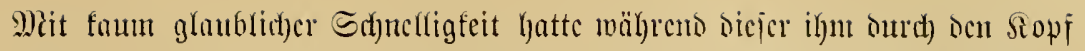

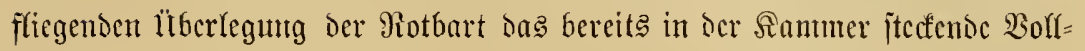

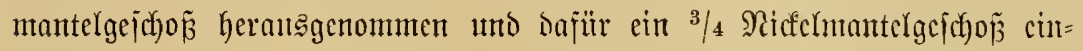

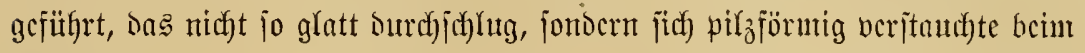

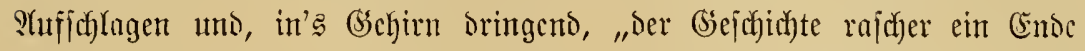

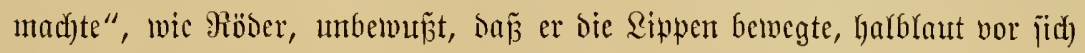

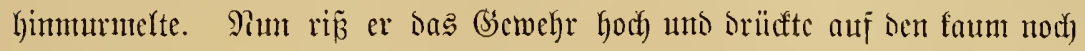
30 Nieter entfernten Bulfen ab, - alfein es gab ž feincm Entickzen mur

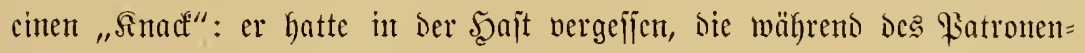
austaujiches ungelegte Sicherung wieser zurütffulegen!

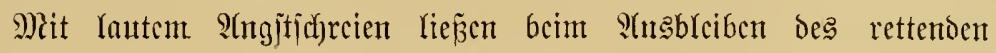
Sthujics bie Farbigen ihren zujammentnicfenten Bana Rojchebegg fallent

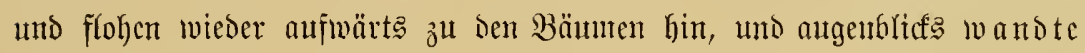

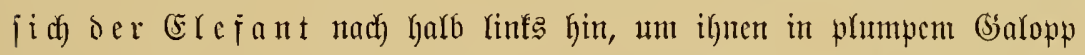

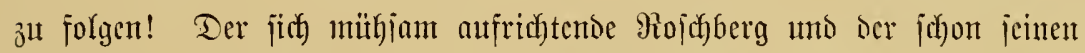

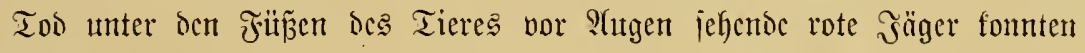
befreit aufatmen!

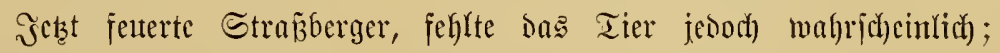

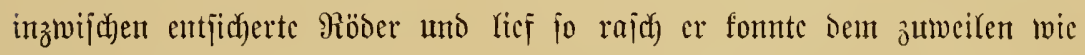

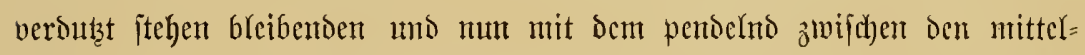

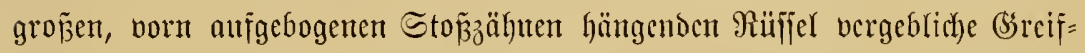

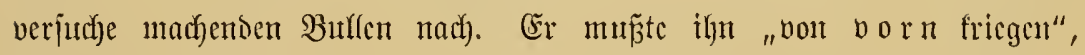

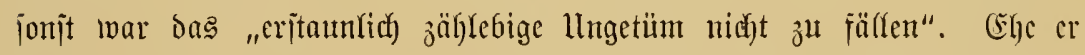
es aber erreichte, batten jich einige der Schwarzen angitbeflügclt, wie

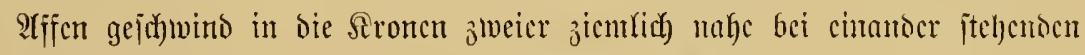

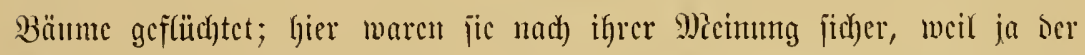

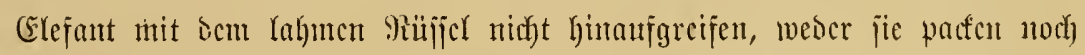

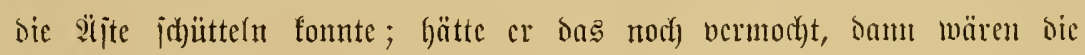
Menịchen wic Mangofrüd)te auf bie Erobe geflogen! Matm cinter ber Rente,

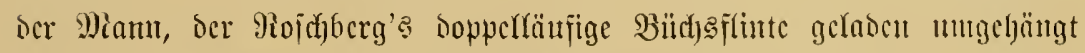
trug, hattc ben Baum nicht erflimmen fömtucu, on er zubciunal abgcruticht

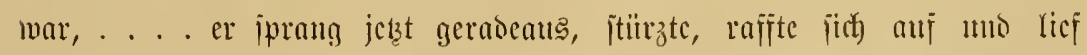
3um nächjten Baum, an ben cr aber nicht herantounte, weil sicffer Jumg=

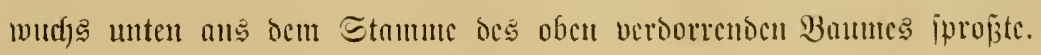


„M pumbafu, punda la mtu, piga (ङd) a a d fop

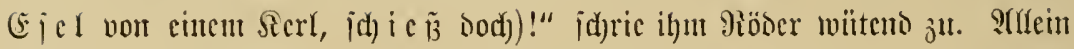

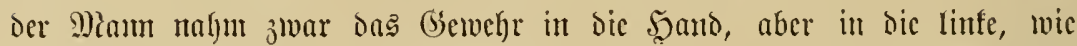

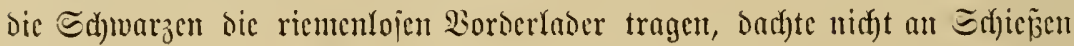
jontorn ramte, vor IIngjt immer "nakufa (idf) iterbe)!" fidsceiento, um

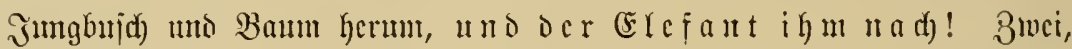

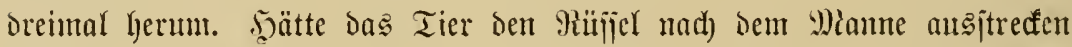
fömmen, er twäre nidyt halb um die Bülfhe gefommen! 9iöber itand

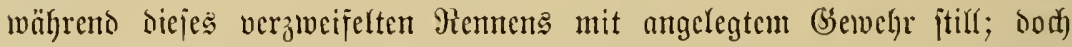

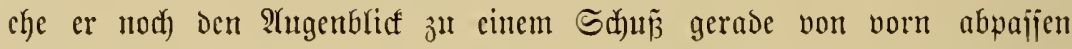
founte, merfte bas Tier, Da $\tilde{\beta}$ in ben beioen näd)jent Baututronen Mienjichen

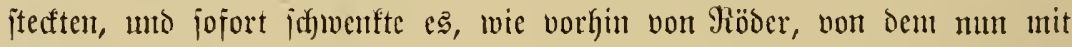

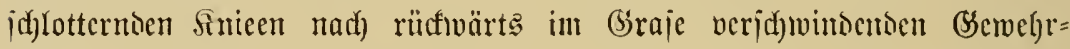

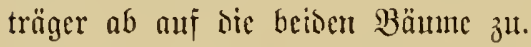

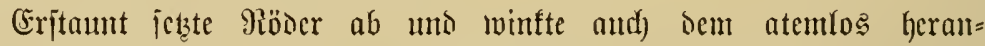

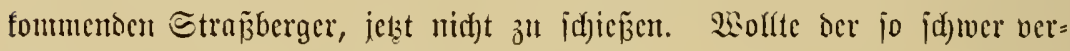
muntete Bulle bic Serte da oben "belagern", wie ę gereizte Elefanten mand)mal halbe Tage lang tum jollen? Soer wollte or Den Baum mit Der mäd)tig breiteu Stirn untraumen? Pecin, baran badbte woht bas

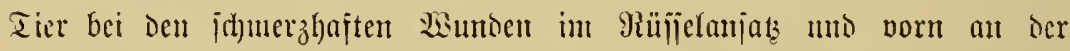
Ctim nidjt: es legte jid), mit dem ganzen (bemidjt jeines ungehcuren

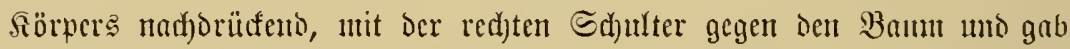

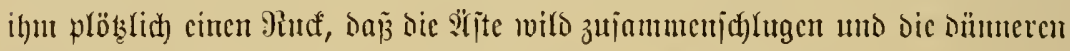
SSurjeln fnalfent aus der Eroc iprangen! Dic Farbigen jetoch hatteu

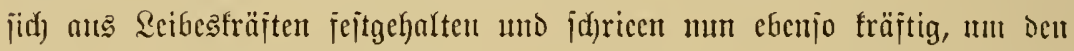

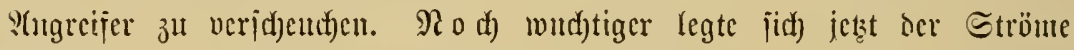

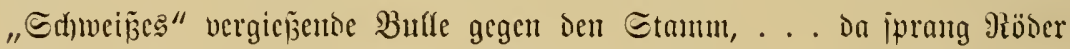

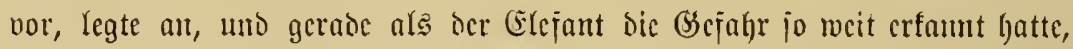

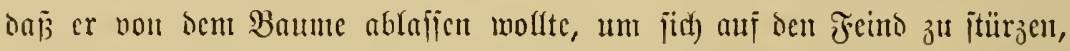

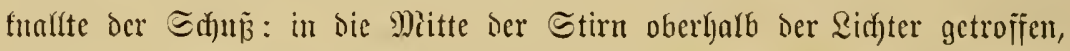

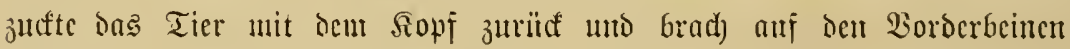

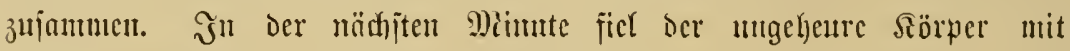

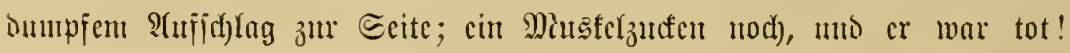

Un jo lebentiger wurden jekst bic Echuwarzen! Sie rutjd)ten unter

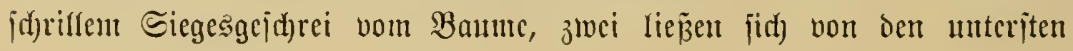




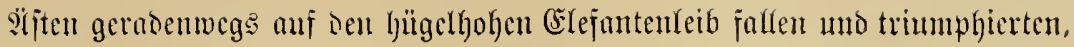
Darauf herumipringent: "Der rote Jäger hat auch den z we it en 2200 u getötet!", währeno der ältere der beiden farbigen Ӭ̈̈ger mit feimem Bujich=

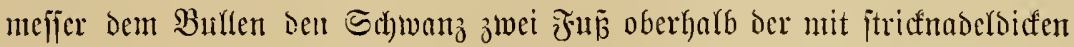

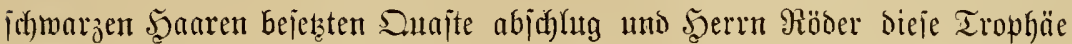

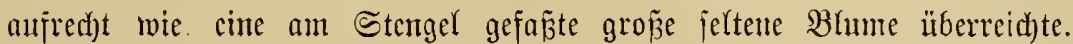

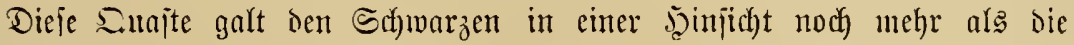

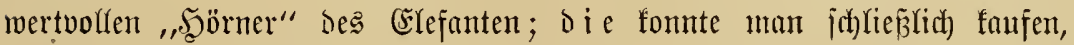

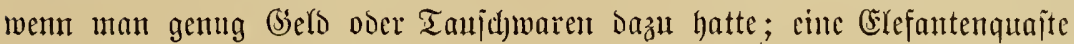

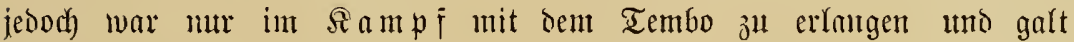

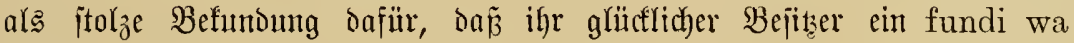
tembo war!

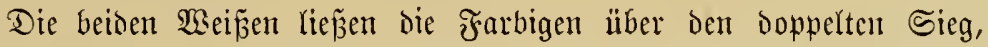

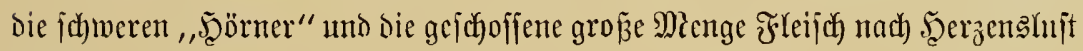

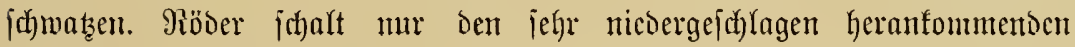

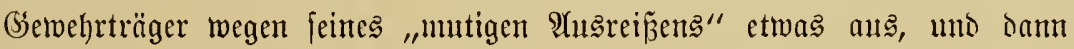

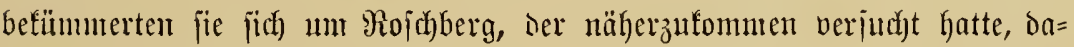
bei aber entweder niedergebrod)en war oder fitch, weil er nicht mehr weiter fonnte, in das zertretene, überall blutbejpritzte Bras gelegt hatte. $5 \mathrm{~b} \mathrm{cr}$ am Enoe bo d) etwas (Emitlides weggefriegt hatte? 3u vermuten war's

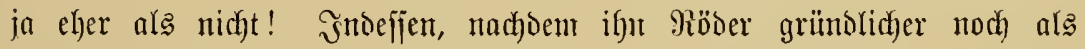
vorbin überalf befühlt uno beflopft uno ign hatte tief ein= umo ausatmen

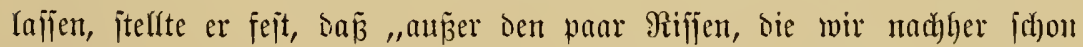

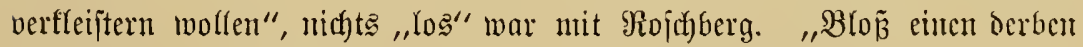

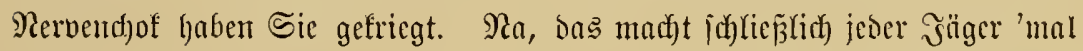

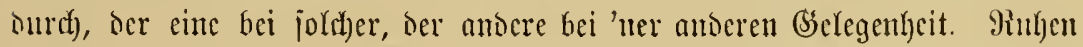

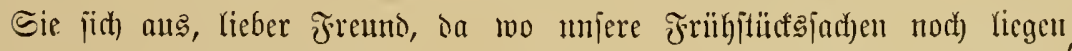

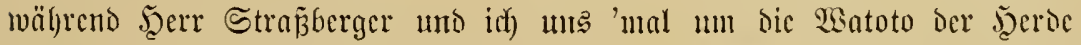

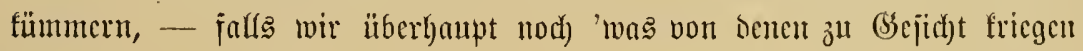
jollten!"

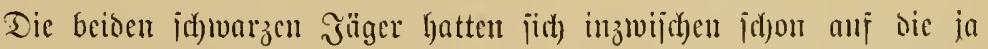

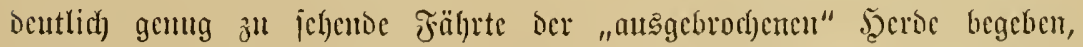
nactbom jie noch in aller Eile bei dem eriterlegten Bullutu, ber immer tiejer in ben weid)en Eumpigrmo einjacte mo morgen woht j(h)on nicht 


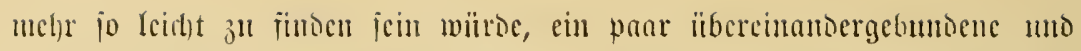

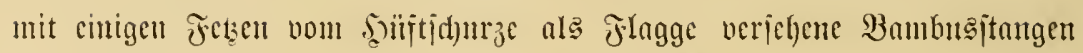
in Den Moorbonen getricben hatten. Tie Schwanzquajte founten fie biejem

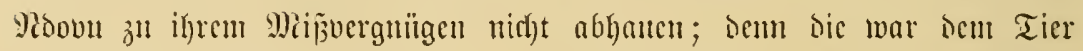
frïher johon abfanden getonmen. "Wabrid)eintidy im Sampi mit cinem Sömen, als her (ETejunt nod) Babu war", meinte Straß̧berger.

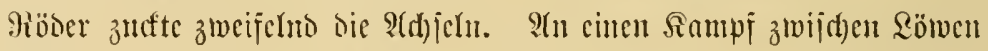

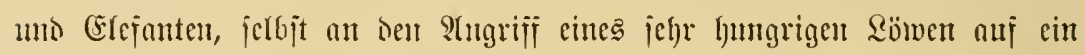

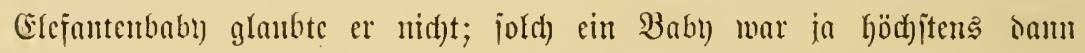

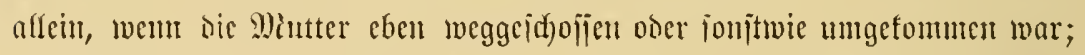
mo wax jie bei nem jungen Tierc, io wagte jid bejtimnt fein Simba

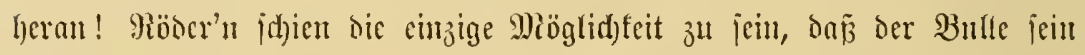

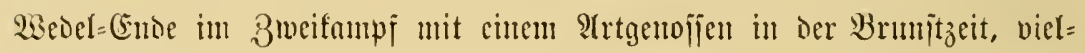

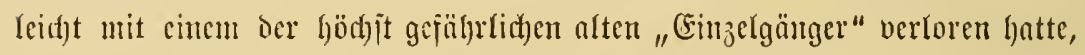

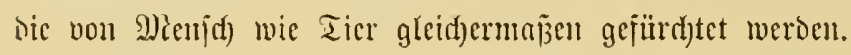

Die Fülyrte ber Secroc zh verfolgen war ein idjlimmes Dintg. Sit bis an bie Brnit janfen dic hinter ben beiten j(d)warzen Jägern gehenden

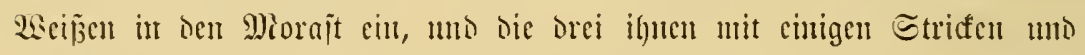

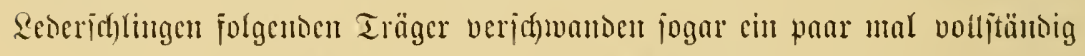

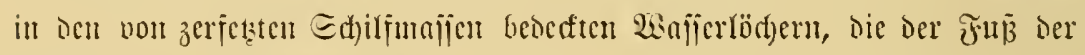

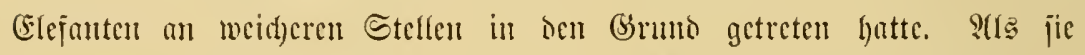
heransgezogen waren, jah)n jic nad) Piöber's ?tusornct "lvie Die Brastenjel"

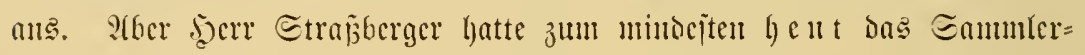

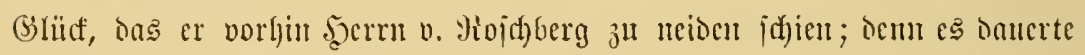

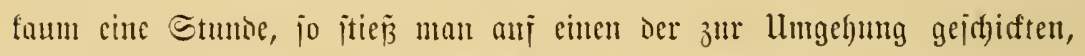

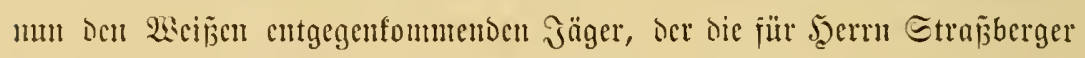

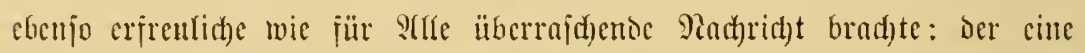

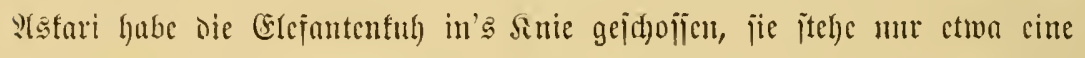
halbe Ctumbe cutifernt vou hier, anf hartem Boden, und das Sialb "reme immer um jie hermm uno toolie die stngreifer verjagen".

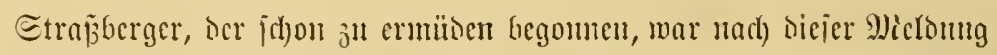
wic eleftrifiert. "Sorwärts, Eente," rici cr ans mo watete mit Fener= cifer weiter, obmohl ifmu bas übelricd)ende Smmpjwajier an den "bejten"

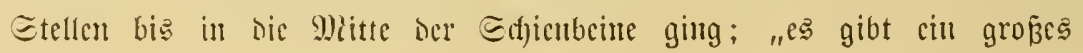




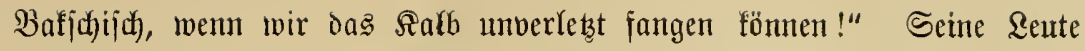
fannten dies Zauberwort des Drients jhon, obwohl es in Jnnerafrifa bisher noch) ungebräuchlich war, benn Straf̧berger felber hatte den Farbigen

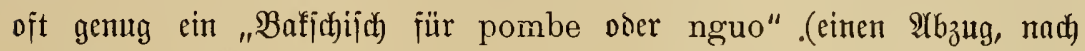
europäifjer $2(r t)$ veriprochen, um jie anzueifern, uno ctliche der Seute

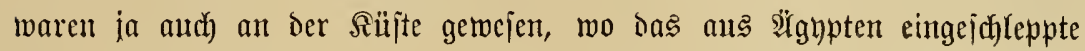
Wort ichon in (Seltung war. (5s tat auth) jebzt icine Wirfung; atre îtapften uno mateten mit größżter Encrgie im Morajt vorlwärts, bis man an eine Bodenfidwelfe ähnlich ber vorigen fau unt borten, unweit einer S)ruppe von vieffecicht fünf ftarten uno cingen jüngeren \&aubbäumen im hohen Rohrgraje den angejchoffenen meiblichen (Elefanten uno bie beiten farbigen' '̧äger nebjt dem $\mathfrak{A}$ sfari jtehen jab.

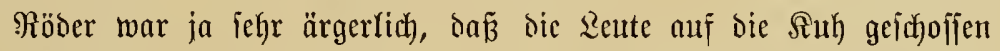

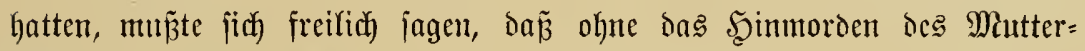

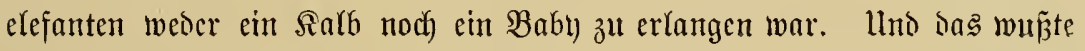

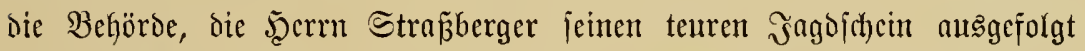
jomie die Erraubnis jum Fang junger Tiere gegebcu hatte, cbenjo gut wie er, jorlte es menigftens miffen! - Şm, die Erlaubnis hatte er;

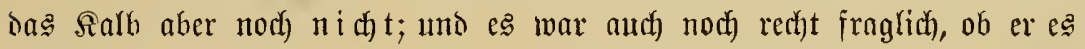
friegen würto! Denn ale es jeţt hinter ber müteno blajenden, mit dem hoch erboben vorgebogenen Rüjfel in bie Ruft greifenten, jonjt aber regungslos jtehen bleibenten Mitter herbor einen förmlichen $2(u \mathfrak{s f a l l}$ auf

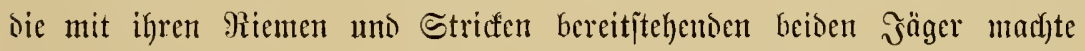

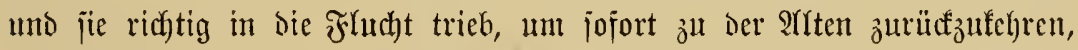

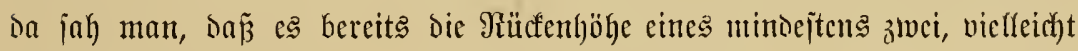

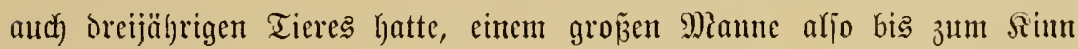

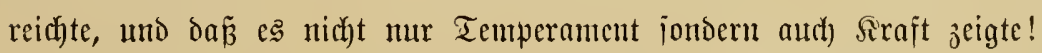

Strap̧berger ging mit ben Farbigen in rejpeftwollem Bogen unt bie

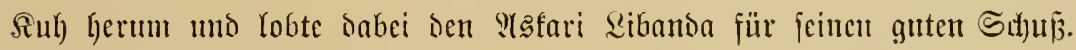

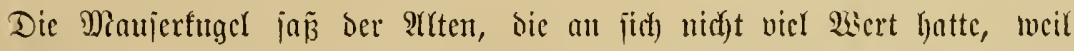

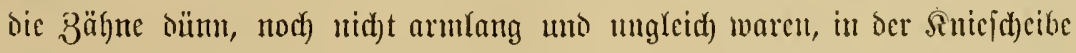

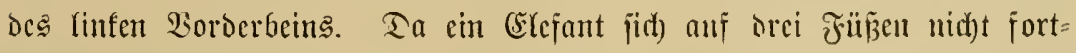

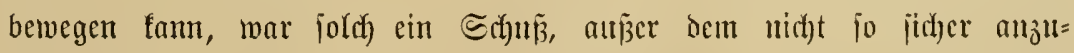

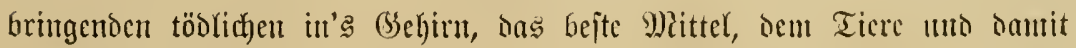




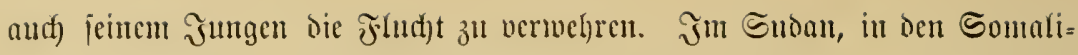

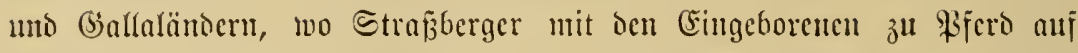

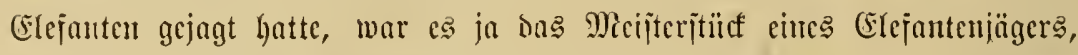
bem Ticre mit Dem Edhlage cines hanridarjen Sdjwertes bie "P(d)illes=

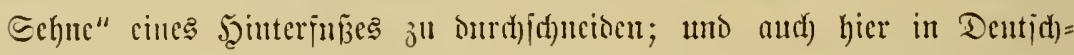

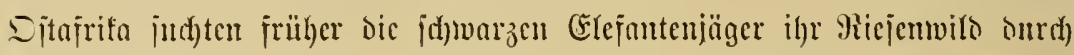

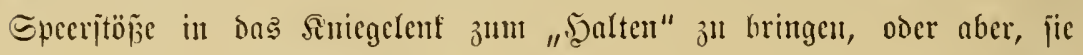

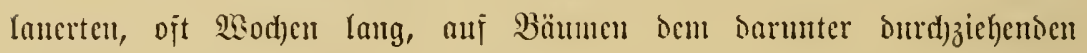

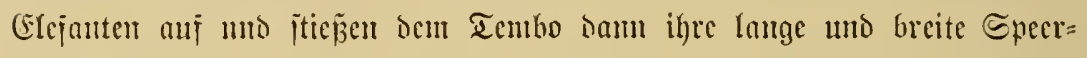

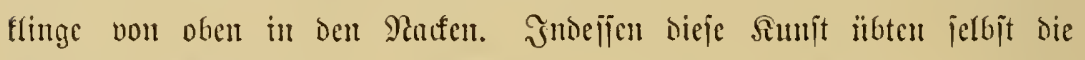
Miatua feit Cinführung ber Fenerwafifen mur nod) felten aus - jie war

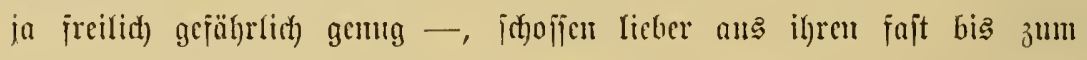

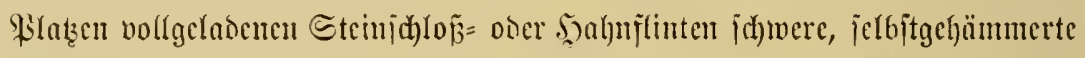

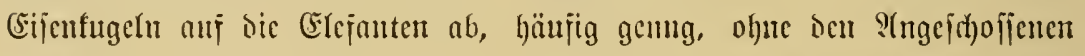
ju crlegen. Eo manther Elejant ging an bicien Dermumomngen nad)

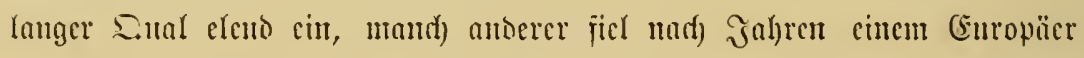

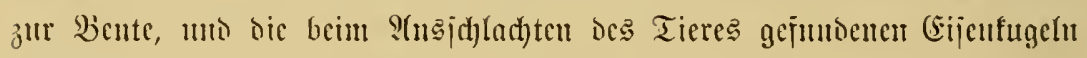

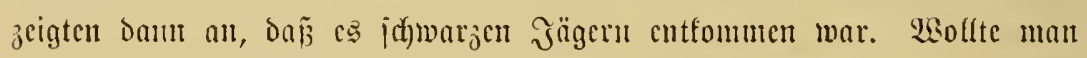
cin Jumges lebendig haben, jo gab es mur jwei $2 \mathfrak{s e g e : ~ e n t w e d e r ~ m a n ~ j u d j t e , ~}$

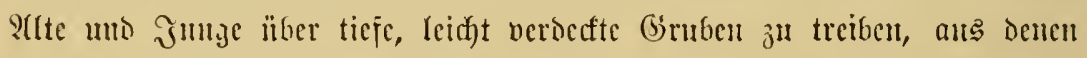
feine S(njtrengung jie wicoser befreien fonnte, oicr man mad)te bic s(tten fampimrjäbjg, ol)ne jie zu töten; Deun bie Miöglidfffeit lag immer nor,

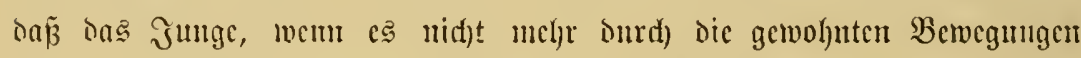

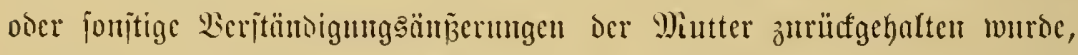

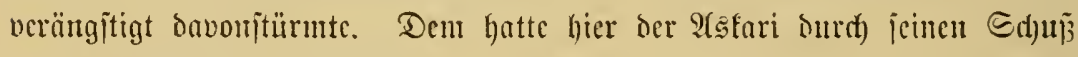

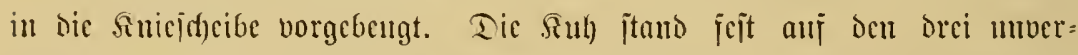

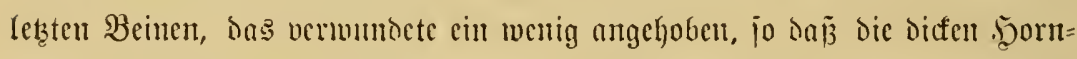

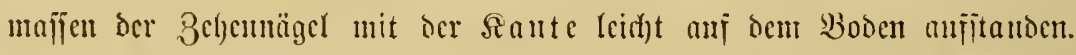

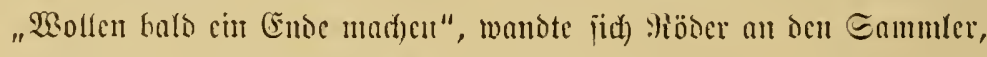

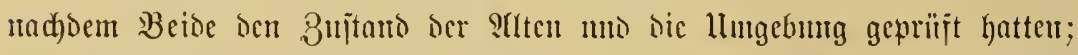

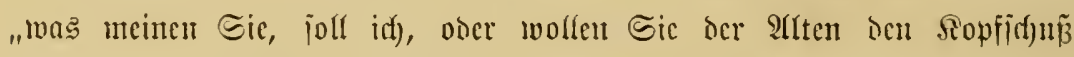

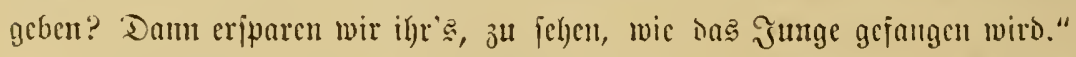

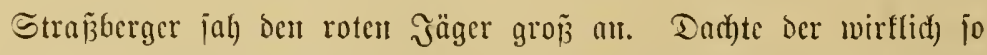

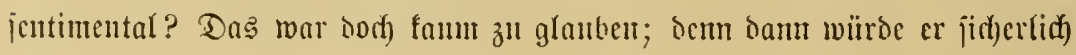


nicht die Jagoerfolge arziclt haben, bie ihm nad) der Berjicherung von

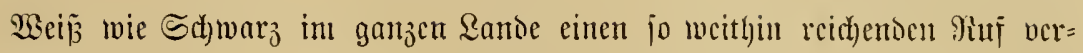

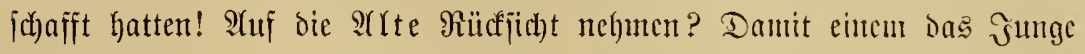

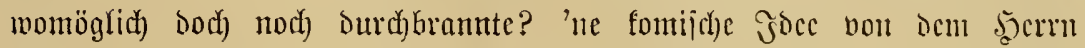

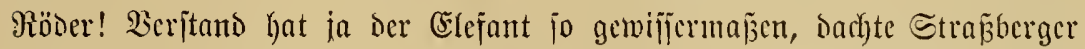

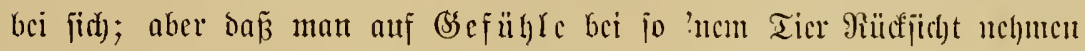

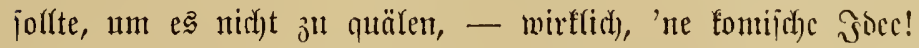

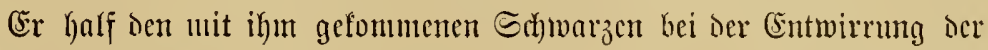

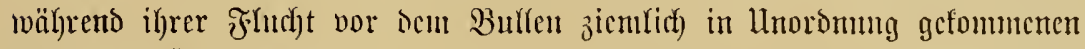

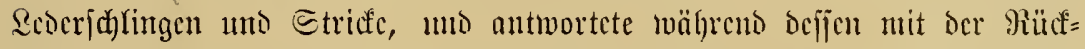
jrage: "Ja, wem foff Der Tembo cigentlich) geljören? Af

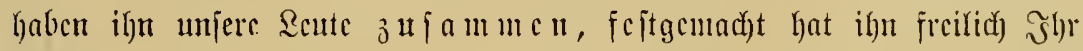
'Tatari. Weoffen wir "Sopf obcr Schrift" gelten lafjen?" (5r jog babci

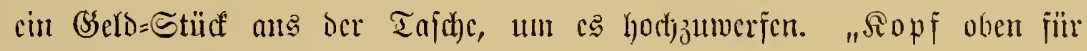

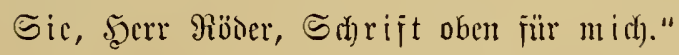

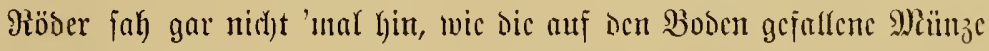
jür ihn cutjchieden hatte. "Gut, gut," murmelte er nut, als Straj̧berger

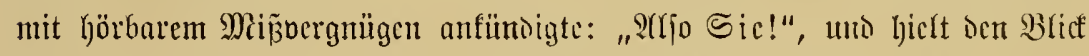
unverwant weiter auf bie beisen Ticre gchcftet. Scket entijichcrte cr bas Ssewehr langam. Seätte Strajberger an ctwas antores ale un jeit

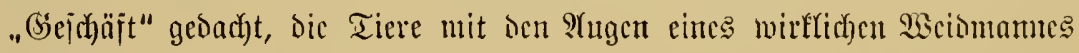

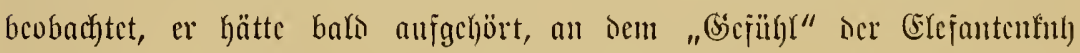

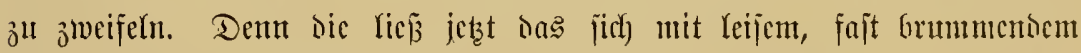

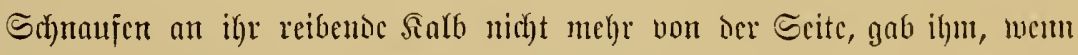

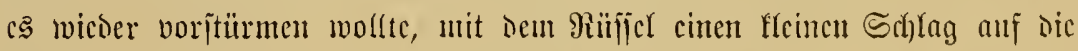

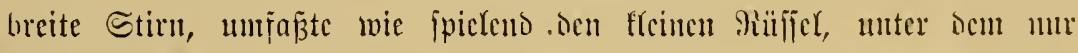

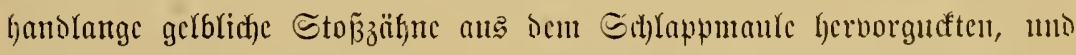

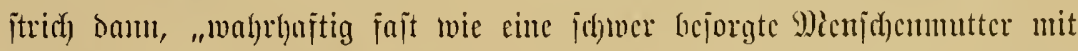

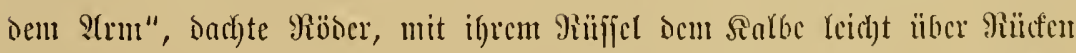

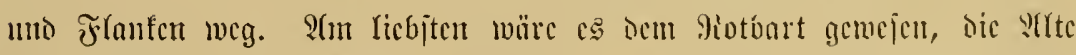

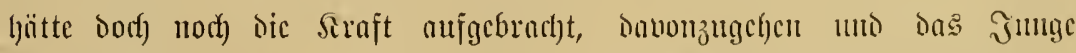

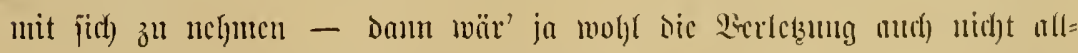

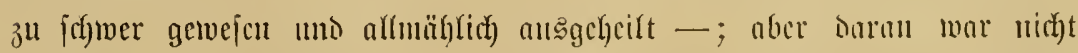

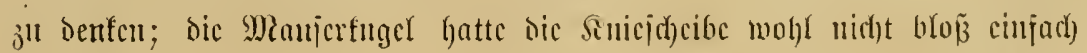


burd)bohrt, jondern zugleid) geiplittert. S(lio möglidfit rajef) ein (Ende marhen; das war in diejem Falle wicter einmal die größ̈te Barmlyerzigfeit!

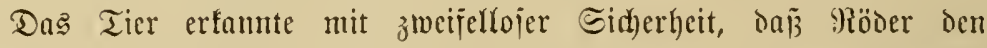
Angrifi vorhatte, obwohl er jidf) nicht rührte, nadfoem er den (semelyrfolben

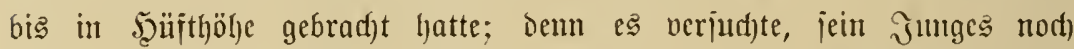
beljer zu decfen als bisher, fonnte das aber bei ieiner Rörperbetwegungs:

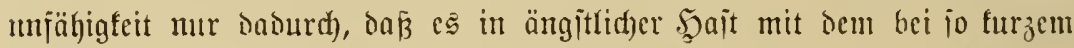

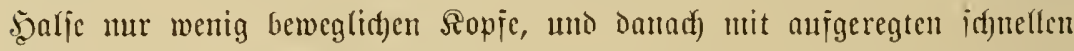

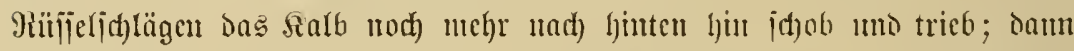

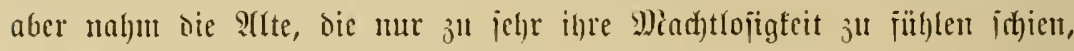
Den fopj nad) der Secite bes Эägers herum uno tat unter wilocm Trompetenton cinten mächtigen (Srifi mit frumm bod)geidhwungencm uno

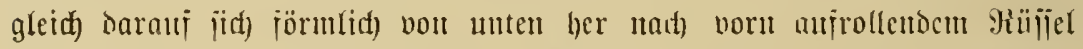

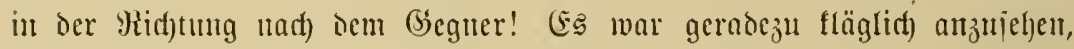
wie das Iier jid) einen siutef gab, jid) norwärts itïrzen soolite tumb

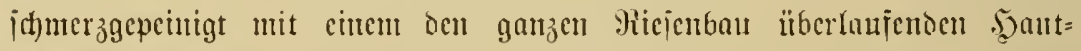

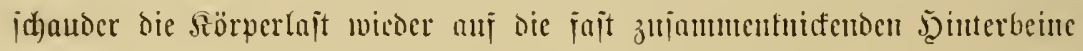

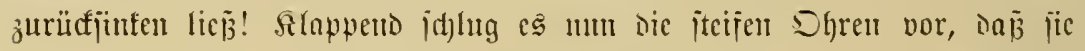
wie Eafirme quer gegen ien turzen Paafen itanten, legte jie ftatichento

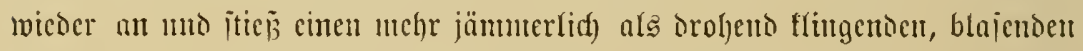

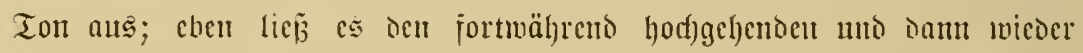

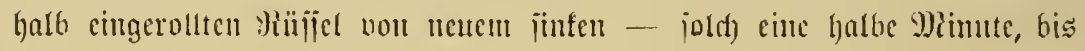

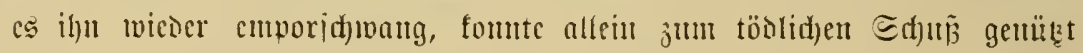
werden - uto Der Fingerjortjal itreifte babei nad) red)te wie lints hin

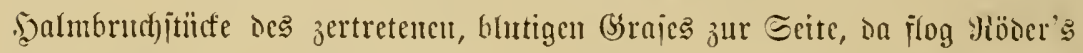

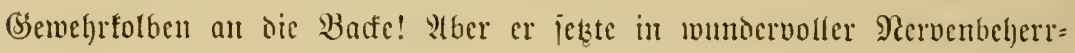
idfung glüctlid)ernveije nod) ab, che er ben Finger anun verhängntiavollen

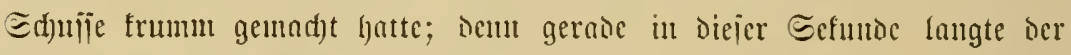

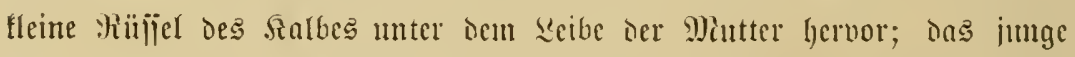
Tier orüben war nienergefniect umb iffien jïd) unter Der Miutter Durd)=

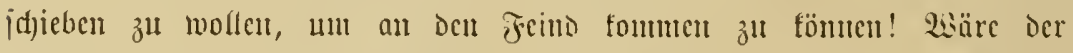
Fotbart nid)t an tas langjame, Icid)te "Durd)jichen" beim S(boriliden

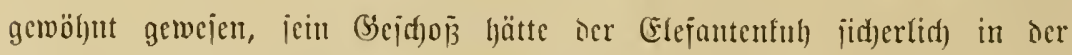

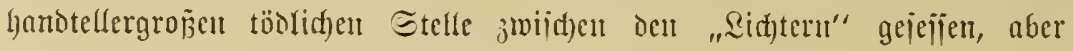




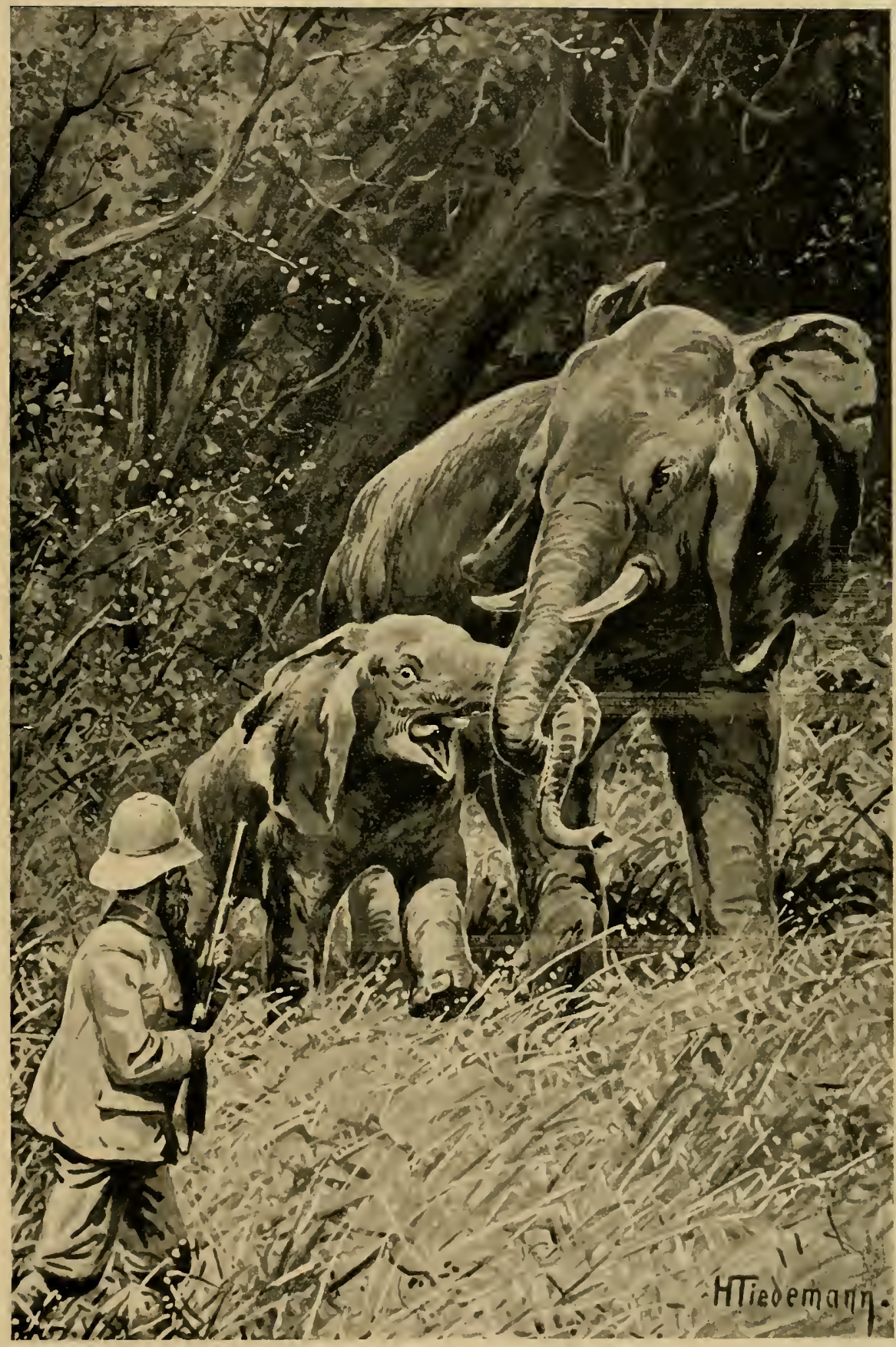

Am lieb[ten wäre es dem Rotbart gewejen, die Alte hätte doch noch) die Kraft aufgebracht, mit dem Jungen davonzugehen.

(Geite 467.) 



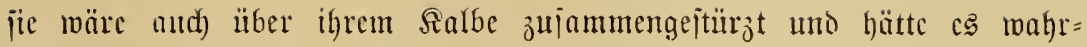
id)einlich totgeorïtft oocr ifm sod) cin pare finochen gebrod)en und es jo für Strap̧berger unbrauchbar gemadht!

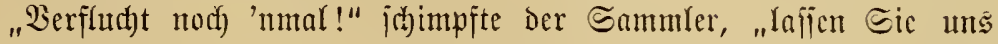

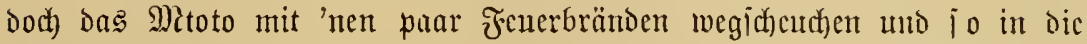

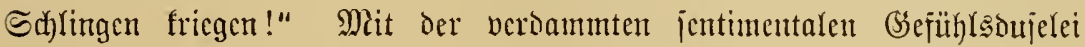
würde der Şerr Röser eineu nod den ganjen Fang verderben!

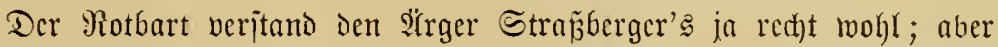
Der Mamn gefiel igm jetzt nidyt mehr jo gut wic früher, nachoen er jein Denfen bejijer fennen gclernt, uno deshalb fümmerte er jid) um bie T(bfirhten

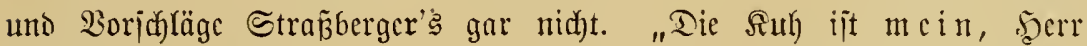

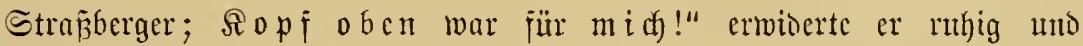

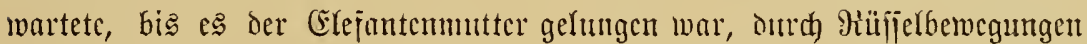
und jeitlidjen Drud des Siörpere, Der jic ungewollt ju offenbar höbj)

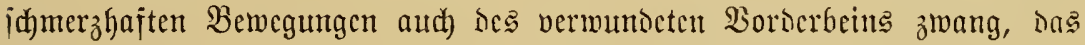
Salb wicber in bie frühcre, mehr gcdecfte Stclfung zurütffubringen. Dorh

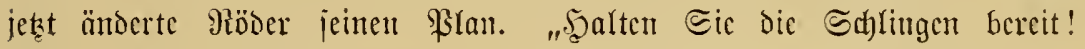

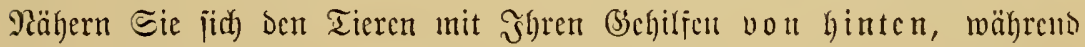

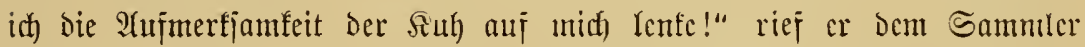

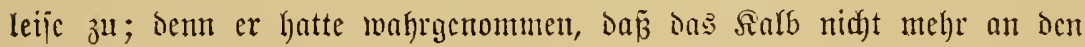
Borderbeinen scr Mutter jtand wic vorbin, jontern mit jcincm Sopje neben

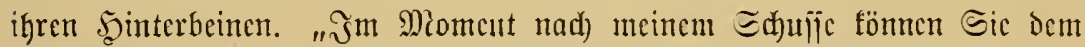

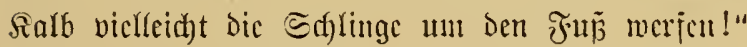

Darauj wartete Der alte Elcjantenjüger Eeju wohl jojon; cr Beutcte

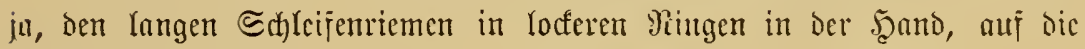
Sinterjeite Dor Ticre.

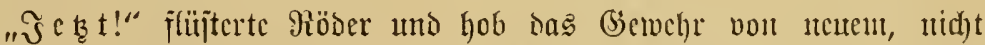
um jojort ju jojiejen, jondern um bic sffte ju bejchäjtigen und jo bas Ulmgehungsmanöbcr Strafjbcrgcr's uno bcr bcioen furbigen Säger ju ermögricten.

Das glücfte; cin paar Minuten .jpäter itanocn Scju, ber antocre

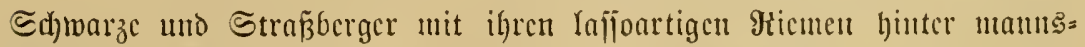

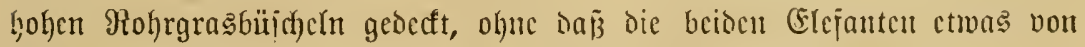
Den Dorbercitungen bicjer neuen (bicguer wah)rgenounuen hatten. 


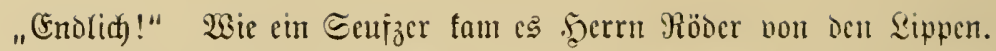
Err legte mit fabelhafter Shntlligfcit an, als die $\mathfrak{U}$ (tte nad) cincm neuen wütenden Blajen oen rüjijel hatte jünfen lajien, blicfte jejt auj dic fleine

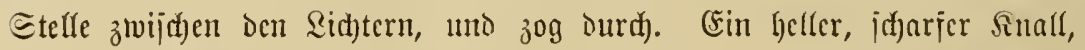

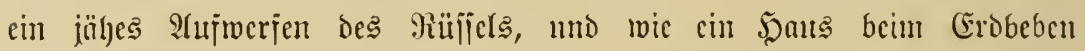

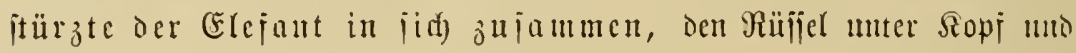
Brnjt begrabent! Ĵn der nämlichen Mimute aber waren હtrap̃berger

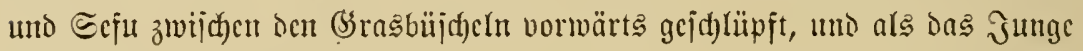

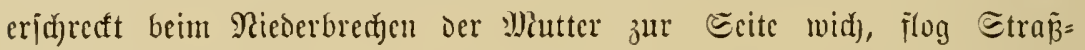
berger's Shlycifenticmen in Lojem Bogen über das jertretene (jras bin, ein

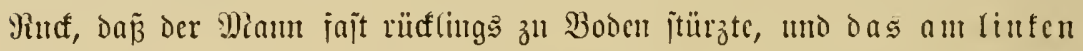

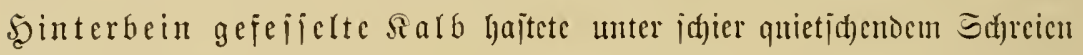
burd) (Sras und Bujdmert babon, Den Eammler, Der jid) das Micuen= ende cin paarmal um den red)ten Unterarm gewunden hatte, mit unbioer=

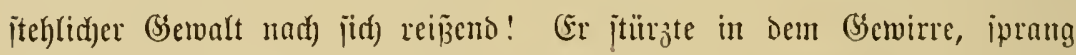

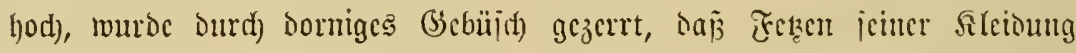

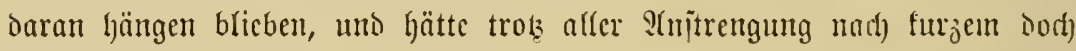

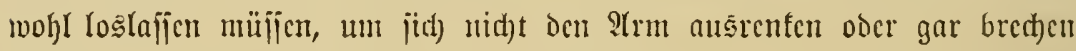

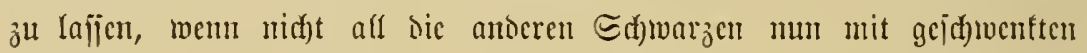
Semehren, Stricfen uno Tüd)crn herbeigcrannt wären, unD ङeju jowie cin

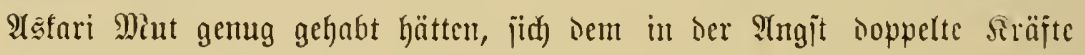

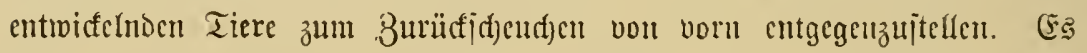
ituz̧te, brach plump zur Ecite auts, itużte wicber vor cincm bod $=$

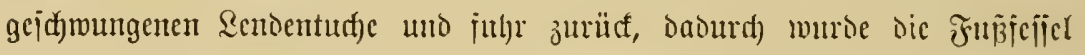

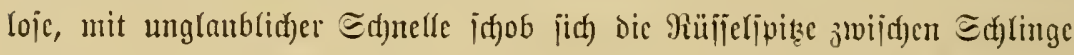

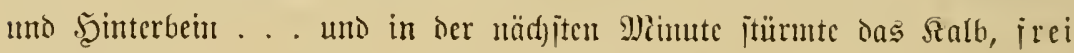
geworden, auj die bciben Farbigen los! Der Igtari iprang jur Ecite;

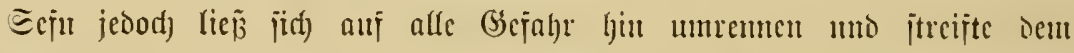

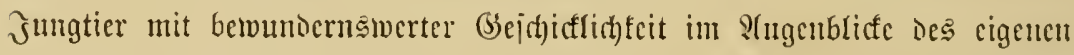

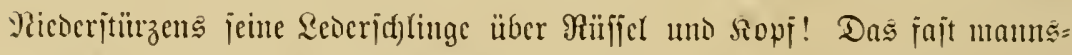

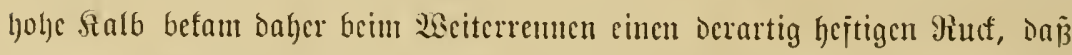

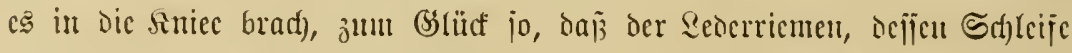
jiich) Ginter Den Dhren jejt jugezogen hatte, แnter Dem förper lag, von vorn bis hinten! (Ége es jid) nod) ganz roieder hodfrappeln tonnte, batten 


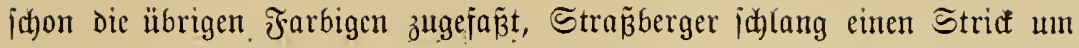
den seib des Tieres, vor deffen Şinterbeinen, und Seju, der wohl alle Sinochen im Rörper ipürte, ichrie fcuchend aus iem (Braje: "llm den $\mathfrak{B a u m}$ binden!", indem cr einem der $\mathfrak{A}$ staris den Srhlingenriemen jurcidte. Der Istari jprang zu dem Baume hin - es ftand hier nutr e in gebüjchumgebente

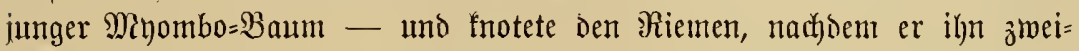

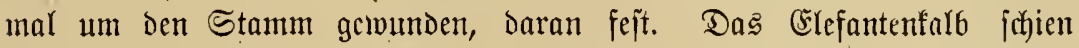

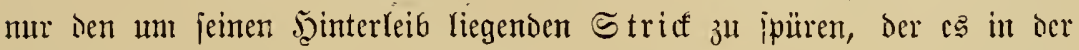
Bcregung aber noch nidgt behinderte; es mad)te zmei furze (Saloppiprünge borwärts, beim britten befam es einen neuen gemaltigen $\Re$ u durch ben

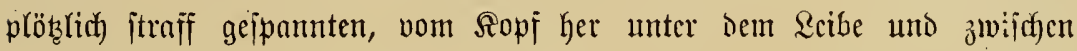

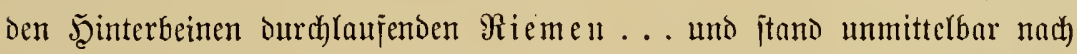

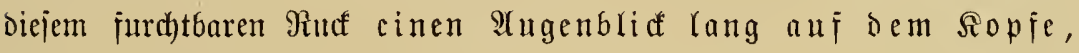
ehe es jeitlings umficl.

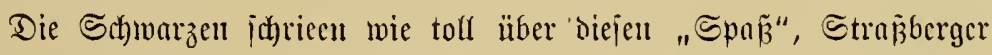

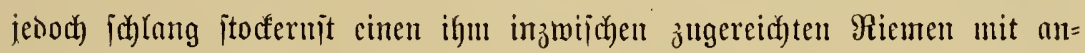

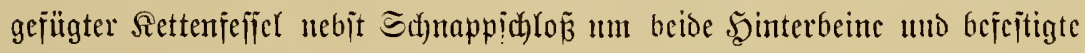
auth Diejen ßiemen an dem Stamme!

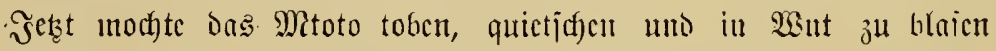

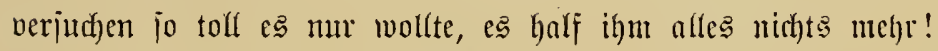

(Es wurbe mul eine Ruhepauje von zwei Stunden gematht, die

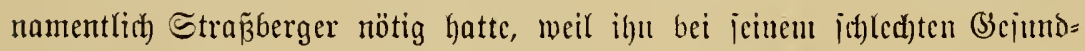

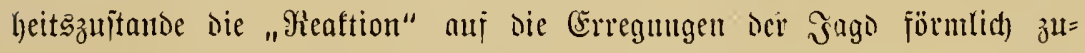

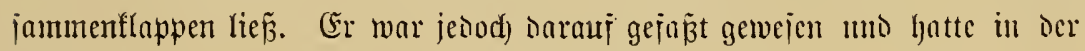
Traglajt oes cinen Miasmes "'n Füllefen Seft" mitnehmen Iafjen. Shau=

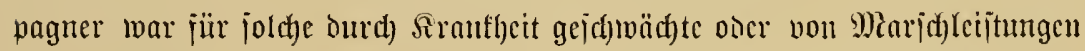

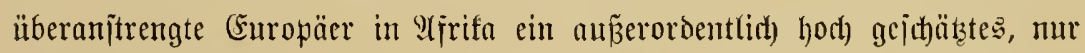
leiber oer hohell Transportfojten wegen nur jelten mitgcïïlytes Stärfungs=

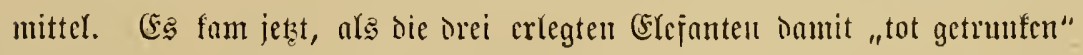

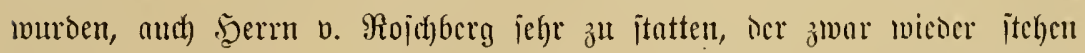
uno gehen founte, jcood) inmer nod) ons (bicfïhl hatte, als jei ihm tein cinziger snodyen im ścibe heil geblieben. Borderlyan mar jomolyl jeiuc

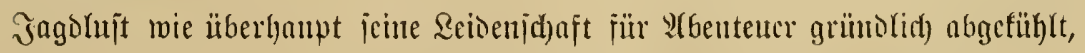

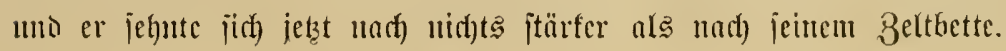


Dazu joflte er inveifen junäd)ît nod) nirht tommen. Die Zeit war

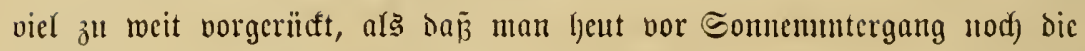
voraujgejandte Sarawane bätte crreichen fömnell, um jo weniger, als Rojdberg mur langjam maridjicren founte; Der Nervend)oc hatte ifn eben

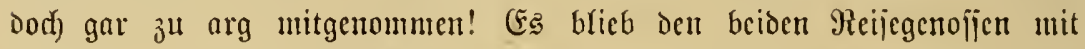
ihrell paar Scuten nidfts S(nocres übrig, afs was nad) längerer Beratung

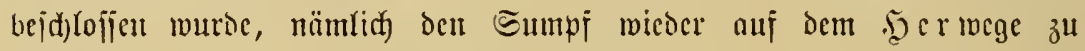

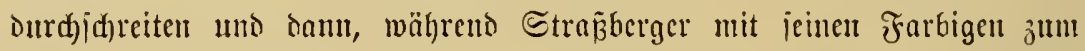
Sager zurïđfmarjujicrte, im ßori unter $\mathfrak{B a ̈ u m e n ~ i m ~ F r e i e n ~ z u ~ n a ̈ đ t i g e n . ~}$ Das war jwar "die bejte Matuer, wieder von neucm cin Fieberthen zu

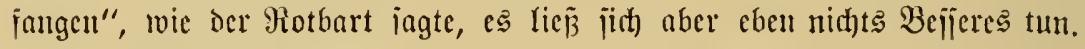

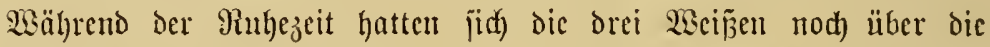

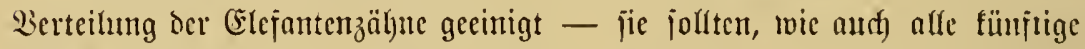

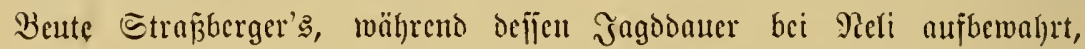
uni nach)her jollten Räber's uno Rojdjberg's Afnteile vou dem Sammler in Miuanza abgegeben werden für jie -, uns mun wurde mit möglidyiter Ext)nelligfeit losmaridjiert, um jo bald als tunlich aus Dem namentlid)

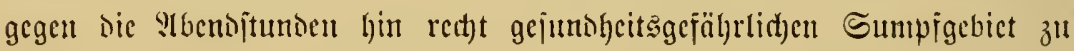
fommen. Miorgen joltte Straß̧berger's, „ganze Sippidyaft" licrherfommen,

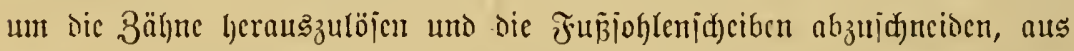

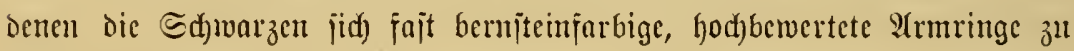

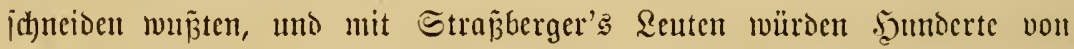

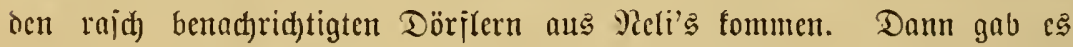

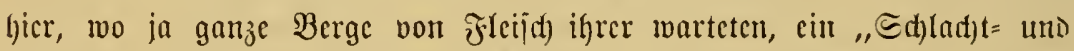

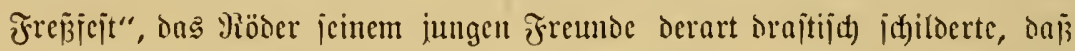

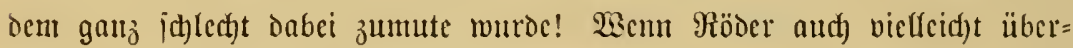
trieb in jeiner @efilocrung: wic Dic Edjwarzen, im Eslejantenleibe jteheno,

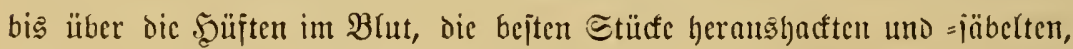

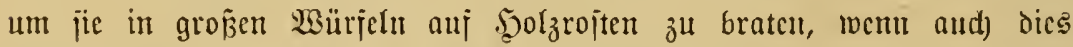
Ricjengemäloe von Blut uno Feuer viclfeidjt injernalijader war als dic

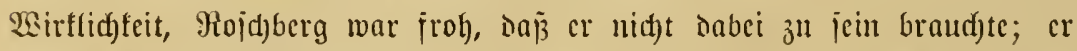

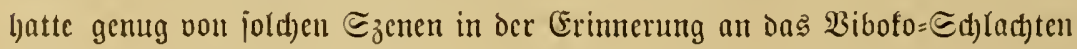
am Miani baribi! 
Beim 3ujammenbinden ber Sachen waren dem jungen (Furopäer aud) Die Doppellajten mit den veridhraubbaren Cifenitngen wieder zu Bsejidyt gefommen, uo' er hatte gefragt, mozu bie bienten? - Daraus würde eiu Iransportfäfig zulanmengejtelft, war die SYntwort Strap̧berger's gerwejen.

",Ath jo, ba foll bem wohl der junge Elefant hincin?"

Troţdem es bem Sammler auch nach oer Stärfung durch drei (ssläjer Seft nod immer mijerabel ging, hatte er laut aujgelacht. ,Niein;

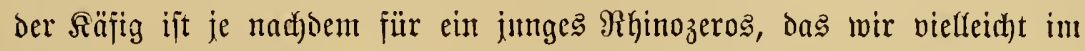
Fori an der Sumpfgrenze erwijhen, oder nber für einen jungen Sdjim=

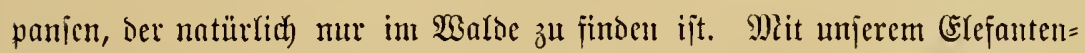
fälfchten haben wir zum (šlüaf viel weniger Mähe."

Ulno fo zeigte jidf's aud beim Ulbmurich. Das itarf ermüncte

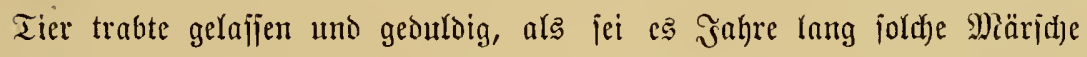
jwijchen Menichen gemohnt, hinter ben farbigen Эägern uno vor Şerrn

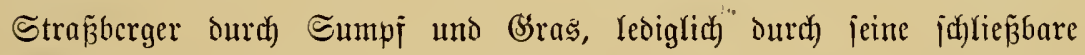

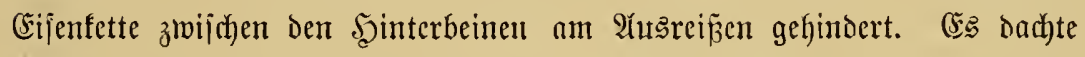

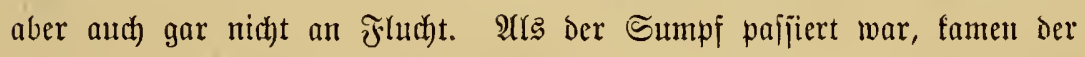

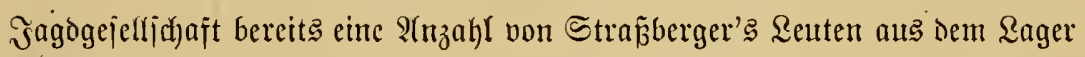
entgegen, begiérig zu hören, ob, „biel Fleijch gejchoijen" jei, uno ciner von diejen Enwarzen hatte in ther Erwartung eines Fanges cin bicfes Büntel des bei Neli's verjud)sweije angebauten 3urferrol)res mitgebrad)t. Bon

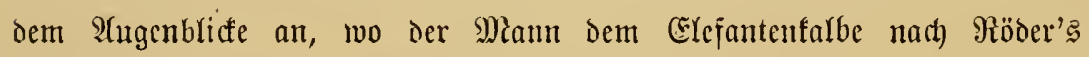

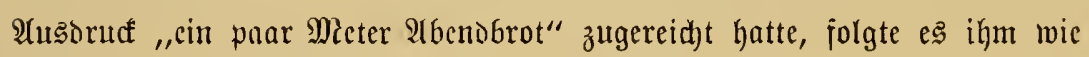
ein Şund jeinem ફ̧errn!

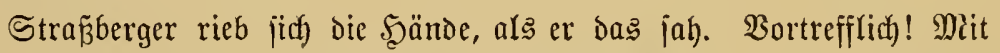

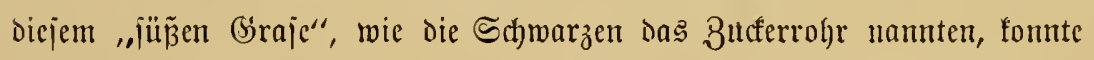
cr das Tiei päter bis an Den Dampjer und auf bie Bahn fricgen, ohne

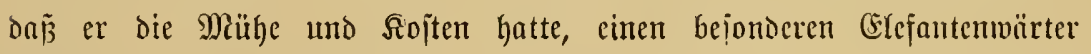
anzuxernen und mitzunefnen! Uno obgleich) er jidt) immer soadectiger auj

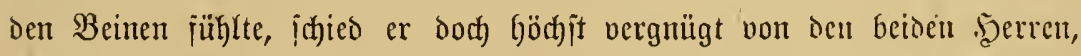
bie eben unter einer Sryirmafajie cine fleine Dornboma jut Sidferbei

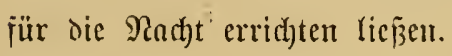

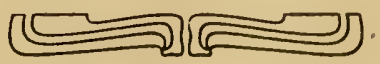




\section{Siebzehntes Kapitel.}

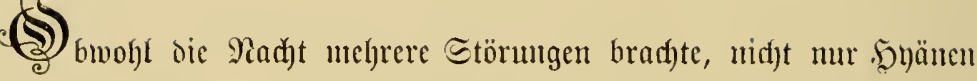

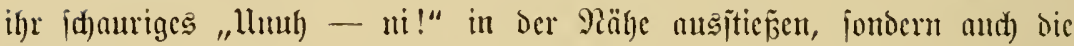

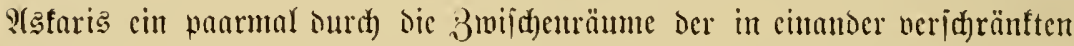
Dornäjte ber Boma nū einen bas fleine Eager mufreijenton, zแแ Brlürf

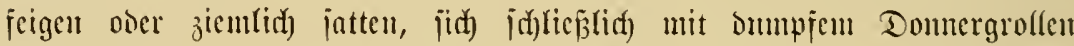

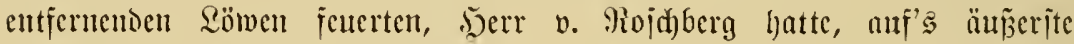

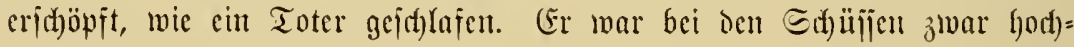

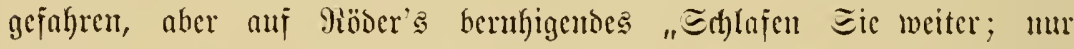

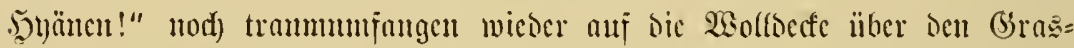

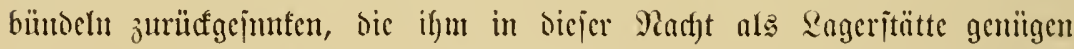
muñten. In cine jweite Deffe hatte er jid) io jeit wie möglich ein=

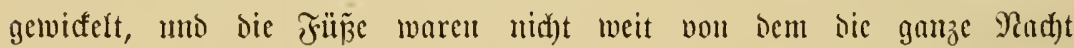
unterfaltenen Feuer entjernt gewejes. Demtod) jühlte er jid) am Miorgen

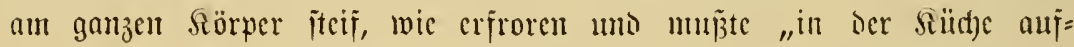

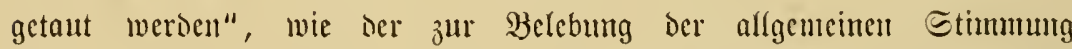
immer joberzbercite Rotbart jagte. Die armen Farbigen besurften Des "S(liftauens" in nod) jtärferem (Grade. Sie hatten jidh ju, abgejehen von

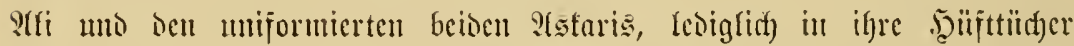

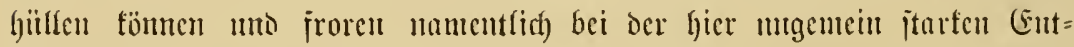

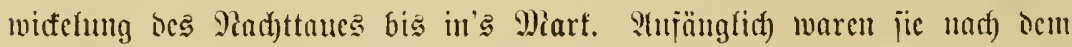

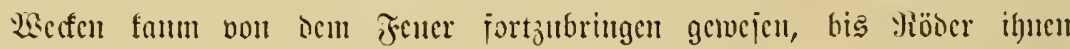

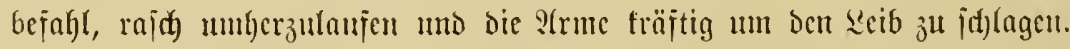

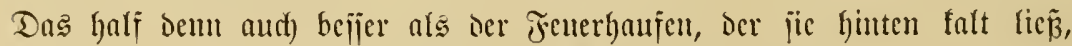
wäbrento er jie vorn jojier röittete! - Snjtatt bes Saffecs gab es in ber 


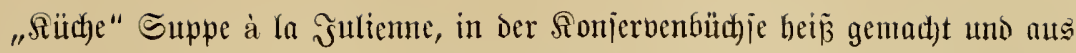
ihr gegefien. Denn weder andere Borräte als bie füt das geitrige Jago=

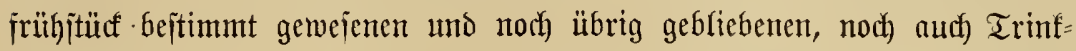

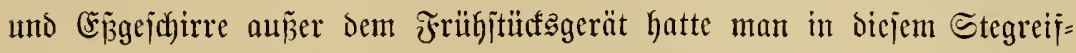
lager. Was abcr dos Bedenflidyjte war, es fchlte nahez̆ an wajfier.

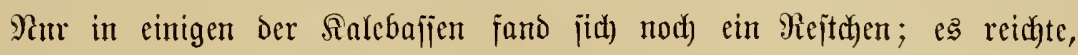

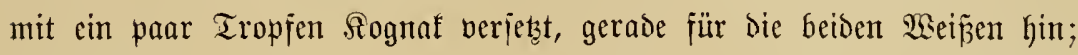

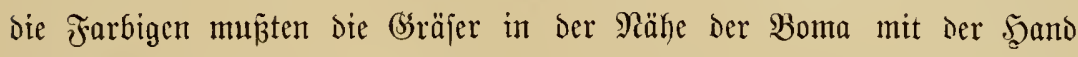

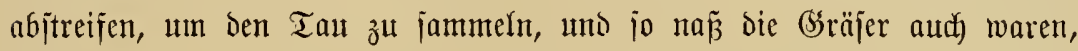

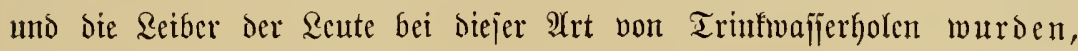

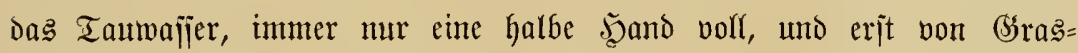

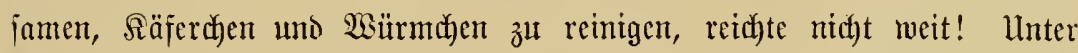

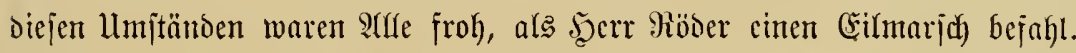
Se eher man bie nach ber Mara=₹urt voraufgejujicte Raramane erreichte, dejto bejīer für Reib und Seele! Allerbings, bic Seelen ber Farbigen waren mit biejer Bemerfung Des Rotbarts nidjt gerade gemeint. Er

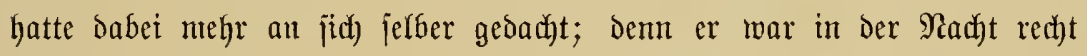
unrufig gewejen über das Tun uno Treiben jeiner inz̧wijden ohne "weižen Sberbefehl“ verbliebenen Expedition. Zwar, auf den alten

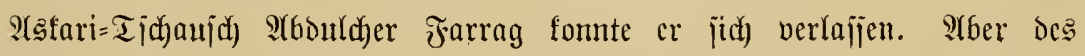
neuen Ober=Mnyampara Mioigo war cr noch nid)t jo jict)er! Unto vielfeidyt Gatte es jwifchen diejen beisen gar eine Pítwarität gegeben, wie bas doch

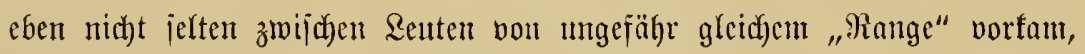

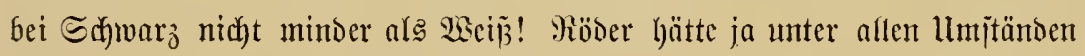

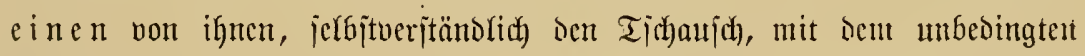

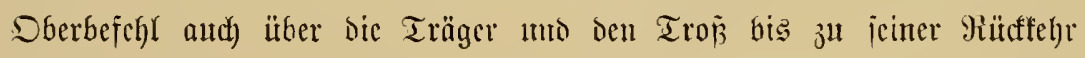
betraut, wenn or nichyt jitfyer gewejen wäre, am jelben atbent bei ser

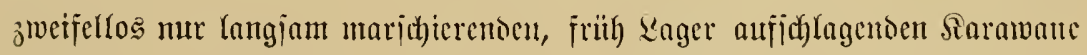

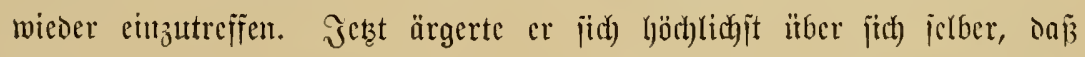

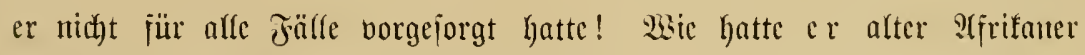

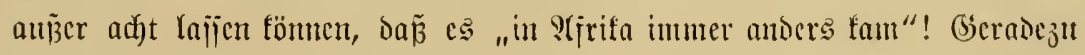

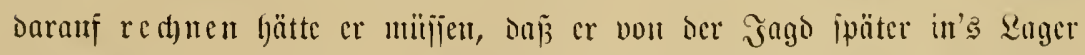
zurücffebrte, als geplant! Entweocr ipäter, oocr ganj ohnte Ergebnis; Das war ja bod) intmer jo! 
(are war audf) in bejug auf Den bejten jetzt cinjulid)lagentoen "Weg"

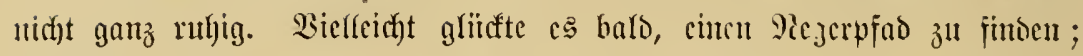

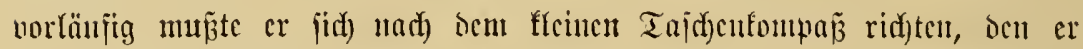

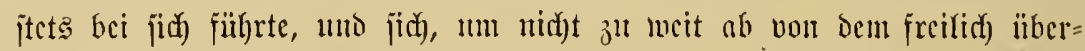

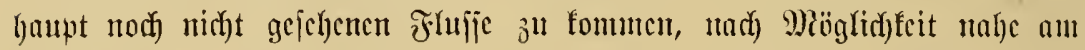

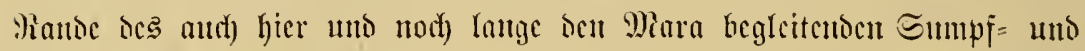

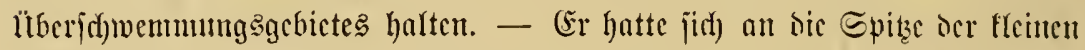

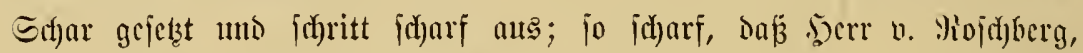

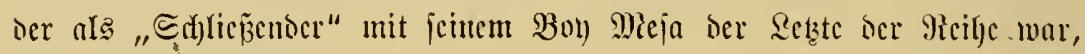

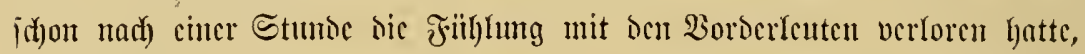

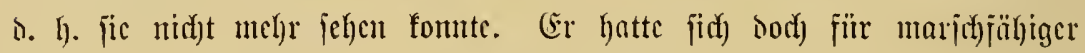

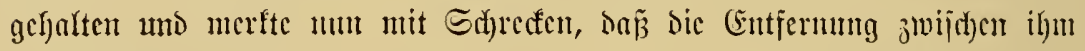

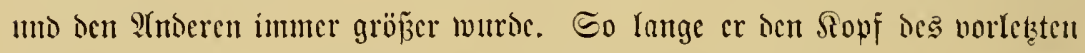
Trägers mit ocr zujammengejd)mürten flemen Rajt nod) ljer umo ba über

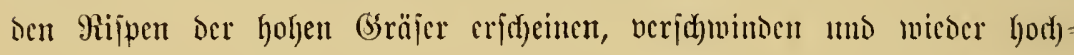

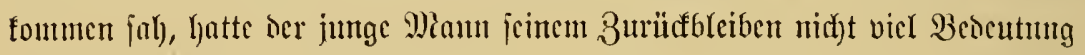

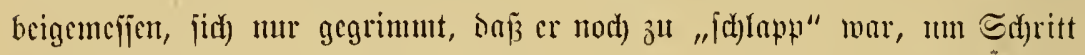

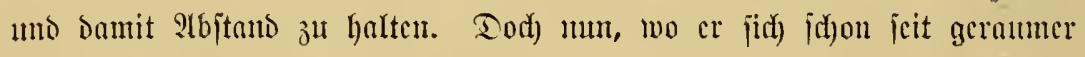

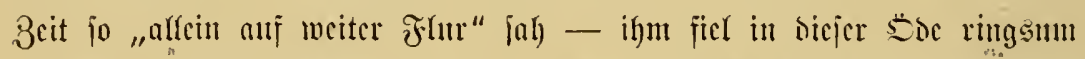

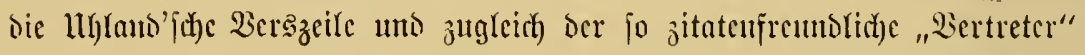
Des in Muanza in fodwerer Sorge anj 9radbridgt ïber (Erfolg ober Midy)t=

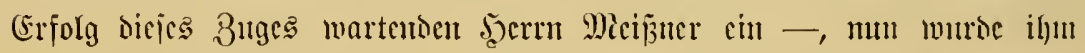

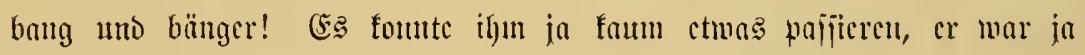
gut bewafifuet! Llub bod) unt bod)!

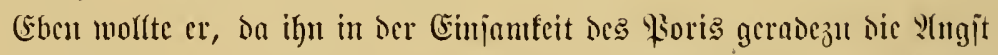

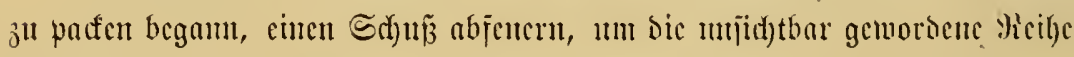

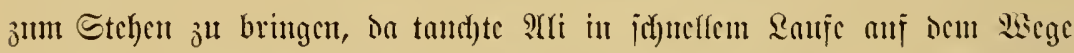

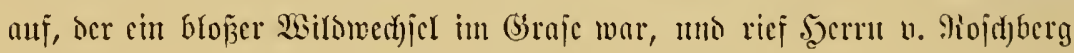

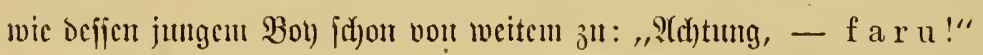

Eridgrocten blicben bie Beioen itehen uno jahen jidf) rajch nad alfen

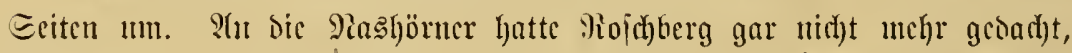

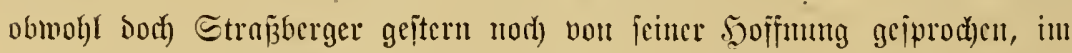
Fori am Sumpjranie jum Fange cincs jungen kifaru ju fommen. Den Icufel aud), wenn (Einem jold llugetïm lier entgegcuîtitumte! 


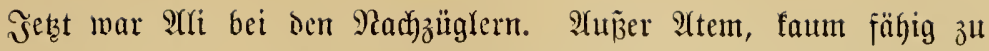

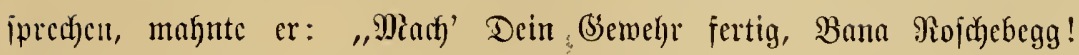
3mei firu jino eben bicht an uns vorbeigefommen!"

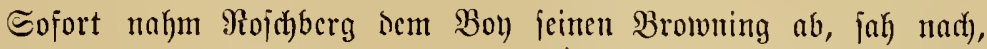

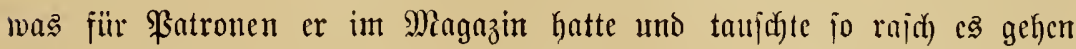

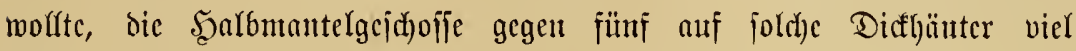

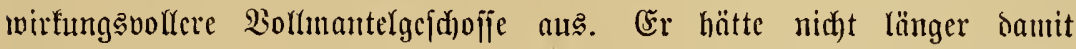
jüumen bürfen, benu eben wie er fertig war, mad)te 9 Ali einen märbtigen Saz zur Seite - Mieja uno ber junge Ermopäer tuten ganz unwilfürrlich)

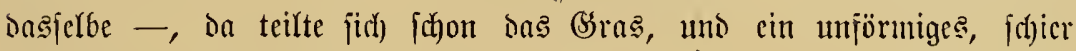
vorjintf(utlich ausjefentes gepanjertes Ungcheucr mit zwei hintereinamocr= jitzenden ungleichon Säbelyörnem vorn auf bem gemaltigen fopje trabte

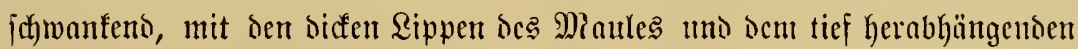
Scibe faft über Den Boden ichleifeno auf bic Stclfe ju, wo eben noch) bie

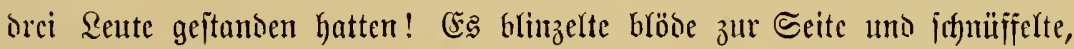

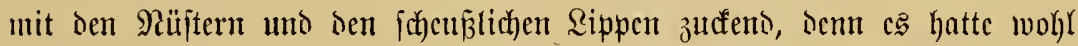

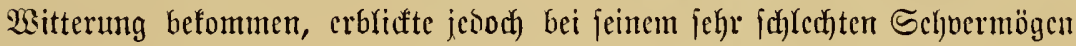

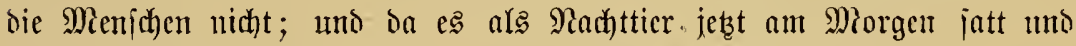

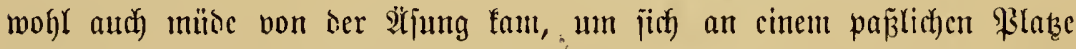
eine (5romanne zur Tagesrube zu wählen, fo war es nickt eben angriffes= lujtig. Mit auf uno ab jofwanfentom Sopfe, uno jo gctajien, als ob cs jede, (Siefahr verad)te, trottete cs unter leijent (birunzen bahin.

$\mathfrak{A}(\mathfrak{E}$ es zeth bis zmölf Mieter vorüber war, fliijterte 9 (rfi, bcr bie

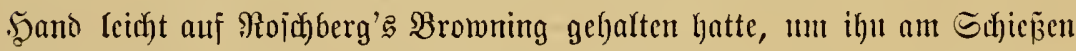
3" verhindern: „Kweli, kama sultani (mahrhaftig, ganz wie cin Sultan)!“, uno Dieja grinite, icm plump=würdevofl meitertrottenden Faru nachblicfend: "Kweli, kweli, ftolz uns bumm wie cin Sultan!" Sifanbar maten

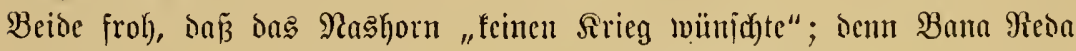

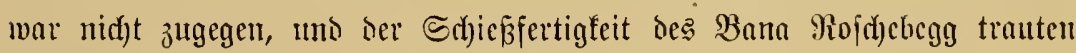
jie bod) nidht fo ganz.

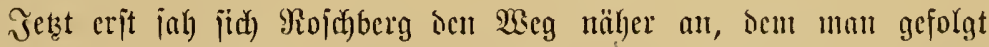

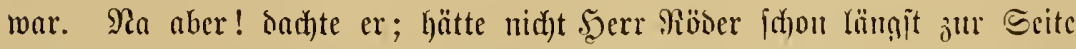

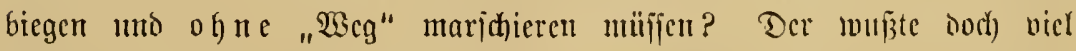

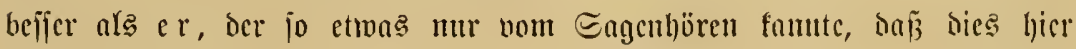




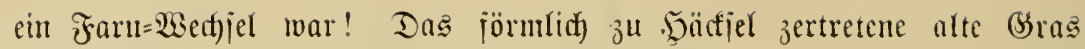
auf hem :

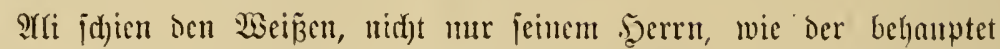

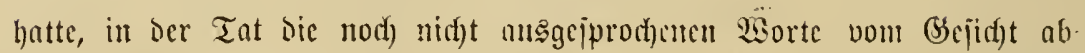

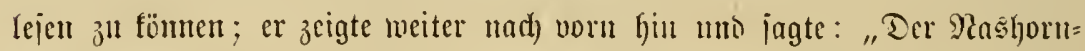
meg war jajon geitorben (vom jungen (Braje wieder überwad)jen), und bic

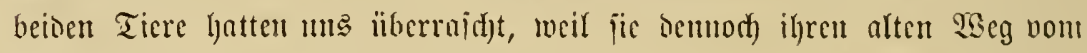
Wajīer her wiener aufgenoumen hatten."

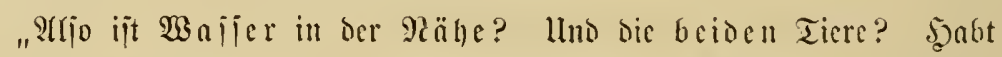

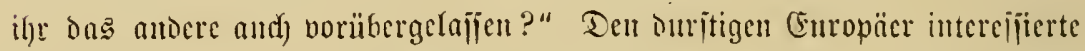

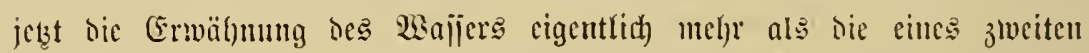

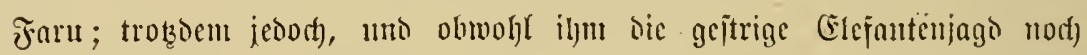

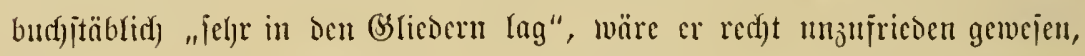
wenn er nid)t mur diejes einc io plötzlid zum Borjd)ein gefommente

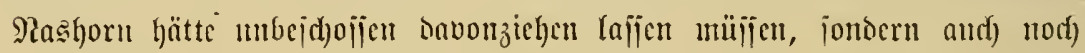
ein jueites. "MEo i jt bas Tier?" Fragte er munttelbar hinterber.

"B̉nun Reda ijt babei, es ju itellen!"

"Danut vorwärte!"

Eine Diertclitunde eiligiten Minrid)es, uns die idjon jeit längerer 3eit wegen Ber Begegnumg mit den Farte haltmadhenden Rente twarell

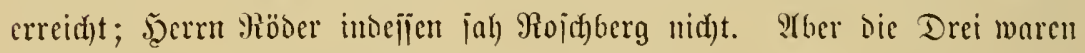
faum bei oen untulyig ausjpähenoen Farbigen autgefoumen, jo tentete ber cinc

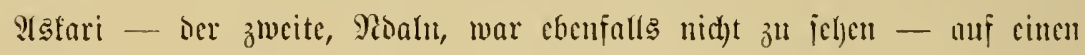

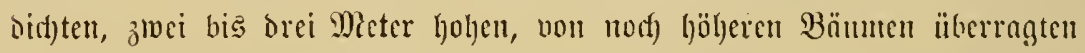
"Bujal, vor bem jïf) ein alter, zacfiger, zum Icil von wegeriffartigem

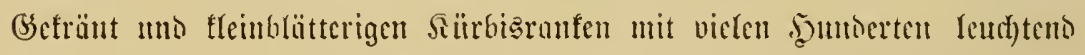

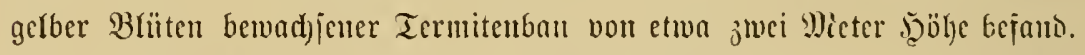

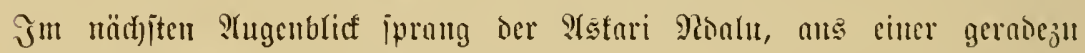

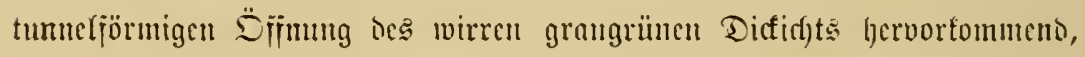
auf̃ den Fuj oes Termitenlyaujens unt id)rie herüber: "Angalia (anjpajien)!

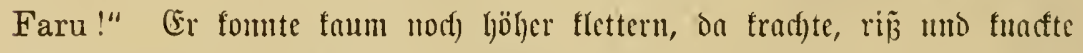

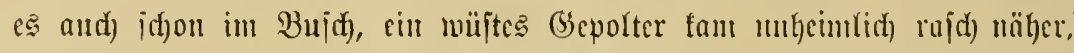

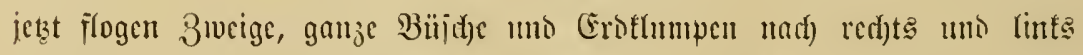

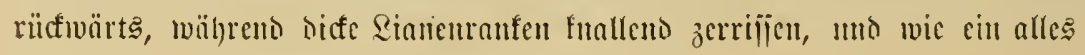




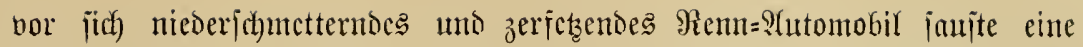
lange dunfelgraue Mafje in's Freic, im Bogen um ben Termitenbau

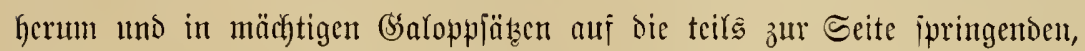
teils entietzt, offencuen Mannos itehen breibenten Sdymarzen zu! Sn ter jerhen Minute jesoch idjon hatte Rojuberg fein (Selwehr an bie Badfe geriffen: ein jofarfer Suall, Sutgelichlag auj bic breite Brujt bes Tieres, bröhnento mie ein \$anfenichlag, . . . aber bas Paghorn rajte, hier $\mathfrak{B} u[$ d)= gefräut unt crose mit dem Borderyorne aujpflügend, Dort Bsrasbüichel mit

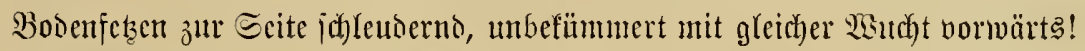
Crin zweitcr Schup! Der Ropf bes bösartig grumzenten Tieres flog mit

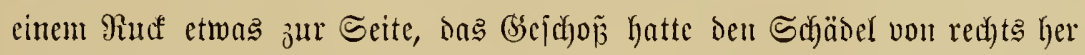

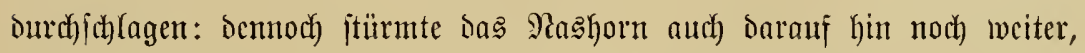
nur jez̧t auf einen ber bciden enolidy in Bewegnng gefommenen, jobreiento

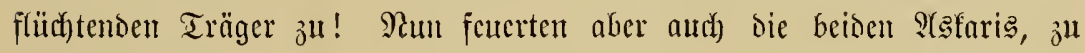

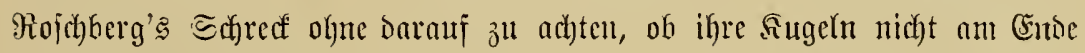
bie flichenden Reute amitatt des Faruts träfen, uno gleich banach tuuchte Der Rotbart aus dem grünen Tumel auj - jo ftarf hinfent, daz er mur mit Mïhe bis an ocn Termitenlyaufen fam.

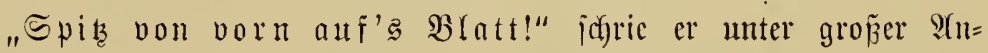

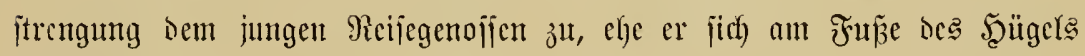

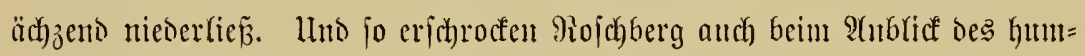

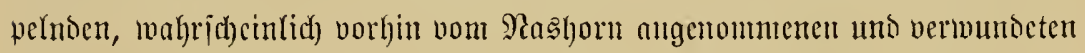

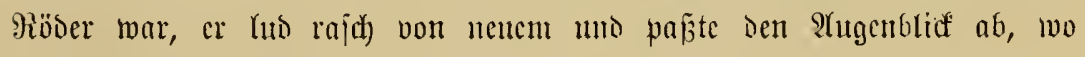

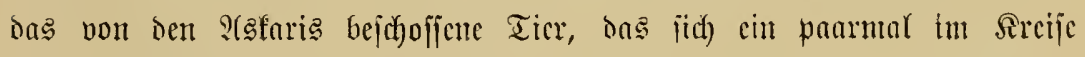

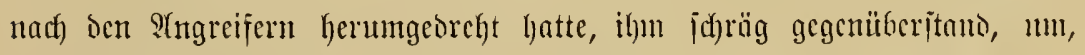

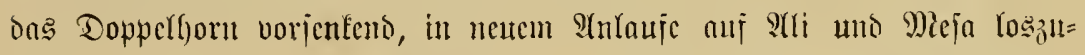

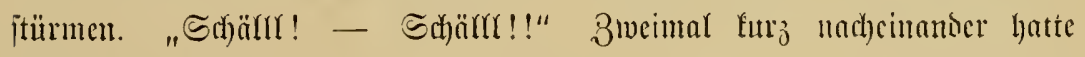

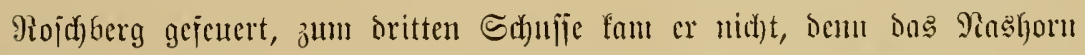

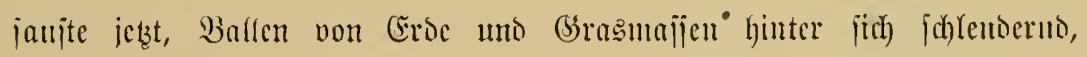

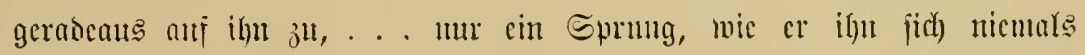

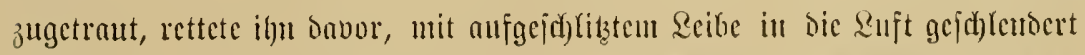

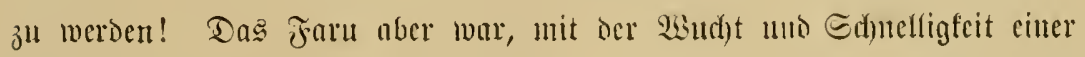

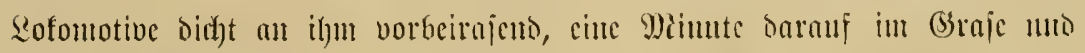
miederen (sebiilidh verichummincu. 
"Sctade", brummte Rojuberg, als er $\mathfrak{A t e m}$ holen tonnte; "bie .̉örner lätte id gern gehabt."

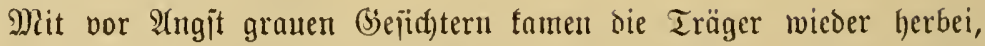

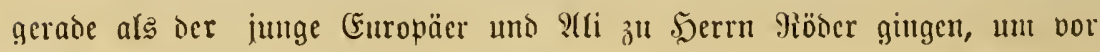

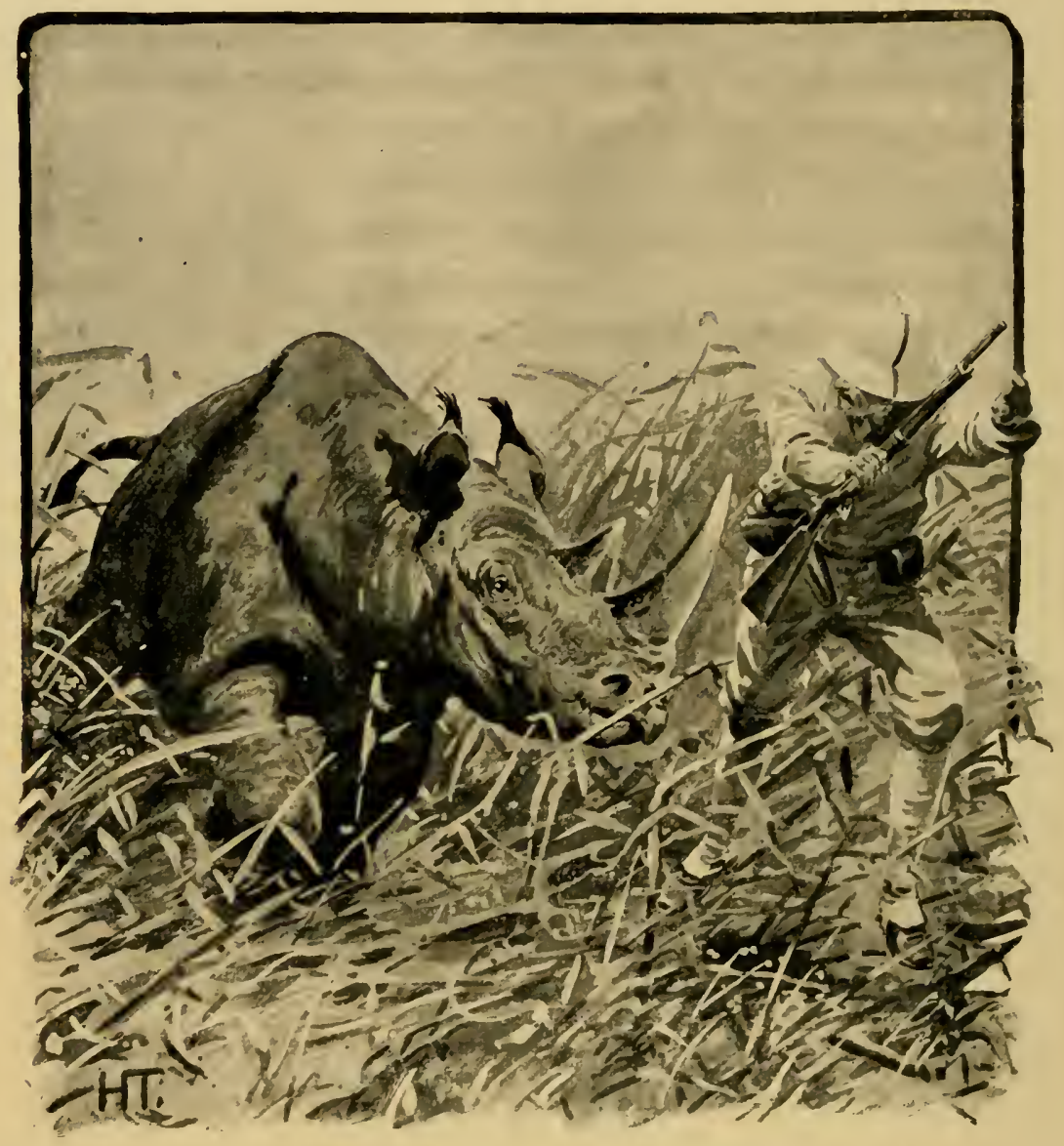

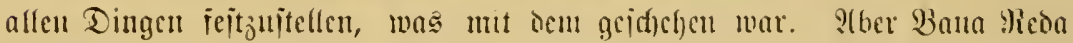

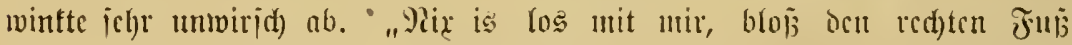
hab' id) mir verfuacfit - an, Donterwetter noct)'n mal! - mun mirt uns aud) wohl bas jue ite Rashorn nod) onvongchen!"

Da riej der cinc ber beiden ?(staris, bie gebünt ter jiemtid) beut= lichen ङ(t)weip̈ipur des ja bieljad) vermmtieten Tieres nad)gegangen waren, plöbslict) frendigen Tontes cin paar Warte herüber, von denen Pojdjberg 


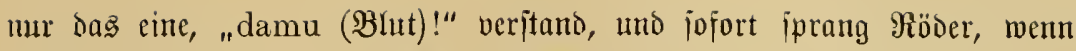
audi) mit einem Sdymerzenslant, von bem Iermitenhügel auf.

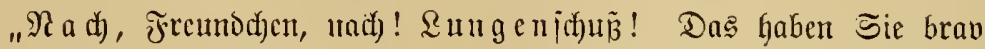
gemarht! Damit fann es wohl j(c)werlith weit fommen!" Uno er humpelte

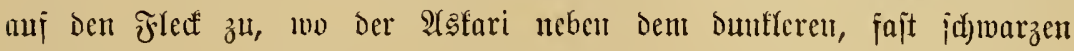
Blute dic helle, Bläşchen zeigende Blutipur gefunden hatte. Sie zeigte in bem nicoergeramten Braje erît mur wenige Tropien, dann aber fanden

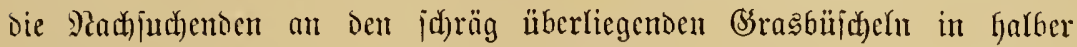
Pashornhöhe cinen breiten hellroten Streifen, ullo nad) ciner Folge

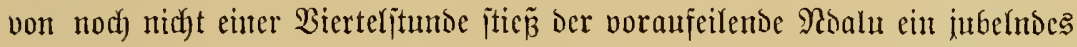
"hapa hier ijt's)!" aus: bereits verentet lag das mächtige will halb auf Dem Reibe, halb auf der Seite!

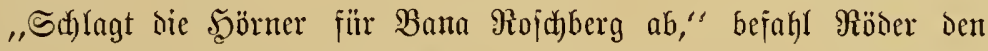

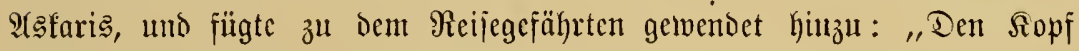
abzulöjen wä̈rde ihnen mit Dem Seitengemehr bod) wohl etwas jaber fallen.

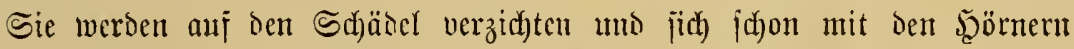
allein begnügen mü̈fîen für diesmal, licber Freund!"

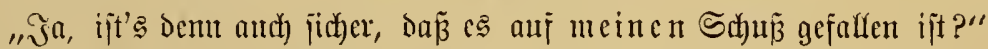

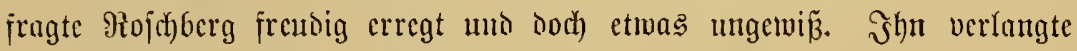
ja oringent nad) biejer wertwollen Trophäe; aber ment das Fart aut

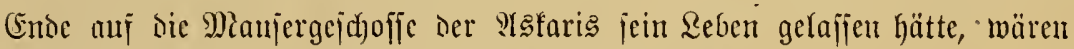

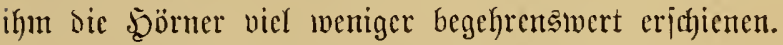

"Da fehen Sic her: Sie haben von vorn jpitz auj's Blatt gehalten,

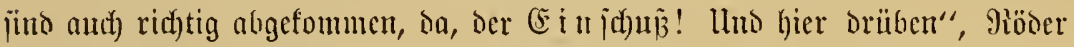

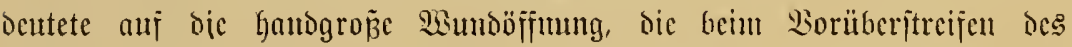

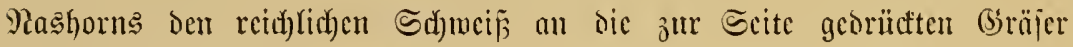

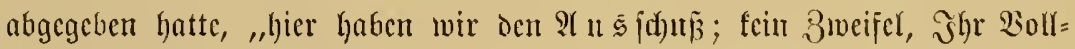

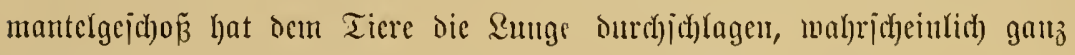

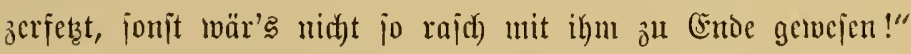

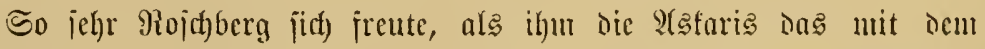

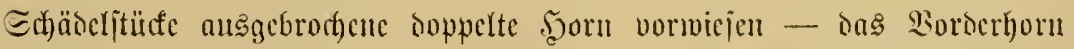
hatte ja cinc Seänge vou mehr als cinem halben Mieter! - jein D ur it

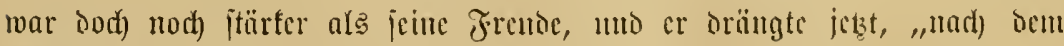
Sisafjer ztl geheu, vou dem bie beinen Tiere getomunen". 
Dod) are man mit vicler Müh) ocu Esed)jel jurïtfuerfolgt hatte,

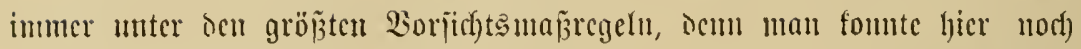

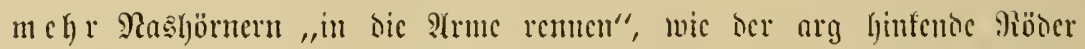

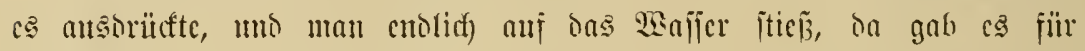

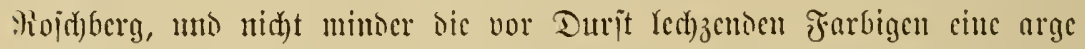

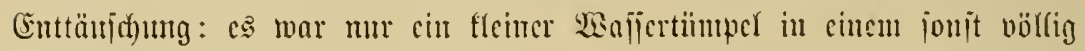

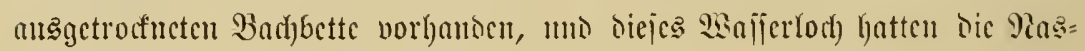

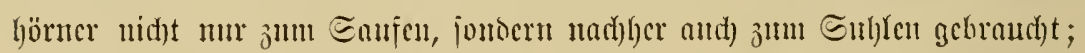

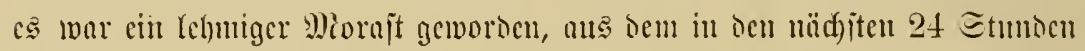

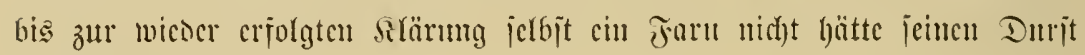
(öid)ent mögen!

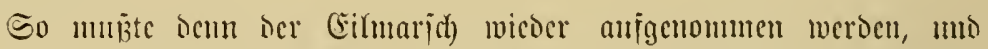

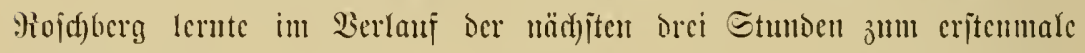

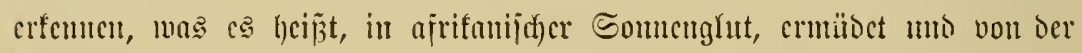

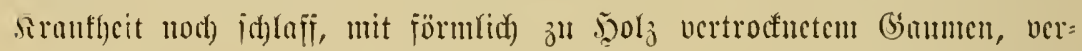

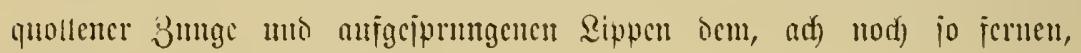
Waja er entgegenjumarjofieren!

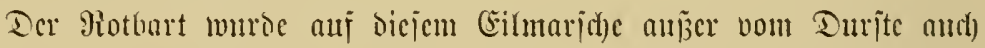
nod) won jeinem "verfnacfiten" Fuje geplagt. Den hatte er jich) in ocm

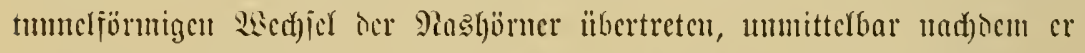

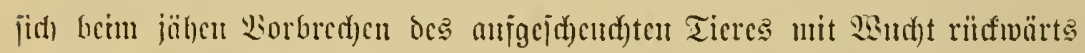

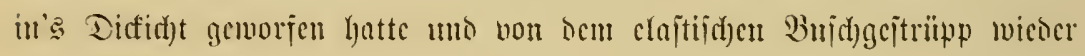

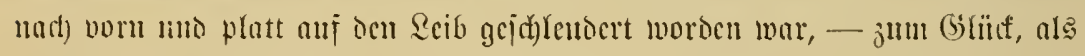

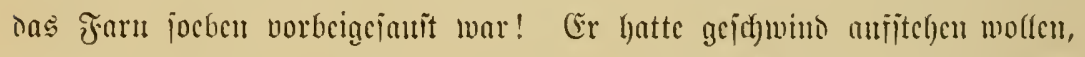
Demu cs founte ichle leidft in

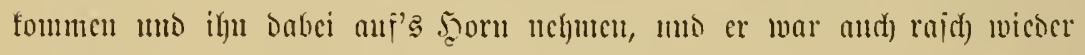

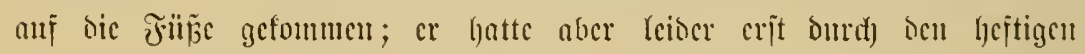

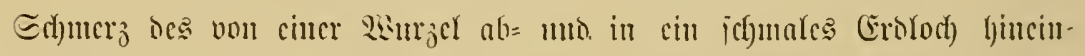

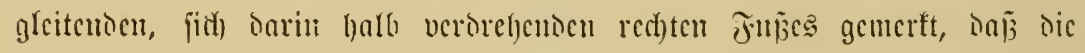

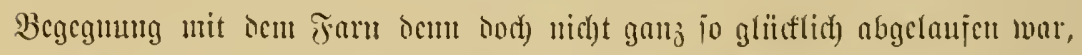

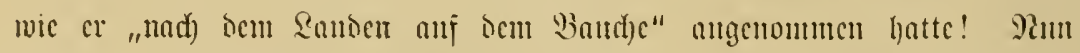
ljič

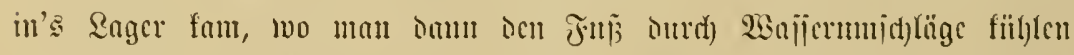

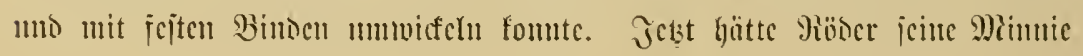


germ jwijd)en Den Eshenteln gelabt, obgleidh er in allgentemen lieber

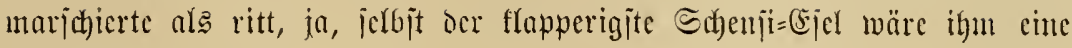
23obltat gewejen!

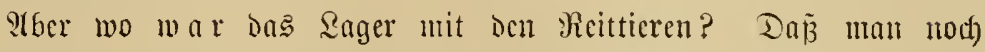

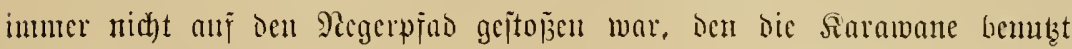
hatte, mad)te dem Fotbart idjon jeit gerammer Beit nodh mehr Sorge als Der Waffermangel mo jein "vertammter $\mathfrak{F} u \tilde{\beta}^{\prime \prime}$. Ob man viclleidjt gar jd)on au Rager vorübermarjd)ert war, ohne es jul jehen? Bei Dem jo

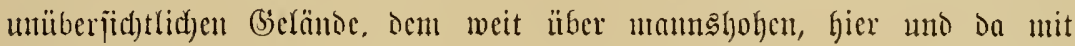

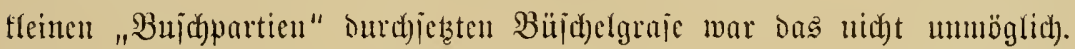

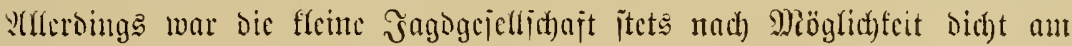

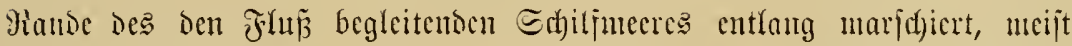

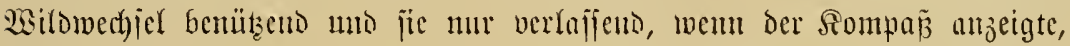

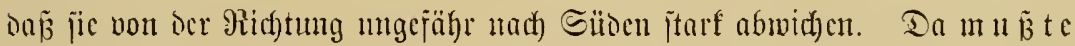

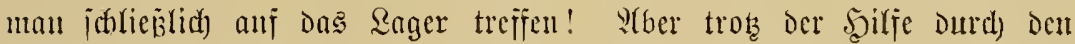

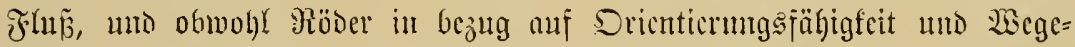

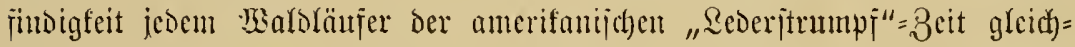
fum: is wollte uno wollte mht gelingen, auf bie Spuren Der gejtern

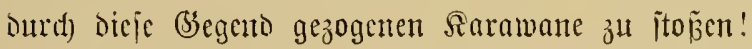

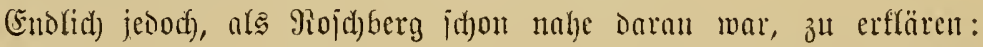

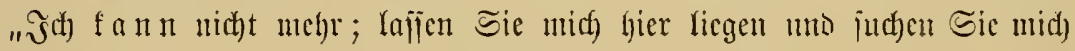
marbher, - wem Sie Das Sager oder 2 afjer gejunden haben", enolid) jeigten

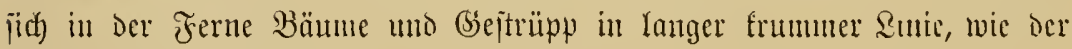

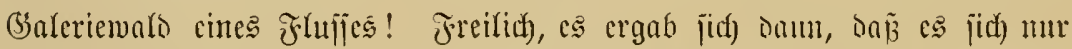

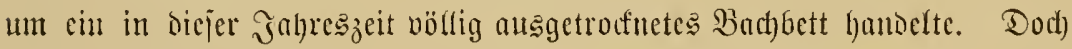

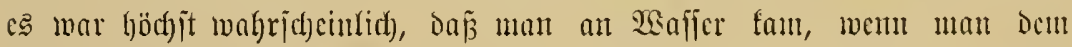
Saute des Baches nact) der \$lïnoung hin jolgte! Dic Farbigen hätten

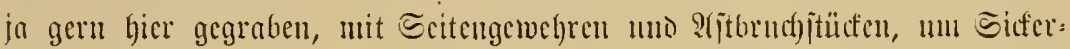

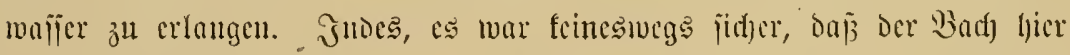
in jeinem Dherlanfe 2saffer in erreich)barer Ticje jührte, แns unjerdem,

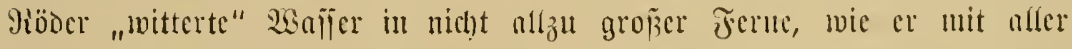
Bejtimuntheit bebauptete, als cr

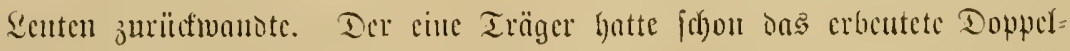

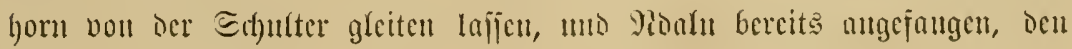




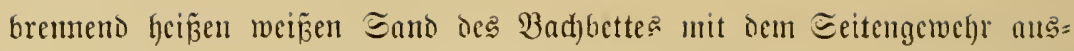

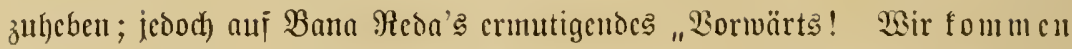
bald an Wajper!" mad)ten jich) S(lfe mit ernenter joofinung wicoer anf. Sic glaubten an dent roten Jäger unbedingt!

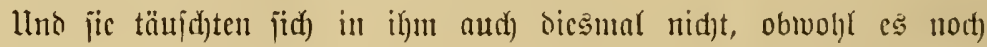
cine lange 3eit Dauerte, his man an bem frifher werdenten Grïn bes

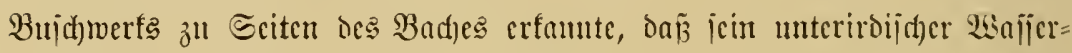
lauf in ber Tat nidht ganz verijegt war uno man hoffel founte, auj offenc

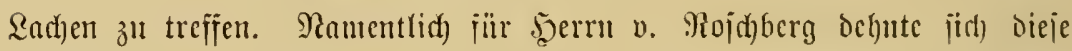

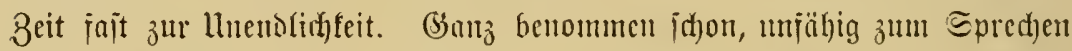

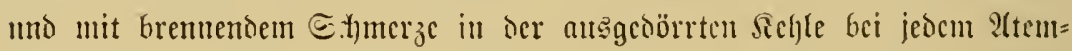

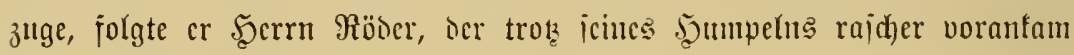
als jein junger Reijegeführte.

Da blieb Röder auf eiumal wic angemurzelt itehen. "S tirke!" gebot er halblaut.

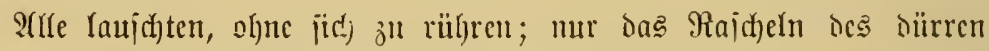
iteifen (Srajes im Yeid)ten Winde war z̆l hören.

"Stirle!!" befahl ocr Potbart norh einmal, - mo glcid) banach

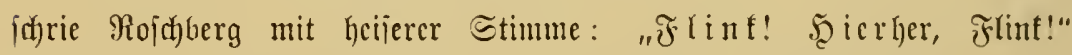
(5) hatte, wie borbin der Shothart, das Blaffen jeines Terriers in ock Ferne gehört!

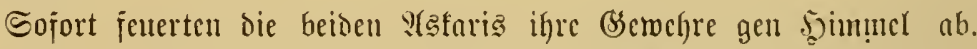

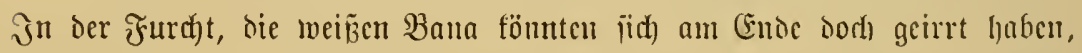
Denn feiner ber Farbigen hatte eincn Das Sager anfündigendon Ton ver= nommen, io idari 2(ugen uno Elyen bei ifnen and) waren, itanden banad)

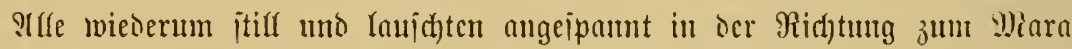
hin. Da raidselte es in (Sebüid) linfs am Bad)e, immer näher fam es,

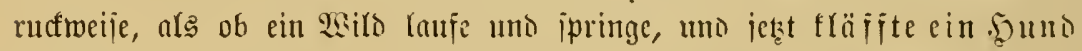
feine hundert Mieter bor Den nenbelebt ifren Saeg im Badjjande jort=

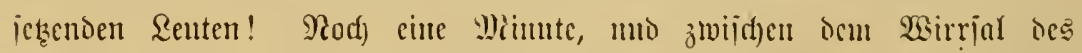

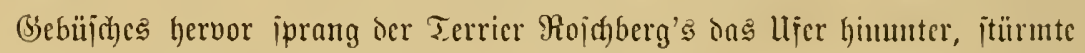

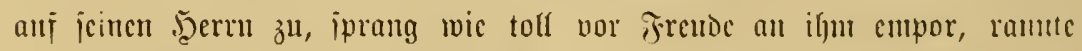

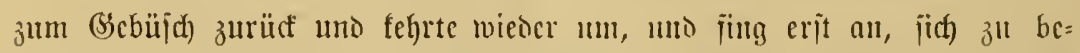
ruhigen, ale żwijacu ien nièrigat Bäumeı am Badjjanne cin par sente 
auftauchten: Der Dmbajd) Utesi mit vicr Maun, bie auf bic Søüffe der Anfommenten hin, ohne erĩt Ŝntwort ju idhię̧en - meil bie Bsemehre zujammengcjeţt nebcu Dem Eurropäerzelte im Sager jtanden - jofort Dem

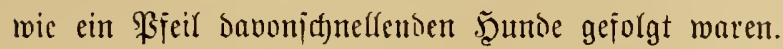

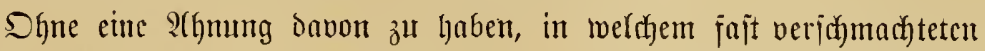

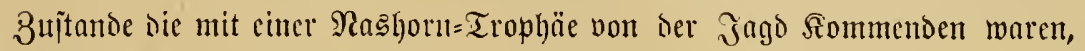

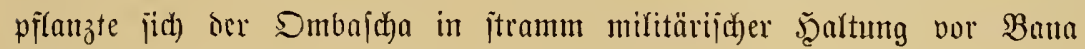
Reda auf und meldete auf Deutịt): "Bur Stelle!"

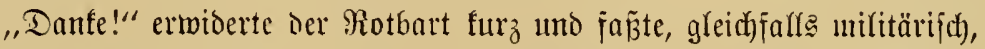

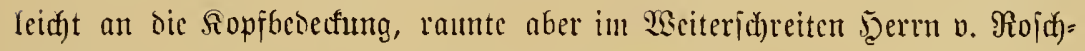

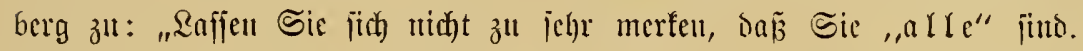

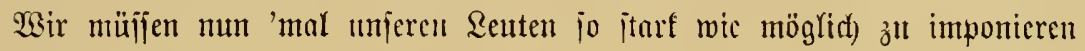
juthen!"

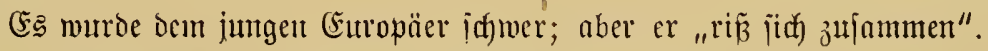
Und es Dauerte aud) nur noch menige Mimuten, damn fá̉ er vor bem

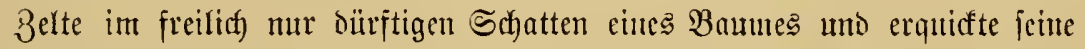

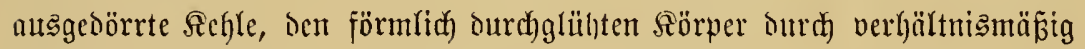

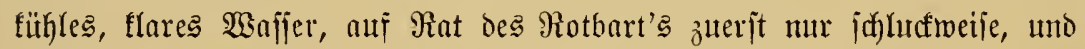

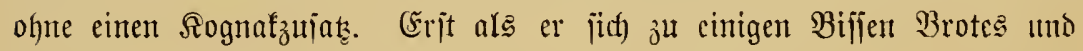
falten Fleiiches gezmungen hatte, wie auch) Rö̈cr, trant er in langen Bügen, als ob er nie gemutg befommen fömte. Dann jtrecfte er jith auf

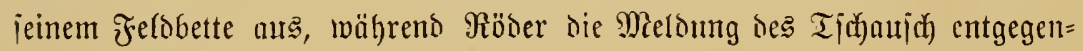

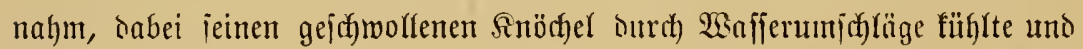

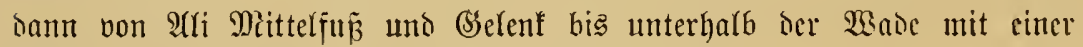

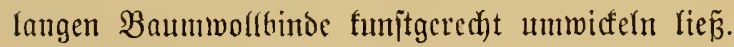

WBie jith) mut crgab, hatte bic vorautfgciantote faramane bas $2 a g e r$ einige Marichitunden ipäter aufgejhlagen, als heabjichtigt war, "wn zmar,

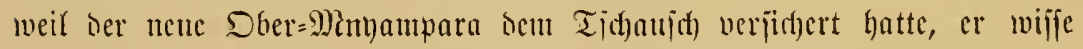

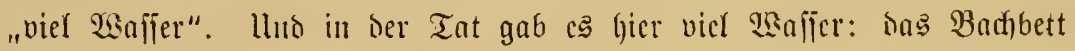

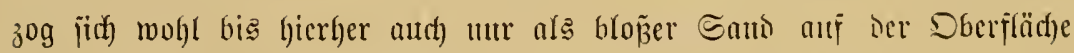
hin, Der aber hatte in bicfer Begent fiteinigen Untergrunt, lagerte

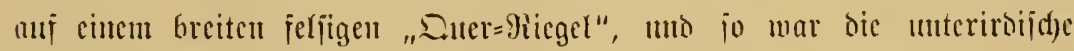

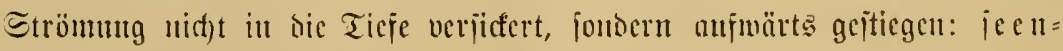
¡̈̈rutge SEat)en vou 60 Mietern \&änge แmo 20 Metcrn Breite reigten 


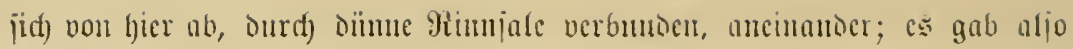

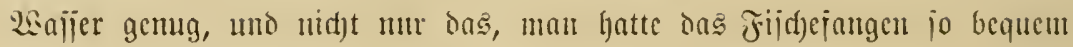

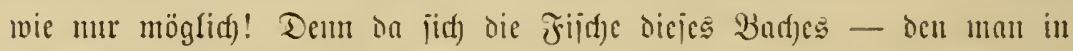

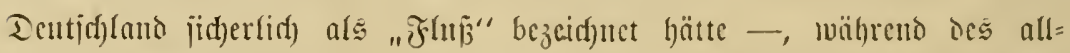

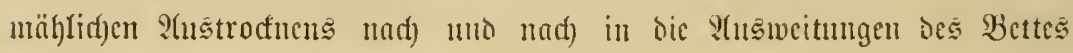

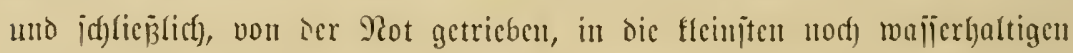

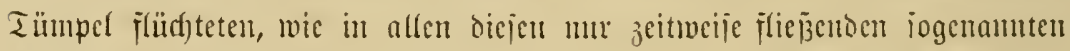

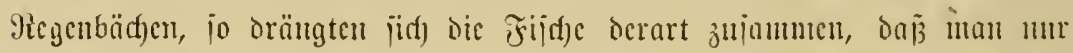

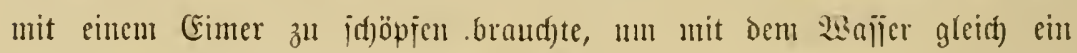

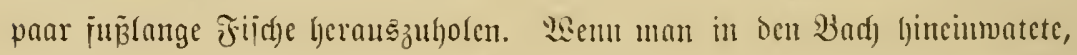

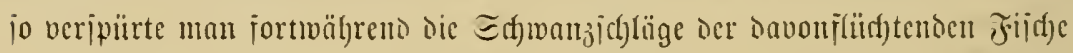

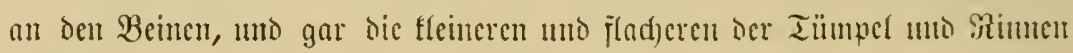

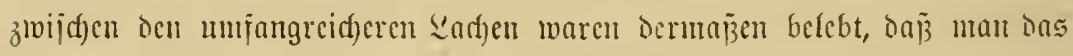
wajier in jortwährender umrnhiger Bewegung jah. Tas hatten die Seute

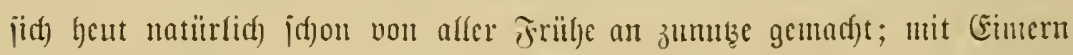

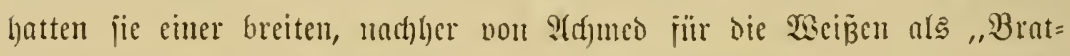

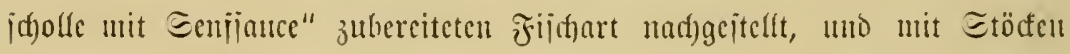

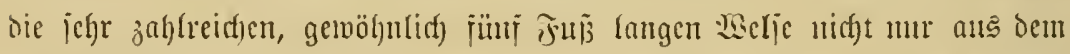

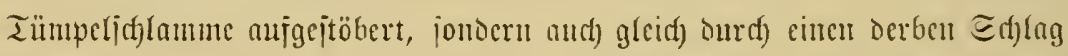

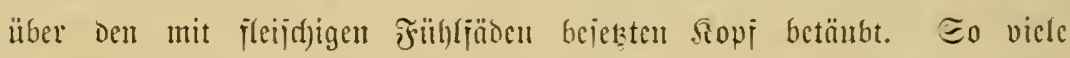

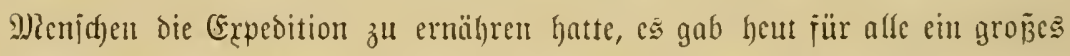

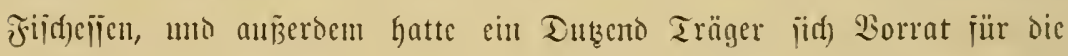

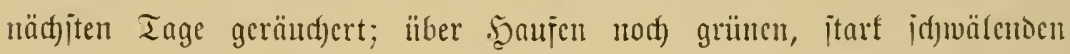

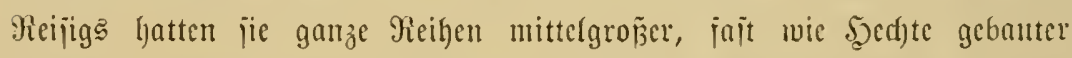

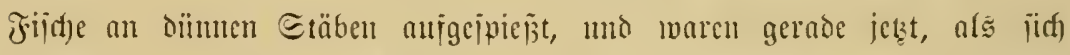

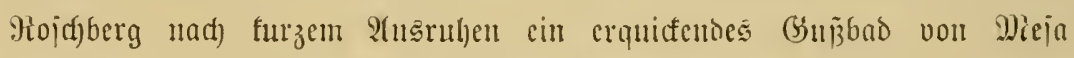

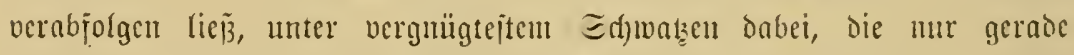

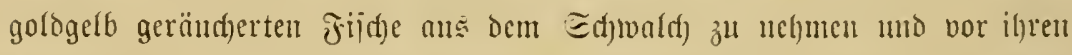
Grashiitten die did)t bejesten Etäbe wageredgt ïber jwei in dic Erre

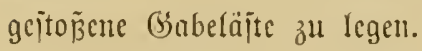

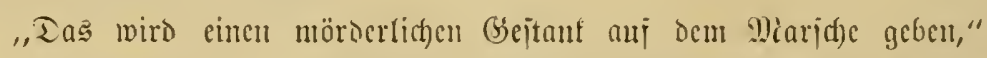

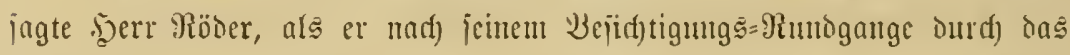

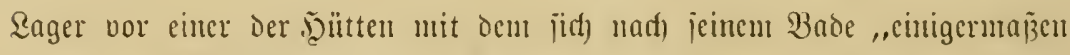
wieder als sienich jühlenden" Mojaberg zujaumentraj; ,aber die sierls, 


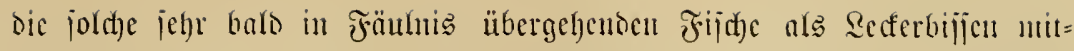

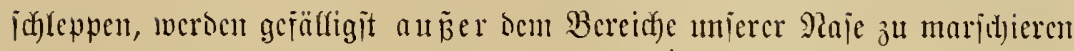

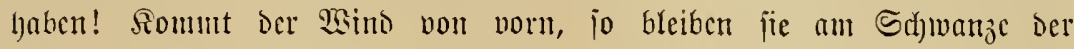
Sarawanc, gleidf)icl, ju weld)er S(btcilung jie gehörcs mögen; unt fommt

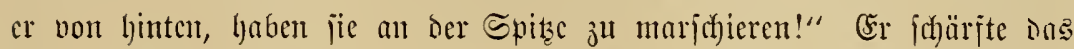

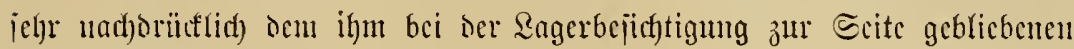
alten Tichauld) cin umo itrecfte jich bann crit, mit cincm Scujar ocr

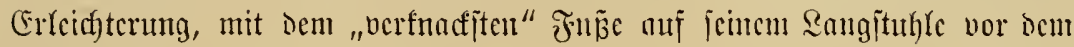
3 cltc aus.

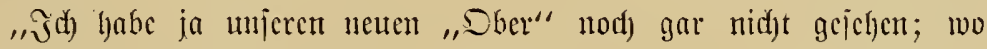
itectt denn ber Miojlo cigentfich?" fragte Miojidberg.

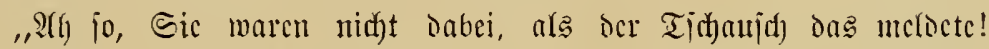

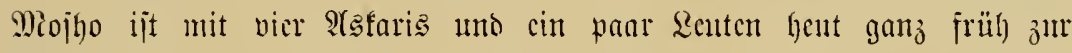

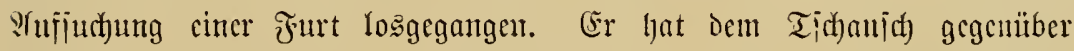
bchauptet, bei ocr jetzigen grojen Trodfenheit jei cine ilym von jrüher her

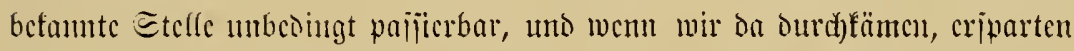

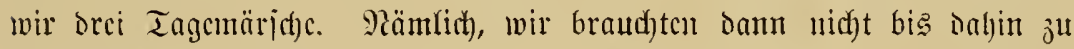

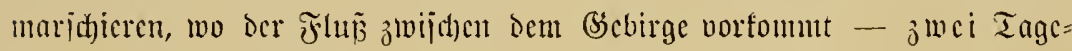

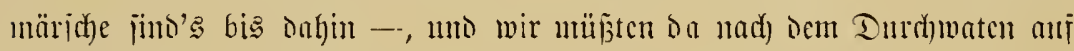
Dem jenjeitigen Herer mindeitene no d) cinen Tagesmarid) wieter jur ü (f, nad)

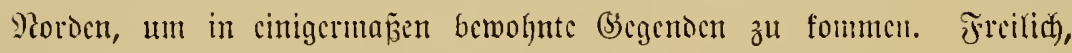
wenn wir dicje nähcre Furt gebrautchen fömen, müffen wir a ud nod) cinc

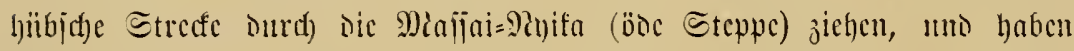

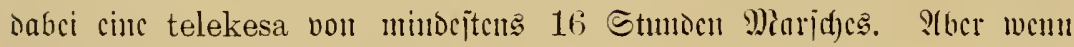
wir Dadurd) orci Tage iparen . . .!"

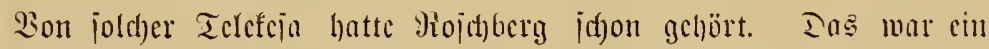

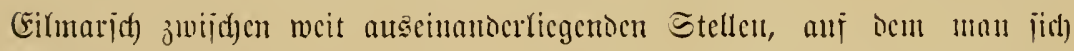

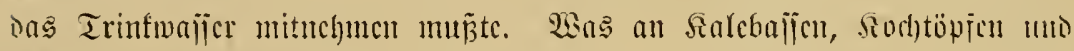

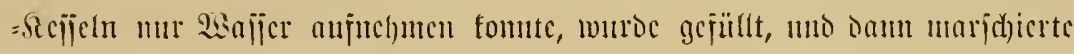

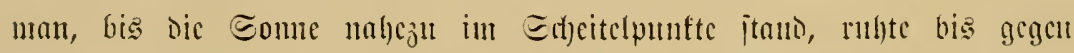

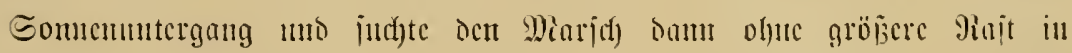

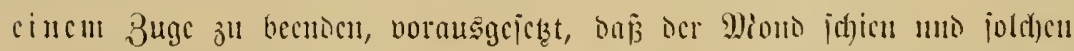

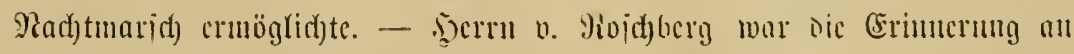

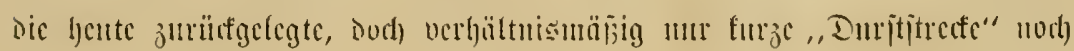




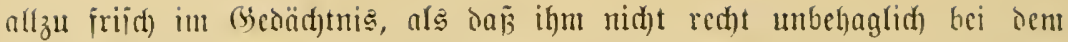
Besanten an cincn joldten Wiarith in majīerlojem Eteppengebiet bätte

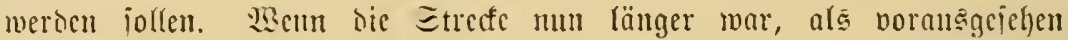

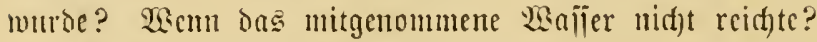

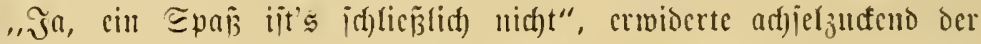

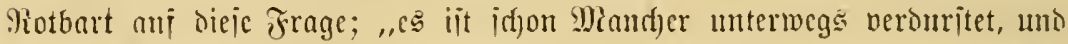
wobl auth gelegentlid) einte ganze finrawane tabei braujgegangen. Ther anj io etwas mus man in meripridsten Sande ja ant Ende immer gejañt

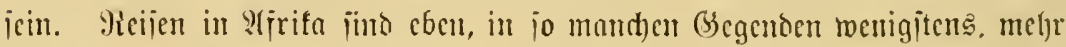

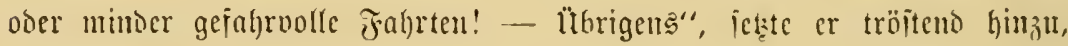

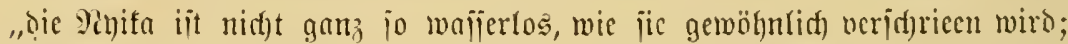

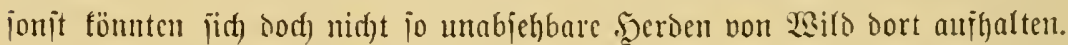
- Eie wollten ja wohl gern cimmal auj Bebra's umo (Sirnfifen zum

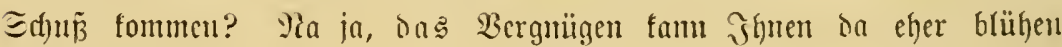
als wo anders!"

Woigo fam mit iemen Seaten hod) erireut zurüd uno berict)tete itolz.

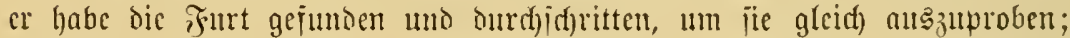
das 2 ajijer ginge den fleinen Eenten mur bis an dic Bruit. - Er wat

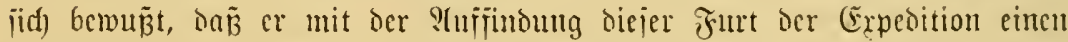

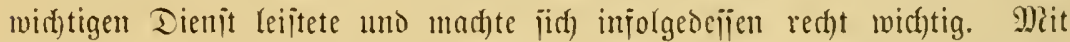

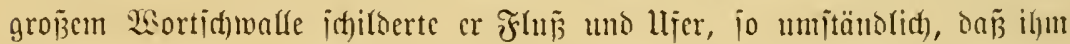

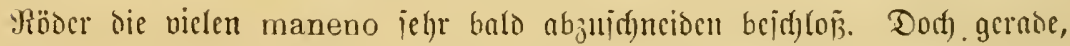
als er ihn abtreten lajfen mollte, iprad) ocr Minuampara von cinem grojisen

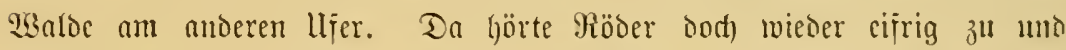

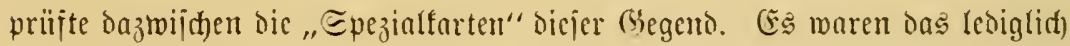

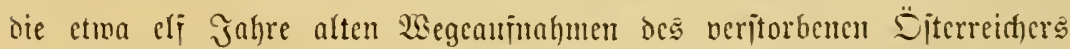
Dr. Banmann nut dic nod) jehr viel älteren eines (Engläıders, Farler,

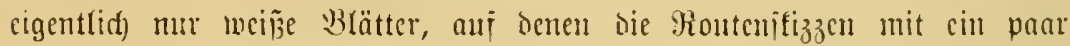
Berg= แnt Fluzangaben banchen eingetragen waren, dic Eageritätten mit

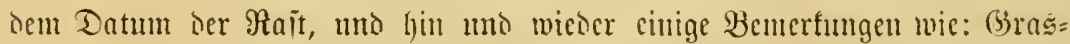
jtevpe, Dori mit Walmen, Bohnenjelocr, Elçantenipuren, obcr: Birafiẹ

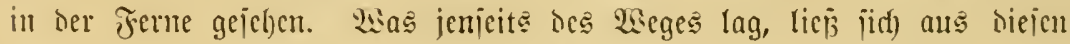
Surten niđ)t erjegcu; nur cinige größ̄ere Bergipizzen waren mitten im

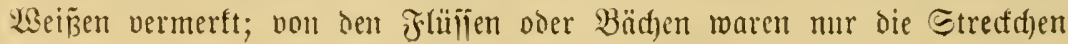




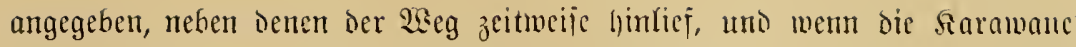

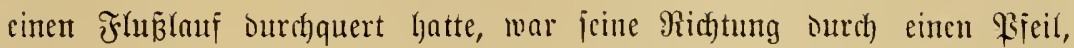

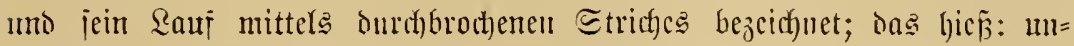
bejtimmt, nad) (Erfuntigung bei den Eingeborenen. Lion cinem grof̈en 92 alse mar auf ocr Banmann'ichen Siarte jo menig etwos bermerft wie

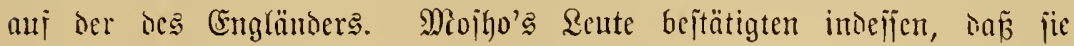

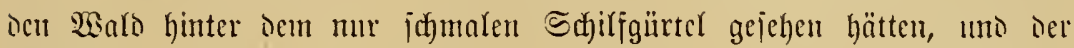

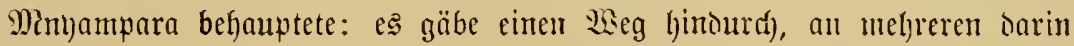
licgenden Dörjern vorüber; er jelber jei einjt, von der Serengeti=Etenpe

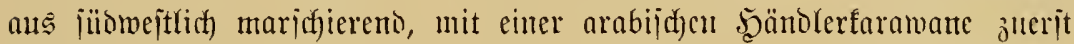

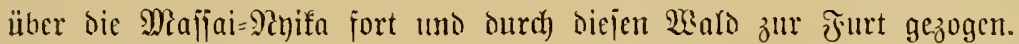

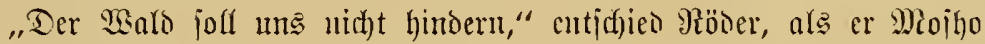

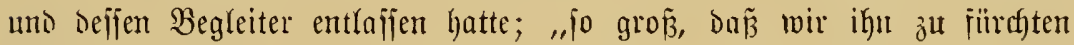
hätten, fant er nad) Dem nicht jein, was wir vou den bselände nöroblich ocs Flujies milijen! Jebenjalls, wir verjudten es."

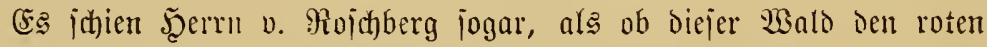
Jüger gallz bejonters anlocte. Märe ner junge Curopäer mit sem Reben

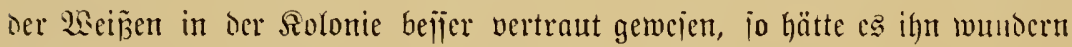

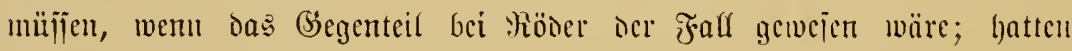

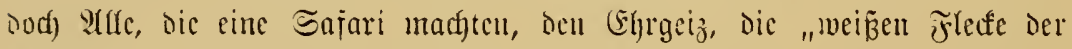

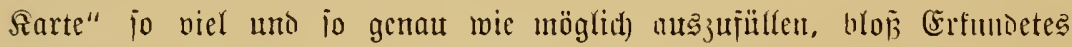

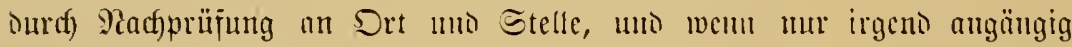

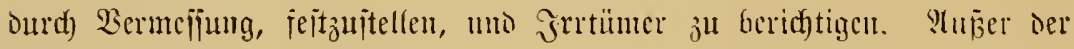

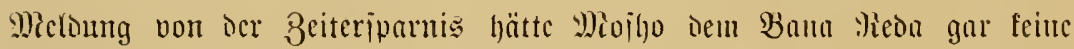

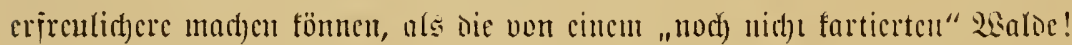

Bbegen Mittag des jolnentes Tages bciano jith Dic Expedition un

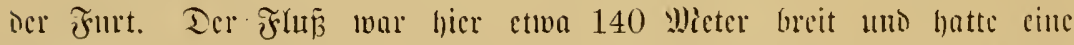

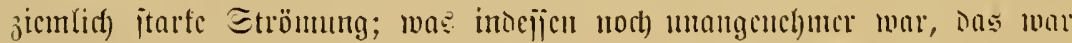

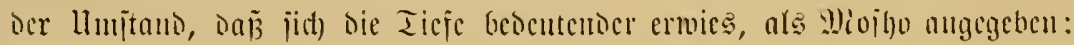

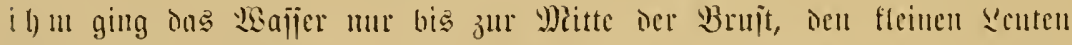

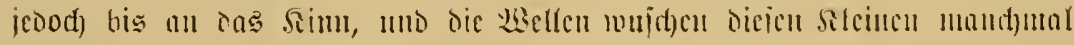

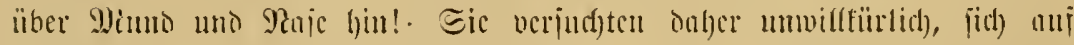

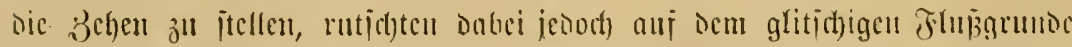

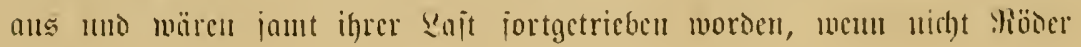




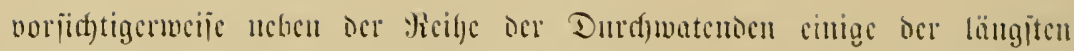

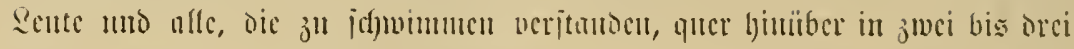
Mictern Y(bitand im Filuje nufgejtellt hätte. So viele Mieter Ecil, wic von

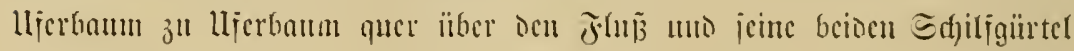

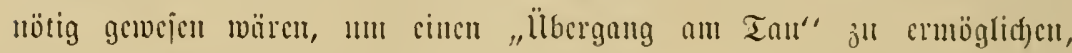

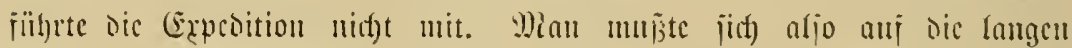

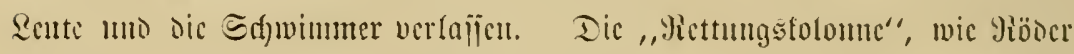

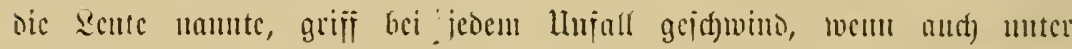

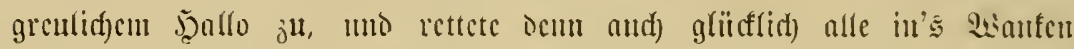

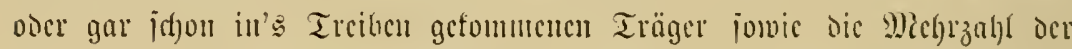

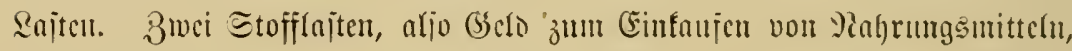

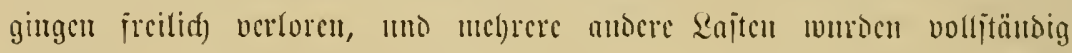

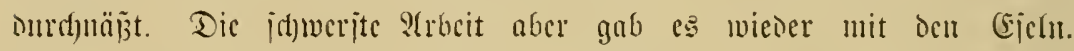

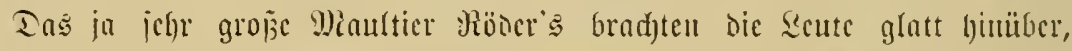

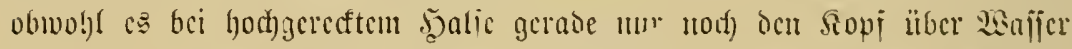

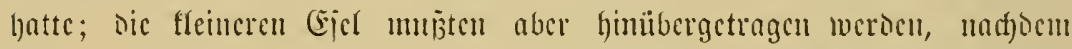

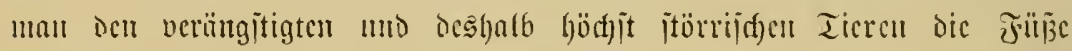

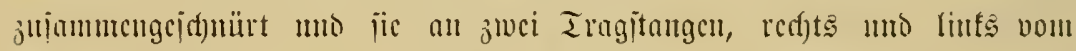

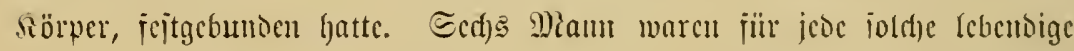
Sajt nötig! (Enolida jesod) waren Tiere mo Menidjen orïben bis anj

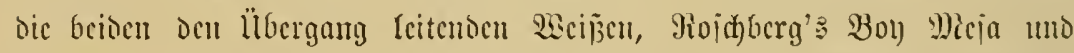

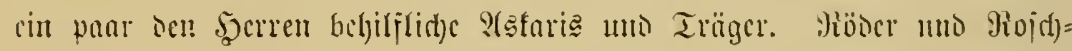

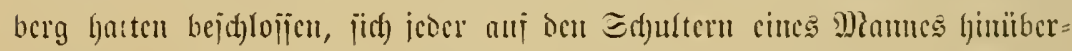

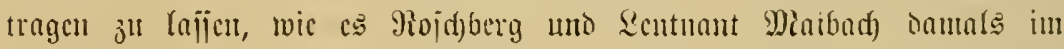

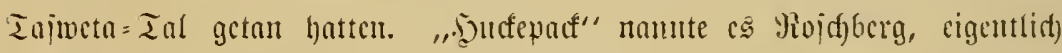

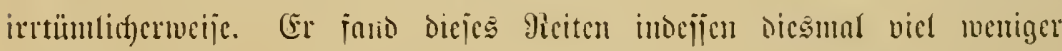

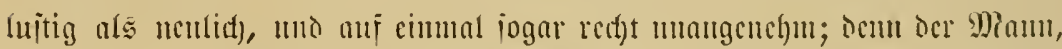

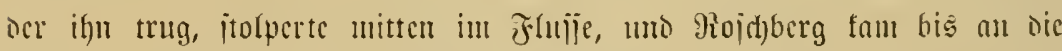

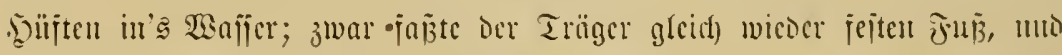

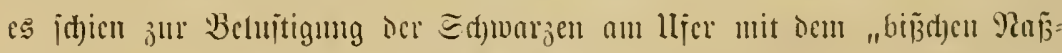

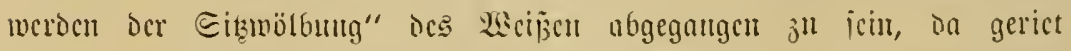

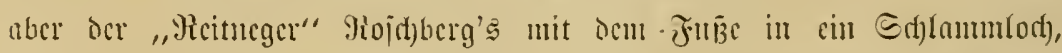

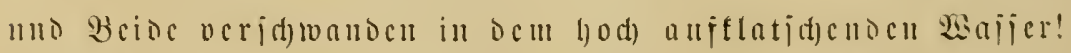

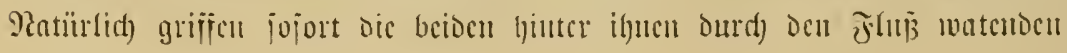




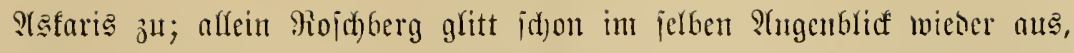
ale cr prujtem mit dem fopf als tom Wsafjer hodgefommen mar; er

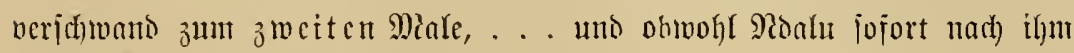
tauthte, er foumte ben wiseisen nicht greifen!

YHf'ę höbjite crichrocfen glitt Röber non icincm Träger berunter,

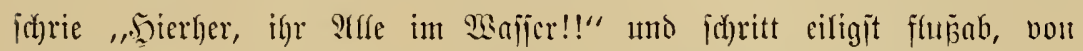

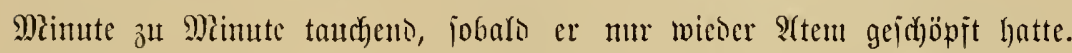

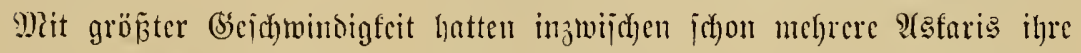
mittels cincs Beugietsens jujammengebüntielt nuf Fatronentajchen, Scitengewehre uno ocn Jnhalt ifrer Tajd)en Dem Bol) jugereicht, ebenjo die (Sewefre cinem Sameraben, mo mm juchten audf jie,

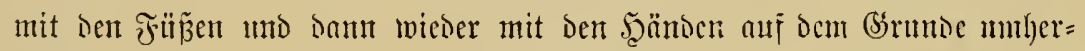

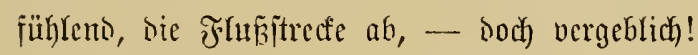

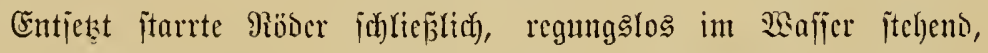

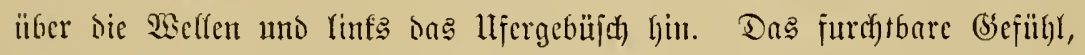
ocn jungen, ihm lieb gewordenen Reijeger̈̈hrten nicht vor cinem fords)

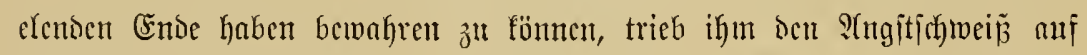
die mafjertricfende Stim und jofmüte ifm dic Sichle zu! So hilflos, twie er jiti) noch) nie empjunden, oüllig ratlos, liej̃ er bie Blicfe balo

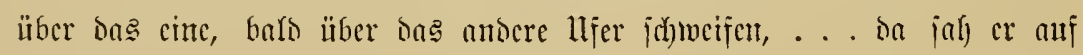

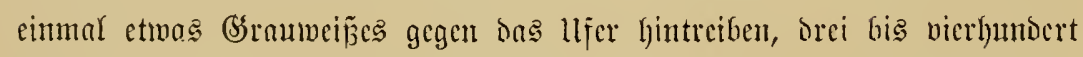

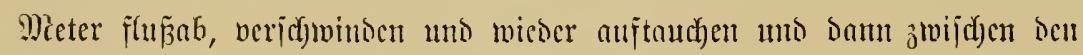

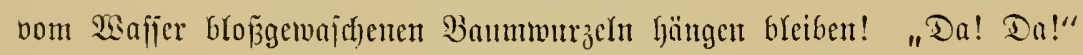

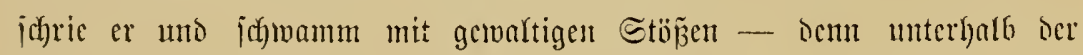

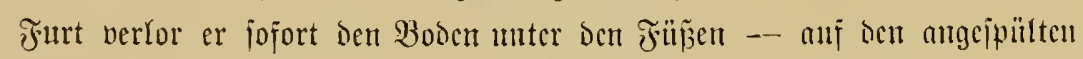

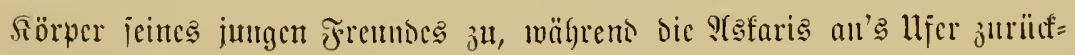

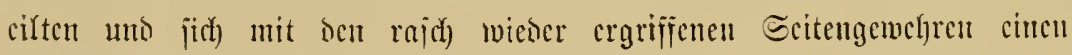

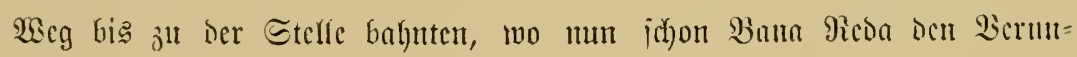

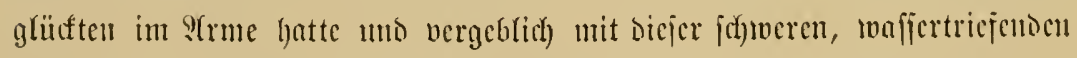

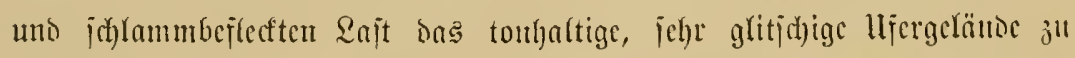
crflimmen benuilyt mar. Sdyon uon weiten ricfen bic Sente bem ruten

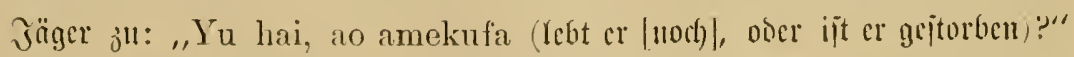

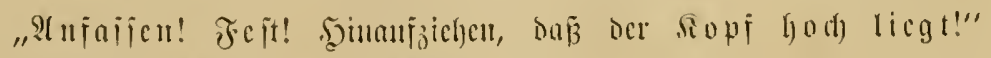
mar dic citzzige ?mtmort Bana Dicda's. 


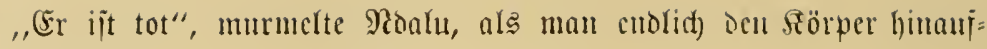
gejogen hatte.

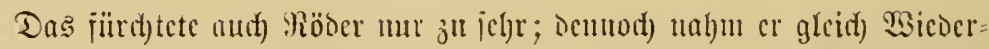

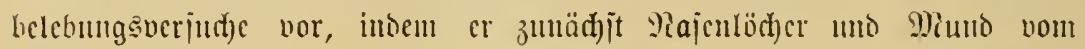

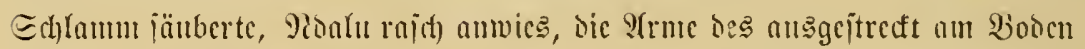

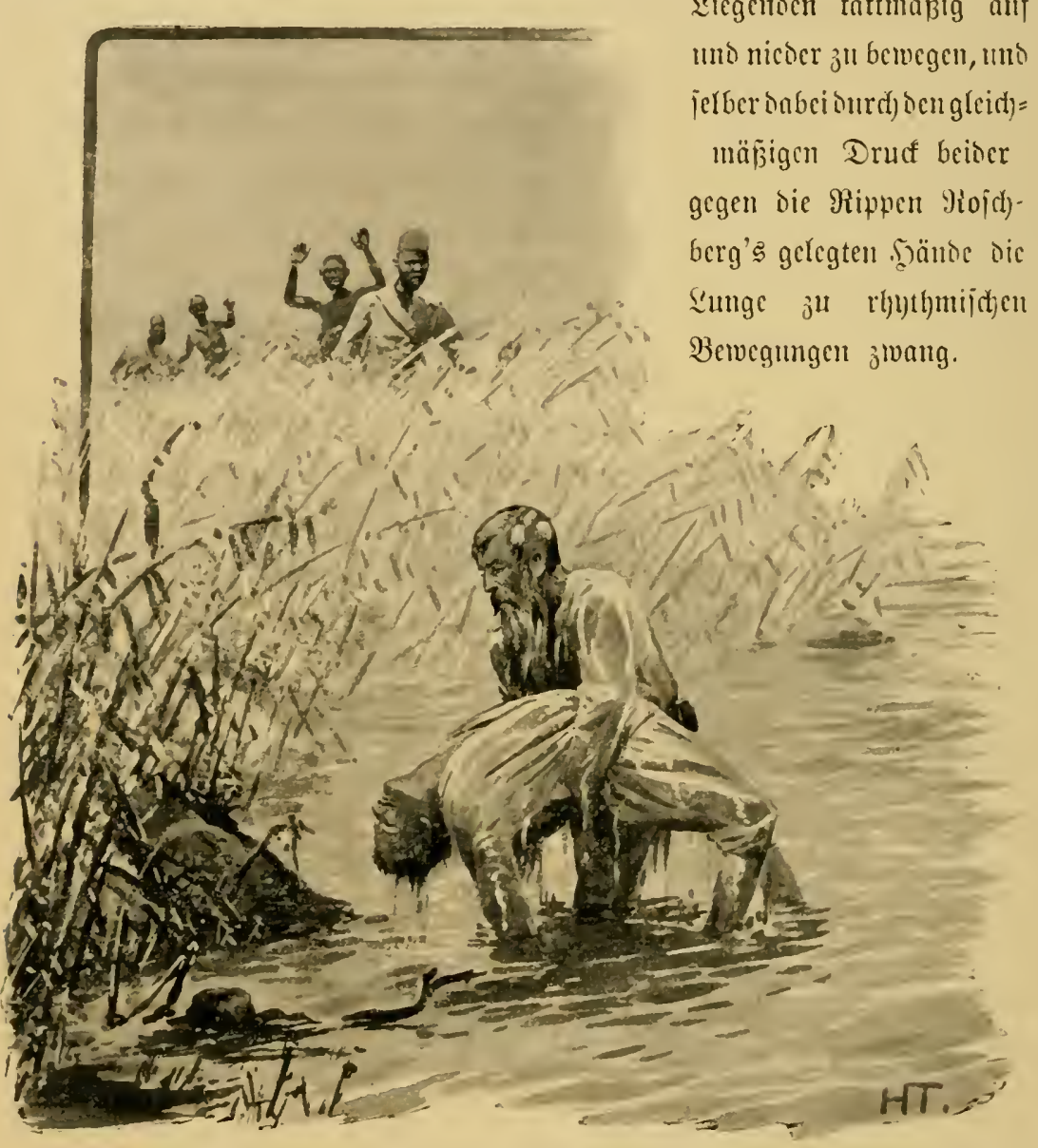

Liegentoen tnftmä̈̄ig aui uno nicoer z"l bewegen, "mo elber tonbei ourd) oen gleid) = mäp̃igen Drucf beiocr

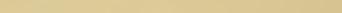
sunge ju rbutflijijthen Bewegungen jowang.

"Yeye ana manti (er, er hat ocu Iod)", flüjterten dic \&ente jid)

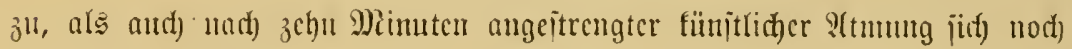
fein Eriolg jeigte.

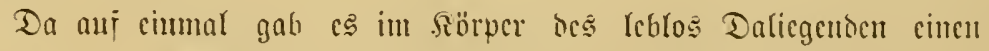

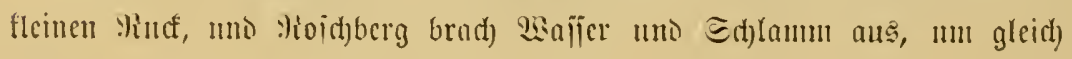




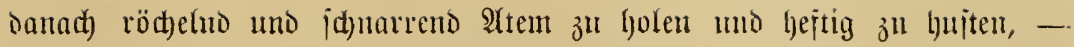
onbei aber jđhlug er jür menige Sefunden die 2(ugen anị!

"Yu hai (er lebt [utod)])!" ¡t)ricen mun sie Farbigen jubelnı über

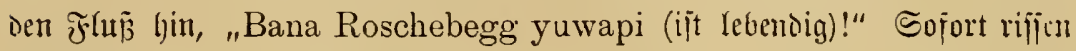

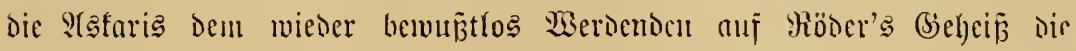

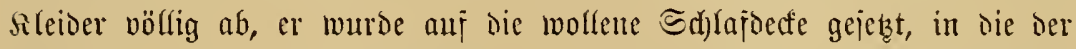

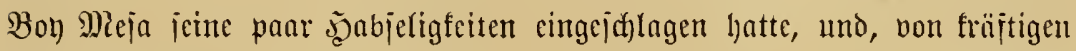
J̨änden gehalten, murde er von nicht mirroer früfigen jo lange frottiert,

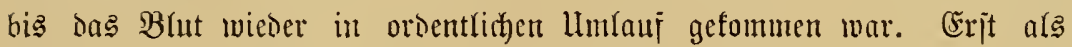

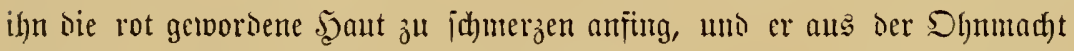

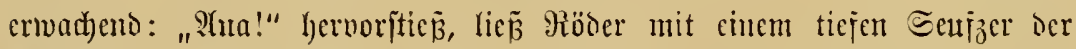
Errleid)terung die ફ̧ände jinfen. "(Sott jei Dant", murntelte er dann.

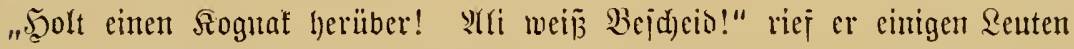

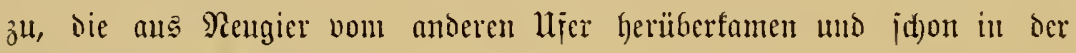
Mitte des Flunjes waren.

Gelaijen juthten 2 staris wie Träger ifgre Gachen auj dem von Sdjilf, Siraut uno Gejtrüpp beitandenen Bosen zujammen. So laut jie

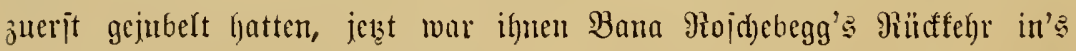
Reben cine ganz gleid)gültige $\Xi_{n d}$; nur Dic l̈tberrajd)ung lyatte jie vorbin

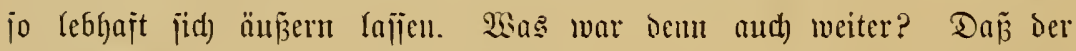

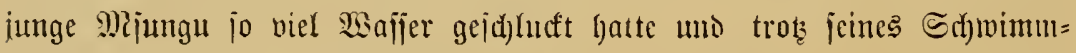
verjuches uid)t an bic Sberfiäd)e hatte fommen fömucn - bie volfgejogene

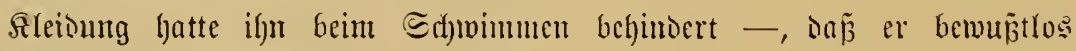
gegen bas lịer getriefen mortes war, uno ihm nom Bana Pieda "Bas 23afier mieder aus Dem Reibe herauggenrüctt" werden fornte, Das war Doch eben amri ya mungu! "Yuu yake kufa bado, $\mathfrak{c}$ s war nod) nich)t auj ifm (ihm stod) mid)t bejtimunt), jul iterben," jagten jie gleid)gïltig, ohme zu beocnfen, daj lesiglid) ocs roten Sügers encrgij(t)es unt rid)tiges Borgeheแ do

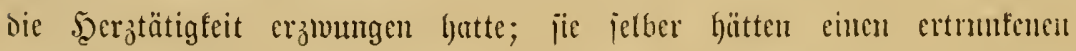
Samernden entweder einfad) liegen lajien oder ifhn böcbjtens bei den Yeinen

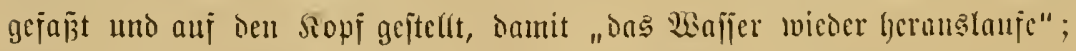

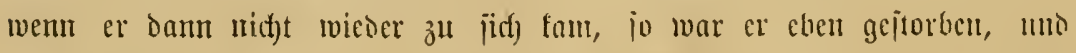
bos hatte daum uach iljrer jatalijtij(f)en :(njidaunug jo jein jollen, war 
ihm vorber bejtimun: ocm hafi illa kwa amri ya mungu, or mon) jtirbt micht, nuj̄er muj Bottes Bcjehr!

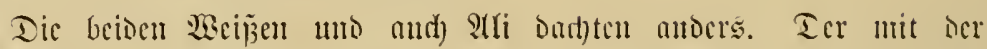
Sognafflajd), aber autd) gleid) Ber auI Dem Sopj getragencu flcincren

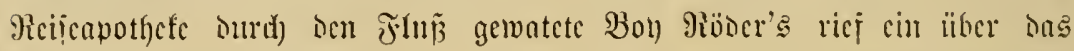

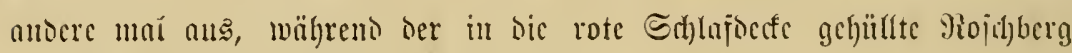

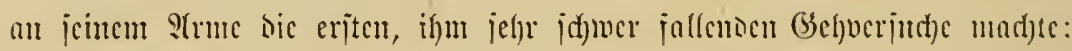

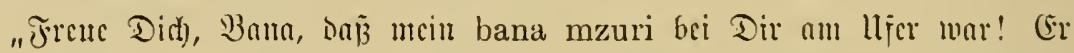

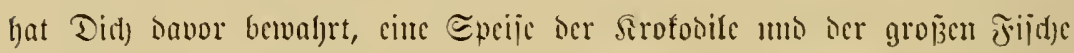
ju merden, wie er jrïher midf Davor bemalytt hat! Furahi frue Didj)!

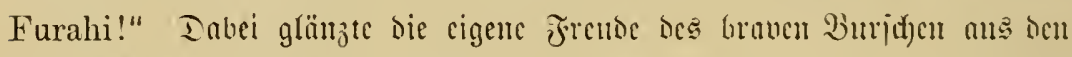

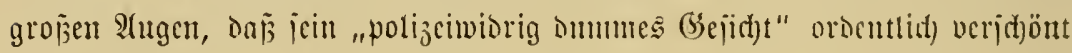
basurd) wurde.

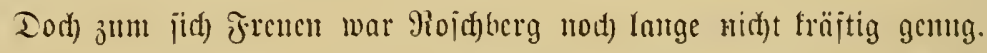

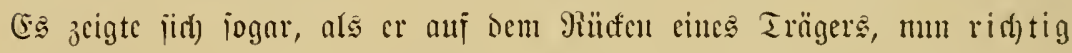

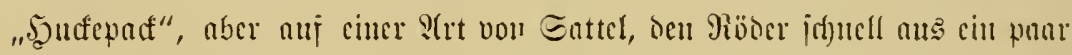

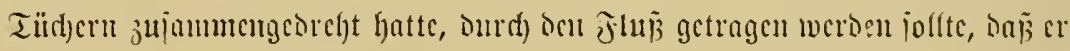

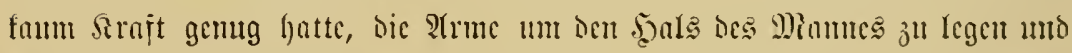

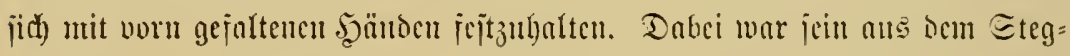
rcij crjuntener Peitjattel Durdfans proftijd) unt gantz bequem. Breit wic

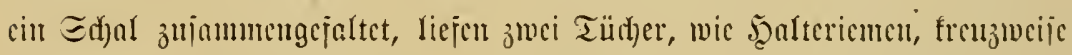

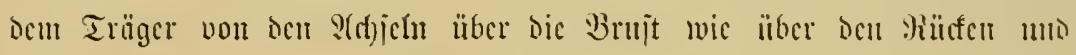

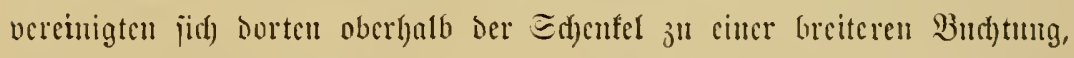

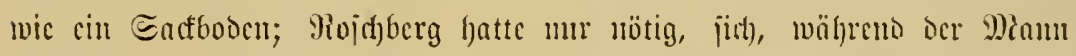

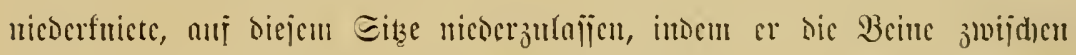

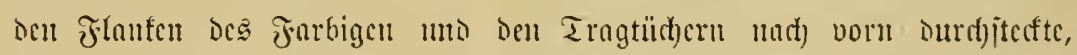

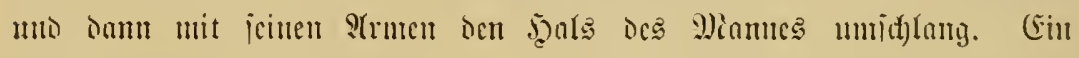

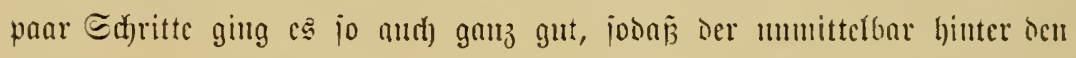
Beioen Durd) bas 2 saljer watende Jiotbart jur Belcbung ocr Etimumumg

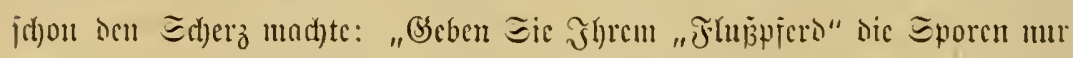

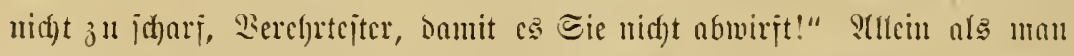
Das crite Drittel oer Etrecte jurücfgelegt und bic ticjite Etelfe ocr jurt

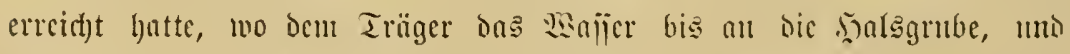

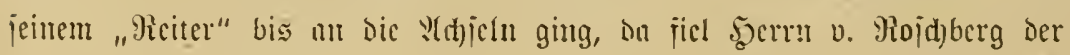




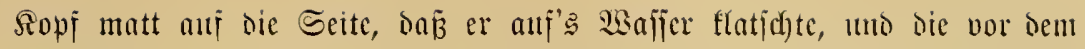

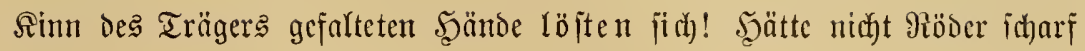

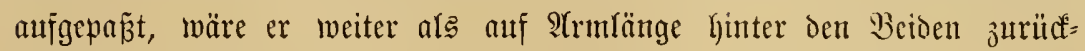

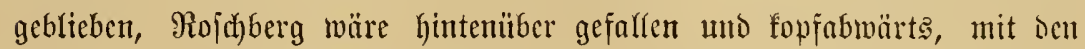
Beinen in Don Tragtüd)ern hängent, unter Waffer gejunfen! So aber

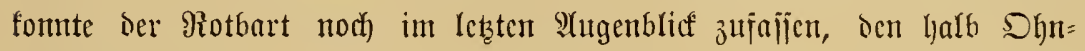
mächtigen wieder in bie ridftige Lage bringen tnto ify bon hinten her

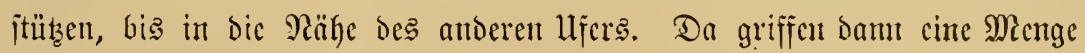

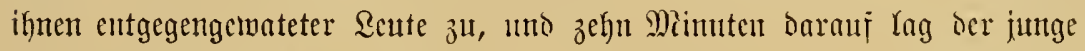
Miam, in eine trodfenc Deffe gemicfelt, im Schatten cines großzent Bammes. (Sr verïtel in einen Siblaf volritänoiger (Erjchöpinung, che noch) jein Bon

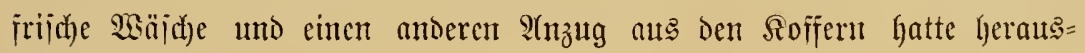
nehmen fönnen.

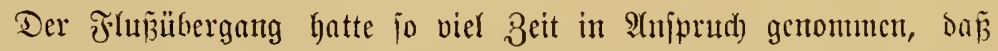

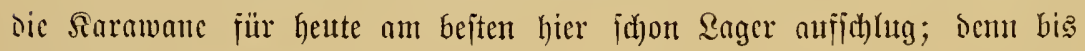
jum Sonnenuntergantg waren ca faum nod) nethr als żwci Stumocn.

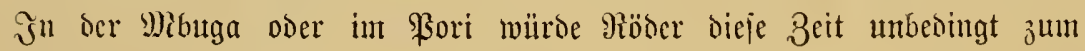

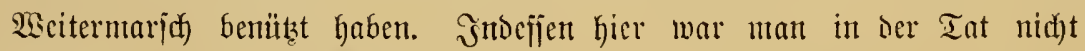

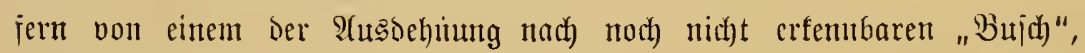
ridftigen llrwalde, uno man tonnte nicht wijjen, of man nod) bei Tageslidyt Darin auj ein Dorf traj, mie Moino Dns als "jeiner (Erinteruntg nach

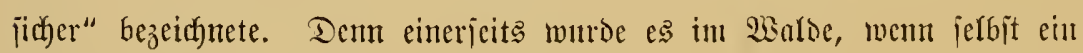
"ausgef)auener" weg hindurchjührte, viel früher oumfel als im Freict,

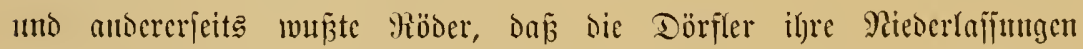
mand)mal j(hon nad) ein paar Jalyren verlegten; mant fant basu ant Etelle ihrer auj müfjam gejd)affener Ridhtumg angelegten Felder wirren

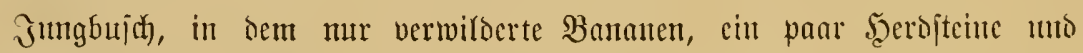

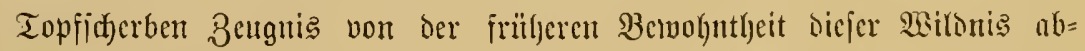

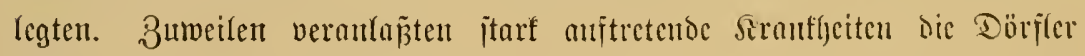

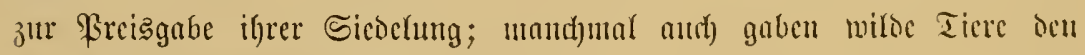

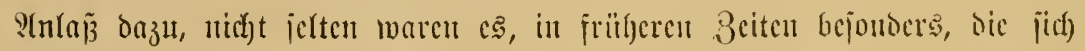

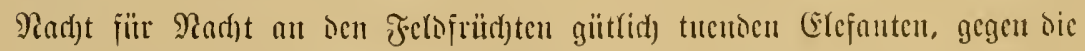

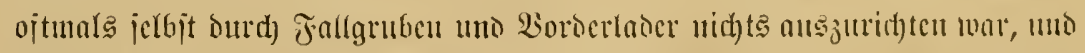

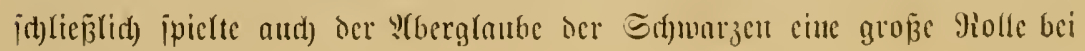




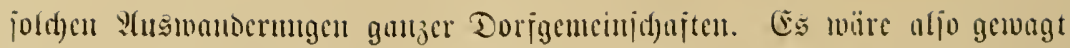

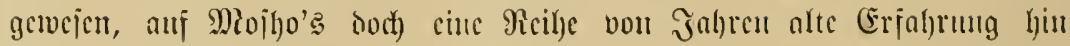

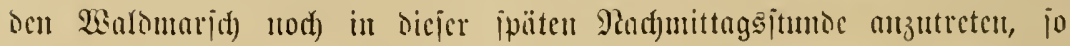

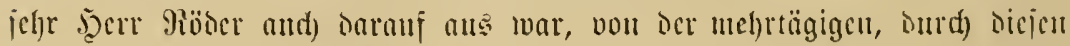

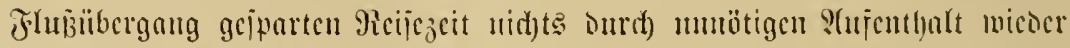

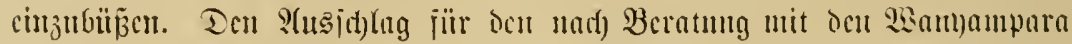

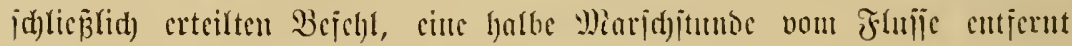
am Rambe ocs salose fïr heut \&uger jul bejichen, gab freilid) ber nad)

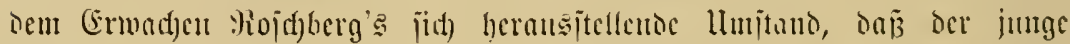

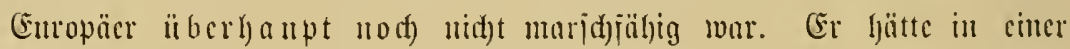

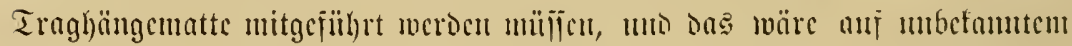

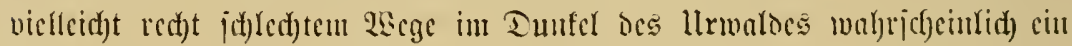

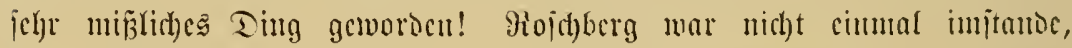

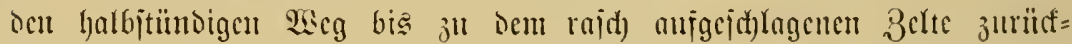

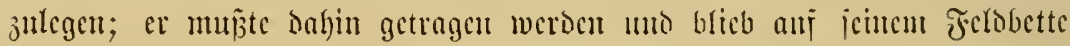

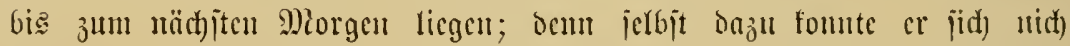

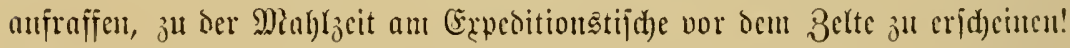

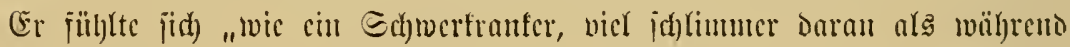
ins Ficbers in oer eroberten Fejte mo nadther im "Rager Miabuumi".

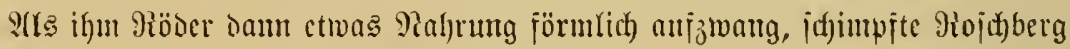

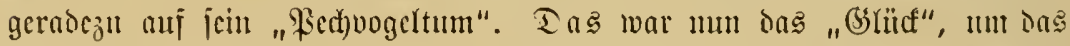

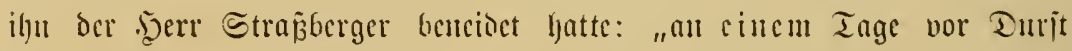

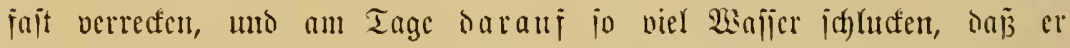

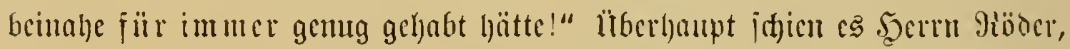

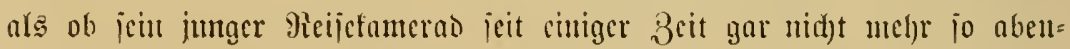

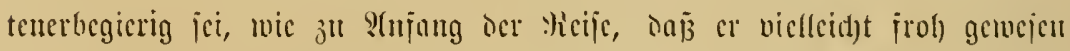

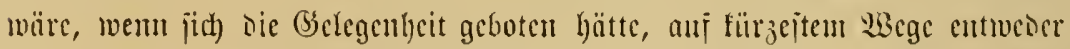

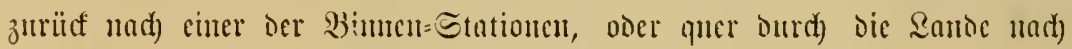

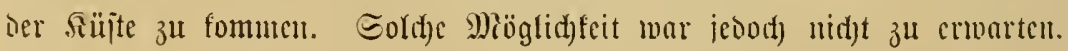

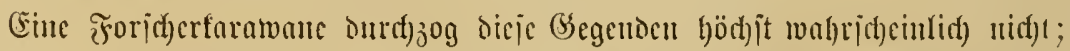
man hätte bejtenfalle auf bic Expedition ciure \$rojpeftors jtojen fömucn,

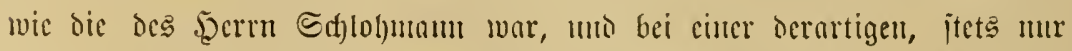

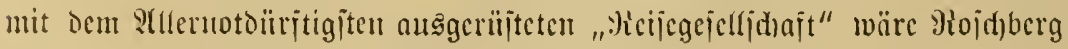
unter allen Unittünoen nod) bicl id)led)ter daran gewejen als bei sicjer 


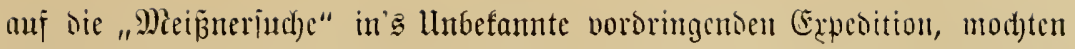

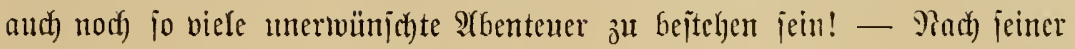

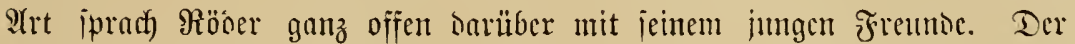

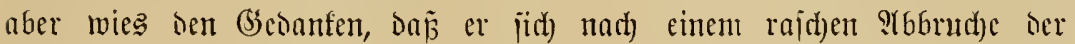

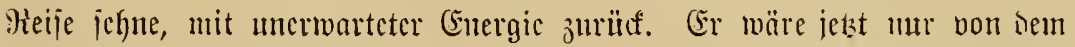

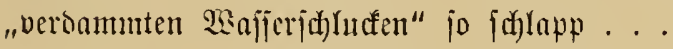

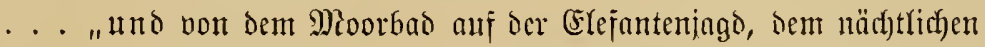

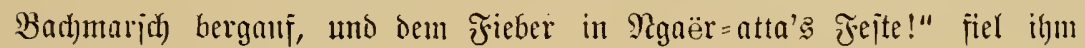

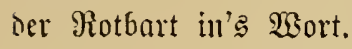

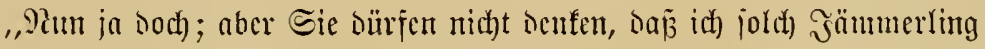

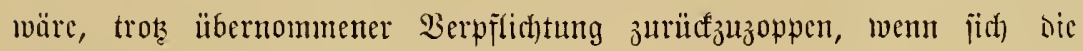
Sabicrigfeiten cincr Sache einjtellen! Rafjen Sie mich nur crit morạen wiciser 'mal feît auj ben Beinen jetehen, uno Sic weroen idjon

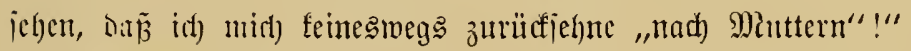

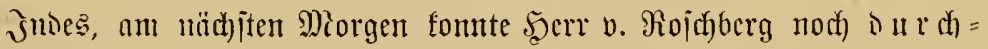

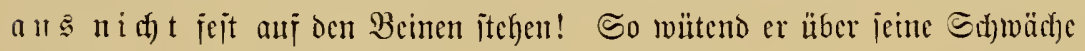

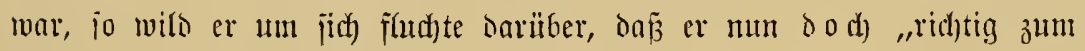

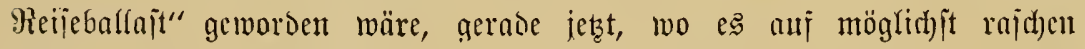
Marid) anfam, - cs blieb ifm nidfts anneres übrig als im Bett ju bleiben

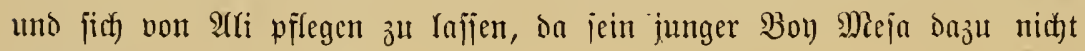
genügento geidyult war.

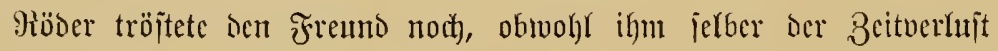
red)t ärgerlich war: "(Es mad)t nidft viel ans. Den hentigen Tag bemïtze

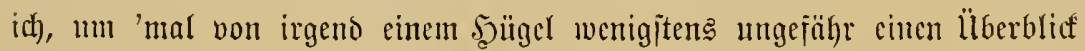

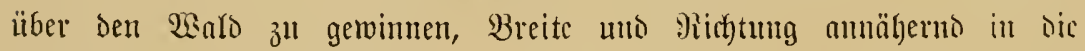

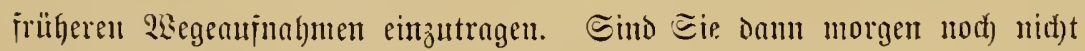

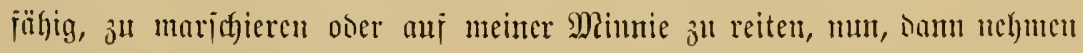

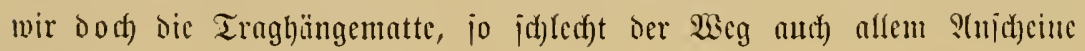
nact) ijt."

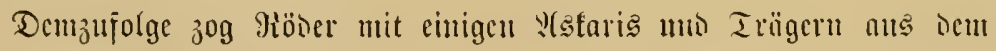

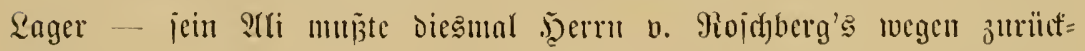
blciben - uno fam crīt jicmlic) fpät, aber bejrtesigt vont bicjem ?tusjuluge

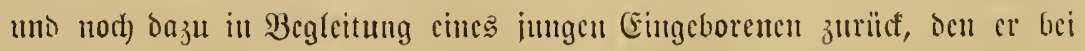

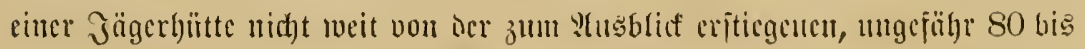




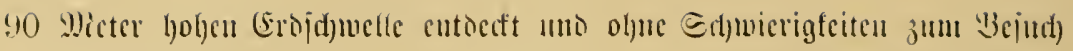
in Sager liberrebet hatte. Ter idfwarze - ober viclmefre bramigraue,

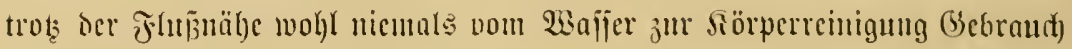

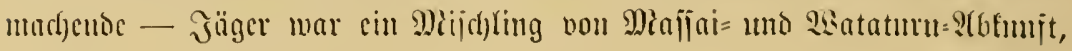
wie es in bicjen Sanditrid)en viele gab, jeit bic Tum=Sente fich) norbwärts

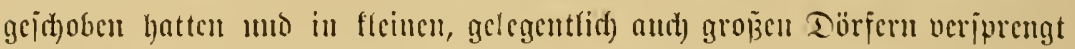

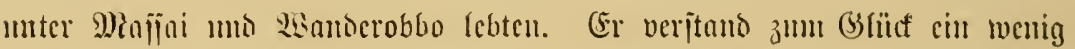
Siijtalgeli mo mar gum gemant in sem hiervon teilweije jtarf abucidgentom

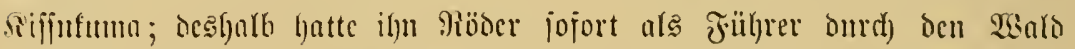

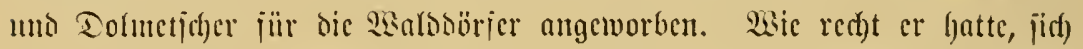

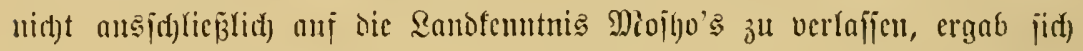

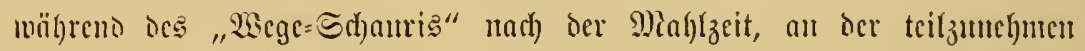

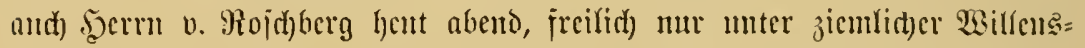

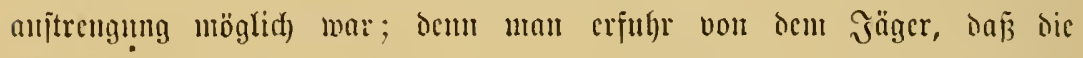

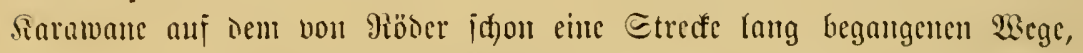

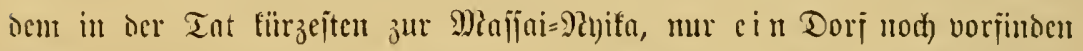

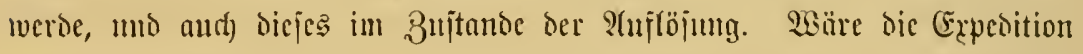
зmei Tage ipäter gefommen, erflärte der Farbige, fie mürbe ce vöflig ver=

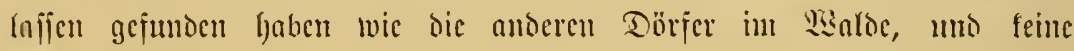
Berpilegung Gaben fauten fömtut.

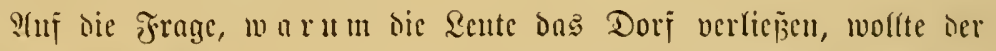

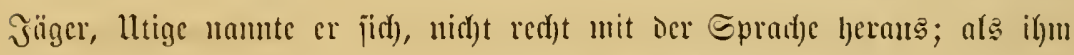
aber als Erjałz f̈̈̈r icinen alten, vielfach gefilidten Rendengürtel mit saran=

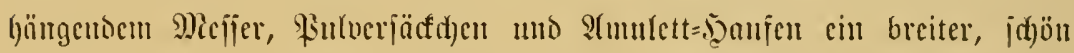
roter Reibgurt von imitiertem Judftenleder mit grof̈er mie હirber glänzentor

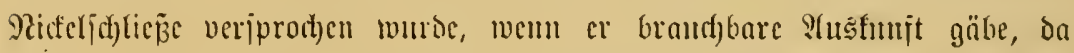

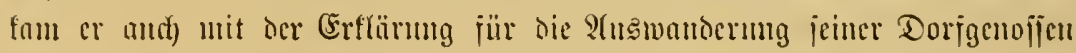

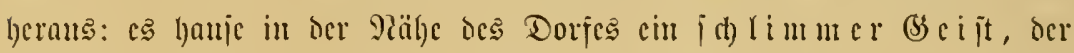

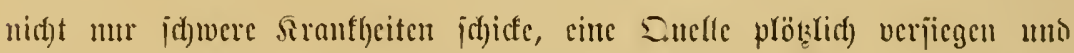

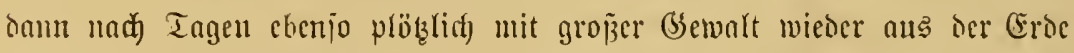
l)ervorbringen lafie, jontem der and die Jeldoc bös vermüite, ja, überdies

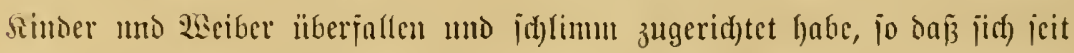

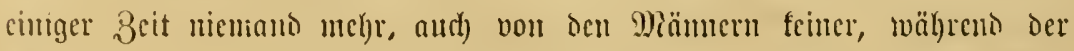
Dumferheit vor die Jjütte wage! Ein berïhmter mganga (3auberdottor) 
habe jür teure $\mathfrak{B}_{\mathfrak{z}} \mathfrak{j}$ ahlung jeine "Miesizin gemadt)

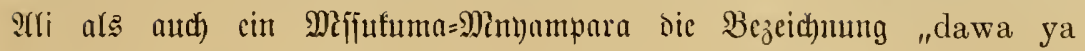
uchawi" -, habe aud) in eitrer Dunflen Racht in ber kilinge (3aubcr=

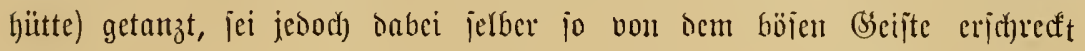

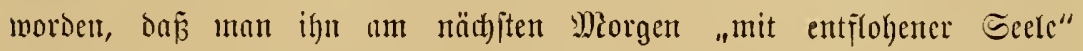

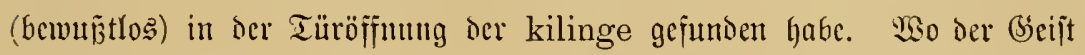
jo itarf jei, ba fönme man jiif) natürlide) nicht burd) zindika (Zautbermittel=

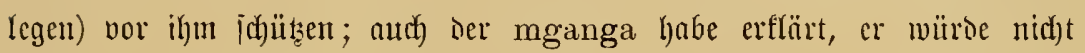
fïr alle Reidftümer ocs Sultnus von llnguna Sanjibar) noch cimmal kago machen gegen Den (Geijt. Da helfe nurr Dna Eine: ocr böjen Macht Dori unto Felser ganz ju überfajfen, Spjer auf bie waege zu legen und meitab cin neues Dorf ju erbauen.

Röber hatte ber mit unverfennbarer Soh)eu vorgebradyten (Erzählung

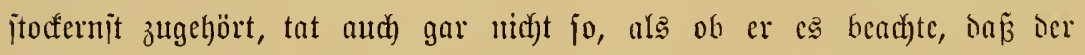
Manm jidf) fogar hier im Bomn=umhegten, von ben Sochfeuern uno ocn iiblichen $\mathfrak{W a d}$ tjeuern beleuthteten Rager ängittlich umjah uno bejontors dic Fronen des Warbrantes erjithecft anjtarte, wenn cin ju Pejt fliegentor Bogel die 3weige hernegte, Die Blätter jum Rajchelı brad)te. Er fragte mur: "5ajt Du ben Dihinn jerber gejehen?" So hatte lltige den „idhlimmen (Beifi" genannt; es war bns cin arabijches Wort, bic Bezcichnung

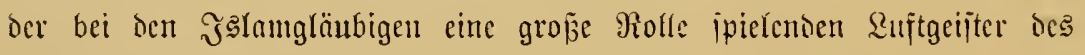
unjichtbaren Reiches Diginijtan, die des Rachts igr llnweien treiben. Ia viele hcionijche Peger ebenfalls an joldhe Padtgeijter glauben, dic jie jid freilich meijtens als Dic Seelen joldher Beritorbenen vorjtel(en, oenen nid)t genügento Pombe uno Mehl geopfert murroe, io hatte jich bic arabijhe

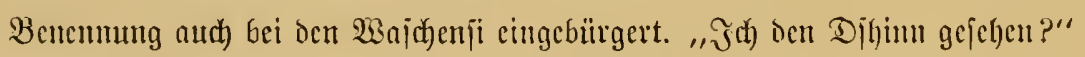

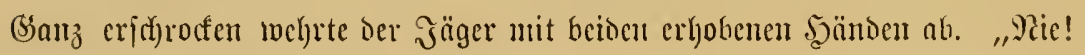
Dns wäre ja mein llnglïa gewejen!"

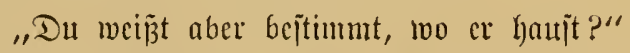

Der Mann nidte. (Er wolle die Baumgruppe nidft meit bom Dorje Dem Bana zeigen. $\mathfrak{a}(\mathfrak{s}$ er bei bicjen Worten dic lächelube, mingläubige

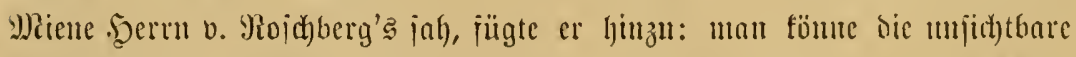

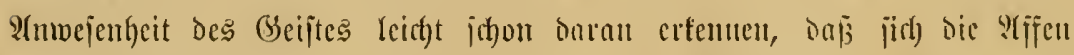

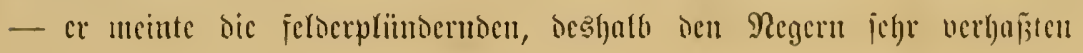


Miecrfatzenarten, dic kima, iprad) aber gleid) dautad) and) von oen nyani,

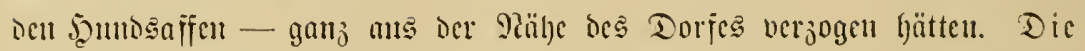

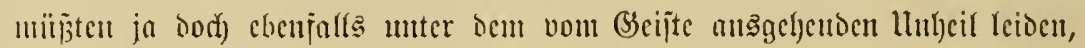
uno deshalh, natïllid), wïren jic gejlohen. - Es lag diejer Micinung

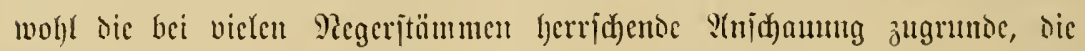
:(fifen jeicu cigentlict) nur vermiroterte Menjd)

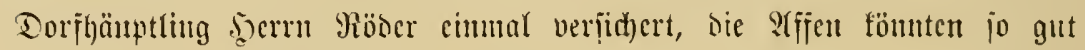

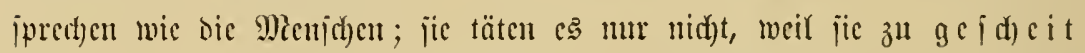

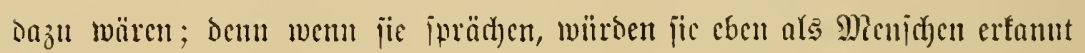
merben und mit $\tilde{B} t e n$ o a n a ud) arbeiten wie bie Menid)en!

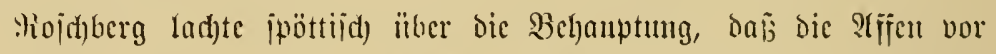
Dem "Bsijt" filichen jollten. Doch dic jull .baraza" verjanmelten

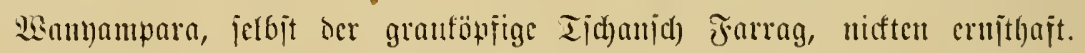
Mian merte ihnen im übrigen aut, on

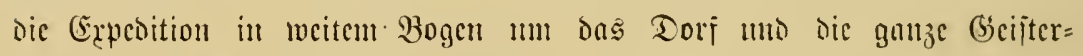
gegeni bätte hermmmarjd)ieren föment. Q(ber das ging num cinmal nid)t.

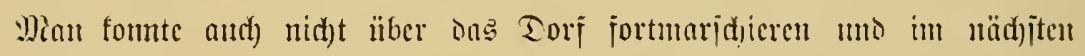

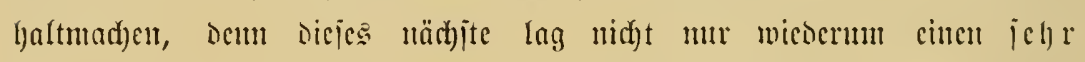
itarfen Tagesmarid) weiter ab, wie Ultige angab, jonocrn war and verlajien.

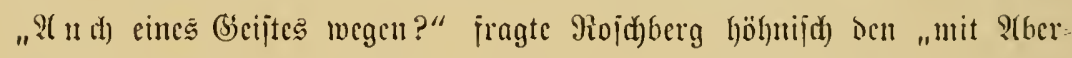
glauben bis un den Minno vollgepfropiten" Эäger. "9ieit," war dic Stutwort, jondern weil vor cin paar Эalyren Diajiai mel)rere Turn=

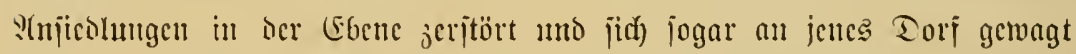

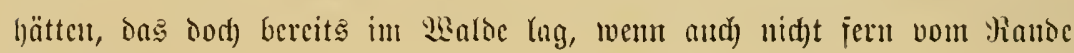
ber Steppe.

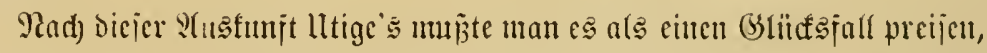

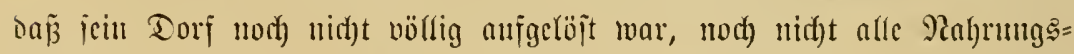
mittel fortgcidgleppt waren. Eeit mehreren SSodjen trugen idjon die Weiber uno fimocr "Plnis uno Bohnen uno Deirje umo Bataten" förbe=

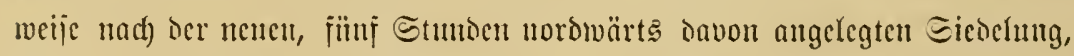

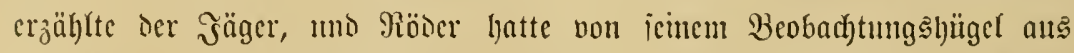

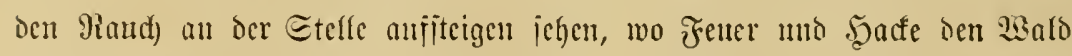

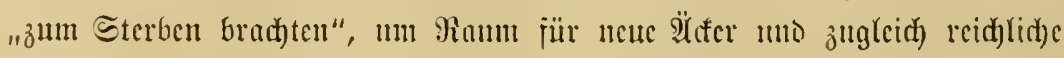

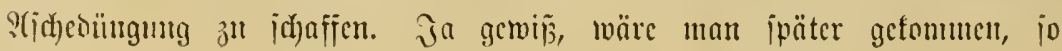




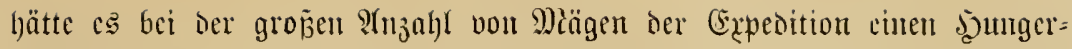

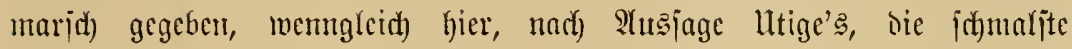

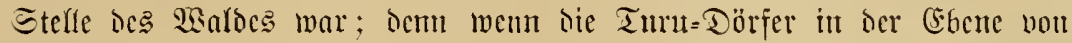

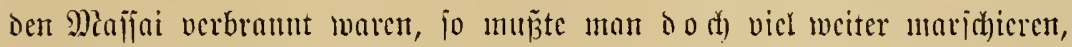

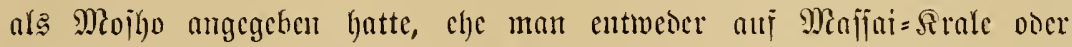

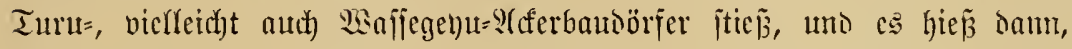

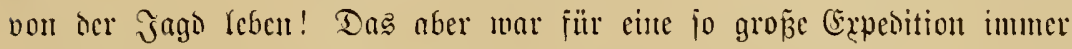
ein höjes Ding! Der Wald bot jidjerlich nidyt viel Wailo - bas

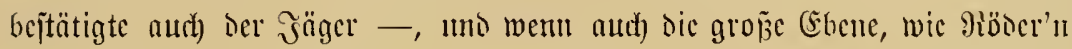

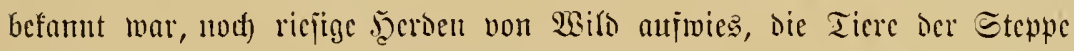

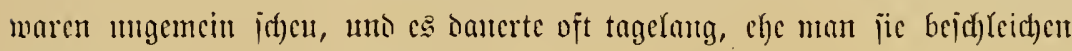

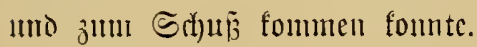

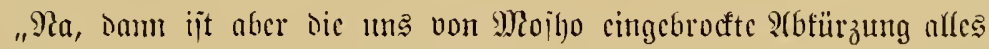
antore als eit Borteil", meinte Hojhberg, ocr hent nbemo jum eritcumtale

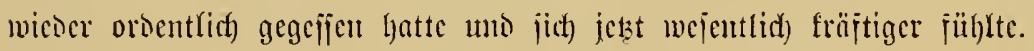

"Das liegt Dori) anters, Berelfrejter", erwiterte der Botbart

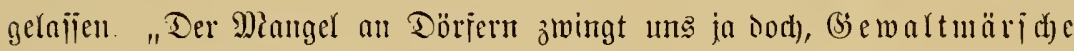

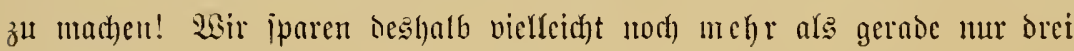

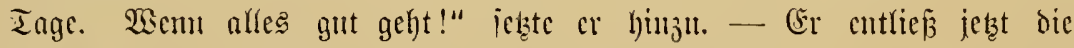

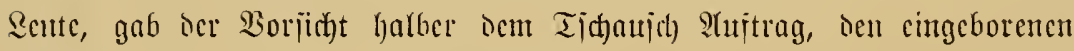

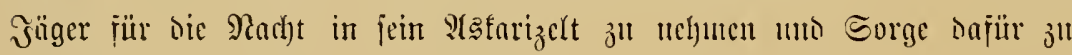

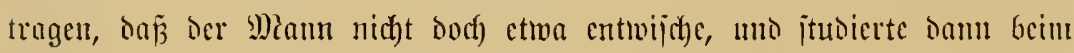

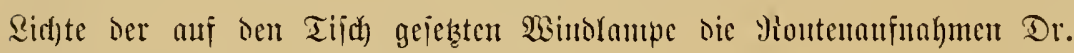

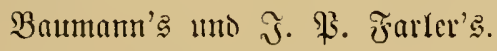

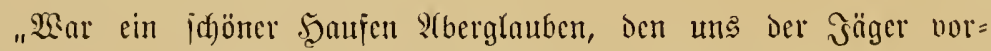

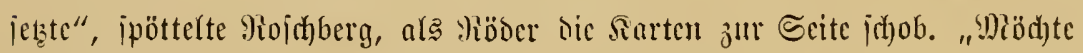

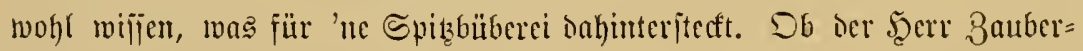
Doftor vielreifyt icine Şand in Spiel hat, den Sentd)en aus irgento cinem ipcfulativen (Srunte den (Beijterift)recten cingejagt hat?"

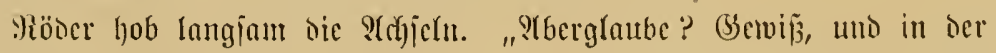

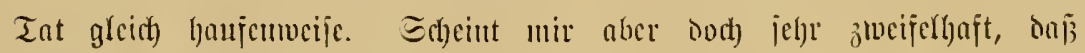

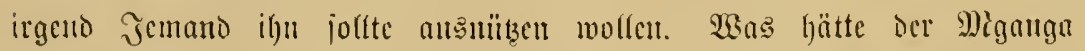

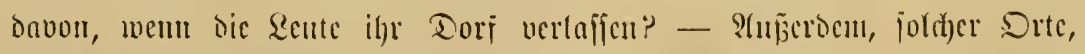

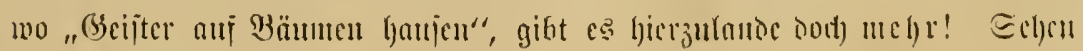




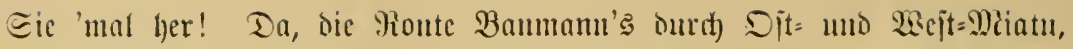

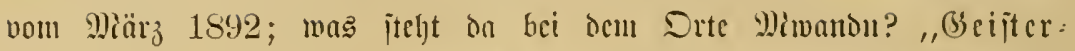

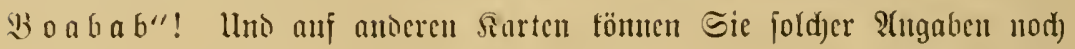
verid)iescure finton."

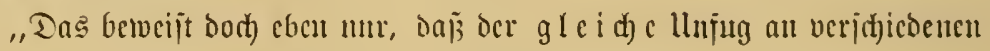
Srten getrichen iit!"

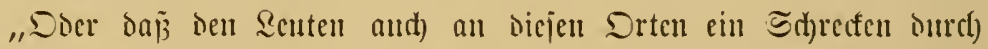

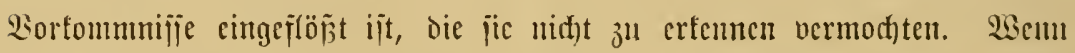
Dinge geid)chen, die fïh) umjere Meger bei ifrem im ganzen böbjit

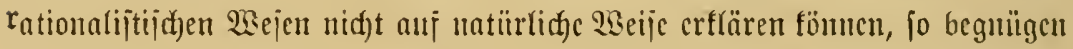
jic jich) mcijtens mit ber "Ertlärung", das jei fo der amri ya mungu.

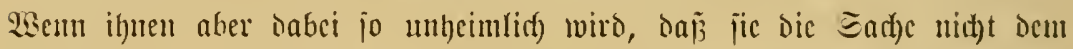

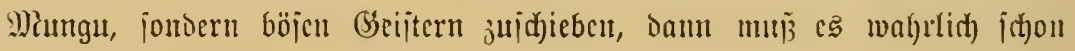
Dicf fommen! Pein," wicicrholte er nad) cincr fleinen Pauje nadjontlict),

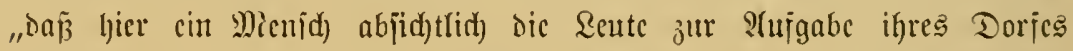
bringen wolfte, fann idj) nidht glauben. S(ber es trijit nad) ocr (Erzäblung Lltige's hier jo Biclcrlei zujanmen, ina die Sache łujammenhängt. Der Dihim joll die Felder vermüjten? Dn

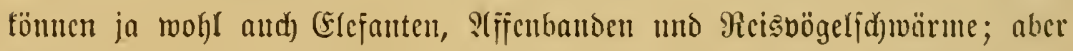
(Elefanten verraten jïd) zum minceiten durd) ihgre Fährten, Micispögct แmo

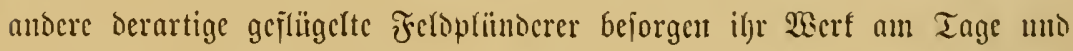

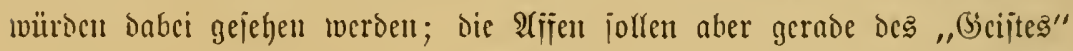

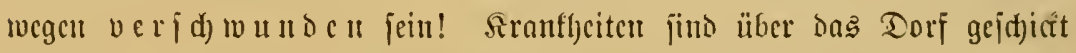
wordon? Die haben jelbjtucritänolid) igre natïrlidjen llrjad)en."

"Uno bie Suclle, die zeitweije auşblcibt unt danu doppelt itart bernordringt, wirt ebenjo anj matïrlid) Urjad)en bin verjiegen uno wieser: fchren. Jntermittierenoc, geijerartige Suelfen gibt's ja bod) id)(iej̈lid) nid)t

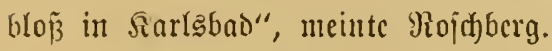

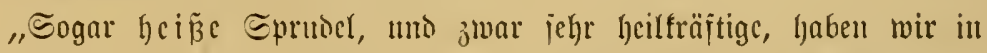
der Solonie; aber wäre das hier ein intermittierender Sprndel, er würoc in regel mä $\tilde{\beta}$ gen 3wijd)enräumen jteigen uno falfen, umo das hätten Die Echmarzen bci ifrer genauen Raturbeobachtung lange bemerft.

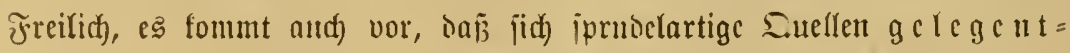
(id) iclbit veritopfen, durd) Eenfungen uno faltumgen oer ticjeren 
Erojdichten; und von jordhen Ilrjachen fönnen natürlid die Pieger nidyte mifien."

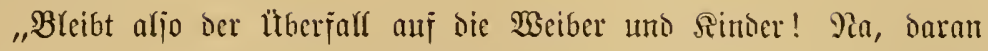

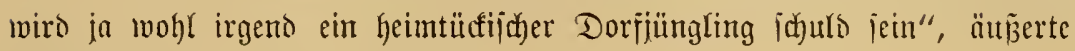
recht ironijid ber junge Curopäer.

"Il no es bleibt die den Renten augenjedeinlict) jo nahe gegangente

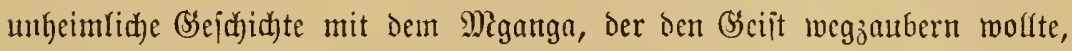

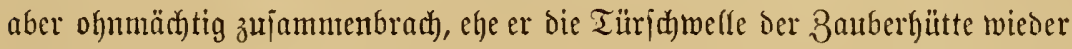
überiffreiten fonnte! Möglich), da $\tilde{s}$ er den (Beijt hat austäuchern wollen

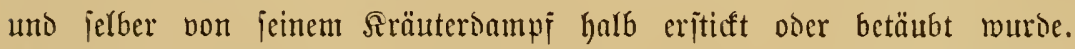
Jedenfalls aber glaubt der Zauberdottor an den föjen Ǵeijt, mindeitens

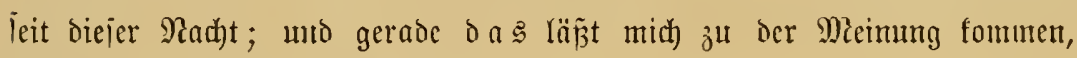
Da $\tilde{\mathfrak{B}}$ o 0 d) ctivas dohinter itectt."

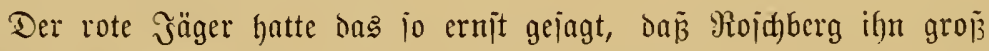

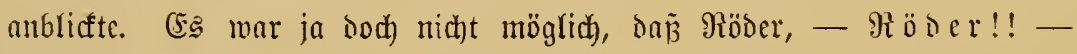

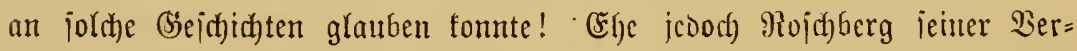
munderung 2usbruef geben fonnte, furhr Der Rotbart fort: ,Plun, wir müfjen unter alfen llmitänien in dem Dori lagern. Da wollen wir bod) 'mal zujehen, wie es fidh damit verhält!"

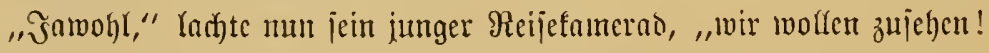

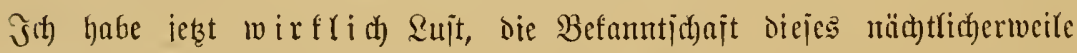

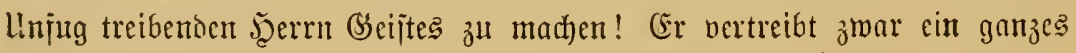

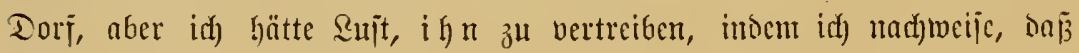
alles bloj Tummheit und Stberglaube ijt."

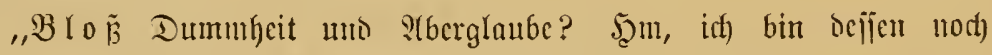

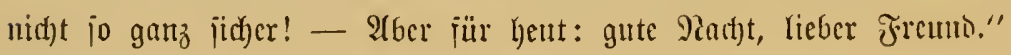

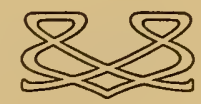




\section{Achtzehntes Kapitel.}

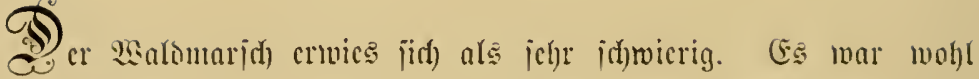

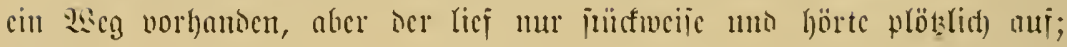

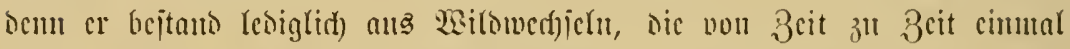

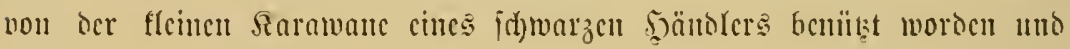
Baburth ctwas gangbarer gemadt waren; jumeilen hatten and die Dörifler

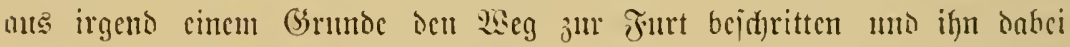

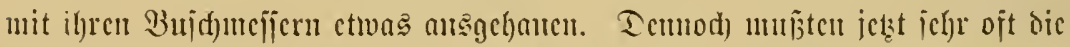

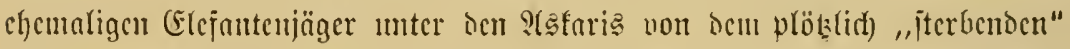

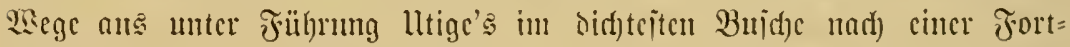

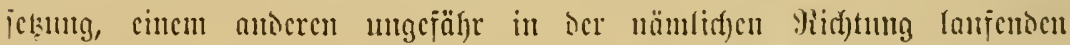

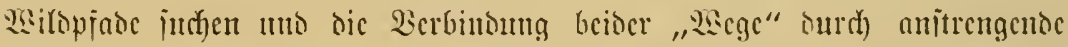

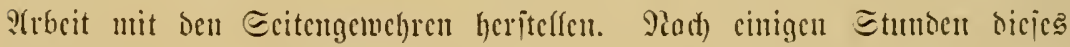

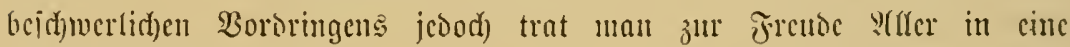

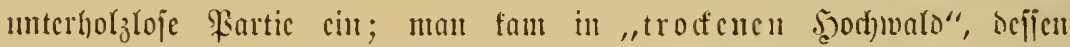

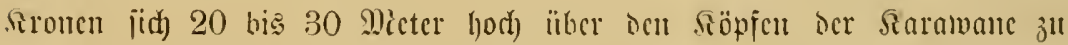

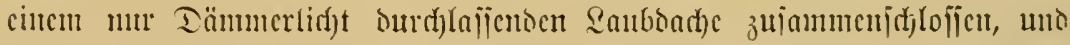
ocfien Dooben mur mit abgejallenen bürren vocr vermoberten Blättern

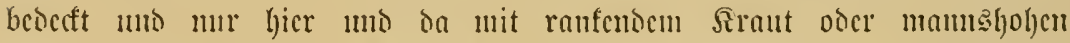

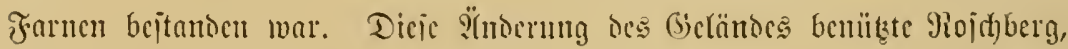

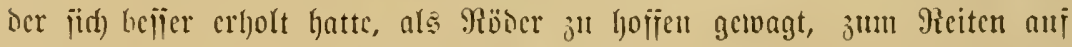

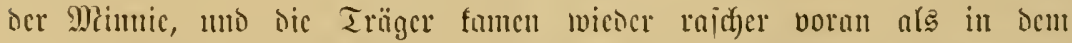

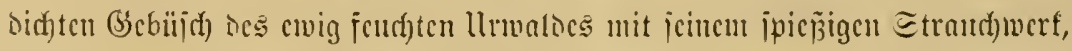

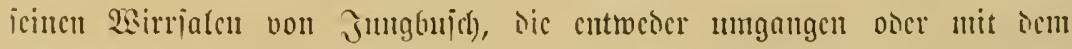

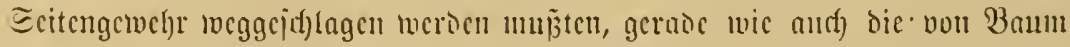

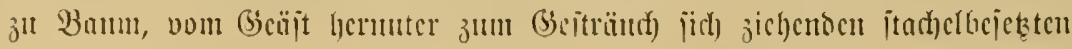


Sianen gefappt werden muñten, damit bie 2 cute mit ihren $R$ ajten durch)=

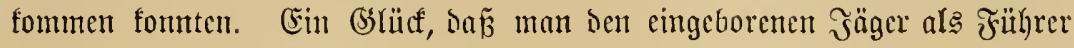

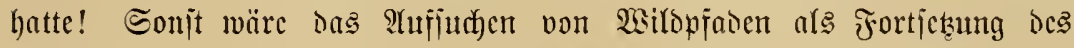
Weges nicht io gut vonjtatten gegangen, bic Suthe hätte jedenfalls un=

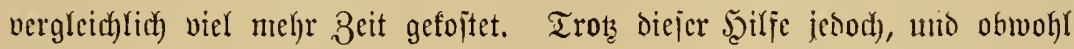

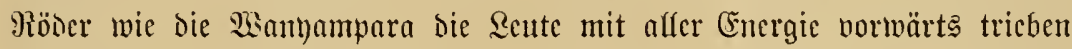
- es murde nur eine \$imujifa von Stumbenlänge gemant — traf bie Expedition erit gegen 4 Uhr nachmittags nor ien Feloern Des "Beifter=

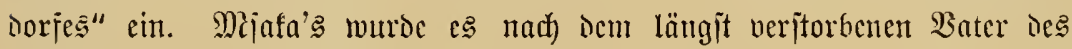
auth) idyon hod) betagten 5̧äuptlings Ennefo genannt.

Utige war juletzt den Fremben vorausgecilt, um jeinc Ramisleute

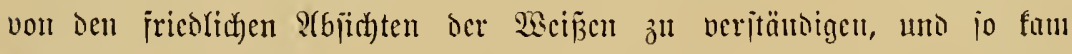

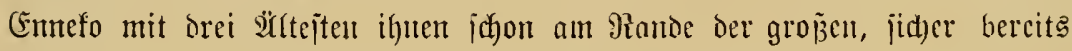
vor orei oder vicr Mienid)enaltern angelegten Walnlichtung entgegen, um

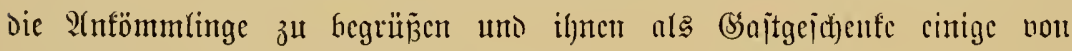
jungen Burichen getragene Büjichel Bananen iowic, anjï̈lltigerweije, cin

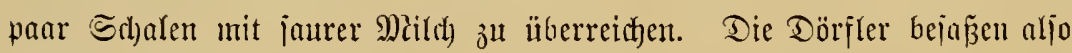

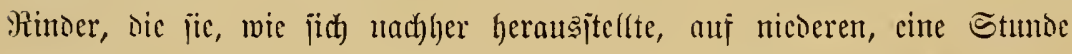

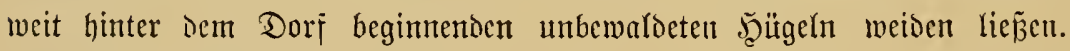
Mancherlei Majijai=Sitten hatten offenbar in biejem Mijichlingsoolf fejten

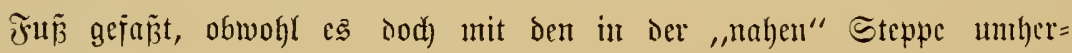
idweifenden Majijai jojujagen in "Erbjeindjifajt" Yebte. - Emeto iprad),

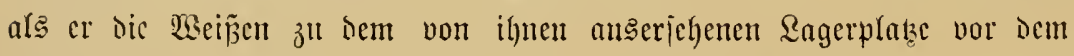

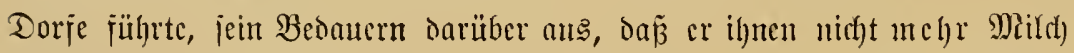

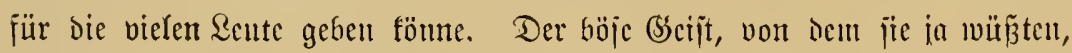

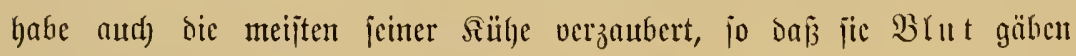
allitatt Mil(d).

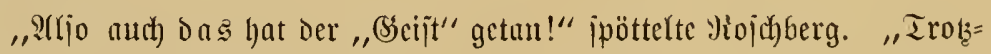

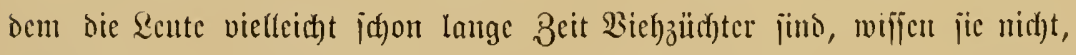

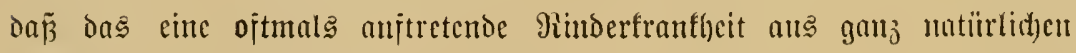

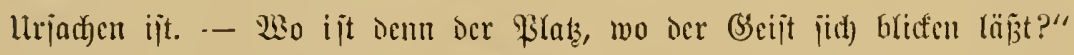

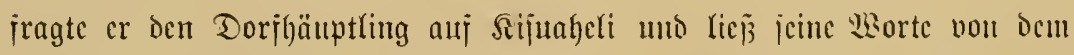

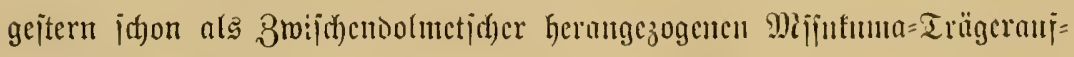
ieher ïberjetzen. 


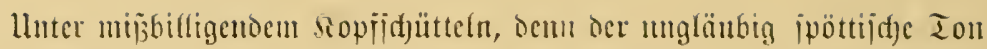

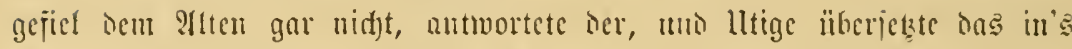

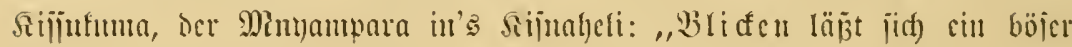

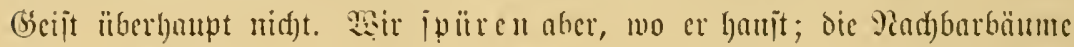
jeuts "Drtes" werien von allen Bögefn genteden, tmo jo fam man

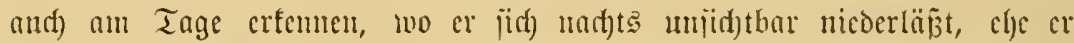
(burd) Dic Seifite fliegt mo jeinen id)limmen (beliiiten nad)geht."

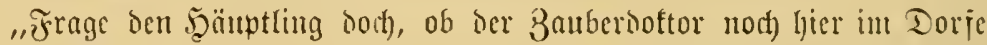

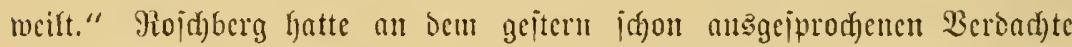

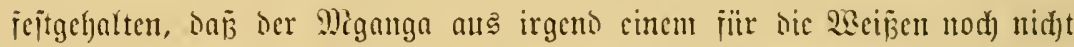

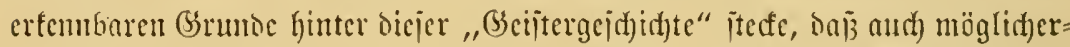
weile nicht, wie er juerit gemeint, rolje junge Buridfen die Weiber ïber= jallen hätten, wenn ïberganpt an dicjen l̈tberjällen etwą ssahres war, jomien baj der 3anberer andh) Gierbei ber litbeltäter gewejen jei.

Ja, ber Mganga wäre im Dorie; hod) cr läge frant in jeiner

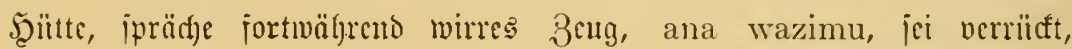
lantete bie vout eriten zum jueiten Dolmeticher weitergegeberic :Intmort eittes bicr Sittert.

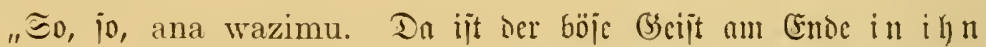

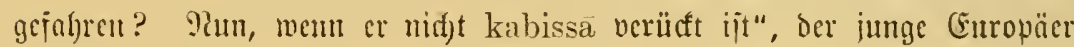

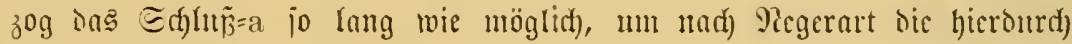

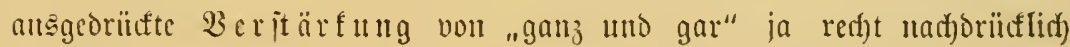

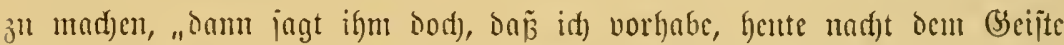

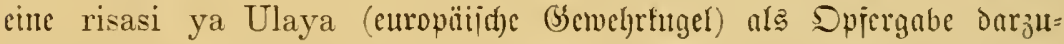

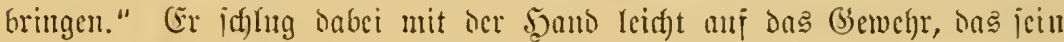
Bou Pieja ihm nadytrug, uno die Edywarjen veritanden ign jegr moht. Todf) jic waren offenbar red)t bejtürat über jeine \$(bjid)t uno marnten ign cinnringlich, er möge dod) ja nichts Feinojeliges gegen ben Bseijt muter=

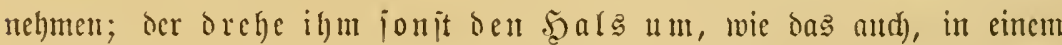
anteren Dorje, mit einem Peger geidehen jei. Der jei bei bent "Seljern" (Mijijionaren) gemejen uno (Egrijt geworden, uno als cr bann in jeine Secimat zurücfgetommen iei, fyabe er nidht an den Bseijt glauben wollen;

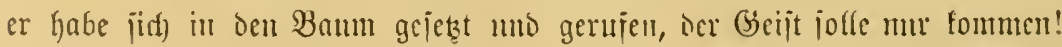

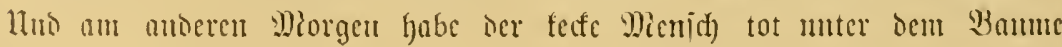




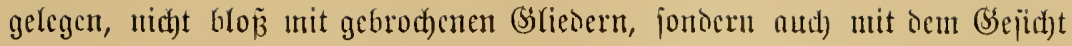
ganz nad) hinten georelyt!

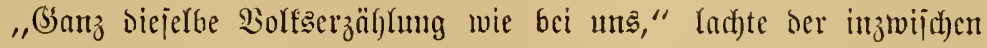

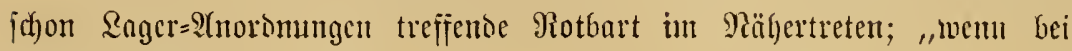

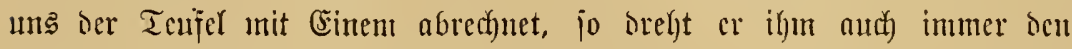

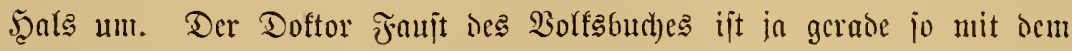

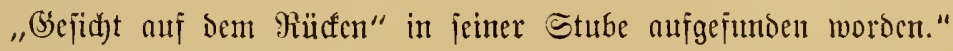

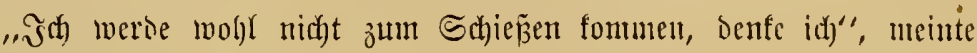

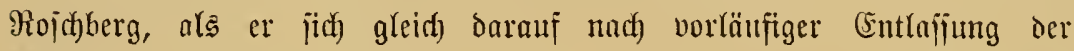

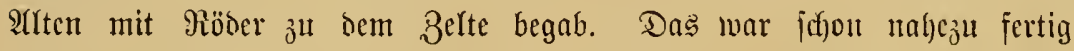

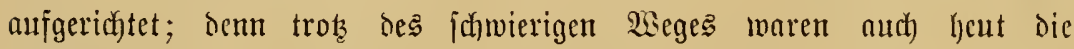
Belthniten unter sen crijten am Ragerplatze eintreffenden gewejen. „Remn

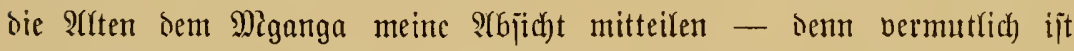
jein verrüufter Buitano nur ,Boripiegelung falicher Tatjad)en", uno cr

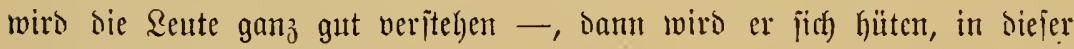
Nadyt zu ipufen."

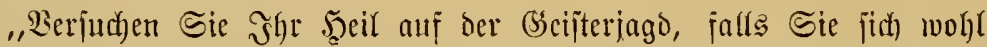

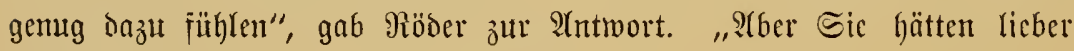
nicht vorher anzeigen jollen, Sic mürden idyiežen. Stecft da ivirflifí) cin

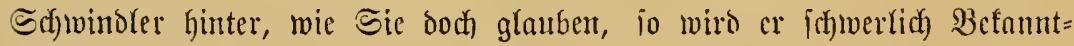
ichaft mit Э̧hrem Bsewehr machen wollen; in haben Sie ganz recht."

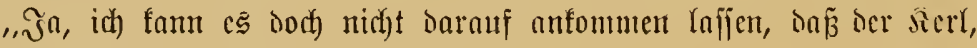
unt weun er zehnmal ein Schwindler iīt ..."

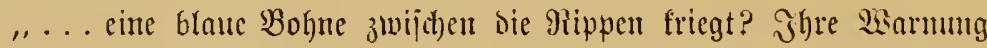

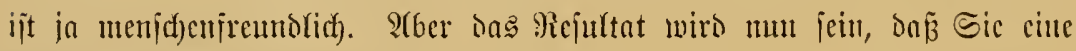

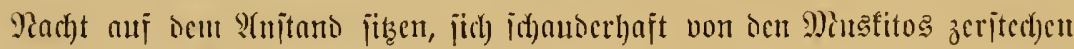

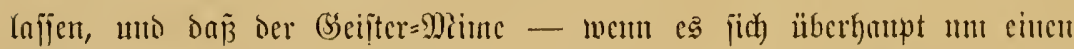

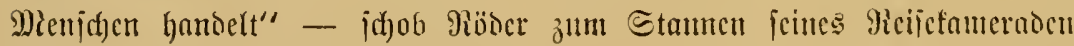
cin - „jid) morgen friif), lvem wir weiterutarj(fieren, vergnïgt hiuter uns in's Fäujt(d)en ladyt!"

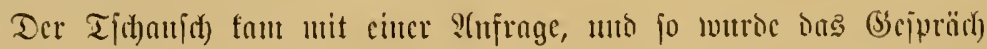

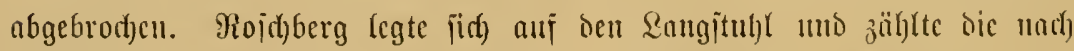

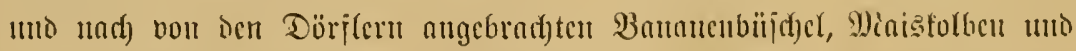
was jonjt nod) gegen bic glcid) anjange verabresete 3 af)lung in Tauj(t)= 


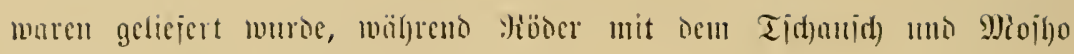
Durd) bag raidh cutittehentic Enger ging.

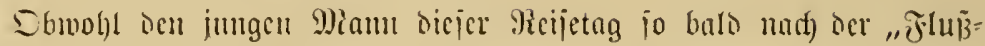
gejdjid)te" itarf angegrijifen hatte, umo obglcid) er jelber cimjah, onj er

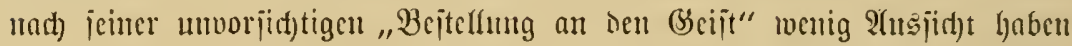

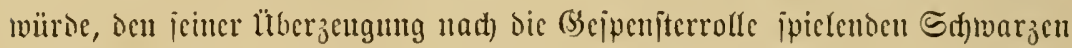

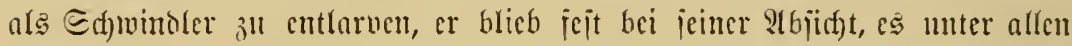

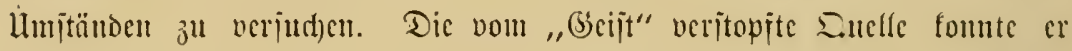

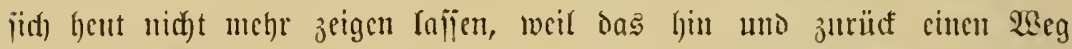
von ic $3 / 4$ Etuntoen erporbert hätte; uno bei jeiner Miibsigteit war ihm

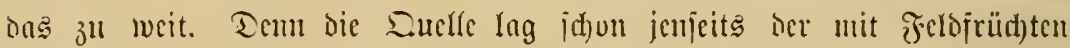

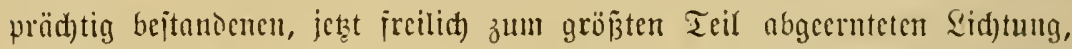

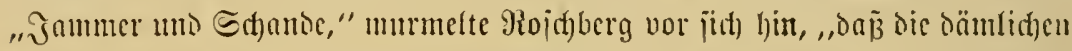

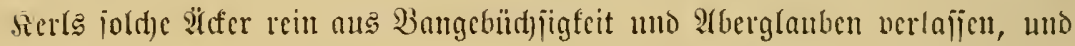

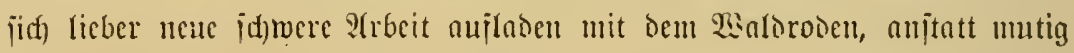

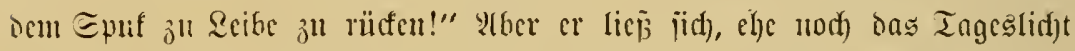

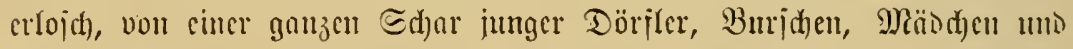

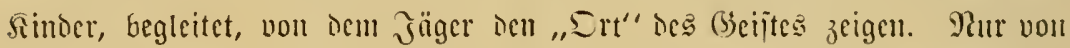

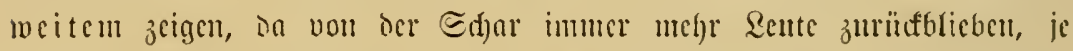

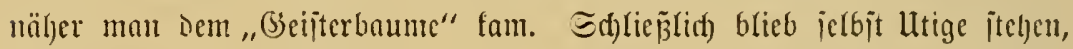

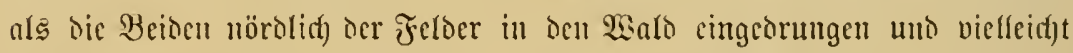
10 Mimuten barin geraienus nad) Norben gegangen maren.

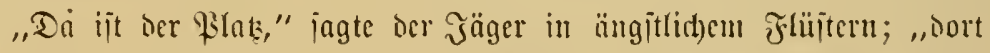
oben in ienen Bäumen haben wir die sijte jidh benegen jehen, unto sie

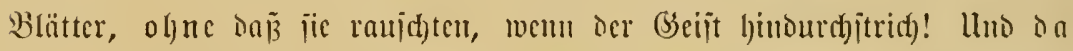

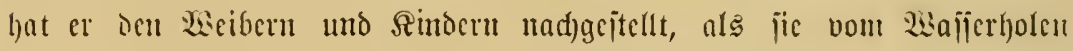
famen." (Er bentete babci auj eime zrije)en den fuorrigen, jïh) über Den

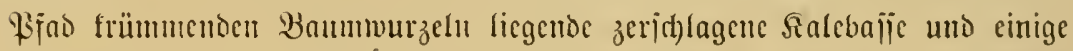
Tud)fetzen, Dic woht von ihm suie von dem ganzen Dorje als llberrejte

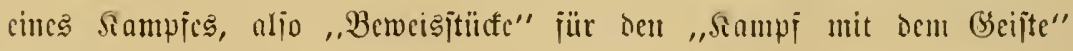
angcjebcu murocn.

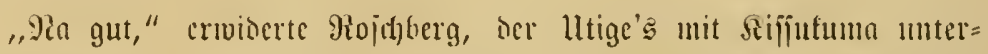
mijhtes Sijuaheli wenigitens cinigermañen veritanton hatte; "wenn das

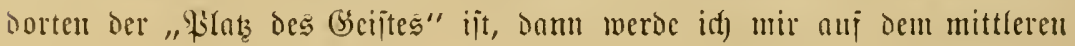




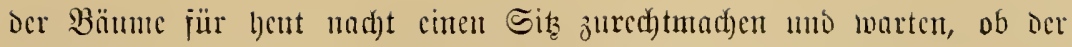
(Sheijt fommt, um meine "Opfergabe" in Empfang ju nelymen."

Der eingeborene Эäger j(hauterte förmlich), als cr bas vernalgm. So hod) jeine mic aller Sdjwarjen Meinung von sen Rünjten ser Wajungn

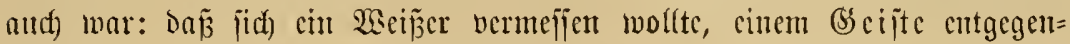

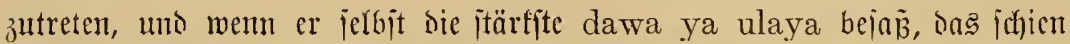

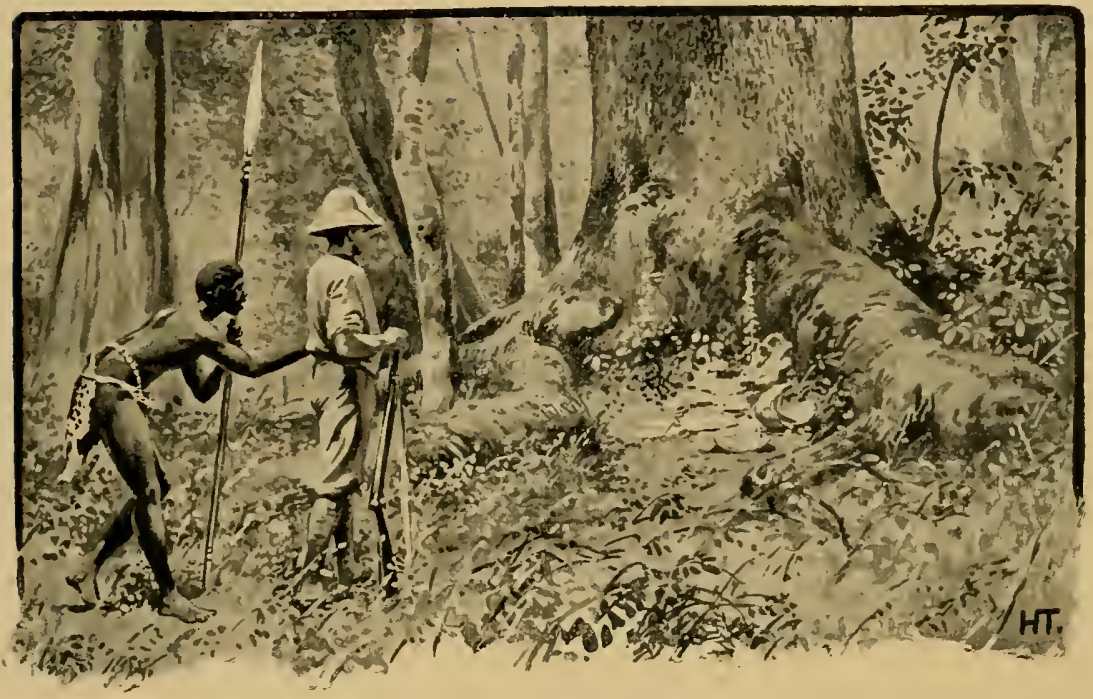

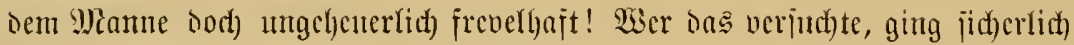

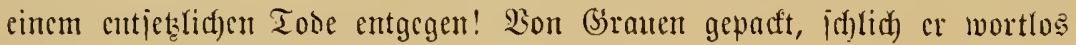

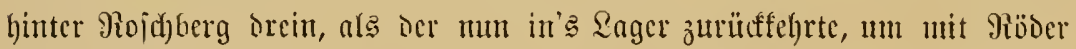

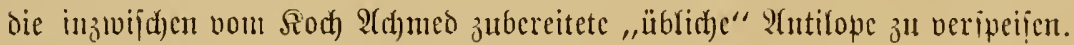

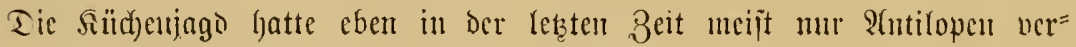

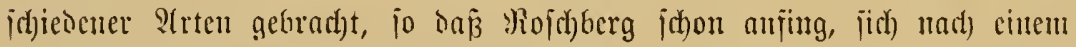

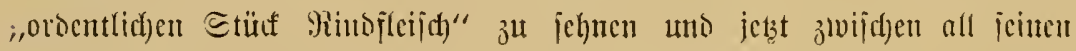

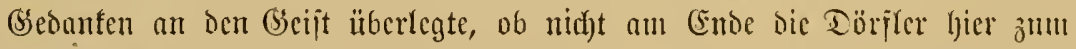
Serfauf cines Rimdes zu belvegen wärcu. Tod) beim Betreten ics Prlałes vor Dem Zelt, bas bei ince rajd) cinjallenoen Dumfelfycit teils nou bem

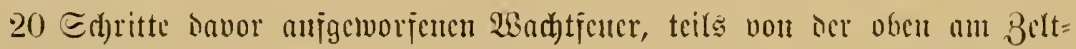

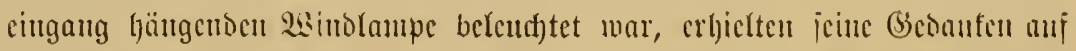

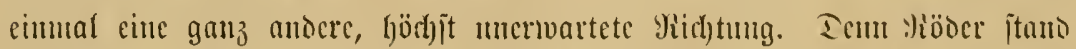

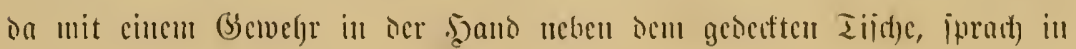




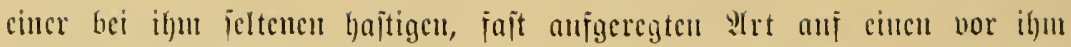

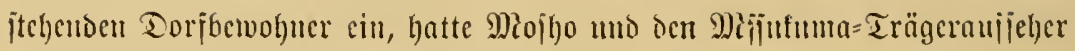

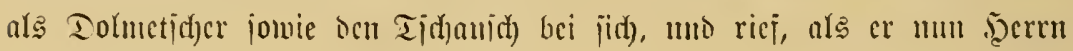

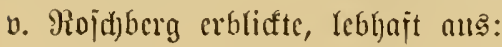

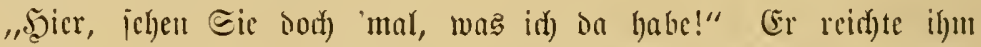

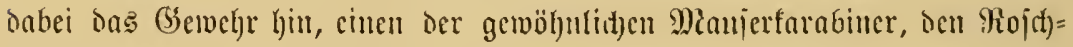

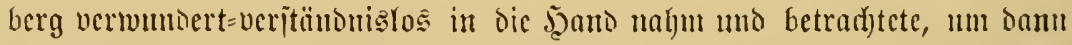

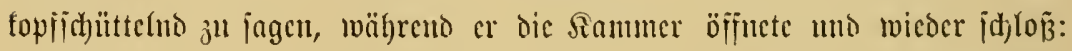

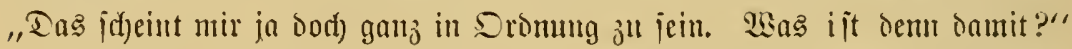

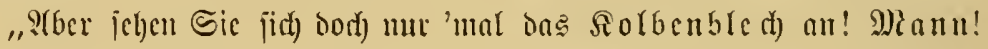
Sojhberg! Da jteht eingraviert tarauf: G. M. 17!"

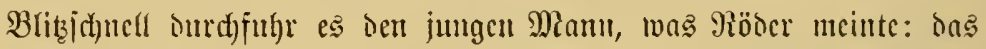

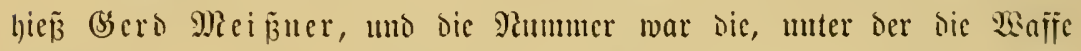
in der Gemefrrijte der Eqpedition des \$roppettors gejührt wurie! Er founte erit mu ein critanntes "Dommerwetter!!" hervorbringen mo jragte

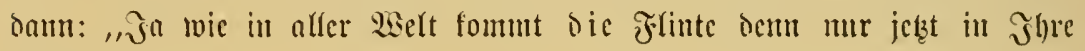

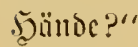

In hajtigen, hörhar jreutig erregten 2isorten crjählte der Motbart num, wie ocr Ceingeborene da währeno des Rajtenoronens an Miojho her= angetreten jei mit Der Frage, ob er ihu nicht cin gutes Borberfadergewelyr

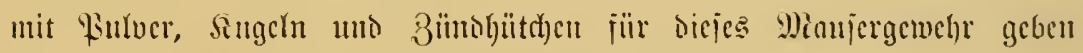

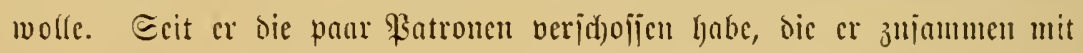

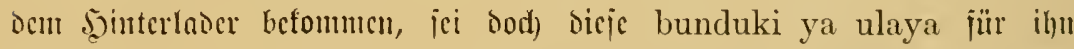

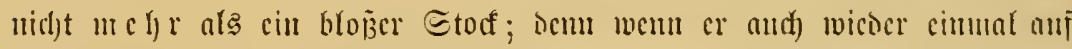
cinte Station fäme, Şinterfaderpatronen mïrben an Eingcborene ia dod)

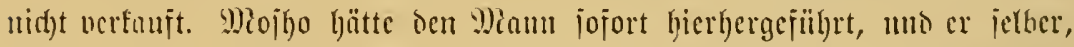

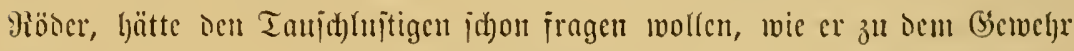

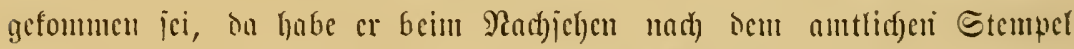

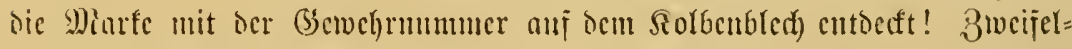

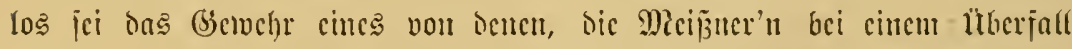

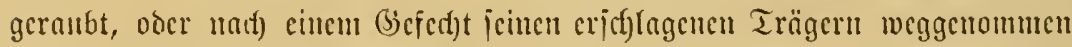

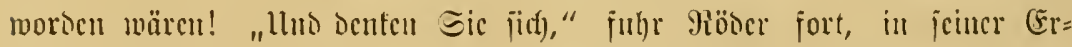
regung oen roten Bart jajt зu Bejtrüpp juiammenwirreno, "loic idt) ten fierl do in bie Enge treibe, friege id) herans, Daj er's von cinem 
Jafluten hat, oier fagen wir 'mal: haben will, ber nod) bor zwei

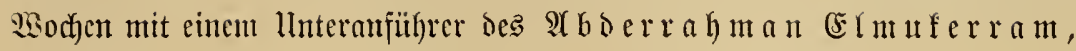

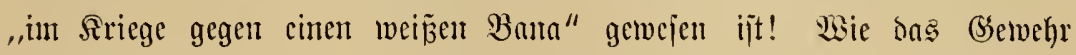

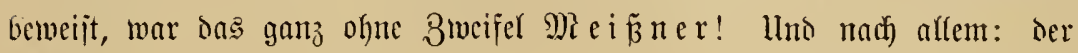
"Sirieg" fann nidjt weiter als etwa 10 bis 14 Tagemäriche bon hicr jenjeits der Steppe im Gebirge itattgefunten haben, Meißner hat alfo

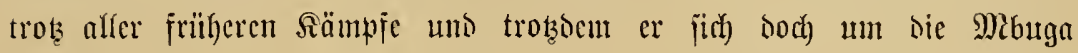

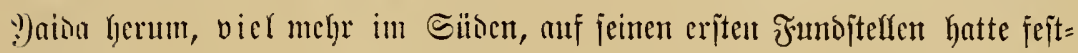

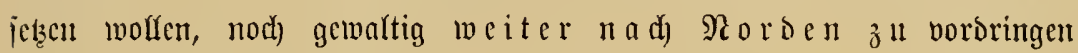

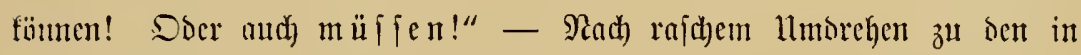
jehr unbehaglidyer Berfafjung baftehenoen Dörflern fragte er Den (Setweh) =

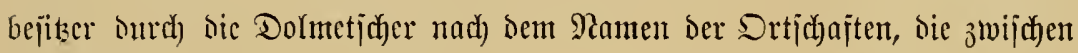

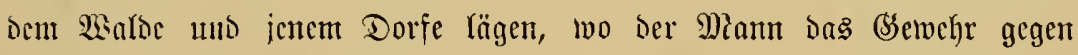

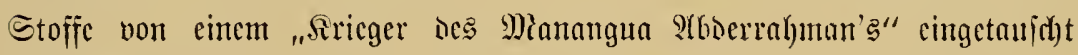

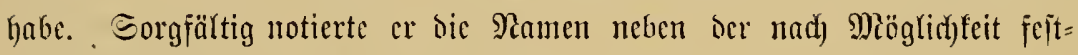

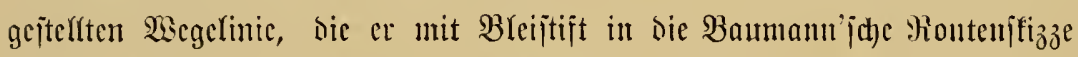

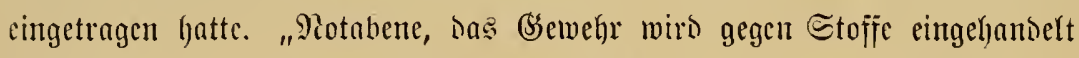

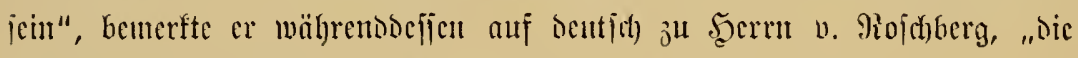

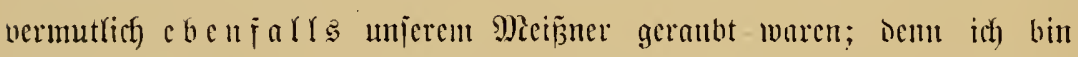

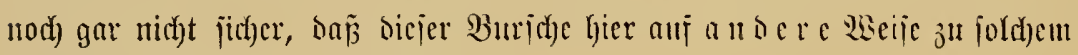
"(S)cloc" hat fommen fönnen."

"Eic meinen, ba

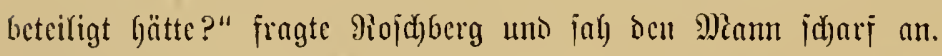

Das jefien ber Botbart allerbings zu meinen, und vecjuthte feine

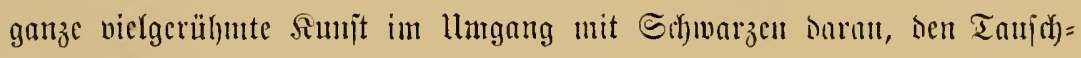

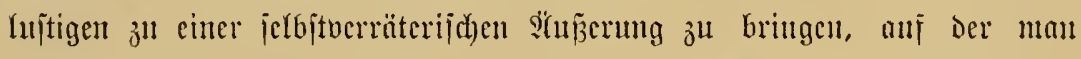
il) hätte "jejtungeln" uno bann Rähcres über Drt uno 3eit bes foge= nannten Siricges aus igm hätte herausprejifen fötmen. Jutofīen, entweincr

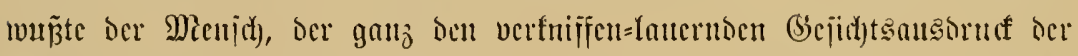

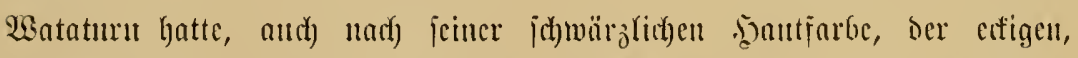

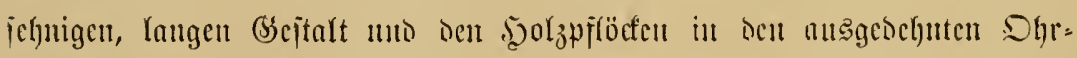

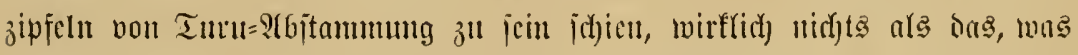

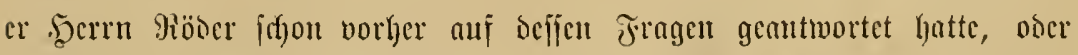
aber ber rote Jäger fand hier in ber "Diplomatic" jeinen Slecifter; jenen= 


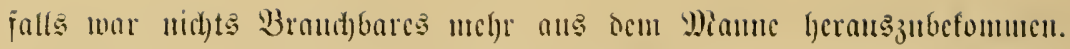

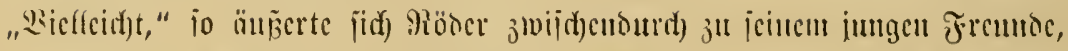

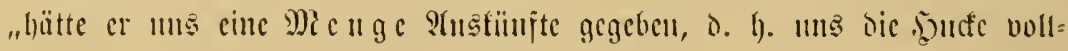

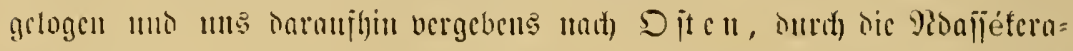

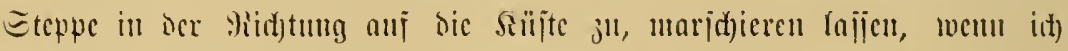

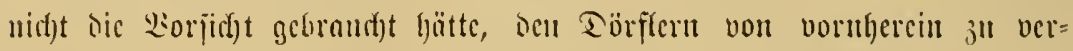

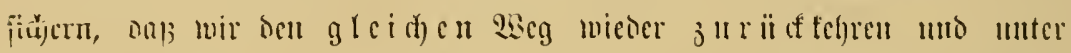

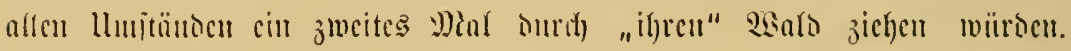

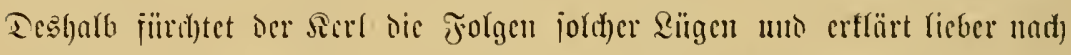

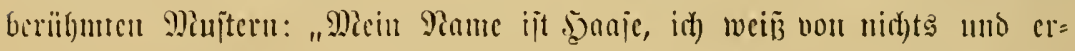

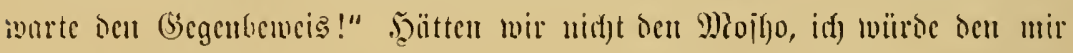

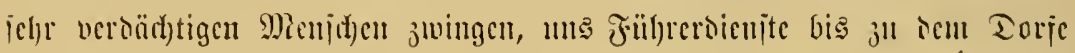

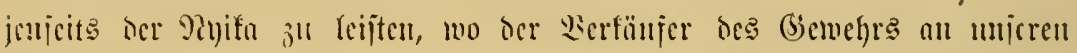

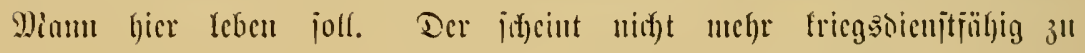

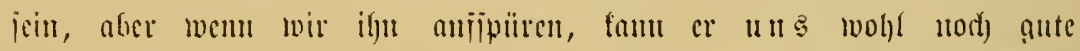

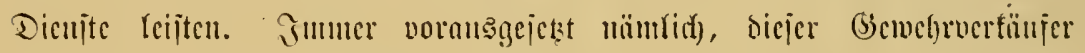
crijticet wo

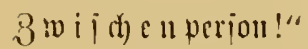

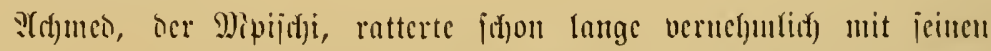

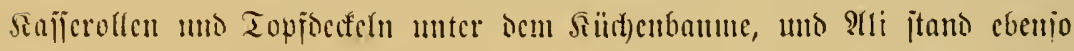
lange cin paur Elf)ritte hinter icinem jeerm,

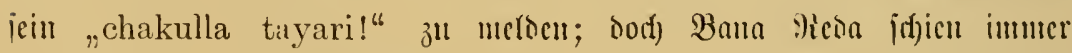

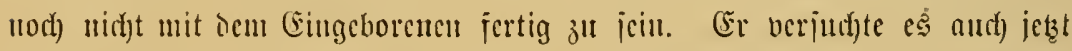

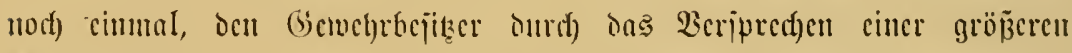

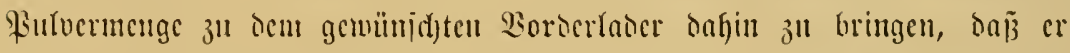

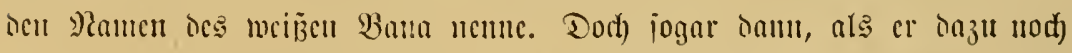

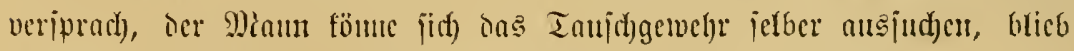

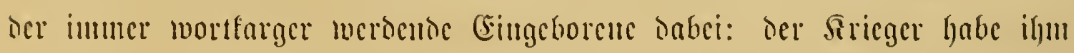

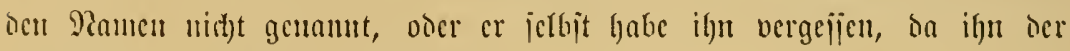
tote 2 Eisiß ja weiter nichte anging.

"Jallo, ocr tote?" juller giöder ali. "Jit oer wocißje Bana im Sampi gefallen? Tavon lyajt Du ja hishcr nod) gar nid)ts gejagt?!"

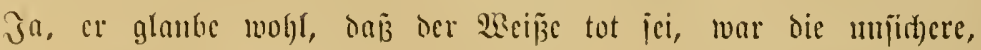

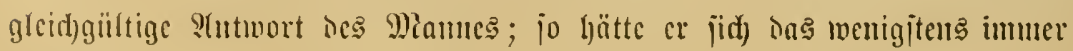




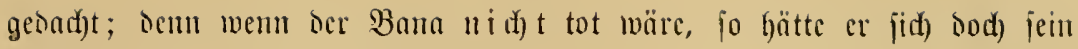
(Geswegr woh)l nidd)t entreipent rajïen.

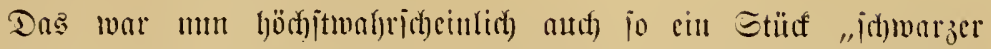

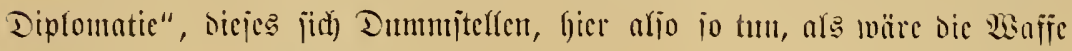

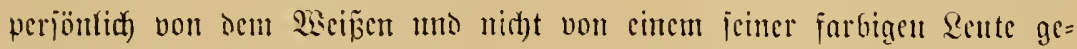
jïl)rt moroen. S(ber man fonute es bem Mann nidyt uad)weijen! "(S) nt,"

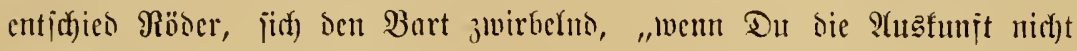

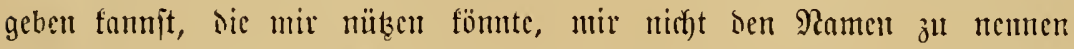

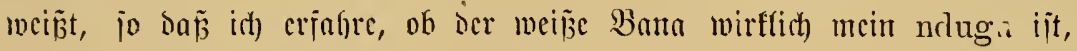
mit bem id zujammen treffen will, uno menn Du audh nich)t jagen fannit, of er nod) left, oder ob er tot ijt, - sanu fante id) Dir Dein (Secwehr überhaupt nirht ab! Daun bchalte Deinten "Stoct" nur, . . . bis ber

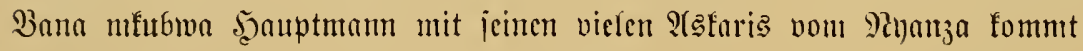

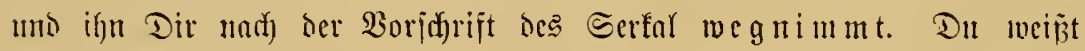

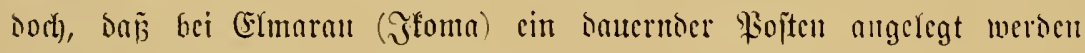

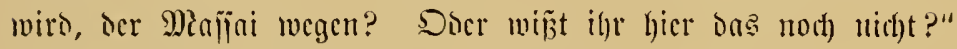

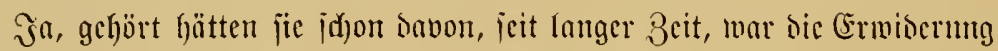

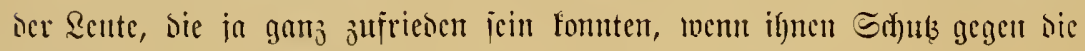
Miajiai gewoührt wurbe; abcr ob es auth) wahr wöre?

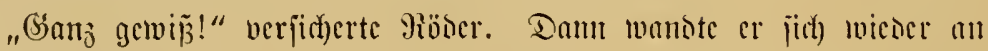

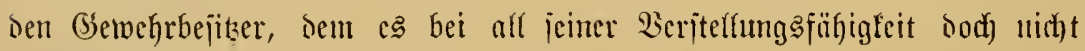

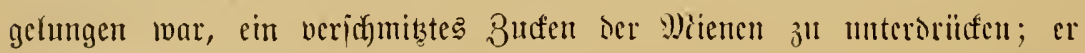

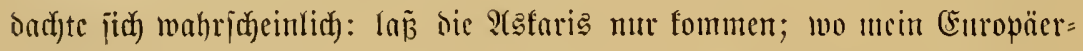

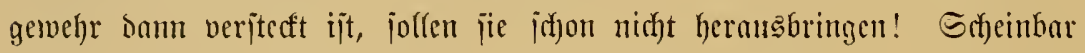

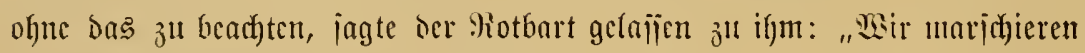
morgen nach $\mathfrak{T}$ uftroducm bes Tats bon hier ab. Wsillit Du Deinen

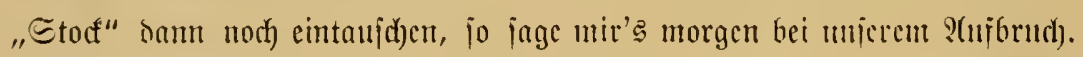

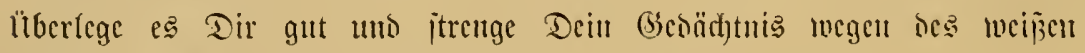
Bana an. Es wirb Dein Sortcil icin! - (Snte Piacht!“

Damit verabjectiesete er bic Sente.

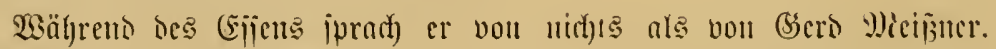

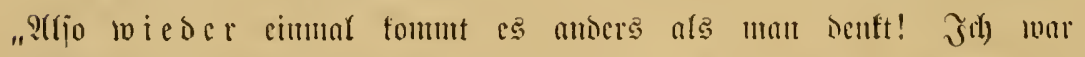

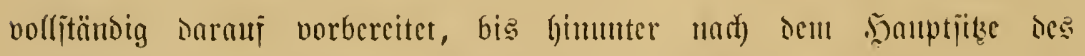

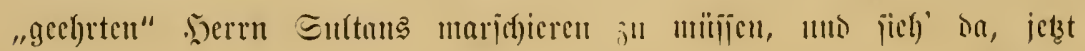




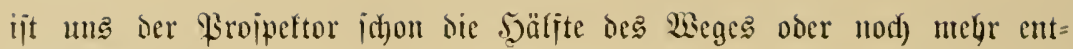
gegengefommen!"

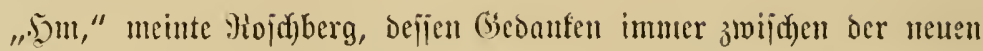
Viachrid)t tmo oer geplanten "Geijterentlarbung" hin uno her pendelten; "ganz abgejehen Davon, baij ber Sierl von vorbin viclleid)t mur allzu rech)t Bamit hat, baj ber íl ühere Gewehrbejizer, oder ridftiger ber Ehej

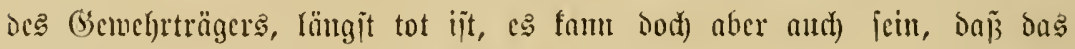

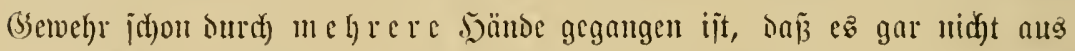

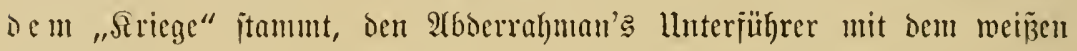
Bana gehaft hat, ichon frither in sie bänoc von Edywarzen fam! Lno

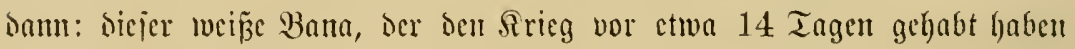
joll, funn sod) wirf(id) leid)t genug cin a no erer Broppeftor iein; wir mijien bock nad)gerade, baj in bicjen (begenden", er madte eine weit

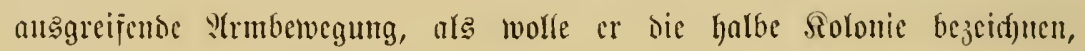

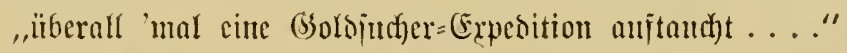

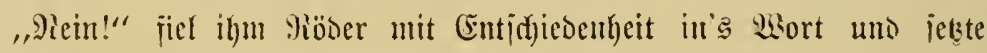

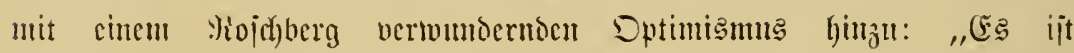

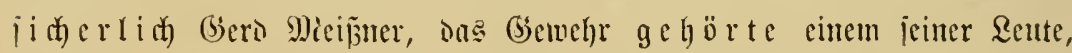

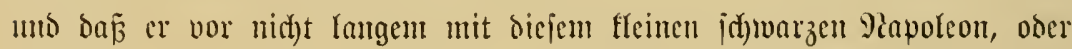

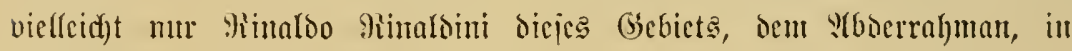

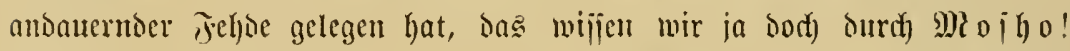

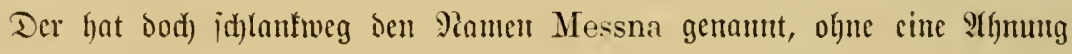

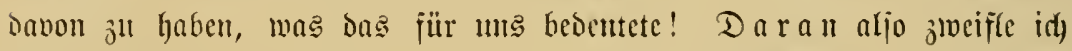

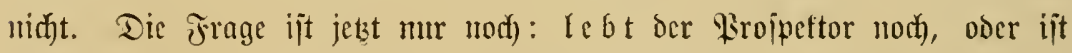

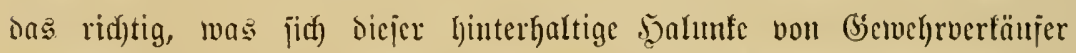
"menigitens immer jo getsad)t" haben will! - Ther pajjen Sie auj,"

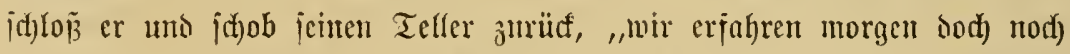

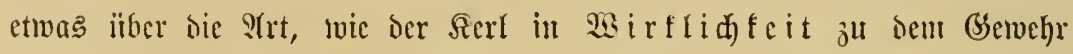
gefommen ijt. Entweder "erimert" er jid) Dam entlid) an bas, mas bod) wohl faum fänger ale 14 Tage zurüffiegt, ober twir tömnen aus

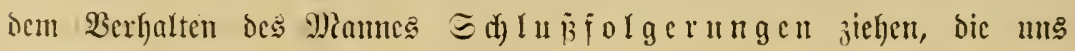
miiltzlich) jein werìen."

Darin jollte ber rote Jäger inem am anderen Miorgen aud) redft bebalten, wenn es aud) Gierbei wiedermm eimmal ,anders fam"! 
Trla der Mond über der Waldfidtunt mit Feldern, Dorf uno Cafari=\&ager ftano, nur als idmale Sidjel uno boch bei ber flaren $2 u f t$

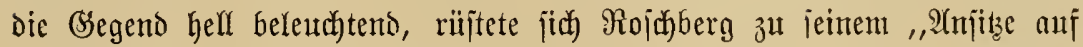

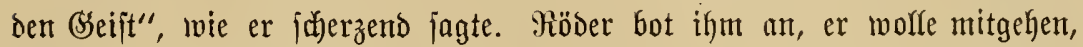

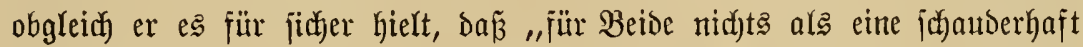

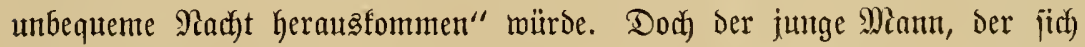

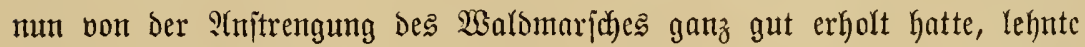

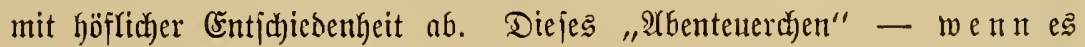
zu einem fam! - wollte er auf eigene Şano bejtefen. Da er aber einen Boy zur Şerridtung eines wenigîtens erträgfichen Sizes auf den sijten

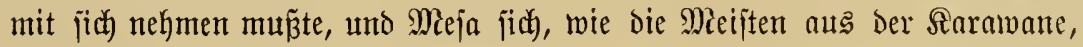
faum minder als bie jesct ftifl in ifren .̧ühten bleibenden Dörfler vor Dem

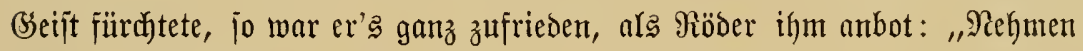

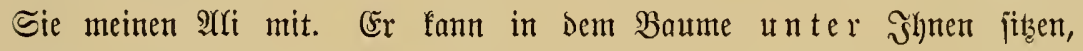
während Sie die żweite Etage beziehen. Und jenenfalla, wenn roir

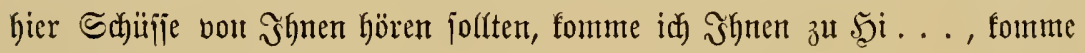

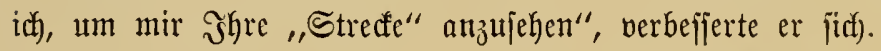

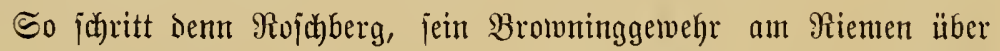
bie Shulter gehängt, in belujtigt=neugieriger Stimmung dem $\mathfrak{B a} a$ b=

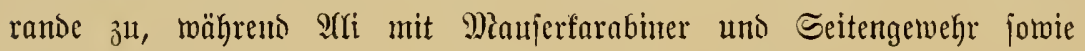
mehreren Wos!decten und einigen Riemen zur Şerrichtung einer leislich)

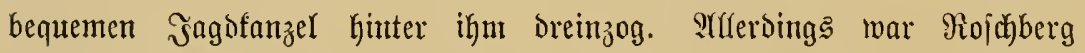

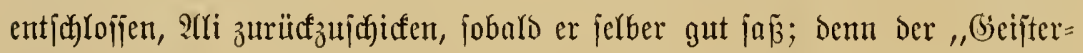
Mime", menn er es überhaupt wagte, zur Errböhung jeines Siufes unter

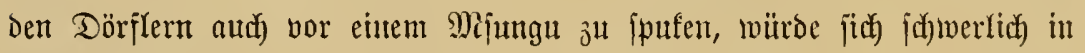
(Siegentwart von zwe i Beobadytern jehen lajjen mögen!

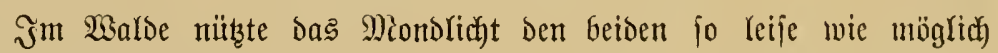

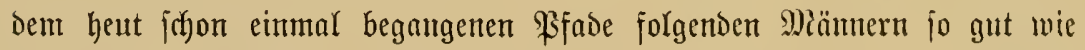
gar nidyts. Im Bsegenteil, bas mur hier umo da zrwijchen cin paar weiter auseinanderjtehenden $\mathfrak{B a ̈ u m e n ~ b i s ~ a u f ~ D e l l ~} 30 \delta e n$ falfente, zitterno an oen Stänmen herunterriefeftroe uno bon gelegentlich) f(d)wantentent 3meigen crjt verbunfelte und bann mieser auffimmernoe Silberlid)t beirrte jun urmociten den jungen Europäer in einer büd)jt itörenden ?(rt; jo jehr, baj er jitr)

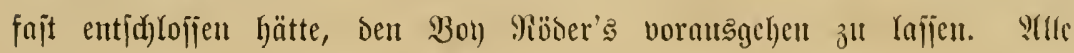




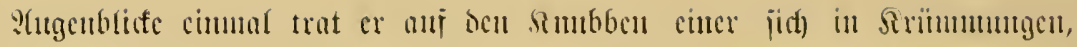

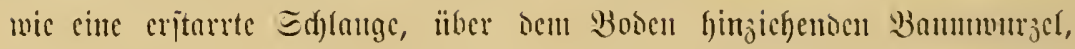

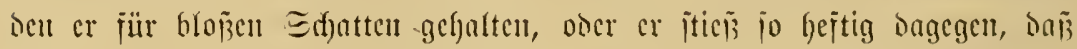

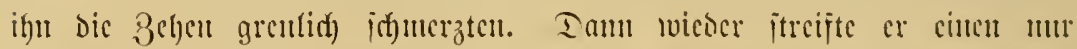

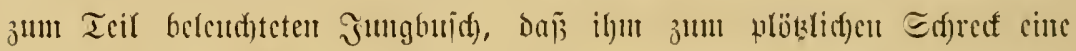

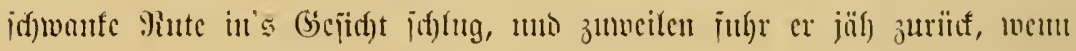

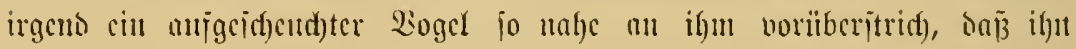

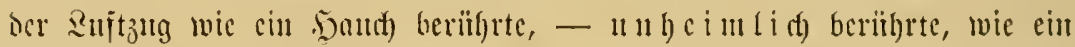

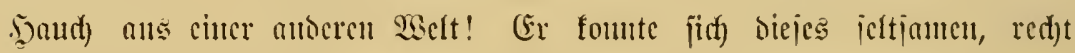

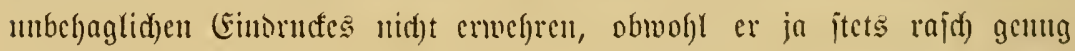

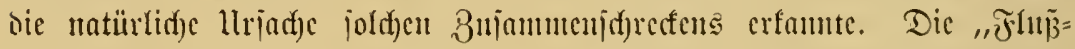
geidhidfte", und vorber ถas Fieber, hatten ifyn bod) nervöjer gemadyt, als cr geglaullt hatte! - llno ... W

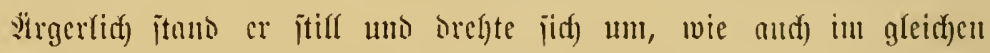

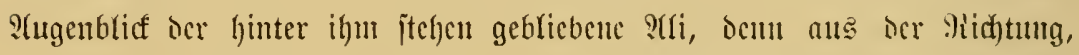
in ber jie gefoumen, juflug ein merfwürdiges flappentes, rajhelnoes

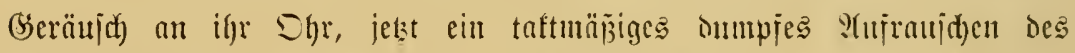

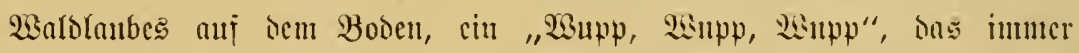

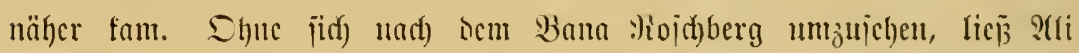

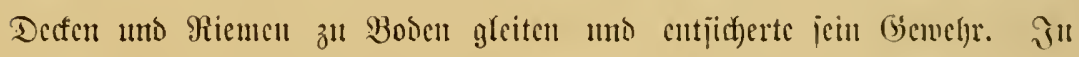

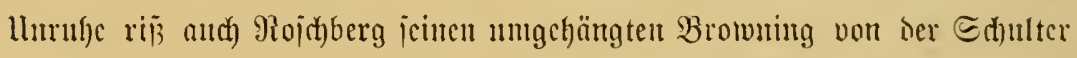

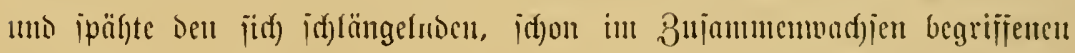

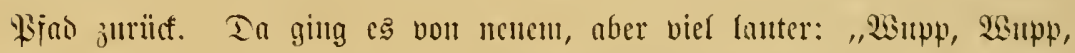

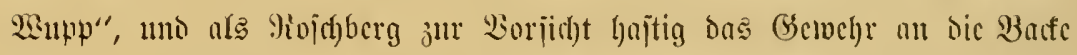

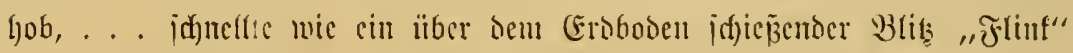

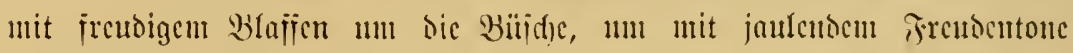

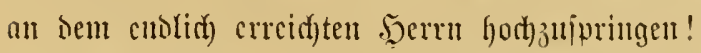

(3crabezu wütent, jomohl megen biejer untötigen (Erregung jeincr in ier Tat "Derbammt hermutergefommenen" Qeerben als and) megen ber $j^{\text {th }}$

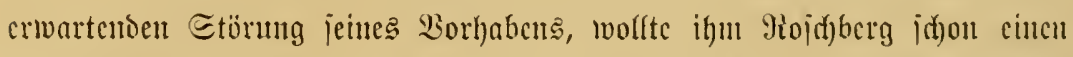

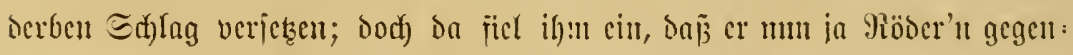

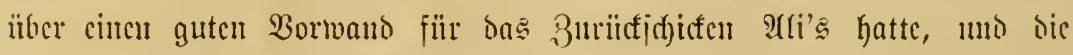

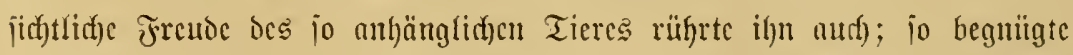

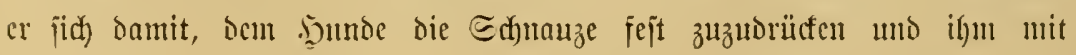




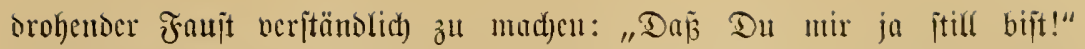

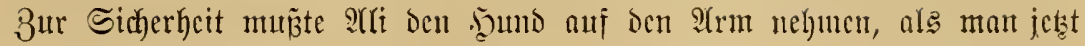

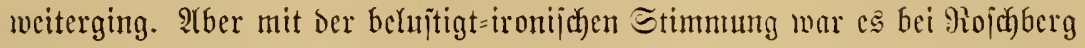

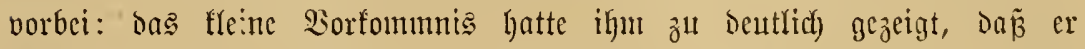

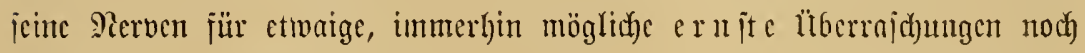

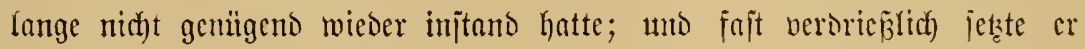

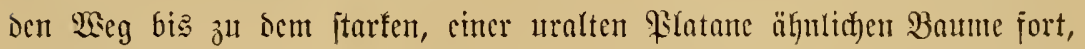

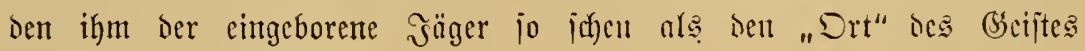
gezeigt hatte.

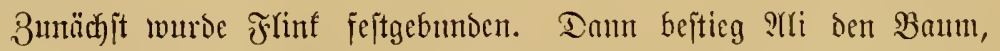

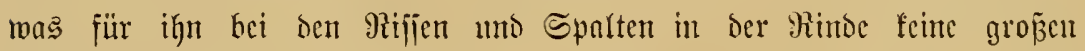

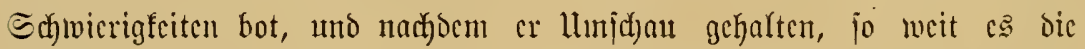
Dunferheit erlaubte, jog er brei brcite Riemen magered)t nebeneinanier quer

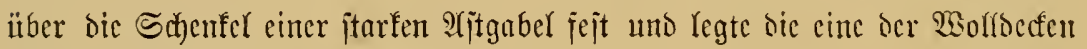
gefaltet ïber bie Riemen. Das gab einen guten, clajtijchen Sits, war vich bejier als bie gewöhnllid) zu fordh ciner Stegreif= Jagstanzel verwenteten Sinüppel, auf Detren man iđjon nach ciucr halben Stunde Sitzets "genug"

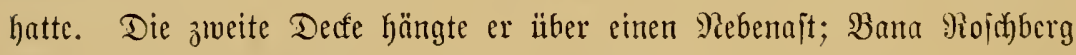
jollte jich darin einbüfren, wenn die Miustitos zu unverjobänt wurben, ober es nadbher in ber 3eit bes Taues falt murbe. Filir fich mollte slli banad) in ben (Sabeln der niederiten, etwa 10 Meter über dem Bosen itehenden fajt magered)ten 2 ijte cinen ähnlichen Sitz crrichten umo fing

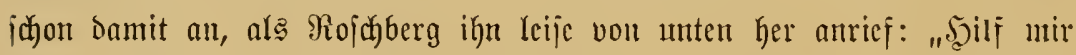

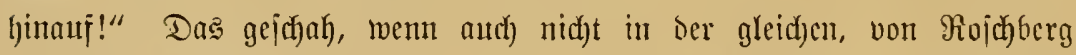

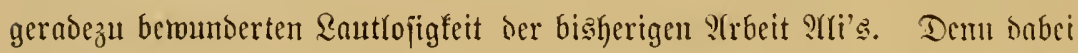
hatte faum einmal ein 3weiglein gefnact, bödjitens dic Epize cincs s(jtes

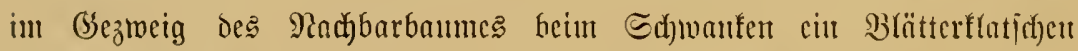

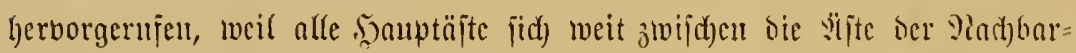

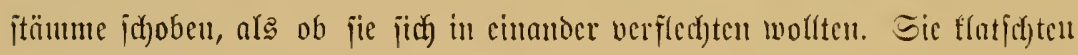

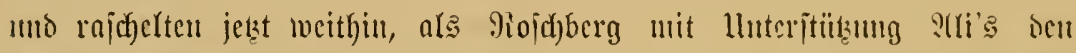

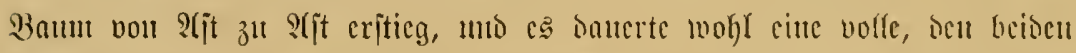

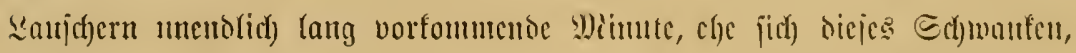

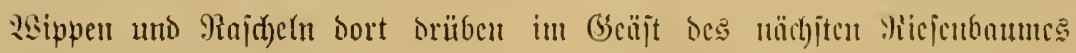
ganz wieder beruthigt ljatte. 


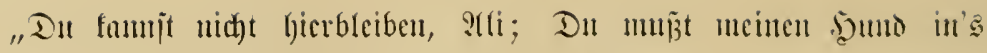

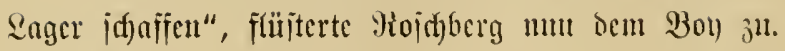

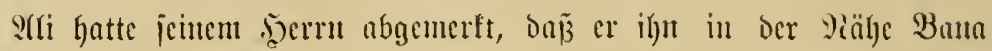
9iojhberg's haben wollte, Imo jo hätte er gern Einmentomigen gegen ben

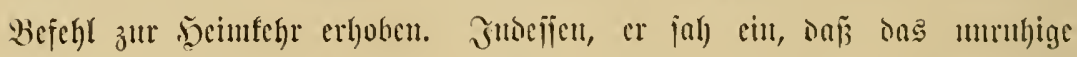
Tier "alles verocrben" mïrote; Deshalb fletterte er himunter, nah)u filinf

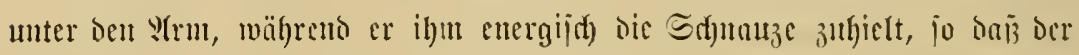

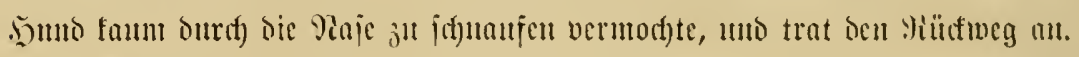

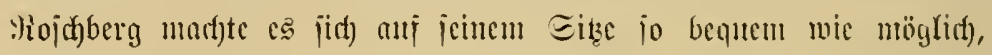

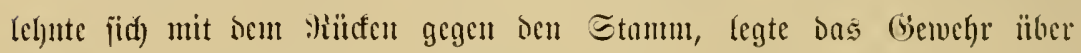

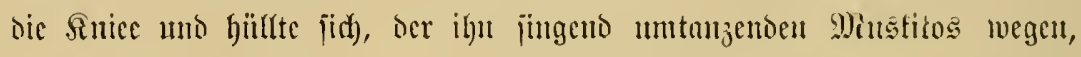

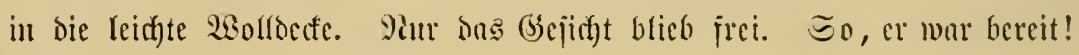
Piun founte Der "Bseit" foumen!

Dod) as douterte eine Etumbe, uno inmer rar nod) nidfts studeres

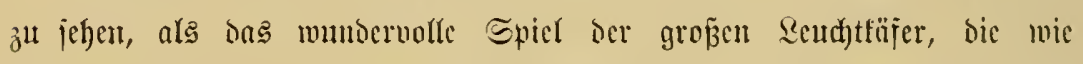

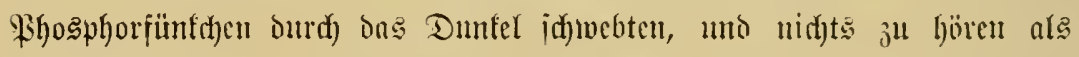
Der burrento fłng itarfer, ifarabäen=älynlicher Wiijt= ober "Iotengräber" =

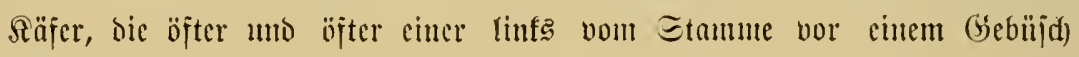

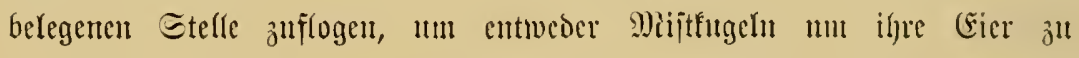
formen, oder cin verwejendes flemes Tier cinjugraben mo jomit dicic

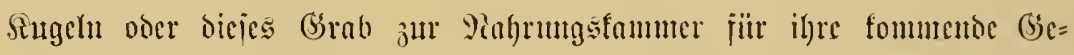

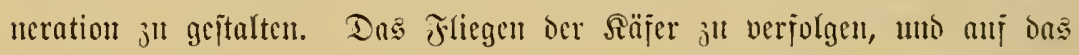

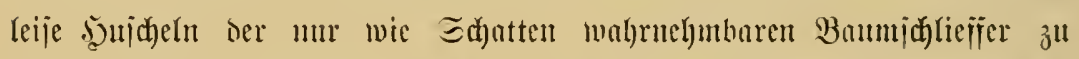

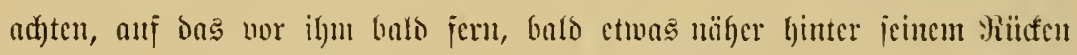

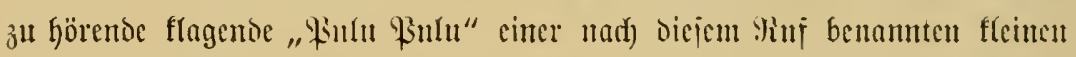

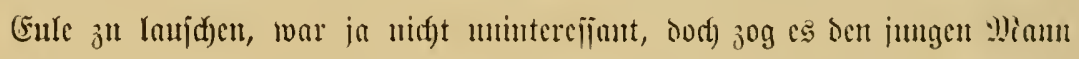

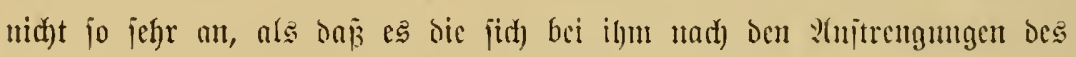

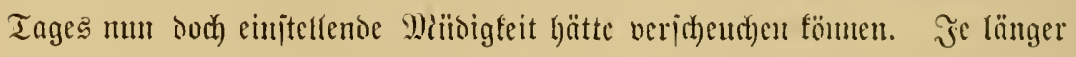

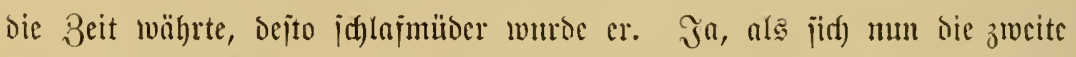
Etumbe jeines 2(njizzens ifrem (Ende zuncigte, niefte er jubeilen tatjäd)lid) ein uno fuhl bamt erjd)rodfen lod), menn von unten her bas leije (Seräujd) cinces größ̈eren, nädthidjermeife auj Beute ausgehenden Tieres icin Shr traj! (5r Durjte nid)t eimidjlajen! Mit (Scmalt hielt $\mathrm{er}$ jidf jekst wad)

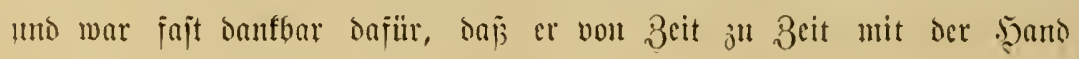




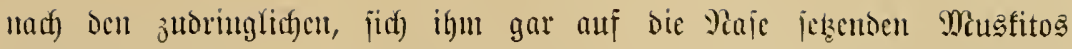
ichlagen mus̄te!

Doch) dicjes gewaltjame jüf) 8wingen griff jeine jelze jo leidgt erreg=

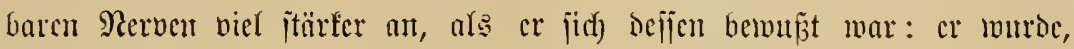

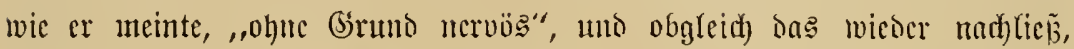

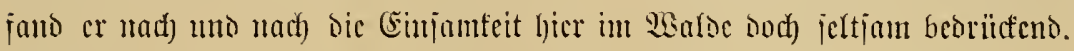
Bor allem die Stiffe uutse ifm fajt uncrträglids), in oce cr mur jein

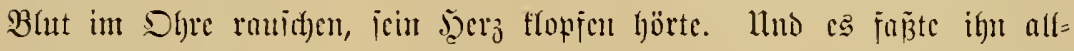
mäblich) eint Unuthe, dic er j(f)wer bencijtern fonnte. Wiel Yieber wärc

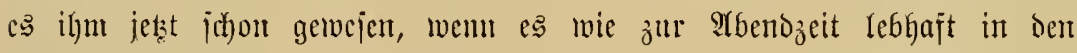
wipipjeln der Bäume зugegangen wäre, wo Doorztauben, Sdjaren von

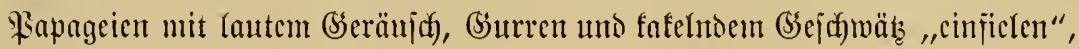

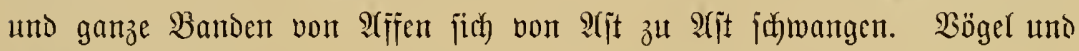
S(fjen? Ridjtig, die follten ja den, Srt des Geijtes" afle fliehen! -

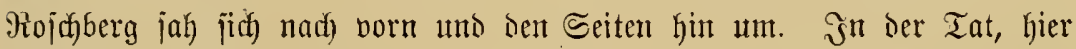
mar von Der Bogclmelt nichts, autf) gar nidfts norhanden! ST(s ob wirk =

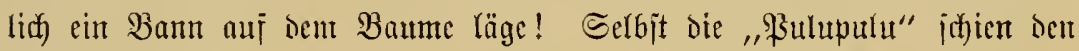

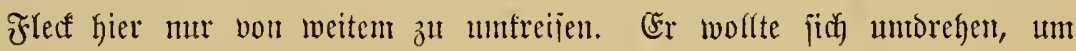

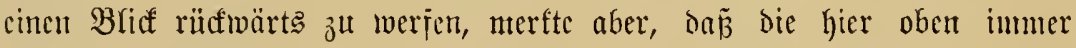
noch beträchtliche Stärfe ocs Stammes ifn vollitändig Daran hinderte.

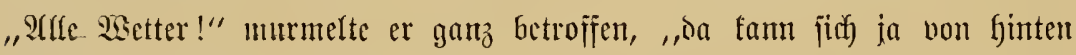

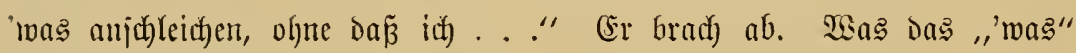

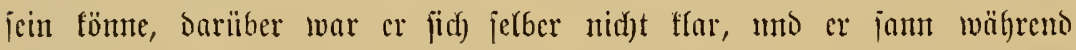
Des vergeblidhen Bemühens, bon jeinem Siz̧e aus um ben Stamm ju

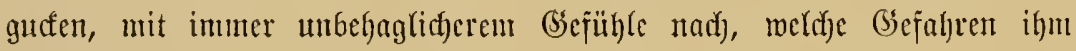
möglid)crueije von hinten her brohen fönnten. Der "Bseijt", wem er überfaupt nod) fam, würde ja gewiés bor igm, ,ipufen", ba mit der

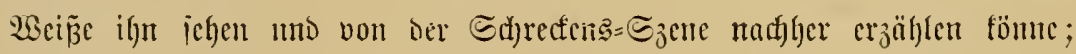

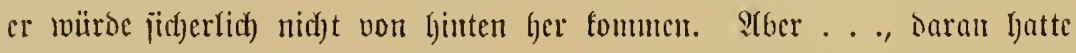
er ja nod) gar nid)t gedad)t: cs fonnte cin Reopard jid) won ?tjt ju S(jt

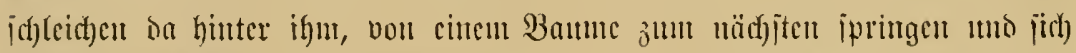

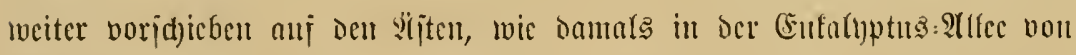
Minanza! Doer cine Der gijtigen jaftgrüuen Waumijhlangen founte heran= gleiten, ja, bielleid)t gar cine ber gewaltigen siefen=\$ilytonjchlangen, wou 


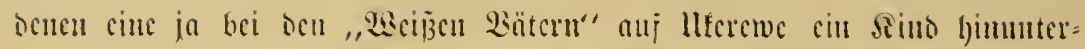
gevoiirgt hatte, uno cine antere im Räjtenfinterfanto jogar cincn jungen,

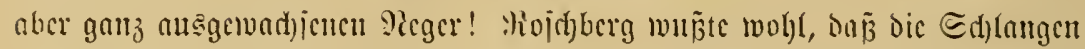

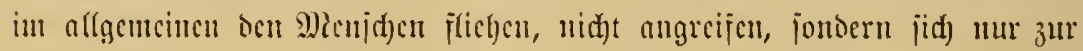

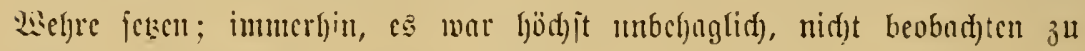

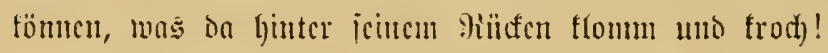

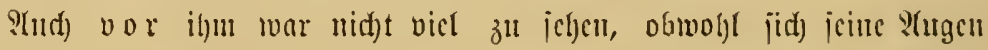
(4)on völlig an ong Dunfel gewöhnt hatten. Dic Mlondojid)cl war längit idjon untergegangen, und bas Sternenlid)t orang nur wie cin jilbriger Edjimmer jwijd)en ien (bipjeln durd), ohne je カch Boden zu crlyellen.

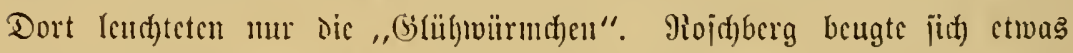

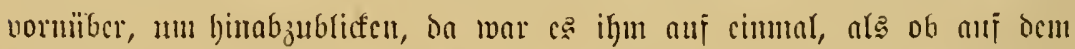

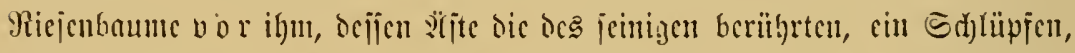

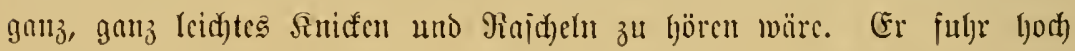

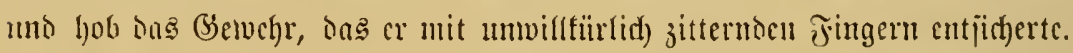

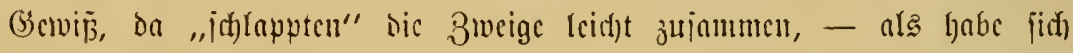
Jemnı, wic vorhin er jelber hicr, mur jegr viel vorjifttiger mo geübter,

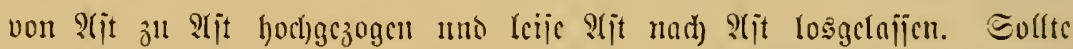

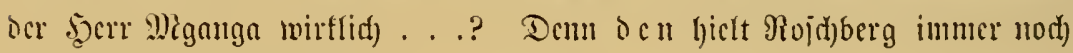

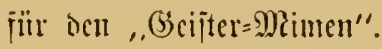

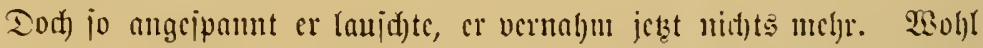

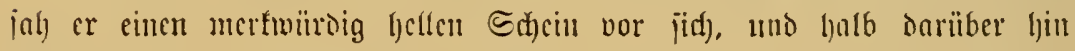

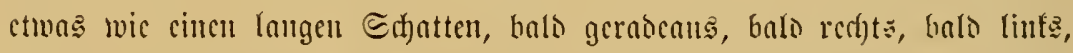

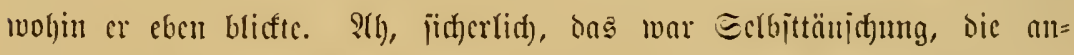
geitrengten Plugen ipiclten ihm on cincn Etrcid)! (Fr hatte jold) einen

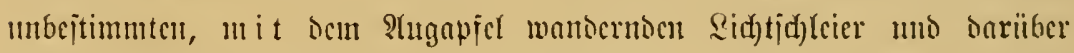

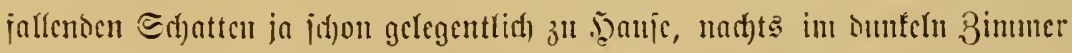
wal)rgenoumen, wenn er cin sscild)en mit offenen ?lugen iagelegen. -

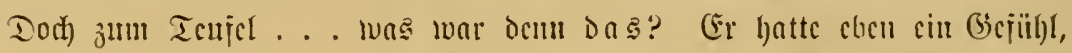

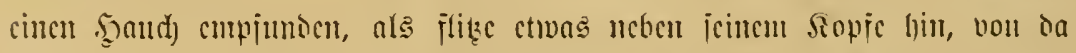

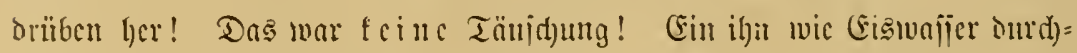

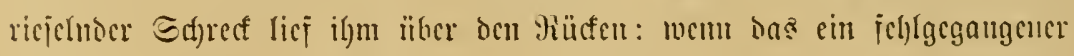
Bicil, cin Gijpieil war! 


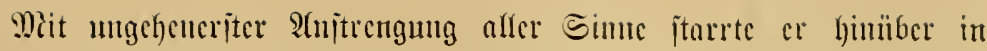

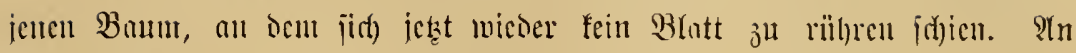

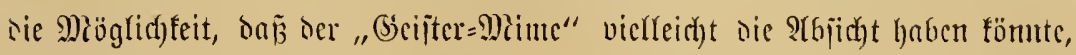

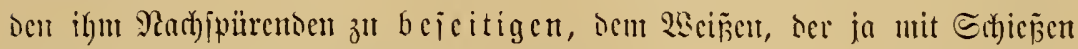

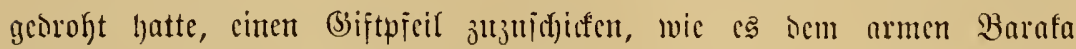
gejd)ehen - Baran hatte Rojd)berg bis ju sicjer Mimute nod) gar nidht

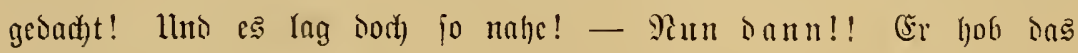

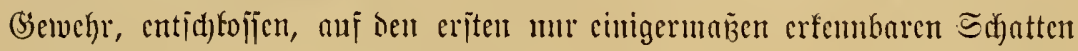
zu fcuern!

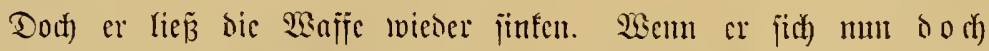

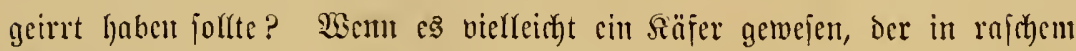
Fluge an ifym vorbci unto mit jenem jijdyenden Tone an ben Blättern neben ifm bingeitritchen war, wenn bicier Bauberdoftor an (Enbe doch mur jozuiagen barmlos, ,iputen" wollte, ourfte et den Menjeden bam

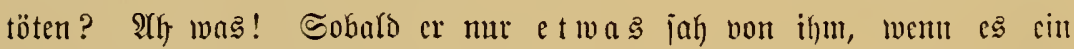
auch) noch) io unbejtimmter Echatten war, er mürte ifn aurufen: "Stel'

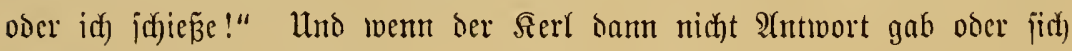
jcitig gemug Davon madfe, fo bef a m cr eine fuget! Semarnt war cr Dann ja, unt , wer fid) in Bsefahr begibt, fommt darin um"!

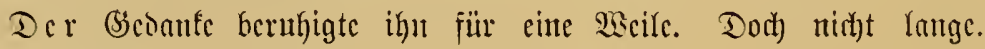

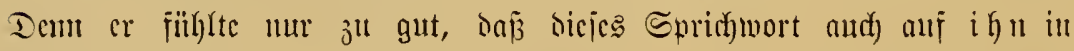

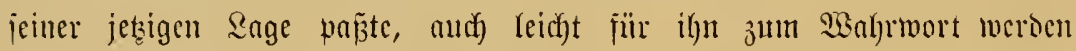

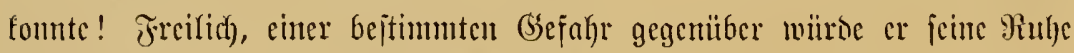

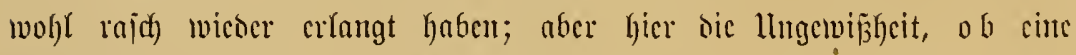

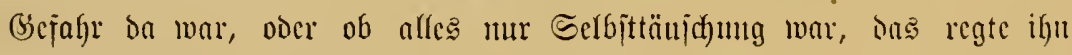

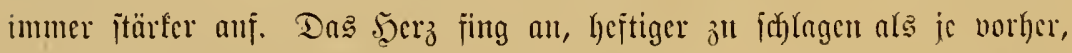

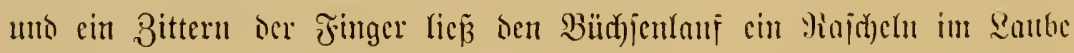
hervorbringen. Je länget er hittunştarte in Dą regıuggloje Dumfel,

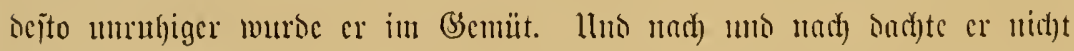

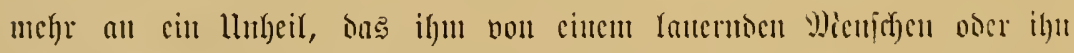

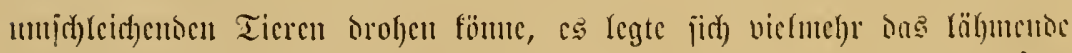

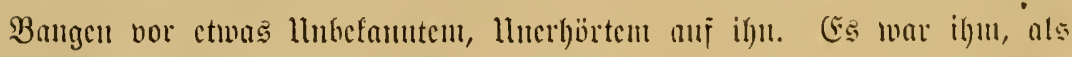

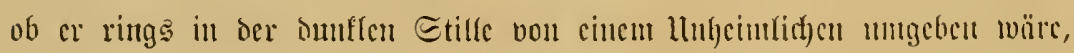
uno als rücfe ons, unjid)tbar uno unvernchmbar, heran, bou allen Eciten 


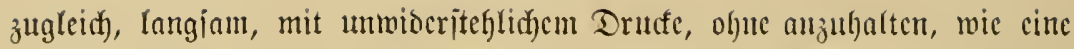

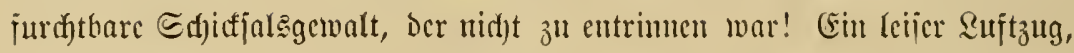

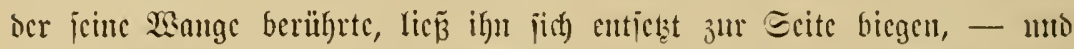

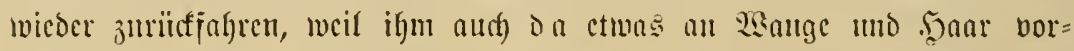

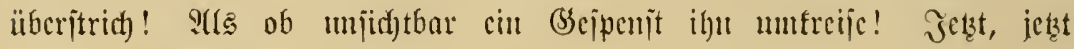

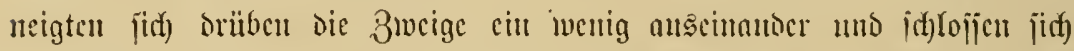

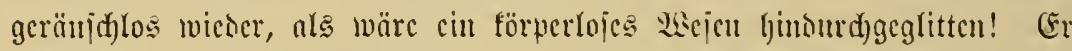

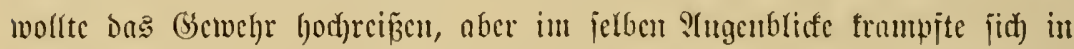

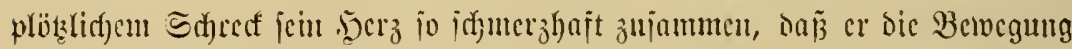

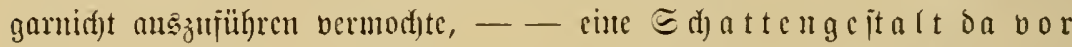
ihm, nidjt wic cin Pienid), bunfel veridumimmeno im Dunfel wic bic

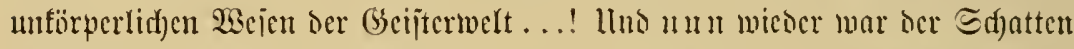

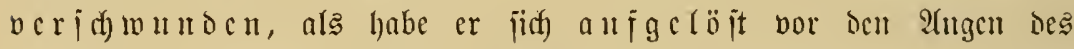

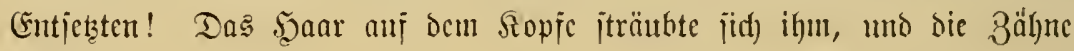
flapperten aufcinander.

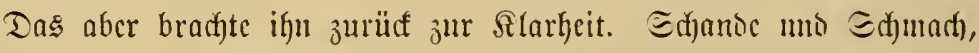

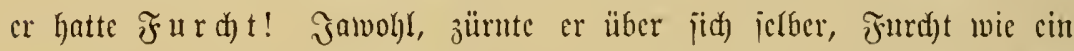

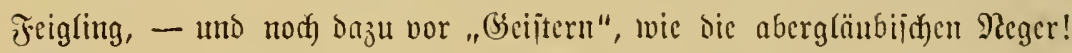

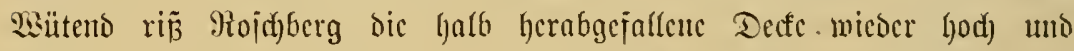

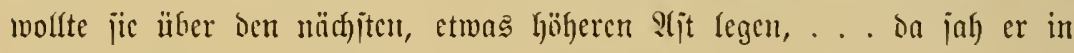

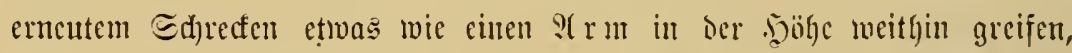

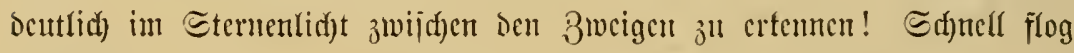
die Büdje hod), - - ovd) idfon war oer A(rm verid)mmtoen.

"Was Denu?!" Dachte Rojaberg ganz betroffen; „ü ber mir fam

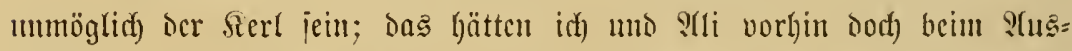

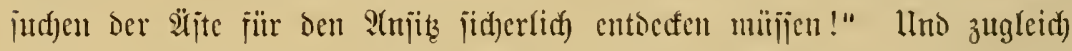

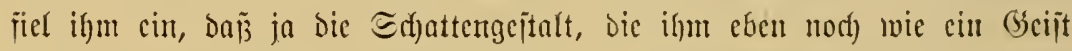
erichicuen war, or $\mathbf{1} \mathfrak{b} \mathfrak{c} n$, anj bem a gegfitten! Eie fonnte dod) nidft gleidjzeitig audf hife jein!

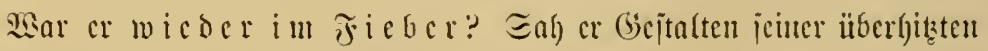

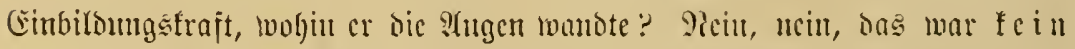
Ficber! Das war aud fein Epicl der ïberreijten Dicrven gemeicu! - 1hto von neucm frod) ibu das cijige (bejühfl ber Furd)t vor chuas llugefanutem,

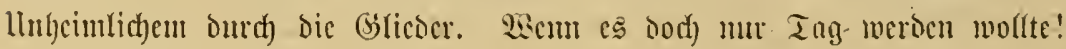


Da raidjelte cs brüben im Baume. Edjarf ipühte jeţt ber junge

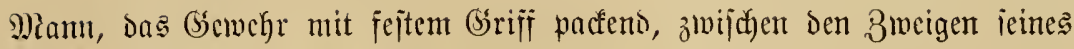

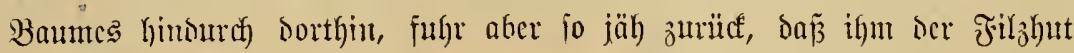

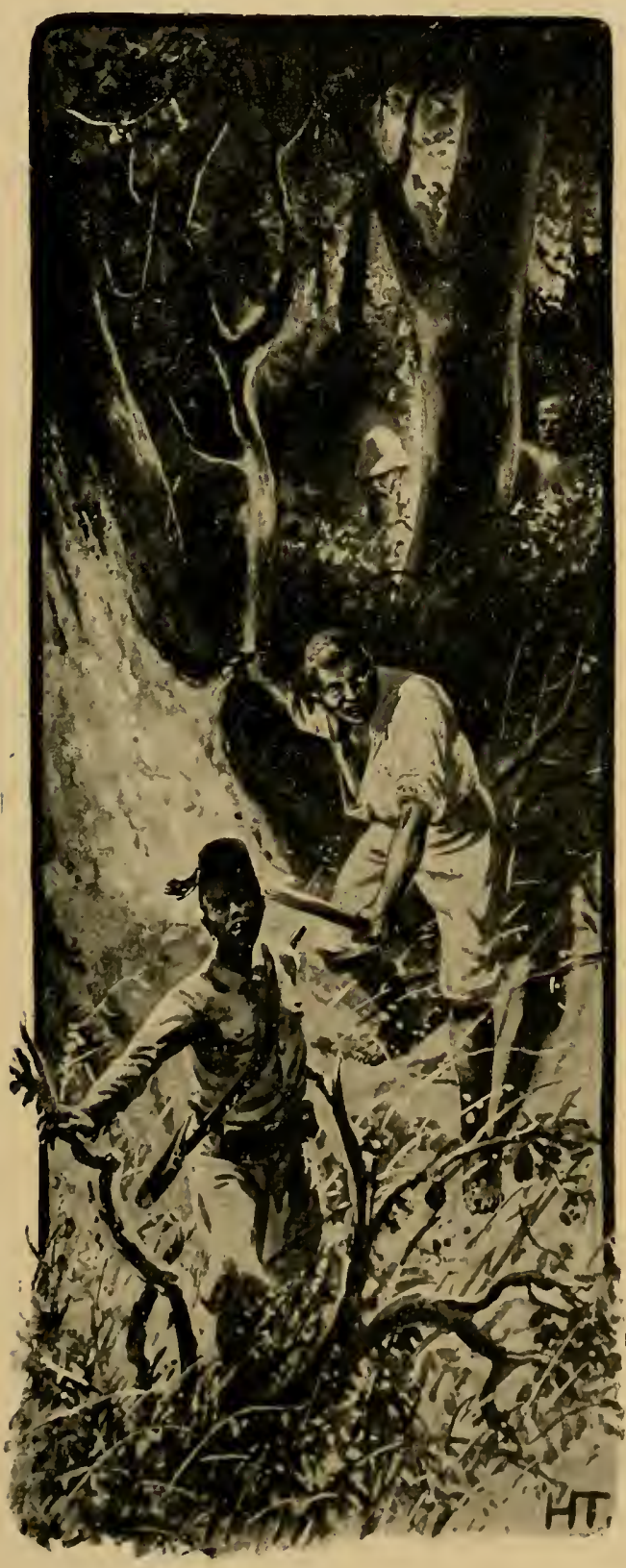

beim atmpralf gegen den Stamm bom Sopfe ficl, Denn bort brüben glitt biejes Sibattentucicm neben bem baume her: unter, leicht, ala ob e aus Rufit beitünoc, hiclt für cinte Sefimise anf Dem unteren Sauptaite, Siojubberg geraide gegenïher, . . uno löjte jiif) miciner in nichtes auf!

Crin Sefühl, aus 2 (ngj!

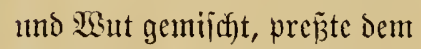
Erjurodenen sie Bruit zu= jammen. Das fonnte fcin Menji) jein, uno (Sseijter gab ç્ nidft! (5r legte ant, in berbijienem (Śrimm ent= ih)loijen, jebst auj oen Sifatten jll jeuern, jobals er jich wieder jeige.

Doch nitfte, nirfte war

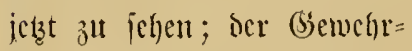
lauf jefluanlte je länger Beîto itärfer in jeiuer Љ̧anto; $c r$ untujte afjeczen.

lluis wicoer hatte er it dem reglojen Dunfel rings unil ign das bangc, melgr nuo mef)r die Brujt bcorïnfende (Befübl, ats fommte cin 


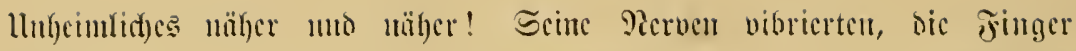

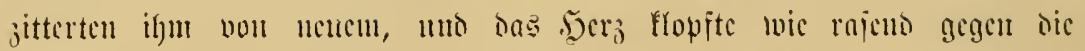

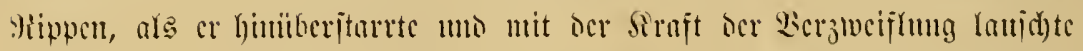

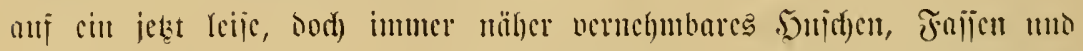

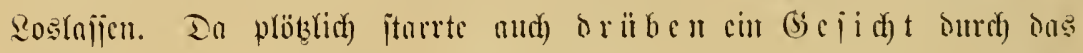

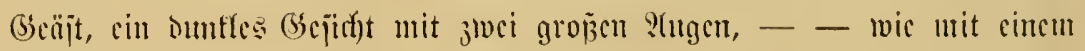
Echlage börte ons Branjen bes Bhutes im Shre anj hei Bojoberg, von

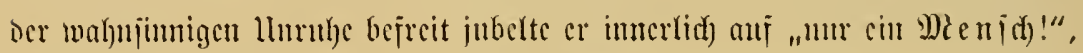
ris ben Browning loch) mo jefric himither:

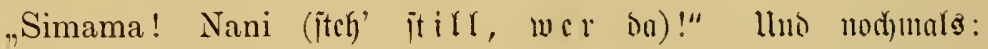

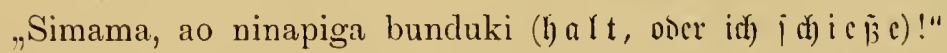

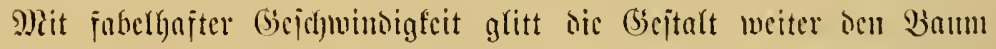

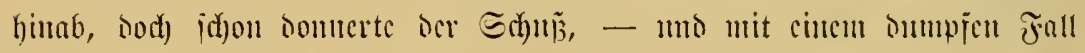

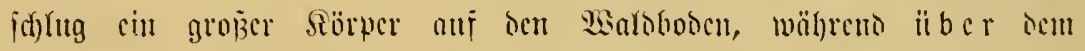

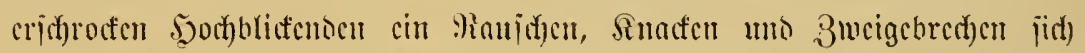

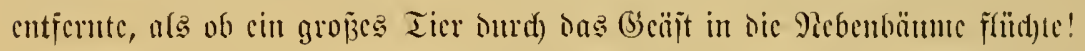

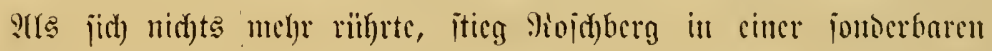

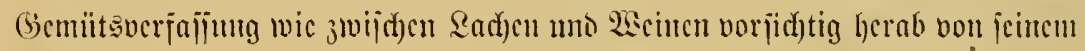

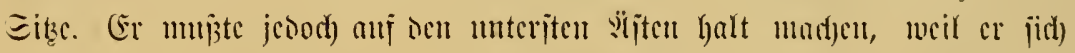

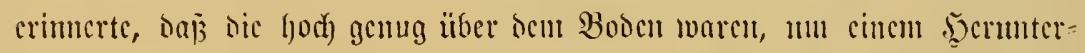

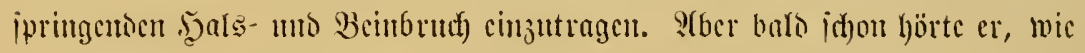

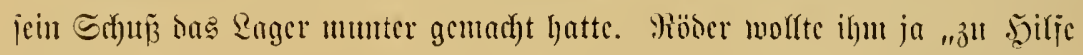

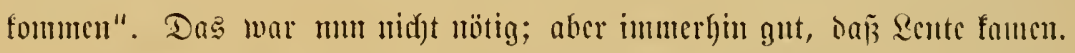

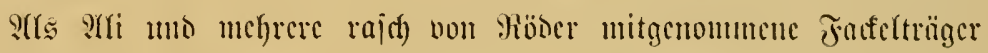

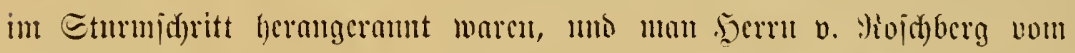

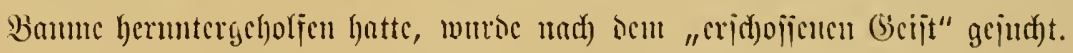

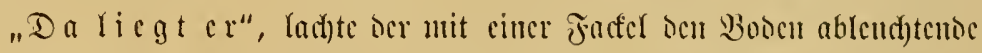

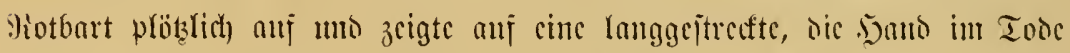

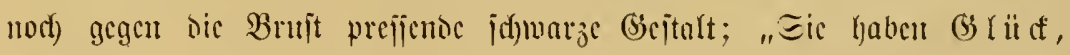

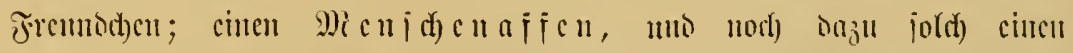

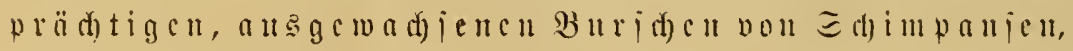
crlegt mon nitht alle Inge!"

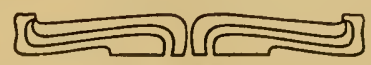




\section{Meunzehntes Kapitel.}

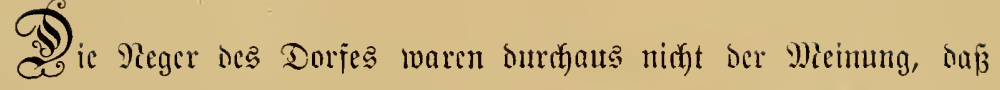
mu. oer Benveis geliefert jei, jie hätten bisher bie in ihrem æarse haujente

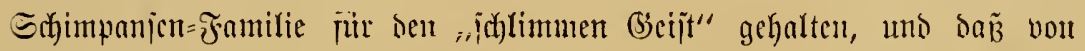

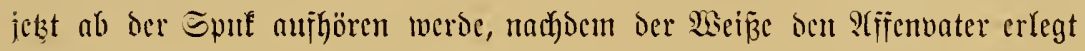

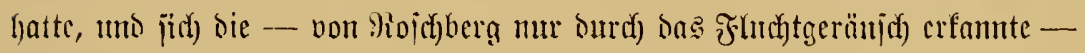
siffin mit beut vielleicht vorfhantonen Jungen aus biejer Gegens verziehen

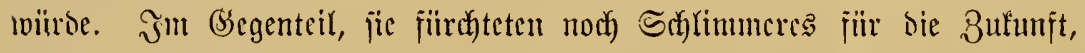

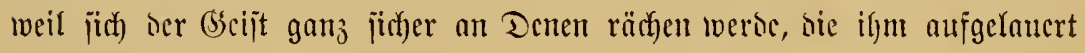
gatten, soie auth an Denen, die bicjen jeuten Fcinben Rabrung berfaujt hatten. Mit ermiter Miene, cbenio bejorgt wie ïberjengt, wiejen ber

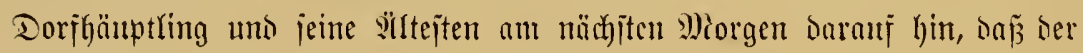
dshinn ja mit jeiner Rache id)on angefangen babe: sas wäre jein Tun, bafj der bana nyekundu uno an bie 40 feiner Reute in biejer Rarht jo idnwer erfrantt jeien! Denn beim Rotbart mar gegen Miorgen

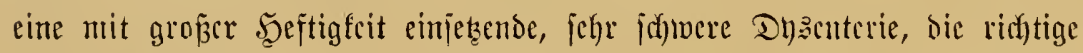

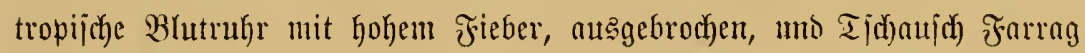
mie die Wanyampara meloeten bie gleiche Erfianfung oes Dmbajudas lllesi

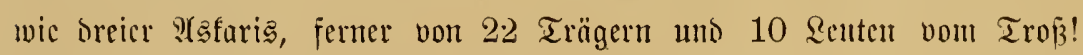

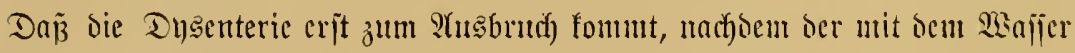

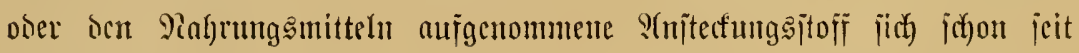

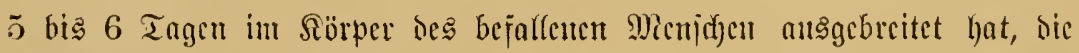
Siranffeit aljo nicht jo urplötżlich, ,angezaubert" jeiu föunc, bas liç̄en bie Dörjler nirgt gelten. Sie blicben bei ifyer 2(njight uns arbeiteten nod)

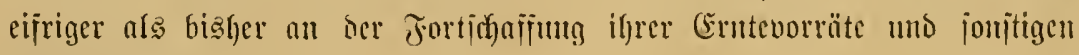
Jabjeligfeiten. 
Dic Expebition bagegen foumte jiir bic nädjitten Iage gar niç)t mu

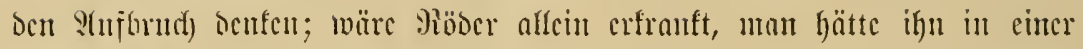

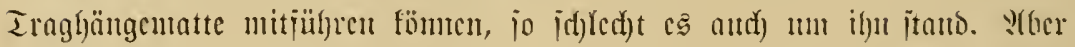

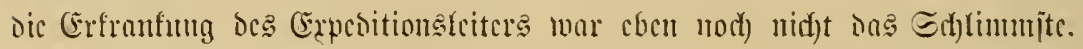

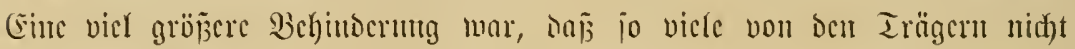

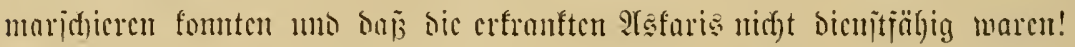

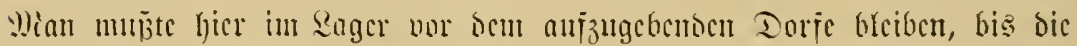

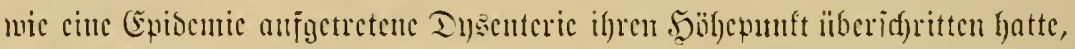
uno bic siranfen mad) Bertcilung ifrer Sajten anj bic (sijuntogehlichenen jid) menigitens einigentuajen mitjd)

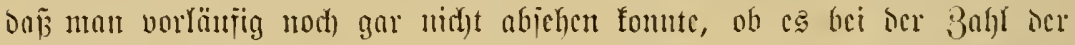
heut gentefocten Sirunfen bleiben, ober ob nod) meht Eeute wou ber Eendfe crgrififen merion wïrocu!

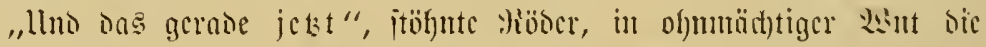

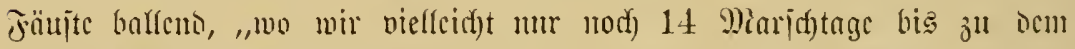

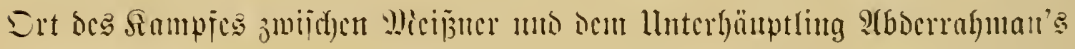

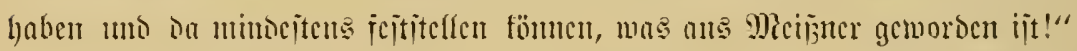

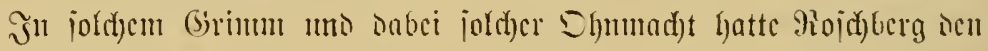

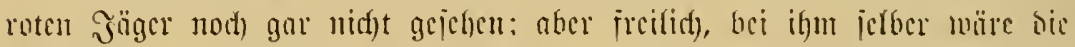

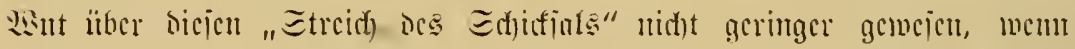

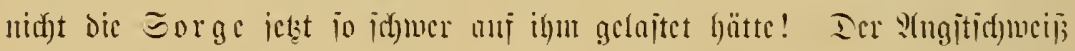

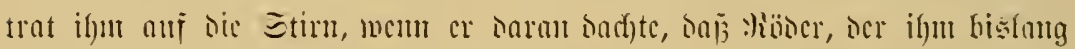
wic gejeit gegen sirantlyciten uorgefoumen mar, momöglid) sicjer in io viele Spjer forthernocn Elyenteric crlicgen föme! Ianu mujte cr bic

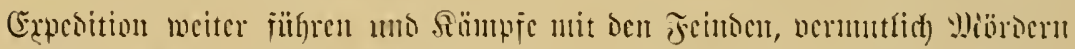

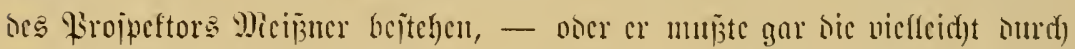

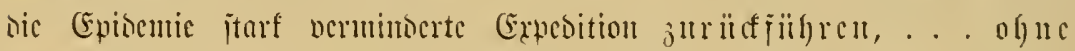

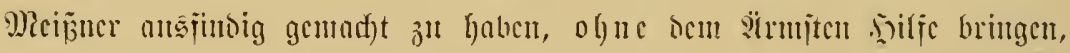

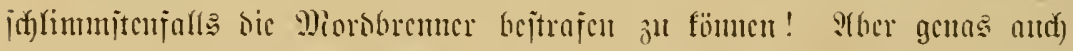

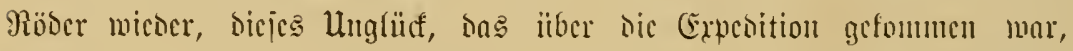

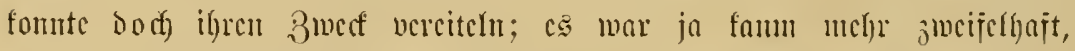

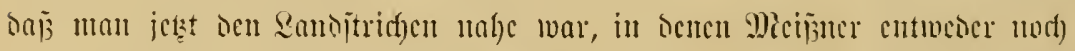

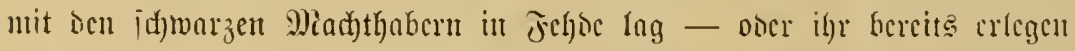

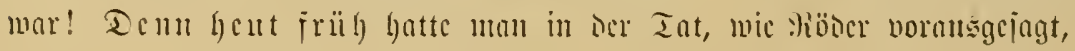


einc "rür die Expedition braudbare Shlunjolgerung aus bem Sierfalten des Maujergemehrbejizeres jiefen fömen"; ter Mann war aller= bings heut nid)t mit den von ifm verlangten bejtimmteren :Yngaben แmo

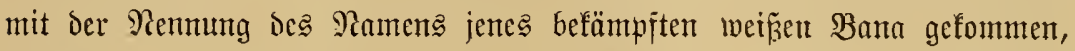
jondern ... im Gegenteil gar nidht gefommen, hatte fich vielmefre vor Tau uno Tag bavongemadyt! Unt daraus war jul julfiefsen, dañ

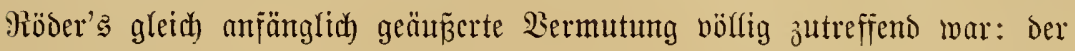
Mann habe jelber mitgefïmpit gegen den Meipen, das (Semehr nicht von beut Rrieger eines anderen Stanmes gefauft, jondern $\mathfrak{E}$ in eigener ßerjon einent Der getöteten Reute Meiñner's abgenonmen! Sonjt wär' er ja wahrlich nidyt gefflïd)tet!

So frant Röber war, er hatte gleidh, al: jid ber Mienjid) nidht ju=

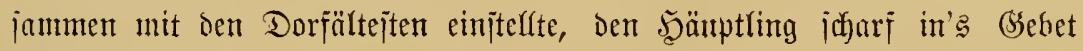

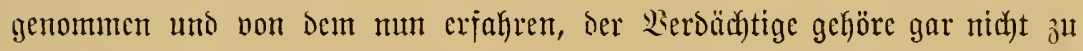
den Dorfesingejeffenen, habe hier erft jeit $\mathfrak{k} u r \mathfrak{z} \mathfrak{m}$ bei cittent ndugu gelebt uno jei heut früh anfgebrochen nach ocr Boma ber sabentichi ain $\Re$ yanza.

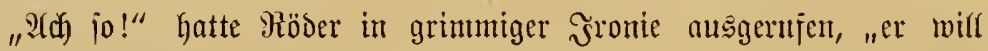
wohl nad) Diuanza, un mur ja bas (semehr an der ridjtigen Stelle abzuliejern!! - Da haben Sie ein \$röbdhen von ocm Şohne," hatte er jid) Dam an Mojdberg gewantot, "Den bie Schwarzen jich leipten, wem jie glauben, das ohne Gefahr tun j̆ll fömten! - Wo fam dent der Niam her, als er jeinen ndugu bier aufjuddte?" jragte er betl 5̧ü̈tptling.

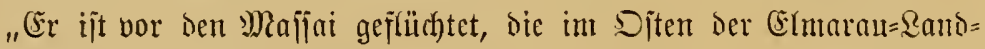

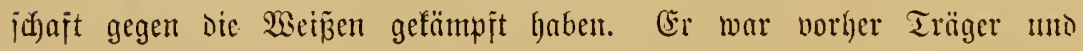

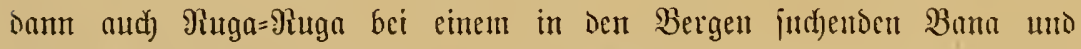
erfielt jeine Entlajiung, weil er licber 2(afari bei eimem Batta mtubwa des Serfal wersen wolite. So jugte er!" jügte (Entefo mit cinten S(d)jel=

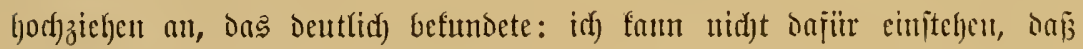
es wahr ijt.

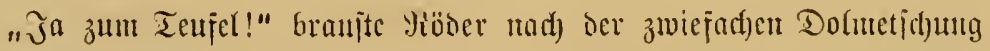
auj, "marum hajt Du mir bas afles nid)t geitern jdyon gejagt?!"

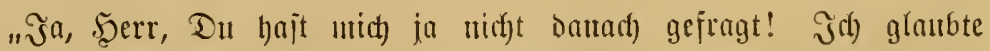
Deshalb, Du wïrjteit das alles von ihu jelber, mit dem Dut tut cin 


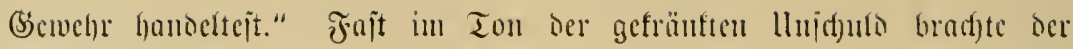
Wlte bas herauts.

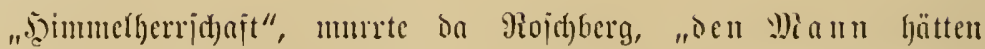

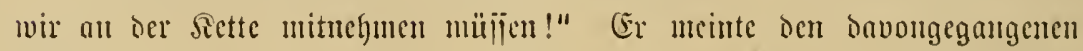
(becwebrverfüıjer, ocm i

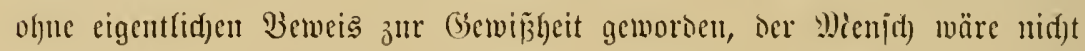

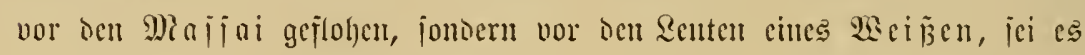

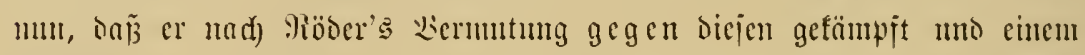

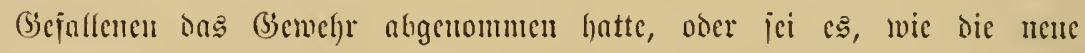

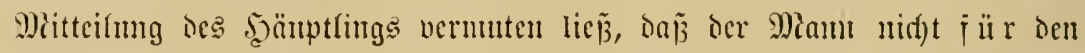

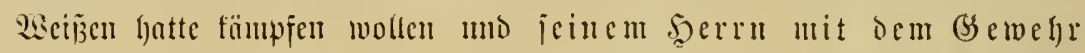

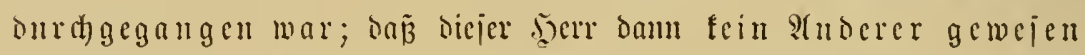
war als Gerd Miciżer, das bemies ja bic Eingravierung auf dem §olbenbled) des Minujerfarabiucr: !

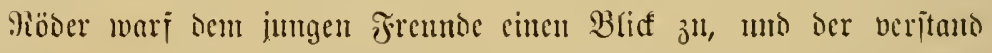

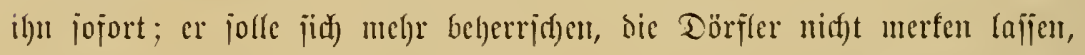

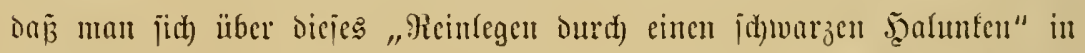

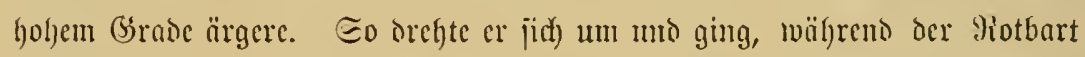

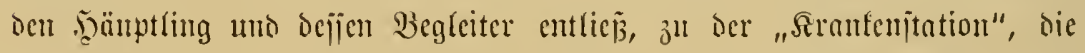

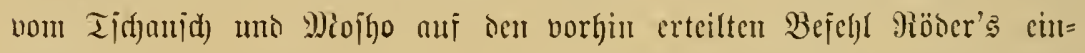

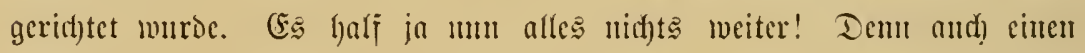

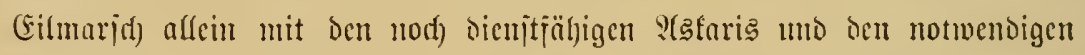

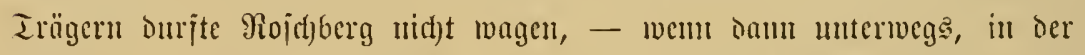

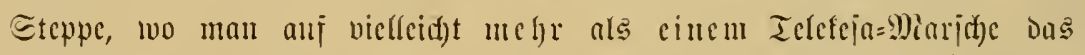

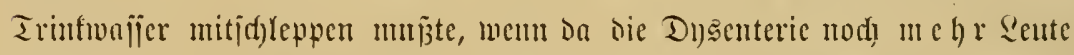
ergrifi ...! Rojefherg idsantorte geradeju bei sem Bedanfen. Rein, jelbjt

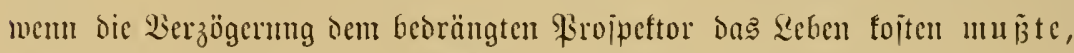

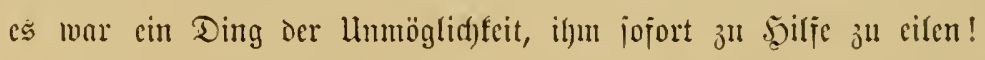

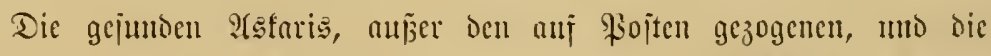
Micl)rzahl oer gejunden Träger waren unter Beiftand Der \$seiber und der

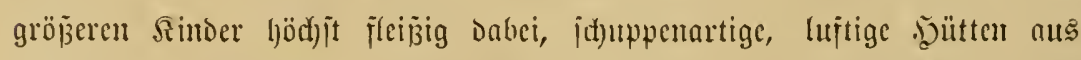

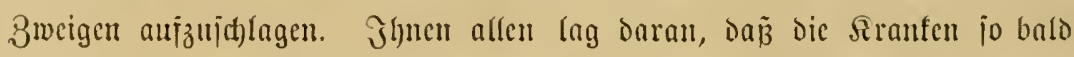

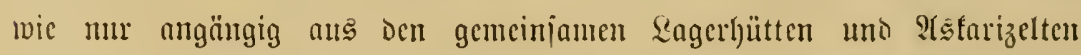

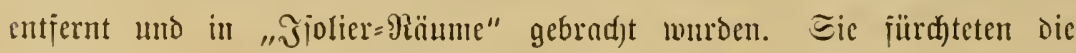


Injtectung, zumal bie Seudhe nnoerfennbar weiter um jid grifif! Der Tidanjid meldete dem chen an bie Şüttenerbauer herantretenden Bana Rojhebegg, noch jmei andere 2(3faris hätten tumbo la kuhara damu,

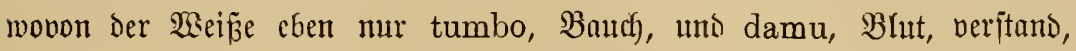

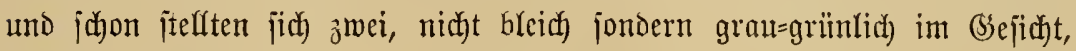
auşehente Trüger neben ifm mit ber Melsung auf: "Tumbo, bana!"

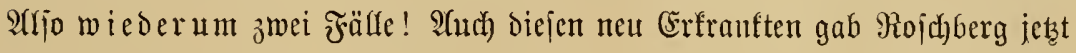

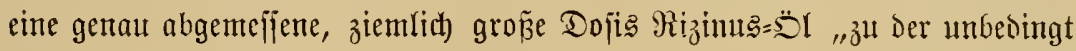

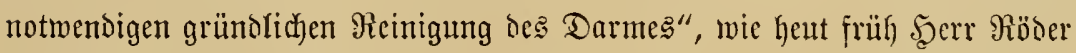
angeordnet hatte. Sr hatte ifm Dann aus der gropen Reijeapothefe die eine der beiden Flajchen Spium gegeben uno gleich felber die Şälfite Der

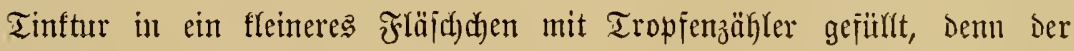

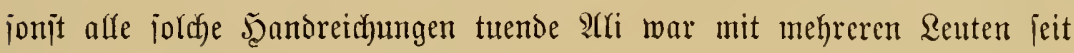

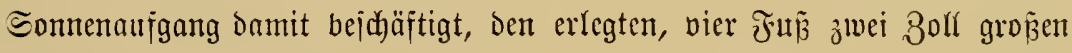
Shimpanien nbzuhäuten, uno die jo jcltene Sagobeute iür ong ipätere

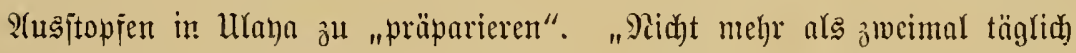

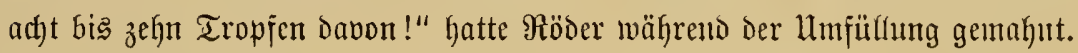

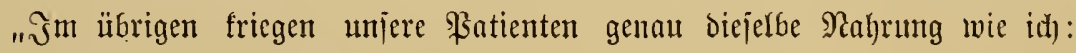
Mehliuppen, aljo bünmiten Hgalfi ohne jeden 3 ujaks, uno weiter nid)t:

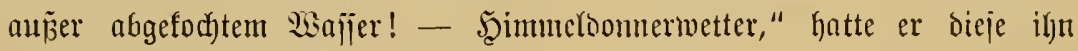

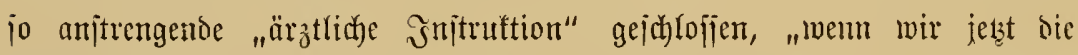

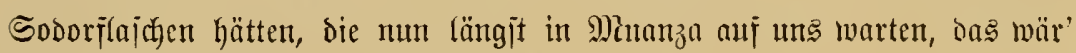
eine Erquicfung für unjere armen fierl’ !"

Irotzden er fich im \&nufe des Tages inmer elender fühlte, er jah gegen :(bento nod) eimual jelber nadh), ob bic Seute jo gut geprlegt würocn, wic das eben unter den obwaltenoen Umitänden möglich war, ob jie cin orocint: lid)es Grazlager unter den Decten hatten, uns ob dic al: "Rnzarett= Boys" angejtelften Jungen aud) jür grünolide Säuberung jorgten, menu einem der Sernnfen "etwas paijierte", ehe er au bie fiuter beul langen Sd)uppen ausgebobenen Crogruben foumen founte. Dou ien Leuten fieberten jekzt gegen Eonuenuntergang die meijten jel)r jitarf; viefe phantajierten, uno nid)t wenige jahen jid) it ifjren Fieberwal)n vou Jeellioen

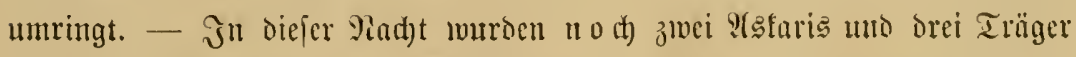

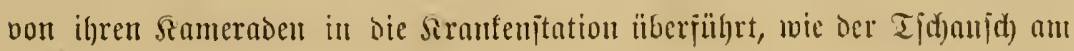




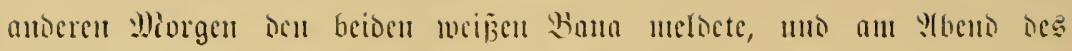
Dritten Tages heturg dic Bahl ier Seranfen 61 !

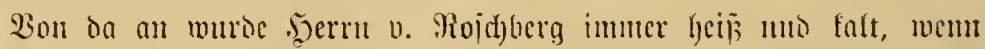

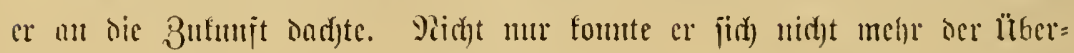

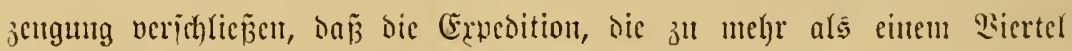

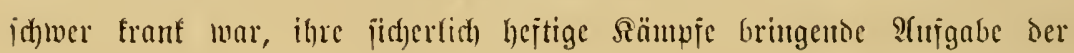

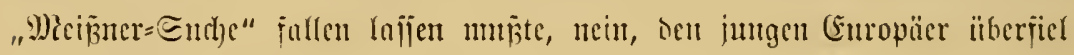

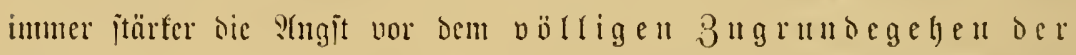

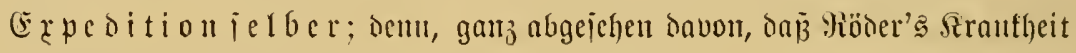

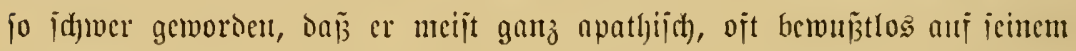

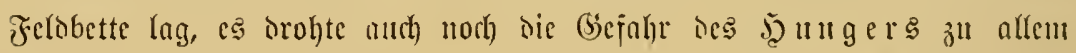

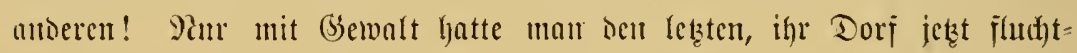

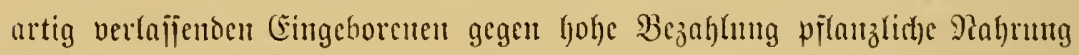

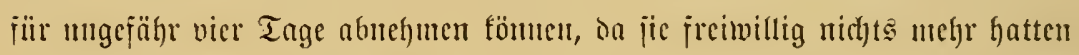
vertaufen wolfer. Rojd)berg hatte sanad), als cine lange folome mit mais: uno hiricgefüllten grojen sïrben ans dem Dorje jog, nod) cinmtal den Beriud) cines S(utaujes madjen wotlen; er war mit jümtlichen nod) Dienīt=

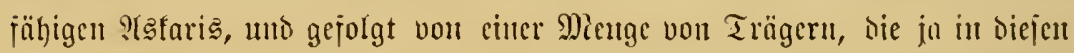
Tugen io gut mie uid)ts ju tum hatten, vor bns Dori gerülft, um den

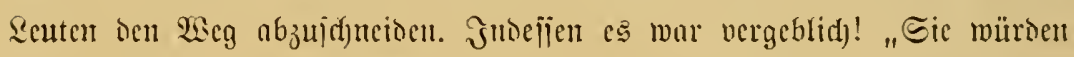

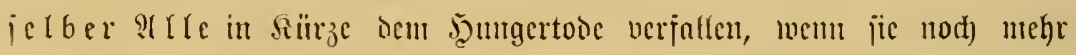

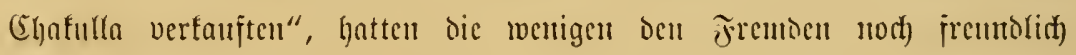

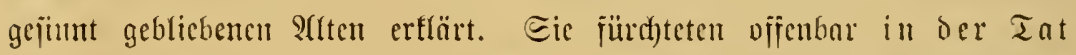

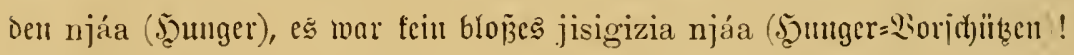

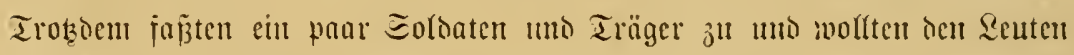

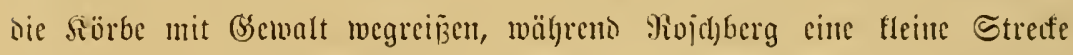

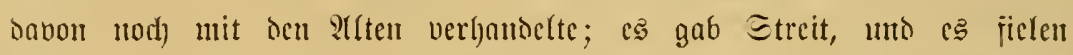

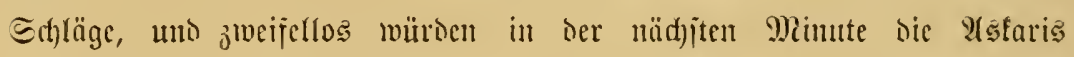
"bie (šclvehre haben ipred)en lajīn, um mefhr fiorn ju befommen", wenn

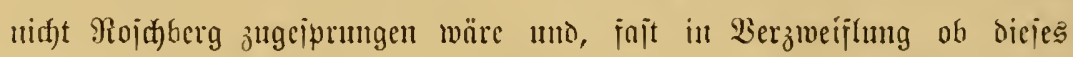

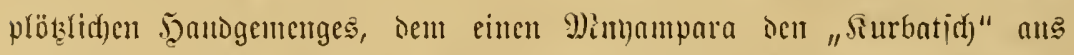

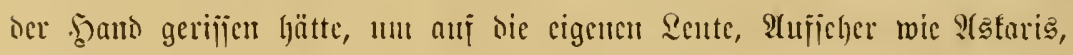

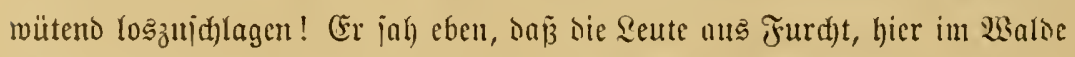

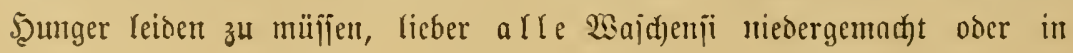




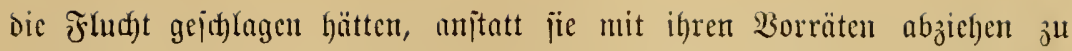
jehen, - Dem was waren ihnen bieje "verrudten Şeiden"; mochten i i c

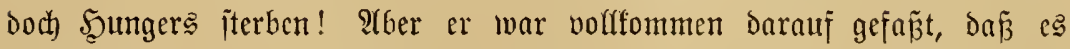
jek̨t burch fein hinderndes Dajuijihentreten cinen :(ufrufhr gab, ja, er fonnte womöglid) bon einem ber (Ergrimmten niedergeichofien werden! Da

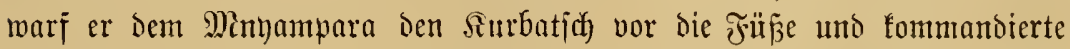

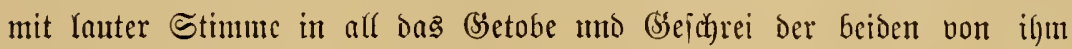

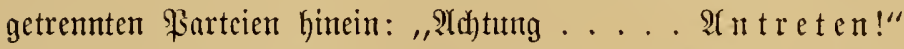

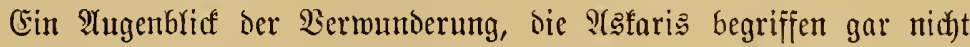
was "los bar", bann wirfte aber das beutiche fommando: Der lantge Flügclmam cilte herbei, jteflte jich) zehn Schritte Roj hberg gegenüber anf,

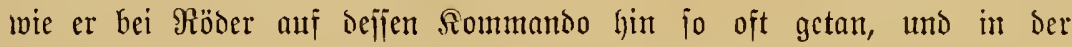
nächjten Mimute Gatte fỉch ein (ślied formiert, während bie Träger fich bahinter fammelten, uno der Tïhaujd bienjteifrig von ber Seite ber

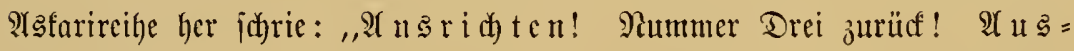
ridjen ...!" (Er jabritt darauf die Front ab, jählte dic Seute,

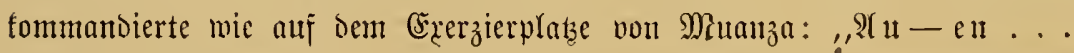

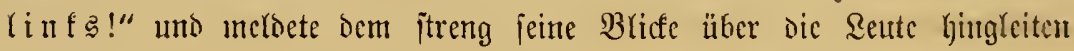

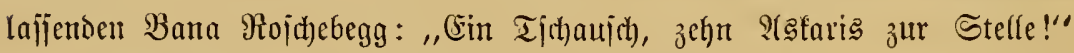

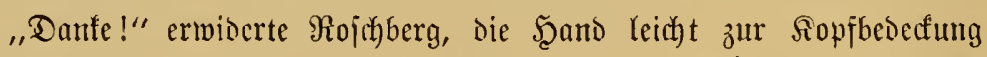
hebent. "Pährt end)! - - P(ataris," hob er bam an, nadboem er den Dörf̈lern zugenvintt hatte abzużehen; "habt ihr anj ber Safari mit

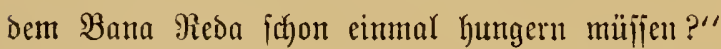

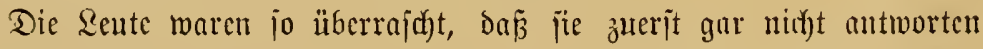
fomuten. Daum rici Giner: "Nein, Bana, wir haben ės nidht!" Uno

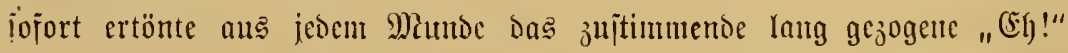

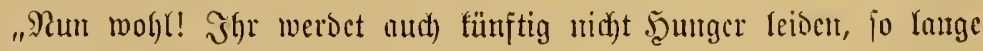
igr mit dem bana nyekundu reift! Nidyt igr habt dajür ju jorgen, er hat es, ocr eurer baba iit."

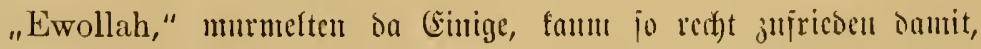
mo "Hewallah" bie 9 nnderen in iiberzengterem Touc. Tos war ia ridftig,

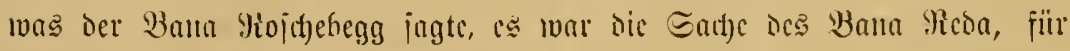
alle jeine watoto ju jorgen. "9ser mit bem Bant Yiobo reijt," id)altete

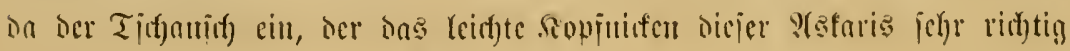




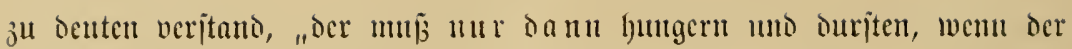
Bana Reda nad) dem amri ya mungu jelber bungert uno büritet. Er wiro für ung jorgcı, inshallah!"

"Ndivyo! Ndivyo!" umo "Kweli (in ocr Tat, jo iit cs! Maghr= (icd))!" \ici cs bic Reihe entlang.

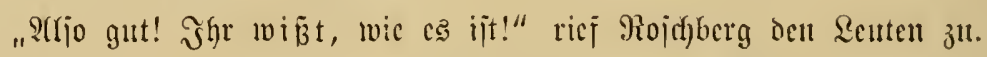

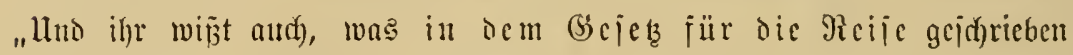

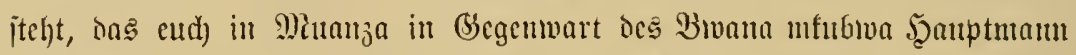

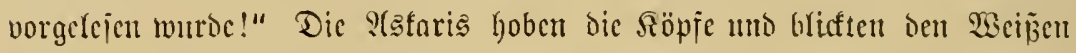

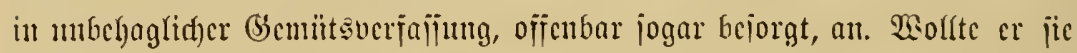
ctwa nun bejtrajen lajien? S⿰氵

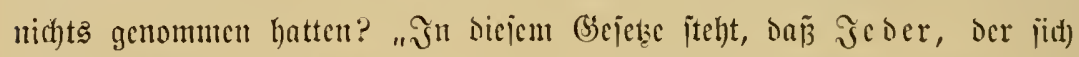
an bent Ceigentum der Cimmohner tes Randes ohue Bcichl vergreift unto die Waffe dabci anmentet, an bic אette gelegt werden wiro, der Safari degradicrt uno zum Träger gemad wird. Hno es iteht weiter

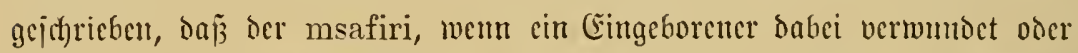

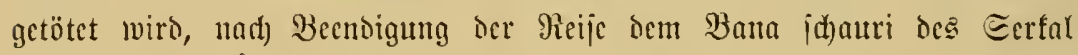
zur idheriten' Beitrafung cingeficfert werden wird! - Sabt ihr ver= itaution?"

Eine Panje von Eefunocnlänge. Dann cin zulitimuncndes, red)t nudt)= Denfliches: "Mir haben, Buna!“

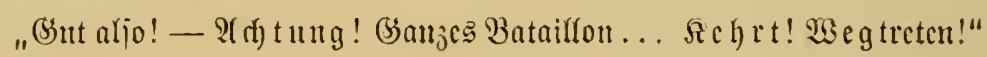

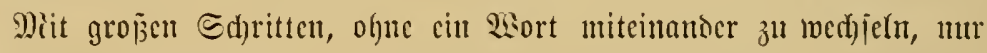

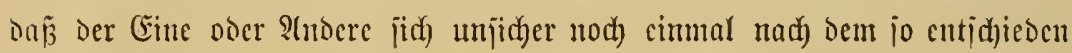

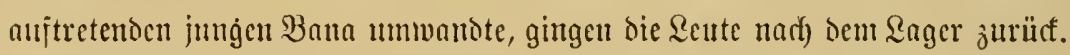

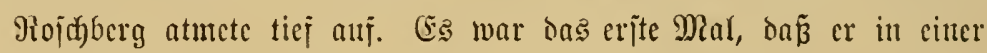
gefährliduen Lage hatte crproben müijen, ob er die Expeditionsmanmidnajt unter jeine S(utorität bringen fonnte, ... uno es war ifm gelungen! Wie ein Stroin von neuer Şofïmung, jajt non 3uverjinft, durd)riejelte es den jungen Manu bei bicicr Errfentmis! Satte er dic Sente unter allen

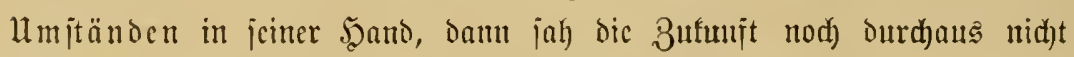

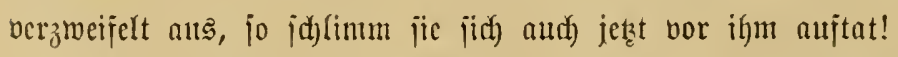

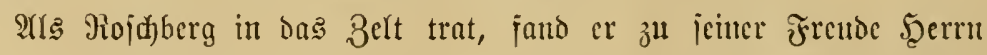

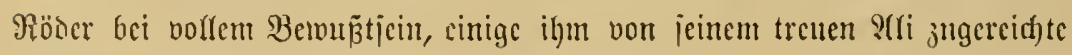




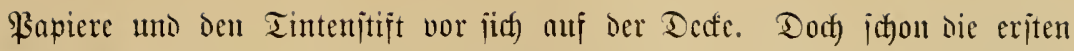

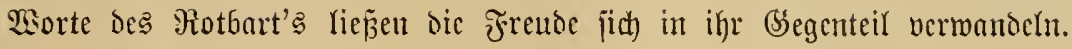
"Es iteht ichlecht mit mir, lieber Freuno," jagte Röser mit hohler Stimme, - „it! it!“, wehrte er bic crmutigeno gemeinten Sinmendungen des jungen Reifefameraiden ab, "mir woffen ums doch nidhts vormathen!

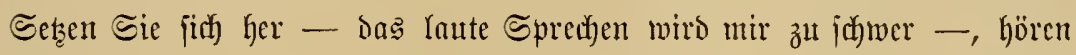
Sie zlt. Micin Tejtament liegt beim Gronbernement in Dar=cs=\{alaam.

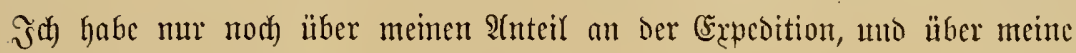
Berpflidutungen diejerhalb Bejtunnumgen zu treffen ..."

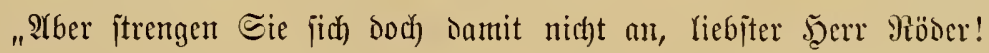

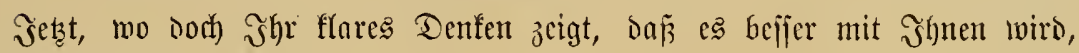
denten Sic an den Too!"

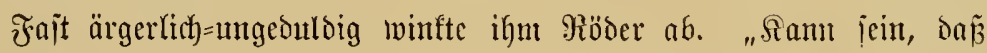

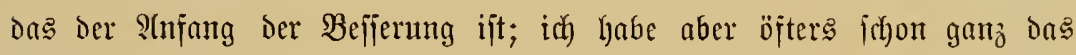
(S)egenteil gejehen! - Bitte, idreiben Sie für mich, - hier, mit bem Stift!" Und er diftierte dem jungen Freunde, dem es heiß und feutht it die \$agen fteigen wollte, mit furzen, auf Finjelheiten nicht eingehenten Sätžen, wie er es mit ber Bererbung jemes Miaterialanteile gerhalten baben wollte; er madyte eine S(nzahl von Reuten nambajt, dic Fojadjerg aus den etwa überbleibenten Taufd)maren bedenfen joflte, bejtimunte auch, ıwas mehreren 5eserren in ber Solonie als : Intoenten zu ïbermitteln jei, uni

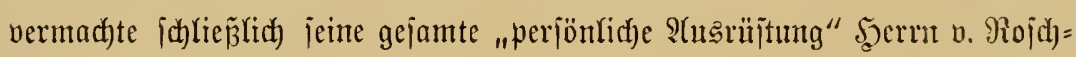

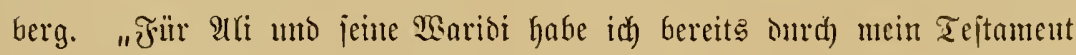

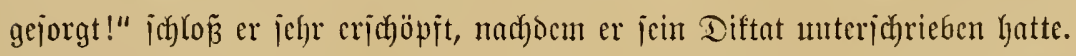

Durch dic Bsemütsbetwegung biefer halben Stumbe von menem recht

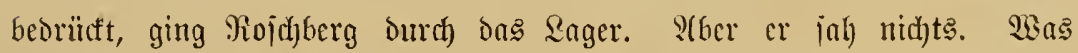

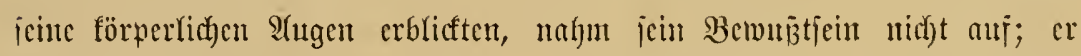
war derart "jeelenblino", da $\tilde{\beta}$ er cine geraume $\mathfrak{B}$ cile vor bem it jener

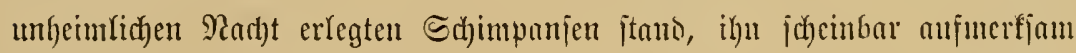
betradtete uno ihn in wairflidfeit bod nidyt wahrnalym! 3u amoerer Zcit

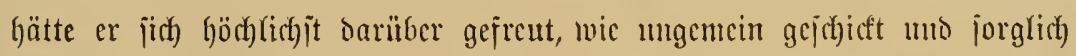
S(li bieje jeltente Beutc präpariert, Flcipd) unt Sfelett aus dem Jefl gelöit

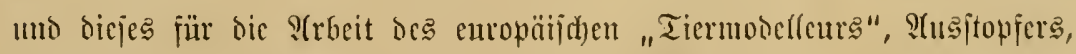

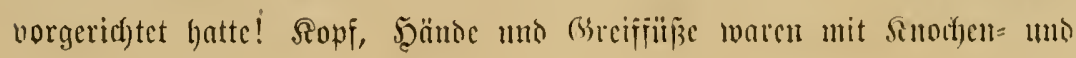




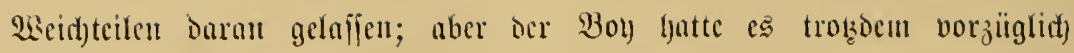

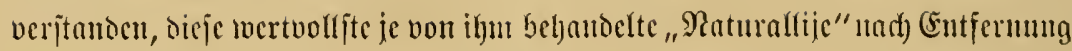

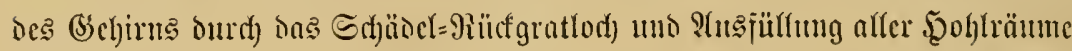

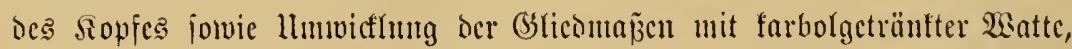

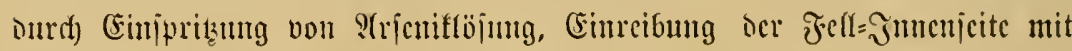

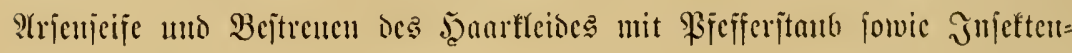

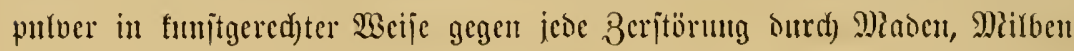

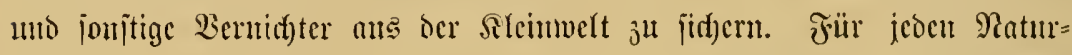

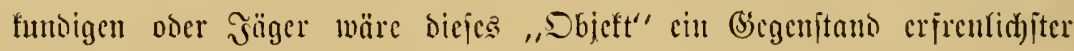

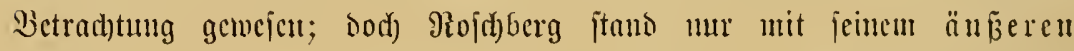

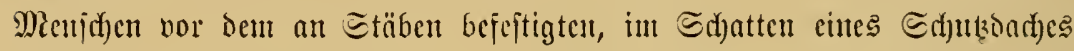

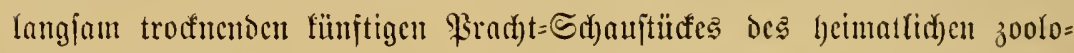

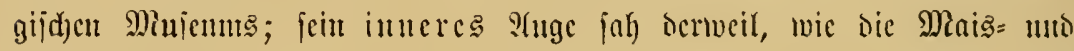

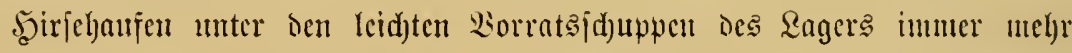

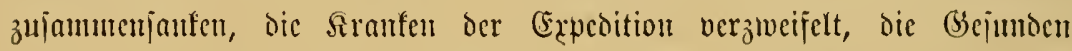

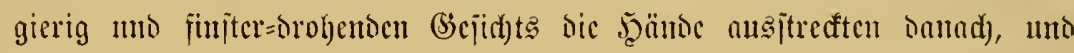

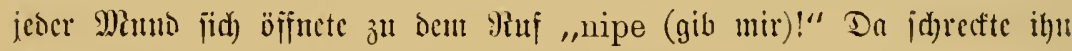

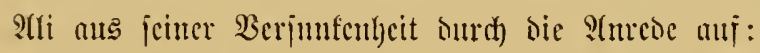

"Ja, Bana, Dn da $\mathfrak{r}\lceil$ it Did) freuen! (Er ijt ungehcuer jelten

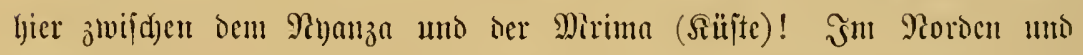
Wejten des Ryanza, in Ruanda, ocu Rande ocr jencripeienden Berge, wo

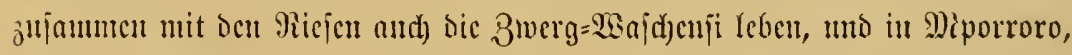

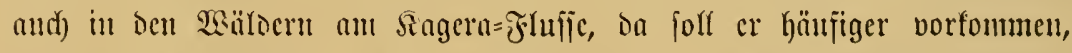
hat meis Bana Picon gejagt. Es ijt ja cin Tid)ego (Sd)wargejict)t=

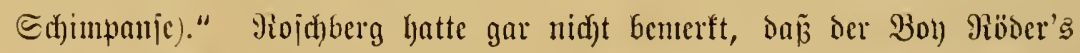

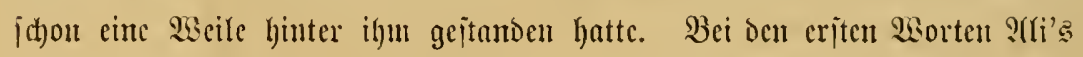
war er herumgefahen uno crwiocrte jetzt, un ocm braven Micnjajen für

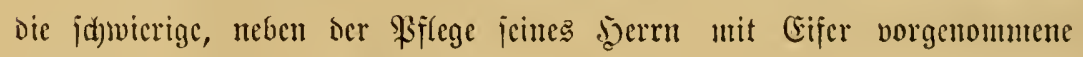

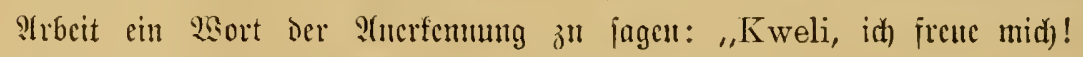
:(ud) Darüber, Daj Du ilgn jo gut hergericf)tet hajt."

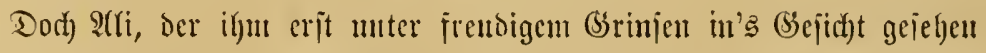
hatte, Dann uber imuter erniter mo ermiter geworden war, ermiderte zur Ütberrajdung Des jungen Minutes: "Du $i \mathrm{ag}$ it, Du freutejt Did); aber

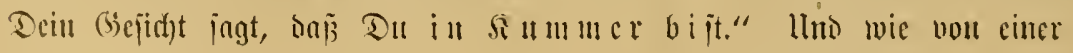


jurd)tbaren S(hnung crgriffen, in plöţrichem Schrecten didht an ihn heran= treteno, fragte er mit jitternoer 9 (ngji in der Stimure: "SSfaubjt Du, ba $\tilde{B}$ es idon auf meinem $\mathfrak{B}$ ana Reda i jt, ju iterben? (Słlaukhit Du wirtfid), Bana?"

(5: malte jith in Ton mo Brict cine jo idywere Sorge um bas

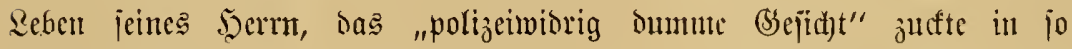

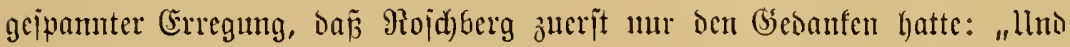

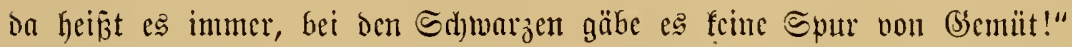

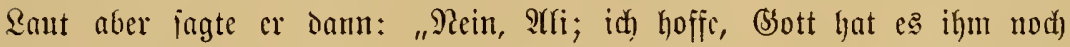

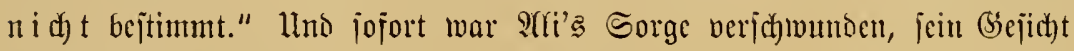

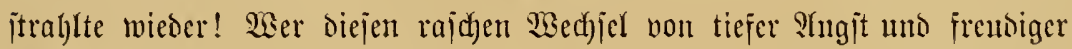

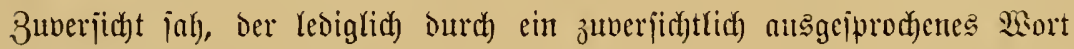

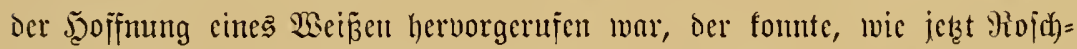

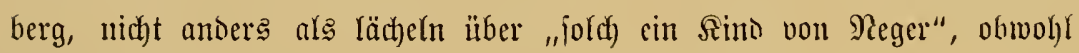
Dem jungen Manne jetżt wahrlidh nicht nad) Rë̈heln jumute war.

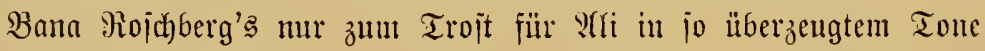

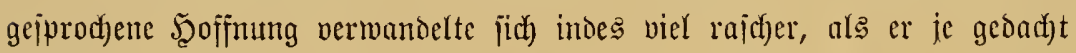
hatte, in wirflid gehegte. Denn jibnon am nädjten Tage machte ocr bisher wie sin dem Tode Berfallener antsjehende Röner einen böllig anderen Einorudf; es war, als ob er in den lekzten 24 Stunden cine Srijis überïtanden habe! Und zwei Tage danad) hjelt cr, ani jeinem Sangituhl liegend, bercits wicoer eine baraza ab, um unit hem jumgen Sanneraben,

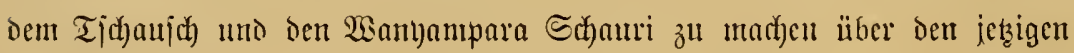

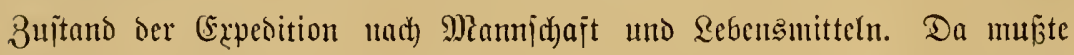

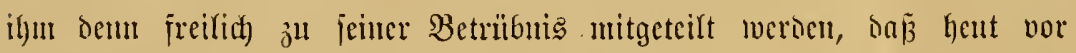
Eomnemuntergang orei Träger unt cin Sisfari begraben tverten jollten.

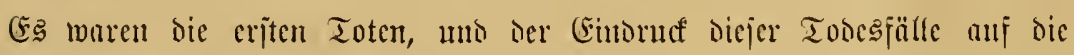
Leute wäre j̈̈herlidh tiej entmutigeno gemejen, wenn nicht inzwijd)en, ciucu uno z'wei Tage ipäter als bei dem Reiter ber Fapedition, nud bei vielen

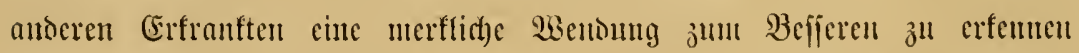

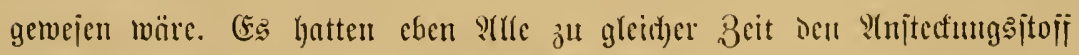

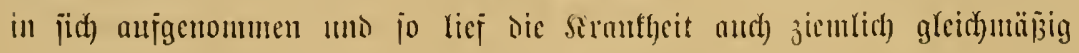

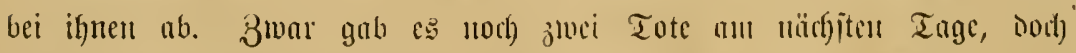

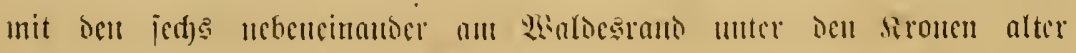


Banmricien Bejtatteten hatte dic Epromemic alle ibre Opfer gejortert!

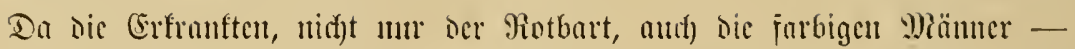

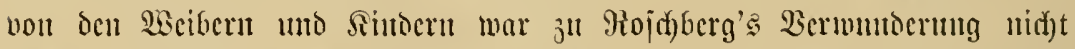

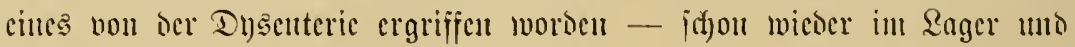
in ben Feloern bes verlafienen Do:fes 1mthergingen, die meijten afferbings

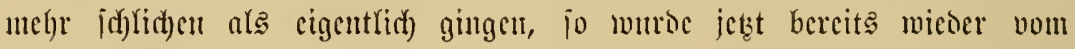
23eiterreijen geiprod)en! Dic Reute iebnten fird eben hiutaus ans dem

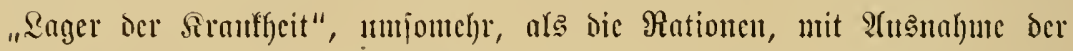

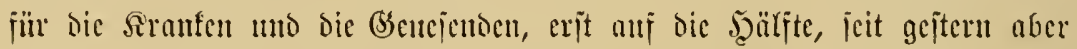
anj ein Drittel her gewolynten, freilid) red)t reichlid)en Micuge hatten cin=

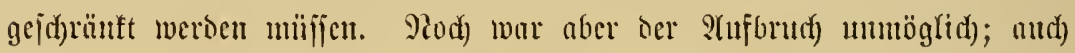

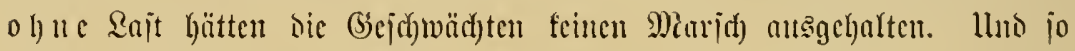

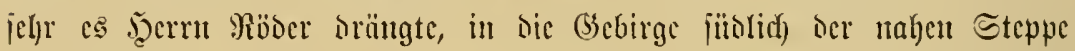

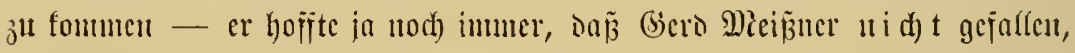

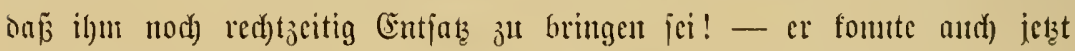

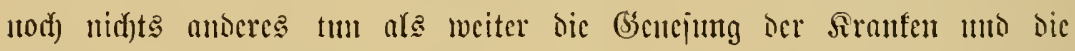

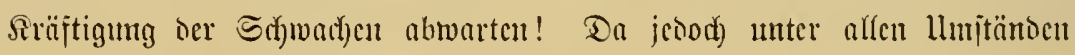

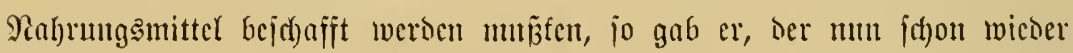

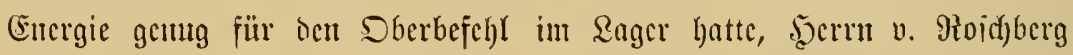
gern bic Erlanbuis, mit cinigen ber chcmaligen Êcejantenjäger unter oen

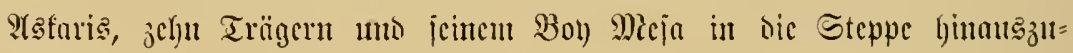

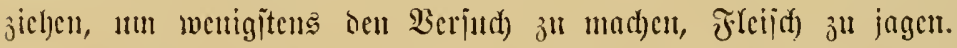

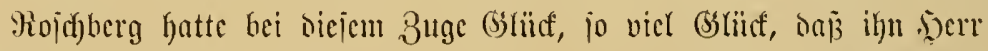

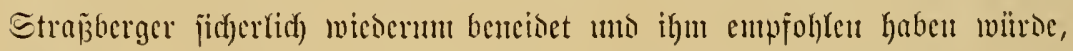

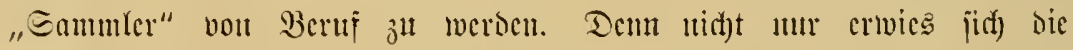

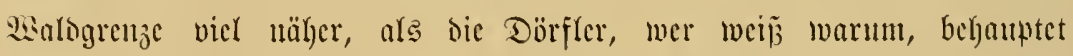

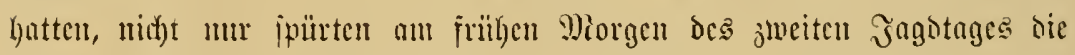
idhwarzen Säger in ber Etcppe mit jabelfajter "simtigfeit" frijd)en

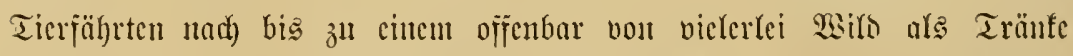

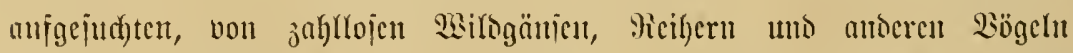

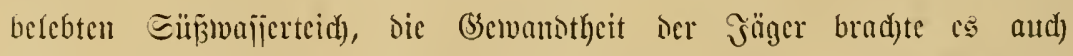

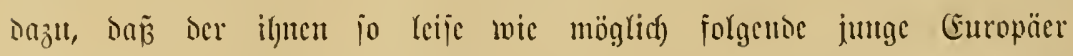

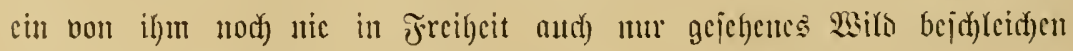

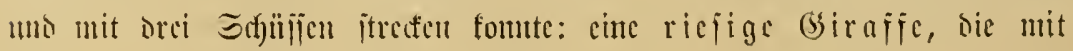




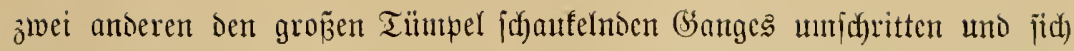

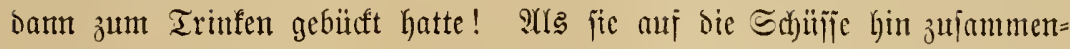

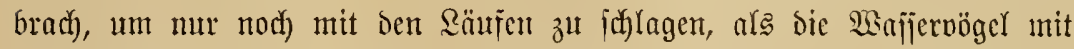

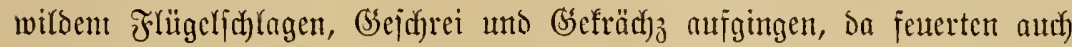

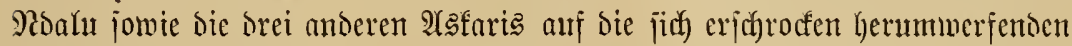

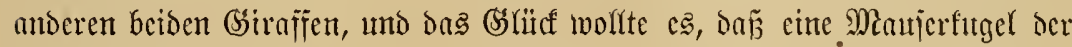

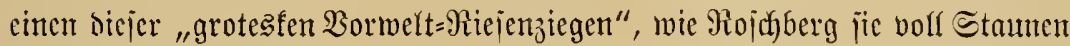

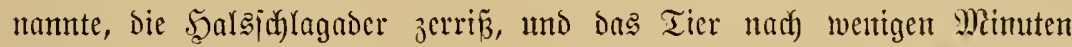
Dahinjtïrmens zu itolpern anjing, auf bie Siniee janf, für einen 2 lugenblicf wieder hod) wurde, um bann "wie ein Tumm in fich jujammenzutïürzen"

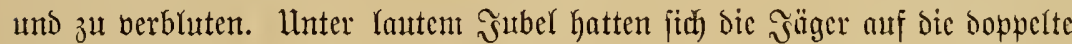

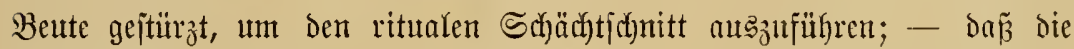

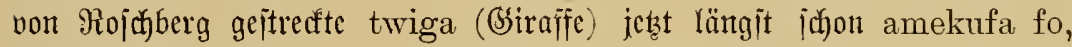
oder gar amekufa kifofofo, ganz tot, jogar maljetot war, bas liez sen

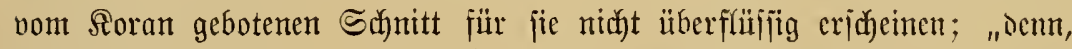

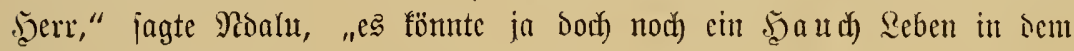
Tier jein; wer fann bas wijfen, auß̄er P(lfah?"

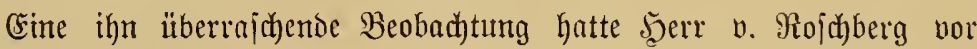

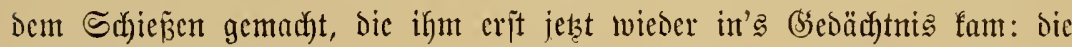
(Siraffen waren feinesinegs niebergefniet, um ju trinten, jic hatten vielmehr bic Borberläufe immer meiter umı meiter nuseintunter=

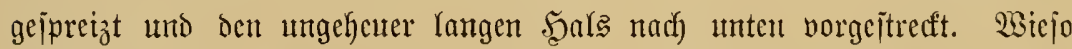

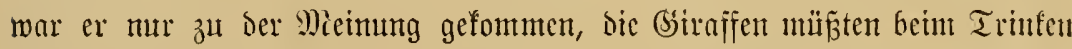

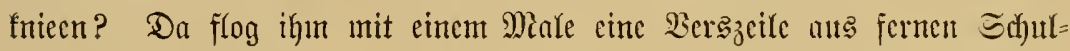

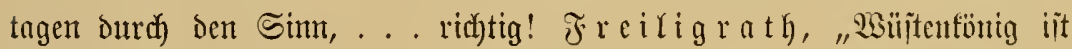

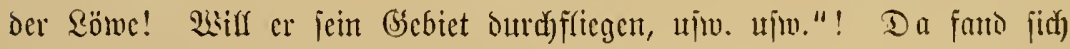
jene jo lange hajten gebliebene Beile: "Siniceno id lürit fie langen

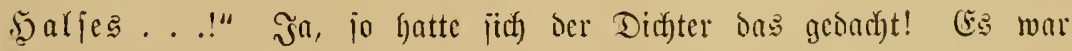

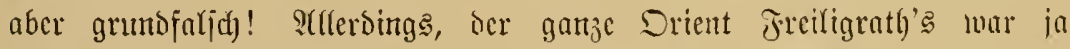
mur cin Phantajic= Drient; jo wenig wie SIfrifa ïberfanpt, batte der

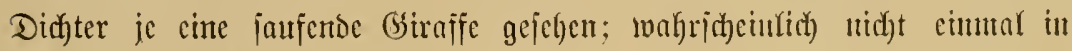
einem Boologijhen Brarten! - - -

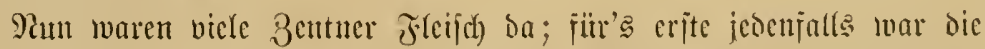

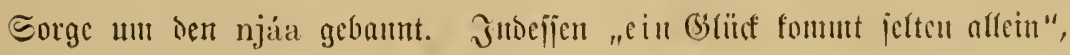




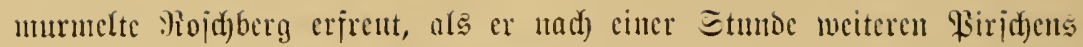

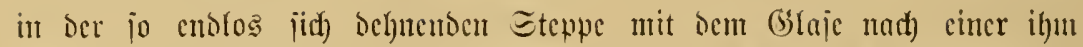

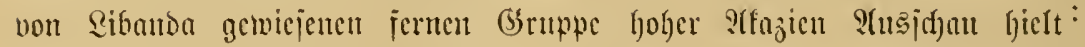

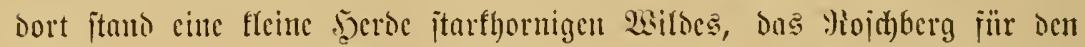

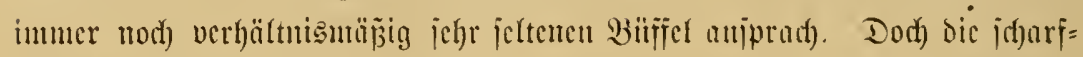

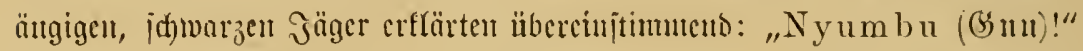

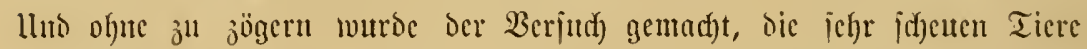

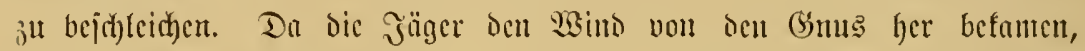

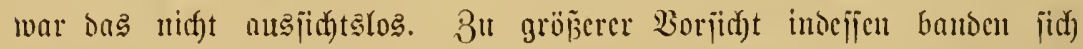

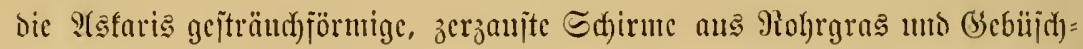

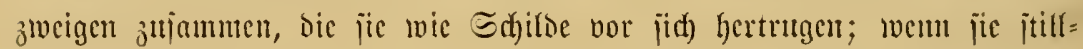

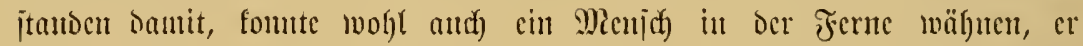
habe mantehohen Bujch vor jid). - (Es bauterte jedod) mehr als anterthalb

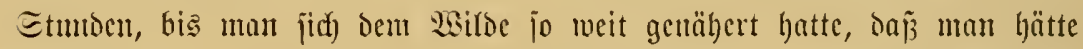

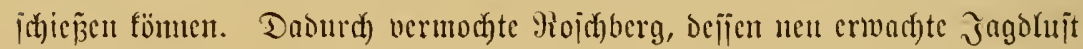
jeden anderen (sebunfen verjadeutht hatte, bie jieben Tiere ganj genau

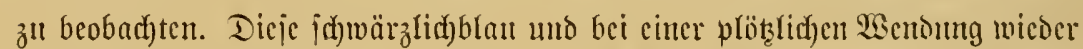
bellgran ausjegenden, mit vermijd)ten butten jenfted)ten Streifen an ben

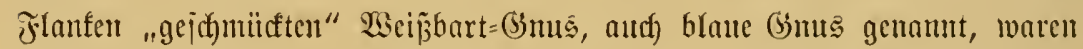

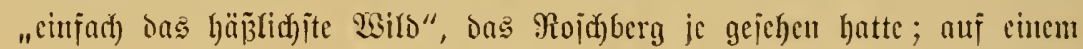

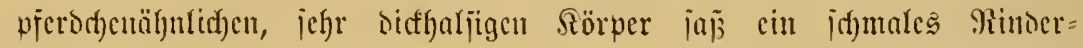

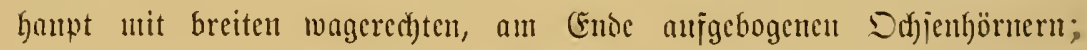
mur bic Beine waren richtige SIntilopentäuje. Dic jehr oümnitruppige

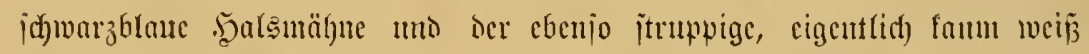

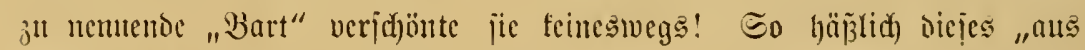

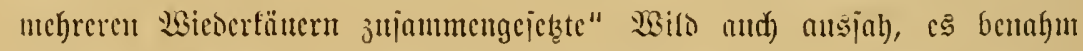

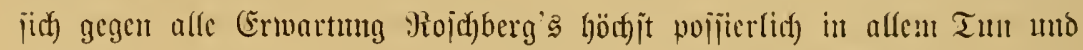
Ireiber. Wiehrere, woht nod) nid)t volf ansgewadjeme Bulfen iprangen in

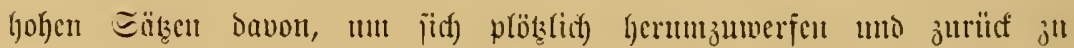

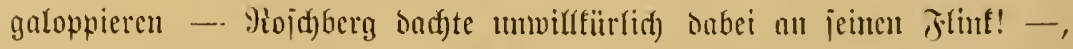
jagten Damu wic toll ill engem Sireiie umber uno jeterten anj cinmul io

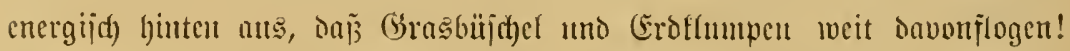
Ja jic iprangen jogar, elajtij(h) mie hochgeid)uellte Bülle, mit alleu

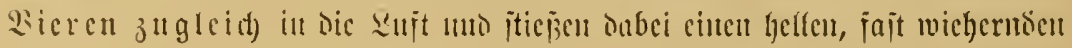




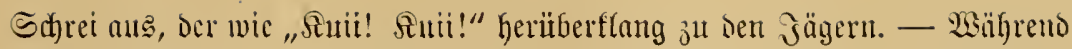

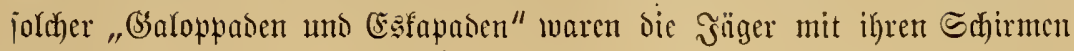
hörhit vorjichtị näher uno nüher gerücft. Da warf abcr jeşt eines ber

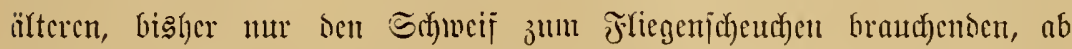

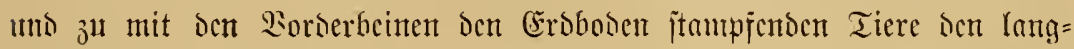

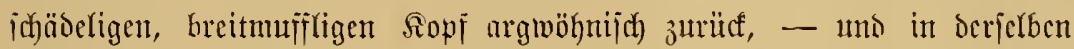

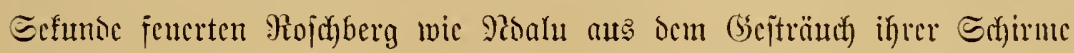

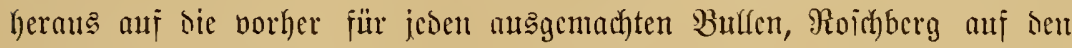

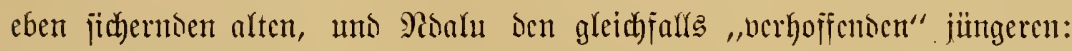
augenflicflid) brad) der alte jujammen, bic übrigen (Słm jtoben oröhnenten

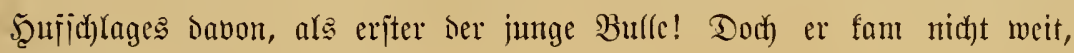
taumelno brad) $\mathrm{cr}$ zujamment.

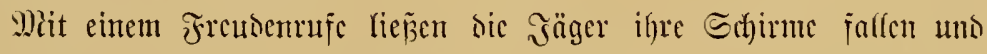

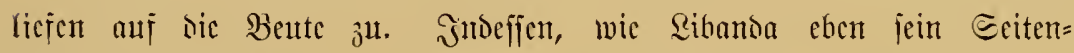

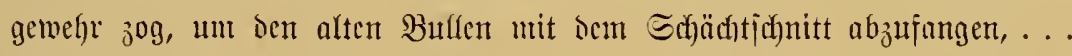

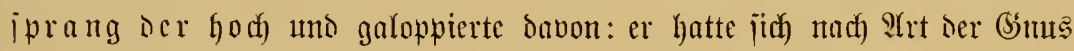

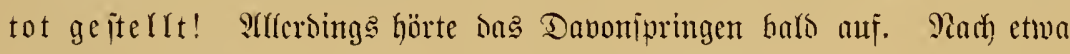

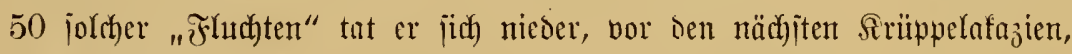
unto der ifgm jo rajh) mie möglid nachgegangene Rojdberg gab ihnt ben

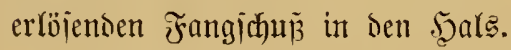

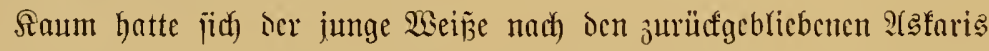
umgejehen, jo fuhr er auth jithon wicser in höd)jent (srabe erjtaunt herum:

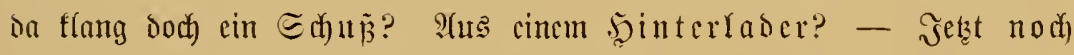

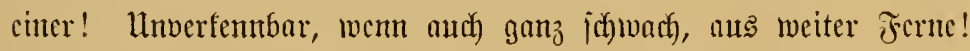

Pidyt minocr critaunt hatten bic Schmarjen gefaujdyt. "Dort jagen Europäer!" erflärte Pobalı. S(ther man hörte nod) cimmal zmei Edjüjī furz hintercinanter. Das waren Signar irjüjïe! Jrgeno Jemano, tocr

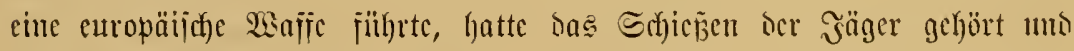
jich ifnen fomerfbar zu madyen bejtrebt. Wiser founte bas wohl fein? $30 \mathrm{~g}$

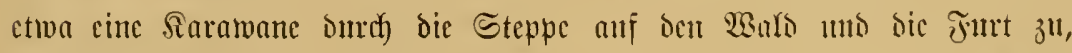

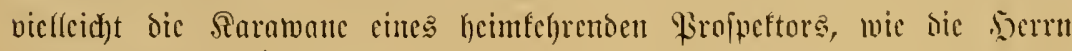
E(d)lohthad)'s?

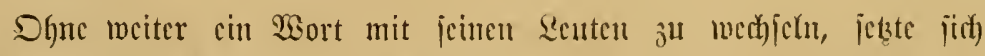
Nojhberg in ber Ridytung auf ben Drt in Bewegung, whor sie Eignal: 


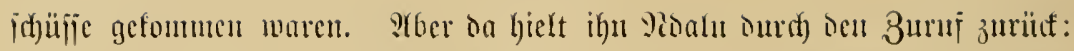

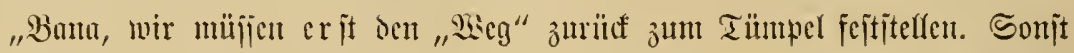

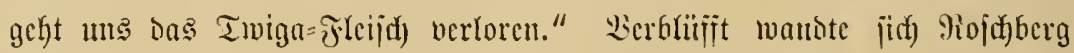

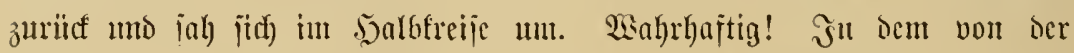

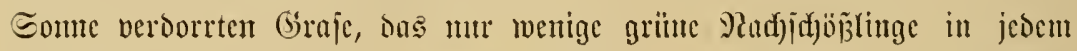

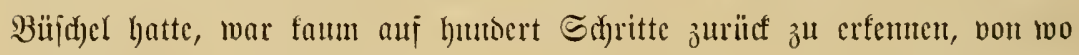
aus man jidf) angefd)(id)en batte; unı bätten nid)t bie $\mathfrak{B} u(d)=$ Edjirme ba

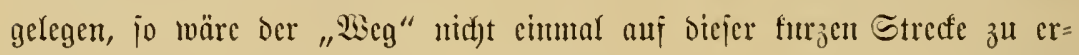
fenten gewejen! 2so modhte Der Tümpel jein, an Den num dic Iräger

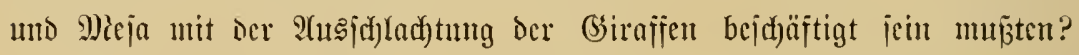

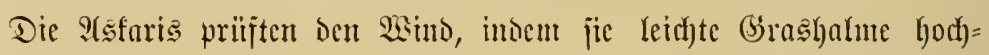

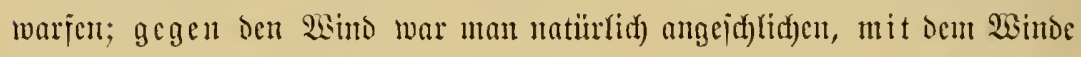

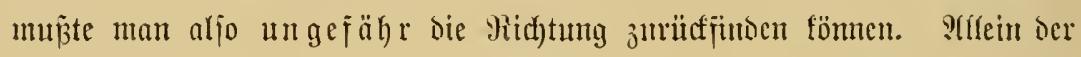
Winto war jeşt, nadjoem dic Sonne immer höher gefommen, nad) unt

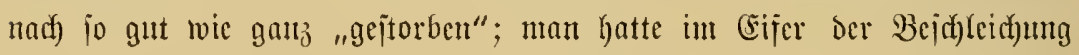
gar nid)t baraut geadfetet, oa $\tilde{\beta}$ cr inmer geringer murde, - umo ob er jidf

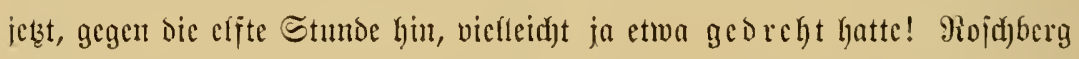

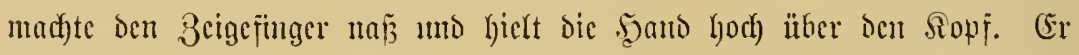

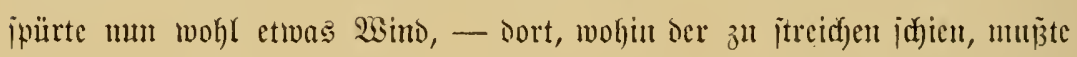

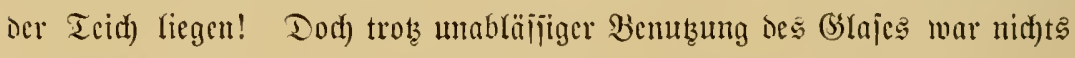

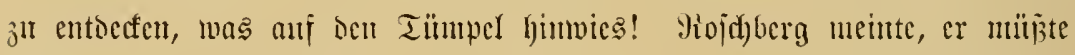
Dod) Durdy bas (blas die "aufitelyenton" unto nad) furzer Frijt wieser ein=

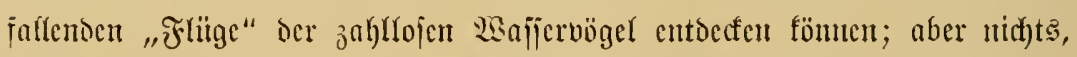

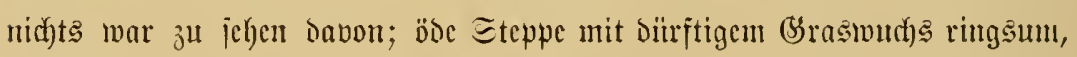

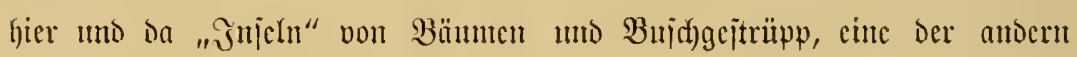

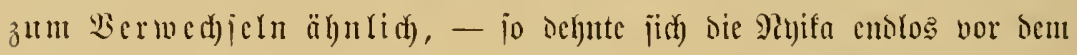

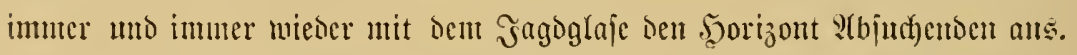

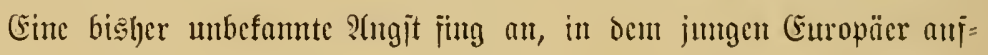

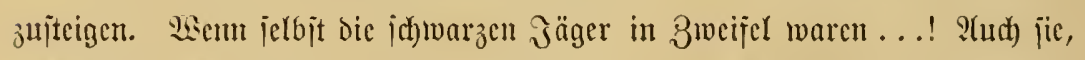

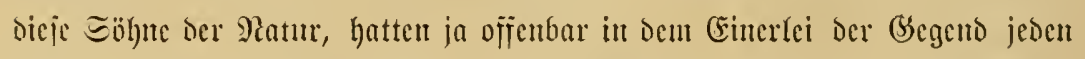
Anlbaft verloren! Ticjer fincin in bie Eteppe Durfe man unter fcinten

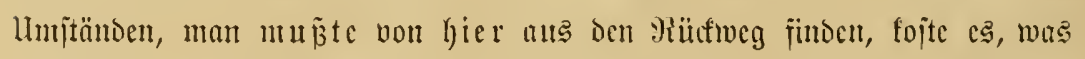
es wolle; Dent cin 2ierirren int ber Steppe bradhte den Too! - Er hatte

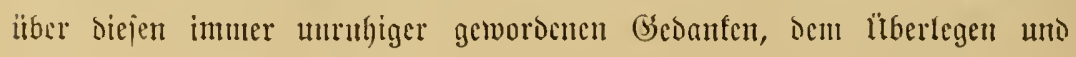




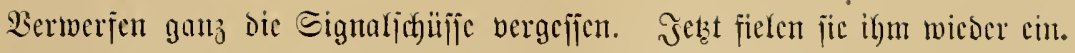
Das waren am Ende Berirrte, bie, vielleidy)t mit iłpen letzeten \$atronen

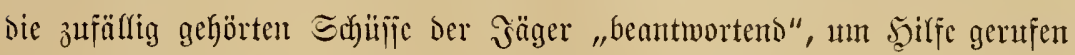
hatten! Stber wer jie auth jein modhten - eine Sefumbe lang war ihm

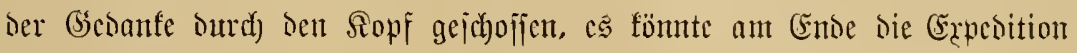

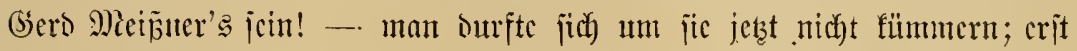

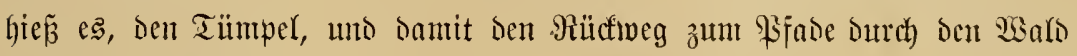
wiescr feititellen!

Da fnaflten wicocrum jweintal jmei rajh hintercinanocr abgegcbenc

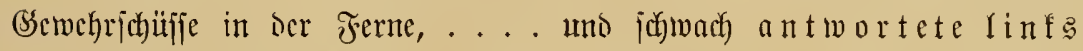

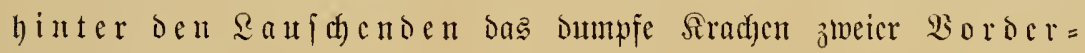
laber sarauf!

"S̆urra!" jhricen Ploalu uno Sibanta, "wir brauthen Den 2 seg nicht zu judfen! Das maren unjere Iräger, bie jenc Srjüjje mu audf) gef̧ört haben!" PRoalut jtrecfte finten STrm aus. "Dort, in geraber Rinic,

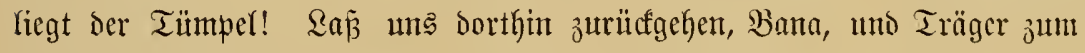

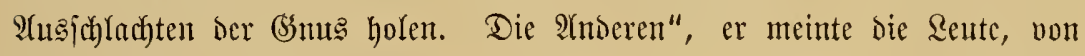

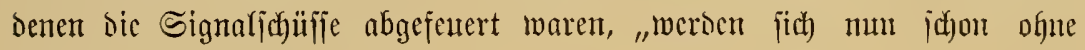
ung วu dem Tümpel finden!"

ate ob ihm ein fufwerer Stein vom Şerzen gefallen wäre, jo

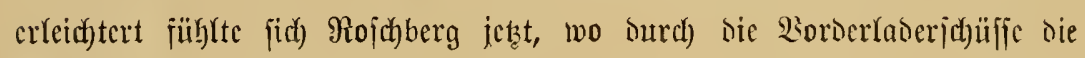
Angit vor ber Berirrung bon ihm genommen war. WSent man bie hörte, jelbjt un it dem Winte, founte Der Tümpel ja gar nid)t jo rocit ab licgen!

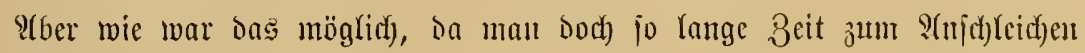
gebraucht hatte? Sr begriff bas gar nicht unt crfonnte bic \&öjung bicjes

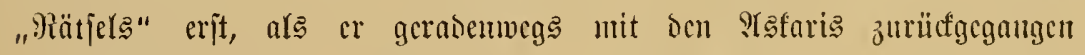

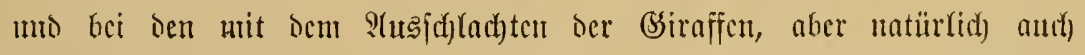

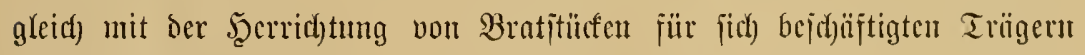

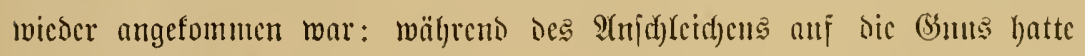

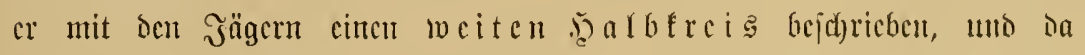

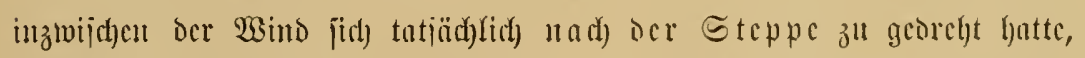

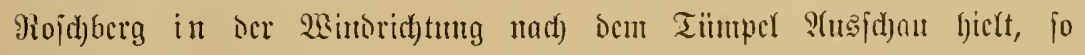

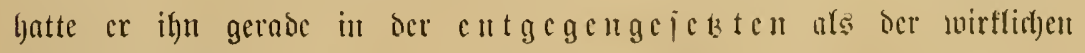
Richtung gejud)t! 


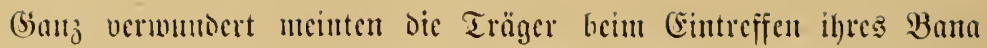

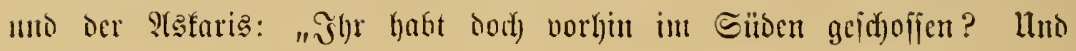
ihr tomme jetzt aus Rorden?"

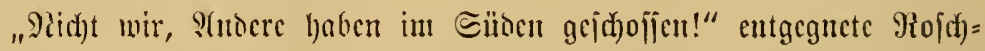

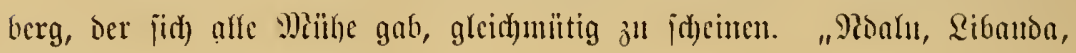
feuert jesct nod) cimmal."

Dic S(ntwort anf iljre Schijife flang jetż id)on zicmlid) nahc, nuo

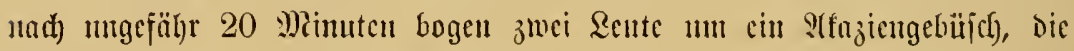

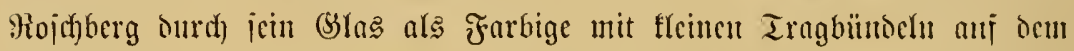

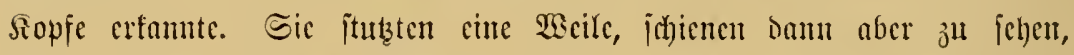

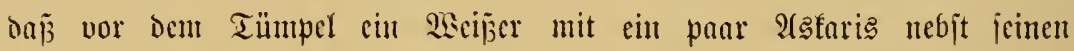
Trägcrn itant, mo famen id) (cppenden (Sanges auf bie Micnid)engruppe 3u. Beide hatten Enropäeriactetts ither ihren Ramus, Maujerfarabincr in

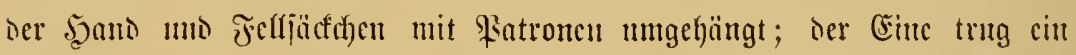

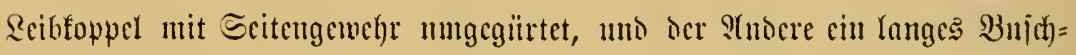

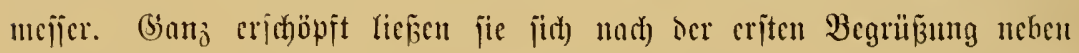

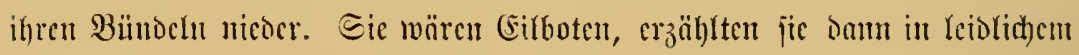

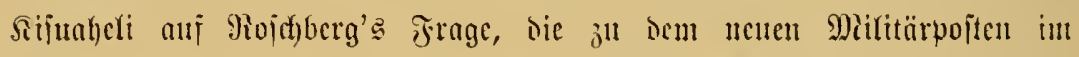

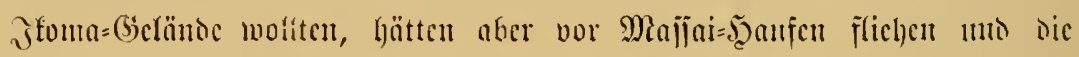

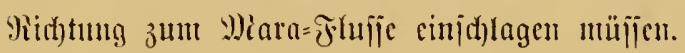

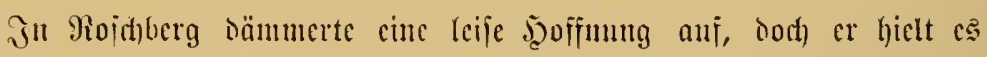
vorlänfig nod) fïr geraten, Dic Reute nid)t nad) den Panen bes Plamtes ju jragen, in ocfien Dicnjt jie itantoen; jie würocn ihn ja nad) 3 raud wohl

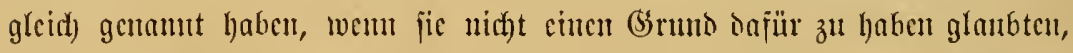

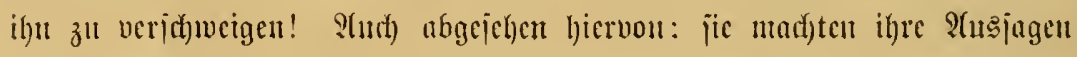

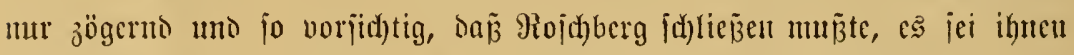

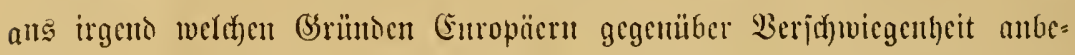

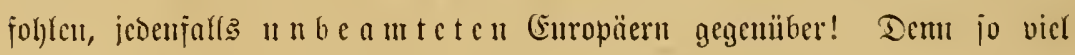
war jofort erfemubar, jie hatten gelyojit, eimen, bana kwa teli ya zahabu",

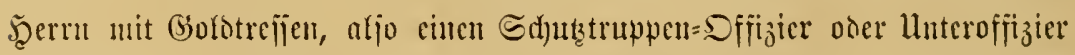
anzutreffen, in Jfomn oder idjon auf ocm Siege Dorthiu, und waren nu

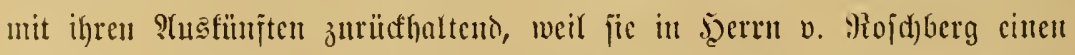

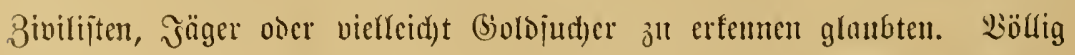

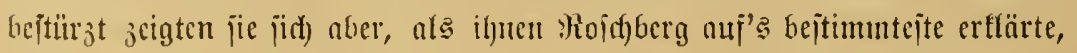




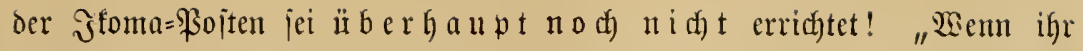

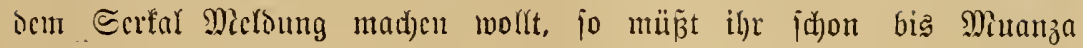
marjdicren; on fommt igre vou hier aus noch cher hin als nach Schirati."

Dic Reute iprachen in jweifeltos rech)t nicoergcorïuter Stınmunty

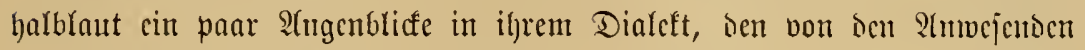

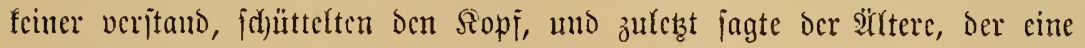
nod) rote J̨iebnarbe auf ocr linfen Stimjeite hatte, mit bejorgtem 2(chjel= heben befïmunerten Touts: "Kweli, iwapo (ja wahrlid), wonn oas io

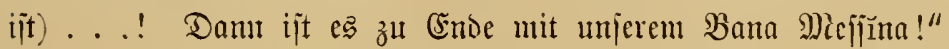

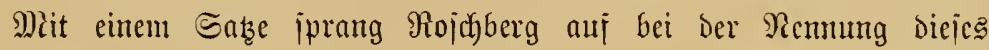

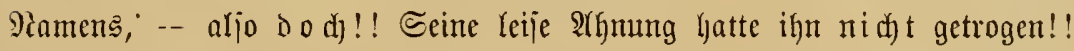
"Ma $\mathfrak{M} \mathfrak{n}$ !" rief er jo aufgeregt, ba

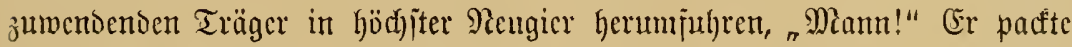

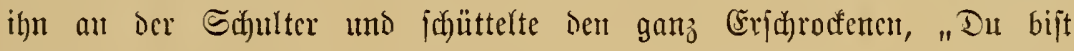

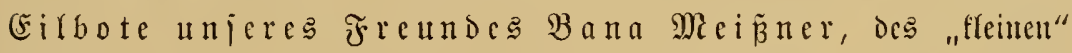
Brubers vom Baua Meiñner in Muanza? Wo i jt $\mathfrak{e} r$ ? Wie lange

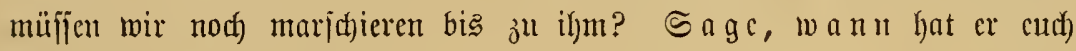
"bgeiduicft? Ts a $\mathfrak{n} \mathfrak{n}$ ? !"

Tllein jo rajh), wie er hoffte, befam ber junge Europäcr feinc $\mathfrak{T}$ us= funjt von Den ifn iprad)los, ntit offenem Mcutide anjtarrenden Senten.

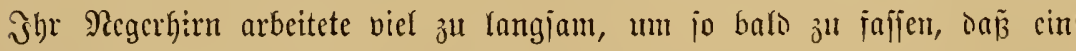

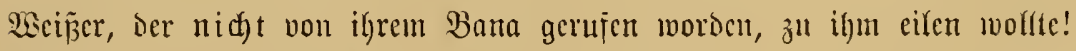
Wiellecidyt aud) überlegten jie, ob das aut) Wahrbcit wärc, was fic bn

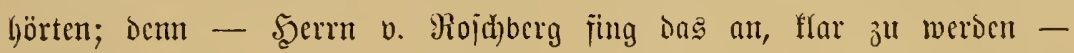

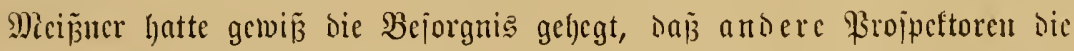
Boten mögliderweije unternegs ausiragen uno jomit mühelos bic (segenden mit dell "Ssoldovorfoumen" ausfimbig machen fönuter, bic cr

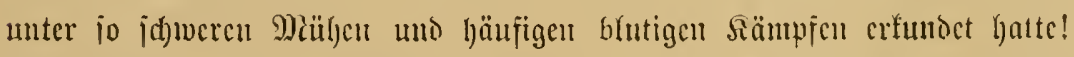
Die Beisen wollten gewiz and) wegen jold)en Mitījtruncus Den Brici nid)t vorzcigen, ben jic nad) iljecr Bchauptung nur Dem bana mkubwa

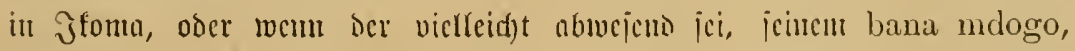

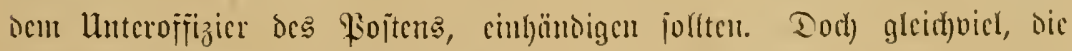

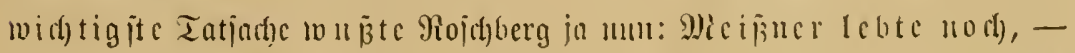

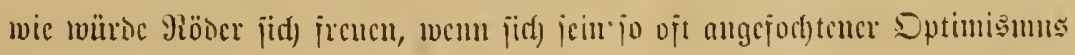




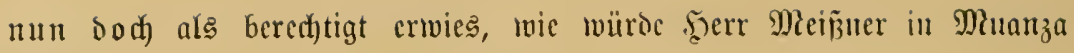
mịatmen nady all ben jumeren Sorgen ...."

Die (Eilboten idjienen inzmiid)en Dod) zu Der Erfentmis gefommen

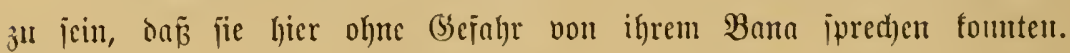
Reun Tage jeien je unterwege; aber mur wegen ber verruthten Majiai

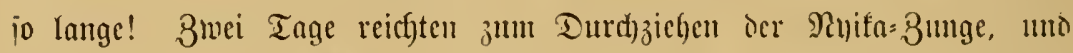

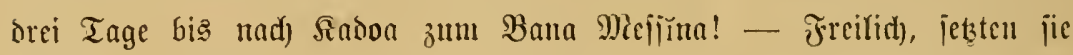
hinzu, es würdx dem banta nichts nüzen, wemn jein Freund mit den wenigen Seuten hier - jie deuteten auj dic ?Sfaris umo Träger - ihu ju Şifie tommen moflte; dic Feinte zählten ja nad) viclen, vielen

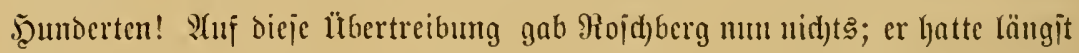
gelernt, was Yegerungaben bedcuteten. In froher 3uverjidyt jagte er den

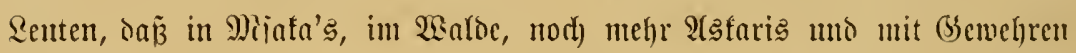

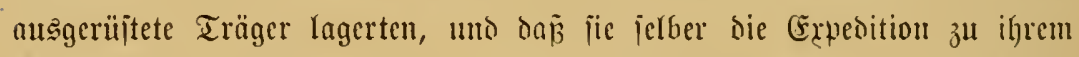

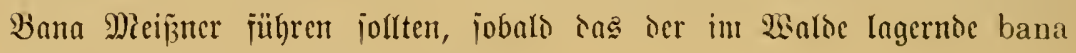
nyekundu Reda bejehlen wïr ic.

Feder von den Farbigen, and) dic STfaris mo die (Eilboten, bcluden

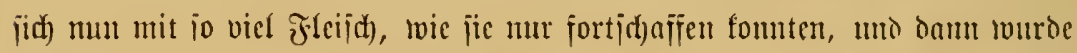
Der Rür(marid) in oen wals angetreten.

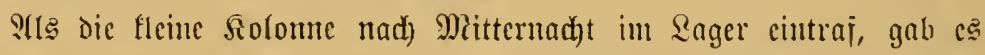
cin lautes Jnbeln: dic unerwartete Sunde, daj die Piljifa fo jeht viel näher liege, als dic weggezogencu Dörfiler ane irgend weld)cm (sirmite

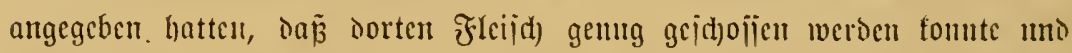
fïr den näd)iten Bedari idjon geicholïen worden war, bas bradte Dic Sente in eine jait übernütige Etimmung, von bor ielbit dic Sranfen

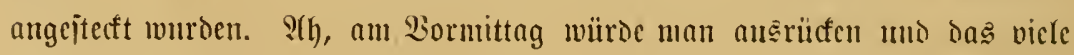

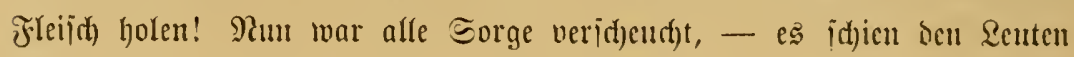
jo: für imumer!

2ud) Miöder war Durd) bie von Roid)berg heimgefradte Doppelfunde

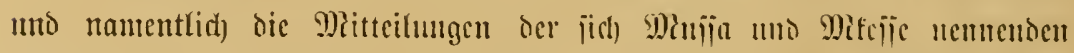

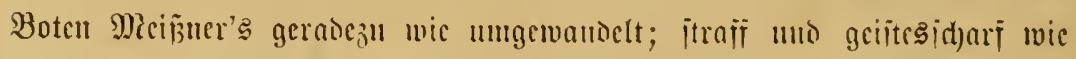
nur ie in jeinen geimbejten Tagen jïhrte er bas näd)tliche Eshauri mit

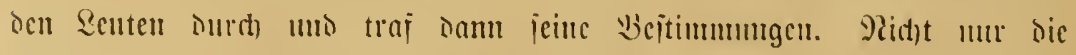

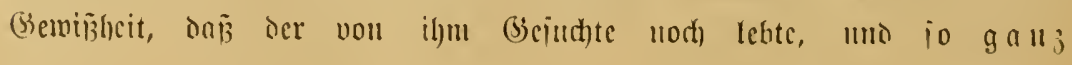


nerwartet nabe lebte - zmm mindejten mit einer $\mathfrak{A n z a b l}_{\text {bon }}$ Seuten nod) gelebt hatte unb verteisigungajälig gewejen war, als er bie

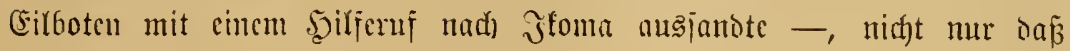

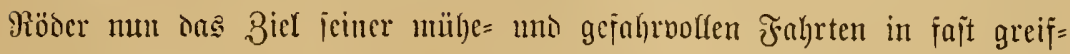

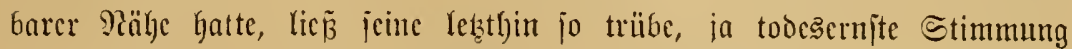

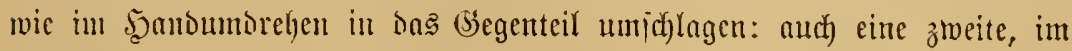

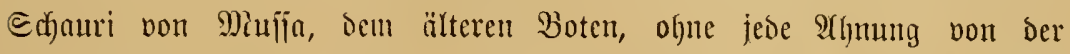
Wisthtigfeit jeiner Mitteilung jo nebenbei ermälynte Tatjathe trug zu Diejem gänzlichen Stimmungsumịlag mejentlich bei! Demn auf die Frage, ob die Beiden währeno ilyres Maridges nut bou Fleijh des von ifnen erlegten

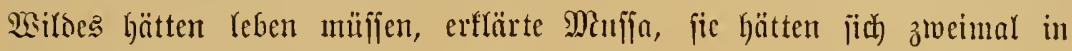

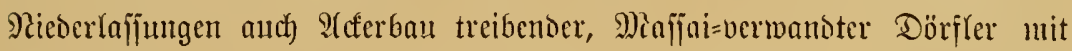
Miehl verjorgen fömen, uno das cine Dorĩ liege non hier nur cinen uno einen halben (Eilmarid entfernt am wejtlidjen Rande ber Steppe!

Das war cine Siunde, dic auch) den zujammen mit dem Tichanjich

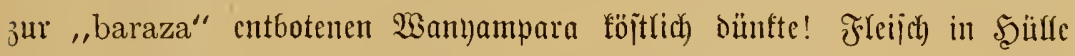

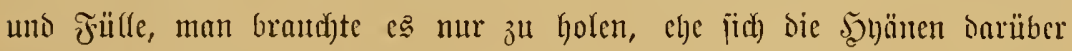

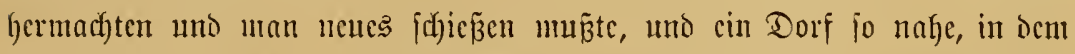
man Meljl uno fiorn uno was man jonjt mod)te, faujen, idhlimmitenfalts

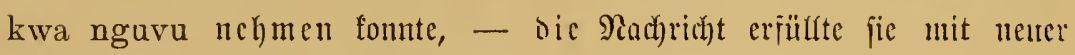
Tatfraft uno liḉ jie alles vergeffen, was hinter iljnen lag!

"Wir fönuten mit umjeren franten uno idjwathen Senten feinten Girl=

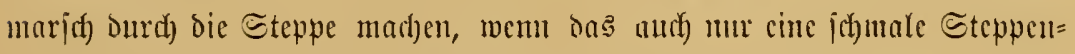

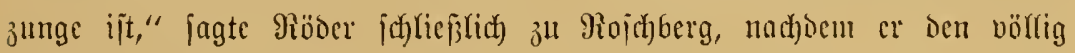

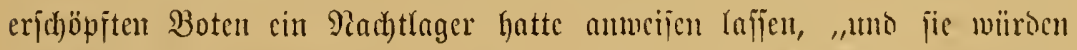

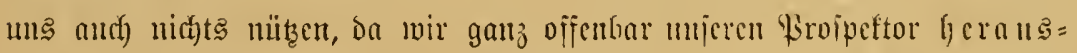

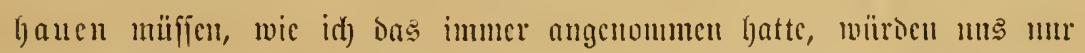

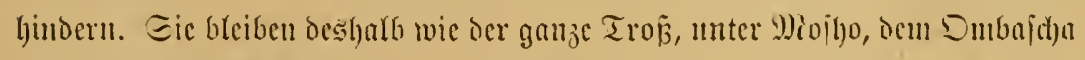

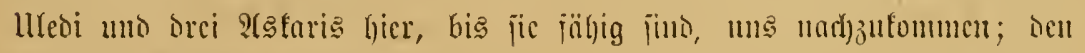

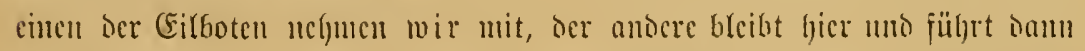

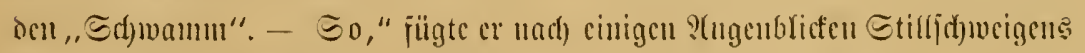

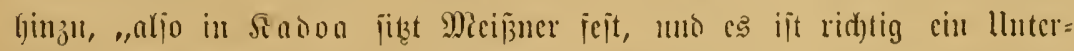

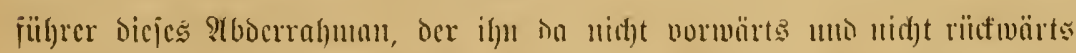

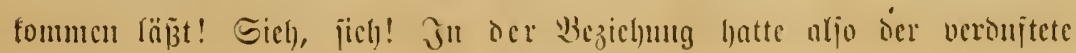




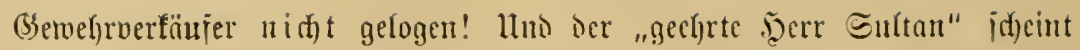

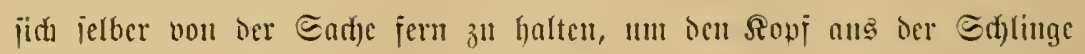
ziehen zu föınen, wenu cimul die 2iergeltung foumut! - Ma, uns ijt ç

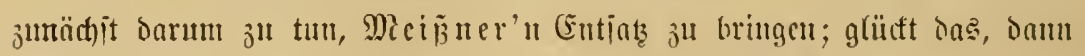

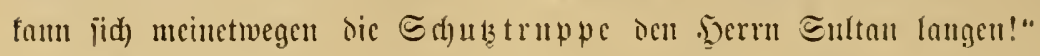

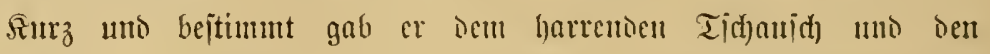

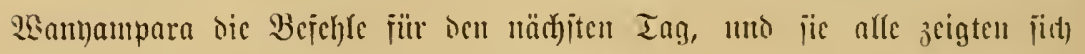

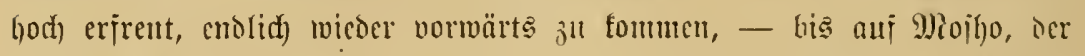
von dem "Werproviantierungsoorie" mit jeln \&euten hicrher jurïffel)ren iollte, แm ihm anjantgs menig; Dodh nad) uno nad) iöhute ihn ocr Stolz Daruli, mit Ulesi Seiter oer Pad)trabsaramane ju jeill, mit sicjem Bejeht ies roten Эägers ans.

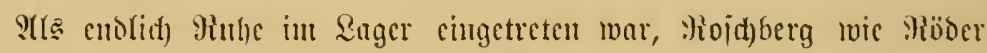

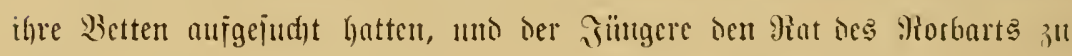

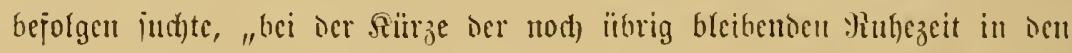

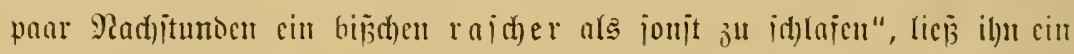

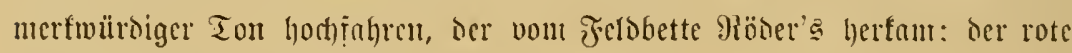

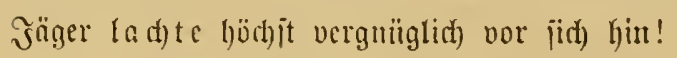

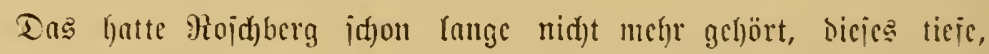

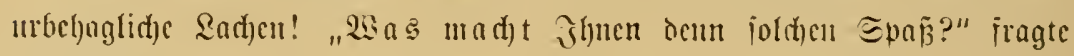
er hinüber.

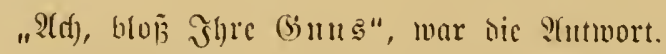

"Jieine Grus?" Ganz vermundert riej Roidhberg Das aus.

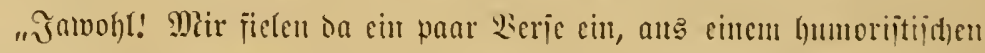

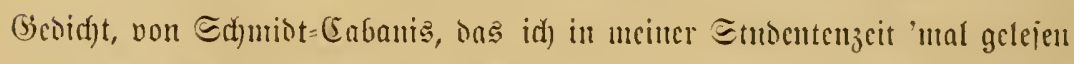

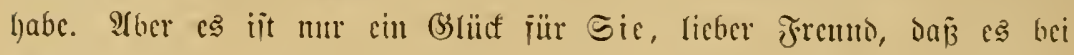

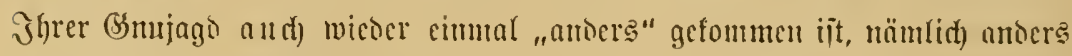

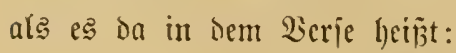

"Eelbit das (3)!n

beiBst mand)mal ju,

uno Denft: паиน

hat die liebe Eecle ginll!"

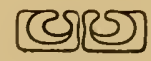




\section{Zwanzigites Kapitel.}

S) Miarich burch die Steppe war um jo bejchwerlider, als vom crĭrn Ragerplaţe ant, - tem Tümpel, wo bie Biraffen erlegt waren -

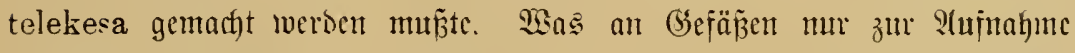

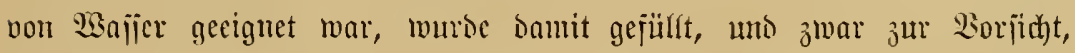

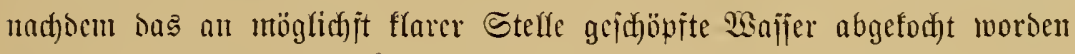
war. Sn grȫ̄ter (File ging cs am jolgenoen Tage vorwärts . . bis

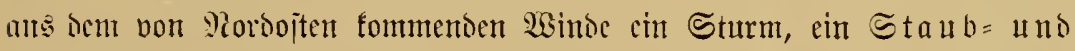

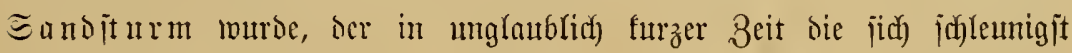

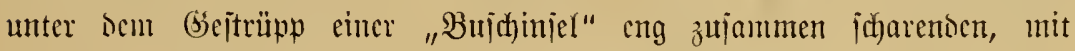
Beltbahnen, Decfen, Türhern jïh) nach Möglichfeit bicht verhülfenten Reute umter locferen Whajien gelbgrauen Staubes uno zerriebener jobarfantiger

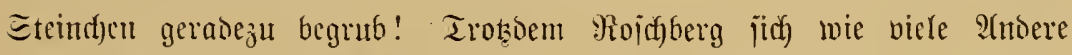

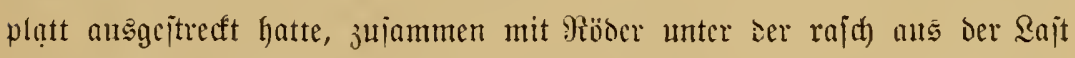

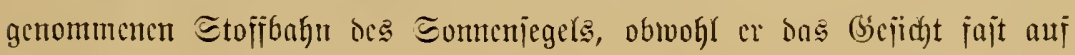

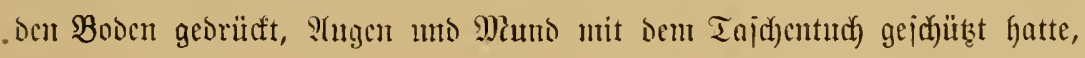

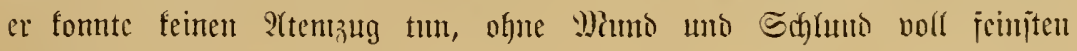

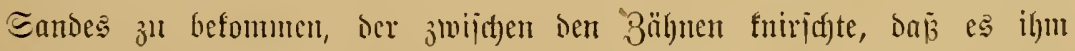

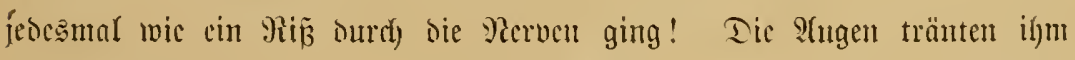

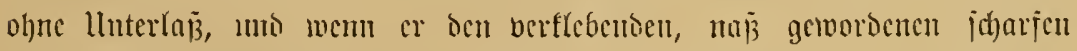

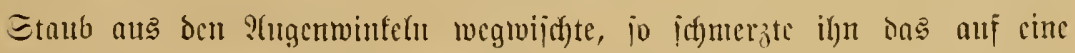

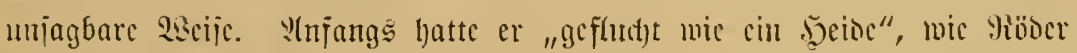

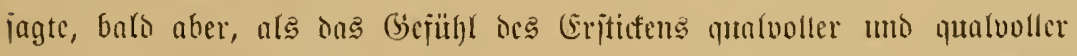

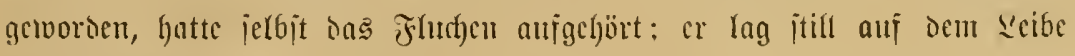
uno röd)clte nur.

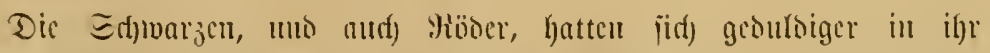
Édjidjal gejunden, obgleid) jie faum mimber litten alङ ocr junge Europüer. 


\section{$-550-$}

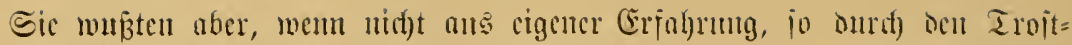

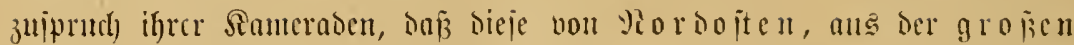

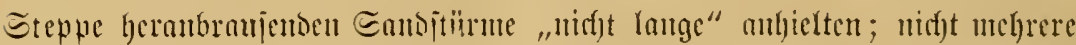

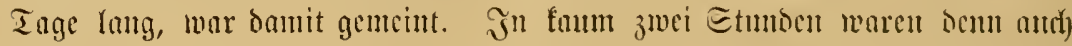

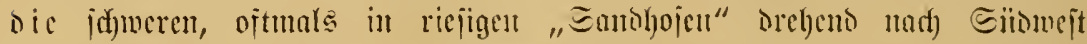

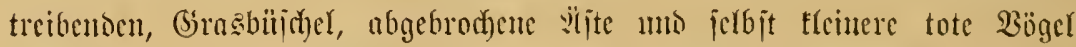

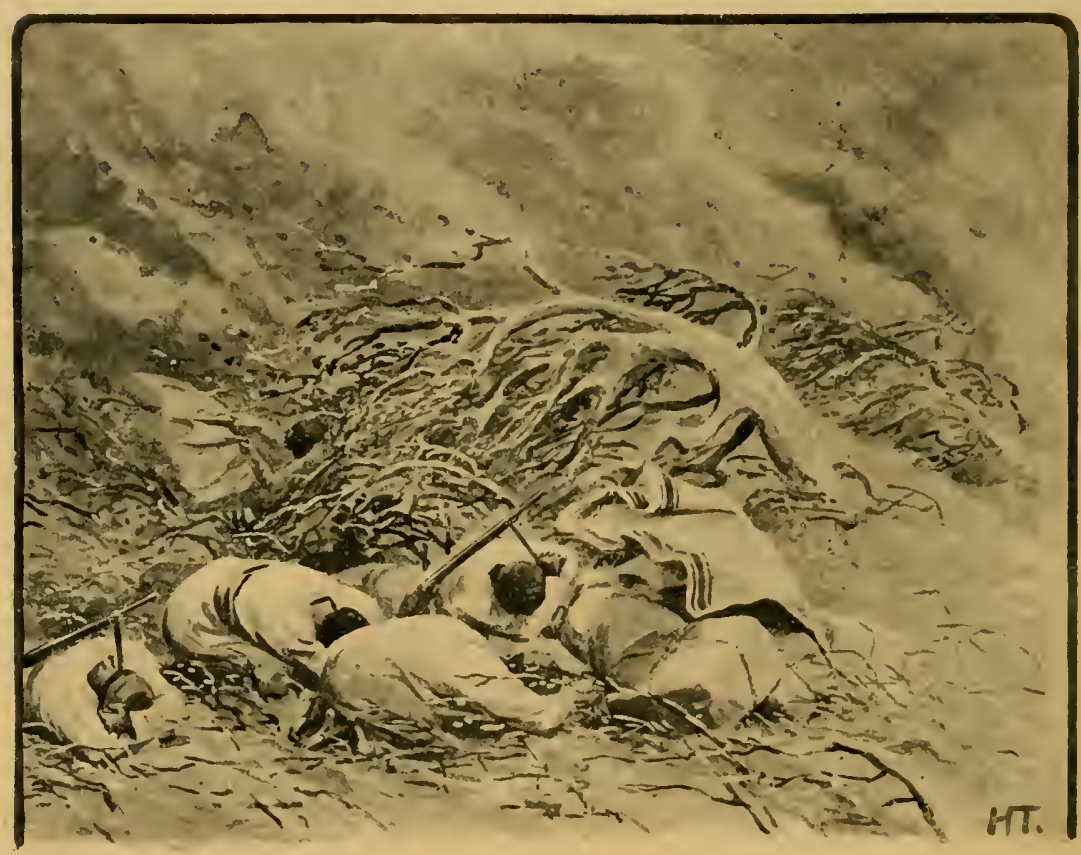

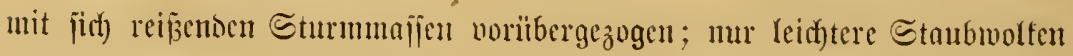

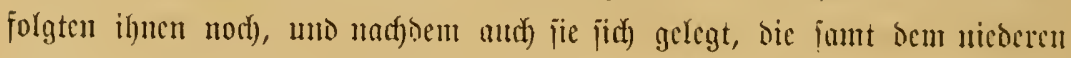

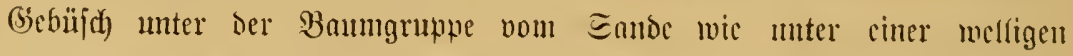
Dïne begrabenen wasafiri Den gröberen $\Xi$ tunb menigitens einigcruna ß̌en

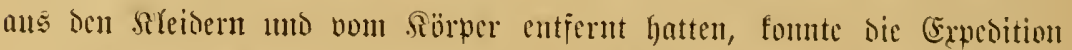

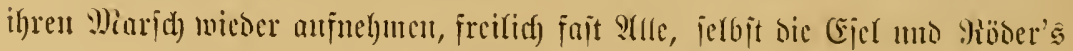
Mimnie, halb blino uno mit biefueridfmollenen $\mathfrak{A}$ ugen.

:iöber, ber fït) nad) ciner fritheren Benerfung ju jeinent jungen

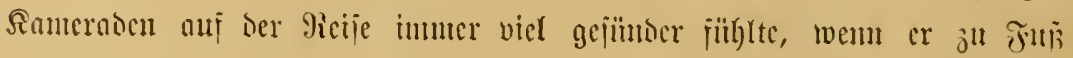

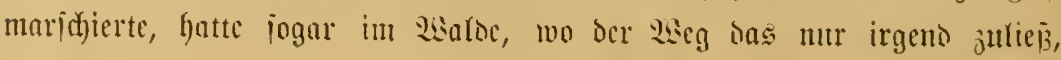


reiten müijen. (Er "fiug" aber mur auf ocu Mianlticr. So überrajcheno

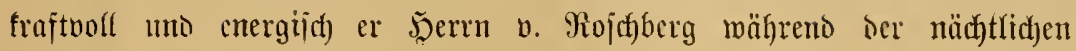

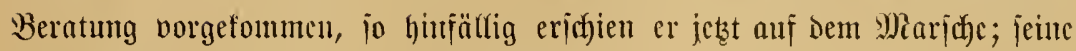

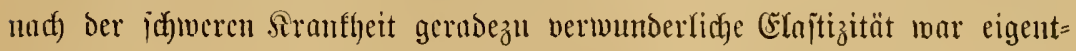

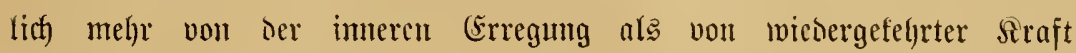

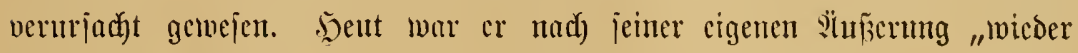
verdanmt fa)lapp", uno andh jeine Stimmung zeigte recht merfmürdige

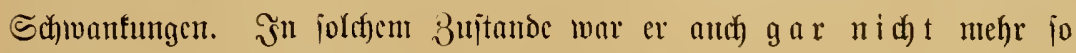
juverjichtlich Der Mieinung, bie Expedition werde "Den Propeftor herans=

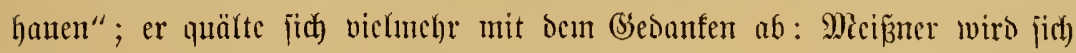

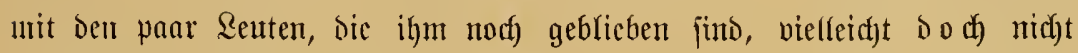
mehr halten tönnen, bis wir anfommen! 3loar jprad) Siöder bas nicht

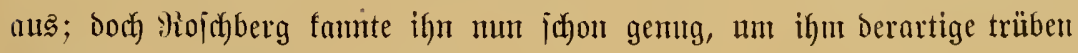
(Sicoanten vom Sicjicht zu lejen.

Einc Ermunterung waro bem in joldhen Stunden von feiner förper=

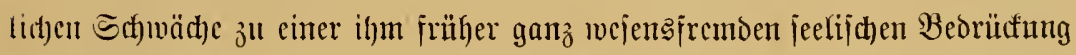
gebrachten Motbart aber zutcil, als die Fiaramane, die währeno Der Telefeja

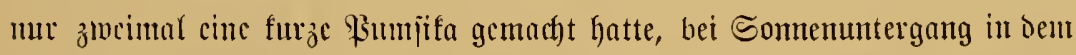
"Werproviantierungsdorfe" cintraf: die Reute hatten eine reiffye (Ernte gef)abt

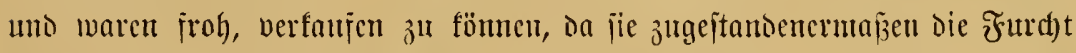
hegter, bei jeinolichen l̈berfällen ihre Borräte แmjonjt, uno woniöglidy nod

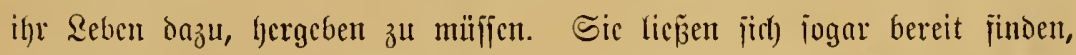

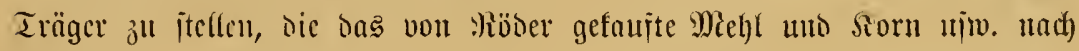

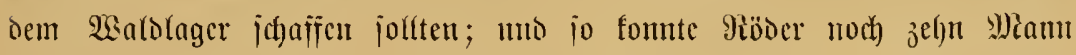
mehr auf iemeu 3 utge mituehuten, als cr geglaubt hatte. Sic mutrocu

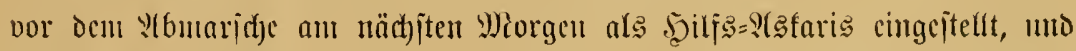

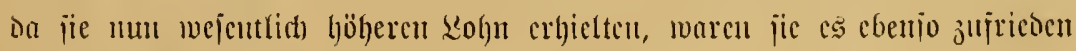

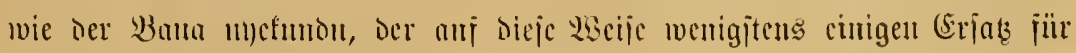

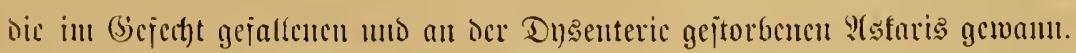

Hö̈or batte wäbreno des Sinfanjs oer Lebcrisnittel verjutht,

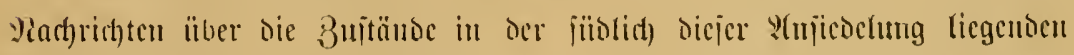

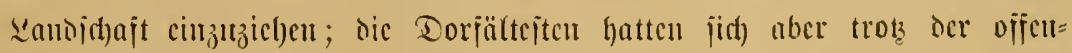

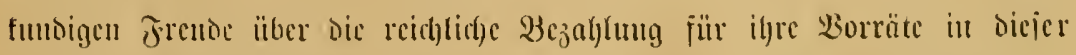

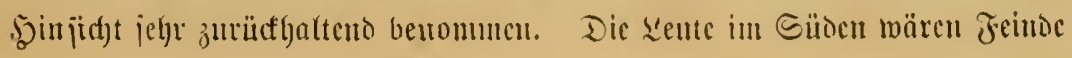




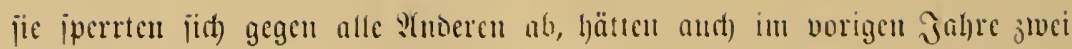

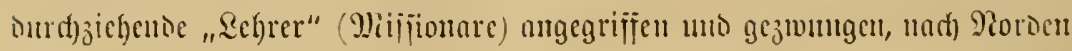

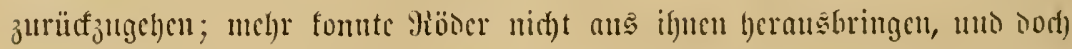
mu

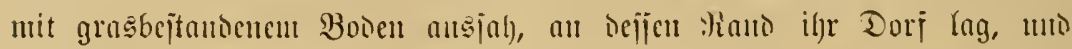

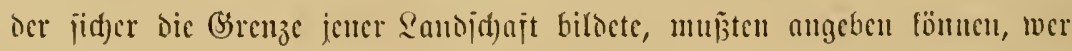
ber Sultan oder ocr etma bort cingeickzte Mianangua, vieffecicht and) mur

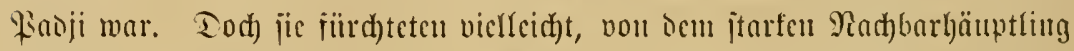

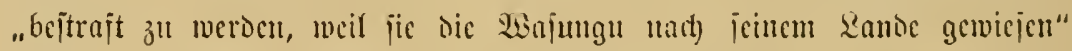

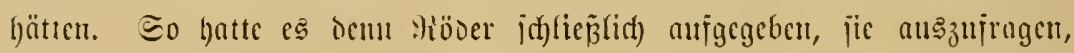

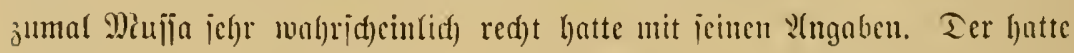

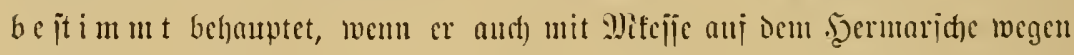

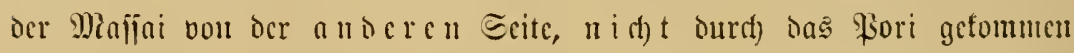

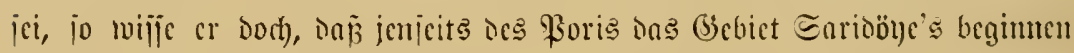
miijie, oer jeituen Bana befriegt habe umo ihn verfintorn wolle, fid) in ten

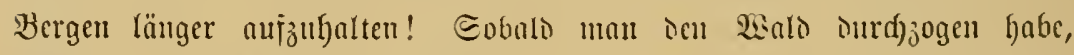

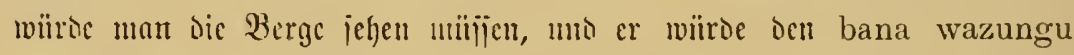
jid)erlidh jichon bon weitem bie "orciectige Spitze von Stein" jeigen fömnen - er meinte bamit wohl cinen feliengipjel --, unter der jein bana Méssina in halber .jöht) bes Berges jein seager auigeidflagen hatte, bevor

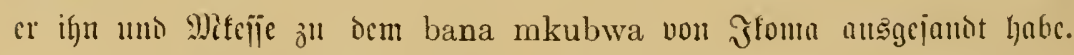

Die (Expedition mar ienoch an Miorgen eben crit in bas Pori ge=

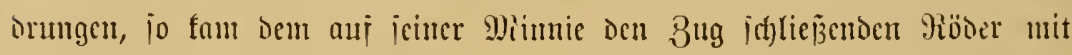
riejig langen, jeocrnien હd)ritten cin etwa jwanjigiühriger Eingeborener

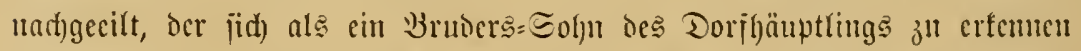

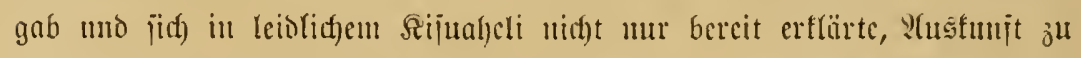

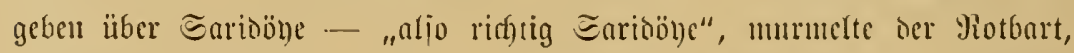
"mic Miufja ifjn yentant hatte", - jomicrn audh) Die Expecbition auf cinem

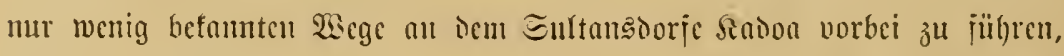

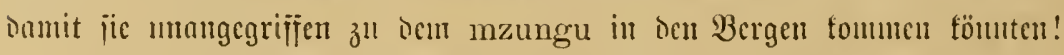

Sallo, der Maun wa uzte aljo, wi e die Ead) en jtanden!

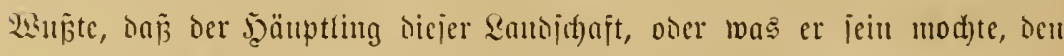

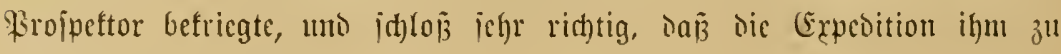
bilfe tommen wollc! 


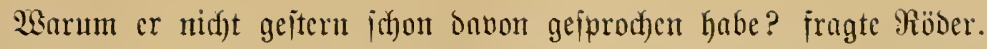

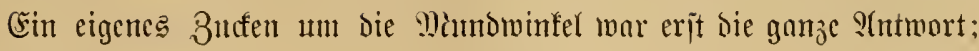
aber basu fam cs heraus: ocr brane sieffe, Bafar hies cr, war heimlid cin bitterböjer Feino jeincs Orcins, hojfte, jidf) Den offenbar mädftigen

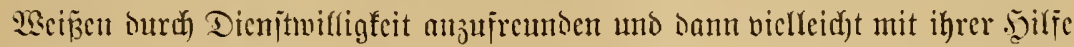
jeiuen Sheim, Den "verïtellten Feino oer wadötschi", wie er hehurptete, vom Thron oder wenigitens Љ̧äuptling

Soldje Familienzwijte waren ocm Rotbart moglbefamnt, jumal cinc

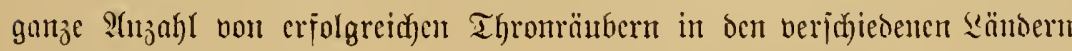

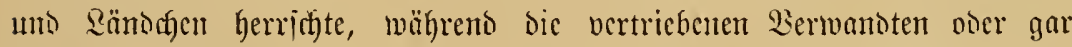

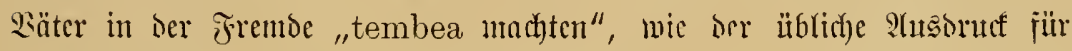
Die unfreiniflige Mañe ber abgejeţten Sultane Yautct. Der Burfhe hier

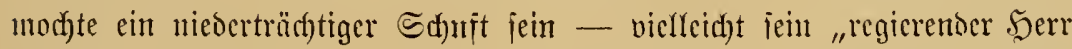
Dheim" nicht minter —, intoijen, icine Dienjte waren ju gebraudhen! Trio

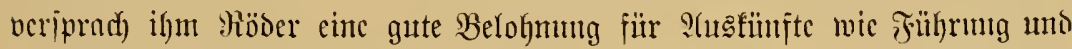

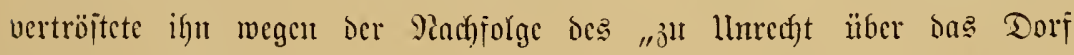

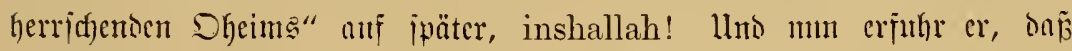

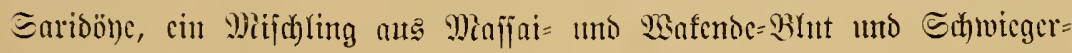

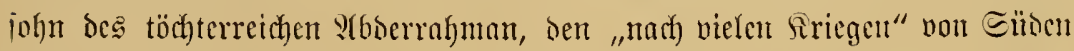

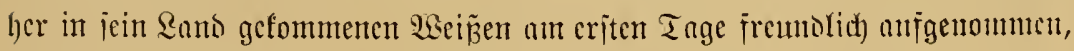

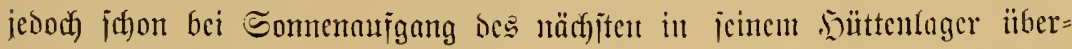

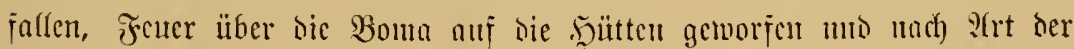

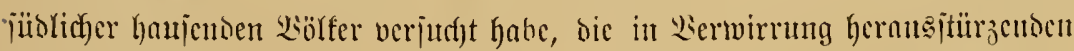
Scute niederzumachen, - weil cin Bote von bem Bater iciner Frau angelungt fei, Der ifm ben Sirieg mit ocm Jecinde s(bocrrahman's befol)len babe. "Du jollit mir ben fopi bes siecijen jenden," habe ber jeinem Iod)ter= mnn jagen lajien, "over idf fomme mit meinen Siriegern affen umb nehme mir ielber dicjen Siopí ums den Deinen tozzu."

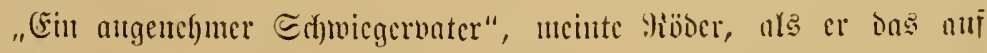

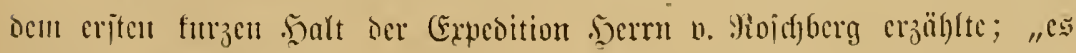

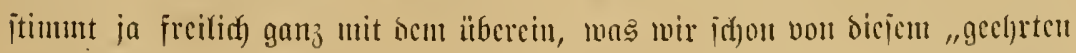

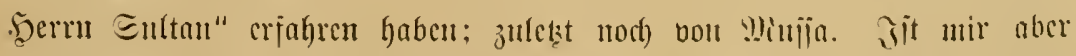

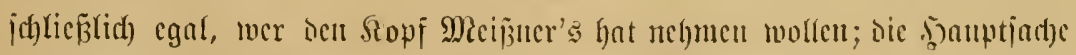

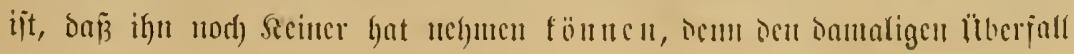




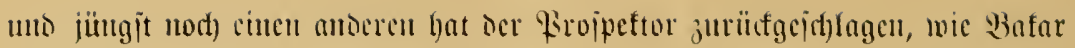

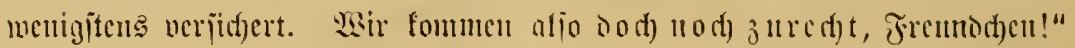

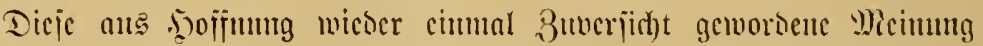

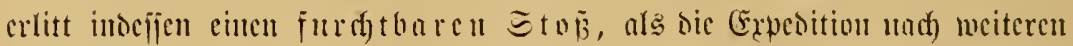

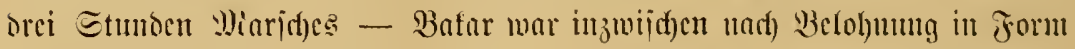
ciutes Dold)mejicrs entajien morben - anz Den

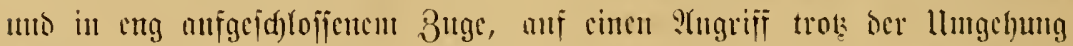
Satons gejaßjt, an Fuñe ber Berge angefonmen war; ja, bie gejante

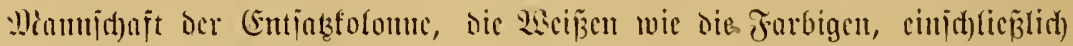

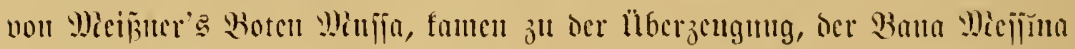

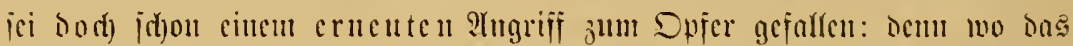

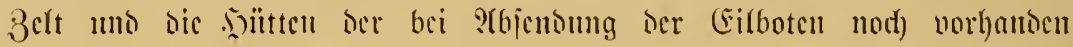

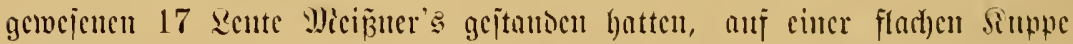

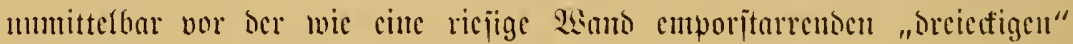
Bergipize, janto jid) jeţt mur cin nicocrgebrantes unto geprä̈nertes

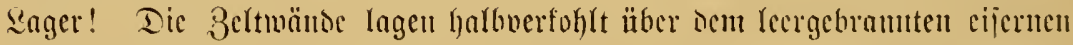

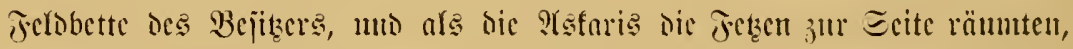

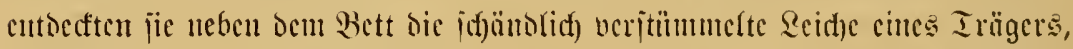

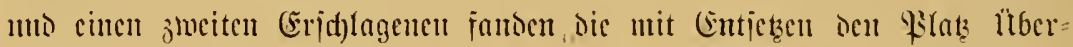

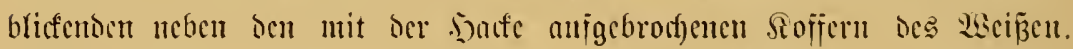

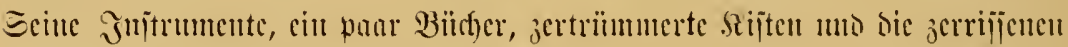

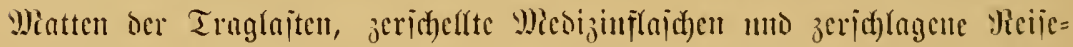

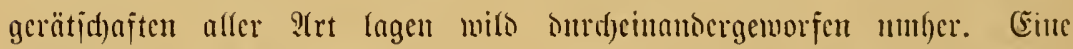

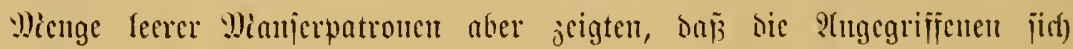
energijuch verteisigt haben muñten.

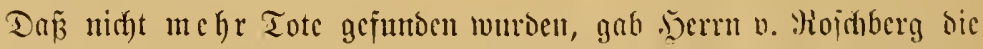

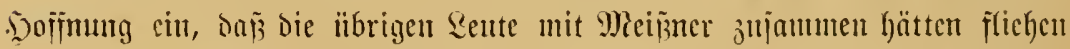

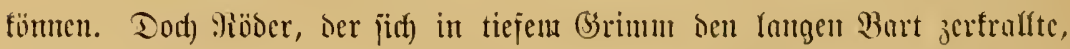

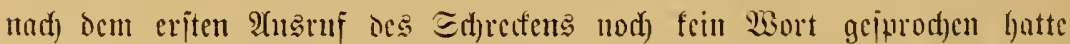

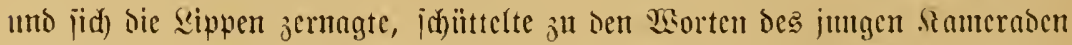

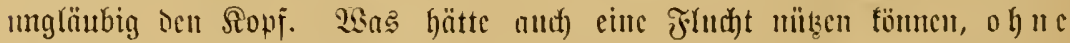

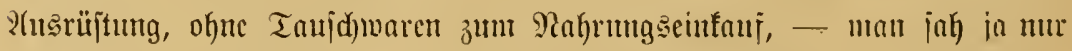

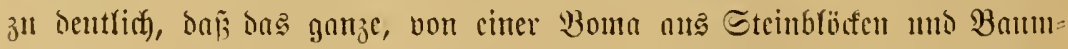

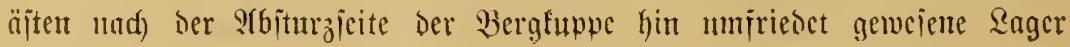




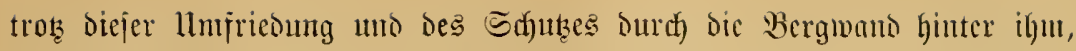

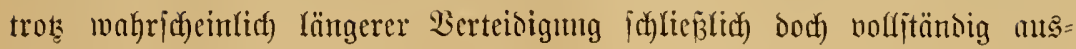
geraubt morden mar:

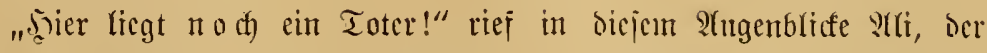
mit bem Tichaujich und cincm Minnampara bic Bergflüfte im Dange Der

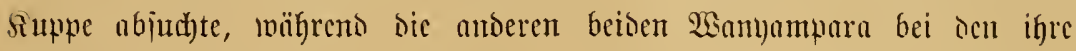
Snjten nieberlegenoen Irägern waren; "er hat cinen Europäeranjug nn!"

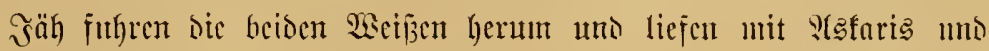

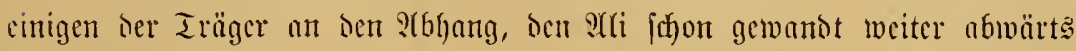
fletterte. (Er war aber noch) nidft bis an ben im Steingejhytre itchenten

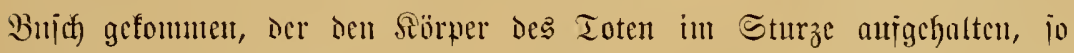

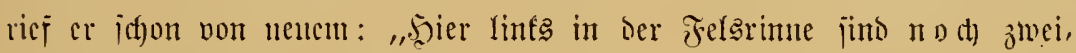

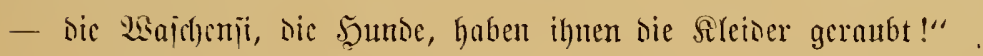

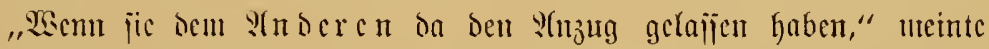

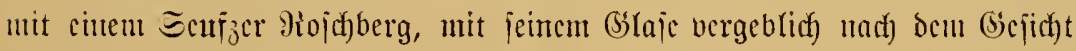

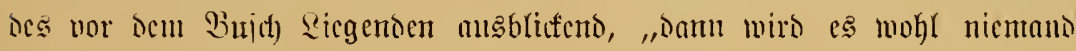

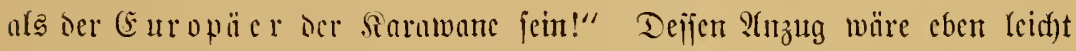

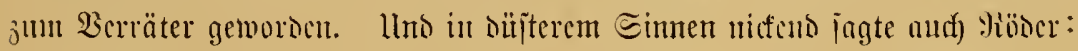

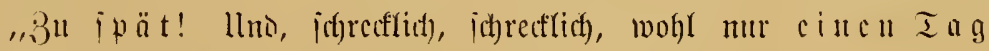
ïuto wir 3n ipät gefonmuncn! Dicje unjelige firantfhcit!!”

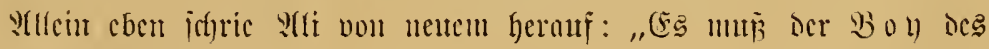
jerrn Wieipnner icin."

"(Sott jei Danf", muruclte Shojhberg, wic von cince jefweren Rajt bejreit. Daun hatte Mieiñner todh woht flichen fömten, ums nicfleidyt, vielleicht lebte or bod) noch!

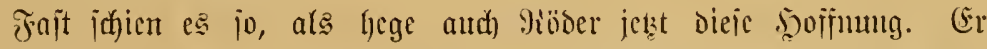

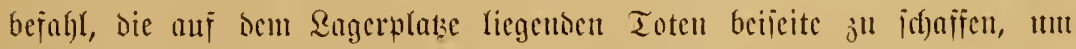
jic nad)her mit ben ba unten Ricgenten zu beersigen, jtellte cill faur bun ocu

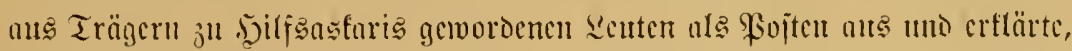

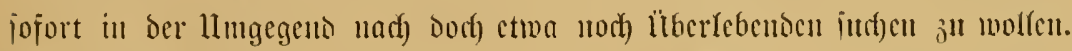

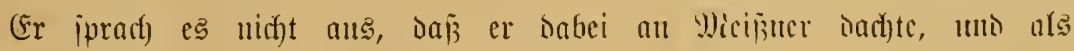

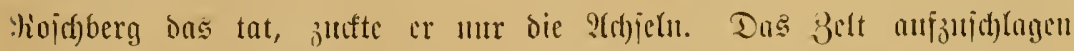
Imb Fener anzumad)en verbot er. (Er molite es jo lauge mic möglida)

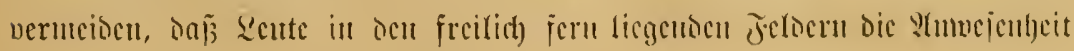




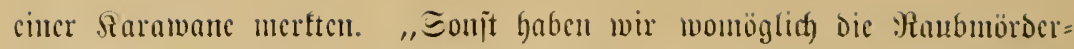
bande Eariböles's jebr balo anj bem .jalje", jagte er in verbijjemem

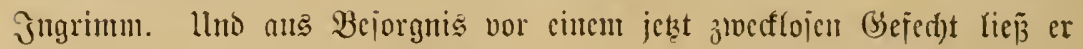
bei der mm vorgenommenen ?(bjud)ung ber llmgegeno aud) nidft bic

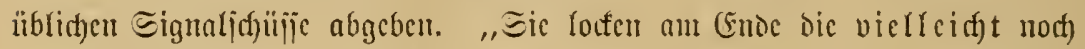

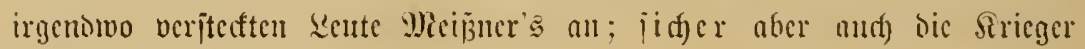
des wacteren .̧äuptfings von Raboa."

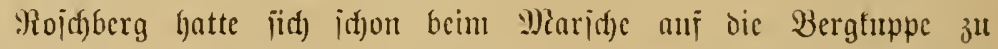

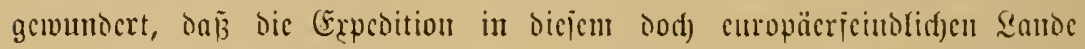
gar mid)t anigefalteu worben war, baj oce Sultan, oder .jäuptling nid)t

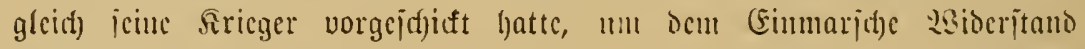

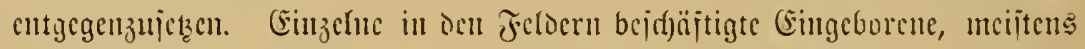

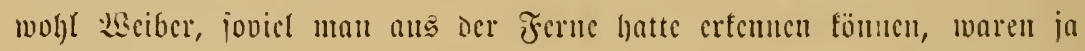

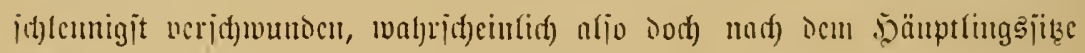

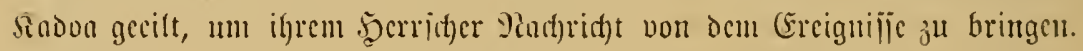

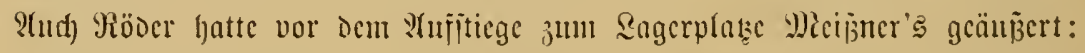

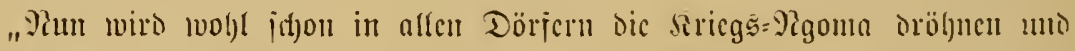

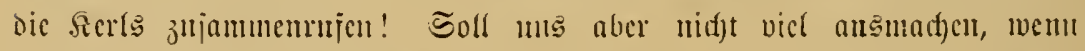

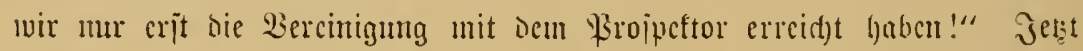

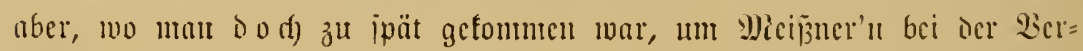

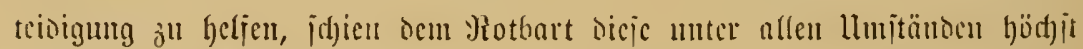

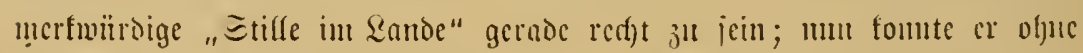
Eorge vor heranjiefenden Femocn cinen vollitändigen ltherblit jiber Das

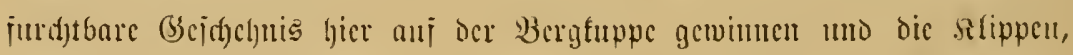

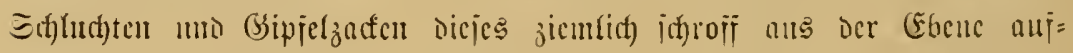

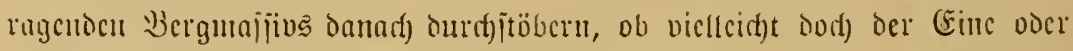

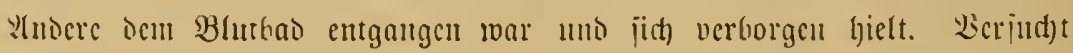

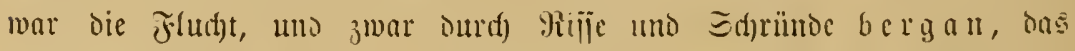

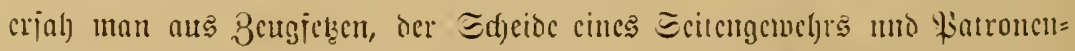

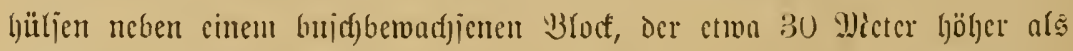

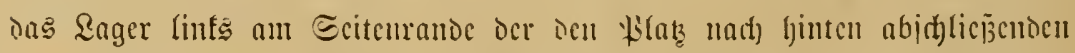

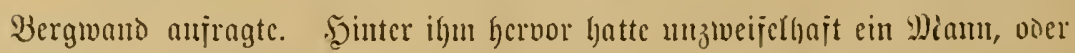

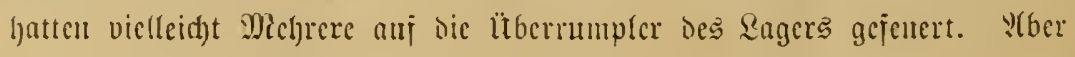

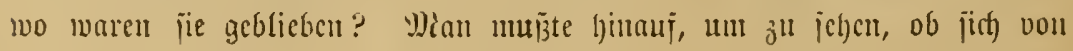




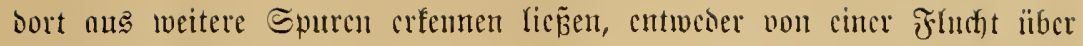

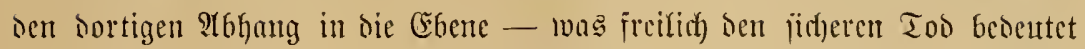
hätte -, oder ïber bic "oreicefige Spitze" fort mehr in's Brebirge hincin.

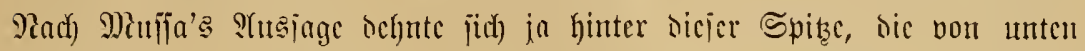

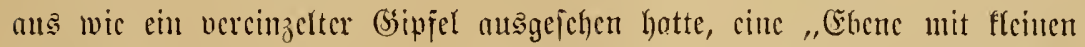

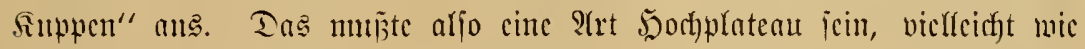
Das auf tem vermeintlichen Bergrünffen von Tajwetn.

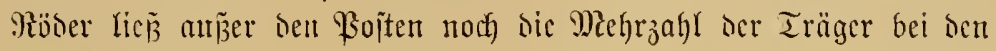

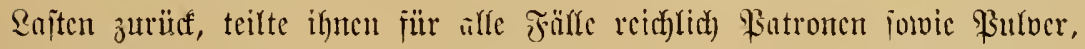

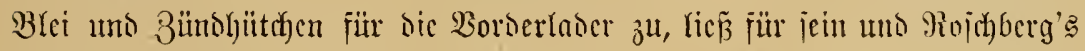

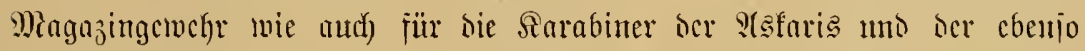

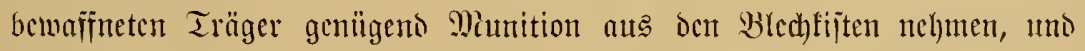
bann jog die fleine Truppe, 37 Miann uns dic Bous MY uno Mieja, bergan.

Ein Fetsen Papict, ein groß̌cs auseinantorgejaltetes, cingerificutes

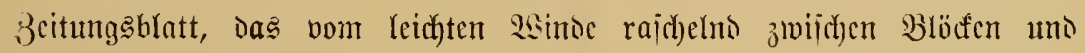

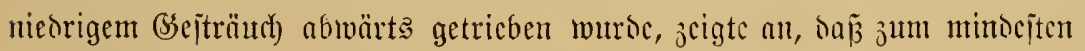
cin Flürbtring höber hinauf gefommen mar, uno bals hatte ser Siotbort

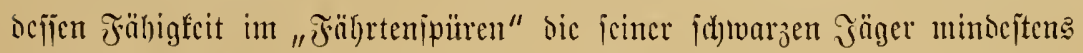

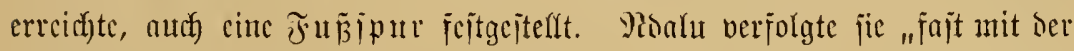

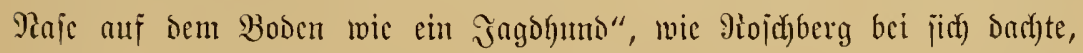

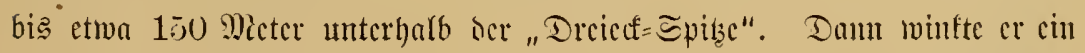

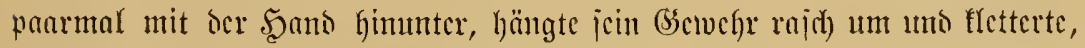

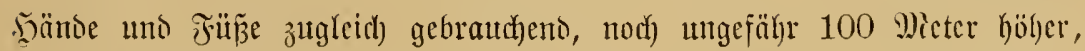

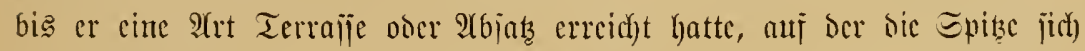

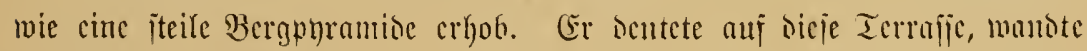

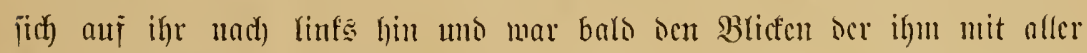

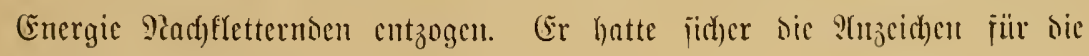
Flucht mefrerer sente entisectt!

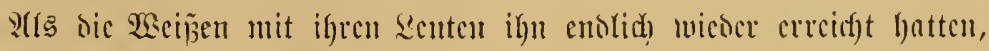

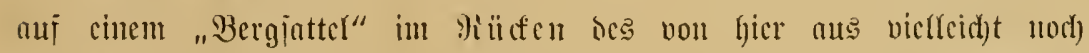
1.00 Wieter böher aufragenton breicefigen oier vichmehr pulumionfürnigen

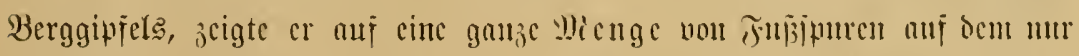

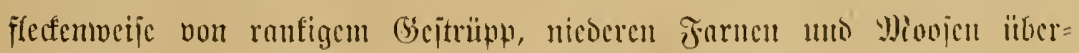

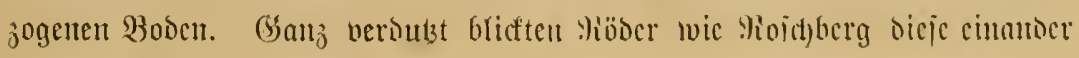




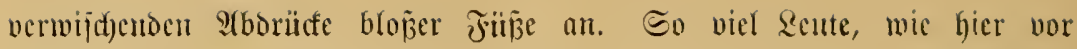
offenbar ganz furzer 3eit nod) gegaugen, batte Micißjuer ja ïberlaut nid)t melhr gehabt! Das founten hier Dusende non Whenichen gewejen

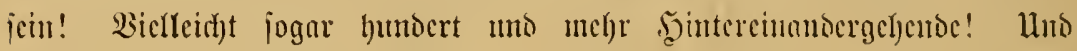

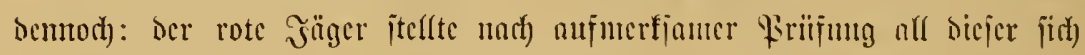

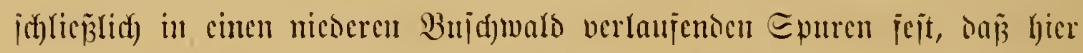

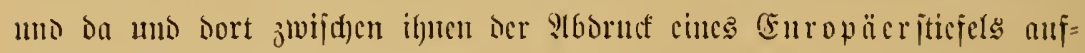

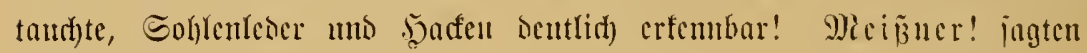

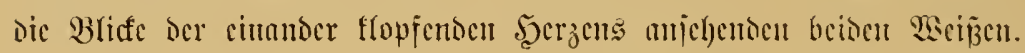

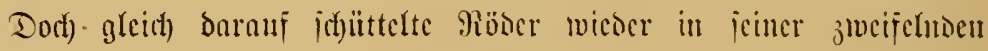

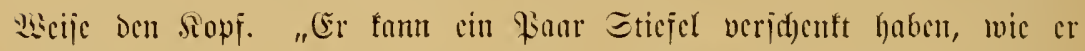
jeinem Bor einen Jactettanzug gejd)entt hat!" Er mics mit Bem Danmen über bie Schulter in Der Ridftung ocs Berghangs, wo ?(ri ben toten Bor aujgcjunton hatte. Dann fnicte er nicoser, wic bas 9loalu neben cincm Etciublocfe bercits getali, uno prüfte sic Epuren zurï̈ffgchaltencn :(tems woh)l

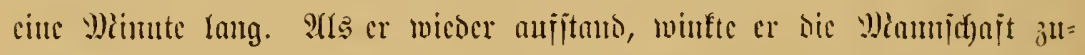

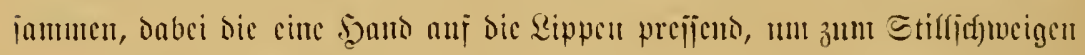

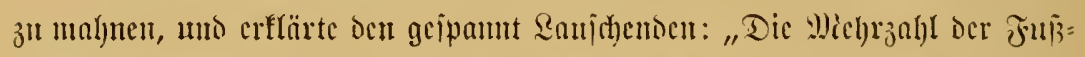

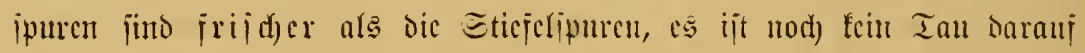

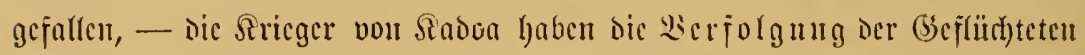

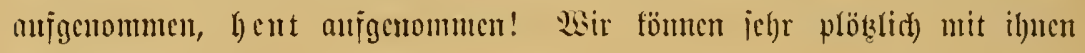
jniammengernten!"

Nisafu uns cin jweiter, injwijgen nehen Bem Piotbart nicoergefuteter Iriil)erer Elefantenjöger nicften. Der rote F̈̈ger "las" Spuren nod) rajd)er

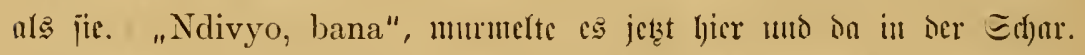

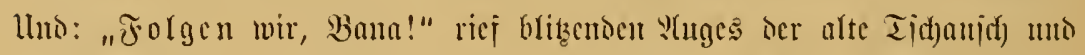

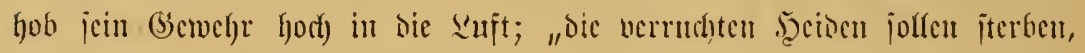

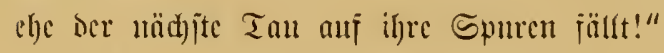

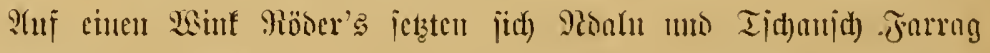

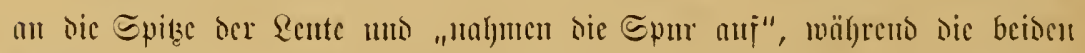

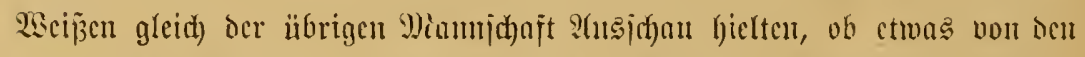

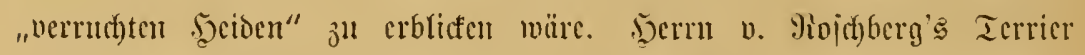

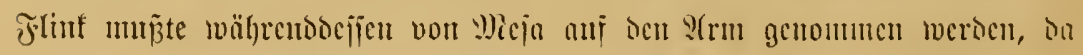
or öfters \&uit bezeigte, Hecine Söd)er am Boden nad) Epringmänjen แm 


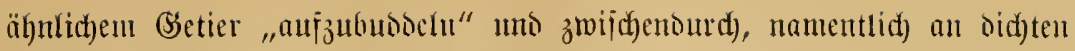

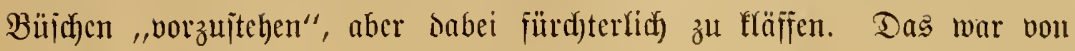
jetzt $a b$ ganj uno gar nidjt ju bulton!

Dic Spur jüfrtte jofrüg üher den ziemlich breiten, mit zumeijt nur

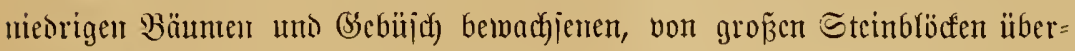

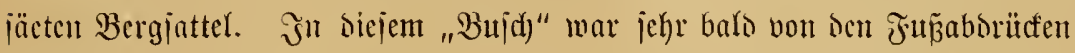
nichts mefr zu erfennen; boch eill gefnicfter $2(j t$, ein umgebrod)ener Farn= wedel uno andere $\mathfrak{A n}_{j}$ eidjen hejagten flor genug, Da

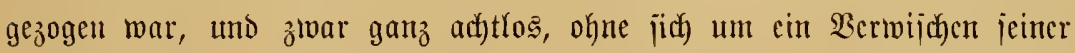
Spur ju fümmern. Weshalb folfte cr aud)! (5r hatte ju feine 2alynung, da

?(les man den Euttel überichritten hatte mo ocn Berghang empor=

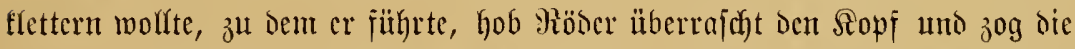
Rujt cin. Der Wino fam über oen Berg uno führte cinen mertwüroigen

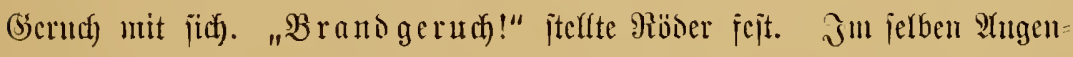

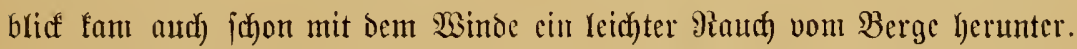

"Sie haben uns entoeft, bic wajhenji, die bunte, uno zünoen Den $\mathfrak{W}$ als an, un ung zu verbrennen!" raunten jich bic Seute ju.

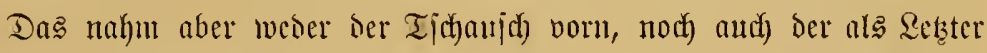

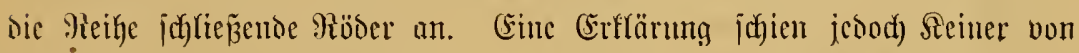

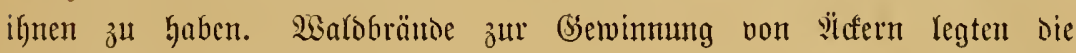
Sdywarzen io hoch auf ben Bergen nic all. "Borwärts!" mahnte ocr

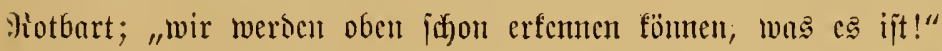

Shne bon ocm feinte etwas ju jehen - hier mif Dem jteilen, wic abgejprengt ausjebenoen Berghang waren nicht cimutal Fußjpuren vor=

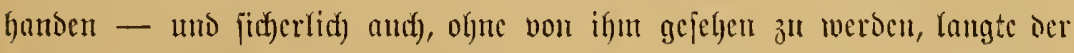
Irupp nad) möglichit reijem Silettern auf ber böhe an, . . aber taum

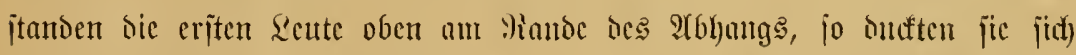

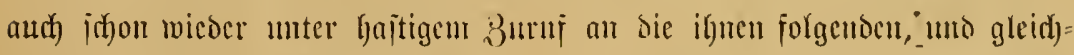

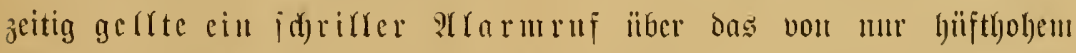

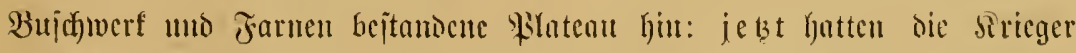

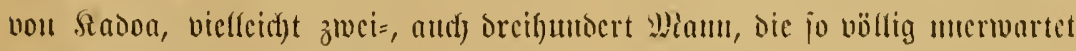

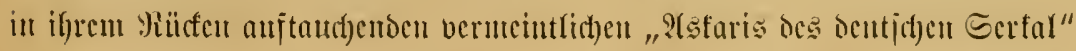

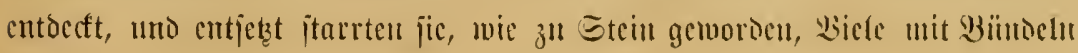


Bujhhols und Gras auf Dem Siopf, Indere mit jprïhenden Jencrbrütton

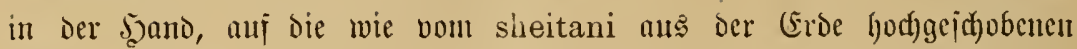

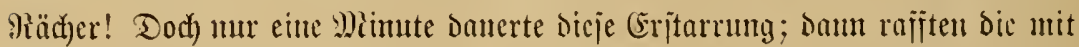

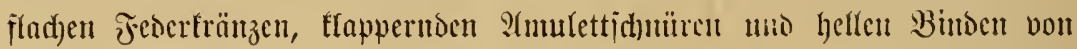

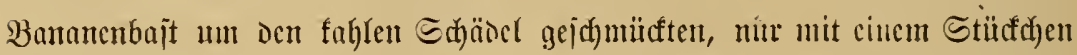

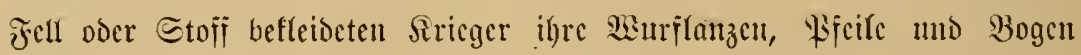

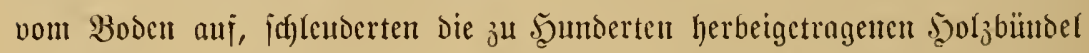
jur Seite uno rotteten jidd), währento hinter ihnen bicter siaud) aus zahl=

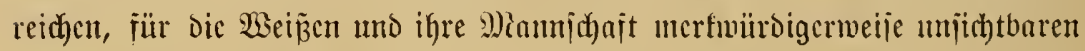

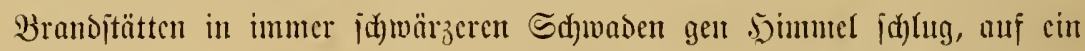

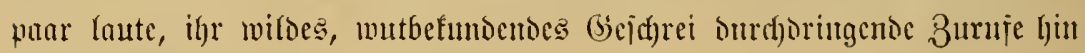
ju einem STnjturmhaufon jujammen!

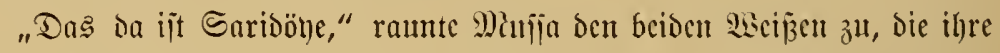
Seutc hatten nicoerfnicen uno "iertig mad)en" Iafijen; "Der Sange mit Dem

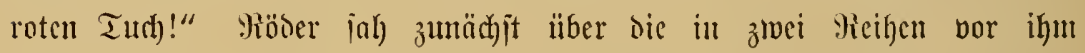

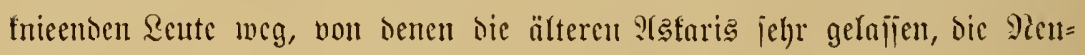
linge jreilich in merflid)er Erregung, oen Befchl zum Salve=Fencrn er=

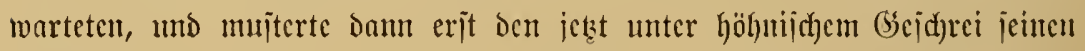

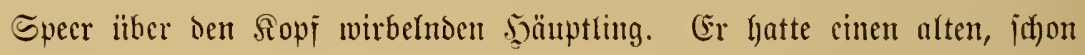
jerfblifienen, in fritheren Beiten wohl als "Eultanggeichent" an ihn ober

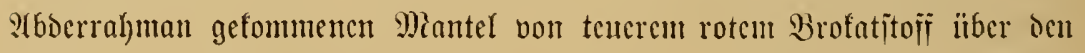

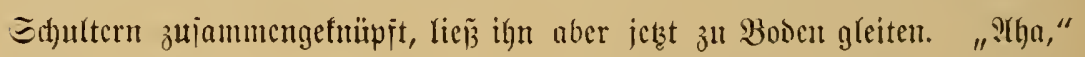
nummelte Röber, "er joll ihn nicht im Eprunglani behinocrn! fiomm

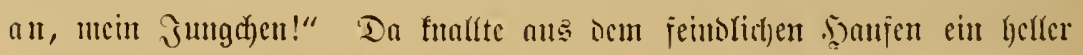

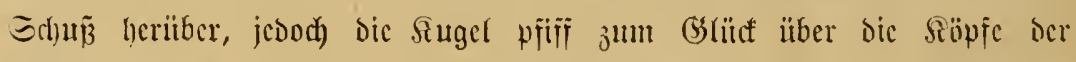

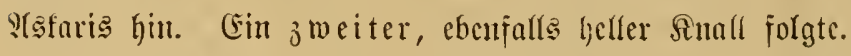

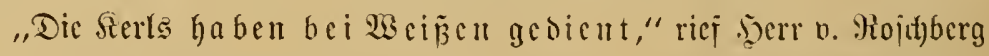
mütent ans, ,jonjt fönnten jie nidgt mit Den geraubten M)(aujergetwel)ren

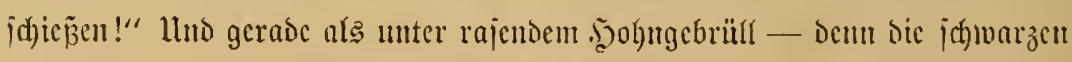

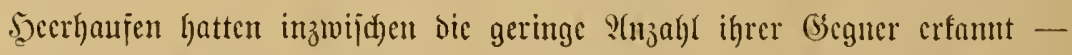

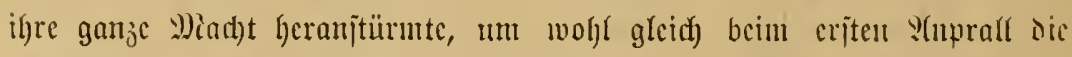

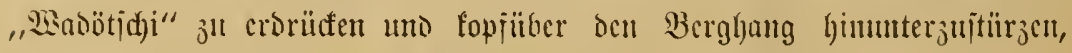

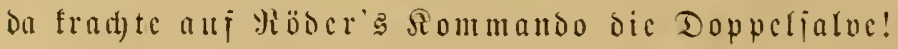




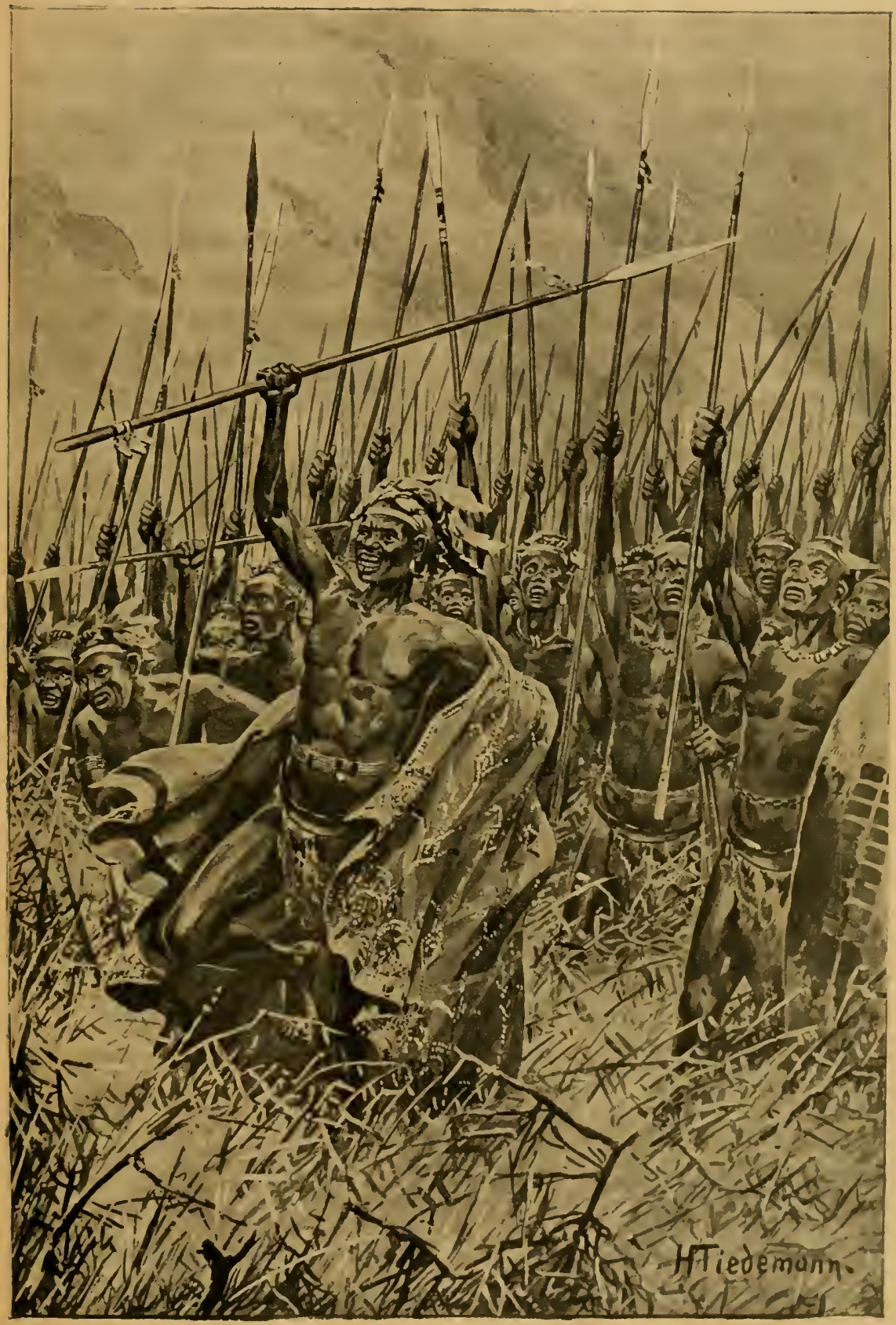

Die \{chwarzen heerhaufen hatten inzwifchen die geringe Anzahl ihrer begner erkannt. 



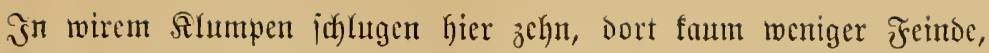

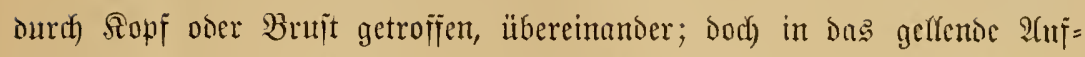

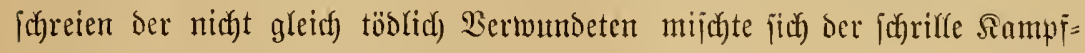

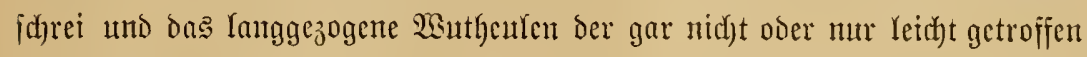
meiter 20 orrementon, die im Lauj ihre Epeere fdyleuterten, ober für einen Shrgenblicf jtehen blieben uno ihre fajt mantslangen

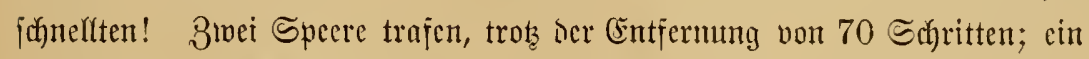

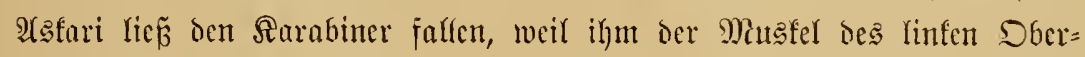
arms aufgerifien war; einem anderen flog oer Tarbujd) vom Sopje, uno aus

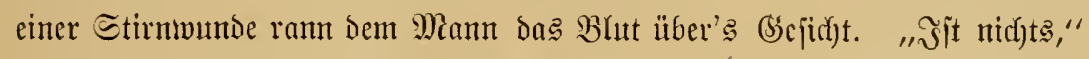

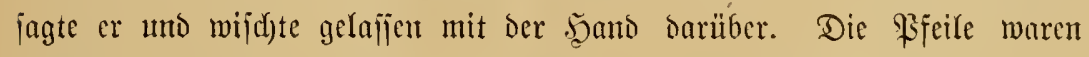

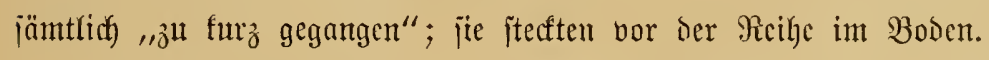

"Beladen! Einjelfeuer!" fommandierte Röber jekzt; aber che noch die erjten netten Sdjüjie fielen, hatte er jelber fein Magazingewehr an bie

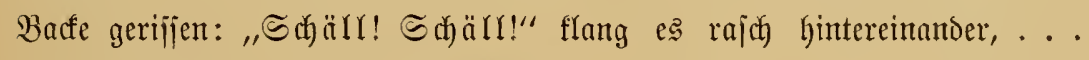

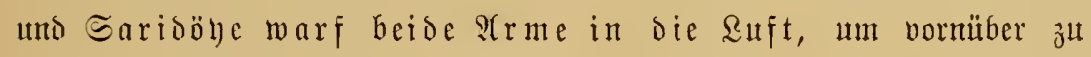
ichlagen uno reglos liegen ju bleiben!

Wic angemurzelt blieben die hinter ilym oreinjtürmenten Sricger

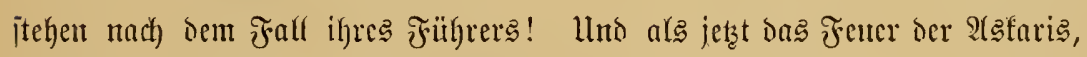

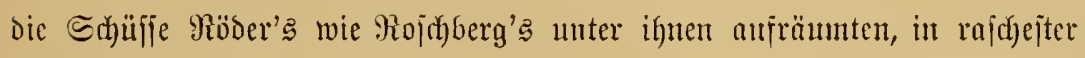

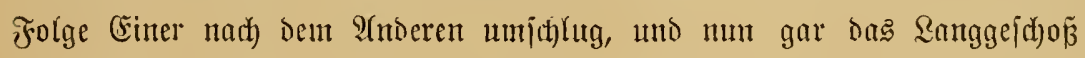
aus dem Browninggeweht Rojhberg's jwei hintercinauder Stehende a uf

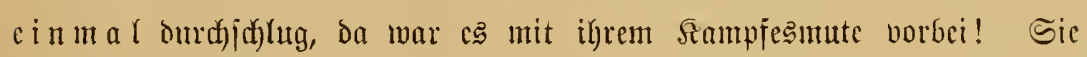

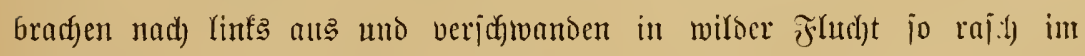

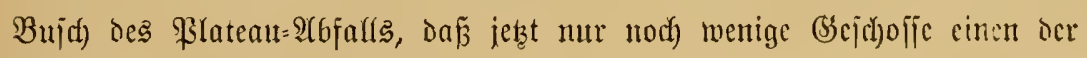
Fliehenten crrectiden fonten.

"5ु)

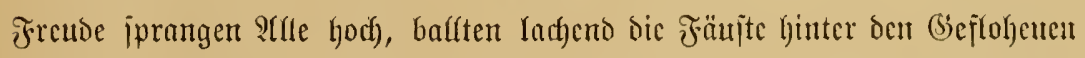

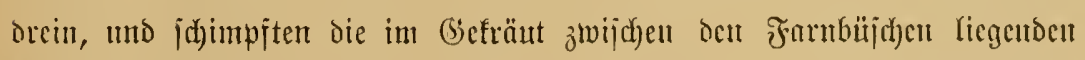

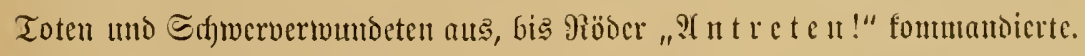

"Das war cin leirgter Sieg!", trimmpticrte anth Moj(t)berg; "mur

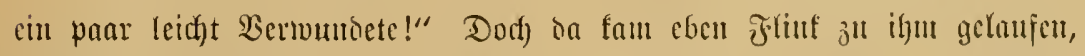

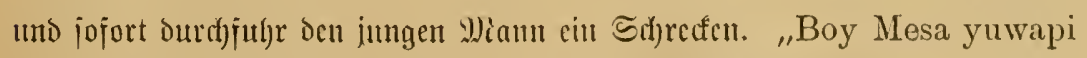
(wo ijt der $\mathfrak{B o y}$ Meja)?" rici cl mo Glicfte juctfento umber. 
Da brefte jït) ciner Der als S(staris cingejtellten Träger Had) der Ecite un, von der bic Truppe aus aujgeiticgen war, sentete finunter unt

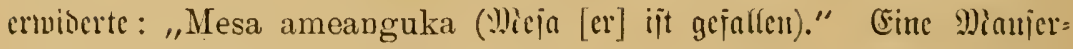

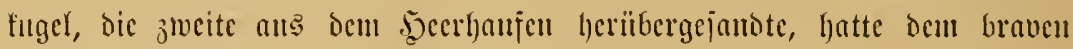
Эungen Dic Stim Durd)bohrt!

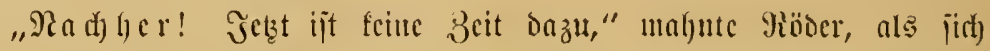

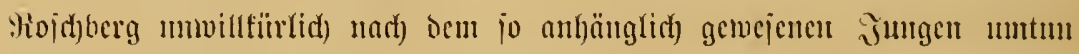

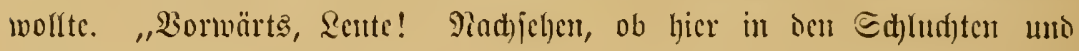

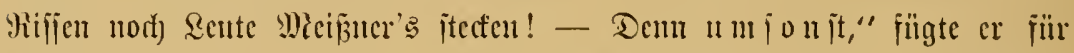

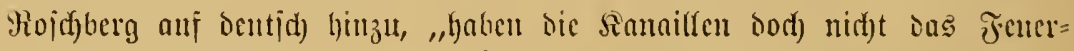
$\mathfrak{h o l}_{3}$ zujammengejd)reppt! Sic wollten natürlich dic ihnen Entfonmenen atรrüu(t)ern, ober jul Tode räud)ern!"

Der an vieffeicht zmmig veridjiedenten Stcllen emporichlagenie,

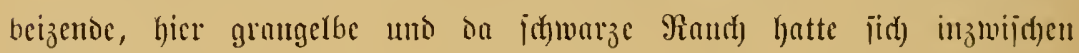

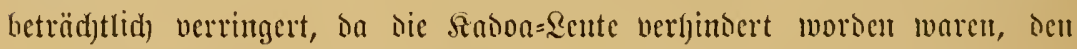

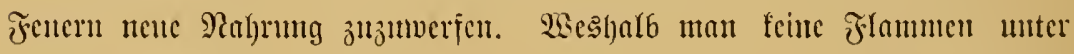

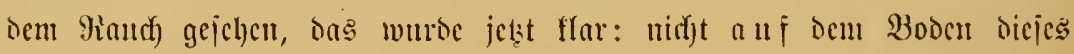

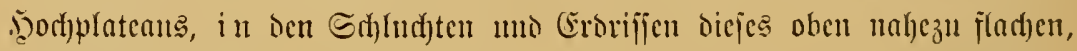
aher vielzerflïfteten Geländes waren bie Brände entfacht wortien! Difenthar

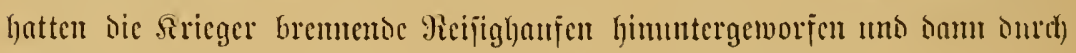
Nadymerfen von oben her bas jabelenie Feuer unterhalten.

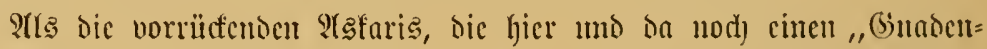

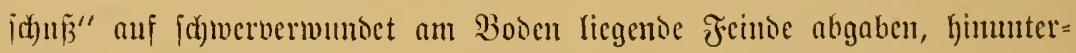

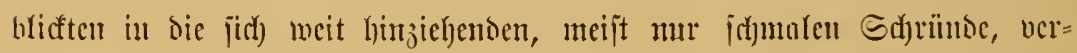

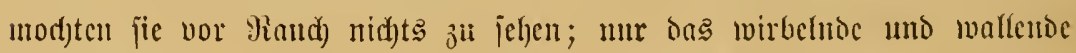

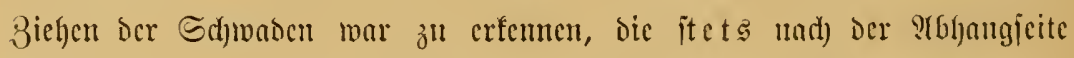

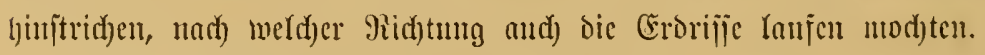

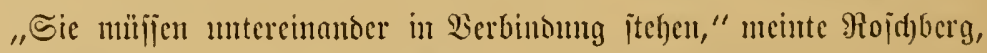

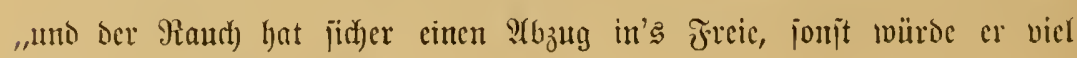
itärter in bie Şöhe gehen."

In verichiedenen Stelfan verjudyten es cin paur Rente, fimunter=

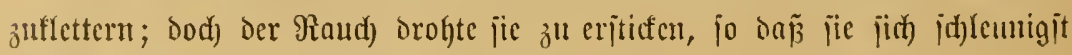

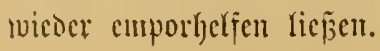




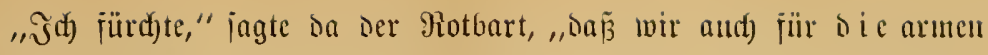
Serls zu jpät gefommen fint; wenn es umjere Sente jo weit oben fdyou nid)t mehr aushalten fönnen, ba wiro Denen unten auf ber Sofice oter Eahludut tas 2 (tmen längit vergangen jein!"

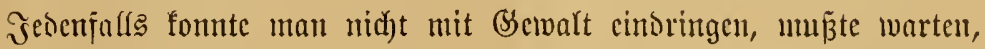

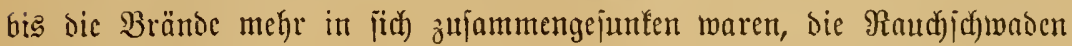
jiif) berzogen hatten. Dic 3eit murbe non Röser jum Berbinten Der

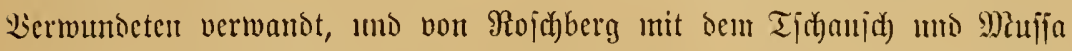

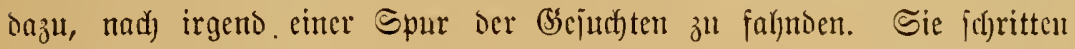
an Rande bald dicjes, balo jenes (Erorifies entlang, riejen aud cin paarmal finunter: "s̃it da unten jemants? Jicr fint Freunto!" Dod) niemand antwortete, nidhts regte fid). Bei cinem ocr beeiter flafifentoen rifije idjicn es ihnen, als tönne man bereits den Boten jebcn, als läge Der Raud) nus nod) wie ein Schleier barauf. Ilno eben wolfte Rojhberg

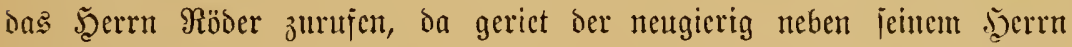

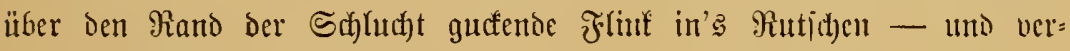
idfuant fopjüber in der Tieje!

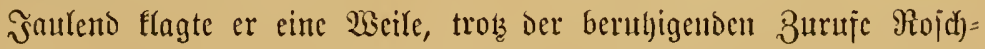

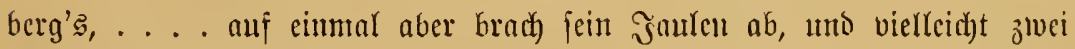

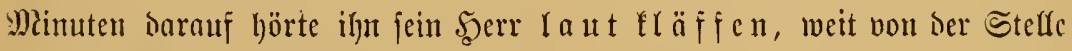
des, ,9tbitulzes" entfernt, uno der Toul hatte einent merfioüroigen, halfenden $\mathfrak{x} \mathfrak{l}$ ang!

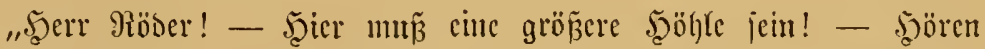
Eic Dodh eimual," jagte er jum Rothart, als der cilig herangefonmen

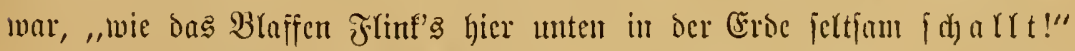

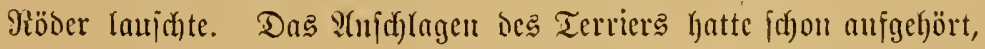
Föocr aber laujd)te immer gejpannter, uno jekst pacte er mit fajt trampí=

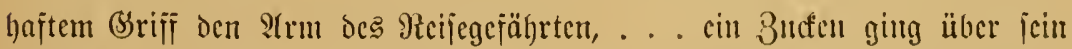

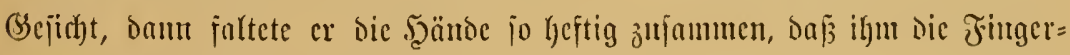
gelenfe fnacten uno idy $r$ ic mehr als er rief:

"Bott ici Danf... wir jims nitht jull ip̈t gefoumen,

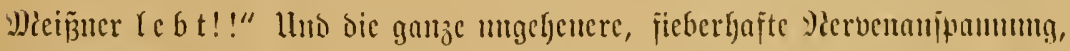

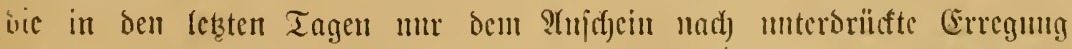

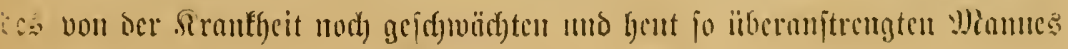


brad) jidh Bahn in einem jweiten, Bojd)berg wahrhajt eridjüternden:

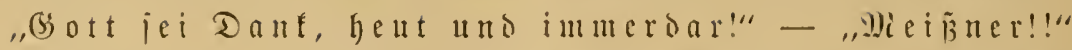
id)rie er Dam jaĩt jubelno fimumter. "Se

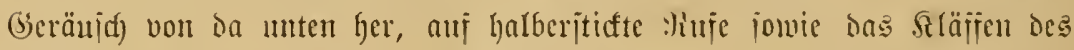

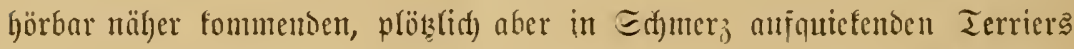

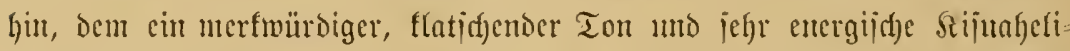

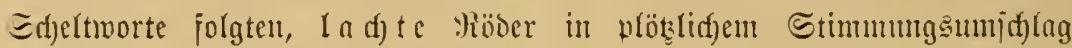

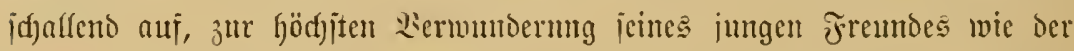

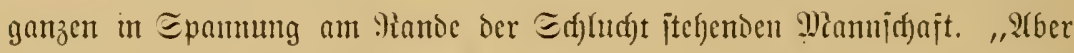
ge wi i lebt ocr Rrojpeftor nod)! (Er ijt jogar hö d) it lebendig: haben Eic nidft gehört, wie er eben einten jeiner fierls ein puar jhalfente k of gab, weil er Jhrem Flinf auf bie Bjoten getreten hat!!”

Pad) menigen Mimuten jtand der von cinem Dutzend fräftiger : Yrute voll oben wie untelt her unteritütste \$rojpeftor oor jeinen Bettern, jerjełst, unit einer bfutverfmiteten E(d)marre ïber bent (bejid)t, aber ungebrod)en von Den Fährnijien umo Rämpjen diejer letzen Mionate. Sas ifm von

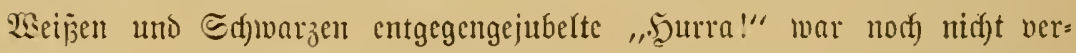
flumgen, ta grifi cr nad) Flinf, damit ber nid)t wieder in bie Edyludft rutidje, uno jtreichelte ihn jajt järtlidg. „Der hat mir meine Erröjung

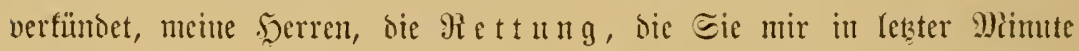

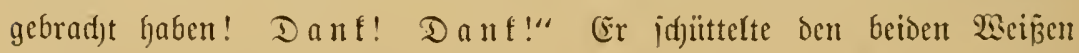

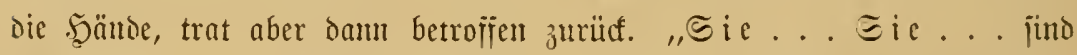

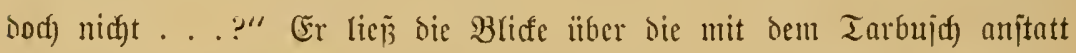

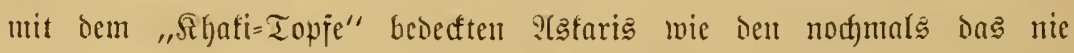

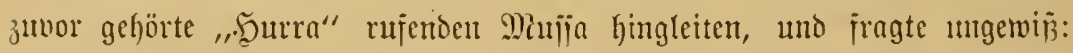
"Sie Saerren jint von Jfomta auj meine Bitte..."

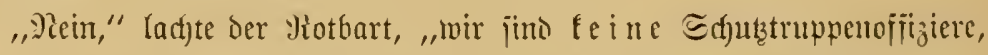

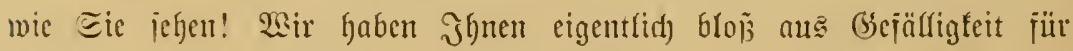

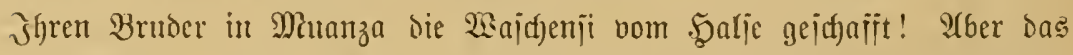

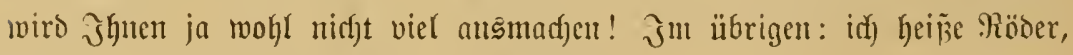
uno fier, mein Freuni: .ֵ̧err v. Kojdjberg."

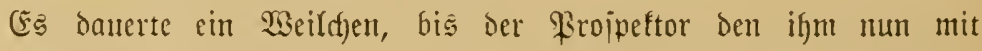
turjen Eorten angedeuteten 3ujammenlyang begrifi. Fann aber flang

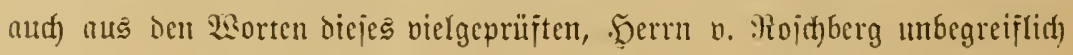




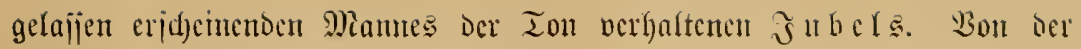
längit errichtet geglaubten Etation Sfoma hatte cr Entiak erbeten, als jeine

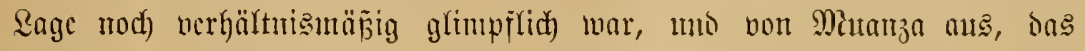
nach jeinel litberzeugung Barafa mit ben Bricjen nic crreid)t hatte, fam ifm in ber Stmnic ier bitteriten 9lot bic Şiffe! Sn einer oon ilym

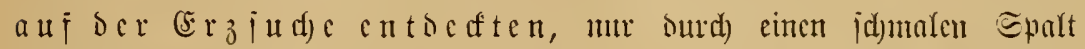
jugäıgliden gro Seuten feit bem gejtrigen l̈tberjall aú bas \&nger gejtecft, jmar uicht mit

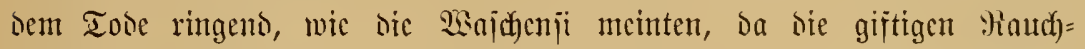

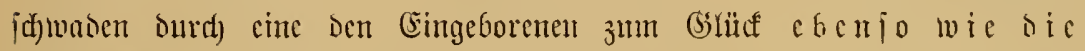

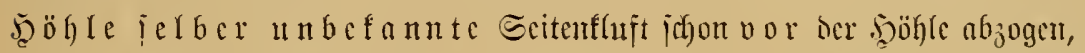
aber dennoch) ntit ber (Semiñ

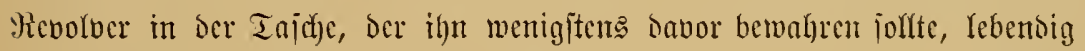

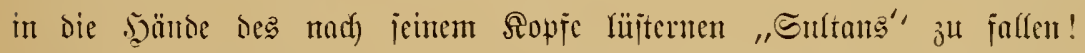

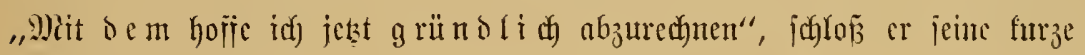
Ěrzäl)lung.

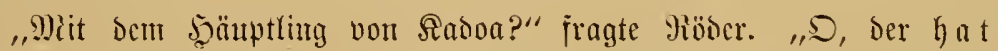

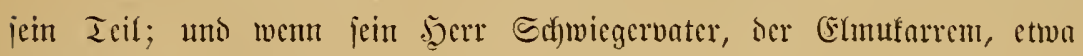
hierherfommt, um jith nad) jeiner Drohung 3 ime i Sïpje zu holen, fam

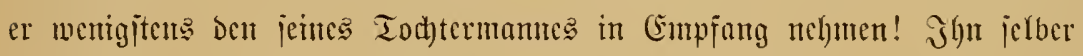

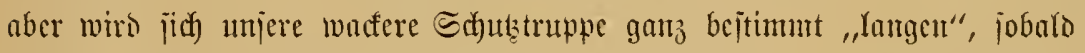

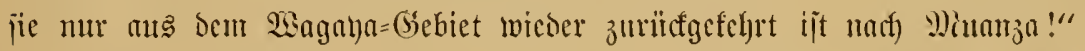

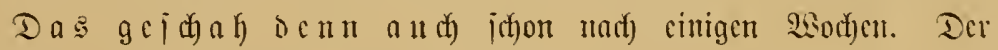
Wiorsbrener, Der graujame Berītümuler. Barafa's fant of al To

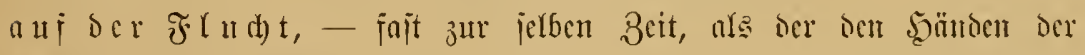

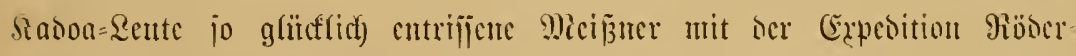

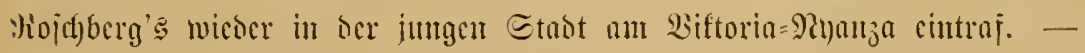

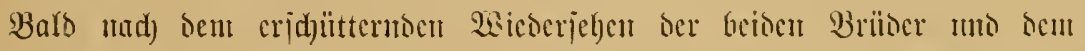

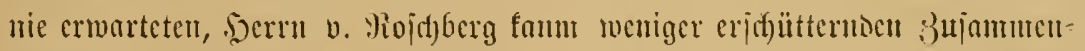
trefjen bes jüngeren Baun Nicijinta mit jecuem getrencu, ben Wifcilgift

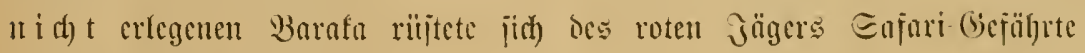

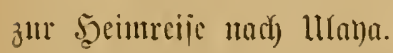

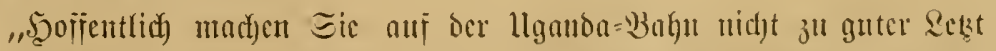
nod) äfnlicf)e Römenbetamntigaften, wic die jocren jübner uno Sinall," 
ingte der Fothart läthelus, als er bem jungen fremus auj bem mäd)tig

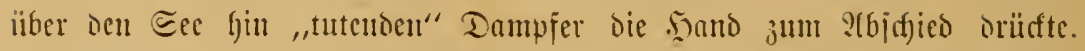
"Eie haben ja bod) mohl vorlüıpig genug von den ?henteuchn uno gejahr= volfen Fal)rten, nad) benen Sic jidf jriilger jo gejehnt haben?"

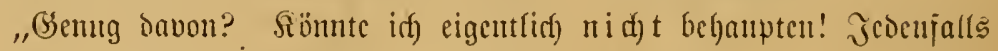
febre id) in Die Folonie zuriict, jobald id) mur fann!"

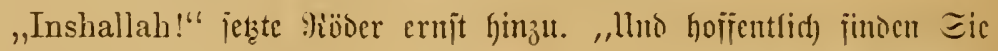

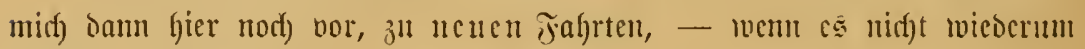
cimmal anders fonturt!"

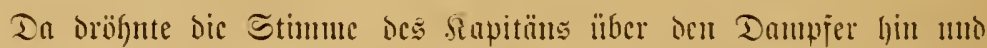

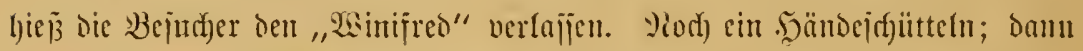

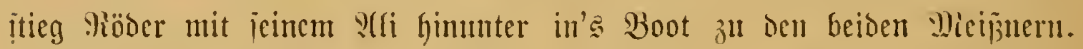

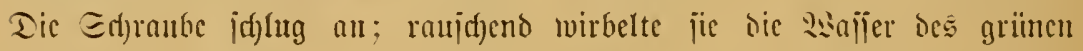

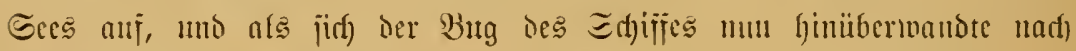

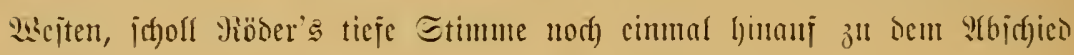
mutemien, ilyu jo fieb gewordenen jutgen jreunte:

„Kwa heri, Niojdberg! K wa heri!"

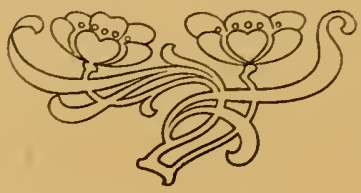




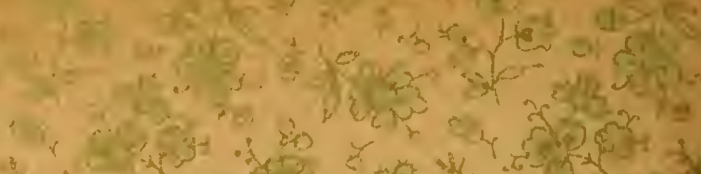

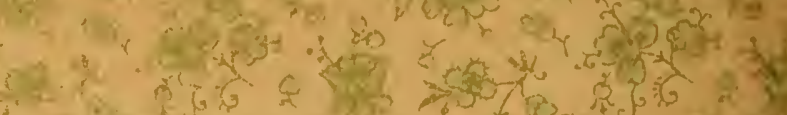

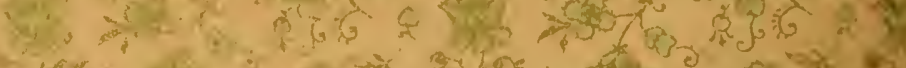

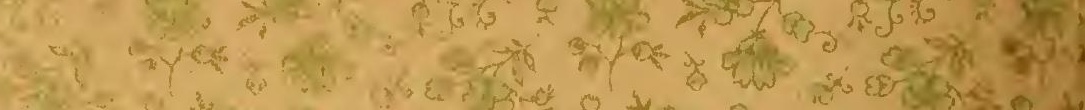

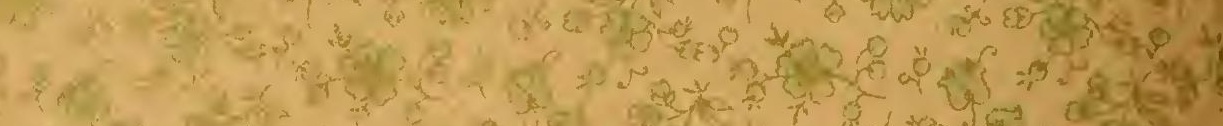

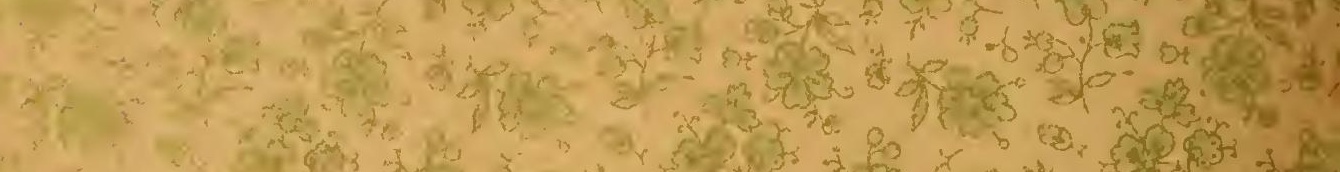

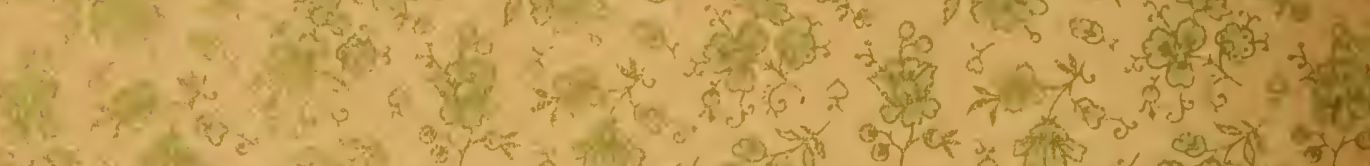
CA A

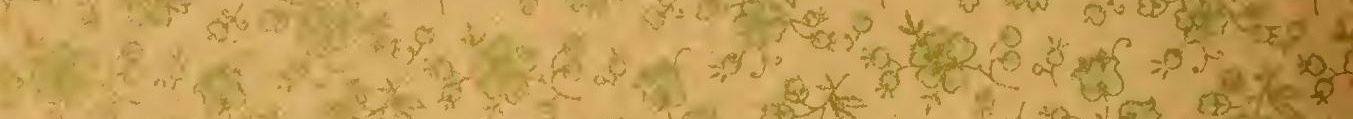

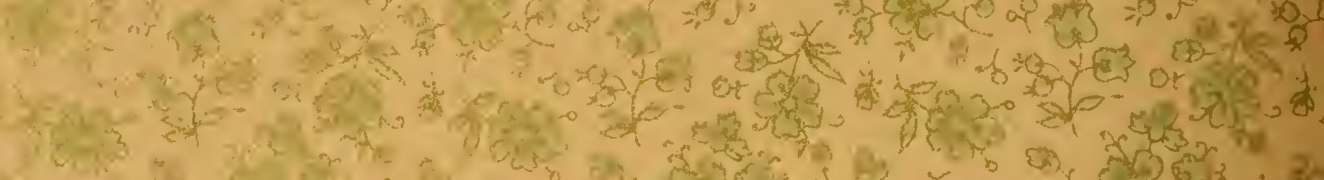
2. 3 (3) Sho

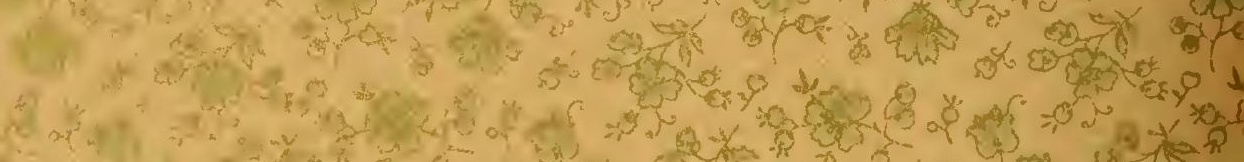

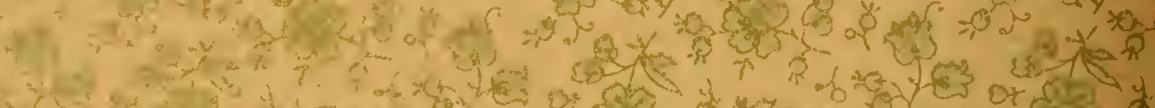

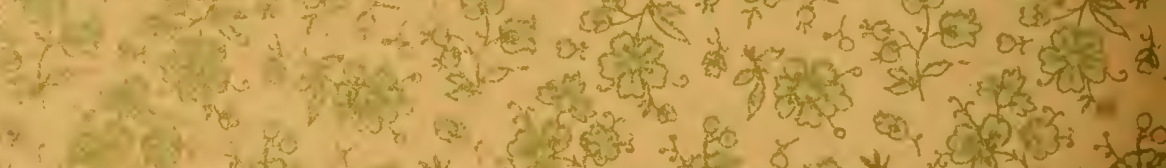

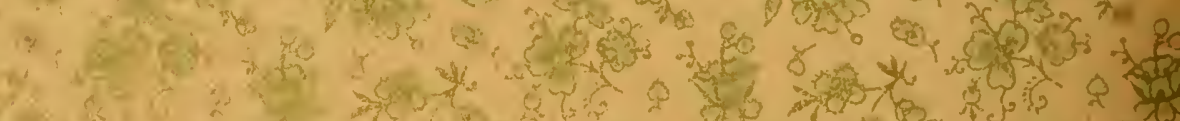

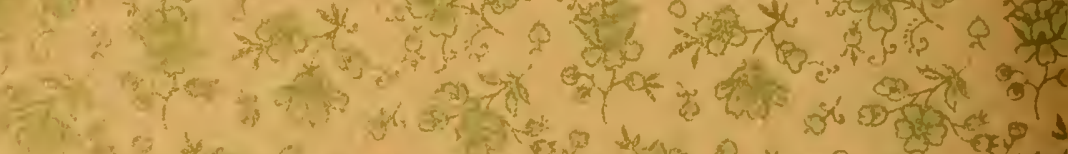

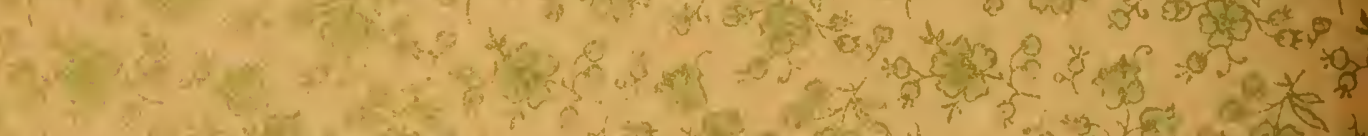

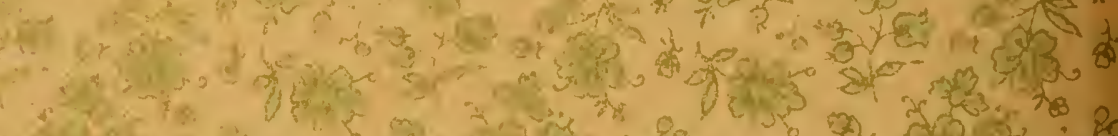

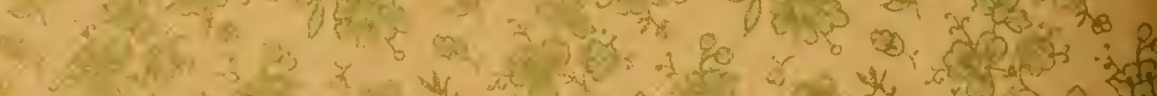

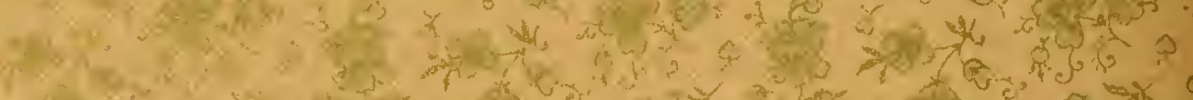
W 140.

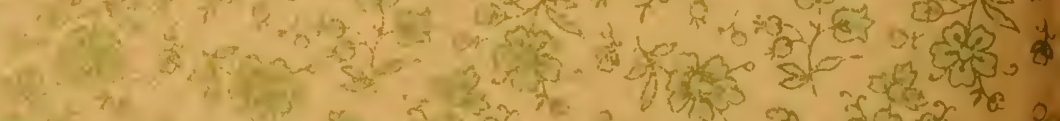

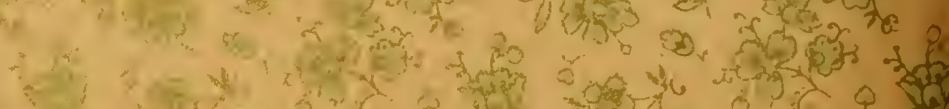

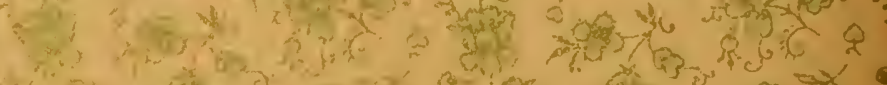

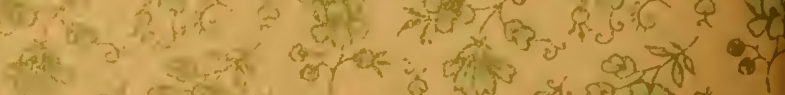

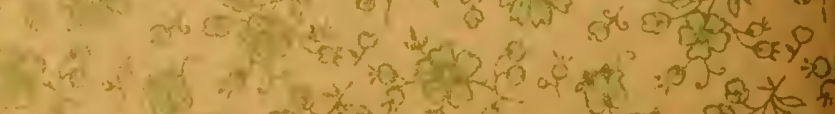

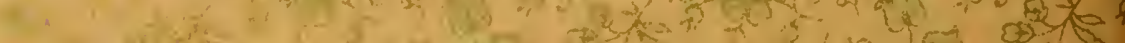


$y=0$ at $58 x$

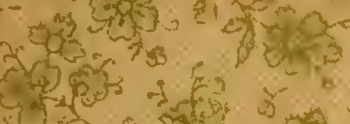

स.

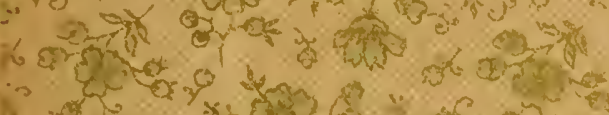

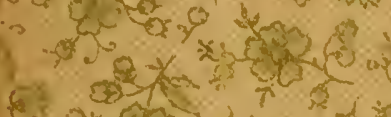

eto of

if \%

40 or the

数给

का

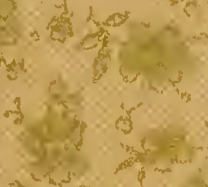

or of

780

Sestion

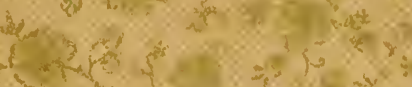

ind.

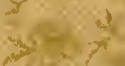

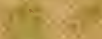

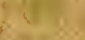

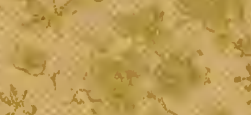

y

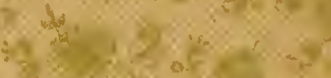

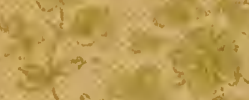

है।

if 5 , then the

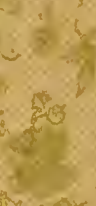

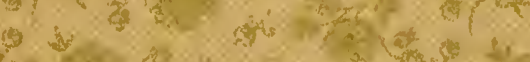

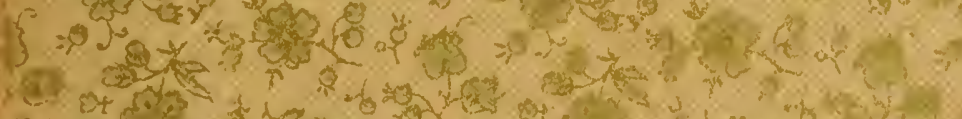

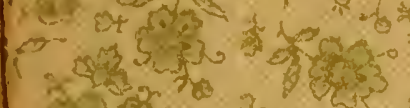

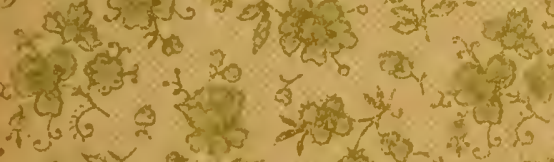

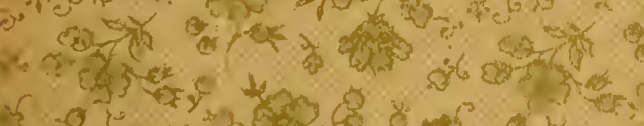

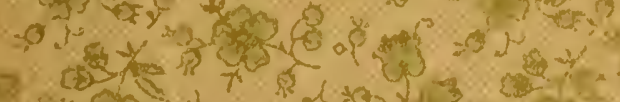

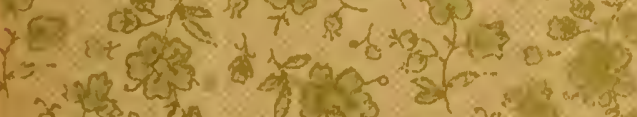

हो

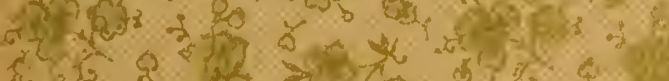

तो है।

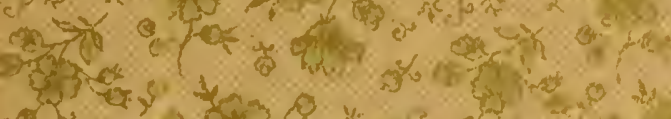

2. $\sin ^{2}+\cos ^{2}$

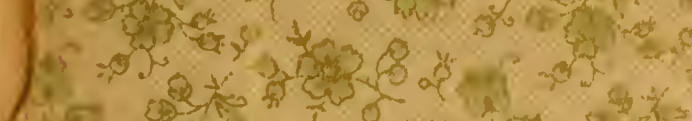

$-x^{2}, x^{2}+x^{2}$

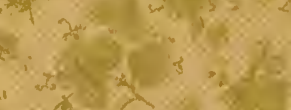

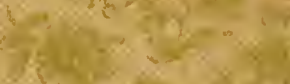

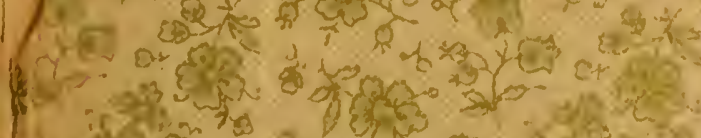

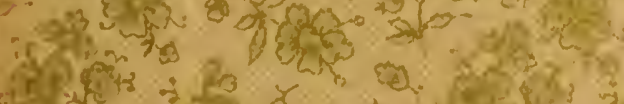

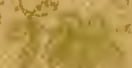

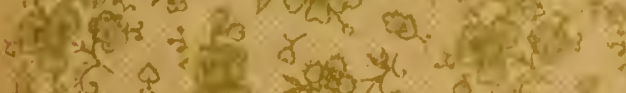

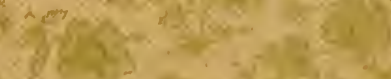

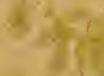

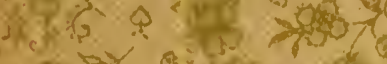

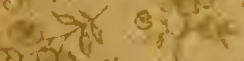

का का एक

के क्षी.

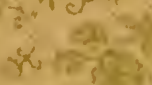

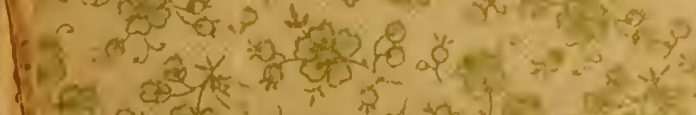


